\title{
Isolierung von DNA und Konstruktion einer \\ Metagenombank aus dem Sediment des Flusses Leine: partielle Sequenzierung und Annotation des Metagenoms sowie Analyse der mikrobiellen Diversität
}

\author{
Dissertation \\ zur Erlangung des Doktorgrades \\ der Mathematisch-Naturwissenschaftlichen Fakultäten \\ der Georg-August-Universität zu Göttingen
}

\author{
vorgelegt von \\ Jessica Estelle Schmitz \\ aus Hamburg
}

Göttingen, 2004 
D7

Referent: PD Dr. R. Daniel

Korreferent: Prof. Dr. W. Liebl

Tag der mündlichen Prüfung: 25. Januar 2005 


\section{INHALTSVERZEIHNIS}

Seite

INHALTSVERZEICHNIS I I

ABKÜRZUNGSVERZEICHNIS XI

1 EINLEITUNG 1

2 MATERIAL UND METHODEN 4

2.1 Verwendete Organismen, Plasmide und Oligonukleotide 4

$\begin{array}{ll}2.2 & \text { Nährmedien }\end{array}$

2.2.1 LB-(Luria-Bertani) Medium (SAMBROK et al., 1989) 6

$\begin{array}{lll}\text { 2.2.2 TB-Medium (SAMBROK et al., 1989) } & 7\end{array}$

$\begin{array}{lll}\text { 2.2.3 SOB-Medium (HANAHAN; 1983) } & 7\end{array}$

2.2.4 Citrobacter-Mineralmedium mit Hefeextraktzusatz $\quad 8$

(AVERHOFF; 1988, modifiziert)

2.2.5 Carbonyl-Indikator-Medium CONWAY et al., 1987, modifiziert 8

2.2.6 Spurenelementelösung SL-4 (PFENNIG und LIPPERT, 1966) 9

2.2.7 Vitaminlösung (WOLIN et al., 1964, modifiziert) 9

$\begin{array}{ll}\text { 2.2.8 Antibiotika und sonstige Medienzusätze } & 10\end{array}$

$\begin{array}{lll}2.3 & \text { Zellanzucht } & 10\end{array}$

$\begin{array}{lll}\text { 2.3.1 } & \text { Aerobe Anzucht } & 10\end{array}$

$\begin{array}{ll}\text { 2.3.2 Anaerobe Anzucht } & 10\end{array}$

$\begin{array}{lll}2.3 .3 & \text { Stammhaltung } & 11\end{array}$

2.3.4 Anzucht von rekombinanten E. coli-Stämmen zur heterologen
Genexpression

2.2.4.1 Expression mit dem “pET Directional TOPO ${ }^{\circledR}$ Expression”-Kit 11 
$\begin{array}{lll}2.4 & \text { Bestimmung von Wachstumsparametern } & 13\end{array}$

$\begin{array}{ll}\text { 2.4.1 Bestimmung der optischen Dichte } & 13\end{array}$

$\begin{array}{lll}\text { 2.4.2 Bestimmung des pH-Wertes } & 13\end{array}$

2.5 Standardtechniken für das Arbeiten mit Nukleinsäuren 13

2.5.1 Behandlung von Geräten und Lösungen 13

$\begin{array}{lll}\text { 2.5.2 Puffer und Lösungen } & 14\end{array}$

2.5.3 Fällung, Reinigung und Konzentration von Nukleinsäuren 14

$\begin{array}{lll}\text { 2.5.3.1 Fällung von Nukleinsäuren } & 14\end{array}$

2.5.3.2 DNA-Fällung nach Saccharose-Dichtegradientenzentrifugation 14

$\begin{array}{lll}\text { 2.5.3.3 Mikrodialyse von DNA } & 15\end{array}$

$\begin{array}{lll}\text { 2.5.3.4 Dialyse von Umwelt-DNA } & 15\end{array}$

$\begin{array}{lll}\text { 2.5.3.5 Konzentrationsbestimmung von Nukleinsäuren } & 15\end{array}$

2.5.3.6 Isolierung von DNA-Fragmenten mittels “QIAquick Gel 16

2.5.3.7 Reinigung von DNA-Fragmenten mittels “QIAquick PCR 16 Purification”-Kit

$\begin{array}{lll}2.6 & \text { Isolierung von Nukleinsäuren } & 16\end{array}$

2.6.1 Isolierung von DNA aus Umweltproben (ZHOU et al., 1996) 16

2.6.2 Reinigung von Umwelt-DANN (HENNE et al., 1999) 17

$\begin{array}{lll}\text { 2.6.3 Isolierung von Plasmid-DNA } & 18\end{array}$

2.6.3.1 Plasmidschnellpräparation (HOLMES \& QUIGLEY, 1981) 18

2.6.3.2 Minipräparation von Plasmiden mittels “QIAprep Spin Miniprep 18 Kit”

2.6.3.3 Minipräparation von Plasmiden mittels „NucleoSpinPlasmid“- $\quad 19$ Kit

2.6.3.4 Präparative Plasmidisolierung über Anionenaustausch- 19 chromatographie 
2.6.3.5 Robotgesteuerte Plasmidpräparation

$\begin{array}{lll}2.7 & \text { Gelelektrophorese von Nukleinsäuren } & 21\end{array}$

$\begin{array}{ll}\text { 2.7.1 Standard-Agarose-Gelelektrophorese } & 21\end{array}$

2.7.2 „Pulse-field“-Gelektrophorese 22

2.7.3 Größenbestimmung von Nukleinsäuren 22

$\begin{array}{lll}2.8 & \text { Enzymatische Modifikation von DNA }\end{array}$

2.8.1 Schneiden von DNA durch Restriktionsendonukleasen 23

2.8.2 Dephosphorylierung von DNA-Fragmenten 23

$\begin{array}{ll}\text { 2.8.3 Ligation von DNA-Fragmenten } & 24\end{array}$

2.8.3.1 Ligation mit T4-DNA-Ligase 24

2.8.3.2 Klonierung mit dem “TOPO-TA-Cloning”-Kit 24

2.9 Saccharose-Dichtegradientenzentrifugation 25 (SAMBROOK et al., 1989, modifiziert

$2.10 \quad$ Polymerasekettenreaktion (PCR) 26

2.10.1 Amplifikation von DNA-Fragmenten mit der Taq- oder PfuDNA Polymerase 26

2.10.2 Amplifikation von DNA-Fragmenten mit der KOD Hifi DNA 27 Polymerase (Fa.Novagen)

2.11 Übertragung von DNA in E. coli und Selektion 28 rekombinanter Klone

2.11.1 Hocheffiziente Transformation in E. coli 28

2.11.2 Transformation in E. coli durch Elektroporation /POWEER et al., $\quad 29$ 1990)

$\begin{array}{lll}2.11 .3 & \text { Transduktion } & 30\end{array}$

2.11.4 Transduktion mit den “Gigapack $®$ III Gold Packaging Extract” $\quad 30$

2.11.4 Der X-Gal-Test zur Selektion rekombinanter Klone 31 
2.11.5 Plattentest zur Überprüfung der Verwertung von C2-C4-Polyolen

2.12 Sequenzierung von DNA

2.12.1 Sequenzierung mit ABI DNA Sequencer 377

2.12.2 Sequenzierung mit dem MegaBACE 1000 Capillar Sequencer 35

$\begin{array}{ll}2.13 & \text { Die Prozessierung von Rohsequenzen }\end{array}$

2.13.1 Einführung in die Prozessierung von DNA-Sequenzen mittels des 36 STADEN-Software-Packets

$\begin{array}{lll}2.13 .1 .1 \quad \text { „Pregap4“ } & 37\end{array}$

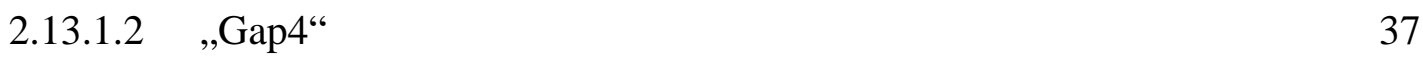

2.14 Methoden zur Überwindung von Sequenzlücken in 38 einem Sequenzierungsprojekt

2.14.1 Identifikation von Contigüberlappungen mit „Gap4“ oder „Align 38 two Sequences“ (NCBI)

2.14.2 „Primer-Walking“ 39

$\begin{array}{lll}\text { 2.14.3 Kombinatorische PCR } & 40\end{array}$

$\begin{array}{ll}2.15 & \mathbf{4 0}\end{array}$

2.15.1 ORF (,open reading frame“)-Vorhersage 40

2.15.2 Annotation der Cosmidsequenzen 41

2.15.3 Untersuchung der 16S rRNA-Gene auf das Vorhandensein 43 chimerer Sequenzen

2.16 Herstellung von Rohextrakten $\quad 44$

2.16.1 Zellaufschluss mit der Frenchpresse $\quad 44$

2.17 Proteinbestimmung (BRADFORD, 1976) 44

2.18 Bestimmung von Enzymaktivitäten 45

2.18.1 Erythrit-Dehydrogenase (RUCH et al., 1974; BOENIGK et al., 46 1991) 
$\begin{array}{lll}\text { 2.18.2 Kinasen (Palmgren, 1990) } & 47\end{array}$

$\begin{array}{lll}\text { 2.18.3 Dihydroxyaceton-Kinase } & 48\end{array}$

2.18.3.1 ATP - abhängige Dihydroxyaceton - Kinase (JOHNSON et al., $\quad 48$ 1984)

2.18.3.2 PEP - abhängige Dihydroxyaceton - Kinase (SUN et al., 2003) 49

2.18.4 Kohlenstoffmonoxid-Dehydrogenase (KRAUT et al., 1989) 50

2.19 Methoden zur Proteinanreicherung 50

2.19.1 Metall-Chelat-Affinitätschromatographie 50

$\begin{array}{lll}\text { 2.19.1.1 Vorbereitung der Säule } & 51\end{array}$

2.19.1.2 Reinigung löslicher Proteine unter nativen Bedingungen 51

2.19.1.3 Regeneration der Säule 52

2.19.1.4 Reinigung löslicher Proteine mit Protino ${ }^{\circledR} \mathrm{Ni}$-Säulen (Fa. 52 Macherey-Nagel, Düren)

2.20 Polyacrylamid-Gelelektrophorese (PAGE) 52

2.20.1 SDS-PAGE nach SCHÄGGER und VON JAGOW 52

$\begin{array}{lll}\text { 2.20.2 Native Gradienten-PAGE } & 54\end{array}$

2.21 Proteinfärbung in Polyacrylamidgelen 55

2.21.1 Coomassie-Färbung 55

2.21.2 Aktivitätsfärbung von Erythrit-Dehydrogenasen (Gabriel, 1971; 56 modifiziert)

2.22 Western Blot (TOBWIN et al., 1979; modifiziert) 56

2.22.1 Immunodetektion von Proteinen auf Blot-Membranen 58

$\begin{array}{lll}\text { 2.22.1.1 Chromogene Methoden } & 58\end{array}$

2.22.1.1.1 Färbung mit dem Anti-V5-Alkalische-Phosphatase-Konjugat 58

2.22.1.1.2 Nachweis des His6-Tag durch Antikörper 59 
$\begin{array}{lll}2.23 & \text { Molekularmassenbestimmung }\end{array}$

2.23.1 Molekularmassenbestimmung durch SDS-PAGE 59

2.23.2 Molekularmassenbestimmung durch Gradienten-PAGE 61 (ANDERSON et al., 1972; NISHIZAWA et al., 1988)

2.24 Chemikalien, Enzyme und Gase 62

$3 \quad$ EXPERIMENTE UND ERGEBNISSE

$\begin{array}{lll}3.1 & \text { Probennahme } & 65\end{array}$

3.2 Konstruktion von Metagenombanken in Escherichia coli 66

3.2.1 Isolierung von chromosomaler DNA aus dem Leinesediment 66

3.2.2 Klonierung der Umwelt-DNA 67

3.2.2.1 Herstellung einer Plasmid-Genbank 68

$\begin{array}{ll}\text { 3.2.2.2 Herstellung einer Cosmid-Genbank } & 70\end{array}$

$\begin{array}{lll}\text { 3.3 Analyse der phylogenetischen Diversität mittels 16S } & 71\end{array}$ rRNA-Genanalyse

3.3.1 Ergebnisse der Analyse der archaeellen 16S-rRNA- 85

Gensequenzen

3.3.2 Ergebnisse der Analyse der bakteriellen 16S-rRNA- 88

Gensequenzen

3.4 Sequenzierung von Cosmiden aus der LeinesedimentMetagenom-Cosmid-Genbank

$\begin{array}{ll}\text { 3.4.1 Ergebnisse der Sequenzierung } & 100\end{array}$

$\begin{array}{ll}\text { 3.4.1.1 Das Cosmid slc_1a } & 126\end{array}$

$\begin{array}{ll}\text { 3.4.1.2 Das Cosmid slc_1f } & 128\end{array}$

$\begin{array}{ll}\text { 3.4.1.3 Das Cosmid slc_1g } & 129\end{array}$

$\begin{array}{lll}\text { 3.4.1.4 Das Cosmid slc_1h } & 129\end{array}$ 
$\begin{array}{ll}\text { 3.4.1.5 Das Cosmid slc_1p } & 131\end{array}$

3.4.1.6 Das Cosmid slc_1q 131

3.4.1.7 Das Cosmid slc_1s 132

3.4.1.8 Das Cosmid slc_1t 132

$\begin{array}{ll}\text { 3.4.1.9 Das Cosmid slc_1u } 134 & 134\end{array}$

$\begin{array}{ll}\text { 3.4.1.10 Das Cosmid slc_1x } & 134\end{array}$

3.4.1.10.1 Experimentelle Untersuchung der Dihydroxyaceton-Kinase $\quad 145$

$\begin{array}{lll}\text { 3.4.1.11 Das Cosmid slc_2g } & 146\end{array}$

$\begin{array}{lll}\text { 3.4.1.12 Das Cosmid slc_2j } & 146\end{array}$

3.5 Sequenzabhängige und auf Aktivität basierende 147 Durchmusterung von Metagenombanken

3.5.1 Sequenzabhängige Durchmusterung von Genbanken 147

3.6 Isolierung und Charakterisierung einer Erythrit- 148 Oxidoreduktase

$\begin{array}{lll}\text { 3.6.1 Stand der Vorarbeiten } & 149\end{array}$

$\begin{array}{ll}\text { 3.6.2 Sequenzierung und Annotation des pEry1-Inserts } & 149\end{array}$

3.6.3 Wachstumskurve des Klons E. coli JM109/pEry1 152

3.6.4 Bestimmung der Größe des nativen Proteins über native 154

Gradienten-PAGE und Aktivitätsfärbung

3.6.5 Photometrische Messung der Enzymaktivität, Pufferbedingungen 155 sowie Coenzym-Spezifität

3.6.6 Klonierung des ORF2 in den pET101/D-TOPO-Vektor 156

3.6.7 Expression des ORF2-Gens sowie Reinigung und Nachweis des 157 von ORF2 kodierten Proteins

3.6.8 Enzymtest mit dem Rohextrakt von E. coli 160 BL21 StarTM/pETEry20

3.6.9 Mutation des ORF2 durch Restriktionsverdau mit BclII 161 
4 DISKUSSION

162

4.1 Phylogenetische Analyse des Leinesedimentes

4.1.1 Versuch einer Rekonstruktion des Kohlenstoff- und

Energiefluxes in der mikrobiellen Gemeinschaft

4.1.2 Versuch einer Rekonstruktion des Stickstoffkreislaufes in der

178 mikrobiellen Gemeinschaft

4.1.3 Kritische Betrachtung der Methode der 16S rRNA-Genanalyse 181

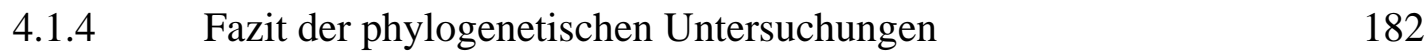

$\begin{array}{llr}4.2 & \text { Metagenom-Sequenzierung } & 184\end{array}$

$\begin{array}{lll}\text { 4.2.1 Das Cosmid slc_1x } & 188\end{array}$

$\begin{array}{lll}\text { 4.2.1.1 Das CO - Dehydrogenase-Gencluster } & 188\end{array}$

$\begin{array}{lll}\text { 4.2.1.2 Das ugp - Gencluster } & 191\end{array}$

$\begin{array}{ll}\text { 4.2.1.3 Das Dihydroxyaceton-Kinase-Cluster } & 194\end{array}$

$\begin{array}{lll}\text { 4.2.2 } & \text { Aminosäurestoffwechsel } & 198\end{array}$

$\begin{array}{ll}4.3 & \text { Annotation und Funktionalität }\end{array}$

4.4 Durchmusterung von Metagenom-Genbanken 204

$\begin{array}{lll}4.5 & \text { Ausblick } & 209\end{array}$

5 ZUSAMMENFASSUNG

211

6 LITERATURVERZEICHNIS 
$7 \quad$ ANHANG

7.1 Das Cosmid slc_1a

7.1.1 Lage der offenen Leserahmen (ORFs)

7.1.2 Sequenz des Cosmides slc_1a

7.2 Das Cosmid slc_1f

7.2.1 Lage der offenen Leserahmen (ORFs)

7.2.2 Sequenz des Cosmides slc_1f

7.3 Das Cosmid slc_1g

7.3.1 Lage der offenen Leserahmen (ORFs)

7.3.2 Sequenz des Cosmides slc_1g

7.4 Das Cosmid slc_1h

7.4.1 Lage der offenen Leserahmen (ORFs)

7.4.2 Sequenz des Cosmides slc_1h

7.5 Das Cosmid slc_1p

7.5.1 Lage der offenen Leserahmen (ORFs)

7.5.2 Sequenz des Cosmides slc_1p

7.6.1 Festlegung der Gene über „Genemark“ A36

7.6.2 Aminosäuresequenzen der übersetzten cDNA A36

$\begin{array}{lll}\text { 7.6.3 Sequenz des Cosmides slc_1q } 1 q & \text { A37 }\end{array}$

7.7 Das Cosmid slc_1s

7.7.1 Lage der offenen Leserahmen (ORFs) A43

7.7.2 Sequenz des Cosmides slc_1s 
7.8 Das Cosmid slc_1t

7.8.1 Lage der offenen Leserahmen (ORFs)

7.8.2 Sequenz des Cosmides slc_1t

A50

7.9 Das Cosmid slc_1u

7.9.1 Lage der offenen Leserahmen (ORFs)

7.9.2 Sequenz des Cosmides slc_1u

7.10 Das Cosmid slc_1x

7.10.1 Lage der offenen Leserahmen (ORFs)

7.10.2 Sequenz des Cosmides slc_1x

7.11 Das Cosmid slc_2g

7.11.1 Lage der offenen Leserahmen (ORFs)

7.11.2 Sequenz des Cosmides slc_2g

7.12 Das Cosmid slc_2j

7.12.1 Lage der offenen Leserahmen (ORFs)

7.12.2 Sequenz des Cosmides slc_2j

7.13 Bakterielle 16S rRNA-Gensequenzen

7.14 Archaeelle 16S rRNA-Gensequenzen

7.15 Das Insert des Plasmides pEry1

7.15.1 Lage der offenen Leserahmen (ORFs) 


\section{Abkürzungsverzeichnis}

A

Abb.

ABC

Amp

APS

ATP

AS

BD

BLAST

BLASTN

BLASTP

bp

bzw.

${ }^{\circ} \mathrm{C}$

$\mathrm{C}$

ca.

$\mathrm{cm}$

$\mathrm{CO}$

CoA

C-terminal

Da

d. h.

dest.

Dha

DNA

dNTP

DTT

E.

E-Cup

EDTA

et al.

Fa.

FAD

FeS-Cluster

FMN

g

G

Gap

$\mathrm{GmbH}$

$\mathrm{x} g$

$\mathrm{h}$

Hrsg.

HPLC

i. d. R.

IPTG

$\mathrm{k}$

$\mathrm{kb}$

$\mathrm{kDa}$
Adenin

Abbildung

ATP-bindende Kassette, ATP-binding cassette

Ampicillin

Ammoniumpersulfat

Adenosin-5'-triphosphat

Aminosäure(n)

Big dye

Basic Local Alignment Search Tool

BLAST auf Nukleotidebene

BLAST auf Proteinebene

Basenpaar(e)

beziehungsweise

Grad Celcius

Cytosin

circa

Zentimeter

Kohlenstoffmonoxid

Coenzym A

carboxyterminal

Dalton

das heißt

destilliert

Dihydroxyaceton

Desoxyribonukleinsäure

Desoxyribonukleotid-5'-triphosphat

Dithiotreitol

Escherichia

Eppendorf-Reaktionsgefäß

Ethylendiamintetraessigsäure

et alteri, und andere

Firma

Flavinadenindinukleotid

Eisen-Schwefel-Cluster

Flavinmononucleotid

Gramm

Guanin

Genomassemblierungsprogramm, genome assembly program

Gesellschaft mit beschränkter Haftung

-fache Erdbeschleunigung $(9,81 \mathrm{~m} / \mathrm{s} 2)$

Stunde

Herausgeber

high performance liquid chromatography

in der Regel

Isopropyl-@-thiogalactopyranosid

Kilo

Kilobasenpaare

Kilodalton 


\begin{tabular}{|c|c|}
\hline 1 & Liter \\
\hline LB & Luria-Bertani \\
\hline$\mu$ & Mikro \\
\hline M & Molar (Mol pro Liter); Mega (106) \\
\hline M. & Mesorhizobium \\
\hline $\mathrm{m}$ & Meter; milli- (10-3) \\
\hline MCS & multiple Klonierungsstelle, multiple cloning site \\
\hline $\min$ & Minute \\
\hline mol & Mol \\
\hline $\mathrm{n}$ & Nano \\
\hline $\mathrm{Na}+$ & Natrium \\
\hline $\mathrm{NAD}(\mathrm{H})$ & Nicotinamidadenindinukleotid (reduzierte Form) \\
\hline NBT & Nitroblau-Tetrazoliumchlorid \\
\hline NCBI & National Center for Biotechnology Information \\
\hline Nr. & Nummer \\
\hline N-terminal & aminoterminal \\
\hline OD & Optische Dichte \\
\hline ORF & offener Leserahmen, open reading frame \\
\hline PCR & Polymerasekettenreaktion, polymerase chain reaction \\
\hline PEP & Phosphoenolpyruvat \\
\hline PFAM & Datenbank für Protein-Familien und Hidden-Markov-Modelle \\
\hline $\mathrm{pH}$ & negativer dekadischer Logarithmus der Protonenkonzentration \\
\hline PMS & Phenazinmethosulfat \\
\hline$R$. & Rhodobacter \\
\hline RDP & Ribosomal Database Project \\
\hline RNA & Ribonukleinsäure \\
\hline rRNA & ribosomale Ribonukleinsäure \\
\hline RSA & Rinderserumalbumin \\
\hline RT & Raumtemperatur \\
\hline S & Sekunde \\
\hline s. & siehe \\
\hline s. 0 . & siehe oben \\
\hline S. u. & siehe unten \\
\hline SDS & Natriumdodecylsulfat \\
\hline sp. & species \\
\hline $\mathrm{T}$ & Thymin \\
\hline TEMED & N, N, N’, N’-Tetramethylethylendiamid \\
\hline $\operatorname{Tm}$ & Schmelztemperatur \\
\hline TM & transmembrane Helix/Helices \\
\hline Tris & Tris-(hydroxymethyl-)aminomethan \\
\hline $\mathrm{U}$ & Unit (Einheit der Enzymaktivität) \\
\hline $\begin{array}{l}\text { ugp } \\
\text { phosphate" }\end{array}$ & Aufnahme von Glycerin-Phosphat, "uptake of glycerol \\
\hline ü. N. & über Nacht \\
\hline Upm & Umdrehungen pro Minute \\
\hline $\mathrm{v} / \mathrm{v}$ & Volumen pro Volumen \\
\hline $\mathrm{V}$ & Volt \\
\hline $\mathrm{w} / \mathrm{v}$ & Masse pro Volumen \\
\hline X-Gal & 5-Brom-4-Chlor-3-Indolyl-D-Galactosid \\
\hline z. B. & zum Beispiel \\
\hline
\end{tabular}




\section{Aminosäuren}

$\begin{array}{llllll}\text { A } & \text { Ala } & \text { Alanin } & \text { M } & \text { Met } & \text { Methionin } \\ \text { C } & \text { Cys } & \text { Cystein } & \text { N } & \text { Asn } & \text { Asparagin } \\ \text { D } & \text { Asp } & \text { Aspartat } & \text { P } & \text { Pro } & \text { Prolin } \\ \text { E } & \text { Glu } & \text { Glutamat } & \text { Q } & \text { Gln } & \text { Glutamin } \\ \text { F } & \text { Phe } & \text { Phenylalanin } & \text { R } & \text { Arg } & \text { Arginin } \\ \text { G } & \text { Gly } & \text { Glycin } & \text { S } & \text { Ser } & \text { Serin } \\ \text { H } & \text { His } & \text { Histidin } & \text { T } & \text { Thr } & \text { Threonin } \\ \text { I } & \text { Ile } & \text { Isoleucin } & \text { V } & \text { Val } & \text { Valin } \\ \text { K } & \text { Lys } & \text { Lysin } & \text { W } & \text { Trp } & \text { Tryptophan } \\ \text { L } & \text { Leu } & \text { Leucin } & \text { Y } & \text { Tyr } & \text { Tyrosin }\end{array}$




\section{EINLEITUNG}

Flüsse stellen einen besonderen Lebensraum dar. Im globalen Wassersystem verbinden sie Land- und Wasserhabitate. Charakteristisch für diesen Standort ist die Bewegung des Wassers, in dem eine Fülle verschiedener Substanzen - wie z. B. organischer Detritus und anorganische Partikel - transportiert wird. Zur Charakterisierung von Flüssen reichen physikalische und chemische Parameter nicht aus. Die mikrobielle Umsetzung organischen - und auch anorganischen Materials - stellt einen wesentlichen Beitrag des gesamten Stofffluxes in diesem Ökosystem dar (BÖCKELMANN et al., 2000). Intensive mikrobiologisch-geochemische Vorgänge finden besonders im Bereich der Sediment-Wassergrenze statt. Dort wird das frisch sedimentierte organische Material zersetzt. Auch wenn zumindest aerobe Sedimente meist sehr heterogen sind, so kann doch eine systematische Abfolge von Redoxprozessen nachgewiesen werden. In der obersten Schicht, die wenige Millimeter bis Zentimeter umfassen kann, findet eine intensive Mineralisierung statt. Es bilden sich über kleine Distanzen Konzentrationsgradienten der gelösten Stoffe, die von der Intensität der ablaufenden Stoffwechselprozesse abhängig sind. Zu den typischen Stoffwechselprozessen gehören die Denitrifikation, die anaerobe Atmung und die Methanogenese (ROTHFUSS und REMDE, 1998). Auch die Sauerstoffkonzentration kann sich innerhalb weniger Millimeter signifikant ändern. Aerobe und anaerobe Zonen können in unmittelbarer Nachbarschaft liegen (MÜLLER und WEHRLI, 1998). Dies führt dazu, dass in einer einzigen Sedimentprobe Mikroorganismen enthalten sein können, die sich stark in den Anforderungen an die Umgebung und in ihren Stoffwechselfähigkeiten unterscheiden. Die Fähigkeit von Mikroorganismen, in Abwesenheit von Sauerstoff organisches Material zu mineralisieren und dabei Stoffwechselenergie zu gewinnen, ist für den Nährstoffkreislauf und Energiefluss in aquatischen Ökosystemen von entscheidender Bedeutung (ROTHFUSS und REMDE, 1998). Dennoch wurden bei biologischen Charakterisierungen von Sedimenten bislang meist nur Erhebungen der Artendiversität von Makroinvertebraten z. B. für Bewertungen des qualitativen Zustandes von Sedimenten herangezogen. Aber auch andere Untersuchungen beschäftigten sich in der Vergangenheit nur wenig mit Süßwassersedimenten. Das ist vor allem dadurch begründet, dass Mikroorganismen aufgrund ihrer Größe extrem schwer in der Natur zu 
untersuchen sind. Dabei ist ihr zahlenmäßiges Vorkommen immens. Es wird geschätzt, dass im Süßwasser etwa $10^{6}$ Mikroorganismen pro Milliliter und etwa 100fach mehr Zellen im Sediment vorkommen (WHITMAN et al., 1998; KÖBEL-BOEHLKE et al., 1988). Aufgrund der Probleme bei der In-situ-Untersuchung wurde versucht, Mikroorganismen zu kultivieren. Dabei stellte sich heraus, dass eine große Diskrepanz zwischen der Anzahl mikroskopisch sichtbarer und der Anzahl kultivierbarer Zellen bestand. Einige Organismen ließen sich deshalb gut charakterisieren, der Großteil blieb allerdings unbekannt (RONDON et al., 1999). Für die meisten natürlichen Habitate wird heute angenommen, dass weniger als $1 \%$ der Mikroorganismen mit Standardtechniken kultiviert werden können (AMANN et al., 1995; GIOVANNONI und RAPPE 2000; GIOVANNONI et al., 1990; KELLENBERGER, 2001). Allerdings sind auch gerade in diesem Bereich in den letzten Jahren große Fortschritte erzielt worden (DANIEL, 2004). Dennoch bleibt die deutliche Mehrheit der Mikroorganismen über Kultivierungen unzugänglich. Um dieses Problem zu lösen, wurden Techniken entwickelt, die kultivierungsunabhängig versuchen, ein detaillierteres Bild der mikrobiellen Diversität und Funktion in natürlichen Umgebungen zu erhalten (RONDON et al., 1999). Entscheidend war hierbei die Entwicklung von Techniken, die es erlauben, DNA aus Umweltproben zu isolieren und direkt zu klonieren (PACE et al., 1985). Inzwischen steht eine Vielzahl verschiedener Methoden zur kulturunabhängigen Charakterisierung von mikrobiellen Gemeinschaften zur Verfügung. Diese erlauben Einblicke sowohl in die Diversität eines Standortes als auch in das genetische Potential und in die physiologischen Aktivitäten. Für die funktionalen und sequenzbasierten Untersuchungen der Gesamtheit aller mikrobiellen Genome einer Umweltprobe wurde der Begriff „Metagenomics“ geprägt (RIESENFELD et al., 2004). In einem ersten Schritt wird häufig die phylogenetische Diversität eines Standortes mittels der Amplifikation und anschließenden Sequenzierung der 16S rRNA-Gene analysiert. Die hierbei gewonnenen Sequenzdaten bestätigen die Annahme, dass durch Kultivierung nur ein kleiner Teil der Diversität erfasst werden kann. So werden die erhaltenen 16S rRNA-Sequenzdaten in 52 Phyla eingeteilt, von denen 26 nur durch 16S rRNAGenseqeunzen in den Datenbanken repräsentiert sind (HUGENHOLTZ et al., 2002). Sequenzierungen größerer klonierter DNA-Fragmente gaben außerdem Hinweise auf bislang unbekannte Stoffwechselfähigkeiten von Mikroorganismen (RIESENFELD et al., 2004). Neben dem Interesse, das mikrobielle Leben in Ökosystemen zu verstehen, eröffnet die direkte Klonierung von Umwelt-DNA die Chance, sich das genetische 
Potential aller Organismen auf der Suche nach Naturprodukten mit industrieller Relevanz nutzbar zu machen. Sequenz- und aktivitätsbasierende Screeningverfahren wurden entwickelt und zur Durchmusterung von Metagenombanken auf das Vorkommen unterschiedlichster Zielgene eingesetzt. Dabei wurden sowohl biotechnologisch interessante Enzyme wie z. B. Lipasen, Amylasen, Chitinasen, Cellulasen, Alkohol-Oxidoreduktasen und Diol-Dehydrogenasen als auch Naturstoffe wie Antibiotika entdeckt (BRADY et al., 2001; COTTRELL, et al., 1999; HEALY et al., 1995; HENNE et al., 2000; KNIETSCH et al., 2003a; KNIETSCH et al, 2003b; RICHARDSON et al., 2002). Die erhaltenen Ergebnisse verdeutlichten das hohe unentdeckte Potential von Mikroorganismen und deren Genprodukten für den Einsatz in biotechnologischen Verfahren. Die Anpassungen von Mikroorganismen an veränderte Umweltbedingungen und Substrate z. B. anthropogenen Ursprungs erfolgt verhältnismäßig schnell. Dadurch sind Mikroorganismen zum einen von Nutzen beim Abbau von Umweltgiften. Zum anderen scheint die Entwicklung von interessanten Abbauwegen, selbst wenn sie zunächst nicht vorhanden sind, in verhältnismäßig kurzer Zeit möglich zu sein (HANDELSMAN und WACKETT, 2002). Neueste Studien haben sich zum Ziel gesetzt, große Teile von Metagenomen wie z. B. von Proben der Sargasso Sea oder eines Trinkwasser-Biofilms auf Sequenzebene zu erfassen (BREITBART et al., 2002; BREITBART et al., 2003; SCHMEISSER et al., 2003; TYSON et al., 2004; VENTER et al., 2004).

Ziel dieser Arbeit war es, durch umfangreiche Sequenzierungen einen Einblick in die phylogenetische und physiologische Diversität im Leinesediment zu gewinnen. Dafür wurde DNA aus Proben des Leinesedimentes isoliert. Diese stand für eine PCRbasierende Amplifikation der 16S rRNA-Gene und deren anschließende Klonierung und Sequenzierung zur Verfügung. Es konnte sowohl ein erster Einblick in die bakterielle als auch in die archaeelle Diversität des Leinesedimentes gewonnen werden. Außerdem wurde sie zur Herstellung von Plasmid- und Cosmid-Genbanken eingesetzt. 14 zufällig ausgewählte Cosmide wurden vollständig sequenziert, die Sequenzdaten ausgewertet und teilweise experimentell überprüft. Des Weiteren stand ein Klon zur Verfügung, der aus einem Screening mit Metagenom-Genbanken hervorgegangen war, bei dem Gene gesucht wurden, die E. coli die Fähigkeit vermitteln, mit Erythrit als einziger C- und Energiequelle zu wachsen. Das für diese Fähigkeit zuständige Gen sollte identifiziert und das Genprodukt biochemisch charakterisiert werden. 


\section{MATERIAL UND METHODEN}

\subsection{Verwendete Organismen, Plasmide und Oligonukleotide}

Die im Rahmen dieser Arbeit verwendeten Organismen sind in Tabelle 1, die Plasmide in Tabelle 2 aufgeführt. Tabelle 3 gibt eine Übersicht über die verwendeten Oligonukleotide.

Tabelle 1: Verwendete Organismen

\begin{tabular}{|c|c|c|}
\hline Stamm & relevanter Geno- oder Phänotyp & Herkunft/Referenz \\
\hline Escherichia coli DH5 $\alpha$ & $\begin{array}{l}\mathrm{F}^{-} \text {endA1, } \phi 80 \operatorname{lac} Z \Delta \mathrm{M} 15 \\
\Delta(\operatorname{lacZYAargF}) \mathrm{U} 169, \text { endA1, } \\
\left.\text { recA1, hsdR17( } \mathrm{r}_{\mathrm{K}}-\mathrm{m}_{\mathrm{K}}+\right) \text {, deoR, thi- } \\
1 \text {, supE44, } \lambda-\text {, gryA96, relA1 }\end{array}$ & HANAHAN, 1983 \\
\hline $\begin{array}{l}\text { Escherichia coli } \\
\text { BL21(DE3) }\end{array}$ & $\begin{array}{l}\mathrm{F}^{-} \text {ompT hsdS } \mathrm{B}_{\mathrm{B}}\left(\mathrm{r}_{\mathrm{B}}-\mathrm{m}_{\mathrm{B}^{-}}\right), \text {gal dcm } \\
\text { rne131 (DE3) }\end{array}$ & $\begin{array}{l}\text { Invitrogen,Carlsbad, } \\
\text { USA }\end{array}$ \\
\hline Escherichia coli TOP10 & $\begin{array}{l}\mathrm{F}^{-} \text {mcrA } \Delta(\text { mrr-hsdRMS-mcrBC }) \\
\text { Ф80lacZ } \Delta \text { M15 } \Delta \text { lacX74 recA1 } \\
\text { deoR araD139 } \Delta(\text { ara-leu }) 7697 \text { galU } \\
\text { galK rpsL }\left(\text { Str }^{\mathrm{R}}\right) \text { endA1 nupG }\end{array}$ & $\begin{array}{l}\text { Invitrogen,Carlsbad, } \\
\text { USA }\end{array}$ \\
\hline Escherichia coli JM109 & $\begin{array}{l}\mathrm{F}^{-}, \text {RecA1, endA1, gyrA96, thi, } \\
\left.\text { hsdR17( } \mathrm{r}_{\mathrm{K}}^{-} \mathrm{m}_{\mathrm{K}}^{+}\right) \text {, supE44, relA1, } \lambda^{-}, \\
\text {c(lac-proAB), traD36, proAB, } \\
\text { lacI }{ }^{\mathrm{q}} \mathrm{lac} Z \Delta \mathrm{M} 15\end{array}$ & \\
\hline Escherichia coli ECL707 & $\begin{array}{l}\mathrm{F}^{-} \text {gld }:: \Delta \operatorname{Tn} 10 \text { glpK }:: \Delta \operatorname{Tn} 10 \text { ptsD } \\
:: \Delta \operatorname{Tn} 10 \text { araD139 flbB } \Delta \text { lacU169 } \\
\text { ptsF25 relA rpsL thi }\end{array}$ & $\begin{array}{l}\text { SPRENGER et al., } \\
1989\end{array}$ \\
\hline
\end{tabular}


Tabelle 2: Vektoren und rekombinante Plasmide

\begin{tabular}{|c|c|c|}
\hline Plasmid & relevantes Merkmal & Herkunft/Referenz \\
\hline \multirow[t]{2}{*}{ pBluescript ${ }^{\circledR}$ IISK+ } & $\mathrm{Ap}^{\mathrm{r}}$, lacPOZ, pMB1-Replikon & Stratagene, San \\
\hline & & Diego, USA \\
\hline \multirow[t]{2}{*}{ pBluescript SK ${ }^{+}$} & $\mathrm{Ap}^{\mathrm{r}}$, lacPOZ, pMB1-Replikon & Stratagene, San \\
\hline & & Diego, USA \\
\hline \multirow[t]{2}{*}{ pCR2.1-TOPO } & $\mathrm{Ap}^{\mathrm{r}}, \mathrm{Kan}^{\mathrm{r},} \mathrm{pMB} 1-$ Replikon & Invitrogen, \\
\hline & & Carlsbad, USA \\
\hline \multirow[t]{2}{*}{ pET101/D-TOPO } & $\mathrm{Ap}^{\mathrm{r}} \mathrm{His}_{6}$-tag C-terminal, V5-epitop-tag & Invitrogen, \\
\hline & & Carlsbad, USA \\
\hline \multirow[t]{2}{*}{ superCos $1(\mathrm{~s} \operatorname{Cos} 1)$} & $\mathrm{Ap}^{\mathrm{r}} ; \mathrm{Kan}^{\mathrm{r}} ; \cos$ & Stratagene, San \\
\hline & & Diego, USA \\
\hline pAK204 & & Knietsch et al., 2002 \\
\hline
\end{tabular}

Tabelle 3: Verwendete Oligonukleotide

\begin{tabular}{|c|c|c|}
\hline Bezeichnung & Sequenz & Referenz \\
\hline rev & 5'-TTCACACAGGAAACAGCT-3` & \\
\hline for & 5'-ACGACGTTGTAAAACGACGGCCAG-3’' & \\
\hline eryrev & 5'-CCGCTTCTGCCGCTCCA-3’' & \\
\hline eryfor & 5'-CACCATGAAGATCGCAGTCATTC-3' & \\
\hline erystop & 5'-TCACCGCTTCTGCCGCTCC-3' & \\
\hline erylong & 5'-GTCCCTCGGCGGCGCC-3' & \\
\hline $\mathrm{T} 7$ & 5'-TAATACGACTCACTATAGGG-3' & $\begin{array}{l}\text { Invitrogen, } \\
\text { Carlsbad, USA }\end{array}$ \\
\hline T7 Reverse & 5'-TAGTTATTGCTCAGCGGTGG-3' & $\begin{array}{l}\text { Invitrogen, } \\
\text { Carlsbad, USA }\end{array}$ \\
\hline pET101rev & 5'-TAGTTATTGCTC-3' & \\
\hline pET101for & 5'-CGATCCCGCGAAATTAATACG-3’ & \\
\hline $16 \mathrm{~S} 08$ & 5'-AGAGTTTGATC(A/C)TGGC-3’ & $\begin{array}{l}\text { MUYZER et al., } \\
1995\end{array}$ \\
\hline
\end{tabular}




\begin{tabular}{|c|c|c|}
\hline $16 \mathrm{~S} 513$ & 5'-CGTGCCAGCAGCCGCGG-3' & \\
\hline 16S1504 & 5'-TACCTTGTTACGACTT-3’ & $\begin{array}{l}\text { MUYZER et al., } \\
1995\end{array}$ \\
\hline A1530R & 5'-GGAGGTGATCCAGCCG-3' & ITOH et al., 2003 \\
\hline $\mathrm{A} 800 \mathrm{~F}$ & $5^{\prime}$-GTAGTCCYGGCYGTAAAC-3`* & $\begin{array}{l}\text { KOLGONOVA et } \\
\text { al., } 2002\end{array}$ \\
\hline 23FPL & $\begin{array}{l}\text { 5'-GCGGATCCGCGGCCGCTGCAGAYCTG } \\
\text { GTYGATYCTG-3** }\end{array}$ & $\begin{array}{l}\text { DEES und } \\
\text { GHIORSE, } 2001\end{array}$ \\
\hline $927 \mathrm{R}$ & $5^{\prime}$-CGSTTGTGGTGCTCCC-3`* & $\begin{array}{l}\text { DEES und } \\
\text { GHIORSE, } 2001\end{array}$ \\
\hline
\end{tabular}

* $\mathrm{Y}=\mathrm{C}+\mathrm{T} \quad \mathrm{S}=\mathrm{G}$ oder $\mathrm{C}$

Die Erkennungssequenz für die gerichtete Klonierung in den Expressionsvektor pET101/D-TOPO ist unterstrichen.

\section{$2.2 \quad$ Nährmedien}

Alle aufgeführten Medien wurden durch 30-minütiges Autoklavieren bei $121^{\circ} \mathrm{C}$ sterilisiert. Die C-Quellen für Mineralmedien wurden separat autoklaviert und erst unmittelbar vor dem Animpfen zugegeben. Zur Herstellung von Agarplatten wurde dem Medium vor dem Autoklavieren 1,5\% (w/v) Agar zugefügt.

Anaerobe Medien wurden nach der von COSTILOW (1981) beschriebenen Methode unter Begasung mit sauerstofffreiem Stickstoff hergestellt.

\subsubsection{LB-(Luria-Bertani) Medium (SAMBROOK et al., 1989)}

$\begin{array}{lrr}\text { Trypton } & 10 & \mathrm{~g} \\ \text { Hefeextrakt } & 5 & \mathrm{~g} \\ \mathrm{NaCl} & 10 & \mathrm{~g} \\ \mathrm{H}_{2} \mathrm{O}_{\text {dest. }} & \text { ad } 1000 & \mathrm{ml}\end{array}$




\subsubsection{TB-Medium (SAMBROOK et al., 1989)}

$\begin{array}{lrr}\text { Trypton } & 12 & \mathrm{~g} \\ \text { Hefeextrakt } & 24 & \mathrm{~g} \\ \text { Glycerin }(87 \%, \mathrm{v} / \mathrm{v}) & 4 & \mathrm{ml} \\ \mathrm{H}_{2} \mathrm{O}_{\text {dest. }} & \mathrm{ad} 980 & \mathrm{ml} \\ 5 \text { x Phosphatpuffer } & & \\ \mathrm{KH}_{2} \mathrm{PO}_{4} & 11,55 & \mathrm{~g} \\ \mathrm{~K}_{2} \mathrm{HPO}_{4} & 62,70 & \mathrm{~g} \\ \mathrm{H}_{2} \mathrm{O}_{\text {dest. }} & \text { ad } 100 & \mathrm{ml}\end{array}$

Nach dem Autoklavieren wurden $20 \mathrm{ml} 5$ x Phosphatpuffer und $20 \mathrm{ml} 10 \%$ ige Glukoselösung zugegeben.

\subsubsection{SOB-Medium (HANAHAN, 1983)}

$\begin{array}{lrr}\text { Trypton } & 20 & \mathrm{~g} \\ \text { Hefeextrakt } & 5 & \mathrm{~g} \\ \mathrm{NaCl} & 0,58 & \mathrm{~g} \\ \mathrm{KCl} & 0,18 & \mathrm{~g} \\ \mathrm{MgCl}_{2} & 2,0 & \mathrm{~g} \\ \mathrm{MgSO}_{4} & 2,5 & \mathrm{~g} \\ \mathrm{H}_{2} \mathrm{O}_{\text {dest. }} & \text { ad } 980 & \mathrm{ml}\end{array}$


2.2.4 Citrobacter-Mineralmedium

mit

Hefeextraktzusatz

(AVERHOFF, 1988; modifiziert)

$\begin{array}{lrr}\mathrm{KH}_{2} \mathrm{PO}_{4} & 6,0 & \mathrm{~g} \\ \mathrm{~K}_{2} \mathrm{HPO}_{4} & 14,0 & \mathrm{~g} \\ \left(\mathrm{NH}_{4}\right)_{2} \mathrm{SO}_{4} & 3,0 & \mathrm{~g} \\ \mathrm{MgSO}_{4} \text { x } 7 \mathrm{H}_{2} \mathrm{O} & 0,2 & \mathrm{~g} \\ \mathrm{CoCl}_{2}(50 \mathrm{mM}) & 85,0 & \mu \mathrm{l} \\ \text { Hefeextrakt } & 1 & \% \\ \mathrm{SL}^{4} & 1,0 & \mathrm{ml} \\ \mathrm{H}_{2} \mathrm{O}_{\text {dest. }} & \text { ad } 1000 & \mathrm{ml} \\ \text { pH-Wert einstellen auf } 7,5 & & \\ \text { zusätzlich bei anaeroben Medien: } & & \\ \text { Resazurin }(0,1 \%) & 1,0 & \mathrm{ml} \\ \text { Cystein- } \mathrm{HCl}(200 \mathrm{~g} / \mathrm{l}) & 1,0 & \mathrm{ml}\end{array}$

Für die Anzucht von rekombinanten E. coli-Stämmen enthielt das Medium zusätzlich Thiamin-HCl (10 mM).

Die Kohlenstoffquelle wurde 0,03 bis 0,05 molar nach dem Autoklavieren hinzugefügt. Bei der Herstellung anaeroben Mediums wurde dieses für 25 min mit $\mathrm{N}_{2}$ durchgast, mit einem Butyl-Gummistopfen verschlossen und für $30 \mathrm{~min}$ bei $121^{\circ} \mathrm{C}$ autoklaviert. Als Reduktionsmittel diente eine Cystein-HCl-Lösung, die direkt vor dem Animpfen zugesetzt wurde.

\subsubsection{Carbonyl-Indikator-Medium (CONWAY et al., 1987, modifiziert)}

Um 11 Indikatormedium zu erhalten, wurde 11 LB-Medium (s. 2.2.1) hergestellt, autoklaviert und auf ca. $45^{\circ} \mathrm{C}$ abgekühlt. Zugefügt wurden:

$\begin{array}{lrc}\text { Pararosanilin } & 20 & \mathrm{mg} \\ \mathrm{Na}_{2} \mathrm{~S}_{2} \mathrm{O}_{5} & 100 & \mathrm{mg}\end{array}$


Pararosanilin und Natriumbisulfit wurden vor der Zugabe im Dunkeln in 20 bis $30 \mathrm{ml}$ $\mathrm{H}_{2} \mathrm{O}$ gelöst und der $\mathrm{pH}-$ Wert auf 7,0 eingestellt. Als C-Quellen wurden dem Medium Glycerin, 1,2-Propandiol oder Ethylenglykol in einer Endkonzentration von $1 \%$ zugesetzt.

\subsubsection{Spurenelementelösung SL-4 (PFENNIG und LIPPERT, 1966)}

$\begin{array}{lrr}\mathrm{Na}_{2}-\mathrm{EDTA} & 5,0 & \mathrm{~g} \\ \mathrm{FeSO}_{4} \times 7 \mathrm{H}_{2} \mathrm{O} & 2,0 & \mathrm{~g} \\ \mathrm{ZnSO}_{4} \times 7 \mathrm{H}_{2} \mathrm{O} & 0,1 & \mathrm{~g} \\ \mathrm{MnCl}_{2} \times 4 \mathrm{H}_{2} \mathrm{O} & 0,03 & \mathrm{~g} \\ \mathrm{H}_{3} \mathrm{BO}_{4} & 0,3 & \mathrm{~g} \\ \mathrm{CoCl}_{2} \times 6 \mathrm{H}_{2} \mathrm{O} & 0,2 & \mathrm{~g} \\ \mathrm{CuCl}_{2} \times 2 \mathrm{H}_{2} \mathrm{O} & 0,01 & \mathrm{~g} \\ \mathrm{NiCl}_{2} \times 6 \mathrm{H}_{2} \mathrm{O} & 0,02 & \mathrm{~g} \\ \mathrm{NaMoO}_{4} \times 2 \mathrm{H}_{2} \mathrm{O} & 0,03 & \mathrm{~g} \\ \mathrm{H}_{2} \mathrm{O}_{\text {dest. }} & \text { ad } 1000 & \mathrm{ml}\end{array}$

Der pH-Wert wurde auf 6,7 eingestellt und die Lösung lichtgeschützt bei $4{ }^{\circ} \mathrm{C}$ gelagert.

\subsubsection{Vitaminlösung (WOLIN et al., 1964, modifiziert)}

$\begin{array}{lrc}\text { Biotin } & 2 & \mathrm{mg} \\ \text { Folsäure } & 2 & \mathrm{mg} \\ \text { Pyridoxin x HCl } & 10 & \mathrm{mg} \\ \text { Thiamin x HCl } & 15 & \mathrm{mg} \\ \text { Riboflavin } & 5 & \mathrm{mg} \\ \text { Nikotinsäure } & 5 & \mathrm{mg} \\ \text { Ca-Pantothenat } & 5 & \mathrm{mg} \\ \text { Vitamin B } & 10 & \mu \mathrm{g} \\ \text { p-Aminobenzoesäure } & 5 & \mathrm{mg} \\ \alpha \text {-Liponsäure } & 1 & \mathrm{mg} \\ \mathrm{H}_{2} \mathrm{O}_{\text {dest. }} & \text { ad } 1000 & \mathrm{ml}\end{array}$




\subsubsection{Antibiotika und sonstige Medienzusätze}

Für die Anzucht rekombinanter E. coli-Stämme wurden die in Tabelle 4 aufgeführten Medienzusätze verwendet.

Tabelle 4: Verwendete Medienzusätze und Konzentrationen

\begin{tabular}{lll}
\hline Medienzusatz & Stammlösung & Arbeitskonzentration \\
\hline Ampicillin & $50 \mathrm{mg} / \mathrm{ml} 50 \%$ Ethanol & $50-100 \mu \mathrm{g} / \mathrm{ml}$ \\
Chloramphenicol & $25 \mathrm{mg} / \mathrm{ml} \mathrm{Ethanol}$ & $25-50 \mu \mathrm{g} / \mathrm{ml}$ \\
IPTG & $25 \mathrm{mg} / \mathrm{ml} \mathrm{H}_{2} \mathrm{O}_{\text {dest. }}$ & $50 \mu \mathrm{g} / \mathrm{ml}$ \\
X-Gal & $20 \mathrm{mg} / \mathrm{ml} \mathrm{Dimethylformamid}$ & $40 \mu \mathrm{g} / \mathrm{ml}$ \\
\hline
\end{tabular}

Die IPTG-Stammlösung wurde steril filtriert. Die Zugabe der Komponenten erfolgte erst nach dem Abkühlen der autoklavierten Medien auf mindestens $60{ }^{\circ} \mathrm{C}$. Die Lagerung erfolgte bei $-20^{\circ} \mathrm{C}$.

\section{$2.3 \quad$ Zellanzucht}

\subsubsection{Aerobe Anzucht}

Die aerobe Anzucht von E. coli erfolgte in Reagenzgläsern oder Erlenmeyerkolben. Das Kulturvolumen betrug ca. $20 \%$ des Füllvolumens der Reagenzgläser bzw. Erlenmeyerkolben. Die Kulturen wurden unter Schütteln bei $30{ }^{\circ} \mathrm{C}$ oder $37{ }^{\circ} \mathrm{C}$ inkubiert.

\subsubsection{Anaerobe Anzucht}

Anaerobe Kulturen wurden mit einem 1 bis 10\%igen (v/v) Inokulum aus einer Stammkultur (s. 2.3.3) oder aus einer aeroben Vorkultur beimpft. Die Inkubation erfolgte bei $30^{\circ} \mathrm{C}$ in Hungate-Röhrchen (Anaerobe Test Tubes, Hungate Type, $16 \times 125$ mm, Fa. Bellco Glass Inc., Vineland, New Jersey, USA). Für das Überimpfen wurden sterile Einwegspritzen benutzt. 


\subsubsection{Stammhaltung}

Agarplatten mit E. coli konnten maximal bis zu 8 Wochen bei $4{ }^{\circ} \mathrm{C}$ gelagert werden. Zur längerfristigen Konservierung wurden Stammkulturen angelegt. Dazu wurden diese bei $30^{\circ} \mathrm{C}$ in LB-Medium (s. 2.2.1) angezogen. In der logarithmischen Wachstumsphase wurden dann 0,9 $\mathrm{ml}$ Zellsuspension entnommen, mit 0,1 $\mathrm{ml}$ DMSO versetzt und bei $-70{ }^{\circ} \mathrm{C}$ gelagert. Zur Konservierung von Stammkulturen in Mikrotiterplatten wurden zu jeder150 $\mu 1$ Kultur in jedem „Well“‘ $15 \mu 1$ DMSO gegeben.

\subsubsection{Anzucht von rekombinanten $E$. coli-Stämmen zur heterologen Genexpression}

\subsubsection{Expression mit dem “pET Directional TOPO ${ }^{\circledR}$ Expression”-Kit}

Der “pET Directional TOPO ${ }^{\circledR}$ Expression”-Kit (Fa. Invitrogen, Carlsbad, USA) nutzt die Klonierungsstrategie des "TOPO-Cloning" (s. Abbildung 3 und detaillierte Erklärung des Grundprinzips unter 2.8.3.2), um blunt-end-PCR-Produkte gerichtet in einen "high-level"-Expressionsvektor zu klonieren.

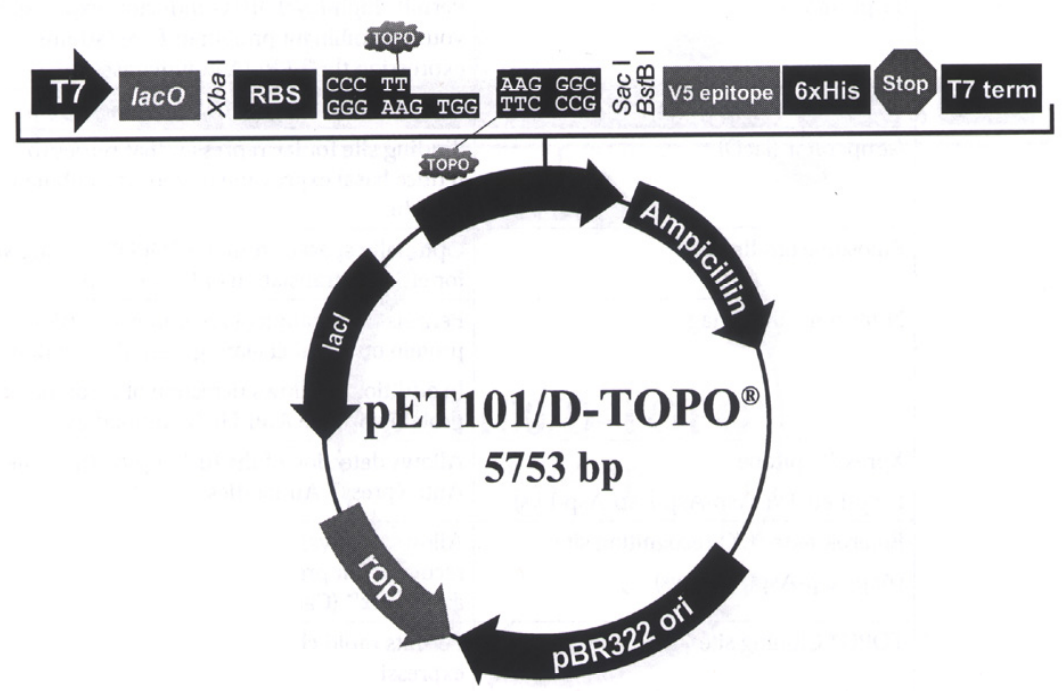

Abbildung 1: Physikalische Karte des Expressionsvektors pET101/D

lacO, lac-Operator; lacI, lac-Repressor; RBS, Ribosomenbindestelle; EK, Enterokinase-Erkennungsstelle; rop, erleichtert "low-copy"-Replikation in E. coli 
Außerdem besteht die Möglichkeit das Zielgen N- oder C-terminal mit einem Tag (u. a. His $_{6}$-Tag) zu versehen, der später eine einfache Detektion mit Antikörpern oder die Reinigung des gebildeten Proteins ermöglicht. Die physikalische Karte des verwendeten Vektors pET101/D ist in Abbildung 1 dargestellt. Die gerichtete TOPO-Klonierung (s. Abbildung 2) wurde durch das Anhängen einer spezifischen Sequenz (5'-CACC) an das durch PCR amplifizierte Zielgen erreicht, die komplementär (3'-GTGG) als Einzelstrang-Überhang auf dem Vektor vorhanden war. Dieser Überhang drang in das 5 '-Ende des PCR-Produkts ein und stabilisierte so die korrekte Orientierung des inserierten Gens.

Das pET-Expressionssystem macht sich die hohe Aktivität und Spezifität der T7-RNAPolymerase zu Nutze. Dies ermöglicht ausgehend vom T7-Promotor eine regulierte Expression von heterologen Genen in E. coli (ROSENBERG et al., 1987; STUDIER und MOFFATT, 1986; STUDIER et al. 1990). Für die Expression wird der E. coliStamm BL21 Star ${ }^{\mathrm{TM}}$ (DE3) herangezogen. Dieser Stamm trägt den defekten, lysogenen $\lambda$-Phagen DE3, der folgende Elemente chromosomal kodiert enthält: den LacRepressor, lacI, die T7-RNA-Polymerase-Gene unter der Kontrolle des lacUV5Promotors und einen Teil des lacZ-Gens.

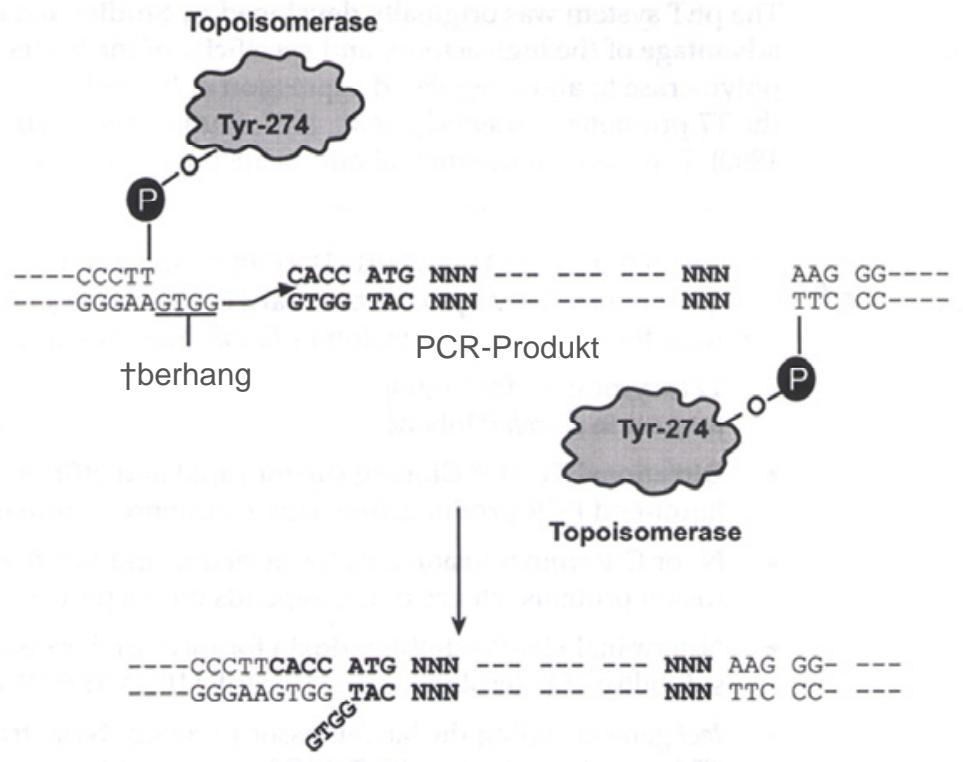

\section{Abbildung 2: Schematische Darstellung der gerichteten TOPO-Klonierung}

Wenn dieser Vektor in einem DE3-lysogenen Stamm etabliert wurde, wirkte der gebildete lac-Repressor zum einen an dem lacUV5-Promotor im Wirtschromosom und reprimierte dort die Expression der T7-Polymerase und zum anderen am T7-Promotor 
des Vektors. Letzteres verhinderte die Expression der inserierten Gene. Die Expression der T7-RNA-Polymerase und der inserierten Gene ließ sich somit durch die Zugabe von IPTG induzieren.

\section{$2.4 \quad$ Bestimmung von Wachstumsparametern}

\subsubsection{Bestimmung der optischen Dichte}

Die Bestimmung der optischen Dichte (OD) erfolgte anhand von Trübungsmessungen bei einer Wellenlänge von $600 \mathrm{~nm}$ in einem Spektralphotometer (UV-VIS Spektrophotometer V-550, Fa. Jasco, Jena) in Plastikküvetten mit einer Schichtdicke von $1 \mathrm{~cm}$. Bei Zelldichten $\mathrm{E}_{600}>0,3$ wurden die Proben mit steriler Nährlösung entsprechend verdünnt. Die Messungen erfolgten gegen Medium als Leerwert.

Die OD bei Wachstumsversuchen konnte direkt im Röhrchen mit Hilfe eines Photometers der Fa. Milton Roy (Spectronic 21, Rochester, New York, USA) bei $600 \mathrm{~nm}$ in einem Extinktionsbereich zwischen 0 und 2,0 verfolgt werden. Als Referenz dienten Röhrchen mit unbeimpftem Medium.

\subsubsection{Bestimmung des $\mathrm{pH}-$ Wertes}

Der pH-Wert wurde mit einem WTW pH-Meter pH 526 (Fa. WTW GmbH, Weilheim) mit einer Glas-Calomel-Elektrode SenTix41 (Fa. WTW GmbH, Weilheim) bestimmt. Vor den Messungen wurde das Gerät für den entsprechenden Messbereich mit Eichlösungen (pH 4,0 und pH 7,0 der Fa. Riedel de Haen AG, Hannover) geeicht.

\subsection{Standardtechniken für das Arbeiten mit Nukleinsäuren}

\subsubsection{Behandlung von Geräten und Lösungen}

Alle hitzestabilen Lösungen und Geräte wurden zur Inaktivierung von Nukleasen für 20 min bei $121{ }^{\circ} \mathrm{C}$ autoklaviert. Hitzelabile Geräte wurden mit $70 \%$ (v/v) Ethanol gewaschen und Metalloberflächen abgeflammt. Hitzelabile Biochemikalien wurden sterilfiltriert. 


\subsubsection{Puffer und Lösungen}

Im Folgenden sind die Zusammensetzungen einiger Puffer und Lösungen aufgeführt, die im nachfolgenden Text nicht näher erläutert werden. Die Herstellung niedrigerer Pufferkonzentrationen erfolgte durch Verdünnung des Puffers mit $\mathrm{H}_{2} \mathrm{O}_{\text {dest. }}$.

\begin{tabular}{lrr}
\hline 10 x TE-Puffer & & \\
1 M Tris-Puffer $(\mathrm{pH} 8,0)$ & 100 & $\mathrm{ml}$ \\
0,5 M EDTA $(\mathrm{pH} \mathrm{8,0)}$ & 10 & $\mathrm{ml}$ \\
$\mathrm{H}_{2} \mathrm{O}_{\text {dest. }}$ & ad 1000 & $\mathrm{ml}$ \\
& & \\
50 x TAE-Puffer & & \\
Tris & 242 & $\mathrm{~g}$ \\
Eisessig & 57 & $\mathrm{ml}$ \\
0,5 M EDTA (pH 8,0) & 100 & $\mathrm{ml}$ \\
$\mathrm{H}_{2} \mathrm{O}_{\text {dest. }}$ & ad 1000 & $\mathrm{ml}$
\end{tabular}

\subsubsection{Fällung, Reinigung und Konzentration von Nukleinsäuren}

\subsubsection{Fällung von Nukleinsäuren}

Die Konzentration von Nukleinsäuren erfolgte durch Fällung mit Ethanol oder Isopropanol. Durch Zugabe von $3 \mathrm{M} \mathrm{Na-Acetat} \mathrm{(pH} \mathrm{5,5)} \mathrm{wurde,} \mathrm{falls} \mathrm{notwendig,} \mathrm{die}$ Ionenstärke erhöht (Endkonzentration 0,3 M). Zur Präzipitation der Nukleinsäuren erfolgte die Zugabe von 2 Vol. Ethanol (96 \%) bzw. 0,6 Vol. Isopropanol (96 \%). Die Ethanolfällung erfolgte durch Inkubation bei $-70{ }^{\circ} \mathrm{C}$ für mindestens $20 \mathrm{~min}$, bei Isopropanol wurde mindestens 5 min bei Raumtemperatur inkubiert. Die Nukleinsäuren wurden durch Zentrifugation (13000 bis $16000 \mathrm{x} \mathrm{g,} 4{ }^{\circ} \mathrm{C}$ oder RT, $30 \mathrm{~min}$ ) pelletiert. Das Pellet wurde mit $1 \mathrm{ml}$ eiskaltem Ethanol (70\%,v/v) gewaschen, getrocknet und in dem gewünschten Volumen sterilem $\mathrm{H}_{2} \mathrm{O}$ oder TE-Puffer aufgenommen.

\subsubsection{DNA-Fällung nach Saccharose-Dichtegradientenzentrifugation}

Ziel dieser Fällung war die Abtrennung von Saccharose nach der SaccharoseDichtegradientenzentrifugation (s. 2.9). Dazu wurde jedes Aliquot aus dem Gradienten mit 0,5 Vol. PEG-NaCl-Lösung (20 \% PEG 6000, 2,5 M NaCl) versetzt und über Nacht 
bei RT inkubiert. Anschließend erfolgte eine Zentrifugation der Lösungen (30 min, 22650 x g, RT). Der Überstand wurde abgenommen, das Pellet mit 0,5 ml Ethanol $(70 \%(\mathrm{v} / \mathrm{v}), \mathrm{RT})$ versetzt und nochmals unter den gleichen Bedingungen zentrifugiert. Wiederum wurde der Überstand abgenommen, das Pellet getrocknet und in 20 - $30 \mu \mathrm{l}$ sterilem $\mathrm{H}_{2} \mathrm{O}$ aufgenommen. Alle Schritte wurden bei RT durchgeführt, da bei Einsatz niedrigerer Temperaturen das Polyethylenglykol ausfällt.

\subsubsection{Mikrodialyse von DNA}

Um die Effizienz der Elektroporation (s. 2.11.2) zu erhöhen, wurden Salze durch eine Mikrodialyse entfernt. Die Dialyse wurde in einer kleinen Petrischale gegen steriles $\mathrm{H}_{2} \mathrm{O}$ als Dialysepuffer durchgeführt. Zunächst wurden kleine Membranfilterscheiben (Porengröße 0,025 $\mu \mathrm{m}$, Fa. Milipore, Eschborn) mit der glänzenden Seite nach oben auf die Wasseroberfläche gegeben. Dann wurden mit einer Pipette vorsichtig 5 bis $10 \mu 1$ der Probe auf die Dialysemembran aufgetragen. Nach 30 min konnten die dialysierten Proben abgenommen werden.

\subsubsection{Dialyse von Umwelt-DNA}

Enthielt die aus den Standort-Proben isolierte DNA zu hohe Salzkonzentrationen, musste sie vor einer weiteren Reinigung zunächst einer Dialyse unterzogen werden. $\mathrm{Zu}$ diesem Zweck wurden 20 bis $30 \mathrm{~cm}$ lange Dialyseschlauchstücke in TE-Puffer autoklaviert. Anschließend wurde die DNA-Lösung in die Schläuche eingefüllt, die an beiden Enden mit Dialyseschlauch-Klammern verschlossen wurden. Die DNA-Lösung wurde dann $24 \mathrm{~h}$ gegen TE-Puffer dialysiert. Nach etwa 4 bis $5 \mathrm{~h}$ wurde der Puffer ausgewechselt. Anschließend erfolgte eine Fällung der DNA mit Ethanol (s. 2.5.3.1).

\subsubsection{Konzentrationsbestimmung von Nukleinsäuren}

Die Bestimmung der Konzentration von Nukleinsäuren in wässriger Lösung erfolgte photometrisch bei einer Wellenlänge von $260 \mathrm{~nm}$.

Eine Extinktion von 1 entspricht etwa:

$50 \mu \mathrm{g} / \mathrm{ml}$ doppelsträngiger DNA,

$40 \mu \mathrm{g} / \mathrm{ml}$ einzelsträngiger DNA oder

$30 \mu \mathrm{g} / \mathrm{ml}$ einzelsträngiger Oligonukleotide.

Die Reinheit von Nukleinsäure-Lösungen konnte durch das Verhältnis $\mathrm{OD}_{260} \mathrm{Zu} \mathrm{OD}_{280}$ bestimmt werden. Bei reinen DNA-Lösungen sollte dieser Wert zwischen 1,8 und 2,0 
liegen (SAMBROOK et al., 1989), niedrigere Werte weisen auf Verunreinigungen mit Proteinen hin.

\subsubsection{Isolierung von DNA-Fragmenten mittels “QIAquick Gel Extraction”- Kit}

Zur Isolierung von DNA-Fragmenten wurde der "QIAquick Gel Extraction"-Kit (Fa. Qiagen GmbH, Hilden) herangezogen. Die Methode beruht auf der Bindung der DNA an eine Silica-Membran in Gegenwart von hohen Salzkonzentrationen. Der Kit kann zur Extraktion von DNA-Fragmenten von einer Größe von 0,1 bis $10 \mathrm{~kb}$ aus Agarosegelen in TAE-Puffer genutzt werden. Die Extraktion erfolgte nach den im Herstellerprotokoll beschriebenen Arbeitsschritten. Die DNA wurde mit $\mathrm{H}_{2} \mathrm{O}_{\text {dest. }}$ eluiert und bis zur weiteren Verwendung bei $-20^{\circ} \mathrm{C}$ aufbewahrt.

\subsubsection{Reinigung von DNA-Fragmenten mittels “QIAquick PCR Purification"-Kit}

Zur Reinigung von PCR-Produkten und anderen linearen DNA-Fragmenten wurde der “QIAquick PCR Purification”-Kit (Fa. Qiagen GmbH, Hilden) genutzt. Wie auch beim “QIAquick Gelextraction”-Kit (s. 2.5.3.6) wird die DNA bei hohen Salzkonzentrationen an eine Silica-Membran gebunden. Die Reinigung wurde nach den Anweisungen des Herstellers durchgeführt. Die Elution der DNA erfolgte mit $\mathrm{H}_{2} \mathrm{O}_{\text {dest. }}$. Die so gereinigten PCR-Produkte wurden bis zu ihrer weiteren Verwendung bei $-20^{\circ} \mathrm{C}$ gelagert.

\subsection{Isolierung von Nukleinsäuren}

\subsubsection{Isolierung von DNA aus Umweltproben (ZHOU et al., 1996)}

Diese Methode der DNA-Isolierung aus Bodenproben beruht auf der direkten Lyse der Zellen, so dass sie vor dem Aufschluss nicht von den Bodenpartikeln abgetrennt werden müssen. Weiterhin wird so die zusätzlich im Boden frei vorliegende DNA erhalten. Zur DNA-Isolierung wurden 50 g Sediment mit 135 ml DNA-Extraktionspuffer (DEP) und $1 \mathrm{ml}$ Proteinase $\mathrm{K}(10 \mathrm{mg} / \mathrm{ml})$ versetzt und für $30 \mathrm{~min}$ bei $37{ }^{\circ} \mathrm{C}$ horizontal geschüttelt (225 Upm). Nach der Zugabe von $15 \mathrm{ml} 20 \%$ SDS (oder $30 \mathrm{ml} 10 \%$ ) wurde das Gemisch für $2 \mathrm{~h}$ bei $65^{\circ} \mathrm{C}$ inkubiert und dabei alle 15 bis 20 min vorsichtig geschüttelt. 
Zur Trennung der bereits gelösten DNA von der Sedimentmatrix wurde anschließend zentrifugiert (10 min, $7000 \mathrm{Upm}$, Rotor GS3, Sorvall Zentrifuge, Fa. Du Pont Instruments, Newton, USA, RT) und der Überstand in einen GS3-Zentrifugenbecher überführt. Das Pellet wurde noch zweimal in je $45 \mathrm{ml}$ DEP und $5 \mathrm{ml} 20 \%$ SDS suspendiert und nach einer 10-minütigen Inkubation bei $65^{\circ} \mathrm{C}$ wie oben beschrieben zentrifugiert.

Zur Extraktion der DNA wurde den gesammelten Überständen 1 Vol. Chloroform/Isoamylalkohol (24:1) zugesetzt und für 10 min bei 7000 Upm (Rotor GS3, Sorvall Zentrifuge, Fa. Du Pont Instruments, Newton, USA) und RT zentrifugiert.

Die Fällung der DNA erfolgte durch Zugabe von 0,6 Vol. Isopropanol für $1 \mathrm{~h}$ bei RT. Nach einer Zentrifugation bei 9000 Upm für 20 min bei RT wurde das Pellet mit eiskaltem Ethanol ( $70 \% \mathrm{v} / \mathrm{v})$ gewaschen und in 4 bis $5 \mathrm{ml}$ sterilem $\mathrm{H}_{2} \mathrm{O}$ aufgenommen.

$\begin{array}{lrrr}\text { DNA-Extraktionspuffer (DEP) } & & \\ \text { Tris } & 100 & \mathrm{mM} \\ \text { EDTA } & 100 & \mathrm{mM} \\ \mathrm{Na}_{2} \mathrm{HPO}_{4} & 100 & \mathrm{mM} \\ \mathrm{NaCl} & 1,5 & \mathrm{M} \\ \mathrm{CTAB} & 1 & \% \\ \text { pH } 8,0 & & \end{array}$

\subsubsection{Reinigung von Umwelt-DNA (HENNE et al., 1999)}

Bei der verwendeten Methode zur Isolierung von DNA aus Standortproben (s. 2.6.1) wurden neben der DNA auch Huminsäuren gefällt, die in nachfolgenden Klonierungsschritten Restriktionsenzyme und Ligase inhibieren können. Durch Reinigung über das "Wizard" Plus Minipreps DNA Purification System" (Fa. Promega Deutschland GmbH, Mannheim) konnten die Huminsäuren zum größten Teil abgetrennt werden. Jedoch ist diese Methode mit einem hohen Verlust an DNA verbunden.

Die Reinigung erfolgte nacheinander über zwei Minisäulen. Dazu wurden $150 \mu$ DNALösung mit $150 \mu \mathrm{l} \mathrm{H}_{2} \mathrm{O}$ verdünnt, mit $1 \mathrm{ml}$ "DNA Purification Resin" versetzt und auf den Säulenkörper gegeben. Nach dem Waschen mit $2 \mathrm{ml}$ "Wash"-Puffer wurde zum Trocknen des Säulenmaterials bei 2000 Upm für 2 min zentrifugiert. Die Elution der 
DNA aus der Säulenmatrix erfolgte mit jeweils $50 \mu 1$ TE-Puffer $\left(65-70{ }^{\circ} \mathrm{C}\right)$. Da bei dieser Methode die Bindekapazität des Säulenmaterials stark überschritten wird, wurde die Elution sechsmal wiederholt. Das vereinigte Eluat wurde wieder mit $1 \mathrm{ml}$ Resin versetzt und auf die zweite Säule aufgetragen. Die Elution wurde viermal wiederholt.

\subsubsection{Isolierung von Plasmid-DNA}

\subsubsection{Plasmidschnellpräparation (HOLMES \& QUIGLEY, 1981)}

Diese Methode diente vor allem zum schnellen Nachweis und zur Charakterisierung von Klonierungsergebnissen.

1,5 ml einer über Nacht gewachsenen Kultur wurden geerntet ( 5000 x g, 5 min, RT) und in $350 \mu$ STET-Puffer suspendiert. Nach Zugabe von $25 \mu l$ Lysozym-Lösung (10 mg/ml 10 mM Tris-HCl, $\mathrm{pH} \mathrm{8,0)} \mathrm{und} \mathrm{einer} \mathrm{kurzen} \mathrm{Inkubation} \mathrm{des} \mathrm{Ansatzes} \mathrm{bei} \mathrm{RT}$ erfolgte anschließend eine Denaturierung für $1 \mathrm{~min}$ bei $100{ }^{\circ} \mathrm{C}$. Zellreste und denaturierte Proteine wurden nach Zentrifugation (16000 x g, $10 \mathrm{~min})$ mit einem sterilen Zahnstocher entfernt. Nach der Zugabe von $40 \mu \mathrm{l} \mathrm{Na-Acetat} \mathrm{(2,5} \mathrm{M,} \mathrm{pH} \mathrm{5,2)}$ und $420 \mu \mathrm{l}$ Isopropanol wurde das Plasmid durch Zentrifugation (16000 x g, 5 min) pelletiert. Das enthaltene Pellet wurde mit Ethanol (70\%, (v/v)) gewaschen, getrocknet und in $50 \mu \mathrm{H}_{2} 0_{\text {dest. }}$ suspendiert.

$\begin{array}{lrr}\text { STET-Puffer } & & \\ \mathrm{NaCl} & 100 & \mathrm{mM} \\ \text { Tris-HCl } & 10 & \mathrm{mM} \\ \text { EDTA } & 1 & \mathrm{mM} \\ \text { Triton X-100 } & 5 & \% \\ \text { pH } 8,0 & & \end{array}$

\subsubsection{Minipräparation von Plasmiden mittels “QIAprep Spin Miniprep Kit”}

Zum Erhalt von sehr sauberer Plasmid-DNA wurde der "QIAprep Spin Miniprep Kit" (Fa. Qiagen) genutzt.

1,5 ml einer 5-ml-Übernachtkultur wurden für 5 min bei $6000 \mathrm{x}$ g zentrifugiert und das Zellpellet in $250 \mu \mathrm{l}$ Puffer P1 suspendiert. Es folgte die Zugabe von $250 \mu$ l Puffer P2, Schwenken bis zum Aufklaren der Lösung und Neutralisation durch Zusatz von $350 \mu 1$ 
Puffer N3. Durch Zentrifugation (10 min, $13000 \mathrm{x} \mathrm{g}$ ) wurden die ausgefällten Proteine und Zelltrümmer sedimentiert. Der Überstand wurde anschließend auf eine „QIAprep“Säule aufgetragen, die eine Silica-Gel-Membran für die selektive Adsorption von Plasmid-DNA enthält. Durch Zentrifugation (1 min, 13000 x g) erfolgte die Bindung der DNA an die Membran, der Durchfluss wurde verworfen. Nach einem Waschschritt mit $750 \mu$ Puffer PE und dem Trocknen durch Zentrifugation (1 min, 13000 x g) wurde die Plasmid-DNA mit 30 bzw. $50 \mu \mathrm{H}_{2} \mathrm{O}_{\text {dest. }}$ eluiert.

Bei der Präparation von Cosmid-DNA wurden in zwei parallelen Ansätzen jeweils $4 \mathrm{ml}$ Übernachtkultur mit zwei Zentrifugationsschritten in je einem $2 \mathrm{ml}$ Reaktionsgefäß pelletiert und anschließend, wie oben beschrieben, mit den Puffern P1, P2 und N3 behandelt. Der gewonnene Überstand in beiden Reaktionsgefäßen wurde nacheinander über eine „QIAprep“-Säule gegeben, so dass die DNA der insgesamt 8 ml Kultur an eine Säule gebunden war. An die Bindung der DNA schloss sich ein Waschschritt mit $500 \mu 1$ PB-Puffer an. Das weitere Vorgehen entsprach dem der Plasmid-Präparation. Die DNA wurde mit $50 \mu 170{ }^{\circ} \mathrm{C}$ warmen $\mathrm{H}_{2} \mathrm{O}_{\text {dest. }}$ eluiert.

Alle verwendeten Puffer wurden vom Hersteller mitgeliefert.

\subsubsection{Minipräparation von Plasmiden mittels „NucleoSpinPlasmid“-Kit}

Alternativ zur Plasmid-Präparation mit dem “QIAprep Spin Miniprep Kit” wurde auch der „NucleoSpinPlasmid“-Kit der Firma Macherey und Nagel genutzt. Prinzip und Vorgehen dieses Kits entsprechen denen des „QIAprep Spin Miniprep Kits“. Es entsprechen sich dabei die Puffer A1 und P1, A2 und P2, A3 (von diesem wurden abweichend $300 \mu \mathrm{l}$ eingesetzt) und N3, AW und PB sowie A4 (von diesem wurden alternativ $600 \mu$ l eingesetzt) und PE. Alle verwendeten Puffer wurden vom Hersteller mitgeliefert.

\subsubsection{Präparative Plasmidisolierung über Anionenaustausch- chromatographie}

Die Isolierung größerer Mengen an Plasmid-DNA erfolgte nach alkalischer Lyse mit den Puffern P1, P2 und P3 über Anionenaustauschchromatographie (Qiagen Plasmid Midi-Kit, Fa. Qiagen).

$25 \mathrm{ml}$ Zellkultur wurden bei einer $\mathrm{OD}_{600}$ von 1 bis 1,5 geerntet und in $4 \mathrm{ml}$ P1-Puffer suspendiert. Es folgte die Zugabe von $4 \mathrm{ml}$ P2-Puffer und eine Inkubation für 5 min bei RT. Anschließend wurden $4 \mathrm{ml}$ P3-Puffer zugefügt und für $30 \mathrm{~min}$ auf Eis inkubiert. 
Nach Zentrifugation (30 min, $16000 \mathrm{x} \mathrm{g}, 4{ }^{\circ} \mathrm{C}$ ) wurde der Überstand abgenommen und zur vollständigen Aufklarung erneut für 15 min zentrifugiert.

Der dabei erhaltene Überstand konnte dann auf eine mit $4 \mathrm{ml}$ QBT-Puffer äquilibrierte „Quiagen-tip-100“-Säule aufgetragen. Es folgte ein Waschschritt mit $20 \mathrm{ml}$ QC-Puffer und die Elution der Plasmid-DNA durch Zugabe von $5 \mathrm{ml}$ QF-Puffer. Die DNA wurde mit 0,7 Vol. Isopropanol gefällt und durch Zentrifugation (30 min, $16000 \mathrm{x} \mathrm{g}, 4{ }^{\circ} \mathrm{C}$ ) pelletiert. Das Sediment wurde anschließend mit Ethanol (70 \%, v/v) gewaschen und getrocknet und in 100 bis $200 \mu \mathrm{H}_{2} \mathrm{O}$ aufgenommen.

Für die Isolierung von Plasmid-DNA aus größeren Kulturvolumina als $100 \mathrm{ml}$ wurde die Menge an P1, P2 und P3 entsprechend erhöht. Die Anionenaustauschchromatographie erfolgte dann in mehreren Durchgängen, wobei die Säule nach jeder Elution mit $4 \mathrm{ml}$ QBT-Puffer neu äquilibriert wurde. Auf diese Weise wurde PlasmidDNA aus Kulturvolumina bis $250 \mathrm{ml}$ isoliert.

Alle verwendeten Puffer wurden vom Hersteller mitgeliefert.

\subsubsection{Robotgesteuerte Plasmidpräparation}

Die große Menge zu sequenzierender rekombinanter Plasmide in einem Sequenzierungsprojekt macht eine Automatisierung der Plasmidpräparation notwendig. Mittels eines robotgesteuertem Systems (Qiagen-BioRobot 9600 ${ }^{\circledR}$ ) konnte die Präparation von Plasmid-DNA im 96er Maßstab durchgeführt werden (http://www.qiagen.com/literature/handbooks/qp/1019952_QPHB_prot04.pdf).

Ausgangsmaterial war dabei ein 96er „Flat-Bottom-Block“, der pro Loch (,Well“) 1,3 ml TB-Medium mit dem entsprechenden Antibiotikum enthielt. Der Block wurde manuell mit 96 rekombinanten Klonen beimpft. Dazu wurden entsprechende einzeln liegende Kolonien von einer Agarplatte mittels Zahnstocher in die einzelnen „Wells“ überimpft. Die Anzucht des mit einem luftdurchlässigen „Aerosheet“ abgeklebten Blocks erfolgte ü. N. (mindestens $18 \mathrm{~h}$ ) bei $37^{\circ} \mathrm{C}$ im Schüttelinkubator (350 Upm). Abzentrifugiert wurde der Block für 20 min bei 3300 Upm mit einer Plattenzentrifuge (Heraeus 2.0 Megafuge). Dieser Block wurde dann in das Robotsystem QiagenBioRobot $9600^{\circledR}$ eingespannt. Prinzipiell erfolgte die Aufreinigung der Plasmid-DNA, wie unter 2.6.3.2 erläutert, über Anionenaustauschchromatographie. Die Puffer P1, P2 und P3 wurden automatisch über eine Nadel in die „Wells“ des „Flat-Bottom-Blocks“ pipettiert. Anschließend transferierte das System das Lysat aus dem Block heraus in 
eine 96er „TurboFilter“-Platte. Automatisch wurde nun durch Anlegen eines Vakuums das gebildete Präzipitat - bestehend aus Zellproteinen und hochmolekularer DNA - aus dem Lysat herausgefiltert. Die das Präzipitat enthaltende „TurboFilter“-Platte wurde verworfen. Der Durchfluss wurde in einer unter der „TurboFilter“-Platte befindlichen 96er „QIAprep“-Platte aufgefangen, welche aus 96 AnionenaustauschchromatographieSäulchen bestand. Die im Durchfluss enthaltene Plasmid-DNA wurde durch erneutes Anlegen eines Vakuums an die 96 Säulchen der „QIAprep“-Platte gebunden, und anschließend mit den Puffern PB und PE gewaschen. Nach Trocknung der „QIAprep“Platte erfolgte die Elution der Plasmid-DNA in eine 96er Mikrotiter-Platte mit $100 \mu \mathrm{l}$ $\mathrm{H}_{2} \mathrm{O}$ pro „Well“. Ausbeuten rangierten i. d. R. im Bereich von 100-300 ng/ $\mu$ l.

\subsection{Gelelektrophorese von Nukleinsäuren}

\subsubsection{Standard-Agarose-Gelelektrophorese}

Zur analytischen Auftrennung von DNA-Fragmenten diente die Standard-AgaroseGelelektrophorese (SAMBROOK et al., 1989). Es wurden Gele mit einem Volumen von 10 bis $25 \mathrm{ml}$ gegossen. Die Agarosekonzentration variierte zwischen 0,8 und 1,5\%. Die Proben wurden vor dem Auftragen mit 0,2 Volumen Stopp-Mix versetzt, um sie zu beschweren und um die Lauffront zu markieren. Als Elektrophoresepuffer wurde 1-fach TAE-Puffer verwendet. Die Elektrophorese wurde bei einer konstanten Spannung zwischen 40 und $100 \mathrm{~V}$ durchgeführt, wodurch sich je nach Gelgröße eine Laufzeit von 1 bis $4 \mathrm{~h}$ ergab. Nach Beendigung der Elektrophorese wurden die Agarosegele in einem Ethidiumbromidbad $\left(1 \mu \mathrm{g} / \mathrm{ml} \mathrm{H}_{2} \mathrm{O}\right)$ für 10 bis 30 min angefärbt. Nach kurzem Entfärben im Wasserbad konnten die Gele auf der Gel Doc 2000-Anlage (Fa. Biorad, München) bei Licht der Wellenlänge $254 \mathrm{~nm}$ begutachtet werden. Zur Dokumentation diente ein Videoprinter (Intas Video Graphic Printer UP-890 CE, Fa. Sony Corporation, Japan), der eine Bildübertragung auf Thermopapier ermöglichte.

$\begin{array}{lrr}\text { Stopp-Mix } & & \\ \text { Saccharose } & 50 & \%(\mathrm{w} / \mathrm{v}) \\ \text { Harnstoff } & 7 & \mathrm{M} \\ \text { EDTA } & 1 & \mathrm{mM} \\ \text { Bromphenolblau } & 0,1 & \%(\mathrm{w} / \mathrm{v})\end{array}$




\subsection{2 „Pulse-field“-Gelelektrophorese}

Die „Pulse-field“-Gelelektrophorese wurde mit dem „Rotaphor R 23“ der Firma Biometra (Göttingen) durchgeführt. Die Vorbereitungen des Gerätes und die Herstellung des Agarose-Gels erfolgten nach Herstellerangaben. Es wurde die „SeaKem ${ }^{\circledR}$ Gold Agarose“ (Fa. Biozym) eingesetzt. Die Elektrophorese fand für 23 Stunden bei $13{ }^{\circ} \mathrm{C}$ und einer logarithmisch von $180 \mathrm{~V}$ auf $120 \mathrm{~V}$ sinkenden Spannung statt. Der Winkel nahm linear von $120^{\circ}$ bis $110^{\circ}$ und das „Pulse“-Intervall logarithmisch von $30 \mathrm{~s}$ auf $5 \mathrm{~s}$ ab.

\section{$\underline{\text { TBE-Puffer }}$}

$\begin{array}{lrr}\text { Tris } \mathrm{HCl} & 89 & \mathrm{mM} \\ \text { Borsäure } & 89 & \mathrm{mM} \\ \text { EDTA } & 2 & \mathrm{mM} \\ \mathrm{pH} 8,3 & & \end{array}$

\subsubsection{Größenbestimmung von Nukleinsäuren}

Als Größenstandard für lineare DNA-Fragmente wurde für die Standard-AgaroseGelelektrophorese der "Ladder-Mix" (Fa. MBI Fermentas, St. Leon-Rot) eingesetzt.

Die Größen der Fragmente betrugen in kb:

$\begin{array}{llll}10,0 & 3,5 & 1,2 & 0,6 \\ 8,0 & 3,0 & 1,03 & 0,5 \\ 6,0 & 2,5 & 0,9 & 0,4 \\ 5,0 & 0,8 & 0,3 \\ 4,0 & 2,0 & 0,7 & \end{array}$

und 2 weitere kleinere Fragmente, die meist im Gel nicht mehr sichtbar waren.

In der „Pulse-field“-Gelelektrophorese wurden die Standards „Lamda Ladder PFG Marker“ und der „Yeast Chromosome PFG Marker“" verwendet:

Der „Lamda Ladder PFG Marker“ enthält Fragmente der folgenden Größen: 48,5 kb, 97 kb, 145 kb, 194 kb, 242,5 kb, 291 kb, 339,5 kb, 388 kb, 436,5 kb, 485,0 kb, 533 kb, $582 \mathrm{~kb}, 630 \mathrm{~kb}, 679 \mathrm{~kb}, 727,5 \mathrm{~kb}, 776 \mathrm{~kb}, 824,5 \mathrm{~kb}, 873 \mathrm{~kb}, 921,5 \mathrm{~kb}, 970 \mathrm{~kb}, 1,018 \mathrm{~kb}$. 
Der „Yeast Chromosome PFG Marker“ zeigt folgende Banden: 1900 kb, 1640 kb, $1120 \mathrm{~kb}, 1100 \mathrm{~kb}, 945 \mathrm{~kb}, 915 \mathrm{~kb}, 815 \mathrm{~kb}, 785 \mathrm{~kb}, 745 \mathrm{~kb}, 680 \mathrm{~kb}, 610 \mathrm{~kb}, 555 \mathrm{~kb}$, $450 \mathrm{~kb}, 375 \mathrm{~kb}, 295 \mathrm{~kb}, 225 \mathrm{~kb}$.

\subsection{Enzymatische Modifikation von DNA}

\subsubsection{Schneiden von DNA durch Restriktionsendonukleasen}

Die Sequenz-spezifische Spaltung von DNA mit Restriktionsendonukleasen lieferte lineare DNA-Fragmente mit definierten Enden. Die Spaltung erfolgte in den vom Hersteller mitgelieferten Puffersystemen bei den empfohlenen Temperaturen. Die Ansätze wurden mit einem Gesamtvolumen von mindestens $15 \mu 1$ für 2 bis 15 Stunden durchgeführt. Zur Vermeidung einer $\mathrm{zu}$ hohen Glycerinkonzentration im Reaktionsansatz durfte das Volumen der zugegebenen Enzymlösung höchstens 1/10 des Gesamtvolumens betragen.

Die partielle Spaltung von Standort-DNA wurde zeitlimitiert durchgeführt. Es wurde routinemäßig mit $1 \mathrm{U}$ Restriktionsenzym gearbeitet. Die Verdauung wurde in bestimmten Zeitabständen durch Zugabe von EDTA (20 mM) und Inkubation auf Eis gestoppt. Die partielle Spaltung der Cosmide zur Erstellung der ShotgunPlasmidgenbanken erfolgte enzymlimitiert. Dafür wurde ausgehend von 0,5 U Enzym pro $40 \mu \mathrm{l}$ Ansatz über eine Verdünnungsreihe in 1:2-Verdünnungsschritten die Enzymkonzentration bis zur Verdünnungsstufe 1/512 reduziert. Die Restriktion erfolgte für $20 \mathrm{~min}$ bei $37^{\circ} \mathrm{C}$ und wurde für $15 \mathrm{~min}$ bei $65^{\circ} \mathrm{C}$ abgestoppt.

\subsubsection{Dephosphorylierung von DNA-Fragmenten}

Zur Erhöhung der Effizienz einer Ligationsreaktion zwischen Insert-DNA und VektorDNA wurde die Vektor-DNA an den 5'-Enden dephosphoryliert. Auf die Weise sollte eine Rezirkularisierung des Vektors verhindert werden. Es wurde die alkalische Phosphatase der Fa. MBI Fermentas GmbH eingesetzt. Nach vollständiger Spaltung des Vektors wurde $1 \mathrm{U}$ alkalische Phosphatase pro $\mu \mathrm{g}$ DNA zugesetzt und für $30 \mathrm{~min}$ bei $37^{\circ} \mathrm{C}$ inkubiert. 


\subsubsection{Ligation von DNA-Fragmenten}

\subsubsection{Ligation mit T4-DNA-Ligase}

Zur Verknüpfung von linearisierter, dephosphorylierter Vektor- und Insert-DNA wurde T4-DNA-Ligase eingesetzt, die in Anwesenheit von ATP eine Phosphordiesterbindung zwischen 3'-OH- und 5'- $\mathrm{PO}_{4}$-Enden von Nukleinsäuren katalysiert. Die Ligationen wurden in einem Volumen von $20 \mu$ durchgeführt. Es wurden jeweils 0,2 bis $1 \mu \mathrm{g}$ Vektor- bzw. Insert-DNA eingesetzt. Der Ansatz enthielt weiterhin 1 U T4-DNA-Ligase und in 1-facher Konzentration den vom Hersteller mitgelieferten Reaktionspuffer. Die Ligationsansätze mit kohäsiven Enden wurden über Nacht bei $16{ }^{\circ} \mathrm{C}$, für 2 bis $4 \mathrm{~h}$ bei Raumtemperatur oder für $48 \mathrm{~h}$ bei $4{ }^{\circ} \mathrm{C}$ inkubiert. Zur Ligation glatter Enden wurden 2 U Ligase eingesetzt und die Ansätze für $1 \mathrm{~h}$ bei $37^{\circ} \mathrm{C}$ inkubiert.

\subsubsection{Klonierung mit dem “TOPO-TA-Cloning®"-Kit}

Für eine besonders effektive Klonierung von PCR-Produkten, die mit der Taq-DNAPolymerase in einer Polymerasekettenreaktion (s. 2.10.1) amplifiziert wurden, wurde der “TOPO-TA-Cloning ${ }^{\circledR}$ "-Kit (Fa. Invitrogen) verwendet. Für diese Art der Klonierung wird keine Ligase benötigt.

Die Taq-DNA-Polymerase besitzt eine von der Matrize unabhängige terminale Transferase-Aktivität und hängt an die 3'-Enden von PCR-Produkten einzelne Desoxyadenosine (A) an. Der im Kit vorhandene, bereits linearisierte Vektor pCR2.1TOPO besitzt analog dazu an den 3'-Enden einzelne Desoyxthymidin-Reste (T). Dies erlaubt eine Ligation nach der sogenannten TA-Methode. Des Weiteren besitzt der Vektor die kovalent gebundene Topoisomerase I des Vaccinia-Virus. Die Topoisomerase I bindet an spezifische Sequenzen doppelsträngiger DNA und spaltet dort das Phosphordiester-Gerüst stromabwärts der Sequenz 5'-CCCTT in einem Strang (SHUMAN, 1991). Die Energie dieser Spaltungsreaktion wird durch Ausbildung einer kovalenten Bindung zwischen dem 3'-Phosphat des gespaltenen Stranges und dem Tyrosin-274 der Topoisomerase I konserviert. Die Reaktion zwischen DNA und Protein kann durch den Angriff des 5'-Hydroxyl-Restes umgekehrt werden, was dann zur Abspaltung der Topoisomerase I führt (SHUMAN, 1994). Dieses Prinzip wird zur effizienten Klonierung von PCR-Produkten genutzt (s. Abbildung 3). 


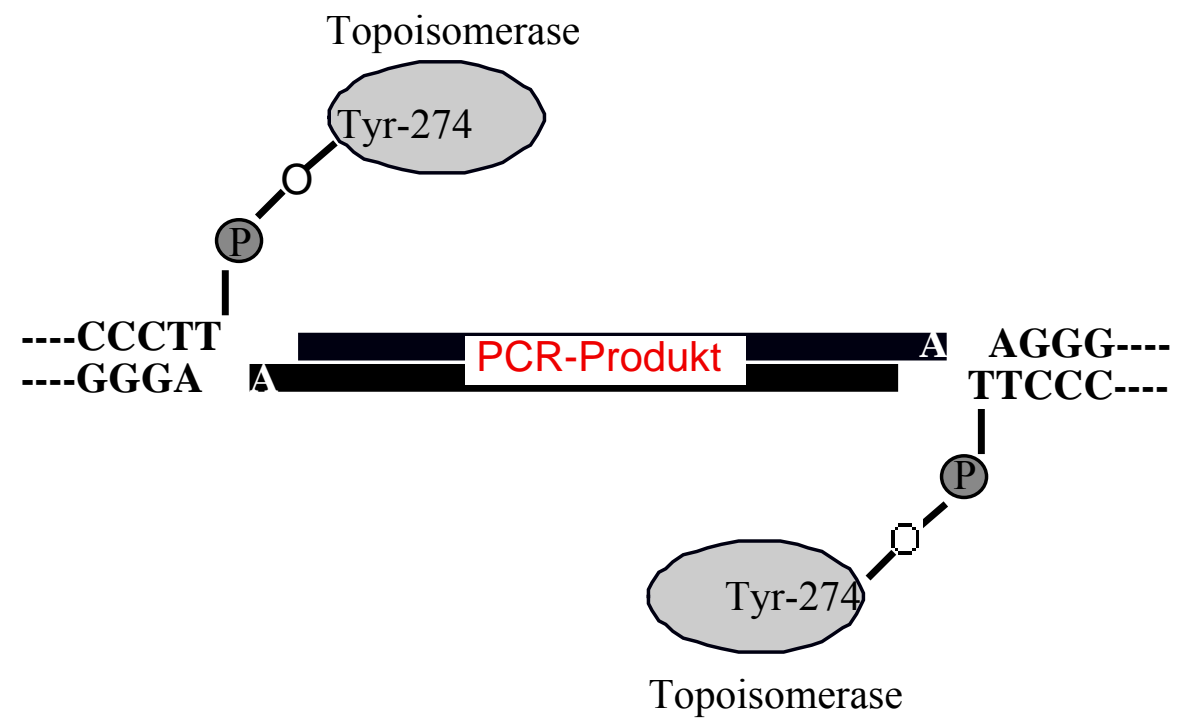

Abbildung 3: Schematische Darstellung der TOPO-TA-Klonierung

\subsection{Saccharose-Dichtegradientenzentrifugation (SAMBROOK et al., 1989; modifiziert)}

Die Größenfraktionierung von Fragmenten partiell verdauter, chromosomaler DNA, die zur Klonierung eingesetzt werden sollte, erfolgte mittels einer SaccharoseDichtegradientenzentrifugation. Bei dieser sehr schonenden Methode werden die verschiedenen Fragmentgrößen entsprechend ihrer Schwebedichte im Saccharosegradienten getrennt. Zunächst wurde ein Saccharose-Stufengradient (10 $40 \%$ ) in 10 ml-Zentrifugenröhrchen (Sorvall Polyallomer 3699, Fa. Du Pont de Nemours Deutschland GmbH, Dreieich) hergestellt. Dazu wurden je 1,9 ml $40 \%$, $32,5 \%, 25 \%, 17,5 \%$ und $10 \%$ Saccharose (jeweils w/v in $1 \mathrm{M} \mathrm{NaCl}, 20 \mathrm{mM}$ Tris$\mathrm{HCl}, 5$ mM EDTA, pH 8,0) beginnend mit der höchsten Konzentration übereinander geschichtet und nach jeder Stufe eingefroren. Auf den fertigen Gradienten wurde 100 $200 \mu \mathrm{g}$ partiell verdaute chromosomale DNA aufgetragen. Die Zentrifugation erfolgte in einem "swing-out"-Rotor (Sorvall TH641, Fa. Du Pont de Nemours) in einer Ultrazentrifuge (Sorvall OTD 55 B, 27000 Upm, 24 h, $20^{\circ} \mathrm{C}$ ). Zur Ernte des Gradienten wurden vorsichtig je $400 \mu \mathrm{l}$ von oben beginnend abgenommen. Anschließend erfolgte eine DNA-Fällung mit PEG/NaCl aus Saccharose (s. 2.5.3.2). $10 \mu$ jeder dritten Fraktion wurden durch Agarose-Gelelektrophorese (s. 2.7.1) auf Größe und Qualität hin überprüft. 


\subsection{Polymerase-Kettenreaktion (PCR)}

\subsubsection{Amplifikation von DNA-Fragmenten mit der Taq- oder Pfu-DNA- Polymerase}

Die Polymerase-Kettenreaktion (PCR) wurde zur Herstellung spezifischer DNAFragmente für Klonierungen oder Sequenzierungen verwendet. Als Enzyme wurden die Taq-DNA-Polymerase (Fa. MBI Fermentas) und die Pfu-DNA-Polymerase (Fa. MBI Fermentas) eingesetzt. Die Reaktionen wurden entsprechend den Herstellerempfehlungen in einem Volumen von $50 \mathrm{bzw} .100 \mu \mathrm{l}$ durchgeführt und enthielten folgende Bestandteile:

$\begin{array}{lrr}\text { DNA } & 0,5-1 & \mu \mathrm{g} \\ \text { Oligonukleotide } & \text { je } 100 & \text { pmol } \\ \text { dNTP-Gemisch } & 200 & \mu \mathrm{M} \\ \text { DNA Polymerase } & 1 & \mathrm{U} \\ \text { Reaktionspuffer (10x) } & 10 & \mu \mathrm{l} \\ \mathrm{MgCl}_{2} \text { oder } \mathrm{MgSO}_{4} & 1,5 & \mathrm{mM} \\ \mathrm{H}_{2} \mathrm{O}_{\text {dest. }} & \text { ad } 100 & \mu \mathrm{l}\end{array}$

Die Temperaturzyklen wurden den jeweiligen Anforderungen in Bezug auf die Hybridisierungstemperatur (x) und die Dauer der Kettenverlängerung (y) angepasst. Sie wurden nach folgendem Schema durchgeführt:

\begin{tabular}{|c|c|c|}
\hline \multirow{4}{*}{30 Zyklen } & Denaturierung & $95^{\circ} \mathrm{C}$ \\
\hline & Denaturierung & $95^{\circ} \mathrm{C}$ \\
\hline & Hybridisierung & $\mathrm{x}^{\circ} \mathrm{C}$ \\
\hline & Kettenverlängerung & 72 o. $75^{\circ} \mathrm{C}$ \\
\hline Ende der Zyklen & Kettenverlängerung & 72 o. $75^{\circ} \mathrm{C}$ \\
\hline
\end{tabular}

Für die Einstellung der Parameter waren die zu erwartende Fragmentlänge und die Schmelztemperatur $T_{m}$ der verwendeten Oligonukleotide entscheidend. Für die Hybridisierung wurde entsprechend der zu erwartenden Fragmentlänge eine Zeit von ca. 1 min/1000 Bp gewählt. Die optimale Hybridisierungstemperatur wurde nach der 
Schmelztemperatur $\mathrm{T}_{\mathrm{m}}$ der Oligonukleotide festgelegt, die über folgende Formel errechnet wurde:

$\mathrm{T}_{\mathrm{m}}=69,3+0,41(\%$ GC-Gehalt $)-650 / \mathrm{L}$

$\mathrm{L}=$ Länge des Oligonukleotids

$\%$ GC-Gehalt $=$ prozentualer GC-Gehalt des Oligonukleotids

Durch Verkürzung der Hybridisierungsdauer, Verringerung der Oligonukleotidkonzentration und Variation der $\mathrm{MgCl}_{2}$-Konzentration konnte die Spezifität der PCR optimiert werden.

Bei der 16S rRNA-Gen spezifischen PCR wurden stark verlängerte Zeiten (ca. $3 \mathrm{x}$ ) für die Kettenverlängerung verwendet, um die Entstehung von chimeren Sequenzen zu minimieren (MEYERHANS et al., 1990; WANG und WANG, 1996).

Die Temperaturzyklen wurden mit dem "Mastercycler Gradient" (Fa. Eppendorf, Hamburg) durchgeführt. Die PCR-Produkte wurden durch Agarose-Gelelektrophorese (s.2.7.1) analysiert.

\subsubsection{Amplifikation von DNA-Fragmenten mit der KOD Hifi DNA Polymerase (Fa. Novagen)}

Für die Amplifikation längerer DNA-Fragmente, die blunt-end in den pET101/DTOPO-Vektor kloniert werden sollten, wurde die KOD Hifi DNA Polymerase (Fa. Novagen) eingesetzt. Diese Polymerase hat eine „Proofreading“-Aktivität und extrem kurze Hybridisierungs- und Verlängerungszeiten. Dadurch wichen das Pipettierschema und die Temperaturzyklen extrem von den der anderen verwendeten Polymerasen ab.

$\begin{array}{lrr}\text { DNA } & 0,5-1 & \mu \mathrm{g} \\ \text { Oligonukleotide } & 0,4 & \mu \mathrm{M} \\ \text { dNTP-Gemisch } & 200 & \mu \mathrm{M} \\ \text { DNA Polymerase } & 1 & \mathrm{U} \\ \text { Reaktionspuffer (10x) } & 5 & \mu \mathrm{l} \\ \mathrm{MgCl}_{2} & 1 & \mathrm{mM} \\ \mathrm{H}_{2} \mathrm{O}_{\text {dest. }} & \operatorname{ad~} 50 & \mu \mathrm{l}\end{array}$


$\underline{\text { Fragmentgröße 1-2 kb }}$

$\begin{array}{lrr}\text { Denaturierung } & 98{ }^{\circ} \mathrm{C} & 5 \mathrm{~min} \\ \text { Zyklen } & 25 & \\ \text { Denaturierung } & 98{ }^{\circ} \mathrm{C} & 15 \mathrm{~s} \\ \text { Hybridisierung } & \mathrm{T}_{\mathrm{m}}-5{ }^{\circ} \mathrm{C} & 2 \mathrm{~s} \\ \text { Kettenverlängerung } & 72 & 20 \mathrm{~s}\end{array}$

$\underline{\text { Fragmentgröße 3-4 kb }}$

$\begin{array}{lrr}\text { Denaturierung } & 98^{\circ} \mathrm{C} & 5 \mathrm{~min} \\ \text { Zyklen } & 25-30 & \\ \text { Denaturierung } & 98^{\circ} \mathrm{C} & 15 \mathrm{~s} \\ \text { Hybridisierung } & \mathrm{T}_{\mathrm{m}}-5^{\circ} \mathrm{C} & 5 \mathrm{~s} \\ \text { Kettenverlängerung } & 72 & 40 \mathrm{~s}\end{array}$

\subsection{1 Übertragung von DNA in E. coli und Selektion rekombinanter Klone}

\subsubsection{Hocheffiziente Transformation in E. coli (INOUE et al., 1990)}

Zur Herstellung hocheffizienter Transformanten wurde E. coli aus einer Stammkultur auf eine LB-Agar-Platte ausgestrichen und über Nacht bei $37^{\circ} \mathrm{C}$ inkubiert. Aus 10 bis 12 Einzelkolonien wurde eine $5 \mathrm{ml}$ Vorkultur angeimpft. Diese diente als Inokulum für $250 \mathrm{ml}$ SOB-Medium (s. 2.2.3). Diese Kultur wurde bei $16{ }^{\circ} \mathrm{C}$ schüttelnd bis zu einer $\mathrm{OD}_{600}$ von 0,6 inkubiert. Nach einer Inkubation für $10 \mathrm{~min}$ auf Eis wurden die Zellen zentrifugiert (10 min, $2500 \mathrm{x} \mathrm{g}, 4^{\circ} \mathrm{C}$ ), in $80 \mathrm{ml}$ eiskalter TB-Lösung suspendiert und für 10 min auf Eis abgekühlt. Es folgte eine Zentrifugation der Zellen (10 min, 2500 x g, $4{ }^{\circ} \mathrm{C}$ ) und Suspension in $20 \mathrm{ml}$ TB-Lösung mit DMSO (Endkonzentration 7 \%, v/v). Nach einer Inkubation für 10 min auf Eis wurden Aliquots von $200 \mu \mathrm{l}$ in flüssigem $\mathrm{N}_{2}$ eingefroren und direkt zur Transformation eingesetzt oder bei $-70{ }^{\circ} \mathrm{C}$ gelagert.

Zur Transformation wurden $200 \mu \mathrm{l}$ Zellsuspension auf Eis aufgetaut und nach der Zugabe von 1 bis $20 \mu$ DNA-Lösung (ca. 10 bis $500 \mathrm{ng}$ ) für 30 min auf Eis inkubiert. 
Es folgte ein Hitzeschock für 1 min bei $42{ }^{\circ} \mathrm{C}$, eine kurze Inkubation auf Eis und die Zugabe von $0,8 \mathrm{ml}$ LB-Medium. Zur Ausprägung der plasmidkodierten Antibiotikaresistenz wurden die Ansätze für 60 min bei $37{ }^{\circ} \mathrm{C}$ inkubiert und anschließend die Suspension auf LB-Agarplatten mit entsprechendem Antibiotikum ausplattiert.

$\begin{array}{lrc}\text { TB-Lösung } & & \\ \text { Pipes } & 10 & \mathrm{mM} \\ \mathrm{MnCl}_{2} & 55 & \mathrm{mM} \\ \mathrm{CaCl}_{2} & 15 & \mathrm{mM} \\ \mathrm{KCl} & 250 & \mathrm{mM} \\ \mathrm{pH} 6,7 & & \end{array}$

Das $\mathrm{MnCl}_{2}$ wurde ungelöst und separat autoklaviert.

\subsubsection{Transformation in E. coli durch Elektroporation (DOWER et al., 1988)}

Diese Methode beruht auf der Permeabilisierung der Zellmembran durch Elektroschock. Dieser verursacht einen kurzfristigen reversiblen lokalen Zusammenbruch des Membranpotentials bzw. eine Desorganisation der Membranstruktur (CHASSY et al., 1988) und erleichtert damit die Aufnahme von Makromolekülen wie z. B. PlasmidDNA in die Zelle.

Zur Herstellung elektrokompetenter Zellen wurde eine 5-ml-Übernachtkultur in $250 \mathrm{ml}$ LB-Medium (s. 2.2.1) überimpft und bei $30^{\circ} \mathrm{C}$ unter Schütteln bis zu einer $\mathrm{OD}_{600}$ von 0,5 bis 1,0 inkubiert. Die Kultur wurde für 15 bis 30 min auf Eis gehalten und danach für $10 \mathrm{~min}$ bei $5000 \mathrm{x}$ g und $4{ }^{\circ} \mathrm{C}$ zentrifugiert. Das Pellet wurde zweimal mit 1 Volumen $\mathrm{H}_{2} \mathrm{O}_{\text {dest. }}$ und anschließend mit $10 \mathrm{ml}$ Glycerin $(10 \%$, (v/v)) gewaschen. Abschließend erfolgte die Suspendierung in 0,5 ml Glycerin (10\%, v/v). Aliquots der Suspension wurden bei $-70{ }^{\circ} \mathrm{C}$ gelagert.

Pro Ansatz wurden $40 \mu 1$ Zellsuspension auf Eis aufgetaut, in eine sterile, vorgekühlte Elektroporationsküvette (Elektrodenabstand $0,2 \mathrm{~cm}$ ) überführt und mit 1 bis $5 \mu \mathrm{l}$ dialysierter DNA-Lösung versetzt. Die Elektroporation erfolgte in einem Gene Pulser TM (Bio Rad Laboratories GmbH, München) bei $25 \mu \mathrm{F}, 200 \Omega$ und 2,5 kV, wodurch eine Feldstärke von $12,5 \mathrm{kV} / \mathrm{cm}$ und eine Zeitkonstante von 3,5 bis 4,5 ms erreicht 
wurde. Nach dem Stromimpuls wurden die Zellen sofort in $1 \mathrm{ml}$ LB-Medium aufgenommen, 60 min bei $37^{\circ} \mathrm{C}$ inkubiert und anschließend auf LB-Agarplatten mit den entsprechenden Antibiotika ausplattiert.

\subsubsection{Transduktion}

\subsubsection{Transduktion mit den “Gigapack $®$ III Gold Packaging Extract”}

Zunächst wurden die vom Hersteller (Fa. Stratagene, San Diego, USA) gelieferten, bei $-70{ }^{\circ} \mathrm{C}$ gelagerten Lysate durch Reiben zwischen den Fingern aufgetaut. Dann wurden sofort $0,1-1,0 \mu \mathrm{g} \quad(\max .4 \mu \mathrm{l})$ ligierte DNA hinzugefügt und vorsichtig mit der Pipettenspitze gemischt. Anschließend wurde das Gemisch kurz (3 - 5 s) zentrifugiert und für $2 \mathrm{~h}$ bei RT inkubiert. Anschließend wurden $500 \mu \mathrm{l}$ SM-Puffer und $20 \mu \mathrm{l}$ Chloroform zugefügt, vorsichtig gemischt und zum Sedimentieren des "Abfalls" kurz (5-10 s) zentrifugiert. Die in Phagenköpfe verpackte DNA befand sich nun im Überstand und konnte bei $4{ }^{\circ} \mathrm{C}$ bis zu 4 Wochen aufgehoben werden.

Für die Infektion mit den durch den "Gigapack ${ }^{\circledR}$ III Gold Packaging Extract" ( Fa. Stratagene) in vitro verpackten Ligationsansätzen wurden E. coli XL1blue eingesetzt. Zur Ausbildung des für die Transduktion notwendigen $\lambda$-Rezeptors wurden die Stämme in LB-Medium (s. 2.2.1) mit 0,2\% (w/v) Maltose und $10 \mathrm{mM} \mathrm{MgSO}_{4}$ für 6 bis $8 \mathrm{~h}$ bei $37^{\circ} \mathrm{C}$ oder für $12 \mathrm{~h}$ bei $30{ }^{\circ} \mathrm{C}$ angezogen. Das Pellet wurde in $\mathrm{MgSO}_{4}$-Lösung (10 mM) suspendiert und auf eine $\mathrm{OD}_{600}$ von 0,5 - 1,0 eingestellt. Diese Suspension wurde bei $4{ }^{\circ} \mathrm{C}$ gelagert und noch am gleichen Tag zur Transduktion eingesetzt.

Vom Verpackungsansatz wurden verschiedene Verdünnungen (z.B. 1:10, 1:50 ) in SMPuffer hergestellt. Jeweils $25 \mu$ dieser Verdünnungen wurden mit $25 \mu 1$ Empfängerzellen vermischt und für $30 \mathrm{~min}$ bei RT inkubiert. Anschließend wurden jeweils $200 \mu$ LB-Medium (s. 2.2.1) hinzugefügt. Zur Ausbildung der entsprechenden Antibiotikaresistenz erfolgte eine Inkubation für $1 \mathrm{~h}$ bei $37^{\circ} \mathrm{C}$. Zum Ausplattieren auf Agarplatten mit entsprechendem Antibiotikum wurden die Ansätze 1 min zentrifugiert, der Überstand abgenommen und die sedimentierten Zellen in $50 \mu$ LB-Medium resuspendiert. 


\section{$\underline{\text { SM-Puffer }}$}

$\begin{array}{lrr}\mathrm{NaCl} & 5,8 & \mathrm{~g} \\ \mathrm{MgSO}_{4} \text { x } 7 \mathrm{H}_{2} \mathrm{O} & 2,0 & \mathrm{~g} \\ \text { Tris }(1 \mathrm{M}) & 50,0 & \mathrm{ml} \\ \text { Gelatine }(2 \%,(w / v)) & 5,0 & \mathrm{ml} \\ \mathrm{H}_{2} \mathrm{O}_{\text {dest. }} & \mathrm{ad} 1000 & \mathrm{ml} \\ \text { pH 7,5 } & & \end{array}$

\subsubsection{Der X-Gal-Test zur Selektion rekombinanter Klone}

Bei Klonierungen ist es entscheidend, Klone, die nach Übertragung von DNA nur den Vektor enthalten, von denjenigen, die ein Plasmid mit Insert tragen, unterscheiden zu können. Aus diesem Grund wurde ein zusätzliches Screeningsystem neben der plasmidkodierten Antibiotikaresistenz benutzt. Plasmide der pBluescript-Reihe enthalten neben dem Promotor- und Operator-Bereich des lac-Operons auch das 5'Ende des lacZ-Genes (VIEIRA und MESSING, 1982). Dieses kodiert für das sogenannte $\alpha$-Peptid, welches die inaktive $\beta$-Galaktosidase von Wirtsstämmen wie $E$. coli DH5 $\alpha$ komplementieren kann. Da sich die multiple Klonierungsstelle der verwendeten Vektoren innerhalb des aminoterminalen Bereichs des lacZ-Gens befindet, ist eine $\alpha$-Komplementation nur möglich, wenn das Plasmid kein Insert besitzt. Der Nachweis der aktiven $\beta$-Galaktosidase auf Agarplatten erfolgte durch Zugabe des Induktors IPTG (Isopropyl-ß-thiogalaktopyranosid) und des Substrats X-Gal (5-Brom4-chlor-indoyl- $\beta$-D-galaktosid), welches durch das Enzym gespalten wird. Dabei entsteht in Anwesenheit von Sauerstoff der blaue Farbstoff 5-Brom-4-chlor-indigo, welcher der Indikator für rekombinante E. coli-Stämme ist, die ein Plasmid ohne Insert tragen.

\subsubsection{Plattentest zur Überprüfung der Verwertung von C2-C4-Polyolen}

Alkohol-Oxidoreduktasen katalysieren eine Vielzahl essentieller mikrobiologischer Redoxreaktionen, bei denen Alkohole, Aldehyde und Ketone umgewandelt werden. 
Alkohol-Oxidoreduktasen werden je nach Kofaktor-Bedürfnissen in 3 Gruppen unterteilt: Man unterscheidet NAD(P) ${ }^{+}$-abhängige Dehydrogenasen (Typ I, Typ II und Typ III). die NAD(P) ${ }^{+}$-unabhängigen Dehydrogenasen (mit Kofaktoren wie FAD, PQQ oder $\mathrm{F}_{420}$ ) und die Oxidasen (REID und FEWSON, 1994). Besonders die NAD(P) ${ }^{+}$ abhängigen sind von biotechnologischem Interesse, da sie meist eine hohe Enatioselektivität besitzen. Damit eigenen sie sich sehr gut zur Synthese chiraler Alkohole, Hydroxysäuren und Aminosäuren (HUMMEL, 1997 und 1999). Aus diesem Grund wurden alle ORFs, die eine entsprechende Annotation hatten zumindest initial auf eine tatsächliche Aktivität hin untersucht. Dabei wurde ein Testsystem genutzt, dass sich zu Nutzen macht, dass bei der Umsetzung kurzkettiger Alkohole durch Oxidoreduktasen Carbonyl-Verbindungen entstehen, die in einem Plattentest nachgewiesen werden können. Hierzu werden dem Indikatormedium, das neben dem Testsubstrat auch Komplexbestandteile enthielt, die allen Klonen ein Wachstum erlaubten, eine Mischung aus Pararosanilin und Natriumbisulfit zugesetzt. Diese beiden Substanzen bilden zusammen ein Schiff'sches Reagenz. Bei der Reaktion mit CarbonyVerbindungen entsteht Azomethin, eine rot gefärbte Schiff'sche Base (CONWAY et al., 1987). Positive Kolonien sind damit aufgrund ihrer Rotfärbung und der Ausbildung eines roten Hofes leicht zu identifizieren.

\subsection{Sequenzierung von DNA}

Die Sequenzierung von DNA, sei es die Sequenzierung von rekombinanten Plasmiden/Cosmiden oder die Sequenzierung von PCR-Produkten, wurde an ABI PRISM 337 Geräten (Applied Biosystems, Weiterstadt) oder am MegaBACE 1000 System (Amersham Bioscience, Molecular Dynamics) durchgeführt. Beide Gerätearten sollen im Folgenden kurz vorgestellt werden. Detaillierte Angaben sind den Internetseiten der beiden Firmen (http://www.appliedbiosystems.com und http://www5.amersham biosciences.com/aptrix/upp01077.nsf/content/na_homepage) zu entnehmen. 


\subsubsection{Sequenzierung mit ABI DNA Sequencer 377}

Der ABI PRISM ${ }^{\circledR} 377$ DNA Sequencer (Fa. Perkin-Elmer/Applied Biosystems) analysiert automatisch DNA-Moleküle, die mit multiplen Fluoreszenzfarbstoffen (Big Dye ${ }^{\circledR}$ Terminatoren) markiert sind, wobei für jede DNA-Base ein anderer Farbstoff gewählt wird. Die Markierung der DNA erfolgt dabei nach dem Prinzip der von SANGER et al. (1977) entwickelten Didesoxy- oder Kettenabbruch-Methode. Die zu sequenzierenden, markierten Proben werden auf ein vertikal verlaufendes Polyacrylamid-Gel aufgetragen und durch Anlegen einer Spannung elektrophoretisch aufgetrennt. 96 Proben können dabei gleichzeitig sequenziert werden. Die Farbstoffe werden beim Durchlaufen des unteren Endes des Gels mittels eines Lasers detektiert und die Signale anschließend einer Computeranalyse unterzogen. Die Fluoreszenzsignale werden dabei über das sogenannte „Base calling“ (s. 2.13) automatisch in Sequenzdaten umgewandelt. Zur Markierung der DNA wurde das „Big Dye ${ }^{\circledR}$ Terminator Cycle Sequencing Kit“ benutzt, das eine spezielle DNA-Polymerase enthielt (Ampli-TaqR DNA-Polymerase). Ein optimal hergestellter Sequenzieransatz (s. u.) konnte so in einem ü. N.-Lauf zu einer auflösbaren DNA-Leseweite von ca. 800 Basen führen. Die Sequenzierungsprozedur mit dem ABI PRISM® 377 umfasste folgende Schritte:

- Reinigung der Glasplatten

- Gießen des Polyacrylamid-Gels zwischen die Glasplatten

- Einbau des Gels in das Gerät

- Plattencheck und Vorlauf

- Beladen des Gels mit 96 Proben

- Starten der Elektrophorese

Tabelle 5 gibt einen Einblick in die Zusammensetzung eines Sequenziergels und in die einzustellenden Parameter am ABI PRISM ${ }^{\circledR} \quad 377$ zur Durchführung eines Sequenzierlaufes. 
Tabelle 5: Parameter zur Beschaffenheit eines Sequenziergels (4,25\%ig) sowie zur Bedienung eines ABI PRISM ${ }^{\circledR} 377$ bei einem ü. N.-Lauf

\begin{tabular}{|c|c|}
\hline Harnstoff $7 \mathrm{M}$ & 18 \\
\hline Acrylamid $(30 \%, 29: 1)$ & 5,3 \\
\hline 10x TBE long run & $\mathrm{ml}$ \\
\hline $\mathrm{H}_{2} \mathrm{Obidest}_{\mathrm{b}}$ & 21,5 \\
\hline $10 \%$ APS & 250 \\
\hline TEMED & 25 \\
\hline Geldicke & $0,2 \mathrm{~mm}$ \\
\hline Gellänge & 48 \\
\hline Spannung & 3500 \\
\hline Stromstärke & $60 \mathrm{~mA}$ \\
\hline Leistung & 40 \\
\hline Temperatur & 45 \\
\hline CCD Offset & 0 \\
\hline CCD Gain & 4 \\
\hline Vorlaufzeit & $90 \mathrm{sec}$ \\
\hline Laufzeit & $1,5+14,5$ \\
\hline $2 \mathrm{x}$ TTE oben, $1 \mathrm{x}$ & TTE unten \\
\hline Minimale Anzahl der „Scans“ & 22000 \\
\hline
\end{tabular}

Die Zusammensetzung eines Sequenzieransatzes variierte je nach Art der DNA (Plasmid, Cosmid oder PCR) sowie nach dessen G+C-Gehalt. Der Ansatz erfolgte normalerweise im 96er Maßstab. Typischerweise wurde zur Sequenzierung von Inserts der Plasmide der Shotgun-Cosmid-Genbanken folgender Ansatz pipettiert (im „Premix“ sind die „ABI Big Dye ${ }^{\circledR}$ Terminatoren“ enthalten): 


\begin{tabular}{|c|c|}
\hline "Premix" & 2 \\
\hline "half BD” & 1 \\
\hline Betain (5 M) & 1 \\
\hline $\begin{array}{l}\text { Oligonukleotid } \\
(5 \mathrm{pmol} / \mu \mathrm{l})\end{array}$ & $\mathrm{x}$ \\
\hline $\mathrm{H}_{2} \mathrm{O}$ & $\mathrm{x} \mu \mathrm{l}=400 \mathrm{ng}$ \\
\hline $\begin{array}{l}\text { DNA-Template } \\
(\max .13 \mu 1)\end{array}$ & 20 \\
\hline
\end{tabular}

Dieser Ansatz wurde dann in einen 96er PCR-Thermoblock (MWG-Primus 96 plus) gegeben und dort 2 min bei $98{ }^{\circ} \mathrm{C}$ denaturiert. Folgendes Programm wurde anschließend gestartet, wobei sich die Anlagerungstemperatur nach den Schmelztemperaturen der verwendeten Oligonukleotide richtete, die meistens zwischen $54{ }^{\circ} \mathrm{C}$ und $60{ }^{\circ} \mathrm{C}$ lag:

$\begin{array}{llrr}\text { Denaturierung } & 96{ }^{\circ} \mathrm{C} & 20 & \text { s } \\ \text { Anlagerung } & \text { i.d. R. } 50{ }^{\circ} \mathrm{C} & 15 & \text { s } \\ \text { Polymerisierung } & 60{ }^{\circ} \mathrm{C} & 4 & \mathrm{~min}\end{array}$

Es schloss sich eine Fällung mit Ethanol (96\%) und 3 M Natriumacetat (pH 4,6) an, um überschüssige, nicht eingebaute farbstoffmarkierte Terminatoren zu entfernen, da diese sonst als „Dye-Blobs“ in den ersten 100 Basen der Sequenz erscheinen würden. Vor dem Auftragen auf das Sequenziergel wurde die gefällte DNA mit $1 \mu$ Stop-Mix (Formamid zu Loading Puffer (50 mg Blue Dextran/ml 25mM EDTA, pH 8,0) im Verhältnis 5:1) versetzt.

\subsubsection{Sequenzierung mit dem „MegaBACE 1000 Capillar Sequencer“}

Das „MegaBACE 1000“-System analysiert wie das „ABI PRISM® 377“-Gerät automatisch DNA-Moleküle, die mit multiplen Fluoreszenzfarbstoffen („DYEnamic ET Dye ${ }^{\circledR}$ Terminatoren“) markiert sind. Ein Lasersystem übernimmt die Detektion der Fluoreszenzsignale. Im Gegensatz zum ABI Gerät benutzt der „MegaBACE 1000“ die Kapillar-Technik: Die Elektrophorese findet in winzig kleinen (ca. $100 \mu \mathrm{m}$ im Durchmesser) Kapillaren statt, die eine Polyacrylamid-Matrix enthalten, die das System über Hochdruck aus 6 Matrix-Tubes in die Kapillaren hineinschießen kann. Diese 
Kapillaren sind in 6 Arrays mit jeweils 16 Einzelkapillaren angeordnet. Zum Beladen des Systems werden die Proben in einer 96er Platte in die Maschine gestellt. Durch eine angelegte Spannung gelangen die Proben in die Kapillaren, in denen dann die elektrophoretische Auftrennung stattfindet. Die Bedienung des Gerätes folgte dann den auf dem Display erscheinenden Anweisungen. Das System kann im Hochdurchsatz arbeiten und dabei 96 Proben in 2-4 Stunden mit einer Leseweite von ca. 600 Basen sequenzieren. Im Gegensatz zum „ABI PRISM ${ }^{\circledR}$ 377“ zeigt der „MegaBACE 1000“ eine höhere Empfindlichkeit bei schwankenden DNA-Konzentrationen, so dass diese nach Möglichkeit im Vorfeld angeglichen werden sollten. Alle gewonnenen Rohdaten werden nach Ende eines Laufes automatisch mittels „Base calling“ ausgewertet. Die Probenbereitung entsprach weitestgehend der bereits beschriebenen Methode für den „ABI PRISM ${ }^{\circledR}$ 377“ (s. 2.12.1). Abweichend davon wurde das „AmershamDYEnamic-ET-Dye-Terminator-Cycle-Sequencing Kit“" benutzt.

\subsection{Die Prozessierung von Rohsequenzen}

Nach einem Sequenzierlauf werden die Rohdaten, die Fluoreszenzsignale und -intensitäten, automatisch analysiert und in DNA-Sequenzen umgerechnet, was als „Base calling“ bezeichnet wird. Benutzt wurde der „Basecaller Phred“ (EWING et al., 1998). Dieser liest die Rohdaten von den DNA Sequenziermaschinen („trace files“), rechnet sie in DNA-Basen um und teilt diesen zusätzlich einen Qualitätswert zu. „Phred“ kann sowohl die Rohdaten vom „ABI 377 DNA-Gerät“ als auch vom „Megabace 1000“ lesen. Die Sequenzen und die dazugehörigen Qualitätswerte können dann zur Assemblierung mit Hilfe von Sequenzassemblierungsprogrammen benutzt werden (BONFIELD \& STADEN, 1996).

\subsubsection{Einführung in die Prozessierung von DNA-Sequenzen mittels des STADEN-Software-Packets}

Das STADEN-Software-Packet beinhaltet verschiedene Programme zum Selektieren, Aufbereiten, Assemblieren und Editieren von DNA-Sequenzen (STADEN et al., 2000). Es würde den Rahmen dieser Arbeit sprengen, auf die Struktur und Funktionsweise der einzelnen Programme einzugehen. Hier soll nur ein Überblick über die Anwendung des Software-Packetes im Rahmen des Leinesediment-Metagenomsequenzierungsprojektes 
gegeben werden. Eine ausführliche Dokumentation kann unter http://www.mrclmb.cam.ac.uk/pubseq/staden_home.html abgerufen werden. Im Wesentlichen wurden zur Prozessierung der DNA-Sequenzen die Programme „Pregap4“ und „Gap4“ genutzt.

\subsubsection{1 „Pregap4“}

Bevor DNA-Sequenzen in das Genomassemblierungsprogramm „Gap4“ eingespeist werden können, müssen diese durch diverse Prozesse geleitet werden, welche das Programm „Pregap4“ leistet (BONFIELD \& STADEN, 1996):

- Screening auf Vektor-Kontaminationen: Sequenzen, die den Vektor-Sequenzen (pBluescriptIISK ${ }^{+}$oder superCos1) entsprechen, fallen aus der Datenbank heraus.

- Screening auf Kontamination mit E. coli DNA: Bei der Herstellung der Genbank kann es zu Kontaminationen mit der DNA des Wirtsstammes (E. coli DH5 $\alpha$ ) kommen. Diese Daten müssen ebenfalls entfernt werden.

- Qualitätskontrolle: Sequenzen mit einer geringen Qualität fallen aus der Datenbank heraus.

- „Vektor-Clipping“: Es werden die Basen einer Sequenz maskiert, die im Übergang zum Insert der Vektor-Sequenz entsprechen.

- Umformatierung in ein neues Dateiformat: Zur Assemblierung benötigt „Gap4“ ein anderes Dateiformat (,experiment files“).

Zur Erleichterung der Prozessierung der Rohdaten wurden im Göttinger Genomanalyselabor Computerskripte entwickelt, die hier nicht näher erläutert werden sollen. Prinzipiell bewerkstelligten solche Skripte das Umbenennen von Dateinamen, das Einleiten der Rohsequenzen in „Pregap4“ und das Sortieren der Ausgabe von „Pregap4“ in mehrere Listen („Failed, Passed, ScreenVector“, etc.).

Bei der Prozessierung der 16S rRNA-Gensequenzen wurde aufgrund der großen Ähnlichkeiten dieser Gene auch zu denen von E. coli auf das Screening nach E. coliKontaminationen verzichtet.

\subsubsection{2 „Gap4“}

Gap4 ist ein Genomassemblierungsprogramm; es kann aber auch wie in diesem Projekt für kleinere DNA-Abschnitte wie Cosmide oder große Plasmide verwendet werden (BONFIELD et al., 1995). Neben der Assemblierung kann das Programm auch zur Editierung der Sequenzen benutzt werden. Gap4 ist des Weiteren unerlässlich beim 
sogenannten „Finishing“, dem Schließen von Sequenzlücken in einem Sequenzierungsprojekt.

Assemblierung: Mit Hilfe von Algorithmen („PHRAP“, http://bozeman.mbt. washington.edu/phrap.docs/phrap.html) werden Sequenzüberlappungen ausfindig gemacht. Sequenzläufe (,readings“), die solche Sequenzüberlappungen aufweisen, werden dann passend zueinander ausgerichtet (,Alignment“) und zu zusammenhängenden DNA-Abschnitten, den sogenannten Contigs, zusammengefasst. Aus den ,,alignten“ Sequenzen innerhalb eines Contigs bildet das Programm dann eine Consensus-Sequenz.

„Editierung“: Ziel ist es hierbei, die Qualität der Consensus-Sequenz eines Contigs zu verbessern und Fehler in der Assemblierung zu detektieren und aufzulösen. Dabei wurden entsprechende Einzelsequenzen markiert, aus dem Contig extrahiert und dann manuell in den Datensatz zu passenden Contigs zurücktransferiert. Die Fehlerrate sollte nicht höher als 1 in 10000 Basen betragen. Dabei lässt sich die Qualität jeder einzelnen Base in der Consensus-Sequenz über deren „Base Confidence“-Wert überprüfen.

„Finishing“: In „Gap4“ können zwei (oder mehrere) Contigs anhand der Lage und Orientierung der enthaltenden ,readings“ zueinander geordnet werden, was eine Hilfe zur Überwindung von Sequenzlücken zwischen Contigs ist. Gegebenenfalls können Contigs dann semi-manuell mit Hilfe der Funktion „Join Contigs“ miteinander verbunden werden.

\subsection{Methoden zur Überwindung von Sequenzlücken in einem Sequenzierungsprojekt}

\subsubsection{Identifikation von Contigüberlappungen mit „Gap4“ oder „Align two Sequences“ (NCBI)}

Nach erfolgter Assemblierung, deren Überprüfung und der ersten Editierung sämtlicher Contigs wurde versucht, überlappende Contigs zu identifizieren. Dies geschah zum einen automatisch über die Funktion „Find Internal Joins,, in „Gap4“. Jede gefundene potentielle Contigüberlappung bedurfte im „Join Contigs Editor“ einer genauen Überprüfung. Zum anderen wurde ,extern' nach überlappenden Contigs gesucht, indem die Enden einiger Contigs gegen die anderer bei NCBI (,National Center for 
Biotechnology; www.ncbi.nlm.nih.gov) mit dem Algorithmus „Align two Sequences“ verglichen wurden. Contigs, die potentiell überlappten, wurden dann in „Gap4“ manuell über „Join Contigs“ zueinander ausgerichtet und gegebenenfalls miteinander verbunden. Bei der Zusammenführung der 16S rRNA-Gen-Sequenzläufe eines Plasmids wurde ausschließlich mit der zweiten Methode gearbeitet, da „Find Internal Joins“ aufgrund der Ähnlichkeit aller Sequenzen nicht genutzt werden konnte.

\subsection{2 „Primer-Walking“}

Mit Hilfe der „Gap4“-Funktion „Template Display“ können einzelne Contigs visuell dargestellt werden: dort sind alle im Contig enthaltenden „Readings“ und deren Templates aufgeführt. Ein Template entspricht dabei einem Insert eines rekombinanten Plasmids der Cosmid-Genbank. Anzumerken ist, dass die Inserts der Plasmide von beiden Seiten her ansequenziert wurden (,forward“ und „reverse“). Da die durchschnittliche Insertgröße zwischen 2 und $4 \mathrm{~kb}$ lag und ein typischer Sequenzierlauf etwa 600-700 Basen lang war, bedeutete dies, dass ein Insert (= Template) nicht vollständig sequenziert wurde. Im „Template Display“ sind die beiden „readings“ desselben Templates zueinander angeordnet. Mit Hilfe der Funktion „Order Contigs“ ließen sich dann solche Contigs aneinander reihen, die an den Rändern „readings“ beinhalteten, die zu demselben Template gehörten: Beispielsweise begann oder endete der Contig A mit dem ,forward reading“ des Templates X, während Contig B nun mit dem „reverse reading“ des Templates $\mathrm{X}$ endete oder begann. Teilweise konnten benachbarte Contigs durch gemeinsame BLAST-Hits bei NCBI (www.ncbi.nlm.nih.gov) mit „BLASTX“ identifiziert werden. Damit war es nun möglich, durch ein sogenanntes „Primer-Walking“ die Lücke zwischen diesen beiden Contigs zu schließen: es wurde ein Sequenzierprimer vom Ende eines der beiden „readings“ abgeleitet (mit der Orientierung zum Insertinneren), der dann zur Sequenzierung des entsprechenden „Templates“ eingesetzt wurde. So konnte man die überbrückende Sequenz zwischen den Contigs ermitteln und die Lücke sofort oder nach einem weiteren Ableiten eines Oligonukleotids schließen. Waren keine Lücken überspannenden Plasmide vorhanden, wurde das Cosmid selbst als „Template“ eingesetzt. Konnte auch mit dieser Methode keine Lücken schließende Sequenz erhalten werden, wurde versucht mit einer PCR-Reaktion mit dem Cosmid als „Template“ und den die Lücke flankierenden Oligonukleotiden das fehlende DNA-Fragment zu 
amplifizieren. Dieses konnte gegebenenfalls in den pCR2.1-TOPO-Vektor (s. 2.8.3.2) kloniert und dann sowohl mit den verwendeten Oligonukleotiden als auch den Standardprimern für den pCR2.1-TOPO-Vektor sequenziert werden.

\subsubsection{Kombinatorische PCR}

Des Weiteren wurde die Methode der kombinatorischen PCR eingesetzt. Hierbei wurden zuerst Oligonukleotide von allen Contigrändern abgleitet mit der Orientierung zum Contigende hin. Nun wurden diese in allen denkbaren Kombinationen miteinander eingesetzt, wobei eine durchschnittliche Lückengröße von nicht mehr als $2 \mathrm{~kb}$ angenommen wurde. Falls die Anzahl an möglichen Kombinationen zu groß erschien, wurden zur Erleichterung der Arbeit auch Subsätze von Oligonukleotidkombinationen angesetzt. Jedes erhaltende PCR-Produkt wurde sofort sequenziert und die Sequenz zum Lückenschluss eingesetzt.

\subsection{Sequenzanalyse}

Nach Beendigung der Sequenzierungsphase und dem Schluss der letzten Lücken in der Cosmid-Sequenz wurde versucht, alle in der Sequenz vorkommenden Gene zu identifizieren. Dafür wurden zunächst mögliche Gene vorhergesagt (ORF (,open reading frame")-Vorhersage) und diesen anschließend mögliche Funktionen zugewiesen.

\subsubsection{ORF („open reading frame“)-Vorhersage}

Alle ORF-Vorhersageprogramme für Prokaryoten basieren auf dem Auffinden von Start (ATG, GTG, TTG)- und Stopcodons (TAA, TGA, TAG) auf allen sechs möglichen Leserahmen. Danach werden solche Sequenzbereiche festgelegt, die zwischen dem Start- und Stopcodon auf demselben Leserahmen eine bestimmte „Cutoff“-Größe erreichen (oft 30 Codons). Dieser Bereich wird als ORF bezeichnet, stellt also ein potentielles Gen dar. In dem Leinesediment-Metagenom-Sequenzierprojekt wurde die ORF-Vorhersage per Hand mit dem Programm „Artemis“ (www.sanger.ac.uk/Software/Artemis) durchgeführt. Dieses Programm zeigt alle möglichen ORFs mit einer minimalen Größe an. In diesem Projekt wurden dabei 30 
Codons als Wert eingestellt. Die daraus resultierenden ORFs in den 6 Leserahmen wurden nun auf folgende Parameter hin untersucht:

Homologien zu bekannten Proteinen: Die angezeigten potentiellen ORFs werden in „Artemis“ auch in die Aminosäuresequenz übersetzt. Damit war es möglich, in der NCBI-Datenbank (www.ncbi.nlm.nih.gov) mittels „BLASTP“ nach ähnlichen Proteinen zu suchen. Gab es solche mit einer guten Übereinstimmung, war dies das stärkste Anzeichen dafür, dass der vorliegende ORF tatsächlich ein Gen darstellte.

Die Länge: Bei der Festlegung der Länge eines ORFs war die Art des Startcodons entscheidend: ATG-Startcodons wurden gegenüber den anderen bevorzugt, TGAStartcodons den TAG-Startcodons vorgezogen. Zum Finden der unterschiedlichen Startcodons eines ORFs wurde die Funktion „Trim selected features to next any“ genutzt.

Der GC-Frameplot: In „Artemis“ ist es möglich sich die G+C-Häufigkeit an den 3 möglichen Codonpositionen graphisch anzeigen zu lassen. Empirische Forschungen (persönliche Mitteilung Heiko Liesegang) haben gezeigt, dass sich diese Häufigkeiten am Start und Stopp eines Genes häufig umkehren. Dies kann eine Hilfe und ein Hinweis für das Vorliegen eines Gens sein, ist aber keine notwendige Bedingung.

Ribosomenbindestelle: Bei jedem ORF wurde überprüft, ob 4-12 Basen stromaufwärts eine Ribosomenbindestelle vorhanden war.

Mit diesen Kriterien wurden die wahrscheinlichsten ORFs übernommen. Dabei wurden soweit es möglich war Überlappungen von ORFs in unterschiedlichen Leserahmen ausgeschlossen.

Im Verlauf der Sequenzierung stellte sich heraus, dass ein Cosmid DNA eukaryotischen Ursprungs enthielt. Für die ORF-Vorhersage musste in diesem Fall berücksichtigt werden, dass eukaryotische Gene anders als prokaryotische organisiert sind. Aus diesem Grund wurde die ORF-Vorhersage in diesem Fall mit dem Programm „GeneMark“ (opal.biology.gatech.edu/GeneMark/eukhmm.cgi) durchgeführt.

\subsubsection{Annotation der Cosmidsequenzen}

Die vorhergesagten ORFs wurden in das ERGO-Programm eingespeist. Dieses berechnet mittels FASTA-Algorithmus' die Ähnlichkeiten aller Cosmid-ORFs - auf Nukleotid- wie auf Proteinebene - zu Sequenzen der internen ERGO-Datenbank. Der für diese Arbeit zugängliche Teil der nicht redundanten internen ERGO-Datenbank 
umfasste zum Zeitpunkt der Annotation (Mai 2004) Sequenzen - i. d. R. vollständige Genome - aus 405 Organismen: 27 Archaeen, 80 Eukaryoten, 90 Viren und 208 Bakterien. Das ERGO-Programm weist allen Cosmid-ORFs automatisch eine Funktion zu, die aus dem Ähnlichkeitsvergleich mit der internen ERGO-Datenbank abgeleitet werden. Wenn keine Ähnlichkeiten in der Datenbank gefunden werden, bezeichnete das Programm den entsprechenden ORF als hypothetisch. Diese automatische Annotation musste für die Leinesediment-Cosmide - ORF für ORF - überprüft werden, da sich der interne Datenbank-Abgleich oftmals als ungenügend herausstellte. Deshalb wurde eine Ähnlichkeitssuche mit allen ORFs mit der NCBI-Datenbank (www.ncbi.nlm.nih.gov) durchgeführt. Der NCBI-Sequenzabgleich umfasst eine Vielzahl von Nukleotid- und Proteinsequenz-Datenbanken wie die PDB-, SwissProt-, Pir-, DDBJ-, EMBL- und die GenBank-Datenbank. Es wurden die Ähnlichkeitswerte berücksichtigt. Dabei wird eine signifikante Homologie zwischen zwei Proteinsequenzen im Allgemeinen als eine Proteinidentität größer als $30 \%$ bei einer Überlappung (,Alignment“) von mehr als $60 \%$ der Eingabe (query)- und der Vergleichssequenz definiert. Insbesondere wurde darauf geachtet, ob sich unter den homologen Proteinen eines betrachteten ORFs auch eines (oder mehrere) befand, das (die) bereits biochemisch charakterisiert ist (sind); dessen (deren) Funktion wurde - bei entsprechend hoher Homologie - dem ORF vorrangig zugewiesen. So z. B. konnte vielen der von ERGO als hypothetisch bezeichneten ORFs durch diesen zusätzlichen externen NCBI-Sequenzabgleich eine Funktion zugewiesen werden. Der externe Sequenzabgleich erwies sich gegenüber dem internen Abgleich i.d. R. als umfassender, aktueller und genauer in der Funktionszuordnung. Als weitere Fehlermöglichkeit der automatischen ERGOAnnotation wurde erkannt, dass ERGO dem betrachteten ORF die Funktion desjenigen Proteins zuwies, das den höchsten Ähnlichkeitswert (Smith-Waterman-Score) zum betrachteten ORF aufwies. Gerade bei geringer Homologie, also einem niedrigen Smith-Waterman-Score, zeigte sich aber oftmals, dass die dem ORF zugewiesene Funktion zu ungenau oder aber auch zu speziell war (WATERMAN, 1984). Außerdem wurde die genetische Umgebung des betrachteten ORFs mit der Umgebung homologer ORFs verglichen. Dies war mit den ERGO-Funktionen „Pinned Regions“ oder „Contig Regions“ oder alternativ bei NCBI möglich. Durch solch eine Vergleich konnte ermittelt werden, wie homolog die genomische Organisation zwischen den verwandten Organismen und dem Cosmid ist und ob ein ORF fehlte oder zusätzlich vorlag, was auf einen Fehler der ORF-Vorhersage hinweisen kann. Im Rahmen der Annotation wurde 
versucht, eine Identifizierung und Entfernung hypothetischer ORFs vorzunehmen, die mit solchen ORFs überlappen, welche mit hoher Wahrscheinlichkeit Gene darstellen. Mit Hilfe homologer Proteine konnten außerdem die Größen der ORFs in „Artemis“ überprüft werden. Wichen die meisten homologen Proteine von der vorhergesagten Größe $a b$ und ein alternativer Start konnte gefunden werden, wurde die Größe modifiziert. Der Abgleich mit den Domänen-Datenbanken „Pfam“ (www.sanger.ac.uk/Software/Pfam) und „ProSite“ (www.expasy.org/prosite) ermöglichte in einigen Fällen auch beim Fehlen homologer (und experimentell bestätigter) Proteinsequenzen anhand konservierter Domänen die Zuordnung von Funktionen. Außerdem konnte das Protein mit TMPred (http://www.ch.embnet.org/software/TMPRED_form.html) auf das Vorhandensein von transmembranen Helices untersucht werden.

\subsubsection{Untersuchung der 16S rRNA-Gene auf das Vorhandensein chimerer Sequenzen}

Die Sequenzen der 16S rRNA-Gene wurden mit den Programmen „CHIMERA_CHECK version 2.7“ des „Ribosomal Database Project“ (RDP; LARSEN et al., 1993) unter der Internetadresse http:rdp.cme.msu.edu/cgis/chimera.cgi und dem Programm „Bellerophon chimera detection programm“ unter der Internetadresse http:foo.math.uq.au/ huber/bellerophon.pl auf das Vorhandensein von Chimeren überprüft. Das Programm „CHIMERA_CHECK version 2.7“ überprüft, ob es einen möglichen Schnittpunkt in der zu untersuchenden Sequenz gibt, der die Sequenz in zwei Teile teilt, die jeweils zu einer anderen Sequenz aus der RDP-Datenbank die größte Übereinstimmung haben. Dabei macht das Programm „CHIMERA_CHECK version 2.7“ keine definitive Aussage darüber, ob eine Sequenz ein Chimer ist, so dass bei jeder Sequenz im Einzelnen auf das Vorhandensein von Artefakten entschieden werden muss. Das Programm „Bellerophon chimera detection programm“ berechnet dagegen 2 mögliche Stammbäume mit dem Anfang und dem Ende aller Sequenzen. Ergeben sich dabei unterschiedliche Verzweigungen, ist dies ein Anzeichen dafür, dass es sich bei den entsprechenden Sequenzen um Chimere handelt. 


\subsection{Herstellung von Rohextrakten}

\subsubsection{Zellaufschluss mit der Frenchpresse}

Für die Herstellung von Rohextrakten mit der French-Presse wurde von einem Kulturvolumen mit mindestens $25 \mathrm{ml}$ ausgegangen. Zunächst wurden die Zellen durch Zentrifugation (6000 Upm, $10 \mathrm{~min}, 4^{\circ} \mathrm{C}$, GS3-Rotor, Sorvall RC-5B-Zentrifuge, Fa. Du Pont de Nemours GmbH) geerntet und das Pellet in einem geeigneten Puffer aufgenommen. Die Zellsuspension wurde dann in eine vorgekühlte French-PressApparatur (Fa. SLM Aminco, Urbana, USA) gefüllt. Der Aufschluss der Zellen fand bei einem Druck von 140 Mpa statt. Der Vorgang wurde zweimal wiederholt, wobei vor dem ersten Mal eine Spatelspitze DNase I (Fa. Boehringer, Mannheim) zugegeben wurde. Anschließend erfolgte eine Zentrifugation bei $15000 \mathrm{Upm}$ und $4{ }^{\circ} \mathrm{C}$ für $30 \mathrm{~min}$ (SS34-Rotor, Sorvall RC-5B-Zentrifuge, Fa. Du Pont de Nemours GmbH). Der erhaltene Extrakt wurde als Rohextrakt bezeichnet und konnte bis zur weiteren Verwendung bei $-20{ }^{\circ} \mathrm{C}$ gelagert werden.

\subsection{Proteinbestimmung (BRADFORD, 1976)}

Die Bestimmung der Proteinkonzentration erfolgte in modifizierter Form nach der Methode von BRADFORD (1976).

Es wurden $20 \mu \mathrm{l}$ einer Probe zu $1 \mathrm{ml}$ Bradford-Reagenz gegeben. Wenn nötig, konnte die Probe mit $\mathrm{H}_{2} \mathrm{O}_{\text {dest. }}$ verdünnt werden. Nach einer Inkubation für 10 min bei RT wurde die Absorption bei einer Wellenlänge von $580 \mathrm{~nm}$ gegen einen Leerwert gemessen. Zur Konzentrationsbestimmung wurde eine Eichgerade mit Rinderserumalbumin in einem Bereich von 0 bis $10 \mu \mathrm{g} / \mathrm{ml}$ aufgenommen. 
$\underline{\text { Bradford-Reagenz }}$

$\begin{array}{lrr}\text { Serva Blau G-250 } & 70 & \mathrm{mg} \\ \text { Ethanol }(96 \%, \mathrm{v} / \mathrm{v}) & 50 & \mathrm{ml} \\ \mathrm{H}_{3} \mathrm{PO}_{4}(85 \%, \mathrm{v} / \mathrm{v}) & 100 & \mathrm{ml} \\ \mathrm{H}_{2} \mathrm{O}_{\text {dest. }} & \text { ad } 1000 & \mathrm{ml}\end{array}$

Nach vollständigem Lösen des Farbstoffs in Ethanol und Zugabe der übrigen Bestandteile erfolgte eine Filtration durch einen Faltenfilter. Das Reagenz wurde lichtgeschützt gelagert und war ca. 1 Jahr haltbar.

\subsection{Bestimmung von Enzymaktivitäten}

Die Enzymaktivitäten wurden im Bereich der linearen Abhängigkeit der Reaktionsgeschwindigkeit von der Proteinmenge bestimmt. Eine Enzymeinheit $1 \mathrm{U}$ entspricht dabei dem Umsatz von $1 \mu \mathrm{mol}$ Substrat pro Minute. Die Volumenaktivitäten [U/ml] wurden nach folgender Formel berechnet.

$$
\mathrm{U} / \mathrm{ml}=\frac{\Delta \mathrm{E} / \min \mathrm{xV}}{\varepsilon \mathrm{x} \mathrm{dxv}}
$$

$\Delta \mathrm{E} / \mathrm{min}=$ Extinktionsänderung pro Minute

$\mathrm{V}=$ Volumen der Küvette [ml]

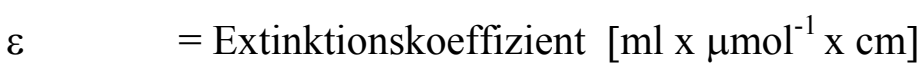

$\mathrm{d}=$ Schichtdicke der Küvette $[\mathrm{cm}]$

$\mathrm{v} \quad=$ Volumen der eingesetzten Probe

Die spezifische Enzymaktivität [U/mg Protein] ergab sich aus der Division der Volumenaktivität [U/ml] durch die ermittelte Proteinkonzentration [mg/ml] (s. 2.17). 


\subsubsection{Erythrit-Dehydrogenase (RUCH et al., 1974; BOENIGK et al., 1991)}

Die Aktivität der Erythrit-Dehydrogenase wurde in Oxidationsrichtung bei Raumtemperatur über die Extinktionsänderung bei $365 \mathrm{~nm}$ aufgrund der $\mathrm{NAD}^{+}$Reduktion bestimmt.

Testansatz:

\begin{tabular}{lrr}
\hline Puffer & $870-970$ & $\mu l$ \\
NAD $^{+}$oder & 10 & $\mu l$ \\
NADP $^{+}(180 \mathrm{mM})$ & & \\
Probe & $10-100$ & $\mu l$ \\
\hline Start mit: & & \\
Substrat $(5 \mathrm{M})$ & 20 & $\mu l$
\end{tabular}

Das Gesamtvolumen des Testansatzes betrug immer $1 \mathrm{ml}$. Es wurden 3 verschiedene Puffer eingesetzt:

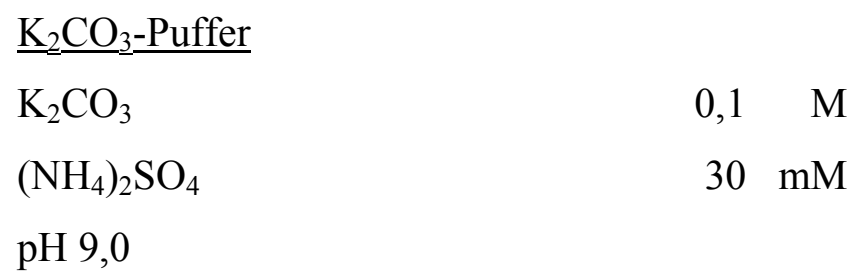

$\underline{\text { Alkohol-Dehydrogenase (ADH)-Puffer }}$

$\mathrm{Na}-\mathrm{PO}_{4}$-Puffer

$50 \mathrm{mM}$

Glycin

$130 \mathrm{mM}$

$\mathrm{pH} 8,5$

HEPES-Puffer

\begin{tabular}{|c|c|}
\hline $\mathrm{HEPES}-\mathrm{NH}_{4} \mathrm{OH}$ & 10 \\
\hline reduziertes Gluthation & 0,9 \\
\hline $\mathrm{MgCl}_{2}$ & 2 \\
\hline pH 8 & \\
\hline
\end{tabular}


Zur Feststellung ob die Erythrit-Dehydrogenase auch in der Lage ist die Reduktion von L-Erythrulose oder D-Erythrose zu Alkoholen zu katalysieren, wurden beide Substanzen als Substrate eingesetzt. Die Oxidation von NADH wurde photometrisch bei $365 \mathrm{~nm}$ in einer Plastikküvette $(\mathrm{d}=1)$ verfolgt.

Testansatz:

\begin{tabular}{lcc}
\hline Triethanolamin-Puffer & 950 & $\mu l$ \\
$(0,1 \mathrm{M}, \mathrm{pH} 7,5)$ & & \\
NADH $(24,5 \mathrm{mM}$ in & 15 & $\mu \mathrm{l}$ \\
$0,6 \mathrm{M} \mathrm{NaHCO}$ & \\
Probe & & \\
\hline Start mit: & 10 & $\mu l$ \\
Substrat $(1 \mathrm{M})$ & 10 & $\mu l$
\end{tabular}

\subsubsection{Kinasen (PALMGREN, 1990)}

Kinase-Aktivitäten von Enzymen können in einem gekoppelten Enzymtest photometrisch gemessen werden. Das durch die Kinase-Aktivität entstehende ADP wird über 2 weitere Enzymreaktionen mit der Pyruvat-Kinase und der Laktat-Dehydrogenase als NADH-Oxidation photometrisch sichtbar gemacht. Die Abnahme der NADHKonzentration wurde bei $365 \mathrm{~nm}$ am Photometer verfolgt.

Testansatz:

\begin{tabular}{lrr}
\hline MOPS & 10 & $\mathrm{mM}$ \\
Saccharose & 330 & $\mathrm{mM}$ \\
$\mathrm{MgCl}_{2}$ & 4 & $\mathrm{mM}$ \\
$\mathrm{KCl}$ & 140 & $\mathrm{mM}$ \\
EDTA & 1 & $\mathrm{mM}$ \\
RSA & 1 & $\mathrm{mg} / \mathrm{ml}$ \\
DTT & 1 & $\mathrm{mM}$ \\
ATP & 2 & $\mathrm{mM}$
\end{tabular}




$\begin{array}{lrr}\text { PEP } & 1 & \mathrm{mM} \\ \text { NADH } & 0,5 & \mathrm{mM} \\ \text { Pyruvat-Kinase } & 60 & \mu \mathrm{g} / \mathrm{ml} \\ \text { Laktat-Dehydrogenase } & 30 & \mu \mathrm{g} / \mathrm{ml} \\ \text { pH } 7 & & \end{array}$

Die Reaktion wurde durch die Zugabe des Substrates gestartet.

\subsubsection{Dihydroxyaceton-Kinase}

Dihydroxyaceton-Kinasen können sowohl ATP- als auch PEP- abhängig sein. Für beide Arten von Dihydroxyaceton-Kinasen gibt es geeignete photometrische Enzymtests, die die Kinase-Aktivität an die NADH-abhängige Reduktion des Reaktionsproduktes Dihydroxyaceton-Phosphat durch die Glycerin-3-phosphatDehydrogenase (G3P-DH) koppeln. Diese Reaktion kann durch die Oxidation von NADH photometrisch bei $340 \mathrm{~nm}$ verfolgt werden. Werden die Tests mit Rohextrakten von E. coli durchgeführt, ist es wichtig, die E. coli eigene Glycerin-Dehydrogenase, die die Reduktion von Dihydroxyaceton NADH-abhängig katalysiert, durch die Zugabe des Chelatbildners $\alpha, \alpha$-Dipyridyl zu inhibieren. Eine Störung des Testes durch die Glycerin-Kinase von E. coli kann durch Zugabe von $100 \mathrm{mM}$ Glycerin umgangen werden.

\subsubsection{ATP - abhängige Dihydroxyaceton - Kinase (JOHNSON et al., 1984)}

Die ATP-abhängige Dihydroxyaceton-Kinase-Aktivität kann mit folgendem Testansatz gemessen werden. Dabei wird die optische Dichte bei $340 \mathrm{~nm}$ verfolgt.

\begin{tabular}{lrr} 
Testansatz $(900 \mu \mathrm{l})$ : & & \\
\hline Triethanolamin-HCl-Puffer $(\mathrm{pH} 7,0)$ & 50 & $\mathrm{mM}$ \\
$\mathrm{MgCl}_{2}$ & 1 & $\mathrm{mM}$ \\
$\alpha, \alpha-D i p y r i d y l$ & 10 & $\mathrm{mM}$ \\
$\mathrm{NADH}$ & 0,1 & $\mathrm{mM}$ \\
G3P-DH & 2 & $\mu \mathrm{g}$ \\
Rohextrakt & $1-50$ & $\mu \mathrm{l}$ \\
Dihydroxyaceton & 1 & $\mathrm{mM}$
\end{tabular}




\begin{tabular}{lrr}
\hline Start mit: & & \\
ATP $(0,1 \mathrm{mM})$ & 100 & $\mu \mathrm{l}$ \\
Glycerin-3-Phosphat-Dehydrogenase & 2 & $\mu \mathrm{g}$
\end{tabular}

Zunächst wurde die optische Dichte bei $340 \mathrm{~nm}$ für 2 Minuten verfolgt, bevor die eigentliche Reaktion durch die Zugabe von $100 \mu \mathrm{ATP}(0,1 \mathrm{mM})$ und $2 \mu \mathrm{g}$ Glycerin-3Phosphat-Dehydrogenase gestartet wurde. Die Reaktion wurde für 4 Minuten verfolgt.

\subsubsection{PEP - abhängige Dihydroxyaceton - Kinase (SUN et al., 2003)}

Eine PEP-abhängige Dihydroxyaceton-Kinase-Aktivität wird mit folgendem Testansatz verfolgt:

\begin{tabular}{lrr} 
Testansatz $(900 \mu \mathrm{l})$ : & & \\
\hline $\mathrm{KH}_{2} \mathrm{PO}_{4}(\mathrm{pH} 7,5)$ & 55,6 & $\mathrm{mM}$ \\
Dihydroxyaceton & 1,11 & $\mathrm{mM}$ \\
$\mathrm{MgCl}_{2}$ & 2,78 & $\mathrm{mM}$ \\
$\alpha, \alpha-D i p y r i d y l$ & 11,1 & $\mathrm{mM}$ \\
DTT & 2,78 & $\mathrm{mM}$ \\
$\mathrm{NADH}$ & 0,56 & $\mathrm{mM}$ \\
Rohextrakt & $1-50$ & $\mu \mathrm{l}$ \\
\hline Start mit: & & \\
PEP (10 mM) & 100 & $\mu l$ \\
Glycerin-3-Phosphat- & 2 & $\mu \mathrm{g}$ \\
Dehydrogenase & &
\end{tabular}

Zunächst wurde die optische Dichte bei $340 \mathrm{~nm}$ für 2 Minuten verfolgt, bevor die eigentliche Reaktion durch die Zugabe von $100 \mu$ PEP (10 mM) und $2 \mu$ g Glycerin-3Phosphat-Dehydrogenase gestartet wurde. Die Reaktion wurde für 4 Minuten verfolgt. 


\subsubsection{Kohlenstoffmonoxid-Dehydrogenase (KRAUT et al., 1989)}

Die Aktivität der Kohlenstoffmonoxid-Dehydrogenase (CO-DH) kann spektroskopisch anhand der Reduktion von INT (2-(4-Iodophenyl)-3-(4-nitrophenyl)-2H-tetrazoliumchlorid) verfolgt werden. MPMS (1-Methoxyphenazin-methosulfat) dient dabei als Elektronenübeträger zwischen der CO-DH und dem INT. Durch die Reduktion des INT entsteht ein rotes Formazan, dessen Bildung bei $496 \mathrm{~nm}$ photometrisch messbar ist. Das $\mathrm{CO}$ wird in Phosphatpuffer gelöster Form mit einer Spritze dem Testansatz in einer $1 \mathrm{ml}$ Plastikküvette zugefügt und damit die Reaktion gestartet. Für den Extinktionskoeffizient bei $496 \mathrm{~nm}$ wurde ein Wert von $\varepsilon=17,981 \mathrm{mM}^{-1} \mathrm{~cm}^{-1}$ angenommen.

Testansatz:

\begin{tabular}{lrr}
\hline INT (9,9 mM) & 250 & $\mu l$ \\
MPMS (8,9 mM) & 50 & $\mu l$ \\
Triton X-100 (25\%) & 500 & $\mu l$ \\
Phosphatpuffer & 19,2 & $\mu l$ \\
(50 mM KH ${ }_{2} \mathrm{PO}_{4}-\mathrm{NaOH}$; pH 7,2) & & \\
Rohextrakt & $1-50$ & $\mu l$ \\
\hline Start mit: & & \\
Phosphatpuffer $\left(50 \mathrm{mM} \mathrm{KH}_{2} \mathrm{PO}_{4}{ }^{-}\right.$ & 200 & $\mu l$ \\
NaOH; pH 7,2) mit $\mathrm{CO}$ bei $25{ }^{\circ} \mathrm{C}$ & & \\
gesättigt & &
\end{tabular}

\subsection{Methoden zur Proteinanreicherung}

\subsubsection{Metall-Chelat-Affinitätschromatographie}

Das Prinzip der Metall-Chelat-Affinitätschromatographie beruht auf der Fähigkeit bestimmter Aminosäuren, z. B. Histidin, als Elektronendonator an Proteinoberflächen $\mathrm{zu}$ fungieren und so an Metallionen wie $\mathrm{Ni}^{2+}$ und $\mathrm{Cu}^{2+} \mathrm{zu}$ binden (HOCHULI et al., 1988; YIP et al., 1989). Die Metallionen wiederum sind über Chelatgruppen an ein Trägermaterial (Agarose oder Sepharose) gebunden. 
Die Metall-Chelat-Chromatographie besitzt im neutralen $\mathrm{pH}$-Bereich ihre größte Spezifität und Effizienz. Die Elution der Proteine findet unter Verwendung eines Imidazolgradienten statt. Imidazol führt $\mathrm{zu}$ einer kompetetiven Verdrängung des Histidins. Alternativ kann eine Elution durch einen $\mathrm{pH}-$ Gradienten erfolgen.

\subsubsection{Vorbereitung der Säule}

Für die Metall-Chelat-Chromatographie wurde $\mathrm{Ni}^{2+}$-Nitrilotriessigsäure-Agarose (NTAAgarose; Fa. Qiagen GmbH) verwendet. Nach dem Einsetzen der unteren Fritte wurden 4 - $6 \mathrm{ml} \mathrm{Ni}{ }^{2+}$-NTA-Agarose in eine PD 10-Säule (Fa. Amersham Pharmacia, Freiburg) eingefüllt. Nach der Sedimentation des Trägermaterials wurde die Säule mit dem Zellaufschlusspuffer gespült und bei $4{ }^{\circ} \mathrm{C}$ aufbewahrt.

\subsubsection{Reinigung löslicher Proteine unter nativen Bedingungen}

Zur Reinigung löslicher Proteine unter nativen Bedingungen wurde der Rohextrakt mit der $\mathrm{Ni}^{2+}$-NTA-Agarose, die mit Zellaufschlusspuffer äquilibriert worden war, unter Rühren bei $4{ }^{\circ} \mathrm{C}$ für $1 \mathrm{~h}$ inkubiert. Nach dieser Inkubation wurde die Lösung in den Säulenkörper einer PD-10 Säule gefüllt. Nach dem Absetzen der Agarose wurde diese zunächst mit einem geeigneten Volumen Zellaufschlusspuffer gewaschen. Es folgte ein weiterer Waschschritt mit Puffer I. Die Elution der Proteine erfolgte in mehreren Schritten mit Puffer II.

Vor einer erneuten Verwendung der Säule wurde das Chromatographiematerial mit Puffer II gespült und dann mit dem Zellaufschlusspuffer äquilibriert.

Zellaufschlusspuffer

$\underline{\text { Puffer I }}$

$\begin{array}{lrlr}\mathrm{NaH}_{2} \mathrm{PO}_{4} & 50 \mathrm{mM} & \mathrm{NaH}_{2} \mathrm{PO}_{4} & 50 \mathrm{mM} \\ \mathrm{NaCl} & 300 \mathrm{mM} & \mathrm{NaCl} & 300 \mathrm{mM} \\ \text { Imidazol } & 10 \mathrm{mM} & \text { Imidazol } & 20 \mathrm{mM} \\ \mathrm{pH} 8,0 & & & \mathrm{pH} \mathrm{8,0}\end{array}$

$\underline{\text { Puffer II }}$

$\begin{array}{lr}\mathrm{NaH}_{2} \mathrm{PO}_{4} & 50 \mathrm{mM} \\ \mathrm{NaCl} & 300 \mathrm{mM} \\ \text { Imidazol } & 250 \mathrm{mM} \\ \mathrm{pH} 8,0 & \end{array}$




\subsubsection{Regeneration der Säule}

Die Notwendigkeit einer Regeneration der $\mathrm{Ni}^{2+}$-NTA-Agarose wurde durch eine Farbänderung von grün-blau nach bräunlich-grau angezeigt. Durch das chelatierende Agens EDTA erfolgte die Elution des Nickels von der Säule. Nach einer anschließenden Wiederbeladung mit $\mathrm{Ni}^{2+}$-Ionen stand das Säulenmaterial erneut für mehrere Reinigungszyklen zur Verfügung. Die Regeneration des Säulenmaterials erfolgte anhand des Herstellerprotokolls.

\subsubsection{Reinigung löslicher Proteine mit Protino ${ }^{\circledR} \mathrm{Ni}$-Säulen (Fa. Macherey- Nagel, Düren)}

Das Prinzip der Proteinaufreinigung mit Hilfe dieser Säulen entspricht dem der MetallChelat-Affinitätschromatographie. Das hier eingesetzte Trägermaterial sind SilicaKügelchen, die als Chelatgruppe TED (Tris-carboxymethylethylendiamin) binden. TED bindet 5 der 6 Koordinationsstellen des Nickels, so dass nur noch eine für das rekombinante Protein zur Verfügung steht. Damit soll sowohl ein Auswaschen des Metalls verhindert als auch eine spezifischere Bindung des aufzureinigenden Proteins verbessert werden. Im Gegensatz zu auf Agarose-basierendem Trägermaterial soll durch weniger Seitenketten unspezifischen Bindungen entgegengewirkt werden. Die Aufreinigung erfolgte nach Herstellerangaben.

\subsection{Polyacrylamid-Gelelektrophorese (PAGE)}

Polyacrylamid-Gelelektrophoresen unter denaturierenden und nicht denaturierenden Bedingungen wurden in Minigel-Elektrophorese-Kammern (Fa. Bio-Rad, München) mit 8,5 × 8,0 x 0,1 cm-großen Glasplatten durchgeführt.

\subsubsection{SDS-PAGE nach SCHÄGGER und VON JAGOW (1987)}

Trenn- und Sammelgel hatten folgende Zusammensetzung (Menge für 2 Gele):

Trenngel:

Gelpuffer

$3 \mathrm{ml}$

$12,5 \%$ ig

Acrylamidlösung

2,25 $\mathrm{ml}$

$\mathrm{H}_{2} \mathrm{O}_{\text {dest. }}$

$3,75 \mathrm{ml}$

APS-Lösung

$50 \mu 1$

TEMED

$5 \mu 1$




$\begin{array}{llrr}\text { Sammelgel: } & \text { Gelpuffer } & 1,13 & \mathrm{ml} \\ & \text { Acrylamidlösung } & 375 & \mu 1 \\ & \mathrm{H}_{2} \mathrm{O}_{\text {dest. }} & 3 & \mathrm{ml} \\ & \text { APS-Lösung } & 45 & \mu 1 \\ & \text { TEMED } & 4,5 & \mu 1\end{array}$

Zunächst wurden Acrylamidlösung, Gelpuffer und $\mathrm{H}_{2} \mathrm{O}_{\text {dest. }}$ gemischt. Nach der Zugabe von TEMED und APS-Lösung wurde das Gel gegossen und mit $\mathrm{H}_{2} \mathrm{O}_{\text {dest. }}$ überschichtet, um eine ebene Fläche zu erhalten. Nach Polymerisation des Trenngels (ca. $30 \mathrm{~min}$ ) konnte das $\mathrm{H}_{2} \mathrm{O}_{\text {dest. }}$ abgenommen und das Sammelgel gegossen werden, in das zur Formung von Geltaschen ein Kamm luftblasenfrei eingesetzt wurde. Nach 30 min war das Gel vollständig polymerisiert und konnte verwendet werden.

Die Proben wurden vor dem Auftragen im Verhältnis 1:3 mit Denaturierungspuffer gemischt. Anschließend wurden die Proben auf das mit Elektrophoresepuffer überschichtete Gel mit Hilfe einer Hamiltonspritze aufgetragen. Die Elektrophorese erfolgte zunächst bei einer Spannung von $100 \mathrm{~V}$, bis die blaue Markerbande das Trenngel erreicht hatte, und wurde dann auf $130 \mathrm{~V}$ erhöht. Als Netzgerät diente ein Gene-Power-Supply GPS 200/400 (Fa. Amersham Pharmacia). Die Elektrophorese wurde beendet, wenn die Markerbande das Gelende erreicht hatte.

Acrylamidlösung

Acrylamid

Bisacrylamid

$\mathrm{H}_{2} \mathrm{O}_{\text {dest. }}$.

Kathodenpuffer

Tris

Tricin

SDS

$\mathrm{H}_{2} \mathrm{O}_{\text {dest }}$

pH 8,5 $\underline{\text { Gelpuffer }}$

$\begin{array}{rrlrr}96 & \mathrm{~g} & \text { Tris } & 181,7 & \mathrm{~g} \\ 3 & \mathrm{~g} & \text { SDS } & 1,5 & \mathrm{~g} \\ \mathrm{ad} 200 & \mathrm{ml} & \mathrm{H}_{2} \mathrm{O}_{\text {dest. }} & \mathrm{ad} 500 & \mathrm{ml} \\ & & \mathrm{pH} 8,4 & & \end{array}$

Denaturierungspuffer

Tris

$0,2 \quad \mathrm{~g}$

SDS

Serva-Blau G250

$1,2 \quad \mathrm{~g}$

$3 \mathrm{mg}$

Glycerin

$3 \mathrm{ml}$

2-Mercaptoethanol

$0,5 \mathrm{ml}$

$\mathrm{H}_{2} \mathrm{O}_{\text {dest. }}$.

ad $10 \mathrm{ml}$

pH 6,8 
$\underline{\text { Anodenpuffer }}$

Tris

$\mathrm{H}_{2} \mathrm{O}_{\text {dest. }}$

pH 8,9

\begin{tabular}{rrlrr} 
& \multicolumn{2}{l}{ APS-Lösung } & & \\
\cline { 3 - 4 } & & Ammoniumpersulfat & 0,1 & $\mathrm{~g}$ \\
ad 1000 & $\mathrm{gl}$ & $\mathrm{H}_{2} \mathrm{O}_{\text {dest. }}$ & ad 1 & $\mathrm{ml}$
\end{tabular}

\subsubsection{Native Gradienten-PAGE}

Für ein Gradientengel von 4 bis $20 \%$ wurden Polyacrylamidlösungen folgender Zusammensetzung verwendet:

"Leichte" Lösung: Acrylamid

Bisacrylamid

Gelpuffer

"Schwere" Lösung: Acrylamid

Bisacrylamid

Glycerin $(87 \%$ [v/v])

Gelpuffer

$\begin{array}{rr}4,0 & \mathrm{~g} \\ 0,2 & \mathrm{~g} \\ \mathrm{~d} 100 & \mathrm{ml}\end{array}$

$20,0 \quad \mathrm{~g}$

$1,0 \quad \mathrm{~g}$

$8,6 \mathrm{ml}$

ad $100 \mathrm{ml}$

Die Lösungen wurde lichtgeschützt bei $4{ }^{\circ} \mathrm{C}$ gelagert.

Für das Trenngel von 4 bis $20 \%$ (w/v) wurden jeweils $2 \mathrm{ml}$ "Leichte" und "Schwere" Lösung in die Kammern eines kleinen Gradientenmischers gefüllt und unter Rühren je $3 \mu \mathrm{l}$ TEMED und $15 \mu \mathrm{l}$ APS-Lösung (s.2.20.1) in die einzelnen Kammern gegeben. Nach dem Öffnen des Gradientenmischers konnte die Acrylamidlösung mit Hilfe einer Peristaltikpumpe (Meredos GS, Fa. Meredos, Nörten-Hardenberg) zwischen die Glasplatten gegossen werden. Anschließend erfolgte die Überschichtung des Trenngels mit ca. $1 \mathrm{ml} \mathrm{H} \mathrm{H}_{2} \mathrm{O}_{\text {dest. }}$ Nach Polymerisierung des Gels für 30 min wurde das $\mathrm{H}_{2} \mathrm{O}_{\text {dest. }}$ abgenommen. Dann wurde das Sammelgel gegossen, für das $2 \mathrm{ml}$ "Leichte" Lösung, $3 \mu 1$ TEMED und $15 \mu 1$ APS-Lösung verwendet wurden. Direkt im Anschluss wurde ein Kamm luftblasenfrei eingesetzt. Nach der Polymerisierung für 30 min konnte das Gel in die Elektrophoresekammer eingesetzt werden und die Pufferreservoirs mit Elektrodenpuffer gefüllt werden. Nachdem der Kamm entfernt worden war, wurde zunächst eine Vorelektrophorese (100 V, 30 min) durchgeführt. Danach konnten die mit 
0,1 Volumen Beschwerungslösung versetzten Proben aufgetragen werden. Die Elektrophorese erfolgte bei $4{ }^{\circ} \mathrm{C}$ und $100 \mathrm{~V}$ für 20 bis $24 \mathrm{~h}$.

Gelpuffer

Tris

pH 8,5
$250 \mathrm{mM}$

(1)

Elektrodenpuffer

Tris $0,1 \quad \mathrm{M}$

Glycin $\quad 0,1 \quad \mathrm{M}$

$\mathrm{pH} 8,7$

Beschwerungslösung

Saccharose

$\begin{array}{rr}4 & \mathrm{~g} \\ 5 & \mathrm{mg} \\ \mathrm{ad} 10 & \mathrm{ml}\end{array}$

Bromphenolblau

$\mathrm{H}_{2} \mathrm{O}_{\text {dest. }}$

ad $10 \quad \mathrm{ml}$

Die Beschwerungslösung wurde bei $-20{ }^{\circ} \mathrm{C}$ gelagert

\subsection{Proteinfärbung in Polyacrylamidgelen}

\subsubsection{Coomassie-Färbung}

Nach Beendigung der Elektrophorese wurden die Gele kurz mit $\mathrm{H}_{2} \mathrm{O}_{\text {dest. }}$ gespült und dann für $60 \mathrm{~min}$ in die Coomassie-Färbelösung gelegt. Nach Spülen mit $\mathrm{H}_{2} \mathrm{O}_{\text {dest. wurde }}$ das Gel entfärbt, wobei die Entfärbelösung mehrfach gewechselt wurde. Bei guter Transparenz des Hintergrundes konnten die Gele ausgewertet werden.

Coomassie-Färbelösung

Entfärbelösung

Coomassie-Blau G-250

$0,08 \%(\mathrm{w} / \mathrm{v})$

Methanol

$33 \%(\mathrm{v} / \mathrm{v})$

Coomassie-Blau R-250

$0,08 \%(\mathrm{w} / \mathrm{v})$

Eisessig

$10 \%(\mathrm{v} / \mathrm{v})$

Methanol

$45 \%(\mathrm{v} / \mathrm{v})$

Eisessig

$10 \%(\mathrm{v} / \mathrm{v})$ 


\subsubsection{Aktivitätsfärbung von Erythrit-Dehydrogenasen (Gabriel, 1971; modifiziert)}

Der spezifische Nachweis der aktiven Erythrit - Dehydrogenase im Gel erfolgte durch Nitroblau-Tetrazoliumchlorid (NBT). Das Testsystem beruhte darauf, dass das bei der Oxidation von Erythrit gebildete NADH NBT direkt oder über den Elektronenüberträger Phenazinmethosulfat (PMS) irreversibel zum Diformazan reduziert. Der mit der Reduktion verbundene Farbwechsel von gelb zu blau ließ das Enzym als distinkte Bande im Gel sichtbar werden.

Die Gele wurden in die Färbelösung überführt und im Dunkeln bei Raumtemperatur bis zum Erscheinen von Banden inkubiert. Anschließend wurden die Gele in $7 \%$ Essigsäure fixiert.

$\begin{array}{lrr}\text { Färbelösung } & & \\ \mathrm{K}_{2} \mathrm{CO}_{3}(100 \mathrm{mM}, \mathrm{pH} 8,5) & 86 & \mathrm{ml} \\ \left(\mathrm{NH}_{4}\right)_{2} \mathrm{SO}_{4} & 0,4 & \mathrm{~g} \\ \mathrm{NAD}^{+}(100 \mathrm{mM}) & 2 & \mathrm{ml} \\ \mathrm{NBT}(10 \mathrm{mg} / \mathrm{ml}) & 5 & \mathrm{ml} \\ \text { PMS }(0,8 \mathrm{mg} / \mathrm{ml}) & 5 & \mathrm{ml} \\ \text { Erythrit } & 12,14 & \mathrm{~g}\end{array}$

\subsection{Western Blot (TOBWIN et al., 1979; modifiziert)}

Die Methode des elektrophoretischen Proteintransfers auf Membranen (TOBWIN et al., 1979) wurde für den spezifischen Nachweis von Proteinen mit His 6 -Tag bzw. V5Epitop angewandt. Der Western-Blot wurde in einer Mini-Blot-Apparatur „Mini TransBlot $^{\circledR}$ Electrophoretic Transfer Cell”, Fa. Bio-Rad Laboratories GmbH, München) durchgeführt. Nach der SDS-Page (s. 2.20.1) wurden das Gel sowie auf Gelgröße zugeschnittene 2 Lagen Whatman-Papier (Whatman $3 \mathrm{~mm}$, Fa. Schleicher und Schuell GmbH, Dassel), die Nitrocellulose-Membran (Hybond ECL Nitrocellulose Membrane; Fa. Amersham, Freiburg) und 2 Glasfiberpads 10 Minuten in gekühltem Transferpuffer getränkt. Anschließend wurde der Blot luftblasenfrei in der Gelhalterungskassette auf der Anodenseite aufgebaut und durch Andrücken der Anodenseite auf die Kathodenseite fest verschlossen: 
Kathode (-)

Galsfiberpad

1 Lage Whatman

SDS-Polyacrylamidgel

Membran

1 Lage Whatman

Glasfiberpad

Anode (+)

Zusammen mit der Blotelektrodeneinheit wurde die Kassette in die mit Puffer gefüllte Blot-Kammer eingesetzt. Der Tranfer erfolgte bei einer Spannung von $120 \mathrm{~V}$ und $4{ }^{\circ} \mathrm{C}$ für eine Stunde.

$\begin{array}{lrr}\text { Transferpuffer } & & \\ \text { Tris-base } & 25 & \mathrm{mM} \\ \text { Glycin } & 192 & \mathrm{mM} \\ \text { Methanol }(20 \%[\mathrm{v} / \mathrm{v}]) & 200 & \mathrm{ml} \\ \text { ad } \mathrm{H}_{2} \mathrm{O}_{\text {dest. }} & 1000 & \mathrm{ml} \\ \text { pH } 8,1-8,4 & & \end{array}$

Der pH-Wert darf nicht mit Säure oder Base eingestellt werden. Lag der pH-Wert außerhalb dieses Bereiches, wurde der Puffer erneut angesetzt.

Bei der vor dem Western-Blot durchgeführten SDS-Page wurde ein sogenannter „Prestained-Marker“ (,peqGold Protein Marker IV (Prestained)”; Fa. PeqLab Biotechnologie $\mathrm{GmbH}$ ) verwendet. Anhand dieser bereits gefärbten Banden konnte der Proteintransfer überprüft werden. Die Membran konnte direkt nach dem Western-Blot der gewünschten Färbung unterzogen werden.

\subsubsection{Immunodetektion von Proteinen auf Blot-Membranen}

Geblottete Antigene bieten die Möglichkeit, sie mit Konjugaten oder Antikörpern anzufärben. Bei der Verwendung von Antikörpern hängt die Spezifität der Immunfärbung von der Spezifität des primären und sekundären Antikörpers und deren eingesetzten Konzentrationen ab. 


\subsubsection{Chromogene Methoden}

\subsection{Färbung mit dem Anti-V5-Alkalische-Phosphatase-Konjugat}

Dieses Verfahren dient dem Nachweis von rekombinanten Proteinen auf BlotMembranen, die das V5-Epitop enthalten. Dieses besteht aus 14 Aminosäuren, die von den P- und V-Proteinen des Paramyxovirus SV5 abgeleitet sind (SOUTHERN et al., 1991). Es wird mit Hilfe des pET101/D-TOPO-Vektors carboxyterminal an rekombinante Proteine angehängt. Der Nachweis beruht auf der Affinität des mit alkalischer Phosphatase gekoppelten Anti-V5-Antikörpers gegen das V5-Epitop. Antigen-Antikörper-Komplexe können durch den Umsatz geeigneter Substrate von der alkalischen Phosphatase anhand der resultierenden Farbänderung sichtbar gemacht werden. Hier fand als Färbelösung das „AP System“ der Firma Promega (Mannheim) Einsatz.

Die Inkubationen und das Waschen der Membranen wurden unter Schwenken bei RT nach folgendem Protokoll durchgeführt:

1. die getrocknete Membran mit $\mathrm{H}_{2} \mathrm{O}_{\text {dest }}$ befeuchten

2. 1,5 Stunden in Block-Puffer inkubieren

3. $2 \times$ mit TBST-Puffer schwenken

4. $1 \times 15$ Minuten in TBST-Puffer waschen

5. $2 \times 5$ Minuten in TBST-Puffer waschen

6. 2 Stunden Inkubation mit $25 \mathrm{ml}$ Antikörperlösung (1:3000-Verdünnung mit TBST mit Blocking-Puffer (Fa. Amersham, Freiburg)

7. Wiederholung der Schritte 3) bis 5)

8. Waschen mit TBS-Lösung

9. Behandlung mit Färbelösung im Dunkeln, bis die Banden deutlich sichtbar sind

10. zum Stoppen der Reaktion 10 Minuten mit Wasser $_{\text {dest. }}$ spülen

Die Membran wurde sofort mit Hilfe eines Scanners dokumentiert und bei RT getrocknet.

$\underline{\text { TBS-Puffer 10-fach }}$

\begin{tabular}{|c|c|c|c|c|c|}
\hline $\mathrm{NaCl}$ & 1,4 & $\mathrm{M}$ & $\mathrm{NaCl}$ & 1,4 & M \\
\hline Tis- $\mathrm{HCl}$ & 0,1 & M & Tis- $\mathrm{HCl}$ & 0,1 & M \\
\hline $\mathrm{pH} 7,4$ & & & Tween-20 & 0,1 & $\%[\mathrm{v} / \mathrm{v}]$ \\
\hline & & & $\mathrm{pH} 7,5$ & & \\
\hline
\end{tabular}

$\underline{\text { TBST-Puffer 5-fach }}$ 


\subsection{Nachweis des His $_{6}$-Tag durch Antikörper}

Mit Hilfe geeigneter Vektoren können 6 aufeinander folgende Histidin-Reste ( His $_{6}$-Tag) carboxy- oder aminoterminal an rekombinante Proteine angehängt werden. An diesen sogenannte His 6 -Tag kann ein primären Antikörper (Maus-anti-His-Antikörper, Fa. Amersham, Freiburg) binden. An diesen primären Antikörper bindet dann in einem zweiten Schritt ein an die alkalische Phosphatase gekoppelter sekundärer Antikörper. Auch bei diesem System kann ein solcher Komplex durch den Umsatz geeigneter Substrate von der alkalischen Phosphatase anhand der resultierenden Farbänderung sichtbar gemacht werden.

Die Inkubationen und das Waschen der Membranen wurden unter Schwenken bei RT nach dem unter 2.22.1.1.1 beschriebenen Protokoll durchgeführt. Da es sich hier um ein System mit einem primären und einem sekundären Antikörper handelt, musste der primäre Antikörper nach Schritt 6 durch Waschen, wie unter den Schritten 3 bis 5 beschrieben, entfernt werden. Außerdem erfolgte die Inkubation dieses Antikörpers nur für eine Stunde. Die nachfolgenden Schritte entsprachen den Schritten 6 bis 10. Die Verdünnung des primären Antikörpers betrug 1:3000, die des sekundären 1:10000.

\subsection{Molekularmassenbestimmung}

\subsubsection{Molekularmassenbestimmung durch SDS-PAGE}

SDS lagert sich an Proteine an und zerstört fast alle nicht-kovalenten Wechselwirkungen, so dass die Dissoziation von Proteinen in ihre Untereinheiten erreicht wird. Durch die Bindung des negativ geladenen Detergenz wird die Eigenladung der Proteine weitgehend vernachlässigbar und damit eine gelelektrophoretische Auftrennung ermöglicht, die nahezu ausschließlich auf der Masse der Moleküle beruht. Nach der SDS-PAGE und Färbung der Proteine konnte die Molekularmasse eines Proteins ermittelt werden, indem dessen Wanderungsgeschwindigkeit mit der von Markerproteinen verglichen wurde. Die Auftragung des Logarithmus der Molekularmassen der Markerproteine gegen den $\mathrm{R}_{\mathrm{f}^{-}}$ Wert (Wanderungsstrecke des Proteins bezogen auf die Wanderungsstrecke des Farbstoffmarkers) ergibt eine Eichgerade, anhand derer die Molekularmasse des jeweiligen Proteins berechnet werden konnte. Als Markerproteine wurden die Proteine 
des “peqGold Protein Marker"-Kits (Fa. PeqLab Biotechnologie GmbH) oder die des „Prestained SDS-PAGE Standard Low Range“ (Fa. Bio-Rad Laboratories) eingesetzt.

Markerproteine "peqGold Protein Marker"-Kits

$\beta$-Galaktosidase $116 \mathrm{kDa}$

Rinderserumalbumin

$66,2 \mathrm{kDa}$

Ovalbumin

$45 \mathrm{kDa}$

Laktat-Dehydrogenase

$35 \mathrm{kDa}$

RE Bsp98I

$25 \mathrm{kDa}$

$\beta$-Laktoglobulin

$18,4 \mathrm{kDa}$

Lysozym

$14,4 \mathrm{kDa}$

Markerproteine " Prestained SDS-PAGE Standard Low Range"

Phosphorylase $b$ $103 \mathrm{kDa}$

Rinderserumalbumin

$77 \mathrm{kDa}$

Ovalbumin $50 \mathrm{kDa}$

„Carbonic Anhydrase“

$34,3 \mathrm{kDa}$

Sojabohnen

Trypsin

$28,8 \mathrm{kDa}$

Inhibitor

Lysozym

$20,7 \mathrm{kDa}$

Alternativ zum ,peqGold Protein Marker”-Kits wurde in SDS-Gelen, von denen die Proteine anschließend in einen Western-Blot (s. 2.22) auf Membranen transferiert werden sollten, der ,peqGold Protein Marker IV (Prestained)”-Kit (Fa. PeqLab Biotechnologie GmbH) verwendet. Da kovalent gebundene Farbstoffe das Laufverhalten von Proteinen beeinflussen, ist dieser Marker nur für annäherungsweise Molekulargewichtsbestimmungen geeignet. Die Banden entsprechen folgenden Größen: 170 kDa, 130 kDa, 100 kDa, 72 kDa, 55 kDa, 40 kDa, 33 kDa, 24 kDa, 17 kDa, 11kDa. 


\subsubsection{Molekularmassenbestimmung durch Gradienten-PAGE (ANDERSON et al., 1972; NISHIZAWA et al., 1988)}

Die Auftrennung von Proteinen im nativen Polyacrylamid-Gradientengel (s.2.20.2) hängt in erster Linie von der Größe der Proteine ab. Mit steigender Acrylamidkonzentration nimmt die Porengröße ab und so wird das Weiterwandern von größeren Proteinen verhindert. Die Eigenladung der Proteine ist hier theoretisch vernachlässigbar (MARGOLIS und KENRICK, 1967).

Nach Auftrennung durch native Gradienten-PAGE (s. 2.20.2) und Anfärben der Proteinbanden (s. 2.21.1) konnte die Molekularmasse von Proteinen berechnet werden, indem die Wanderungsstrecke mit der von Markerproteinen verglichen wurde. Zunächst wurde dafür die Gelkonzentration an den Bereichen bestimmt, in denen die Proteine angefärbt worden waren. Hierfür wurde folgende Formel herangezogen:

$$
\% \text { Acrylamid }=4+\left(\mathrm{cm} \text { Probe } \mathrm{x} 23,5 \mathrm{~cm}^{-1} \mathrm{Gel}\right)
$$

Anschließend kann der Logarithmus des Molekulargewichtes gegen den Logarithmus der Gelkonzentration aufgetragen werden.

Als Markerproteine wurde der "HMW Calibration"-Kit (Fa. Amersham Pharmacia) eingesetzt.

Markerproteine "HMW Calibration"-Kit

\begin{tabular}{lll}
\hline Protein & Molekularmasse & RF-Wert \\
\hline Thyroglobin & $669 \mathrm{kDa}$ & 0,453 \\
Ferritin & $440 \mathrm{kDa}$ & 0,570 \\
Katalase & $232 \mathrm{kDa}$ & 0,651 \\
Laktat-Dehydrogenase & $140 \mathrm{kDa}$ & 0,714 \\
Rinderserumalbumin & $66 \mathrm{kDa}$ & 0,957 \\
\hline
\end{tabular}




\subsection{Chemikalien, Enzyme und Gase}

Es wurden Chemikalien des handelsüblichen Reinheitsgrades der Firmen Boehringer (Mannheim), Fluka (Buchs, Schweiz), Merck (Darmstadt), Riedel de Haen (Hannover), Serva (Heidelberg) und Sigma (Taufkirchen) verwendet. Des Weiteren wurde mit Biochemikalien, Enzymen etc. folgender Firmen gearbeitet:

Amersham Pharmacia, Freiburg:

Nylonmembranen, HMW Calibration-Kit, PD10-Säulen

Bio-Rad Laboratories, München:

Prestained SDS-PAGE Standard Low Range

Biozym GmbH, Hess. Oldendorf:

Elektroporationsküvetten

Dr. Rieks GmbH, Uetersen:

L-Erythrulose

Eppendorf, Wesseling-Berzdorf:

Elektroporationsküvetten

Eurogentec, Seraing, Belgien:

Agarose

Gerbu Biotechnik GmbH, Gaiberg:

IPTG, X-Gal, Ampicillin, Proteinase K

Invitrogen, Carlsbad, CA, USA:

pET Directional TOPO Expression Kit, TOPO TA Cloning Kit

Macherey-Nagel, Düren:

Nucleo Spin Plasmid, Protino ${ }^{\circledR} \mathrm{Ni}-$ Säulen

MBI Fermentas GmbH, St. Leon-Rot:

Taq-DNA-Polymerase, Pfu-DNA-Polymerase T4-DNA-Ligase, Ladder-Mix, Nukleotide, Restriktionsendonukleasen

Messer Griesheim GmbH, Kassel:

Stickstoff

Metabion, Martiensried:

Oligonukleotide

Millipore, Eschborn: 
Mikrodialyse-Filter

New-England Biolabs GmbH, Freiburg:

Restriktionsendonukleasen

Novagen, Darmstadt:

KOD Hifi DNA Polymerase

$\underline{\text { PeqLab Biotechnologie GmbH, Erlangen: }}$

peqGold Protein-Marker, peqGold Protein-Marker IV (Prestained)

Promega, Deutschland GmbH, Mannheim:

Wizard $^{\mathrm{TM}}$ Plus Minipreps DNA Purificaton System, Pfu-DNA-Polymerase, AP-System Qiagen GmbH, Hilden:

Plasmid Midi-Kit, QIAprep Spin Miniprep Kit, Qiaquick PCR-Purification-Kit; Qiaquick Gel Extraction Kit, RNA/DNA Maxi Kit

Sartorius AG, Göttingen:

Sterilfilter

Sigma Chemie GmbH, Deisenhofen:

D-Erythrose, Erythrit, Glycerin-3-Phosphat-Dehydrogenase

Stratagene, USA:

Gigapack ${ }^{\circledR}$ III Gold Packaging Extract

Whatman, Maidstone, England:

Whatman-Filterpapier3MM 
Die komplexe Charakterisierung von Standorten bezüglich ihrer phylogenetischen und physiologischen Aktivität ist mit heutigen molekularbiologischen Methoden unabhängig von Standardkultivierungstechniken möglich (TYSON et al., 2004; VENTER et al., 2004). Grundlage dafür ist die direkte Isolierung der Standort-DNA und die Konstruktion von Genbanken (Metagenombanken), die dann für Sequenzierungsprojekte zur Verfügung stehen. Die angelegten Genbanken können aber auch bei sequenz- oder aktivitätsbasierenden Durchmusterungen als Quelle für biotechnologisch relevante Enzyme oder bioaktive Agenzien dienen (DANIEL, 2004). Es konnten bereits verschiedene Enzyme z.B. Lipasen/Esterasen (HENNE et al., 2000; RONDON et al., 2000), $B_{12}$-abhängige Glycerin-Dehydratasen und Diol-Dehydratasen (KNIETSCH et al., 2003b), Alkohol-Oxidoreduktasen (KNIETSCH et al., 2002) und antibakterielle Wirkstoffe (BRADY et al., 2001; GILLESPIE et al., 2002; OSBURNE et al., 2001; RONDON et al., 2000) aus Umweltproben identifiziert und charakterisiert werden. In dieser Arbeit sollte, wie in Abbildung 4 schematisch dargestellt, sowohl ein

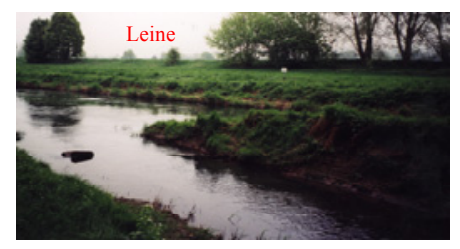

Isolierung von Umwelt-DNA (Kapitel 3.2.1)

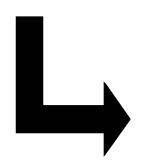

Erstellung von Umweltgenbanken (Kapitel 3.2.2)

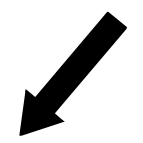

Sequenzierung

(Kapitel 3.4)
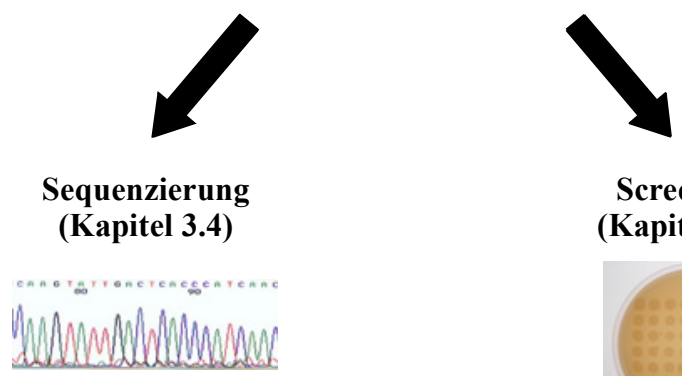
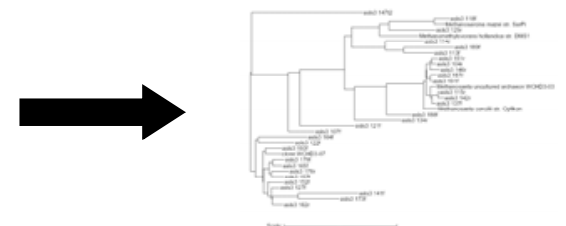

16S rRNA-Genanalyse

(Kapitel 3.3)

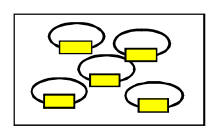

Screening (Kapitel 3.5)

Biochemische Charakterisierung von "Positiven" (Kapitel 3.6)

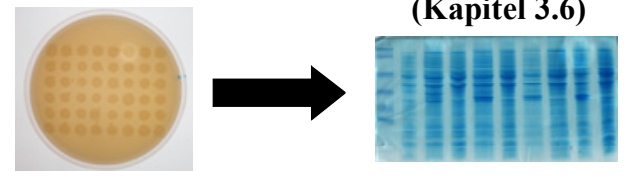


Einblick in die physiologische als auch die phylogenetische Diversität des Metagenoms des Leinesedimentes gewonnen werden. Außerdem sollte eine aus einer BodenMetagenombank isolierte potentielle Erythrit-Dehydrogenase identifiziert und biochemisch charakterisiert werden.

\subsection{Probennahme}

Als Ausgangsmaterial dieser Arbeit diente eine Probe des Leinesedimentes. Die Leine ist ein $247 \mathrm{~km}$ langer Fluss, der in Thüringen in der Nähe der Stadt Leinefelde entspringt. Sie fließt u. a. durch Göttingen und Hannover, bevor sie sich mit der Aller vereinigt, die dann in die Weser mündet.

Die Sedimentprobe wurde am 7. September 2001 in Stockhausen ca. $10 \mathrm{~km}$ südlich von Göttingen genommen. Der Ort der Probennahme liegt etwa $70 \mathrm{~km}$ stromabwärts der Quelle. Das Probenmaterial umfasste die oberen $15 \mathrm{~cm}$ der Sedimentschicht. Die Probe wurde sofort in kleinere Portionen von ca. $100 \mathrm{~g}$ aliquotiert und bei $-70{ }^{\circ} \mathrm{C}$ eingefroren. Die Wassertemperatur zum Zeitpunkt der Probennahme betrug $13{ }^{\circ} \mathrm{C}$, der $\mathrm{pH}-$ Wert des Wassers 7,7. Weitere Angaben zum Vorkommen von Verbindungen von anorganischen Ionen im Sediment und gelösten Ionen im Wasser beruhen auf Angaben des „Niedersächsischen Landesamtes für Ökologie“, die dort persönlich angefordert wurden und in Tabelle 6 wiedergegeben sind. Die Sediment- und Wasseruntersuchungen wurden in Reckershausen (Niedersachsen) etwa $8 \mathrm{~km}$ stromaufwärts von Stockhausen am 5. September (Wasser) bzw. am 18. September 2001 (Sediment) vorgenommen. Die

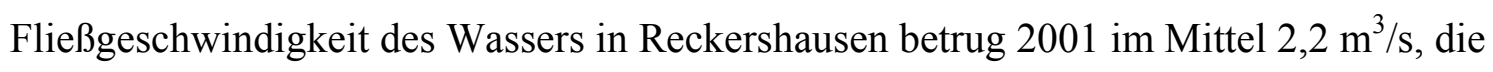
durchschnittliche Wassertemperatur 9,7 ${ }^{\circ} \mathrm{C}$. Im Jahresverlauf traten aber Schwankungen von $1,5^{\circ} \mathrm{C}$ im Januar und $16,3^{\circ} \mathrm{C}$ im August auf. Die Sauerstoffsättigung betrug in den letzten Jahren (1990-2001) über 95 \%. Die Konzentrationen der Ionen der Elemente Hg, As, $\mathrm{Cd}, \mathrm{Cr}$, Ni, $\mathrm{Pb}$, und $\mathrm{Zn}$ lagen im Wasser unterhalb der jeweiligen Nachweisgrenze. 
Tabelle 6: Ergebnisse der Wasser- bzw. Sedimentanalyse des „Niedersächsischen Landesamtes für Ökologie“ am 5. September bzw. 18. September 2001 in Reckershausen (Niedersachsen)

Unter Sediment ist die Fraktion des Sedimentes zu verstehen, die eine Korngröße von weniger als $20 \mu \mathrm{m}$ Durchmesser umfasst. Die Sedimentprobe wurde zunächst gesiebt und anschließend für die Analyse mit Königswasser behandelt, um die gebundenen Ionen in Lösung $\mathrm{zu}$ bringen. Für eine genauere Beschreibung des Vorgehens kann man beim „Niedersächsischen Landesamt für Ökologie“ nachgefragt werden. Die Konzentrationen von gebundenen Kalium-, Natrium-, Calcium-, Magnesium- und Eisenionen wurden für das Sediment nicht ermittelt (-). DOC („Dissolved Organic Carbon“) = gesamter gelöster organischer Kohlenstoff; TOC (,Total Organic Carbon“) = gesamter organischer Kohlenstoff vor Sedimentation oder Filtration; < Wert unterhalb der Nachweisgrenze.

\begin{tabular}{|c|c|c|c|c|c|c|c|c|c|c|c|c|c|}
\hline & K & $\mathrm{Na}$ & $\mathrm{Ca}$ & $\mathrm{Mg}$ & $\mathrm{Fe}$ & $\mathrm{Hg}$ & As & $\mathrm{Cd}$ & $\mathrm{Cr}$ & $\mathrm{Cu}$ & $\mathrm{Ni}$ & $\mathrm{Pb}$ & $\mathrm{Zn}$ \\
\hline 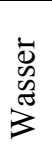 & $\begin{array}{l}4,8 \\
\mathrm{mg} / 1\end{array}$ & $\begin{array}{l}20,0 \\
\mathrm{mg} / 1\end{array}$ & $\begin{array}{l}130,0 \\
\mathrm{mg} / \mathrm{l}\end{array}$ & $\begin{array}{l}21,0 \\
\mathrm{mg} / 1\end{array}$ & $\begin{array}{l}0,1 \\
\mathrm{mg} / \mathrm{l}\end{array}$ & $<$ & $<$ & $<$ & $<$ & $\begin{array}{l}1,6 \\
\mu \mathrm{g} / \mathrm{kg}\end{array}$ & $<$ & $<$ & $<$ \\
\hline 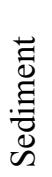 & - & - & - & - & - & $\begin{array}{l}0,11 \\
\mathrm{mg} / \\
\mathrm{kg}\end{array}$ & $\begin{array}{l}9,3 \\
\mathrm{mg} / \\
\mathrm{kg}\end{array}$ & $\begin{array}{l}0,40 \\
\mathrm{mg} / \\
\mathrm{kg}\end{array}$ & $\begin{array}{l}48,0 \\
\mathrm{mg} / \\
\mathrm{kg}\end{array}$ & $\begin{array}{l}40,0 \\
\mathrm{mg} / \\
\mathrm{kg}\end{array}$ & $\begin{array}{l}32,0 \\
\mathrm{mg} / \\
\mathrm{kg}\end{array}$ & $\begin{array}{l}41,0 \\
\mathrm{mg} / \\
\mathrm{kg}\end{array}$ & $\begin{array}{l}260,0 \\
\mathrm{mg} / \\
\mathrm{kg}\end{array}$ \\
\hline
\end{tabular}

\begin{tabular}{|c|c|c|c|c|c|c|c|c|c|c|c|}
\hline & $\overbrace{0}^{1}$ & ס̊ & $\underset{్}{\circlearrowright}$ & $\overbrace{}^{\prime \prime}$ & $\stackrel{O}{Z}^{\prime}$ & 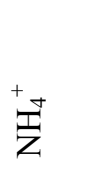 & 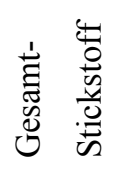 & 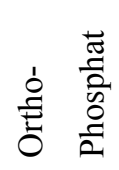 & 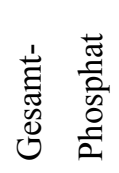 & $\dot{\tau}$ & $\begin{array}{l}\dot{n}_{+}^{+} \\
\overbrace{}^{+}\end{array}$ \\
\hline 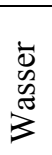 & $\begin{array}{l}244,0 \\
\mathrm{mg} / 1\end{array}$ & $\begin{array}{l}2,5 \\
\mathrm{mg} / \mathrm{l} \mathrm{C}\end{array}$ & $\begin{array}{l}3,1 \\
\mathrm{mg} / \mathrm{l} \mathrm{C}\end{array}$ & $\begin{array}{l}7,0 \\
\mathrm{mg} / 1 \\
\mathrm{~N}\end{array}$ & $\begin{array}{l}0,09 \\
\mathrm{mg} / 1 \\
\mathrm{~N}\end{array}$ & $\begin{array}{l}0,14 \\
\mathrm{mg} / 1 \\
\mathrm{~N}\end{array}$ & $\begin{array}{l}8,9 \\
\mathrm{mg} / 1 \\
\mathrm{~N}\end{array}$ & $\begin{array}{l}0,23 \\
\mathrm{mg} / 1 \\
\mathrm{P}\end{array}$ & $\begin{array}{l}0,28 \\
\mathrm{mg} / 1 \\
\mathrm{P}\end{array}$ & $\begin{array}{l}36,0 \\
\mathrm{mg} / \mathrm{l} \mathrm{Cl}\end{array}$ & $\begin{array}{l}180,0 \\
\mathrm{mg} / 1 \\
\mathrm{SO}_{4}{ }^{2-}\end{array}$ \\
\hline
\end{tabular}

\subsection{Konstruktion von Metagenombanken in Escherichia coli}

\subsubsection{Isolierung von chromosomaler DNA aus dem Leinesediment}

Die Präparation der DNA aus dem Leinesediment erfolgte mit der Methode der direkten Lyse von ZHOU et al. (1996), mit der sowohl frei vorliegende DNA als auch die DNA aus den im Sediment lebenden Bakterien isoliert werden kann. Bei dieser Methode werden die Zellen durch eine Hitzeinkubation des Sedimentes in einem Hochsalzextraktionspuffer mit Proteinase K, Detergenzien (SDS, CTAB) und EDTA aufgeschlossen. Nach der Abtrennung der Sedimentpartikel und der Zelltrümmer durch Zentrifugation und der Extraktion der DNA mit Chloroform/Isoamylalkohol konnte die DNA mit Isopropanol gefällt werden (s. 2.6.1). Da meist bei der Präzipitation der DNA viel Salz auskristallisierte, musste eine Dialyse in TE-Puffer bei $4{ }^{\circ} \mathrm{C}$ über Nacht 
durchgeführt werden (s. 2.5.3.4). Anschließend wurde die DNA erneut gefällt. Wurden zudem viele Matrixbestandteile wie z. B. Huminsäure koextrahiert, was anhand der Braunfärbung der DNA-Lösung erkannt werden konnte, wurde die DNA mit Hilfe des "Wizard DNA Purification Systems" (s. 2.6.2) gereinigt. Dies war wichtig, da Huminsäuren Restriktionsenzyme, Polymerasen und Ligasen inhibieren (TEBBE und VAHJEN, 1993), die für die nachfolgenden Modifikationsschritte der DNA benötigt wurden. Mit diesem Vorgehen konnten zwischen 23 und $27 \mu \mathrm{g}$ DNA pro g Leinesediment erhalten werden. Wie in Abbildung 5 A) dargestellt, konnte mit einer DNA-Trennung durch eine „Pulse-Field“-Gelelektrophorese (s. 2.7.2) gezeigt werden, dass hochmolekulare DNA (über $450 \mathrm{~kb}$ ) isoliert werden konnte.

A)

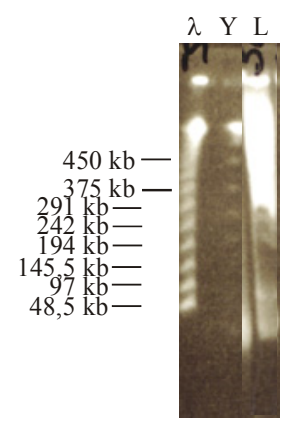

B)

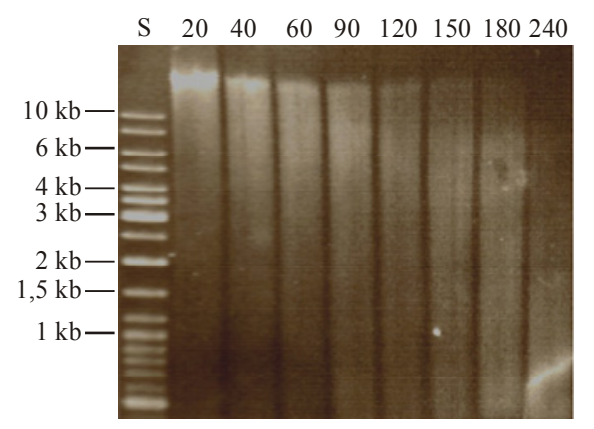

C)

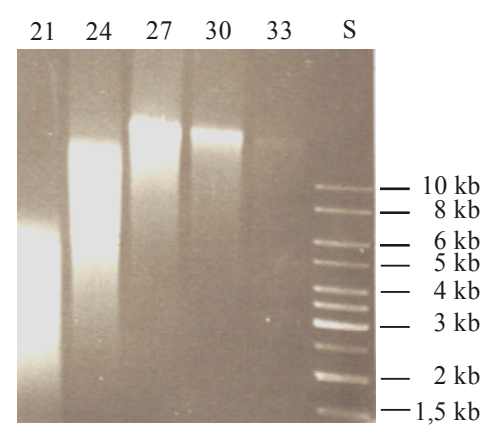

\section{Abbildung 5: Isolierte Leinesediment-DNA, partieller Verdau und Saccharosegradient}

A) „Pulse-Field“-Gelelektrophorese (s. 2.7.2) mit isolierter DNA aus einer Leinesediment-Probe (L): Die DNA wurde, wie unter 2.6.1 beschrieben, isoliert. Es wurden $3 \mu 1$ eingesetzt. Die mit „, $\lambda$ “ beschriftete Spur enthält den Standard „Lamda Ladder PFG-Marker“ (Fa. Biolab), dessen zugehörige Größen links vermerkt sind. Die beiden obersten Angaben entsprechenden den Größen des Standards „Yeast Chromosome PFG Marker“ (Fa. Biolabs). Dieser Standard ist in der Spur „Y“ aufgetragen.

B) Partieller Verdau der Leinesediment-DNA: Die isolierte DNA wurde wie unter 2.6.2 beschrieben gereinigt und anschließend, wie unter 2.8.1 beschrieben, partiell mit Bsp143I verdaut. Die Reaktion wurde nach den über den Spuren verzeichneten Sekunden mit EDTA auf Eis abgestoppt. Es wurden $5 \mu 1$ des Verdaus aufgetragen. $S$ bedeutet Standard.

C) Saccharosegradienten-Dichtezentrifugation: Die partiell verdaute DNA wurde mittels einer Saccharosegradienten-Dichtegradientenzentrifugation (s. 2.9) größenfraktioniert und anschließend, wie unter 2.5.3.2 beschrieben, gefällt. Die Zahlen über den Spuren entsprechen den aufgetragenen Fraktionen des Gradienten. Es wurden jeweils $6 \mu$ l eingesetzt.

\subsubsection{Klonierung der Umwelt-DNA}

Bei der Konstruktion der Leinesediment-Metagenombanken wurden zwei unterschiedliche Strategien verfolgt. Zum einen sollte die Umwelt-DNA für die Durchmusterung nach Genen mit gewünschten Aktivitäten zur Verfügung stehen, zum 
anderen sollten größere zusammenhängende DNA-Fragmente sequenziert werden. Dementsprechend wurden zwei verschiedene Vektorsysteme für die Klonierung der DNA genutzt. Kleinere DNA-Fragmente wurden in den Plasmid-Vektor pBluescript ${ }^{\circledR} \mathrm{II} \mathrm{SK}+$ (bzw. pBluescript $\mathrm{SK}^{+}$, ältere Variante; beide von der Fa. Stratagene, San Diego, USA), größere in den Cosmid-Vektor superCosI (Stratagene, San Diego, USA) kloniert.

Unabhängig von der Wahl des Vektors wurde die Umwelt-DNA für die Klonierung mit dem Enzym Bsp143I zeitlimitiert partiell verdaut. Bsp143I ist ein Isoschizomer von Sau3AI und hat eine 4 bp-lange Erkennungssequenz ( $\downarrow$ GATC). Damit schneidet das Enzym so häufig, dass mit hoher Wahrscheinlichkeit eine nahezu gleichmäßige Verteilung aller vorkommenden DNA-Fragmente erreicht werden kann. Limitierend wirken dabei stark unterschiedliche $\mathrm{G}+\mathrm{C}-$ Gehalte der verschiedenen Fragmente. Dem Restriktionsansatz wurden innerhalb von 5 Minuten 8 Proben entnommen und die DNA-Spaltung mit EDTA auf Eis abgestoppt (s. 2.8.1). Anschließend wurde der Verdau im Agarosegel analysiert. Ein solches Agarosegel ist in Abbildung 5 B) dargestellt. Mittels einer Saccharose-Dichtegradientenzentrifugation (s. 2.9) wurde die DNA größenfraktioniert. Nach der Saccharose-Dichtegradientenzentrifugation wurde die DNA gefällt (s. 2.5.3.2) und die Größe der in den unterschiedlichen Fraktionen enthaltenen DNA im Agarosegel analysiert. In der Abbildung 5 C) sind die Fraktionen eines Saccharosegradienten dargestellt, die für die anschließenden Klonierungen verwendet werden konnten. Für die Klonierung in den Vektor pBluescript ${ }^{\circledR}$ II SK+ wurden Fraktionen genommen, welche DNA-Fragmente enthielten, die größer als $2 \mathrm{~kb}$ waren (Fraktionen 24 und 27, Abbildung 5 C)). Fraktionen mit Fragmenten $>10 \mathrm{~kb}$ eigneten sich für die Klonierung in superCosI (Fraktionen 30 und 33, Abbildung 5 C)).

\subsubsection{Herstellung einer Plasmid-Genbank}

Der Plasmid-Vektor pBluescript ${ }^{\circledR}$ II SK+ (Stratagene, San Diego, USA) eignet sich aus verschiedenen Gründen für die Herstellung von Plasmid-Genbanken, die anschließend in Screening-Systemen eingesetzt werden sollen: Er liegt in E. coli in hoher Kopienzahl vor, was gegebenenfalls eine detektierbare heterologe Genexpression ermöglicht. Die auf dem Vektor kodierte Ampicillin-Resistenz erlaubt eine Selektion der Transformanten und das ebenfalls vektorkodierte lacZ-Gen die Identifizierung rekombinanter Plasmide durch den X-Gal-Test (s. 2.11.14). In pBluescript ${ }^{\circledR}$ II SK+ können, wie bereits beschrieben, DNA-Fragmente bis zu einer Größe von ca. 10 kb 
kloniert werden. Dies kann einer Größe von mehreren Genen entsprechen. Ziel war es, um möglichst viel Umwelt-DNA mit wenig Klonen durchmustern zu können, möglichst große DNA-Fragmente zu klonieren. Außerdem ermöglichen größere Inserts das Vorhandensein von kleineren Genclustern und damit ein Screening nach von ihnen kodierten Funktionen.

Saccharose-Dichtegradientenzentrifugations-Fraktionen mit DNA-Fragmenten, die größer als $2 \mathrm{~kb}$ waren, wurden mit der T4-Ligase in pBluescript ${ }^{\circledR} \mathrm{II}$ SK + ligiert (s. 2.8.3.1). Dieser war zuvor mit BamHI-geschnitten (s. 2.8.1) und anschließend dephosphoryliert (s. 2.8.2) worden. Die Ligationsansätze wurden dann in E. coli DH5 $\alpha$ (s. 2.10.1) transformiert und die Transformanten auf LB-Ampicillin-Agar mit X-Gal und IPTG ausplattiert. Zur Charakterisierung der Genbank wurden die Klone auf den Platten ausgezählt und mittels des X-Gal-Testes das Verhältnis von Kolonien mit Inserts tragenden Plasmiden zu Kolonien mit Plasmiden ohne Insert bestimmt. Außerdem wurden 30 Klone in LB-Ampicillin-Medium angezogen. Ihre Plasmide wurden präpariert und mit SacI und HindIII verdaut. Mit diesem Vorgehen konnten die maximale, minimale und durchschnittliche Insertgröße ermittelt werden. War die durchschnittliche Insertgröße größer als 2,5 kb, wurden die Klone zur Konservierung der Genbank von den Platten abgeschwemmt, die Plasmide isoliert (s. 2.6.3.4) und bei $-20{ }^{\circ} \mathrm{C}$ gelagert. In Tabelle 7 sind die auf diese Weise bestimmten Parameter der partiellen Genbanken aufgeführt.

\section{Tabelle 7: Zusammenfassung der Eigenschaften der Plasmid-Genbanken aus Leinesediment}

Die Insertgrößen wurden durch Isolierung (s. 2.6.6.2) und Restriktionsverdau (s. 2.8.1) von 30 Plasmiden ermittelt. Die Bestimmung des Anteils der Insert-tragenden Plasmide erfolgte durch den X-Gal-Test (s. 2.10.4). Dazu wurde je Genbank $1 \mu$ l Plasmid-DNA in E. coli DH5 $\alpha$ transformiert (s. 2.10.1). Die Transformanten wurden auf LB-Agar, der mit Ampicillin, X-Gal und IPTG versetzt war, ausplattiert.

\begin{tabular}{lccccc}
\hline $\begin{array}{l}\text { Bezeichnung } \\
\text { der Genbank }\end{array}$ & $\begin{array}{c}\text { Plasmiden } \\
\text { mit Insert }\end{array}$ & $\begin{array}{c}\text { minimale } \\
\text { Insertgröße }\end{array}$ & $\begin{array}{c}\text { maximale } \\
\text { Insertgröße }\end{array}$ & $\begin{array}{c}\varnothing \\
\text { Insertgröße }\end{array}$ & $\begin{array}{c}\text { Insert- } \\
\text { häufigkeit }\end{array}$ \\
\hline S11 & 5700 & $1,1 \mathrm{~kb}$ & $8,5 \mathrm{~kb}$ & $3,3 \mathrm{~kb}$ & $63 \%$ \\
S12 & 7600 & $1,1 \mathrm{~kb}$ & $7,8 \mathrm{~kb}$ & $3,7 \mathrm{~kb}$ & $28 \%$ \\
S13 & 2000 & $1,8 \mathrm{~kb}$ & $14,0 \mathrm{~kb}$ & $6,1 \mathrm{~kb}$ & $77 \%$ \\
S14 & 7500 & $1,2 \mathrm{~kb}$ & $11,1 \mathrm{~kb}$ & $4,1 \mathrm{~kb}$ & $76 \%$ \\
S15 & 9000 & $1,0 \mathrm{~kb}$ & $6,8 \mathrm{~kb}$ & $3,8 \mathrm{~kb}$ & $68 \%$ \\
\hline
\end{tabular}

Gesamtzahl der Klone: 31800 Gesamtinsertgröße: 124080 kb 
Insgesamt wurden ca. 32000 Plasmide mit Insert gewonnen. Das entspricht ca. $124 \mathrm{Mb}$ klonierter DNA. Die durchschnittliche Insertgröße der Klone aller Teilgenbanken beträgt 3,9 kb. Die Insertgrößen liegen zwischen 1,0 und 14,0 kb.

\subsubsection{Herstellung einer Cosmid-Genbank}

Die Verwendung von Cosmiden zur Erstellung einer Genbank hat gegenüber den Plasmiden den Vorteil, dass große DNA-Abschnitte kloniert werden können. Damit besteht die Möglichkeit, die Genbank nach Enzymen oder Aktivitäten zu durchsuchen, die in großen Genclustern organisiert vorliegen. Außerdem stehen für Sequenzierungsprojekte wie diesem große (funktionell) zusammenhängende DNAFragmente zur Verfügung, die einen gewissen Einblick in die Aktivitäten des unbekannten Ursprungsorganismus gewähren. Der in dieser Arbeit verwendete CosmidVektor superCosI (Abbildung 6) trägt Gene zur Ausbildung einer zweifachen Antibiotikaresistenz gegen Ampicillin $\left(A m p^{R}\right)$ und Neomycin $\left(\mathrm{Neo}^{\mathrm{R}}\right)$, wodurch eine Selektion der Cosmide ermöglicht wird. Außerdem besitzt der Vektor eine doppelte Kopie des Cos-Elementes des Bakteriophagen Lambda.

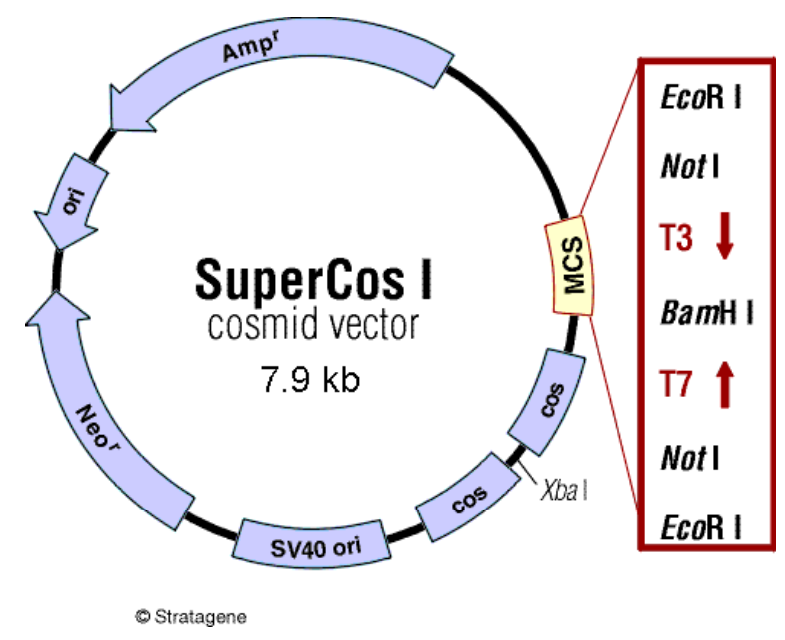

Abbildung 6: Der Cosmid-Vektor SuperCos1 (Fa. Stratagene, EVANS et al., 1989)

Dieses wird zur Verpackung concatemerer DNA in Phagenköpfe benötigt. Die doppelte Kopienzahl dieses Elementes soll die Klonierungseffizienz dadurch erhöhen, dass beim Ausschneiden eines der Cos-Elemente zwei unterschiedliche Vektorenden generiert werden. Damit sinkt die Anzahl an Kolonien, die sich aufgrund der Verpackung von concatemerer Vektor-DNA ohne klonierte Umwelt-DNA bilden (WENZEL und 
HERMANN, 1996). Bei der Vektorpräparation wird zunächst der Vektor mit dem Restriktionsenzym XbaI linearisiert und mit alkalischer Phosphatase dephosphoryliert. Nach Reinigung der DNA mit dem „PCR Purification Kit“ (Fa. Qiagen, s. 2.5.3.7) erfolgte eine zweite Spaltung mit dem Enzym BamHI, eine weitere Dephosphorylierung und eine weitere Reinigung. Der präparierte Cosmid-Vektor konnte dann mit der Leinesediment-DNA ligiert werden. Der superCosI-Vektor hat eine Klonierungskapazität von 31 bis $48 \mathrm{~kb}$, das heißt, dass nur Cosmide mit solchen Insertgrößen erfolgreich verpackt werden. Deshalb wurden in den Ligationen solche Fraktionen aus der Saccharose-Dichtegradientenzentrifugation eingesetzt, die mindestens $10 \mathrm{~kb}$-große DNA-Fragmente beinhalteten. Die Verpackungsreaktion und Transduktion erfolgte mit dem in vitro-Verpackungsextrakt Gigapack ${ }^{\circledR}$ III XL (s. 2.11.3). Mit dieser Methode konnten 400 cosmidtragende E. coli-Klone gewonnen werden. Bei der Sequenzierung einzelner Cosmide konnten Insertgrößen zwischen 33732 bp und 44530 bp festgestellt werden (s. 3.4.1). Die Insertgrößen liegen damit in der Größenordnung der Klonierungskapazität. Die rekombinanten Klone wurden zur Konservierung in Mikrotiterplatten gepickt und bei $-70^{\circ} \mathrm{C}$ gelagert.

\subsection{Analyse der phylogenetischen Diversität mittels 16S rRNA- Genanalyse}

Die Untersuchung der phylogenetischen Diversität des Leinesedimentes erfolgte durch die Amplifikation von 16S rRNA-Genen mittels PCR (s. 2.10.1) und anschließender Sequenzierung (s. 2.12.1). Als Template wurde die direkt aus dem Boden extrahierte DNA eingesetzt (s. 2.6.1). In 4 verschiedenen PCR-Reaktionen fanden 3 verschiedene Oligonukleotidpaare Verwendung, von denen laut Literaturangaben die Oligonukleotidpaare A1530R und A800F (ITOH et al., 2003; KOLGONOVA et al., 2002) und 23FPL und 927R (DEES und GHIORSE, 2001) gegen archaeelle und das Oligonukleotidpaar 16S08 und 16S1504 (MUYZER et al., 1992) gegen bakterielle 16S rRNA-Gene gerichtet waren. Die Nummerierung bezieht sich dabei auf die entsprechende Position des 16S rRNA-Gens bei E. coli. Bei der PCR können bei einer unvollständigen Strangsynthese während der Elongation artifizielle PCR-Produkte entstehen, die aus der rDNA zweier Organismen zusammengesetzt sind (WANG und WANG, 1996). Auch fragmentierte Template-DNA fördert die Entstehung solcher 
Artefakte (LIESACK et al., 1991; PÄÄBO et al., 1990). Um diesem Problem zu begegnen, wurden stark verlängerte Elongationszeiten gewählt. Die Kettenverlängerung der vollständigen bakteriellen 16S rRNA-Gene (ca. 1500 bp) erfolgte für 4 Minuten, die der 900 bp-langen archaeellen 16S rRNA-Gen-Fragmente für 2 Minuten bzw. die der 730 bp umfassenden Gen-Fragmente für 1,5 Minuten. Bei einer Syntheseleistung der Taq-DNA-Polymerase von 2 bis $4 \mathrm{~kb}$ pro Minute entspricht dies einer 2- bis 5-fach verlängerten Elongationszeit. Zusätzlich wurde die eingesetzte Template-DNA vor der PCR durch eine Agarose-Gelelektrophorese (s. 2.7.1) auf das Vorliegen hochmolekularer DNA kontrolliert. Die erhaltenen PCR-Produkte wurden aus einem Agarosegel ausgeschnitten, extrahiert (s. 2.5.3.6) und anschließend in den pCR2.1TOPO-Vektor kloniert. Die Ansätze wurden in E. coli TOP10-Zellen transformiert und auf LB-Medium mit Ampicillin, IPTG und X-Gal ausplattiert. 25 weiße Kolonien wurden in LB-Medium mit Ampicillin angezogen, die Plasmide präpariert und mit EcoRI geschnitten. Enthielten mehr als 70 \% der Plasmide ein Insert mit der erwarteten Größe, wurden von 960 Klonen des Transfomationsansatzes Stammkulturen in Mikrotiterplatten angelegt (s. 2.3.3). Pro PCR-Ansatz wurde eine Mikrotiter-Platte zum Beimpfen eines „Flat-Bottom-Blocks“ für eine robotgesteuerte Plasmidpräparation (2.6.3.5) herangezogen. Die präparierten Plasmide wurden dann in einer Sequenzreaktion (s. 2.12.1) eingesetzt. Die Sequenzierung erfolgte mit den Standardoligonukleotiden rev und for (s. Tabelle 3) mit dem „ABI DNA Sequencer 377“. Es folgten das „Basecalling“ der Rohdaten mit dem Programm „Phred“ (s. 2.13.1), die Prozessierung der von „Phred“ generierten Daten mit dem Programm „Pregap4“ (s. 2.13.1.1) und die Bearbeitung der Sequenzen in dem Programm „Gap4“ (s. 2.13.1.2). Konnten die ,forward“- und ,reverse“-Sequenzläufe nicht zu einer Gesamtsequenz zusammengesetzt werden, wurde durch eine erneute Sequenzreaktion mit dem Oligonukleotid 16S513 (s. Tabelle 3) die bestehende Sequenzlücke geschlossen. Sequenzbereiche mit schlechter Qualität wurden durch wiederholte Sequenzierungen verbessert. Wie der Tabelle 8 entnommen werden kann, wurden mit den Oligonukleotiden, die gegen bakterielle 16S rRNA-Gene gerichtet sind, 35 (PCR 1) bzw. 55 (PCR 2) 16S rRNA-Gene sequenziert (Nummerierung der PCR-Reaktionen s. Tabelle 8). Aus der PCR mit den gegen archaeelle 16S rRNA-Gene gerichteten Oligonukleotiden 23FPL und 927R (PCR 3) gingen 57 bzw. mit den Oligonukleotiden A800F und A1530R (PCR 4) 60 Sequenzen hervor. Die vollständigen Sequenzen wurden anschließend mit den Programmen „CHIMERA_CHECK version 2.7“ des 
„Ribosomal Database Project“ (RDP; LARSEN et al., 1993) und dem Programm „Bellerophon chimera detection programm“ auf das Vorhandensein von Chimeren überprüft (s. 2.15.3). Es ergaben sich folgende in Tabelle 8 dargestellten Ergebnisse:

Tabelle 8: Überblick über die generierten 16S rRNA-Gensequenzen und die Häufigkeit von Chimeren

\begin{tabular}{|l|l|l|c|c|c|}
\hline $\begin{array}{c}\text { PCR- } \\
\text { Reaktion }\end{array}$ & $\begin{array}{c}\text { Bezeichnung } \\
\text { der } \\
\text { Sequenzen }\end{array}$ & Oligonukleotidpaar & $\begin{array}{c}\text { Sequenzierte } \\
16 \mathrm{~S} \text { rRNA-Gene }\end{array}$ & $\begin{array}{c}\text { Anzahl } \\
\text { chimerer } \\
\text { Sequenzen }\end{array}$ & $\begin{array}{c}\text { Prozentualer } \\
\text { Anteil chimerer } \\
\text { Sequenzen }\end{array}$ \\
\hline PCR 1 & $\begin{array}{l}\text { sl11xx bzw. } \\
\text { sl12xx }\end{array}$ & $16 \mathrm{~S} 08+16 \mathrm{~S} 1504$ & 35 & 8 & $22 \%$ \\
\hline PCR 2 & sl13xx & $16 \mathrm{~S} 08+16 \mathrm{~S} 1504$ & 55 & 11 & $20 \%$ \\
\hline PCR 3 & sl31xx & 23FPL+927R & 57 & 3 & $5 \%$ \\
\hline PCR 4 & sl32xx & A800F+A1530R & 60 & 3 & $5 \%$ \\
\hline
\end{tabular}

$\mathrm{xx}=$ Klonnummer

Die Untersuchung der in der PCR 1 generierten Sequenzen ergab eine starke Häufung von chimeren Sequenzen, deren einer Teil $100 \%$ Identität zu E. coli zeigte. In diesem Fall muss davon ausgegangen werden, dass hier eine Kontamination des PCR-Ansatzes mit E. coli (-DNA) vorlag. Diese Sequenzen wurden trotzdem zur phylogenetischen Charakterisierung des Leinesedimentes herangezogen, da der Rest der Sequenzen eindeutig einem anderen Organismus zugeordnet werden konnte. Diese Sequenzen weichen deshalb von der erwarteten Länge von ca. 1500 bp ab. HUGENHOLTZ und HUBER (2003) raten bei Chimeren dazu, sie entweder gar nicht in öffentliche Datenbanken zu integrieren oder aber als 2 getrennte Fragmente einzuführen. Insofern ist ein solches Vorgehen durchaus zu rechtfertigen, da in diesem Fall eine klare Grenze zwischen dem Teil, der auf E. coli-DNA zurückzuführen ist, und dem Teil, der anhand der DNA anderer Organismen amplifiziert wurde, vorliegt. In anderen Fällen, besonders bei Chimeren aus Sequenzen nah verwandter Organismen, ist dies nur noch schwer möglich. Im Folgenden sind auch die Chimere in die Tabellen und Stammbäume aufgenommen, die eine Entscheidung bezüglich der Schnittstelle zwischen den Sequenzen erlaubten. Sie werden durch einen Stern (*) gekennzeichnet. Wie aus der Tabelle 8 entnommen werden kann, entstanden besonders viele Chimere bei der Amplifikation mit dem Oligonukleotidpaar 16S08/16S1504.

Die chimerbereinigten Sequenzen wurden nun mit den Datenbanken von NCBI und RDP (LARSEN et al., 1993) verglichen. Jede Sequenz wurde anschließend mit den 
ähnlichsten Sequenzen der beiden Datenbanken mit dem Programm „ClustalW“ verglichen, um die Identität der Sequenzen über ihre Gesamtlänge zu erhalten. In der Tabelle 9 ist zu jeder Sequenz die ähnlichste Sequenz aus beiden Datenbanken wiedergegeben, dabei wurden nur Sequenzen berücksichtigt, die mehr als 400 bp umfassen. Außerdem wurde soweit vorhanden zu jeder Datenbank-Sequenz der Standort, aus dem sie amplifiziert wurde, und die phylogenetische Klassifizierung vermerkt.

\section{Tabelle 9: Phylogenetische Einordnung der 16S rRNA-Gensequenzen des Leinesedimentes anhand ihrer nächsten Verwandten aus den Datenbanken von NCBI und RDP}

In der Tabelle werden folgende Abkürzungen und Formulierungen verwendet:

Rotsee $=$ Sediment des Rotsees, Schweiz; Valkea Kotinen $=$ Oberflächenwasser aus finnischen Waldsee Valkea Kotinen; DCP $=$ Dichlorpropan dechlorierende Mischkultur; $\mathbf{T C B}=$ anaerobes Trichlorbenzen umsetzendes mikrobielles Konsortium; KWL $=$ Wasserrohrsystem, kontaminiert mit Kohlenwasserstoffen und chlorierten Lösungsmitteln;

Klone, bei denen in der Klassifikationsspalte „unklassifiziert“ steht, sind überhaupt nicht klassifiziert. Sie wurden entsprechend der Anordnung in den Stammbäumen in die Tabelle übernommen. Bei Klonen, bei denen die Bezeichnung, ,nicht genauer klassifiziert“ auftritt, ist bislang nur eine ungenaue Klassifizierung erfolgt. Solche Sequenzen sind entsprechend der letzten Kategorie in der Tabelle klassifiziert.

Bei 16S rRNA-Gensequenzen, bei denen die nächst verwandte Sequenz in der NCBI und der RDPDatenbank die gleiche Identität zeigte, sind beide in die Tabelle mit aufgenommen.

I. Archaea

\section{I.I Methanomicrobia}

\section{I.I.I Methanosarcinales}

\section{I.I.I.I Methanosaetaceae}

\begin{tabular}{|c|c|c|c|c|}
\hline $\begin{array}{l}\text { Se- } \\
\text { quenz- } \\
\text { name: } \\
\text { slxxxx }\end{array}$ & $\begin{array}{l}\text { Länge } \\
\text { in bp }\end{array}$ & $\begin{array}{l}\text { Ähnlichste Sequenz aus den } \\
\text { Datenbanken von NCBI und } \\
\text { RDP }\end{array}$ & $\begin{array}{l}\text { Accession- } \\
\text { Nummer } \\
\text { der } \\
\text { Datenbank- } \\
\text { sequenz }\end{array}$ & $\begin{array}{l}\text { Phylogenetische Klassifikation } \\
\text { der Datenbanksequenz }\end{array}$ \\
\hline 3104 & 899 & Klon Rot11 & Y18087 & Methanosaeta \\
\hline 3109 & 899 & Klon Rot18 & Y18091 & Methanosaeta \\
\hline 3115 & 896 & Klon Rot11 & Y18087 & Methanosaeta \\
\hline 3116 & 899 & Klon S15-8 & AJ236489 & Methanosaeta \\
\hline 3125 & 899 & Klon Rot11 & Y18087 & Methanosaeta \\
\hline 3128 & 899 & Klon Rot18 & Y18091 & Methanosaeta \\
\hline 3130 & 901 & $\begin{array}{l}\text { Methanosaeta unkultiviertes } \\
\text { Archeon WCHD3-03 }\end{array}$ & AF050611 & Methanosaeta \\
\hline 3131 & 899 & Klon Rot11 & Y18087 & Methanosaeta \\
\hline 3132 & 898 & $\begin{array}{l}\text { Methanosaeta concilii Stamm } \\
\text { VeAc9 }\end{array}$ & Y15402 & Methanosaeta \\
\hline 3134 & 899 & $\begin{array}{l}\text { Methanosaeta concilii Stamm } \\
\text { Opfikon }\end{array}$ & X51423 & Methanosaeta \\
\hline 3137 & 899 & Klon Rot16 & Y18090 & Methanosaeta \\
\hline 3142 & 899 & Klon Rot16 & Y18090 & Methanosaeta \\
\hline 3143 & 899 & $\begin{array}{l}\text { Methanosaeta concilii Stamm } \\
\text { Opfikon }\end{array}$ & X51423 & Methanosaeta \\
\hline
\end{tabular}

Herkunft der

Datenbanksequenz

Rotsee

Rotsee

Rotsee

Anaerober Reisfeldboden

Rotsee

Rotsee

KWL

Rotsee

Organismus

Organismus

Rotsee

Rotsee

Organismus
Identität

in $\%$

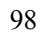

98

98

96 


\begin{tabular}{|c|c|c|c|c|}
\hline $\begin{array}{l}\text { Se- } \\
\text { quenz- } \\
\text { name: } \\
\text { slxxxx }\end{array}$ & $\begin{array}{l}\text { Länge } \\
\text { in bp }\end{array}$ & $\begin{array}{l}\text { Ähnlichste Sequenz aus den } \\
\text { Datenbanken von NCBI und } \\
\text { RDP }\end{array}$ & $\begin{array}{l}\text { Accession- } \\
\text { Nummer } \\
\text { der } \\
\text { Datenbank- } \\
\text { sequenz }\end{array}$ & $\begin{array}{l}\text { Phylogenetische Klassifikation } \\
\text { der Datenbanksequenz }\end{array}$ \\
\hline 3144 & 899 & Klon Rot 25 & Y18094 & Methanosaeta \\
\hline 3146 & 899 & Klon Rot11 & Y18087 & Methanosaeta \\
\hline 3151 & 899 & Klon Rot11 & Y18087 & Methanosaeta \\
\hline 3153 & 899 & Klon Rot11 & Y18087 & Methanosaeta \\
\hline 3155 & 899 & Klon Rot11 & Y18087 & Methanosaeta \\
\hline 3158 & 899 & Klon Rot18 & Y18091 & Methanosaeta \\
\hline 3166 & 99 & Klon Rot11 & Y18087 & Methanosaeta \\
\hline 3170 & 899 & Klon Rot11 & Y18087 & Methanosaeta \\
\hline 3171 & 889 & Klon Rot18 & Y18091 & Methanosaeta \\
\hline 3172 & 899 & Klon Rot16 & Y18090 & Methanosaeta \\
\hline 3174 & 899 & Klon Rot11 & Y18087 & Methanosaeta \\
\hline 3176 & 899 & Klon Rot11 & Y18087 & Methanosaeta \\
\hline 3180 & 899 & Klon Rot11 & Y18087 & Methanosaeta \\
\hline 3181 & 899 & Klon Rot11 & Y18087 & Methanosaeta \\
\hline 3187 & 899 & Unkultiviertes Archaeon S15-8 & AJ236489 & Umweltprobe \\
\hline 3189 & 900 & Methanosaeta sp. Klon A1 & AJ133791 & Methanosaeta \\
\hline 3194 & 677 & $\begin{array}{l}\text { Methanosaeta unkultiviertes } \\
\text { Archeon WCHD3-03 }\end{array}$ & AF050611 & Methanosaeta \\
\hline
\end{tabular}

Herkunft der

Datenbanksequenz

Rotsee

Rotsee

Rotsee

Rotsee

Rotsee

Rotsee

Rotsee

Rotsee

Rotsee

Rotsee

Rotsee

Rotsee

Rotsee

Rotsee

Boden

Keine Angabe

KWL
Identität

in $\%$

97

97

98

98

98

98

97

98

96

97

98

98

98

97

99

83

92

\section{I.I.I.II Methanosacrinaceae}

\begin{tabular}{|c|c|c|}
\hline 3106 & 791 & $\begin{array}{l}\text { Methanomethylovorans } \\
\text { hollandica DMS1 }\end{array}$ \\
\hline 3113 & 900 & Klon S30-19 \\
\hline $3114 *$ & 510 & $\begin{array}{l}\text { Unkultiviertes „Green Bay“ } \\
\text { Archaeon }\end{array}$ \\
\hline 3118 & 902 & $\begin{array}{l}\text { Methanosarcina sp. Stamm } \\
\text { VeA23 }\end{array}$ \\
\hline 3138 & 902 & Klon 2MT7 \\
\hline
\end{tabular}

AF120163 Methanomethylovorans

AJ236528 Methanomethylovorans

AF293017 Unklassifiziert

Y15400 Methanosarcina

AF015991 Nicht genauer klassifiziert
Süßwasser-Sediment

Anaerober Reisfeldboden Süßwasser

Anaerober Reisfeldboden

Küstensalzmarsch

\section{I.I.II Methanomicrobiales}

\section{I.I.II.I MCU. Bourgense-Untergruppe}

$\begin{array}{lll}3110 & 896 & \text { Klon Rot7 } \\ 3117 & 896 & \text { Klon Rot7 } \\ 3119 & 897 & \text { Klon VAL1 } \\ 3122 & 896 & \text { Klon Rot24 } \\ 3127 & 897 & \text { Klon Va19 } \\ & & \text { Klon Rot26 } \\ 3135 & 898 & \text { Klon VAL9 } \\ 3141 * & 631 & \text { Klon VAL47 } \\ 3145 & 896 & \text { KlonVAL1 } \\ & & \text { Klon Rot26 } \\ 3148 & 849 & \text { Klon Rot26 } \\ 3152 & 897 & \text { Klon VAL9 } \\ 3157 & 894 & \text { Klon Rot7 }\end{array}$

$\begin{array}{ll}\text { Y18085 } & \text { Nicht genauer klassifiziert } \\ \text { Y18085 } & \text { Nicht genauer klassifiziert } \\ \text { AJ131263 } & \text { Unklassifiziert } \\ \text { Y18093 } & \text { Nicht genauer klassifiziert } \\ \text { AJ131273 } & \text { Nicht genauer klassifiziert } \\ \text { Y18095 } & \text { Nicht genauer klassifiziert } \\ \text { AJ131273 } & \text { Nicht genauer klassifiziert } \\ \text { AJ131268 } & \text { Unklassifiziert } \\ \text { AJ131263 } & \text { Unklassifiziert } \\ \text { Y18095 } & \\ \text { Y18095 } & \text { Nicht genauer klassifiziert } \\ \text { AJ131273 } & \text { Nicht genauer klassifiziert } \\ \text { Y18085 } & \text { Nicht genauer klassifiziert }\end{array}$

$\begin{array}{ll}\text { Rotsee } & 99 \\ \text { Rotsee } & 99 \\ \text { Valkea Kotinen } & 96 \\ \text { Rotsee } & 94 \\ \text { Valkea Kotinen } & 97 \\ \text { Rotsee } & \\ \text { Valkea Kotinen } & 97 \\ \text { Valkea Kotinen } & 93 \\ \text { Valkea Kotinen } & 98 \\ \text { Rotsee } & \\ \text { Rotsee } & 97 \\ \text { Valkea Kotinen } & 97 \\ \text { Rotsee } & 98\end{array}$




\begin{tabular}{|c|c|c|}
\hline $\begin{array}{l}\text { Se- } \\
\text { quenz- } \\
\text { name: } \\
\text { slxxxx }\end{array}$ & $\begin{array}{l}\text { Länge } \\
\text { in bp }\end{array}$ & $\begin{array}{l}\text { Ähnlichste Sequenz aus den } \\
\text { Datenbanken von NCBI und } \\
\text { RDP }\end{array}$ \\
\hline 3162 & 896 & Klon VAL47 \\
\hline 3163 & 895 & Klon Rot26 \\
\hline 3164 & 898 & Klon ABS22 \\
\hline 3165 & 896 & $\begin{array}{l}\text { Klon ABS20 } \\
\text { Klon Rot } 7\end{array}$ \\
\hline 3169 & 899 & Klon VAL9 \\
\hline $3173 *$ & 577 & Klon VAL9 \\
\hline 3177 & 892 & Klon Rot7 \\
\hline 3178 & 896 & Klon Rot6 \\
\hline 3179 & 896 & Klon Rot7 \\
\hline 3182 & 866 & $\begin{array}{l}\text { Unkultiviertes Archeon } \\
\text { 'Soyang 1Af-1100Ar' }\end{array}$ \\
\hline 3186 & 897 & $\begin{array}{l}\text { Methanogenes Archaeon } \\
\text { NOBI-1 }\end{array}$ \\
\hline 3192 & 885 & Klon Rot26 \\
\hline 3193 & 895 & Klon VAL1 \\
\hline
\end{tabular}

$\begin{array}{ll}\begin{array}{l}\text { Accession- } \\ \text { Nummer } \\ \text { der } \\ \begin{array}{l}\text { Datenbank- } \\ \text { sequenz }\end{array}\end{array} & \begin{array}{l}\text { Phylogenetische Klassifikation } \\ \text { der Datenbanksequenz }\end{array} \\ \text { AJ131268 } & \text { Unklassifiziert } \\ \text { Y18095 } & \text { Nicht genauer klassifiziert } \\ \text { Y15397 } & \text { Nicht genauer klassifiziert } \\ \text { Y15395 } & \text { Nicht genauer klassifiziert } \\ \text { Y18085 } & \text { Nicht genauer klassifiziert } \\ \text { AJ131273 } & \text { Nicht genauer klassifiziert } \\ \text { AJ131273 } & \text { Nicht genauer klassifiziert } \\ \text { Y18085 } & \text { Nicht genauer klassifiziert } \\ \text { Y18084 } & \text { Nicht genauer klassifiziert } \\ \text { Y18085 } & \text { Nicht genauer klassifiziert } \\ \text { AF056360 } & \text { Nicht genauer klassifiziert } \\ \text { AB162774 } & \text { Nicht genauer klassifiziert } \\ \text { Y18095 } & \text { Nicht genauer klassifiziert } \\ \text { AJ131263 } & \text { Unklassifiziert }\end{array}$

Herkunft der

Datenbanksequenz

Identität

in $\%$

Valkea Kotinen

Rotsee

Anaerober Reisfeldboden

97

Rotsee

Valkea Kotinen

Valkea Kotinen

Rotsee

Rotsee

Rotsee

Sediment, Süßwassersee,

Südkorea

Anaerober Schlamm

Rotsee

Valkea Kotinen

98

\section{I.II Thermoplasmales und Verwandte}

$3139899 \quad$ Unkultiviertes Euryarchaeot

VAL147

\section{Bacteria}

\section{II.I Proteobacteria}

\section{II.I.I $\alpha$-Proteobacteria}

\section{II.I.I.I Rhizobiales}

\begin{tabular}{|c|c|c|}
\hline 1106 & 671 & Rhizobium sp. NK-4 \\
\hline 3207 & 739 & $\begin{array}{l}\text { Hyphomicrobium zavarzinii } \\
\text { Stamm ZV-622 }\end{array}$ \\
\hline 3209 & 716 & Unbenannter Organismus \\
\hline 3233 & 738 & $\begin{array}{l}\text { Methylobacterium } \\
\text { fujisawaense Stamm DSM } \\
5686\end{array}$ \\
\hline 3247 & 595 & Agrobacterium tumefaciens \\
\hline 3249 & 739 & $\begin{array}{l}\text { Hyphomicrobium zavarzinii } \\
\text { Stamm ZV-622 }\end{array}$ \\
\hline 3257 & 736 & Pedomicrobium manganicum \\
\hline 3265 & 742 & Mesorhizobium tianshanense \\
\hline 3274 & 741 & $\begin{array}{l}\text { Mesorhizobium mediterraneum } \\
\text { Stamm PECA20 }\end{array}$ \\
\hline $3294 *$ & 742 & $\begin{array}{l}\text { Sinorhizobium meliloti Stamm } \\
\text { LMTR32 }\end{array}$ \\
\hline
\end{tabular}

$\begin{array}{cl}\text { AF511498 } & \begin{array}{l}\text { Rhizobiaceae; } \\ \text { Rhizobium/Agrobacterium } \\ \text { Gruppe; Rhizobium }\end{array} \\ \text { Y14305 } & \begin{array}{l}\text { Hyphomicrobiaceae; } \\ \text { Hyphomicrobium }\end{array} \\ \mathrm{AJ} 001345 & \begin{array}{l}\text { Brucellaceae } \\ \text { Methylobacteriaceae; } \\ \text { Methylobacterium }\end{array} \\ \mathrm{D} 14500 & \begin{array}{l}\text { Rhizobiaceae; } \\ \text { Rhizobium/Agrobacterium } \\ \text { Gruppe; Rhizobium }\end{array} \\ \mathrm{Y} 14305 & \begin{array}{l}\text { Hyphomicrobiaceae; } \\ \text { Hyphomicrobium }\end{array} \\ \mathrm{X} 97691 & \begin{array}{l}\text { Hyphomicrobiaceae; } \\ \text { Pedomicrobium }\end{array} \\ \mathrm{AF} 041447 & \begin{array}{l}\text { Phyllobacteriaceae; } \\ \text { Mesorhizobium }\end{array} \\ \mathrm{AY} 195844 & \begin{array}{l}\text { Phyllobacteriaceae; } \\ \text { Mesorhizobium } \\ \text { Rhizobiaceae; } \\ \text { AY196963 }\end{array} \\ & \begin{array}{l}\text { Sinorhizobium/Ensifer } \text { Gruppe; } \\ \text { Sinorhizobium }\end{array}\end{array}$

Keine Angabe

Boden 


\section{II.I.I.II Sphingomonadales}

\begin{tabular}{|c|c|c|c|c|}
\hline $\begin{array}{l}\text { Se- } \\
\text { quenz- } \\
\text { name: } \\
\text { slxxxx }\end{array}$ & $\begin{array}{l}\text { Länge } \\
\text { in bp }\end{array}$ & $\begin{array}{l}\text { Ähnlichste Sequenz aus den } \\
\text { Datenbanken von NCBI und } \\
\text { RDP }\end{array}$ & $\begin{array}{l}\text { Accession- } \\
\text { Nummer } \\
\text { der } \\
\text { Datenbank- } \\
\text { sequenz }\end{array}$ & $\begin{array}{l}\text { Phylogenetische Klassifikation } \\
\text { der Datenbanksequenz }\end{array}$ \\
\hline 1176 & 559 & Sphingomonas sp. SaS2 & AJ620194 & $\begin{array}{l}\text { Sphingomonadaceae; } \\
\text { Sphingomonas }\end{array}$ \\
\hline 3212 & 743 & Sphingomonas sp. SA-3 & AF327069 & $\begin{array}{l}\text { Sphingomonadaceae; } \\
\text { Sphingomonas }\end{array}$ \\
\hline 3236 & 730 & Sphingomonas sp. B18 & AF410927 & $\begin{array}{l}\text { Sphingomonadaceae; } \\
\text { Sphingomonas }\end{array}$ \\
\hline 3237 & 689 & Unidentifiziertes Bakterium & Z93995 & $\begin{array}{l}\text { Sphingomonadaceae; } \\
\text { Novosphingobium }\end{array}$ \\
\hline 3238 & 741 & Sphingomonas asaccharolytica & Y09639 & $\begin{array}{l}\text { Sphingomonadaceae; } \\
\text { Sphingomonas }\end{array}$ \\
\hline 3248 & 744 & Novosphingobium sp. TUT562 & $\mathrm{AB} 177883$ & $\begin{array}{l}\text { Sphingomonadaceae; } \\
\text { Novosphingobium }\end{array}$ \\
\hline 3251 & 744 & Novosphingobium sp. TUT562 & $\mathrm{AB} 177883$ & $\begin{array}{l}\text { Sphingomonadaceae; } \\
\text { Novosphingobium }\end{array}$ \\
\hline 3258 & & Sphingomonas sp. B18 & AF410927 & $\begin{array}{l}\text { Sphingomonadaceae; } \\
\text { Sphingomonas }\end{array}$ \\
\hline 3268 & 740 & Novosphingobium sp. K16 & AJ000920 & $\begin{array}{l}\text { Sphingomonadaceae; } \\
\text { Novosphingobium }\end{array}$ \\
\hline 3279 & 744 & Sphingomonas sp. K101 & AJ009706 & $\begin{array}{l}\text { Sphingomonadaceae; } \\
\text { Sphingomonas }\end{array}$ \\
\hline 3280 & 742 & Sphingomonas sp. B18 & AF410927 & $\begin{array}{l}\text { Sphingomonadaceae; } \\
\text { Sphingomonas }\end{array}$ \\
\hline
\end{tabular}

Herkunft der

Datenbanksequenz

Identität

in $\%$

Satower See, Deutschland

Keine Angabe

96

Plussee, Deutschland 97

Belebtschlamm 97

Keine Angabe 96

Boden 95

Keine Angabe 95

Plussee, Holstein 98

Grundwasser 93

Grundwasser 95

Plusee, Holstein 99

Keine Angabe

97

Satower See, Deutschland

97

\section{II.I.I.IV Rhodobacterales}

$\begin{array}{lll}3253 & 720 & \text { Unidentifiziertes Bakterium } \\ 3275 & 722 & \text { Rhodobacter sp. TCRI 14 } \\ 3281 & 721 & \begin{array}{l}\text { Unkultiviertes } \\ \text { Schlammbakterium A26 }\end{array}\end{array}$

$\begin{array}{ll}\text { AJ224988 } & \text { Umweltprobe } \\ \text { AB017799 } & \text { Rhodobacteraceae; Rhodobacter } \\ \text { AF234745 } & \text { Unklassifiziert }\end{array}$

Gossenkoellesee, Österreich 98

Keine Angabe

Belebtschlamm

\section{II.I.I.V Weitere $\alpha$-Proteobacteria}

$\begin{array}{rrl}1312 & 832 & \begin{array}{l}\text { Alpha- Proteobakterium } \\ \text { Shinshu-th1 }\end{array} \\ & & \text { Klon LBS14 } \\ 1317 & 1480 & \begin{array}{l}\text { Cytophaga } \text { sp. arc18 } \\ \end{array}\end{array}$

AB121772 Nicht genauer klassifiziert

AJ232817 Unklassifiziert

CSU76098 Cytophaga
Boden 


\section{II.I.II $\beta$-Proteobacteria}

\section{II.I.II.I Rhodocyclales}

\section{II.I.II.I.I Rhodocyclaceae}

\begin{tabular}{|c|c|c|}
\hline $\begin{array}{l}\text { Se- } \\
\text { quenz- } \\
\text { name: } \\
\text { slxxxx }\end{array}$ & $\begin{array}{l}\text { Länge } \\
\text { in bp }\end{array}$ & $\begin{array}{l}\text { Ähnlichste Sequenz aus den } \\
\text { Datenbanken von NCBI und } \\
\text { RDP }\end{array}$ \\
\hline 1117 & 1499 & $\begin{array}{l}\text { Unidentifiziertes } \\
\text { Belebtschlamm- Bakterium } \\
\text { CL10 }\end{array}$ \\
\hline 1128 & 647 & Thauera sp. mz1t \\
\hline 1351 & 1487 & Bakterium H15 \\
\hline 1345 & 1263 & $\begin{array}{l}\text { Zoogloea unkultiviertes } \\
\text { Proteobakterium OCS7 } \\
\text { Azoarcus toluclasticus Stamm } \\
\text { MF63 }\end{array}$ \\
\hline & & $\begin{array}{l}\text { Azoarcus indigens Stamm } \\
\text { VB32 LMG } 9092(\mathrm{~T})\end{array}$ \\
\hline
\end{tabular}

\begin{tabular}{|c|c|}
\hline $\begin{array}{l}\text { Accession- } \\
\text { Nummer } \\
\text { der } \\
\text { Datenbank- } \\
\text { sequenz }\end{array}$ & $\begin{array}{l}\text { Phylogenetische Klassifikation } \\
\text { der Datenbanksequenz }\end{array}$ \\
\hline U45697 & Azoarcus \\
\hline AF110005 & Thaurea \\
\hline AY345557 & Unklassifiziert \\
\hline AF001645 & Zoogloea \\
\hline AF123077 & Azoarcus \\
\hline
\end{tabular}

Herkunft der

\section{II.I.II.II Weitere $\beta$-Proteobacteria}

\begin{tabular}{|c|c|c|}
\hline 1143 & 768 & $\begin{array}{l}\text { Unidentifiziertes Beta- } \\
\text { Proteobakterium }\end{array}$ \\
\hline 1288 & 1488 & $\begin{array}{l}\text { Comamonadaceae Bakterium } \\
\text { MWH55 }\end{array}$ \\
\hline 1289 & 1493 & $\begin{array}{l}\text { Unkultiviertes Beta- } \\
\text { Proteobakterium, Klon } \\
\text { JG36-GS-54. }\end{array}$ \\
\hline 1302 & 1493 & Methylophilus arc33 \\
\hline 1313 & 1493 & Klon OPS92B \\
\hline 1335 & 1495 & $\begin{array}{l}\text { Antarktisches Bakterium R- } \\
7724\end{array}$ \\
\hline 1339 & 1498 & $\begin{array}{l}\text { Unkultiviertes Beta- } \\
\text { Proteobakterium Klon } \\
\text { Elb168 }\end{array}$ \\
\hline 1354 & 1491 & Klon env_18 \\
\hline $1367 \mathrm{a}$ & 1040 & Nitrosospira sp. Nsp57 \\
\hline
\end{tabular}

\begin{tabular}{|c|c|}
\hline AJ231067 & Nicht genauer klassifiziert \\
\hline AJ556799 & $\begin{array}{l}\text { Burkholderiales; } \\
\text { Comamonadaceae }\end{array}$ \\
\hline AJ582038 & Umweltprobe \\
\hline U76100 & $\begin{array}{l}\text { Methylophilales; } \\
\text { Methylophilaceae; Methylophilus; } \\
\text { Umweltprobe }\end{array}$ \\
\hline AF026986 & Umweltprobe \\
\hline AJ440986 & Unklassifiziert \\
\hline AJ421928 & Nicht genauer klassifiziert \\
\hline
\end{tabular}

Elbe

\section{II.I.III $\gamma$-Proteobacteria}

\section{II.I.III.I Xanthomodales}

\section{II.I.III.I.I Xanthomonadaceae}

$\begin{array}{cclll}1108^{*} & 957 & \begin{array}{l}\text { Unidentifiziertes Eubakterium } \\ \text { Klon vadinHA77 }\end{array} & \text { U81732 } & \text { Unklassifziert } \\ 1118 & 1482 & \begin{array}{l}\text { Stenotrophomonas maltophilia } \\ \text { Stamm LMG 957 }\end{array} & \text { AJ131114 } & \text { Stenotrophomonas } \\ 1174 * & 785 & \begin{array}{l}\text { Xanthomonas axonopodis } \\ \text { Stamm S53 }\end{array} & \text { AB101447 } & \text { Xanthomonas }\end{array}$

Anaerober Fermenter 
Herkunft der

Datenbanksequenz

Identität in $\%$

Belebtschlamm

Boden

Meer

Boden

Keine Angabe

Bioreaktor der Abwassereinigung

97

96

94

94

95

\begin{tabular}{|c|c|c|}
\hline $\begin{array}{l}\text { Se- } \\
\text { quenz- } \\
\text { name: } \\
\text { slxxxx }\end{array}$ & $\begin{array}{l}\text { Länge } \\
\text { in bp }\end{array}$ & $\begin{array}{l}\text { Ähnlichste Sequenz aus den } \\
\text { Datenbanken von NCBI und } \\
\text { RDP }\end{array}$ \\
\hline 1178 & 675 & $\begin{array}{l}\text { Xanthomonas axonopodis } \\
\text { Stamm S54 }\end{array}$ \\
\hline 1316 & 1503 & $\begin{array}{l}\text { Grasland- Boden- Klon } \\
\text { sl3_616 }\end{array}$ \\
\hline $1336^{*}$ & 1188 & Xanthomonas sp. \\
\hline 1340 & 1504 & Grasland- Boden Klon s11_216 \\
\hline 1344 & 1503 & Bakterium SG-3 \\
\hline $1380^{*}$ & 1211 & $\begin{array}{l}\text { Bakterium aus } \\
\text { Anreicherungskultur LB-P }\end{array}$ \\
\hline
\end{tabular}

Accession- Phylogenetische Klassifikation Nummer der Datenbanksequenz der

Datenbanksequenz

$\begin{array}{ll}\text { AB101446 } & \text { Xanthomonas } \\ \text { AF07842 } & \text { Unklassifiziert } \\ \text { U64004 } & \text { Xanthomonas } \\ \text { AF078353 } & \begin{array}{l}\text { Nicht genauer klassifiziert } \\ \text { Nicht genauer klassifiziert }\end{array} \\ \text { AF538773 } & \text { Unklassifiziert }\end{array}$

\section{II.I.III.II Pseudomonadales}

\begin{tabular}{|c|c|c|}
\hline 1121 & & $\begin{array}{l}\text { Bakterium aus dem Eis des } \\
\text { artischen Meeres ARK10038 }\end{array}$ \\
\hline $1131 *$ & 882 & $\begin{array}{l}\text { Klon TBS23 } \\
\text { Pseudomonas sp. AEBL3 }\end{array}$ \\
\hline * & 463 & Cellvibrio fulvus NCIMB 8634 \\
\hline $\begin{array}{l}1364 \mathrm{~b} \\
*\end{array}$ & 750 & $\begin{array}{l}\text { Cellvibrio vulgaris NCIMB } \\
8633\end{array}$ \\
\hline 1376 & 1497 & $\begin{array}{l}\text { Grasland- Boden- Klon } \\
\text { s13_611 }\end{array}$ \\
\hline 1377 & 1040 & $\begin{array}{l}\text { Unidentifiziertes Gamma- } \\
\text { Proteobakterium, Isolat } \\
\text { HTA527 }\end{array}$ \\
\hline $1392 *$ & 1011 & Pseudomonas mandelii \\
\hline $1393^{*}$ & 1091 & $\begin{array}{l}\text { Pseudomonas putida Stamm } \\
\text { MM1 }\end{array}$ \\
\hline 3202 & & $\begin{array}{l}\text { Stamm DhA-51 } \\
\text { Pseudomonas fluorescens } \\
\text { Stamm PC20 }\end{array}$ \\
\hline 3273 & 741 & $\begin{array}{l}\text { Pseudomonas fluorescens } \\
\text { Stamm PC17 }\end{array}$ \\
\hline
\end{tabular}

Arktischer

Schmelzwassersee

95

Boden

Keine Angabe

Keine Angabe

100

Keine Angabe

Boden

Tiefseesediment

98

Mineralwasser

92

Bakterioplankton

99

Resin-Säure

Keine Angabe

Flusswasser

99

\section{II.I.III.III Weitere $\gamma$-Proteobacteria}

\author{
AB015571 Umweltprobe \\ AF141546 Nicht genauer klassifiziert \\ AJ292676 Unklassifiziert \\ AY499920 Umweltprobe \\ AF140016 Alteromonadales; \\ Alteromonadaceae; Shewanella \\ AJ240989
}

Tiefseesediment

“Columbia River”, USA

Boden

Meer 


\section{II.I.IV $\delta$-Proteobacteria}

\section{II.I.IV.I Desulfomondales}

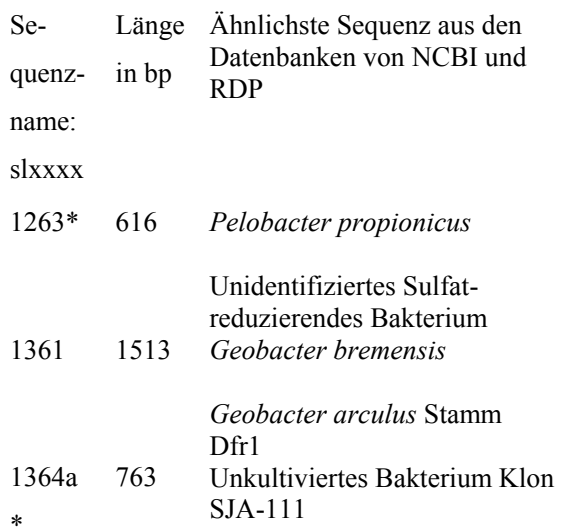

Accession- Phylogenetische Klassifikation

Nummer der Datenbanksequenz

der

Datenbank-

sequenz

X70954 Pelobacteraceae; Pelobacter

U49429

U96917

Geobacteraceae; Geobacter

U96917

AJ009485 Umweltprobe

\section{II.I.IV.II Weitere $\delta$-Proteobacteria}

\begin{tabular}{|c|c|c|}
\hline 1127 & 1504 & $\begin{array}{l}\text { Unkultiviertes Sulfat- } \\
\text { reduzierendes Bakterium } 141\end{array}$ \\
\hline 1147 & 1503 & $\begin{array}{l}\text { Desulfobacterium } \\
\text { catecholicum Stamm DSM } \\
3882\end{array}$ \\
\hline 1177 & 883 & $\begin{array}{l}\text { Unkultiviertes Bakterium } \\
\text { ODP8-U3 }\end{array}$ \\
\hline 1283 & 462 & Syntrophobacter sp. \\
\hline 1310 & 1517 & $\begin{array}{l}\text { Sulfat-reduzierendes } \\
\text { Bakterium STP23 }\end{array}$ \\
\hline
\end{tabular}

$\begin{array}{lllr}\text { AJ389624 } & \text { Umweltprobe } & \text { Cadagno-See, Schweiz } & 97 \\ \text { AJ237602 } & \begin{array}{l}\text { Desulfobacterales; } \\ \text { Desulfobacteraceae; } \\ \text { Desulfobacterium }\end{array} & \text { „Delaware Bay”, } & 99 \\ \text { AF121085 } & \text { Unklassifiziert } & \text { Marines Sediment } & 95 \\ \text { AJ237605 } & \begin{array}{l}\text { Syntrophobacterales; } \\ \text { Syntrophobacteraceae; } \\ \text { Syntrophobacter }\end{array} & \text { Keine Angabe } & 88 \\ \text { AJ006620 } & \text { Unklassifiziert } & \text { Seesediment } & 96\end{array}$

\section{II.II $B C F$-Gruppe}

\section{II.II.I Sphingobacteria}

\begin{tabular}{|c|c|c|c|c|}
\hline 1152 & 1487 & Unidentifiziertes Eubacterium & AF010082 & Unklassifiziert \\
\hline 1158 & 1484 & Unidentifiziertes Bakterium & $\mathrm{AB} 011315$ & Unklassifiziert \\
\hline 1224 & 437 & $\begin{array}{l}\text { Rhizosphären Bodenbakterium } \\
\text { Klon RSC-II- } 44\end{array}$ & AJ252683 & Unklassifiziert \\
\hline 1269 & 688 & $\begin{array}{l}\text { Flexibacter sancti Stamm IFO } \\
15057\end{array}$ & AB078066 & $\begin{array}{l}\text { Sphingobacteria; } \\
\text { Sphingobacteriales; } \\
\text { Flexibacteraceae; Flexibacter }\end{array}$ \\
\hline 1307 & 1484 & Bakterium CS57 & AY 124340 & $\begin{array}{l}\text { Bacteroidetes; Sphingobacteria; } \\
\text { Sphingobacteriales }\end{array}$ \\
\hline 1309 & 1488 & Bodenbakterium SC-I-12 & $\mathrm{AJ} 252615$ & Unklassifiziert \\
\hline $1347^{*}$ & 613 & $\begin{array}{l}\text { Unkultiviertes Bacteroidetes } \\
\text { Klon BIhii16 }\end{array}$ & AJ318142 & $\begin{array}{l}\text { Bacteroidetes; unklassifizierte } \\
\text { Umweltprobe }\end{array}$ \\
\hline $\begin{array}{l}1348 b \\
*\end{array}$ & 613 & $\begin{array}{l}\text { Unkultiviertes Bacteroidetes } \\
\text { Klon BIhii16 }\end{array}$ & AJ318142 & $\begin{array}{l}\text { Bacteroidetes; unklassifizierte } \\
\text { Umweltprobe }\end{array}$ \\
\hline $1369 *$ & 1487 & $\begin{array}{l}\text { Unkultiviertes Bakterium } \\
\text { FukuS59 }\end{array}$ & AJ290042 & $\begin{array}{l}\text { Bacteroidetes; Unklassifizierte } \\
\text { Umweltprobe }\end{array}$ \\
\hline 1390 & 1474 & $\begin{array}{l}\text { Unkultivierter Bakterien Klon } \\
\text { TLM11/TLMdgge04 }\end{array}$ & AF534435 & Unklassifiziert \\
\hline
\end{tabular}

\section{Herkunft der}

Datenbanksequenz

Keine Angabe

Keine Angabe

TCB (1)

1




\section{II.II.II Flavobacteria}

\begin{tabular}{|c|c|c|}
\hline $\begin{array}{l}\text { Se- } \\
\text { quenz- } \\
\text { name: } \\
\text { slxxxx }\end{array}$ & $\begin{array}{l}\text { Länge } \\
\text { in bp }\end{array}$ & $\begin{array}{l}\text { Ähnlichste Sequenz aus den } \\
\text { Datenbanken von NCBI und } \\
\text { RDP }\end{array}$ \\
\hline 1126 & 1474 & unkultiviertes Bakterium BAx3 \\
\hline 1151 & 1490 & Flavobacterium ferrugineum \\
\hline 1305 & 1471 & Klon BA9 \\
\hline 1320 & 1474 & Klon LBS24 \\
\hline $\begin{array}{l}1325 / \\
1326\end{array}$ & 1474 & Klon BA9 \\
\hline 1327 & 1530 & Flavobakterium sp. Wuba46 \\
\hline 1331 & 1474 & Klon LBS24 \\
\hline 1350 & 1487 & Flavobacterium ferrugineum \\
\hline
\end{tabular}

Accession- Phylogenetische Klassifikation Nummer der Datenbanksequenz

der

Datenbank-

sequenz

AF087084 Umweltprobe

M62798

Flavobacteria; Flavobacteriales, Flavobacterium

AF087051 Nicht genauer klassifiziert

AJ232834 Nicht genauer klassifiziert

AF087051 Nicht genauer klassifiziert

AF336355

Flavobacteria; Flavobacteriales; Flavobacteriaceae;

Flavobacterium

AJ232834 Nicht genauer klassifiziert

M62798 Flavobacteriaceae;
Herkunft der

Datenbanksequenz

Belebtschlamm

Keine Angabe

Belebtschlamm

Boden

Belebtschlamm

Wasserrohrsystem

Boden

Keine Angabe
Flavobacteriaceae;

Flavobacterium

Identität

in $\%$

97

91

97

96

\section{II.II.III Bacteroidetes}

$\begin{array}{lll}1319 & 1472 & \text { Klon TRE23 } \\ 1365 & 1472 & \begin{array}{l}\text { Boden- Bakterium Klon SC-I- } \\ 93\end{array} \\ 1378 & 1022 & \text { Klon B-AQ60 } \\ 1389 & 1305 & \begin{array}{l}\text { Unidentifiziertes Eubakterium } \\ \text { Unidentifiziertes Eubakterium }\end{array}\end{array}$

AJ232807 Nicht genauer klassifiziert

Boden

94

Boden

AY622255 Nicht genauer klassifiziert t

Marines Sediment

Boden

Boden

\section{II.III Planctomycetes}

\section{II.III.I Planctomycetacia}

\section{II.III.I.I Planctomycetales}

\begin{tabular}{|c|c|c|}
\hline $1379 a$ & 998 & Pirellula staleyi \\
\hline 3206 & 745 & $\begin{array}{l}\text { Planctomyces sp. (Schlesner } \\
\text { 269) }\end{array}$ \\
\hline 3211 & 745 & Planctomycet Stamm 555 \\
\hline 3214 & 743 & Pirellula staleyi \\
\hline 3227 & 735 & Planctomycet Stamm 555 \\
\hline 3228 & 746 & Pirellula sp. (Schlesner 302) \\
\hline 3239 & 750 & $\begin{array}{l}\text { Gemmata obscuriglobus } \\
\text { (Schlesner 633) }\end{array}$ \\
\hline 3241 & 746 & Pirellula sp. (Schlesner 302) \\
\hline 3242 & 748 & $\begin{array}{l}\text { Planctomyces sp. (Schlesner } \\
642 \text { ) }\end{array}$ \\
\hline 3261 & 753 & clone OM190 \\
\hline 3270 & 746 & $\begin{array}{l}\text { Planctomyces sp. (Schlesner } \\
\text { 269) }\end{array}$ \\
\hline 3283 & 744 & $\begin{array}{l}\text { Planctomyces sp. (Schlesner } \\
658 \text { ) }\end{array}$ \\
\hline
\end{tabular}

$\begin{array}{ll}\text { M34126 } & \text { Planctomycetaceae; Pirellula } \\ \text { X81953 } & \text { Nicht genauer klassifiziert } \\ \text { AJ231178 } & \text { Nicht genauer klassifiziert } \\ \text { M34126 } & \text { Nicht genauer klassifiziert } \\ \text { AJ231178 } & \text { Planctomycetaceae } \\ \text { X81942 } & \text { Planctomycetaceae; Pirellula } \\ \text { X81957 } & \text { Planctomycetaceae; Gemmata } \\ \text { X81942 } & \text { Planctomycetaceae; Pirellula } \\ \text { X81950 } & \begin{array}{l}\text { Planctomycetaceae; } \\ \text { Planctomyces }\end{array} \\ \text { X70712 } & \text { Umweltprobe } \\ \text { X81953 } & \begin{array}{l}\text { Planctomycetaceae; } \\ \text { Planctomyces }\end{array} \\ \text { X81954 } & \begin{array}{l}\text { Planctomycetaceae; } \\ \text { Planctomyces }\end{array}\end{array}$

Keine Angabe 93

Keine Angabe 92

Keine Angabe 95

Keine Angabe 95

Keine Angabe 93

Keine Angabe 92

Keine Angabe $\quad 86$

Keine Angabe 92

Keine Angabe 94

Marines Pikoplankton $\quad 88$

Keine Angabe 91

Keine Angabe $\quad 95$ 


\begin{tabular}{|c|c|c|}
\hline $\begin{array}{l}\text { Se- } \\
\text { quenz- } \\
\text { name: } \\
\text { slxxxx }\end{array}$ & $\begin{array}{l}\text { Länge } \\
\text { in bp }\end{array}$ & $\begin{array}{l}\text { Ähnlichste Sequenz aus den } \\
\text { Datenbanken von NCBI und } \\
\text { RDP }\end{array}$ \\
\hline 3286 & 754 & $\begin{array}{l}\text { Unidentifizierter Planctomycet } \\
\text { OM190 }\end{array}$ \\
\hline 3289 & 744 & Pirellula sp. (Schlesner 302) \\
\hline 3292 & 747 & $\begin{array}{l}\text { Planctomyces sp. (Schlesner } \\
\text { 269) }\end{array}$ \\
\hline
\end{tabular}

Accession- Phylogenetische Klassifikation Nummer der Datenbanksequenz der

Datenbanksequenz

U70712

X81942

X81953 269)

\section{II.IV Acidobacteria}

$\begin{array}{lll}1109 & 1517 & \text { Klon RB30 } \\ 1164 & 726 & \text { clone ii3-7 } \\ 1171 & 1517 & \text { Unkultiviertes } \\ & & \begin{array}{l}\text { Holophaga/Acidobakterium } \\ \text { Sva0515 }\end{array} \\ 1385^{*} & 1511 & \text { Klon ii3-36 } \\ 3217 & 739 & \text { Klon ii3-7 } \\ 3226 & 742 & \text { Klon ii3-36 } \\ 3263 & 748 & \text { Klon kb2426 }\end{array}$

$\begin{array}{ll}\text { Z95720 } & \text { Nicht genauer klassifiziert } \\ \text { Z95727 } & \text { Nicht genauer klassifiziert } \\ \text { AJ241004 } & \text { Nicht genauer klassifiziert } \\ & \\ \text { Z95726 } & \text { Nicht genauer klassifiziert } \\ \text { Z95727 } & \text { Nicht genauer klassifiziert } \\ \text { Z95726 } & \text { Nicht genauer klassifiziert } \\ \text { Z95732 } & \text { Nicht genauer klassifiziert }\end{array}$

Keine Angabe

Keine Angabe

Marines Sediment

97

92

86

Keine Angabe

96

Keine Angabe

Keine Angabe

Keine Angabe
Identität

in $\%$

\section{II.IV.I ,Nitrospina“}

\begin{tabular}{|c|c|c|}
\hline 1349 & 1481 & $\begin{array}{l}\text { Unidentifiziertes Eubakterium } \\
\text { aus dem Amazonas }\end{array}$ \\
\hline 1384 & 1479 & Unbenannter Organismus \\
\hline 1149 & 1479 & $\begin{array}{l}\text { Grasland- Boden- Klon } \\
\text { saf1_208 }\end{array}$ \\
\hline $1352 /$ & 1493 & Klon 2952 \\
\hline \multicolumn{3}{|l|}{1355} \\
\hline 3222 & 744 & Klon 29523 \\
\hline 3267 & 741 & Klon RB40 \\
\hline 3269 & 734 & Klon 11-25 \\
\hline
\end{tabular}

\section{II.V Chloroflexi}

$\begin{array}{ccllll}1185 & 514 & \begin{array}{l}\text { Unkultiviertes Bakterium, } \\ \text { Klon SJA-101 }\end{array} & \text { AJ009480 } & \text { Umweltprobe } \\ 3223 & 723 & \begin{array}{l}\text { Unkultiviertes Bakterium SJA- } \\ 35\end{array} & \text { AJ009460 } & \text { Umweltprobe } \\ 1330 & 1451 & \begin{array}{l}\text { Unkultiviertes Bakterium SJA- } \\ 101\end{array} & \text { AJ009480 } & \text { Umweltprobe } \\ 3232 & & \begin{array}{l}\text { Unkultiviertes Bakterium SJA- } \\ 101\end{array} & \text { AJ009480 } & \text { Umweltprobe } \\ 3235 & 730 & \begin{array}{l}\text { Unkultiviertes Bakterium SJA- } \\ 35\end{array} & \text { A009460 } & \text { Umweltprobe } \\ 3246 * & 637 & \begin{array}{l}\text { Unkultivierter Klon SHA-31 } \\ \text { AJ306745 }\end{array} & \text { Unklassifiziert }\end{array}$




$\begin{array}{lllll}\begin{array}{l}\text { Se- } \\ \text { quenz- }\end{array} & \text { Länge } & \begin{array}{l}\text { Ähnlichste Sequenz aus den } \\ \text { Datenbanken von NCBI und } \\ \text { RDP }\end{array} & \begin{array}{l}\text { Accession- } \\ \text { Nummer } \\ \text { der }\end{array} & \begin{array}{l}\text { Phylogenetische Klassifikation } \\ \text { der Datenbanksequenz }\end{array} \\ \text { slxxxx } & & \begin{array}{l}\text { Datenbank- } \\ \text { sequenz }\end{array} & \\ 3255 & 729 & \begin{array}{l}\text { Unkultiviertes Bakterium SJA- } \\ 101\end{array} & \text { AJ009480 } & \text { Umweltprobe } \\ 3277^{*} & 609 & \begin{array}{l}\text { Unkultiviertes Bakterium SJA- } \\ 68\end{array} & \text { AJ009475 } & \text { Umweltprobe } \\ 3296 * & 608 & \begin{array}{l}\text { Unkultivieres Bakterium Klon } \\ \text { SHA-31 }\end{array} & \text { AJ306745 } & \text { Unklassifiziert }\end{array}$

Herkunft der

Datenbanksequenz

Identität

in $\%$

TCB

87

TCB

90

DCP

\section{II.VI Nitrospirae}

\section{II.VI.I Nitrospirales}

$\begin{array}{lll}1193 & 1253 & \text { Klon 1405-19 } \\ 1342 & 1473 & \text { Nitrospira marina } \\ \begin{array}{l}1367 \mathrm{~b} \\ *\end{array} & 454 & \text { Boden- Bakterium SC-I-12 } \\ 1395 & 552 & \text { Nitrospira sp. Klon b30 }\end{array}$

$\begin{array}{ll}\text { AJ007652 } & \text { Unklassifiziert } \\ \text { X82559 } & \text { Nitrospiraceae; Nitrospira } \\ \text { AJ252615 } & \text { Unklassifiziert } \\ \text { AJ224041 } & \text { Nitrospiraceae; Nitrospira }\end{array}$

Baikalsee, Sibirien

Keine Angabe

\section{II.VII Firmicutes}

\section{II.VII.I Clostridia}

\section{II.VII.I.I Clostridiales}

$\begin{array}{lll}1322 & 1470 & \text { Clostridium sp. 9B4 } \\ 3205 & 740 & \text { Anaerobacter polyendosporus } \\ 3266 & 740 & \text { Fusibacter paucivorans }\end{array}$

\section{II.VIII Chlorobi}

\author{
AY554416 Clostridiaceae; Clostridium \\ AJ222546 Clostridiaceae; \\ Anaerobacter \\ AF050099 Peptostreptococcaceae; \\ Fusibacter
}

Keine Angabe 96

Arktischer See 94

Ölloch 93

\section{II.IX Kandidat-Division TM7}

AJ009458 Chlorobi; Umweltprobe

AF010023 unklassifiziert
TCB

Boden
84

87
$1394 \quad 1434 \quad$ Unkultivierter Klon der Kandidat-Division TM7 SM1G12

\section{II.X Verrucomicrobia}

AF445701 Nicht genauer klassifizeirt

Heiße Quelle, "Yellowstone National Park", USA 
II.XI Actinobacteria

II.XI.I Actinobacteridae

II.XI.I.I Actinomycetales

$\begin{array}{lll}\text { Se- } & \text { Länge } & \text { Ähnlichste Sequenz aus den } \\ \text { quenz- } & \text { in bp } & \begin{array}{l}\text { Datenbanken von NCBI und } \\ \text { RDP }\end{array} \\ \text { name: } & & \\ \text { Slxxxx } & & \\ 3218 & 730 & \text { Microbispora bispora }\end{array}$

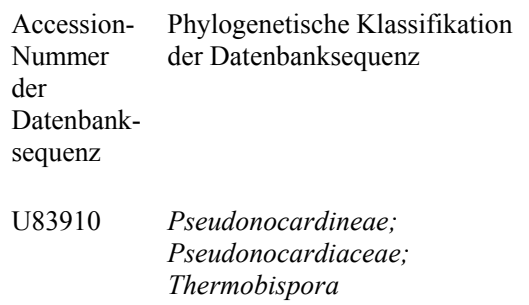

Die in den Abbildungen 8 und 10 bis 17 abgebildeten Stammbäume wurden mit dem Programm „TREEFINDER“ (JOBB, 2004) erstellt. Für die Berechnung der Stammbäume wurde von den Sequenzen zunächst mit dem Programm „Phylip“ eine „Distance Matrix“ berechnet, um feststellen zu können, wie viele Basenpositionen in jeder Sequenz für ein gemeinsames „Alignment“ zur Verfügung stehen. In dem Programm „Phylip“ selbst wird darauf verwiesen, dass die erforderlichen „MultiAlignments“ für die Erstellung zuverlässiger Stammbäume mindestens 400 Basenpositionen enthalten sollten. Aufgrund unterschiedlicher in den PCR-Reaktionen amplifizierter Sequenzbereiche und aufgrund chimerer Sequenzen, deren Sequenzen gekürzt worden sind, mussten zum Erhalt der geforderten 400 Basenpositionen einige Sequenzen aus dem „Alignment“ entfernt werden. Damit enthalten die Stammbäume nicht alle in dieser Arbeit generierten Sequenzen. Die „Multi-Alignments“ wurden mit dem Programm „ClustalW“ erstellt und konnten anschließend mit dem Programm „TREEFINDER“ zu Stammbäumen verrechnet werden. Dabei verwendet das Programm „TREEFINDER“ die „Maximum Likelihood“-Methode. Die Wahrscheinlichkeit der Verzweigungen wurde mittels einer „Bootstrap“-Analyse mit 100-facher Wiederholung überprüft. Dabei wurden die Standard-Einstellungen des Programms verwendet. Nach der „Bootstrap“-Analyse wurden die Stammbäume einem „Rerooting“ unterzogen, bei dem als gemeinsamer entferntester Verwandter („outgroup“) bei den Stammbäumen mit bakteriellen Sequenzen entweder Bacillus subtilis oder Thermotoga maritima und bei dem Stammbaum mit den archaeellen Sequenzen die Sequenz s13139 gewählt wurde. In letzterem Fall wurde eine eigene Sequenz gewählt, um diese überhaupt sinnvoll in den Stammbaum integrieren zu können, da sie sonst verwandtschaftlich zu weit entfernt ist. 


\subsubsection{Ergebnisse der Analyse der archaeellen 16S-rRNA-Gensequenzen}

Alle gewonnenen archaeellen 16S rRNA-Gensequenzen zeigen die größte Ähnlichkeit zu Sequenzen von Euryarchaeota. Mit den speziell gegen Crenarchaeota gerichteten Oligonukleotiden A800F und A1530R konnten keine 16S rRNA-Gensequenzen von Crenarchaeota, sondern nur bakterielle Sequenzen, amplifiziert werden (s. Tabelle 9). Die größte Identität zu kultivierten Organismen weisen die Sequenzen s13104, s13151, sl3153, s13155, s13170, s13174 und sl3176 mit 95 \% zu Methanothrix soehngenii auf. Eine $98 \%$ ige Identität besteht zwischen den Sequenzen des Klons sl3118 und Methanosarcina sp. Str. VeA23. Die meisten anderen Sequenzen zeigen allerdings die größte Identität zu nur durch 16S rRNA-Gensequenzen repräsentierten, unkultivierten Klonen, die ebenfalls aus Süßwasserhabitaten gewonnen wurden. $\mathrm{Zu}$ diesen gehören z. B. die 8 verschiedenen Sequenzen (Rot 6, 7, 11, 16, 18, 24, 25, 26) aus dem anaeroben Sediment des Rotsees (Schweiz; FALZ et al., 1999) und die 4 verschiedenen Sequenzen (Val 1, 9, 47, 147) aus dem Oberflächenwasser des finnischen Waldsees Valkea Kotinen (JURGENS et al., 2000). Dies entspricht ca. 65 bzw. $17 \%$ aller archaeellen 16S rRNA-Gensequenzen dieser Arbeit. Ähnlichkeiten konnten aber auch zu 16S rRNA-Gensequenzen gefunden werden, die aus anaeroben Reisfeldböden, aus mikrobiellen Mischkulturen, die Trichlorbenzen umsetzen bzw. 1,2-Dichlorpropan dechlorieren können, amplifiziert werden konnten. Sequenzen von unkultivierten Archaeen anderer Standorte sind weniger stark vertreten. 49 der 60 Sequenzen zeigen eine mindestens 95 \%ige Identität zu einer Sequenz aus den verwendeten Datenbanken. Untereinander weisen viele Sequenzen dieser Arbeit ebenfalls große Identitäten auf. Allerdings sind nur die Klone s13177 und s13179 sowie die Klone s13151 und sl3174 identisch.

Wie dem Stammbaum in Abbildung 8 und der Tabelle 9 entnommen werden kann, gehören alle Sequenzen der Leinesediment-16S rDNA-Klone dem Phylum der Euryarchaeota und der Klasse der Methanomicrobia an. Der Klon s13139 hat die größte Identität zu Vertretern der Ordnung Thermoplasmales. Eine genauere Klassifikation ist nicht möglich. Bei der taxonomischen Einteilungen der Thermoplasmales unterschieden sich die Datenbanken von NCBI und RDP. Bei NCBI gehören sie in die Klasse der Thermoplasmata, bei RDP in die Klasse der Methanomicrobia. Die in dieser Arbeit durchgeführte „Bootstrap-Analyse“, bei der die Sequenz s13139 als „outgroup“ gewählt wurde, zeigt, dass diese Sequenz und die nächst verwandte Datenbank-Sequenz 
VAL147 nur eine sehr geringe Übereinstimmung zu den übrigen Sequenzen aufweisen. Die übrigen in dieser Arbeit gewonnenen Sequenzen teilen sich in 2 nahezu gleich große Gruppen auf: 35 Sequenzen (58,3 \%) lassen sich der Ordnung der Methanosarcinales und 24 (40 \%) der Ordnung Methanomicrobiales zuteilen.

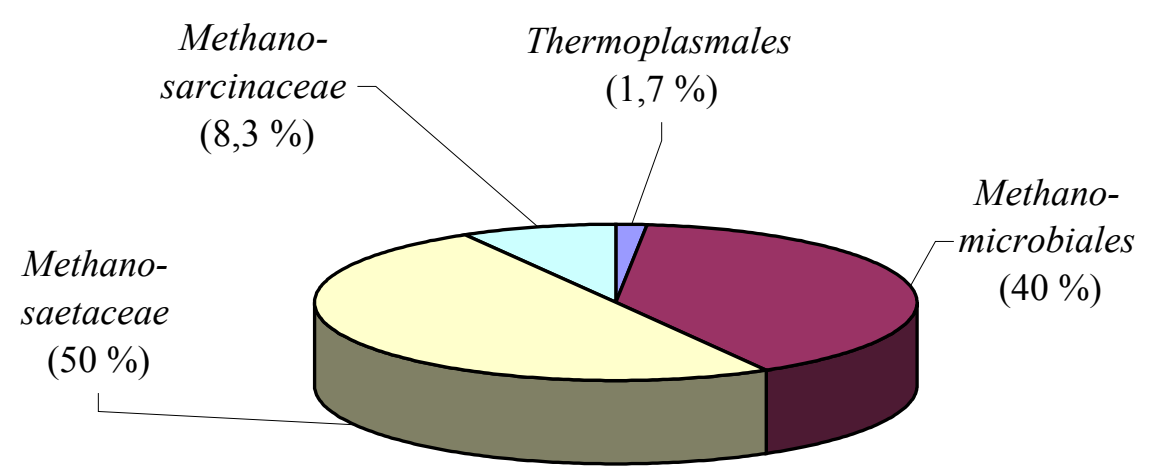

\section{Abbildung 7: Verteilung der archaeellen 16S rRNA-Gensequenzen}

Alle Sequenzen, die in die Ordnung Methanomicrobiales eingeordnet werden können, bilden ein Cluster mit Sequenzen von 16S rRNA-Genen, die in der RDP-Datenbank einer Gruppe zugeordnet werden, die nach ihrem namengebenden Organismus Methanocculeus bourgensis Stamm MS2 „MCU-Bourgense-Untergruppe“ genannt wird. Im NCBI-Taxonomy-Browser gibt es diese Gruppe nicht. Die Sequenzen dieses Clusters haben ein Ähnlichkeit von 90 - 98 \%. Die Sequenzen, die den Methanosarcinales zugeteilt werden, können in 2 - 3 Familien gruppiert werden. Die meisten (50 \%) dieser Sequenzen zeigen die größte Ähnlichkeit zu Sequenzen aus der Familie der Methanosaetaceae. Vermutlich gehören sie sogar alle dem Genus Methanosaeta an. Die Ähnlichkeiten liegen zwischen 91 und 98 \%. Die übrigen 5 Klone, deren Sequenzen zu den Methanosarcinales gehören, zeigen die größte Ähnlichkeit zu Angehörigen der Familie Methanosarcinaceae, der Klon s13118 kann vermutlich in den Genus Methanosarcina gruppiert werden. Die restlichen 5 Sequenzen (s13106, s13113, s13114, s13138 und s13189) bilden ein eigenes Cluster. Sie zeigen nur eine recht geringe Ähnlichkeit von 83 - 88 \% zu Methanomethylovorans hollandica Stämmen (s13106, sl3113, und sl3189) bzw. zu dem Klon 2MT7 (s13138; $90 \%$ ). Die Ähnlichkeit dieser Klone untereinander beträgt 93 - 98\% und ist damit größer als die zum nächsten Verwandten aus den Datenbanken. 


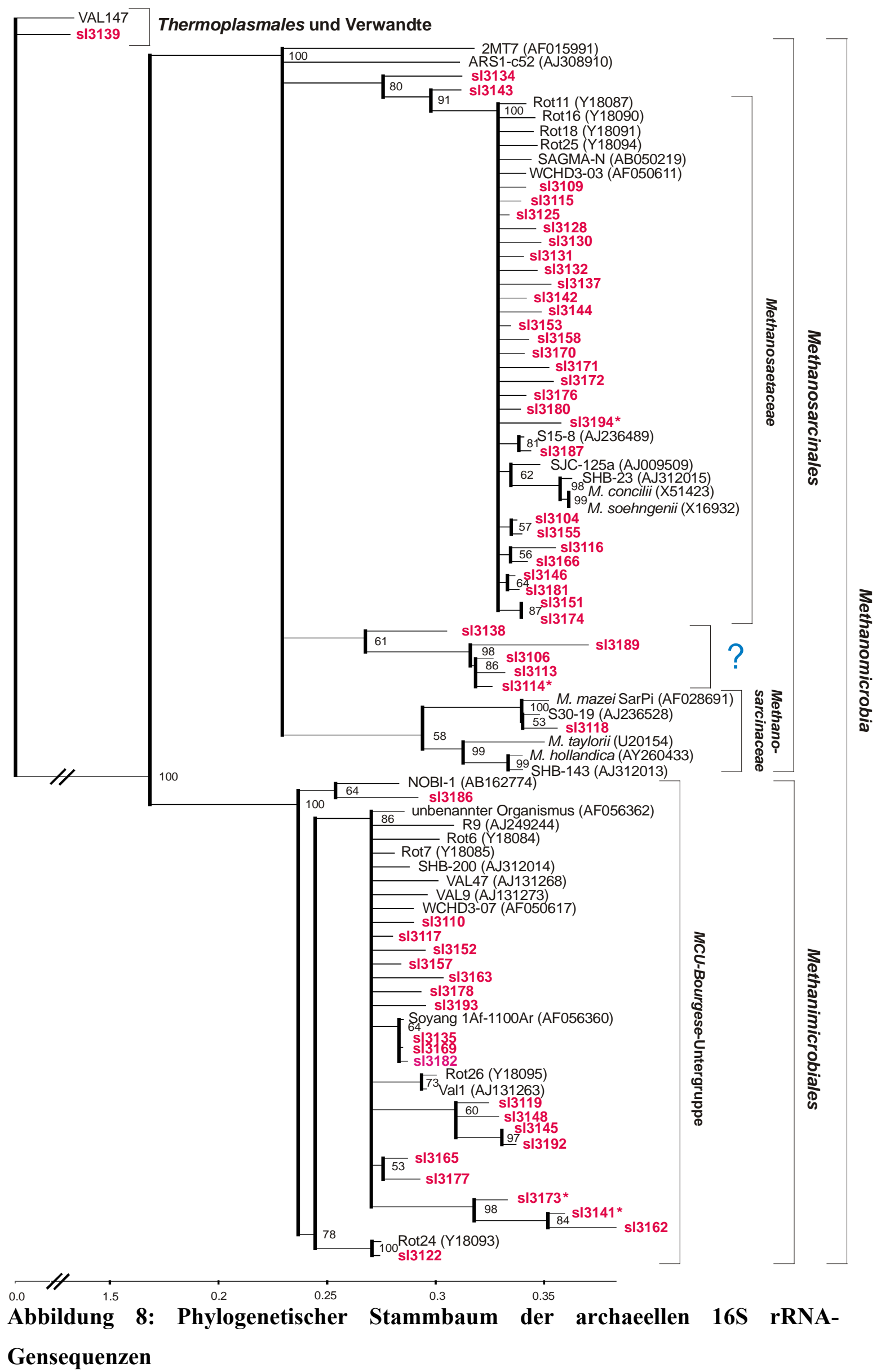


Mit der aus dem Leinesediment isolierten DNA (s. 2.6.1) wurde mit den Oligonukleotiden 23FPL und 927R eine PCR durchgeführt. Die PCR-Produkte wurden durch eine Gelextraktion (s. 2.5.3.6) gereinigt und anschließend in den Vektor pCR2.1-TOPO kloniert. Der Ligationsansatz wurde in E. coli TOP10 mittels Hitzeschock transformiert (s. 2.11.1). Der Transfomationsansatz wurde auf LB-Medium mit Ampicillin, IPTG und X-Gal ausplattiert. Von 96 Klonen wurde, wie unter 2.6.3.5 beschrieben, eine robotgesteuerte Plasmidpräparation vorgenommen. Die Plasmide wurden in einer Sequenzreaktion (s. 2.12.1) mit den Oligonukleotiden rev und for eingesetzt. Die Sequenzierung fand mit dem „ABI DNA Sequencer 377“ statt. Die Sequenzen wurden mit dem Programm „Gap4“ bearbeitet. Das „Multialignment“ der resultierenden Sequenzen, das mit dem Programm „Phylip“ bei RDP erstellt wurde, enthielt 538 „Alignment“-Positionen. Das „Multialignment“, das der Berechnung des Stammbaumes zugrunde gelegt wurde, wurde mit dem Programm „ClustalW“ berechnet. Die „Bootstrap“-Analyse wurde mit dem Programm „Treefinder“ mit 100-facher Wiederholung mit Standardeinstellungen erstellt. Der Größenmaßstab gibt die Zahl der Substitutionen pro Base an. Nicht enthalten sind in diesem Stammbaum die Sequenzen s13127 und s13164.

\subsubsection{Ergebnisse der Analyse der bakteriellen 16S-rRNA-Gensequenzen}

Die bakteriellen 16S rRNA-Gensequenzen weisen eine größere Diversität auf als die archaeellen. Die Sequenzen können den in Tabelle 10 aufgeführten 14 phylogenetischen Gruppen zugeordnet werden. Sie zeigen in den meisten Fällen deutlich geringere Identitäten zu bereits bekannten Sequenzen als die archaeellen 16S rRNA-Gene (s. Tabelle 9). Auch bei den bakteriellen Sequenzen stammt die nächst verwandte Sequenz meist von unkultivierten Bakterien ab. Nur 80 der 147 Sequenzen sind zu mehr als $95 \%$ identisch zu Datenbanksequenzen, davon zeigen 14 eine Identität von mindestens 99 \%. 6 dieser Datenbanksequenzen gehören zu der Familie Pseudomonadaceae (s11377, s11393, s13202, s13273, s11131, s11165b und s11364b), 5 weitere stammen aus anderen kultivierten Organismen. Die Sequenz sl1165b ist zu $100 \%$ identisch mit der von Cellvibrio fulvus NCIMB 8634, die Sequenz 1376 zeigt 100 \% Identität zu dem Grasland-Boden-Klon sl3_611. Häufig wurden die nächst verwandten Sequenzen aus den Datenbanken ebenfalls aus Süßwasserhabitaten gewonnen. In einigen Fällen aus dem Boden, dem Meer, Belebtschlamm oder anderen Lebensräumen. Die beiden verwendeten Oligonukleotidpaare 16S08/16S1504 und A800F/A1530R zeigten deutliche Unterschiede in ihrer Spezifität. Mit dem ersten Oligonukleotidpaar 16S08/16S1504 wurden beiden PCR-Reaktionen (PCR 1 und PCR 2) vor allem Sequenzen von $\gamma$-Proteobakterien amplifiziert. Dabei war der Anteil der Sequenzen mit einem Ursprung aus der Bacteroides-Cytophaga-Flexibacter-Gruppe $(B C F)$ deutlich höher im PCR-Ansatz 2. Mit dem Oligonukleotidpaar A800F/A1530R wurden dagegen hauptsächlich Sequenzen der $\alpha$-Proteobakterien und des Phylums Planctomycetes gewonnen. $\beta$-Proteobakterien und Angehörige der BacteroidesCytophaga-Flexibacter-Gruppe konnten mit diesem Oligonukleotidpaar gar nicht bzw. 
nur wenig erfasst werden. Insgesamt konnten vor allem Sequenzen von $\alpha$ - und $\gamma$ Proteobakterien (18 \% bzw. 17 \%), von Angehörigen der Bacteroides-CytophagaFlexibacter-Gruppe (16\%) von Acidobacteria (11\%) und von Planctomycetes (10\%) amplifiziert werden. $72 \%$ der Sequenzen gehen vermutlich auf Vertreter dieser 5 Gruppen zurück.

\section{Acidobacteria}

$(10,9 \%)$

CFB-Gruppe

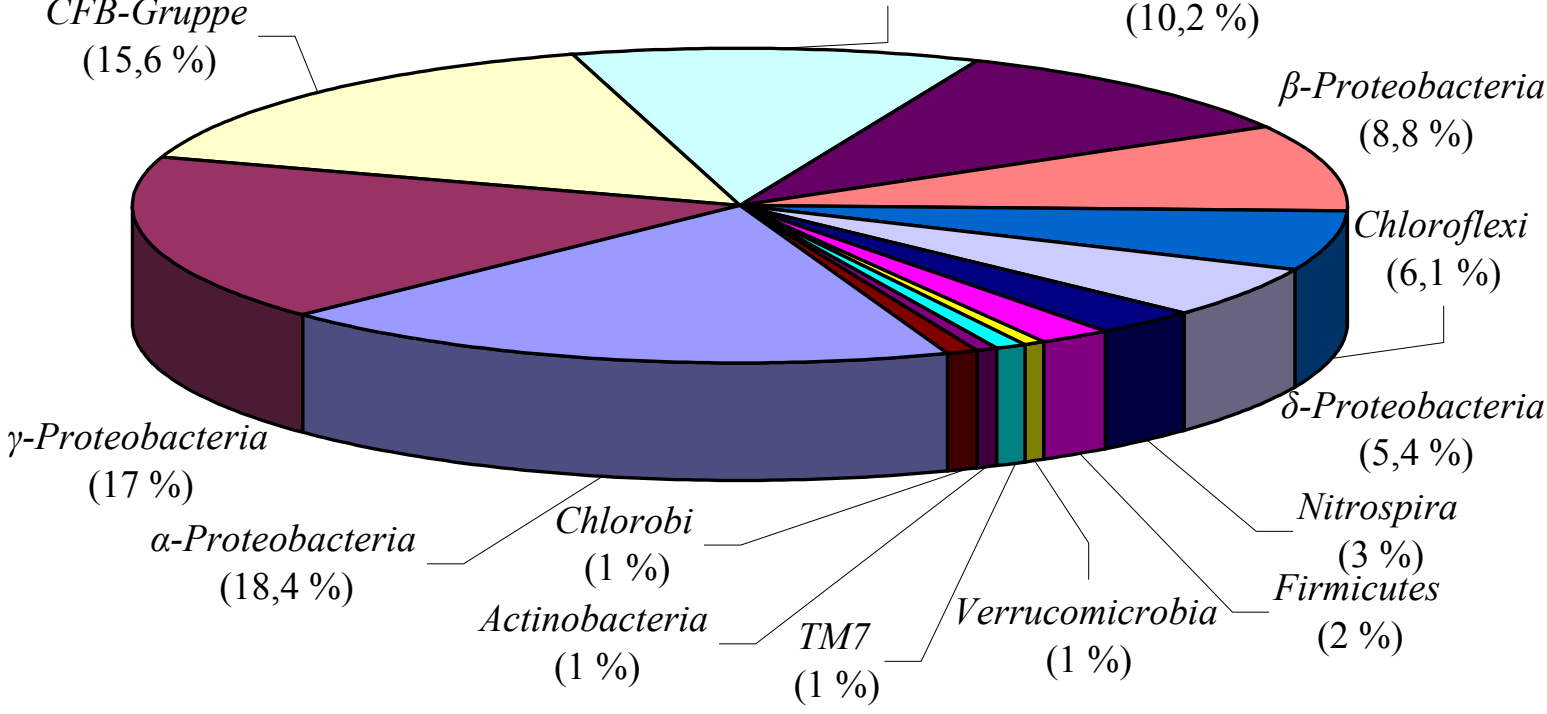

\section{Abbildung 9: Verteilung der bakteriellen 16S rRNA-Gensequenzen}

Tabelle 10: Zusammenfassung der Klassifizierung der nächst verwandten Sequenzen der bakteriellen 16S rRNA-Gene

\begin{tabular}{|c|c|c|c|c|c|c|c|c|c|c|c|c|c|c|c|}
\hline Uీ & 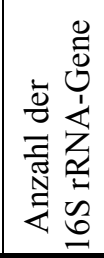 & 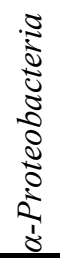 & $\mid \begin{array}{c}0 \\
0 \\
0 \\
0 \\
0 \\
0 \\
0 \\
0 \\
0 \\
0 \\
0 \\
0 \\
0\end{array}$ & 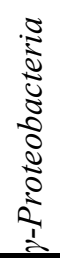 & $\begin{array}{r}0 \\
0 \\
0 \\
0 \\
0 \\
0 \\
0 \\
0 \\
0 \\
0 \\
0 \\
0 \\
0\end{array}$ & $\bigcup_{\infty}^{T}$ & 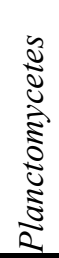 & 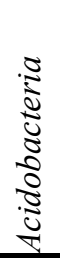 & $\frac{\sqrt[3]{3}}{\frac{\pi}{0}}$ & 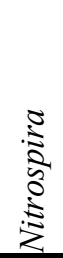 & 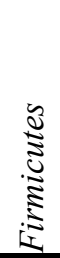 & 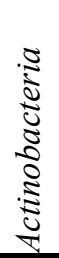 & $\begin{array}{l}\tilde{0} \\
\vdots \\
0 \\
0\end{array}$ & $\sum_{i}$ & 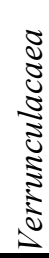 \\
\hline 1 & 35 & 2 & 5 & 11 & 5 & 6 & 0 & 0 & 1 & 1 & 0 & 0 & 1 & 0 & 0 \\
\hline 2 & 55 & 2 & 8 & 12 & 3 & 17 & 1 & 5 & 1 & 3 & 1 & 0 & 0 & 1 & 0 \\
\hline 3 & 57 & 23 & 0 & 2 & 0 & 0 & 14 & 6 & 7 & 0 & 2 & 1 & 0 & 0 & 1 \\
\hline$\Sigma$ & 147 & 27 & 13 & 25 & 8 & 23 & 15 & 16 & 9 & 4 & 3 & 1 & 1 & 1 & 1 \\
\hline$\%$ & & 18 & 9 & 17 & 5 & 16 & 10 & 11 & 6 & 3 & 2 & 1 & 1 & 1 & 1 \\
\hline
\end{tabular}

In der Abbildung 10 ist der Stammbaum der $\boldsymbol{\alpha}$-Proteobakterien dargestellt. Es wurden Sequenzen aus den 4 Ordnungen Sphingomonadales, Rhizobiales, Caulobacteriales und Rhodobacteriales gewonnen. Außerdem zeigte die Sequenz s11312 eine $96 \%$ ige Identität zu der 16S rRNA-Gensequenz aus dem nicht genauer klassifizierten Klon 
Shinshu-th1. Die in die Ordnung Rhodobacterales eingeteilten Sequenzen ähneln am stärksten unkultivierten Bakterien, während sie zu Rhodobacter sp. TCRI 14 deutlich weniger Ähnlichkeit zeigen. Die geringste Identität zu Datenbanksequenzen hat die Sequenz des Klons s13212 (92 \% zu Sphingomonas sp. SA-3), die höchste weist die Sequenz s13247 (100\% zu Agrobacterium tumefaciens) auf.

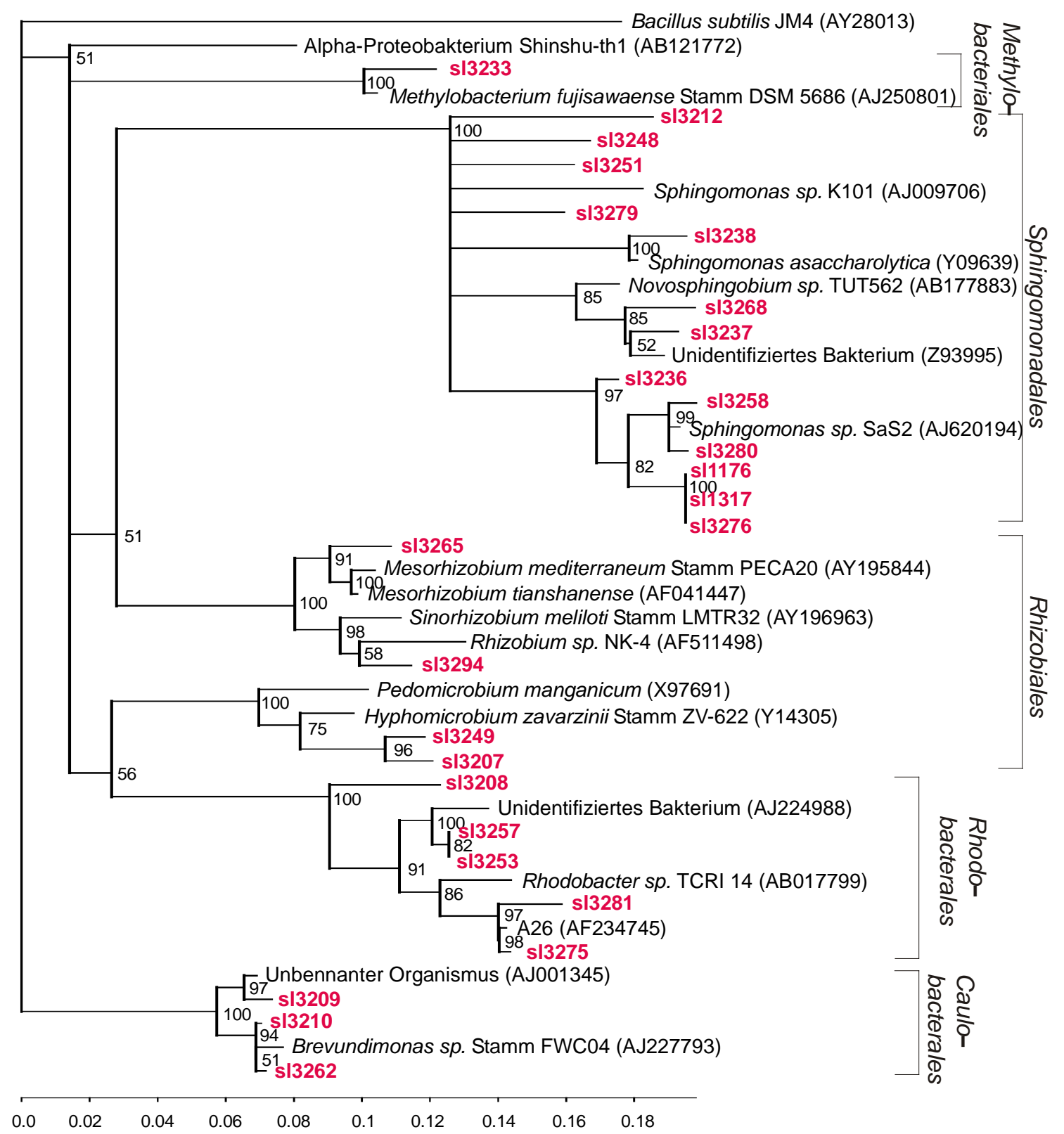

\section{Abbildung 10: Phylogenetischer Stammbaum der a-Proteobacteria des Leinesedimentes}

Dem „Multialignment“ liegen 456 Positionen zugrunde. Nicht enthalten sind die Sequenzen s11106, sl1312, sl3247 und s13274. Für die Beschreibung des Vorgehens siehe Abbildungsbeschriftung unter Abbildung 17. 
Die 16S rRNA-Gensequenzen der $\boldsymbol{\beta}$-Proteobakterien, die aus dem Leinesediment generiert wurden, können in die Ordnungen Rhodocyclales, Burkholderiales, Methylophilales und Nitrosomonadales eingeteilt werden. Auch hier sind, wie aus dem Stammbaum in Abbildung 11 und der Tabelle 9 hervorgeht, die nächsten Verwandten in einigen Fällen Sequenzen von unkultivierten Bakterien, die nicht näher klassifiziert worden sind.

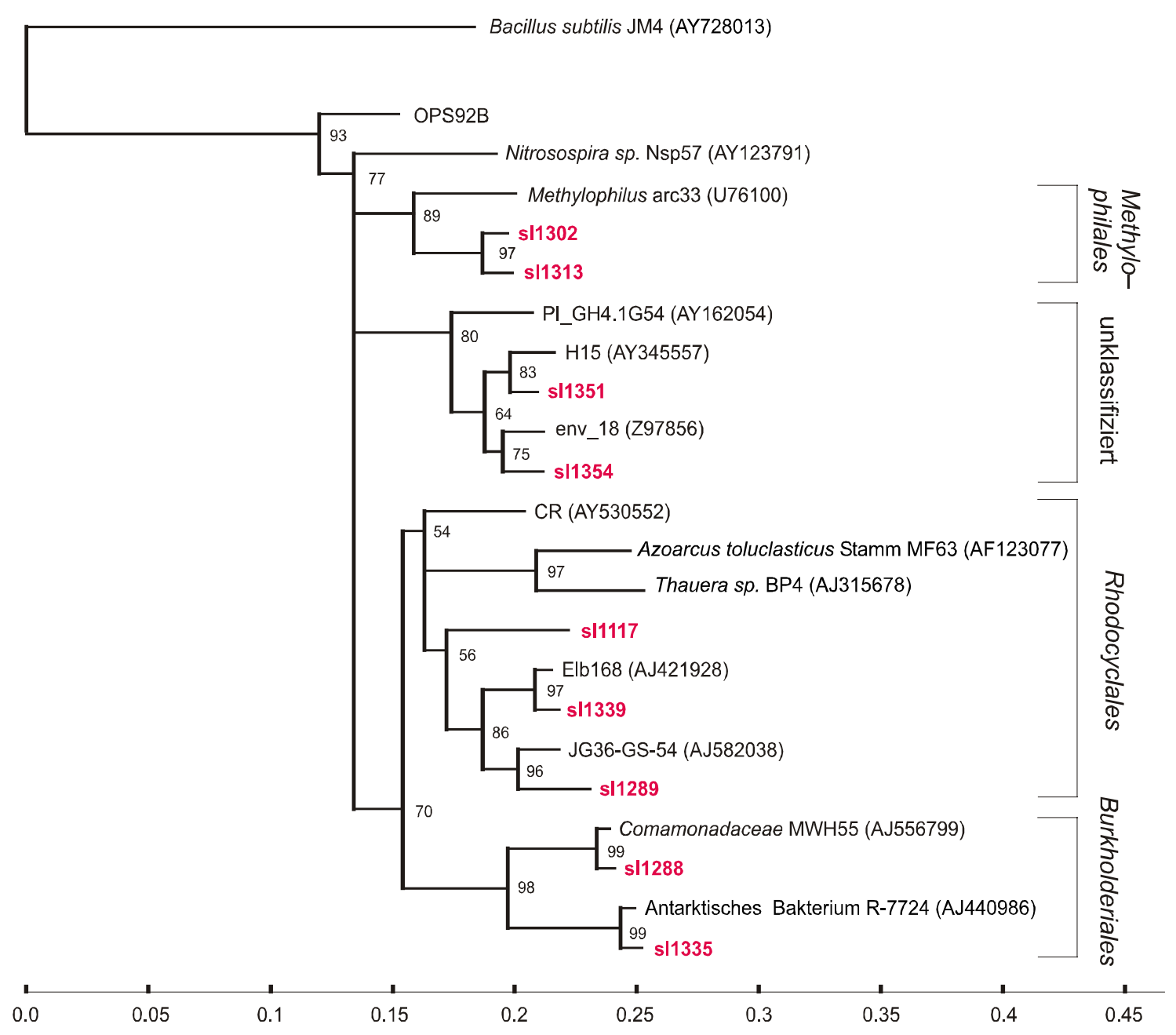

\section{Abbildung 11: Phylogenetischer Stammbaum der $\beta$-Proteobacteria des Leinesedimentes}

Dem "Multialignment" liegen 413 Positionen zugrunde. Nicht enthalten sind die Sequenzen s11177, sl1128, sl1143, sl1283 und sl1364a, sl1367a, sl1345, und sl3234. Für die Beschreibung des Vorgehens siehe Abbildungsbeschriftung unter Abbildung 17.

Bei den $\boldsymbol{\delta}$-Proteobakterien können in der Abbildung 123 Äste unterschieden werden, innerhalb derer aus dem Leinesediment gewonnene Sequenzen vertreten sind. Die Sequenzen s11310, s11147 und s11127 gehören zu den Desulfobacterales, die Sequenzen 
sl1361 und sl1364a zu den Desulfomondales. Die Sequenz s11263 hat nur eine Identität von $88 \%$ zu der Sequenz von Pelobacter propionicus, einem Vertreter der Desulfomondales. In dem Stammbaum in der Abbildung 12 bildet er mit der Sequenz des unklassifizierten und unkultivierten Bakteriums ODP8-U3 einen eigenen Ast. Auch die Sequenz s11177 ist zu der Sequenz des Bakteriums ODP8-U3 zu 95 \% identisch. Es scheint sich hier um ein eigenes Cluster mit Sequenzen zu handeln, die untereinander auch nur geringe Identitäten haben.

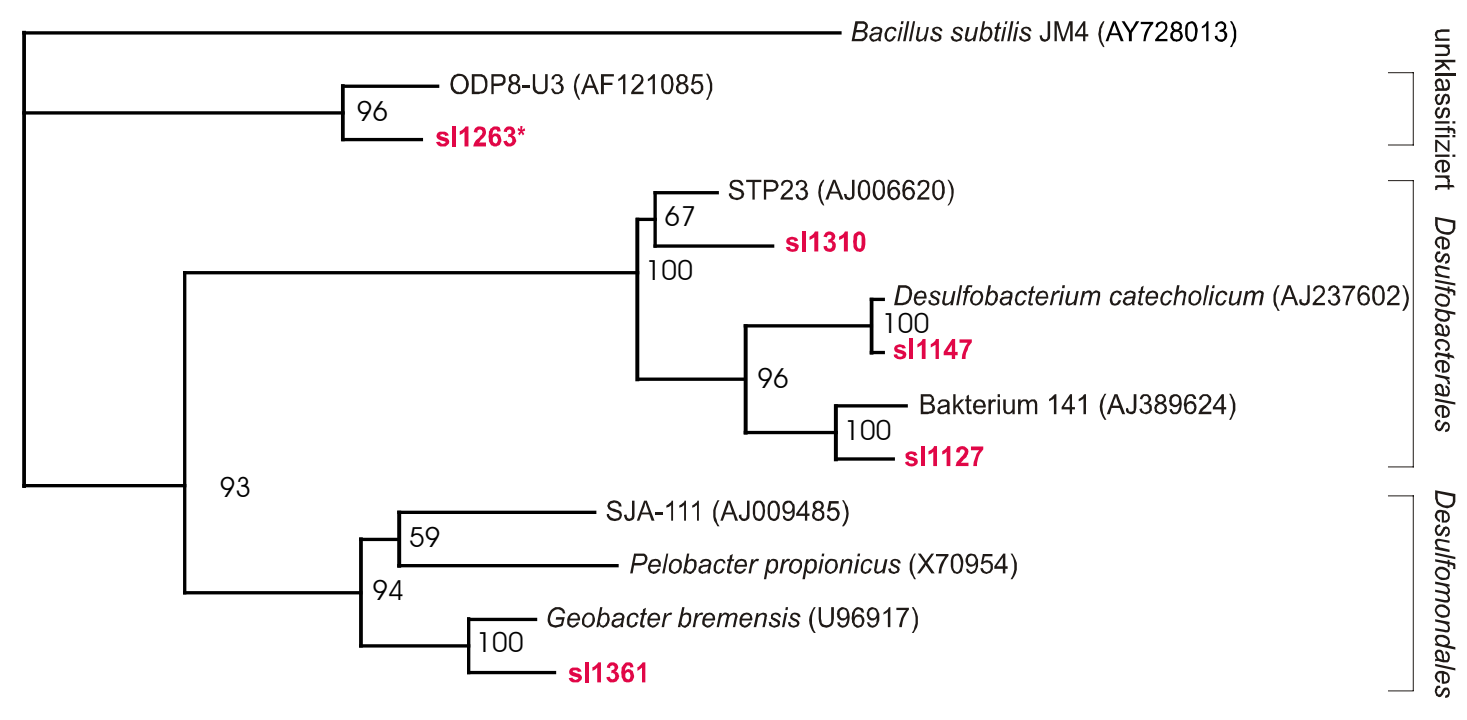

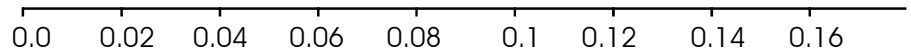

\section{Abbildung 12: Phylogenetischer Stammbaum der $\delta$-Proteobacteria des Leinesedimentes}

Dem "Multialignment" liegen 413 Positionen zugrunde. Nicht enthalten sind die Sequenzen s11177, sl1128, sl1143, sl1283 und s11364a, s11367a, s11345, und sl3234. Für die Beschreibung des Vorgehens siehe Abbildungsbeschriftung unter Abbildung 17.

Bei den über die $16 \mathrm{~S}$ rRNA-Gensequenzen nachgewiesenen $\boldsymbol{\gamma}$-Proteobakterien im Leinesediment dominieren vor allem die Pseudomonadaceae und die Xanthomonadaceae. Auffällig sind hier vor allem die schon erwähnten starken Identitäten zu Pseudomonas-Arten und ein eigenes Cluster von Leine-SedimentSequenzen innerhalb der Xanthomonadaceae, das lediglich den unklassifizierten Klon SG-3 enthält. Die „Bootstrap“-Analyse gibt für diese Verzweigung einen Wert von 100 an, so dass davon ausgegangen werden kann, dass sie richtig ist. Außerdem bilden in der Abbildung 13 die Sequenzen s11293, s11121 und s11167 ein Cluster mit Sequenzen von unkultivierten nicht näher klassifizierten Organismen, die $\mathrm{zu}$ den Pseudomonadaceae gezählt werden. 
Außer den Sequenzen sl3261 und s13286 sowie der Sequenz des nur auf Phylum-Niveau klassifizierten Klons OMP190, die einen eigenen Ast in Abbildung 14 bilden, formen alle anderen zu den Planctomycetes gehörende Sequenzen aus dem Leinesediment Cluster mit Vertretern der Genera Gemmata, Planctomyces und Pirellula, die in die Familie der Planctomycetaceae gehören. Einige der Datenbanksequenzen sind, wie aus der Tabelle 9 hervorgeht, selbst nicht weiter klassifiziert. Insgesamt zeichnen sich die Sequenzen des Leinesedimentes, die in dieses Phylum eingeordnet werden können, durch verhältnismäßig geringe Ähnlichkeiten aus. Sie liegen zwischen 86 und $95 \%$.

Der Stammbaum der $\boldsymbol{C F B}$-Gruppe in Abbildung 15 enthält die Angehörigen der 2 Klassen Flavobacteria und Sphingobacteria. Erstaunlich ist die Anordnung von Flavobacterium ferrugineum und der nächst verwandten Sequenzen aus dem Leinesediment s11151 und s11350 in dem Ast, der ansonsten Angehörige der Klasse Sphingobacteria enthält. Außerdem wirkt die Anordnung der Sequenzen s11347 und s11348b zweifelhaft, welche die größte Ähnlichkeit $\mathrm{zu}$ dem unkultivierten und unklassifizierten Klon Blhii 16 zeigen. Da der „Bootstrap“-Wert von 58 für die Verzweigung des Klons Blhiil6 verhältnismäßig niedrig ist, bleibt unklar, wo diese 3 Sequenzen einzuordnen sind. Mit eindeutigen „Bootstrap“-Werten gruppieren sich die Sequenzen s11360, s11320 und s11331 getrennt von den anderen Flavobakterien in einem eigenen Cluster.

Die Sequenzen des Leinesedimentes, die am stärksten verwandt zu Bakterien der Acidobacteria sind, bilden 2 Äste in dem Stammbaum in Abbildung 16. Der eine Ast enthält Leinesediment-Sequenzen wie s11349, s11352, s13222 und s13269, deren nächste Verwandte bei RDP und NCBI uneinheitlich klassifiziert wurden. Der nächste Verwandte bei NCBI wurde in das Phylum der Acidobacteria gruppiert, während der nächste Verwandte bei RDP der „Subdivision“ Nitrospina, genauer in die UmweltKlon-Gruppe S027, zugeordnet wurden. Bei allen Datenbanksequenzen handelt es sich um nicht genauer klassifizierte Umwelt-Sequenzen. Bei ihnen bleibt unklar, ob es sich um kultivierte Organismen handelt. 


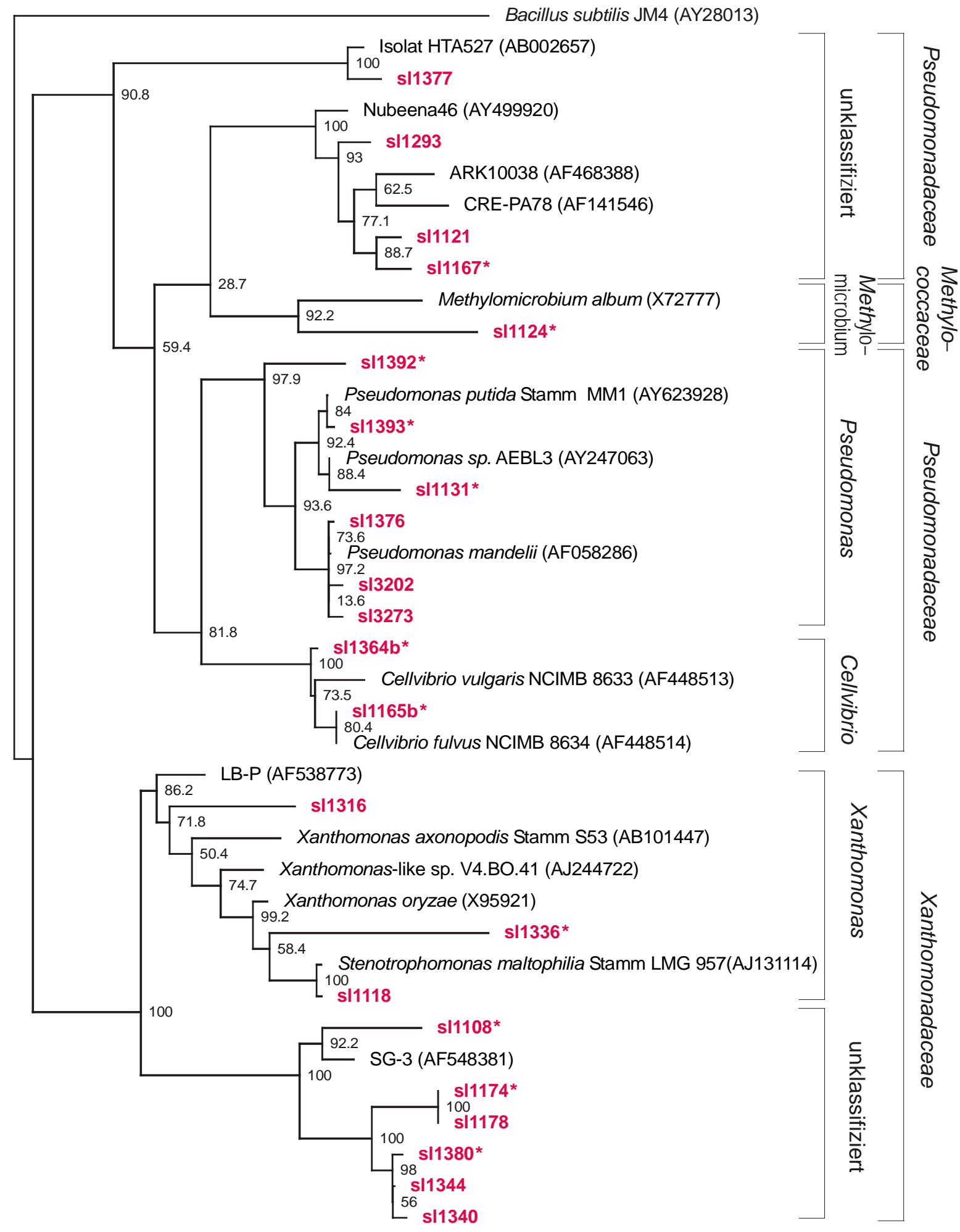

\section{Abbildung 13: Phylogenetischer Stammbaum der $\gamma$-Proteobacteria des Leinesedimentes}

Dem „Multialignment“ liegen 457 Positionen zugrunde. Nicht enthalten sind die Sequenzen sl1187, sl1323 und sl1337, s11340, sl1362, s11372 und sl3240. Für die Beschreibung des Vorgehens siehe Abbildungsbeschriftung unter Abbildung 17. 


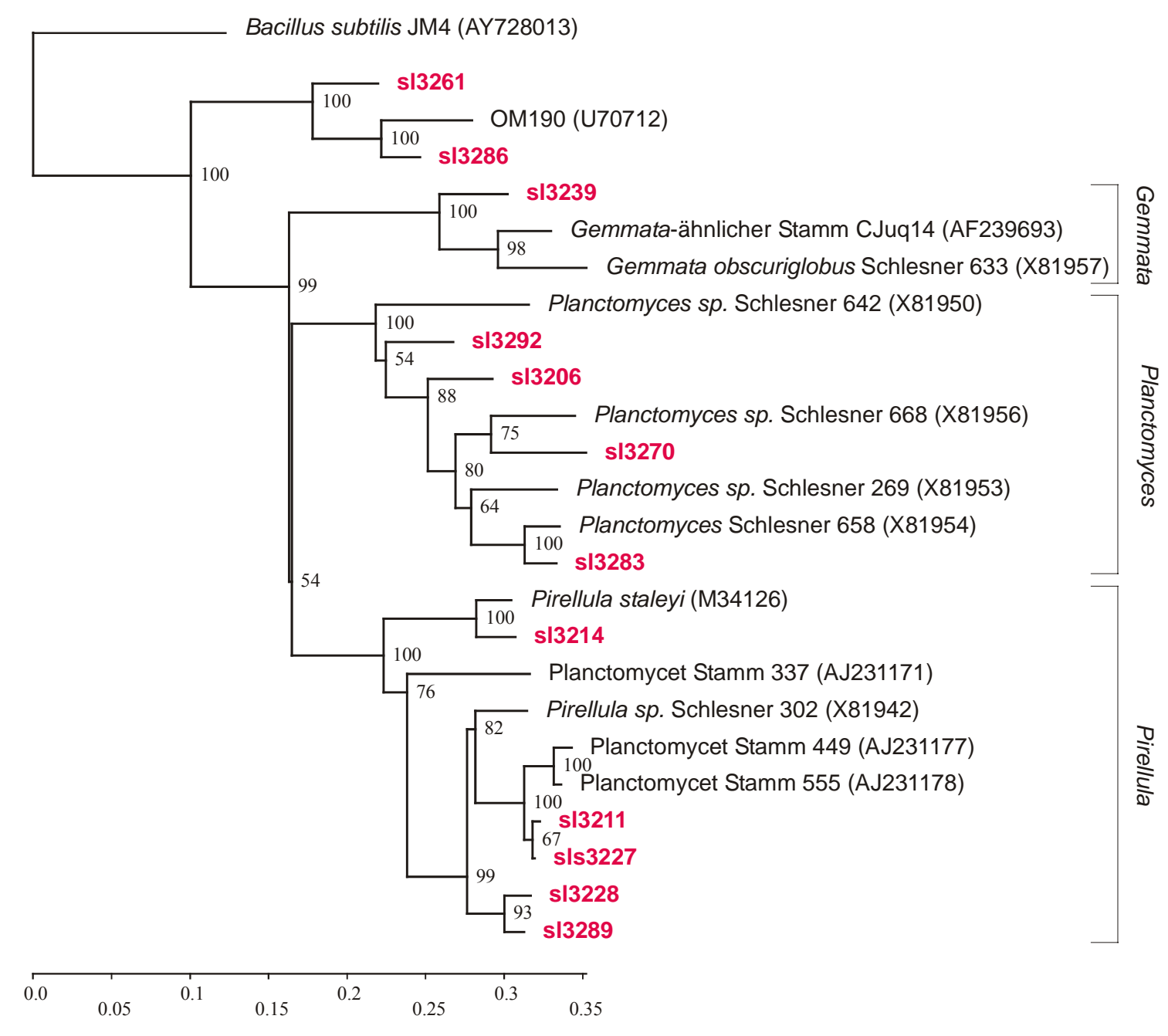

\section{Abbildung 14: Phylogenetischer Stammbaum der Planctomycetes des Leinesedimentes}

Dem „Multialignment“ liegen 605 Positionen zugrunde. Nicht enthalten sind die Sequenzen sl1364a, sl1379a, sl3241 und sl3242. Für die Beschreibung des Vorgehens siehe Abbildungsbeschriftung unter Abbildung 17.

Bei den nächsten Verwandten der Leinesediment-Sequenzen, die in das Phylum der Chloroflexi eingeordnet werden können, handelt es sich ausschließlich um UmweltSequenzen von Organismen, die nicht genauer klassifiziert wurden und nur durch $16 \mathrm{~S}$ rRNA-Gensequenzen in Datenbanken repräsentiert sind. Im Stammbaum in Abbildung 17 zeichnet sich eine Zweiteilung der Sequenzen ab, bei der die Sequenzen s13235, s13223 und SJA-35 ein eigenes Cluster bilden. Die Ähnlichkeiten zu den Datenbanksequenzen betragen nur 85 bis $90 \%$.

Die übrigen Sequenzen des Leinesedimentes gehören ausschließlich an diesem Standort selten vertretenen Phyla an, weshalb hier auf eine genauere Betrachtung verzichtet werden soll. 


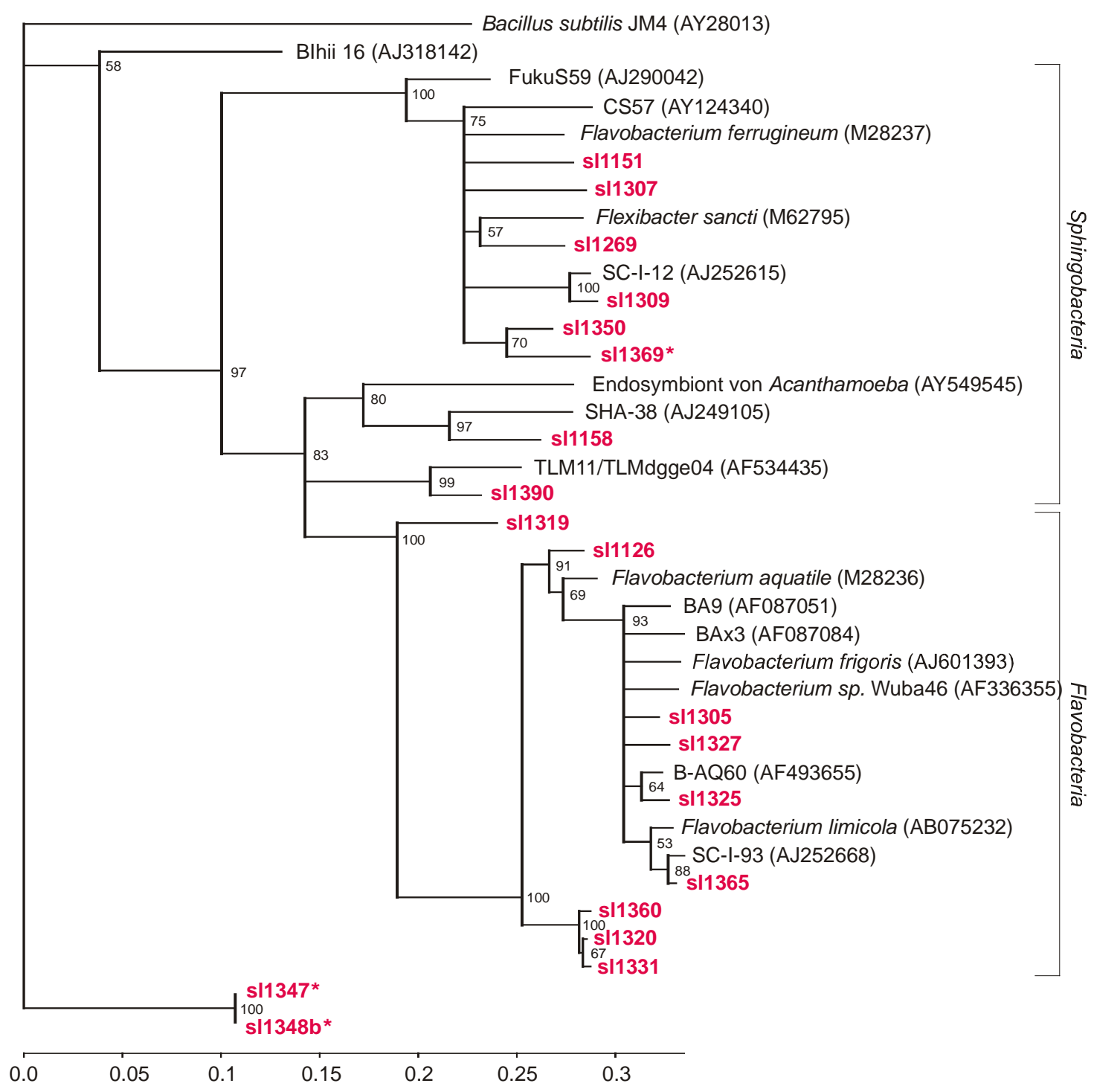

\section{Abbildung 15: Phylogenetischer Stammbaum der CFB-Gruppe des Leinesedimentes}

Dem „Multialignment“ liegen 402 Positionen zugrunde. Nicht enthalten sind die Sequenzen sl1152, sl1224, s11378 und sl1389. Für die Beschreibung des Vorgehens siehe Abbildungsbeschriftung unter Abbildung 17. 


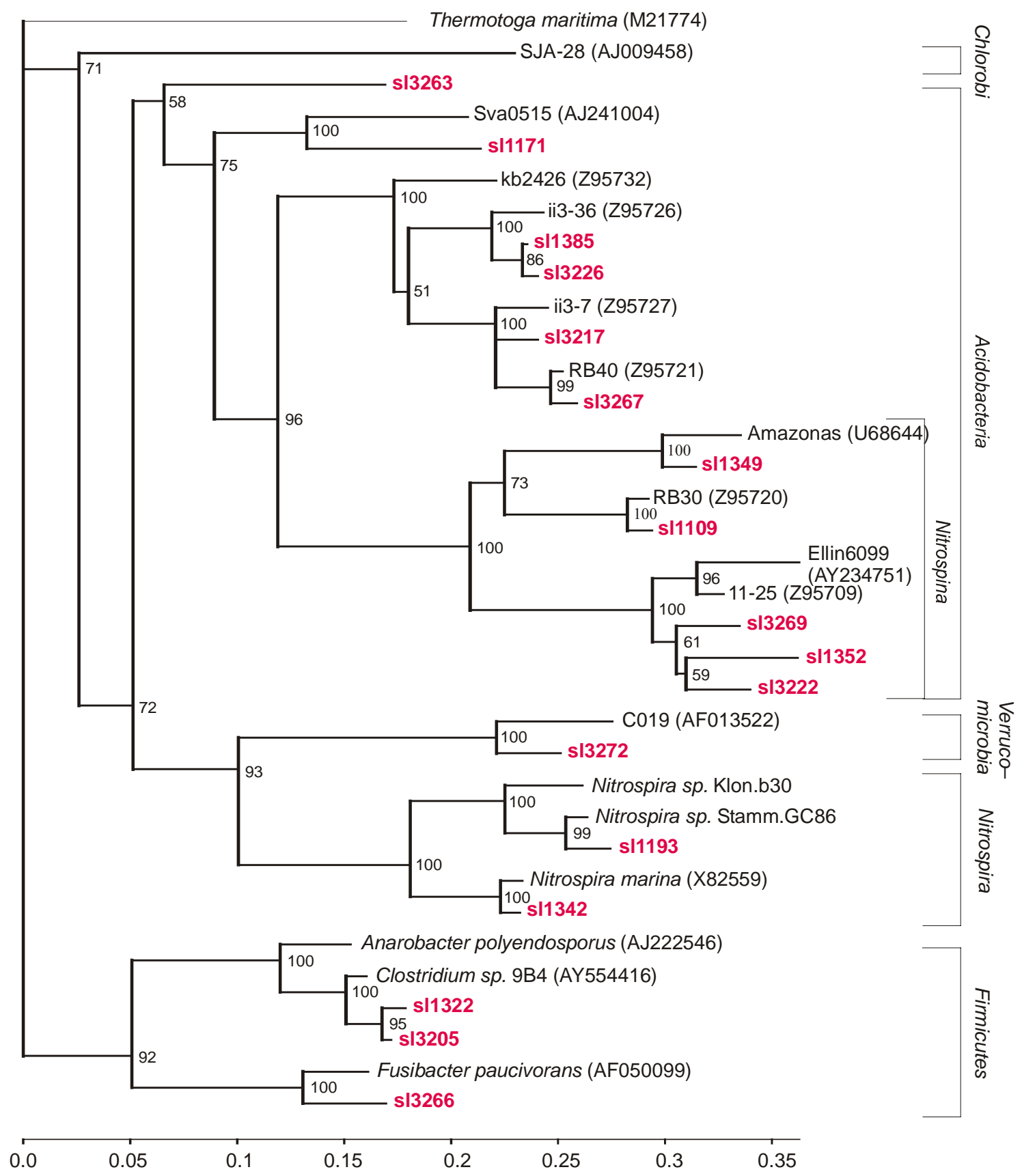

Abbildung 16: Phylogenetischer Stammbaum der Chlorobi, Acidobacteria, Nitrospira, Verrucomicrobia und Firmicutes des Leinesedimentes

Dem „Multialignment" liegen 501 Positionen zugrunde. Nicht enthalten sind die Sequenzen s11149, s11384, und s11395. Für die Beschreibung des Vorgehens siehe Abbildungsbeschriftung unter Abbildung 17. 


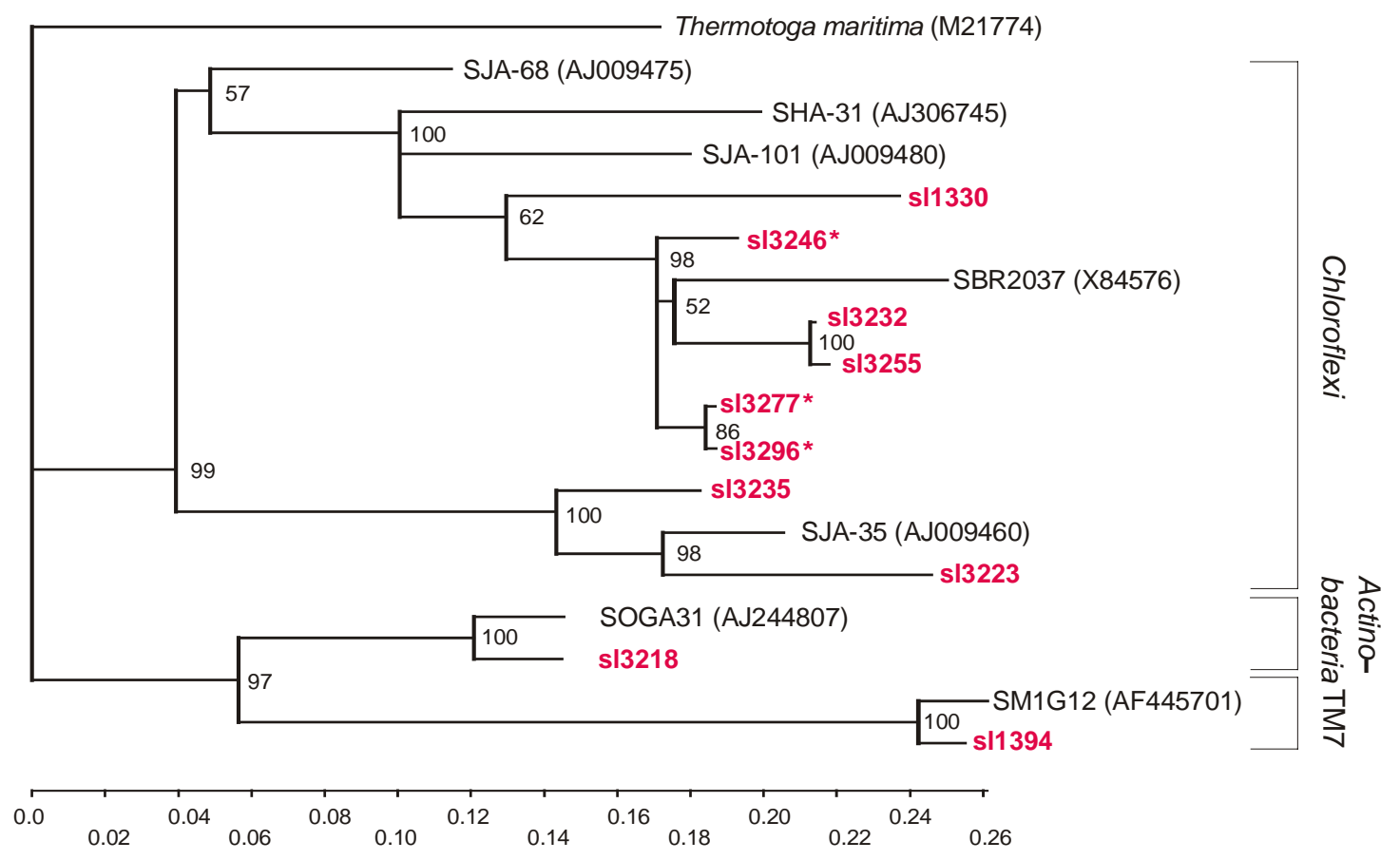

\section{Abbildung 17: Phylogenetischer Stammbaum der Chloroflexi, Actinobacteria und der Kandidat-Division TM7 des Leinesedimentes}

Dem „Multialignment“ liegen 387 Positionen zugrunde.

Mit der aus dem Leinesediment isolierten DNA (s. 2.6.1) wurden mit den Oligonukleotiden 16S08 und 16S1504 sowie A800F und A1530R 3 Polymerase-Kettenreaktionen durchgeführt. Die PCR-Produkte wurden durch Gelextraktionen (s. 2.5.3.6) gereinigt und anschließend in den Vektor pCR2.1-TOPO kloniert. Die Ansätze wurden in E. coli TOP10 mittels Hitzeschock transformiert (s. 2.11.1). Die Transfomationsansätze wurden auf LB-Medium mit Ampicillin, IPTG und X-Gal ausplattiert. Von jeweils 96 Klonen wurde, wie unter 2.6.3.5 beschrieben, eine robotgesteuerte Plasmidpräparation vorgenommen. Die Plasmide wurden in einer Sequenzreaktion (s. 2.12.1) mit den Oligonukleotiden rev und for eingesetzt. Die Sequenzierung fand mit dem „ABI DNA Sequencer 377“ statt. Die Sequenzen wurden mit dem Programm „Gap4“ bearbeitet. Mit dem Programm „Phylip“ bei RDP wurde jeweils ein „Multialignment" der resultierenden Sequenzen erstellt, um die Anzahl der in allen Sequenzen enthaltenen „Alignment“-Positionen zu ermitteln. Die „Multialignments“, die der Berechnung der Stammbäume zugrunde gelegt wurden, wurden mit dem Programm „ClustalW“ berechnet. Die „Bootstrap“-Analyse wurde mit dem Programm „Treefinder" mit 100-facher Wiederholung mit Standardeinstellungen erstellt. Der Größenmaßstab gibt die Zahl der Substitutionen pro Base an.

Insgesamt zeigen die Ergebnisse, dass einige 16S rRNA-Gensequenzen zwar sehr große Identitäten zu Datenbanksequenzen aufweisen, dass jedoch bei etwa die Hälfte der Sequenzen nur Übereinstimmungen von weniger als $95 \%$ vorliegen. Die überwiegende Mehrheit der aus dem Leinesediment amplifizierten 16S rDNA-Sequenzen ähneln den Sequenzen von Mikroorganismen, die bislang nur durch ihre 16S rRNA-Gene in den Datenbanken repräsentiert sind. 


\subsection{Sequenzierung von Cosmiden aus der Leinesediment- Metagenom-Cosmid-Genbank}

Die Sequenzierung zufällig ausgewählter Cosmide sollte einen Einblick in die Verteilung der Gene im Leinesediment und das physiologische Potential der dort lebenden Organismen gewähren. Außerdem standen die gewonnenen Sequenzen einem breiten sequenzbasierten Screening zur Verfügung. 14 der 400 Cosmide der CosmidMetagenombank der Leine wurden für eine vollständige Sequenzierung ausgewählt, nachdem durch einen Restriktionsverdau mit EcoRI bzw. NotI sichergestellt worden war, dass sich die Restriktionsmuster der Cosmide unterschieden. Für die Sequenzierung wurden sogenannte „Shotgun“-Genbanken aller Cosmide angelegt. Bei genomischen „Shotgun“-Genbanken wird versucht, durch mechanische Behandlung unterschiedlich große DNA-Fragmente zu erhalten und anschließend zu klonieren, so dass jedes Fragment statistisch gleich häufig in der resultierenden Genbank vertreten ist. Bei den Cosmiden wurde die Fragmentierung der DNA abweichend durch Restriktionsspaltung erreicht. Da Restriktionsenzyme aufgrund ihrer spezifischen Erkennungssequenzen nicht zufällig schneiden und damit auch keine statistische Verteilung der resultierende DNA-Fragmente erhalten wird, wurden, um eine ausgewogenere Verteilung der Fragmente $\mathrm{zu}$ bekommen, 2 verschiedene Restriktionsenzyme eingesetzt. Zum einen wurde wie bei der Erstellung der PlasmidLeinesediment-Genbanken Bsp143I verwendet, zum anderen fand das blunt-endschneidene Enzym AluI Verwendung. Ziel war die Klonierung 2 bis 4 kb großer DNAFragmente in den Klonierungsvektor pBluescript ${ }^{\circledR} \mathrm{II}$ SK+ (Stratagene, San Diego, USA). Der partielle Restriktionsverdau wurde für die „Shotgun“-Genbanken enzymlimitiert durchgeführt. Das Ergebnis der Spaltung wurde in einem Agarosegel kontrolliert. Für die Klonierung wurde die Verdünnungsstufe ausgewählt, die die größte Konzentration an 2 bis $4 \mathrm{~kb}$ großen DNA-Fragmenten enthielt. Diese wurde dann auf ein präparatives Agarosegel aufgetragen und die Fragmente mit der gewünschten Größe aus dem Gel extrahiert (s. 2.5.3.6). Die Vorbereitung des Vektors, die Klonierung, die Transformation und die Kontrolle der Inserts erfolgte wie unter 3.2.2.1 beschrieben. Abweichend war nur die Spaltung von pBluescript ${ }^{\circledR} I I$ SK + mit SmaI für die Klonierung der mit AluI gespaltenen DNA. Enthielten mindestens $80 \%$ der überprüften Klone ein 
Insert mit der gewünschten Größe, wurden für die robotgesteuerte Plasmidpräparation meist je Enzym 2 96er „Flat-Bottom-Blöcke“ mit Zahnstochern beimpft. Die robotgesteuerte Plasmidpräparation und die anschließende Sequenzierung erfolgte wie unter 2.6.3.5 bzw. 2.12.1 und 2.12.2 beschrieben. Das „Basecalling“ der Rohdaten und die Prozessierung der Sequenzen wurden, wie unter 2.13 und 2.13.1 beschrieben, durchgeführt. Die Sequenzen wurden letztlich mit dem Programm „Gap4“ bearbeitet (s. 2.13.1.2), bestehende Sequenzlücken geschlossen bzw. Sequenzbereiche mit schlechter Qualität oder Abdeckung überarbeitet (s. 2.14). Auf den geschlossenen Cosmiden wurden dann mit dem Programm „Artemis“ potentielle offene Leserahmen festgelegt (s. 2.15.1) und diese anschließend annotiert (s. 2.15.2).

\subsubsection{Ergebnisse der Sequenzierung}

Bislang ist die Sequenzierung von 9 der 14 Cosmide abgeschlossen. 2 Cosmide, die Cosmide slc_1g und slc_1q, weisen jeweils nur eine Lücke auf, die sich aufgrund von Sekundärstrukturen nicht schließen ließen, obwohl lückenüberspannende PCR-Produkte erhalten werden konnten. Das Cosmid slc_1a besteht ebenfalls nur noch aus 2 Contigs, weist aber Sequenzbereiche mit schlechter Qualität auf. 2 Cosmide müssen noch stark bearbeitet werden. Sie umfassen noch mehr als 10 Contigs, von denen einzelne Größen bis $12 \mathrm{~kb}$ aufweisen. Sie wurden in dieser Arbeit nicht weiter berücksichtigt. Die InsertGrößen der Cosmide liegen zwischen 33740 bp und 44155 bp. Berücksichtigt man nur die in dieser Arbeit behandelten Cosmide, erhält man insgesamt ca. $456 \mathrm{~kb}$ sequenzierter Metagenom-DNA. Ein Cosmid, das Cosmid slc_1q, ist eukaryotischen Urspungs, alle anderen enthalten klonierte bakterielle DNA. Aufgrund der Genorganisation bei Eukaryoten enthält das Cosmid slc_1q nur 8 Gene. Insgesamt wurden 382 ORFs festgelegt. Davon konnte bei 166 ORFs der übersetzten Aminosäuresequenz keine Funktion zugeordnet werden. Hatten die abgeleiteten Proteine signifikante Sequenzähnlichkeiten mit Datenbanksequenzen, wurden sie als „konservierte Proteine“ annotiert, konnte keine signifikante Ähnlichkeit festgestellt werden, wurde ihnen die Bezeichnung „hypothetisches Protein“ gegeben. Wie die nähere Beschreibung der einzelnen Cosmide noch zeigen wird, konnte bei einzelnen Cosmiden anhand der Sequenz nur sehr wenigen Proteinen eine Funktion zugeordnet werden. Bei anderen Cosmiden wie dem Cosmid slc_1x kodieren die ORFs fast ausschließlich für Proteine mit großer Ähnlichkeit zu Proteinen aus der NCBI- 
Datenbank. Fast man die Funktionen der abgeleiteten Proteinsequenzen der ORFs zu funktionalen Gruppen zusammen, ergibt sich die in Abbildung 18 und Tabelle 11 dargestellte Verteilung. Den deutlich größten Teil (33\%) stellen die als ,hypothetische Proteine“ annotierten abgeleiteten Sequenzen der ORFs dar, gefolgt von den abgeleiteten Sequenzen, die als „konservierte Proteine“ annotiert (9\%) wurden. Damit kann $42 \%$ der auf den Cosmiden kodierten Proteinen keine Funktion zugeordnet werden. Viele Proteine scheinen eine Rolle im Kohlenhydrat-Transport und Metabolismus (7\%) und im Aminosäure-Stoffwechsel (10\%) zu spielen. Weitere häufige Funktionen sind in der Zellhüll-Biosynthese und dem Lipid-Metabolismus sowie der Signal-Transduktion $\mathrm{zu}$ finden. Im Folgenden sollen nun die einzelnen Cosmide genauer betrachtet werden. Die Annotationen der auf den Cosmiden kodierten Proteine und die ähnlichsten Datenbanksequenzen sind in der Tabelle 12 wiedergegeben.

Tabelle 11: Charakterisierung der sequenzierten Cosmide

\begin{tabular}{|c|c|c|c|c|c|}
\hline Cosmid & Insert-Größe & G+C-Gehalt & ORFs & $\begin{array}{c}\text { Ohne } \\
\text { bekannte } \\
\text { Funktion }\end{array}$ & $\begin{array}{c}\text { Mit } \\
\text { bekannter } \\
\text { Funktion }\end{array}$ \\
\hline slc_1a & ca. 39620 & $65,4 \%$ & 36 & $7(19,4 \%)$ & $29(80,6 \%)$ \\
\hline slc_1f & 37395 & $66,2 \%$ & 27 & $19(70,0 \%)$ & $8(30,0 \%)$ \\
\hline slc_1g & ca. 44530 & $64,4 \%$ & 43 & $19(44,0 \%)$ & $24(56,0 \%)$ \\
\hline slc_1h & 37311 & $59,1 \%$ & 38 & $11(28,9 \%)$ & $27(71,1 \%)$ \\
\hline slc_1p & 37601 & $63,0 \%$ & 35 & $18(51,4 \%)$ & $17(48,6 \%)$ \\
\hline slc_1q ${ }^{\mathrm{E}}$ & ca. 36250 & $38,8 \%$ & 8 & $2(25 \%)$ & $6(75 \%)$ \\
\hline slc_1s & 34637 & $63,7 \%$ & 25 & $11(44,0 \%)$ & $14(55,6 \%)$ \\
\hline slc_1t & 39084 & $60,2 \%$ & 42 & $19(45,2 \%)$ & $23(54,8 \%)$ \\
\hline slc_1u & 33732 & $69,9 \%$ & 27 & $18(66,7 \%)$ & $9(33,3 \%)$ \\
\hline slc_1x & 38011 & $64,6 \%$ & 39 & $4(10,3 \%)$ & $35(89,7 \%)$ \\
\hline slc_2g & 39068 & $67,2 \%$ & 28 & $16(57,1 \%)$ & $12(42,9 \%)$ \\
\hline slc_2j & 39483 & $66,1 \%$ & 34 & $22(64,7 \%)$ & $12(35,3 \%)$ \\
\hline Gesamt & $456 \mathrm{~kb}$ & & $374^{*}$ & $164(43,9 \%)^{*}$ & $210(56,1 \%)^{*}$ \\
\hline
\end{tabular}


Tabelle 12: "BLAST"-Ergebnisse der ORFs aller Cosmide und Annotation

\section{A) Cosmid slc_1a}

\begin{tabular}{|c|c|c|c|c|c|c|c|c|c|}
\hline $\begin{array}{l}\text { ORF- } \\
\text { Name }\end{array}$ & Größe & Annotation & Ähnlichstes Protein bei NCBI & Organismus & $\begin{array}{l}\text { Accession- } \\
\text { Nummer }\end{array}$ & $\begin{array}{l}\text { e- } \\
\text { Value }\end{array}$ & $\begin{array}{l}\text { I in } \\
\%\end{array}$ & Konservierte Domänen bei NCBI & $\begin{array}{l}\text { Funk- } \\
\text { tion }\end{array}$ \\
\hline 101 & 396 & $\begin{array}{l}\text { Potentieller Kationen-Protonen- } \\
\text { Antiporter }\end{array}$ & Hypothetisches Protein CC1500 & $\begin{array}{l}\text { Caulobacter } \\
\text { crescentus CB15 }\end{array}$ & $\begin{array}{l}\text { NP_420311. } \\
1\end{array}$ & e-123 & 57 & $\begin{array}{l}\text { CDD10348, COG0475, KefB, Kef-Typ } \\
\text { Kransport-System, Membran-Komponente } \\
\text { (5e- } \\
\text { 16) }\end{array}$ & I-TM \\
\hline 102 & 1132 & Potentielle $\beta$-Galaktosidase & $\beta$-Galaktosidase & $\begin{array}{l}\text { Bacteroides } \\
\text { thetaiotaomicron } \\
\text { VPI-5482 }\end{array}$ & $\begin{array}{l}\text { NP_810681. } \\
1\end{array}$ & e-142 & 31 & $\begin{array}{l}\text { CDD25976, pfam02837, Glykosyl-Hydrolase- } \\
\text { Familie 2, Zucker-Bidedomäne (5e-11) }\end{array}$ & KH-M \\
\hline 103 & 290 & Potentielle $\beta$-Galaktosidase I & $\beta$-Galaktosidase I & $\begin{array}{l}\text { Bacteroides } \\
\text { thetaiotaomicron } \\
\text { VPI-5482 }\end{array}$ & $\begin{array}{l}\text { NP_813063. } \\
1\end{array}$ & $3 e-37$ & 37 & $\begin{array}{l}\text { CDD12835, COG3507, XynB, } \beta \text {-Xylosidase } \\
\text { (5e-07) }\end{array}$ & KH-M \\
\hline 104 & 423 & $\begin{array}{l}\text { Potentielle } \\
\text { glukosamin 2-Epimerase }\end{array}$ & $\begin{array}{lcc}\begin{array}{l}\text { Potentielle } \\
\text { Epimerase }\end{array} & \text { N-acyl-D-glukosamin } & 2- \\
\end{array}$ & $\begin{array}{l}\text { Bacteroides } \\
\text { fragilis YCH46 }\end{array}$ & $\begin{array}{l}\text { YP_098134. } \\
1\end{array}$ & $5 e-35$ & 27 & $\begin{array}{lccc}\text { CDD17798, } & \text { cd00249, } & \text { AGE; } & \text { N-Acyl-D- } \\
\text { glukosamine 2-Epimerase-Domäne } & \end{array}$ & KH-M \\
\hline 105 & 452 & $\begin{array}{l}\text { Potentielles } \alpha \text {-L-Fucosidase- } \\
\text { Vorläuferprotein }\end{array}$ & $\alpha$-L-Fucosidase-Vorläuferprotein & $\begin{array}{l}\text { Bacteroides } \\
\text { thetaiotaomicron } \\
\text { VPI-5482 }\end{array}$ & $\begin{array}{l}\text { AAO78770. } \\
1\end{array}$ & $1 e-96$ & 40 & $\begin{array}{l}\text { CDD12992, COG3669, } \quad \text { COG3669, } \\
\text { Fucosidase (8e-57) }\end{array}$ & KH-M \\
\hline 106 & 71 & Hypothetisches Protein & Keine signifikante Übereinstimmung & & & & & & \\
\hline 107 & 283 & $\begin{array}{l}\text { Potentielles } \quad \text { Transkriptions- } \\
\text { Terminations-Faktor NusB }\end{array}$ & $\begin{array}{l}\text { Potentielles } \\
\text { Terminations-Faktor NusB }\end{array}$ & $\begin{array}{l}\text { Thermotoga } \\
\text { maritima MSB8 }\end{array}$ & $\begin{array}{l}\text { ZP_229562. } \\
1\end{array}$ & $7 e-15$ & 43 & $\begin{array}{l}\text { CDD24170, } \\
\text { CD00619, Terminator_NusB, } \\
\text { Transkriptions-Terminations-Faktor NusB ("N } \\
\text { protein-Utilization Substance B") }\end{array}$ & TS \\
\hline 108 & 236 & $\begin{array}{l}\text { Potentielle 6,7-Dimethyl-8- } \\
\text { ribityllumazin-Synthase } \\
\text { 2.5.1.9) (DMRL-Synthase) }\end{array}$ & $\begin{array}{l}\text { COG0054: } \\
\text { Untereinheit }\end{array}$ & $\begin{array}{l}\text { Rubrivivax } \\
\text { gelatinosus } \\
\text { PM1 }\end{array}$ & $\begin{array}{l}\text { ZP_0024429 } \\
0.1\end{array}$ & $4 \mathrm{e}-17$ & 37 & $\begin{array}{l}\text { CDD7812, pfam00885, DMRL_Synthase, 6,7- } \\
\text { Dimethyl-8-ribityllumazin-Synthase (7e-23) }\end{array}$ & CE-M \\
\hline 109 & 349 & $\begin{array}{l}\text { Riboflavin-Biosynthese-Protein } \\
\text { ribA [mit: GTP-Cyclohydrolase } \\
\text { II (EC 3.5.4.25); 3,4-Dihydroxy- } \\
\text { 2-butanon-4-phosphate Synthase } \\
\text { (DHBP-Synthase)] }\end{array}$ & $\begin{array}{l}\text { COG0108: 3,4-Dihydroxy-2-butanon-4- } \\
\text { phosphat-Synthase }\end{array}$ & $\begin{array}{l}\text { Moorella } \\
\text { thermoacetica } \\
\text { ATCC } 39073\end{array}$ & $\begin{array}{l}\text { ZP_0033055 } \\
7.1\end{array}$ & $\mathrm{e}-110$ & 59 & $\begin{array}{l}\text { CDD|7832, pfam00925, GTP_cyclohydro2, GTP } \\
\text { Cyclohydrolase II (2e-61) }\end{array}$ & CE-M \\
\hline 110 & 220 & $\begin{array}{l}\text { Eisenabhängiger Repressor, } \\
\text { Metallbinde- } \\
\text { Dimerisationsdomäne und N- } \\
\text { terminale DNA-Bindedomäne }\end{array}$ & $\begin{array}{ll}\text { COG1321: } & \text { Mn-abhängiger } \\
\text { Transkriptionsregulator } & \end{array}$ & $\begin{array}{l}\text { Thermobifida } \\
\text { fusca }\end{array}$ & $\begin{array}{l}\text { ZP_0029438 } \\
8.1\end{array}$ & $2 \mathrm{e}-39$ & 41 & $\begin{array}{l}\text { CDD11037, COG1321, TroR, Mn-abhängiger } \\
\text { Transkriptionsregulator (6e-37) }\end{array}$ & TS \\
\hline 111 & 246 & Konserviert Protein & $\begin{array}{l}\text { COG1566: "Multidrug"-Resistenz- } \\
\text { Efflux-Pumpe }\end{array}$ & $\begin{array}{l}\text { Ralstonia } \\
\text { metallidurans } \\
\text { CH34 }\end{array}$ & $\begin{array}{l}\text { ZP_0027340 } \\
4.1\end{array}$ & $2 \mathrm{e}-50$ & 41 & $\begin{array}{l}\text { CDD11279, COG1566, EmrA, "Multidrug"- } \\
\text { Resistenz-Efflux-Pumpe (2e-19) }\end{array}$ & A \\
\hline 112 & 434 & $\begin{array}{l}\text { "Outer membrane"-Efflux- } \\
\text { Protein, potentielles "drug"- } \\
\text { Efflux-Lipoprotein }\end{array}$ & COG1538: “Outer membrane"-Protein & $\begin{array}{l}\text { Ralstonia } \\
\text { metallidurans } \\
\text { CH34 }\end{array}$ & $\begin{array}{l}\text { ZP_0027340 } \\
5.1\end{array}$ & $2 \mathrm{e}-60$ & 34 & $\begin{array}{l}\text { CDD11252, COG1538, } \\
\text { membrane"-Protein (8e-38) }\end{array}$ & $\begin{array}{l}\text { ZH-B } \\
\text { /ITS/A }\end{array}$ \\
\hline
\end{tabular}




\begin{tabular}{|c|c|c|c|c|c|c|c|c|c|}
\hline $\begin{array}{l}\text { ORF- } \\
\text { Name }\end{array}$ & Größe & Annotation & Ähnlichstes Protein bei NCBI & Organismus & $\begin{array}{l}\text { Accession- } \\
\text { Nummer }\end{array}$ & $\begin{array}{l}\text { e- } \\
\text { Value }\end{array}$ & $\begin{array}{l}I \text { in } \\
\%\end{array}$ & Konservierte Domänen bei NCBI & $\begin{array}{l}\text { Funk- } \\
\text { tion }\end{array}$ \\
\hline 113 & 323 & $\begin{array}{l}\text { Potentielle L-Asparaginase, } \\
\text { periplasmisches } \\
\text { Vorläuferprotein (EC 3.5.1.1) }\end{array}$ & Periplasmatische L-Asparaginase II & $\begin{array}{l}\text { Vibrio } \\
\text { parahaemolyticus } \\
\text { RIMD } 2210633\end{array}$ & $\begin{array}{l}\text { NP_799884. } \\
1\end{array}$ & $4 \mathrm{e}-93$ & 54 & CDD17797, cd00411, Asparaginase (1e-91) & AS-M \\
\hline 114 & 86 & Hypothetisches Protein & \multicolumn{6}{|l|}{ Keine signifikante Übereinstimmung } & $\mathrm{HP}$ \\
\hline 115 & 203 & $\begin{array}{l}\text { Poteintielle } \\
\text { Glyoxalase/Bleomycin- } \\
\text { Resistenz-Protein/Dioxygenase- } \\
\text { Superfamilie }\end{array}$ & $\begin{array}{l}\text { COG3324:Vorausgesagtes } \quad \text { Enzym; } \\
\text { verwandt mit Laktoylglutathion-Lyase }\end{array}$ & $\begin{array}{l}\text { Rubrobacter } \\
\text { xylanophilus DSM } \\
9941\end{array}$ & $\begin{array}{l}\text { ZP_0018732 } \\
2.2\end{array}$ & $2 \mathrm{e}-17$ & 32 & & A \\
\hline 116 & 68 & Hypothetisches Protein & \multicolumn{6}{|l|}{ Keine signifikante Übereinstimmung } & HP \\
\hline 117 & 328 & Cystein-Synthase (EC 4.2.99.8), & Potentielle Cystein-Synthase, Protein A & $\begin{array}{l}\text { Ralstonia } \\
\text { solanacearum } \\
\text { GMI1000 }\end{array}$ & $\begin{array}{l}\text { NP_521837. } \\
1\end{array}$ & e-119 & 66 & $\begin{array}{l}\text { CDD9907, COG0031, CysK, Cystein-Synthase } \\
\text { (2e-94) }\end{array}$ & AS-M \\
\hline 118 & 228 & $\begin{array}{l}\text { COG1526: Uncharakterisiertes } \\
\text { Protein, das für die Formiat- } \\
\text { Dehydrogenase-Aktivität } \\
\text { gebraucht wird }\end{array}$ & $\begin{array}{l}\text { COG1526: Uncharakterisiertes Protein, } \\
\text { das für die Formiat-Dehydrogenase- } \\
\text { Aktivität gebraucht wird }\end{array}$ & $\begin{array}{l}\text { Trichodesmium } \\
\text { erythraeum } \\
\text { IMS101 }\end{array}$ & $\begin{array}{l}\text { ZP_0032819 } \\
9.1\end{array}$ & $3 e-61$ & 51 & $\begin{array}{l}\text { CDD3141, pfam02634, } \quad \text { FdhD-NarQ, } \\
\text { FdhD/NarQ-Familie. Nitrat-Assimilationsprotein } \\
(2 \mathrm{e}-41)\end{array}$ & KH-M \\
\hline 119 & 203 & $\begin{array}{l}\text { Protein mit Ähnlichkeit zur } \gamma \text { - } \\
\text { Untereinheit der Sarcosin- } \\
\text { Oxidase }\end{array}$ & $\begin{array}{l}\text { Protein mit Ähnlichkeit zur } \quad \gamma- \\
\text { Untereinheit der Sarcosin-Oxidase }\end{array}$ & $\begin{array}{l}\text { Mesorhizobium } \\
\text { loti MAFF303099 }\end{array}$ & $\begin{array}{l}\text { NP_107652. } \\
1\end{array}$ & $3 e-21$ & 34 & $\begin{array}{l}\text { CDD9827, pfam04268, SoxG, Sarcosin-Oxidase, } \\
\gamma \text {-Untereinheit-Familie. (4e-25) }\end{array}$ & AS-M \\
\hline 120 & 632 & $\begin{array}{ll}\text { Sarcosin-Oxidase, } & \alpha- \\
\text { Untereinheit (EC1.5.3.1) } & \end{array}$ & Sarcosin-Oxidase, $\alpha$-Untereinheit & $\begin{array}{l}\text { Mesorhizobium } \\
\text { loti MAFF303099 }\end{array}$ & $\begin{array}{l}\text { NP_107653. } \\
1\end{array}$ & $e-177$ & 56 & $\begin{array}{lrr}\text { CDD10278, COG0404, } & \text { GcvT, } & \text { Glycin- } \\
\text { Spaltungssystem } & \text { Protein } & T \\
\text { (Aminomethyltransferase) } & (7 \mathrm{e}-93) & \end{array}$ & AS-M \\
\hline 121 & 376 & $\begin{array}{l}\text { Sarcosin-Oxidase, } \\
\text { Untereinheit (EC1.5.3.1) }\end{array}$ & Sarcosin-Oxidase, $\alpha$-Untereinheit & $\begin{array}{l}\text { Mesorhizobium } \\
\text { loti MAFF303099 }\end{array}$ & $\begin{array}{l}\text { NP_107653. } \\
1\end{array}$ & $e-120$ & 59 & $\begin{array}{l}\text { CDD10320, COG0446, HcaD, Uncharakterisierte } \\
\text { NAD(FAD)-abhängige Dehydrogenase (7e-16) }\end{array}$ & AS-M \\
\hline 122 & 50 & $\begin{array}{l}\text { Sarcosin-Oxidase, } \\
\text { Untereinheit (EC1.5.3.1) }\end{array}$ & $\begin{array}{lll}\text { Potentielle } & \text { Sarcosin-Oxidase, } & \delta- \\
\text { Untereinheit }\end{array}$ & $\begin{array}{l}\text { Mesorhizobium } \\
\text { loti }\end{array}$ & CAD31287.1 & $2 \mathrm{e}-07$ & 21 & $\begin{array}{l}\text { CDD9826, pfam04267, SoxD Sarcosin-Oxidase, } \\
\delta \text {-Untereinheit-Familie (7e-08) }\end{array}$ & AS-M \\
\hline 123 & 418 & $\begin{array}{l}\text { Sarcosin-Oxidase, } \\
\text { Untereinheit (EC1.5.3.1) }\end{array}$ & Sarcosin-Oxidase, $\beta$-Untereinheit & $\begin{array}{l}\text { Mesorhizobium } \\
\text { loti MAFF303099 }\end{array}$ & $\begin{array}{l}\text { NP_106778. } \\
1\end{array}$ & 0.0 & 74 & $\begin{array}{l}\text { CDD10534, COG0665, DadA, Glycin/D- } \\
\text { Aminosäure-Oxidase (deaminierend) } \\
(2 \mathrm{e}-51)\end{array}$ & $\overline{\text { AS-M }}$ \\
\hline 124 & 466 & $\begin{array}{l}\text { Alkyldihydroxyacetonephosphat } \\
\text {-Synthase (EC 2.5.1.26) }\end{array}$ & Hypothetisches Protein ECs3629 & $\begin{array}{l}\text { Escherichia coli } \\
\text { O157:H7 }\end{array}$ & $\begin{array}{l}\text { NP_311656. } \\
1\end{array}$ & $e-175$ & 63 & $\begin{array}{l}\text { CDD10151, COG0277, GlcD, FAD/FMN- } \\
\text { enthaltende Dehydrogenasen }(3 \mathrm{e}-55)\end{array}$ & $\mathrm{E}$ \\
\hline 125 & 465 & Zucker-Kinase & Hypothetische Zucker-Kinase ygcE & $\begin{array}{l}\text { Escherichia coli } \\
\text { CFT073 }\end{array}$ & $\begin{array}{l}\text { NP_755212. } \\
1\end{array}$ & e-115 & 46 & $\begin{array}{l}\text { CDD10793, COG1070, XylB, Zucker (Pentulose } \\
\text { und Hexulose) Kinasen (2e-52) }\end{array}$ & KH-M \\
\hline 126 & 122 & $\begin{array}{l}\text { Potentielle 2-Deoxy-D-gluconat- } \\
\text { 3-Dehydrogenase (EC } \\
1.1 .1 .125)\end{array}$ & Potentielle Oxidoreduktase & $\begin{array}{l}\text { Escherichia coli } \\
\text { O157:H7 }\end{array}$ & ${ }_{2}^{N P} 3311657$. & $1 \mathrm{e}-55$ & 83 & $\begin{array}{l}\text { CDD25396, pfam00106, adh_short, Kurzketten- } \\
\text { Dehydrogenase (3e-23) }\end{array}$ & KH-M \\
\hline 127 & 222 & $\begin{array}{l}\text { Potentielle 2-Deoxy-D-gluconat- } \\
\text { 3-Dehydrogenase (EC } \\
1.1 .1 .125)\end{array}$ & Hypothetische Oxidoreduktase ygcW & $\begin{array}{l}\text { Escherichia coli } \\
\text { CFT073 }\end{array}$ & $\begin{array}{l}\text { NP_755210. } \\
1\end{array}$ & $7 \mathrm{e}-31$ & 51 & $\begin{array}{l}\text { CDD25396, pfam00106, adh_short, Kurzketten- } \\
\text { Dehydrogenase (3e-23) }\end{array}$ & KH-M \\
\hline 128 & 618 & 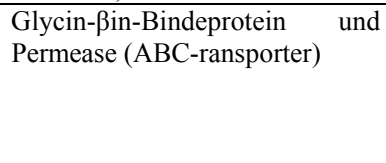 & $\begin{array}{l}\text { 1.Teil } \\
\text { Potentielles Glycin- } \beta \text { in-Bindeprotein } \\
\text { 2. Teil } \\
\text { Potentielle ABC-Transporter Permease }\end{array}$ & $\begin{array}{l}\text { Sinorhizobium } \\
\text { meliloti } 1021 \\
\\
\text { Photobacterium } \\
\text { profundum SS9 }\end{array}$ & $\begin{array}{l}\text { NP_436936. } \\
1 \\
\text { YP_133403. } \\
1\end{array}$ & $\begin{array}{l}1 e-91 \\
1 e-72\end{array}$ & 55 & $\begin{array}{l}\text { CDD|11821, COG2113, ProX, ABC-Typ } \\
\text { Prolin/Glycin-Betain-Transport-Systeme, } \\
\text { periplasmatische Komponente (1e-77) }\end{array}$ & AS-M \\
\hline
\end{tabular}




\begin{tabular}{|c|c|c|c|c|c|c|c|c|c|}
\hline $\begin{array}{l}\text { ORF- } \\
\text { Name }\end{array}$ & Größe & Annotation & Ähnlichstes Protein bei NCBI & Organismus & $\begin{array}{l}\text { Accession- } \\
\text { Nummer }\end{array}$ & $\begin{array}{l}\text { e- } \\
\text { Value }\end{array}$ & $\begin{array}{l}I \text { in } \\
\%\end{array}$ & Konservierte Domänen bei NCBI & $\begin{array}{l}\text { Funk- } \\
\text { tion }\end{array}$ \\
\hline 129 & 400 & $\begin{array}{l}\text { Glycin-Betain/L-Prolin- } \\
\text { Transport } \quad \text { ATP-Bindeprotein } \\
\text { proV }\end{array}$ & ABC-Transporter, ATP-Bindeprotein & $\begin{array}{l}\text { Mesorhizobium } \\
\text { loti MAFF303099 }\end{array}$ & $\begin{array}{l}\text { NP_104013. } \\
1\end{array}$ & $\mathrm{e}-102$ & 59 & $\begin{array}{l}\text { CDD13440, COG4175, ProV, ABC-Typ } \\
\text { Prolin/Glycin-Betain-Transport-Systeme, } \\
\text { ATPase-Komponente (5e-105) }\end{array}$ & AS-M \\
\hline 130 & 212 & $\begin{array}{ll}\text { Potentieller } & \text { TonB-abhängiger } \\
\text { Rezeptor } & \end{array}$ & $\begin{array}{l}\text { COG1629: "Outer membrane" Rezeptor- } \\
\text { Protein, meist Fe-Transport }\end{array}$ & $\begin{array}{l}\text { Novosphingobium } \\
\text { aromaticivorans } \\
\text { DSM } 12444\end{array}$ & $\begin{array}{l}\text { ZP_0030204 } \\
6.1\end{array}$ & $9 \mathrm{e}-12$ & 44 & & I-TM \\
\hline 131 & 555 & $\begin{array}{ll}\text { Potentieller } & \text { TonB-abhängiger } \\
\text { Rezeptor } & \end{array}$ & $\begin{array}{l}\text { COG1629: "Outer membrane" Rezeptor- } \\
\text { Protein, meist Fe-Transport }\end{array}$ & $\begin{array}{l}\text { Novosphingobium } \\
\text { aromaticivorans } \\
\text { DSM } 12444\end{array}$ & $\begin{array}{l}\text { ZP_0030204 } \\
6.1\end{array}$ & $1 \mathrm{e}-49$ & 33 & $\begin{array}{l}\text { CDD28191, cd01347, ligand_gated_channel, } \\
\text { TonB abhängige/Ligand-"gated"Kanäle (2e-27) }\end{array}$ & I-TM \\
\hline 132 & 526 & Hypothetisches Protein & Hypothetisches Protein mll1230 & $\begin{array}{l}\text { Mesorhizobium } \\
\text { loti MAFF303099 }\end{array}$ & $\begin{array}{l}\text { NP_102866. } \\
1\end{array}$ & e-175 & 63 & $\begin{array}{l}\text { CDD25126, pfam06253, MTTB, Trimethylamin- } \\
\text { Methyltransferase (MTTB) (EC:2.1.1.-) (2e-162) }\end{array}$ & HP \\
\hline 133 & 700 & Potentielle Peptidase & Potentielle Peptidase & $\begin{array}{l}\text { Shewanella } \\
\text { oneidensis MR-1 }\end{array}$ & $\begin{array}{l}\text { NP_717820. } \\
1\end{array}$ & $2 \mathrm{e}-74$ & 29 & $\begin{array}{l}\text { CDD11220, COG1506, DAP2, Dipeptidyl- } \\
\text { Aminopeptidases/Acylaminoacyl-peptidases (2e- } \\
\text { 65) }\end{array}$ & AS-M \\
\hline 134 & 80 & Hypothetisches Protein & Keine signifikante Übereinstimmung & & & & & & HP \\
\hline 135 & 87 & Hypothetisches Protein & Keine signifikante Übereinstimmung & & & & & & HP \\
\hline 136 & 177 & $\begin{array}{l}\text { Konserviertes hypothetisches } \\
\text { Protein }\end{array}$ & Konserviertes hypothetisches Protein & $\begin{array}{l}\text { Sinorhizobium } \\
\text { meliloti } 1021\end{array}$ & $\begin{array}{l}\text { NP_386094. } \\
1\end{array}$ & $2 e-51$ & 58 & $\begin{array}{l}\text { CDD13207, COG3894, } \\
\text { Metall-bindende Proteine }\end{array}$ & KHP \\
\hline
\end{tabular}

\section{B) Cosmid Slc_1f}

\begin{tabular}{|c|c|c|c|c|c|c|c|c|c|}
\hline 201 & 165 & Hypothetisches Protein & \multicolumn{6}{|l|}{ Keine signifikante Übereinstimmung } & HP \\
\hline 202 & 261 & Hypothetisches Protein & \multirow{2}{*}{\multicolumn{6}{|c|}{$\begin{array}{l}\text { Keine signifikante Übereinstimmung } \\
\text { Keine signifikante Übereinstimmung }\end{array}$}} & $\mathrm{HP}$ \\
\hline 203 & 209 & Hypothetisches Protein & & & & & & & $\mathrm{HP}$ \\
\hline 204 & 921 & $\begin{array}{l}\text { Potentielles integrales } \\
\text { Membranprotein (ComEC) }\end{array}$ & $\begin{array}{ll}\text { Potentielles } & \text { Kompetenzprotein } \\
\text { ComEC/Rec2 } & \end{array}$ & Pirellula sp. 1 & $\begin{array}{l}\text { NP_869100. } \\
1\end{array}$ & $6 e-38$ & 26 & $\begin{array}{l}\text { CDD12009, COG2333, ComEC, Vorausgesagte } \\
\text { Hydrolase (Metallo- } \beta \text {-Laktamase-Superfamilie) } \\
\text { (1e-23) }\end{array}$ & RKT \\
\hline 205 & 454 & Vorausgesagte ATPase & Konserviertes hypothtisches Protein & $\begin{array}{ll}\text { Coxiella } & \text { burnetii } \\
\text { RSA } 493 & \\
\end{array}$ & $\begin{array}{l}\text { NP_820995. } \\
1\end{array}$ & $2 \mathrm{e}-48$ & 37 & $\begin{array}{l}\text { CDD11089, COG1373, Vorausgesagte ATPase } \\
\text { (AAA+ Superfamilie) (1e-39) }\end{array}$ & E \\
\hline 206 & 79 & Hypothetisches Protein & \multicolumn{6}{|l|}{ Keine signifikante Übereinstimmung } & HP \\
\hline 207 & 840 & $\begin{array}{l}\text { Hypothetisches membran- } \\
\text { durchspannendes Protein }\end{array}$ & \multicolumn{6}{|l|}{ Keine signifikante Übereinstimmung } & HP \\
\hline 208 & 222 & $\begin{array}{ll}\text { Hypothetisches } & \text { membran- } \\
\text { assoziiertes Protein } & \end{array}$ & \multicolumn{6}{|l|}{ Keine signifikante Übereinstimmung } & HP \\
\hline 209 & 250 & $\begin{array}{l}\text { Hypothetisches membran- } \\
\text { assoziiertes Protein }\end{array}$ & \multicolumn{6}{|l|}{ Keine signifikante Übereinstimmung } & HP \\
\hline 210 & 333 & $\begin{array}{l}\text { Prolipoprotein-Diacylglyceryl- } \\
\text { Transferase (EC 2.4.99.-) }\end{array}$ & $\begin{array}{l}\text { Prolipoprotein-Diacylglyceryl- } \\
\text { Transferase }\end{array}$ & $\begin{array}{l}\text { Photorhabdus } \\
\text { luminescens } \\
\text { subsp. laumondii } \\
\text { TTO1 }\end{array}$ & $\begin{array}{l}\text { NP_927967. } \\
1\end{array}$ & $1 \mathrm{e}-29$ & 31 & $\begin{array}{l}\text { CDD24591, pfam01790, LGT, Prolipoprotein } \\
\text { Diacylglyceryl-Transferase. (6e-35) }\end{array}$ & ZH-B \\
\hline
\end{tabular}




\begin{tabular}{|c|c|c|c|c|c|c|c|c|c|}
\hline $\begin{array}{l}\text { ORF- } \\
\text { Name }\end{array}$ & Größe & Annotation & Ähnlichstes Protein bei NCBI & Organismus & $\begin{array}{l}\text { Accession- } \\
\text { Nummer }\end{array}$ & $\begin{array}{l}\text { e- } \\
\text { Value }\end{array}$ & $\begin{array}{l}I \text { in } \\
\%\end{array}$ & Konservierte Domänen bei NCBI & $\begin{array}{l}\text { Funk- } \\
\text { tion }\end{array}$ \\
\hline 211 & 186 & $\begin{array}{ll}\text { Uncharakterisiertes } & \\
\text { konserviertes } & \text { Protein } \\
\text { (COG4276) } & \end{array}$ & Konserviertes Protein & $\begin{array}{l}\text { Cytophaga } \\
\text { hutchinsonii }\end{array}$ & $\begin{array}{l}\text { ZP_0011672 } \\
1.1\end{array}$ & $8 e-23$ & 40 & $\begin{array}{l}\text { CDD13523, COG4276, } \quad \text { COG4276, } \\
\text { Uncharakterisiertes konserviertes Protein } \\
(4 \mathrm{e}-10)\end{array}$ & KP \\
\hline 212 & 322 & $\begin{array}{l}\text { Vorausgesagte } \\
\text { und verwydrogenase } \\
\text { undter Proteine } \\
(\mathrm{COG} 0673)\end{array}$ & Hypothetisches Protein & $\begin{array}{l}\text { Staphylococcus } \\
\text { aureus subsp. } \\
\text { aureus Mu50 }\end{array}$ & $\begin{array}{l}\text { NP_370741. } \\
1\end{array}$ & $2 \mathrm{e}-17$ & 31 & $\begin{array}{l}\text { CDD10542, COG0673, MviM, vorausgesagte } \\
\text { Dehydrogenasen und verwandte Proteine }(4 \mathrm{e}-32)\end{array}$ & E \\
\hline 213 & 997 & Protein der Subtilase-Familie & $\begin{array}{l}\text { COG1404: Subtilisin-ähnliche } \\
\text { Protease }\end{array}$ & $\begin{array}{l}\text { Geobacter } \\
\text { Metallireducens }\end{array}$ & $\begin{array}{l}\text { ZP_0008095 } \\
2.1\end{array}$ & $3 \mathrm{e}-19$ & 30 & $\begin{array}{l}\text { pfam00082, Peptidase_S8, Subtilase-Familie } \\
(4 \mathrm{e}-24)\end{array}$ & AS-M \\
\hline 214 & 653 & $\begin{array}{l}\text { Glukosamin-6-phosphat- } \\
\text { Isomerase } 2 \text { (EC 3.5.99.6) }\end{array}$ & $\begin{array}{l}\text { COG0363: 6-Phosphoglukono- } \\
\text { laktonase/Glukosamin-6-phosphat- } \\
\text { Isomerase/Deaminase }\end{array}$ & $\begin{array}{l}\text { Cytophaga } \\
\text { hutchinsonii }\end{array}$ & $\begin{array}{l}\text { ZP_0011764 } \\
2.1\end{array}$ & 0.0 & 57 & $\begin{array}{lr}\text { CDD25704, pfam01182, } & \text { Glucosamin-iso, } \\
\text { Glucosamin-6-phosphat } \\
\text { phosphogluconolactonasen } \\
\text { 6e-47 }\end{array}$ & KH-M \\
\hline 215 & 545 & $\begin{array}{l}\text { Konserviertes } \\
\text { Protein }\end{array}$ & Hypothetisches Protein & $\begin{array}{l}\text { Methanosarcina } \\
\text { mazei Goe1 }\end{array}$ & $\begin{array}{l}\text { NP_635222. } \\
1\end{array}$ & $4 \mathrm{e}-80$ & 40 & $\begin{array}{l}\text { CDD23022, pfam00561, Abhydrolase_1, } \alpha / \beta \\
\text { Hydrolase_Faltung. This catalytic domain is } \\
\text { found in a very wide range of enzymes. }(2 \mathrm{e}-06)\end{array}$ & KHP \\
\hline 216 & 277 & Konserviertes Protein & Konserviertes hypothtisches Protein & $\begin{array}{l}\text { Bacteroides } \\
\text { thetaiotaomicron } \\
\text { VPI-5482 }\end{array}$ & $\begin{array}{l}\text { NP_812740. } \\
1\end{array}$ & $3 \mathrm{e}-08$ & 36 & $\begin{array}{l}\text { CDD21440, } \\
\text { KOnservieres Protein }(3 \mathrm{e}-061,\end{array}$ & KP \\
\hline 217 & 740 & Hypothetisches Protein & Keine signifikante Übereinstimmung & & & & & & HP \\
\hline 218 & 856 & $\begin{array}{l}\text { Alkalische Phosphatase } \quad \text { (EC } \\
\text { 3.1.3.1) }\end{array}$ & Konserviertes hypothetisches Protein & Brucella suis 1330 & $\begin{array}{l}\text { NP_699800. } \\
1\end{array}$ & e-128 & 39 & & DRR \\
\hline 219 & 157 & Hypothetisches Protein & Keine signifikante Übereinstimmung & & & & & & HP \\
\hline 220 & 141 & Hypothetisches Protein & Keine signifikante Übereinstimmung & & & & & & HP \\
\hline 221 & 243 & $\begin{array}{l}\text { Hypothetisches membran- } \\
\text { assoziiertes Protein }\end{array}$ & Keine signifikante Übereinstimmung & & & & & & HP \\
\hline 222 & 1005 & $\begin{array}{ll}\begin{array}{l}\text { Hypothetisches } \\
\text { assoziiertes Protein }\end{array} & \text { membran- } \\
\end{array}$ & Keine signifikante Übereinstimmung & & & & & & HP \\
\hline 223 & 250 & $\begin{array}{l}\text { Hypothetisches membran- } \\
\text { durchspannendes Protein }\end{array}$ & Keine signifikante Übereinstimmung & & & & & & HP \\
\hline 224 & 83 & Hypothetisches Protein & Keine signifikante Übereinstimmung & & & & & & HP \\
\hline 225 & 477 & Konserviertes Protein & Vorausgesagte Isoflavin-Reduktase & $\begin{array}{ll}\text { Bacillus } & \text { cereus } \\
\text { ZK }\end{array}$ & $\begin{array}{l}\text { VP_084357. } \\
1\end{array}$ & $6 e-57$ & 36 & $\begin{array}{l}\text { CDD10325, COG0451, WcaG, Nucleosid- } \\
\text { diphosphat-Zucker-Epimerasen (8e-14) }\end{array}$ & KP \\
\hline 226 & 392 & Konserviertes Protein & Hypothetisches Protein glr3508 & $\begin{array}{l}\text { Gloeobacter } \\
\text { violaceus }\end{array}$ & $\begin{array}{l}\text { NP_926454. } \\
1\end{array}$ & $2 \mathrm{e}-17$ & 57 & $\begin{array}{l}\text { CDD11391, COG1680, AmpC, } \beta \text {-Lactamase } \\
\text { Klasse C und andere Penicillin-Bindeproteine } \\
(8 \mathrm{e}-08)\end{array}$ & KP \\
\hline 227 & 497 & $\begin{array}{l}\text { Konserviertes } \\
\text { (hypothetisches Sensor-Protein) }\end{array}$ & sensor protein atoS & Pirellula sp. 1 & $\begin{array}{l}\text { NP_868275. } \\
1\end{array}$ & $3 e-51$ & 31 & $\begin{array}{l}\text { gnl|CDD|13167, } \begin{array}{l}\text { COG3852, NtrB, } \\
\text { Transduktion: } \\
\text { spezifisch (6e-15) }\end{array} \text { Histidin-Kinase, } \\
\text { sperickstoff- }\end{array}$ & ST \\
\hline
\end{tabular}




\section{C) Cosmid Slc_1g}

\begin{tabular}{|c|c|c|c|c|c|c|c|c|c|}
\hline $\begin{array}{l}\text { ORF- } \\
\text { Name }\end{array}$ & Größe & Annotation & Ähnlichstes Protein bei NCBI & Organismus & $\begin{array}{l}\text { Accession- } \\
\text { Nummer }\end{array}$ & $\begin{array}{l}\text { e- } \\
\text { Value } \\
\end{array}$ & $\begin{array}{l}\text { I in } \\
\%\end{array}$ & Konservierte Domänen bei NCBI & $\begin{array}{l}\text { Funk- } \\
\text { tion }\end{array}$ \\
\hline 301 & 279 & $\begin{array}{ll}\text { Potentielle } & \text { L-sorboson- } \\
\text { Dehydrogenase } & \end{array}$ & Potentielle L-sorboson-Dehydrogenase & $\begin{array}{l}\text { Geobacter } \\
\text { sulfurreducens } \\
\text { PCA }\end{array}$ & $\begin{array}{l}\text { NP_951254. } \\
1\end{array}$ & $9 \mathrm{e}-95$ & 65 & $\begin{array}{l}\text { CDD11841, } \quad \text { COG2133, } \\
\text { Dehydrogenases (1e-46) }\end{array}$ & KH-M \\
\hline 302 & 375 & Potentielle Transposase & Transposase & $\begin{array}{l}\text { Leptospira } \\
\text { borgpetersenii }\end{array}$ & S43117 & $6 e-68$ & 39 & 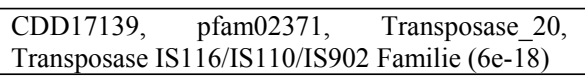 & RKT \\
\hline 303 & 121 & Hypothetisches Protein & \multicolumn{3}{|l|}{ Keine signifikante Übereinstimmung } & & & & HP \\
\hline 304 & 316 & $\begin{array}{l}\text { Potentielles periplasmatisches } \\
\text { ATP/GTP-Bindeprotein }\end{array}$ & $\begin{array}{ll}\text { Periplasmatisches } & \text { ATP/GTP- } \\
\text { Bindeprotein } & \end{array}$ & $\begin{array}{l}\text { Mesorhizobium } \\
\text { loti }\end{array}$ & BAB51206 & $6 e-37$ & 36 & & RKT \\
\hline 305 & 238 & $\begin{array}{l}\text { Potentielle } \\
\text { glukonolaktonase (EC 3.1.1.31) }\end{array}$ & $\begin{array}{l}\text { 6-Phospho-glukonolaktonase ähnliches } \\
\text { Protein }\end{array}$ & $\begin{array}{l}\text { Rubrobacter } \\
\text { xylanophilus DS } \\
9941\end{array}$ & $\begin{array}{l}\text { ZP_0060025 } \\
5\end{array}$ & $9 e-23$ & 40 & $\begin{array}{l}\text { CDD10237, COG0363, NagB, } \\
\text { Phosphoglukonolaktonase/Glukosamin-6- } \\
\text { phosphat-Isomerase/Deaminase (7e-33) }\end{array}$ & KH-M \\
\hline 306 & 465 & $\begin{array}{l}\text { Glukose-6-phosphat- } \\
\text { Dehydrogenase (EC 1.1.1.49) }\end{array}$ & $\begin{array}{ll}\text { COG0364: } & \text { Glukose-6-phosphat- } \\
\text { Dehydrogenase } & \end{array}$ & $\begin{array}{l}\text { Nostoc } \\
\text { punctiforme }\end{array}$ & $\begin{array}{l}\text { ZP_0011043 } \\
9.1\end{array}$ & $1 \mathrm{e}-154$ & 54 & $\begin{array}{l}\text { CDD10238, COG0364, Zwf, Glukose-6-phosphat } \\
\text { 1-Dehydrogenase (1e-149) }\end{array}$ & KH-M \\
\hline 307 & 56 & Hypothetisches Protein & \multicolumn{6}{|l|}{ Keine signifikante Übereinstimmung } & $\mathrm{HP}$ \\
\hline 308 & 134 & Hypothetisches Protein & Potentielle Acyltransferase & $\begin{array}{l}\text { Streptomyces } \\
\text { coelicolor A3(2) }\end{array}$ & $\begin{array}{l}\text { NP_625385. } \\
1\end{array}$ & $3 e-12$ & 33 & $\begin{array}{l}\text { CDD25558, pfam00583, } \quad \text { Acetyltransf_1, } \\
\text { Acetyltransferase (GNAT)-Familie. (2e-09) }\end{array}$ & HP \\
\hline 309 & 256 & $\begin{array}{l}\text { Pantoat- } \beta \text {-Alanin-Ligase } \quad(\mathrm{EC} \\
6.3 .2 .1)\end{array}$ & Pantoat- $\beta$-Alanin-Ligase & $\begin{array}{l}\text { Thermotoga } \\
\text { maritime }\end{array}$ & $\begin{array}{l}\text { NP_228883. } \\
1\end{array}$ & $2 \mathrm{e}-69$ & 50 & $\begin{array}{l}\text { CDD10288, COG0414, PanC, Panthothenat- } \\
\text { Synthetase (3e-94) }\end{array}$ & CE-M \\
\hline 310 & 243 & $\begin{array}{l}\text { Potentielle 3-Methyl-2- } \\
\text { oxobutanoat-Hydroxymethyl- } \\
\text { Transferase }\end{array}$ & $\begin{array}{l}\text { Potentielle 3-Methyl-2-oxobutanoat- } \\
\text { Hydroxymethyl-Transferase }\end{array}$ & $\begin{array}{l}\text { Chlorobium } \\
\text { tepidum TLS }\end{array}$ & $\begin{array}{l}\text { NP_662228. } \\
1\end{array}$ & $3 e-63$ & 50 & $\begin{array}{l}\text { CDD10287, COG0413, PanB, Ketopantoat- } \\
\text { Hydroxymethyltransferase }(2 \mathrm{e}-79)\end{array}$ & CE-M \\
\hline 311 & 349 & $\begin{array}{l}\text { Aldose-1-Epimerase } \quad(\mathrm{EC} \\
5.1 .3 .3)\end{array}$ & $\begin{array}{l}\text { COG2017: Galactose-Mutarotase und } \\
\text { verwandte Enzyme }\end{array}$ & $\begin{array}{l}\text { Microbulbifer } \\
\text { degradans 2-40 }\end{array}$ & $\begin{array}{l}\text { ZP_0006776 } \\
1.1\end{array}$ & $7 \mathrm{e}-91$ & 51 & $\begin{array}{l}\text { CDD19392, KOG1604, KOG1604, KOG1604, } \\
\text { Vorausgesagte Mutarotase (1e-89) }\end{array}$ & KH-M \\
\hline 312 & 222 & Hypothetisches Protein & \multirow{2}{*}{\multicolumn{6}{|c|}{$\begin{array}{l}\text { Keine signifikante Übereinstimmung } \\
\text { Keine signifikante Übereinstimmung }\end{array}$}} & HP \\
\hline 313 & 136 & $\begin{array}{l}\text { Hypothetisches membran- } \\
\text { durchspannendes Protein }\end{array}$ & & & & & & & HP \\
\hline 314 & 426 & $\begin{array}{l}\text { Hypothetisches membran- } \\
\text { durchspannendes Protein }\end{array}$ & Unbekanntes Protein & $\begin{array}{l}\text { Gloeobacter } \\
\text { violaceus }\end{array}$ & $\begin{array}{l}\text { NP_924023. } \\
1\end{array}$ & $2 \mathrm{e}-13$ & 33 & $\begin{array}{lcc}\text { CDD13469, } & \text { COG4219, } & \text { MecR1, "drug } \\
\text { resistance" } & \text { regulierender } & \text { Antirepressor, } \\
\text { vorausgesagte } & \text { Signal-Transduktion, N-terminale } \\
\text { Membran-Komponente }(2 \mathrm{e}-15) & \end{array}$ & HP \\
\hline 315 & 129 & Hypothetisches Protein & Potentieller $\beta$-Laktamase-Repressor & Pirellula sp. 1 & $\begin{array}{l}\text { NP_870928. } \\
1\end{array}$ & $4 \mathrm{e}-07$ & 30 & $\begin{array}{lcc}\text { CDD13004, } & \text { COG3682, } & \text { COG3682, } \\
\text { Vorausgesagter Transkriptionsregulator }(6 e-15)\end{array}$ & TS \\
\hline 316 & 202 & $\begin{array}{ll}\begin{array}{l}\text { Hypothetisches } \\
\text { assoziiertes Protein }\end{array} & \text { membran- } \\
\end{array}$ & \multicolumn{6}{|l|}{ Keine signifikante Übereinstimmung } & HP \\
\hline 317 & 368 & Hypothetisches Protein & \multicolumn{6}{|l|}{ Keine signifikante Übereinstimmung } & HP \\
\hline 318 & 511 & $\begin{array}{l}\text { Konserviertes hypothetisches } \\
\text { membranassoziiertes Protein }\end{array}$ & Konserviertes hypothetisches Protein & Pirellula sp. 1 & $\begin{array}{l}\text { NP_866523. } \\
1\end{array}$ & $9 e-23$ & 29 & & HP \\
\hline 319 & 809 & Potentielle Permease & Unbekanntes Protein & $\begin{array}{l}\text { Gloeobacter } \\
\text { violaceus }\end{array}$ & $\begin{array}{l}\text { NP_924147. } \\
1\end{array}$ & $1 \mathrm{e}-71$ & 28 & $\begin{array}{l}\text { CDD25940, pfam02687, FtsX, Vorausgesagte } \\
\text { Permease. (1e-16) }\end{array}$ & KP \\
\hline
\end{tabular}




\begin{tabular}{|c|c|c|c|c|c|c|c|c|c|}
\hline $\begin{array}{l}\text { ORF- } \\
\text { Name }\end{array}$ & Größe & Annotation & Ähnlichstes Protein bei NCBI & Organismus & $\begin{array}{l}\text { Accession- } \\
\text { Nummer }\end{array}$ & $\begin{array}{l}\text { e- } \\
\text { Value }\end{array}$ & $\begin{array}{l}I \text { in } \\
\%\end{array}$ & Konservierte Domänen bei NCBI & $\begin{array}{l}\text { Funk- } \\
\text { tion }\end{array}$ \\
\hline 320 & 150 & Hypothetisches Protein & Konserviertes hypothetisches Protein & $\begin{array}{l}\text { Deinococcus } \\
\text { radiodurans }\end{array}$ & $\begin{array}{l}\text { NP_296348. } \\
1\end{array}$ & $1 \mathrm{e}-10$ & 45 & $\begin{array}{lcc}\text { CDD11406, } & \text { COG1695, } & \text { COG1695, } \\
\text { Vorausgesagte Transkriptionsregulatoren (3e-14) }\end{array}$ & TS \\
\hline 321 & 809 & $\begin{array}{ll}\begin{array}{l}\text { Hypothetisches } \\
\text { assoziiertes Protein }\end{array} & \text { membran- } \\
\end{array}$ & $\begin{array}{l}\text { Keine signifikante Übereinstimmung } \\
\text { Bester hit zu ORF } 660(2 \mathrm{~J}): 3.6 \mathrm{e}-22 \\
\end{array}$ & & & & & $\begin{array}{l}\text { CDD24254, smart00327, VWA, von Willebrand } \\
\text { factor (vWF) type A domain; (8e-11) }\end{array}$ & $\mathrm{HP}$ \\
\hline 322 & 458 & $\begin{array}{l}\text { Potentielles Cytochrom P450 } \\
\text { (EC 1.14.14.1) }\end{array}$ & Hypothetisches Protein & $\begin{array}{l}\text { Chloroflexus } \\
\text { aurantiacus }\end{array}$ & $\begin{array}{l}\text { ZP_0001905 } \\
7.1\end{array}$ & $3 e-69$ & 38 & $\begin{array}{l}\text { CDD17954, KOG0157, } \quad \text { Cytochrom } \\
\text { CYP4/CYP19/CYP26 Subfamilien (1e-54) }\end{array}$ & $\begin{array}{l}\text { SM- } \\
\text { BT, } \\
\text { LM }\end{array}$ \\
\hline 323 & 302 & $\begin{array}{ll}\begin{array}{l}\text { Konserviertes } \\
\text { der }\end{array} \text { Protein (Protein } \\
\text { Familie) } & \\
\end{array}$ & COG0457: FOG: TPR-Protein & $\begin{array}{l}\text { Trichodesmium } \\
\text { erythraeum } \\
\text { IMS101 }\end{array}$ & $\begin{array}{l}\text { ZP_0007201 } \\
8.1\end{array}$ & $1 \mathrm{e}-33$ & 35 & $\begin{array}{l}\text { CDD22401, KOG4626, , } \\
\text { acetylglukosamin-Transferase OGT (6e-23) }\end{array}$ & $\begin{array}{l}\text { KH-M, } \\
\text { PPM } \\
\text { und ST }\end{array}$ \\
\hline 324 & 119 & Hypothetisches Protein & Hypothetisches Protein & $\begin{array}{l}\text { Myxococcus } \\
\text { xanthus }\end{array}$ & $\begin{array}{l}\text { AAO22884. } \\
1\end{array}$ & 1e-10 & 42 & $\begin{array}{l}\text { CDD15816, pfam04519, DUF583, Protein mit } \\
\text { unbekannter Funktion, DUF583. (6e-13) }\end{array}$ & $\mathrm{HP}$ \\
\hline 325 & 513 & Potentielle Histidin-Kinase & $\begin{array}{lll}\begin{array}{l}\text { 2-Komponenten-Hybrid } \\
\text { Regulator }\end{array} & \text { Sensor } & \text { und } \\
\end{array}$ & $\begin{array}{l}\text { Gloeobacter } \\
\text { violaceus }\end{array}$ & $\begin{array}{l}\text { NP_923045. } \\
1\end{array}$ & $2 \mathrm{e}-77$ & 36 & $\begin{array}{lccc}\text { CDD10512, } & \text { COG0642, } & \text { BaeS, } & \text { Signal- } \\
\text { Transduktion: Histidin-Kinase } & (4 \mathrm{e}-34) & \end{array}$ & ST \\
\hline 326 & 86 & $\begin{array}{l}\text { Potenteieller "response-regulator } \\
\text { receiver"-Domäne }\end{array}$ & "response-regulator receiver" & $\begin{array}{l}\text { Desulfovibrio } \\
\text { vulgaris }\end{array}$ & YP_009495 & $2 \mathrm{e}-11$ & 42 & $\begin{array}{l}\text { CDD5334, cd00156, REC, "Signal receiver"- } \\
\text { Domäne (5e-12) }\end{array}$ & ST \\
\hline 327 & 253 & $\begin{array}{l}\text { Konserviertes Protein } \text { (Protein } \\
\text { der "Tetratricopeptide } \\
\text { Familie) }\end{array}$ & COG0457: FOG: "TPR repeat" & $\begin{array}{l}\text { Trichodesmium } \\
\text { erythraeum } \\
\text { IMS101 }\end{array}$ & $\begin{array}{l}\text { NP_840112. } \\
1\end{array}$ & $3 e-18$ & 35 & $\begin{array}{l}\text { CDD5390, cd00189, TPR, “Tetratricopeptide } \\
\text { repeat"-Domäne (2e-09) }\end{array}$ & KP \\
\hline 328 & 200 & $\begin{array}{l}\text { Konserviertes } \\
\text { (Cytochrom P460-Vorläufer) }\end{array}$ & Cytochrom P460-Vorläufer & \begin{tabular}{l}
\multicolumn{2}{l}{$\begin{array}{l}\text { Nitrosomonas } \\
\text { europaea } \\
19718\end{array} \quad$ ATCC } \\
\end{tabular} & $\begin{array}{l}\text { NP_864013. } \\
1\end{array}$ & $4 \mathrm{e}-28$ & 25 & & KP \\
\hline 329 & 380 & $\begin{array}{l}\text { Konserviertes membran- } \\
\text { durchspannendes Protein }\end{array}$ & Vorausgesagte Permease & Pirellula sp. 1 & $\begin{array}{l}\text { NP_644604. } \\
1\end{array}$ & $7 e-87$ & 41 & $\begin{array}{l}\text { CDD10498, COG0628, PerM, Vorausgesagte } \\
\text { Permease (8e-27) }\end{array}$ & KP \\
\hline 330 & 499 & $\begin{array}{ll}\text { Potentielle } & \text { Cardiolipin- } \\
\text { Synthetase } & \end{array}$ & Cardiolipin-Synthetase & $\begin{array}{l}\text { Xanthomonas } \\
\text { axonopodis } \\
\text { citri str. } 306\end{array}$ & & & & $\begin{array}{l}\text { Phosphatidylserin/Phosphatidylglycerophosphat/ } \\
\text { Cardiolipin-Synthasen und verwandte Enzyme } \\
\text { (2e-60) }\end{array}$ & LM \\
\hline 331 & 162 & 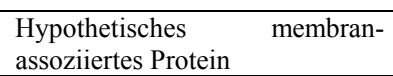 & Keine signifikante Übereinstimmung & & & & & & $\mathrm{HP}$ \\
\hline 332 & 62 & $\begin{array}{ll}\begin{array}{l}\text { Hypothetisches } \\
\text { assoziiertes Protein }\end{array} & \text { membran- } \\
\end{array}$ & Keine signifikante Übereinstimmung & & & & & & HP \\
\hline 333 & 389 & $\begin{array}{lr}\text { Konserviertes } & \text { Protein } \\
\text { (uncharakterisiertes } & \text { Eisen- } \\
\text { reguliertes Membranprotein) }\end{array}$ & Mögliche Oxidoreduktase & $\begin{array}{l}\text { Pseudomonas } \\
\text { aeruginosa PA01 }\end{array}$ & $\begin{array}{l}\text { NP_253203. } \\
1\end{array}$ & $2 \mathrm{e}-24$ & & $\begin{array}{lcr}\text { CDD17408, } & \text { pfam03929, } & \text { DUF337, } \\
\begin{array}{l}\text { Uncharakterisiertes } \\
\text { (DUF337) }(1 \mathrm{e}-35)\end{array} & \text { Eisen-reguliertes } & \text { Protein } \\
\end{array}$ & I-TM \\
\hline 334 & 226 & Eisen-Aufnahme Faktor & $\begin{array}{l}\text { COG3128: Uncharakterisiertes Eisen- } \\
\text { reguliertes Protein }\end{array}$ & $\begin{array}{l}\text { Microbulbifer } \\
\text { degradans 2-40 }\end{array}$ & $\begin{array}{l}\text { ZP_0006841 } \\
1.1\end{array}$ & $2 \mathrm{e}-81$ & & $\begin{array}{l}\text { CDD12467, COG3128, PiuC, Uncharakterisiertes } \\
\text { Eisen-reguliertes Protein (1e-84) }\end{array}$ & I-TM \\
\hline 335 & 850 & TonB-abhängiger Rezeptor & $\begin{array}{l}\text { COG4774: Rezeptor für momomere } \\
\text { Catechole in der äußeren Membran }\end{array}$ & $\begin{array}{l}\text { Azotobacter } \\
\text { vinelandii }\end{array}$ & $\begin{array}{l}\text { ZP_0008869 } \\
6.1\end{array}$ & $1 \mathrm{e}-102$ & & $\begin{array}{l}\text { CDD13912, COG4774, Fiu, "Outer membrane"- } \\
\text { Rezeptor für monomere Catechole (5e-133) }\end{array}$ & I-TM \\
\hline 336 & 90 & Hypothetisches Protein & Keine signifikante Übereinstimmung & & & & & & $\mathrm{HP}$ \\
\hline 337 & 270 & $\begin{array}{l}\text { Potentielle } \quad \text { Methyltransferase } \\
\text { (EC 2.1.1.-) }\end{array}$ & Potentielle Methyltransferase & $\begin{array}{l}\text { Bordetella } \\
\text { parapertussis }\end{array}$ & $\begin{array}{l}\text { NP_882473. } \\
1\end{array}$ & $1 \mathrm{e}-39$ & 42 & $\begin{array}{l}\text { CDD21836, } \\
\text { KOnservieres Protein }(3 \mathrm{e}-17)\end{array}$ & KH-M \\
\hline
\end{tabular}




\begin{tabular}{|c|c|c|c|c|c|c|c|c|c|}
\hline $\begin{array}{l}\text { ORF- } \\
\text { Name }\end{array}$ & Größe & Annotation & Ähnlichstes Protein bei NCBI & Organismus & $\begin{array}{l}\text { Accession- } \\
\text { Nummer }\end{array}$ & $\begin{array}{l}\text { e- } \\
\text { Value } \\
\end{array}$ & $\begin{array}{l}\text { I in } \\
\%\end{array}$ & Konservierte Domänen bei NCBI & $\begin{array}{l}\text { Funk- } \\
\text { tion }\end{array}$ \\
\hline 338 & 398 & $\begin{array}{l}\text { Mögliche } \\
\text { Aminomethyltransferase }\end{array}$ & Mögliche Aminomethyltransferase & $\begin{array}{l}\text { Sinorhizobium } \\
\text { meliloti }\end{array}$ & $\begin{array}{l}\text { NP_436414. } \\
1\end{array}$ & $1 \mathrm{e}-72$ & 39 & $\begin{array}{l}\text { CDD10278, COG0404, GcvT, Glycin-Spaltungs- } \\
\text { System Protein T (Aminomethyltransferase) (2e- } \\
77 \text { ) }\end{array}$ & AS-M \\
\hline 339 & 98 & Hypothetisches Protein & \multicolumn{6}{|l|}{ Keine signifikante Übereinstimmung } & HP \\
\hline 340 & 534 & Potentielle Phytoen-Desaturase & Phytoen-Desaturase & $\begin{array}{l}\text { Mesorhizobium } \\
\text { loti }\end{array}$ & $\begin{array}{l}\text { NP_104734. } \\
1\end{array}$ & 1e-148 & 48 & $\begin{array}{l}\text { CDD22030, KOG4254, KOG4254, KOG4254, } \\
\text { Phytoen-Desaturase (1e-80) }\end{array}$ & CE-M \\
\hline 341 & 519 & Potentielle Phytoen-Desaturase & Phytoen-Desaturase & $\begin{array}{l}\text { Mesorhizobium } \\
\text { loti }\end{array}$ & $\begin{array}{l}\text { NP_104734. } \\
1\end{array}$ & $2 \mathrm{e}-80$ & 36 & $\begin{array}{l}\text { CDD22030, KOG4254, KOG4254, KOG4254, } \\
\text { Phytoen-Desaturase (2e-63) }\end{array}$ & CE-M \\
\hline 342 & 240 & Potentieller "resonse-regulator" & $\begin{array}{l}\text { „Response“-Regulatoren bestehend aus } \\
\text { CheY-ähnlicher Receiver-Domäne und } \\
\text { einer ,"winged“-Helix-DNA-bindenden } \\
\text { Domäne }\end{array}$ & $\begin{array}{l}\text { Symbiobacterium } \\
\text { thermophilum }\end{array}$ & YP_0758361 & $6 e-40$ & 35 & $\begin{array}{l}\text { CDD10613, COG0745, OmpR, „Response“- } \\
\text { Regulatoren bestehend aus CheY-ähnlicher } \\
\text { Receiver-Domäne und einer ,winged“-Helix- } \\
\text { DNA-bindenden Domäne (7e-48) }\end{array}$ & ST \\
\hline 343 & 413 & $\begin{array}{l}\text { Potentielles "outer membrane" } \\
\text { Protein }\end{array}$ & Bakterielles Oberflächen-Antigen & Brucella suis 1330 & $\begin{array}{l}\text { NP_698159. } \\
1\end{array}$ & $2 \mathrm{e}-19$ & 29 & $\begin{array}{l}\text { CDD13913, COG4775, COG4775, "Outer } \\
\text { membrane" Protein/schützendes Antigen OMA87 } \\
(2 \mathrm{e}-35)\end{array}$ & ZH-B \\
\hline
\end{tabular}

\section{D) Cosmid Slc_1h}

\begin{tabular}{|c|c|c|c|c|c|c|c|c|c|}
\hline 401 & 315 & $\begin{array}{l}\text { Rhizobiozin-Sekretionsprotein } \\
\text { RspE }\end{array}$ & COG0845: Membran-Fusionsprotein & $\begin{array}{l}\text { Rhodobacter } \\
\text { sphaeroides }\end{array}$ & $\begin{array}{l}\text { ZP_0000515 } \\
9.1\end{array}$ & $3 e-80$ & 57 & $\begin{array}{l}\text { CDD25537, pfam00529, Sektretionsprotein der } \\
\text { HlyD-Familie. (3e-05) }\end{array}$ & SM-BT \\
\hline 402 & 577 & $\begin{array}{l}\text { Rhizobiozin-Sekretionsprotein } \\
\text { RspD (ABC-Transporter) }\end{array}$ & \begin{tabular}{lrr} 
ABC-Typ & \multicolumn{2}{c}{ Protease/Lipase- } \\
Transportsystem; ATPase- & und \\
Permease-Komponenten & \\
\end{tabular} & $\begin{array}{l}\text { Rhodobacter } \\
\text { sphaeroides }\end{array}$ & $\begin{array}{l}\text { ZP_0000515 } \\
8.1\end{array}$ & 0.0 & 66 & $\begin{array}{l}\text { CDD13766, COG4618, ArpD, ABC-Typ } \\
\text { Protease/Lipase-Transportsystem; ATPase- und } \\
\text { Permease-Komponenten (5e-142) }\end{array}$ & SM-BT \\
\hline 403 & 259 & $\begin{array}{l}\text { VacJ, Oberflächen-Lipoprotein } \\
\text { (COG2853) }\end{array}$ & COG2853: Oberflächen-Lipoprotein & $\begin{array}{l}\text { Rhodobacter } \\
\text { sphaeroides }\end{array}$ & $\begin{array}{l}\text { ZP_0000515 } \\
7.1\end{array}$ & $1 \mathrm{e}-73$ & 58 & $\begin{array}{l}\text { CDD12206, COG2853, VacJ, Oberflächen- } \\
\text { Lipoprotein (3e-48) }\end{array}$ & ZH-B \\
\hline 404 & 202 & $\begin{array}{l}\text { Potentielles } \quad \text { Toluen-Toleranz } \\
\text { Protein Ttg2 (pfam05494) }\end{array}$ & $\begin{array}{l}\text { COG2854: ABC-Typ Transportsystem } \\
\text { beteiligt an Resistenzen zu organischen } \\
\text { Lösungsmitteln }\end{array}$ & $\begin{array}{l}\text { Rhodobacter } \\
\text { sphaeroides }\end{array}$ & $\begin{array}{l}\text { ZP_0000515 } \\
6.1\end{array}$ & $9 \mathrm{e}-52$ & 55 & $\begin{array}{l}\text { CDD23719, pfam05494, Toluen-Toleranz Protein } \\
\text { Ttg2 (4e-13) }\end{array}$ & ZH-B \\
\hline 405 & 731 & $\begin{array}{l}\text { Membran Carboxypeptidase } \\
\text { MrcB (Penicillin-Bindeprotein) } \\
\text { (COG0744) }\end{array}$ & $\begin{array}{l}\text { COG0744: Membran Carboxypeptidase } \\
\text { MrcB (Penicillin-Bindeprotein) }\end{array}$ & $\begin{array}{l}\text { Rhodobacter } \\
\text { sphaeroides }\end{array}$ & $\begin{array}{l}\text { ZP_0000600 } \\
9.1\end{array}$ & 0.0 & 65 & $\begin{array}{l}\text { CDD10612, COG0744, MrcB, Membran } \\
\text { Carboxypeptidadse (Penicillin-Bindeprotein) (8e- } \\
\text { 125) }\end{array}$ & ZH-B \\
\hline 406 & 112 & $\begin{array}{l}\text { Stickstoff-Regulationsprotein P- } \\
\text { II, GlnK (COG0347) }\end{array}$ & $\begin{array}{l}\text { COG0347: Stickstoff-Regulationsprotein } \\
\text { P-II }\end{array}$ & $\begin{array}{l}\text { Rhodobacter } \\
\text { sphaeroides }\end{array}$ & $\begin{array}{l}\text { ZP_0000600 } \\
8.1\end{array}$ & $1 \mathrm{e}-46$ & 87 & $\begin{array}{l}\text { CDD10221, COG0347, GlnK, } \\
\text { Regulationsprotein P-II (8e-35) }\end{array}$ & AS-M \\
\hline 407 & 494 & Ammonium-Transporter, AmtB & Ammonium-Transporter AmtB & $\begin{array}{l}\text { Azorhizobium } \\
\text { caulinodans }\end{array}$ & CAA12410.1 & e-122 & 57 & $\begin{array}{l}\text { CDD9880, COG0004, AmtB, Ammonium- } \\
\text { Permease }(3 \mathrm{e}-96)\end{array}$ & I-TM \\
\hline 408 & 393 & $\begin{array}{l}\text { Amino-Transferase } \\
\text { aromatische Aminosäuren } \\
\text { (EC 2.6.1.57) }\end{array}$ & $\begin{array}{l}\text { COG1448: Aspartat/Tyrosin/aromatische } \\
\text { Aminosäuren Transferase }\end{array}$ & $\begin{array}{l}\text { Rhodobacter } \\
\text { sphaeroides }\end{array}$ & $\begin{array}{l}\text { ZP_0000600 } \\
6.1\end{array}$ & e-149 & 65 & $\begin{array}{lr}\text { CDD11162, COG1448, } & \text { TyrB, } \\
\text { Aspartat/Tyrosin/aromatische } \\
\text { Transferase (5e-128) }\end{array}$ & AS-M \\
\hline 409 & 286 & $\begin{array}{l}\text { Rhodanes-verwandte Schwefel- } \\
\text { Transferase SseA, (COG2897) }\end{array}$ & $\begin{array}{l}\text { COG2897: } \quad \text { Rhodanes-verwandte } \\
\text { Schwefel-Transferase }\end{array}$ & $\begin{array}{l}\text { Rhodobacter } \\
\text { sphaeroides }\end{array}$ & $\begin{array}{l}\text { ZP_0000600 } \\
5.1\end{array}$ & e-128 & 82 & $\begin{array}{l}\text { CDD12247, COG2897, SseA, Rhodanes- } \\
\text { verwandte Schwefel-Transferase }(4 \mathrm{e}-78)\end{array}$ & I-TM \\
\hline
\end{tabular}

DD25537, pfam00529, Sektretionsprotein der

Protease/Lipase-Transportsystem; ATPase- und onenten (5e-142)

ipoprotein (3e-48)

CD 23719 , pfam05494, Toluen-Toleranz Protein Carboxypeptidadse (Penicillin-Bindeprotein) (8eRegulationsprotein P-II (8e-35) Permease $(3 \mathrm{e}-96)$ 


\begin{tabular}{|c|c|c|c|c|c|c|c|c|c|}
\hline $\begin{array}{l}\text { ORF- } \\
\text { Name }\end{array}$ & Größe & Annotation & Ähnlichstes Protein bei NCBI & Organismus & $\begin{array}{l}\text { Accession- } \\
\text { Nummer }\end{array}$ & $\begin{array}{l}\text { e- } \\
\text { Value }\end{array}$ & $\begin{array}{l}\text { I in } \\
\%\end{array}$ & Konservierte Domänen bei NCBI & $\begin{array}{l}\text { Funk- } \\
\text { tion }\end{array}$ \\
\hline 410 & 94 & Hypothetisches Protein & \multicolumn{6}{|l|}{ Keine signifikante Übereinstimmung } & HP \\
\hline 411 & 160 & $\begin{array}{l}\text { tm-RNA-Bindeprotein, SmpB, } \\
\text { (COG0691) }\end{array}$ & COG0691: tm-RNA-Bindeprotein & $\begin{array}{l}\text { Rhodobacter } \\
\text { sphaeroides }\end{array}$ & $\begin{array}{l}\text { ZP_0000600 } \\
4.1\end{array}$ & $1 \mathrm{e}-57$ & 73 & $\begin{array}{l}\text { CDD10560, COG0691, } \\
\text { Bindeprotein }(2 \mathrm{e}-40)\end{array}$ & PPM \\
\hline 412 & 98 & Hypothetisches Protein & \multicolumn{6}{|l|}{ Keine signifikante Übereinstimmung } & HP \\
\hline 413 & 291 & $\begin{array}{l}\text { Dihydrodipicolinat-Synthase/N- } \\
\text { Acetylneuraminat-Lyase } \quad \text { (EC } \\
4.2 .1 .51 \text { ) }\end{array}$ & $\begin{array}{l}\text { COG0329: } \quad \text { Dihydrodipicolinat- } \\
\text { Synthase/N-Acetylneuraminat-Lyase }\end{array}$ & $\begin{array}{l}\text { Rhodobacter } \\
\text { sphaeroides }\end{array}$ & $\begin{array}{l}\text { ZP_0000600 } \\
3.1\end{array}$ & e-142 & 86 & $\begin{array}{lrl}\text { CDD10203, COG0329, } & \text { DapA, } \\
\text { Dihydrodipicolinat-Synthase/N- } & \\
\text { Acetylneuraminat-Lyase (2e-87) } & \end{array}$ & $\begin{array}{l}\text { AS-M } \\
\text { und } \\
\text { ZH-B }\end{array}$ \\
\hline 414 & 651 & $\begin{array}{l}\text { Potentielle lösliche lytische } \\
\text { Murein-Transglykosylase }\end{array}$ & $\begin{array}{l}\text { COG0741: Lösliche lytische Murein- } \\
\text { Transglykosylase und verwandte } \\
\text { regulatorische Proteine }\end{array}$ & $\begin{array}{l}\text { Rhodobacter } \\
\text { sphaeroides }\end{array}$ & $\begin{array}{l}\text { ZP_0000600 } \\
2.1\end{array}$ & e-175 & 58 & $\begin{array}{l}\text { CDD10609, COG0741, MltE, Lösliche lytische } \\
\text { Murein-Transglykosylase und verwandte } \\
\text { regulatorische Proteine (einige } \\
\text { LysM/Invasin-Domänen) } \\
\text { (1e-20) }\end{array}$ & ZH-B \\
\hline 415 & 294 & $\begin{array}{l}\text { Konserviertes membran- } \\
\text { durchspannendes Protein }\end{array}$ & $\begin{array}{l}\text { COG0697: } \quad \text { Permeasen } \\
\text { "drug"/Metabolit-Transporter (DMT) } \\
\text { Superfamilie }\end{array}$ & $\begin{array}{l}\text { Rhodobacter } \\
\text { sphaeroides }\end{array}$ & $\begin{array}{l}\text { ZP_0000599 } \\
9.1\end{array}$ & $5 e-53$ & 43 & & $\mathrm{KP}$ \\
\hline 416 & 226 & Konserviertes Protein & $\begin{array}{l}\text { COG4121: } \\
\text { konserviertes Protein }\end{array}$ & $\begin{array}{l}\text { Rhodobacter } \\
\text { sphaeroides }\end{array}$ & $\begin{array}{l}\text { ZP_0000600 } \\
0.1\end{array}$ & $7 e-65$ & 61 & $\begin{array}{l}\text { CDD23656, pfam05430, DUF752, Protein mit } \\
\text { unbekannter Funktion (DUF752).( (3e-48). }\end{array}$ & KP \\
\hline 417 & 348 & 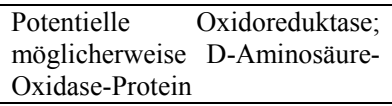 & $\begin{array}{l}\text { COG0665: } \quad \text { Glycin-D-Aminosäure- } \\
\text { Oxidase (deaminierendes Protein) }\end{array}$ & $\begin{array}{l}\text { Rhodobacter } \\
\text { sphaeroides }\end{array}$ & $\begin{array}{l}\text { ZP_0000600 } \\
1.1\end{array}$ & $3 e-83$ & 49 & $\begin{array}{l}\text { CDD10534, COG0665, DadA, Glycin-D- } \\
\text { Aminosäure-Oxidase (deaminierendes } \\
\text { (2e-06) }\end{array}$ & AS-M \\
\hline 418 & 100 & Hypothetisches Protein & Keine signifikante Übereinstimmung & & & & & & HP \\
\hline 419 & 163 & $\begin{array}{l}\text { Potentielle Acetyltransferase } \\
(\text { EC 2.3.1) }\end{array}$ & $\begin{array}{l}\text { COG0454: Histone-Acetyl-Transferase } \\
\text { HPA2 und verwandte Acetyltransferasen }\end{array}$ & $\begin{array}{l}\text { Rhodobacter } \\
\text { sphaeroides }\end{array}$ & $\begin{array}{l}\text { ZP_0000599 } \\
8.1\end{array}$ & $2 \mathrm{e}-46$ & 63 & $\begin{array}{l}\text { CDD25558, pfam00583, } \\
\text { (GNAT)-Facetylltransferase } \\
(4 \mathrm{e}-09)\end{array}$ & DRR \\
\hline 420 & 1151 & $\begin{array}{l}\text { Chromosomen-Teilungs-Protein } \\
\text { smc }\end{array}$ & Chromosomen-Teilungs-Protein smc & $\begin{array}{l}\text { Rhodobacter } \\
\text { sphaeroides }\end{array}$ & CAD66603.1 & $1 \mathrm{e}-97$ & 89 & $\begin{array}{l}\text { CDD10914, COG1196, Smc, Chromosomen- } \\
\text { Teilungs-ATPasen (1e-57) }\end{array}$ & ZT \\
\hline 421 & 389 & $\begin{array}{l}\text { membrangebundene lytische } \\
\text { Murein-Transglykosylase B }\end{array}$ & Lytische Murein-Transglykosylase & $\begin{array}{l}\text { Agrobacterium } \\
\text { tumefaciens } \\
\text { Stamm C58 } \\
\text { (U. Washington) }\end{array}$ & $\begin{array}{l}\text { NP_532796. } \\
1\end{array}$ & e-117 & 55 & $\begin{array}{l}\text { CDD12298, COG2951, MltB, membran- } \\
\text { gebundene lytische Murein-Transglykosylase B } \\
\text { (6e-75) }\end{array}$ & ZH-B \\
\hline 422 & 306 & $\begin{array}{l}\text { Cobalamin-Biosynthese Protein } \\
\text { CobD/CbiB }\end{array}$ & Cobalamin-Biosynthese Protein CobD & Pseudomonas sp. & $\begin{array}{l}\text { P21634|COB } \\
\text { D PSEDE }\end{array}$ & $2 \mathrm{e}-56$ & 45 & $\begin{array}{l}\text { CDD10986, COG1270, CbiB, Cobalamin } \\
\text { biosynthesis protein CobD/CbiB (1e-57) }\end{array}$ & CE-M \\
\hline 423 & 321 & CobC-Protein & Cobalamin-Biosynthese Protein & $\begin{array}{l}\text { Bradyrhizobium } \\
\text { japonicum }\end{array}$ & $\begin{array}{l}\text { NP_769898. } \\
1\end{array}$ & $2 \mathrm{e}-65$ & 46 & 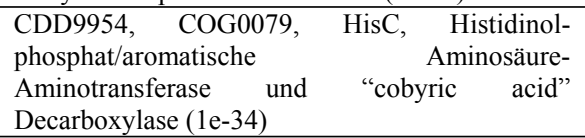 & AS-M \\
\hline 424 & 126 & Hypothetisches Protein & Keine signifikante Übereinstimmung & & & & & & HP \\
\hline 425 & 116 & Konserviertes Protein & Hypothetisches Protein & $\begin{array}{l}\text { Rhodobacter } \\
\text { sphaeroides }\end{array}$ & $\begin{array}{l}\text { ZP_0000599 } \\
1.1\end{array}$ & $2 \mathrm{e}-32$ & 52 & & KP \\
\hline 426 & 156 & $\begin{array}{l}\text { Konserviertes } \\
\text { uncharakterisiertes } \\
\text { (COG3034) }\end{array}$ & $\begin{array}{l}\text { COG3034: Uncharakterisiertes, } \\
\text { Bakterien konserviertes Protein }\end{array}$ & $\begin{array}{l}\text { Novosphingobium } \\
\text { aromaticivorans }\end{array}$ & $\begin{array}{l}\text { ZP_0009358 } \\
8.1\end{array}$ & $3 e-28$ & 51 & $\begin{array}{l}\text { CDD12374, } \begin{array}{c}\text { COG3034, } \\
\text { Uncharacterized protein conserved in bacteria } \\
\text { (9e-19) }\end{array}\end{array}$ & $\mathrm{KP}$ \\
\hline
\end{tabular}




\begin{tabular}{|c|c|c|c|c|c|c|c|c|c|}
\hline $\begin{array}{l}\text { ORF- } \\
\text { Name }\end{array}$ & Größe & Annotation & Ähnlichstes Protein bei NCBI & Organismus & $\begin{array}{l}\text { Accession- } \\
\text { Nummer }\end{array}$ & $\begin{array}{l}\text { e- } \\
\text { Value }\end{array}$ & $\begin{array}{l}\text { I in } \\
\%\end{array}$ & Konservierte Domänen bei NCBI & $\begin{array}{l}\text { Funk- } \\
\text { tion }\end{array}$ \\
\hline 427 & 390 & $\begin{array}{l}\text { MalY, Bifunktionales PLP- } \\
\text { Abhängiges Enzym mit } \beta \text { - } \\
\text { Cystathionase und Maltose- } \\
\text { Regulon-Repressor-Aktivität }\end{array}$ & $\begin{array}{l}\text { COG1168: MalY, Bifunktionales PLP- } \\
\text { Abhängiges Enzym mit } \beta \text {-Cystathionase } \\
\text { und } \\
\text { Aktivität }\end{array}$ & $\begin{array}{l}\text { Rhodobacter } \\
\text { sphaeroides }\end{array}$ & $\begin{array}{l}\text { ZP_0000599 } \\
2.1\end{array}$ & e-161 & 66 & $\begin{array}{l}\text { CDD10887, COG1168, MalY, Bifunktionales } \\
\text { PLP-Abhängiges Enzym mit } \beta \text {-Cystathionase und } \\
\text { Maltose-Regulon-Repressor-Aktivität (1e-111) }\end{array}$ & AS-M \\
\hline 428 & 172 & $\begin{array}{l}\text { Def, N-Formyl-methionyl- } \\
\text { tRNA-Deformylase (COG0242) }\end{array}$ & $\begin{array}{l}\text { COG0242: N-Formyl-methionyl-tRNA- } \\
\text { Deformylase }\end{array}$ & $\begin{array}{l}\text { Rhodobacter } \\
\text { sphaeroides }\end{array}$ & $\begin{array}{l}\text { ZP_0000599 } \\
3.1\end{array}$ & $1 \mathrm{e}-71$ & 75 & $\begin{array}{l}\text { CDD10117, COG0242, } \\
\text { methionyl-tRNA-Deformylase }(8 \mathrm{e}-58)\end{array}$ & TLR \\
\hline 429 & 167 & $\begin{array}{l}\text { Def, N-Formyl-methionyl- } \\
\text { tRNA-Deformylase (COG0242) }\end{array}$ & $\begin{array}{l}\text { COG0242: N-Formyl-methionyl-tRNA- } \\
\text { Deformylase }\end{array}$ & $\begin{array}{l}\text { Rhodobacter } \\
\text { sphaeroides }\end{array}$ & $\begin{array}{l}\text { ZP_0000599 } \\
5.1\end{array}$ & $8 \mathrm{e}-64$ & 69 & $\begin{array}{l}\text { CDD10117, COG0242, } \\
\text { methionyl-tRNA-Deformylase }(7 \mathrm{e}-37)\end{array}$ & $\begin{array}{l}\text { TLR } \\
\end{array}$ \\
\hline 430 & 296 & $\begin{array}{l}\text { Methionyl-t-RNA- } \\
\text { Formyltransferase (EC 2.1.2.9) }\end{array}$ & $\begin{array}{ll}\text { COG0223: } & \text { Methionyl-t-RNA- } \\
\text { Formyltransferase } & \\
\end{array}$ & $\begin{array}{l}\text { Rhodobacter } \\
\text { sphaeroides }\end{array}$ & $\begin{array}{l}\text { ZP_0000599 } \\
6.1\end{array}$ & e-110 & 71 & $\begin{array}{l}\text { CDD10098, COG0223, Fmt, Methionyl-t-RNA- } \\
\text { Formyltransferase (2e-99) }\end{array}$ & TLR \\
\hline 431 & 77 & Hypothetisches Protein & Keine signifikante Übereinstimmung & & & & & & HP \\
\hline 432 & 146 & Hypothetisches Protein & Keine signifikante Übereinstimmung & & & & & & HP \\
\hline 433 & 154 & Ribonuklease HI (EC 3.1.26.4) & COG0328: Ribonuklease HI & $\begin{array}{l}\text { Rhodobacter } \\
\text { sphaeroides }\end{array}$ & $\begin{array}{l}\text { ZP_0000598 } \\
8.1\end{array}$ & $2 \mathrm{e}-65$ & 83 & $\begin{array}{l}\text { CDD10202, COG0328, RnhA, Ribonuklease HI } \\
(1 \mathrm{e}-43)\end{array}$ & DRR \\
\hline 434 & 316 & $\begin{array}{l}\text { LytB, } \\
\text { Protein }\end{array}$ & COG0761: Penicillin-Toleranz-Protein & $\begin{array}{l}\text { Rhodobacter } \\
\text { sphaeroides }\end{array}$ & $\begin{array}{l}\text { ZP_0000564 } \\
8.1\end{array}$ & e-129 & 81 & $\begin{array}{l}\text { CDD10629, COG0761, LytB, } \\
\text { Toleranz-Protein }(6 e-108)\end{array}$ & ZH-B \\
\hline 435 & 190 & Konserviertes Protein & $\begin{array}{l}\text { COG1432: } \\
\text { konserviertes Protein }\end{array}$ & $\begin{array}{l}\text { Rhodobacter } \\
\text { sphaeroides }\end{array}$ & $\begin{array}{l}\text { ZP_0000564 } \\
9.1\end{array}$ & $1 \mathrm{e}-88$ & 88 & $\begin{array}{l}\text { CDD25850, pfam01936, DUF88, Protein mit } \\
\text { unbekannter Funktion. (5e-43) }\end{array}$ & KP \\
\hline 436 & 190 & $\begin{array}{l}\text { FolK, } \quad 7,8 \text {-Dihydro-6- } \\
\text { hydroxymethylpterin- } \\
\text { Pyrophosphokinase }\end{array}$ & $\begin{array}{l}\text { 7,8-Dihydro-6-hydroxymethylpterin- } \\
\text { Pyrophosphokinase }\end{array}$ & $\begin{array}{l}\text { Synechocystis } \\
\text { sp. PCC } 6803\end{array}$ & $\begin{array}{l}\text { NP_440071. } \\
1\end{array}$ & $9 \mathrm{e}-16$ & 32 & $\begin{array}{l}\text { CDD10669, COG0801, FolK, 7,8-Dihydro-6- } \\
\text { hydroxymethylpterin-Pyrophosphokinase (1e-27) }\end{array}$ & CE-M \\
\hline 437 & 117 & $\begin{array}{l}\text { Hypothetische DNA-gerichtete } \\
\text { RNA-Polymerase omega- } \\
\text { Untereinheit (EC 2.7.7.6) }\end{array}$ & $\begin{array}{lcc}\text { COG1758: } & \text { DNA-gerichtete } & \text { RNA- } \\
\text { Polymerase omega-Untereinheit } & \end{array}$ & $\begin{array}{l}\text { Rhodobacter } \\
\text { sphaeroides }\end{array}$ & $\begin{array}{l}\text { ZP_0000565 } \\
0.1\end{array}$ & $2 \mathrm{e}-38$ & 88 & $\begin{array}{l}\text { CDD11469, COG1758, RpoZ, DNA-gerichtete } \\
\text { RNA-Polymerase omega-Untereinheit (1e-10) }\end{array}$ & TS \\
\hline 438 & 411 & $\begin{array}{l}\text { Protein der Familie der } \\
\text { Guanosinphosphat- } \\
\text { Pyrophosphohydrolasen/ } \\
\text { Synthetasen } \\
\end{array}$ & $\begin{array}{l}\text { COG0317: Protein der Familie der } \\
\text { Guanosinphosphat- } \\
\text { Pyrophosphohydrolasen/Synthetasen }\end{array}$ & $\begin{array}{l}\text { Rhodobacter } \\
\text { sphaeroides }\end{array}$ & $\begin{array}{l}\text { ZP_0000565 } \\
1.1\end{array}$ & 0.0 & 88 & $\begin{array}{l}\text { CDD10191, COG0317, SpoT, Guanosin- } \\
\text { polyphosphat- } \\
\text { Pyrophosphohydrolasen/Synthetasen (1e-142) }\end{array}$ & ST \\
\hline
\end{tabular}

\section{E) Cosmid Slc_1p}

\begin{tabular}{|c|c|c|c|c|c|c|c|c|c|}
\hline 501 & 398 & $\begin{array}{l}\text { COG0205: } \\
\text { fruktokinase (EC 2.7.1.11) }\end{array}$ & COG0205: 6-Phosphofruktokinase & $\begin{array}{l}\text { Geobacter } \\
\text { metallireducens }\end{array}$ & $\begin{array}{l}\text { ZP_0007947 } \\
6.1\end{array}$ & $7 e-82$ & 45 & $\begin{array}{l}\text { CDD10080, COG0205, } \\
\text { Phosphofruktokinase (2e-76) }\end{array} \quad$ PfkA, $\quad$ 6- & KH-M \\
\hline 502 & 151 & Hypothetisches Protein & Keine signifikante Übereinstimmung & & & & & & HP \\
\hline 503 & 433 & $\begin{array}{lr}\text { Uncharakterisiertes } & \text { Protein mit } \\
\text { unbekannter } & \text { Funktion } \\
\text { (COG4198) } & \end{array}$ & $\begin{array}{l}\text { Konserviertes hypothetisches Protein, } \\
\text { potentielle Phosphatase }\end{array}$ & Pirellula sp.1 & $\begin{array}{l}\text { NP_865025. } \\
1\end{array}$ & $\mathrm{e}-124$ & 50 & & KP \\
\hline 504 & 209 & $\begin{array}{lr}\text { Konserviertes } & \text { Protein mit } \\
\text { unbekannter } & \text { Funktion } \\
\text { (DUF820) } & \end{array}$ & Keine signifikante Übereinstimmung & & & & & $\begin{array}{l}\text { CDD23909, pfam05685, DUF820, Protein mit } \\
\text { unbekannter Funktion (DUF820). (9e-20) }\end{array}$ & KP \\
\hline
\end{tabular}




\begin{tabular}{|c|c|c|c|c|c|c|c|c|c|}
\hline $\begin{array}{l}\text { ORF- } \\
\text { Name }\end{array}$ & Größe & Annotation & Ähnlichstes Protein bei NCBI & Organismus & $\begin{array}{l}\text { Accession- } \\
\text { Nummer }\end{array}$ & $\begin{array}{l}\text { e- } \\
\text { Value } \\
\end{array}$ & $\begin{array}{l}\text { I in } \\
\%\end{array}$ & Konservierte Domänen bei NCBI & $\begin{array}{l}\text { Funk- } \\
\text { tion }\end{array}$ \\
\hline 505 & 437 & $\begin{array}{l}\text { Adenosylhomocysteinase } 1 \text { (EC } \\
\text { 3.3.1.1) }\end{array}$ & S-Adenosylhomocystein-Hydrolase & Danio rerio & $\begin{array}{l}\text { NP_954688. } \\
1\end{array}$ & 0.0 & 47 & $\begin{array}{lccc}\text { CDD10370, } & \text { COG0499, } & \text { SAM1, } & \text { S- } \\
\text { Adenosylhomocystein-Hydrolase }(0.0) & \end{array}$ & CE-M \\
\hline 506 & 225 & $\begin{array}{l}\mathrm{N}-(5 \text { 'phosphoribosyl)anthranilat- } \\
\text { Isomerase (EC 5.3.1.24) }\end{array}$ & $\begin{array}{l}\mathrm{N}-(5 \text { 'phosphoribosyl)anthranilat- } \\
\text { Isomerase (EC 5.3.1.24) }\end{array}$ & \begin{tabular}{lr}
\multicolumn{2}{l}{ Pseudomonas } \\
syringae & $p v$. \\
tomato & Stamm \\
DC3000 & \\
\end{tabular} & $\begin{array}{l}\text { NP_793590. } \\
1\end{array}$ & $3 e-24$ & 36 & $\begin{array}{l}\text { CDD10010, COG0135, } \quad \text { TrpF, } \\
\text { (5'phosphoribosyl)anthranilat-Isomerase (1e-38) }\end{array}$ & AS-M \\
\hline 507 & 501 & $\begin{array}{ll}\text { Hypothetisches } & \text { membran- } \\
\text { assoziiertes Protein } & \end{array}$ & Keine signifikante Übereinstimmung & & & & & & HP \\
\hline 508 & 484 & $\begin{array}{l}\text { Potentielles Protein A eines } \\
\text { generellen Sekretionsweges }\end{array}$ & $\begin{array}{l}\text { Potentielles Protein A eines generellen } \\
\text { Sekretionsweges }\end{array}$ & Pirellula sp.1 & $\begin{array}{l}\text { NP_864633. } \\
1\end{array}$ & $3 e-28$ & 32 & $\begin{array}{l}\text { CDD12603, COG3267, ExeA, } \\
\begin{array}{l}\text { Sekretionsweg, Type II } \\
\text { (vorausgesagte ATPase) }(9 \mathrm{e}-23)\end{array}\end{array}$ & ITS \\
\hline 509 & 414 & Potentielles ATP-Bindeprotein & Kettenlängen-bestimmendes Protein & $\begin{array}{l}\text { Nitrosomonas } \\
\text { europaea ATCC } \\
19718\end{array}$ & $\begin{array}{l}\text { NP_842280. } \\
1\end{array}$ & $1 \mathrm{e}-10$ & 25 & $\begin{array}{l}\text { CDD10360, COG0489, Mrp, ATPasen, die in die } \\
\text { Chromosomenverteilung involviert sind (4e-12) }\end{array}$ & ZT \\
\hline 510 & 442 & $\begin{array}{l}\text { Hypothetisches membran- } \\
\text { durchspannendes Protein }\end{array}$ & Kettenlängen-bestimmendes Protein & $\begin{array}{l}\text { Nitrosomonas } \\
\text { europaea ATCC } \\
19718\end{array}$ & $\begin{array}{l}\text { NP_842280. } \\
1\end{array}$ & $1 \mathrm{e}-10$ & 25 & & HP \\
\hline 511 & 270 & $\begin{array}{l}\text { Dolicholphosphat- } \\
\text { Mannosyltransferase } \\
\text { (KOG2978) }\end{array}$ & $\begin{array}{l}\text { Glykosyl-Transferase, } \\
\text { Gruppe 2-Familie }\end{array}$ & $\begin{array}{l}\text { Geobacter } \\
\text { sulfurreducens } \\
\text { PCA }\end{array}$ & $\begin{array}{l}\text { NP_952839. } \\
1\end{array}$ & $1 \mathrm{e}-48$ & 39 & $\begin{array}{l}\text { CDD20764, KOG2978, KOG2978, KOG2978, } \\
\text { Dolicholphosphat-Mannosyltransferase (1e-42) }\end{array}$ & ZH-B \\
\hline 512 & 224 & Potentielle Transposase & Transposase & $\begin{array}{lll}\begin{array}{l}\text { Nostoc } \\
7120\end{array} & \text { sp. PCC } \\
\end{array}$ & $\begin{array}{l}\text { NP_478210. } \\
1\end{array}$ & $8 \mathrm{e}-58$ & 56 & & RKT \\
\hline 513 & 193 & Hypothetische Transposase & Transposase & $\begin{array}{lll}\text { Nostoc } & s p . \quad \text { PCC } \\
7120 & & \\
\end{array}$ & $\begin{array}{l}\text { NP_478211. } \\
1\end{array}$ & $5 e-21$ & 34 & & RKT \\
\hline 514 & 243 & 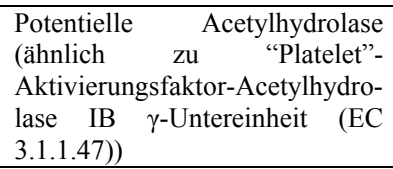 & $\begin{array}{ll}\text { COG1472: } & \beta \text {-Glukosidase-verwandte } \\
\text { Glukosidasen } & \end{array}$ & $\begin{array}{l}\text { Microbulbifer } \\
\text { degradans 2-40 }\end{array}$ & $\begin{array}{l}\text { ZP_0006486 } \\
0.1\end{array}$ & $4 e-56$ & 48 & $\begin{array}{l}\text { CDD19177, KOG1388, KOG1388, KOG1388, } \\
\text { Attractin und "Platelet"-Aktivierungsfaktor- } \\
\text { Acetylhydrolase (6e-24) }\end{array}$ & KH-M \\
\hline 515 & 199 & $\begin{array}{l}\text { Uracil-DNA-Glykosylase } \\
\text { (COG1573) }\end{array}$ & Konserviertes hypothetisches Protein & $\begin{array}{l}\text { Streptomyces } \\
\text { coelicolor A3(2) }\end{array}$ & $\begin{array}{l}\text { NP_626251. } \\
1\end{array}$ & $2 \mathrm{e}-50$ & 50 & & DRR \\
\hline 516 & 568 & $\begin{array}{l}\text { Konserviertes } \\
\text { assoziiertes Protein, }\end{array}$ & Hypothetisches transmembranes Protein & Pirellula sp. 1 & $\begin{array}{l}\text { NP_864010. } \\
1\end{array}$ & $3 e-57$ & 40 & & KP \\
\hline 517 & 978 & $\begin{array}{l}\text { Hypothetisches membran- } \\
\text { assoziiertes Protein }\end{array}$ & \multicolumn{6}{|l|}{ Keine signifikante Übereinstimmung } & HP \\
\hline 518 & 334 & $\begin{array}{l}\text { Hypothetisches } \\
\text { assoziiertes Protein }\end{array}$ & \multicolumn{6}{|l|}{ Keine signifikante Übereinstimmung } & $\mathrm{HP}$ \\
\hline 519 & 265 & Hypothetisches Protein & \multirow{2}{*}{\multicolumn{6}{|c|}{$\begin{array}{l}\text { Keine signifikante Übereinstimmung } \\
\text { Keine signifikante Übereinstimmung }\end{array}$}} & HP \\
\hline 520 & 153 & $\begin{array}{ll}\text { Hypothetisches } & \text { membran- } \\
\text { assoziiertes Protein } & \end{array}$ & & & & & & & HP \\
\hline 521 & 154 & $\begin{array}{l}\text { Hypothetisches Biopolymer- } \\
\text { Transport-Protein exbD }\end{array}$ & \multicolumn{3}{|l|}{ Keine signifikante Übereinstimmung } & & & $\begin{array}{l}\text { CDD10714, COG0848, ExbD, Biopolymer- } \\
\text { Transport-Protein (1e-06) }\end{array}$ & ITS \\
\hline
\end{tabular}




\begin{tabular}{|c|c|c|c|c|c|c|c|c|c|}
\hline $\begin{array}{l}\text { ORF- } \\
\text { Name }\end{array}$ & Größe & Annotation & Ähnlichstes Protein bei NCBI & Organismus & $\begin{array}{l}\text { Accession- } \\
\text { Nummer }\end{array}$ & $\begin{array}{l}\text { e- } \\
\text { Value } \\
\end{array}$ & $\begin{array}{l}\text { I in } \\
\%\end{array}$ & Konservierte Domänen bei NCBI & $\begin{array}{l}\text { Funk- } \\
\text { tion }\end{array}$ \\
\hline 522 & 287 & $\begin{array}{l}\text { TolQ, } \quad \text { Biopolymer-Transport- } \\
\text { Protein (COG0811) }\end{array}$ & Potentielles TolQ-Protein & Pirellula sp. 1 & $\begin{array}{l}\text { NP_865808. } \\
1\end{array}$ & $4 \mathrm{e}-25$ & 34 & $\begin{array}{l}\text { CDD10678, COG0811, } \\
\text { Transport-Protein (4e-18) }\end{array}$ & ITS \\
\hline 523 & 209 & $\begin{array}{l}\text { TolQ, Biopolymer } \\
\text { Protein (COG0811) }\end{array}$ & Potentielles TolQ-Protein & Pirellula sp. 1 & $\begin{array}{l}\text { NP_869566. } \\
1\end{array}$ & $1 \mathrm{e}-50$ & 45 & $\begin{array}{l}\text { CDD10678, COG0811, } \\
\text { Transport-Protein (2e-15) }\end{array}$ & ITS \\
\hline 524 & 162 & $\begin{array}{ll}\begin{array}{l}\text { Hypothetisches } \\
\text { assoziiertes Protein }\end{array} & \text { membran- } \\
\end{array}$ & \multicolumn{6}{|l|}{ Keine signifikante Übereinstimmung } & HP \\
\hline 525 & 206 & $\begin{array}{l}\text { Hypothetisches membran- } \\
\text { assoziiertes Protein }\end{array}$ & \multicolumn{6}{|l|}{ Keine signifikante Übereinstimmung } & HP \\
\hline 526 & 365 & $\begin{array}{l}\text { Hypothetisches membran- } \\
\text { assoziiertes Protein }\end{array}$ & \multicolumn{6}{|l|}{ Keine signifikante Übereinstimmung } & HP \\
\hline 527 & 215 & $\begin{array}{l}\text { Hypothetisches membran- } \\
\text { assoziiertes Protein }\end{array}$ & \multicolumn{6}{|l|}{ Keine signifikante Übereinstimmung } & HP \\
\hline 528 & 235 & $\begin{array}{l}\text { Transkriptionsregulator } \mathrm{KdpE} \\
\text { des KDP-Operons }\end{array}$ & $\begin{array}{l}\text { Transkriptionsregulator KdpE des KDP- } \\
\text { Operons (CheY-ähnliche "receiver"- } \\
\text { Domäne und HTH-Type DNA- } \\
\text { Bindedomäne) }\end{array}$ & $\begin{array}{l}\text { Clostridium } \\
\text { acetobutylicum }\end{array}$ & $\begin{array}{l}\text { NP_350258. } \\
1\end{array}$ & $8 \mathrm{e}-51$ & 45 & $\begin{array}{l}\text { CDD10613, COG0745, OmpR, "Response } \\
\text { regulator" bestehend aus einer CheY-ähnlichen } \\
\text { "Receiver"-Domäne und einer "winged-helix" } \\
\text { DNA-Bindedomäne (2e-39) }\end{array}$ & ST; TS \\
\hline 529 & 432 & $\begin{array}{l}\text { Sensor-Histidin-Kinase } \quad \text { KdpD } \\
\text { eines 2-Komponenten-System } \\
\text { (EC 2.7.3.-) (COG2205) }\end{array}$ & Sensor-Histidin-Kinase & $\begin{array}{l}\text { Vibrio cholerae } \\
\text { O1 biovar eltor } \\
\text { Stamm } 16961\end{array}$ & $\begin{array}{l}\text { NP_232922. } \\
1\end{array}$ & $9 \mathrm{e}-37$ & 41 & $\begin{array}{l}\text { CDD11912, COG2205, KdpD, Osmosensitive } \\
\text { K+-Kanal-Histidin-Kinase (2e-56) }\end{array}$ & ST \\
\hline 530 & 124 & Hypothetisches Protein & & HP \\
\hline 531 & 226 & Hypothetisches Protein & & \multicolumn{5}{|c|}{ Keine signifikante Übereinstimmung } & HP \\
\hline 532 & 369 & $\begin{array}{llr}\text { Insertions } & \text { Element } & \text { IS630 } \\
\text { hypothetisches } & 39 \mathrm{kDa} \text { Protein } \\
\text { (pfam00665, } & \text { rve, } \quad \text { Integrase } \\
\text { Kern-Domäne) } & \\
\end{array}$ & Sensor-Histidin-Kinase & $\begin{array}{l}\text { Vibrio cholerae } \\
\text { O1 biovar eltor } \\
\text { Stamm N16961 }\end{array}$ & $\begin{array}{l}\text { NP_232922. } \\
1\end{array}$ & $9 e-37$ & 41 & & RKT \\
\hline 533 & 622 & Transposase & Hypothetisches Protein & $\begin{array}{l}\text { Magnetococcus } \\
\text { sp. MC-1 }\end{array}$ & $\begin{array}{l}\text { ZP_0004448 } \\
8.1\end{array}$ & $1 \mathrm{e}-41$ & 27 & $\begin{array}{l}\text { CDD14505, COG5421, COG5421, Transposase } \\
(4 \mathrm{e}-20)\end{array}$ & RKT \\
\hline 534 & 950 & $\begin{array}{l}\text { Serin/Threonin-Protein-Kinase } \\
\text { (smart00220) }\end{array}$ & Serin/Threonin-Protein- & Pirellula sp. 1 & $\begin{array}{l}\text { NP_869105. } \\
1 \mid\end{array}$ & $2 \mathrm{e}-69$ & 45 & $\begin{array}{l}\text { CDD25296, smart00220, S_TKc, Serin/ } \\
\text { Threonin-Protein-Kinase, katalytische Domaine; } \\
\text { Phosphotransferasen. Serin- oder Threonin- } \\
\text { spezifische Kinase-Superfamilie (9e-58) }\end{array}$ & ST \\
\hline 535 & 141 & Hypothetisches Protein & \multicolumn{6}{|l|}{ Keine signifikante Übereinstimmung } & HP \\
\hline
\end{tabular}


F) Cosmid Slc_1q

\begin{tabular}{|c|c|c|c|c|c|c|c|c|c|}
\hline $\begin{array}{l}\text { ORF- } \\
\text { Name }\end{array}$ & Größe & Annotation & Ähnlichstes Protein bei NCBI & Organismus & $\begin{array}{l}\text { Accession- } \\
\text { Nummer }\end{array}$ & $\begin{array}{l}\text { e- } \\
\text { Value }\end{array}$ & $\begin{array}{l}I \text { in } \\
\%\end{array}$ & Konservierte Domänen bei NCBI & $\begin{array}{l}\text { Funk- } \\
\text { tion }\end{array}$ \\
\hline 601 & 487 & $\begin{array}{l}\text { Serin/Threonin-Protein- } \\
\text { Pphosphatase mit "EF-hands-1"- } \\
\text { Motiv (EC 3.1.3.16) }\end{array}$ & $\begin{array}{l}\text { Serin/Threonin-Protein-Pphosphatase mit } \\
\text { "EF-hands-1"-Motiv (EC 3.1.3.16) }\end{array}$ & Homo sapiens & $\begin{array}{l}\text { NP_689410. } \\
1\end{array}$ & $2 \mathrm{e}-52$ & 32 & $\begin{array}{l}\text { CDD3753, smart00156, PP2Ac, Protein- } \\
\text { Phosphatase 2A-Homologe, Serin/Threonin- } \\
\text { Protein-Phosphatase, katalytische Domäne (1e- } \\
\text { 52) }\end{array}$ & ST \\
\hline 602 & 298 & $\begin{array}{l}\begin{array}{l}\text { Mitochondrielles } \\
\text { somales Protein S2 }\end{array} \\
\end{array}$ & $\begin{array}{lcc}\begin{array}{l}\text { Mitochondrielles } \\
\text { Protein S2 }\end{array} & 28 \mathrm{~S} & \text { ribo-somales } \\
\end{array}$ & Homo sapiens & $\begin{array}{l}\text { NP_057118. } \\
1\end{array}$ & $2 \mathrm{e}-46$ & 40 & $\begin{array}{l}\text { CDD18625, KOG0832, Mitochondrial/ } \\
\text { chloroplast ribosomal protein S2 (2e-28) }\end{array}$ & TLR \\
\hline 603 & 1028 & Kinesin-ähnliches Boursin & Kinesin-ähnliches Boursin & $\begin{array}{l}\text { Paracentrotus } \\
\text { lividus }\end{array}$ & CAC20783.1 & $1 \mathrm{e}-162$ & 37 & $\begin{array}{l}\text { SDD27860, cd01364, KISc_BimC_Eg5, } \\
\text { BimC/Eg5 Spindel-Pol-Proteine, Kinesin-Motor- } \\
\text { Domäne, (2e-137) }\end{array}$ & ZT \\
\hline 604 & 708 & $\begin{array}{l}\text { ATP-Bindekassete, Sub-Familie } \\
\text { D, Mitglied } 2\end{array}$ & $\begin{array}{l}\text { Vorausgesagte ATP-Bindekassete, Sub- } \\
\text { Familie D, (ALD) Mitglied } 1 \\
\text { Adrenoleukodystrophy-Protein; }\end{array}$ & Gallus gallus & $\begin{array}{l}\text { NP_000024. } \\
2\end{array}$ & $1 \mathrm{e}-163$ & 46 & $\begin{array}{lll}\text { CDD13443, } & \text { COG4178, } & \text { ABC-Typ- } \\
\text { uncharakterisiertes } & \text { Transportsystem, } \\
\text { und ATPase-Komponente (1e-56) } & \text { Permease }\end{array}$ & LM \\
\hline 605 & 104 & $\begin{array}{l}\text { Ras-verwandtes GTP-bindende } \\
\text { B kurze Isoform B; GTP- } \\
\text { Bindeprotein RagB }\end{array}$ & Rraga-Protein & Homo sapiens & CAA62131.1 & $5 e-49$ & 90 & CDD21664, GTP-binding protein (2e-07) & ST \\
\hline 606 & 216 & Konserviertes Protein & Proteinprodukt ohne Namen & $\begin{array}{l}\text { Tetraodon } \\
\text { nigroviridis } \\
\end{array}$ & & $8 \mathrm{e}-48$ & 42 & CDD15976, pfam04670, Gtr1_RagA (2e-26) & HP \\
\hline 607 & 535 & $\begin{array}{l}\text { Quinon-Oxidoreduktase } \\
\text { (NADPH:Quinon-Reduktase) } \\
\text { (Zeta-crystallin) }\end{array}$ & GA11817-PA & $\begin{array}{l}\text { Drosophila } \\
\text { pseudoobscura }\end{array}$ & $\begin{array}{l}\text { QOR_CAVP } \\
\text { O }\end{array}$ & $5 e-45$ & 46 & CDD5398, cd00200, WD40-Domäne (1e-22) & E \\
\hline 608 & 176 & Hypothetisches Protein & Keine signifikante Übereinstimmung & & & & & & $\mathrm{HP}$ \\
\hline
\end{tabular}

\section{G) Cosmid slc_1s}

\begin{tabular}{|c|c|c|c|c|c|c|c|c|c|}
\hline 701 & 76 & $\begin{array}{l}\text { Hypothetischer ABC-Typ Nitrat/ } \\
\text { Sulfit/Bicarbonat-Transport- } \\
\text { system, Permease-Komponente }\end{array}$ & ABC-Transporter Permease & $\begin{array}{l}\text { Bradyrhizobium } \\
\text { japonicum }\end{array}$ & $\begin{array}{l}\text { NP_772730. } \\
1\end{array}$ & $1 \mathrm{e}-07$ & 39 & $\begin{array}{l}\text { CDD10470, COG0600, TauC, ABC-Typ } \\
\text { Nitrat/Sulfit/Bicarbonat-Transportsystem, } \\
\text { Permease-Komponente (1e-10) }\end{array}$ & I-TM \\
\hline 702 & 527 & $\begin{array}{l}\text { Hypothetischer ABC-Typ } \\
\text { Nitrat/Sulfit/Bicarbonat- } \\
\text { Transportsystem, } \\
\text { periplasmatische Komponente }\end{array}$ & Unbekanntes Protein & $\begin{array}{l}\text { Gloeobacter } \\
\text { violaceus }\end{array}$ & $\begin{array}{l}\text { NP_923121. } \\
1\end{array}$ & $2 \mathrm{e}-11$ & 26 & $\begin{array}{l}\text { CDD10584, COG0715, TauA, ABC-Typ } \\
\text { Nitrat/Sulfit/Bicarbonat-Transportsystem, } \\
\text { periplasmatische Komponente (1e-11) }\end{array}$ & I-TM \\
\hline 703 & 253 & Hypothetisches Protein & Keine signifikante Übereinstimmung & & & & & & $\mathrm{HP}$ \\
\hline 704 & 254 & $\begin{array}{ll}\text { Hypothetisches membran- } \\
\text { assoziiertes Protein }\end{array}$ & Keine signifikante Übereinstimmung & & & & & & $\mathrm{HP}$ \\
\hline 705 & 352 & $\begin{array}{l}\text { Konserviertes Protein } \\
\text { (hypothetische } \\
\text { Dihydrodipicolinat-Synthase/N- } \\
\text { Acetylneuraminat-Lyase) }\end{array}$ & Hypothetisches Protein RB7999 & Pirellula sp. 1 & $\begin{array}{l}\text { NP_868135. } \\
1\end{array}$ & e-104 & 59 & $\begin{array}{lrl}\text { CDD10203, COG0329, } & \text { DapA, } \\
\text { Dihydrodipicolinat-Synthase/N- } & \\
\text { Acetylneuraminat-Lyase (4e-08) } & \end{array}$ & $\begin{array}{l}\text { AS-M / } \\
\text { ZH-B }\end{array}$ \\
\hline
\end{tabular}




\begin{tabular}{|c|c|c|c|c|c|c|c|c|c|}
\hline $\begin{array}{l}\text { ORF- } \\
\text { Name }\end{array}$ & Größe & Annotation & Ähnlichstes Protein bei NCBI & Organismus & $\begin{array}{l}\text { Accession- } \\
\text { Nummer }\end{array}$ & $\begin{array}{l}\text { e- } \\
\text { Value }\end{array}$ & $\begin{array}{l}I \text { in } \\
\%\end{array}$ & Konservierte Domänen bei NCBI & $\begin{array}{l}\text { Funk- } \\
\text { tion }\end{array}$ \\
\hline 706 & 328 & Konserviertes Protein & Hypothetisches Protein RB7998 & Pirellula sp. 1 & $\begin{array}{l}\text { NP_868134. } \\
1\end{array}$ & $4 \mathrm{e}-90$ & 50 & $\begin{array}{l}\text { CDD10325, COG0451, WcaG, Nukleosid- } \\
\text { diphosphat-Zucker-Epimerasen (9e-06) }\end{array}$ & $\begin{array}{l}\mathrm{ZH}-\mathrm{B} / \\
\mathrm{KH}-\mathrm{M}\end{array}$ \\
\hline 707 & 221 & Konserviertes Protein & Hypothetisches Protein RB7926 & Pirellula sp. 1 & $\begin{array}{l}\text { NP_868101. } \\
1\end{array}$ & $6 \mathrm{e}-29$ & 38 & & $\mathrm{KP}$ \\
\hline 708 & 282 & $\begin{array}{lr}\text { Hypothetische } & \text { Serin/Threonin- } \\
\text { Protein-Kinase } & \text { (katalytische } \\
\text { Domäne) } & \end{array}$ & Serin/Threonin-Protein-Kinase & $\begin{array}{l}\text { Gloeobacter } \\
\text { violaceus }\end{array}$ & $\begin{array}{l}\text { NP_924042. } \\
1\end{array}$ & $1 \mathrm{e}-07$ & 29 & $\begin{array}{l}\text { CDD25380, pfam00069, Protein-Kinase-Domäne } \\
\text { (8e-10) }\end{array}$ & ST \\
\hline 709 & 973 & $\begin{array}{l}\text { Potentielle } \\
\text { Protein-Kinase } \\
\text { durchit membannender Domäne) }\end{array}$ & $\begin{array}{ll}\text { Potentielle } & \text { Serin/Threonin-Protein- } \\
\text { Kinase } & \end{array}$ & $\begin{array}{l}\text { Myxococcus } \\
\text { xanthus }\end{array}$ & AAF87929.1 & $1 \mathrm{e}-34$ & 42 & $\begin{array}{l}\text { CDD17776, cd00180, S_TKc, } \begin{array}{r}\text { Potentielle } \\
\text { katalytische } \\
\text { Serin/Threonin-Protein-Kinase, } \\
\text { Domäne (3e-44) }\end{array} \\
\end{array}$ & ST \\
\hline 710 & 314 & $\begin{array}{l}\text { Konserviertes } \quad \text { Protein } \\
\text { (potentielle Phospholipase/ Leci- } \\
\text { thinase/Hämolysin; COG3240) }\end{array}$ & Protein mit Ähnlichkeit zu Esterasen & $\begin{array}{l}\text { Gloeobacter } \\
\text { violaceus }\end{array}$ & $\begin{array}{l}\text { NP_923900. } \\
1\end{array}$ & $1 \mathrm{e}-25$ & 35 & $\begin{array}{lcc}\text { CDD12577, } & \text { COG3240, } & \text { COG3240, } \\
\text { Phospholipase/Lecithinase (2e-21) } & \end{array}$ & LM \\
\hline 711 & 715 & $\begin{array}{l}\text { Potentielles AslA (Arylsulfatase } \\
\text { A und verwandte Enzyme) }\end{array}$ & Potentielle Sulfatase & $\begin{array}{l}\text { Streptomyces } \\
\text { coelicolor A3(2) }\end{array}$ & $\begin{array}{l}\text { NP_733737. } \\
1\end{array}$ & $2 \mathrm{e}-23$ & 24 & $\begin{array}{l}\text { CDD12458, COG3119, AslA, Arylsulfatase A } \\
\text { und verwandte Enzyme (4e-38) }\end{array}$ & I-TM \\
\hline 712 & 1135 & $\begin{array}{l}\text { Potentielles } \text { OmpA-verwandtes } \\
\text { Protein }\end{array}$ & OmpA-verwandtes Protein & $\begin{array}{l}\text { Xanthomonas } \\
\text { campestris pv. } \\
\text { campestris Stamm } \\
\text { ATCC } 33913 \\
\end{array}$ & $\begin{array}{l}\text { NP_639471. } \\
1\end{array}$ & $1 \mathrm{e}-21$ & 31 & & ZH-B \\
\hline 713 & 443 & $\begin{array}{lr}\text { Hypothetische } & \text { Imidazolen- } \\
\text { Propionase oder } & \text { verwandte } \\
\text { Amidohydrolasen } & \end{array}$ & $\begin{array}{lcr}\text { COG1228: } & \text { Hypothetische } & \text { Imidazolen- } \\
\text { Propionase } & \text { oder } & \text { verwandte } \\
\text { Amidohydrolasen } & \end{array}$ & $\begin{array}{l}\text { Azotobacter } \\
\text { vinelandii }\end{array}$ & $\begin{array}{l}\text { ZP_0008947 } \\
1.1\end{array}$ & $4 \mathrm{e}-25$ & 29 & $\begin{array}{l}\text { CDD10946, COG1228, HutI, Imidazolen- } \\
\text { Propionase oder verwandte Amidohydrolasen } \\
(2 \mathrm{e}-09)\end{array}$ & SM-BT \\
\hline 714 & 262 & $\begin{array}{l}\text { Hypothetisches membran- } \\
\text { assoziiertes Protein }\end{array}$ & Keine signifikante Übereinstimmung & & & & & & HP \\
\hline 715 & 427 & $\begin{array}{l}\text { Alkohol-Dehydrogenase, Klasse } \\
\text { IV }\end{array}$ & $\begin{array}{l}\text { Eisen-enthaltende Alkohol-Dehydro- } \\
\text { genase; Alkohol-Dehydrogenase } 8\end{array}$ & Mus musculus & $\begin{array}{l}\text { NP_780445. } \\
1\end{array}$ & e-125 & 57 & $\begin{array}{l}\text { CDD21636, KOG3857, Alkohol-Dehydrogenase, } \\
\text { Klasse IV (3e-132) }\end{array}$ & E \\
\hline 716 & 600 & $\begin{array}{ll}\begin{array}{l}\text { Hypothetisches } \\
\text { assoziiertes Protein }\end{array} & \text { membran- } \\
\end{array}$ & Hypothetisches Protein & Nostoc unctiforme & $\begin{array}{l}\text { ZP_0011077 } \\
5.1\end{array}$ & $4 \mathrm{e}-10$ & 20 & & HP \\
\hline 717 & 1123 & OmpA-verwandtes Protein & OmpA-verwandtes Protein & $\begin{array}{l}\text { Xanthomonas } \\
\text { campestris pv. } \\
\text { campestris Stamm } \\
\text { ATCC } 33913\end{array}$ & $\begin{array}{l}\text { NP_639471. } \\
1\end{array}$ & $8 \mathrm{e}-23$ & 30 & $\begin{array}{l}\text { CDD25563, pfam00593, TonB abhängiger } \\
\text { Rezeptor. (9e-08) }\end{array}$ & ZH-B \\
\hline 718 & 208 & Hypothetisches Protein & Keine signifikante Übereinstimmung & & & & & & HP \\
\hline 719 & 96 & Hypothetisches Protein & Keine signifikante Übereinstimmung & & & & & & HP \\
\hline 720 & 223 & $\begin{array}{l}\text { Hypothetisches membran- } \\
\text { assoziiertes Protein }\end{array}$ & Keine signifikante Übereinstimmung & & & & & & $\mathrm{HP}$ \\
\hline 721 & 115 & Hypothetisches Protein & Keine signifikante Übereinstimmung & & & & & & $\mathrm{HP}$ \\
\hline 722 & 751 & $\begin{array}{l}\text { 1,4- } \alpha \text {-Glukan } \quad \text { verzweigendes } \\
\text { Enzym (EC 2.4.1.18) }\end{array}$ & $\begin{array}{l}\text { COG0296: } 1,4-\alpha-\text {-Glukan verzweigendes } \\
\text { Enzym }\end{array}$ & $\begin{array}{l}\text { Clostridium } \\
\text { thermocellum } \\
\text { ATCC } 27405\end{array}$ & $\begin{array}{l}\text { ZP_0006116 } \\
6.1\end{array}$ & 0.0 & 55 & $\begin{array}{l}\text { CDD10170, COG0296, GlgB, 1,4- } \alpha \text {-Glukan } \\
\text { verzweigendes Enzym (0.0) }\end{array}$ & KH-M \\
\hline 723 & 545 & $\begin{array}{lr}\text { ATPase-Komponente } & \text { eines } \\
\text { ATP-Transporters } & \text { mit } \\
\text { verdoppelter ATPase-Domäne }\end{array}$ & $\begin{array}{l}\text { ATPase-Komponente e eines } \text { ATP- } \\
\text { Transporters mit verdoppelterATPase- } \\
\text { Domäne }\end{array}$ & $\begin{array}{l}\text { Rhodopseudomon } \\
\text { as palustris }\end{array}$ & $\begin{array}{l}\text { NP_950064. } \\
1\end{array}$ & e-172 & 56 & $\begin{array}{l}\text { CDD10359, COG0488, Uup, ATPase- } \\
\text { Komponente eines ATP-Transporters mit } \\
\text { verdoppelter ATPase-Domäne }(1 \mathrm{e}-145)\end{array}$ & KH-M \\
\hline
\end{tabular}




\begin{tabular}{|c|c|c|c|c|c|c|c|c|c|}
\hline $\begin{array}{l}\text { ORF- } \\
\text { Name }\end{array}$ & Größe & Annotation & Ähnlichstes Protein bei NCBI & Organismus & $\begin{array}{l}\text { Accession- } \\
\text { Nummer }\end{array}$ & $\begin{array}{l}\text { e- } \\
\text { Value }\end{array}$ & $\begin{array}{l}I \text { in } \\
\%\end{array}$ & Konservierte Domänen bei NCBI & $\begin{array}{l}\text { Funk- } \\
\text { tion }\end{array}$ \\
\hline 724 & 143 & $\begin{array}{l}\text { Uncharakterisiertes } \\
\text { konserviertes } \\
\text { (COG2947) }\end{array}$ & Hypothetisches Protein & $\begin{array}{l}\text { Chloroflexus } \\
\text { aurantiacus }\end{array}$ & $\begin{array}{l}\text { ZP_0001902 } \\
5.1\end{array}$ & $3 e-30$ & 50 & $\begin{array}{lcc}\text { CDD12295, COG2947, } & \text { COG2947, } \\
\text { Uncharakterisiertes konserviertes Protein (6e-30) }\end{array}$ & KP \\
\hline 725 & 333 & $\begin{array}{l}\text { Serin/Threonin Protein-Kinase, } \\
\text { katalytische Untereinheit }\end{array}$ & $\begin{array}{l}\text { Serin/Threonin } \\
\text { katalytische Untereinheit }\end{array}$ & $\begin{array}{l}\text { Streptomyces } \\
\text { avermitilis MA- } \\
4680\end{array}$ & $\begin{array}{l}\text { NP_825515. } \\
1\end{array}$ & $5 \mathrm{e}-39$ & 36 & & ST \\
\hline
\end{tabular}

\section{H) Cosmid Slc_1t}

\begin{tabular}{|c|c|c|c|c|c|c|c|c|c|}
\hline 801 & 215 & Kalium-Aufnahme-Protein & AGR_C_1288p & $\begin{array}{l}\text { Agrobacterium } \\
\text { tumefaciens }\end{array}$ & $\begin{array}{l}\text { NP_353736. } \\
1\end{array}$ & $1 \mathrm{e}-49$ & 61 & $\begin{array}{l}\text { CDD12497, COG3158, Kup, K+ transporter (1e- } \\
579\end{array}$ & I-TM \\
\hline 802 & 462 & $\begin{array}{l}\text { Mit GGDEF-Motiv gekoppelte } \\
\text { "response regulator receiver"- } \\
\text { Donäne }\end{array}$ & AGR_C_2387p & $\begin{array}{l}\text { Agrobacterium } \\
\text { tumefaciens }\end{array}$ & $\begin{array}{l}\text { NP_354305. } \\
1\end{array}$ & $2 \mathrm{e}-92$ & 42 & $\begin{array}{l}\text { CDD13026, COG3706, PleD, "Response } \\
\text { regulator" mit CheY-ähnlicher "receiver"- } \\
\text { Domäne und einer GGDEF-Domäne (3e-84) }\end{array}$ & ST \\
\hline 803 & 92 & Hypothetisches Protein & Hypothetisches Protein & $\begin{array}{l}\text { Rhodobacter } \\
\text { sphaeroides }\end{array}$ & $\begin{array}{l}\text { ZP_0000613 } \\
7.1\end{array}$ & $7 \mathrm{e}-10$ & 41 & & HP \\
\hline 804 & 136 & Hypothetisches Protein & Keine signifikante Übereinstimmung & & & & & & HP \\
\hline 805 & 232 & $\begin{array}{l}\text { Potentielle Halogensäuren } \\
\text { Dehalogenase-artige Hydrolase }\end{array}$ & COG0546: Vorausgesagte Phosphatase & $\begin{array}{l}\text { Rhodobacter } \\
\text { sphaeroides }\end{array}$ & $\begin{array}{l}\text { ZP_0000613 } \\
6.1\end{array}$ & $6 e-46$ & 46 & $\begin{array}{l}\text { CDD10417, COG0546, Gph, Vorausgesagte } \\
\text { Phosphatasen }(3 e-20)\end{array}$ & $\begin{array}{l}\text { AS-M/ } \\
\text { KH-M }\end{array}$ \\
\hline 806 & 519 & $\begin{array}{l}\text { Trimethylamin- } \\
\text { Methyltransferase (MTTB) }\end{array}$ & Hypothetisches Protein & $\begin{array}{l}\text { Mesorhizobium } \\
\text { loti }\end{array}$ & $\begin{array}{l}\text { NP_102853. } \\
1\end{array}$ & e-148 & 50 & $\begin{array}{l}\text { CDD25126, pfam06253, MTTB, Trimethylamin- } \\
\text { Methyltransferase (MTTB). (3e-169) }\end{array}$ & AS-M \\
\hline 807 & 162 & Hypothetisches Protein & Keine signifikante Übereinstimmung & & & & & & HP \\
\hline 808 & 185 & $\begin{array}{ll}\begin{array}{l}\text { Hypothetisches } \\
\text { assoziiertes Protein }\end{array} & \text { membran- } \\
\end{array}$ & Keine signifikante Übereinstimmung & & & & & & $\mathrm{HP}$ \\
\hline 809 & 323 & Kationen-Transport-Protein & COG0598: $\mathrm{Mg}^{2+}$ und $\mathrm{Co}^{2+}$-Transporter & $\begin{array}{l}\text { Microbulbifer } \\
\text { degradans 2-40 }\end{array}$ & $\begin{array}{l}\text { ZP_0006634 } \\
6.1\end{array}$ & $7 e-53$ & 36 & $\begin{array}{l}\text { CDD10468, COG0598, CorA, Mg2+ und Co2+- } \\
\text { Transporter (4e-43) }\end{array}$ & I-TM \\
\hline 810 & 221 & $\begin{array}{ll}\begin{array}{l}\text { Konserviertes } \\
\text { assoziiertes Protein }\end{array} & \text { membran- } \\
\end{array}$ & Hypothetisches Protein & $\begin{array}{l}\text { Rhodobacter } \\
\text { sphaeroides }\end{array}$ & $\begin{array}{l}\text { ZP_0000585 } \\
7.1\end{array}$ & $2 e-43$ & 44 & & KP \\
\hline 811 & 467 & $\begin{array}{l}\text { UDP-N-acetylmuramoylalanin- } \\
\text { D-Glutamat-Ligase (EC 6.3.2.9) }\end{array}$ & $\begin{array}{l}\text { COG0771: UDP-N- } \\
\text { acetylmuramoylalanin-D-Glutamat- } \\
\text { Ligase }\end{array}$ & $\begin{array}{l}\text { Rhodobacter } \\
\text { sphaeroides }\end{array}$ & $\begin{array}{l}\text { ZP_0000457 } \\
8.1\end{array}$ & e-151 & 60 & $\begin{array}{l}\text { CDD10639, COG0771, MurD, UDP-N- } \\
\text { acetylmuramoylalanin-D-Glutamat-Ligase } \quad(4 \mathrm{e}- \\
\text { 100) }\end{array}$ & ZH-B \\
\hline 812 & 70 & Hypothetisches Protein & Lactoylgluthation-Lyase & $\begin{array}{l}\text { Microbulbifer } \\
\text { degradans 2-40 }\end{array}$ & $\begin{array}{l}\text { ZP_0006708 } \\
0.1\end{array}$ & $1 \mathrm{e}-14$ & 52 & & HP \\
\hline 813 & 91 & $\begin{array}{ll}\begin{array}{l}\text { Hypothetisches } \\
\text { assoziiertes Protein }\end{array} & \text { membran- } \\
\end{array}$ & Keine signifikante Übereinstimmung & & & & & & HP \\
\hline 814 & 85 & $\begin{array}{ll}\text { Uncharakterisiserte } & \text { Protein- } \\
\text { Familie (UPF0156) } & \end{array}$ & Hypothetisches Protein UPF0156.1 & Vibrio cholerae & $\begin{array}{l}\text { YV6A_VIB } \\
\text { CH }\end{array}$ & $1 \mathrm{e}-14$ & 55 & $\begin{array}{l}\text { CDD5735, pfam03693, } \\
\text { Uncharakterisiserte Protein-Familie } \\
\text { Unit konserviertem GRY-Motif. (2e-21) }\end{array}$ & KP \\
\hline 815 & 103 & $\begin{array}{l}\text { Hypothetical protein (COG3668, } \\
\text { ParE (Plasmid-Stabilisierungs- } \\
\text { system) }\end{array}$ & Konserviertes hypothetisches Protein & $\begin{array}{l}\text { Sinorhizobium } \\
\text { meliloti }\end{array}$ & $\begin{array}{l}\text { NP_436603. } \\
1\end{array}$ & $5 e-08$ & 38 & $\begin{array}{l}\text { CDD12991, COG3668, ParE, Proteine eines } \\
\text { Plasmid-Stabilisationssystems (5e-11) }\end{array}$ & HP \\
\hline
\end{tabular}




\begin{tabular}{|c|c|c|c|c|c|c|c|c|c|}
\hline $\begin{array}{l}\text { ORF- } \\
\text { Name }\end{array}$ & Größe & Annotation & Ähnlichstes Protein bei NCBI & Organismus & $\begin{array}{l}\text { Accession- } \\
\text { Nummer }\end{array}$ & $\begin{array}{ll}\text { e- } \\
\text { Value }\end{array}$ & $\begin{array}{l}\text { I in } \\
\%\end{array}$ & Konservierte Domänen bei NCBI & $\begin{array}{l}\text { Funk- } \\
\text { tion }\end{array}$ \\
\hline 816 & 448 & $\begin{array}{l}\text { MiaB, 2-Methylthioadenin- } \\
\text { Synthetase (COG0621) }\end{array}$ & $\begin{array}{l}\text { COG0621: MiaB, 2-Methylthioadenin- } \\
\text { Synthetase }\end{array}$ & $\begin{array}{l}\text { Rhodobacter } \\
\text { sphaeroides }\end{array}$ & $\begin{array}{l}\text { ZP_0000647 } \\
2.1\end{array}$ & 0.0 & 78 & $\begin{array}{l}\text { CDD10491, COG0621, } \\
\text { Methylthioadenin-Synthetase }(8 \mathrm{e}-113)\end{array}$ & TLR \\
\hline 817 & 232 & 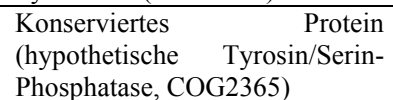 & Hypothetisches Protein & $\begin{array}{l}\text { Caulobacter } \\
\text { crescentus } \mathrm{CB} 15\end{array}$ & $\begin{array}{l}\text { NP_419125. } \\
1\end{array}$ & $2 \mathrm{e}-28$ & 36 & $\begin{array}{l}\text { CDD12037, COG2365, COG2365, Protein- } \\
\text { Tyrosin/Serin-Phosphatase (3e-09) }\end{array}$ & ST \\
\hline 818 & 556 & $\begin{array}{l}\text { SUL1, Sulfat-Permease und } \\
\text { verwandte Transporter (MFS- } \\
\text { Superfamilie) (COG0659) }\end{array}$ & $\begin{array}{ll}\text { Sulfat-Permease } & \text { und } r \text { verwandte } \\
\text { Transporter } & \text { (MFS-Superfamilie) } \\
\text { (COG0659) } & \\
\end{array}$ & $\begin{array}{l}\text { Magnetococcus } \\
\text { sp. MC-1 }\end{array}$ & $\begin{array}{l}\text { ZP_0004343 } \\
0.1\end{array}$ & $e-159$ & 58 & $\begin{array}{l}\text { CDD10529, COG0659, SUL1, Sulfat-Permease } \\
\text { und verwandte Transporter (MFS-Superfamilie) } \\
\text { (3e-98) }\end{array}$ & I-TM \\
\hline 819 & 665 & $\begin{array}{l}\text { N-MethylhydantoinaseA/ } \\
\text { Aceton-Carboxylase, } \quad \beta- \\
\text { Untereinheit, HyuA (COG0145) }\end{array}$ & $\begin{array}{l}\text { COG0145: } \quad \text { N-MethylhydantoinaseA/ } \\
\text { Aceton-Carboxylase, } \beta \text {-Untereinheit }\end{array}$ & $\begin{array}{l}\text { Rhodobacter } \\
\text { sphaeroides }\end{array}$ & $\begin{array}{l}\text { ZP_0000526 } \\
5.1\end{array}$ & e-157 & 55 & $\begin{array}{l}\text { CDD10020, COG0145, HyuA, } \\
\text { MethylhydantoinaseA/ Aceton-Carboxylase, } \\
\text { Untereinheit }(3 \mathrm{e}-78)\end{array}$ & $\begin{array}{l}\text { AS-M } \\
\text { SM-BT }\end{array}$ \\
\hline 820 & 407 & $\begin{array}{l}\text { CsdB, Selenocystein-Lyase } \\
(\mathrm{COG} 0520)\end{array}$ & COG0520: Selenocystein-Lyase & $\begin{array}{l}\text { Rhodobacter } \\
\text { sphaeroides }\end{array}$ & $\begin{array}{l}\text { ZP_0000428 } \\
2.1\end{array}$ & $\mathrm{e}-173$ & 70 & $\begin{array}{l}\text { CDD10391, COG0520, CsdB, Selenocystein- } \\
\text { Lyase (4e-129) }\end{array}$ & AS-M \\
\hline 821 & 338 & $\begin{array}{l}\text { NodQ, bifunktionales Enzym } \\
\text { (Nodulationsprotein) } \\
\text { [beinhaltet: Sulfat-Adenylyl- } \\
\text { Transferase Untereinheit 1 } \\
\text { (Sulfat-Adenylat-Transferase) } \\
\text { (SAT) (ATP-Sulfurylase, große } \\
\text { Untereinheit); Adenylylsulfat- } \\
\text { Kinase (APS kinase) (ATP- } \\
\text { adenosine-5'-phosphosulfate 3'- } \\
\text { phosphotransferase) }\end{array}$ & NodQ & $\begin{array}{l}\text { Azospirillum } \\
\text { brasilense }\end{array}$ & $\begin{array}{l}\text { NP_638517. } \\
1\end{array}$ & e-109 & 58 & $\begin{array}{l}\text { CDD10400, COG0529, CysC, Adenylylsulfat- } \\
\text { Kinase und verwandte Kinasen (1e-82) }\end{array}$ & I-TM \\
\hline 822 & 69 & Potentielles Kälteschock-Protein & AGR_C_161p & $\begin{array}{l}\text { Agrobacterium } \\
\text { tumefaciens }\end{array}$ & $\begin{array}{l}\text { NP_353140. } \\
1\end{array}$ & $4 \mathrm{e}-21$ & 66 & $\begin{array}{l}\text { CDD10994, COG1278, CspC, Kälteschock- } \\
\text { Proteine (2e-21) }\end{array}$ & TS \\
\hline 823 & 247 & Hypothetisches Protein & Keine signifikante Übereinstimmung & & & & & & HP \\
\hline 824 & 357 & $\begin{array}{l}\text { 4-Hydroxyphenylpyruvat- } \\
\text { Dioxygenase }\end{array}$ & 4-Hydroxyphenylpyruvat-Dioxygenase & $\begin{array}{l}\text { Chromobacterium } \\
\text { violaceum } \\
\text { ATCC12472 }\end{array}$ & $\begin{array}{l}\text { NP_900639. } \\
1\end{array}$ & e-127 & 65 & $\begin{array}{l}\text { CDD12523, COG3185, COG3185, } \\
\text { Hydroxyphenylpyruvat-Dioxygenase } \\
\text { undverwandte Hämolysine }(2 \mathrm{e}-125)\end{array}$ & AS-M \\
\hline 825 & 151 & $\begin{array}{ll}\begin{array}{l}\text { Konserviertes } \\
(\text { COG3791) }\end{array} & \text { Protein } \\
\end{array}$ & Hypothetisches Protein & $\begin{array}{l}\text { Sinorhizobium } \\
\text { meliloti }\end{array}$ & $\begin{array}{l}\text { NP_386112. } \\
1\end{array}$ & $1 \mathrm{e}-38$ & 48 & & KP \\
\hline 826 & 223 & $\begin{array}{l}\text { Maleylacetoacetat-Isomerase } \\
\text { (EC 5.2.1.2) }\end{array}$ & $\begin{array}{l}\begin{array}{l}\text { Protein } \\
\text { Familie }\end{array} \\
\text { der Glutathion-S-Transferase- }\end{array}$ & $\begin{array}{l}\text { Shewanella } \\
\text { oneidensis MR-1 }\end{array}$ & $\begin{array}{l}\mathrm{NP}_{-} 717282 . \\
1\end{array}$ & $2 \mathrm{e}-43$ & 44 & $\begin{array}{l}\text { CDD18661, KOG0868, } \\
\text { Transferase (1e-44) }\end{array}$ & PPM \\
\hline 827 & 380 & $\begin{array}{l}\text { Homogentisat 1,2-Dioxygenase } \\
\text { (EC 1.13.11.5) }\end{array}$ & Homogentisat 1,2-Dioxygenase & $\begin{array}{l}\text { Chromobacterium } \\
\text { violaceum ATCC } \\
12472\end{array}$ & $\begin{array}{l}\text { NP_900640. } \\
1\end{array}$ & e-122 & 56 & $\begin{array}{l}\text { CDD12836, COG3508, HmgA, Homogentisat- } \\
\text { 1,2-Dioxygenase (3e-67) }\end{array}$ & SM-BT \\
\hline 828 & 291 & Hypothetisches Protein & Keine signifikante Übereinstimmung & & & & & & HP \\
\hline 829 & 137 & $\begin{array}{l}\text { Hypothetisches } \\
\text { assoziiertes Protein }\end{array}$ & Keine signifikante Übereinstimmung & & & & & & HP \\
\hline 830 & 320 & $\begin{array}{l}\text { Protein der Fumarylacetoacetat- } \\
\text { Hydrolase-Familie }\end{array}$ & $\begin{array}{lcc}\text { Protein } & \text { der } & \text { Fumarylacetoacetat- } \\
\text { Hydrolase-Familie } & \end{array}$ & $\begin{array}{l}\text { Caulobactercresce } \\
\text { ntus CB15 }\end{array}$ & $\begin{array}{l}\text { NP_421334. } \\
1\end{array}$ & e-126 & 70 & $\begin{array}{l}\text { CDD10054, COG0179, MhpD, 2-Keto-4- } \\
\text { pentenoat-Hydratase/2-Oxohepta-3- } \\
\text { en-1,7-diol-säure-Hydratase (Catechol-Weg) (3e- } \\
\text { 41) }\end{array}$ & SM-BT \\
\hline
\end{tabular}




\begin{tabular}{|c|c|c|c|c|c|c|c|c|c|}
\hline $\begin{array}{l}\text { ORF- } \\
\text { Name }\end{array}$ & Größe & Annotation & Ähnlichstes Protein bei NCBI & Organismus & $\begin{array}{l}\text { Accession- } \\
\text { Nummer }\end{array}$ & $\begin{array}{l}\text { e- } \\
\text { Value }\end{array}$ & $\begin{array}{l}I \text { in } \\
\%\end{array}$ & Konservierte Domänen bei NCBI & $\begin{array}{l}\text { Funk- } \\
\text { tion }\end{array}$ \\
\hline 831 & 179 & Hypothetisches Protein & Hypothetisches Protein Bcep02006917 & $\begin{array}{l}\text { Burkholderia } \\
\text { fugorum LB400 }\end{array}$ & $\begin{array}{l}\text { ZP_0027835 } \\
0.1\end{array}$ & $9 \mathrm{e}-14$ & 27 & & HP \\
\hline 832 & 233 & $\begin{array}{l}\text { Acyl-CoA:Acetate/3-Ketosäure- } \\
\text { CoA-Transferase, Untereinheit } \\
\text { A, AtoD (EC 2.8.3.5) }\end{array}$ & $\begin{array}{l}\text { COG1788: } \quad \text { Acyl-CoA:Acetate/3- } \\
\text { Ketosäure-CoA-Transferase, } \quad \alpha- \\
\text { Untereinheit }\end{array}$ & $\begin{array}{l}\text { Rhodobacter } \\
\text { sphaeroides }\end{array}$ & $\begin{array}{l}\text { ZP_0000507 } \\
3.1\end{array}$ & $2 \mathrm{e}-95$ & 75 & $\begin{array}{l}\text { CDD11499, COG1788, AtoD, Acyl- } \\
\text { CoA:Acetate/3-Ketosäure-CoA-Transferase, } \quad \alpha- \\
\text { Untereinheit (7e-82) }\end{array}$ & LM \\
\hline 833 & 215 & $\begin{array}{l}\text { Potentielles Phospholipid- } \\
\text { Bindeprotein (COG1881) }\end{array}$ & COG1881: Phospholipid-Bindeprotein & $\begin{array}{l}\text { Desulfitobac- } \\
\text { terium hafniense }\end{array}$ & $\begin{array}{l}\text { P_00100879. } \\
1\end{array}$ & $7 \mathrm{e}-20$ & 44 & $\begin{array}{lll}\text { CDD11590, COG1881, } & \text { Phospholipid- } \\
\text { Bindeprotein (2e-21) } & \\
\end{array}$ & LM \\
\hline 834 & 209 & $\begin{array}{l}\text { Acyl-CoA:Acetat/3-Ketosäure- } \\
\text { CoA-Transferase, Untereinheit } \\
\text { B, AtoA (EC 2.8.3.5) }\end{array}$ & $\begin{array}{l}\text { COG2057: } \quad \text { Acyl-CoA:Acetat/3-Keto- } \\
\text { säure-CoA-Transferase, Unterienheit B }\end{array}$ & $\begin{array}{l}\text { Rhodobacter } \\
\text { sphaeroides }\end{array}$ & $\begin{array}{l}\text { ZP_0000507 } \\
2.1\end{array}$ & $2 \mathrm{e}-80$ & 76 & $\begin{array}{l}\text { CDD11765, COG2057, AtoA, } \\
\text { CoA:Acetat/3-Ketosäure-CoA-Transferase, } \\
\text { Untereinheit B }(1 \mathrm{e}-78)\end{array}$ & LM \\
\hline 835 & 143 & $\begin{array}{l}\text { Hypothetisches membran- } \\
\text { assoziiertes Protein }\end{array}$ & Keine signifikante Übereinstimmung & & & & & & HP \\
\hline 836 & 88 & $\begin{array}{l}\text { Hypothetisches membran- } \\
\text { durchspannendes Protein }\end{array}$ & Keine signifikante Übereinstimmung & & & & & & HP \\
\hline 837 & 476 & $\begin{array}{ll}\text { Konserviertes } & \text { Protein } \\
(\text { COG5361) }\end{array}$ & $\begin{array}{l}\text { COG5361: } \\
\text { konserviertes Protein }\end{array}$ & $\begin{array}{l}\text { Ralstonia } \\
\text { metallidurans }\end{array}$ & $\begin{array}{l}\text { ZP_0002582 } \\
6.1\end{array}$ & $1 \mathrm{e}-52$ & 34 & $\begin{array}{l}\text { CDD14456, COG5361, } \\
\text { konserviertes Protein }(6 e-49)\end{array}$ & KP \\
\hline 838 & 731 & $\begin{array}{l}\text { Peroxidase/Katalase } \quad(\mathrm{EC} \\
1.11 .1 .6)\end{array}$ & Peroxidase/Katalase & $\begin{array}{l}\text { Mesorhizobium } \\
\text { loti }\end{array}$ & $\begin{array}{l}\text { NP_107344. } \\
1\end{array}$ & 0.0 & 65 & $\begin{array}{llll}\begin{array}{l}\text { CDD10250, COG0376, } \\
\text { (Peroxidase I) }(0.0)\end{array} & \text { KatG, } & \text { Katalase } \\
\end{array}$ & I-TM \\
\hline 839 & 191 & $\begin{array}{l}\begin{array}{l}\text { Konserviertes } \\
\text { (DUF1080) }\end{array} \\
\end{array}$ & $\begin{array}{lll}\begin{array}{l}\text { Potentielle } \\
\text { Hydrolase }\end{array} & \text { sekretierte } & \text { Glykosyl- } \\
\end{array}$ & Pirellula sp. 1 & $\begin{array}{l}\text { NP_867662. } \\
1\end{array}$ & $2 \mathrm{e}-11$ & 30 & $\begin{array}{l}\text { CDD26552, pfam06439, DUF1080, Domäne mit } \\
\text { unbekannter Funktion (DUF1080). (2e-13) }\end{array}$ & KP \\
\hline 840 & 457 & Cytochrom P450 & AGR_C_2890p & $\begin{array}{l}\text { Agrobacterium } \\
\text { tumefaciens }\end{array}$ & $\begin{array}{l}\text { NP_354568. } \\
1\end{array}$ & $1 \mathrm{e}-67$ & 36 & $\begin{array}{lll}\text { CDD17954, KOG0157, Cytochrome } & \text { P450 } \\
\text { CYP4/CYP19/CYP26 Subfamilien (9e-66) } & \end{array}$ & $\begin{array}{l}\text { E; } \\
\text { LM }\end{array}$ \\
\hline 841 & 179 & Hypothetisches Protein & COG1309: Transkriptionsregulator & $\begin{array}{l}\text { Rhodopseudo- } \\
\text { monas palustris }\end{array}$ & $\begin{array}{l}\text { ZP_0001040 } \\
3.1\end{array}$ & $5 e-10$ & 28 & $\begin{array}{lcc}\text { CDD11025, } & \text { COG1309, } & \text { AcrR, } \\
\text { Transkriptionsregulator (5e-06) } & \end{array}$ & HP \\
\hline 842 & 216 & Potentielle Kynureninase & Kynureninase & $\begin{array}{l}\text { Unkultiviertes } \\
\text { Bakterium } 439\end{array}$ & AAR37647.1 & $6 e-51$ & 39 & CDD13160, COG3844, Kynureninase (3e-51) & AS-M \\
\hline
\end{tabular}

\section{I) Cosmid Slc 1 1u}

\begin{tabular}{|c|c|c|c|c|c|c|c|c|c|}
\hline 901 & 1007 & $\begin{array}{l}\text { Potentielles Typ I Restriktions- } \\
\text { modifikationssystem, Restrik- } \\
\text { tionsuntereinheit R und ver- } \\
\text { wandte Helikasen (EC 3.1.21.3) }\end{array}$ & $\begin{array}{l}\text { COG0610: Potentielles Typ I } \\
\begin{array}{l}\text { Restriktionsmodifikationssystem, } \\
\text { Restriktionsuntereinheit R } \\
\text { verwandte Helikasen }\end{array} \quad \text { und } \\
\end{array}$ & $\begin{array}{l}\text { Methanosarcina } \\
\text { barkeri }\end{array}$ & $\begin{array}{l}\text { ZP_0007896 } \\
2.1\end{array}$ & 0.0 & 39 & $\begin{array}{l}\text { CDD10480, COG0610, Typ I seitenspezifisches } \\
\text { Restriktions-modifikationssystem, r } \\
\text { (Restriktions-) Untereinheit und verwandte } \\
\text { Helikasen (6e-62) }\end{array}$ & A \\
\hline 902 & 174 & $\begin{array}{l}\text { Konserviertes hypothetisches } \\
\text { Protein }\end{array}$ & Hypothetisches Protein & $\begin{array}{l}\text { Ralstonia } \\
\text { solanacearum }\end{array}$ & $\begin{array}{l}\text { NP_521370. } \\
1\end{array}$ & $2 \mathrm{e}-21$ & 32 & & KHP \\
\hline 903 & 383 & $\begin{array}{l}\text { Konserviertes hypothetisches } \\
\text { Protein }\end{array}$ & Konserviertes hypothetisches Protein & $\begin{array}{l}\text { Chlorobium } \\
\text { tepidum TLS }\end{array}$ & $\begin{array}{l}\text { NP_663126. } \\
1\end{array}$ & $9 e-67$ & 40 & $\begin{array}{l}\text { CDD12209, COG2856, Vorausgesagte Zn- } \\
\text { Peptidase (1e-15) }\end{array}$ & KHP \\
\hline 904 & 477 & Konserviertes Protein & MC29 & $\begin{array}{l}\text { Micrococcus sp. } \\
28\end{array}$ & $\begin{array}{l}\text { NP_862407. } \\
1\end{array}$ & $7 e-46$ & 31 & $\begin{array}{l}\text { CDD10085, COG0210, UvrD, Superfamilie I } \\
\text { DNA- und RNA-Helikasen }(5 \mathrm{e}-12)\end{array}$ & DRR \\
\hline
\end{tabular}




\begin{tabular}{|c|c|c|c|c|c|c|c|c|c|}
\hline $\begin{array}{l}\text { ORF- } \\
\text { Name }\end{array}$ & Größe & Annotation & Ähnlichstes Protein bei NCBI & Organismus & $\begin{array}{l}\text { Accession- } \\
\text { Nummer }\end{array}$ & $\begin{array}{ll}\text { e- } \\
\text { Value }\end{array}$ & $\begin{array}{l}I \text { in } \\
\%\end{array}$ & Konservierte Domänen bei NCBI & $\begin{array}{l}\text { Funk- } \\
\text { tion }\end{array}$ \\
\hline 905 & 566 & $\begin{array}{l}\text { Konserviertes } \\
\text { Protein }\end{array}$ & Konserviertes hypothetisches Protein & $\begin{array}{l}\text { Ralstonia } \\
\text { eutropha }\end{array}$ & $\begin{array}{l}\text { NP_942789. } \\
1\end{array}$ & $5 e-47$ & 28 & $\begin{array}{l}\text { CDD12918, COG3593, Vorasugesagte ATP- } \\
\text { abhängige Endonuklease der OLD Familie (5e- } \\
\text { 08) }\end{array}$ & KHP \\
\hline 906 & 424 & $\begin{array}{l}\text { Potentielles Typ I Restriktions- } \\
\text { modifikationssystem, } \\
\text { Spezifitätsuntereinheit }\end{array}$ & $\begin{array}{l}\text { COG0732: } \text { Restriktionsendonuklease } \\
\text { Untereinheit S }\end{array}$ & $\begin{array}{l}\text { Trichodesmium } \\
\text { erythraeum } \\
\text { IMS101 }\end{array}$ & $\begin{array}{l}\text { ZP_0007158 } \\
6.1\end{array}$ & $4 \mathrm{e}-54$ & 30 & $\begin{array}{lcc}\text { CDD10601, } & \text { COG0732, } & \text { HsdS, } \\
\text { Restriktionsendonuklease S-Untereinheit } & (4 \mathrm{e}-19)\end{array}$ & A \\
\hline 907 & 390 & Konserviertes Protein & $\begin{array}{ll}\text { COG0286: } & \text { Typ } \\
\text { Restriktionsmodifikationssystem } & \text { I } \\
\text { Methyltransferase-Untereinheit } & \end{array}$ & $\begin{array}{l}\text { Desulfovibrio } \\
\text { desulfuricans G20 }\end{array}$ & $\begin{array}{l}\text { ZP_0012916 } \\
9.1\end{array}$ & $6 e-20$ & 50 & & KP \\
\hline 908 & 405 & $\begin{array}{l}\text { Potentielle Serin-Protease DO- } \\
\text { like }\end{array}$ & Potentielle Trypsin-artige Serin-Protease & $\begin{array}{l}\text { Myxococcus } \\
\text { xanthus }\end{array}$ & $\begin{array}{l}\text { AAF_87931. } \\
1\end{array}$ & $1 \mathrm{e}-49$ & 36 & $\begin{array}{l}\text { CDD10140, COG0265, DegQ, Trypsin-ähnliche } \\
\text { Serin-Protease, normal periplasmatisch, enthalten } \\
\text { C-terminale PDZ-Domäne (2e-44) }\end{array}$ & PPM \\
\hline 909 & 720 & Hypothetisches Protein & Keine signifikante Übereinstimmung & & & & & & HP \\
\hline 910 & 324 & Hypothetisches Protein & Keine signifikante Übereinstimmung & & & & & & HP \\
\hline 911 & 421 & $\begin{array}{l}\text { Konserviertes Protein } \\
\text { (Hypothetische Peptidase) }\end{array}$ & $\begin{array}{l}\text { Protein mit Ähnlichkeit } \mathrm{zu} \\
\text { Polyhydroxyalkanoat-Depolymerase- } \\
\text { Vorläufer }\end{array}$ & Pirellula sp. 1 & $\begin{array}{l}\text { NP_869281. } \\
1\end{array}$ & $8 \mathrm{e}-12$ & 25 & $\begin{array}{lcc}\text { CDD13381, } & \text { COG4099, } & \text { COG4099, } \\
\text { Vorausgesagte Peptidase }(2 \mathrm{e}-15) & \end{array}$ & AS-M \\
\hline 912 & 410 & $\begin{array}{l}\text { Hypothetisches Lantibiotin } \\
\text { modifizierendes Enzym }\end{array}$ & CinM-Protein & $\begin{array}{l}\text { Streptomyces } \\
\text { cinnamoneus }\end{array}$ & CAD60521.1 & 1e-13 & 30 & $\begin{array}{l}\text { CDD13634, COG4403, LcnDR2, Lantibiotin- } \\
\text { modifizierendes Enzym (6e-17) }\end{array}$ & A \\
\hline 913 & 957 & Hypothetisches Protein & Keine signifikante Übereinstimmung & & & & & & HP \\
\hline 914 & 230 & Hypothetisches Protein & Keine signifikante Übereinstimmung & & & & & & HP \\
\hline 915 & 199 & $\begin{array}{l}\text { Hypothetisches Prolipoprotein- } \\
\text { Diacyglyceryl-Transferase } \\
\text { (LGT) }\end{array}$ & $\begin{array}{l}\text { Potentielles } \\
\text { Diacyglyceryl-Transferase }\end{array}$ & $\begin{array}{l}\text { Clostridium tetani } \\
\text { E88 }\end{array}$ & $\begin{array}{l}\text { NP_780960. } \\
1\end{array}$ & $8 \mathrm{e}-11$ & 34 & $\begin{array}{l}\text { CDD24591, pfam01790, LGT, Prolipoprotein- } \\
\text { Diacyglyceryl-Transferase (2e-18) }\end{array}$ & ZH-B \\
\hline 916 & 294 & Hypothetisches Protein & Keine signifikante Übereinstimmung & & & & & & HP \\
\hline 917 & 350 & $\begin{array}{lr}\begin{array}{l}\text { Konserviertes } \\
\text { (Vorausgesagte }\end{array} & \text { Protein } \\
\text { Transferase) } & \text { Glyceryl- }\end{array}$ & Hypothetisches Protein glr1064 & $\begin{array}{l}\text { Gloeobacter } \\
\text { violaceus }\end{array}$ & $\begin{array}{l}\text { NP_924010. } \\
1\end{array}$ & $2 \mathrm{e}-32$ & 39 & $\begin{array}{lcc}\text { CDD13814, } & \text { COG4671, } & \text { COG4671, } \\
\text { Vorausgesagte Glyceryl-Transferase } & (6 \mathrm{e}-47)\end{array}$ & KP \\
\hline 918 & 133 & $\begin{array}{lr}\begin{array}{l}\text { Konserviertes } \\
\text { (hypothetisches } \\
\text { curing" Protein) }\end{array} & \text { "death-on- } \\
\end{array}$ & Doc protein & $\begin{array}{l}\text { Chlorobium } \\
\text { tepidum TLS }\end{array}$ & $\begin{array}{l}\text { NP_661237. } \\
1\end{array}$ & $2 \mathrm{e}-24$ & 47 & $\begin{array}{l}\text { CDD12977, COG3654, Doc, } \text { Prophagen- } \\
\text { Erhaltungssystem-Killerprotein (3e-18) }\end{array}$ & HP \\
\hline 919 & 460 & Hypothetisches Protein & Keine signifikante Übereinstimmung & & & & & & HP \\
\hline 920 & 292 & $\begin{array}{l}\text { Hypothetisches membran- } \\
\text { durchspannendes Protein }\end{array}$ & Keine signifikante Übereinstimmung & & & & & & HP \\
\hline 921 & 116 & Hypothetisches Protein & Keine signifikante Übereinstimmung & & & & & & HP \\
\hline 922 & 352 & Hypothetisches Protein & Keine signifikante Übereinstimmung & & & & & & HP \\
\hline 923 & 353 & Hypothetisches Protein & Keine signifikante Übereinstimmung & & & & & & HP \\
\hline 924 & 296 & Hypothetisches Protein & Keine signifikante Übereinstimmung & & & & & & HP \\
\hline 925 & 366 & $\begin{array}{l}\text { 3-Isopropylmalat- } \\
\text { Dehydrogenase (EC 1.1.1.85) }\end{array}$ & $\begin{array}{l}\text { COG0473: Isocitrat/Isopropylmalat- } \\
\text { Dehydrogenase }\end{array}$ & $\begin{array}{l}\text { Desulfitobacteriu } \\
m \text { hafniense }\end{array}$ & $\begin{array}{l}\text { ZP_0009828 } \\
2.1\end{array}$ & $9 e-35$ & 36 & $\begin{array}{lr}\text { CDD16655, } & \text { pfam00180, } \\
\text { Isocitrat/Isopropylmalat-Dehydrogenase. (4e-38) }\end{array}$ & KH-M \\
\hline
\end{tabular}




\begin{tabular}{|c|c|c|c|c|c|c|c|c|c|}
\hline $\begin{array}{l}\text { ORF- } \\
\text { Name }\end{array}$ & Größe & Annotation & Ähnlichstes Protein bei NCBI & Organismus & $\begin{array}{l}\text { Accession- } \\
\text { Nummer }\end{array}$ & $\begin{array}{l}\text { e- } \\
\text { Value } \\
\end{array}$ & $\begin{array}{l}\text { I in } \\
\%\end{array}$ & Konservierte Domänen bei NCBI & $\begin{array}{l}\text { Funk- } \\
\text { tion }\end{array}$ \\
\hline 926 & 573 & $\begin{array}{l}\text { Aldehyd-Dehydrogenase } \\
\text { (thermostabil) (EC 1.2.1.3) }\end{array}$ & $\begin{array}{l}\text { Protein mitÄhnlichkeit zu einer NAD+- } \\
\text { abhängigen Aldehyd-Dehydrogenase }\end{array}$ & $\begin{array}{l}\text { Alkalilimnicola } \\
\text { ehrlicheiMLHE-1 }\end{array}$ & $\begin{array}{l}Z_{1} P_{-} 0086553 \\
1.1\end{array}$ & 2e-119 & 42 & $\begin{array}{l}\text { CDD10741, COG1012, PutA, NAD-dependent } \\
\text { aldehyde dehydrogenases (3e-81) }\end{array}$ & KH-M \\
\hline 927 & 128 & $\begin{array}{ll}\text { Hypothetisches } & \text { membran- } \\
\text { assoziiertes Protein } & \end{array}$ & $\begin{array}{ll}\text { Procollagen-Lysin, 2-Oxoglutarat } & 5- \\
\text { Dioxygenase 3, Procollagen-Lysin, } & 2- \\
\text { Oxoglutarat 5-Dioxygenase } 3 & \end{array}$ & Rattus norvegicus & $\begin{array}{l}\text { NP_835202. } \\
1\end{array}$ & $5 \mathrm{e}-12$ & 40 & & HP \\
\hline
\end{tabular}

\section{J) Cosmid Slc_1x}

\begin{tabular}{|c|c|c|c|c|c|c|c|c|c|}
\hline 1001 & 261 & $\begin{array}{l}\text { 4-Hydroxy-2-oxovalerat- } \\
\text { Aldolase (EC 4.1.2.-) }\end{array}$ & 4-Hydroxy-2-oxovalerat-Aldolase & $\begin{array}{l}\text { Mesorhizobium } \\
\text { loti }\end{array}$ & $\begin{array}{l}\text { NP_106094. } \\
1\end{array}$ & $4 \mathrm{e}-70$ & 60 & $\begin{array}{lll}\text { CDD13153, COG3836, } \mathrm{HpcH}, & 2,4- \\
\text { Dihydroxyhept-2-en-1,7-diol-säure-Aldolase } & (4 \mathrm{e}- \\
\text { 47) }\end{array}$ & KH-M \\
\hline 1002 & 409 & Aminotransferase (EC 2.6.1.-) & Potentielle Aminotransferase & $\begin{array}{l}\text { Ralstonia } \\
\text { solanacearum }\end{array}$ & $\begin{array}{l}\text { NP_522355. } \\
1\end{array}$ & $4 \mathrm{e}-75$ & 40 & $\begin{array}{l}\text { CDD10310, COG0436, Aspartat/Tyrosin/aroma- } \\
\text { tischeAminosäuren-Aminotransferase (1e-73) }\end{array}$ & AS-M \\
\hline 1003 & 265 & $\begin{array}{l}\begin{array}{l}\text { Extrazelluläres } \\
\text { (Familie 3) }\end{array} \\
\text { Bindeprotein }\end{array}$ & Unbekanntes Protein & $\begin{array}{l}\text { Mesorhizobium } \\
\text { loti }\end{array}$ & $\begin{array}{l}\text { NP_106092. } \\
1\end{array}$ & $2 \mathrm{e}-95$ & 70 & $\begin{array}{l}\text { CDD25526, pfam00497, SBP_bac_3, Bakterielle } \\
\text { extrazelluläre "Solute“-Bindeprotein-Familie, } \\
\text { family 3. (2e-46) }\end{array}$ & AS-M \\
\hline 1004 & 224 & ABC-Transporter-Permease & ABC-Transporter-Permease & $\begin{array}{l}\text { Mesorhizobium } \\
\text { loti }\end{array}$ & $\begin{array}{l}\text { NP_106091. } \\
1\end{array}$ & $3 e-76$ & 71 & $\begin{array}{lll}\text { CDD10633, COG0765, HisM, } & \text { ABC-Typ } \\
\text { Aminosäure-Transport-System, } & \text { Permease- } \\
\text { Komponente (1e-39) } & \\
\end{array}$ & AS-M \\
\hline 1005 & 426 & Potentielle Aminotransferase & Aminotransferase nifS & $\begin{array}{l}\text { Mesorhizobium } \\
\text { loti }\end{array}$ & $\begin{array}{l}\text { NP_106090. } \\
1\end{array}$ & 0.0 & 83 & $\begin{array}{l}\text { CDD10391, COG0520, CsdB, Selenocystein- } \\
\text { Lyase (3e-87) }\end{array}$ & AS-M \\
\hline 1006 & 475 & $\begin{array}{l}\text { Aldehyd-Dehydrogenase }(\mathrm{EC} \\
\text { 1.2.1.3) }\end{array}$ & Aldehyd Dehydrogenase & $\begin{array}{l}\text { Mesorhizobium } \\
\text { loti }\end{array}$ & $\begin{array}{l}\text { NP_107368. } \\
1\end{array}$ & e-164 & 58 & $\begin{array}{l}\text { CDD10741, COG1012, PutA, NAD-abhängige } \\
\text { Aldehyd-Dehydrogenase (4e-113) }\end{array}$ & E \\
\hline 1007 & 295 & $\begin{array}{l}\text { Potentielle Metall-abhängige } \\
\text { Hydrolase (COG3618) }\end{array}$ & Hypothetisches Protein & $\begin{array}{l}\text { Mesorhizobium } \\
\text { loti }\end{array}$ & $\begin{array}{l}\text { NP_103232. } \\
1\end{array}$ & e-147 & 84 & 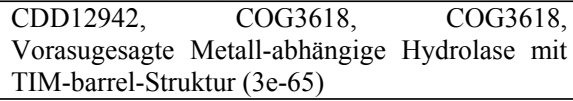 & E \\
\hline 1008 & 376 & $\begin{array}{lllr}\text { CoxE, Protein } & \text { mit } & \text { von } \\
\text { Willebrand } & \text { Faktor } & \text { Typ } & \text { A } \\
\text { (COG3552) } & & & \\
\end{array}$ & Hypothetisches Protein & $\begin{array}{l}\text { Mesorhizobium } \\
\text { loti }\end{array}$ & $\begin{array}{l}\text { NP_103231. } \\
1\end{array}$ & e-109 & 67 & $\begin{array}{l}\text { CDD12879, COG3552, CoxE, Protein mit von } \\
\text { Willebrand Faktor Typ A (vWA) Domäne (1e- } \\
\text { 64) }\end{array}$ & E \\
\hline 1009 & 292 & $\begin{array}{l}\text { CoxD (MoxR-ähnliche ATPase, } \\
\text { COG0714) }\end{array}$ & Hypothetisches Protein mlr1705 & $\begin{array}{l}\text { Mesorhizobium } \\
\text { loti }\end{array}$ & $\begin{array}{l}\text { NP_103230. } \\
1\end{array}$ & e-113 & 76 & $\begin{array}{l}\text { CDD10583, COG0714, COG0714, MoxR- } \\
\text { ähnliche ATPasen (1e-25) }\end{array}$ & E \\
\hline 1010 & 334 & CoxL & Vorausgesagte Dehydrogenase & $\begin{array}{l}\text { Mesorhizobium } \\
\text { loti }\end{array}$ & $\begin{array}{l}\text { NP_254264. } \\
1\end{array}$ & e-153 & 80 & $\begin{array}{l}\text { CDD11243, COG1529, CoxL, } \\
\text { Kohlenmonoxid-Dehydrogenase, } \\
\text { Untereinheit CoxL/CutL Homologe (1e-51) }\end{array}$ & E \\
\hline 1011 & 456 & CoxL & Vorausgesagte Dehydrogenase & $\begin{array}{l}\text { Mesorhizobium } \\
\text { loti }\end{array}$ & $\begin{array}{l}\text { NP_254264. } \\
1\end{array}$ & 0.0 & 80 & $\begin{array}{l}\text { CDD11243, COG1529, CoxL, } \\
\text { Kohlenmonoxid-Dehydrogenase, } \\
\text { Untereinheit CoxL/CutL Homologe (4e-87) }\end{array}$ & $\mathrm{E}$ \\
\hline 1012 & 160 & CoxS (COG2080) & Potentielle Dehydrogenase & $\begin{array}{l}\text { Mesorhizobium } \\
\text { loti }\end{array}$ & $\begin{array}{l}\text { NP_103227. } \\
1\end{array}$ & $8 \mathrm{e}-69$ & 85 & $\begin{array}{l}\text { CDD11788, COG2080, CoxS, aerobe } \\
\text { Kohlenmonoxid-Dehydrogenase, } \\
\text { Untereinheit CoxS/CutS Homologe (5e-52) }\end{array}$ & E \\
\hline
\end{tabular}




\begin{tabular}{|c|c|c|c|c|c|c|c|c|c|}
\hline $\begin{array}{l}\text { ORF- } \\
\text { Name }\end{array}$ & Größe & Annotation & Ähnlichstes Protein bei NCBI & Organismus & $\begin{array}{l}\text { Accession- } \\
\text { Nummer }\end{array}$ & $\begin{array}{ll}\text { e- } \\
\text { Value }\end{array}$ & $\begin{array}{l}\text { I in } \\
\%\end{array}$ & Konservierte Domänen bei NCBI & $\begin{array}{l}\text { Funk- } \\
\text { tion }\end{array}$ \\
\hline 1013 & 265 & CoxM (COG1319) & Potentielle Oxidoreduktase & $\begin{array}{l}\text { Mesorhizobium } \\
\text { loti }\end{array}$ & $\begin{array}{l}\text { NP_103226. } \\
1\end{array}$ & $2 \mathrm{e}-74$ & 68 & $\begin{array}{l}\text { CDD11035, COG1319, CoxM, } \\
\text { Kohlenmonoxid-Dehydrogenase, } \\
\text { Untereinheit CoxM/CutM Homologe } \\
\text { (5e-33) }\end{array}$ & E \\
\hline 1014 & 147 & Konserviertes Protein & Unbekanntes Protein & $\begin{array}{l}\text { Mesorhizobium } \\
\text { loti }\end{array}$ & $\begin{array}{l}\text { NP_103225. } \\
1\end{array}$ & $2 \mathrm{e}-55$ & 69 & $\begin{array}{l}\text { CDD23587, pfam05146, DUF704, Aha1- } \\
\text { Domäne. (3e-05) }\end{array}$ & $\mathrm{KP}$ \\
\hline 1015 & 274 & $\begin{array}{l}\text { Potentieller } \begin{array}{l}\text { Transkriptions- } \\
\text { regulator, AraC-Familie }\end{array} \\
\end{array}$ & Potentieller Transkriptionsregulator & $\begin{array}{l}\text { Mesorhizobium } \\
\text { loti }\end{array}$ & $\begin{array}{l}\text { NP_103224. } \\
1\end{array}$ & $1 \mathrm{e}-49$ & 74 & $\begin{array}{l}\text { CDD11914, COG2207, AraC, AraC-Typ DNA- } \\
\text { Bindedomäne enthaltendes Protein (1e-18) }\end{array}$ & TS \\
\hline 1016 & 443 & $\begin{array}{l}\text { ABC-Transporter, periplasma- } \\
\text { tisches Substrat-bindendes } \\
\text { Protein, UgpB (COG1653) }\end{array}$ & $\begin{array}{l}\text { ABC-Transporter periplasmatisches } \\
\text { Substrat-bindendes Protein }\end{array}$ & $\begin{array}{l}\text { Mesorhizobium } \\
\text { loti }\end{array}$ & $\begin{array}{l}\text { NP_105991. } \\
1\end{array}$ & 0.0 & 81 & $\begin{array}{lrr}\text { CDD11364, COG1653, } & \text { UgpB, ABC-Typ } \\
\text { Zucker-Transport-System, } & \text { periplasmatische } \\
\text { Komponente (6e-30) } & \end{array}$ & KH-M \\
\hline 1017 & 332 & $\begin{array}{l}\text { ABC-Transporter, } \\
\text { UgpA (COG1175, }\end{array}$ & ABC-Transporter, Permease & $\begin{array}{l}\text { Mesorhizobium } \\
\text { loti }\end{array}$ & $\begin{array}{l}\text { NP_105990. } \\
1\end{array}$ & e-143 & 83 & $\begin{array}{llll}\text { CDD10893, COG1175, } & \text { UgpA, } & \text { ABC-Typ } \\
\text { Zucker-Transport-System, } & & \text { Permease- } \\
\text { Komponente (2e-60) } & & \end{array}$ & KH-M \\
\hline 1018 & 315 & $\begin{array}{ll}\text { ABC-Transporter, } & \text { Permease, } \\
\text { UgpE (COG0395) }\end{array}$ & ABC-Transporter, Permease & $\begin{array}{l}\text { Mesorhizobium } \\
\text { loti }\end{array}$ & $\begin{array}{l}\text { NP_105989. } \\
1\end{array}$ & e-144 & 90 & $\begin{array}{l}\text { CDD10269, COG0395, UgpE, ABC-Typ Zucker- } \\
\text { Transport-System, Permease-Komponente (4e- } \\
54)\end{array}$ & KH-M \\
\hline 1019 & 68 & Hypothetisches Protein & Unbekanntes Protein & $\begin{array}{l}\text { Mesorhizobium } \\
\text { loti }\end{array}$ & $\begin{array}{l}\text { NP_105988. } \\
1\end{array}$ & $3 e-17$ & 73 & & HP \\
\hline 1020 & 369 & $\begin{array}{lr}\text { ABC-Transporter, } & \text { ATPase- } \\
\text { Komponente, } & \text { MalK } \\
\text { (COG3839) } & \end{array}$ & ABC-Transporter, ATP-Bindeprotein & $\begin{array}{l}\text { Mesorhizobium } \\
\text { loti }\end{array}$ & $\begin{array}{l}\text { NP_105987. } \\
1\end{array}$ & e-179 & 85 & $\begin{array}{l}\text { CDD13156, COG3839, MalK, ABC-Typ Zucker- } \\
\text { Transport-System, ATPase-Komponente (9e-115) }\end{array}$ & KH-M \\
\hline 1021 & 338 & $\begin{array}{lr}\text { ABC-Transporter, } & \text { ATPase- } \\
\text { Komponente, } & \text { MalK } \\
\text { (COG3839) } & \end{array}$ & ABC-Transporter, ATP-Bindeprotein & $\begin{array}{l}\text { Mesorhizobium } \\
\text { loti }\end{array}$ & $\begin{array}{l}\text { NP_105986. } \\
1\end{array}$ & e-143 & 75 & $\begin{array}{l}\text { CDD13156, COG3839, MalK, ABC-Typ Zucker- } \\
\text { Transport-System, ATPase-Komponente (8e-103) }\end{array}$ & KH-M \\
\hline 1022 & 200 & Dak2 & Hypothetisches Protein & $\begin{array}{l}\text { Mesorhizobium } \\
\text { loti }\end{array}$ & $\begin{array}{l}\text { NP_105984. } \\
1\end{array}$ & $5 e-52$ & 65 & $\begin{array}{l}\text { CDD25948, pfam02734, Dak2, DAK2 Domäne } \\
(6 \mathrm{e}-29)\end{array}$ & $\mathrm{E}$ \\
\hline 1023 & 129 & EIIA-man, PTS & Hypothetisches Protein & $\begin{array}{l}\text { Mesorhizobium } \\
\text { loti }\end{array}$ & $\begin{array}{l}\text { NP_105983. } \\
1\end{array}$ & $9 \mathrm{e}-41$ & 87 & $\begin{array}{l}\text { CDD12743, COG3412, Uncharakterisiertes } \\
\text { Protein, konserviert in Bakterien (4e-32) }\end{array}$ & $\mathrm{E}$ \\
\hline 1024 & 103 & $\begin{array}{l}\begin{array}{l}\text { HPr-verwandtes Protein, PTS } \\
\text { (COG1925) }\end{array} \\
\end{array}$ & Phosphocarrier-Protein HP & $\begin{array}{l}\text { Mesorhizobium } \\
\text { loti }\end{array}$ & $\begin{array}{l}\text { NP_105982. } \\
1\end{array}$ & $4 \mathrm{e}-21$ & 64 & $\begin{array}{l}\text { CDD11633, COG1925, FruB, Phosphotrans- } \\
\text { ferase-System, HPr-verwandte Proteine }(1 \mathrm{e}-10)\end{array}$ & $\mathrm{E}$ \\
\hline 1025 & 533 & $\begin{array}{l}\text { EI, PTS (Phosphoenolpyruvat- } \\
\text { Protein-Kinase) }\end{array}$ & Phosphoenolpyruvat-Protein & $\begin{array}{l}\text { Mesorhizobium } \\
\text { loti }\end{array}$ & $\begin{array}{l}\text { NP_105981. } \\
1\end{array}$ & e-145 & 61 & $\begin{array}{lr}\text { CDD10803, COG1080, } & \text { PtsA, } \\
\text { Phosphoenolpyruvat-Protein-Kinase } & \text { (PTS- } \\
\text { System EI Komponente in Bakterien) } & (8 \mathrm{e}-114)\end{array}$ & $\mathrm{E}$ \\
\hline 1026 & 144 & Konserviertes Protein & Unbekanntes Protein & $\begin{array}{l}\text { Mesorhizobium } \\
\text { loti }\end{array}$ & $\begin{array}{l}\text { NP_105980. } \\
1\end{array}$ & $1 \mathrm{e}-48$ & 76 & & $\mathrm{KP}$ \\
\hline 1027 & 328 & $\begin{array}{l}\text { Dihydroxyacetonkinase, } \\
\text { Dak1 (COG2376) }\end{array}$ & Hypothetisches Protein & $\begin{array}{l}\text { Mesorhizobium } \\
\text { loti }\end{array}$ & $\begin{array}{l}\text { NP_105979. } \\
1\end{array}$ & e-127 & 73 & $\begin{array}{lcc}\text { CDD12048, } & \text { COG2376, } \\
\text { Dihydroxyacetone-Kinase (1e-77) } & \text { DAK1, } \\
\end{array}$ & $\mathrm{E}$ \\
\hline 1028 & 278 & $\begin{array}{l}\text { Potentielles universelles Stress- } \\
\text { Protein UspA }\end{array}$ & Unbekanntes Protein & Rhizobium etli & $\begin{array}{l}\text { NP_660023. } \\
1\end{array}$ & $2 \mathrm{e}-27$ & 32 & $\begin{array}{l}\text { CDD10459, COG0589, UspA, universelles } \\
\text { Stress-Protein UspA und verwandte Nukleotid- } \\
\text { bindende Verwandte (5e-05) }\end{array}$ & ST \\
\hline 1029 & 527 & Sensor-Protein FixL (EC 2.7.3.-) & $\begin{array}{l}\text { FixL Sauerstoff-regulierte Histidin- } \\
\text { Kinase }\end{array}$ & $\begin{array}{l}\text { Sinorhizobium } \\
\text { meliloti }\end{array}$ & $\begin{array}{l}\text { NP_435916. } \\
1\end{array}$ & e-136 & 65 & $\begin{array}{l}\text { CDD13451, COG4191, Signal-Transduktions- } \\
\text { Histidin-Kinase regulierendes C4-Dicarboxylat- } \\
\text { Transport-System (2e-40) }\end{array}$ & ST \\
\hline
\end{tabular}




\begin{tabular}{|c|c|c|c|c|c|c|c|c|c|}
\hline $\begin{array}{l}\text { ORF- } \\
\text { Name }\end{array}$ & Größe & Annotation & Ähnlichstes Protein bei NCBI & Organismus & $\begin{array}{l}\text { Accession- } \\
\text { Nummer }\end{array}$ & $\begin{array}{l}\text { e- } \\
\text { Value }\end{array}$ & $\begin{array}{l}I \text { in } \\
\%\end{array}$ & Konservierte Domänen bei NCBI & $\begin{array}{l}\text { Funk- } \\
\text { tion }\end{array}$ \\
\hline 1030 & 207 & Transkriptionsregulator FixJ & Transkriptionsaktivator FixJ & $\begin{array}{l}\text { Sinorhizobium } \\
\text { meliloti }\end{array}$ & $\begin{array}{l}\text { NP_435915. } \\
1\end{array}$ & $1 \mathrm{e}-61$ & 66 & $\begin{array}{l}\text { CDD13729, COG4566, } \\
\text { regulator" (3e-59) }\end{array}$ & ST \\
\hline 1031 & 121 & $\begin{array}{lr}\begin{array}{l}\text { Hypothetisches } \\
\text { (potentieller }\end{array} & \text { Protein } \\
\text { regulator FixT2) } & \text { Transkriptions- }\end{array}$ & FixT2 Transkriptionsregulator & $\begin{array}{l}\text { Sinorhizobium } \\
\text { meliloti }\end{array}$ & $\begin{array}{l}\mathrm{NP} \_435653 . \\
1\end{array}$ & $2 \mathrm{e}-08$ & 36 & $\begin{array}{l}\text { CDD13729, COG4566, } \\
\text { regulator" }(2 \mathrm{e}-05)\end{array}$ & ST \\
\hline 1032 & 216 & $\begin{array}{l}\text { Regulationsprotein bei der } \\
\text { Stickstofffixierung, FixK }\end{array}$ & $\begin{array}{l}\text { Regulationsprotein bei } \quad \text { der } \\
\text { Stickstofffixierung, FixK }\end{array}$ & $\begin{array}{l}\text { Mesorhizobium } \\
\text { loti }\end{array}$ & $\begin{array}{l}\text { NP_107057. } \\
1\end{array}$ & $2 \mathrm{e}-65$ & 69 & $\begin{array}{l}\text { CDD10533, COG0664, Crp, cAMP-bindendes } \\
\text { Protein - Katabolit-Genaktivator und } \\
\text { regulatorische Untereinheit von cAMP- } \\
\text { abhängigen Protein-Kinasen (7e-26) }\end{array}$ & ST \\
\hline 1033 & 445 & Konserviertes Protein & Konserviertes hypothetisches Protein & Brucella suis 1330 & $\begin{array}{l}\text { NP_699686. } \\
1\end{array}$ & e-101 & 47 & $\begin{array}{l}\text { CDD13703, } \\
\begin{array}{l}\text { COG4529, } \\
\text { Uncharakterisiertes }\end{array} \\
\begin{array}{l}\text { Protein }(3 \mathrm{e}-88) \\
\text { in }\end{array}\end{array}$ & KP \\
\hline 1034 & 295 & $\begin{array}{l}\text { Dienlacton-Hydrolase und } \\
\text { verwandte Enzyme (COG0412) }\end{array}$ & Potentielles Enzym & $\begin{array}{l}\text { Escherichia coli } \\
\text { O157:H7 EDL933 }\end{array}$ & $\begin{array}{l}\text { NP_289577. } \\
1\end{array}$ & e-127 & 75 & $\begin{array}{l}\text { CDD10286, COG0412, COG0412, Dienelacton- } \\
\text { Hydrolase und verwandte Enzyme (4e-42) }\end{array}$ & SM-BT \\
\hline 1035 & 491 & $\begin{array}{l}\text { Uncharakterisiertes, in den } \\
\text { Propionat-Katabolismus } \\
\text { involviertes Protein } \\
\text { (COG2079, PrpD) }\end{array}$ & $\begin{array}{l}\text { COG2079: Uncharakterisiertes, in den } \\
\text { Propionat-Katabolismus involviertes } \\
\text { Protein }\end{array}$ & $\begin{array}{l}\text { Burkholderia } \\
\text { fungorum }\end{array}$ & $\begin{array}{l}\text { ZP_0002783 } \\
4.1\end{array}$ & $2 \mathrm{e}-43$ & 33 & $\begin{array}{l}\text { CDD11787, } \\
\text { Uncharakterisiertes, in den }\end{array} \begin{array}{l}\text { PrpD, } \\
\text { Katabolismus involviertes Protein }(7 \mathrm{e}-41)\end{array}$ & $\mathrm{E}$ \\
\hline 1036 & 373 & $\begin{array}{l}\text { COG1804, Vorausgesagte Acyl- } \\
\text { CoA-Transferase/Carnitin- } \\
\text { Dehydratase, CaiB }\end{array}$ & Blr 7246 & $\begin{array}{l}\text { Bradyrhizobium } \\
\text { japonicum }\end{array}$ & $\begin{array}{l}\text { NP_773886. } \\
1\end{array}$ & $1 \mathrm{e}-99$ & 52 & $\begin{array}{l}\text { CDD11514, COG1804, CaiB, Vorausgesagte } \\
\text { Acyl-CoA-Transferase/Carnitin-Dehydratase } \\
\text { (2e-85) }\end{array}$ & LM \\
\hline 1037 & 392 & $\begin{array}{l}\text { Acyl-CoA- } \quad \text { Dehydrogenase, } \\
\text { CaiA (EC 1.3.99.3), (COG1960) }\end{array}$ & $\begin{array}{l}\text { Protein der Acyl-CoA- Dehydrogenase- } \\
\text { Familie }\end{array}$ & $\begin{array}{l}\text { Caulobacter } \\
\text { crescentus CB15 }\end{array}$ & $\begin{array}{l}\text { NP_419926. } \\
1\end{array}$ & e-163 & 74 & $\begin{array}{l}\text { CDD11668, COG1960, } \\
\text { Dehydrogenasen }(4 \mathrm{e}-70)\end{array}$ & LM \\
\hline 1038 & 389 & $\begin{array}{l}\text { L-Alanin-DL-Glutamat- } \\
\text { Epimerase und verwandte } \\
\text { Enzyme der Enolase- } \\
\text { Superfamilie (COG4948) }\end{array}$ & $\begin{array}{l}\text { Protein der Familie der Mandelat- } \\
\text { Racemasen/Muconat-laktonisierenden } \\
\text { Enzyme }\end{array}$ & $\begin{array}{lr}\begin{array}{l}\text { Pseudomonas } \\
\text { syringae }\end{array} \\
\text { tomato } & \text { Stamm } \\
\text { DC3000 } & \end{array}$ & NP_793824 & $7 \mathrm{e}-164$ & 72 & $\begin{array}{l}\text { CDD14081, COG4948, L-Alanin-DL-Glutamat- } \\
\text { Epimerase und verwandte Enzyme der Enolase- } \\
\text { Superfamilie (5e-44) }\end{array}$ & ZH-B \\
\hline 1039 & 110 & Hypothetisches Protein & Keine signifikante Übereinstimmung & & & & & & HP \\
\hline
\end{tabular}

\section{K) Cosmid Slc_2g}

\begin{tabular}{|c|c|c|c|c|c|c|c|c|c|}
\hline 1101 & 211 & Potentielle Protease & N-Acyl-L-Aminosäure-Amidohydrolase & $\begin{array}{l}\text { Xanthomonas } \\
\text { axonopodis pv. } \\
\text { Citri Stamm } 306\end{array}$ & $\begin{array}{l}\text { NP_644153. } \\
1\end{array}$ & $8 \mathrm{e}-31$ & 45 & $\begin{array}{l}\text { CDD11187, COG1473, AbgB, } \\
\text { unabhängige Amidase/ } \\
\text { Aminoacylase/Carboxypeptidase (2e-40) }\end{array}$ & AS-M \\
\hline 1102 & 120 & Hypothetisches Protein & Keine signifikante Übereinstimmung & & & & & & HP \\
\hline 1103 & 738 & $\begin{array}{l}\text { Potentielle Protease yuxL (EC } \\
\text { 3.4.21.-) }\end{array}$ & $\begin{array}{l}\begin{array}{l}\text { Peptidase } \\
\text { Familie }\end{array} \\
\end{array}$ & $\begin{array}{l}\text { Bacillus anthracis } \\
\text { A2012 }\end{array}$ & $\begin{array}{l}\text { NP_654107. } \\
1\end{array}$ & $1 \mathrm{e}-60$ & 27 & $\begin{array}{l}\text { CDD11220, COG1506, DAP2, Dipeptidylamino- } \\
\text { peptidasen/Acylaminoacyl-Peptidasen (9e-63) }\end{array}$ & AS-M \\
\hline 1104 & 1113 & Konserviertes Protein & Hypothetische Amidohydrolase & $\begin{array}{l}\text { Shewanella } \\
\text { oneidensis MR-1 }\end{array}$ & $\begin{array}{l}\text { NP_715659. } \\
1\end{array}$ & $1 \mathrm{e}-138$ & 30 & $\begin{array}{l}\text { CDD10690, COG0823, TolB, Periplasmatische } \\
\text { Komponente des Tol Biopolymer-Transport- } \\
\text { Systems (2e-13) }\end{array}$ & KP \\
\hline
\end{tabular}




\begin{tabular}{|c|c|c|c|c|c|c|c|c|c|}
\hline $\begin{array}{l}\text { ORF- } \\
\text { Name }\end{array}$ & Größe & Annotation & Ähnlichstes Protein bei NCBI & Organismus & $\begin{array}{l}\text { Accession- } \\
\text { Nummer }\end{array}$ & $\begin{array}{l}\text { e- } \\
\text { Value }\end{array}$ & $\begin{array}{l}\text { I in } \\
\%\end{array}$ & Konservierte Domänen bei NCBI & $\begin{array}{l}\text { Funk- } \\
\text { tion }\end{array}$ \\
\hline 1105 & 189 & $\begin{array}{l}\text { Hypothetisches } \\
\text { assoziiertes Protein }\end{array}$ & \multicolumn{6}{|l|}{ Keine signifikante Übereinstimmung } & HP \\
\hline 1106 & 136 & Konserviertes Protein & Hypothetisches Protein & $\begin{array}{l}\text { Mesorhizobium } \\
\text { loti }\end{array}$ & $\begin{array}{l}\text { NP_103254. } \\
1\end{array}$ & $4 \mathrm{e}-18$ & 48 & $\begin{array}{l}\text { CDD11497, COG1786, } \\
\text { Uncharakterisiertes konserviertes Protein }(3 \mathrm{e}-20)\end{array}$ & $\mathrm{KP}$ \\
\hline 1107 & 423 & $\begin{array}{ll}\begin{array}{l}\text { Konserviertes } \\
\text { (pfam04412) }\end{array} & \text { Protein } \\
\end{array}$ & $\begin{array}{l}\text { COG1679: } \\
\text { konserviertes Protein }\end{array}$ & $\begin{array}{l}\text { Burkholderia } \\
\text { fungorum }\end{array}$ & $\begin{array}{l}\text { ZP_0002799 } \\
8.1\end{array}$ & $1 \mathrm{e}-101$ & 49 & $\begin{array}{l}\text { CDD15710 pfam04412, DUF521, Protein mit } \\
\text { unbekannter Funktion (DUF521). (3e-98) }\end{array}$ & KP \\
\hline 1108 & 260 & $\begin{array}{ll}\text { Konserviertes } & \text { membran- } \\
\text { assoziiertes Protein } & \end{array}$ & Potentielle Methyltransferase & $\begin{array}{l}\text { Bdellovibrio } \\
\text { bacteriovorus }\end{array}$ & CAE79571.1 & $8 \mathrm{e}-14$ & 27 & $\begin{array}{l}\text { CDD11934, COG2227, UbiG, 2-Polyprenyl-3- } \\
\text { methyl-5-hydroxy-6-metoxy-1,4-benzoquinol- } \\
\text { Methylase (6e-10) }\end{array}$ & $\mathrm{KP}$ \\
\hline 1109 & 346 & $\begin{array}{l}\text { Threonin-Dehydratase } \quad \text { (EC } \\
\text { 4.2.1.16) }\end{array}$ & COG1171: Threonin-Dehydratase & $\begin{array}{l}\text { Nostoc } \\
\text { punktiformis }\end{array}$ & $\begin{array}{l}\text { ZP_0011013 } \\
2.1\end{array}$ & $2 \mathrm{e}-51$ & 40 & $\begin{array}{l}\text { CDD10889, COG1171, IlvA, } \\
\text { Dehydratase (6e-76) }\end{array}$ & AS-M \\
\hline 1110 & 147 & $\begin{array}{l}\text { Potentielles } \\
\text { induzierbares Protein }\end{array}$ & $\begin{array}{lr}\text { COG1764: } & \text { Vorausgesagtes } \\
\text { Redoxprotein, Regulation } & \text { von } \\
\text { Disulfidbrückenbildung } & \end{array}$ & $\begin{array}{l}\text { Cytophaga } \\
\text { hutchinsonii }\end{array}$ & $\begin{array}{l}\text { ZP_0011805 } \\
8.1\end{array}$ & $8 e-27$ & 47 & 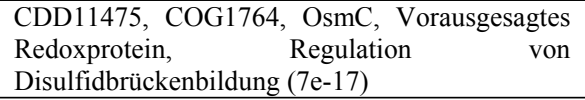 & PPM \\
\hline 1111 & 330 & $\begin{array}{l}\begin{array}{l}\text { Hypothetisches } \\
\text { assoziiertes Protein }\end{array} \\
\end{array}$ & Hypothetisches Protein & $\begin{array}{l}\text { Microbulbifer } \\
\text { degradans 2-40 }\end{array}$ & $\begin{array}{l}\text { ZP_0006611 } \\
7.1\end{array}$ & $2 \mathrm{e}-24$ & 32 & & HP \\
\hline 1112 & 555 & $\gamma$-Glutamyl-Transpeptidase & Potentielle Glutamyltransferase & $\begin{array}{l}\text { Bordetella } \\
\text { bronchiseptica } \\
\text { RB50 }\end{array}$ & $\begin{array}{l}\text { NP_888143. } \\
1\end{array}$ & $6 e-83$ & 42 & $\begin{array}{lc}\text { CDD24503, } & \text { pfam01019, } \\
\text { Glutamyltranspeptidase }(5 e-126)\end{array}$ & AS-M \\
\hline 1113 & 734 & Glutamin-Synthetase & Gluthamin-Synthetase & $\begin{array}{l}\text { Chlorobium } \\
\text { tepidum TLS }\end{array}$ & $\begin{array}{l}\text { NP_662297. } \\
1\end{array}$ & 0.0 & 51 & $\begin{array}{l}\text { CDD13274, COG3968, } \\
\text { Uncharakterisiertes Protein mit Verwandtschaft } \\
\text { zu Gluthamin-Synthetasen }(0.0)\end{array}$ & AS-M \\
\hline 1114 & 1075 & $\begin{array}{l}\text { Hypothetisches membran- } \\
\text { durchspannendes Protein }\end{array}$ & \multicolumn{6}{|l|}{$\begin{array}{l}\text { Keine signifikante Übereinstimmung } \\
\text { Kommentar: Ähnlichkeit zu ORF } 85 \text { (2e-28) }\end{array}$} & HP \\
\hline 1115 & 836 & $\begin{array}{l}\text { Hypothetisches membran- } \\
\text { durchspannendes Protein }\end{array}$ & \multicolumn{6}{|c|}{$\begin{array}{l}\text { Keine signifikante Übereinstimmung } \\
\text { Kommentar: Ähnlichkeit zu ORF } 84 \text { (2e-28) }\end{array}$} & HP \\
\hline 1116 & 325 & $\begin{array}{l}\text { Potentielle } \\
\text { Dehydratase (EC 4.2.1.16) } \\
\end{array}$ & Threonin-Dehydratase-Familien-Protein & $\begin{array}{l}\text { Pseudomonas } \\
\text { putida KT2440 }\end{array}$ & $\begin{array}{l}\text { NP_745335. } \\
1\end{array}$ & $2 \mathrm{e}-59$ & 44 & $\begin{array}{llll}\text { CDD10889, } & \text { COG1171, } & \text { IlvA, } & \text { Threonin- } \\
\text { Dehydratase (2e-66) } & & \\
\end{array}$ & AS-M \\
\hline 1117 & 589 & $\begin{array}{l}\text { COG2989, Uncharakterisiertes } \\
\text { in Bakterien konserviertes } \\
\text { Protein }\end{array}$ & $\begin{array}{l}\text { COG2989: Uncharakterisiertes } \\
\text { Bakterien konserviertes Protein }\end{array}$ & $\begin{array}{l}\text { Ralstonia } \\
\text { metallidurans }\end{array}$ & $\begin{array}{l}\text { ZP_0002568 } \\
1.1\end{array}$ & $9 e-51$ & 31 & $\begin{array}{l}\text { CDD12333, } \\
\text { Uncharakterisiertes } \\
\text { Protein (6e-64) }\end{array}$ & KP \\
\hline 1118 & 434 & Glutamin-Synthetase & $\begin{array}{l}\text { Gluthamin-Synthetase } \\
\text { Ammonium-Ligase) }\end{array}$ & $\begin{array}{l}\text { Clostriduium } \\
\text { saccharobutylicum }\end{array}$ & $\begin{array}{l}\text { GLNA_CLO } \\
\text { SA }\end{array}$ & $1 \mathrm{e}-147$ & 57 & $\begin{array}{l}\text { CDD10049, COG0174, GlnA, } \text { Glutamin- } \\
\text { Synthetase }(2 \mathrm{e}-140)\end{array}$ & AS-M \\
\hline 1119 & 321 & $\begin{array}{l}\begin{array}{l}\text { Hypothetisches } \\
\text { assoziiertes Protein }\end{array} \\
\end{array}$ & \multicolumn{6}{|l|}{ Keine signifikante Übereinstimmung } & HP \\
\hline 1120 & 282 & $\begin{array}{ll}\begin{array}{l}\text { Konserviertes } \\
(\text { COG2107) }\end{array} & \text { Protein }\end{array}$ & Potentielles Protein & Aquifex aeolicus & $\begin{array}{l}\text { NP_213214. } \\
1\end{array}$ & $4 e-75$ & 53 & $\begin{array}{l}\text { CDD3149, pfam02642, } \quad \text { DUF191, } \\
\text { Uncharakterisiertes Protein ACR, COG2107. (2e- } \\
\text { 71) }\end{array}$ & KP \\
\hline 1121 & 1051 & $\begin{array}{l}\text { Potentielles Sensor-Protein AtoS } \\
\text { (EC 2.7.3.-) }\end{array}$ & Hypothetisches Protein & $\begin{array}{l}\text { Chloroflexus } \\
\text { aurantiacus }\end{array}$ & $\begin{array}{l}\text { ZP_0001789 } \\
6.1\end{array}$ & $4 \mathrm{e}-43$ & 42 & $\begin{array}{lccc}\text { CDD10512, } & \text { COG0642, } & \text { BaeS, } & \text { Signal- } \\
\text { Transductions Histidin-Kinase } & (2 \mathrm{e}-30) & \\
\end{array}$ & ST \\
\hline
\end{tabular}




\begin{tabular}{|c|c|c|c|c|c|c|c|c|c|}
\hline $\begin{array}{l}\text { ORF- } \\
\text { Name }\end{array}$ & Größe & Annotation & Ähnlichstes Protein bei NCBI & Organismus & $\begin{array}{l}\text { Accession- } \\
\text { Nummer }\end{array}$ & $\begin{array}{l}\text { e- } \\
\text { Value }\end{array}$ & $\begin{array}{l}I \text { in } \\
\%\end{array}$ & Konservierte Domänen bei NCBI & $\begin{array}{l}\text { Funk- } \\
\text { tion }\end{array}$ \\
\hline 1122 & 222 & Hypothetisches Protein & \multicolumn{6}{|l|}{ Keine signifikante Übereinstimmung } & HP \\
\hline 1123 & 529 & $\begin{array}{ll}\text { Potentielle } & \text { Sensor-Hisidin- } \\
\text { Kinase } & \end{array}$ & Sensor-Box-Hisidin-Kinase & $\begin{array}{l}\text { Geobacter } \\
\text { sulfurreducens } \\
\text { PCA }\end{array}$ & $\begin{array}{l}\text { NP_952058. } \\
1\end{array}$ & $1 \mathrm{e}-26$ & 33 & $\begin{array}{lccc}\text { CDD10512, } & \text { COG0642, } & \text { BaeS, } & \text { Signal- } \\
\text { Transductions Histidin-Kinase } & (8 \mathrm{e}-26) & \end{array}$ & ST \\
\hline 1124 & 118 & $\begin{array}{l}\text { Hypothetisches “,response- } \\
\text { regulator-receiver“ Protein }\end{array}$ & \multicolumn{3}{|c|}{ Kein Hit; Annotation beruht auf konservierter Domäne AtoC (e-value: 1e-10) } & & & $\begin{array}{l}\text { CDD11911, COG2204, AtoC, “,response- } \\
\text { regulator “ Protein mit CheY-ähnlicher } \\
\text { "receiver”-Domäne, AAA-Type ATPase und } \\
\text { DNA-Bindedomänen (4e-10) }\end{array}$ & ST \\
\hline 1125 & 173 & Hypothetisches Protein & \multicolumn{6}{|l|}{ Keine signifikante Übereinstimmung } & HP \\
\hline 1126 & 239 & $\begin{array}{l}\text { Potentielle } \quad \text { Kurzketten- } \\
\text { Dehydrogenase/Reduktase }\end{array}$ & Glukose-1-Dehydrogenase; YwfD & $\begin{array}{l}\text { Halobacterium sp. } \\
\text { NRC-1 }\end{array}$ & $\begin{array}{l}\text { NP_280345. } \\
1\end{array}$ & $2 \mathrm{e}-14$ & 35 & $\begin{array}{l}\text { CDD18519, KOG0725, KOG0725, KOG0725, } \\
\text { Reduktasen mit breitem Substratspektrum }\end{array}$ & KH-M \\
\hline 1127 & 297 & Hypothetisches Protein & \multicolumn{6}{|l|}{ Keine signifikante Übereinstimmung } & HP \\
\hline 1128 & 55 & Hypothetisches Protein & \multicolumn{6}{|c|}{ Keine signifikante Übereinstimmung; unvollständiger ORF } & $\mathrm{HP}$ \\
\hline
\end{tabular}

\section{L) Cosmid Slc_2j}

\begin{tabular}{|c|c|c|c|c|c|c|c|c|c|}
\hline 1201 & 321 & Hypothetisches Protein & \multicolumn{6}{|l|}{ Keine signifikante Übereinstimmung } & HP \\
\hline 1202 & 653 & Potentielle Aminopeptidase & Aminopeptidase $\mathrm{N}$ & $\begin{array}{l}\text { Thermoanaerobac } \\
\text { ter tengcongensis }\end{array}$ & $\begin{array}{l}\text { NP_624209. } \\
1\end{array}$ & $6 e-21$ & 25 & $\begin{array}{l}\text { CDD10182, COG0308, PepN, Aminopeptidase N } \\
\text { (3e-19) }\end{array}$ & AS-M \\
\hline 1203 & 332 & $\begin{array}{ll}\begin{array}{l}\text { Konserviertes } \\
(\text { COG3804) }\end{array} & \text { Protein }\end{array}$ & Konserviertes hypothetisches Protein & $\begin{array}{l}\text { Thermoanaerobac } \\
\text { ter tengcongensis }\end{array}$ & $\begin{array}{l}\text { NP_622857. } \\
1\end{array}$ & $2 \mathrm{e}-52$ & 37 & $\begin{array}{lll}\text { CDD13123, COG3804, } & \text { COG3804, } \\
\text { Uncharacterized conserved protein } & \text { related to } \\
\text { dihydrodipicolinate reductase (1e-34) }\end{array}$ & KP \\
\hline 1204 & 515 & $\begin{array}{lr}\text { Uroporphyrinogen } & \text { III- } \\
\text { Synthase/Methyltransferase } & \text { (EC } \\
4.2 .1 .75) & \\
\end{array}$ & $\begin{array}{lll}\text { COG0007: } & \text { Uroporphyrinogen } & \text { III- } \\
\text { Methylase } & & \end{array}$ & $\begin{array}{l}\text { Geobacter } \\
\text { metallireducens }\end{array}$ & $\begin{array}{l}\text { ZP_0008200 } \\
4.1\end{array}$ & $5 e-83$ & 38 & $\begin{array}{l}\text { CDD9883, COG0007, CysG, Uroporphyrinogen- } \\
\text { III methylase (1e-52) }\end{array}$ & CE-M \\
\hline 1205 & 308 & $\begin{array}{l}\text { Hypothetisches } \\
\text { assoziiertes Protein }\end{array}$ & \multicolumn{6}{|l|}{ Keine signifikante Übereinstimmung } & HP \\
\hline 1206 & 299 & $\begin{array}{l}\text { Hypothetisches membran- } \\
\text { assoziiertes Protein }\end{array}$ & \multicolumn{6}{|l|}{ Keine signifikante Übereinstimmung } & HP \\
\hline 1207 & 136 & $\begin{array}{l}\text { Hypothetisches membran- } \\
\text { durchspannendes Protein }\end{array}$ & \multicolumn{6}{|l|}{ Keine signifikante Übereinstimmung } & HP \\
\hline 1208 & 314 & $\begin{array}{l}\text { Konserviertes Protein (potentiell } \\
\text { AtpB, F0F1-Typ ATP-Synthase, } \\
\text { Untereinheit A) }\end{array}$ & ATP-Synthase F0, Untereinheit A & $\begin{array}{l}\text { Chlorobium } \\
\text { tepidum TLS }\end{array}$ & $\begin{array}{l}\text { NP_660927. } \\
1\end{array}$ & $4 \mathrm{e}-23$ & 34 & $\begin{array}{l}\text { CDD10230, COG0356, AtpB, F0F1-Typ ATP- } \\
\text { Synthase, Untereinheit A (5e-15) }\end{array}$ & $\mathrm{E}$ \\
\hline 1209 & 82 & Hypothetisches Protein & \multicolumn{6}{|l|}{ Keine signifikante Übereinstimmung } & HP \\
\hline 1210 & 167 & $\begin{array}{l}\text { Konserviertes Protein (potentiell } \\
\text { AtpB, F0F1-Typ ATP-Synthase, } \\
\text { Untereinheit B) }\end{array}$ & ATP-Synthase F0, Untereinheit B & $\begin{array}{l}\text { Chlorobium } \\
\text { tepidum TLS }\end{array}$ & $\begin{array}{l}\text { NP_660925. } \\
1\end{array}$ & $2 \mathrm{e}-15$ & 31 & $\begin{array}{l}\text { CDD10580, COG0711, AtpF, F0F1-Typ ATP- } \\
\text { Synthase, Untereinheit B (2e-12) }\end{array}$ & $\mathrm{E}$ \\
\hline 1211 & 307 & $\begin{array}{l}\text { Konserviertes hypothetisches } \\
\text { Protein }\end{array}$ & Hypothetisches Protein & $\begin{array}{l}\text { Chloroflexus } \\
\text { aurantiacus }\end{array}$ & $\begin{array}{l}\text { ZP_0001988 } \\
9.1\end{array}$ & $2 \mathrm{e}-27$ & 36 & $\begin{array}{l}\text { CDD10566, COG0697, RhaT, Permease der } \\
\text { "drug/metabolite"-Transporter } \\
\text { Superfamilie (3e-07) }\end{array}$ & KHP \\
\hline
\end{tabular}




\begin{tabular}{|c|c|c|c|c|c|c|c|c|c|}
\hline $\begin{array}{l}\text { ORF- } \\
\text { Name }\end{array}$ & Größe & Annotation & Ähnlichstes Protein bei NCBI & Organismus & $\begin{array}{l}\text { Accession- } \\
\text { Nummer }\end{array}$ & $\begin{array}{l}\text { e- } \\
\text { Value }\end{array}$ & $\begin{array}{l}I \text { in } \\
\%\end{array}$ & Konservierte Domänen bei NCBI & $\begin{array}{l}\text { Funk- } \\
\text { tion }\end{array}$ \\
\hline 1212 & 442 & Hypothetisches Protein & Keine signifikante Übereinstimmung & & & & & & $\mathrm{HP}$ \\
\hline 1213 & 612 & $\begin{array}{l}\text { Potentielle membranständige } \\
\text { GTPase (Stress-Antwort) }\end{array}$ & $\begin{array}{l}\text { Potentielle membranständige } \\
\text { (Stress-Antwort) }\end{array}$ & $\begin{array}{l}\text { Thermoanaero- } \\
\text { bacter } \\
\text { tengcongensis }\end{array}$ & $\begin{array}{l}\text { NP_622534. } \\
1\end{array}$ & 0.0 & 56 & 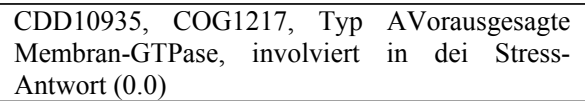 & ST \\
\hline 1214 & 167 & $\begin{array}{l}\text { Hypothetisches } \quad \text { Protein } \\
\text { (Hypothetisches Fe-S-Cluster) }\end{array}$ & COG0723: Rieske Fe-S Protein & $\begin{array}{l}\text { Desulfitobacteriu } \\
\text { m hafniense }\end{array}$ & $\begin{array}{l}\text { ZP_0009865 } \\
4.1\end{array}$ & $1 \mathrm{e}-16$ & 43 & $\begin{array}{l}\text { CDD10592, COG0723, QcrA, Rieske Fe-S } \\
\text { Protein (1e-16) }\end{array}$ & $\mathrm{E}$ \\
\hline 1215 & 523 & $\begin{array}{l}\text { Menaquinol-c-Reduktase, } \\
\text { Cytochrom B-Untereinheit }\end{array}$ & $\begin{array}{l}\text { COG1290: Cytochrom B-Untereinheit } \\
\text { des BC-Komplexes }\end{array}$ & $\begin{array}{l}\text { Geobacter } \\
\text { metallireducens }\end{array}$ & $\begin{array}{l}\text { ZP_0008115 } \\
8.1\end{array}$ & $3 e-46$ & 32 & $\begin{array}{l}\text { CDD11006, COG1290, QcrB, Cytochrom b- } \\
\text { Untereinheit des bc-Komplexes (9e-48) }\end{array}$ & $\bar{E}$ \\
\hline 1216 & 993 & $\begin{array}{l}\text { Konserviertes Protein (poten- } \\
\text { tielle Dipeptidylaminopep- } \\
\text { tidase/Acylaminoacylpeptidase) }\end{array}$ & Konserviertes hypothetisches Protein & $\begin{array}{l}\text { Chromobacterium } \\
\text { violaceum ATCC } \\
12472\end{array}$ & $\begin{array}{l}\text { NP_901973. } \\
1\end{array}$ & $1 \mathrm{e}-52$ & 36 & $\begin{array}{l}\text { CDD11220, COG1506, DAP2, Dipeptidyl- } \\
\text { Aminopeptidases/Acylaminoacyl-Peptidases (3e- } \\
\text { 29) }\end{array}$ & $\overline{\text { AS-M }}$ \\
\hline 1217 & 251 & Hypothetisches Protein & \multicolumn{6}{|l|}{ Keine signifikante Übereinstimmung } & $\mathrm{HP}$ \\
\hline 1218 & 163 & Hypothetisches Protein & \multicolumn{6}{|l|}{ Keine signifikante Übereinstimmung } & HP \\
\hline 1219 & 172 & Hypothetisches Protein & \multicolumn{6}{|l|}{ Keine signifikante Übereinstimmung } & HP \\
\hline 1220 & 549 & Hypothetisches Protein & \multicolumn{6}{|l|}{ Keine signifikante Übereinstimmung } & $\mathrm{HP}$ \\
\hline 1221 & 587 & $\begin{array}{l}\text { Hypothetisches membran- } \\
\text { assoziiertes Protein }\end{array}$ & \multicolumn{6}{|l|}{ Keine signifikante Übereinstimmung } & $\mathrm{HP}$ \\
\hline 1222 & 721 & $\begin{array}{l}\text { Dehydrogenase von verzweigten } \\
\alpha \text {-Ketosäuren E1 (KOG0525) }\end{array}$ & $\begin{array}{l}\text { (Pyruvat) Oxoisovalerat-Dehydrogenase } \\
\text { Fusion der } \alpha \text { - und } \beta \text { - Untereinheit }\end{array}$ & $\begin{array}{l}\text { Chlamydia } \\
\text { trachomatis }\end{array}$ & $\begin{array}{l}\text { NP_219847. } \\
1\end{array}$ & $1 \mathrm{e}-128$ & 41 & 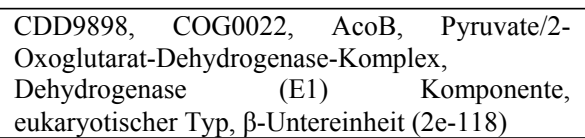 & $\mathrm{E}$ \\
\hline 1223 & 136 & Hypothetisches Protein & Konserviertes hypothetisches Protein & $\begin{array}{l}\text { Solibacter usitatus } \\
\text { Ellin6076 }\end{array}$ & $\begin{array}{l}\text { ZP_0052150 } \\
3\end{array}$ & $5 e-11$ & 36 & & HP \\
\hline 1224 & 256 & $\begin{array}{lr}\text { Konserviertes } & \text { membran- } \\
\text { durchspannendes } & \text { Protein } \\
(\text { COG0705) } & \end{array}$ & Protein der Rhomboid-Familie & $\begin{array}{l}\text { Leptospira } \\
\text { interrogans } \\
\text { serovar lai Stamm } \\
56601\end{array}$ & $\begin{array}{l}\text { NP_711400. } \\
1\end{array}$ & $1 \mathrm{e}-22$ & 31 & $\begin{array}{l}\text { CDD10574, COG0705, } \\
\text { Uncharakterisiertes } \\
\text { von Drosophila Rhomboid) } \\
\text { von-Protein }\end{array}$ & KP \\
\hline 1225 & 512 & Virulenz-Faktor MviN & $\begin{array}{l}\text { COG0728: } \quad \text { Uncharakterisierter } \\
\text { Membran-Protein; potentieller Virulenz- } \\
\text { Faktor }\end{array}$ & $\begin{array}{l}\text { Geobacter } \\
\text { metallireducens }\end{array}$ & $\begin{array}{l}\text { ZP_0007983 } \\
9.1\end{array}$ & $4 \mathrm{e}-46$ & 27 & $\begin{array}{l}\text { CDD3517, pfam03023, MviN-ähnliches Protein } \\
\text { (9e-61) }\end{array}$ & A \\
\hline 1226 & 149 & $\begin{array}{l}\text { Konserviertes hypothetisches } \\
\text { Protein (COG1610) }\end{array}$ & Hypothetisches Protein & $\begin{array}{l}\text { Myxococcus } \\
\text { xanthus }\end{array}$ & S70830 & $3 e-16$ & 38 & & KHP \\
\hline 1227 & 380 & Hypothetisches Protein & \multicolumn{6}{|l|}{ Keine signifikante Übereinstimmung } & HP \\
\hline 1228 & 327 & Konserviertes Protein & WalW Protein & $\begin{array}{l}\text { Photorhabdus } \\
\text { luminescens } \\
\text { subsp. laumondii } \\
\text { TTO1 }\end{array}$ & $\begin{array}{l}\text { NP_932004. } \\
1\end{array}$ & $2 \mathrm{e}-30$ & 27 & $\begin{array}{l}\text { CDD25772, pfam01522, } \\
\text { Deacetylase }(4 \mathrm{e}-05)\end{array}$ & KP \\
\hline 1229 & 347 & Hypothetisches Protein & \multicolumn{6}{|l|}{ Keine signifikante Übereinstimmung } & HP \\
\hline 1230 & 282 & $\begin{array}{lr}\text { Hypotheisches } & \text { Protein } \\
\text { Methylase involviert } & \text { in } \\
\text { Ubiquinon/Menaquinon- } & \\
\text { Biosynthese (COG2226) } & \end{array}$ & $\begin{array}{l}\text { Methyltransferase } \\
\text { Menaquinon/Biotin-Biosynthese }\end{array}$ & $\begin{array}{l}\text { Xanthomonas } \\
\text { campestris pv. } \\
\text { campestris Stamm } \\
\text { ATCC } 33913\end{array}$ & $\begin{array}{l}\text { NP_638675. } \\
1\end{array}$ & $5 \mathrm{e}-14$ & 40 & $\begin{array}{l}\text { CDD11933, COG2226, UbiE, Methylase } \\
\text { involviert in Ubiquinon/Menaquinon-Biosynthese } \\
\text { (2e-18) }\end{array}$ & CE-M \\
\hline
\end{tabular}




\begin{tabular}{|c|c|c|c|c|c|c|c|c|c|}
\hline $\begin{array}{l}\text { ORF- } \\
\text { Name }\end{array}$ & Größe & Annotation & Ähnlichstes Protein bei NCBI & Organismus & $\begin{array}{l}\text { Accession- } \\
\text { Nummer }\end{array}$ & $\begin{array}{l}\text { e- } \\
\text { Value }\end{array}$ & $\begin{array}{l}I \text { in } \\
\%\end{array}$ & Konservierte Domänen bei NCBI & $\begin{array}{l}\text { Funk- } \\
\text { tion }\end{array}$ \\
\hline 1231 & 313 & Hypothetisches Protein & Keine signifikante Übereinstimmung & & & & & & HP \\
\hline 1232 & 174 & Hypothetisches Protein & Keine signifikante Übereinstimmung & & & & & & $\mathrm{HP}$ \\
\hline 1233 & 527 & $\begin{array}{l}\text { Hypothetisches membran- } \\
\text { durchspannendes Protein }\end{array}$ & Keine signifikante Übereinstimmung & & & & & & HP \\
\hline 1234 & 254 & $\begin{array}{l}\text { Dolichol-phosphat- } \\
\text { Mannosyltransferase } \\
2.4 .1 .83 \text { ) }\end{array}$ & Dolichol-phosphat-Mannosyltransferase & $\begin{array}{l}\text { Pyrococcus } \\
\text { horikoshii }\end{array}$ & $\begin{array}{l}\text { NP_142068. } \\
1\end{array}$ & $2 \mathrm{e}-38$ & 40 & $\begin{array}{l}\text { CDD20764, KOG2978, } \\
\text { mannosyltransferase (5e-34) }\end{array}$ & KH-M \\
\hline
\end{tabular}

TS $=$ Transkription

AS-M = Aminosäure-Transport und-Metabolismus

KH-M $=$ Kohlenhydrat-Metabolismus

CE-M = Coenzym-Metabolismus

ZH-B $=$ Zellhüllen-Biogense

$\mathrm{ST}=$ Signaltransduktion

DRR $=$ DNA-Replikation und Reparatur

TLR $=$ Translation und Ribosomenstruktur und -biogenese

RKT $=$ Rekombination und Transposons

$\mathrm{ZT}=$ Zellteilung

I-TM $=$ Transport von anorganischen Ionen und Metabolismus

SM-BT $=$ Sekundär-Metabolit Transport- und Biogenese

PPM $=$ Posttranslationales Protein-Modifikation, Chaperone

LM $=$ Lipid-Metabolismus

ITS = Intrazelluläres "Trafficing” und Sekretion

$\mathrm{E}=$ Energie-Produktion und - Umwandlung

$\mathrm{A}=$ Abwehrmechanismus oder Resistenz

$\mathrm{HP}=$ Hypothetisches Protein

$\mathrm{KP}=$ Konserviertes Protein

$\mathrm{KHP}=$ Konserviertes hypothetisches Protein 


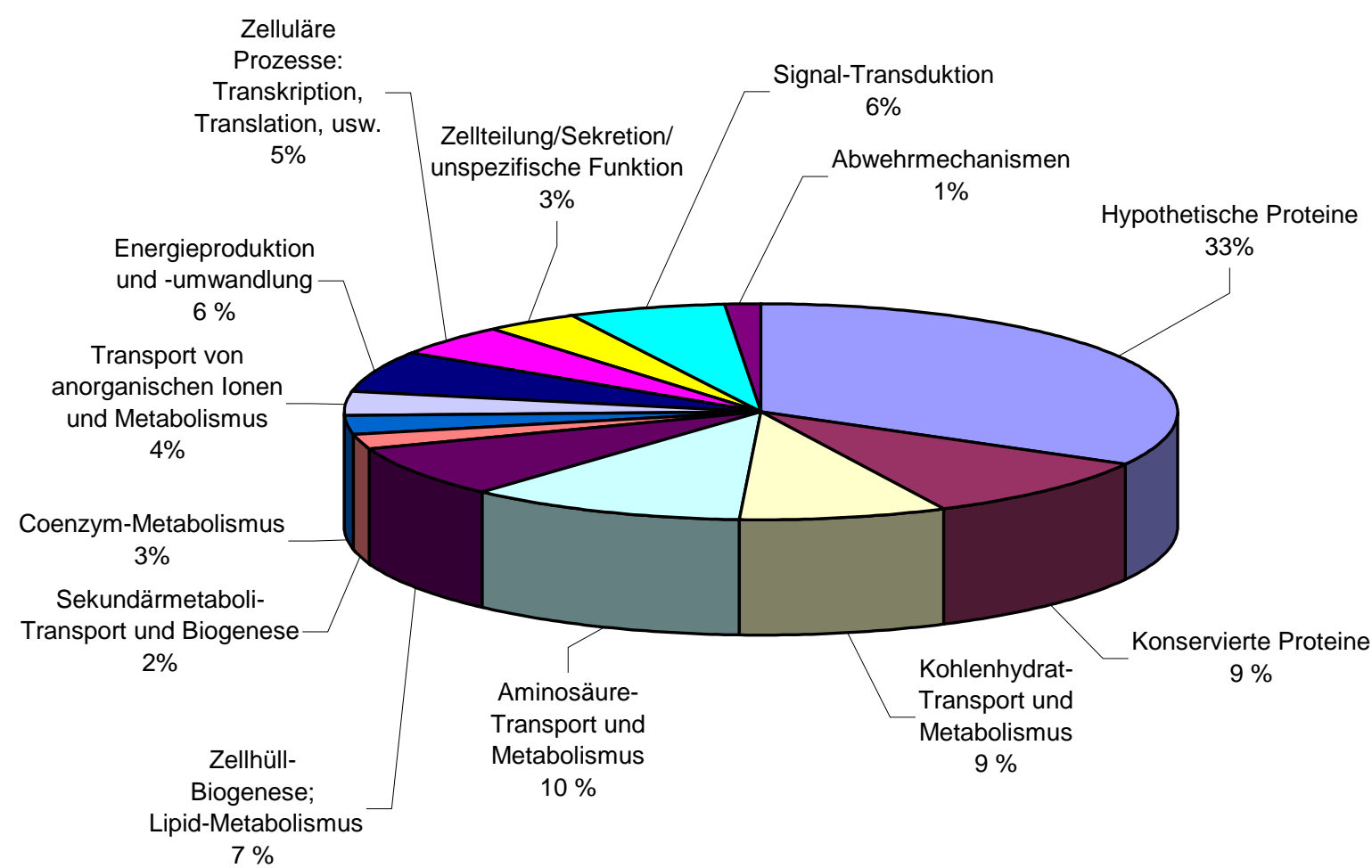

\section{Abbildung 18: Verteilung der annotierten ORFs auf unterschiedliche Funktionsbereiche}

\subsubsection{Das Cosmid slc_1a}

Wie bereits erwähnt, ist die Sequenzierung dieses Cosmides noch nicht abgeschlossen. Das Insert des Cosmids slc_1a besteht noch aus 2 Contigs, die zusammen eine Länge von 35875 bp haben. Die „ORF-Map“ des größeren der beiden Contigs (Contig 1) ist in der Abbildung 19 dargestellt. In der im Anhang hinterlegten Sequenz sind unsichere Basen zunächst als „N“ markiert, einfach abgedeckte Sequenzbereiche und Nukleotide mit einem kleineren Qualitätswert als 35 in dem Programm „Gap4“ sind rot geschrieben. 27 (77,1 \%) der 36 ORFs konnten Funktionen zugeordnet werden. Dies ist der zweithöchste Wert aller Cosmide. Die ORFs 119 bis 123 bilden ein Cluster, dessen abgeleitete Aminosäuresequenzen die größte Ähnlichkeit zu Proteinen aus Mesorhizobium loti MAFF303099 zeigen (KANEKO et al., 2000), die für die Untereinheiten einer Sarcosin-Oxidase kodieren. Das ORF119-Protein ähnelt der $\gamma$ Untereinheit, das ORF122-Protein der $\delta$ - und das ORF123-Protein der $\beta$-Untereinheit der Sarcosin-Oxidase aus M. loti. In der $\alpha$-Untereinheit befindet sich ein „frame-shift“, der wahrscheinlich auf die schlechte Sequenzqualität in diesem Bereich zurückgeführt 
werden kann, deshalb ist sowohl das ORF120- als auch das ORF121-Protein als $\alpha$ Untereinheit annotiert. Hier muss eine Verbesserung der Sequenzqualität zu genaueren Ergebnissen führen. Wie der Tabelle 12 A) entnommen werden kann, sind die Ähnlichkeiten $\mathrm{zu}$ den $M$. loti-Proteinen und den konservierten Domänen sehr unterschiedlich.

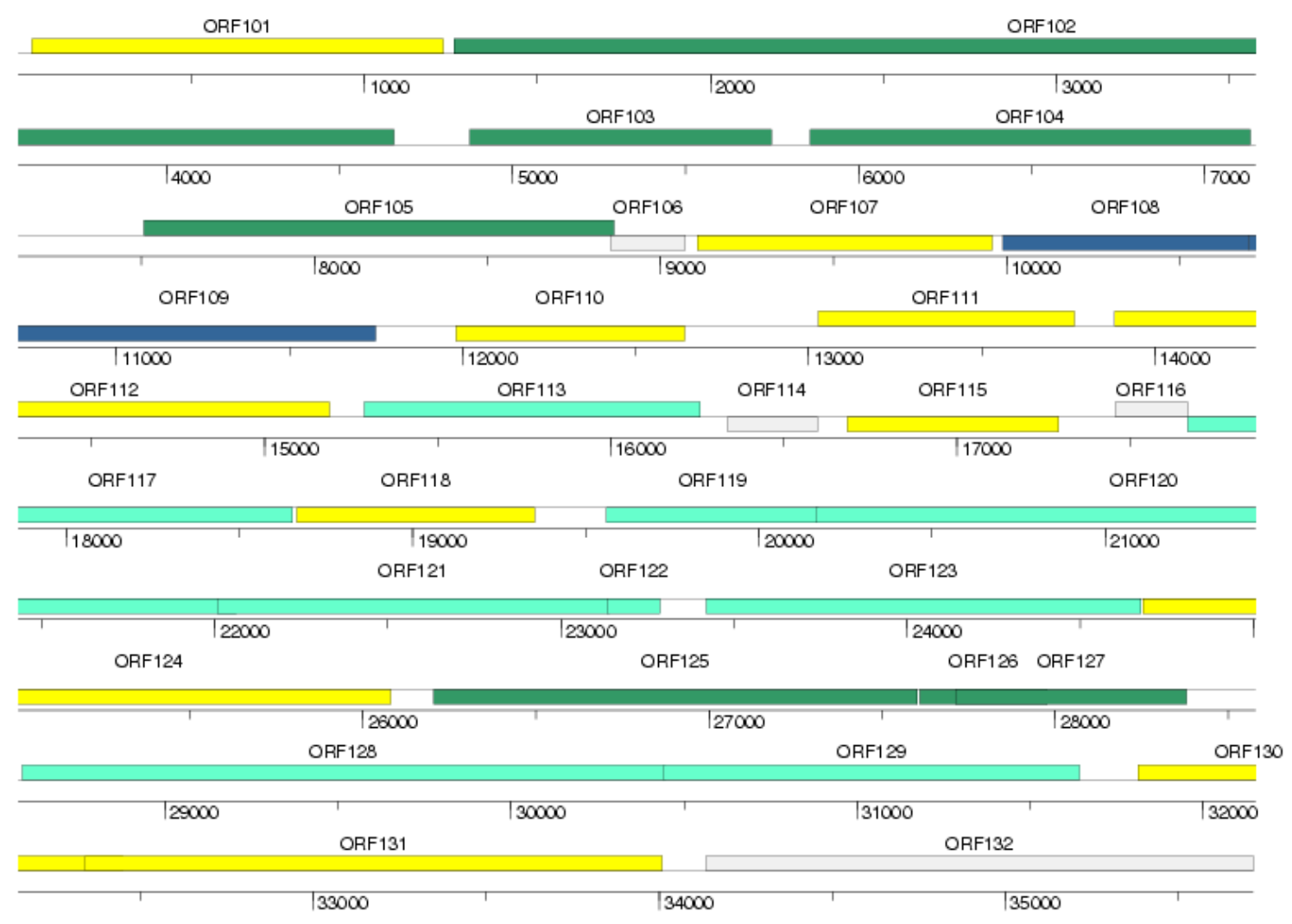

\section{Abbildung 19: "ORF-Map" des Cosmids slc_1a (Contig 1)}

ORFs sind in Blöcken dargestellt. Anhand der Lage der Blöcke in Bezug auf die Führungslinie kann die Richtung der Kodierung erkannt werden. Die Genprodukte der ORFs haben folgende Funktionen:

türkis Aminosäure-Metabolismus

grün Kohlenhydrat-Transport und -Metabolismus

blau Coenzym-Metabolismus

gelb verschiedene Funktionen

grau Hypothetische Proteine

Die Identität der Aminosäuresequenz des ORF119 beträgt 56 \%. Die Identität des ORF122 nur $21 \%$. Die Aminosäuresequenz des ORF128 zeigt im 1. Teil die größte Übereinstimmung mit einem potentiellen Glycin-Betain-Bindeprotein aus Sinorhizobium meliloti 1021 und im 2. Teil mit einer potentiellen ABC-TransporterPermease aus Photobacterium profundus SS9 (55 \% bzw. 51 \% Identität). Das ORF129-Protein kodiert für ein ATP-Bindeprotein. 
Auch die ORFs 102, 103, 104 und 105 bilden ein zusammenhängendes Cluster, dessen übersetzte Proteine im Kohlenhydrat-Stoffwechsel eine Rolle spielen. Die ORFs 102 und 103 kodieren für Beta-Galaktosidasen, der ORF104 für eine potentielle N-Acyl-Dglukosamin-2-Epimerase und der ORF105 für ein L-Fukosidase-Vorläufer-Protein. Die nächst verwandten Proteine stammen alle außer dem des ORF104, das aus Bacteroides fragilis stammt, aus dem Bakterium Bacteroides thetaiotaomicron. Die Identitäten liegen zwischen 27 und $40 \%$ (s. Tabelle 12 A)).

Das ORF108-Protein ist als potentielle 6,7-Dimethyl-8-ribityllumazin-Synthase und das ORF109-Protein als Riboflavin-Biosynthese-Protein RibA annotiert. Beide Enzyme sind an der Biosynthese von Riboflavin beteiligt.

\subsubsection{Das Cosmid slc_1f}

Das Insert des Cosmides slc_1f ist 37400 bp groß. Der G + C-Gehalt beträgt 66,2 \%. Dieses Cosmid zeichnet sich durch extrem geringe Übereinstimmungen in der Sequenz mit Datenbanksequenzen aus. 14 der 27 auf dem cosmidkodierten Proteine wurden als hypothetische Proteine, 5 weitere als konservierte Proteine annotiert. Damit zeigen nur $8(30 \%)$ der 27 ORFs auf Aminosäureebene so große Ähnlichkeit zu bekannten Proteinen, dass ihnen Funktionen zugeordnet werden konnten. Dies ist, wie aus der Tabelle 11 entnommen werden kann, der niedrigste Wert aller Cosmide. Die Proteine aus den Datenbanken, die die größten Ähnlichkeiten zeigen, stammen aus den unterschiedlichsten Bakterien-Phyla. Ein cosmidkodiertes Protein ist zu $40 \%$ mit einem hypothetischen Protein aus dem Archaeon Methanosarcina marzei Gö1 identisch. Unter anderem wurden das von dem ORF212 kodierte Protein als ein Enzym mit einer vermutlichen Dehydrogenase-Aktivität und das von dem ORF213 kodierte Protein als ein Protein der Subtilase-Familie annotiert. Ausschlaggebend für die Annotation war in beiden Fällen die relativ deutliche Übereinstimmung mit den konservierten Domänen COG0673 bzw. pfam00082 mit „e-Values“ von $4 \mathrm{e}^{-32}$ bzw. $4 \mathrm{e}^{-24}$. Deutlichere Übereinstimmungen auf Aminosäureebene ergaben sich für die ORFs 214 und 218. Die übersetzte Aminosäuresequenz des ORF214 stimmt mit einem „e-Value“ von $5 \mathrm{e}^{-42}$ mit einer experimentell bestätigten Glukosamin-6-Phosphat-Isomerase aus Giardia lamblia (Accesion-Nummer AAF03257.1) überein. Der ähnlichste experimentell bestätigte BLAST-Hit des von dem ORF218 kodierten Proteins ist eine alkalische Phosphatase aus Synechococcus sp. (Accession-Nummer AAA27331.1) mit einem „e-Value“ von $1 \mathrm{e}^{-16}$. 


\subsubsection{Das Cosmid slc_1g}

Das Cosmid slc_1g besteht noch aus 2 Contigs. Es konnte mit an den Contig-Enden abgeleiteten Oligonukleotiden ein 450 bp großes PCR-Produkt amplifiziert werden. Alle Versuche, dieses PCR-Produkt kloniert oder unkloniert zu sequenzieren, sowie alle Versuche, Lücken überspannende Sequenzläufe mit dem Cosmid oder „Shotgun“Plasmiden“" zu erhalten, scheiterten bislang. Unter Berücksichtigung des PCR-Produktes kann für das Insert insgesamt eine Größe von ca. 44530 bp angenommen werden. Damit enthält dieses Cosmid das größte Insert der in dieser Arbeit sequenzierten Cosmide. Der G+C-Gehalt beträgt $64,4 \%$. Dieses Cosmid weist viele ORFs auf, deren in Aminosäuren übersetzte Nukleotidsequenzen nur wenig oder keine Ähnlichkeiten zu bekannten Proteinen haben. Wie aus Tabelle 11 hervorgeht, konnten von den 43 kodierten Proteinen nur 24 mit einer Funktion belegt werden. 5 Proteine wurden als konservierte Proteine und 15 als hypothetische Proteine annotiert. Damit sind auch bei diesem Cosmid $44 \%$ der potentiellen Proteine ohne annotierte Funktion. $\mathrm{Zu}$ den Proteinen, denen eine potentielle Funktion zugewiesen wurde, gehören neben den ORF325- und ORF326-Proteinen, die ein 2-Komponenten-Regulationssystem darstellen, die ORF334- und ORF335-Proteine, die vermutlich eine Rolle bei der Eisenaufnahme spielen. Die von den ORFs 305 und 306 kodierten Proteine haben eine Funktion im Zuckerstoffwechsel. Der ORF305 kodiert vermutlich für ein Enzym mit einer 6-Phosphoglukonolaktonase- oder Glukosamin-6-phosphat-Isomerase/DeaminaseAktivität. Die größte Ähnlichkeit dieses Proteins besteht $\mathrm{zu}$ einem ORF von Arabidopsis thaliana mit einem „e-Value“ von $1 \mathrm{e}^{-19}$. Das ORF306-Protein hat mit einem ,e-Value“ von $1 \mathrm{e}^{-154}$ eine deutlich höhere Übereinstimmung zu einem Protein aus Nostoc punctiforme. Außerdem weist es eine deutliche Übereinstimmung mit der konservierten Domäne COG0364 von Glukose-6-phosphat-1-Dehydrogenasen auf und wurde deshalb als Glukose-6-phosphat-1-Dehydrogenase annotiert. Die ORFs 340 und 341 sind auf Aminosäureebene $\mathrm{zu} 40 \%$ identisch und kodieren vermutlich für eine Phytoen-Desaturase.

\subsubsection{Das Cosmid slc_1h}

Das Cosmid slc_1h trägt ein Insert mit einer Größe von 37311 bp. Die DNA des Inserts hat einen $\mathrm{G}+\mathrm{C}$-Gehalt von 59,1 \%. 38 ORFs wurden festgelegt. 6 der von ihnen kodierten Proteine wurden als hypothetische Proteine und 4 als konservierte Proteine annotiert. Damit konnten $74 \%$ der cosmidkodierten Proteine mit Funktionen belegt 
werden. Dieser Wert wird nur, wie aus der Tabelle 11 hervorgeht, von den Cosmiden slc_1a und slc_1x übertroffen. Mit Ausnahme von 4 Proteinen ähneln alle anderen am stärksten Proteinen von Rhodobacter sphaeroides mit Identitäten bis zu $88 \%$. In Abbildung 20 ist eine „ORF-Map“ des Cosmids slc_1h abgebildet.

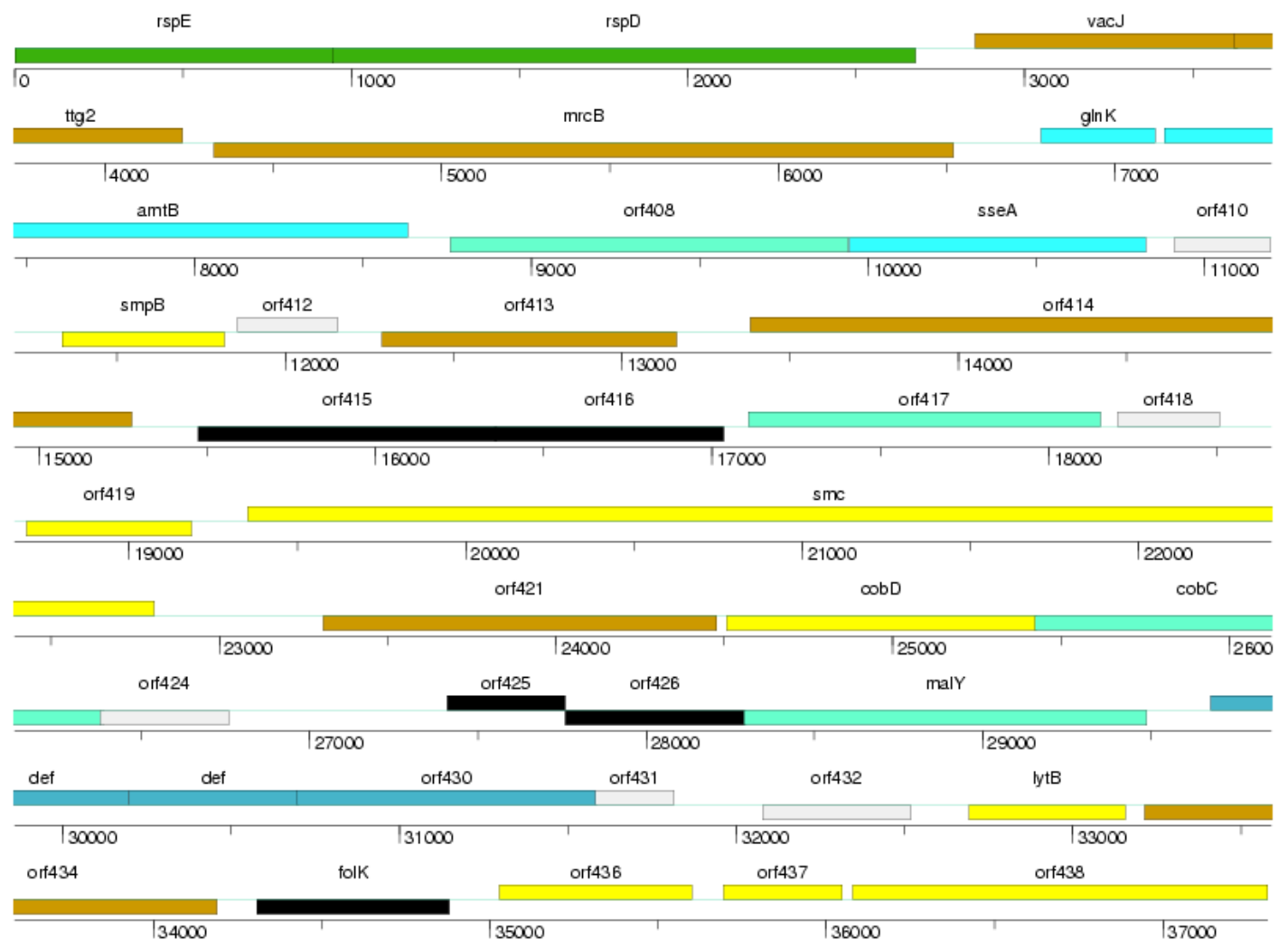

\section{Abbildung 20: "ORF-Map" des Cosmids slc_1h}

ORFs sind in Blöcken dargestellt. Anhand der Lage der Blöcke in Bezug auf die Führungslinie kann die Richtung der Kodierung erkannt werden. Die Genprodukte der ORFs haben folgende Funktionen:

türkis Aminosäure-Metabolismus

grün Sekundärmetabolit-Biosynthese und -Transport

blau Translation, Ribosomenstruktur- und -biogenese

braun Zellhüllen-Biogenese

gelb verschiedene Funktionen

schwarz konservierte Proteine

grau hypothetische Proteine

Besonders viele auf dem Cosmid kodierte Proteine könnten eine Rolle in der ZellhüllBiogenese spielen wie z. B. das ORF413-Protein, das für eine „Dihydrodipicolinat-

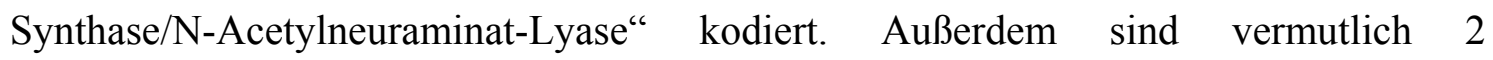
verschiedene lytische Murein-Transglykosylasen auf dem Cosmid kodiert. Der ORF414 kodiert vermutlich für eine lösliche und der ORF421 für eine membrangebundene 
Form. Die Identitäten für die Übereinstimmung der Aminosäuresequenzen dieser ORFs mit denen der ORFs aus Rhodobacter sphaeroides betragen 86 bzw. 55 \%. Außerdem kodieren die ORFs 405 und 434 sowohl für ein Penicillin-Bindeprotein als auch für ein Penicillin-Toleranzprotein (65 bzw. $81 \%$ Identität). Für ein Toluol-Toleranz vermittelndes Protein kodiert der ORF404. Außerdem sind auf diesem Cosmid vermutlich ein Teil eines Rhizobiocin-Transportsystems (ORF401 und ORF402), das Stickstoff-Regulationsprotein GlnK neben dem Ammonium-Transportprotein AmtB (ORF406 und ORF407) und 2 Proteine, die in der Cobalamin-Biosynthese eine Rolle spielen, kodiert (s. Tabelle $12 \mathrm{D})$.

\subsubsection{Das Cosmid slc_1p}

Das Insert des Cosmides slc_1p ist 37601 bp groß. Der durchschnittliche G+C-Gehalt beträgt $63 \%$. Es wurden 35 ORFs festgelegt. 15 der von ihnen kodierten Proteine wurden als hypothetische Proteine und 3 als konservierte Proteine annotiert. Auch die übrigen von den ORFs abgeleiteten Aminosäuresequenzen lassen kaum zusammenhängende Funktionen erkennen. Lediglich die Gene für ein 2-KomponentenRegulationssystem vermutlich, des KDP-Operons (ORF528 und ORF529), und Gene für Proteine, die am Biopolymer-Transport (ORF521 bis ORF523) beteiligt sind, bilden aufeinander folgende funktionelle Einheiten. Als Ursprungsorganismus der nächst verwandten Proteine tritt das Bakterium Pirellula sp. 1 in 6 von 20 Fällen auf. Die von dem ORF505 kodierte Adenosylhomocysteinase 1 ähnelt am meisten der des Frosches Danio rerio mit einem ,e-Value“ von 0.0 und einer Identität von 47 \%. .

\subsubsection{Das Cosmid slc_1q}

Das Cosmid slc_1q trägt als einziges der im Rahmen dieser Arbeit sequenzierten Cosmide eukaryotische DNA. Die Sequenz ist noch nicht vollständig geschlossen. Momentan liegen noch 2 Contigs vor, zwischen denen PCR-Produkte mit Größen von 800 bp erzeugt werden konnten. Vermutlich beträgt die Insertgröße ca. 37050 bp. Der $\mathrm{G}+\mathrm{C}$-Gehalt liegt mit 38,8 \% deutlich unter dem der übrigen Cosmide. Die annotierten Funktionen der Gene können der Tabelle 12 F) entnommen werden. 


\subsubsection{Das Cosmid slc_1s}

Auch bei diesem Cosmid konnten kaum ORFs festgelegt werden, deren in Aminosäuren übersetzten Sequenzen Funktionen zugeordnet werden konnten. $44 \%$ der Proteine sind nur hypothetisch oder konserviert. 5 der auf dem 34084 bp großen Insert kodierten Proteine zeigen allerdings deutliche Übereinstimmungen mit Datenbank-Sequenzen. Bei dem ORF722-Protein scheint es sich recht wahrscheinlich um ein 1,4-alphaGlukan-verzweigendes Enzym zu handeln. Bei diesem Protein ist auch die Übereinstimmung mit der konservierten Domäne solcher Enzyme COG0296 mit einem „e-Value“ von 0.0 sehr groß. Wie aus der Tabelle $12 \mathrm{G}$ ) hervorgeht, sind auch die Übereinstimmungen der von den ORFs 705, 706 und 723 abgeleiteten Aminosäuresequenzen mit den nächst ähnlichen Datenbank-Sequenzen mit 59, 50 bzw. $56 \%$ sehr hoch. Diese kodieren für 2 hypothetische Proteine und für eine ATPaseKomponente eines ATP-Transporters mit verdoppelter ATPase-Domäne aus Pirellula sp. 1. Besonders interessant ist das ORF715-Protein, das zu $57 \%$ mit der AlkoholDehydrogenase Klasse IV aus der Maus (Mus musculus) übereinstimmt.

\subsubsection{Das Cosmid slc_1t}

Das Cosmid slc-1t kodiert für einige Proteine mit großen Übereinstimmungen mit Datenbank-Sequenzen. Auf dem 39084 bp großen Insert sind 42 Proteine kodiert. 23 von ihnen konnte eine Funktion zugeordnet werden. 2 funktional unterschiedliche Cluster lassen sich erkennen. Das erste umfasst die ORFs 824 bis 830, die für Proteine kodieren, die an dem Abbau von Phenylalanin und Tyrosin beteiligt sind. Das erste von dem ORF824 kodierte Enzym ist eine 4-Hydroxyphenylpyruvat-Dioxygenase. Die Identität $\mathrm{zu}$ dem gleich annotierten Protein aus Chromobacterium violaceum ATCC12472 beträgt $65 \%$. Die Aminosäuresequenz des ORF824 beinhaltet die konservierte Domäne COG3185. Für diese Übereinstimmung wird ein „e-Value“ von $2 \mathrm{e}^{-125}$ angegeben. Diese konservierte Domäne wird bei 4-HydroxyphenylpyruvatDioxygenasen und verwandten Enzymen gefunden. Der ORF826 kodiert vermutlich für eine Maleylacetoacetat-Isomerase und der ORF827 für eine Homogentisat-1,2Dioxygenase. Die Übereinstimmung $\mathrm{zu}$ dem gleich annotierten Protein aus Chromobacterium violacum ATCC12472 hat einen ,e-Value“ von $1 \mathrm{e}^{-122}$. Die 
konservierte Domäne COG3508 der Homogentisat-1,2-Dioxygenasen kann in dem von dem ORF827 kodierten Protein mit einem ,e-Value“ von $3 \mathrm{e}^{-67}$ gefunden werden. Das

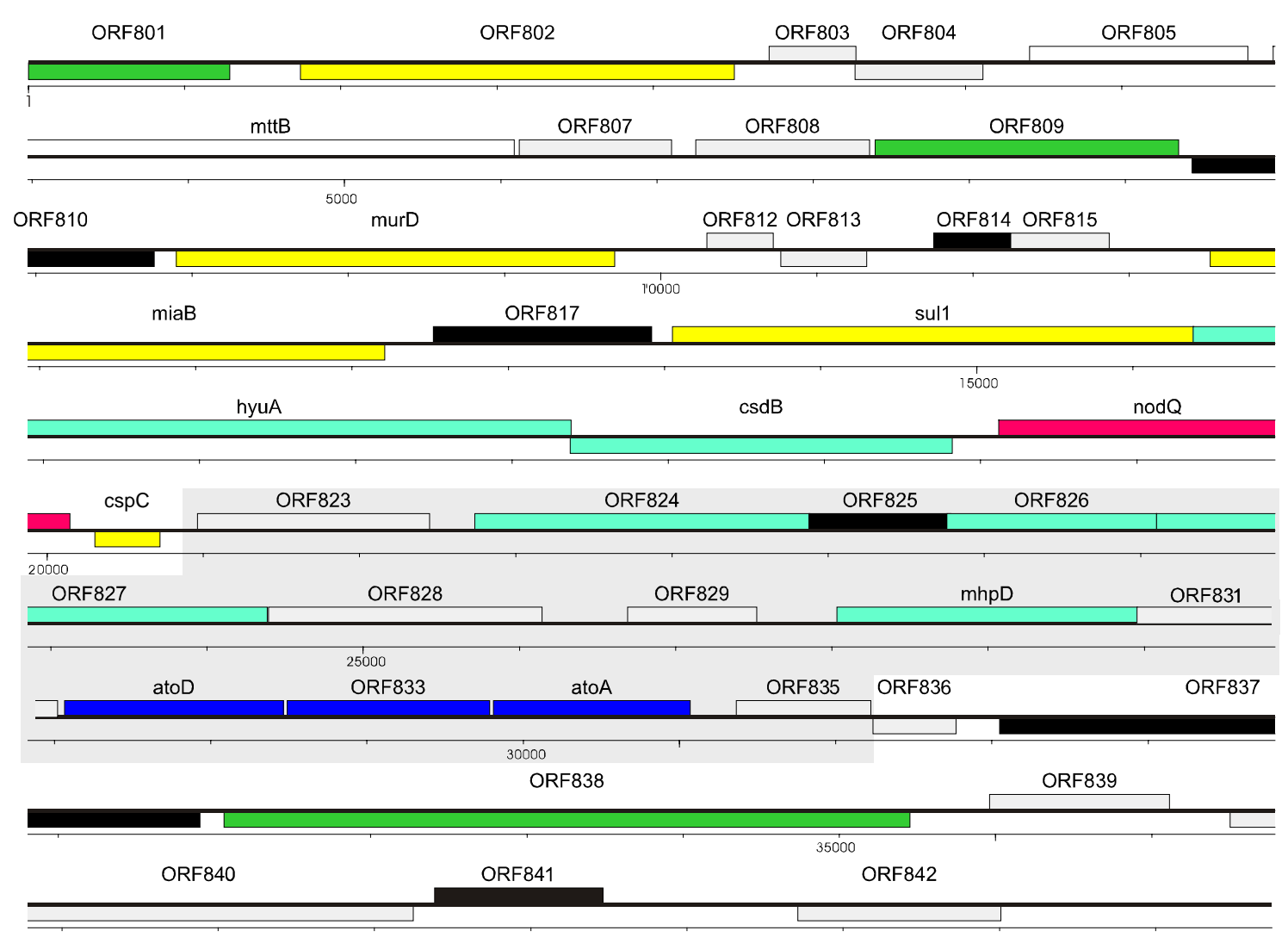

\section{Abbildung 21: "ORF-Map" des Cosmids slc_1t}

ORFs sind in Blöcken dargestellt. Anhand der Lage der Blöcke in Bezug auf die Führungslinie kann die Richtung der Kodierung erkannt werden. Grau unterlegt ist der Sequenzbereich, dessen ORFs vermutlich für Enzyme kodieren, die an dem Abbau von Tyrosin beteiligt sind. Die Genprodukte der ORFs haben folgende Funktionen:

$\begin{array}{ll}\text { grün } & \text { Transport und Metabolismus anorganischer Ionen } \\ \text { türkis } & \text { Aminosäure-Metabolismus } \\ \text { blau } & \text { Lipid-Metabolismus } \\ \text { grau } & \text { hypothetische Proteine } \\ \text { schwarz } & \text { konservierte Proteine } \\ \text { gelb } & \text { verschiedene Funktionen }\end{array}$

ORF830-Protein zeigt eine 70\%ige Identität mit einem Protein aus Caulobacter crescentus CB15. Die ORFs 832 bis 834 kodieren vermutlich für Enzyme, die den Abbau von kurzkettigen Fettsäuren katalysieren (s. Abbildung 21). Der ORF832 kodiert für das Protein AtoD, die Untereinheit A der Acyl-CoA:Acetat/3-Ketosäure-CoATransferase, der ORF833 für ein Phospholipid-Bindeprotein und der ORF834 für das Protein AtoA, die Untereinheit B der Acyl-CoA:Acetat/3-Ketosäure-CoA-Transferase. Wie aus der Tabelle $12 \mathrm{H}$ ) entnommen werden kann, bestehen sowohl große Ähnlichkeiten zu den nächst verwandten Proteinen (44 - 46 \% Identität) als auch zu der 
jeweils konservierten Domäne mit „e-Values“ von $2 \mathrm{e}^{-21}$ bis $7 \mathrm{e}^{-82}$. Eine Identität von $58 \%$ weist das ORF821-Protein zu dem Protein NodQ aus Azospirillium brasilense auf. Dieses bifunktionale Enzym hat sowohl eine Sulfat-Adenylyl-Transferase-Untereinheit als auch eine Adenylylsulfat-Kinase-Untereinheit. Der ORF818 kodiert für eine SulfatPermease mit großer Identität (58 \%) zu einem Enzym aus Magnetococcus sp. MC-1. Der „e-Value“ für die konservierte Domäne COG0659 beträgt $3 \mathrm{e}^{-98}$. Diese ist typisch für Sulfat-Permeasen und verwandte Transporter.

\subsubsection{Das Cosmid slc_1u}

Von 66,7 \% der von den 27 ORFs des Cosmids slc_1u kodierten Proteinen ist die Funktion unbekannt. Es ist mit 33732 bp das Cosmid mit dem kleinsten Insert. Der ORF925 kodiert vermutlich für eine 3-Isopropylmalat-Dehydrogenase, der ORF926 für eine hitzestabile Aldehyd-Dehydrogenase. Die Übereinstimmungen zu den gleich annotierten Datenbank-Sequenzen aus Desulfitobacterium hafniense bzw. Nostoc sp. PCC7120 betragen 36 bzw. 32 \%. Der „e-Value“ für die in dem ORF926 enthaltene konservierte Domäne COG1012, die typisch für $\mathrm{NAD}^{+}$-abhängige AldehydDehydrogenasen ist, beträgt $3 \mathrm{e}^{-81}$. Die von den ORFs 901 und 906 und 907 kodierten Proteine sind vermutlich Bestandteile eines TypI Restriktionsmodifikationssystems. Die ähnlichsten Proteine aus der NCBI-Datenbank stammen, wie der Tabelle 12 entnommen werden kann, aus 3 verschiedenen Organismen, dem Archaeon Methanosarcina barkeri, den Bakterien Trichodesmium erythracum und dem Bakterium Desulfovibrio desulfuricans G20. Unterbrochen sind diese Gene von den ORFs 902, 903, 904 und 905, die signifikante Ähnlichkeiten zu konservierten hypothetischen Protein aus Ralstonia solanacearum, Chlorobium tempidum TLS, Micrococcus sp. 28 bzw. Ralstonia eutropha zeigen.

\subsubsection{Das Cosmid slc_1x}

Das Cosmid slc_1x ist das Cosmid, von dem die meisten auf ihm kodierten Proteine Ähnlichkeit zu Datenbank-Sequenzen mit bekannten Funktionen zeigen (79,5\%). Die sie kodierenden ORFs bilden funktionelle Cluster, die in den meisten Fällen in ähnlicher Anordnung auch an unterschiedlichen Stellen im Genom von Mesorhizobium loti gefunden werden können. Die entsprechenden ähnlichen Bereiche im M. loti-Genom sind in Tabelle 13 wiedergegeben. 
Tabelle 13: Zu den ORFs des Cosmides slc_1x ähnliche Bereiche im M. loti-Genom

\begin{tabular}{|c|c|c|}
\hline ORFs des Cosmids slc_1x & Sequenzbereich bei $M$. loti & Vermutete Funktion \\
\hline ORF1001 bis ORF1005 & 4339674 bis 4341729 & $\begin{array}{l}\text { Aminosäure-Metabolismus und } \\
\text {-Transport }\end{array}$ \\
\hline ORF1006 & 5728474 bis 5729964 & Aldehyd-Dehydrogenase \\
\hline ORF1007 bis ORF1015 & 1427455 bis 1420821 & CO-Dehydrogenase \\
\hline ORF1016 bis ORF1027 & 4218375 bis 4230201 & $\begin{array}{l}\text { ABC-Transporter } \\
\text { PTS-abhängige Dihydroxyaceton- } \\
\text { Kinase }\end{array}$ \\
\hline ORF1028-1032: & & $\begin{array}{l}\text { Signaltransduktion (evt. für die } \\
\text { Stickstofffixierung): }\end{array}$ \\
\hline ORF1028 & 5381975 bis 5382487 & $\begin{array}{l}\text { potentielles universelles Stress- } \\
\text { Protein UspA }\end{array}$ \\
\hline ORF1029 & 5409341 bis 5410939 & FixL \\
\hline ORF1030 & 240094 bis 240708 & FixJ \\
\hline ORF1031 & $\begin{array}{l}\text { kein signifikant ähnliches Protein } \\
\text { in } M . \text { loti }\end{array}$ & FixT2? \\
\hline ORF1032 & 219852 bis 220499 & FixK \\
\hline
\end{tabular}

Das erste Cluster wird von den ORFs 1002 bis 1005 gebildet. Wie aus der Tabelle 12 J) hervorgeht, scheinen die hier kodierten Proteine Funktionen im AminosäureMetabolismus und -Transport zu haben. Die entdprechende Region im M. loti-Genom umfasst den Bereich von Nukleotid 4339674 bis 4341729. Die Anordnung der ORFs entspricht in etwa der Anordnung im M. loti-Genom: Der ORF1002 ist bei M. loti nicht vorhanden, zudem unterscheidet sich die Leserichtung des ORF1004 von der des ähnlichen ORFs aus M. loti.

Nach diesem Cluster dreht sich die Leserichtung um. Es folgt ein Cluster, das Gene enthält, die sehr wahrscheinlich für eine Kohlenstoffmonoxid-Dehydrogenase (CODehydrogenase) kodieren. CO-Dehydrogenasen sind die Schlüsselenzyme für die COOxidation in carboxydotrophen Bakterien, die auf $\mathrm{CO}$ als einziger Kohlenstoff- und Energiequelle wachsen (KIM und HEGEMAN, 1983; MEYER et al., 1993). Diese ORFs tragen die Namen coxMSLLDE und sind in der Abbildung 22 mit roten Blöcken dargestellt. Alle ORFs beginnen mit einem ATG-Start-Codon. Nur der ORF1014 beginnt mit dem alternativen Start-Codon GTG. Die CO-Dehydrogenasen carboxydotropher Bakterien bestehen aus 3 nicht-identischen Untereinheiten (CoxS, CoxM und CoxL). Dabei steht S (,small“) für kleine Untereinheit, M (,medium“) für 
mittlere und L (,large“) für große Untereinheit. Sie enthalten FAD- und MolybdopterinCytosin-Dinukleotid-Cofaktoren und 2 verschiedene [2Fe-2S]-Cluster (KANG und KIM, 1999). Die CoxL-Untereinheit der auf dem Cosmid slc-1x kodierten CODehydrogenase besteht aus 2 Teilen, die im gleichen Leserahmen liegen und durch 3 Basen getrennt sind. Beide besitzen potentielle Ribosomen-Bindestellen. Die Ribosomen-Bindestelle des ORF1010 liegt 3 Basen aufwärts des ATG-Startcodons und lautet GGAG. Die Ribosomen-Bindestelle des ORF1011 umfasst die Basen GGAGGAA im Bereich -9 bis -16 .

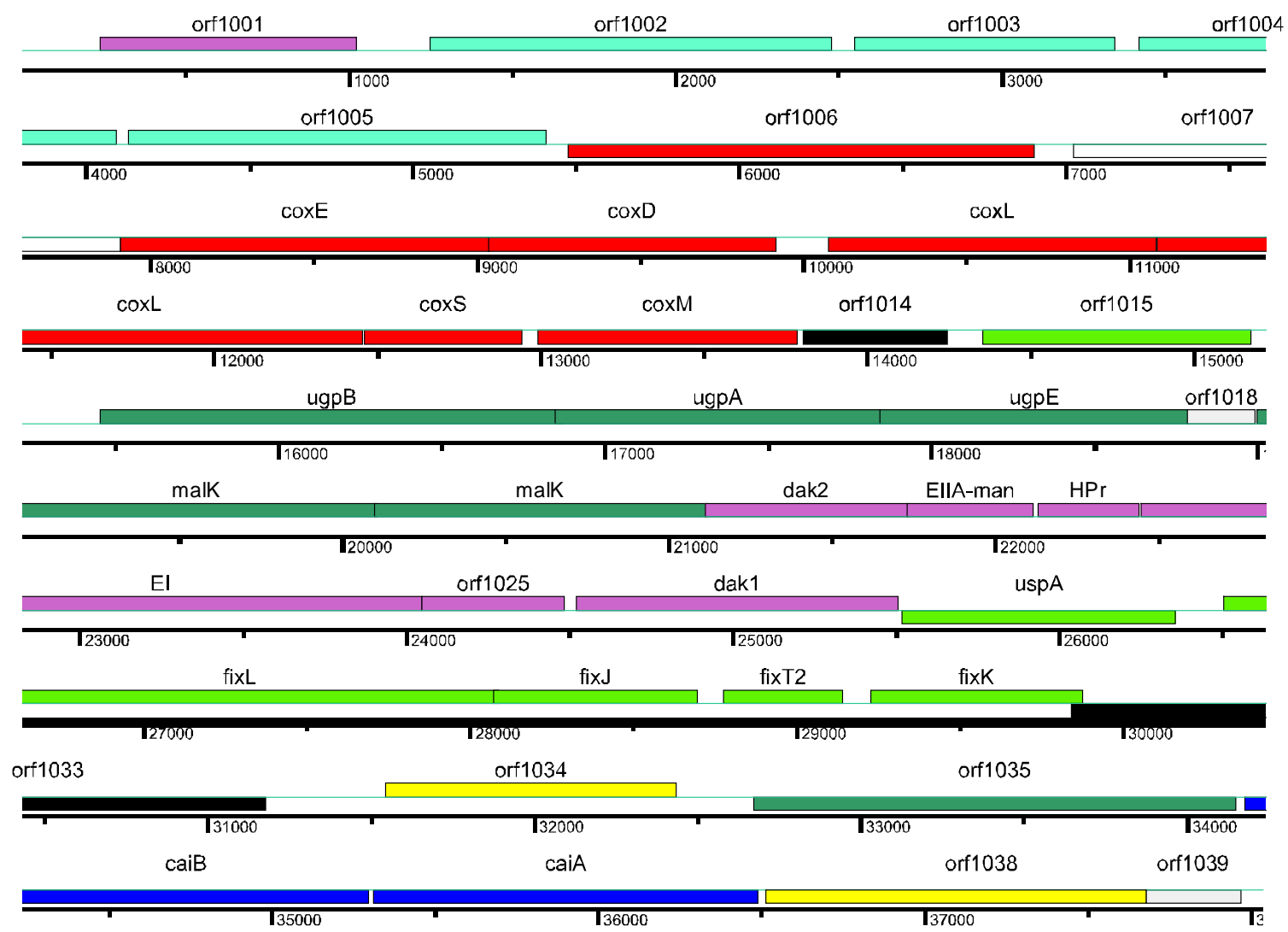

\section{Abbildung 22: "ORF-Map" des Cosmids slc_1x}

ORFs sind in Blöcken dargestellt. Anhand der Lage der Blöcke in Bezug auf die Führungslinie kann die Richtung der Kodierung erkannt werden. Die Genprodukte der ORFs haben folgende Funktionen:

rot Energiegewinnung und-konservierung

hell-grün Regulation

dunkel-grün Kohlenhydrat-Metabolismus, ugp-Cluster

lila

türkis

blau

Kohlenhydrat-Metabolismus, Dihydroxyaceton-Kinase-PTS-Cluster

grau

schwarz

Aminosäure-Metabolismus

Lipid-Metabolismus

hypothetische Proteine

gelb

konservierte Proteine

verschiedene Funktionen, nur einfach auf dem Cosmid kodiert 
Bei der M. loti Sequenz ist bei NCBI ein „frameshift“ vermerkt, allerdings ohne Angabe der Position. Fügt man die Aminosäure-Sequenzen direkt hintereinander, entsteht mit der Consensus-Sequenz für CoxL-Domänen (COG1529) ein Alignment über die gesamte Länge mit einem „e-Value“ von $5 \mathrm{e}^{-145}$. Das potentielle coxL-Gen von M. loti stimmt mit einem ,e-Value“ von $4 \mathrm{e}^{-149}$ mit der Sequenz der COG1529 überein. Die zusammengesetzte CoxL-Sequenz hat eine 80 \%ige Identität mit der von M. loti. Das Alignment der 3 Sequenzen ist in Abbildung 23 dargestellt. An der Unterbrechungsstelle, die pink unterlegt ist, hat die COG1529-Sequenz im Vergleich zu der M. loti-Sequenz 3 Aminosäuren, die CoxL-Untereinheit des Cosmides slc_1x eine Aminosäure weniger.

Die Aldehyd-Oxidoreduktase von Drosophila gigas ist homolog zu CODehydrogenasen. Sie besteht nur aus der großen und der kleinen Untereinheit. Durch Röntgen-Strukturanalyse konnten in der großen Untereinheit 5 Regionen in der Aldehyd-Oxidoreduktase von Drosophila gigas nachgewiesen werden, die an der Bindung des Molybdopterin-Cofaktors beteiligt sind (ROMAO et al., 1995). Diese Regionen sind auch in den Sequenzen der ORFs 1010 und 1011 konserviert. Die Aminosäuren $\mathrm{G}_{262}$ und $\mathrm{G}_{750}$ sind in allen CoxL-Untereinheiten von CO-Dehydrogenasen konserviert (KANG und KIM, 1999). Sie entsprechen den Aminosäuren $\mathrm{G}_{800}$ und $\mathrm{G}_{1266}$ in der Xanthin-Dehydrogenase von Drosophila melanogaster, deren Austausch durch Glutamat bzw. Aspartat bekannt für rosy-Mutationen ist (HUGHES et al., 1992). Das Gen rosy kodiert in Drosophila melanogaster für die Xanthin-Dehydrogenase, die für die Synthese bestimmter Pigmente benötigt wird. rosy-Mutanten haben hellere Augen als Wildtyp-Fliegen.

\begin{tabular}{|c|c|c|c|}
\hline CoxL : & 16 & DDLKELGQGLQRSDVPGHVTGKTTYFADRHFPGMLYLKMVRSPHHHARIRKIDTSEAEKH & 75 \\
\hline M. loti: & 15 & DDLHEIGQPRPRSDSPGHVTGKTAFFADRSFPGMLHLKMVRSPHHHARIRSIDTSEAEKH & 74 \\
\hline COG1529: & 1 & ADAEIIGRSVLRADGLGKVTGKGRYADDIVAPGMLYAAFVRSPYAHARIVSIDVSEAQGL & 60 \\
\hline CoxL : & 76 & PGVARVITHKDVPHNVYTILILIQVGPEDEQVLAEDKVRWKGEAVVAVLADSQRAAEEAA & 135 \\
\hline M. loti: & 75 & PGVVKVLTAKDVPHNVYTILILIQIGPEDETVLADGKVRWKGEAVVAVLAETERAAQEAA & 134 \\
\hline COG1529: & 61 & PGVLAVITAEELPA - - -WSPVRVELAPADE - VLARGKVRYTGEPVAAVVAEDEYQARAAA & 116 \\
\hline CoxL & 136 & AKVKVDYEVLPAVFDMEEALKPGAPLVNEYHGQNHYMYDSGASRKVRFGDVEKGFAEADH & 95 \\
\hline M. loti: & 135 & AKVKIDYEVLPAVFDMEEALKPGAPLVNEYHGQNYYLYDSGECRKVRFGDVEAGFAGADH & 194 \\
\hline C0G1529: & 117 & ELVLVEYEALPPVVDPEEALAEDAPVIHDELNI - - - - - - -ARDATFGDDDA-FAAAAV & 166 \\
\hline CoxL & 196 & ILEQTYFSSPIEQAPTETTGCIVTPDGNDRFTCYTNTQAMFFTLDNTSIILQMPGHKLHM & \\
\hline M. loti: & 195 & ILEQSYQSSPIEHAPTETTGCVVAPEGNDRFTCYTNTQAMFFTLDNTSIILQMPGSKLHF & 25 \\
\hline C0G1529: & 167 & VVEAPYKTPRKDPNPMEPHGVVAVPDDGDKLTVWASTQIPHRLRGMLAAVLGIPPSKVRV & 226 \\
\hline CoxL & 256 & VGGTVGGGFGGKVDVTVEPI - AILAAKLTGRPVSFIYSRHEEMQISSPRAAEKIVLKDGV & \\
\hline M. $\operatorname{loti}$ & 255 & VGGTVGGGFGGKVDVIVEPI - AILGAKLTGRPVCFIYSREEEMQISSPRAAEKVVIKDGV & \\
\hline C0G1529: & 227 & ISPDVGGGFGSKGVVYVEEILAALAAVVAGRPVKWIETREELFVATGHRRATLIDVKLGA & \\
\hline
\end{tabular}




\begin{tabular}{|c|c|c|c|}
\hline COXL : & 315 & MKDGRLIARQVTGYTDAGAYSRHSPYGAQKGAAHYPGPYTVPNVSVDTYCVYTNRTPSSA & 374 \\
\hline M. loti: & 314 & \multirow{2}{*}{$\begin{array}{l}\text { MKDGRIVARKVTGYTDAGAYSRHSPYGAQKGAGHYPGPYTIPNVWIDTYCVYTNRTPSSA } \\
\text { DKDGRLLAIKGTVAADTGAYN - - GPTVPAAAAGLARGPYKIEAVYIEPYLVHTNMPPNGA }\end{array}$} & 373 \\
\hline C0G1529: & 287 & & 44 \\
\hline CoxL & 75 & MRGFGVTIADFALEVQMDKLARVIGMDPLEFRFINAYRDGDMKAHRQPTTGAALIECMQE & 43 \\
\hline M. loti: & 74 & \multirow{2}{*}{\multicolumn{2}{|c|}{$\begin{array}{l}\text { MRGFGVTIGDFALEVQMDKLARL IGMDPLEFRFINAYRDGDMKAHRQPTEGAALIECMQE } \\
\text { YRGAGRPEGTFALERAVDELAEELGIDPVEIRLRNLIRGGPFG - LGRRYDSGDYLEELDE }\end{array}$}} \\
\hline OG1529: & 45 & & \\
\hline \multicolumn{4}{|c|}{ * } \\
\hline CoxL & 35 & \multirow{3}{*}{$\begin{array}{l}\text { ASRLANWPVAEKYLKMSSY - KEA - MAIRRGRGVAAINYPTGMNLGGDPSQALVHSTPTGN } \\
\text { ASRAANWPVAEKYMAMSSYRKGADMAIRRGRGVAAINYPTGMNLGGDPTQALVHSTPTGN } \\
\text { AAKRFGWS - - ERPVKPIWTREG - D - - LRRGVGRAMYTEPSGAGPGE - - - GARVRLEADGT }\end{array}$} & 492 \\
\hline 4. loti: & 34 & & \\
\hline COG1529: & $4 \odot 4$ & & 457 \\
\hline CoxL & 95 & FMVTLSSVDLGQGLKQVMAQICAETIGVKTEQVTIDTADTDTGPHCMGTFASRGTHRIGN & \\
\hline M. Ioti: & 494 & \multirow{2}{*}{$\begin{array}{l}\text { FMVTLSSVDLGQGMKQIMAQICAETIGVPTDRVVVDTADTDTGPHCMGTFASRGTHRAGN } \\
\text { VTVRTGATDIGQGTDTVLAQIAAEELGIPPDDVEVVHGDTDVPVGGWGSVGSRGTAVAGS }\end{array}$} & \\
\hline COG1529 & 458 & & 1 \\
\hline COXL & & AVIQAAQEARQVMLEVAAEALEVNAADLDTDGEGNIHVKGAPQKSISIFDTALMAHFKLG & 1 \\
\hline M. loti: & 554 & AVIQAAREARQVMLEVAAEELEVNASDLETDGQGNILVKGAPQKSISIFDVALSAHFKRG & \\
\hline COG1529: & 518 & AVIDAAAKLAEKDPVAAARMLGADAEDVVLEDGAFKVGGGDRRSAVSLKEVAGKG - - - - & 57 \\
\hline COXL & & RSISGRGMFLVPRSYPEVETGAMKPATCYAHACTVAEVDVDDETGEVTVVSVKNVFEIGR & \\
\hline M. loti: & 14 & RSISGRGMFLIPRSYPEKETGAMKPSTCYAHACTVAEVEVDDETGEVTVLTVKNVFEIGR & \\
\hline C0G15 & 71 & - - - - - LAPGLAVAASFGSDNTYPYGAHIAEVEVDPETGEVRVLRVVAVDDCGR & \\
\hline CoxL & & ALNPKMVEQQLVGGSWMGISHALYETTEPYYPARDHGGTDFNEYLMPGPGDLADTEIVVL & 73 \\
\hline M. loti: & 674 & ALNPKMVEQQLVGGSWMGISHALYETTEPYYPNRDHGGTDFNQYLMPGPGDLAQTEIIVL & \\
\hline C0G1529: & 621 & \multicolumn{2}{|l|}{ VVNPKLAEGQVEGGILMGIGMALYEEA - IYDEDGQLLNSNLADYGIPRAADAPEVEVEFV } \\
\hline CoXL & 735 & ERPAADGPYGAKGPGEMCANPQIPAVANAVFDA & \\
\hline & 734 & ERPSADGPYGAKGPGEMCANPQIPAVANAVFDAVGVRIDTLPITPERILRALKA & \\
\hline COG & & ESPSPFGPLGAKGVGEGGIIGIAPAIANAVFDATGKRIRDLPITPERILAALRS & \\
\hline
\end{tabular}

Abbildung 23: Alignment der COG1529 mit CoxL des Cosmides slc_1x und der Aminosäuresequenz des ORFs mlr1703m von Mesorhizobium loti MAFF303099 (AccessionNummer NP_254264)

CoxL steht für die zusammengesetzte Aminosäuresequenz der ORFs 1010 und 1011des Cosmides slc_1x. M. loti steht für die Aminosäuresequenz des ORFs mlr1703m von Mesorhizobium loti MAFF303099 (Accession-Nummer NP 254264), COG1529 für die Consensus-Sequenz von CoxL (große Untereinheit der CO-Dehydrogenase). Das Multialignment wurde mit dem Programm „ClustalW“ berechnet. .

* Erste Aminosäure des ORF1010

Bindestellen für den Molybdopterin-Cytosin-Dinukleotid-Cofaktor

Molybdopterin-Co-Faktor-Bindestelle, von KING (2003) zur Klassifizierung der CO-

Dehydrogenasen herangezogen

Den $\mathrm{G}_{800}$ und $\mathrm{G}_{1266}$ aus der Xanthin-Dehydrogenase von Drosophila melanogaster entsprechende Aminosäuren, die in der rosy-Mutante ausgetauscht wurden (HUGHES et al., 1992)

In der mittleren Untereinheit der Xanthin-Dehydrogenase von D. melanogaster führt der Austausch der Aminosäuren $\mathrm{G}_{348}$ und $\mathrm{G}_{353}$ durch Gluthamat bzw. Aspartat zu rosyMutanten. Diese beiden Aminosäuren liegen in der hoch konservierten K3-Region, die für die FAD-Bindung verantwortlich ist (HUGHES et al., 1992). Die FAD-Bindung dieser Region ist deshalb sehr wahrscheinlich. Die K5- und N-Region binden NAD (KANG und KIM, 1999; HUGHES et al., 1992). In der CoxM-Sequenz des Cosmides slc_1x ist nur die K3-Region enthalten. In dem Alignment in Abbildung 24 sind außerdem die K3-Region von D. melanogaster und die Consensus-Sequenz verschiedener FAD-enthaltener mittlerer Untereinheiten wiedergegeben: Die mittleren Untereinheiten der CO-Dehydrogenasen von $H$. pseudoflava, 
P. thermocarboxydovorans bzw. O. carboxydovorans (CutM, CutB und CoxM), der Nikotin-Dehydrogenase von A. nicotinovorans und der Quinolin-2-Oxidoreduktase von P. putida (KANG und KIM, 1999). Diese Enzyme enthalten ebenfalls nur die K3Region. Die Region besteht aus in allen Sequenzen konservierten identischen Aminosäuren $\mathrm{G}_{347}$ und $\mathrm{G}_{348}$ und einigen anderen ähnlichen, die in der ConsensusSequenz durch Sterne markiert sind.

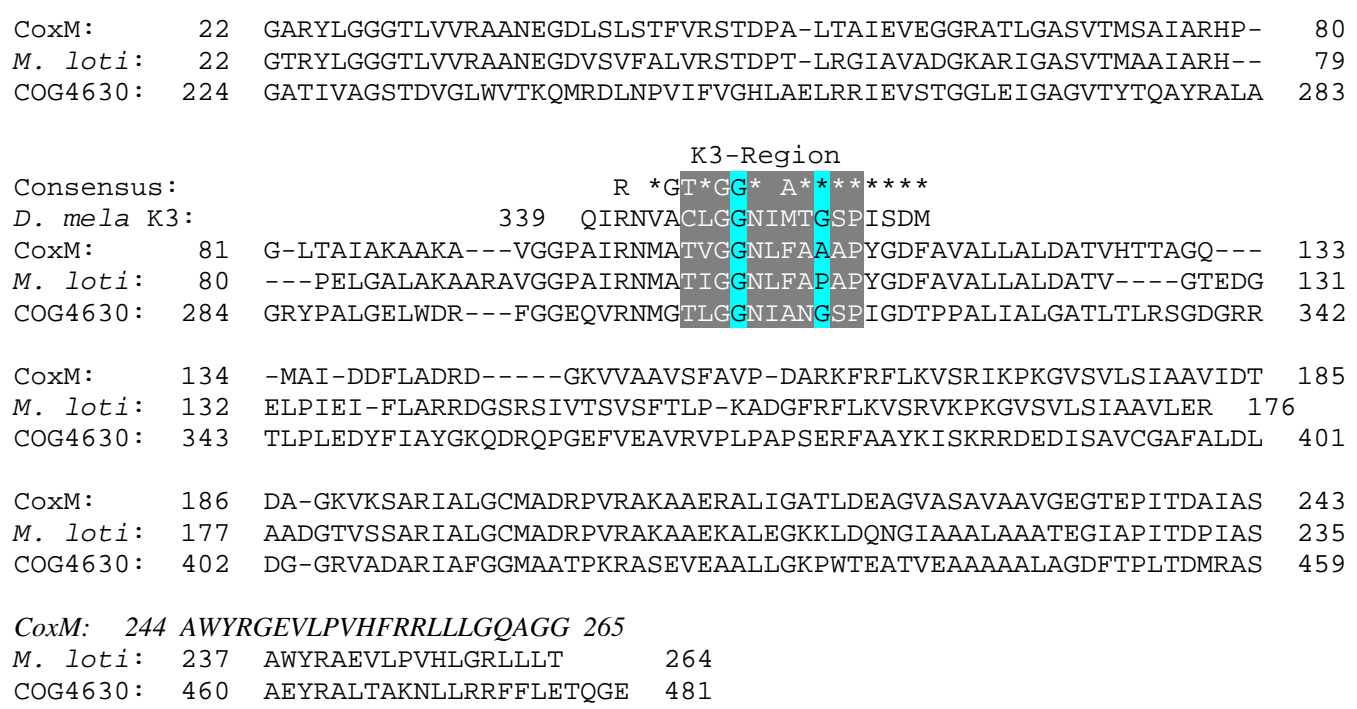

\section{Abbildung 24: Alignment der COG4630 mit CoxM des Cosmides slc_1x und der Aminosäuresequenz des ORFs mlr1703m von Mesorhizobium loti MAFF303099 (Accession-Nummer NP_103226)}

CoxM steht für die Aminosäuresequenz des ORF1013 des Cosmides slc_1x. M. loti steht für die Aminosäuresequenz des ORFs mlr1703m von Mesorhizobium loti MAFF303099 (Accession-Nummer NP_103226), COG4036 für die konservierte Domäne COG4036 von CoxM (mittlere Untereinheit der CO-Dehydrogenase), D. mela K3 für die Sequenz der K3-Region aus Drosophila melanogaster, Consensus für die Consensus-Sequenz im Bereich der K3-Region der mittleren Untereinheiten der Enzyme: CO-Dehydrogenasen von $H$. pseudoflava, P. thermocarboxydovorans bzw. $O$. carboxydovorans, der Nikotin-Dehydrogenase von A. nicotinovorans und der Quinolin-2-Oxidoreduktase von P. putida (KANG und KIM, 1999). Sterne in der Consensus-Sequenz stehen für ähnliche Aminosäuren dieser Enzyme. Das Multialignment wurde mit dem Programm „ClustalW“ berechnet.

K3-Region

Den $\mathrm{G}_{347}$ und $\mathrm{G}_{348}$ aus der Xanthin-Dehydrogenase von Drosophila melanogaster entsprechende Aminosäuren, die in der rosy-Mutante ausgetauscht wurden (HUGHES et al., 1992)

Die kleine Untereinheit enthält in allen molybdänbindenden Hydroxylasen 2 verschiedene [2Fe-2S]-Cluster, die von 8 konservierten Cysteinen koordiniert werden. Auch die CoxS-Sequenz des Cosmides slc_1x enthält diese Cysteine (s. Abbildung 25). Die erste Region beinhaltet die Cysteine in den Positionen 42, 47, 50 und 62. Diese Positionen stimmen mit denen der kleinen Untereinheit der CO-Dehydrogenase CutS aus $H$. pseudoflava überein und entsprechen dem typischen Sequenzmotiv C- $\mathrm{X}_{4}-\mathrm{C}-\mathrm{X}_{2}-$ 
$\mathrm{C}-\mathrm{X}_{\mathrm{n}}-\mathrm{C}$, das in bakteriellen und pflanzlichen Ferredoxinen gefunden werden kann (KANG und KIM, 1999). Die zweite Region ist in Molybdän enthaltenden Hydroxylasen stärker konserviert und beinhaltet das Sequenzmotiv C- $\mathrm{X}_{2}-\mathrm{C}-\mathrm{X}_{\mathrm{n}}-\mathrm{C}-\mathrm{X}-\mathrm{C}$ entsprechend den Aminosäuren $\mathrm{C}_{101}, \mathrm{C}_{104}, \mathrm{C}_{136}$ und $\mathrm{C}_{138}$. Bei dieser Untereinheit führen die Austausche $\mathrm{G}_{42} \rightarrow \mathrm{E}$ und $\mathrm{E}_{89} \rightarrow \mathrm{K}$ zu rosy-Mutanten bei D. melanogaster. Diese Aminosäuren sind auch in der von dem ORF1012 kodierten Sequenz an den Positionen 41 und 71 konserviert. Das Vorhandensein dieser konservierten Aminosäuren und der 8 konservierten Cysteine weist auf 2 [2Fe-2S]-Cluster auch in der CoxS-Untereinheit hin.

$\begin{array}{llll}\text { CoxS: } & 3 & \text { KVPVQFTLNGEEKAEFVDSGATLLKVLRDKLGDTSPKGGCSQGTCGACSVLIDGELTLSC } & 62 \\ \text { M. loti: } & 3 & \text { KVPVQFILNGSEKAEFIDSGTTLLNALRDKIGDTSPKGGCHQGTCGACSVIIDGELRLSC } & 62 \\ \text { CoG2080: } & 1 & \text { KMPITLTVNGEPVELDVDPRTPLLDVLRDELGLTGTKKGCGHGQCGACTVLVDGEAVNSC } & 60 \\ & & & \\ \text { CoxS: } & 63 & \text { LTLAETCEGANILTTGGLA-TDGVLHPLQRAFVDEFAAQCGFCTPGMIMAAKALLDRTPN } & 121 \\ \text { M. loti: } & 63 & \text { LTLAETCDGAAITTTSGLAE-GGVLHPLQRAFLDTFATQCGFCTPGMIMAAKVLLDQTPN } & 121 \\ \text { CoG2080: } & 61 & \text { LTLAVQAEGAEITTIEGLAKKDGGLHPVQQAFLEHDAFQCGYCTPGQIMSATALLDRNPA } & 120 \\ \text { CoxS: } & 122 & \text { PSRDDVVEALSGNICRCTGYEPIIRAVLTAAR } & 153 \\ \text { M. loti: } & 122 & \text { PSRDEVVEALSGNICRCTGYEPIIQAVLTAAR } & 153 \\ \text { Cog2080: } & 121 & \text { PTDEEIREALSGNLCRCTGYQNIVAAILDAAE } & 152\end{array}$

\section{Abbildung 25: Alignment der COG4630 mit CoxS des Cosmides slc_1x und der Aminosäuresequenz des ORFs mlr1703m von M. loti MAFF303099 (Accession- Nummer NP_103226)}

CoxS steht für die Aminosäuresequenz des ORF1012 des Cosmides slc 1x. M. loti steht für die Aminosäuresequenz des ORFs mlr1703m von Mesorhizobium loti MAFF303099 (Accession-Nummer NP_103227), COG2080 für die Sequenz der konservierten Domäne COG2080 von CoxS (kleine Untereinheit der CO-Dehydrogenase). Die türkis unterlegten Sequenzen markieren die konservierten Cysteine der [2Fe-2S]-Cluster. Das Multialignment wurde mit dem Programm „ClustalW“ berechnet.

Konservierten Cysteine der [2Fe-2S]-Cluster

Den $\mathrm{G}_{42}$ und $\mathrm{E}_{89}$ aus der Xanthin-Dehydrogenase von Drosophila melanogaster entsprechende Aminosäuren, die in der rosy-Mutante ausgetauscht wurden (HUGHES et al., 1992)

Die Aktivität der auf dem Cosmid slc_1x kodierten Kohlenmonoxid-Dehydrogenase wurde mit dem unter 2.18.4 beschriebenen Testsystem überprüft. Die bislang erhaltenen Ergebnisse lassen nicht erkennen, ob eine Aktivität vorliegt. Diese Untersuchung muss Gegenstand zukünftiger Forschung bleiben.

Nach diesem Cluster dreht sich die Leserichtung für die nächsten 13 ORFs erneut um. Wie aus der Tabelle 14 J) hervorgeht, bestehen große Ähnlichkeiten der Genprodukte der ORFs 1016 (ugpB) bis 921 (malK) zu den konservierten Domänen der Komponenten des Ugp-Transport-Systems (,uptake of glycerol phosphate“), das snGlycerin-3-Phosphat ATP-abhängig in die Zelle transportiert. Zu allen Komponenten dieses ABC-Transport-Systems können entsprechende Proteine in der cosmidkodierten Sequenz gefunden werden, die die größte Ähnlichkeit zu Proteinen aus M. loti zeigen: Das ORF1016-Protein hat eine Identität von $83 \% \mathrm{zu}$ einem periplasmatischen 
Bindeprotein eines ABC-Transporters (Accession-Nummer: NP_105991.1). Die ORF1017- und ORF1018-Proteine stimmen zu 79 \% bzw. $90 \%$ mit 2 verschiedenen Permease-Komponenten (Accession-Nummer: NP_105990.1 bzw. NP_105989.1) überein. Die ORF1020- und ORF1021-Proteine zeichnen sich durch eine 86\%ige bzw. 75\%ige Identität zu ATP-Bindeproteinen (NP_105987.1 bzw. NP_105986.1) aus. Die Größe und Anordnung der cosmidkodierten ORFs entsprechen denen der ORFs aus $M$. loti. Der ORF1019 umfasst nur 68 Aminosäuren, ist aber ebenfalls bei M. loti vorhanden (NP_105988.1). Da keine signifikanten Übereinstimmungen zu funktionell untersuchten ORFs vorhanden sind, kann keine Aussage über die Funktion gemacht werden. In E. coli gehört dieses System zum pho-Regulon. Die Gene des pho-Regulons werden in Abhängigkeit von der Phosphatkonzentration im Medium positiv durch den Transkriptions-Aktivator $\mathrm{PhoB}$ reguliert, der an sogenannte pho-Boxen bindet (MAKINO et al., 1988). In der slc_1x-Cosmidsequenz konnten jedoch vor keinem der oben genannten ORFs den pho-Boxen aus E. coli entsprechende Sequenzmotive identifiziert werden.

In der gleichen Leserichtung liegt ein Cluster (Abbildung 26), das von den ORFs 1022 und 1027 eingerahmt wird. Diese kodieren vermutlich für die 2 Komponenten Dak2 (ORF1022) und Dak1 (ORF1027) einer Dihydroxyaceton-Kinase. Der Vergleich der Aminosäuresequenz mit den konservierten Domänen der Komponenten von Dihydroxyaceton-Kinasen pfam02734 und COG2376 liefert „e-Values“ von 6e $\mathrm{e}^{-29}$ bzw. $1 \mathrm{e}^{-77} \mathrm{Zu}$ den experimentell bestätigten E. coli Untereinheiten der DihydroxyacetonKinase DhaL (Accession-Nummer NP_415717.1) und DhaK (Accession-Nummer NP_415716.1) waren die Genprodukte der ORFs 1022 und 1027 zu 49 \% bzw. 37 \% identisch. Auch bei diesem Cluster stammen die ähnlichsten Proteine zu den auf dem Cosmid kodierten Genprodukten aus M. loti. Die Identität der Genprodukte der ORFs 1022 und 1027 betragen zu den entsprechenden Proteinen von M. loti 65 \% bzw. 73 \%. Beide Proteine sind als hypothetische Proteine (Acession-Nummer NP_105984.1 bzw. NP_105979.1) annotiert. Die Anordnung der ORFs 1021 bis 1028 sowie die genetische Organisation des dha-Operons aus E.coli sind in Abbildung 26 dargestellt. In der Abbildung ist außerdem der Bereich des M. loti-Genoms enthalten, in dem die Gene lokalisiert sind, deren Genprodukte zu denen der ORFs 1021 bis 1027 die größten Übereinstimmungen haben. 


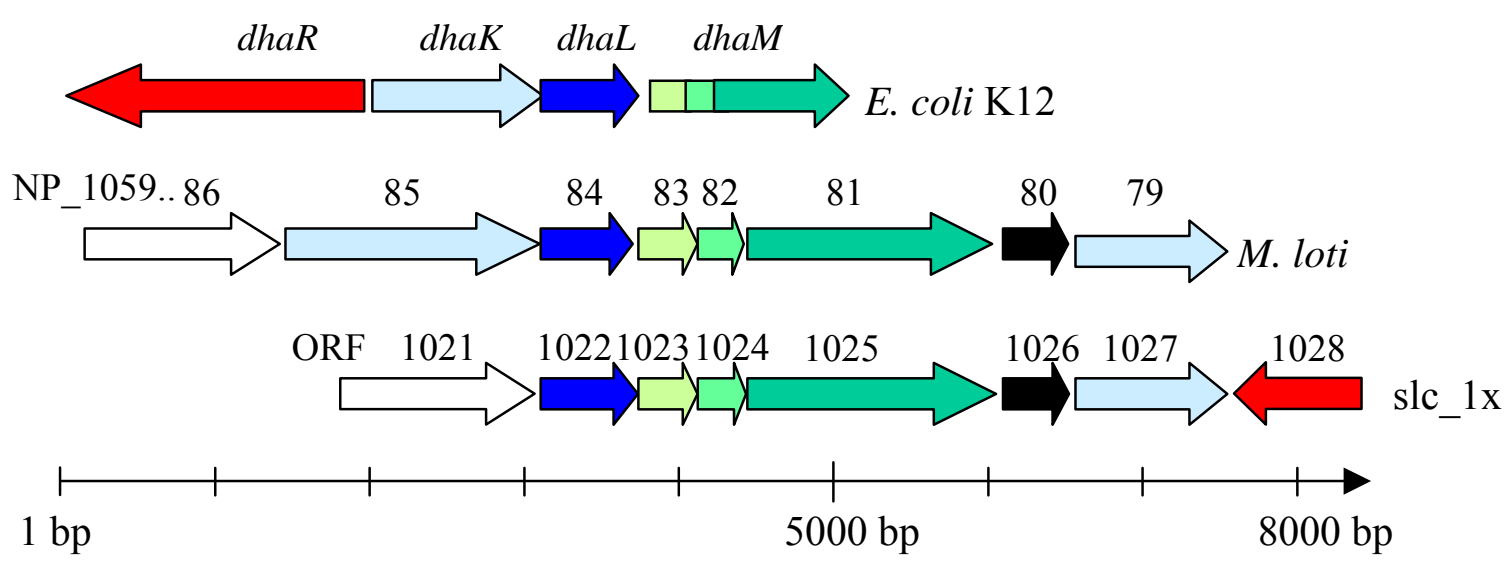

\section{Abbildung 26: Genetische Organisation der Dihydroxyaceton-Kinase-Gene und der für das Phosphotransferase-System kodierenden Gene}

Berücksichtigt sind die Gene dhaR (Accession-Nummer NP 415719.1), dhaK (Accession-Nummer NP_415716.1), dhaL (Accession-Nummer NP_415717.1) und dhaM (Accession-Nummer NP_415716.1) von E. coli und die ORFs von M. loti, zu de-en Genprodukten die von den ORFs 1021 bis 1028 vom Cosmid slc_1x kodierten Proteine die größte Ähnlichkeit zeigen. Die Gene aus M. loti sind in der Abbildung mit ihrer Accession-Nummer benannt.

Potentielle Funktion der ORFs:

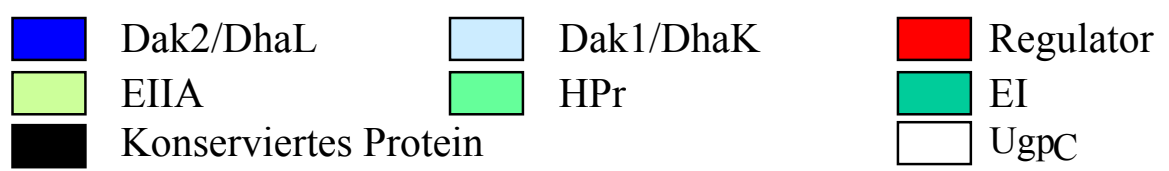

Die Aminosäuresequenz von Dak1 (ORF1027-Genprodukt) beinhaltet die Glycinreichen konservierten Motive SGGGSGHEP (AS 50 - 58) und GIHGEPG (AS 212 218) und das dritte invariante Sequenzmotiv KNYEGD (AS 104 - 109), die in ATPund PEP-abhängigen Dihydroxyaceton-Kinasen gefunden werden können. Ein Alignment dieser Motive des ORF1027-Genproduktes, des hypothetischen Proteins von M. loti (Acession-Nummer NP_105979.1) und der Dihydroxyaceton-Kinasen von E. coli (Accession-Nummer NP_415716.1) und Citrobacter freundii (AccessionNummer P45510) ist in Abbildung 27 dargestellt. Die 3 Sequenzmotive befinden sich im aktiven Zentrum des DhaK-Proteins von E. coli. SIEBOLD et al. (2003) konnten für das E. coli-Enzym mittels Röntgen-Strukturanalyse zeigen, dass das Dihydroxyaceton kovalent über das $\mathrm{H}_{230}$ an das Enzym gebunden wird. Dieses Histidin entspricht dem $\mathrm{H}_{214}$ im ORF1027-Genprodukt. Wasserstoffbrückenbindungen tragen zur Fixierung des Substrates in dieser Position bei. In E. coli bildet das Histidin-66 eine Wasserstoffbrückenbindung zur Hydroxylgruppe des C-2-Atoms des Dihydroxyacetons 
aus (SIEBOLD et al., 2003). Diesem Histidin entspricht das $\mathrm{H}_{56}$ des ORF1027-Proteins. Die Hydroxylgruppen des C-1- und C-3-Atoms des Dihydroxyacetons werden von der Carboxylgruppe des $\mathrm{D}_{119}$ des DhaK von E. coli koordiniert (SIEBOLD et al., 2003). Auch diese Aminosäure ist in der abgeleiteten Aminosäuresequenz des ORF1027 an der Position 109 vorhanden. Im Vergleich zu der Sequenz von DhaK von E. coli ist im dritten Sequenzmotiv ein Tyrosin gegen ein Glutamat ausgetauscht (GUTKNECHT et al., 2001).

$\begin{array}{ll}\text { E. coli } & \text { 53-AGKVALLSGGGSGHEPMHC-71 } \\ \text { C. freundii } & \text { 48-KNNVAVISGGGSGHEPAHV-66 } \\ \text { M. loti } & \text { 43-PGKVALISGGGSGHEPLHA-61 } \\ \text { Slc_1x } & \text { 43-PGKVALISGGGSGHEPLHG-61 }\end{array}$

E. coli 222-EMEFGVGIHGEPGI-236

C. freundii 214-HAELGMGIHGEPGA-228

M. loti 205-EMEFGVGIHGEPGR-219

slc_1X 205-EMEFGVGIHGEPGR-219

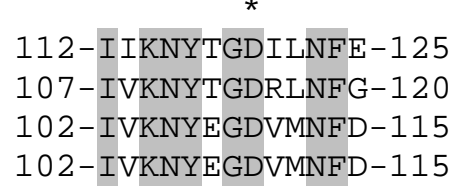

112 - IIKNYTGDILNFE - 125

102 - IVKNYEGDVMNFD - 115

102 - IVKNYEGDVMNFD - 115

\section{Abbildung 27: Alignment von Sequenzbereichen im aktiven Zentrum von ATP- und PEP-abhängigen Dihydroxyaceton-Kinasen}

In dem Alignment wurden die Sequenzen der ATP-abhängigen Dihydroxyaceton-Kinase von C. freundii (Accession-Nummer P45510), von DhaK von E. coli (Accession-Nummer NP_415716.1), des hypothetischen Proteins aus M. loti (Acession-Nummer NP_105979.1) und der Aminosäuresequenz des ORF1027 verglichen. Mit einem Stern ${ }^{*}$ ) sind die Aminosäuren $\mathrm{H}_{66}, \mathrm{D}_{119}$ und $\mathrm{H}_{230}$ markiert, die für die kovalente Bindung des Dihydroxyacetons bzw. die Ausbildung von Wasserstoffbrückenbindungen in DhaK von E. coli verantwortlich sind.

Bei E. coli liegen die ORFs, die für die beiden Untereinheiten DhaK und DhaL der Dihydroxyaceton-Kinase kodieren, direkt hintereinander. Vor ihnen ist das Transkriptionsregulator-Protein DhaR (Accession-Nummer NP_415719.1) und hinter ihnen das Multiphosphorylprotein des Kohlenhydrat:Phosphotransferase-Systems (PTS) DhaM (Accession-Nummer NP_415716.1) kodiert. Dieses Protein hat Sequenzähnlichkeiten zu der EIIA-Domäne des PTS-Mannose-Transporters, zum Phosphoryl-Carrier-Protein HPr und zur N-terminalen Domäne des Enzyms I (GUTKNECHT et al., 2001). Auch bei M. loti liegen 2 ORFs hintereinander, deren Genprodukte Sequenzähnlichkeiten zu DhaK und DhaL haben. Jedoch ist nur das Genprodukt des ersten als Dihydroxyaceton-Kinase annotiert (Accession-Nummer NP_105985). Dieses entspricht der DhaK-Domäne der Dihydroxyaceton-Kinase aus E. coli. Dieser ORF ist auf dem Cosmid slc_1x nicht vorhanden. Dort schließt sich direkt an das ugp-Gencluster der ORF 1022 an, der, wie oben beschrieben, vermutlich für die DhaL-Domäne der Dihydroxyaceton-Kinase kodiert. Auch in M. loti ist ein 
entsprechender ORF vorhanden. Er ist, wie oben erwähnt, als hypothetisches Protein annotiert. Von diesem ORF an entsprechen sich, wie der Abbildung 26 entnommen werden kann, die genetischen Organisationen des Cosmides und von M. loti. Es folgen nun die ORFs 1023 bis 1025, deren abgeleitete Aminosäuresequenzen signifikante Ähnlichkeiten mit den konservierten Domänen der Proteine EIIA, HPr und EI des Phosphoenolpyruvat-Phosphotranferase-Systems (PTS) von Mannose haben. Die Identitäten der Genprodukte dieser ORFs zu den entsprechenden Proteinen aus M. loti liegen zwischen 64 und 87 \%. Die Anordnung der für die PTS-Komponenten kodierenden ORFs entspricht der Reihenfolge, in der auch die Domänen in dem dhaMGen von E. coli kodiert sind (s. Abbildung 26). Allerdings ist sowohl bei M. loti als auch auf dem Cosmid slc_1x der für das EI-Protein kodierende ORF deutlich größer als der für die EI-Domäne kodierende Genbereich des dhaM-Gens bei E. coli. Die „eValues“ für die Übereinstimmungen der cosmidkodierten ORFs mit den entsprechenden konservierten Domänen sind jedoch sehr unterschiedlich. Die potentielle HPrKomponente (ORF1024-Protein) hat nur einen „e-Value“ von $1 \mathrm{e}^{-10}$, die EI-Komponente (ORF1025-Protein) dagegen einen „e-Value“ von 8e $\mathrm{e}^{-114}$. Der ORF1023 stimmt mit einem „e-Value“ von $4 \mathrm{e}^{-32}$ mit der konservierten Proteindomäne COG3412 überein, deren Funktion noch nicht bekannt ist. Eine geringere Ähnlichkeit besteht zu der konservierten Proteindomäne pfam03610, die in der EIIA-Komponente des PTS für Mannose gefunden werden kann. SIEBOLD et al. (2003) konnte durch strukturelle Untersuchung zeigen, dass die EIIA-Komponente von E. coli am His ${ }_{10}$ phosphoryliert wird. Das Asp 67 stabilisiert und/oder aktiviert das Histidin durch die Ausbildung einer Wasserstoffbrückenbindung zum N $\delta 1$. Im EIIA (Genprodukt des ORFs1023) des Cosmides nimmt ein Histidin die Position 11 und ein Aspartat die Position 69 ein. Die Aminosäuresequenz des auf dem Cosmid kodierten HPr-Proteins (Genprodukt des ORF1024) weist abweichend von der E. coli-DhaM-Sequenz das Sequenzmotiv GLHARP statt GLHVRP an der Phosphorylierungsstelle und 30 statt 31 Aminosäuren später das konservierte Serin auf. Auch das SHS-Motiv der EI-Phosphorylierungsstelle ist im ORF1025-Protein leicht abgewandelt in SHV. Im Gegensatz zu der DhaM-EIDomäne aus E. coli fehlt dem EI-Protein des Cosmides die C-terminale Domäne nicht. Das ORF1026-Protein musste aufgrund fehlender Ähnlichkeiten zu funktionell untersuchten Proteinen als konserviertes Protein annotiert werden.

Für einen ORF, den ORF1028, dreht sich nun wieder die Leserichtung um. Dieser kodiert vermutlich für ein Regulatorprotein, das Ähnlichkeit zu der konservierten 
Domäne COG0589 des universellen Stress-Proteins UspA hat. An diesen ORF schließt sich ein Cluster an (ORFs 1029 bis ORF1032), das die Information für 4 regulatorische Proteine enthält, deren größte Übereinstimmungen zu den Proteinen FixL, FixJ, FixT2 und FixK aus M. loti bzw. aus S. meliloti bestehen (s. Abbildung 22). Die Identitäten betragen $36 \%$ bis $69 \%$.

$\mathrm{Zu}$ den restlichen auf dem Cosmid slc_1x kodierten Proteinen gibt es in M. loti ebenfalls Proteine mit signifikanter Ähnlichkeit. Die z. T. wesentlich größeren Übereinstimmungen gibt es aber zu Proteinen anderer Organismen. Es sollen hier nur noch die ORFs 1036 und 1037 erwähnt werden, die für die Proteine CaiB und CaiA kodieren. Die Ähnlichkeit von CaiB zur konservierten Domäne COG1804, die in AcylCoA-Transferasen/Carnitin-Dehydrogenasen enthalten ist, hat einen „e-Value“ von $9 \mathrm{e}^{-86}$. Der ,e-Value“ für die Ähnlichleit zwischen CaiA und der konservierten Domäne COG1960, einer Domäne, die in Acyl-CoA-Dehydrogenasen gefunden wird, beträgt $4 \mathrm{e}^{-70}$. Die nächst verwandten Enzyme, die der Tabelle $12 \mathrm{~J}$ ) entnommen werden können, stimmen mit noch größeren ,e-Values“ $1 \mathrm{e}^{-99}$ bzw. $1 \mathrm{e}^{-163}$ mit den Genprodukten der ORFs 1036 und 1037 überein, es handelt sich bei ihnen aber um keine experimentell bestätigten Proteine.

\subsection{Experimentelle Untersuchung der Dihydroxyaceton-Kinase}

Das Cosmid slc_1x wurde sowohl auf die Kohlenmonoxid-Dehydrogenase- als auch auf die Dihydroxyaceeton-Kinase-Aktivität hin untersucht. Hierfür wurde das Cosmid in die Glycerin-negative E. coli-Mutante ECL707 transformiert (s. 2.11.1). Eine Kolonie wurde dann in einem 5 ml-Röhrchen Citrobacter-Mineralmedium mit $10 \mathrm{mM}$ Dihydroxyaceton und $30 \mathrm{mM}$ Pyruvat angezogen und für 2 Tage bei $30^{\circ} \mathrm{C}$ geschüttelt. Mit dieser Vorkultur wurde dann eine 250 ml-Hauptkultur im gleichen Medium angeimpft und ebenfalls für 2 Tage inkubiert. Die Zellen wurden dann zentrifugiert und mit der French Press (s. 2.16.1) aufgeschlossen. Die Zelltrümmer wurden abzentrifugiert und der Rohextrakt sofort im Enzym-Aktivitätstest eingesetzt. Als Negativ-Kontrolle wurde ein Rohextrakt von einer E. coli ECL707-Kultur mit dem insertlosen Vektor unter gleichen Bedingungen hergestellt. Für die Überprüfung der Dihydroxyacetonphosphat-Kinase-Aktivität kamen zwei verschiedene Testansätze zum Einsatz. Beiden ist gemein, dass sie 2 enzymatische Reaktionen koppeln. Zunächst erfolgt, falls eine Dihydroxyaceton-Kinase im Rohextrakt vorhanden ist, der Umsatz des Dihydroxyacetons zu Dihydroxyaceton-Phosphat. Diese Reaktion kann ATP- oder 
PEP-abhängig erfolgen. Der unter 2.18.3.2 beschriebene Enzymtest eignet sich zum Messen einer ATP-abhängigen, der unter 2.18.3.1 beschriebene zum Messen einer PEPabhängigen Reaktion. Da die Messungen mit einem Rohextrakt von E. coli durchgeführt wurden, musste die E. coli-eigene Glycerin-Kinase durch Zugabe von $\alpha, \alpha$-Dipyridyl bzw. $100 \mathrm{mM}$ Glycerin inhibiert werden. Trotzdem war die NADH-Oxidation bereits vor dem Start der Reaktion durch die Zugabe der Glycerin-3-phosphat-Dehydrogenase und des ATP bzw. PEP sehr stark. Aus diesem Grund war die Auswertung des erhaltenen Testergebnisses stark erschwert. Eine quantitative Auswertung ergab eine spezifische Aktivität von $8,33 \cdot 10^{-3} \quad \mathrm{U} / \mathrm{mg}$ Enzym. Eine ATP-abhängige Dihydroxyaceton-Kinase-Aktivität konnte nicht detektiert werden.

\subsubsection{Das Cosmid slc_2g}

Die Sequenzierung des Cosmides slc_2g ergab eine Insert-Länge von 39069 bp. Der G+C-Gehalt des Inserts beträgt 67,2 \%. 28 ORFs wurden festgelegt. Von den 12 kodierten Proteinen, denen Funktionen zugeordnet werden konnten, sind 7 in den Aminosäure-Metabolismus integriert. Das entspricht $25 \%$ aller auf dem Cosmid kodierten Proteine. Ein Cluster bilden die ORFs 1112 bis 1118, wobei die ORFs 1114 und 1115 aufgrund fehlender Ähnlichkeiten zu Sequenzen aus Datenbanken als hypothetische membrandurchspannenden Proteine annotiert werden mussten.

Der ORF1112 kodiert für eine $\gamma$-Glutamyl-Transpeptidase, der ORF1113 für eine Glutamin-Synthetase, der ORF1116 für eine potentielle Threonin-Dehydratase und der ORF1118 für eine weitere Glutamin-Synthetase. Zusätzlich wurde der ORF1109 als Threonin-Dehydratase annotiert. Die Identitäten zu den ähnlichsten Proteinen aus der NCBI-Datenbank betragen 31 bis $57 \%$. Bei den ORF1101- und ORF1103Genprodukten handelt es sich vermutlich um Proteasen.

\subsubsection{Das Cosmid slc_2j}

Auf diesem Cosmid sind vermutlich 34 Proteine kodiert, von denen 64,7 \% nur als hypothetische oder konservierte Proteine annotiert werden konnten. Einige Proteine könnten in die Energieumwandlung und -gewinnung integriert sein: Die Genprodukte der ORFs 1208 und 1210 könnten die Untereinheiten einer F0F1-Typ-ATPase darstellen. Das ORF1215-Protein könnte die Cytochrom B-Untereinheit einer Menaquinol-C-Reduktase, das ORF1213-Protein eine membranständige GTPase sein. Die übrigen Annotationen lassen keine funktionellen Cluster erkennen. 


\subsection{Sequenzabhängige und auf Aktivität basierende Durchmusterung von Metagenombanken}

Neben der Charakterisierung von Standorten ist ein weiteres Ziel der Metagenomforschung die Nutzbarmachung von Umwelt-DNA als Quelle für bioaktive Agenzien und biotechnologisch interessante Enzyme (RONDON et al., 2000). Dabei können die erstellten Genbanken sowohl für sequenzabhängige als auch für auf Aktivität basierende Durchmusterungsmethoden genutzt werden. Deshalb wurden in dieser Arbeit zum einen die Annotationen der sequenzierten Cosmide auf das Vorhandensein von biotechnologisch interessanten Enzymen untersucht. Zum anderen wurde ein rekombinanter E. coli-Klon näher charakterisiert, der bei Vorarbeiten bei der Durchmusterung von Umwelt-DNA-Genbanken auf Gene gefunden worden war, die die Fähigkeit verleihen, mit Erythrit als einziger Kohlenstoff- und Energie-Quelle zu wachsen.

\subsubsection{Sequenzabhängige Durchmusterung von Genbanken}

Zur sequenzabhängigen Durchmusterung von Genbanken stehen verschiedene Verfahren zur Verfügung: Wie z. B. die Amplifikation von Genen oder Genfragmenten in PCR-Reaktionen mit Oligonukleotiden, die aus konservierten Bereichen abgeleitet wurden oder die Detektion von Genen mit DNA-Sonden in Hybridisierungsexperimenten. In dieser Arbeit wurden die vorhandenen Sequenzen der LeinesedimentCosmide auf ORFs hin überprüft, deren Annotationen ihnen bioaktive Funktionen oder biotechnologisch relevante Enzymaktivitäten zuwiesen. ORFs, denen entweder Oxidoreduktase- oder Protease-Aktivitäten zugeschrieben wurden, wurden in Plattentests auf die Aktivität hin untersucht.

Der Nachweis der Oxidoreduktasen erfolgte durch Transformation aller sequenzierten Cosmide oder parallel, falls vorhanden, durch zusätzliche Transformation von ShotGun-Plasmiden, die entsprechdende ORFs enthielten, in die Glycerin-negative E. coliMutante ECL707. Damit wurde verhindert, dass die E. coli eigene GlycerinDehydrogenase-Aktivität bei dem Nachweis störte (SPRENGER et al., 1989). Als Testsubstrate wurden 1,2-Ethandiol und ein Gemisch aus Propandiol und Glycerin in einer Konzentration von $1 \%$ eingesetzt. Die Platten wurden unter Lichtausschluss bei 
$30{ }^{\circ} \mathrm{C}$ inkubiert und konnten bis etwa eine Woche nach dem Ausplattieren ausgewertet werden. Als Positiv-Kontrolle wurde das Plasmid pAK204 (KNIETSCH et al., 2003) parallel in den selben Stamm transformiert. Das Cosmid pAK204 trägt einen ORF, der die eingesetzten Testsubstrate oxidieren kann (KNIETSCH et al., 2003). Bei keinem der überprüften $E$. coli-Transformanten zeigte sich mit den eingesetzten Testsubstraten eine rote Hofbildung.

Alle Cosmide wurden außerdem auf eine Protease-Aktivität hin untersucht. Damit sollten Annotationen von ORFs als „Protease“ oder „Peptidase“ überprüft werden. Als Testsystem dienten LB-Agar-Platten mit 2 \% Skim-Milk. Die Skim-Milk führt zu einer Trübung des Mediums. Werden Proteasen von Bakterien produziert und gelangen diese aus den Zellen, wird die Skim-Milk abgebaut, was zu einer Aufklarung des Agars um die Kolonien führt. Es konnte allerdings keine cosmidvermittelte Protease-Aktivität festgestellt werden (persönliche Mitteilung Tanja Waschkowitz).

\subsection{Isolierung und Charakterisierung einer Erythrit- Oxidoreduktase}

Ein weiteres Ziel dieser Arbeit war die Charakterisierung eines Klons, der bei der Durchmusterung einer Boden-Metagenombank die Fähigkeit aufwies, mit Erythrit als einziger Kohlenstoff- und Energie-Quelle zu wachsen. Das für das Wachstum verantwortliche Gen sollte identifiziert und das korrespondierende Genprodukt charakterisiert werden. Enzyme, die ein Wachstum mit Erythrit als einziger Kohlenstoff- und Energie-Quelle ermöglichen, sind z. B. Erythrit-Oxidoreduktasen. Diese katalysieren sowohl die Oxidation des Erythrits als auch die Reduktion des entstehenden Produktes. Mögliche Produkte der Oxidation von Erythrit sind DErythrose wie z. B. bei Schizophyllum commune (BRAUN et al., 1969) oder LErythrulose wie z. B. bei Enterobacter aerogenes (GRIFFIN, 1992). Auch eine primäre Phosphorylierung zu D-Erythrit-1-Phosphat und eine anschließende Oxidation zu DErythrulose-1-Phosphat wie bei Brucella abortus (SPERRY und ROBERTSON, 1974) ist denkbar. Bekannte Enzyme nutzen für die Oxidation unterschiedliche Coenzyme, wie z. B. NADP, NAD und PQQ (LEE et al., 2003; MOONMANGEE et al., 2002). 


\subsubsection{Stand der Vorarbeiten}

Der in dieser Arbeit näher untersuchte E. coli-Klon JM109/pEry1 geht aus einer Durchmusterung von Genbanken auf Gene hervor, die ein Wachstum mit Erythrit als einziger C- und Energiequelle ermöglichen. Bei dem Screening wurden CitrobacterMineralmedium-Platten mit Ampicillin (s. 2.2.4) eingesetzt, die Spuren von Hefeextrakt enthielten. Der Hefeextrakt sollte allen rekombinanten E. coli-Klonen ein minimales Anwachsen erlauben, ein deutliches Wachstum sollte aber nur beim Vorhandensein der Fähigkeit der Erythritverwertung möglich sein. Das aus diesem Klon isolierte Plasmid pEry1 wurde vollständig sequenziert.

\subsubsection{Sequenzierung und Annotation des pEry1-Inserts}

Die Annotation des vollständig sequenzierten pEry1-Inserts ergab eine Insertgröße von 5176 bp und einen G+C-Gehalt des Inserts von 69,4 \%. Es wurden 5 ORFs in dem Programm Artemis (s. 2.15.1) festgelegt und ihren Genprodukten die in Tabelle 14 aufgeführten Funktionen zugeordnet. Die genetische Organisation ist in Abbildung 28 dargestellt. Wie in Tabelle 14 zu sehen ist, kann nur dem Genprodukt des ORF2 eine Funktion zugewiesen werden. Dieser ist auf Aminosäureebene zu 42 \% identisch zu einer Phosphoglycerat-Dehydrogenase aus Burkholderia cepacia R18194. Da zusätzlich zu diesem Blast-Hit auch eine gute Übereinstimmung mit einem „e-Value“ von $3 \mathrm{e}^{-71} \mathrm{zu}$ der konservierten Domäne COG0111 der Phosphoglycerat-Dehydrogenasen gefunden wurde, ist es sehr wahrscheinlich, dass der ORF2 tatsächlich zumindest für eine Dehydrogenase kodiert.

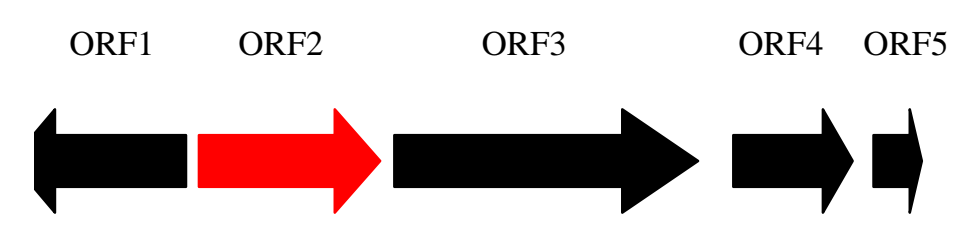

\section{Abbildung 28: Genetische Organisation des Inserts von pEry1}

Pfeile und Pfeilspitzen repräsentieren die Länge, Position und Orientierung von möglichen Genen. Der partielle ORF1 ist durch einen abgebrochenen Pfeil gekennzeichnet. Schwarze Pfeile bilden offene Leserahmen (ORF; „,open reading frame“) ab, die als hypothetische Proteine annotiert wurden. Dem roten ORF 2 wurde als einzigem eine Funktion zugewiesen. Er wurde als Dehydrogenase mit konservierter Domäne COG0111 annotiert. 


\section{Tabelle 14: ORFs des Plasmids pEry1 mit ihrer zugeordneten Annotation}

In dem Programm Artemis wurde die Sequenz des Inserts des Plasmids pEry1 auf mögliche ORFs untersucht. Dabei wurde, wie unter 2.15.1 beschrieben, vorgegangen. Festglegte ORFs wurden der NCBIDatenbank verglichen, wobei auch das Vorhandensein konservierter Domänen überprüft wurde. Ähnlichkeiten mit einem „e-Value“ von mehr als $1 \mathrm{e}^{-10}$ wurden als nicht signifikant eingestuft und bei der Annotation nicht weiter berücksichtigt.

\begin{tabular}{|c|c|c|c|c|c|c|}
\hline ORF & $\begin{array}{l}\text { Größe } \\
\text { in AS }\end{array}$ & $\begin{array}{l}\text { Lese- } \\
\text { rahmen }\end{array}$ & \begin{tabular}{lr} 
Ähnlichstes & Protein \\
aus der & NCBI- \\
Datenbank & mit \\
\multicolumn{2}{c}{ „Accession-Nr.“ }
\end{tabular} & $\begin{array}{l}\text { Identität/ } \\
\text { „e-Value“ }\end{array}$ & $\begin{array}{l}\text { Konservierte } \\
\text { Bereiche }\end{array}$ & Annotation \\
\hline 1 & 317 & -2 & OprF (AAR015891) & $39 / 3 e^{-07}$ & $\begin{array}{l}\text { pfam00691, } \\
\text { OmpA, } 2 \mathrm{e}^{-05}\end{array}$ & $\begin{array}{l}\text { Hypothetisches } \\
\text { Protein }\end{array}$ \\
\hline 2 & 329 & +2 & $\begin{array}{l}\text { COG0111: } \\
\text { Phosphoglycerat- } \\
\text { Dehydrogenase und } \\
\text { verwandte } \\
\text { Dehydrogenasen } \\
\text { (ZP_00214657.1) }\end{array}$ & $42 / 3 e^{-71}$ & $\begin{array}{l}\text { COG0111, SerA, } \\
\text { Phosphoglycerat- } \\
\text { Dehydrogenase } \\
\text { und verwandte } \\
\text { Dehydrogenasen, } \\
1 e^{-49}\end{array}$ & $\begin{array}{l}\text { Dehydrogenase } \\
\text { mit konservierter } \\
\text { Domäne } \\
\text { COG0111 }\end{array}$ \\
\hline 3 & 551 & +2 & Kein Hit & & & $\begin{array}{l}\text { Hypothetisches } \\
\text { Protein }\end{array}$ \\
\hline 4 & 217 & +3 & $\begin{array}{l}\text { RNA-Polymerase } \\
\text { Sigma-Faktor-54 } \\
\text { (ZP_00235003) }\end{array}$ & $34 / 0.002$ & & $\begin{array}{l}\text { Hypothetisches } \\
\text { Protein }\end{array}$ \\
\hline 5 & 87 & +2 & Kein Hit & & & $\begin{array}{l}\text { Hypothetisches } \\
\text { Protein }\end{array}$ \\
\hline
\end{tabular}

Die anderen auf dem Plasmid kodierten Proteine zeigen keine oder nur sehr geringe Ähnlichkeiten zu anderen Proteinen, so dass keinem eine Funktion zugewiesen werden konnte. Bei einer genaueren Betrachtung der Proteinsequenz des ORF2 konnten drei Signaturen ausgemacht werden, die sonst bei fast allen D-Isomer spezifischen 2Hydroxysäure-Dehydrogenasen gefunden werden und auch fast ausschließlich bei diesen vorkommen. Die Signaturen sind in der Abbildung 29 dargestellt. Die gelb unterlegten Aminosäuren entsprechen denen, die in der Sequenz des ORF2 des Plasmids pEry1 auftreten. Rot geschrieben sind Aminosäuren die abweichend von den Signaturen in der ORF2-Sequenz enthalten sind. 
Signatur 1: [LIVMA]-[AG]-[IVT]-[LIVMFY]-[AG]-x-G-[NHKRQGSAC]-[LIV]-G-x(13,14)[LIVMFT]-x(2)-[FYwCTH]-[DNSTKG]

Signatur 2: [LIVMFYWA]-[LIVFYWC]-x(2)-[SAC]-[DNQHR]-[IVFA]-[LIVF]-X-[LIVF]-[HNI]$\mathrm{x}-\mathrm{P}-\mathrm{x}(4)-[\mathrm{STN}]-\mathrm{x}(2)-[\mathrm{LIVMF}]-\mathrm{x}-[\mathrm{GSDNT}]$

Signatur 3: [LMFATC]-[KPQ]-x-[GSTDN]-x-[LIVMFYWR]-[LIVMFYW](2)-N-x-[STAGC]-R[GPA]-x-[LIVH]-[LIVMC]-[DNVE]

\section{Abbildung 29: PROSITE: PDOC00063 D-Isomer-spezifische 2-Hydroxysäure- Dehydrogenase-Signaturen}

Das erste Sequenz-Motiv umfasst die Aminosäuren 149 bis 176. Abweichend von der Signatur 1 ist die letzte Aminosäure im ORF2 ein Glycin. Dieses tritt auch in den im Alignment (Abbildung 30) enthaltenen anderen Sequenzen auf. Auch die letzte Aminosäure in der Signatur 2 weicht im ORF2 ab. In dieser Sequenz wie auch in den Sequenzen der potentiellen D-3-Phosphoglycerat-Oxidoreduktase von Ralstonia solanacearum GMI1000 (NP_518137.1) und der D-3-Phosphoglycerat-Dehydrogenase von Xanthomonas campestris pv. campestris Stamm ATCC 33913 (NP_635415.1) befindet sich dort ein Threonin. Die ORF2-Sequenz weicht im Vergleich mit der dritten Signatur um 2 Aminosäuren ab.

Das Alanin an der fünft letzten Stelle ist in allen anderen Sequenzen vorhanden. Das Glutamat an der letzten Stelle ist dagegen nur in der ORF2-Sequenz vorhanden. Aufgrund der Sequenzähnlichkeit zu D-Isomer spezifischen 2-HydroxysäureDehydrogenasen schien es am wahrscheinlichsten, dass der ORF2 für die Umsetzung von Erythrit verantwortlich sein könnte. Deshalb wurde er für weitere Untersuchungen ausgewählt.

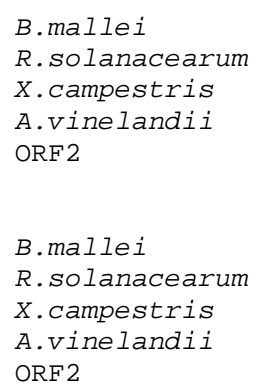

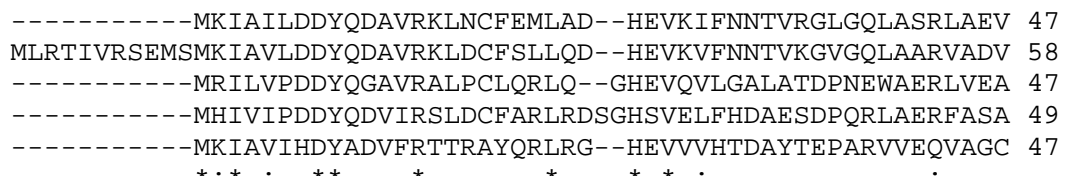
MLRTIVRSEMSMKIAVLDDYQDAVRKLDCFSLLQD - - HEVKVFNNTVKGVGQLAARVADV 58 - - - - - - - MRILVPDDYQGAVRALPCLQRLQ - -GHEVQVLGALATDPNEWAERLVEA 47

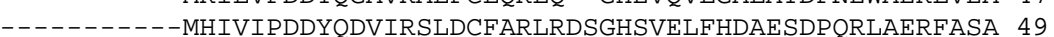
- - - - - - MKIAVIHDYADVFRTTRAYQRLRG - HEVVVHTDAYTEPARVVEQVAGC 47

EALVLIRERTHITSQLLGKLPHLRMISQTGRVS - - - - THIDLEACTERGIAVLEGTGSP - 102 EAIVLIRERTRVTRQLLDRLPKLKIISQTGRVSRDAGGHIDLEACTDKGVVVLEGKGSP - 117 DALVLIRERTRVDATLLRRLPRLKLISQTGRIG - - - -PHVDVAACTEFGVAVTEGVGSP - 102 DALVLTRERTRIDEALLARLPRLKLISQTGKIA - - - - AHLDLDACTRRGVAVAEGRGSP - 104 EAVLLTQQRVPVTREIVARLPDLRFISQTSANV - - - YHIDVAACTEHGVVVSAGRGGAR 103

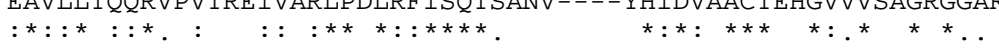




Consensus
B.mallei
R. solanacearum
X. campestris
A. vinelandii
ORF2
Consensus
B.mallei
R. solanacearum
X. campestris
A. vinelandii
ORF2

Consensus
B. mallei
R. solanacearum
X. campestris
A. vinelandii
ORF2
B. mallei
R. solanacearum
A. campestris
ORF2

LGI

- - TAPAELTWALIMAAQRRIPQYVANLKQGAWQQSGLKTSAMPPNFGLGQVLRGQTLGI 159 - - VAPAELTWALVMAAQRRIPQYVASLKHGAWQQSGLKSTTMPPNFGIGRVLKGQTLGI 174 - - - VAPAELTWALILSASRRLTEYQRALHQGRWQALGDSA - - - - - - LGRTLHGRTLGI 151 - - - IAPAELAWTLILNARRRLLPAIAAFREGRWQTN - - - - - - - - IGERLAGLTLGI 149 TAFSTTAELTWGLIIASLRHLPFEVERLKQGFWHST - - - - - - - VGTRLEGQTLGI 151 $:{ }^{* * *}:{ }^{*}:::{ }^{*}:: \quad: .^{*}{ }^{*}::^{*}{ }^{*}{ }^{* *} *$

$$
\text { WGXGKIG VXXW? } \quad X x \quad X P X
$$

WGYGKVGRLVAGYGKAFGMNVLIWGREHSLEAARADGFEAAESREAFFEQADVLSLHLRL 219 FGYGKIGQLVAGYGRAFGMNVLVWGRENSKERARADGFAVAESKDALFEQSDVLSVHLRL 234 WSYGRIGQRVAAFGRAFGMHVLVWGGEVSCAQAARDGYAIADSREALFERSDVLSLHRRL 211 WGYGKIGQRLARYAQAFEMPVLVWGSEASRQAAVAHGHRAAASREAFFAEADVLTLNLRL 209 YAFGHIGAAVARVGRAFGMKVVSWGREGSTARARAEGFEVAPSREAFFEGADVVSLHLPG 211 $::^{*}::^{*}:{ }^{*}:{ }^{*}{ }^{*}{ }^{*}{ }^{*} *{ }^{*}{ }^{*},{ }^{*}::^{*}:{ }^{*}{ }^{*}::::$

\section{XXXTXXIX? MKXTXLLVNXSR?XII?}

HDDTRGIVKLDDLLRMKPTSLLVNTSRAELLEENALVSALAHNRPGMVAIDVYESEPILQ 279 NDETRGIVTVADLTRMKPTALFVNTSRAELVEENGMVTALNRGRPGMAAIDVFETEPILQ 294 SAQTRHDVTTADLLRMRPDALLVNTSRAELIAPGALIAALDAGRPGHAAVDVFEREPVLD 271 SPSTRHIVGFDDLARMKPDALLVNVSRAELIAPGALLRALDAGRPGFAALDVFEQEPILD 269 GTETRGIVTADDLARMKPTALLVNTSRAPIIEEGALVAALGKGRPGFAAVDVFETEPVVG 271

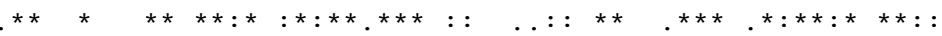

G-YSLLRMENVICTPHIGYVERESYELYFSAAFRNILAFDAGDLSSVANPDALTQGRVRR 338 G-HTLLRMENCICTPHIGYVERESYEMYFGIAFQNILDILQGNVDSVANPTALAPALIRA 353 ARDPLLQHPRVLATPHLGYVERDSYAAYFEAAFDNVLAFAAGTPRNLVNPEALLVAR - - - 328 PAHPLPNHPRVLCTPHLGYVEKHGYELYFGDAFDNLLAFFAGQPLNLANPQVLAER - - - - 325 AAHPLLKMPNALCTPHLGYGEREGYEGIYAGGVERLLAWVAGTPIDVINPEALERQKR - - 329

\section{Abbildung 30: Alignment der Aminosäuresequenz des ORF2 von pEry1 mit ähnlichen Sequenzen aus den Datenbanken}

Das Alignment wurde mit dem Programm "ClustalW" erstellt. Die Abkürzungen entsprechen: B.mallei, Glyoxylat-Reduktase von Burkholderia mallei ATCC 23344 (YP_101977.1); R.solanacearum, potentielle D-3-Phosphoglycerat-Oxidoreduktase von Ralstonia solanacearum GMI1000 (NP_518137.1); X.campestris, D-3-Phosphoglycerat-Dehydrogenase von Xanthomonas campestris pv. campestris Stamm ATCC 33913 (NP_635415.1); A.vinelandii, COG0111: Phosphoglycerat-Dehydrogenase und verwandte Dehydrogenasen von Azotobacter vinelandii (ZP_00342599.1). In Klammern ist die jeweilige AccessionNummer angegeben. „*“ steht für identische Aminosäuren in allen Sequenzen, ,,“" für konservierte und „““ für semi-konservierte Substitutionen. In der Consensus-Sequenz sind die den D-Isomer-spezifischen 2-Hydroxysäure-Dehydrogenase-Signaturen entsprechenden Aminosäuren angegeben.

\subsubsection{Wachstumskurve des Klons E. coli JM109/pEry1}

Zur Charakterisierung des Klons E. coli JM109/pEry1 sollte zunächst eine Wachstumskurve erstellt werden. Da das Wachstum des Klons in CitrobacterMineralmedium-Flüssigkulturen mit Erythrit als einziger C- und Energiequelle sehr langsam war, wurde der Klon zunächst in $5 \mathrm{ml}$ Flüssigkulturen (CitrobacterMineralmedium) mit $30 \mathrm{mM}$ Glukose angezogen. Von dieser Kultur wurde dann mit $100 \mu \mathrm{l}$ in eine neue $5 \mathrm{ml}$ Flüssigkulture mit $50 \mathrm{mM}$ Erythrit und $10 \mathrm{mM}$ Glukose und schließlich aus dieser in eine Flüssigkultur mit $50 \mathrm{mM}$ Erythrit überimpft. Auch mit diesen Adaptations-Schritten benötigte der Klon zum Anwachsen mit Erythrit als einzigem Substrat ca. 4 Wochen. Nach erneutem Überimpfen war das Wachstum wesentlich schneller, so dass eine Wachstumskurve des Klons E. coli JM109/pEry1 in $5 \mathrm{ml}$ flüssigem Citrobacter-Mineralmedium mit Ampicillin und $50 \mathrm{mM}$ Erythrit erstellt 
werden konnte (s. Abbildung 31). Dazu wurden $5 \mathrm{ml}$ flüssiges CitrobacterMineralmedium mit Ampicillin und $50 \mathrm{mM}$ Erythrit mit $100 \mu \mathrm{l}$ einer Vorkultur angeimpft. In Abbildung 31 sind 3 Wachstumskurven zu erkennen, deren Werte durch Mittelwertbildung aus je 3 Parallelansätzen gewonnen wurden.

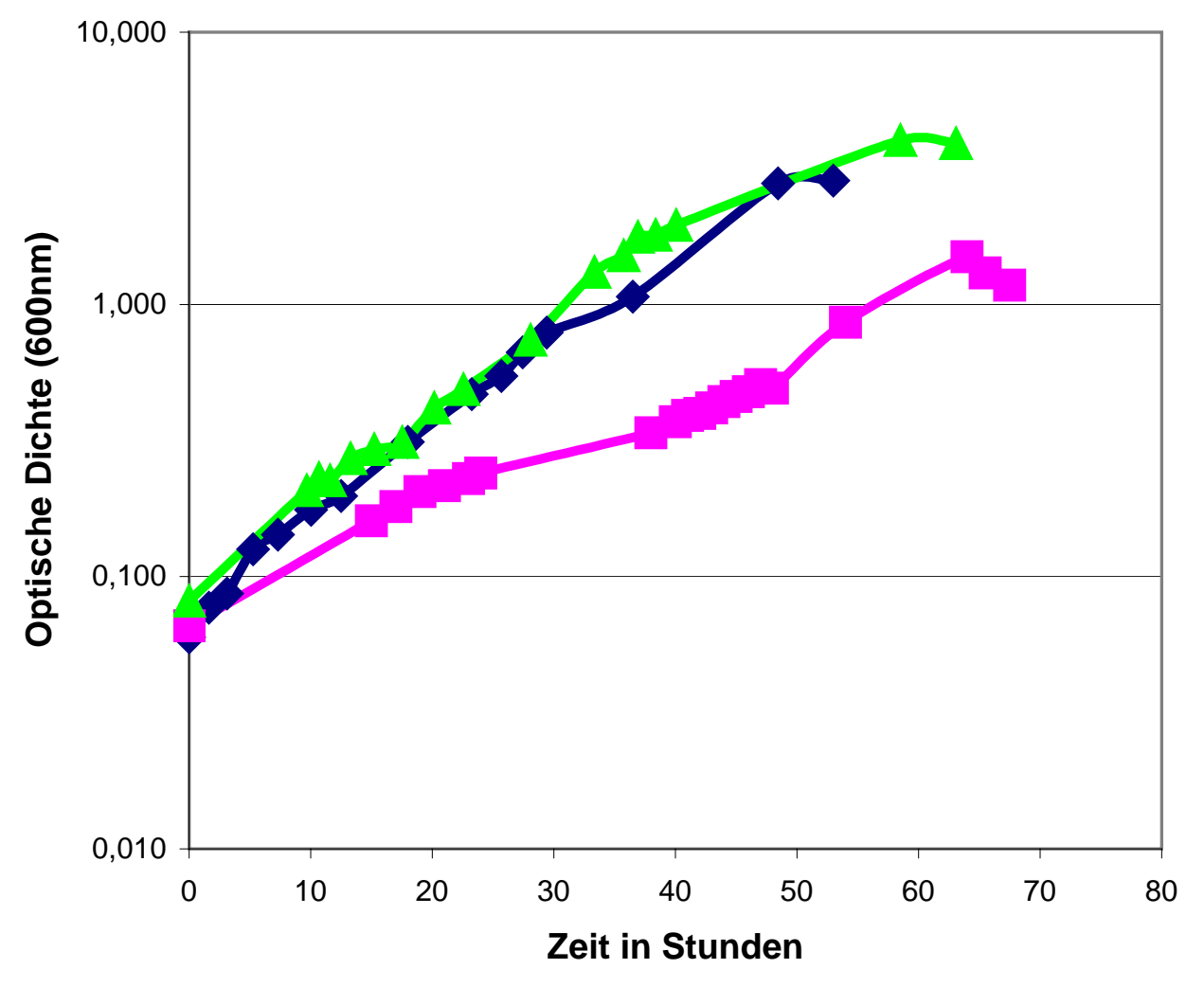

\section{Abbildung 31: Wachstumskurve des Klons E. coli JM109/pEry1 in Citrobacter- Mineralmedium-Flüssigmedium mit Ampicillin und $50 \mathrm{mM}$ Erythrit}

5 ml flüssiges Citrobacter-Mineralmedium (s. 2.2.4) mit Ampicillin und 50 mM Erythrit als einziger Cund Energiequelle wurden mit $100 \mu \mathrm{l}$ einer Vorkultur des Klons E. coli JM109/pEry1 beimpft und bei $30{ }^{\circ} \mathrm{C}$ geschüttelt. $\mathrm{Zu}$ verschiedenen Zeitpunkten wurde die optische Dichte bei $600 \mathrm{~nm}$ direkt in den Röhrchen mit Hilfe eines Photometers der Fa. Milton Roy (Spectronic 21, Rochester, New York, USA) bestimmt. Ab einer optischen Dichte von 2 wurden die Kulturen verdünnt und die optische Dichte in Plastikküvetten mit einer Schichtdicke von $1 \mathrm{~cm}$ in einem Spektralphotometer (UV-VIS Spektrophotometer V-550, Fa. Jasco, Jena) gemessen. Die drei Wachstumskurven zeigen je die gemittelten Werte von drei parallel beimpften Röhrchen.

Es zeigt sich, dass das Wachstum von E. coli JM109 mit dem Plasmid pEry1 sehr langsam ist. Es konnte eine maximale Verdopplungszeit von 8,5 h berechnet werden. Die größte optische Dichte bei 600 nm wurde nach etwa 63 Stunden mit 4,6 erreicht. Auch die Fähigkeit von E. coli JM109 mit D-Erythrose oder L-Erythrulose, möglichen Produkten der Erythrit-Umsetzung, wachsen zu können, wurde mit Citrobacter- 
Mineralmedium mit Ampicillin und jeweils einer der Substanzen (50 mM) getestet. E. coli JM109 konnte mit beiden Substraten wachsen.

Außerdem sollte überprüft werden, ob der Klon E. coli JM109/pEry1 auch anaerob mit Erythrit als einziger Kohlenstoff- und Energiequelle wachsen konnte. Dafür wurde ebenfalls das Citrobacter-Mineralmedium mit Ampicillin in Hungate-Röhrchen verwendet, die mit dem Medium vor dem Autoklavieren für 20 Minuten mit Stickstoff begast wurden. Auch hier wurde aus Vorkulturen mit $30 \mathrm{mM}$ Glukose in Vorkulturen mit $10 \mathrm{mM}$ Glukose und $50 \mathrm{mM}$ Erythrit überimpft. Aus diesen wurde dann die Hauptkultur mit $50 \mathrm{mM}$ Erythrit angeimpft. Das Inoculum betrug anaerob jeweils $250 \mu$ l. Selbst nach 8-10 Wochen konnte kein Wachstum festgestellt werden.

\subsubsection{Bestimmung der Größe des nativen Proteins über native Gradienten-PAGE und Aktivitätsfärbung}

Die Molekularmasse des nativen Enzyms, das für die Erythrit-Verwertung verantwortlich ist, sollte über ein natives Polyacrylamid-Gradientengel ermittelt werden, mit dem eine Aktivitätsfärbung, wie unter 2.21.2 beschrieben, durchgeführt wurde. Das Testsystem beruhte darauf, dass das bei der Oxidation von Erythrit gebildete NADH NBT direkt oder über den Elektronenüberträger Phenazinmethosulfat (PMS) irreversibel zum Diformazan reduzieren kann. Mit dieser Reduktion ist ein Farbwechsel von gelb zu blau verbunden, der ein aktives Enzym als distinkte Bande im Gel sichtbar werden läßt. Für den Nachweis wurde E. coli JM109/pEry1 in CitrobacterMineralmedium mit $50 \mathrm{mM}$ Erythrit für 3 - 4 Tage bei $30^{\circ} \mathrm{C}$ geschüttelt. Die Zellen wurden zentrifugiert, mit der French Press aufgeschlossen, die Zelltrümmer abzentrifugiert und der Rohextrakt in der nativen Gradienten-PAGE (s. 2.20.2) eingesetzt. Nach der Aktivitätsfärbung erschien eine deutliche Bande, der eine Molekularmasse von ca. 94 kDa zugeordnet werden konnte. Das Gel ist in Abbildung 32 dargestellt. Man erkennt auch in dem mit Coomassie-gefärbten Teil ein Protein mit dieser Molekularmasse. 


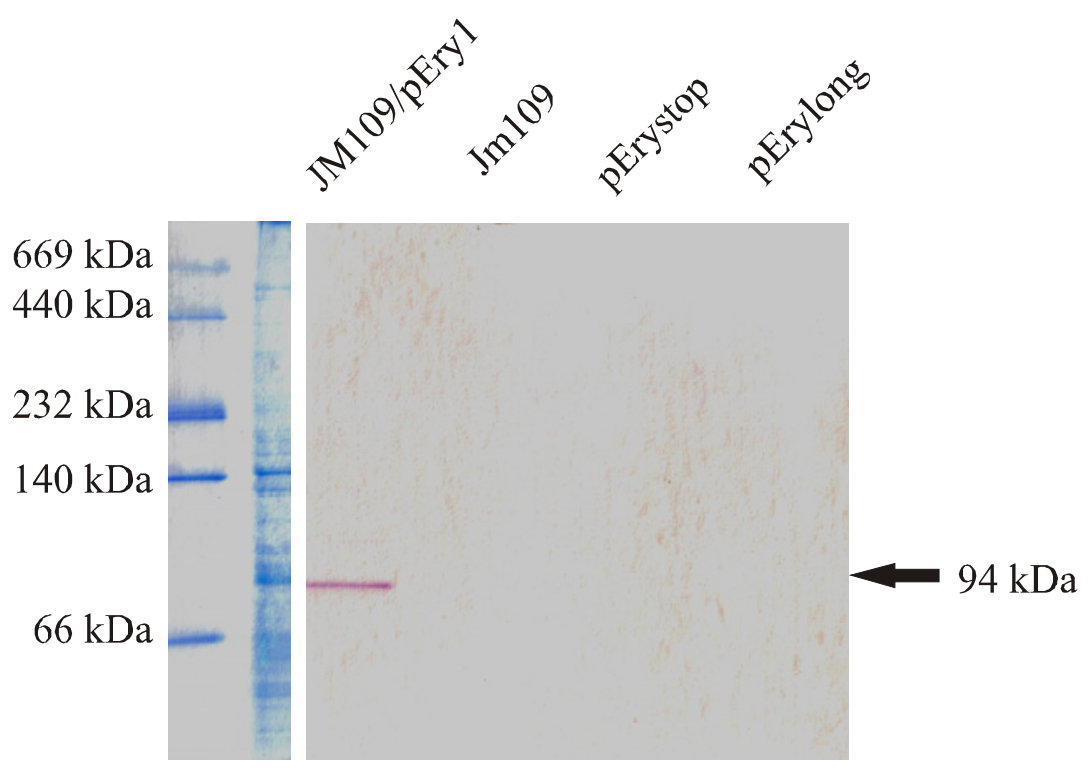

Abbildung 32: Nachweis einer Erythrit-Dehydrogenase-Aktivität in der nativen Gradienten-PAGE mit den Rohextrakten von E. coli JM109/pEry1, und E. coli BL21 Star ${ }^{\mathrm{TM}}$ mit den Plasmiden pETEry20, pErystop und pErylong

$500 \mathrm{ml}$ Citrobacter-Mineralmedium-Kulturen (s. 2.2.4) wurden mit $50 \mathrm{mM}$ Erythrit (E. coli JM109/pEry1) bzw. $30 \mathrm{mM}$ Glukose und 0,2 mM IPTG (E. coli BL21 Star ${ }^{\mathrm{TM}}$ mit den Plasmiden pETEry20, pErystop und pErylong) für 3-4 Tage bzw. über Nacht bei $30{ }^{\circ} \mathrm{C}$ geschüttelt, abzentrifugiert und mit der French Press aufgeschlossen. Zelltrümmer wurden abzentrifugiert (s. 2.16.1) und der Rohextrakt auf ein natives 12,5 \%iges Polyacrylamid-Gel aufgetragen. Die Auftrennung der Proteine erfolgte für 18 Stunden bei $4{ }^{\circ} \mathrm{C}$ und 100 V. Die Spur mit dem Marker sowie ein Stück der zweiten Spur wurden mit Coomassie gefärbt (s. 2.21.1). Mit dem restlichen Gel wurde eine Aktivitätsfärbung, wie unter 2.21.2 beschrieben, durchgeführt.

\subsubsection{Photometrische Messung der Enzymaktivität, Pufferbedingungen sowie Coenzym-Spezifität}

Oxidoreduktasen unterschieden sich in den für eine Aktivität erforderlichen Pufferverhältnissen. Deshalb wurden 3 verschiedene Puffer, die von anderen Oxidoreduktasen bekannt waren, bei den Enzymaktivitätsmessungen ausprobiert: Der $\mathrm{K}_{2} \mathrm{CO}_{3}$-Puffer wurde erfolgreich bei Aktivitätsmessungen mit Alkohol-Dehydrogenasen (KNIETSCH et al., 2003) und der Phosphat-Puffer z. B. mit der AlkoholDehydrogenase der Bäckerhefe eingesetzt. Außerdem wurde mit allen Puffersystemen getestet, ob mit $\mathrm{NAD}^{+}$oder/und $\mathrm{NADP}^{+}$eine Aktivität messbar ist, da, wie bereits oben erwähnt, für Erythrit-Oxidoreduktasen unterschiedliche Cofakor-Spezifitäten bekannt sind.

Für die Aktivitätsmessungen wurde E. coli JM109/pEry1 in CitrobacterMineralmedium mit Ampicillin und $50 \mathrm{mM}$ Erythrit in $500 \mathrm{ml}-$ Kulturen angezogen und nach 3-4 Tagen geerntet. Die Zellen wurden in dem Puffer, in dem die 
Aktivitätsmessung durchgeführt werden sollte, aufgenommen, mit der French Press (s. 2.16.1) aufgeschlossen und die Zelltrümmer bei $4{ }^{\circ} \mathrm{C}$ für 30 min abzentrifugiert. Der Überstand wurde dann in den Aktivitätsmessungen, wie unter 2.18.1 beschrieben, eingesetzt. Aktivität konnte nur mit $\mathrm{NAD}^{+}$als Co-Faktor sowohl in dem $\mathrm{K}_{2} \mathrm{CO}_{3}$-Puffer als auch mit dem HEPES-NH$H_{4} \mathrm{OH}$-Puffer gemessen werden. Mit $\mathrm{NADP}^{+}$war mit keinem Puffer und mit Puffer 2 auch mit NAD ${ }^{+}$keine Aktivität messbar. Mit $\mathrm{NAD}^{+}$als Cofaktor und dem $\mathrm{K}_{2} \mathrm{CO}_{3}$-Puffer wurde eine spezifische Aktivität von 0,049 U/mg Enzym gemessen. Außerdem wurde, wie unter 2.18.1 beschrieben, untersucht, ob der Rohextrakt eine Rückreaktion mit Erythrose oder mit Erythrulose als Substrat zeigte. Wegen der E. coli eigenen NADH-Dehydrogenase wurden die Plastik-Küvetten mit dem Testpuffer und allen Komponenten außer den Substraten mit Stickstoff begast. Es konnte keine NADH-Oxidation gemessen werden. Da eine Phosphorylierung des Erythrits oder des Oxidationsproduktes wahrscheinlich ist, wurde außerdem mit Erythrit, Erythrose und Erythrulose ein Kinasetest (s. 2.18.2) durchgeführt. Auch hier konnte keine Aktivität bestimmt werden.

\subsubsection{Klonierung des ORF2 in den pET101/D-TOPO-Vektor}

Für die Produktion von Proteinen, ihre anschließende Aufreinigung und ihren spezifischen Nachweis wurde das pET101/D-TOPO-Vektorsystem verwendet (s. 2.3.4.1). Durch die gerichtete Klonierung in diesen Vektor werden Proteine mit einem C-terminalen $\mathrm{His}_{6}$-Tag und V5-Epitop versehen. Über den His ${ }_{6}$-Tag ist eine Aufreinigung über Metall-Chelat-Affinitätschromatographie (s. 2.19.1) möglich. Außerdem kann das Protein über den His 6 -Tag im Western-Blot (s. 2.20) nachgewiesen werden.

Für die gerichtete Klonierung des ORF2 in den pET101/D-TOPO-Vektor wurden anhand der bekannten Sequenz die Oligonukleotide eryrev und eryfor abgeleitet und in einer Polymerasekettenreaktion mit der Pfu-DNA-Polymerase eingesetzt (s. 2.10.1). Es konnte ein DNA-Fragment amplifiziert werden, welches der erwarteten Größe von 990 bp entsprach. Dieses Fragment wurde aus dem Agarosegel extrahiert (s. 2.5.3.6) und in den pET101/D-TOPO-Vektor, wie unter 2.8.3.2 beschrieben, inseriert. Der Ansatz wurde in E. coli TOP10-Zellen transformiert und auf LB-Ampicillin-AgarPlatten ausplattiert. 50 Kolonien wurden in 5 ml-LB-Röhrchen mit Ampicillin angezogen und die Plasmide präpariert. Die Orientierung der Inserts in den Plasmiden 
konnte durch einen XbaI und AatII-Doppelverdau analysiert werden. XbaI schneidet einmal im Vektor und AatII einmal im Insert. Alle Konstrukte, die den ORF2 enthielten, sind in Abbildung 33 dargestellt. Dabei sind auch mögliche Größen von Fragmenten nach dem Restriktionsverdau mit XbaI und AatII angegeben.

In zwei Plasmiden war das Insert so orientiert, dass bei der Synthese des Proteins der His $_{6}$-Tag und das V5-Epitop C-terminalen angehängt werden konnten. Sie wurden anschließend sequenziert. In beiden Fällen waren keine Abweichungen von der Originalsequenz von pEry1 vorhanden. Die Plasmide werden im Folgenden als pETEry20 und pETEry47 bezeichnet.

\subsubsection{Expression des ORF2-Gens sowie Reinigung und Nachweis des von ORF2 kodierten Proteins}

Nachdem sichergestellt war, dass die Plasmide pETEry20 und pETEry47 keine Mutationen enthielten, wurden mit beiden Plasmiden Pilot-Expressionen durchgeführt.

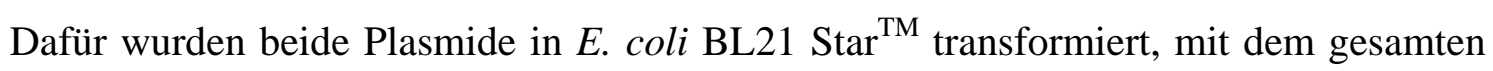
Transformationsansatz $10 \mathrm{ml-LB}-U ̈ b e r n a c h t k u l t u r e n$ angeimpft und $500 \mu \mathrm{l}$ dieser Kultur zum Animpfen von 10 ml-LB-Kulturen für die Expression genutzt. Diese wurden beim Erreichen einer optischen Dichte (600 nm) von 0,5 bis 1 auf zwei $5 \mathrm{ml}$ Kulturen aufgeteilt, von der jeweils eine mit 0,5 mM IPTG induziert wurde. Die Kontrolle der Genexpression fand durch stündliche Probennahmen nach 0 - 4 Stunden statt. Dazu wurden den Kulturen $500 \mu \mathrm{l}$ entnommen, die Zellen zentrifugiert und bis zur Analyse durch eine SDS-PAGE (s. 2.20.1) eingefroren. Abbildung 34 zeigt eine SDSPAGE-Analyse des Expressionsversuches mit dem pETEry20-Genprodukt. Der ORF2 sollte mit dem angehängten $\mathrm{His}_{6}$-Tag eine Molekularmasse von ca. $38 \mathrm{kDa}$ haben. Zu keinem Zeitpunkt ist nach IPTG-Zugabe eine verstärkte Produktion eines Proteins mit der Masse von 38 kDa erkennbar. Ferner war keine Reinigung des Proteins durch $\mathrm{Ni}^{2+}$ Affinitätschromatographie möglich. 


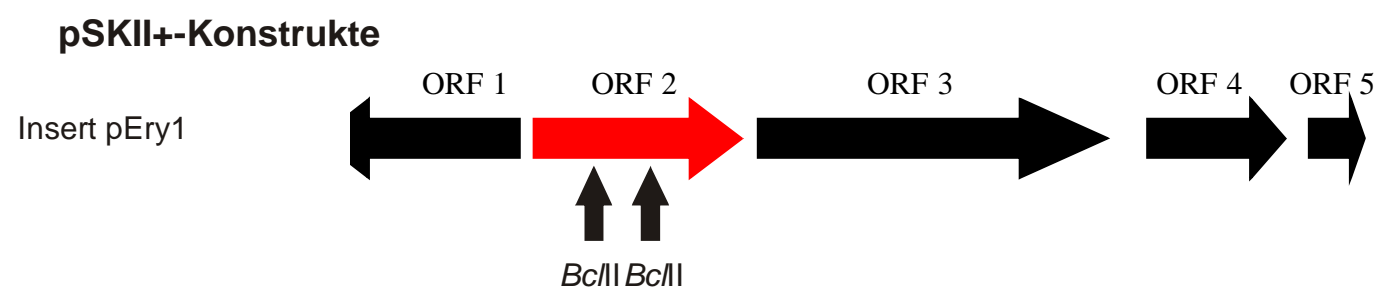

Insert pEry1 mit

Bcl/l geschnittten

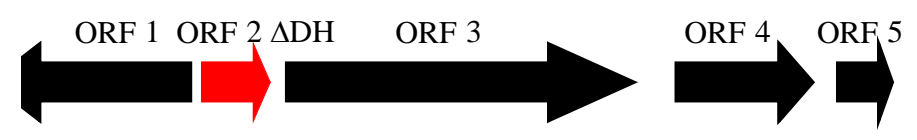

pET-Konstrukte

pETEry20
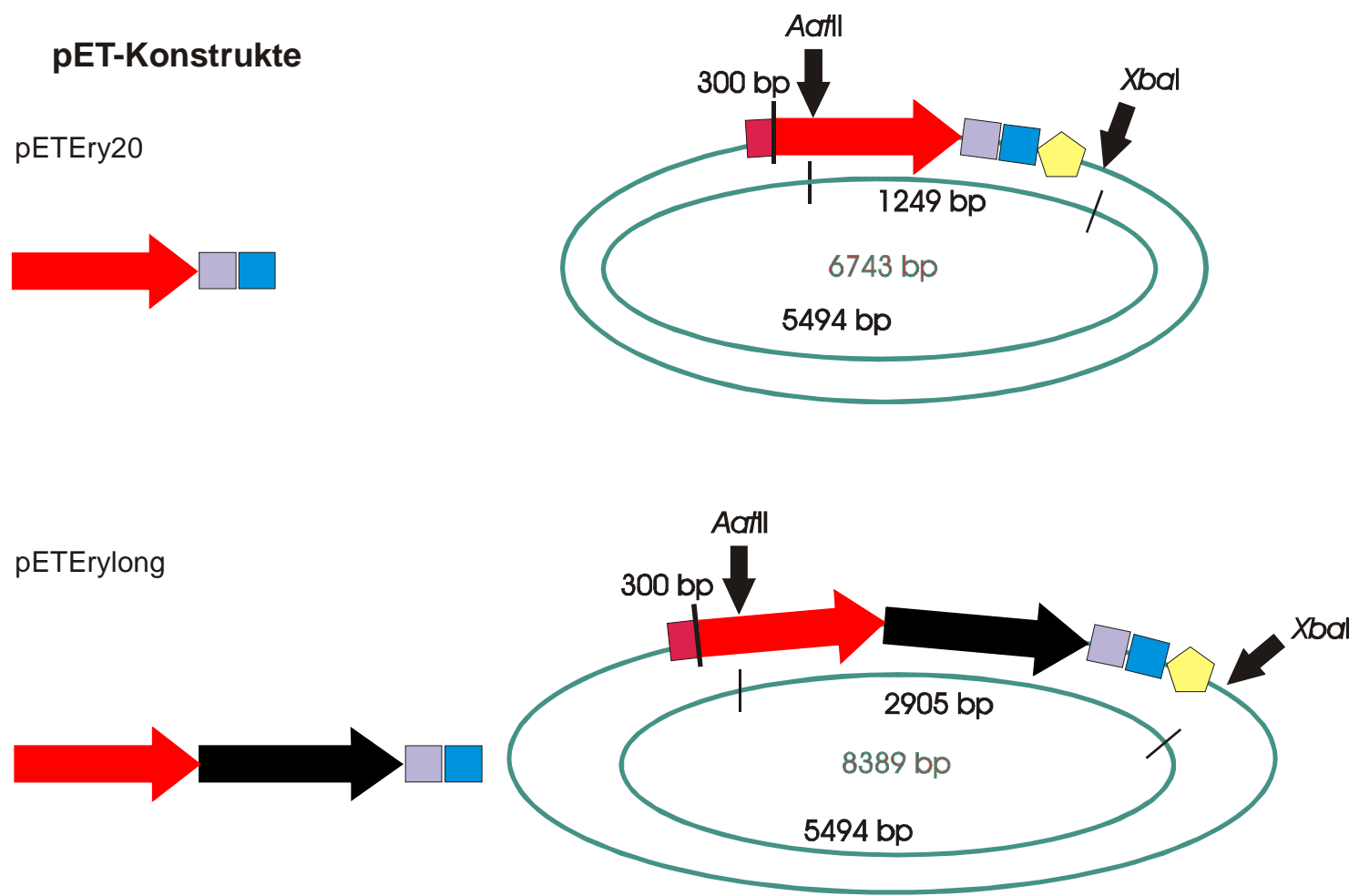

pETErystop

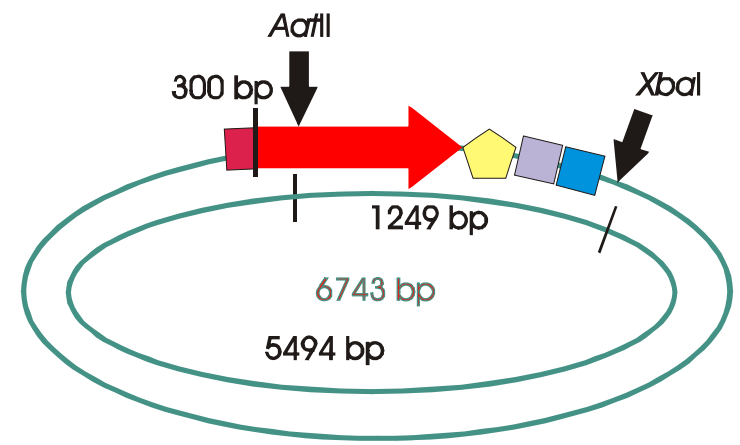

V5-Epitop $\square$ His-Tag $\square$ Stopp $\square$ Ribosomen-Bindestelle mit nachfolgenden Start-Kodon

Abbildung 33: In dieser Arbeit konstruierte Vektoren und die korrespondierenden Genprodukte 


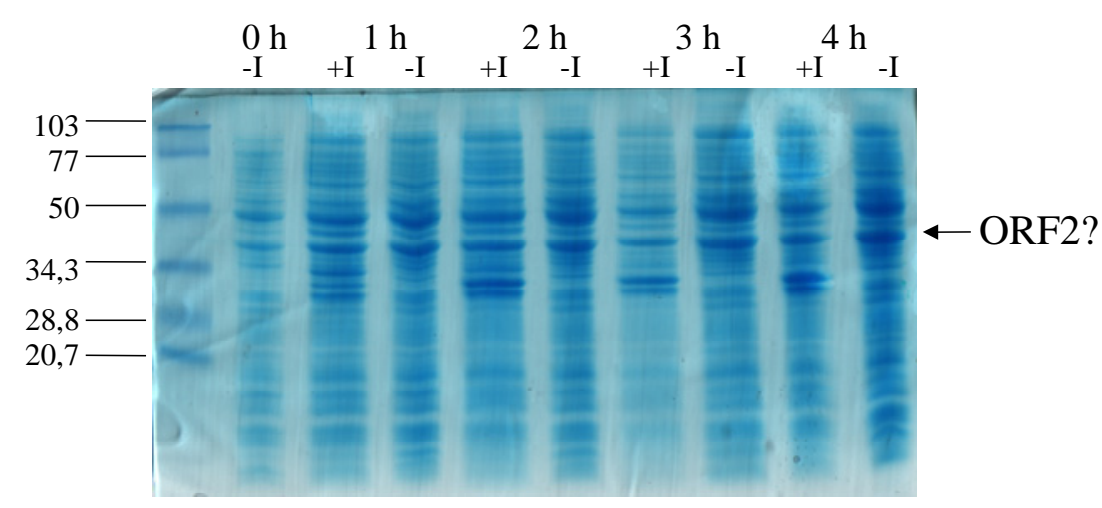

\section{Abbildung 34: Pilot-Überexpression des ORF2 mit dem Plasmid pETEry20 in E. coli BL21 Star ${ }^{\text {TM }}$}

Eine $10 \mathrm{ml}$ LB-Kultur von E. coli BL21 Star ${ }^{\mathrm{TM}}$ mit dem Plasmid pETEry20 wurde bei einer OD 600 von 0,5 bis 1 aufgeteilt, von denen eine Kultur mit0,5 mM IPTG induziert wurde. Nun wurden sofort und dann im Abstand von jeweils einer Stunde den beiden Kulturen $500 \mu$ l-Proben entnommen, abzentrifugiert und eingefroren. Die Proben wurden nach beendigter Überexpression aufgetaut, mit $80 \mu \mathrm{l}$ Lysis-Puffer versetzt, $5 \mathrm{~min}$ bei $95{ }^{\circ} \mathrm{C}$ gekocht und schließlich $5 \mu \mathrm{l}$ auf ein SDS-Gel (s. 2.20.1) aufgetragen. Die SDS-Page fand bei $100 \mathrm{~V}$ statt. Abweichend von allen anderen SDS-Pages wurde hier der Standard "Prestained SDS-PAGE Standard Low Range" in der ersten Spur eingesetzt. Das Molekulargewicht der Banden ist am linken Rand vermerkt. Es ist jeweils zunächst die induzierte Probe $(+\mathrm{I})$ und dann die nicht-induzierte Probe (-I) zu den Zeitpunkten 0 bis 4 Stunden $(0 \mathrm{~h}-4 \mathrm{~h})$ aufgetragen.

Aus diesem Grund wurde zum Nachweis des Proteins ein Western-Blot, wie unter 2.22 beschrieben, durchgeführt und sowohl das V5-Epitop mit einem Anti-V5-AlkalischenPhosphatase-Konjugat als auch der His 6 -Tag mit einem Antikörper-System, dessen primärer Antikörper gegen den His 6 -Tag gerichtet war, nachgewiesen (s. 2.21.1.1.1 und 2.21.1.1.2, s. Abbildung 34). Ein Signal eines Proteins mit der erwarteten Masse konnte mit dem gegen den $\mathrm{His}_{6}$-Tag gerichteten Antikörper-System nachgewiesen werden.

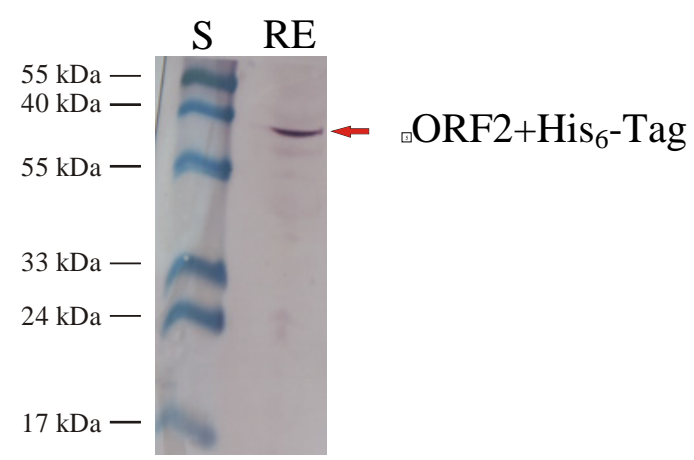

\section{Abbildung 35: Western-Blot mit dem ORF2+His6-Tag mit einem Anti-His- Antikörper}

Eine 5 ml LB-Kultur von E. coli BL21 Star ${ }^{\mathrm{TM}}$ mit dem Plasmid pETEry20 wurde bei einer $\mathrm{OD}_{600}$ von 0,5 bis 1 aufgeteilt und mit 0,5 mM IPTG induziert. Nach 4 Stunden wurde eine $500 \mu$ l-Probe entnommen, abzentrifugiert und mit $80 \mu \mathrm{l}$ Lysis-Puffer versetzt, 5 min bei $95{ }^{\circ} \mathrm{C}$ gekocht und schließlich $5 \mu \mathrm{l}$ auf ein SDS-Gel (s. 2.20.1) aufgetragen. Die SDS-Page fand bei $100 \mathrm{~V}$ statt. Der Proteintransfer und der Nachweis des His $_{6}$-Tags erfolgte wie unter 2.22 beschrieben. In Spur S ist ist der „Prestained-Marker“ „peqGold Protein Marker IV (Prestained)” (Fa. PeqLab Biotechnologie GmbH) und in der Spur RE der Rohextrakt aufgetragen. 


\section{$\begin{array}{lllllll}\text { 3.6.8 } & \text { Enzymtest } & \text { mit } & \text { dem } & \text { Rohextrakt } & \text { von } & E\end{array}$ BL21 Star TM/pETEry20}

Weil die Aufreinigungen des Enzyms fehl schlugen, wurden Enzymaktivitätstests mit Rohextrakten von E. coli BL21 Star ${ }^{\mathrm{TM}}$ mit den in Abbildung 33 dargestellten VektorKonstrukten pETEry20 und pETErystop durchgeführt. Mit dem pETErystop-Konstrukt konnte das Enzym ohne $\mathrm{His}_{6}$-Tag produziert werden. Die Produktion des Enzyms erfolgte unter verschiedenen Anzucht- und Induktionsbedingungen. Mit keinem der Rohextrakte war eine Aktivität messbar.

Aufgrund der Molekularmasse von $94 \mathrm{kDa}$ des aktiven Proteins, die in einem Aktivitätsgel bestimmt worden war (s. 2.21.2), war bislang davon ausgegangen worden, dass es sich bei dem Protein mindestens um ein Homodimer handeln musste. Eine andere Erklärung wäre natürlich auch die, dass das Protein ein Monomer und größer als erwartet war. Daraufhin wurde das Insert des Plasmids pEry1 noch einmal genauer betrachtet, wobei auffiel, dass der ORF unmittelbar nach dem ORF2 im gleichen Leserahmen lag und mit einem TGA-Codon endete, welches sowohl für ein StoppSignal als auch für die „21.“-Aminosäure Selenocystein kodieren kann. Daraufhin wurde ein weiteres pET101/D-TOPO-Vektor-Konstrukt hergestellt, das die beiden hintereinander liegenden ORFs als Insert enthielt. Für die Amplifikation dieses Inserts wurde das Oligonukleotid erylong aus der pEry1-Sequenz abgeleitet. Da die Polymerasekettenreaktion mit der Pfu-DNA-Polymerase nicht gelang, wurde hier die KOD Hifi DNA Polymerase eingesetzt (s. 2.10.2). Das pET101/D-TOPO-VektorKonstrukt mit diesem Insert wurde pErylong genannt. Auch bei diesem Konstrukt wurde die Orientierung des Inserts durch einen XbaI und AatII-Verdau überprüft. Eine Pilot-Expression ließ keine stärker werdende Proteinbande im der SDS-Page erkennen. Auch mit diesem Konstrukt wurden Rohextrakte sowohl aus einer LBÜberexpressionskultur (Induktion mit 0,5 mM IPTG für 4 Stunden) als auch aus einer Citrobacter-Mineralmedium-Kultur mit $30 \mathrm{mM}$ Glukose und 0,02 mM IPTG hergestellt. Beide Rohextrakte wurden im Enzymtest eingesetzt. Außerdem wurde ein Aktivitätsgel (s. 2.21.2) mit den Rohextrakten aller bislang beschriebenen Konstrukte angefertigt, die in der Abbildung 33 zusammengefasst sind. Die Rohextrakte der pErylong-Kulturen zeigten in keinem der Puffer Aktivität. Auch im nativen Gel, das für die Reaktion von $\mathrm{NAD}^{+}$zu NADH sensitiver ist, wurde bei keinem Rohextrakt der Kulturen mit den pET101/D-TOPO-Vektor-Konstrukten eine Bande sichtbar 
(Abbildung 32). Nur in der ersten Spur, die teilweise mit Coomassie angefärbt wurde, ist bei ca. $94 \mathrm{kDa}$ eine deutliche Bande zu erkennen

\subsubsection{Mutation des ORF2 durch Restriktionsverdau mit BclII}

Ein indirekter Nachweis der Funktion des ORF2 sollte dadurch erfolgen, dass aus diesem ORF ein Stück rausgeschnitten und der Rest des Vektors religiert werden sollte. Beim Verlust der Fähigkeit der Erythrit-Verwertung von Klonen, die mit diesem Vektor transformiert werden, kann indirekt darauf geschlossen werden, dass der ORF tatsächlich für ein Enzym kodiert, das die Umsetzung des Erythrits katalysiert. Ein geeignetes Enzym muss 2 mal im ORF2 und darf nicht im übrigen Insert oder im Vektor selbst schneiden. Diese Anforderungen wurden von dem Enzym BclII erfüllt. Dieses Enzym schneidet ein 630 bp Fragment aus dem 990 bp großen ORF2. Der das Plasmids pEry1 wurde mit BclII, wie unter 2.8.1 beschrieben, angesetzt und anschließend religiert (s. 2.8.3.1). Der Ligationsansatz wurde in E. coli JM109-Zellen transformiert. Aus 20 rekombinanten E. coli-Stämmen wurden die Plasmide isoliert (s. 2.6.3.1) und mit einer Restriktion mit SacI der Verdau überprüft. SacI schneidet in dem ORF2 in dem Bereich, der durch den BclII-Verdau rausgeschnitten sein sollte, und einmal in $\mathrm{pSKII}^{+}$. Bei einem erfolgreichen Verdau sollte SacI damit nur noch im $\mathrm{pSKII}^{+}$ schneiden. Nach dieser Kontrolle wurde ein Plasmid ausgewählt. Da die Sequenzierung nicht erfolgreich war, wurde vorerst die Sequenz zusätzlich mit einer PCR mit den Oligonukleotiden eryfor und eryrev überprüft. Es wurde ein Insert erhalten, das der erwarteten Größe von 330 bp entsprach. Das entsprechende Plasmid wurde in E. coli JM109 transformiert (s. 2.11.1). Nach 5 Wochen Inkubation der auf CitrobacterMineralmediumplatten ohne Hefeextrakt ausplattierten Transformationsansätze, konnte nur bei der Positiv-Kontrolle Wachstum festgestellt werden. Demnach war der ORF2 für die Erythrit-Verwertung essentiell. 


\section{$4 \quad$ DISKUSSION}

Die Entwicklung von Methoden, die die direkte Klonierung von DNA aus der Umweltprobe ermöglichen und der große Fortschritt der Sequenzierungstechnik in den letzten Jahren ermöglichen die Sequenzierung großer Teile von Metagenomen (AMANN et al., 1995; GIOVANNONI und RAPPE 2000; GIOVANNONI et al., 1990; KELLENBERGER, 2001). VENTER et al. (2004) sequenzierten beispielsweise einen großen Teil des Metagenoms aus Wasserproben der Sargasso Sea. Andere Metagenome wie das eines für die „,acid mine drainage“ verantwortlichen Biofilms und das eines Trinkwasserleitungsbiofilms wurden untersucht (SCHMEISSER et al., 2003; TYSON et al., 2004). Auch in dieser Arbeit sollten über die Sequenzierung von aus dem Leinesediment isolierter DNA, Informationen über die phylogenetische und physiologische Diversität der dort vorkommenden Mikroorganismen gewonnen werden.

\subsection{Phylogenetische Analyse des Leinesedimentes}

Die Untersuchung der phylogenetischen Diversität mikrobieller Habitate hat sich im letzten Jahrzehnt stark gewandelt. Durch die Etablierung molekularbiologischer Methoden wie der Sequenzanalyse (z. B. der 16S rRNA-Gene) konnten auch hier die Grenzen konventioneller Kultivierungstechniken überwunden werden. Die molekularbiologische Analyse der phylogenetischen Diversität bedient sich des Vergleiches der Nukleinsäuresequenz von Markermolekülen, die aufgrund ihrer zentralen Rolle im Metabolismus (,housekeeping“) der Organismen ubiquitär verbreitet sind und sich im Verlauf der Evolution nur wenig verändert haben. Sie müssen homolog sein und ihre Funktionalität von ihrer Sequenz abhängen, wodurch der Evolutionsdruck sich direkt auf die Sequenz auswirkt. Außerdem sollte die Primärsequenz eines solchen Markermoleküls unabhängig evolvierende Domänen besitzen, die es erlauben, die Relevanz lokaler Identitäten oder Differenzen zu testen (DOOLITTLE, 1999). Beispiele solcher Marker sind das Chaperon-60 (HILL et al., 2002) oder das Hitzeschock-Protein HSP70 (GRIFFITHS und GUPTA, 2001) und vor allem Proteine, die in so wichtige zelluläre Prozesse wie die Translation integriert sind wie z. B. die $\beta$-Untereinheit der RNA-Polymerase (DAHLLOF et al., 2000). Der bedeutendste phylogenetische Marker 
ist allerdings die 16S rRNA. Dieses Molekül besitzt fast alle erforderlichen Eigenschaften. Es ist essentiell und ubiquitär, es hat konservierte, weniger konservierte und variable Regionen und weist eine universell konservierte Struktur auf. Die konservierten Bereiche erlauben die Konstruktion universeller Oligonukleotide, die zur Amplifikation des vollständigen Gens oder kurzer DNA-Abschnitte eingesetzt werden können (WOESE, 1987). Ein Nachteil dieses Gens ist aber, dass sich die rrn-Operons in ihrer Anzahl zwischen 1 und 15 Kopien von Organismus zu Organismus unterscheiden (KLAPPENBACH et al., 2000). Wenn die Anzahl dieser Operons mit der Wachstumsrate positiv korreliert ist, dann muss davon ausgegangen werden, dass unkultivierbare, langsam wachsende Bakterien nur wenig in durch PCR generierten 16S rRNA-Genbanken und auch in Genbanken mit klonierter Umwelt-DNA vertreten sind (KLAPPENBACH et al., 2000). Umgekehrt reicht eine einzige Kopie eines 16S rRNAGens für die Zuordnung von Metagenomsequenzen. VENTER et al. (2004) sequenzierten mit 2 Mio. Sequenzläufen 1,6 Billionen bp klonierter Umwelt-DNA aus Proben der Sargasso Sea. Sie untersuchten die sequenzierte DNA auf vorhandene 16S rRNA-Gene, aber auch auf das Vorkommen anderer molekularer Marker wie z. B. der Gene für das RecA-Protein, den Elongationsfaktor EF-Tu, das HSP70 und die $\beta$-Untereinheit der RNA-Polymerase. Dabei stellten sie fest, dass im Vergleich zu den anderen Markern phylogenetische Gruppen besonders häufig oder eher selten durch 16S rRNA-Gene vertreten waren. Dies erklärten auch sie durch die unterschiedliche Kopienzahl der 16S rRNA-Gene in verschiedenen Organismengruppen.

Analysen mikrobieller Gemeinschaften mittels der Sequenzierung der 16S rRNA-Gene wurden für viele unterschiedliche Habitate beschrieben: z. B. für Ozeane (GIOVANNONI et al., 1990; LIM et al., 1993), Seen (FALZ et al., 1999; HIORNS et al., 1997), Böden (LIESACK und STACKEBRANDT, 1992), heiße Quellen (HUGENHOLTZ et al.,1998), Grundwasser (PEDERSEN et al., 1996) und Flüsse (BÖCKELMANN et al., 2000; CRUMP et al., 1999). Mitte der 70er Jahre begann WOESE mit seinen Mitarbeitern 16S rRNA-Gensequenzen zu sammeln. Am 1. April 2004 umfasst allein die „Genbank“-Datenbank 21466 16S rRNA-Gensequenzen von kultivierten und 54655 von unkultivierten Organismen. Solche Zahlen lassen das Ausmaß der unbekannten Sequenzen erahnen.

Die aus den Studien der letzten Jahre gewonnenen 16S rRNA-Gensequenzen haben eine große mikrobielle Diversität erkennen lassen, die sich mit traditionellen Standardtechniken nicht detektieren ließ (LIESACK und STACKEBRANDT, 1992; 
PACE et al., 1986). Die Sequenzen lassen sich inzwischen nicht nur in 12 (WOESE, 1987), sondern in mindestens 52 große Phyla einteilen (RAPPE und GIOVANNONI, 2003). 26 von ihnen enthalten keine, 22 nur wenige kultivierte Organismen. Nur aus 4 Phyla konnten viele Organismen kultiviert werden. Die Phyla ohne kultivierte Vertreter werden als „candidate divisions“ bezeichnet. Phyla (oder Divisionen) unterscheiden sich in ihrer 16S rRNA-Gensequenz um ca. 20 bis $25 \%$ (HUGENHOLTZ et al., 1998). Mit Zunahme der verfügbaren $16 \mathrm{~S}$ rRNA-Gensequenzen wird immer deutlicher, dass einzelne dieser „candidate divisions“ wie z. B. OP11 eine wichtige Rolle in verschiedenen Habitaten spielen (HARRIS et al., 2003). Sowohl kulturabhängige als auch kulturunabhängige Studien belegen, dass einige Phyla ubiquitär, andere nur auf bestimmte Standorte beschränkt vorkommen. $90 \%$ der kultivierten Bakterien, die durch 16S rRNA-Gensequenzen charakterisiert sind, gehören entweder der Gruppe der Proteobacteria, der Cytophagales (Bacteroides-Cytophaga-Flexibacter-Gruppe), den Gram-positiven Actinobacteria oder den Gram-positiven Firmicutes an (HUGENHOLTZ et al., 1998). $76 \%$ der in „Genbank“-Datenbank enthaltenen Sequenzen kultivierter Bakterien und auch $70 \%$ der Umweltsequenzen lassen sich diesen vier Gruppen zuteilen (HUGENHOLTZ, 1998; HUGENHOLTZ et al., 2002). Dies entspricht auch in etwa dem Ergebnis dieser Arbeit (66 \%). Eine wichtige Rolle in Umweltprozessen scheinen aber auch die Acidobacteria, die Chloroflexi und die Planctomycetes zu spielen. Auch $27 \%$ der Leinesediment-16S rRNA-Gensequenzen gehen vermutlich auf Angehörige dieser Bakteriengruppen zurück. Diese z. T. ubiquitär verbreiteten Phyla weisen bislang kaum oder gar keine kultivierten Vertreter auf. Dementsprechend ist wenig über ihre physiologischen und morphologischen Eigenschaften bekannt. Ihr ubiquitäres Vorkommen lässt aber auf ihre Bedeutung in mikrobiellen Gemeinschaften schließen (HUGENHOLTZ et al., 1998; RIESENFELD et al., 2004; WARD et al., 1995).

Ein direkter quantitiver Vergleich der in dieser Arbeit gewonnenen Sequenzen mit anderen Süßwasserhabitaten ist allerdings schwierig. Die mikrobielle Diversität in Süßwasserhabitaten, speziell die von Flusssedimenten, ist in der Vergangenheit weniger intensiv untersucht worden als andere wie etwa die von Böden und Ozeanen (HUGENHOLTZ et al., 1998; O'SULLIVAN et al., 2002). Verschiedene Studien zeigen, dass große Unterschiede der mikrobiellen Zusammensetzung zwischen den unterschiedlichen ökologischen Nischen von Süßwasserhabitaten bestehen und sich die Zusammensetzung häufig stark mit den Umwelteinflüssen, z. B. den Jahreszeiten, 
ändert (BÖCKELMANN et al., 2000). So stellen Sedimente, das freie Wasser, Schwebeteilchen und Biofilme, z. B. auf Steinen, unterschiedliche ökologische Nischen dar (CRUMP et al., 1999; O’SULLIVAN et al., 2002). Außerdem konnten Unterschiede im Vorkommen von Mikroorganismen im Verlauf des Changjiang-Flusses festgestellt werden (SEKIGUSHI et al., 2002). Die Zusammensetzung variierte ebenfalls stark zwischen mündungsnahen Bereichen und Standorten mitten im Flussverlauf des Columbia Rivers (CRUMP et al., 1999).

In dieser Arbeit wurde die DNA aus der oberen Sedimentschicht ( 0 bis $15 \mathrm{~cm}$ ) der Leine isoliert. Der Ort, an dem die Probe entnommen wurde, liegt im oberen Flussverlauf (s. 3.1). Bei der Probennahme wurde nicht ausgeschlossen, dass auch Flusswasser mit in die Probe gelangte. Da die Zellzahl frei lebender Bakterien eher gering ist, kann aber doch davon ausgegangen werden, dass die Zusammensetzung am ehesten der eines Flusssedimentes entspricht. Ein quantitativer Vergleich mit anderen Standorten ist nicht möglich, weil das Verhältnis der Klone in der 16S rRNA-Genbank gewöhnlich nicht der natürlichen Verteilung der Organismen eines Habitates entspricht. Eine bevorzugte Amplifikation und/oder Klonierung einzelner rDNA-Moleküle kann zu einer Überrepräsentation in den angelegten Genbanken führen. Die Ursachen für eine bevorzugte PCR-Amplifikation können vielfältig sein. Neben der Genomgröße und der Anzahl der rrn-Genkopien (KLAPPENBACH et al., 2000) sind der G+C-Gehalt der rDNA (REYSENBACH et. al., 1994), die Konzentration der Template-DNA (CHANDLER et al., 1997) und die Wahl der für die Amplifikation verwendeten Oligonukleotide (SUZUKI und GIOVANNONI, 1996; WEISBURG et al., 1991) als mögliche Ursachen beschrieben. Auch in dieser Arbeit führte der Einsatz von unterschiedlichen Oligonukleotiden zu unterschiedlichen Ergebnissen. Wie unter 3.3.2 beschrieben, konnten mit dem Oligonukleotid-Paar 4 (A800F+A1530R) keine $\beta$ Proteobakterien amplifiziert werden. Dafür übertraf die Anzahl der gewonnenen $\alpha$ Proteobakterien-Sequenzen deutlich die der anderen PCR-Ansätze mit dem Oligonukleotidpaar 16S08/16S1504. Aber auch mit dem gleichen Primerpaar waren die Ergebnisse in unabhängigen PCR-Ansätzen nicht identisch (s. PCR 1 und 2). Fasst man die Ergebnisse der einzelnen PCR-Ansätze zusammen und geht man davon aus, durch die Amplifikation mit zwei verschiedenen Oligonukleotid-Paaren ein weniger verzerrtes Bild der mikrobiellen Gemeinschaft erhalten zu haben, so kann festgestellt werden, dass vor allem $\alpha$ - und $\gamma$-Proteobakterien und die BCF- Gruppe im Leinesediment vertreten sind. Insgesamt ist die Zusammensetzung sehr divers (s. Abbildung 36). Auch die $\beta$ - 
und $\delta$-Proteobacterien, die Planctomycetes, die Acidobacteria und die Chloroflexi stellen jeweils mindestens $5 \%$ der Sequenzen. 11 Phyla sind mindestens mit einer Sequenz vertreten, mit der Sequenz s11394 auch ein Vertreter der „candidate Division“ TM7. Damit ist die Diversität größer als in anderen Studien.

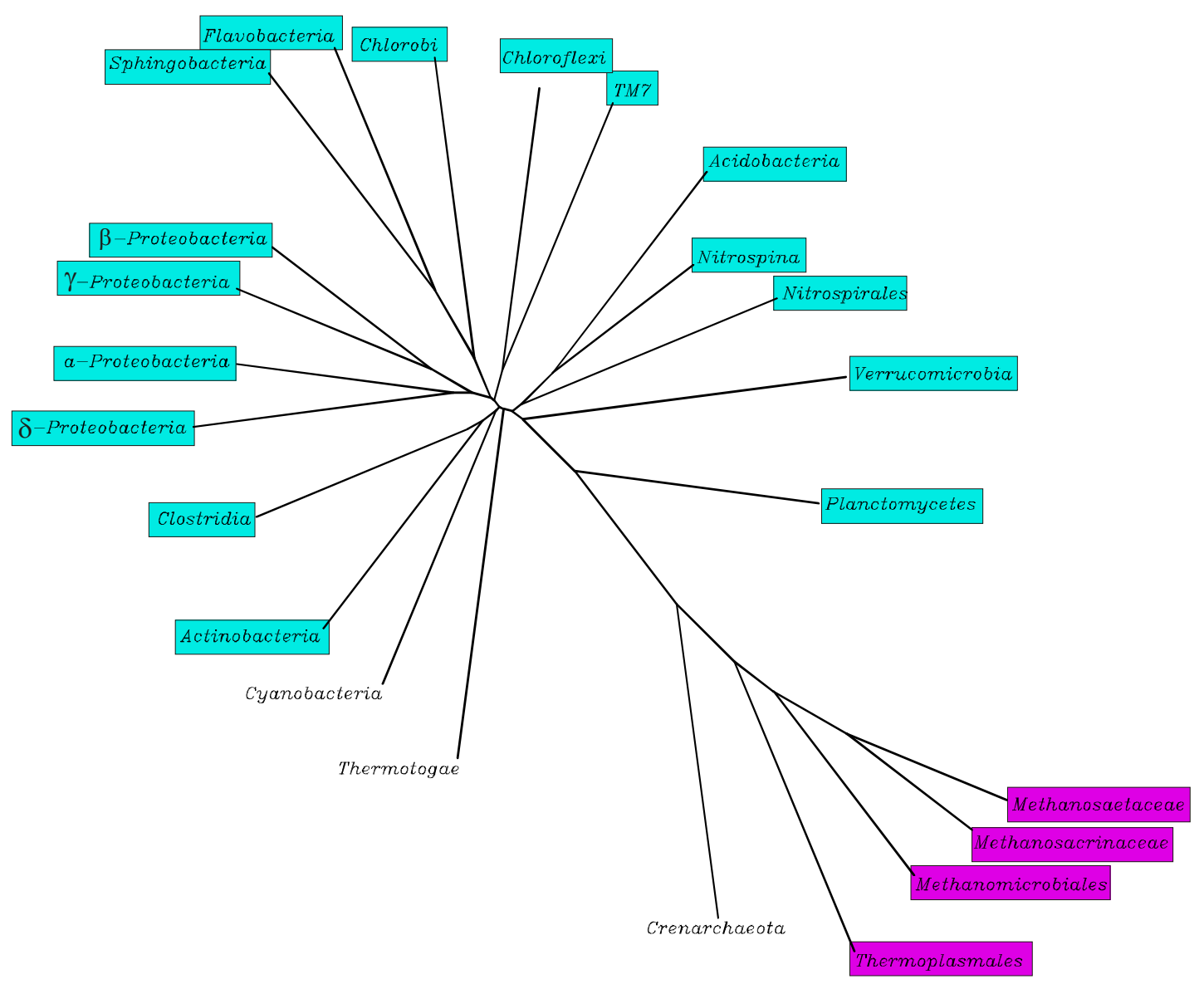

\section{Abbildung 36: Nachgewiesene Organismengruppen im Leinesediment}

Eingerahmt sind die Oragnismengruppen, aus denen mindestens eine Sequenz im Leinesediment nachgewiesen werden konnte. Bakterielle Gruppen sind türkis, archaeelle violett angefärbt.

Auffällig ist außerdem, dass keine Cyanobakterien und nur wenig Gram-positive Bakterien nachgewiesen werden konnten, die in anderen Süßwasserhabitaten stärker vertreten waren (CRUMP et al., 1999; GLÖCKNER et al., 2000 O'SULLIVAN et al., 2002; SEKIGUCHI et al., 2002). Im Epilithon des Flusses Taff bei Cardiff wurden ebenfalls am meisten Sequenzen mit Ähnlichkeit zur CFB-Gruppe und $\alpha$ - und $\gamma$ Proteobakterien gefunden. Dort waren die $\beta$-Proteobakterien wie auch in dieser Arbeit weniger stark vertreten (O’SULLIVAN et al., 2002). Im Sediment des „Rainbow Bays“, 
einer von mehreren natürlich vorkommenden, schmalen, eliptischen Mulden im Savannah-Fluss-Gebiet, die ihr Wasser hauptsächlich vom Regen und dem Grundwasser beziehen, wurden keine $\gamma$-Proteobakterien, sondern nur $\alpha$-, $\beta$ - und $\delta$ Proteobakterien nachgewiesen, außerdem Firmicutes, Verrucomicrobia, Acidobacteria und Chloroflexi (WISE et al., 1997). In anderen Süßwasserhabitaten waren die $\gamma$ Proteobakterien ebenfalls seltener, dafür die $\beta$-Proteobakterien wesentlich häufiger wie z. B. im Flussverlauf des Chanjiang (s. SEKIGUSHI et al., 2002) und in den Seen Fuchskuhle, Baikal-See und Gossenkölle-See (GLÖCKNER et al., 2000). Eine noch stärker abweichende Zusammensetzung zeigte der „Fluss-Schnee“ der Elbe. Bei diesem handelt es sich um Aggregate, die sich aus organischem Detritus, lebenden photosynthetischen und heterotrophen Microorganismen und anorganischen Partikeln zusammensetzen. Dort waren die $\beta$-Proteobakterien die am stärksten vorkommende Gruppe. Das Vorkommen von $\alpha$ - und $\gamma$-Proteobakterien variierte in dem „Fluss-Schnee“ der Elbe stark mit der Jahreszeit. CFB-Bakterien stellten je nach Jahreszeit 5 - $10 \%$ der Bakterien und waren damit seltener als an anderen Standorten (BÖCKELMANN et al., 2000). Diese Zahlen wurden allerdings abweichend von den anderen erwähnten Untersuchungen mittels Fluoreszenz-in-situ-Hybridisierung gewonnen. Die Zusammensetzung der Bakterien der in dieser Arbeit untersuchten Leinesedimentprobe beinhaltet abgesehen von Cyanobakterien alle häufig in Süßwasserhabitaten vertretenen Bakterien-Phyla und ähnelt am ehesten der aus dem Epilithon des Flusses Taff. Zusätzlich sind andere Phyla vertreten, die in anderen Süßwasserhabitaten seltener oder gar nicht erfasst wurden wie etwa die Chloroflexi, die weder in der Elbe noch in den drei von GLÖCKNER et al. (2000) untersuchten Seen noch im Chanjiang-Fluss oder im Epilithon des Flusses Taff vorkamen.

Interessant war der Nachweis der Sequenz s11394, die in die „candidate division“ TM7 eingruppiert werden muss. Die Sequenz stimmt zu $97 \%$ mit der des unkultivierten Klons SM1G12 überein, die aus einer Quelle aus dem Yellowstone Nationalpark gewonnen wurde (AF445701). Der „candidate division“ TM7 gehören bislang 50 unkultivierte Bakterien an, deren Sequenzen aus verschiedenen Standorten isoliert wurden: aus metallkontaminiertem Boden, Schlämmen aus der Abwasserreinigung, einem Termitendarm, dem Meer, „Sequencing batch reactor“ und dem menschlichen Mund. Außerdem wird vermutet, dass Angehörige dieser „candidate division“ an Entzündungen unterhalb des Zahnfleischsaumes beteiligt sind (Accession-Nummer AY134895). Neben der Sequenz aus der Quelle des Yellowstone Nationalparks sind 
bislang nur 2 weitere Sequenzen, Grundwasser-Klon JN18e (Z69283) und ein Klon aus einem alpinen See, Klon LCK-60 (AF109142), aus natürlichen Süßwasserhabitaten gewonnen worden. Bislang wird die „candidate division“ TM7 in 3 Unterdivisionen unterteilt (HUGENHOLTZ et al., 2001). Das erneute Auffinden einer solchen Sequenz mit einer hohen Identität mit einer bereits bekannten bestätigt erneut die Existenz dieser Division und ihre ubiquitäre Verbreitung.

Im Gegensatz zu GLÖCKNER et al. (2000), die aus den drei von ihnen untersuchten Seen nur Sequenzen gewannen, die zu anderen aus Süßwasser oder Boden isolierten Sequenzen die größte Ähnlichkeit hatten, sind in dieser Arbeit auch Sequenzen vorhanden, die z. B. den 16S rRNA-Genen von marinen Bakterien ähneln. Allerdings sind auch in dieser Arbeit Sequenzen mit nächsten Nachbarn aus dem Boden oder dem Süßwasser am häufigsten vertreten. Dass bei Süßwasserhabitaten verstärkt auch typische Bodenorganismen gefunden werden, kann wohl damit erklärt werden, dass es immer einen Abtrag des Bodens in Seen und Flüsse gibt.

Ebenso wie für marine Habitate, für die die SAR-Cluster als habitatspezifische Gruppe bekannt sind, konnte ZWART et al. (1998) auch für das Süßwasser spezifische Gruppen, Cluster A, B und C, identifizieren. Cluster A beinhaltet $\alpha$-Proteobakterien, die Cluster B und C $\beta$-Proteobakterien. Alle sind ausschließlich aus 16S rRNAGensequenzen, die aus Süßwasserhabitaten isoliert wurden, zusammen-gesetzt. Keine der Leinesediment-16S rDNA-Sequenzen kann in eines dieser Cluster eingeordnet werden. In dieser Arbeit treten aber andere Cluster von 16S rRNA-Gensequenzen auf, die nur eigene Klone und andere Umweltklone enthalten. Bei den Sequenzen, die zu den $\gamma$-Proteobakterien gezählt werden, fällt ein Cluster auf, das die LeinesedimentSequenzen s11108, s11174, s11178, s11340, s11344, s11380 und den Klon SG-3 enthält (s. Abbildung 11). Dieses Cluster zweigt so früh von den verschiedenen zum Genus Xanthomonas gehörenden Sequenzen ab, dass es sich hier um eine neue Gattung innerhalb der Familie Xanthomonadaceae handeln könnte. Bei der BCF-Gruppe bilden die Sequenzen s11360, s11320 und s11331 ein eigenes Cluster innerhalb der Flavobacteria. Auch hier handelt es sich vermutlich um eine neue Gattung. Die Sequenzen s13235, sl3223 und SJA-35 innerhalb der Chloroflexi unterscheiden sich von den anderen Sequenzen eventuell schon auf Familienniveau. Alle LeinesedimentSequenzen mit Ähnlichkeit zu den Chloroflexi ähneln am stärksten Sequenzen von unkultivierten Mikroorgansimen. Insgesamt betragen die Ähnlichkeiten nur 85 bis $91 \%$. Dies lässt erkennen, wie wenig über dieses Phylum bislang bekannt ist. Die 
großen Unterschiede innerhalb der Planctomycetes sind nicht ungewöhnlich. Die von WARD et al. (1995) untersuchten Planctomycetes waren untereinander häufig ebenfalls nur zu 80 \% identisch. Hier bilden die Sequenzen s13261, s13286 und OM190 einen eigenen Ast, der sich deutlich von den Gattungen Gemmata, Planctomyces und Pirellula abgrenzt. Insgesamt sind weitere Einzelsequenzen nur entfernt (unter $90 \%$ Identität) mit bekannten 16S rRNA-Gensequenzen verwandt. Die in dieser Arbeit vorgestellten Ergebnisse bestätigen, dass trotz der vielen phylogenetischen Studien der letzten Jahre und der zahlreichen 16S rRNA-Gensequenzen in den öffentlichen Datenbanken noch vieles unbekannt ist und bleibt. Einzelne Sequenzen mit nur geringen Identitäten zu Datenbank-Sequenzen bedürfen weiteren ähnlichen Sequenzen, um klassifiziert werden zu können.

In dieser Arbeit wurde auch, wie unter 3.3.1 beschrieben, die Diversität der Archaea im Leinesediment untersucht. Lange wurde davon ausgegangen, dass Archaea auf extreme Standorte beschränkt wären. Inzwischen konnten sie an verschiedenen anderen Standorten mit moderaten Bedingungen wie dem Meer und Süßwasserhabitaten nachgewiesen werden (FUHRMAN et al., 1992; DeLONG et al., 1992; SCHLEPER et al., 1997) Auffällig war die große Identität zu verschiedenen Sequenzen unkultivierter Organismen aus dem Rotsee in der Schweiz (FALZ et al., 1999) und dem finnischen Waldsee Valkea Kotinen (JURGENS et al., 2000). In der Studie des Rotsees wurde eine Probe aus dem anoxischen Sediment untersucht. Dabei war eine klare Verteilung der Sequenzen auf 2 verschiedene Cluster erkennbar. 6 der untersuchten 17 archaeellen Sequenzen waren nah verwandt mit Methanosaeta concilii mit einer Homologie von mehr als 97 \%. Mittels Fluoreszenz-in-situ-Hybridisierung (FISH) konnten FALZ et al. (1999) zeigen, dass die Organismen dieses Clusters $91 \%$ der Archaeen in diesem Habitat ausmachten. Das zweite Cluster bildeten Sequenzen mit der größten Identität zu dem methanogenen Endosymbionten des anaeroben Ciliaten Plagiopyla nasuta. 2 Sequenzen konnten in das Reis-Cluster IV gruppiert werden. Damit entsprach die Zusammensetzung des Sedimentes etwa der eines Reisfeldbodens, in dem allerdings zusätzlich auch Vertreter der Arten Methanosarcina und Methanobacterium gefunden wurden (GROSSKOPF et al., 1997). Im Bakterioplankton des Valkea Kotinen konnten dagegen weder Angehörige der Familie Methanosaetaceae noch der Familie Methanosarcinaceae nachgewiesen werden. Von den 28 sequenzierten 16S rRNAGenen ähnelten 12 Sequenzen denen von unkultivierten Crenarchaeota. Die 16 Sequenzen euryarchaeotischen Ursprungs gliederten sich in 4 Cluster: 2, ValII und 
ValIII, die nur Vertreter aus dem See Valkea Kotinen beinhalten, eines mit größter Verwandtschaft $\mathrm{zu}$ den Thermoplasmales und eines, bestehend aus Sequenzen aus Süßwasserhabitaten und Torfmoor in der Ordnung Methanomicrobiales. Die Sequenzen des letzten Clusters werden in der RDP-Datenbank ebenso wie die zu dem Endosymbionten Plagiopyla nasuta verwandten Sequenzen aus dem Rotsee in die MCU-Bourgense-Untergruppe klassifiziert. Die Zusammensetzung des Leinesediments entspricht damit am ehesten der des Rotsees. Auch im Leinesediment sind die am stärksten vertretenen Organsimengruppen Angehörige der Familie Methanosaetaceae und der MCU-Bourgense-Untergruppe der Ordnung Methanomicrobiales. Zusätzlich konnten hier aber auch Angehörige der Familie Methanosarcinaceae und ein Verwandter der Thermoplasmales nachgewiesen werden. Außerdem scheinen die Sequenzen s13106, s13113, s13114, s13138 und sl3189 ein eigenes Cluster zu bilden, das in die Ordnung Methanosarcinales zwischen die Familien Methanosarcinaceae und Methanosaetaceae eingeordnet werden muss. Dass in dieser Arbeit auch seltenere Organismengruppen gefunden wurden, kann an der größeren Anzahl der untersuchten Sequenzen liegen. Da hauptsächlich sehr nah verwandte Sequenzen nachgewiesen wurden, würde eine Sequenzierung weiterer Klone der Genbank hauptsächlich zu einer Anhäufung dieser Sequenztypen führen. Es ist davon auszugehen, dass die wesentlichen Vertreter der archaeellen mikrobiologischen Gemeinschaft erfasst wurden. Dass keine DNA von Crenarchaeota amplifiziert werden konnte, kann zum einen bedeuten, dass tatsächlich in diesem Habitat keine Vertreter dieser Organismengruppe vorkommen, zum anderen ist es aber auch denkbar, dass sich die DNA von Crenarchaeota mit den eingesetzten Oligonukleotiden nicht amplifizieren lässt. Um dies weitestgehend ausschließen zu können, müssten weitere Oligonukleotide ausgetestet werden.

Interessant wäre die Frage, wie der tatsächliche Anteil der Organismengruppen in diesem Habitat ist. Die Fluoreszenz-in-situ-Hybridisierung (FISH), bei der ganze fixierte Zellen identifiziert werden können, erlaubt die Quantifizierung bestimmter Organismengruppen. Dafür werden spezifische Oligunukleotid-Sonden mittels PCR amplifiziert und Fluoreszens-markiert, die homolog zu Bereichen der 16S rRNA-Gene der zu quantifizierenden Organismen sind. Die damit fluoreszens-mikroskopisch sichtbaren Signale können dann ins Verhältnis zur absoluten Zellzahl gesetzt werden, die über DAPI-Färbung (4', 6-Diamidino-2-phenylindol) ermittelt werden kann (AMANN et al., 1995). Diese Technik war lange begrenzt auf stark expremierte Gene, was bereits zu einer schlechten Detektion von Bakterien führte, die nur ein 16S rRNA- 
Gen besitzen (RIESENFELD et al., 2004). Eine Verbesserung der Methode durch eine höhere Sensitivität der Detektion konnte von ZWIRGLMAIER et al. (2004) mit der sogenannten „RING-FISH“ (,recognition of individual genes-FISH“) erreicht werden.

\subsubsection{Versuch einer Rekonstruktion des Kohlenstoff- und Energiefluxes in der mikrobiellen Gemeinschaft}

Eine phylogenetische Ähnlichkeit zweier Organismen zieht nicht zwangsläufig eine Übereinstimmung ihrer Physiologie nach sich, so dass selbst große Ähnlichkeiten zu kultivierten Organismen nicht immer Schlüsse auf den Stoffwechsel zulassen (AMANN, 2000; RODRIGUEZ-VALERA, 2002). Bei der Sequenzierung von UmweltDNA ist in vielen Fällen der nächste Verwandte ebenfalls ein unkultivierter Organismus, daher ist eine Vorhersage von Stoffwechselvorgängen zusätzlich erschwert. Dennoch soll hier auch unter Zuhilfenahme der Sequenzdaten der CosmidSequenzierungen versucht werden, ein Bild $\mathrm{zu}$ entwerfen, das, wenn auch nur unvollständig, die möglichen physiologischen Vorgänge im Leinesediment wiedergibt. Photosynthetisch-aktive Organismen sind in der Lage Lichtenergie in chemische Energie umzuwandeln. Es kann eine oxygene und eine anoxygene Photosynthese unterschieden werden. Bei beiden Prozessen wird ein elektrochemischer Protonengradient über die photosynthetische Membran aufgebaut, der zur ATPSynthese und für andere energieverbrauchende Prozesse genutzt werden kann. Bei der oxygenen Photosynthese, die in den Chloroplasten der Eukaryoten, bei Cyanobakterien und den Prochlorophyta stattfindet, werden zudem Reduktionsäquivalente für die $\mathrm{CO}_{2}$ Fixierung gebildet (STANIER und COHEN-BAZIRE, 1977). In der Probe des Leinesedimentes konnten keine Cyanobakterien nachgewiesen werden. Da die Absorptionsmaxima des Chlorophyll A der Cyanobakterien im Bereich kürzerer Wellenlängen liegen als die der Bakteriochlorophylle a, b, c, d, e und g, den Pigmenten der anoxygenen Photosynthese, kommen Cyanobakterien verstärkt in den oberen Wasserschichten vor (PFENNING, 1978). Dass keine Cyanobakterien im Sediment der Leine nachgewiesen werden konnten, war daher nicht überraschend. Auch im Sediment des „Rainbow Bays“ wurden keine Cyanobakterien nachgewiesen (WISE et al., 1997). Die anoxygene Photosynthese wird z. B. von Vertretern der Gattungen Rhodobacter, Rhodopseudomonas und Rhodospirillium der $\alpha$-Proteobakterien, der Gattung Rhodocyclus der $\beta$-Proteobakterien sowie den Grünen-Schwefel-Bakterien 
(Chlorobium) und den Grünen-nicht-Schwefel-Bakterien (Chloroflexi) durchgeführt (RAYMOND et al., 2002). Die Photosynthese dieser Bakterien unterscheidet sich unter anderem in dem Bakteriochlorophyll, der Art ihres Photosystems (I oder II) und den Elektronendonatoren. Chlorobi nutzen ausschließlich Schwefel oder Schwefelwasserstoff als Elektronendonator für die Atmungskette. Die anderen hier aufgezählten Gruppen können auch andere Elektronendonatoren nutzen. Die horizontale Anordnung der Bakteriengruppen innerhalb des Sedimentes ist von der Lichtintensität und der Sulfidkonzentration abhängig. Aus diesen Gründen kommen die Proteobakterien in höheren Schichten vor als die Chlorobiaceae, die eine größere Schwefelwasserstofftoleranz aufweisen (XIONG et al., 2000). Die Sequenz s13275 hatte die größte Ähnlichkeit (94 \%) mit Rhodobacter sp. TCRI 14. In die Gattung Rhodocyclus können 4 Sequenzen gruppiert werden. Die Sequenz s11165a zeigt eine geringe Ähnlichkeit von 84 \% zu einem Klon, der der Gruppe der Chlorobi zugeteilt wurde. In diesem Fall ist eine Voraussage der physiologischen Fähigkeiten des Ursprungsorganismus jedoch sehr unsicher, obwohl bislang nur photosynthetisch-aktive Vertreter der Chlorobi bekannt sind. $\mathrm{Zu}$ den Chloroflexi gehören anaerobe und fakultativ anaerobe Organismen, die sowohl phototroph als auch obligat chemotroph sein können (PFENNING und TRÜPER, 1998). 6 Sequenzen aus dem Leinesediment zeigen die größten Identitäten zu Vertretern dieses Phylums. Aufgrund der auch hier geringen Identität können keine sicheren Aussagen darüber getroffen werden, ob es sich um Sequenzen handelt, die auf photosynthetisch aktive Organismen zurückgehen. Im Leinesediment wurden 10 Sequenzen aus dem Phylum der Planctomycetes nachgewiesen. Auch in diesem Phylum gibt es photosynthetisch aktive Organismen (HELLINGWERF et al., 1994).

Bei der Sequenzierung des Cosmides slc_1g wurden 2 ORFs gefunden (ORF340 und ORF341), die als Phytoen-Desaturase annotiert wurden und damit für die Photosynthese von Bedeutung sein könnten. Phytoen-Desaturasen spielen eine Rolle in der CarotinoidBiosynthese von Pflanzen, Pilzen und Bakterien. Carotinoide sind Pigmente, die sowohl in photosynthetisch aktiven als auch in nicht-photosynthetisch aktiven Bakterien synthetisiert werden. In photosynthetisch aktiven Bakterien sind sie essentielle Komponenten des Photosynthese-Apparates. Außerdem spielen sie eine wichtige Rolle beim Schutz vor oxidativen Schäden (GOODWIN, 1980; HIRSCHBERG und CHAMOVITZ, 1994). Die Carotinoid-Synthese erfolgt in mehreren Schritten. Dabei 
katalysiert die Phytoen-Desaturase die Umwandlung von Phytoen über Phytofluen zu $\zeta$ Caroten (HABLE et al., 1998).

Die meisten phototrophen Organismen können $\mathrm{CO}_{2}$ fixieren. Die photosynthetischen Proteobakterien fixieren $\mathrm{CO}_{2}$ über den Calvin-Zyklus, die Chlorobi über den reduktiven Tricarbonsäure-Zyklus, die Chloroflexi über den 3-Hydroxypropionat-Weg. Der von den photoautotrophen Organismen gebundene Kohlenstoff wird zum Aufbau organischen Materials verwendet und gelangt in die Nahrungskette. Auch die meisten chemolithotrophen Bakterien, also Bakterien, die anorganische Verbindungen als Elektronendonatoren für die Atmungskette nutzen, können wie die photosynthetischen Bakterien $\mathrm{CO}_{2}$ über den Calvin-Zyklus fixieren und sind damit ebenfalls für den Aufbau organischen Materials verantwortlich (PERETO et al., 1999). Auf den Cosmiden konnten keine Gene identifiziert werden, die für Proteine kodieren, die eine Rolle bei der $\mathrm{CO}_{2}$-Fixierung spielen.

Im Zuge des Abbaus organischen Materials wird der gebundene Kohlenstoff letztlich zu Methan und $\mathrm{CO}_{2}$ umgewandelt. Zunächst werden Polymere wie Cellulose oder Stärke von heterotrophen Organismen wie z. B. Xanthomonas, Pseudomonas, Planctomycetes, Bacteroides, Flavobacteria, Actinomycetes und Clostridia, die auch im Leinesediment nachgewiesen wurden, $\mathrm{zu}$ Monomeren und schließlich $\mathrm{zu}$ primären Fermentationsprodukten wie z. B. kurzkettigen Fettsäuren abgebaut (RATLEDGE, 1993, BERKENHEGER und FISCHER, 2004; WILSON, 1992, GRANT et al., 2004). Der nächste Verwandte der Sequenz sl1322 (96 \%), das Clostridium sp. 9B4, ist als cellulolytisches Bakterium beschrieben. Bei der Sequenzierung der Cosmide konnten ORFs identifiziert werden, die vermutlich Funktionen beim Abbau von Polymeren erfüllen. Zu nennen wären da der ORF105 des Cosmides slc_1a und die ORFs 522 bis 523 des Cosmides slc_1p. Letztere sind vermutlich Komponenten eines Biopolymertransportsystems. Der ORF105 kodiert für eine $\alpha$-L-Fucosidase. $\alpha$-LFucosidasen sind am N-Glukan-Abbau beteiligt. Sie katalysieren die Hydrolyse der Oglykosidischen Bindung von $\alpha$-L-Fucosiden, wobei L-Fucose abgespalten wird.

Nach dem Abbau der Polymere, der als „primäre Fermentation“ bezeichnet wird, werden die daraus resultierenden Zwischenprodukte weiterverwertet. Dies kann aerob, aber auch anaerob geschehen. Sauerstoff kann als terminaler Elektronenakzeptor in der Atmungskette oder als Co-Substrat zum Abbau komplizierterer Substrate wie Aromaten dienen. Auf dem Cosmid slc_2j sind ORFs lokalisiert, die vermutlich für Komponenten der Atmungskette kodieren. Bei den Genprodukten der ORFs 1208 und 1210 könnte es 
sich um die Untereinheiten A bzw. B einer F0F1-Typ-ATP-Synthase und bei dem ORF1215 um die Cytochrom B Untereinhet einer Menachinon-C-Reduktase handeln. $\mathrm{Zu}$ der „sekundären Fermentation“ sind fast alle heterotrophen Bakterien in der Lage. Ein Beispiel eines solchen Abbaus stellt der Abbau von Aminosäuren dar. Auf dem Cosmid slc_1t befindet sich ein Cluster von Genen (ORF824 bis ORF830), die für Enzyme kodieren, die vermutlich für den mehrstufigen Abbau von Tyrosin verantwortlich sind (s. 3.4.1.8). Ein anderes Beispiel ist die auf dem Cosmid slc_la von den ORFs 118 bis 122 kodierte Sarcosin-Oxidase, die die oxidative Demethylierung von Sarcosin katalysiert, wobei Glycin, $\mathrm{H}_{2} \mathrm{O}_{2}$ und 5,10- $\mathrm{CH}_{2}$-Tetrahydrofolat entsteht.

Die theoretische Energieausbeute der sekundären Fermentation hängt von der Differenz der Redoxpotentiale des Elektronendonors und -akzeptors ab. Da fast alle Elektronenakzeptoren niedrigere Redoxpotentiale als Sauerstoff haben, ist der anaerobe Elektronentransport in der Atmungskette weniger effizient als der aerobe. Deshalb wird Sauerstoff von fakultativen Organismen zuerst verbraucht. Da die Sauerstoffkonzentration in der Wassersäule von oben nach unten abnimmt und sich diese Tendenz auch im Sediment fortsetzt, kann in Sedimenten eine Schichtung der Organismen beobachtet werden, die sich nach dem Redoxpotential des von den Organismen nutzbaren terminalen Elektronenakzeptors richtet. Die Produkte der sekundären Fermentation sind $\mathrm{H}_{2}, \mathrm{CO}_{2}$, Acetat und Formiat.

Nitrat ist imVergleich zu Sauerstoff als terminaler Elektronenakzeptor ebenfalls sehr effizient. Die Reduktion von Nitrat zu Nitrit ist der erste Schritt der mehrstufigen Reduktion von Nitrat zu molekularem Stickstoff, die als Denitrifikation bezeichnet wird. Auch die anderen Teilreaktionen sind ebenfalls energieliefernd (ZUMFT, 1997). Die Denitrifikation ist unter 4.1.2 näher beschrieben.

$\mathbf{F e}^{3+}$-Ionen stellen einen weiteren terminalen Elektronenakzeptor für die anaerobe Atmung dar. Dissimilatorisch $\mathrm{Fe}^{3+}$-reduzierende Bakterien oxidieren ebenfalls die typischen Abbau-Produkte organischen Materials wie Acetat und molekularen Wasserstoff. Im Gegenzug reduzieren sie $\mathrm{Fe}^{3+} \mathrm{zu} \mathrm{Fe}^{2+}$ (LOVLEY, 1991). Nach theoretischen thermodynamischen Berechnungen ist die Nutzung von $\mathrm{Fe}^{3+}$-Ionen als terminalem Elektronenakzeptor mit einer größeren Energieausbeute verbunden als die Nutzung von weniger stark oxidierten Verbindungen wie $\mathrm{CO}_{2}$ und $\mathrm{SO}_{4}{ }^{2-}$. Es ist bekannt, dass $\mathrm{Fe}^{3+}$-reduzierende Bakterien sich gegenüber Sulfat-reduzierenden Organismen und Methanogenen im Konkurrenzkampf um limitierende Elektronendonatoren wie $\mathrm{H}_{2}$ durchsetzen können (CHAPELLE et al., 1992; LOVLEY et al., 1991). Jedoch sind die 
Löslichkeitsprodukte der verschiedenen in der Natur vorkommenden $\mathrm{Fe}^{3+}$ Verbindungen bei neutralem pH meist so gering, dass die Nutzung dieses terminalen Elektronenakzeptors nicht immer begünstigt ist (COEY et al., 1974). Die Fe ${ }^{3+}$-IonenKonzentration im Wasser der Leine betrug $0,1 \mathrm{mg} / 1$. In der zu den $\delta$-Proteobakterien gehörenden Familie Geobacteraceae, in der anaerobe dissimilatorische Metallreduzierer zusammengefasst sind, ist die Fähigkeit, $\mathrm{Fe}^{3+} \mathrm{zu}$ reduzieren, weit verbreitet (CUMMINGS et al., 2000; LOVLEY et al., 1993). Die Sequenzen s11361, sl1364a und sl3245 stimmen zu 96, 95 bzw. 86 \% mit isolierten Geobacter-Stämmen überein. Es ist deshalb denkbar, dass die Nutzung von $\mathrm{Fe}^{3+}$-Ionen oder anderer Metallionen wie z. B. $\mathrm{Mn}^{4+}$ als terminale Elektronenakzeptoren auch in der Leine stattfindet.

Sulfatreduzenten kommen in 4 verschiedenen bakteriellen und einem archaeellen Phylum vor. Dabei sind nah verwandte Organismen bekannt, die nicht in der Lage sind, Sulfat zur Energiegewinnung anaerob zu reduzieren (LOY et al., 2002). Die Klone sl1127 und sl1147 sind zu 97 bzw. sogar zu $99 \%$ identisch mit Sulfatreduzenten der $\delta$ Proteobakterien. In diesen Fällen ist es wahrscheinlich, dass diese Sequenzen tatsächlich auf Sulfatreduzenten zurückgeführt werden können. Bei den Sequenzen s11177, s11283, s11263 und s13234 mit 87 - 94 \% Identität zu Sulfatreduzenten kann nicht sicher davon ausgegangen werden. Sulfatreduzenten können Sulfat als terminalen Elektronenakzeptor in der Atmungskette nutzen. Dabei können $\mathrm{H}_{2}$ oder verschiedene organische Verbindungen als Elektronendonatoren genutzt werden (STACKEBRANDT et al., 1995). Bei der Reduktion des Sulfates mit $\mathrm{H}_{2}$ entstehen Schwefelwasserstoff und Wasser.

Die unterste Schicht ist die der Methanogenen. Neben Reisfeldern, dem Rumen von Wiederkäuern, den anaeroben Fermentern der technischen Abwasserreinigung sind Süßwassersedimente die wichtigsten Orte der Methanogenese. Der nächsten kultivierte Verwandte fast aller archaeellen Leinesedimetsequenzen ist ein methanogenes Archaeon. Die Methanogenese ist der finale Schritt der Verwertung organischer Materie. $\mathrm{H}_{2}-\mathrm{CO}_{2}$, Formiat und Acetat sind mögliche Substrate, die zu Methan umgesetzt werden. Die nachgewiesenen Archaeen-Gruppen unterscheiden sich bezüglich ihrer Substrat-Spezifitäten. Alle Vertreter der Methanosaetaceae verwerten ausnahmslos Acetat als Substrat (BOONE et al., 1993). Dagegen nutzen sowohl Methanocculeus als auch die endosymbiontischen Angehörigen der MCU-Bourgense-Untergruppe der Methanomicrobiales $\mathrm{H}_{2}-\mathrm{CO}_{2}$ zur Methanbildung (FENCHEL et al., 1991). Methanosarcina kann mit $\mathrm{H}_{2}-\mathrm{CO}_{2}$, Formiat und Acetat wachsen, benötigt allerdings 
eine deutlich höhere Acetat-Konzentration als Methanosaeta, um es nutzen zu können (GROSSKOPF et al., 1998). Die Produktivität methanogener Gemeinschaften in Süßwassersedimenten hängt von der Temperatur und der Verfügbarkeit der Substrate ab (CAPONE et al., 1988; CONRAD, 1993). Bei höheren Temperaturen ist die Methanbildung gesteigert und erfolgt verstärkt durch die hydrogenotrophe Methanogenese und weniger stark durch die Acetat verbrauchende. Bei niedrigeren Temperaturen findet vornehmlich die acetoclastische Methanogenese statt (SCHULZ und CONRAD, 1996). Zum Zeitpunkt der Probennahme betrug die Temperatur der Leine $13{ }^{\circ} \mathrm{C}$. Bei einer solchen Temperatur ist ein Gleichgewicht beider Prozesse denkbar, so dass eine numerische Verteilung der Methanogenen entsprechend der der generierten 16S rRNA-Gene möglich ist. Dies ist allerdings reine Spekulation und müsste über FISH, wie oben erwähnt, überprüft werden. FISH könnte mit geeigneten Sonden ebenfalls zur Klärung der Frage eingesetzt werden, ob es sich bei den Vertretern der MCU-Bourgense-Untergruppe, deren nächste kultivierte Verwandte Endosymbionten anaerober Ciliaten sind, ebenfalls um Endosymbionten oder um freilebende Mikroorgansimen handelt. In solchen Symbiosen erhalten die Endosymbionten von den Hydrogenosomen des Wirtes den bei dem Abbau von Pyruvat entstehenden $\mathrm{H}_{2}$. Dies ist besonders in Habitaten von Vorteil, in denen die Methanogenen mit Sulfatreduzenten um den $\mathrm{H}_{2}$ konkurrieren. Die Verringerung der $\mathrm{H}_{2}$ Konzentration ermöglicht es dem Wirt vermutlich komplexes organisches Material unter optimaler ATP-Ausbeute vollständig zu Acetat und $\mathrm{CO}_{2}$ abzubauen (FINLAY und FENCHEL, 1992). Da im Leinesediment tatsächlich Sulfatreduzenten (z. B. s11126 und s11147) nachgewiesen wurden, stehen die methanogenen Archaea mit ihnen in Konkurrenz. Da Sulfatreduzenten ein breiteres Substratspektrum als die methanogenen Archaea haben und bei der Sulfat-Reduktion mehr Energie frei wird als bei der Methanogenese, setzen sich die Sulfatreduzenten an sulfatreichen Standorten wie dem Meerwasser mit einem Sulfatgehalt von ca. $28 \mathrm{mM}$ gegen die methanogenen Archaeen durch (BARTON, 1995). Im Wasser der Leine wurde eine Sulfatkonzentration von ca. $2 \mathrm{mM}$ gemessen. Bei dieser Sulfatkonzentration scheinen beide Organismengruppen im Leinesediment nebeneinander existieren $\mathrm{zu}$ können. Eine Koexistenz beider Organismengruppen ist bereits z. B. für anaerobe Biofilme beschrieben worden (RASKIN et al., 1996).

Im Leinesediment scheinen zumindest an einigen Stellen anaerobe Verhältnisse bestanden zu haben, da strikt anaerobe Organismen wie Clostridien nachgewiesen 
wurden. Andere Organismen wie z. B. Geobacter sind bekannt dafür, dass sie zur Energiegewinnung unter anaeroben Bedingungen in ihrer Atmungsketten alternative Elektronenakzeptoren wie Metallionen nutzen. Die bei der anaeroben Atmung entstandenen Endprodukte wie z. B. $\mathbf{H}_{2} \mathbf{S}, \mathbf{M n}, \mathbf{F e}^{2+}$ und $\mathbf{C H}_{4}$ können durch aerobe Organismen re-oxidiert werden:

Methylotrophe Bakterien sind Gram-negativ und nutzen Methan als ihre einzige C- und Energie-Quelle. Der initiale Schritt beinhaltet die Umwandlung von Methan in Methanol durch eine Methan-Monooxygenase. Bei dieser Reaktion wird ein Reduktionsäquivalent NADH verbraucht und Wasser entsteht. Methanol wird anschließend zu Formaldehyd weiteroxidiert, das entweder für den Aufbau von Biomasse genutzt oder $\mathrm{zu} \mathrm{CO}_{2}$ oxidiert wird (SEMRAU et al., 1995). $\mathrm{Zu}$ den methylotrophen Bakterien gehören z. B. die Gattungen Methylobacterium der $\beta$ Proteobakterien (94 \%ige Identität zu s13233), Methylophilus der $\alpha$-Proteobakterien (94 \%ige Identität $\mathrm{zu}$ sl1302) und Methylomicrobium der $\gamma$-Proteobakterien (91 \%ige Identität zu s11124).

$\mathbf{H}_{2} \mathbf{S}$ kann z. B. von Chlorobium und den photosynthetisch aktiven Proteobakterien oxidiert werden. Die Oxidation von $\mathbf{F e}^{2+}$ durch das unklassifizierte Proteobakterium Stamm SW2 ist ebenfalls bereits in dem Abschnitt der anaeroben Photosynthese erwähnt worden. Das $\alpha$-Proteobakterium Pedomicrobium manganicum, zu dessen $16 \mathrm{~S}$ rRNA-Gen der Klon s13257 eine 94 \%ige Identität hat, oxidiert Mangan. Dabei ist die Ähnlichkeit auffällig gering für Pedomicrobium-Arten, die sonst sehr eng verwandt sind und untereinander eine Ähnlichkeit von 96,2 bis 99,9\% aufweisen (COX und SLY, 1997).

Carboxidotrophe Organismen können Kohlenstoffmonoxid (CO) als einzige Energieund Kohlenstoffquelle nutzen. Die carboxytrophen Bakterien bilden eine diverse Gruppe von aeroben Bakterien, zu denen vor allem $\alpha$-Proteobakterien und Firmicutes gehören (MOERSDORF et al., 1992). KING (2003) konnte nachweisen, dass auch Genera, von denen bislang angenommen wurde, dass sie nicht in der Lage wären, CO zu oxidieren, Kohlenstoffmonoxid-Dehydrogenasen besitzen und diese auch nutzen. Zu diesen Genera gehören z. B. Stenotrophomonas und Mesorhizobium, die auch in dieser Arbeit nachgewiesen werden konnten. Allerdings blieb dabei unklar, ob die Fähigkeit in diesen Genera weit verbreitet ist oder sich nur auf wenige Stämme beschränkt. Die 16S rRNA des von KING isolierten Stenotrophomonas-Stammes Stenotrophomonas sp. Stamm LUP war wie die Sequenz s11118 zu $99 \%$ identisch mit der von 
Stenotrophomonas maltophilia Stamm LMG957. Das Cosmid slc_1x weist, wie unter 2.4.1.10 beschrieben, ein Cluster mit 6 cox-Genen ( $E, D, L, L, S$ und $M)$ auf, die für die verschiedenen Untereinheiten einer CO-Dehydrogenase kodieren. Die Gene sind den entsprechenden Genen aus Mesorhizobium loti am ähnlichsten.

\subsubsection{Versuch einer Rekonstruktion des Stickstoffkreislaufes in der mikrobiellen Gemeinschaft}

Die Denitrifikation ist eine Möglichkeit der anaeroben Atmung, bei der Nitrat über 4 Schritte über Nitrit, Stickstoffmonoxid und Distickstoffoxid letztlich zu molekularem Stickstoff umgewandelt wird. Die Fähigkeit der Denitrifikation ist auf 40 Genera der Bakterien verteilt. Viele Gram-negative Bakterien wie Pseudomonas, Alcaligenes, Hyphomikrobium und Thauera können Nitrat als terminalen Elektronenakzeptor nutzen. Dabei wird ein geeignetes organisches Substrat $\mathrm{zu} \mathrm{CO}_{2}$ und Wasser umgesetzt und das Nitrat, wie oben beschrieben, stufenweise zu molekularen Stickstoff reduziert (ZUMFT, 1997). Im Wasser der Leine betrug die Nitrat-Konzentration 7 mg/l und die NitritKonzentration 0,09 mg/1 (s. 3.1). Gerade Sequenzen von Pseudomonaden konnten mehrfach und mit hohen Identitäten von bis zu 100 \% mit kultivierten PseudomonasStämmen in dem Leinesediment nachgewiesen werden. Die Sequenzen s13207 und s13249 sind zu 93 \% identisch mit Hyphomicrobium zavarzinii. Damit ist das Ablaufen der Denitrifikation im Leinesediment sehr wahrscheinlich. Die Nitrifikation, die Oxidation von Ammonium zu Nitrat, wird in 2 Schritten von unterschiedlichen Organismen durchgeführt. Zunächst wird aus dem Ammonium z. B. durch Nitrosomonas oder Nitrosospira Nitrit gebildet (CÉBRON et al., 2003). Die Sequenz s11367a ist $\mathrm{zu} 99 \%$ mit der $16 \mathrm{~S}$ rRNA-Gensequenz des $\beta$-Proteobakteriums Nitrosospira sp. Nsp.57 identisch. Bei diesen beiden Organismen handelt es sich vermutlich um Bakterien der gleichen Art. Die Sequenz s11339 stellt mit einer Ähnlichkeit von 97 \% zu Gallionella ferruginea Stamm Johan, einem Vertreter der Gattung Nitrosomonas, sicherlich auch eine zu dieser Gattung gehörende Art dar. Der zweite Schritt der Nitrifikation, die Oxidation von Nitrit zu Nitrat, erfolgt durch Organismen wie Nitrospina, Nitrobacter und Nitrospira. Zu dem Phylum Nitrospira gehören obligat chemoautotrophe Bakterien, die $\mathrm{CO}_{2}$ als einzige Kohlenstoffquelle nutzen (HOLT et al., 1994; CÉBRON et al., 2003). Die Sequenzen s11193, s11342, sl1367b und s11395 zeigten große Ähnlichkeiten mit Nitrospira-Datenbank-Sequenzen. 
Aus dem Leinesediment konnten außerdem 16S rRNA-Gene von Stickstofffixierern wie die Gattung Rhizobium (s11106), Sinorhizobium (s13294) amplifiziert werden. Die Fähigkeit der Stickstofffixierung ist auf Bakterien beschränkt, unter diesen aber weit verbreitet. Symbiosen mit höheren Pflanzen gehen allerdings nur wenige ein. Rhizobien können als frei lebende Bodenbakterien oder als Symbionten mit Pflanzen der Familie Leguminosae auftreten (FISHER und LONG, 1992). In der Symbiose bildet die Pflanze nach dem Austausch bestimmter Botenstoffe mit den Bakterien Wurzelknöllchen aus, deren zentrales Gewebe von den Bakterien infiziert wird. Dort differenzieren sich die Bakterien im Cytoplasma der Pflanzenzellen zu Stickstofffixierenden Bakteroiden. Diese reduzieren den molekularen Stickstoff aus der Atmosphäre zu Ammonium. In der Symbiose beziehen die Bakterien Nährstoffe und die Pflanze den gebundenen Stickstoff in Form des Ammoniums (FISHER und LONG, 1992). Der ORF 821 des Cosmids slc_1t kodiert vermutlich für das Protein NodQ, das an der Bildung eines Nodulationsfaktors beteiligt ist, der als Botenstoff vom Bakterium ausgesendet wird. Diese Faktoren bestehen aus Oligomeren aus N-Acetylglukosamin, die am nichtreduzierenden Ende mit einer N-Acyl-Gruppe und am C-6 des reduzierenden Endes mit einer Sulfat-Gruppe substituiert sind. NodQ ist für die Bildung einer aktivierten SulfatGruppe verantwortlich, die vom Protein NodH auf das N-Acetylglukosamin übertragen wird.

Das aktive Zentrum der für die Stickstofffixierung verantwortlichen Nitrogenase ist stark reduzierend und deshalb sehr empfindlich gegenüber Sauerstoff. Aus diesem Grund wird in den Wurzelknöllchen eine mikro-oxische Atmosphäre geschaffen. Die Stickstofffixierung wird in Abhängigkeit von der Sauerstoffkonzentration reguliert (KAMINSKI et al., 1998; OKE und LONG, 1999). Auf dem Cosmid slc_1x wurden Gene gefunden, deren Genprodukte den Proteinen FixL und FixJ von Sinorhizobium meliloti, einem 2-Komponentensystem, ähnelten. Das Sensor-Protein FixL, ein Hämprotein, misst die Sauerstoffkonzentration. Entspricht diese mikro-oxischen Bedingungen, unterliegt das Protein einer Autophosphorylierung und gibt dann den Phosphatrest an den „Response regulator“ NifJ weiter. Dieses Protein ist ein Transkriptionsaktivator und reguliert die Expression der Gene fixK und nifA, indem es an spezifische Promotorsequenzen, sogenannte ,anaeroboxes“, bindet (OKE und LONG, 1999). Auf dem Cosmid slc_1x ist ebenfalls ein zu fixK von M. loti bzw. zu fixK1 von Sinorhizobium loti homologes Gen vorhanden. FixK bzw. FixK1 wiederum sind Fnr/Crp-artige Transkriptionsfaktoren, die die Expression der Gene fixNOQP 
kontrollieren. Diese kodieren in Bradyrhizobium japonicum für eine terminale Oxidase mit hoher Affinität für Sauerstoff, die für die Atmung unter sauerstoffarmen Bedingungen und die Stickstofffixierung wichtig ist (BARNETT et al., 2001). Das Gen eines weiteren Transkriptionsregulators, fixT2 wird auf dem Cosmid Slc_1x von den Genen fixJ und fixK eingerahmt. Dieser Trankriptionsregulator interagiert mit FixL, wodurch er die Aktivität des 2-Komponentensystems FixL/FixJ aufhebt (GALIBERT et al., 2001). Hierbei ist jedoch zu berücksichtigen, dass selbst bei großen Ähnlichkeiten zwischen 2 2-Komonentensystemen unterschiedliche Funktionen vorliegen können. Da aber mit FixK und FixT2 weitere Komponenten der Regulationskaskade der Stickstofffixierung vorhanden sind, scheint eine solche Interpretation der Sequenzdaten wahrscheinlich.

Auch auf dem Cosmid slc-1h konnten Gene gefunden werden, die in die Regulation der Stickstofffixierung integriert sind. Der ORF 406 und 407 kodieren für das Regulationsprotein GlnK bzw. den (Methyl-) Ammoniumtransporter AmtB. Diese beiden Proteine werden in vielen Organismen kotranskribiert. Die größte Ähnlichkeit besteht zu Rhodobacter sphaeroides. Dieses Bakterium bildet keine Symbiosen aus. In dem verwandten Bakterium Rhodobacter capsulatus werden die Synthese und die Aktivität der beiden vorhandenen Nitrogenase-Systeme streng kontrolliert. Dabei werden zum einen Stickstoffmangelbedingungen und zum anderen die AmmoniumKonzentration festgestellt. Außerdem wird über eine dritte Kontrollebene die Aktivität beider Nitrogenasen in Abhängigkeit von der Ammonium-Konzentration und der Dunkelheit reguliert. AmtB wirkt dabei als Ammonium-Sensor. GlnK scheint die Aktivität des Transkriptionsaktivators NifA beider Nitrogenase-Systeme in Abhängigkeit von der Ammonium-Konzentration zu kontrollieren (DREPPER et al., 2003).

Geht man davon aus, dass die hier erwähnten 16S rRNA-Gene auf Organismen mit den besprochenen Fähigkeiten zurückgeführt werden können, kann der Stickstoffkreislauf im Leinesediment geschlossen werden. Die zentrale Bedeutung dieser Stoffwechselwege wird auch durch das verhältnismäßig starke Vorkommen von Genen, die an diesem Kreislauf direkt oder indirekt beteiligt sind, im Zuge der Sequenzierung der Cosmide des Leinesedimentes deutlich. MÜLLER et al. (1997) quantifizierten das Vorkommen von Schlüsselenzymen der Sulfatreduktion, der Denitrifikation und Sickstofffixierung in Süßwassersedimenten mittels PCR. Dabei konnten die Gene für die Sulfit-Reduktase (dsrAB), der Nitrit-Reduktase (nirS) und der Nitrogenase (nifD) in 
Konzentrationen von $10^{8}-10^{9}, 10^{6}-10^{9}$ bzw. $10^{9}-10^{10}$ pro Gramm Sediment (Nassgewicht) bestimmt werden. Auch diese Ergebnisse belegen die Wichtigkeit dieser Stoffwechselwege in Süßwassersedimenten.

\subsubsection{Kritische Betrachtung der Methode der 16S rRNA-Genanalyse}

Aufgrund der verschiedenen unter 4.1 beschriebenen Probleme und der Grenzen der Aussagekraft der 16S rRNA-Genanalyse erscheint diese Methode vermehrt in einem anderen Licht. Eine Schwierigkeit liegt in der Beurteilung der Ergebnisse. Die Entscheidung, wie groß die verwandtschaftliche Beziehung zwischen Mikroorganismen ist, lässt sich nicht mit absoluten Zahlen festlegen. Die Sequenzheterogenität der verschiedenen 16S rRNA-Gene eines Organismus kann sehr groß sein. Bei den extremen Fällen des Archaeons Haloarcula marismortui und des Bakteriums Thermobispora bispora unterscheiden sich die Gene um 5 bzw. um $6 \%$ (MYLVANAGAM und DENNIS, 1992; WANG et al., 1997). VENTER et al. (2004) dagegen gehen bei der phylogenetischen Einordnung der gewonnenen 16S rRNAGensequenzen der Umwelt-Genom-,,Shotgun“-Genbank der Sargasso Sea davon aus, dass die Identität innerhalb einer Art mehr als $97 \%$ beträgt. Außerdem ist die Einordnung von Sequenzen durch Fragmente in den öffentlichen Datenbanken erschwert, die weniger als 500 bp umfassen. HUGENHOLTZ et al. (1998) hält 500 bp für die Einordnung unbekannter Sequenzen $(<85 \%)$ für unzureichend. RODRIGUEZVALERA (2002) hält sogar eine Einordnung bei $95 \%$ Identität unabhängig von der Länge des amplifizierten rDNA-Fragmentes für unsicher. Wie bereits unter 4.1.1 erwähnt, lässt sich schon bei großen Identitäten von Umweltsequenzen zu kultivierten Organismen häufig keine sichere Aussage mehr über den Stoffwechsel oder z. B. die Morphologie machen. Außerdem können aufgrund der 16S rRNA-Genanalyse keine quantitativen Aussagen zum Vorkommen von Mikroorganismen gemacht werden. Letztlich bleibt die Frage, ob die Verwendung von 16S rRNA-Gensequenzen als alleiniges Mittel zur Einordnung von Bakterien ausreicht. DOOLITTLE (1999) führt dagegen an, dass die Nukleotid-Bausteine, die in intramolekulare Wechselwirkungen integriert sind, langsamer evolvieren als die, die für intermolekulare Wechselwirkungen von Bedeutung sind. Auch wenn meist von der Untransferierbarkeit von Bestandteilen der Transkriptions- bzw. Translationsmaschinerie ausgegangen wird, gibt es auch bei dem 16S rRNA-Gen Nachweise für die Möglichkeit des lateralen Gentranfers: So 
konnte die 16S rRNA von E. coli vollständig durch die von Proteus vulgaris ersetzt werden, ohne das Wachstum um mehr als 10 bis $30 \%$ zu beeinflussen. Unter NichtWachstumsbedingungen wie unter Antibiotikadruck ist es sogar vorstellbar, dass ein lateraler Gentransfer Selektionsvorteile bringt wie bei Amino-acyl-t-RNA-SynthetaseGenen. Auf diese Weise könnte auch die große Heterogenität der 16S rRNA-Gene innerhalb von Streptomyces-Stämmen erklärt werden. Laut DOOLITTLE kann mit der 16S rDNA-Analyse lediglich die Evolution dieses Gens, nicht aber des gesamten Organismus untersucht werden. Der Organismus selbst könne aufgrund der verschiedenen Evolutionen seiner Markermoleküle zu verschiedenen Phyla gehören nicht wie bislang angenommen- nur zu einem. Da aber in dieser Arbeit nicht die evolutive Herkunft der Organismen ergründet, sondern lediglich ein Einblick gewonnen werden sollte, welche Organismen im Leinesediment vorkommen, hat das Ergebnis ungeachtet der Kritik eine Aussagekraft.

\subsubsection{Fazit der phylogenetischen Untersuchungen}

Die Ergebnisse der Sequenzierung der archaeellen 16S rRNA-Gene bezüglich der Zusammensetzung der Archaeen in der mikrobiellen Gemeinschaft ähneln den Ergebnissen von Arbeiten zu anderen Süßwasserstandorten. Die Archaeen im Rotsee und im Leinesediment waren ähnlichen Umwelteinflüssen ausgesetzt. Es handelt sich in beiden Fällen um Sedimente aus Süßwasserstandorten. Das Vorkommen ähnlicher Archaeen, kann auf eine an diese Verhältnisse angepasste Physiologie der Ursprungsorganismen verstanden werden. Dass sehr ähnliche Organismen auch im finnischen Waldsee Valkea Kotinen gefunden wurden, bestätigt die generelle Anpassung dieser Organismen an den Standort Süßwasser.

Die Ergebnisse der bakteriellen 16S rRNA-Genanalyse zeigen dagegen, dass sich die bislang untersuchten Süßwasserstandorte in ihrer bakteriellen Zusammensetzung zwar ähneln, dass aber auch deutliche Unterschiede bestehen. Wie oben bereits geschrieben, kann dies leicht durch die Unterschiede der Standorte an sich erklärt werden. Zusammenfassend kann also festgestellt werden, dass es typische standortspezifische Organismengruppen gibt, dass aber die mikrobielle Zusammensetzung dennoch einer gewissen Variation unterliegt.

Zudem wurden im Leinesediment Cluster von Bakterien identifiziert, die neue Gattungen bekannter Familien darstellen. Einzelne Klone zeigten so wenig Identität, 
dass sie nur sehr grob in das Klassifikationssystem eingeordnet werden konnten. Dies und die Tatsache, dass die meisten Klone die größte Identität zu unkultivierten Prokaryoten zeigten, verdeutlichen, dass auch im Leinesediment viele bislang unbekannte und uncharakterisierte Mikroorganismen leben. Durch den Nachweis der Sequenz s11394 mit größter Ähnlichkeit zu einer Sequenz, die in die „candidate division“ TM7 eingeordnet ist, konnte verdeutlicht werden, dass nicht nur vieles innerhalb schon lange bekannter Phyla noch unbekannt ist, sondern dass mit Untersuchungen wie dieser ganz wesentliche Erkenntnisse auf Phylum-Niveau erhalten werden können. Die Sequenz s11394 war, wie oben beschrieben, erst die 51. Sequenz der „candidate division“ TM7, die bislang aus Umweltproben gewonnen werden konnte. Der Nachweis solcher Bakterien im Leinesediment lässt ein ubiquitäres Vorkommen dieser Bakterien vermuten. Bislang konnte noch kein TM7-Bakterium kultiviert werden, so dass über die physiologische Fähigkeiten bislang noch nichts bekannt ist.

Es wurde außerdem der Versuch unternommen, den Kohlenstoff- und Energieflux und den Stickstoffkreislauf im Leinesediment nachzuzeichnen. Dabei muss beachtet werden, dass neben der Unsicherheit solcher Aussage anhand von Verwandtschaftsbeziehungen nur grundlegende Stoffwechselfähigkeiten bekannter Organismen wie z. B. die Nutzung alternativer Elektronenakzeptoren in der Atmungskette oder die Fähigkeit, Stickstoff zu fixieren, berücksichtigt werden können. Organismengruppen mit wenigen oder keinen kultivierten Vertretern wie z. B die Acidobacteria oder Chloroflexi oder Organismengruppen mit sehr unterschiedlichen Stoffwechselaktivitäten können in solch eine Betrachtung kaum eingehen. Damit ist die Aussagekraft von phylogenetischen Untersuchungen, die auf der Sequenzierung von Markermolekülen basieren, sehr begrenzt.

Auch wenn die Zahl der Phyla innerhalb der Bacteria nicht mehr in dem Ausmaß zuzunehmen scheint wie zwischen 1987 und heute, so gibt es innerhalb der Phyla noch vieles zu entdecken. Um die nackten Sequenzdaten mit Leben zu erfüllen, müssen aber auch verstärkt Kultivierungen und anschließende physiologische Charakterisierungen der Bakterien folgen. Eine weitere Möglichkeit die Zusammenhänge zwischen Struktur (phylogenetische Zusammensetzung) und Funktion (physiologische Aktivität) an einem Standort besser zu verstehen, bietet die Sequenzierung von größeren Teilen des Metagenoms. 


\subsection{Metagenom-Sequenzierung}

Die Klärung der Zusammenhänge von Struktur und Funktion in einer Umweltprobe kann im Rahmen der Sequenzierung von Umwelt-DNA durch drei verschiedene Vorgehensweisen erfolgen. Zum einen kann die klonierte Umwelt-DNA zunächst nach phylogenetischen Markern durchsucht werden. In einem zweiten Schritt steht dann die flankierende DNA zur weiteren Sequenzierung zur Verfügung. Diese Methode wurde von QUAISER et. al. (2002) genutzt, die ein Fosmid aus einer Genbank mit klonierter Boden-DNA sequenzierten, das ein 16S rRNA-Gen eines bislang unkultivierten Crenarchaeoten enthielt. Ebenfalls aus einer Genbank mit klonierter Boden-DNA stammte ein „bacterial artificial chromosome“ (BAC) mit einem 16S rRNA-Gen eines Acidobakteriums eines bislang unkultivierten Zweiges. Die Sequenzierung dieses BACs (LILES et al., 2003) wie auch die des Fosmids erlaubten erste Einblicke in die Genome dieser unkultivierten Organismen. BEJA et al. (2001) nutzten dieses Vorgehen und identifizierten auf einem BAC mit mariner DNA ein 16S rRNA-Gen eines Bakteriums, das $\mathrm{zu}$ der bislang unkultivierten SAR86-Gruppe der $\gamma$-Proteobakterien gehört. Außerdem war auf diesem BAC eine lichtbetriebene Protonenpumpe kodiert, die Ähnlichkeiten zu Rhodopsin zeigte. Durch Expression in E. coli konnte die Funktionalität bewiesen werden. Zuvor war davon ausgegangen worden, dass das Vorkommen von Rhodopsinen auf Archaea beschränkt wäre. Mit dieser Entdeckung konnte zum einen ein wesentlicher Beitrag zur Einordnung des Stoffwechsels der bislang unkultivierten SAR86-Gruppe gewonnen und zum anderen ein falsches Dogma verworfen werden. Letztlich wurde die grundlegende Erkenntnis gewonnen, dass die Kopplung des Kohlenstofffluxes in den Ozeanen mit der Licht-Energie-Sammlung zum Teil ohne Chlorophyllbeteiligung möglich ist.

Eine andere Methode der Verbindung der Struktur mit der Funktion bedient sich des umgekehrten Weges. Zunächst wird nach bestimmten Zielgenen gesucht. Im zweiten Schritt wird hier versucht, auf dem restlichen DNA-Fragment phylogenetische Marker ausfindig zu machen. Dabei werden alle phylogenetischen Markermoleküle berücksichtigt, um die Wahrscheinlichkeit einer Zuordnung zu erhöhen (RIESENFELD et al., 2004). Die wesentliche Grenze dieser beiden Methoden ist die nötige Anordnung von interessanten Genen in der Nachbarschaft von Genen phylogenetischer Marker.

Die dritte Möglichkeit der Verknüpfung von Phylogenie und Physiologie ist die Rekonstruktion von Metagenomen. Dafür wurden bislang meist ähnlich wie in 
Genomsequenzierungsprojekten „Shotgun“-Genbanken mit kleinen Inserts von ca. $3 \mathrm{~kb}$ erstellt und sequenziert. RIESENFELD et al. (2004) listen bislang erfolgte MetagenomStudien, die auf einer Sequenzierung von zufällig ausgewählter DNA beruhen auf (Tabelle 15):

Tabelle 15: Metagenomstudien basierend auf der Sequenzierung zufällig ausgewählter DNA nach RIESENFELD et al. (2004), modifiziert und mit Ergebnissen dieser Arbeit ergänzt

\begin{tabular}{|c|c|c|c|c|c|}
\hline $\begin{array}{l}\text { Herkunft der } \\
\text { Umweltprobe }\end{array}$ & $\begin{array}{c}\text { Insert- } \\
\text { Größe in kb }\end{array}$ & $\begin{array}{l}\text { Sequenz- } \\
\text { läufe }\end{array}$ & $\begin{array}{l}\text { Sequenz- } \\
\text { information } \\
\text { in bp }\end{array}$ & Ziel & Herkunft \\
\hline Menschlicher Kot & LASL* & 532 & $\sim 37000$ & $\begin{array}{l}\text { Zufällige } \\
\text { Virenklon- } \\
\text { Sequenzierung } \\
\end{array}$ & $\begin{array}{l}\text { BREITBART et } \\
\text { al., } 2003\end{array}$ \\
\hline Meer & LASL* & 1061 & $\sim 740000$ & $\begin{array}{l}\text { Zufällige } \\
\text { Virenklon- } \\
\text { Sequenzierung } \\
\end{array}$ & $\begin{array}{l}\text { BREITBART et } \\
\text { al., } 2002\end{array}$ \\
\hline $\begin{array}{lr}\text { Biofilm einer } \\
\text { Trinkwasserleitung }\end{array}$ & $\begin{array}{l}\text { Plasmide und } \\
\text { Cosmide }\end{array}$ & 2496 & $2 \cdot 10^{6}$ & $\begin{array}{l}\text { Zufällige Klon- } \\
\text { sequenzierung }\end{array}$ & $\begin{array}{l}\text { SCHMEISSER } \\
\text { et al., } 2003\end{array}$ \\
\hline $\mathrm{AMD}^{*}$ & 3,2 & 103462 & $76,2 \cdot 10^{6}$ & $\begin{array}{l}\text { Rekonstruktion } \\
\text { von Genomen } \\
\text { einer mikrobiellen } \\
\text { Gemeinschaft } \\
\end{array}$ & $\begin{array}{l}\text { TYSON et al. } \\
2004\end{array}$ \\
\hline Meer & 2,6 & $2 \cdot 10^{6}$ & $1,63 \cdot 10^{9}$ & $\begin{array}{l}\text { „Pilot-Studie“: } \\
\text { Sequenzierung } \\
\text { einer gesamten } \\
\text { mikrobiellen } \\
\text { Gemeinschaft in } \\
\text { großem Umfang }\end{array}$ & $\begin{array}{l}\text { VENTER et al. } \\
2004\end{array}$ \\
\hline Leinesediment & Cosmide & 4765 & 456000 & $\begin{array}{l}\begin{array}{l}\text { Zufällige Klon- } \\
\text { sequenzierung }\end{array} \\
\end{array}$ & \\
\hline
\end{tabular}

In der Tabelle 15 sticht besonders der Umfang der Untersuchungen von TYSON et al. (2004) und VENTER et al. (2004) hervor. TYSON et al. (2004) untersuchte die mikrobielle Gemeinschaft eines Biofilms, der an der ,acid mine drainage“ in einem Bergwerk verantwortlich war. Dabei konnten sie die Genome eines Bakteriums der Leptospirillium Gruppe II und eines Archaeons, das zu den Ferroplasma Typ II gehört, fast vollständig zusammensetzen. 3 weitere Genome von einem Bakterium der Leptospirillium Gruppe III, von Sulfolbacillus und einem weiteren Archaeon des Ferroplasma TypII konnten teilweise rekonstruiert werden. Dafür war ein Sequenzierungsaufwand von 103462 Sequenzläufen, die zusammen eine DNA-Länge von 76,2 Mbp umfassten, nötig. Eine Rekonstruktion der Genome war trotz des großen 
Aufwandes nur deshalb möglich, weil dieser isolierte Standort nur eine sehr begrenzte Anzahl unterschiedlicher Organismen, im Wesentlichen die 5 sequenzierten Mikroorganismen, enthielt und sich die DNA in verschiedene Sequenzgruppen einteilen ließ. Als Unterscheidungskriterien wurden hier der GC-Gehalt und die Abdeckung der DNA-Fragmente benutzt. Die erhaltenen partiellen Genome erlaubten wesentliche Rückschlüsse auf die Stoffwechselfähigkeiten der Organismen. Aufgrund der vielen Aminosäure- und Zuckertransporter in den Genomen von Ferroplama Typ I und Typ III wurde auf einen heterotrophen Lebensstil dieser Archaeen geschlossen. Für die Stickstofffixierung in dem Biofilm scheint das Bakterium der Leptospirillium Gruppe III verantwortlich zu sein. Nur in diesem Genom konnte ein Operon mit Stickstofffixierungsgenen entdeckt werden. Zur $\mathrm{CO}_{2}$-Fixierung über den reduktiven Acetyl-CoA-Weg waren alle Organismen in der Lage. Weitere für diesen Standort erforderliche physiologische Eigenschaften konnten mit entsprechenden Genen belegt werden wie etwa die Säure- und Metalltoleranz.

Einen Standort mit wesentlich größerer Artenvielfalt untersuchten VENTER et al. (2004). Sie nahmen Proben aus der Sargasso Sea. Bei diesem Abschnitt des Atlantischen Ozeans mit nährstoff- und phosphatarmem Wasser in der Nähe der Bermuda-Inseln handelt es sich um einen intensiv untersuchten Bereich des Atlantischen Ozeans. Aus den 2 Millionen Sequenzläufen, die 1,6 Billionen bp umfassten, ließen sich sogenannte „Scaffolds“ rekonstruieren, bei denen es sich um zusammenhängende genetische Regionen handelt, die Lücken bestimmter Größe enthalten dürfen. Unter anderem ließen sich größere „Scaffolds“ zusammensetzen, die auf Sequenzbereiche von 10 Megaplasmiden und von verschiedenen Genomen wie z. B. dem eines unkultivierten Archaeons und dem eines SAR86-Klons zurückgeführt werden konnten. Insgesamt wurden ca. 1,2 Mio. Gene annotiert, von denen 794061 ohne bekannte Funktion sind. Ein wesentliches Erkenntnisse dieser Studie war das häufige Vorkommen von Genen, die vermutlich für Rhodopsine kodieren. Es konnten anhand der Ergebnisse verschiedene Klassen von Rhodopsinen eingeteilt werden. Die Kopplung mit phylogenetischen Markern lässt auf eine wesentlich weitere Verbreitung der Rhodopsine schließen, als bislang angenommen wurde. Entgegen der bisherigen Annahme, dass ausschließlich Bakterien für die Nitrifikation im Meer verantwortlich sind, konnte außerdem auf einem zu einem Archaeon gehörigen „Scaffold“ ein Gen für eine Ammonium-Monooxigenase gefunden werden. Die Ergebnisse des Sequenzierungsprojektes lassen auf eine errechnete Artenvielfalt von 1800 Arten in den 
gesammelten Proben schließen. Die Autoren gehen davon aus, dass mit einer 12-fachen Erhöhung des Sequenzieraufwandes eine 95 \%ige Abdeckung der gesamten Sequenzen aus den Proben möglich wäre. Dabei ist jedoch zum einen zu beachten, dass die Proben selbst nur einen kleinen Ausschnitt der wirklichen Diversität darstellen, da das Meerwasser filtriert wurde. Zum anderen werden Organismen, die sehr selten sind, auch bei einer solchen Erhöhung des Sequenzieraufwandes nicht alle erfasst. Die Studien von TYSON et al. (2004) und VENTER et al. (2004) verdeutlichen die Möglichkeiten des Erkenntnisgewinns durch Sequenzierung von metagenomischer DNA. Durch die physiologischen Eigenschaften von unkultivierten Organismen, die anhand der Metagenomsequenzierung erkannt werden können, kann eine spätere Kultivierung erleichtert werden.

Bei der zufälligen Sequenzierung von DNA aus Phagenpartikeln, die aus menschlichem Kot und einer marinen Probe gewonnenen wurden, sollte ein genereller Einblick in die virale Population gewonnen werden (BREITENBART et al., 2002; BREITENBART et al., 2003). Einen Einblick in die mikrobielle Gemeinschaft und deren physiologisches Potential sollte die „snapshot"-Genomsequenzanalyse eines Trinkwasserbiofilms gewähren. Die Sequenzierung von 2 Mbp Plasmid-DNA und 144 kb Cosmid-DNA und der anschließende Datenbankabgleich der erhaltenen Sequenzdaten ließ erkennen, dass die Biofilm-Gemeinschaft ein breites Spektrum komplexer Substanzen verwerten kann (SCHMEISSER et al., 2003).

Abgesehen von den 4 Cosmiden mit Trinkwasserbiofilm-DNA wurden in den vorgestellten Sequenzierungsprojekten aus der Tabelle 15 Inserts von Plasmiden mit Größen von unter $5 \mathrm{~kb}$ sequenziert. Sequenzbereiche wurden nur zufällig mehrfach abgedeckt, wobei es sehr unwahrscheinlich ist, dass erneut das gleiche DNA-Fragment sequenziert wurde. Nukleotidheterogenitäten aufgrund der Abdeckung von Sequenzbereichen mit Sequenzen unterschiedlichen Ursprungs wurden bewusst in Kauf genommen. Da selbst ähnliche Genome durch horizontalen Gentransfer, Insertionen, Deletionen und Rekombinationen voneinander abweichen können, besteht dabei die Gefahr der Bildung von „Scaffolds“ mit chimärer DNA. Diese Gefahr ist umso größer, je heterogener eine mikrobielle Gemeinschaft ist. In dieser Arbeit wurde eine andere Strategie verfolgt. Statt der Plasmide wurden Cosmide als Träger der Umwelt-DNA verwendet. Die Sequenzen der Inserts sollten qualitativ hochwertig sein. Deshalb wurde die Sequenzierung an das Vorgehen bei Genomsequenzierungsprojekten angelehnt. Es wurde eine Sequenzabdeckung von 4,5- bis 9,8-fach erreicht. Eine vollständige 
Rekonstruktion des Metagenoms des Leinesedimentes war damit nicht möglich und auch kein Ziel. Mit diesem Konzept ist es im Gegensatz zu den anderen Arbeiten möglich, Gene für komplexe Stoffwechselwege aus einem Organismus oder für Enzyme mit mehreren Untereinheiten $\mathrm{zu}$ identifizieren, detailliert $\mathrm{zu}$ betrachten und ihre Funktionalität zu überprüfen. Im Folgenden sollen Beispiele solcher Gen-Cluster, die auf den Leinesediment-Cosmiden identifiziert werden konnten, vorgestellt werden.

\subsubsection{Das Cosmid slc_1x}

Die aus den auf dem Cosmid lokalisierten Genen abgeleiteten Proteine zeigten große Ähnlichkeiten zu Proteinen, die in Clustern organisiert auch an unterschiedlichen Stellen in dem Genom von M. loti vorkommen. Im Rahmen der 16S rRNA-Genanalyse hatte keine Sequenz die größte Ähnlichkeit zu M. loti selbst. Die Sequenz s13265 war allerdings zu 97 \% mit der von M. tianshanense identisch. Dies ließ vermuten, dass es sich bei dem Insert dieses Cosmides tatsächlich um klonierte DNA eines Verwandten von $M$. loti handelt. Ebenfalls ist natürlich auch ein horizontaler Gentransfer denkbar. Allerdings erscheint dieser unwahrscheinlicher, da es sich nicht um einen zusammenhängenden Abschnitt des Genoms handelt. Die ORFs auf diesem Cosmid sind in Clustern mit unterschiedlichen Funktionen angeordnet. Aufgrund von Abweichungen von bekannten Genorganisationen bzw. neuer, bislang wenig untersuchter Stoffwechselwege, erschien eine genauere Untersuchung dieser Cluster bzw. der durch sie kodierten Proteine interessant.

\subsubsection{Das CO - Dehydrogenase-Gencluster}

CO-Dehydrogenasen kommen in aeroben und anaeroben Bakterien und in Archaeen vor. Sie katalysieren formal die reversible Reaktion (MOERSDORF et al., 1992):

$$
\mathrm{CO}+\mathrm{H}_{2} \mathrm{O} \leftrightarrow \mathrm{CO}_{2}+2 \mathrm{H}^{+}+2 \mathrm{e}^{-}
$$

Es gibt 2 strukturell unterschiedliche Formen. Die CO-Dehydrogenasen von anaeroben Bakterien und Archaeen enthalten Nickel und bestehen aus 2 identischen Untereinheiten. Aerobe, carboxydotrophe Bakterien besitzen CO-Dehydrogenasen, die aus 3 nicht-identischen Untereinheiten (CoxS, CoxM und CoxL) aufgebaut sind. Dabei steht S (,small“) für die kleine Untereinheit, M („medium“) für die mittlere und L 
(,large“) für die große Untereinheit. Sie enthalten FAD- und Molybdopterin-CytosinDinukleotid-Cofaktoren und 2 verschiedene [2Fe-2S]-Cluster (KANG und KIM, 1999). Die Sequenzen zeigen große Ähnlichkeiten mit verschiedenen eukaryotischen XanthinDehydrogenasen wie z. B. zu der von Drosophila melanogaster. Auch andere aus 3 Untereinheiten bestehende Molybdän-beinhaltenden Hydroxylasen wie z. B. die Nicotin-Dehydrogenase von Arthrobacter nicotinovorans, die Quinolin-2Oxidoreduktase von Pseudomonas putida und die 4-Hydroxybenzoyl-CoenzymAReduktase von Rhodopseudomonas palustris zeigen große Sequenzübereinstimmungen (KANG und KIM, 1999). Wie unter 3.4.1.10 gezeigt werden konnte, ist auf dem Cosmid slc_1x vermutlich eine CO-Dehydrogenase kodiert, die alle an der Bindung der CO-Faktoren beteiligten, konservierten Sequenzmotive besitzt. Die großen Übereinstimmungen der Aminosäuresequenz der mittleren Untereinheit mit der K3Region und das Fehlen der K5- und der N-Region lässt vermuten, dass die CoxMUntereinheit FAD aber kein NAD bindet (s. 3.4.1.10).

Durch Anreicherungen und Isolierung von CO-Oxidierern und durch Kultur-basierende Untersuchungen von Taxa, von denen angenommen wurde, dass sie CoxL-Gene enthielten, konnte nachgewiesen werden, dass die Verbreitung der Fähigkeit $\mathrm{CO}$ zu oxidieren unter aeroben Bakterien weiter verbreitet $\mathrm{zu}$ sein scheint als lange angenommen wurde. Auch Genom-Sequenzierungen geben Hinweise darauf, dass weitere Bakteriengruppen CO oxidieren können (KING, 2003). Zu den Organismen, bei denen von KING (2003) ausgehend von der Genomsequenz überprüft wurde, ob die CO-Dehydratase auch in vivo aktiv ist, gehört auch $M$. loti. Die Bildung des Enzyms wird meist von $\mathrm{CO}$ induziert und von organischen Komponenten repremiert. Es bestehen große Unterschiede bezüglich der CO-Toleranz. Viele carboxydotrophe Bakterien werden durch CO-Konzentrationen über $1 \%$ im Wachstum gehemmt (KING, 2003). Die CO-Dehydrogenasen von Hydrogenophaga pseudoflaga und Acinetobacter sp. Strain JC1 werden konstitutiv expremiert (KANG und KIM, 1999).

KING (2003) unterscheidet 2 verschiedene Gruppen von CO-Dehydrogenasen, die sich in der strukturellen Organisation der Gene der Untereinheiten und in der Aminosäuresequenz der zweiten Molybdopterin-Bindestelle der CoxL-Untereinheit unterscheiden. Die eine Gruppe (OMP) enthält CO-Dehydrogenasen, deren strukturelle CO-Dehydrogenase-Gene coxL, coxM und coxS die Reihenfolge MSL aufweisen und durch weitere accessoirische Gene eingerahmt werden. Zu dieser Gruppe gehört z. B. die CO-Dehydrogenase von Oligotropha carboxydovorans, deren 14,5 kb-langes cox- 
Gencluster die Gene coxBCMSLDEFGHIK umfasst (SANTIAGO et al., 1999). Die zweite Molybdopterin-Bindestelle der CoxL-Untereinheit dieser Gruppe trägt das Sequenzmotiv AYRCSFR (s. Abbildung 23). Die strukturellen Gene der anderen Gruppe (BMS) sind in der Reihenfolge MLS angeordnet. Das aktive Zentrum der CoxL-Untereinheit beinhaltet hier das Sequenz-Motiv AYRGAGR. Ein Beispiel für diese Gruppe ist die CO-Dehydrogenase von $R$. eutropha (Accession-Nummern ZP_00169403, ZP_00169404 und ZP_00169405).

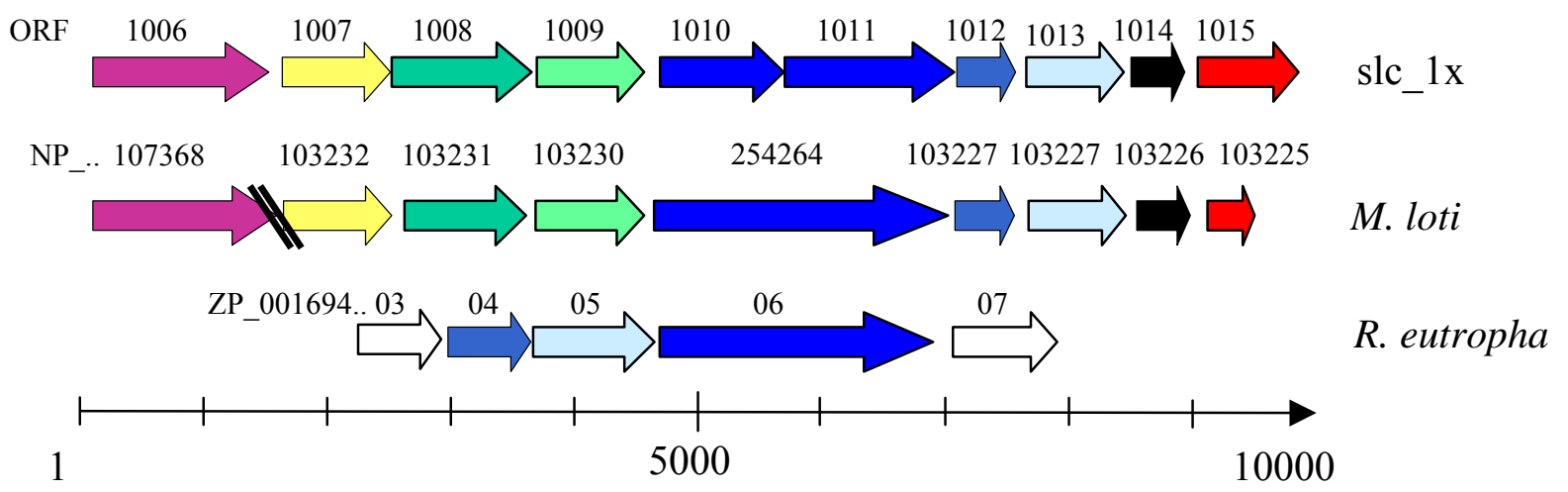

Abbildung 37: Genetische Organisation des CO-Dehydrogenase-Clusters bei M. loti, R. eutropha und dem Cosmid slc_1x

Berücksichtigt sind die ORFs von M. loti, zu deren Genprodukten die von den ORFs 1006 bis 1015 vom Cosmid slc_1x kodierten Proteine die größte Ähnlichkeit zeigen. Die Gene aus M. loti sind in der Abbildung mit ihrer Accession-Nummer benannt. Der ORF mit der Accession-Nummer NP_107368 ist an einer anderen Stelle im Genom lokalisiert. Außerdem sind die für eine aerobe CO-Dehydrogenase kodierenden Gene von Ralstonia eutropha dargestellt. Auch die Benennung der ORFs von R. eutropha erfolgte nach den entsprechenden Accession-Nummern.

Funktion der ORF-Genprodukte:
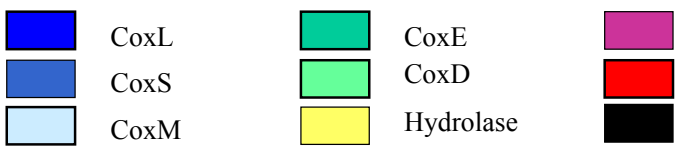

Alkohol-Dehydrogenase
Transkriptionsregulator
Konserviertes Protein

Keine Ähnlichkeit zu den Proteinen aus $M$. loti und dem Cosmid slc_1 $1 \mathrm{x}$

Von KING (2003) wird die CO-Dehydrogenase von M. loti in die zweite Gruppe eingeteilt. Ausgehend von der Genomsequenz von M. loti geht er davon aus, dass M. loti nur eine CO-Dehydrogenase besitzt. Die Proteine von M. loti, die Ähnlichkeit zu den von den cox-Genen des Cosmids kodierten Proteinen haben, sind trotz der relativ hohen Übereinstimmungen für die konservierten Domänen von CoxMSLDE nicht als Untereinheiten einer CO-Dehydrogenase annotiert, sondern als ,predicted dehydrogenase“, „hypothetical protein“ bzw. ,probable oxidoreductase“ (KANEKO et 
al, 2000; s. Tabelle 14). Die typische Reihenfolge der coxMSLDE-Gene (entsprechend der ORFs 1008 bis 1013) legt, abgesehen von der Unterbrechung des für die CoxLUntereinheit kodierenden Genes (ORF1010 und ORF1011) auf dem Cosmid, eine Annotation als strukturelle Gene einer CO-Dehydrogenase aber nicht nur für diesen Sequenzbereich von $M$. loti sondern auch für den des Cosmides slc_1x nahe (s. Abbildung 37). M. loti scheint also 2 CO-Dehydrogenasen zu besitzen. Die zweite Molybdopterin-Bindestelle der auf dem Cosmid kodierten CoxL-Untereinheit lautet AMRGFGV und ist auf dem ORF1011 kodiert. Damit ähnelt es eher dem der BMSGruppe (zu der auch die CO-Dehydrogenase von Ralstonia eutropha gehört, s. Abbildung 37), während die Anordnung der Gene der Untereinheiten auch durch die Erweiterung mit den Genen coxD und coxE der Anordnung der OMP-Gruppe entspricht. Eine eindeutige Zuordnung ist deshalb nicht möglich. Eine Zweiteilung der CoxL-Untereinheit ist ungewöhnlich. Sie wurde beim Sequenzabgleich nur noch einmal bei der Sequenz von Moorella thermoacetica ATCC 39073 (Accession-Nummern ZP_00329963.1 und ZP_00329964.1), einem Angehörigen der Clostridien, gefunden, deren vorderer und hinterer Teil zu $34 \%$ zu dem jeweils entsprechenden Teil der cosmidkodierten CO-Dehydrogenase identisch sind (ORF1010 und ORF1011). Die Unterbrechung der Aminosäuresequenz liegt in beiden Fällen an der gleichen Stelle. Hieraus kann man schließen, dass es sich bei dem Genprodukt der ORFs 1010 bis 1013 tatsächlich um ein funktionales Protein handelt, da das Vorkommen eines auf gleiche Weise defekten, aber gleichzeitig stark konservierten Proteins in zwei verwandtschaftlich weit entfernten Bakterien unwahrscheinlich ist.

\subsubsection{Das ugp - Gencluster}

Das Ugp-System (,uptake of glycerol phosphate“) ist ein typisches PeriplasmatischesBindeprotein-abhängiges Mehrkomponenten-Transportsystem, das spezifisch für die Aufnahme von sn-Glycerin-3-Phosphat und Glycerylphosphorylphosphodiester, die Diacylierungsprodukte von Phospholipiden, ist (ARGAST et al., 1978; SCHWEIZER et al., 1982). In E. coli ist das ugp-Operon bei Minute 76 der Chromosomkarte lokalisiert und umfasst die Gene ugpB, ugpA, ugpE, ugpC und ugpQ (OVERDUIN et al., 1988). Das ugpQ-Gen kodiert für ein Protein, das Glycerinphosphoryldiester hydrolysiert, die anderen ORFs für das Transportsystem selbst (KASAHARA et al., 1989; OVERDUIN et al., 1988). Dabei ist das ugpB-Genprodukt das periplasmatische Bindeprotein. UgpA und UgpE stellen die membranständigen Komponenten dar. UgpC liefert durch die 

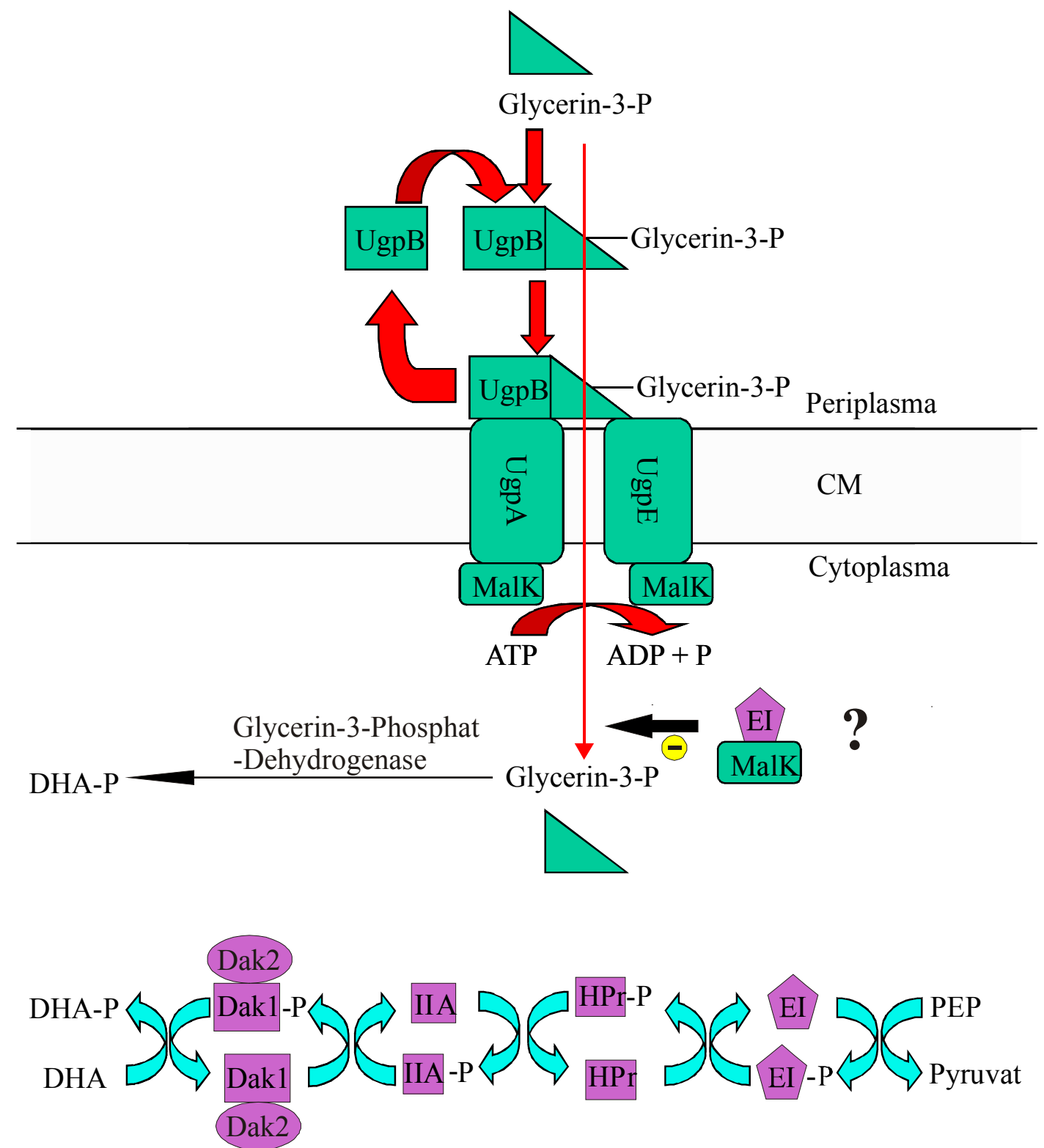

\section{Abbildung 38: Rekonstruktion der durch das ugp- und das dha-PTS-Cluster kodierten Prozesse}

Die Abbildung zeigt die möglichen Reaktionen und Anordnungen der auf dem Cosmid slc_1x durch die ORFs 1016 bis 1027 kodierten Proteine. In grün sind die Genprodukte der ORFs 1016 bis 1021 und in lila die Genprodukte der ORFs 1022 bis 1027 dargestellt. Alle durch farbige Kästen dargestellten Proteine sind auch auf dem Cosmid slc_1x kodiert.

Hydrolyse von ATP die für den Transport nötige Energie (OVERDUIN et al., 1988). Die Anordnung der Komponenten des Ugp-Systems ist in Abbildung 38 schematisch dargestellt. $\mathrm{Zu}$ allen Komponenten dieses ABC-Transport-Systems sind, wie unter 3.4.1.10 beschrieben, ähnliche Proteine auf dem Cosmid kodiert (ORFs 1016 bis 1021). Ob es sich bei den von den ORFs 1019 und 1020 um Homologe des MalK-Proteins des Maltose-Transporters oder um UgpC handelt ist aufgrund der großen Ähnlichkeit dieser 
Proteine und der Ersetzbarkeit des UgpC-Proteins durch MalK in E. coli nicht endgültig zu beantworten (HEKSTRA et al., 1993). Beide Proteine und auch die auf dem Cosmid kodierten ORFs tragen ATP-Bindestellen und das typische Sequenz-Motiv von ATPasen. Auf dem Cosmid ist kein Gen vorhanden, das Ähnlichkeit zu ugpQ zeigt.Das Ugp-System gehört in E. coli zum pho-Regulon, das durch Phosphatmangel induziert wird. Die Gene des pho-Regulons werden positiv durch den Transkriptions-Aktivator PhoB reguliert, der an sogenannte pho-Boxen bindet (MAKINO et al., 1988). Die Phosphat-Konzentration im Medium wird durch das Phosphatbindeprotein PstS bestimmt und das Signal über die vom pst-Operon kodierten Gene zu PhoR übertragen. Unter Phosphat-limitierenden Bedingungen aktiviert PhoR PhoB, indem es PhoB phosphoryliert (MAKINO et al., 1989). Bei hohen Phosphatkonzentrationen im Medium ist PhoB inaktiv und die Aufnahme von sn-Glycerin-3-Phosphat repremiert. SCHWEIZER et al. (1982) konnten zeigen, dass E. coli, wenn sn-Glycerin-3-Phosphat ausschließlich mit dem Ugp-System transportiert wird, das sn-Glycerin-3-Phosphat als einzige Phosphat-Quelle nicht aber als einzige C-Quelle nutzen kann. Dies kann laut XAVIER et al. (1995) dadurch begründet werden, dass sich bei dem Transport von snGlycerin-3-Phosphat mit dem Ugp-System das Phosphat durch den Umsatz des snGlycerin-3-Phosphats in der Zelle anreichert. Wird eine Grenzkonzentration von $13 \mathrm{mM}$ überschritten, wird Phosphat ins Medium sekretiert. Dadurch steigt die Phosphatkonzentration im Medium an, was letztlich zu einer Repression des phoRegulons führt. E. coli besitzt neben dem Ugp-System noch zwei weitere sn-Glycerin3-Phosphat-Aufnahmesysteme: Das GlpT- und das Uhp-System, das spezifisch für Hexose-Phosphate ist und nur in der Anwesenheit von Glukose-6-Phosphat induziert wird (LIN, 1987; KARDNER et al., 1993). Wird ausschließlich das GlpT-System zur sn-Glycerin-3-Phosphat-Aufnahme verwendet, kann sn-Glycerin-3-Phosphat sowohl als alleinige C- als auch -Phosphatquelle dienen. Bei dem sn-Glycerin-3-PhosphatTransport mit dem GlpT-System wird im Gegenzug entweder anorganisches Phosphat aus der Zelle oder Protonen in die Zelle transportiert (AMBUDKAR et al., 1986; ELVIN et al., 1985). Dies verhindert einen Anstieg der Phosphatkonzentration in der Zelle. Ist die Konzentration aufgrund der Aktivität des Ugp-Systems hoch, kann die Aufnahme von sn-Glycerin-3-Phosphat aufgrund des Antiport-Mechanismus durch das GlpT-System sogar stimuliert werden. Das Ugp-System muss in E. coli insgesamt also vor allem als Phosphat-Transport-System bei Phosphat-limitierenden Bedingungen betrachtet werden, während das GlpT-System dann aktiv ist, wenn sn-Glycerin-3- 
Phosphat als C-Quelle genutzt werden soll (XAVIER et al., 1995). Glycerin-3-Phosphat kann z. B. von Klebsiella pneumoniae aerob und anaerob zu Dihydroxyacetonphosphat oxidiert werden (JOHNSON et al., 1984).

\subsubsection{Das Dihydroxyaceton-Kinase-Cluster}

Dihydroxyaceton-Kinasen wandeln freies Dihydroxyaceton in DihydroxyacetonPhosphat um, das in die Glykolyse eingeschleust werden kann. In Bakterien entsteht Dihydroxyaceton bei der Aldol-Spaltung von Fruktose-6-Phosphat oder bei der Oxidation von Glycerin (NONOMURA et al., 1992; SCHURMANN und SPRENGER, 2001). Dihydroxyaceton-Kinasen nutzen unterschiedliche Phosphoryl-Donatoren. In Eukaryoten, die kein PTS besitzen, sind alle Dihydroxyaceton-Kinasen ATP-abhängig. In Bakterien sind die meisten dagegen PEP-abhängig. Eine der wenigen Ausnahmen stellt die Dihydroxyaceton-Kinase von Citrobacter freundii dar (SIEBOLD et al., 2003; DANIEL et al., 1995). Klebsillea pneumoniae besitzt beide Arten. Aufgrund der stark konservierten Aminosäure-Sequenz aller Dihydroxyaceton-Kinasen, kann angenommen werden, dass sie auf ein gemeinsames Vorläufer-Protein zurückgehen (SIEBOLD et al., 2003). Die auf dem Cosmid kodierten Untereinheiten Dak1 (ORF1027) und Dak2 (ORF1022) zeigen neben den Ähnlichkeiten zu DhaK und DhaL von E. coli auch Identitäten auf Aminosäure-Ebene von $33 \%$ bzw. $30 \%$ zu den entsprechenden Bereichen der Dihydroxyaceton-Kinase DhaK von C. freundii. In allen 3 Enzymen sind 3 Sequenzmotive, die an der Dihydroxyacetonbindung beteiligt sind, konserviert (s. 3.4.1.10). Die stärkere Ähnlichkeit zu dem Enzym aus E. coli ließ darauf schließen, dass auch die cosmidkodierte Dihydroxyaceton-Kinase PEP-abhängig ist. Auch die Organisation der Gene stimmt mit der von E. coli überein. Tatsächlich konnte eine PEPabhängige, nicht aber eine ATP-abhängige Aktivität im Rohextrakt von E. coli ECL707 mit dem Cosmid slc_1x nachgewiesen werden (s. 3.4.1.10.1). Durch das Einrahmen der PTS-Gene durch die Gene dak1 und dak2 ist eine gemeinsame Transkription der beiden Untereinheiten der Dihydroxyaceton-Kinase und damit verbunden auch eine CoTranskription der PTS-Gene vorstellbar.

Die PEP-abhängigen Dihydroxyaceton-Kinasen nutzen Komponenten des Phosphoenolpyruvat-Zucker-Phosphotransferasesystems (PTS) zur Übertragung des Phosphatrestes vom PEP auf das Dihydroxyaceton. Das PTS wird in Zellen meist dazu genutzt, die Zuckerkonzentration durch Phosphorylierung klein zu halten. Der Phosphotransfer vom Phosphoenolpyruvat (PEP) auf die Zucker erfolgt über eine 
Kaskade von 4 Proteinen, die an Histidin- oder Cystein-Resten phosphoryliert werden. Am Ende dieser Kaskade vom PEP ausgehend steht meistens ein Zucker-spezifischer Transportmechanismus, der für eine Transport-gekoppelte Phosphorylierung der Zucker sorgt. Das erste Enzym der Kaskade ist das aus 2 Domänen bestehende lösliche Protein EI (LICALSI et al., 1991). EI katalysiert den Phosphoryl-Transfer vom PEP auf das kleine HPr-Protein, das ebenfalls löslich ist. HPr selbst dient als Phosphoryl-Donor für die unterschiedlichen PTS-Transporter, die als Enzym II (EII) bezeichnet werden und aus 3 bis 4 Untereinheiten oder aus diesen ensprechenden Domänen eines Proteins bestehen (EIIA, EIIB, EIIC und EIID). Die Untereinheit EIIA empfängt den PhosphatRest vom HPr und gibt ihn an EIIB weiter. Dieses phosphoryliert schließlich den Zucker. EIIC und EIID sind membrandurchspannende Komponenten, die die Translokation des Zuckers durch die Membran ermöglichen (LENGELER et al., 1994; ROBILLIARD und BROOS, 1999; SAIER und REIZER, 1992). Die PEP-abhängige Dihydroxyaceton-Kinase von E. coli besteht aus 3 löslichen Proteinen: den Proteinen YcgT und YcgS (oder DhaK und DhaL), die den C- und N- terminalen Hälften der Dihydroxyaceton-Kinase von C. freundii ähneln, und $\mathrm{YcgC}$ oder DhaM, das ein Multiphosphoryl-Transfer-Protein ist (DANIEL et al., 1995; GUTKNECHT et al., 2001). DhaM besteht aus 3 Domänen. Die erste zeigt vor allem strukturelle Ähnlichkeit zu der EIIA-Komponente des Mannose-Transporters. Die zweite und dritte Domäne stellen die HPr- und EI-Komponente mit 29 \%iger bzw. 33 \%iger Sequenzidentität zu dem multiphosphoryl-Transfer-Protein MTP von Rhodobacter capsulatus dar (GUTKNECHT et al., 2001). Auch die PEP-abhängigen Dihydroxyaceton-Kinasen aus K. pneumoniae und Clostridium butyricum bestehen aus 3 Proteinen. Auf dem Cosmid slc_1x sind dagegen abweichend die PTS - Komponenten durch einzelne ORFs (ORFS 1023, 1024 und 1025) kodiert. Wie unter 3.4.1.10 beschrieben, fehlt der EIKomponente im Gegensatz zu DhaM von E. coli auch die C-terminale Domäne nicht, die für den Phosphoryltransfer zwischen PEP und dem Histidin der SHS-Gruppe des HPr verantwortlich ist. Es sind alle wichtigen Sequenzmotive vorhanden (s. 3.4.1.10). Das auf dem Cosmid und auch bei E. coli kodierte Dihydroxyaceton-spezifische Phosphotransferase-System weicht von dem Standardtyp des PTS durch das Fehlen des Transportmechanismus ab. Außerdem erfolgt die Phosphorylierung des Substrates Dihydroxyaceton nicht über die EIIB-Komponente, sondern über DhaK (SIEBOLD et al., 2003) bzw. voraussichtlich über Dak1. Beide Enzyme zeigen keine Ähnlichkeiten zu den membranständigen Komponenten von PTS-Systemen. Erstaunlich ist außerdem 
die geringe Ähnlichkeit des HPr zu der konservierten Domäne COG1925 dieser Enzymklasse, da es sonst, wie oben beschrieben, für den Phosphoryltransfer bei verschiedenen PTS-Systeme verantwortlich ist. Aufgrund der erforderlichen Wechselwirkung zu unterschiedlichen EII-Protein wäre eine stärkere Konservierung der Sequenz zu erwarten gewesen. Die geringe Ähnlichkeit zu anderen HPr-Proteinen kann ein Anhaltspunkt dafür sein, dass das HPr-Protein in diesem Cluster spezifisch für den Phosphoryltransfer der Kaskade zwischen dem PEP und dem Dihydroxyaceton ist. Das Enzym EIIA zeigt eine signifikante Ähnlichkeit zu der konservierten Proteindomäne COG3412, der bislang noch keine Funktion zugeordnet werden konnte, und außerdem eine geringere zu der für EIIA typischen Domäne pfam03610. Eine geringere Identität zu bekannten EIIA-Komponenten ist aufgrund der Wechselwirkungen mit den anderen Komponenten der Kaskade zu erwarten, da der Phosphoryltransfer auf das EIIA durch das recht stark vom Standard-Typ abweichende HPr erfolgt und der Phosphat-Rest nicht auf EIIB, sondern auf Dak1 übertragen wird.

$\mathrm{Ob}$ es sich bei dem ugp-Gen-Cluster und dem Dihydroxyaceton-Kinase-Cluster um ein Operon handelt, kann aufgrund des Fehlens von Promotorinformationen nicht entschieden werden. Die ORFs beider Cluster sind ausschließlich in eine Leserichtung kodiert. Es ist auch keine größere Unterbrechung in der Kodierung vorhanden. Über einen Sinn einer Co-Transkription lassen sich Vermutungen anstellen. Die Produkte beider Prozesse sind sehr ähnlich. Dihydroxyaceton-Phospat kann auf verschiedenen Wegen entstehen. Zum einen ist die Bildung des Dihydroxyaceton-Phosphates durch NAD-abhängige Oxidation von Glycerin und eine anschließende Phosphorylierung durch eine ATP-abhängige Kinase möglich. Zum anderen kann auch Glycerin-3Phosphat FAD-abhängig oxidiert werden. M. loti besitzt laut der Annotation der Genomsequenz 2 solcher Glycerin-3-Phosphat-Dehydrogenasen (KANEKO et al., 2000) Eine dritte Möglichkeit stellt die oben diskutierte Phosphorylierung von Dihydroxyaceton über ein PTS-System dar (JOHNSON et al., 1984). Es wird deutlich, dass die beiden benachbarten Gencluster Produkte liefern, die durch eine einzige Enzymreaktion in einander umgewandelt werden können. Dihydroxyaceton-Phosphat wird vermutlich in die Glykolyse eingeschleust und kann damit als C - und Energie Quelle dienen. An dieser Stelle muss allerdings beachtet werden, dass das ugp-System eigentlich nicht zum Nutzen von Glycerin-3-Phosphat als C-Quelle Verwendung findet (s. oben). Da auf der Insertsequenz des Cosmides keine DNA-Motive gefunden wurden, die auf eine Regulation des Clusters hinweisen, kann über eine Regulation keine 
Aussage getroffen werden. Es bleibt unklar, ob dieses Cluster zu einem Äquivalent des Pho-Regulons gehört. Ebenso ist natürlich eine zufällige Anordnung der Cluster oder eine alternative Substrat-Nutzung möglich. Gerade die unterschiedlich großen Ähnlichkeiten der einzelnen Komponenten zu bereits bekannten kann ein Anzeichen dafür sein.

Häufig liegen in der unmittelbaren Nachbarschaft des katalytischen dak(dha)-Operons regulatorische Elemente. C. freundii und K. pneumoniae haben das Regulatorprotein DhaR (DANIEL et al., 1995; SUN et al., 2003). Ebenso sind DhaK-ähnliche Proteine als potentielle Transkriptionsregulatoren bekannt (SIEBOLD et al., 2003). Auf dem Cosmid slc_1x ist weder ein DhaK-Paralog noch DhaR kodiert, die eine regulatorische Funktion übernehmen könnten. In C. perfringens und C. butyricum sind 2Komponenten-Signal-Transduktionssyteme vorhanden, deren „Response-regulator“Proteine am C-Terminus ein AraC-Helix-Turn-Helix-Motiv aufweisen (SIEBOLD et al., 2003). Der vor dem ugp-Gencluster lokalisierte ORF1015 kodiert für ein Protein, das eine Helix-Turn-Helix-Struktur aufweist, die mit einem e-Value von $1 \mathrm{e}^{-18}$ mit der in AraC-Typ DNA-bindenden Proteinen übereinstimmt. Es handelt sich recht wahrscheinlich um einen Transkriptionsregulator. Falls er eine regulatorische Funktion hat, muss diese nicht zwangsläufig mit dem ugp- bzw. Dihydroxyaceton-KinaseGencluster verknüpft sein. Dem davor liegenden ORF1014 konnte keine Funktion zugewiesen werden. Dass es sich bei diesem ORF um ein Sensorprotein handelt ist aufgrund der Konserviertheit dieser Proteine sehr fraglich. Die Leserichtung beider ORFs ist im Verhältnis zu dem ugp-Cluster entgegengesetzt.

Eine weitere Regulation ist auch zwischen dem EIIA und dem MalK vorstellbar. MalK dient als Target für EIIA ${ }^{\text {Glc }}$ im Zuge der ,inducer exclusion“ (HEKSTRA und TOMMASSEN, 1993). Unphosphoryliertes EIIA bindet an MalK und inhibiert damit den Bindeprotein-abhängigen Transport. In Anwesenheit von Dihydroxyaceton liegen die Komponenten des PTS eher unphosphoryliert vor, da das Phosphat letztlich auf das Dihydroxyaceton übertragen wird. Das Dihydroxyaceton-Phosphat wird in die Glykolyse eingeschleust. Eine energieverbrauchende Aufnahme von Glycerin-3Phosphat über das ugp-System ist zur Energiegewinnung für die Zelle bei diesen Bedingungen nicht nötig. Das Aufnahmesystem wird durch Interaktion von EIIA und MalK inhibiert. 


\subsubsection{Aminosäurestoffwechsel}

$9 \%$ der annotierten ORFs hatten eine Funktion im Aminosäure-Transport und -Metabolismus. Zu ihnen wurden auch die ORFs gezählt, bei denen es sich vermutlich um Proteasen oder Peptidasen handelte. Wie unter 3.5.1.2 beschrieben, konnte jedoch mit Skim-Milk-Agar keine Protease-Aktivität festgestellt werden. Bei diesem Plattentest wird auf sekretierte Proteasen, die die in der Trockenmilch enthaltenden Peptide umsetzen können, getestet. Das bedeutet, dass Proteasen, die generell nicht sekretiert werden oder aber nicht von dem Wirt sekretiert werden können, ebenso wie Proteasen, die Skim-Milk nicht als Substrat verwerten können, nicht detektiert werden. Andere Beispiele für ORFs, die eine Rolle im Aminosäure-Metabolismus haben, sind z. B. die auf dem Cosmid slc_2g kodierten 2 Threonin-Dehydratasen (ORF1109 und ORF1116) und die 2 Glutamin-Synthetasen (ORF1113 und ORF1118).

Die ORFs 128 und 129 des Cosmids slc_1a stellen vermutlich einen ABC-Transporter für Glycin-Betain dar. Im Zuge des Abbaus der nicht-proteinogenen Aminosäure Betain entsteht Sarcosin. Durch die oxidative Demethylierung von Sarcosin in Anwesenheit von Sauerstoff und Tetrahydrofolat durch Sarcosin-Oxidasen entstehen Glycerin, Wasserstoffperoxid und 5,10- $\mathrm{CH}_{2}$-Tetrahydrofolat. Sarcosin-Oxidasen können in 2 Gruppen unterteilt werden. Bei der einen handelt es sich um monomere Enzyme, bei den anderen um Enzyme, die aus 4 verschiedenen Untereinheiten bestehen (CHLUMSKY et al., 1995). Die ORFs 119 bis 123 des Cosmids slc_1a kodieren vermutlich für eine Sarcosin-Oxidase der zweiten Gruppe. In der $\alpha$-Untereinheit befindet sich vermutlich aufgrund der schlechten Sequenzqualität in diesem Bereich ein „frame-shift“. Sowohl das Genprodukt des ORF 120 als auch das des ORF 121 sind deshalb als $\alpha$-Untereinheit annotiert. Eine erneute Sequenzierung muss hier folgen. Die ORFs 119, 122 und 123 kodieren führ die $\beta$-, $\gamma$ - und $\delta$-Untereinheiten der SarcosinOxidase.

Ein weiteres Cluster, das in den Aminosäure-Stoffwechsel integriert ist, stellen die ORFs 824 bis 830 des Cosmids slc_1t dar. Diese ORFs kodieren für Enzyme, die am Abbau von Tyrosin über den Homogentisat-Weg letztlich zu Fumarat und Acetoacetat beteiligt sind. Der Abbau erfolgt in den in Abbildung 39 dargestellten Schritten. In der gleichen Leserichtung folgen die ORFs 832 bis 834, die für Enzyme kodieren, die den Abbau kurzkettiger Fettsäuren katalysieren (s. Abbildung 19). Der ersten Schritt des

Tyrosin-Abbaus, beinhaltet die Deaminierung von L-Tyrosin zu 4- 
Hydroxyphenylpyruvat. Auf dem Cosmid konnte kein ORF gefunden werden, der für eine solche Aktivität kodieren könnte. Allerdings sind in dem Cluster auch ORFs enthalten wie der ORF 823, die nur als hypothetische ORFs annotiert werden konnten. Aufgrund der Anordnung in diesem Cluster ist es wahrscheinlich, dass auch diese ORFs eine Funktion beim Tyrosinabbau erfüllen. Der zweite Schritt, die Decarboxylierung des 4-Hydroxyphenylpyruvats zu Homogentisat, wird durch die 4-Hydroxyphenylpyruvat-Dioxygenase (ORF824) katalysiert. Das Homogentisat wird durch eine Homogentisat-1,2-Dioxygenase (ORF827) zu 4-Maleylacetoacetat oxidiert, das durch eine Maleylacetoacetat-Isomerase (ORF826) in 4- Fumaryl- acetoacetat überführt werden kann. Den letzten Schritt des Tyrosin-Abbaus im engeren Sinn stellt die Hydrolyse des 4-Fumarylacetoacetats in Acetoacetat und Fumarat durch eine Fumarylacetoacetase (ORF830) dar. Das in diesem Schritt entstandene Acetoacetat kann zu Acetyl-CoA abgebaut werden, das dann in den Citrat-Zyklus eingeschleust werden kann. Bei E. coli wird die erste Reaktion, die Übertragung des CoA-Restes von Acetyl-CoA auf Acetoacetat, von der Acetoacetyl-CoA-Transferase, katalysiert.
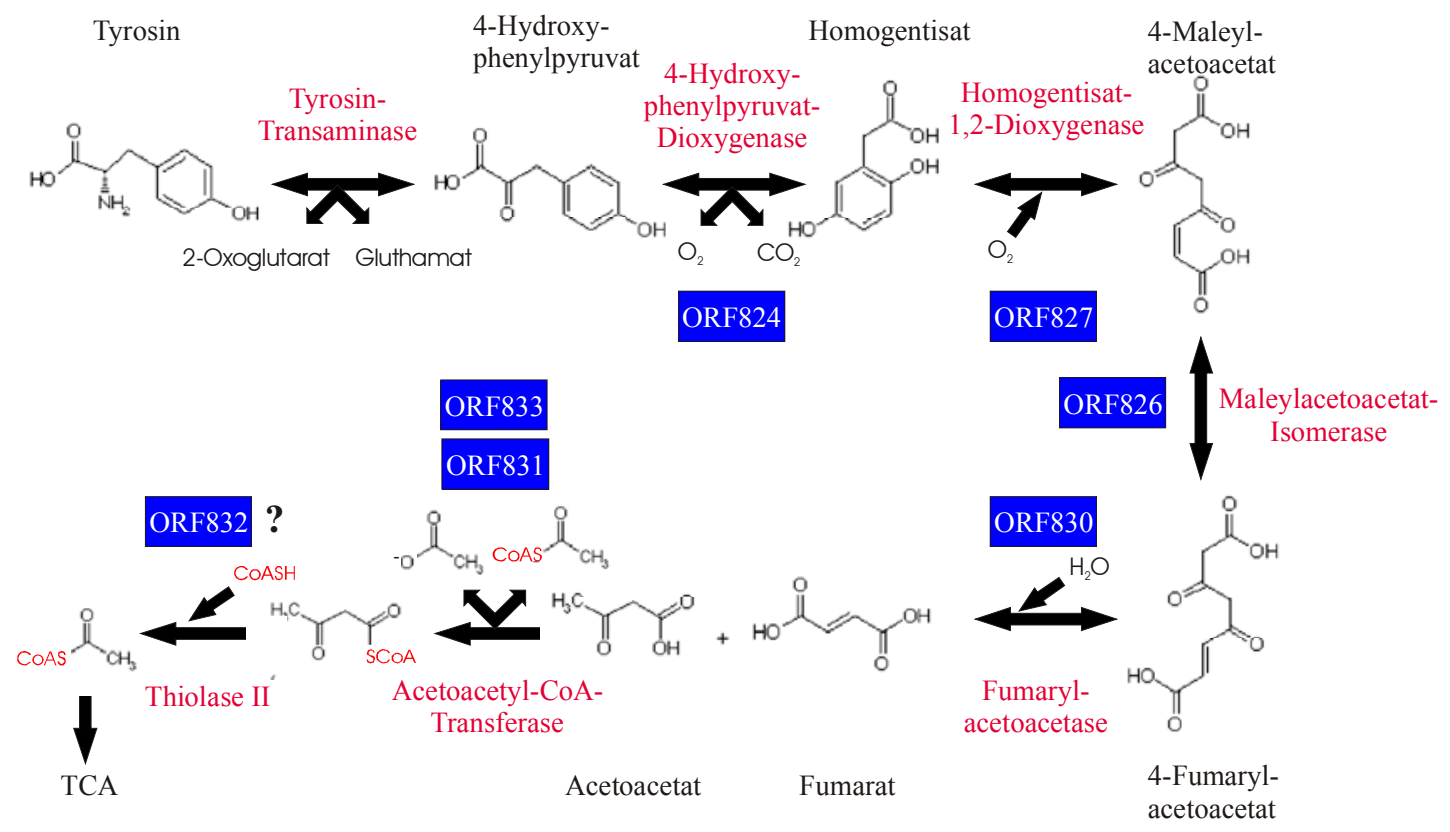

Abbildung 39: Aerober Tyrosin-Abbau über den Homogentisat-Weg

Dieses Enzym ist ein Tetramer und besteht aus je zwei Untereinheiten aus AtoA und AtoD (JENKINS und NUNN, 1987). Zu diesen Proteinen aus Rhodobacter sphaeroides zeigen die ORFs 832 und 834 große Identitäten (s. 3.4.1.8). Der anschließende Schritt, die Spaltung des Acetoacetyl-CoA zu Acetyl-CoA, wird bei E. coli von der Thiolase II, 
dem AtoB-Protein, katalysiert. Dieses ist ein Homotetramer (JENKINS und NUNN, 1987). $\mathrm{Zu}$ AtoB konnte auf dem Cosmid kein ORF gefunden werden, der für ein dazu ähnliches Protein kodiert.

Bei $R$. sphaeroides liegen die beiden Gene für AtoA und AtoD direkt hintereinander. In E. coli weicht die genetische Organisation etwas ab. Die Gene atoA, atoB und atoD sind in einem Operon organisiert und liegen in der Reihenfolge atoDAB vor. Vor diesem Operon liegt das Gen des Aktivators atoC. Auf dem Cosmid slc_1t werden die ORFs 832 und 834 durch den ORF333 getrennt. Dieser wurde als ein PhospholipidBindeprotein annotiert. Möglicherweise erfüllt er auch eine Funktion in diesem Weg. Die bislang untersuchten Gencluster wie das für die CO-Dehydrogenase, die auf dem Cosmid slc_1x kodiert ist, enthielten überwiegend Gene mit größter Ähnlichkeit zu denen aus einem einzigen Organismus (bei der CO-Dehydrogenase zu M. loti). Im Gegensatz dazu ist das hier behandelte Cluster aus Genen zusammengesetzt, die zu 6 verschiedenen Organismen die größte Ähnlichkeit zeigten (s. Tabelle 14).

\subsection{Annotation und Funktionalität}

Ein wesentlicher Aspekt der Metagenomforschung muss neben der Sequenzierung auch die funktionale Überprüfung der Annotationen sein. Im letzten Kapitel wurde gezeigt, dass auf großen Fragmenten metagenomischer DNA größere funktional zusammenhängende Gencluster identifiziert werden können. Die Größen und die Anzahl der jeweils beteiligten Gene der hier vorgestellten Cluster sind in Tabelle 16 zusammengefasst. Außerdem konnte bei dem Dihydroxyaceton-Kinase-PTS-Gencluster gezeigt werden, dass auch durch heterologe Genexpression in E. coli Aktivitäten der von solchen Genclustern kodierten Enzyme nachgewiesen werden können. Damit wird zumindest ein erster Anhaltspunkt der Funktionalität gewonnen, wenngleich ein direkter Nachweis der Aktivität der einzelnen Proteine noch erfolgen muss. In anderen Fällen wie bei der CO-Dehydrogenase und auch bei den Tests auf Protease- und Oxidoreduktase-Aktivität wurde deutlich, dass häufiger eine Diskrepanz zwischen der Annotation und dem überprüften Phänotyp rekombinanter E. coli-Klone besteht. Dies kann zum einen dadurch erklärt werden, dass die Gene in E. coli nicht expremiert werden. Zum anderen können die verwendeten Testsysteme ungeeignet oder die Annotationen falsch sein. Gerade bei dem Test auf Oxidoreduktase- und ProteaseAktivität war vermutlich das Testsystem begrenzend. Die betroffenen ORFs waren z. T 
sehr generell annotiert, so dass die geringe Auswahl der in den Plattentests eingesetzten Substrate die Möglichkeit des Nachweises einer Aktivität stark einschränkte. Hier müssten weitere Substrate getestet werden. Bei dem Protease-Test war zusätzlich begrenzend, dass auf extrazelluläre Enzyme getestet wurde. Die Enzyme können allerdings nur aus der Zelle gelangen, wenn E. coli einen Transportmechanismus für sie besitzt und die Sekretionssignale erkennt oder wenn die Zellen lysieren. Hier kann es ein Nachteil sein, dass Cosmide in geringerer Kopienzahl in der Zelle vorkommen als Plasmide, da der Anteil des durch Lyse der Zellen freigesetzten Proteins zu gering für einen Nachweis sein könnte.

\section{Tabelle 16: Cosmidkodierte größere Gencluster}

\begin{tabular}{|c|c|c|c|c|}
\hline Cosmid & $\begin{array}{l}\text { Durch die ORFs } \\
\text { des Clusters } \\
\text { kodierte Funktion }\end{array}$ & $\begin{array}{c}\text { Sequenzlänge in } \\
\text { bp }\end{array}$ & $\begin{array}{l}\text { ORFs in dem } \\
\text { Bereich }\end{array}$ & $\begin{array}{c}\text { ORFs mit } \\
\text { Annotation } \\
\text { passend zur } \\
\text { Cluster-Funktion }\end{array}$ \\
\hline slc_1a & $\begin{array}{l}\text { Sarcosin-Oxidase } \\
\text { Aufnahme von } \\
\text { Glycin-Betain }\end{array}$ & $\begin{array}{l}4000 \\
3000\end{array}$ & 5 & 5 \\
\hline slc_1t & $\begin{array}{l}\text { Tyrosin-Abbau } \\
\text { Abbau von } \\
\text { kurzkettigen } \\
\text { Fettsäuren } \\
\text { Acetoacetat } \\
\end{array}$ & $\begin{array}{l}7000 \\
2000\end{array}$ & $\begin{array}{l}8 \\
3\end{array}$ & $\begin{array}{l}4 \\
2\end{array}$ \\
\hline \multirow[t]{4}{*}{ slc_1x } & CO-Dehydrogenase & 6000 & 6 & 6 \\
\hline & $\begin{array}{l}\text { Aufnahme von } \\
\text { Glycerin-Phosphat } \\
(\text { ugp })\end{array}$ & 5500 & 6 & 5 \\
\hline & $\begin{array}{l}\text { Dihydroxyaceton- } \\
\text { Kinase }\end{array}$ & 4500 & 6 & 5 \\
\hline & \begin{tabular}{|l|}
$\mathrm{N}_{2-}$ \\
Fixierungsregulation
\end{tabular} & 3500 & 5 & 5 \\
\hline
\end{tabular}

Ganz offensichtlich lag bei dem Enzymtest zur Messung der CO-DehydrogenaseAktivität ein experimentelles Problem vor. Für E. coli ist bislang keine CODehydrogenase beschrieben, so dass ein höherer Wert bei der Negativ-Kontrolle als bei dem Testansatz nicht erklärt werden kann. Zwei weitere grundsätzliche Probleme der heterologen Genexpression in E. coli werden am Beispiel der CO-Dehydrogenase deutlich. Um die Wahrscheinlichkeit zu erhöhen, dass die cox-Gene expremiert werden, kann eine erhöhte CO-Konzentration in der Gasphase eingesetzt werden. Diese kann allerdings für E. coli toxisch sein. D. h., E. coli ist als Wirt nicht für die Expression jedes Gens geeignet. Ebenso können die Stoffwechselprodukte für E. coli toxisch sein 
(DANIEL, 2004). Dieses auch bei anderen Durchmusterungssystemen relevante Problem kann durch die Wahl eines alternativen Wirtes oder durch den Einsatz von Vektoren, deren Kopienzahl regulierbar ist, umgangen werden (DANIEL, 2004; RIESENFELD et al., 2004). Das zweite grundsätzliche Problem bei der Wahl von E. coli als Wirt für eine heterologe Genexpression ist die Expression selbst. Aufgrund eines alternativen Promotor- und Codon-Gebrauchs auf der Umwelt-DNA kann eine Expression der Gene unterbleiben. Selbst bei einer erfolgten Expression ist eine Enzymaktivität keinesfalls garantiert. Es ist möglich, dass E. coli wichtige Cofaktoren für die zu messende Enzymaktivität fehlen. Auch hier ist der Einsatz alternativer Wirte wie Streptomyceten möglich. Außerdem sind Vektoren, die z. B. alternative tRNAs zur Verfügung stellen oder „Shuttle“-Vektoren, die eine Expression in beiden Wirten ermöglichen, erhältlich (DANIEL et al., 2004). Die hier vorgestellten Limitationen gelten bei auf Aktivität basierenden Durchmusterungsverfahren generell. Durch ein Sequenz-basiertes „Screening“ können zumindest im ersten Schritt auch die nicht expremierten Gene erfasst werden. Der wesentliche Nachteil ist allerdings, dass keine Enzyme mit neuartigen Sequenzen gefunden werden können (DANIEL, 2004). Auf die Möglichkeiten der Durchmusterung von Metagenom-Genbanken soll im Kapitel 4.3 näher eingegangen werden.

Die Erkenntnismöglichkeit durch breitangelegte Sequenzierprojekte von metagenomischer DNA wird begrenzt durch die Tatsache, dass einem Großteil der erhaltenen Sequenzdaten aufgrund fehlender Ähnlichkeit zu bekannten Sequenzen keine Funktionen zugeordnet werden kann. Im Fall des Sargasso Sea-Projektes waren dies immerhin fast $70 \%$ der erhaltenen ORFs (VENTER et al., 2004), in dieser Arbeit $44 \%$. $24 \%$ der ORFs der aus dem Trinkwasserbiofilm isolierten DNA hatten ebenfalls keine Proteine mit signifikater Ähnlichkeit in den Datenbanken (SCHMEISSER et al., 2003). Allerdings wurde hier mit einem ,e-Value“ von $1 \mathrm{e}^{-4}$ ein Grenzwert für signifikante Übereinstimmungen gewählt, der deutlich unter dem in dieser Arbeit gewählten mit $1 \mathrm{e}^{-10}$ liegt. Die Angaben sind also nur bedingt vergleichbar. Auch für den Trinkwasserbiofilm müssen im Vergleich deutlich höhere Werte angenommen werden. In Bezug auf spätere Expressionsversuche von ORFs aus unkultivierten Phyla, liefern aber auch hypothetische Proteine mit ihrem G+C-Gehalt, der „Codon-usage“, Promotorsequenzen und anderen Charakteristika wichtige Erkenntnisse (RIESENFELD et al., 2004). Die Anordnung von Genen mit unbekannter Funktion in funktionell zusammenhängenden Genclustern kann Anhaltspunkte auf eine mögliche Funktion 
geben wie beim ORF833, der zwischen den strukturellen Genen der zwei Untereinheiten der Acetoacetyl-CoA-Transferase lokalisiert ist. Diese Möglichkeit bietet vor allem die Sequenzierung größerer DNA-Fragmente wie in dieser Arbeit. Auch wenn Genbanken mit kleinen Inserts für die Identifikation einzelner Gene und für die experimentelle Überprüfung der von ihnen kodierten Proteine ausreichend sein können, so kann die Funktion von Enzymen mit mehreren Untereinheiten nur dann überprüft werden, wenn alle nötigen Untereinheiten vorhanden sind oder vom Wirt komplementiert werden können. Gleiches gilt für Enzyme, die in komplexe Stoffwechselwege integriert sind. Ein Vorteil bei der Erstellung von MetagenomGenbanken mit kleinen Inserts ist allerdings die Möglichkeit der Anwendung weniger schonender Methoden beim Zellaufschluss, die die DNA für die Klonierung in Cosmide, Fosmide oder BACs zu sehr beschädigen würden. Durch Methoden wie „Bead-beating“ kann auch die DNA weniger leicht aufschließbarer Zellen erhalten werden. Damit wird das Spektrum der klonierbaren metagenomischen DNA bei der Verwendung kleiner Inserts gegenüber der Verwendung großer Inserts deutlich erhöht (RIESENFELD et al., 2004). Allerdings wurde in den in Tabelle 15 aufgeführten Studien diese Möglichkeit nicht genutzt. Ein letzter Aspekt sei hier noch betrachtet: Selbst wenn es durch Verbesserungen der DNA-Isolierung, Klonierung und Expression möglich ist, die Funktionalität von Genen nachzuweisen, so kann trotzdem keine Aussage darüber gemacht werden, ob die Gene in einem Bakterium unter den spezifischen Umweltbedingungen an einem Standort überhaupt expremiert werden. Über die tatsächlich ablaufenden biochemischen Vorgänge an einem Standort kann die Sequenzierung allein nichts aussagen. Eine Möglichkeit auch hier Einblicke zu gewinnen, ist die Methode des ,stable isotope probing“. Bei dieser Methode werden ${ }^{13} \mathrm{C}$-Isotopen-markierte Substrate eingesetzt. Setzen die Mikroorganismen diese um, wird das ${ }^{13} \mathrm{C}$ in die DNA eingebaut. Die DNA der ,aktiven“ Organismen ist dann schwerer als die der anderen und kann durch Dichtegradienten-Zentrifugation von ihr getrennt werden. Die markierte DNA kann dann nach funktionalen und taxonomischen Markern durchsucht werden (WELLINGTON et al., 2003). Statt der DNA können auch RNA oder Phospholipid-Fettsäuren genutzt werden. Allerdings ist die Möglichkeit der phylogenetischen Analyse eingeschränkter. Starke Limitationen sind hier die großen Kosten und die notwendige Voraussetzung, dass die Organismen nur das markierte Substrat als Kohlenstoffquelle nutzen, da die Markierung sonst nicht ausreichend für die Auftrennung der DNA im Dichtegradienten ist. Längere Wachstumsphasen können 
durch Nutzung markierter Abbauprodukte durch andere Organismen führen zur Verfälschung des Ergebnisses. Aufgrund des schnelleren Umsatzes scheint die Untersuchung von rRNA geeigneter zu sein (WELLINGTON et al., 2003).

Wie aus den Ausführungen deutlich geworden ist, kann ein möglichst umfangreiches Verständnis dessen, welche Prozesse in einer mikrobiellen Gemeinschaft ablaufen, welche Wechselwirkungen bestehen und aus welchen Mikroorganismen die Gemeinschaft zusammengesetzt ist, nur durch die Kombination vieler Methoden erhalten werden. Dabei liefert die Sequenzierung von metagenomischer DNA wichtige Erkenntnisse. Der Einsatz großer DNA-Fragmente erlaubte es gößere zusammenhängende Gencluster zu identifizieren, deren Genprodukte auch in E. coli produziert wurden und in Enzymtests aktiv waren. Dies zeigt das hohe Potential, auch Gene für biotechnologisch einsetzbare Enzyme und Stoffwechselwege auf metagenomischer DNA zu finden, die auch in E. coli aktiv sind. Damit bietet die Metagenomik sowohl die Möglichkeit einer detaillierten Grundlagenforschung bakterieller Ökologie als auch die Chance der Entdeckung kommerziell produzierbarer Naturstoffe.

\subsection{Durchmusterung von Metagenom-Genbanken}

Die meisten Enzyme sind stark chemo-, regio- und enantiospezifisch. Aufgrund dieser Eigenschaften werden Enzyme z. B. in der pharmazeutischen Industrie zur Produktion chiraler Substanzen eingesetzt. Sie finden aber auch Verwendung in anderen Herstellungsverfahren, in denen die chemische Synthese nicht möglich oder zu kostspielig ist (GRAY et al., 2003). Neben den Enzymen sind auch andere Biomoleküle wie z. B. Antibiotika für die Industrie von großem Interesse. In der Vergangenheit stammten die Naturprodukte meist aus kultivierten Mikroorganismen. Da nur ein kleiner Teil der Organismen mit Standardkultivierungstechniken erfasst werden kann, führte die Suche nach biotechnologisch interessanten Enzymen auf diesem Weg in den letzten Jahren verstärkt zur wiederholten Entdeckung derselben Substanzen (DANIEL, 2004). Metagenom-Genbanken erschließen das vollständige genetische Potential eines Standortes. So werden auch unkultivierbare Mikroorganismen für eine wirtschaftliche Nutzung zugänglich (STREIT et al., 2004). Sie können, wie zuvor erwähnt, sowohl sequenzbasierend als auch aktivitätsbasierend durchmustert werden. Bei der sequenzabhängigen Durchmusterung ist es möglich, Oligonukleotide von konservierte 
Bereiche abzuleiten und diese in Polymerasekettenreaktionen mit der Umwelt-DNA einzusetzen. Dadurch konnten bereits ganze Gene oder Genfragmente amplifiziert werden, die funktional sind (KNIETSCH et al., 2003b; ROSADO et al., 1998; SEOW et al., 1997). Eine andere Anwendung ist die phylogenetische Untersuchung von Standorten durch die Amplifikation von 16S rRNA-Genen (HUGENHOLTZ et al., 1998). Diese Methode fand auch in dieser Arbeit Anwendung (s. 3.3). Außerdem ist es möglich, durch die PCR-Amplifikation von konservierten Bereichen bekannter Gene Sonden zu generieren, die in Hybridisierungsexperimenten mit Umwelt-DNA zum Nachweis neuer Gene bekannter Enzymklassen verwendet werden können. KNIETSCH et al. (2003b) konnten mit dieser Methode Gene für Glycerin- und Diol-Dehydratasen identifizieren. In dieser Arbeit wurden die vorhandenen Sequenzen nach Genen für biotechnologisch interessante Enzyme durchsucht. Anschließend wurden die Genprodukte, die als Dehydrogenasen oder Proteasen annotiert worden waren, auf Aktivität getestet (s. 3.5.1).

Durch solche sequenzabhängigen Durchmusterungsmethoden ist allerdings nur die Identifizierung solcher Gene möglich, die eine ausreichend große Ähnlichkeit zu bereits bekannten Genen aufweisen. Neuartige Enzymklassen mit derselben Funktion können mit einem solchen Vorgehen nicht gefunden werden (DANIEL, 2004). Diese Möglichkeit bietet das auf Aktivität basierende Screening. Voraussetzung sind hier nicht Kenntnisse über Sequenzen, sondern die Entwicklung geeigneter Screeningsysteme. Diese können sehr unterschiedlich sein. Der Nachweis der Aktivität kann durch die Komplementation von Negativmutanten, durch die Entstehung farbiger oder anfärbbarer Reaktionsprodukte (z. B. Nachweis von entstandenen Carbonylverbindungen s. 2.11.5) oder Wachstumsversuche mit Substraten, die vom Wirt nicht verwertet werden können, erfolgen (KNIETSCH et al., 2003a; KNIETSCH et al., 2003b; MAJERNIK et al., 2001). Da in den meisten Fällen sehr viele Klone durchmustert werden müssen, um einige wenige Enzyme mit der gewünschten Eigenschaft nachzuweisen, ist die Entwicklung von Hochdurchsatz-Systemen häufig unumgänglich (STREIT et al., 2004). Mit der auf Aktivität basierenden Durchmusterung konnten neuartige Enzyme verschiedener Enzymklassen, wie z. B. 4Hydroxybutyrat-Dehydrogenasen (HENNE et al., 1999) und Alkohol-Dehydrogenasen (KNIETSCH et al., 2003a), gefunden werden. Aber auch Lipasen, Amylasen und Antibiotika gehören in die Gruppe der Naturstoffe, nach denen mit Hilfe von Metagenomgenbanken intensiv gesucht wurde. Auch hier konnten funktionale Enzyme 
isoliert werden (BRADY et al., 2001; GILLESPIE et al., 2002; HENNE et al., 2000; RICHARDSON et al., 2002). Da für den industriellen Einsatz ganz bestimmte Eigenschaften wie z. B. Hitzestabilität, pH-Toleranz und natürlich eine hohe Aktivität gefordert werden, muss der Identifikation der Gene eine Charakterisierung der Genprodukte folgen. Scheint ein Einsatz lohnenswert, schließt sich an die Charakterisierung häufig noch eine Phase der Optimierung des Enzyms und/oder des Wirtstammes an (CHOTANI et al., 2000).

Für die kommerzielle Produktion wird meist E. coli als Wirtsorganismus verwendet. Dies hat verschiedene Nachteile (s. 4.2.3), aber auch den Vorteil, dass viele verschiedene genetische Werkzeuge vorhanden sind und die Fermentation auch im großen Maßstab erprobt ist. Damit kann viel Zeit für die Entwicklung geeigneter Produktionsverfahren gespart werden (DANIEL, 2004). Dies ist entscheidend, da meist die Entwicklungszeit für biotechnologische Verfahren deutlich länger als die chemischen Syntheseverfahren ist (GRAY et al., 2003).

Ein Beispiel für ein biotechnologisches Herstellungsverfahren ist die Synthese von Erythrit mit einer Mutante von Aureobasidium (ISHIZUKA et al., 1989). Auch eine chemische Synthese von Erythrit aus Dialdehyd-Stärke bei hohen Temperaturen in Anwesenheit von Nickel als Katalysator ist möglich, findet allerdings aufgrund der geringen Effizienz keine Verwendung (LEE et al., 2003; PFEIFER et al., 1960). Auch einige Bakterien und osmophile Hefen können Erythrit produzieren (RYU et al., 2000; VEIGA-DA-CUNHA et al., 1992). Meso-Erythrit oder D-erythro-Tetritol ist ein in der Natur weit verbreitetes Polyol. Es wird als Metabolit oder Speicherstoff in Seetang, Pilzen und Früchten gefunden. Erythrit kann als nicht-karyogener und kalorienarmer Süßstoff eingesetzt werden, der auch für Diabetiker geeignet ist (MUNRO et al., 1998).<smiles>OCC(O)C(O)CO</smiles>

\section{Abbildung 40: Strukturformel von meso-Erythrit}

Ein Oxidationsprodukt von Erythrit, L-Erythrulose, wird in der kosmetischen Industrie z. B. als Zusatz in Selbstbräunungsprodukten eingesetzt. In dieser Arbeit wurde 
versucht, ein Gen (ORF2) auf dem Plasmid (pEry1) zu identifizieren, welches E. coli die Fähigkeit zu Wachstum mit Erythrit als einziger C- und Energie-Quelle vermittelte. Dieses Plasmid war aus einer Durchmusterung von Genbanken auf eine solche Fähigkeit hin hervorgegangen.

Aufgrund bestehender Übereinstimmung von Sequenzbereichen mit Signaturen von 2Hydroxysäure-Dehydrogenasen wurde angenommen, dass das Genprodukt des ORF2 des Plasmides pEryl eine Erythrit-Dehydrogenase-Aktivität vermittelt. Eine wichtige Rolle dieses Gens für die Erythritverwertung des E. coli-Klons war angezeigt, da E. coli nach einer Deletion eines DNA-Fragmentes aus diesem ORF nicht mehr in der Lage war, Erythrit zu verwerten. Der direkte Nachweis, welches plasmidkodierte Genprodukt für die Oxidation des Erythrits verantwortlich ist, konnte jedoch nicht erbracht werden, da das durch eine Klonierung in einen Überexpressions-Vektor produzierte Protein unter den hier gewählten Testbedingungen keine Aktivität zeigte (s. 3.6.6). Die Deletion könnte auch eine negative Beeinflussung der Transkription der stromabwärts liegenden Gene hervorrufen. Falls eines dieser Gene für die Erythrit-Dehydrogenase kodieren sollte, wäre dann auch in diesem Fall kein Wachstum auf Erythrit zu beobachten. Auch die These, dass die ORFs 2 und 3 nicht durch das TGA-Codon unterbrochen sind, sondern dass dieses für Selenocystein kodiert, kann aufgrund der Ergebnisse nicht verworfen werden. Um einen Anhaltspunkt für die Größe des kodierenden ORFs zu bekommen, wurde die Molekularmasse des nativen Proteins in einer nativen Gardienten-PAGE bestimmt. Die dadurch ermittelte Molekularmasse von 94 kDa lässt darauf schließen, dass es sich um ein Homotrimer des ORF2-Genproduktes handeln könnte oder um ein Monomer des gemeinsamen Genproduktes von den ORFs 2 und 3. Oxidoreduktasen bestehen häufig aus einer geraden Anzahl von identischen Untereinheiten. Bei der Erythrose-Reduktase von Candida magnoliae und der NADabhängigen meso-Erythritol-Dehydrogenase von Gluconobacter frateurii CHM43 handelt es sich um Homodimere (LEE et al., 2003; MOONMANGMEE et al., 2002). Deshalb wäre das Vorliegen eines Homotrimeres ungewöhnlich. Allerdings ließ auch die genauere Untersuchung der auf das TGA-Codon folgenden Sequenz und der Vergleich mit der typischen Signalsequenz für den Einbau von Selenocystein in die Formiat-Dehydrogenase von E. coli (LIU et al., 1998), keine eindeutigen Schlüsse zu. Die Ausbildung von Sekundärstrukturen scheint möglich, allerdings fehlen wichtige Eigenschaften der E. coli-Selenocystein-Insertionssequenz (Daten nicht gezeigt). Da aber nicht bekannt ist, aus welchem Organismus die DNA des Inserts des Plasmides 
pEry1 stammt, ist auch nichts über Selenocystein-Insertionssequenzen aus diesem Organismus bekannt. Hier müssen für den direkten Nachweis, welches Genprodukt bzw. welche Genprodukte für die Verwertung des Erythrits verantwortlich sind, weitere Experimente folgen.

Neben der Molekularmasse konnten auch die Co-Faktor-Bedürfnisse des Enzyms zumindest mit dem Rohextrakt von E. coli JM109/pEry1 untersucht werden. Für Erythrit-Dehydrogenasen sind unterschiedliche Coenzym-Abhängigkeiten bekannt. So benötigt die Erythrose-Reduktase von Torula corallina NADP(H) für die Reduktion von Erythrose bzw. die Oxidation von Erythrit (LEE et al., 2003); Gluconobacter frateurii CHM43 wandelt Erythrit sowohl irreversibel durch eine membrangebundene PQQ- und $\mathrm{Ca}^{2+}$-abhängige Erythrit-Oxidase als auch durch eine reversible cytoplasmatische $\mathrm{NAD}(\mathrm{H})$-abhängige meso-Erythrit-Dehydrogenase zu L-Erythrulose um (MOONMANGEE et al., 2002). Die Erythrose-Reduktase von Candida magnoliae zeigt sogar eine ungewöhnliche duale Coenzym-Spezifität für NAD(H) und NADP(H) (LEE et al., 2003). Die auf dem Plasmid pEry1 kodierte Erythrit-DehydrogenaseAktivität war mit NAD, nicht aber mit NADP nachweisbar (s. 3.6.5). Weitere Messungen zur biochemischen Charakterisierung müssen mit der gereinigten ErythritDehydrogenase folgen. Dazu gehört auch die Identifikation des Reaktionsproduktes. Mögliche Produkte der Oxidation von Erythrit sind D-Erythrose wie z. B. bei Schizophyllum commune (BRAUN et al., 1969) oder L-Erythrulose wie z. B. bei Enterobacter aerogenes (GRIFFIN, 1992). Auch eine primäre Phosphorylierung zu DErythrit-1-Phosphat und eine anschließende Oxidation zu D-Erythrulose-1-Phosphat wie bei Brucella abortus (SPERRY und ROBERTSON, 1974) ist denkbar. Da ein Wachstum auf Erythrit die Fähigkeit von E. coli JM109 voraussetzt, das bei der Erythritumwandlung entstehende Reaktionsprodukt weiterverwerten zu können, wurde getestet, ob E. coli JM109 mit D-Erythrose oder L-Erythrulose wachsen kann. Dabei konnte mit beiden Substraten ein Wachstum beobachtet werden.

Bislang konnte mit E. coli JM109/pEry1-Rohextrakten mit den hier gewählten Testbedingungen eine Erythrit-Dehydrogenase-Aktivität gemessen werden. Ebenfalls im Rohextrakt wurde ein Enzym mit einer Erythrit-Dehydrogenase-Aktivität mit einer Molekularmasse von $94 \mathrm{kDa}$ nachgewiesen. Ob dieses Protein aus mehreren Untereinheiten besteht und wie es kodiert wird, konnte bislang nicht errmittelt werden. 


\subsection{Ausblick}

In dieser Arbeit konnte ein Einblick in die mikrobielle Zusammensetzung des Leinesedimentes gewonnen werden. Dabei zeigte sich, dass die bakterielle Diversität groß war. Es wurden nur sehr selten 16S rRNA-Gensequenzen doppelt erhalten. Somit muss davon ausgegangen werden, dass eine weitere Sequenzierung zu Sequenzen führen würde, die bislang noch nicht im Datensatz enthalten sind. Für eine fortgesetzte Sequenzierung sollte die 16S cDNA-Genbank erweitert werden. Dabei wäre es sinnvoll, andere Oligonukleotide zur Amplifikation der 16S rRNA-Gene heranzuziehen, da die bislang verwendeten eindeutig gezeigt haben, dass eine Spezifität für bestimmte Organismengruppen auch bei sogenannten „universellen“ 16S rRNA-GenOligonukleotiden vorhanden ist.

Die archaeelle Diversität war deutlich geringer als die bakterielle. Mit den eingesetzten Oligonukleotiden wurden fast ausschließlich sehr ähnliche Sequenzen aus hauptsächlich 2 Ordnungen amplifiziert. Auch hier könnte durch den Einsatz anderer Oligonukleotide getestet werden, ob weitere Archaeen-Gruppen nachgewiesen werden können. Vor allem sollten weitere gegen 16S rRNA-Gene von Crenarchaeoten gerichtete Oligonukleotide verwendet werden, da diese nicht im Leinesediment, wohl aber in anderen Süßwassersedimenten nachgewiesen werden konnten (MacGREGOR et al., 1997; SCHLEPER et al., 1996). Interessant wäre auch der Einsatz der Fluoreszenz-insitu-Hybridisierung (FISH), um die über die 16S rRNA-Genanalyse gewonnenen qualitativen Ergebnisse zu quantifizieren.

Die im Rahmen der Cosmid-Sequenzierung gewonnenen Ergebnisse lassen zwar erste Einblicke in die Physiologie der mikrobiellen Gemeinschaft zu, der Umfang der in dieser Arbeit generierten Sequenzdaten kann aber nur als ein erster kleiner Schritt bei der Erfassung des gesamten Potentials des Metagenoms der Leine angesehen werden. Um einen detaillierteren Einblick zu erhalten, müsste die Sequenzierung im großen Maßstab fortgesetzt werden. Hierbei wäre über einen Wechsel der Sequenzierungsstrategie nachzudenken. Um möglichst viele Informationen zu erhalten, sollten dann statt der Cosmid-Genbanken Genbanken mit kleinen Inserts wie bei der Sequenzierung des Metagenoms der Sargasso Sea verwendet werden (VENTER et al., 2004). Allerdings ist eine solche Strategie sehr kostspielig. Für die Suche nach weiteren Genclustern bietet sich allerdings eine weitere Sequenzierung von Cosmiden an. 
Insgesamt ist über den Einsatz anderer Methoden wie z. B. des „Stable isotope probings“ oder der FISH mit radioaktiv-markierten Substraten nachzudenken, wenn ein authentischer Einblick in die physiologischen Vorgänge im Leinesediment gewonnen werden soll. Nur so ist es möglich, detaillierte Erkenntnisse bezüglich der Interaktionen in der mikrobiellen Gemeinschaft und der dort stattfindenden Stoffwechselprozesse zu gewinnen.

In dieser Arbeit wurde begonnen, die erfolgten Annotationen der auf den Cosmiden kodierten Genprodukte experimentell zu bestätigen. Dies müsste weiter fortgesetzt werden. Besonders im Hinblick auf die als Oxidoreduktasen und Proteasen annotierten Proteine, die von biotechnologischem Interesse sein könnten, wäre das Austesten weiterer Substrate und Testbedingungen sinnvoll. Dies gilt auch für die potentielle CODehdrogenase, deren Untereinheiten von den ORFs 1010 bis 1013 des Cosmides slc_1x kodiert werden, da hier ein initialer Test ebenfalls kein Ergebnis brachte. Für den Nachweis von Funktionen der auf den Cosmiden kodierten Genprodukte könnten Subklonierungen der Gene oder Klonierungen in Expressionsvektoren hilfreich sein.

Die Experimente mit dem Plasmid pEry1 befinden sich erst in der Anfangsphase. Da kein direkter Nachweis erbracht werden konnte, welcher ORF für die ErythritDehydrogenase kodiert oder ob mehrere Genprodukte für die Aktivität verantwortlich sind, müssen weitere Klonierungen oder Subklonierungen des ORF2, aber eventuell auch der anderen ORFs erfolgen. Über den Einsatz alternativer Expressionsvektoren, die eine weniger starke Expression gewähren, muss nachgedacht werden. Auch die Testbedingungen im Enzymtest sind weiter zu prüfen. Ein weiterer Ansatzpunkt wäre der Verdau des aktiven Enzyms. Dieses könnte aus einer nativen Gradienten-PAGE gewonnen werden, da hier eine distinkte Bande über eine DehydrogenaseAktivitätsfärbung erhalten wurde. Über die Größe der über den Verdau erhaltenen Fragmente könnte durch den Vergleich mit den bestehenden Sequenzdaten der Nachweis erbracht werden, welches Genprodukt für die Aktivität verantwortlich ist. Das Protein muss gereinigt werden und es müssen Experimente zur biochemischen Charakterisierung folgen. 


\section{ZUSAMMENFASSUNG}

1. Zur Herstellung von Metagenombanken wurde eine Probe vom Leinesediment entnommen (Stockhausen, Niedersachsen). Die DNA wurde aus dieser Probe mit der Methode der direkten Lyse isoliert, gereinigt und partiell verdaut. Die dabei erhaltenen DNA-Fragmente wurden entweder in den Plasmidvektor pBluescript ${ }^{\circledR} \mathrm{II}$ SK + oder in den Cosmidvektor SuperCos 1 ligiert. Es wurden insgesamt 31800 verschiedene rekombinante Plasmide gewonnen. Die durchschnittliche Insertgröße der partiellen Genbanken reichte von 3,3 kb bis 6,1 kb. Damit konnten insgesamt $124 \mathrm{Mbp}$ UmweltDNA kloniert werden. Die resultierende Cosmid-Genbank enthielt 400 Klone, deren Insertgrößen zwischen $34 \mathrm{~kb}$ und $45 \mathrm{~kb}$ betrug. Dies entspricht ca. 15,2 Mbp klonierter DNA.

2. Zur phylogenetischen Analyse der mikrobiellen Gemeinschaft des Leinesedimentes wurde die isolierte DNA in PCR-Reaktionen mit Oligonukleotiden eingesetzt, die gegen archaeelle bzw. bakterielle 16S rRNA-Gene gerichtet waren. Die erhaltenen PCR-Produkte wurden kloniert und sequenziert. Es konnten 60 archaeelle und 147 bakterielle 16S rRNA-Gensequenzen generiert und anschließend in phylogenetische Stammbäume integriert werden.

3. Ein Vergleich der erhaltenen archaeellen 16S rRNA-Gensequenzen mit den Sequenzen der Datenbanken ergab, dass nur Sequenzen aus dem Phylum der Euryarchaeota gewonnen wurden. Fast alle Sequenzen haben die größte Identität zu Archaeen, die nur durch ihre $16 \mathrm{~S}$ rRNA-Gene in den Datenbanken repräsentiert sind. Fast alle 16S rRNA-Gensequenzen konnten in die Ordungen Methanosarcinales und Methanomicrobiales aus der Klasse der Methanomicrobia eingeordnet werden. Nur eine Sequenz zeigt die größte Ähnlichkeit zu einer Umweltsequenz, die in die Ordnung der Thermoplasmales (Klasse Thermoplasmata) gruppiert wurde. Die meisten 16S rRNAGensequenzen mit Ähnlichkeit zu den Methanosarcinales gehören vermutlich zu den Methanosaetaceae. 5 Leinesediment-Sequenzen (s13106, s13113, s13114, s13138, s13189) scheinen ein eigenes Cluster auf Familienniveau zu bilden, das nur Sequenzen aus dem Leinesediment enthält. Nur eine Sequenz gehört zu den Methanosarcinaceae. 
Die Sequenzen aus der Ordnung Methanomicrobales gehören alle in die MCUBourgese-Untergruppe.

4. Die bakteriellen 16S rRNA-Gensequenzen konnten 11 verschiedenen Phyla zugeordnet werden. Auch hier zeigen die meisten Sequenzen die größten Übereinstimmungen $\mathrm{zu}$ 16S rRNA-Genen aus unkultivierten Organismen. Es dominieren vor allem Sequenzen, deren nächst verwandte Sequenzen zu der Gruppe der Proteobakterien (49\%), zu der BCF-Gruppe (16\%), zu den Planctomycetes (10\%) oder zu den Acidobacteria (11\%) gezählt werden. Bei den 16S rRNA-Gensequenzen aus dem Leinesediment mit Ähnlichkeit zu Sequenzen der Proteobakterien dominieren vor allem die $\alpha$ - und die $\gamma$-Proteobakterien (18 \% bzw. $17 \%$ aller $16 \mathrm{~S}$ rRNAGensequenzen). Andere Phyla sind z. T. nur mit einer Sequenz vertreten. Es konnten verschiedene Cluster entdeckt werden, die nur Umweltsequenzen und Sequenzen aus dem Leinesediment enthielten. Eine Sequenz (s11394) zeigt eine 97 \%ige Identität zu der 16S rRNA-Gensequenz des unkultivierten Klons SM1G12, der in die KandidatDivision TM7 gruppiert ist.

5. Um einen Einblick in die genetische und physiologische Diversität des Leinesedimentes zu erhalten, wurden von 14 Cosmiden „Shotgun“-Genbanken erstellt. Die Sequenzierung von 9 Cosmiden ist abgeschlossen. 3 weitere weisen jeweils eine Sequenzlücke auf. 2 Cosmide bestehen noch aus mehr als 10 Contigs. Mit den Sequenzen der vollständig bzw. fast vollständig sequenzierten Cosmide wurde ein „ORF-Finding“ durchgeführt. Dabei stellte sich heraus, dass das Cosmid slc_1q eukaryotische DNA enthält. Auf den übrigen Cosmid-Inserts wurden 374 ORFs festgelegt. Diese wurden mit der NCBI-Datenbank verglichen. Dabei konnte 164 (ca. $44 \%$ ) Genprodukten der auf den Cosmiden kodierten ORFs aufgrund fehlender signifikanter Ähnlichkeiten keine Funktion zugewiesen werden. Sie wurden als hypothetische oder konservierte Proteine annotiert. Bei den abgeleiteten Aminosäuresequenzen der übrigen ORFs war eine Zuweisung einer Funktion möglich. Besonders häufig wurden den Genprodukten Funktionen im Kohlenhydrat- oder Aminosäuremetabolismus und -Transport zugewiesen (9 \% bzw. $10 \%$ ). 
6. Einige Cosmide (slc_1f, slc_1p, slc_1s, slc_1u, slc_2j) zeichneten sich durch sehr geringe Sequenzübereinstimmungen ihrer ORFs auf Aminosäureebene mit bekannten Proteinsequenzen aus. Andere trugen Cluster von Genen, die vermutlich für die verschiedenen Enzyme ganzer Stoffwechselwege oder die verschiedenen Untereinheiten eines Enzyms kodieren. Auf dem Cosmid slc_1t konnten ORFs identifiziert werden, die vermutlich für den Abbau von 3-Hydroxyphenylpyruvat bis zu Acetyl-CoA (ORFs 824 bis 834) kodieren. Das Cosmid slc_1a beinhaltet 5 ORFs, die vermutlich für die 4 Untereinheiten einer Sarcosin-Oxidase (ORFs 119 bis 123), und 2 ORFs, die für einen Glycin-Betain-Transporter (ORF128 und ORF129) kodieren.

7. Auf dem Insert des Cosmides slc_1x waren verschiedene Gencluster lokalisiert. Ähnliche Cluster wurden ebenfalls in der Genomsequenz von M. loti entdeckt. Ein solches Cluster stellen die ORFs 1010 bis 1013, die vermutlich für eine Kohlenmonoxid-Dehydrogenase kodieren, dar. Die abgeleiteten Aminosäuresequenzen dieser ORFs zeigten alle typischen Sequenzmotive von KohlenmonoxidDehydrogenasen von carboxidotrophen Bakterien. Erste Versuche, eine CODehydrogenase-Aktivität nachzuweisen, waren nicht erfolgreich. Des Weiteren kodieren die ORFs 1016 bis 1021 vermutlich für einen Glycerin-3-Phosphattransportierenden ABC-Transporter. Diese ORFs liegen in der gleichen Leserichtung wie die ORFs 1022 bis 1027, deren Genprodukte große Ähnlichkeit zu den 2 Untereinheiten Dak1 und Dak2 von Dihydroxyaceton-Kinasen bzw. zu Komponenten des PTS-Systems zeigen. Mit einem photometrischen Enzymtest konnte eine PEPabhängige Dihydroxyaceton-Kinase-Aktivität im Rohextrakt von E. coli ECL707 mit dem Cosmid slc_1x nachgewiesen werden.

8. Aus einer Durchmusterung von Boden-Metagenombanken nach Genen, die E. coli die Fähigkeit vermittelten, auf Erythrit als einziger C- und Energiequelle zu wachsen, ging ein Klon hervor, auf dessen Plasmid (pEry1) das Gen oder die Gene identifiziert werden sollten, die für die Ausprägung des Phänotyps verantwortlich waren. Zunächst wurde eine Wachstumskurve mit E. coli JM109/pEry1 in Mineralmedium mit Erythrit als einziger C- und Energiequelle erstellt. Die Verdopplungszeit betrug 8,5 h. Im Rohextrakt von E. coli JM109 mit pEry1 konnte mit NAD eine spezifische Aktivität von 0,049 U/mg Enzym gemessen werden. Mit NADP 
war das Enzym nicht aktiv. Nach einer nativen Gradienten-PAGE konnte ein aktives Enzym mit einer Molekülmasse von ca. $94 \mathrm{kDa}$ über eine Erythrit-DehydrogenaseAktivitätsfärbung nachgewiesen werden.

9. Die Analyse des vollständig sequenzierten Inserts des Plasmides pEry1 ergab für das von ORF2 kodierte Protein eine Identität von 42 \% zu einer PhosphoglyceratDehydrogenase aus Burkholderia cepacia R18194. Es konnten außerdem 3 typische Sequenz-Signaturen von 2-Hydroxysäure-Dehyrogenasen mit nur minimalen Abweichungen identifiziert werden. Alle anderen Genprodukte der 5 auf dem Plasmid festgelegten ORFs zeigten keine signifikanten Ähnlichkeiten zu bekannten Proteinsequenzen. Die Funktion von ORF2 in der Erythritverwertung von E. coli/pEry1 war angezeigt, da nach Deletion dieses ORFs keine Erythritverwertung mehr nachgewiesen werden konnte.

10. Der ORF2 wurde in den pET101/D-TOPO-Vektor kloniert. Der His ${ }_{6}$-Tag konnte in einem Western-Blot nachgewiesen werden, jedoch hatte das Enzym unter den getesteten Bedingungen keine Erythrit-Dehydrogenase-Aktivität. Auch die Genprodukte anderer pET101/D-TOPO-Vektorkonstrukte, die eine Produktion des ORF2-Proteins ohne His $_{6}$-Tag bzw. mit dem Genprodukt des ORF3 zusammen erlaubten, zeigten keine solche Aktivität. 
ABREU, C., JURGENS, G., DE MARCO, P., SAANO, A. , BORDALO, A. A. (2001). Crenarchaeota and Euryarchaeota in temperate estuarine sediments. Journal of Applied Microbiology 90: 713-718.

AMANN, R. (2000): Who is out there? Microbial aspects of biodiversity. Systematic and applied Microbiology 23: 1-8.

AMANN, R. I. (2000). Methoden zur Bestimmung der in situ-Funktion von Mikroorgansimen. Biospektrum 4/2002: 274-277.

AMANN, R.I., LUDWIG, W., SCHLEIFER, K.-H. (1995). Phylogenetic identification and in situ detection of individual microbial cells without cultivation. Microbiol. Rev. 59: 143-169.

AMBUDKAR, S. V., LARSON, T. J., MALONEY, P. C. (1986). Reconstitution of sugar phosphate transport systems of Escherichia coli. J. Biol. Chem. 261 (20):9083-6.

ANDERSON, L. O., BORG, H., MIKAELSON, M. (1972). Molecular weight estimation of proteins by electrophoresis in polyacrylamide gel of graded porosity. FEBS Lett. 20: 199-202.

AOKI, M. A. Y., PASTORE, G. M., PARK, K. (1993). Microbial transformation of sucrose and glucose to erythritol. Biotechnol. Lett. 15: 383-388.

ARGAST, M. LUDTKE, D., SILHAVY, T. J., BOOS, W. (1978). A second transport system for sn-glycerol-3-phosphate in Escherichia coli. J. Bacteriol. 136: 1070-1083.

AVERHOFF B. (1988). Optimierung der Succinat- und Trimethylenglycol-Produktion durch Variation von Wachstumsparametern und Zugabe externer H-Donatoren. Dissertation, Göttingen.

BARNETT, M. J., FISHER, R. F., JONES, T., KOMP, C., ABOLA, A. P., BARLOY-HUBLER, F., BOWSER, L., CAPELA, D., GALIBERT, F., GOUZY, J., GURJAL, M., HONG, A., HUIZAR, L., HYMAN, R.W., KAHN, D., KAHN, M. L., KALMAN, S., KEATING, D. H., PALM, C., PECK, M. C., SURZYCKI, R., WELLS, D. H., YEH, K.-C., DAVIS, R. W., FEDERSPIEL, N. A., LONG, S. R. (2001). Nucleotide sequence and predicted functions of the entire Sinorhizobium meliloti pSymA megaplasmid. Proc. Natl. Acad. Sci. 98 (17): 9883-9888.

BARTON, L. L., TOMEI, F. A. (1995). Characteristics and activities of sulfatereducing bacteria. In: L. L. Barton (Hrsg.). Sulfate-reducing bacteria, S. 1-32. Plenum Press, New York, N.Y. 
BEJA, O., KOONIN, E. V., ARAVIND, L., TAYLOR, L. T., SEITZ, H., STEIN, J. L., BENSEN, D. C., FELDMAN, R. A., SWANSON, R. C., DELONG, E. F. (2002). Comparatative genomic analysis of archeal genotypic variants in a single population and in two different oceanic provinces. Appl. Environ. Microbiol. 68: 335-345.

BEJA, O., SPUDICH, E. N., SPUDICH, J. L., LECLERC, M., DeLONG, E. F. (2001). Proteorhodopsin phototrophy in the ocean. Nature 411 (6839): 786-9.

BEJA, O., SUZUKI, M. T., KOONIN, E. V., ARAVIND, L., HADD, A., NGUYEN, L. P., VILLACORTA, R., AMJADI, M., GARRIGUES, C., JOVANOVICH, S.B., FELDMAN, R.A, DELONG, E.F. (2000). Construction and analysis of bacterial artificial chromosome libraries from a marine microbial assemblage. Environ. Microbiol. 2: 516-529.

BERKENHEGER, I., FISCHER, U. (2004). Competition for polymers among heterotrophic bacteria, isolated from particles of the Equatorial Atlantic. International Microbiology 7: 13-18.

BILLAUX, M. S., FLOURIE, B., JACQUEMIM, C., MESSING, B. (1991). Sugar alcohols.. In S. MARIE und F. R. POGOLT (Hrsg.), Handbook of sweeteners, S. 72. Blackie Academic \& Professional, Glasgow, United Kingdom.

BOONE, D. R. WHITMAN, W. B., ROUVIERE, P. (1993). Diversity and taxonomy of methanogens. In: J. G. FERRY (Hrsg.). Methanogenesis: ecology, physiology, biochemistry and genetics, S. 35-80. Chapman and Hall, New-York, N.-Y..

BONFIELD, J. K., STADEN, R. (1996): Experiment files and their application during large-scale sequencing projects. DNA Sequence 6: 109-117.

BONFIELD, J. K., SMITH, K., STADEN, R. (1995): A new DNA sequence assembly program. Nucleic Acids Res. 24: 4992-4999.

BÖCKELMANN, U., MANZ, W., NEU, T. R., SZEWZYK, U. (2000). Characterization of the microbial community of lotic organic aggregates ('river snow') in the Elbe River of Germany by cultivation and molecular methods. FEMS Microbiology Ecology 33: 157-170.

BRADFORD, M. M. (1976). A rapid and sensitive method for the quantitation of microgram quantities of protein utilizing the principle of protein dye binding. Anal. Biochem. 72: 248-254.

BRADY, S. F., CHAO, C. J., HANDELSMAN, J., CLARDY, J. (2001). Cloning and heterologous expression of a natural product biosynthetic gene cluster from eDNA. Org. Let. 3: 1981-1984.

BRAUN, M. L. \& NIEDERPRUEM, D. J. (1969). Erythritol Metabolism in WildType and Mutant Strains of Schizophyllum commune. J. Bacteriol. 100: 625-634. 
BREITENBART, M., HEWSON, I., FELTS, B., MAHAFFY, J. M., NULTON, J. (2003). Metagenomic analysis of an uncultured viral community from human feces. J. Bacteriol. 185: 6220-23.

BREITENBART, M., SALAMON, P., ANDRESEN, B., MAHAFFY, J. M., SEGALL, A. M. (2002). Genomic analysis of uncultured marine viral communities. Proc. Natl. Acad. Sci. USA 99: 14250-55.

CAPONE, D. G., KIENE, R. P. (1988). Comparison of microbial dynamics in marin and freshwater sediments: contrasts in anaerobic carbon metabolism. Limnol. Oceanogr. 33: 725-749.

CÈBRON, A., BERTHE, T., GARNIER, J. (2003). Nitrification and nitrifying bacteria in the Lower Seine River and Estuary (France). Appl. Environ. Microbiol. 69: 7091-7100.

CHANDLER, D. P., FREDRICKSON, J. K., BROCKMAN, F. J. (1997) Effect of PCR template concentration on the composition and distribution of total community 16S rDNA clone libraries. Mol. Ecol. 6 (5): 475-82.

CHAPELLE, F. H. und LOVLEY, D. R. (1992). Competetive exclusion of sulfate reduction by $\mathrm{Fe}(\mathrm{III})$ reducing bacteria: a mechanism for producing discrete zones of high iron ground waters. Ground Water 30: 29-36.

CHASSY, B. M., MERCENIER, A., FLICKINGER, J. (1988). Transformation of bacteria by electroporation. TIBTECH 6: 303-309.

CHOTANI, G., DODGE, T., HSU, A., KUMAR, M., LADUCA, R., TRIMBUR, D., WEYLER, W. SAFORD, K. (2000). The commercial production of chemicals using pathway engineering. Biochim. Biophys. Acta 1543: 434-455.

CHLUMSKI, L. J., ZHANG, L., SCHUMAN-JORNS, M. (1995). Sequence analysis of sarcosine oxidase and nearby genes reveals homologies with key enzymes of folate one-carbon metabolism. J. Biol. Chem. 270 (31): 18252-9.

COEY, J. M. D., SCHINDLER, D. W., WEBER, F. (1974). Iron compounds in lake sediments. Can. J. Earth Sci. 11:1489-1493.

CONRAD, R. (1993). Anaerobic hydrogen metabolism in aquatic sediments. In: ADAMS, D. D., SEITZINGER, S. P., CCRILL, P. M. (Hrsg.). Cycling of reduced gases in the hydrospere, S. 15-24. Schweizerbart'sche Verlagsbuchhandlung, Deutschland.

CONWAY, T., SEWELL, G. W., OSMAN, Y. A., INGRAM, L. O. (1987). Cloning and sequencing of the alcohol dehydrogenase II gene from Zymomonas mobilis. J. Bacteriol. 169: 2591-2597.

COTTRELL, M. T., MOORE, J .A ., KIRCHMAN, D. L. (1999). Chitinases from uncultured marine microorganisms. Appl. Environ. Microbiol. 65 (6): 2553-7. 
COX, T. L., SLY, L. I. (1997). Phylogenetic relationships and uncertain taxonomy of Pedomicrobium species. Int. J. Syst. Bacteriol. 47 (2): 377-80.

COSTILOW R. N. (1981). Biophysical factors in growth. In: GERHARDT P., MURRAY G. E., COSTILOW N., NESTER E. W., WOOD W. A., KRIEG R., PHILIPS G. B. (Hrsg.). Manual of methods for general bacteriology, S. 66-78. American Society for Microbiology, Washington D.C., USA.

CRUMP, B. C., ARMBRUST, E. V., BAROSS, J. A. (1999). Phylogenetic analysis of particle-attached and free-living bacterial communities in the Columbia river, its estuary, and the adjacent coastal ocean. Appl. Environ. Microbiol. 65 (7): 3192-204.

CUMMINGS, D. E., MARCH, A. W., BOSTICK, B., SPING, S., CACCAVO, F., FENDORF, S., ROSENZWEIG, F. (2000). Evidence for microbial Fe(III) reduction in anoxic, mining-impaced lake sediments (Lake Coeur dÀlene, Idaho). Appl. Environ. Microbiol. 66: 154-162.

CURTIS, T. P., SLOAN, W. T., SCANNELL, J. W. (2002). Estimating prokaryotic diversity and its limits. Proc. Natl. Acad. Sci. U S A 99 (16): 10494-9.

DAHLLOF, I., BAILLIE, H., KJELLEBERG, S. (2000). rpoB-based microbial community analysis avoids limitations inherent in 16S rRNA gene intraspecies heterogeneity. Appl. Environ. Microbiol. 66 (8): 3376-80.

DANIEL, R. (2004). The soil metagenome - a rich resource for the discovery of novel natural products. Current Opinion In Biotechnology 15: 199-204.

DANIEL, R., STUERTZ, K., GOTTSCHALK, G. (1995). Biochemical and molecular characterization of the oxidative branch of glycerol utilization by Citrobacter freundii. J. Bacteriol. 177: 4392-4401.

DEES, P. M., GHIORSE, W. C. (2001). Microbial diversity in hot synthetic compost as revealed by PCR-amplified rRNA sequences from cultivated isolates and extracted DNA. FEMS Microbiol. Ecol. 35: 207-216.

DELONG, E.F. (1992). Archaea in coastal marine environments. Proc. Natl. Acad. Sci. USA 89: 5685-5689.

DeLONG, E. F., PRESTON, C. M., FELDMAN, R. A., WU, K. Y., SWANSON, R. V. (1998). Genomic analysis reveals chromosomal variation in natural populations in the uncultured psychrophilic archaeon Cenarchaeum symbiosum. J. Bacteriol. 180: 5003-5009.

DOOLITTLE, W. F. (1999). Phylogenetic classification and the universal tree. Science 284 (5423): 2124-9.

DOWER, W. J., MILLER, J. F., RAGSDALE, C. W. (1988). High efficiency transformation of E. coli by high voltage electroporation. Nucl. Acids Res. 16: 61276145. 
DREPPER, T., GROSS, S., YAKUNIN, A. F., HALLENBECK, P.C., MASEPOHL, B., KLIPP, W. (2003). Role of GlnB and GlnK in ammonium control of both nitrogenase systems in the phototrophic bacterium Rhodobacter capsulatus. Microbiology 149 (8): 2203-12.

ELVIN, C. M., HARDY, C. M., ROSENBERG, H. (1985). $\mathrm{P}_{\mathrm{i}}$ exchange mediated by the GlpT-dependent sn-glycerol-3-phosphate transport system in Escherichia coli. J. Bacteriol. 161: 1054-1058.

EVANS, G. A., LEWIS, K., ROTHENBERG, B. E. (1989). High efficiency vectors for cosmid microcloning and genomic analysis. Gene 79 (1): 9-20.

EWING, B., HILLIER, L., WENDL, M. C., GREEN, P. (1998): Base-calling automated sequencer traces using phred. I. Accuracy assessment. Genome Res. 8: 175185.

FALZ, Z. K., HOLLIGER, C., GROSSKOPF, R., LIESACK, W., NOZHEVNIKOVA, A. N., MULLER, B., WEHRLI. B., HAHN, D. (1999). Vertical distribution of methanogens in the anoxic sediment of Rotsee (Switzerland). Appl. Environ. Microbiol. 65 (6): 2402-8.

FENCHEL, T., FINLAY, B. J. (1991). Endosymbiotic methanogenic Bacteria in anaerobic ciliates: Significance for the growth efficiency of the host. J. Protozool. 38: $18-22$.

FENCHEL, T., FINLAY, B. J. (1992). Production of methane and hydrogen by anaerobic ciliates containing symbiotic methanogens. Arch. Microbiol. 157: 475-480.

FERIS, K. P., RAMSEY, P. W., FRAZAR, C., RILLIG, M. C., GANNON, J. E., HOLBEN, W. E. (2003). Structure and seasonal dynamics of hyporheic zone microbial communities in free-stone rivers of the western United States. Microb. Ecol. 46 (2): 200-15.

FISHER, R. F., LONG, S. R. (1992). Rhizobium--plant signal exchange. Nature 357 (6380): 655-60.

FULLER, R. C. (1978). Photosynthetic Carbon metabolism in green and purple bacteria. IN: CLAYTON, R. K., SISTROM, W. R. (Hrsg.), The Photosynthetic Bacteria. Editors Plenum Press, New-York and London.

FUHRMAN, J. A., MCCALLUM, K., DAVIS, A. A. (1992). Novel major archaebacterial group from marine plankton. Nature 356 (6365): 148-9.

GABRIEL, O. (1971). Analytical disc gel electrophoresis. Methods Enzymol. 22: 565578.

GALIBERT, F., FINAN,T. M., LONG,S. R., PUHLER, A., ABOLA, P., AMPE, F., BARLOY-HUBLER, F., BARNETT, M. J., BECKER, A., BOISTARD, P., BOTHE, G., BOUTRY, M., BOWSER, L., BUHRMESTER, J., CADIEU, E., CAPELA, D., CHAIN, P., COWIE, A., DAVIS, R. W., DREANO, S., Federspiel,N. 
A., FISHER, R. F., GLOUX, S., GODRIE, T., GOFFEAU, A., GOLDING, B., GOUZY, J.,GURJAL, M., HERNANDEZ-LUCAS, I., HONG, A., HUIZAR, L., HYMAN, R. W., JONES, T., KAHN, D., KAHN, M. L., KALMAN, S., KEATING, D. H., KISS, E., KOMP, C., LEAURE, V., MASUY, D., PALM, C., PECK, M.C., POHL,T. M., PORTELLE, D., PURNELLE, B., RAMSPERGER, U., SURZYCKI, R.,THEBAULT, P., VANDELBOL, M., VORHOLTER, F. J., WEIDNER, S., WELLS, D. H., WONG, K., YEH, K. C., BATUT, J. (2001). The composite genome of the legume symbiont Sinorhizobium meliloti. Science 293 (5530): 668-672.

GILLESPIE, D. E., BRADY, S. F., BETTERMANN, A. D., CIANCIOTTO, N. P., LILES, M. R., RONDON, M. R., CLARDY, J., GOODMAN, R. M., HANDELSMAN, J. (2002). Isolation of antibiotics turbomycin A and B from metagenomic library of soil microbial DNA. Appl. Environ. Microbiol. 68: 4301-4306.

GRAY, K. A., RICHARDSON, T. H., ROBERTSON, D. E., SWANSON, P. E., SUBRAMANIAN, M. V. (2003). Soil-based gene discovery: a new technology to accelerate and broaden biocatalytic applications. Adv. Appl. Microbiol. 52: 1-27.

GIOVANNONI, S. J., RAPPE, M. (2000). Evolution, diversity, and molecular ecology of marine prokaryotes.. In: D. L. KIRCHMAN (Hrsg.), Microbial ecology of the oceans, S. 47-84. Wiley-Liss, Inc., New-York, N.Y.

GIOVANNONI, S. J., BRITSCHGI, T. B., MOYER, C. L., FIELD, K. G. (1990). Genetic diversity in Saragosso Sea bacterioplankton. Nature 345: 60-63.

GLÖCKNER, F. O., ZAICHIKOV, E., BELKOVA, N., DENISSOVA, L., PERNTHALER, J., AMANN, R. (2000): Comparative 16S analysis of lake bacterioplancton reveals globally distributed phylogenetic clusters including an abundant group of actinobacteria. Appl. Environ. Microbiol. 66: 5053-5365.

GOODWIN, T. W. (1980). The biochemistry of carotenoids, vol. 1. Chapman \& Hall, New York, N.Y.

GRANT, S., SOROKIN, D. Y., GRANT, W. D., JONES, B. E., HEAPHY, S. (2004). A phylogenetic analysis of Wadi el Natrun soda lake cellulase enrichment cultures and identification of cellulase genes from these cultures. Extremophiles. In Druck.

GRIFFIN, B. W. 1992. Functional and structural relationships among aldose reductase, l-hexonate dehydrogenase (aldehyde reductase), and recently identified homologous proteins. Enzyme Microb. Technol. 14: 690-695.

GRIFFITHS, E., GUPTA, R. S. (2001). The use of signature sequences in different proteins to determine the relative branching order of bacterial divisions: evidence that Fibrobacter diverged at a similar time to Chlamydia and the Cytophaga-FlavobacteriumBacteroides division. Microbiology 147 (9): 2611-22.

GROSSKOPF, R., JANSSEN, P. H., LIESACK, W. (1998). Diversity and structure of the methanogenic community in anoxic rice pady soil microcosms as Examined by cultivation an direct 16S rRNA gene sequence retrieval. Appl. Environ. Microbiol. 64: 960-969. 
GUTKNECHT, R., BEUTLER, R., GARCIA-ALLES, L. F., BAUMANN, U., ERNI, B. (2001). The dihydroxyacetone kinase of Escherichia coli utilizes a phosphoprotein instead of ATP as phosphoryl donor. EMBO J. 20 (10): 2480-6.

HABLE, W. E., OISHI, K. K., SCHUMAKER, K. S. (1998).Viviparous-5 encodes phytoene desaturase, an enzyme essential for abscisic acid (ABA) accumulation and seed development in maize. Mol. Gen. Genet. 257 (2): 167-76.

HANAHAN, D. (1983). Studies on transformation of Escherichia coli with plasmid. J. Mol. Bol. 166: 557-580.

HANDELSMANN, J., RONDON, M. R., BRADY, S. F., CLARDY, J., GOODMAN, R. M. (1998). Molecular biological access to the chemistry of unknown soil microbes: a new frontier for natural products. Chem. \& Biol. 5: 245-249.

HANDELSMAN, J, WACKETT, L. P. (2002). Ecology and industrial microbiology: Microbial diversity - sustaining the Earth and industry. Curr. Opin. Microbiol. 5 (3): 237-9.

HEALY, F. G., RAY, R. M., ALDICH, A. C., WILKIE, L. O., INGRAM. L. O., SHANMUGAM, K. T. (1995). Direct isolation of functional genes encoding cellulases from the microbial consortia in thermophilic, anaerobic digester maintained on lignocellulose. Appl. Microbiol. Biotechnol. 43: 667-674.

HEKSTRA, D., TOMMASSEN, J. (1993). Functional exchangeability of the ABC proteins of the periplasmic binding protein-dependent transport systems Ugp and Mal of Escherichia coli J. Bacteriol. 175 (20): 6546-6552.

HILL, J. E., SEIPP, R. P., BETTS, M., HAWKINS, L., VAN KESSEL, A. G., CROSBY, W. L., HEMMINGSEN, S. M. (2002). Extensive profiling of a complex microbial community by high-throughput sequencing. Appl. Environ. Microbiol. 68 (6): 3055-66.

HIRSCHBERG, J., CHAMOVITZ, D. (1994) Carotenoids in Cyanobacteria. In: BRYANT, D. (Hrsg.), The Molecular Biology of Cyanobacteria, 55ff. Advances in Photosynthesis, 1 . Auflage.

KIM, Y. M., HEGEMAN, G. D. (1983). Oxidation of carbon monoxide by bacteria. Int. Rev. Cytol. 81: 1-32.

HARRIS, J. K, KELLEY, S. T., PACE, N. R. (2003). New perspective on uncultured bacterial phylogenetic division OP11. Appl. Environ. Microbiol. 70 (2): 845-9.

HEKSTRA, D., TOMMASSEN, J. (1993). Functional exchangeability of the ABC proteins of the periplasmic binding protein-dependent transport systems Ugp and Mal of Escherichia coli. J. Bacteriol. 175 (20): 6546-52.

HELLINGWERF, K. J., CRIELAARD, W., HOFF, W. D., MATTHIJS, H. C. P., MUR, L. R., van ROTTERDAM, B. J. (1994). Photobiology of Bacteria. Antonie van Leeuwenhoek. 65: 331-349. 
HENNE, A., DANIEL, R., SCHMITZ, R.A., GOTTSCHALK, G. (1999). Construction of environmental DNA libraries in Escherichia coli and screening for the presence of genes conferring utilization of 4-hydroxybutyrate. Appl. Evironm. Microbiol. 65: 3901-3907.

HENNE, A., SCHMITZ, R.A., BÖMEKE, M., GOTTSCHALK, G, DANIEL, R. (2000). Screening of environmental DNA libraries for the presence of genes conferring lipolytic activity on Escherichia coli. Appl. Evironm. Microbiol. 66: 3113-3116.

HIORNS, W. D., METHE, B. A., NIERZWICKI-BAUER, S. A., ZEHR, J. P. (1997). Bacterial diversity in Adirondack mountain lakes as revealed by $16 S$ rRNA gene sequences. Appl. Environ. Microbiol. 63 (7): 2957-60.

HIRSCHBERG, J., D. CHAMOVITZ. (1994). Carotenoids in cyanobacteria. In: D. A. Bryant (Hrsg.), The molecular biology of cyanobacteria, S. 559-579. Kluwer, Dordrecht, The Netherlands.

HOCHULI, E., BANNWARTH, W., DOBELI, H., GENTZ, R., STÜBER, D. (1988). Genetic approach to facilitate purification of recombinant proteins with a novel metal chelate adsorbent. Bio. Technology 6: 1321-1325.

HOLMES, D.S, QUIGLEY, M. (1981). A rapid boiling method for the preparation of bacterial plasmids. Anal. Biochem. 114: 193-197.

HOLT, J. G., KRIEG, N. R., SNEATH, P. H. A., STALEY, J. T., WILLIAMS, S. T. (1994). Bergey's manual of determinative bacteriology, 9. Auflage Williams \& Wilkins, Baltimore, Md.

HUGENHOLTZ, P., TYSON, G. W., WEBB, R. I., WAGNER, A. M., BLACKALL, L. L. (2001). Investigation of candidate division TM7, a recently recognized major lineage of the domain Bacteria with no known pure-culture representatives. Appl. Environ. Microbiol. 67: 411-419.

HUGENHOLTZ, P. (2002). Exploring prokaryotic diversity in the genomic era. Genome Biol. 2002;3(2):REVIEWS0003.

HUGENHOLTZ, P. und HUBER, T. (2003). Chimeric 16S rDNA sequences of diverse origin are accumulating in the public databases. International Journal of Systematic and Evolutionary Microbiology 53: 289-293.

HUGenholtz, P., GOEBEL, B. M., PACE, N. R. (1998). Impact of cultureindependent studies on the emerging phylogenetic view of bacterial diversity. J. Bacteriol. 180: 4765-4774.

HUGHES, R. K., DOYLE, W. A., CHOVNICK, A., WHITTLE, J. R., BURKE, J. F., BRAY, R. C. (1992). Use of rosy mutant strains of Drosophila melanogaster to probe the structure and function of xanthine dehydrogenase. Biochem. J. 285 (2): 50713. 
HUMMEL, W. (1997). New alcohol dehydrogenases for the synthesis of chiral compounds. Adv. Biochem. Eng. Biotechnol. 58: 145-184.

HUMMEL, W. (1999). Large-scale applications of NAD(P)-dependent oxidoreduktases: recent developments. TIBTECH 17: 487-492.

INOUE, H., NOJIMA, H., OKAYAMA, H. (1990). High efficiency transformation of Escherichia coli with plasmids. Gene 96: 23-28.

ISHIZUKA, H., WAKO, H., KASUMI, T. SASAKI, T. (1989). Breeding of a mutant of Aureobasidium sp. with high erythritol production. J. Ferment. Bioeng. 68: 310

ITOH,T., SUZUKI, K.-I., SANCHEZ, P. C., NAKASE, T. (2003). Caldispaera lagunensis gen. Nov., sp. nov., anovel thermoacidophilic renarchaeote isolated from a hot spring at Mt. Maquiling, Philippines. Intern. J. Syst. Evol. Microbiol. 53 (4): 114954.

JENKINS, L.S., NUNN, W.D. (1989). Genetic and molecular characterization of the genes involved in short-chain fatty acid degradation in Escherichia coli: the ato system. J. Bacteriol. 169 (1): 42-52.

JOBB, G., VON HAESELER, A., STRIMMER, K. (2004). TREEFINDER: A powerful graphical analysis environment for molecular phylogenetics. BMC Evolutionary Biology.

JOHNSON, E.A., BURKE, S.K., FORAGE, R.G., LIN, E.C.C. (1984). Purification and properties of dihydroxyacetone kinase from Klebsiella pneumoniae. J. Bacteriol. 160: $55-60$.

LEE, J.-K., KIM, S.-Y., RYU, Y.-W., SEO, J.-H., KIM, J.-H. (2003). Purification and Characterization of a Novel Erythrose Reductase from Candida magnoliae. Appl. Environ. Microbiol. 69 (7): 3710-3718.

JURGENS, G., GLÖCKNER, F., AMANN, R., SAANO, A., MONTONEN, L., LIKOLAMMI, M., MUNSTER, U. (2000). Identification of novel Archaea in bacterioplankton of a boreal forest lake by phylogenetic analysis and fluorescent in situ hybridization(1). FEMS Microbiol. Ecol. 34 (1): 45-56.

KAMINSKI, P. A., BATUT, J., BOISTARD, P. A. (1998). Survey of nitrogen fixation by rhizobia. In: PAINK, H. P., KONDOROSI, A., HOOYKAAS, P. J. J. (Hrsg.), The Rhizobiaceae, 431-460. Dordrecht: Kluwer Academic Publishers.

KANEKO, T., NAKAMURA, Y., SATO, S., ASAMIZU, E., KATO, T., SASAMOTO, S., WATANABE, A., IDESAWA, K., ISHIKAWA, A., KAWASHIMA, K., KIMURA,T., KISHIDA, Y., KIYOKAWA, C., KOHARA, M., MATSUMOTO, M., MATSUNO, A.,MOCHIZUKI, Y., NAKAYAMA, S., NAKAZAKI, N., SHIMPO, S., SUGIMOTO, M.,TAKEUCHI, C., YAMADA, M., TABATA, S. (2000). Complete genome structure of the nitrogen-fixing symbiotic bacterium Mesorhizobium loti. DNA Res. 7 (6): 331-338. 
KANG, B. S., KIM, Y. M. (1999). Cloning and molecular characterization of the genes for carbon monoxide dehydrogenase and localization of molybdopterin, flavin adenine dinucleotide, and iron-sulfur centers in the enzyme of Hydrogenophaga pseudoflava. J. Bacteriol. 181 (18): 5581-90.

KARDNER, R. J.,WEBBER, C. A., ISLAND, M. D. (1993). The family of organophosphate transport proteins includes a transmembrane regulatory protein. J. Bioenerg. Bioembr. 25: 637-645.

KASAHARA, M., MAKINO, K., AMEMURA, M., NAKATA, A. (1989) Nucleotide sequence of the ugpQ gene encoding glycerophosphoryl diester phosphodiesterase of Escherichia coli K-12. Nucleic Acids Res. 17: 2854.

KELLENBERGER, E. (2001). Exploring the unknown: the silent revolution of microbiology. EMBO Rep. 2: 5-7.

KIESSLING, M. MEYER, O. (1982). Profitable oxidation of carbon monoxide and hydrogen durin hetterotrophic growth of Pseudomonas carboxydoflava. FEMS Microbiol. Lett. 13: 333-338.

KIM, Y. M., HEGEMAN, G. D. (1983). Oxidation of carbon monoxide by bacteria. Int. Rev. Cytol. 81: 1-32.

KING, G. M. (2003). Molecular and culture-based analysis of aerobic carbon monoxide oxidizer diversity. Appl. Environ. Microbiol. 69: 7257-7265.

KLAPPENBACH, J. A., DUNBAR, J. M., SCHMIDT, T. M. (2000). rRNA operon copy number reflects ecological strategies of bacteria. Appl. Environ. Microbiol. 66 (4): 1328-33.

KNIETSCH, A., WASCHKOWITZ, T., BOWIEN, S., HENNE, A., DANIEL, R. (2003b). Identification and characterization of coenzyme $\mathrm{B}_{12}$-dependent glycerol dehydratase- and diol dehydratase-encoding genes from metagenomic DNA libraries derived from enrichment cultures. Appl. Environ. Microbiol. 69: 3048-3060.

KNIETSCH, A., BOWIEN, S., WHITED, G., GOTTSCHALK, G., DANIEL, R. (2003a). Construction and screening of metagenomic libraries derived from enrichment cultures: Generation of a gene bank for genes conferring alcohol oxidoreductase activity on Escherichia coli.. Appl. Environ. Microbiol. 69: 1408-1416.

KOLBEL-BOELKE, J., ANDERS, E.-M., NEHRKORN, A. (1998). Microbial communities in the saturated groundwater environment. II. Diversity of bacterial communities in a Pleistocene sand aquifer and their in vitro activities. Microb. Ecol. 16: $31-48$.

KOLGANOVA, T. V., KUZNETSOV, B. B., TOUROVA, T. T. (2002). Designing and testing oligonucleotide primers for amplification and sequencing of archaeal $16 \mathrm{~S}$ rRNA genes. Microbiology 71: 243-246.

KOH, E. - S., LEE, T. - H., LEE, D. - Y., KIM, H. - J., RYU, Y. - W., SEO, J. H. (2003). Scale-up of erythritol production by an osmophilic mutant of Candida 
magnoliae. Biotechnology Letters 25: 2103 - 2105.

KRAUT, M., HUGENDIECK, I., HERWIG, S., MEYER, O. (1989). Homology and distribution of CO dehydrogenase structural genes in carboxydotrophic bacteria. Arch. Microbiol. 152 (4): 335-41.

LARSEN, N., OLSEN, G. J., MAIDAK, B. L., MCCAUGHEY, M. J., OVERBEEK, R., MACKE, T. J., MARSH, T. L., WOESE, C. R. (1993). The ribosomal database project. Nucleic Acids Res. 21 (13): 3021-3.

LIU, Z., RECHES, M., GROISMAN, I., ENGELBERG-KULKA, H. (1998). The nature of the minimal 'selenocysteine insertion sequence' (SECIS) in Escherichia coli. Nucleic Acids Res. 26 (4): 896-902.

LEE, J. - K., KIM, S. - Y., RYU, Y. - W., SEO, J. - H., KIM, H. - J. (2003). Purification and Characterization of a Novel Erythrose Reductase from Candida magnoliae. Applied and Environmental Microbiology 69: 3710-3718.

LEE, J. - K., HONG, K. - W., KIM, S. - Y. (2003). Purification and Properties of a NADPH-Dependent Erythrose Reductase from the Newly Isolated Torula corallina. Biotechnol. Prog. 19: 495-500.

LENGELER, JW., JAHREIS, K., WEHMEIER, UF.. (1994). The nature of the minimal 'selenocysteine insertion sequence' (SECIS) in Escherichia coli. Nucleic Acids Res. 26 (4): 896-902.

LICALSI, C., CROCENZI, T. S., FREIRE, E., ROSEMAN, S. (1991). Sugar transport by the bacterial phosphotransferase system. Structural and thermodynamic domains of enzyme I of Salmonella typhimurium. J. Biol. Chem. 266: 19519-19527.

LIESACK, W., BAK, F., KREFT, J. U., STACKEBRANDT, E. (1991). Holophaga foetida gen. nov., sp. nov., a new, homoacetogenic bacterium degrading methoxylated aromatic compounds. J. Bacteriol. 174 (15): 5072-8.

LILES, M. R., MANSKE, B. F., BINTRIM, S. B., HANDELSMAN, J., GOODMAN, R. M. (2003). A census of rRNA genes and linked genomic sequences within a soil metagenomic library. Appl. Environ. Microbiol. 69 (5): 2684-91.

LIM, E. L., AMARAL, L. A., CARON, D. A., DeLONG, E. F. (1993). Application of rRNA-based probes for observing marine nanoplanktonic protists. Appl. Environ. Microbiol. 59 (5): 1647-55.

LIN, E. C. C. (1987). Dissimilatory pathways for sugar, polyols, and carboxylates. In Neidhardt, F. C., INGRAHAM, J. L., LOW, K. B., MAGASANIK, E., SCHAECHTER, M., UMBARGER, H. E. (Hrsg.), Escherichia coli and Salmonella typhimurium: Cellular and molecular biology, S. 244-284. American Society for Microbiology, Washington, D. C..

LORENZ, M. G., WACKERNAGEL, W. (1987). Adsorption of sand and variable degradation rates of adsorbed DNA. Appl. Environ. Microbiol. 53: 2948-2952. 
LOVLEY, D. R., GIOVANNONI, S. J., WHITE, D. C., CHSMPINE, J. E., PHILLIPS, E. J. P., GORBY, Y. A., GOODWIN, S. (1993). Geobacter metallireducens gen. nov. sp. nov., a microorganism capable of coupling the complete oxidation of organic compounds to the reduction of iron and other metals. Arch. Microbiol. 159: 336-344.

LOVLEY, D. R. (1991). Dissimilatory Fe(III) and Mn(IV) reduction . Microbiol. Rev. 55: 259-287.

LOVLEY, D. R., PHILLIPS, E. J. P. (1986). Competative mechanisms for inhibition of sulfate reduction and methane productionin the zone of ferrric ion reductionin sediments. Appl. Environ. Microbiol. 51: 2636-2641.

LOY, A., LEHNER, A., LEE, N., ADAMCZYK, J., MEIER, H., ERNST, J, SCHLEIFER, K.-H., WAGNER, M. (2002). Oligonukleotid microarray for 16 S rRNA gene-based detection of all recognized lineages of sulfate-redicing procaryotes in the environment. Appl. Environ. Microbiol. 68: 5064-5081.

MAJERNIK, A., GOTTSCHALK, G., DANIEL, R. (2001). Screening of environmental DNA libraries for the presence of genes conferring $\mathrm{Na}^{+}\left(\mathrm{Li}^{+}\right) / \mathrm{H}^{+}$ antiporter activity on Escherichia coli: characterization of the recovered genes and the corresponding gene products. J. Bacteriol. 183: 6645-6653.

MAKINO, K., SHINAGAVA, H., AMEMURA, M., KAWAMOTO, M., YAMADA, M., NAKATA, A. (1989). Signal transduction in the posphate regulon of Escherichia coli involves phosphotransfer between PhoR and PhoB proteins. J. Mol. Biol. 210: 551-559.

MAKINO, K., SHINAGAVA, H., AMEMURA, M., KIMURA, S., NAKATA, A., ISHIHAMA, A. (1988). Regulation of the phosphate regulon of Escherichia coli:activation of pstS transcription by PhoB protein in vitro. J. Mol. Biol. 203: 85-95.

MARGOLIS, J., KENRICK, K.G. (1967). Polyacrylamide gel electrophoresis across a molecular sieve gradient. Nature 214: 1334-1336.

MacGREGOR, B., MOSER, D. P., ALM, E. W., NIELSON, K. H., STAHL, D. A. (1997). Crenarchaeota in Lake Michigan Sediment. Appl. Environm. Micobiol. 63: 1178-1181.

MEYER, O., FRUNZKE, K., MÖRSDORF, G. (1993). Biochemistry of the aerobic utilization of carbon monoxide. In: MURELL, J. C., KELLY, D. P. (Hrsg.): Microbial growth on $\mathrm{C}_{1}$ compounds, 433-459. Intercept Limited, Andover, Mass.

MEYERHANS, A., VARTANIAN, J. P., WAIN-HOBSON, S. (1990). DNA recombination during PCR. Nucleic Acids Res. 18 (7): 1687-1691.

MÖRSDORF, G., KRAUT, M., SCHÜBEL, U., MEYER, O. (1992) Genetic aspects of carboxidotrophy. Bioengineering, 2 (92): 75. 
MOONMANGMEE, D., ADACHI, O., SHINAGAWA, E., TOYAMA, H., THEERAGOOL, G., LOTONG, N., MATSUSHITA, K. (2002) L-erythrulose production by oxidative fermentation is catalyzed by PQQ-containing membrane-bound dehydrogenase. Biosci. Biotechnol. Biochem. 66 (2): 307-18.

MOERSDORF, G., FRUNZKE, D, GADKARI, K, AND MEYER, O. (1992). Microbial growth on carbon monoxide. Biodegredation 3: 61

MÜLLER, B., WEHRLI, B., POWER, M., VAN DER MEER, J. R. (1997). Structer and activity in microbial commuities in sediments. Chimia. 51: 878-883.

MÜLLER, B., WEHRLI, B. (1998). Anwendung von chemischen Sensoren in Sediment-Porenwasser. In: VAAM (Hrsg.): Mikrobiologische Charakterisierung aquatischer Sedimente -Methodensammlung-, 1. Auflage. Oldenbourg Verlag, München.

MUNRO, I. C., BERNDT, W. O., BORZELLECA, J. F., FLAMM, G., LYNCH, B. S., KENNEPOHL, E., BAR, E. A., MODDERMAN, J., BERNT, W. O. (1998). Erythritol: an interpretive summary of biochemical, metabolic, toxicological and clinical data. Food Chem. Toxicol. 36 (12): 1139-74.

MYLVAGANAM, S., DENNIS, P. P. (1992). Sequence heterogeneity between the two genes encoding 16S rRNA from the halophilic archaebacterium Haloarcula marismortui. Genetics 130 (3): 399-410.

MUYZER, G., DE WAAL, E.C., UITTERLINDEN, A.G. (1992). Profiling of complex microbial populations by denaturing gradient gel electrophoresis analysis of polymerase chain reaction-amplified genes coding for 16S rRNA. Appl. Environ. Microbiol. 59: 695-700.

NAKATA, A., AMEMURA, M., MAKINO, K., SHINAGAWA, H. (1987). Genetic an biochemical analysis of the phosphat-specific transport system in Escherichia coli. In TORRIANI-GORINI, A., ROTHMAN, F. G., SILVR, S., WRIGHT, A., YAGIL, E. (Hrsg.), Phosphate metabolism and cellular regulation in microorganisms, S. 150-155. American Sociaty for microbiology, Washington, D. C..

NISHIZAWA, H., KITA, N. OKIMURA, S., TAKAO, E., ABE, Y. (1988). Determination of molecular weight of native proteins by polyacrylamide gradient gel electrophoresis. Electrophoresis 9: 803-806.

NONOMURA, A. M., BENSON, A. A. (1992). The path of carbon in photosynthesis: improved crop yields with methanol. Proc. Natl. Acad. Sci. U S A 89 (20): 9794-8.

OKE, V., LONG, S. R. (1999):Bacterial genes induced within the nodule during the Rhizobium-legume symbiosis. Mol. Microbiol. 32: 837-849.

OSBURNE, M. S., GROSSMANN, T. H., AUGUST, P. R., MACNEIL, I. (2000). Tapping into microbial diversity for natural products drug discovery. ASM News 66: 411-417. 
O'SULLIVAN, L., WEIGHTMAN, A. J., FRY, J. C. (2002): New degenerate Cytophaga-Flexibacter-Bacteroides-specific 16S ribosomal DNA-targeted oligonucleotide probes reveal high bacterial diversity in river taff epilithon. Appl. Environ. Microbiol. 68 : 201-210.

OVERDUIN, P., BOOS, W., TOMMASSEN, J. (1988). Nucleotide sequence of the ugp genes of Escherichia coli K12: homology to the maltose system. Mol. Microbiol. 2: 767-775.

PÅÅBO, S., IRWIN, D. M., WILSON, A. C. (1990). DNA damage promotes jumping between templates during enzymatic amplification. J. Biol. Chem. 265 (8): 4718-21.

PACE, N. R., STAHL, D. A., LANE, D. J., OLSEN, G. J. (1986). The analysis of natural microbial populations by ribosomal RNA sequences. Adv. Microbiol. Ecol. 9: 155.

PALMGREN, M. G., LARSSON, C., SOMMARIN, M. (1990). Proteolytic activation of the plant plasma membrane $\mathrm{H}(+)$-ATPase by removal of a terminal segment. J. Biol. Chem. 265 (23): 13423-6.

PERETO, J. G., VELASCO, A. M., BECERRA, A., LAZCANO, A. (1999). Biochemistry of CO2 fixation and the evolution of autotrophy. Int. Microbiol. 2 (1): 310. Comparative

PEARSON, W. R., LIPMANN, D. J. (1988). Improved tools for biological sequence comparison. Proc. Natl. Acad. Sci. 85: 2444-2448.

Pedersen, K., ARLinger, J., HAllbeCK, L., PETTERSSON, C. (1996). Diversity and distribution of subterranean bacteria in groundwater at Oklo in Gabon, Africa, as determined by 16S rRNA gene sequencing. Mol. Ecol. 5 (3): 427-36.

PFEIFER, V. F.,. SOHNS, V. E., CONWAY, H. E., LANCASTER, E. B., DABIC, S., JR., AND GRIFFIN, E. L. (1960). Two -stage process for dialdehyde starch using electrolytic regeneration of periodic acid. Ind. Eng. Chem. 52: 201-205.

PFENNIG, N., LIPPERT, K. D. (1966). Über das Vitamin B 12$_{2}$-Bedürfnis phototropher Schwefelbakterien. Arch. Mircobiol. 55: 245-256

PFENNING, N. (1978). General Physiology and Ecology of Photosynthetic Bacteria. IN: The Photosynthetic Bacteria. Editors Clayton, R. K., SISTROM, W. R. Plenum Press, New-York and London.

PFENNIG, N., TRÜPER, H. G. (1989) Anoxygenic phototrophic bacteria. In: STALEY, J. T., BRYANT, M. P., PFENNIG, N., HOLT, J. G. (Hsrg.): Bergey's manual of systematic bacteriology, S. 1635-1709. 3. Auflage, Williams and Wilkins, Baltimore.

QUAISER A, OCHSENREITER T, KLENK HP, KLETZIN A, TREUSCH AH, MEURER G, ECK J, SENSEN CW, SCHLEPER C. (2002). First insight into the genome of an uncultivated crenarchaeote from soil. Environ. Microbiol. 4 (10): 603-11. 
RAPPE MS, GIOVANNONI SJ. (2003). The uncultured microbial majority. Annu. Rev. Microbiol. 57: 369-94.

RASKIN, L., RITTMAN, B. E., STAHL, D. A. (1996). Competition and coexistence of sulfate-reducing and methanogenic Populations in anaerobic biofilms. Appl. Environ. Microbiol. 62: 3847-3857.

RATLEDGE, C. (1993). Biochemistry of microbial degradation. Kluwer, Dordrecht.

RAYMOND, J., ZHAXYBAYEVA, O., GOGARTEN, J. P., GERDES, S. Y., BLANKENSHIP, R. E. (2002). Whole-genome analysis of photosynthetic prokaryotes. Science 298 (5598): 1616-20.

REANNEY, D. C., GOWLAND, P. C., SLATER, J. H. (1983). Genetic interactions among microbial communities. In: SLATER, J. H., WHITTENBURRY, R., WIMPENNY, J. W. T. (Hrsg.), Microbes in their natural environment, S. 379-421. Cambridge University Press, Cambridge.

REID, M. F., FEWSON, C. A. (1994). Molecular characterization of microbial alcohol dehydrogenases. Crit. Rev. Mikrobiol. 20: 13-56.

REYSENBACH, A. L., WICKHAM, G. S., PACE, N. R. (1994). Phylogenetic analysis of the hyperthermophilic pink filament community in Octopus Spring, Yellowstone National Park. Appl. Environ. Microbiol. 60 (6): 2113-9.

RICHARDSON, T. H, TAN, X., FREY, G., CALLEN, W., CABELL, M., LAM, D., MACOMBER, J., SHORT, J. M., ROBERTSON, D. E., MILLER, C. (2002). A novel, high performance enzyme for starch liquefaction. Discovery and optimization of a low pH, thermostable alpha-amylase. J. Biol. Chem. 277 (29): 26501-7.

RIESENFELD, C. S., SCHLOSS, P. D., HANDELSMAN, J. (2004). METAGENOMICS: Genomic Analysis of Microbial Communities. Annu. Rev. Genet. 38: 525-52.

ROBILLARD, G. T., Broos, J. (1999).Structure/function studies on the bacterial carbohydrate transporters, enzymes II, of the phosphoenolpyruvate-dependent phosphotransferase system. Biochim. Biophys. Acta. 1422 (2): 73-104.

RODRIGUEZ-VALERA, F. (2002). Approaches to prokaryotic biodiversity: a population genetics perspective. Environ. Microbiol. 4 (11): 628-33.

ROMAO, M.J., ARCHER, M., MOURA, I., MOURA, J.J., LEGALL, J., ENGH, R., SCHNEIDER, M., HUBER, R. (1995). Crystal structure of a xanthine oxidaserelated aldehyde-oxidoreductase from Desulfovibrio gigas. Science 270: 1170-1176.

RONDON, M.R., AUGUST, P.R., BETTERMANN, A.D., BRADY, S.F., GROSSMAN, T.H., LILES, M.R., LOIACONO, K.A., LYNCH, B.A., MACNEIL, I.A., MINOR, C., TIONG, C.L., GILMAN, M., OSBURNE, M.S., CLARDY, J. HANDELSMAN, J. GOODMAN, R.M. (2000). Cloning the soil metagenome: a strategy for accessing the genetic and functional diversity of uncultured microorganisms. Appl. Environ. Microbiol. 66: 2541-2547. 
RONDON, M. R., GOODMAN, R. M., HANDELSMAN, J. (1999). The earth's bounty: assessing and accessing soil microbial diversity. TIBTECH 17: 403-409.

ROSADO, A. S., DUARTE, G. F., SELDIN, L., VAN ELSAS, J. D. (1998). Genetic diversity of nifH Gene sequences in Paenibacillus azotofixans strains and soil samples analyzed by denaturing gradient gel electrophoresis of PCR-amplified gene fragments. Appl. Environ. Microbiol. 64: 2770-2779.

ROSENBERG, A. H., LADE, B. N., CHUI, D.-S., LIN, S.-W., DUNN, J. J., STUDIER, F. W. (1987): Vectors for selective expression of cloned DNAs by T7 RNA Polymerase. Gene 56: 125-135.

RUCH, F. E., LENGELER, J., LIN, E. C. C. (1974). Regulation of glycerol catabolism in Klebsiella aerogenes. J. Bacteriol. 119: 50-56.

ROTHFUSS, F., REMDE, A. (1998). Methanogenese. In: VAAM (Hrsg.): Mikrobiologische Charakterisierung aquatischer Sedimente -Methodensammlung-, 1. Auflage. Oldenbourg Verlag, München.

RYU, Y. W., PARK, C. Y., PARK, J. B., KIM, S. Y., SEO, J. H. (2000). Optimization of erythritol production by Candida magnoliae in fedbatch culture

SAIER, M. H., REIZER, J. (1992). Proposed Uniform Nomenclature for the Proteins and Protein Domains of the Bacterial Phosphoenolpyruvate:Sugar Phosphotransferase System. J. Bacteriol. (174): 1433-1438.

SAMBROOK, J., FRITSCH, E., MANIATIS, T. (1989). Molecular cloning: a laboratory manual (2.Aufl.). Cold Spring Harbor Laboratory, Cold Spring Habor, New York, USA

SANGER, F., NICKELEN, S., COULSON, A. R. (1977). DNA sequencing with chain-terminating inhibitors. Proc. Natl. Acad. Sci. USA 74: 5463-5467.

SANTIAGO, B., SCHUBEL, U., EGELSEER, C., MEYER, O. (1999). Sequence analysis, characterization and CO-specific transcription of the cox gene cluster on the megaplasmid pHCG3 of Oligotropha carboxidovorans. Gene 236 (1): 115-24.

SCHAGGER, H., VON JAGOW, G. (1987). Tricine-sodium dodecyl sulfatepolyacrylamide gel electrophoresis for the separation of proteins in the range from 1 to 100 kDa. Anal. Biochem. 166 (2): 368-79.

SCHLEPER, C., HOLBEN, W., KLENK, H.-P. (1997). Recovery of crenarchaeotal ribosomal DNA sequences from freshwater-lake sediments. Appl. Environm. Micobiol. 63: 321-323..

SCHLEPER, C., SWANSON, R. V., MATHUR, E. J., DELONG, E. F. (1997). Characterization of a DNA from the uncultivated psychrophilic archeon Cenarchaeum symbiosum. J. Bacteriol. 179: 7803-7811. 
SCHMEISSER, C., STÖCKIGT, C., RAASCH, C., WINGENDER, J., TIMMIS, K. N., WENDEROTH, D. F., FLEMMING, H. C., LIESEGANG, H., SCHMITZ R. A., JAEGER, K. E., STREIT, W. R. (2003). Metagenome survey of biofilms in drinking-water networks. Appl. Environ. Microbiol. 69 (12): 7298-309.

SCHULZ, S., CONRAD, C. (1996). Influence of temperature on pathways to methan production in the permanantly cold profundal sediment of Lake Constance. FEMS Microbiol. Ecol. 20: 1-14.

SCHURMANN, M., SPRENGER, G. A. (2001). Fructose-6-phosphate aldolase is a novel class I aldolase from Escherichia coli and is related to a novel group of bacterial transaldolases. J. Biol. Chem. 276 (14): 11055-61.

SCHWEIZER, H., ARGAST, M., BOOS, W. (1982). Charasteristics of a binding protein-depending transport system for sn-glycerol-3-phosphate in Escherichia coli that is part of the pho regulon. J. Bacteriol. 150: 1154-1163.

SEKIGUCHI, H ., WATANABE, M., NAKAHARA, T., XU, B. (2002):Succession of bacterial community structure along the Changjiang River detemined by denaturing gradient gel electrophoresis and clone library analysis. Appl. Environ. Microbiol. 68 : 5142 - 5150.

SEMRAU, J. D., CHISTOSERDOV, A., LEBRON, J., COSTELLO, A., DAVAGNINO, J., KENNA, E., HOLMES, A. J., FINCH, R., MURRELL, J. C., LIDSTROM, M. E. (1995). Particulate methane monooxygenase genes in methanotrophs. J Bacteriol. 177 (11): 3071-9.

SEOW, K.-T., MEURER, G., GERLITZ, M., WENDT-PIENKOWSKY, E., HUTCHINSON, C. R., DAVIES, J. (1997). A study of iterative type II polyketide synthases, using bacterial genes cloned from soil DNA: a means to access and use genes from uncultured microorganisms. J. Bacertiol. 179: 7360-7368.

SHUMAN, S. (1991). Site-specific interaction of vaccinia virus DNA topoisomerase I with duplex DNA: minimal DNA substrate for strand cleavage in vitro. J. Biol. Chem. 266: 11372-11379.

SHUMAN, S. 1994. Novel approach to molecular cloning and polynucleotide synthesis using vaccinia DNA topoisomerase. J. Biol. Chem. 265 (51): 32678-32684.

SIEBOLD, C, GARCIA-ALLES, L. F., ERNI, B., BAUMANN, U. A.) (2003). Mechanism of covalent substrate binding in the $\mathrm{x}$-ray structure of subunit $\mathrm{K}$ of the Escherichia coli dihydroxyacetone kinase. Proc. Natl. Acad. Sci. U S A. 100 (14): 818892..

SPERRY, J. F., ROBERTSON, D. C. (1974). Erythritol Catabolismus by Brucella abortus. J. Bacteriol. 121: 619-630.

SPRENGER, G. A., HAMMER, B. A., JOHNSON, E. A., LIN, E. C. C. (1989). Anaerobic growth of Escherichia coli on glycerol by importing genes of the dha regulon from Klebsiella pneumoniae. J. Gen. Microbiol. 135: 1255-1262. 
STACKEBRANDT, E., STAHL, D. A., DEVEREUX, R. (1995). Taxonomic relationships. In L.L. Barton (Hrsg.), Sulfate-reducing bacteria, S. 49-87. Plenum Press, New-York, N. Y..

STADEN, R., BEAL, K. F., BONFIELD, J. K. (2000): The Staden package, 1998. Methods Mol. Biol. 132: 115-130.

STANIER, R. Y., COHEN-BAZIRE, G. (1977). Phototrophic prokaryotes. The cyanobacteria. Annual Reviews of Microbiology 31: 225-274

STREIT, W. R., DANIEL, R., JAEGER, K. E. (2004). Prospecting for biocatalysts and drugs in the genomes of non-cultured microorganisms. Curr. Opin. Biotechnol. 15 (4): $285-90$.

STUDIER, F.W., MOFFAT, B. A. (1986). Use of bacteriophage T/ RNA polymerase to selective high-level expression of cloned genes. J. Mol. Biol. 189: 113-130.

STUDIER, F. W., ROSENBERG, A. H., DUNN, J. J., DUBENDORFF, J. W. (1990). Use of T7 RNA polymerase to direct expression of cloned genes. Meth. Enzymol. 185: 60-89.

SUN, J., VAN DEN HEUVEL, J., SOUCAILLE, P., QU, Y., ZENG, A. P. (2003). Comparative genomic analysis of $d h a$ regulon and related genes for anaerobic glycerol metabolism in bacteria. Biotechnol. Progr. 19 (2):263-272.

SUZUKI, M. T., GIOVANNONI, S. J. (1996). Bias caused by template annealing in the amplification of mixtures of 16S rRNA genes by PCR. Appl. Environ. Microbiol. 62 (2): 625-30.

TEBBE, C. C., VAHJEN, W. (1993). Interference of Humic Acids and DNA Extracted Directly from Soil in Detection and Transformation of Recombinant DNA from Bacteria and Yeast. Appl. Environm. Micorbiol. 59: 2657-2665.

TYSON, G. W., CHAPMAN, J., HUGENHOLTZ, P., ALLEN, E. E., RAM, R. J., RICHARDSON, P. M., SOLOVYEV, V. V., RUBIN, E. M., ROKHSAR, D . S., BANFIELD, J. F. (2004). Community structure and metabolism through reconstruction of microbial genomes from the environment. Nature 428: 37-43.

VANDAMME, P. , POT, B., GILLIS, M., DE VOS, P., KERSTERS, K., SWINGS, J. (1996). Polyphasic taxonomy, a consensus approach to bacterial systematics. Microbiological Reviews 60 (2): 407-438.

VEIGA-DA-CUNHA, M., FIRME, P., SAN ROMÃO, M. V., SANTOS, H. (1992). Application of ${ }^{13} \mathrm{C}$ nuclear magnetic resonance to elucidate the unexpected biosynthesis of erythritol by Leuconostoc oenos. Appl. Environ. Microbiol. 58: 2271-2279.

VEIGA-da CUNHA, M., SANTOS, H., VAN SCHAFTINGEN, E. (1993). Pathway and regulation of erythritol formation in Leuconostoc oenos. J Bacteriol. 175 (13): 3941-8. 
VENTER, J. C., REMINGTON, K., HEIDELBERG, J. F., HALPERN, A. L., RUSCH, D., EISEN, J.A., WU, D., PAULSEN, I., NELSON, K. E., NELSON, W., FOUTS, D. E., LEVY, S., KNAP, A. H., LOMAS, M. W., NEALSON, K., WHITE, O., PETERSON, J., HOFFMANN, J., PARSON, R., BADEN-TILLSON, H., PFANNKOCH, C., ROGERS, Y.-H., SMITH, H. O. (2004). Environmental genome shotgun sequencing of the Sargosso Sea. Science 304: 66-74.

VIEIRA, J., MESSING, J. (1982). The pUC plasmids, a M13mp7-derived system for insertion mutagenesis and sequencing with synthetic universal primers. Gene 19: 259268.

WARD, D. M., WELLER, R., BATESON, M. M. (1990). 16S rRNA sequences reveal numerous uncultured microorganisms in a natural community. Nature 345: 6365.

WANG, G. C., WANG, Y. (1996). The frequency of chimeric molecules as a consequence of PCR co- amplification of 16S rRNA genes from different bacterial species. Microbiology (142): 1107-1114.

WANG, Y., ZHANG, Z., RAMANAN, N. (1997). The actinomycete Thermobispora bispora contains two distinct types of transcriptionally active $16 \mathrm{~S}$ rRNA genes. J. Bacteriol. 179 (10): 3270-6.

WARD, N, RAINEY, F. A., STACKEBRANDT, E., SCHLESNER, H. (1995). Unraveling the extent of diversity within the order Planctomycetales. Appl Environ Microbiol. 61 (6): 2270-5.

WATERMAN, M. S. (1984): Efficient sequence alignment algorithms. J. Theor. Biol. 108: 333-337.

WEISBURG, W. G., BARNS, S. M., PELLETIER, D. A., LANE, D. J. (1991). 16S ribosomal DNA amplification for phylogenetic study. J. Bacteriol. 173 (2): 697-703.

WELLINGTON, E. M. H. BERRY, A., KRSEK, M. (2003). Resolving functional diversity in relation to microbial community structure in soil.. Curr. Opin. Microbiol. 6: 295-301.

WENZEL, R. HERRMANN, R., (1996): Cosmid cloning with small genomes. In BIRREN, B., LAI, E. (Hrsg.). Nonmammalian genomic analysis: a practical guide. Academic Press Inc.

WHITE, D. C., SUTTON, S. D., RINGELBERG, D. B. (1996). The genus Sphingomonas: physiology and ecology. Curr. Opin. Biotechnol. 7 (3): 301-6.

WILSON, E. O. (1992). In: The diversity of life, S. 131-162: W.W. Norton \& Co. New York, USA. 
WINTZINGERODE v., F., GÖBEL, U. B., STACKEBRANDT, E. (1997). Determination of microbial diversity in environmental samples: pitfalls of PCR-based rRNA analysis. FEMS Microbiol. Let. 21: 213-229.

WISE, M. G., MCARTHUR, J. V., SHIMKETS, L. J. (1997). Bacterial diversity of a Carolina Bay as determined by 16S rRNA gene analysis: confirmation of novel taxa. Appl. Environm. Microbiol. 63: 1505-1514.

WOESE, C.R. (1987). Bacterial evolution. Microbiol. Rev. 51: 221-271.

WOLIN, E. A., WOLFE, R. S., WOLIN, M. J. (1964). Virologen dye inhibition of methane formation by Methanobacterium omelanskii. J. Bacteriol. 87: 993-998.

XAVIER, K. B., KOSSMANN, M., SANTOS, H., BOOS, W. (1995). Kinetic analysis by in vivo ${ }^{31} \mathrm{P}$ nuclear magnetic resonance of internal $\mathrm{P}_{\mathrm{i}}$ during the uptake of sn-glycerol-3-phosphate by the pho regulon dependent Ugp system and glp regulondependent GlpT system. J. Bacteriol. 177: 699-704.

XIONG, J., FISCHER, W. M., INOUE, K., NAKAHARA, M., BAUER, C. E. (2000). Molecular evidence for the early evolution of photosynthesis. Science 289:1724-1730.

YANG, S. - W., PARK, J. - B., HAN, N. M., RYU, Y. - W., SEO, J. - H. (1999). Production of erythritol from glucose by an osmophilic mutant of Candida magnoliae. Biotechnology Letters 21: 887-890.

YIP, T.-T., NAKAGAWA, Y., PORTATH, J. (1989). Evaluation of the interaction of peptides with $\mathrm{Cu}(\mathrm{II}), \mathrm{Ni}(\mathrm{II})$, and $\mathrm{Zi}(\mathrm{II})$ by high-performance immobilized metal ion affinity chromatography. Anal. Biochem. 183: 159-171.

ZHOU, J., BURNS, M. A., TIEDJE, J. M. (1996). DNA Recovery from soils of diverse composition. Appl. Environm. Microbiol. 62: 316-322.

ZUNFT, W. G. (1997). Cell biology and molecular basis of denitrification. Microbiol. Mol. Biol. Rev. 61 (4): 533-616.

ZWART, G., HIORNS, W. D., METHE, B. A., VAN AGTERVELD, M. P., HUISMANS, R., NOLD, S. C., ZEHR, J. P., LAANBROEK, H. J. (1998). Nearly identical 16S rRNA sequences recovered from lakes in North America and Europe indicate the existence of clades of globally distributed freshwater bacteria. Syst. Appl. Microbiol. 21 (4): 546-56.

ZWIRGLMAIER, K., LUDWIG, W., SCHLEIFER, K. -H. (2004). Recognition of individual genes in a single bacterial cell by fluorescence in situ hybridization - RINGFISH. Mol. Microbiol. 51 (1): 89-96. 
$7 \quad$ Anhang

\subsection{Das Cosmid slc_1a}

\subsubsection{Lage der offenen Leserahmen (ORFs)}

\begin{tabular}{|c|c|c|c|c|}
\hline ORF & Annotation & Start & Stopp & $\begin{array}{l}\text { Orien- } \\
\text { tierung }\end{array}$ \\
\hline 101 & Potentieller Kationen-Protonen-Antiporter & 39 & 1229 & + \\
\hline 102 & Potentielle $\beta$-Galaktosidase & 1260 & 4658 & + \\
\hline 103 & Potentielle $\beta$-Galaktosidase I & 4877 & 5749 & + \\
\hline 104 & Potentielle N-acyl-D-glukosamin 2-Epimerase & 5861 & 7132 & + \\
\hline 105 & Potentielles $\alpha$-L-Fucosidase-Vorläuferprotein & 7508 & 8866 & + \\
\hline 106 & Hypothetisches Protein & 8856 & 9071 & - \\
\hline 107 & Potentielles Transkriptions-Terminations-Faktor NusB & 9106 & 9957 & - \\
\hline 108 & Potentielle 6,7-Dimethyl-8-ribityllumazin-Synthase (EC 2.5.1.9) (DMRL-Synthase) & 9989 & 10699 & - \\
\hline 109 & $\begin{array}{l}\text { Riboflavin-Biosynthese-Protein ribA } \\
\text { [mit: GTP-Cyclohydrolase II (EC 3.5.4.25); 3,4-Dihydroxy-2-butanon-4-phosphate Synthase } \\
\text { (DHBP-Synthase)] }\end{array}$ & 10700 & 11749 & - \\
\hline 110 & $\begin{array}{l}\text { Eisenabhängiger Repressor, Metallbinde- und Dimerisationsdomäne und N-terminale DNA- } \\
\text { Bindedomäne }\end{array}$ & -11980 & 12642 & - \\
\hline 111 & Konserviert Protein & 13028 & 13768 & + \\
\hline 112 & “'Outer membrane”-Efflux-Protein, potentielles “drug”-Efflux-Lipoprotein & 13884 & 15188 & + \\
\hline 113 & Potentielle L-Asparaginase, periplasmisches Vorläuferprotein (EC 3.5.1.1) & 15288 & 16259 & + \\
\hline 114 & Hypothetisches Protein & 16338 & 16598 & - \\
\hline 115 & Poteintielle Glyoxalase/Bleomycin-Resistenz-Protein/Dioxygenase-Superfamilie & 16683 & 17294 & - \\
\hline 116 & Hypothetisches Protein & 17457 & 17666 & + \\
\hline 117 & Cystein-Synthase (EC 4.2.99.8), & 17667 & 18653 & - \\
\hline 118 & $\begin{array}{l}\text { COG1526: Uncharakterisiertes Protein, das für die Formiat-Dehydrogenase-Aktivität } \\
\text { gebraucht wird }\end{array}$ & 18666 & 19352 & - \\
\hline 119 & Protein mit Ähnlichkeit zur $\gamma$-Untereinheit der Sarcosin-Oxidase & 19560 & 20171 & - \\
\hline 120 & Sarcosin-Oxidase, $\alpha$-Untereinheit (EC1.5.3.1) & 20164 & 22062 & - \\
\hline 121 & Sarcosin-Oxidase, $\alpha$-Untereinheit (EC1.5.3.1) & 22008 & 23138 & - \\
\hline 122 & Sarcosin-Oxidase, $\delta$-Untereinheit (EC1.5.3.1) & 23135 & 23287 & - \\
\hline 123 & Sarcosin-Oxidase, $\beta$-Untereinheit (EC1.5.3.1) & 23420 & 24676 & - \\
\hline 124 & Alkyldihydroxyacetonephosphat-Synthase (EC 2.5.1.26) & 24681 & 26081 & - \\
\hline 125 & Zucker-Kinase & 26205 & 27602 & - \\
\hline 126 & Potentielle 2-Deoxy-D-gluconat-3-Dehydrogenase (EC 1.1.1.125) & 27609 & 27977 & - \\
\hline 127 & Potentielle 2-Deoxy-D-gluconat-3-Dehydrogenase (EC 1.1.1.125) & 27712 & 28380 & - \\
\hline 128 & Glycin- $\beta$ in-Bindeprotein und Permease (ABC-ransporter) & 28588 & 30444 & + \\
\hline 129 & Glycin-Betain/L-Prolin-Transport ATP-Bindeprotein proV & 30441 & 31643 & + \\
\hline
\end{tabular}




\begin{tabular}{|l|l|l|l|l|}
\hline 130 & Potentieller TonB-abhängiger Rezeptor & 31812 & 32450 & + \\
\hline 131 & Potentieller TonB-abhängiger Rezeptor & 32342 & 34009 & + \\
\hline 132 & Hypothetisches Protein & 34136 & 35716 & + \\
\hline 133 & Potentielle Peptidase & 159 & 2261 & + \\
\hline 134 & Hypothetisches Protein & 2299 & 2541 & + \\
\hline 135 & Hypothetisches Protein & 2634 & 2897 & - \\
\hline 136 & Konserviertes hypothetisches Protein & 2933 & 3463 & - \\
\hline
\end{tabular}

\subsubsection{Sequenz des Cosmides slc_1a}

Unsichere Sequenzbereiche sind mit rot gekennzeichnet.

\section{Contig 1}

CGCAATTAACCCTCACTAAAGGGATCGGCCAACCGCAGGTGGTCGGCGAGATGATCGCCGGGGTGCTGCTGGGCCCCTCTCTGTTGGG GGCCCTCTGGCCCGAATCGGCGAATCTCATCTTCACCCAGGAATCGCGCGGCATCCTCTACACCGGCTCCCAACTCGGGGTGGGGCTC TACATGTTCGTCGTCGGCCTCGAATTCAACACCGGCCACTTCCGCTCGCGCGCCCGCAGCGCGGCCTGCGTCTCGATCGCCGGCATGG CCGTGCCCTTCGTGCTCGGCGCCATCCTCGTGTTGTGGCTCCAACACGTGCCGGGCATCTTCAGCCCGCAGGTGCGCTACTTCGAGGG CGCGCTGTTCCTCGGCGCGGCCATCGCGATCACCGCTTTCCCCATGCTCGCCCGGATCATTTCCGAACGCGGACTCTCCGGCACTCCG CTTGGCACCCTTGCGCTGGCAGCCGGCGCGATCGACGACGCCGCCGCCTGGTGCGTGCTCGCCGTGGTGCTGGCCACCTTCGGCGCCT CCCAACCGGTGGAGATCGCCGGCATGTTCTCGGCCGCATGGCCGAGCGCCGTGGCGAGGTCTCCCAACCCGTGATGGCGGTGGTGCTC GCCTTGTTCTGCCTCGCCGCCTGGTACACCGACATCATCGGCGTGCATGCCGTGTTCGGCGGGTTCATCCTCGGCATCGCCATGCCGC GAGGGGTCTTCGCCGAGGACATCCGGCGGAAAATCGAACCCTTCGCCATCGTCTTCCTGCTGCCGATGTTCTTCACCTTCTCCGGCCT CAACACCAAACTCGACGTGCTGGTGGAGCCCGGGCTGATGCTCGCGGGTGTCGTCATCCTGGCAGCTTCTCTGCTAGGCAAGGGCGTC GCCTGTTGGGCCGCCGCACGACTCAACGGCGAGGACAACGCCACCTCCATGGCCGTCGGCACCCTGATGAACGCGCGCGGGCTGATGG AACTCATCATCATCAACATCGGCCTCCAGCGCGGCATCATCGGCGAGGCCTTGTTTTCGATCCTCGTCATCATGGCCATCGTCACCAC CCTGATGGCCACGCCGATTTTCGAGTGGGTCTATGGCCGCAAGGCCCGCGCGGCCGGCACGCTCGGCGAAGGACACATCGATGGCTGA CAGGACCCGATCTCCCCATAACCCGGACCCGTGCGCCAGTTCCGAATCATCGCCGCCCGCTCGTTTGTGGTCCTCTCCGCAACGACAG TGCCCCTGCCGGCGGCTGTCGAATACGCCGGTGAATTCGCCCCATCCCCGCCATTGGTTGCGGAGAGCGAGCGTCCGTTCCGCGACGC CGTCCCGCTGAATGGCTCCTGGCAGTTCCAGCCCCAGGCGCTTCCCGCAGGGTATCGCCCGGACCAGGGCACGGCGCCGGACTTGAAC CCGCCGACCGCCGGCGCATGGGAGAGAACTCCAATCAAGATCCCATCACCGTGGAACGTGAACACCTGGGGTTCGGGACGCCACACCG GTGAGGGCACCGCCAAGCCGTATTGGCCGGATTCGGTCTTCTTCCCCAGCTATCCGGAATCCTGGGACGATGTGAAGATGGGCTGGTT GCGGCGCAGCTTCGTCGTCCCCGCATCATGGCAGGGCCGCCGCATCATCCTCCACTTCGAGGCGGTCGCCGGGGATTGCATTGTGCTG GTCAATGGACGGGCCGCCGGCACCCATTTCGACAAATACCTGCCCTTCGATCTCGATGTCACCGACCTCGTCTCGCCGGGCAATGACC ACGAACTCCTGGTCGGCGTGCGCTCGCACGAGTTGTTCAACAAGCGCAGCACCACCTTCCCGAAGATGGTCGCACCCTATCCATGCGG CTCGACCACCTCCCACCTCGCCGGAATCTGGCAGGACGTCAGCATCCGGGCACTGCCGCCCGCACGCATCGCCGAGGTGTTCGTCAAA CCACAGGTCAAGGCGGACACGCTCGCCATCGAGGTGGTTGTTAGAAACGACACTGCCGAACCCCGGACTCTGGGCGTCGGCGCCATGG TCGCCCCCTGGATCAACCGCGCCGGTTCCGATCCCGCCACCGCCCCGGTCCCCGCGGGCGGATACGGCGCCACGGTGCTGCGGATTCC GGCCGTGGATCTCACGGTCGCCGCCGGTCAATCCGCGCGGATCGGGCTAACGGTCCCCGTGAATGGCGCGCTCAAGACCTGGGCGCCC GGCGCACCGAACCTCCATGGCGTCGATGTCGTCCTGACCTCCGGCGGGACGACGCTCGACGTCTCCACCACCCGCTTCGGTTGGCGCG AGTTCGAGATCCGGGGCAGGGACCTGCTTCTCAACGGCAACAAGATCCAGCTCACCGGCGACCTGCTGCATCCGTTCAGCCCGCTCAT CATGTCCCGCCGCCATGCCTGGGCATGGTACAAGCTCATCCAGGACTTCGGCGGAAACGCCGCGCGACCCCATGCCCAGATCCATCCC CGCCACTACCTCGATCTCGCCGATGAAATGGGCATCGTGGTGCTCGATGAAACCGCCATCTTCGGCAGCTCAATCGCCCTCAACTTCG AGGAACCAGCCGCCTGGGCACGCTTTGAAGATCACTTCGACGGCCTCGTGCTGCGGGATCGCAACCACCCCAGCGTCGTCGGTTGGAG CTTCGGCAATGAACTGTTCGCGATCTTCGACCTCAACAACGTGCCCGCCGACCAGGCCGCGGCGTGGTATGCCAGGCTGACCGAACTC GGGCTGCGTGCCCGCCGGCTCGATCCCACCCGGCAGTGGATCTCCTGCGACGGCGACGAGGATCTCGGCGGCACGCTGCCGGTGTGGA GCAAACACTTCGGCCACGGCCCGCAGCAAGGCCGCCTGCCGGCTCTCGACAAGCCGCTCATGGTCGGCGAGTCGGGCGGAACCTACTA TGCCCGCCCGTCCCAGTTGGCGGAGTTCAACGGCCGGCGCGCCTACGAAGACTACCACGGCCGCAGCGAGGCGCTCGCCATCGACGCC TACGACAACATCGTCAACATGGCACGCCCGCACCTCGCCTACTTCTCCGCCAGCGAAACCGCCTGGTTCGGCGTCGAGCACCTCAATT TCGGNTACCGGGATTTTTCCCGGCTGCCGACGATGCGCGACGGCGTCCACTTCACCCGGCCCTGNCGGGAGGGTGCACCCGGNNTGCN GATCGAACGCATNCCCCCCTACGTGGACACCCTCAATCCCGGCTGGGATCCGCAGCTTCCACTCTATCAGCCATTGCCGATGTTCGAG GCGGTGAAGGCCGCTCTAGCGATTCCTGCTCCCGCCGTGTGCCCGTGGAGCAGCCGGGCCACCCCCGCCGATCCGACGCCCGCCGCGG TCGAAGCCACCATCACCTCCATCGCCTTCGTCGGCGACCGGGCCGGGCCGCTCGCCCGCCGCCTCCTTGACCTCGGCCTGCCCGTCGC CGGGGGCCTCCACTCATTCTCCATCATCGACCACCAGAGTGCCGCCCCCGCCGATGCGGACGCCGCCCTGGACCGCGTCAAATCCTCC GGCGGCGTGGCCATGCTCATGCTCGGCGAGGGTGACCAGGCCGGTCTTCCCGCCGGTCTCCGTCTAACAGATCGCCCGGCCACCGCGC TCGTCCCCGACCCGGCCCACCCGTGGACCTCGGCATTCCGCCTGCCCGACCTCTACTTCGCCGAGGACGGCCCGCTGCGTTTCATCAT GCGCTGCGGCATTGGCGGTGATCTTCCCCCCGATTCCAAAGTCCTCCTCCGCGCCAGCGACACCGATTGGTCGCTCTTCAACGATGCT CCGGAATTCGCCAAGTGCGCGGCCGTCGTGCTCCATGAGAAGATGAAGAAACCCGCCGGAGCCGCCGTCATCGAAATTCCCTGGGGCA GGGGATCCCTGGTCGTCTCCAGCCTCGACTATCACATCGGGTCCTCCACCGCCGATGCCATGTGGCGCACCCTCTTCACCCGCGCCGG CATCAAGCTGGAAACTCGCCGGGACCACGGCACCCCCGCATTCGACGCCCAGGGTGTCCTCGTCAATGCCCTTGCCGCGGGACGTTTC GCCGCCGCCGATCTGCAAACCGCCATCGACACCGACTGGACCGGTGAAGCCGGCGTCGCCCCGGTATCGGACGCCGCCGGCCAGGGCA TCGTCTGGAAACCCGTCACCAGCCCCAGCCGCGACCGGTTCCAGTTGGACGCGCTTGGACTGGATGGCCCGCAGACCGGCGCCTTCGC CACCTGTTTCAGCTTCTGGATCAGGAGCCCGCGCGCATTGGACGACATCCTAACCGCCGGACCGGACGCCCCACGCTTCACCATGCGC TGCTACATCTCGGATGACTGCCGGCTGTTCCTCAACGGCAATCCGGTGGCGGCGGCGCGGACCGAGGACGCGGATTACCGCAAGCTCA TCACCTTCGACCCGCTGCTGCTGCAGAAAGGTTGGAACCGGTTCCTGATCAAGGTGGCGGCCGACTCGCTGGCCGGTGAACAACCCGG CACCCTCGCCGTGCGGATCTCCTCCAACCGNCCCGAATTCCTGCGCCAGTTGGACTCCGCGACCGAACGCAGGGATGCCGAGTGACCC CGGCCCCGGGGAAATCCCCGNGCCTCGAAAGTATCGANCANCCCGGCACGTTTTCCCACGTCAGAACCAGCACCANCCGNCGACCTAA 
CATACNAACAGCCATGATCCACCGNCTCCTGCCCGCCGCGCTGATCGGCNCCGNCNTGCCCGCCACGTTCGCCGCCGACGGGAACACC ACCGTCCTGTCGTNCTTCCGCGGCAACGGGGAGGCCGGCGTGTTCCTCGCCGCCAGCGACGACGGGCACAAGTTCCGCGCCCTCAACG ACGACAAGCCGGTCTTCGCCCCGCCGAAGTGGCCCGATCAGTCGCTGACCCGCGACCCGTCGATCCTCTTTCACGACGGCACCTTCCA CATGGTCTGGACCAGCAATTGGAAGGGCGGGGTCTTCGGCTACGCCCACTCGCCCGACCTGGTCGATTGGTCCGAGCCGGTGATGGTC GAGCCGTTCCCGCAGTCGCTGCCCGGGGAGGACCAACCGCTCAACGTCTGGGCGCCGGAAATCCACCGCGACCCGCTGCACAATGATT TCCTCATCCTGTTCTCGGCGACCACCCGCCGGGAACTCGACGACGGCGACAGCAAGATCGCCCACGGCCTCGACCACCGCACCTATGT CGTCCGCAGCCCCGATGGCAGGTCGTTTTCCCCCGCCAGGCTGTTCTTTGATCCGGGCTTCAGCGTGATCGACCCGGTGCTCCAGCCG GACCCCGGCAACAAACGCTGGGTGATGGTGCTCAAACATGAACTCGATCCCGCAGACGGCGGCAAGAACCTGCGGCTGGCATTCGCAC CGGCCGACCTTGAGCAGGATTTTCCTCCCAAGTTCACCAAGCTCTCCGGGCCGATCCTCGGCCCCGGCTCACCGCTCCGCCCGCACGA GCAGGTCGAAGGCCCCAGCCTGTTCCGCCGCGACGGCCGCTGGTTCCTCTACTGCGATGCGTTCACCAGCCACCATTACACCCTCATC ACCTCCGCCGACCTAACAACCTGGCAGGACGAAACCGACCAACTCGAAATGCCGGGCGGGCTCCGCCACGGCACCGTCTTCACCGCCC CGCGCGACAAGGTCGGCTGGCTCAAGAAGTGACACTGTTCCTTGCCACCCGCCACCCGCCATTCGCTACTCACCGTGATGTTCACGTT CCCCCTCTCCGTGCCTGCCCGACGTGCTGCCATCGCCTGCTGTCTCGCCCTGCCCATGACCCGATGCCCGTGCGCACATTCCGCGGAG CTGGCCGACCAGGCCGCCGCCTGCCGGAATCTCGTCGCCGACAAGTTCCTCCCTTACTGGTACGACACCACCATCGACCGCGAACACG GCGGCTACCTGCTGGCAGACGACGCGGTGAAAGGCCGCTCCCGGCCTGACGAAAAGCAACTTGTCTCACAGGCCCGCGAAATCTGGGC CTTCTCGCTGGCCCACCGCAAGGGATTCAGCACGCCGGAACGCAACTACCTCGACGCCGCCGCCCACGGCGCGCGCTTCCTGCGCGAG CGGATGCACGACCCGCAACACGGCGGGTATTTCTGGAGCGTCGGGATCGACGGCCAACTGCGCGACCCGCACAAGCGCCTCTACGGCG AGGCATTCGTCATCTACGCACTGGTCGAGTTCCACCGGGCGGGCGGCGGACGCGAGCCTCTCGACGACGCCCTGCAGCTCCACCGCGA GATCCAACAGCACGCCCACGACGCCCAACACGGCGGCTGGACGGAACACTTCCGGCGCGACTGGACGCCGCTGCCATTGCGCGATCCT AACGGCCTGGTCGAGGTCGCCGGATACAAGAGCGCCAACACCCACCTGCACCTGATGGAGGCCCTCACCGAACTCCACTCCGAGACCA GGGACCCCGCCGTCAAGGAATCGCTGTTGGAGGCACTGGAACTCAACCGCAGGTACTTCTACCCCGCCGACCCGTCCAAGTCCGCCTT CCATTTCCTGCCCGACTGGTCGCCCGTCACCGACCCACGCAGCGCCGGCCTGAGCTACGGGCACAATATCGAGTTCGCCTGGCTGATG ATCCGCGCCGAGGAATCGCTCGGCCTGCCCCCGTCGTGGGATCACTTCTTCAAACACCTCGACCACACCCTGCTCCACGGCACCGACC ACCAGCGCGGCGGCATCTACGAACGGGGTGCCGGCAACGATCCCGCCGACGACACCGACAAGGTCTGGTGGGTGCAGGCCGAGGGGCT TGCCGCCCTAACCGATGCGCTGTGCCGCTCGCCGCTCAAGGACCTGGCCGGCGAGGCCGGCAGCAAGGCCCGCGCCCCCTACCTGCTA GCCCTGCGGCAGTTGCTCACCTTCACCGACACCCACATGAGCGACCCGAAGACCGGCGTGTGGATCGACACCGTGACTGCCGACGGCA CCCCCAAGGGGCACGGGCTCGCCCACTCATGGAAGGCCAACTACCACGACCTGCGCGCCTTCCTGAAGTTCATCGAGGCCTTCGGGCA GGAGTGATCCCCGCCGGGCTCCCAGGTCAAAAATCGCCATGCTATGGTCAACTTTGGCCATTCACGCGGCCGTGCCGACCGGCCATGA TCAACAACGCTGCGGACGGTTGACCCGATCCGGCCACCCGCCCGAACAACCCGTCTCCCGCCCGATCACCCGCATCCCGGTCACCAGA TCATCATGAAATCCAAGCCCCGCACCGCCATCGCCGCCACGCTTCTCATCGTGGCCGCCACCAACCTGTCCGCCGCCGAAACCCCGCA GCTCGCCATCGCCGACGGGCCGTTCAAGCCGGACGACGAATCGTTCAAGCAATACCAGTACCCCGACTGGTTCCGTGACGCCAAGTTC GGCATCTGGTCGCACTGGGGGCCGCAGGCCGTGCCGCGGCAGGGCGACTGGTATGCCCGCAAACTCTACGAACACGACGGCATCGACC GCAAGACCGGCAAGCCAAGCGGGCAGAACCCCGCCAACAAACACCACCTCGAACACTACGGCCACCCGTCCAAGTTCGGCTACAAGGA CATCATCCCGCTGTGGAAGGCGGAACGGTGGGATCCCGATCAGCTCATGGCCCGCTACAAGAAGGCCGGCGCAAAATACTTCGTCAGC ATGGGCACCCACCATGACAACTTCTTCCTCTGGGACTCGAAGATCCACCGCTGGAACGCGGTGAAAATGGGGCCTAACAAAGACGTCG TCGGGCTGTGGCAGAAGGCCGCCCGCAAGGAGGGGCTGCGCTTCGGGGTCTCCGAGCACCTCGGCGCCAGCTACACATGGTTCCAGAC CAGCCACCGCGCCGACACCACCGGGCCGATGGCCGGCGTCCCCTACGACGGCAACGACCCGCAGTTCGAGGACCTCTATCACGGCAAG GCCGCGCCGGACGACAACGGCTGGCTGACCAACAACCCCGTGTGGCAACGCGAGTGGTTCGATTCCATCAAGGAGCTGATCGACGCCT ATCAGCCGGATCTCCTCTACTCCGACAGCCCGCTGCCCTTCGGCGACGTCGGCCGCACCATGCTGGCCCATTTCTACAACCAGGACAT TGCCCGCAATGGCGGCAAGCTCGAGGCGGTTTACAACTGCAAGCAGGAATCCGCGGGCAAATGGGTGCGCGACATCGAACGCGGCGTG GCGGAGGGCATCAGCCCCGAGCCATGGCAGACCGACACCTCGATCGGCGACTGGTATTACCGCACCGGGCAGAAATACAAGAGTGCCG GGGAGATCGTCCAGATGCTGGCGGACATCGTCAGCAAGAATGGCAACCTGCTCATCAACATCGTGCAGACCCCGGAGGGGGACCTGGA GGACGACATGCTCAAAACCCTGGACGAGATCGGCGCCTGGATCGCCATCAACGGCGAGGGGATCTACAGCACCCGCCCGTGGCGAACC TACGGCGAGGGCCCCAGCACCCGCACCCAGGAAAAGGGCCGCTTCGGTGGCTTGAAGGATGTCCCCGACAAGGGATACACCCACGAAG ACTTCCGCTTCACCACCTCCAAGGACGGCAAGACGCTCTACGCCGTGATGCTCGGCTGGCCGGCCGGCACCCCGGTGACGATCAAGTC GCTCGCCGACGGTGAAGAGCCCGCGCGGATCGGATCGGTGACCATGTTAGGATGCCCGGACAAGATCGAGTGGACCCGCGACGCAGAC GGCCTCAAGCTGACGCCGCCCGCGAAGAAACCGTGCGATCACGCCTTCGTGTTCAAGATCACGCAGTGACGGCGCCCGGCGGGGGGCG GGAGGGATGCGCAAAATGCAGCGGCGCAGCCGCCCTTGGACTGCTGCAATTCTTTGCAGCTCTGGGGGAGACGTTTGAATCCGCAGCG GGTTGCAAAGCATCCCCGAGGGCTGGGAATGATCCCAGCAGTCCGAGAGCGCCGCTGCGCGGCGCGCAATGATGCGAGCTTCGCTGCC ACAGCACCATTCGGTTGGCCTGCCAATCCCCAAAGGCATTGTGTTCAGCGGGGATCTTGGGCGAGGTGGTCGAGGATGCCGTTGACGA AGCGGGCGGAATCCTCGGTGCCCATGCGCCTGGCGATTTCCACGGCCTCGTTGATGGCGACGGCCTTGGGGACCTCCGGGTCTTCGAG GATCTCCCAGGTGGCGAGGCGCAGGATCGAGCGATCGACCGGGTCGATGCGCTCGGGCGAGTAGTTGTCGATGGTGGAGGCGAGCCGG GCGTCGATCGAATCGAGGACGGCGTGGACCTTGGCGACGTAATGTTCCGCGCCCTCGCGCAGTCCGGTTAGATCGTTGCGCGCCTTGT GCAGGGCGTCGAACTCGGGGCGTTCGGGAAGTGGCTGGCCGGGGTCGATCTGGCGCAGGCGCTGGTTGGCGCGGGCGAGCCGGCGGAG CGGGCCGAACACCGGTTCGAGTGCCGGGGCGAGGGCGGGGTGGTCTTCGGCGGCCTCGATCAGCCGCCGCTGCGCGCATTCCAACTCG CGGCTGGTGGCCACCAGTTGGTCGAGGGCGGACTGCATGCGGGTGATGGCCTGGTCGTCGGGCAGGTCGGTGTCGAGCCGGTCGAGCA CCCTGACGGCGGTGGAGAGGCGGGATTCGAGCGCGGCCACCGAATCGAGGGCGCCGAGCAGCTTGGTGGCGTCGGGGTCGGCGGCGAC CTGGGCGCGGGCGACGGGGAAGCGCGCGGTCCATTCGGCGAGCCGTTCCTCGCGCCCCTGGCCGAGGTGGCGGGCGGTGCGCAGGGAG ATGGTCAGCAGGCTGCGGCGGGCGGACTCGCTGACGAGTTGCCAGAACCGTTCCCGCTCGCCGGTGCTGGGTTCGCCACCCGAAACGT GCAACCAGTAGAGCATCTGGACCGCCGCTTCGCGGGTCTGTCGGCGGCTAGCCATTGCGGCGCGGATTGCGGGTCGGGATGCGCTCGA GTTCGCTGAACACCTCGAGCATGCCGGCGGCGGCGCGGGCGGCTTCGCGGCCGCGGTTGAGGTTGGCGCCGATGCAGCGGGCGTAGGC TTGCTTTTCGTCATCGACCAGCAGCACCTCATGGATCACCGGCCGGCGGTGGTCGATGGCGATCTGCATCAGGCCGTCGGTGACCGCC TTGCTGATCAGGTCGGCGTGGGCGGTGGCGCCGCGGATGACCAGGCCGAGGGCGATCACGCAGCTCGGGGCCTCCCGTTCGAGCATGG TTTCGACGGTGACCGGGATCTCGAACACGCCGGGCACGCGGATCAGGTCGATGCGGGCATTGGGCACCAACTCACCGAGCTCTTCGAT CGCGTTTTCGACCAAGGCATCGGTGAACTGCTCGTTGTATTTCGAGGCGACGATGCTGATGCGGATCTTCTGGCCGACGATGCGGGGT TTGGGTGGCAGGGCCGAGGACATGGCGGGGGTATGGAGGGGGTGGGGGGAGAAATGAAGAATGAAAAATGAGAAAATGAAAAATGCCG ACGGGGGCAGGGACGCTTTTCCGAAGCGTCCGGCTGGGTTGATGGGTTGGTGGGAGGAGGTTAAGTGGCGCTTTGAGGTCGGTCCAGA TGGATTGGGGTGCGGTGCGCCAGCAGCCGGACCGTTCGGAAAACGGTCCCTGCCTTATAGCGTATGCCCCATCCGGGAGCGCTTGGTT TCGAGGTAGCGTTCGTTGTGGGGGTTGGCCGGCAGCCGCAGCGGGATCTGTTCGACCAGTTCGATCTGATAGCCTTCGAGGCCGACCA TCTTCTTCGGGTTGTTGGTCAGCAGGCGCAGGCGGCGCACGCCGAGGTCGTGGAGGATCTGGGCGCCCATGCCGTAGTCGCGCAGATC GGACGGGAAGCCGAGCTTCTCGTTGGCCTCGACGGTGTCGAGCCCCTGCTCCTGCAGCTTGTAGGCGTGGATCTTGTTAGCCAGCCCG ATCCCGCGGCCTTCCTGGCGCAGATAGAGCAGCACGCCGCCCTCGGCGGCGATCTGCTCGAGCGCGCTGTGAAGCTGGCCGCCGCAGT CGCAACGCCTGGATTGGAACACGTCGCCGGTCAGGCACTCGGAGTGGACGCGGACCAGGGTCGGCTTGCGCGGGTCGATCTCGCCGCG GACCAGGGCGAGGTGGTGGGAGTCGTCGGTATCGATGTGATAGAGGTGGCAGCGGAAGTTGCCGAACTCGGTGGGCAGGTCGATGACC TCCCTGAGGAAGACATGTTTTTCCGAGCGGCGGCGGTATTCGATCAGTTGGGAGATGGTGCAGGCCATCAGGCCGTGGCGTTGTTGGA AGGGACCGAGCTGGCCGACGCGGGCCATGGTTCCGTCCTCGTTCATCACCTCGCAGATCACGCCGGCCTGCGGCAGGCCGGCGAGGCG GGCGAGATCGACGGCGGTTTCGGTGTGGCCGGCGCGCCGCAGCACGCCGCCGGGCATCGCGCGCAGCGGGAACACGTGGCCCGGTTGG 
ACGAAGGCCTCGGGGCCGGCGCCGGGTTCGGCGAGCAGGCGGATGGTGTGGGCGCGGTCGGCGGCGGAGATTCCGGTGGTCACGCCGG TGGCGGCATCGACGGTGACGGTGAACGCGGTGCGCTGGACTTCGCGGTTCCTGCGGGCCATCTGGGGCAGGTCGAGCGCCTCGGCCCG TTCCGCGGTGAGCGGGGCGCAGATCAGCCCGCGGGCATGCACCGCCATGAAGTTGATCATCTCCGGCGTGGCATGGCAGGCGGCCCCG ATCAGGTCCGCTTCGTTTTCCCGGCCGGGATCGTCGGCAGCGATGATCAGGCGGCCGGCAGCGATCTCGGCGATGATTTCCTCGATCG GGCTGAATGAAAGAGCTTCCACGATGAATTGCAGATGGGTTGGGGCAGTAGTCGGGCGGCCGGGCAACGAGGTCAAGCCCCGAGGCGG CGGGTGGATCGCGGTCAACCCGCCGGCTTGACGAGCAATCGCTGGGCGGCGTTGGTGCCGAATTGGAGATTCTCGTGGCGGCCGTCGA TCAGGATTCGCAGCAGCCCGGCCGGCCGGTCGTGGTCAATCAGGCGCAGGCGGGTGCCGGGTCTGAGTTTGTTGCGGCCAAGCCAGTC GAGGAACGTGGTGTCGTACCCCGCCACCCGCAGCAGACGGTAATGGCCGGGCCCGCAGTCGGCAAGGGGGACGCCCTCCGGCTCCGGC AGGTGGCCGTCGGCATCCGGAATCGGGTCGCCATGGGGGTCGCGGGTCGGGTGGCCGAGCATCTCATCGATGCGATCCAGCAGGCCGT CGGAAATCACGTGTTCGAGCACCTCGGCCTCTTGGTGGACCTTGGTCCAGTCGATCTGCATCACCTCGACCAGGAACAACTCGATCAA CCGGTGCCGGCGCACCACCCGCATCGCCGCATCGCGGCCCTTGGGACGCAGGGCAACCCCCTGCCGTGGGGTGTAGTCGATCAGTCCG TTGCGGCCCAGATGCTTCATCATGGTGGTCACGGTTCCCGGTGTGACCTCCATTTCGGTGGCAATCCGGCCGACGGCGACCGGTCCCG GGTCGGCCCGTTCGAGCCGCAGGATGGTCTTGAGGTAGTTCTCGACGGTGCTGGTCGGCATCGCTGTCAAATCCATACCATGGGTTGA TTGATTGAGCGATCAAAAAGAAAAAATTCNTGATACATATGGGATTTGATCCATCTNGGCAGTCGGTTTCCATGATTCAATTTTGATG AATCAAACATTTGACTTTGATTCGATTGCCTGCCATTGGTGACGTCGATGAGACTCGGCAAGGCGAGTGACCGGCGGGTATGGGTGGA GGATGCGTTGAAGCATCTGCTCGACTGCGAGCAGGCTGGTGGGGTGGCGACGGTGGACAGTGTGGCGGGGGCCTTGGGGTGGCATCGG GGGCGGGCGACGGAGGTGATGGGGGTATTGAGGGCGCGTGGATTGGCGAATCCGGAGGGGGACGGGTGGAGATTGAGCGAGGATGGGC GGCAGTATGCGGTGCAGATCGCGGATTGCCCTCACGCAGACTCGCGTGAAGCAGAATCGAGAGCTGGCAGCCACCGGAGCCGGCAACC GGTTCGATCTCGAGCAGGCCGAGACCGACCTGCGTGACCTTGATGCGCAACTGAGCACGGCCATGGCGAACGAGGCGCAGGTCCGCGC CCAGCTGACAGCCACCGTCGGTGGTGATATCGCTTCGGTCGCCAAGATCAAGGCCGAGCTGGCCAATGCAGAATGGGAGCTCGAGCAG ACCACCGTGCGTTCGCCCTGCGAGTGCTACGTCATCAACCTGGCGCTGCGGCCTGGCGCCTTTGTCGCCGGCATGCCCTTCAATCCGG TGATGACGCTGGTCGAGGCCGATGGCCAGGTCGTCGCGCTGTTCAACCAGAACGAGTTGCACCAGGTCGCGCCTGGCAATTACGCCGA GTTTTCGCTCAAGACGAATCCCGGCCGTATCGTCCGGGCCAAGGTCGATTCGGTGATCTGGGCCCAGGGCATGGGCCAGATGCAGCAG AGCGGGACGATCCCGATGACAGGCGTGCTGGCGGCGCCGCCCAATCGCTTCGCGGTCAAGTTCGACATCGAGGACGCCGACAAGGGTC TGCTCGTTGCGGCGGGTGCGGCAGGCCAAGCAGCGATTTACACGGAGCACGGCAAGATGATCCACATCATTCGGATGGTCATCCTGCG CGTGGGCGCGTACACGGACTACCTGGTCCTGAAGTTGCATTGACGCCATGAGCACTCGCTACACATCGTTGGCGCTGGCGATGTTCGC CATGCTCTCTGCCTGTGCGCTGGAGCCCGCACCGAAGCCAGTCGATTACCGTGCCGAGGCGCTCGGCGGGGTGCACCCTCCGGGTCAG TGGTCCGCGGAAGGTGCGGCGGCGGAGTCGGTCGCCGGCTCATGGCTCGGGACTTTCGGTGATCCACGGNTCGACGCGCTGGTGACCG AAGCGATGGCAAACAANCTCGACCTGAGGGTTGCGGNTGNCCGGGTGCAGGTCNNCTCCGAGTACTTGAAGCTCGCCGACTCGACACT CTGGCCGCAGGTCAACCTGCTGGCCCGCGGTGGTGGCGAGATGGGGGGTGACTCGAGCGGGCTCAACGGCGTAGGGCTCTACGCGAAC TGGGAGCTCGACCTGTGGGGCCGGGTGCGATCGGCACGTGCTGCGACCGAGGCGACGTACGGTTCCGCCGTCGCGGATGCAGAGTATG CGCGGCAGTCGGTCGCGGCGCTGGTGGCCAAGGCCTATTTTTTGGCAGTCGAGGCGACGCTGCAACTGCGGCTGGCGCAGGAGTCGGT CGCAACGTCGCAGCAACTGGTTGCATTAGCCGAACAACGTCAGCGCATCGGCAAGGGCGACGGCTACGACTCTGCATTGGCGCGCGGC AATGTCGAGACGTACCGCGACTCGGTCGAGAAGTTGGCGTTGTCACGTGGACAGGCGCTGCGTGCGCTCGAGGTGCTGGTCGGTCGTT ATCCGGCCGCGGATGTCGAGGTTGCCACGCAACTGGCGCAGCCGCCGGGACCGGTGCCGGCCGGCCTGCCGTCGGAGTTGCTGGAGCG GCGTCCGGACGTCGTCGCAGCCGACAGACGTGTCGCCGCCGCGTTCTACGGTGTCCAGGAAGCCAAGGCAGCCCGGCTGCCGAGCATT TCACTGACGGCATCGGTCAGCGACATTTCGAGCGACTTGTTTGTCCTTAAAAACAGCGATAACCCGATCTGGAGTGGGGGCGCGAGCC TGCTGCAACCGGTGTTCAACGCAGGGGCCCTGCAGACGCAGGTCCGTATTCGCACGGCCGAGCAGAAACAGTCGATCGCGGAGTACGG TCAGATCGGTGCCCGTGCATTCGCGGAGGTCGAAGACGCTTTGTCGGCCGAGTTTGCCGCAAGCCGGCGCGAAGCCGTCCTGCTCCGC GCCGTCGGCGAGAACAAGACGGCGCTGGAGTTCGGGCAGCAACGCTTCAAGGTCGGCTCCGGCGATATGCGGGCCGTCTCACAGCAGC AACTCGCGGTGTTCGGCACCCAGTCGGCGCTGCTGCGTGTGCAGAGCGAGCGGCTCGTCCAGCGCGTCAACCTCTACCTGGCCCTTGG CGGAGGATTCGATGCGGTGCCGGCAGCGACGCCGGTCGCGCAAGCGAAGGAGTAAATCATCTACAGCCGATCGGTCGCTCTGAGCATC GCAACGATTGTCGCCACGGGCGGCCTCTCCGCCAGCCTGCAGGCTGCAGACCTGCCCAACATCCGAGTGCTCGCCACGGGCGGCACGA TCGCGGGCGCGCAGGCGAGCGCGACGGACTACGGCTACAGGTCCGGCGCCTACGACGTGAATTCGCTGATCAGCGCGGTGCCGAACCT CGGCAAGCTGGCCGTGATCACGGGCGAGCAGGTCGCGAATATCGGCAGCCAGGACATGAACGACGAGGTCTGGCTCAAGCTCGCCAAG CGCGTCAATGCGGTGCTGGCCGAGCCCGACACCGATGGTGTCCTGATCACGCACGGCACGGACACGCTCGAGGAGACGAGTTACTTCC TGTCGCTGGTCACCAGGAGCGACAAGCCGGTGGTGATGGTGGGTTCGATGCGACCCGCAACGGCCATCAGTGCCGACGGCCCCGGCAA CATCTACAACGGCGTTGCCGTGATTGCCGACCCGCGCGCGAAGGGCAAGGGCACGCTGGTCAGCCTGAACGACGAATTCCACTATGCG CGCAATGTGACGAAGACCGTCACGACGAGCGTGCAGACCTTCCAGAGCCTGAATCGTGGGCCAGCCGGCGTCGTGCACACCGGCAAGG TCGAGTGGTTCGAGCCGATGGACAAGAAGCACGGCAAGGCCACTGAGTTCTCGGTGGACGGGCTCGACCAACTGCCACGGGTGGACGT GATCTACGCGCACGCGAATATGAGCGCGGACCTCATCGAGGCTGCAATCAAGAACGGCGCGAAGGGCATCGTGATCGCGGGCGTGGGT GACGGCAACATGACGACTCCGGCGCTCGAGGTGCTCACCAAGGCCGCGAAGAACGGCACCGTTGTTGTTCGCAGCACGCGACTTGCTT CGGGTCTCGTGCTTCGCAACAACGAAGTCAACGATGACGAGAAAGGATTCATCGCCTCGGGCGAGCTGAATCCTGCGAAGTCGCGCGT GCTGTTGCAGCTGGCGTTGACCAGGACCAACGACCCGATCCGGATCCAGAAGATGTTCTACGAGTATTGAGCCCGGATCGAAACCCTC AGCGTCGGCGCGGCATCGGTCGCGGTGCGGGCCGCGGTGACGGTCGGCTGGTGGGCCGGCTCACGTTCGAGGGTCGCGACGAGGGCAT CGGCGCAGCCTTGGTGGAGGGGCGATTGACCTCGGCTGGCAATGTCGTCGGCTTGTCCGGACGGTTACCCGCACCGCCGCCATTGCCA GGCCGGTCCGGCGGCACGACGACCACCGGCGGATATCCACCCGGGTAGTAGCCCGGGTAATAGCCACCGCCGTAATAGCCGCCGTAGC CGTAGCCGACGCTGACGCTGGTGGAGACACCGCCGTAGCTGGAGTCGCCGCCGTCACTGGCACATCCGCCGAGCATTGTCACCGCCGT CACTACCGCCACAGCCGTGGCCAGCCGGACGTTGAATCTGACATTGCGCTGGCTCATGGCTGCGCCTCCGGGGTCGGCACCTGCACAA TGCCGACGGGGGCTCCGGTCGGGTCGGCGATGATCGCAACCGTCGTGCGACTCATGGCGAGCGGTTCCAGCAACACTTTGCCACCGGC AGCCCTGGCGGCCTCCGCAGACGACTTGGCGTCGGCGACGCGAATGTATGGCAGCCAGGTCGGCGACGCCTTGTTGCTTTGCTTCTGC ATGATGCCGGCGCGCGCGAAGCCGCCCGACATCAGGCGCAGCCCCGTGCGCGGACCATCGTCGGTAATCGGCACCGTCTCGAAGCCTA CGACCGTGCGATAGAAAGCCGCGGCTTTCTCGACGTCGCCGGTCCAGAGATCGACCCAGAACCACTCGTTGACGTCCCCTGCGTAATC GAGCGGATCGCCGTTCTTCGACTTCACGACACCGAACAGGACGCCTTCCGGGTCCTTGAACACGGCCGTCTCGCCGCGCTCACCGAGC ATGACCGGTGCATAGACGACCTTGCCGCCACTCGCGGTCACGGCCGCAGTCGCTGCCTTCACGTCGGCAACCGAGATCAGCCCGACCC AACGTGCCGAAGGGGTCTTGCCCTTCATGGCTCGCTGGTCGAAAACCATGCCGCCGATCGGCAATCCGTCGGCGAGGGCGAGCGTGTA GGTGTCGTGGTCGTCGTCCCCGCCGTACGTTTCGAACGTCCAGCCAAAGACCTTGCCATAAAACTCGGCGGCCGCTGCAACGTCCGAC GTCACCAGGTCACCCCAGACGAATCGACCCGGGATGTGCTGCCCGGTGGGTGGGTCGACGATTGGCGGCCAGAAGCGATCGCCTGCCT GGGCGCCGGACGCCAGCATCGAGGCCAGCATGCCGAGCCACCAGCGACCGCTTGCGCGACGTTGTACGGGAGACGGATGAAGCATGTC TGGCTGGCCCCCGGGACAATGGTGCTTGAATATTCGTCGACTATAGCGCGACCGACGGAGACCGCGTAACTATCCCGTGTGTTGCAGC AGACCCTTGGATTCGAGCCACTCGCGGTTGTAGAACCGTGACAGGTACTTGTGTCCGCCATCACAGAGAACGGTGACGATCGTGTGGC CGGGACCGAGGTCACGTGCGACGCGAATGGCGGCCGCGACGTTCGCACCGCTGGTGCTGCCCAGGAACAGGCCTTCCTCGCGCAGCAG CTGGTAGGTCGTGCGGACGATCTCCGGATCATCTACCTGCACCGCGTCGTCGATCGGCGAGTCCGCGAGGTTGGCCGTGACGCGGCCG ATGCCGATGCCTTCGGTGACAGCACTCGAACCAGACGACTTCAGTGCGCCATGCTTCACCCAGTGATGCAACGCACTCCCCATTGGAT CGGCCAGCACGATGCGCACGGCCGGCTTCTGTTCCTTGAGGTAACGGGACACGCCACCGAGCGTGCCGCCGGTTCCCGTCGCGCAGGT GAACGCGTCGATGCGTCCCTGCGTGTCGCGCCAGATCTCGGGTCCCGTCGTCGCGTAGTGCGCGTCGCGATTCGCCGTATTGTCGAAC TGGTTGCCAATGGCCGCGCCGAGTTCTTCGGCCACCTTCGGCGCCAGCTTCTGGTAGTGATTGGGATCGGAGTAGGGCACCGTCTTTA 
CGACGCGAACTTCGGCGCCCAGCGTGCGCAGCAGCGCCGCCTTTTCCGGTGACTGGTTGTCCGGCATCACGATCACGCACTTGTAGCC GCGCGCGTTGCAGAGGTGGGCGAAGCCGATGCCGGTATTGCCAGCCGTACCTTCGACGAATGTGCCACCACGCGCGATCAAGCCCCGG CGCTCGGCGTCGTCCAGGATGCCGCGAGCGGCTCGGTCCTTGACGGAGCCGCCCGGGTTCAGGAACTCGGCCTTGCCGAGGATCTCGC AGCCCGTGGCCTCGCTGGCGCGGCGCAGGCGGATCAGCGGCGTATTGCCGATCGTGGCAGAAAAGCCGTCGCGTACTTCCTGGCGCAT GGAGGTGCCCATTCAGTCGTGGACCAGGCGCTCGCCGCCCGCGTAGACGTTGAAGCGCTGGCCGCGAACGAAGCCAAGCAGCGTGACG CCGAACTCGCGCGCGGCATCGACGGCGAGACTGGAAGGCGCACCCACCGCACAGACGACCGGGATCCCGGCCATCACGGCTTTCTGCA GCAGCTCGAAGCTCGCGCGGCCGCTCAGGAACAGGATCGTGTCATCGGCTGGCAACGTGCCGGCAAGGAAGCGCGCTCCGATCAGCTT GTCGAGCGCATTGTGGCGACCGACGTCTTCGCGCAGGCCGAGCAACTCGCCGGTGCGGGAGAACAGGGCGGAGGCGTGCAGGCCGCCG GTCGAGCGGAACACGTGTTGCTGCGTCTGCAGGCGCTCGGGCAGCTCGTCGATCAGATGCGCGTCGATGGTGAAGCCCGCCGGCGGCG CGACCGGCCGTGCCCCGGTCGCCAGCGCTTCGATCGAGGTTTTGCCACACACGCCGCAACTCGACGTCGTATAAAAATTGCGCTCCAG CCGCTTCATGTCGACATCGACGTCCGCAACTAGATCGACGCGCAAGGTGTTGGTCGCGCCCTTGCCCTTGCCGCAGTGTTGGATTTCG TGGACCTGCGCGCTCGATTGCAGGATGCCTTCCGTGAANAGGAATCCTGCCGNNNGTTCGAAATCGTCGCCCGGCGTGCGCATCGTGA TCGAAATCGNNNNATGACGAAGCTTGCCATTCTCGACCCGGCCGAGGCGGATCTCGAGCGGCTCCTCGACGGCGACGGCGTCGTCCTC TGTTGCAGTGGGTCGCCCCGACTCATATCGCTGGATCGCAGCCTGGCTGGCTTCGGGTCGGCCGGTCAGCGACGGTTTCGAGCCTGGC GGTGGCAAGTTGCGGCTCCGGTGCGATCAGGTCGAGTGGGACGCGTAGGGCAACGGTGCAAGGACCTCGCAACCGTATGCAGCCGCGG AGACGGCGAGCCAGCGCCAGAGGCTATCGAAGTACGTGCGCACGACCAGCAGACGATAGACCGGTTCGTCGGTAACTTGCCAGAGGTG CACGGCGAGATGCGACGCCGTGGTGACCGCCACGTCGCCCGTCTTGAAGGCGCGCGGATGCAGGTCGATCGACACGCCCTTGGCGAGC ACGTCGCGCACGTGGGGTCCGCGCAGTTCGAGCAGGACGCGGCTGCCGCTCTGATCGAAGACCGAGGCGTGCGATCCGAACATGGCGC TGAAGCGTGCCTCGACGGGCTCCGTCCCCTGCGATTCGAGGGCGAGCCAGTGTCCTGGCCCCGACCAGAGAAAGGCAAGGTCGCCACT GCTCGTGATTGCTGGCGAGGAAGGCAGCGTCGTGCCGCAAGCCTGCAACGCGGCCGCTGCAGCGAGCCCGGCTTGATTGCGGCGGGCA ATGACGCTGGCCAGTGAAAACTGCGTGTACTCCTGCAGCACGAGGCCAGGTGCTCCTTCGTAGCGACCGAAGCGACCCGGGCCGTAGT CCAAGCGCAATTCGTCAGCCACGGAGGCGCACTCCTTCGGGATCGATGAACACTGGCGCGCAGACCTCGACGAGAGTCTCGGCCCCGC GCAACGGGTCGACGACCATGATTTGCTCGCCATGGCGCTCCGGACCGTTGCTGAGCAGGCCCAGGCCGATCCACTGCCCCAAGTGCGG CGAGTAACACACGGACGTGACGTAGCCCTGATCGTGCTCGATGCTGCGTTTCGCGTGCTGCGGAATGAAGTGCATGCCGCCGGCCAGC TTCGCGTTCCGATCCACGGTCTTGATGCCCACGAGCCGGGGACGCGCAGGATCGACCAGGTTCGCCCGGCGAGCCAGCACGACACCGA TGAAGTCCTTTTGCGTCGAGAGCATGCGGCTGAATCCAAGATCGTACGCGGTCGTCTGGCCATTGAGTTCGCTGCCGACGACGTGGCC TTTCTCGACGCGCAGCATGTTGAGTGCCTCGAGGCCGTAGGGAACGACCCCAAGGTCCTGTCCGGCGTCATGCAGTACGCGAATCAAT GCATCGCCTCGGTGGCCGGGCACGGCGATCTCGTAGGCCAGCTCGCCCGAGAACGAGATGCGGAAGAGTCGCGCTGGTTCGCCCGTGC GCAGCGTGACTTCACCGGCCGCCATGAACGGAAACGCCGCGTTCGCAAGGTCGCACCGGGGGTCGAGCACGCGTTGCAGCAGTTCACG CGAGCGTGGACCCGCCACGGCGAACTGTGCCCACTGATCGGTCACTGATACGAACTGCACGTCGAGTTCGGGCCACAGCGTCTGATGG CACAGGTGCATGTGCTGGTACACCTGCACTGCGTGCGACGTGGTGGTCGTGATCAGGTAGCGATTCGGGGCCAGGCGTGCGGCCGTGC CGTCGTCGAGCATGAAGCCGTCTTCGCGCAGCATGATGCCGTAGCGGGCGCGGCCAACGGCGAGGGTCGCGAAGTTGTTGGCGTACAG GCGTTCGATGAACTGCAGGGCGTCCGGACCCTGCACGTCGATCTTGCCGAGGGTGGAGACGTCGCACAGGCCGACGGCCGAGCGCACG GCTTTCACTTCGCGGCAGGTGGGCTCGAACCAGTCGGTTTCGCCGGCTCGGGGGAACCACTGCGCGCGCAGCCACGGTCCGCTCTCGG TGAACGACGCGCCCAACTCGCTCGCCCAGCTGTGCGACGGGGCATAACGGGTCGGGCGGAAATCCATTCCGCGGTGGTGTCCGGCCAT CGCACCCATGGCGATCGGCGTGTAGGGTGGACGGAACGTGGTAGTGCCGGTGTCGGCGATCGAGCGGCCACGGTGCTGTGCAAGCAAG GCAATACCGGTGACGTTCGAAGTCTTGCCCTGGTCAGTTGCCATGCCGAGCGTCGTGTAACGCTTGGCGTGCTCGACGGAGCGGAAGC CCTCGCGTTCGGCGATCTCGATGTCGTCCGCCGTGACGTCATTCTGGAAATCGACGAAACACTTGCCTGCCGCCCGCTTGACCCGCCA GAGCGGAACCCGCCGTGTGGATTCTTCAGGAATCCGCGGCAGCGCAGGCATCGAGCCCGCATGACCACAGGAGACCGCCGCCGCGAGG CCTGCGCGGTATCCCGTGAGCAGGGCTTCGCCGAGCGCCAGGTTGCCATTGGCCGCGCCAGCGACGCGCATGCCCACAGGCAGCTTGT CCGGCACGNAAGTNNGCNCGGNTTTCNGTCCCAGCGCGNNNNNNNCCCTTNGTGCNACGTCAGGTGCCAACGTTGGGAGAANNNNCCC GCCNGACATGNCCACGAGATCGCANTAGATNCGGCGCGAACTTCCCGTATGGCTGGTAACTTTTACCGACTCGACGCGTTGNCCACCA CTNNNATCAATTAACCTCGCCGGCAATGGCCTCGAAATTTGGATAACGACGCGCGAGTGCGGCAAACGACGAAGGGCCCACGNGAGTC CACGACCGCGGCCACGTCTGNNNCTGCCGCCAAGAGGTCCGTCGCCGTGGTCCAGCCATCGTCGTTGTCCGTGAATACCAGCCCACGC TCGCCCGGCAGTACGGCGTAGCGATTGACGTATGTGCGCACCGCACCCGCCAGCATCACGCCCGGCAAGTCGTTGTTACCGAACACGA GCGGACGTTCGATCGAGCCGGACGCCAGTACCGACTGCTTTGCGATGATGCGCCATACGCGCTGGCGCGGTTCGAACGGCGGCGGAAC CGGCAGGTGATCACTGACGCGCTCGACGGCGCCATAGATGCCGTCATCGTAAACGCCGAAGACCGTCGTGCGCGGAAGCAACCGCACT TCAGGCATTGAACTCAGTTCCGCAACAGCCCTTGTGACCCAATCGGCCGCCGGCATGCCGTCGATCGTGCGTCGTTCCGCGAGGCAGC GTCCGCCCAGCCGGAAATCCTCATCGGCAACGATGACGCGCGCACCACAGCGCGCGGCACTCAACGCGGCGGCCAGGCCGGCAGGCCC GGCGCCAATCACCAGTACGTCGCAATGCGCCCAGCTTTTCTCGTAGTGGTCCGGGTCGGGCTCGAGTGCAGCGCGACCGAGACCCGCG GCCCGACGGATCAGCGGCTCGTACACTTTTTCCCAGAATGAAGCAGGCCACATGAAGGTCTTGTAATAGAACCCGGCCACGAACAGCT TCGAGAACAGGCTGTTGATCGCGTGGACGTCGTAGTGCAGCGACGGCCAGCGGTTCTGGCTCGTGGCTTCGAGGCCGTCATAGAGTTC GATCACGGTTGCGCGCGTATTGGGCTCGCGGCGGGCGCCGCTGCGCAGCTCGACCAGCGCGTTGGGTTCTTCGGGACCGGCGCTCAGC AGGCCGCGTGGCCGGTGATACTTGAACGAGCGGCCAACCAGGCGCACCTCGTTGGCAAGCAAAGCCGAAGCCAGCGAATCTCCGACGC AACCGGCGTAGGTTTTGCCGTCGAAGGTGAAGCGCAATTTCTGCTGCCGATCGATCACTCCGCCATGGGCGAGGCGGAAACTCACTGG GCGTCTCCCGGCGCGAAGGCTGTGCGAGCGGCGACGGCGCCCTTGATGTCGTGATTGCGCGTGTCGCGCTCGACGACCAGCCATTCGT GGCAGCCGCCCTGGTGGAACCAGAGTTCACGGTGCAGGCCGAACGGATTGTTGCGCACGTAGACATAGTCGTAGAAAGCGGACTCGGC GTCGGGACCCGTTGCTGACGGGCGCCGCACGGTGGCGTCGCCGTGATACGTGAATTCGTCGTGTGTGCGGGGCCCGCAGTAGGGGCAG GGGATGCGCATGGTTCAGTGCCGGTTGGGGTGAGCGCCGGAGCCGTTCTCGTCGATCAGCTTGCCACTGGCAAACCGGTCAAGTCGAT ACGCCATTGCGACCTCATGGGGCTGGTCCGTGGCCAGCAGGTGGGCGAAGCACCAACCCGAGGCCGGCGTGGCCTTGAAGCCGCCATA GCACCAGCCGGCATTGAGGTAGAGGCCGTCCACCGCGGTGCGGTCGATGATCGGTGAGCCGTCCATCGACATGTCCATGATGCCGCCC CACGAACGCAGCAGCCGCACCCGGCTCAGCCACGGGAACAGCGCCACGCCTTCCTCGCAGACTTCCTCCACGATGGGCAGGTTGCCTC GTTGCGCGTACGAGTTGTACAGGTCGATGCTGCCGCCGAATACCAGGCCGCCCTTGTCGGATTGGCTGATGTAGAAATGACCTGCGCC GAAGGTAATCACGCACGGCACGATCGGCTTGAGGCCCTCGGAGACGAATGCCTGCAGCAGGTGGCTCTCGATCGGCAGGCGCAGGCCG GCCAGCGCTGCCACGCGGCTGCTATTGCCGGCGCAGGCCAGCCCGATGCGTCGGCTGGCGATGAAGCCACGCGTGGTCTCAACGCCCG TGACACCGTTGTCGTCCTGGCGGATACCGGTCACCTCGCAGTTCTGCAGGATGTCGACACCCAGGCTGTCGGCCGCGCGCGCGAAGCC CCACGCGACGGCGTCGTGACGCACCGTGCCGCCGCGTCGTTGCAGCAGGCCGCCGAGGATCGGGAAACGGGCGTTGTCGAAGTCGGCC GTGGGCAGCAGCTTGCGCACCTGCTCCCGATTCAGCAGTTCTCCGTCGACTCCGTGCAGGTGCATCGCATTGCCGCGGCGGACGCAGG CATCACGCTGCGAGTCATTGTGAAACAGGTTCAGCACGCCGCGCTGGCTGATCATCGCGTTGTAGTTGATGGACTGCTCGAGGCCTTC CCACAGCTTGAGCGAGTGCTCGTAGAAGGGGATGTTGCCAGGCATCAGGTAGTTCGACCGGATGATGGTGGTGTTGCGGCCGACGTTG CCGCTGCCGATGTAGCCCTTTTCCAGCACTGCGATGCGGCGGGCCCTGTGGTTCTTCGCCAGGTAGTAAGCAGTGGCCAGGCCATGAC CGCCGCCACCGACGATGATGAAGTCGTACGCCGACTTTGGTTCAGGATCGCGCCAGGCCGGTGCCCAGCCCCGGTGGCCGCGGAGCGA TTCCCTGAGCAGGCCAAAAATCGAGTATCGGTTAGTCACGGCGTCAGTCCGGGAGGATGCAGCCCTTGTTCATGACGCCGTTCGGGTC GAACGCGCGCTTCAACCGCTCGAGTATGTAGTACGACGAGTCGTACTCCTCCCGTATCCAGGGCGTGCGGGCCTTGCCCATGCCGTGG TGATGCACGACCGAACCGCCGAGCTTCAGCGTTTCCTCACAGATTACGCGGTTGATCTCGGTGCGGTATTTCTCCACTTCCTGCTCGG GCGGGCAGTTCACGTTGTAGTAATAGATGAAGTACATGTTGGTGCCGTTGATGTAGCTGTGCGAGCTGTGCCCGCCAGCCACGGTTAT GTCCGGCACATCGACCTTGAGACGCCGCAGCGCGTTCTCGTAGATGTCGCAGATCGTGCTCCAGTCGGCAGAGACCTCCGTGGTGCGG 
CCCATGGTTTTCGTCGCGACGATCTCCTTGCGCTCGTTGGCGATCTTGTCCGGGCCCCAGTTGAGGTCGGCAAACCATTCCTCGAGGT GGTGCGCATCCACCGGCTGGCACTCGGGAAATTCCTTGACGATCTGCTCGATACCCTCGATCGTCGCCTTGACGACGCCGGCCGGGCC TTCGGCCATGAACAGCAGGACGCAGTCGTCGCTCGCGGCAAACTTCGAGAAATGGAAGGCGCCGTCCGGCGGATCGTAGAGCCGGGCG ACCGAGGGGCGATAGCCTTCGACCATGACTTTGCGCAGCGCCTCGAAGCCCGTGCGCATGTTCTTCAGCGTGTAGCCGACGAACGTAT TGTTCTGCGGCAGGTACGGGAACAGCTTCACCGTGACTTCAGTGATGTAGCAGAGCGCACCCTCATTGCCGATCACGACGTGGCGGAT ATCCGGGCCCACGGCGCGGCGCGGCACGTTCTTGATGCGGGTGACCGTGCCATCGGCGAAGACGGCCTCGACGCCGACGACCATGTCT TCGATGCCGCCATACAGTGTCGAGAACTGGCCGATGCTGCGCGTGGCCACGAGTCCGCCCATCTGCGCGATCGGCTTCGACTGCGGCG AGTGCCCGGTGGTGAGGCCTTGCTTGCGCACCTCGTCCTCGAGTGTCTGCAGGCACACGCCGCACTGCGCCGTCGCCTGCATGTTGTA GGCATCGATTTTCAGGATGCGGTTCATTCCTGAGCCATCGAGGACGATGGAATTGGCGACTGCCGTCTCGAGCCCACCTTCCGTCGCG GTACGTCCCGTGCGAGCGACCACGTTGATCCGGCTCTTGTTGGCGTACTTCAGCACGTCGGCCACGTGTTGGGTGCTGCGTGCCATGA CCACCGCGGCCGGAATCGGCCGCGTGAAGACGCCATGCACGTCCTCGTAAAGGCGCAGGCGGTCGATGCTGCTCTGTTTCAGTTCCTT CTCATCGGTGATCACGTTGGGGCCGCCAACGATCACCTGGAGTCCCTGGACGATGGCGGTCTTGCTCAAGGCCATGATGCGGTCCTTT TCGGTCGTCCCGGCAGGTGCCGGAGTCAATGAAAGAGTGGCCAGGACCGTTCGAGGACCTGGTCGGTTGAATTACGGATGTCGCGGAA GACCTCGTCGCTCATGCGGCGGTACACCGCCGTGTTGCCGGCAATTCGGTGCAAATGACTCGCGGGGTTTCTCCATGCGCGCGACGGC GGTCGCGAAATCCGGATAAACGCCAGTTGCGACGGCCGCACAGATCGCAGAACCGAGGCTGGCGCCGCCAGGGCCGCTCGCTCGTGTT GCGGGAATTCCAAAGACATCGGCGAAGATCTGCATGAAGAGCGGGCTCGACGAGCCACCGCCCGAGATCACGATCTCGCGCAGTTGGA TGCCGAGTTCGTCCGCCATGCCGTCGACCTTGTCCTTCATCGTGAGTGCGATCGCTTCGAGGATCGAACGGTAGGCGTGCGCACGCGT GTGCCGCGCGTCGAAGCCGAGCATGATGCCCTTGCGGAAGGGCTTGTCGGTGGGCGCGAGCCAGTCGAGCACGCTCAGCAGGCCGTCG CAGCCGGCCGGCACCTGCAGTGCTTCCTGTTCCAGCACGTGCTCGCGCGTCTCGCCACGAGCCGTCGCTGCGGCAGCGAACTCCGGCC CGAGCAGGTCCATGAACCAGGTGAGTGTCCACATGCCGCGACGAATGCCATGACTCTCGTAGAGGTAGCGGTGCGGGATGCAGCCGAA ATTGGTCCAGAACTGCTGGGCATCCTGGCGGTTGTGCTCGCCGTGCACCATCGATGCGATGTACGTGCCCAGCGAAATGAGCGCAGTG CGGTTGTCGAGGGAGCCCGAGCCGAGTGCTTCGACGGCTTTGTCGTTGGCCGTCACGACGACGGGCAGCCCGGCTGGGAGGCCGGTGG CCGCGGCAGCTGCGGCGGTCACGTGGCCGGCGACCACGCCTGGCAGCAACAGCTCGAACAATTGTTCGCGCCGGAGGTTGAACTGTTG CAGCAGCGTGTCATCAGCGCTCCATTGCCACGTGTCCGTGTCGATGGGCCACTGCAACGCGATGCTGTTCGCCGCAGTGTCCTTGAAC TCGCCCGTGAACCGATGCGTAAGGTAGCCGGAGGAGGTGGTCGCATACGCCACTGCCGGATCCTCGGGCCTATAGGGCTGGTAAGCAC GAGTGTCCATCCAGCTCAGGACCGGCTGTGCCAGCGAGCCGTCGGCCCGCAGGAACGCCTTGCAACAACGGATGGTGCAGAGACCGAT GCCGATGATCTCGCGTGGATCGCCCTTGAAATTCGCGAGCGCCTGCCGGCTCGCACTGACGATCGAATCCCACAGATCGTCATCCGGA TGTTCGACCAGGCCAGGGAGCGGTCGACTGGCGGCGCGCAGCAGTTGCCGGCCTTCCGCAACGGCATTGCCCTCGAGGTCGTAGATCA CGACCTTCGTGCTCTGCGAGCCGTTGTCGATGCCGACGATGTAACGCCCACGGGTCGCCATCTCGCGTCAGCGCACCAGGTAGCCGCC GTCGACGACGAGCAGGTGACCGTTGACGTAGTTGGAGGCGCGGCTTGCGAGATAGACCAGTGCTCCCATCAGGTCGACCGGCTCACCC CAGCGTTCGGCCGGGATGTGGTCGAGCACACGCCGGTTGGTTTCCGGATTGCTGCGCGTCTGGCGCGTGATCTCGGTGGCGTAGTAGC CGGGCGCAATGCCGTTCACCTGGATGTTGTGCATTGCGAGCTCGTCGCAATACGCCTTGGTAAAGCCGGCGAGGCCATGCTTGGTCGC TGCGTAAGCCGACGACCAGCGACCGCCCAGGAACGAGAACAGCGAGCAGATGTTGATGATCTTGCCGCTGCGTTGCGGAATCATTCTC TGCGCCGCTTCGTAGCTCGAACGCGGCCGTGAGGTTCACTGCGACGGTGGCATCCCATTGCGGACGACCAAAATCGAGCACCTCAGCC ATCGGGCAGATGCCCGCGCTGTTGACCAGGATGTCGACGGCGCCGAAACGCTCGATGCAGGTGTCGATGACCTTTGCGGCAGCCCCAG GCGCCGTGATGTCGATCCTGAGGTATTCGTAGCGACGACCGGTCGCCGCGATGATAGGACCTGTCTTGCCGTCATCGTCCATGACGCT CGGCACGAACACGTCCGCGCCCGCCTTGGCGAGCGCGAGCGCAAAAGCCTGGCCGAGACCCGTGTTGCCGCCGGTGACGATGGCTTTC TTGCCCGCGAGCGAGAAGAAGTCCATCGAGAATTCGCTGATCTCCATCAGGGCTCGCTCCATCGGCGTCGTCACCGCATCTTCACGGC GGGGCTCGTTTTTGATGATGGCGCTCGCCGCCAGCACGCGCGCCGAAGTATAGCCTGCGAGTTTGTGCCACGACGCAGCCGATGGCCG TGTTTTGCAGCCATGTTTGACGCGGGCTGCCGCTCCCTGTTACCAATGCGTCAGAAGATTTTTACGCAGGGGAAGGCAATGCGTTCGA GCTGGCACCCAGGGGCGGGTCCTGTGCTCCGTGGGCGGCGGTCGCTGGCTGTCGTGGCCCTCACGCTGCTCGGGCTTGCATCCGGGTT CGGTCACGCGGCCGCCGCGACTGCCGAACCGCCCAGTTGCCGCGTGGTGCGGCTCGCCGACGTTGGCTGGACGGCCGAGACCGCGACC ACCGCCGTCCTGGGCCAGATTCTTACGAACCTCGGCTACCAGCCCGTGATTACCGTGCTTTCCGTGCCGGTCACGTTCGAATCGATGA AGAACGGCGATATCGACGTTTTCCTTGGCAACTGGATCCCGGCGCAGCAATCGATGCTGCAGCCTTTCACCGACGAAGGCTCCGTCGA AGTCGTCCGCGACAACCTGGTCGGTGCGAAGTACACGCTCGGCGTACCCGCCTATCTGCACGACGCGGGGCTCAAGGACTTCGCGGAC ATCAATCGATTCAGAAAAGAGCTGGGGGCATCGATTTACGGCATCGAGCCGGGCAACGATGGCAACCACCTTGTCCTCGATCTGATCA AGAAGAACGAGTTCGGTCTCGGTGGCTTCAAACTCGTCGAGTCGAGCGAGCAGGGCATGCTGGCGCAGGTCGAGCGGGCCTACCGGAC CCAGCAGCCGGTCGTGTTCCTGGCGTGGGCGCCCCATCCGATGAACACGCATTTCAACGTGCGCTACCTCACCGGCGGCGACGCCATC TTCGGCCCGGATTACGGCGCTGCCACTGTCCGCACGCTGGTGCGCAAGGGCTTCCAGCAGGAATGCCCGAACGTCGCGCGGTTGTTGC AGAACCTCGAGTTTTCAGTCGAGCTCGAGAACGAATGGATGGACCGCATCCTGAGCGACAAGGTGCGAACTTCGGATCTCGCAGTCGA ATGGCTCGCCAGGCGTCCGCCCGTCGTGGCGACCTGGCTCAACGGTGTCACCGGCTTCGATGGTCGACCCGCGCAGCAGGCAGTCGAT GAGCCTTCGCGAGTCAGTCACCTCAGCGCGTTTGAAGACTGGATCACGACCAACAAGATTCCGGTCGGCGACGCCGCGACCACGTTCG TCGAATACACCAAGAAGCACGCGCGTGGGCTGTTCGACGGCATCGCGGCCGTGCTGACCGGTTCAACCAACGTGGTGGCGAGAATCCT GAACAGCGTTCCAGCCCCGGTACTCATCGTGCTGATTGCCGCCCTGTCTTGGGTGCTGCGGCGCTCGATCGGGTTGGCCGTATTCGTC ATCCTTGCGTTGCTGTTCATCATGAACCAGGGTTACTGGGACGCAACGCTCGAGACGCTGACGCTGGTGCTGGTCGCGGCCCTCGTGG CGACACTGATCGGCGTGCCGCTGGGCATCTGGAACGCCAAGCGTCCGCGCCTGTATGCGGCGATGCGCCCCGTGCTCGACCTGATGCA GACGTTGCCGACGTTCGTCTACCTGACGCCGACGCTGGTCCTGTTCGGGCTCGGCATCGTGCCGGGCCTGATCTCCACGATCATCTTC GCGCTGCCGGCGCCGATCCGGCTCACGCAAATCGGCATTTCATCCGTGCCCAAGACGCTGCGCGAAGCAGGGCAGGCGTTCGGCGCGA CGCCTCTGCAACTGCTGTTCAAGGTCGAGCTGCCGAGCGCGGCTCCGATGATCCTCGCGGGCATCACGCAGTGCATCATGTTGAGTCT GTCGATGGTCGTGATCGCGGCGCTGGTCGGAGCGGGTGGACTCGGCGTGCCTGTGGTGCGCGCGCTCAATACCGTGCAGGTCGGCATG GGCTTCGAGGCAGGCATTGCGATCGTGCTGCTCGCCATCATGCTTGATCGCATCAGCCGGCCGGCCGAGAAGAAGGGGCAGGAATGAG CAGCGCAGCGCTCGAGTTCGACCAGGTCGACATCCTGTTTTCAGCCGAGTCGGGACGCAAGCGCGAAGCCGCGATCAAGTCCGCATTG CAGCGCCTCGACGAAGGCCGCGATCGCAACGAGATCGAGACCGCGACGGGCGTCGTCGTCGGCGTGAGCCAGGCGAGCCTGAGCGTGC AGCACGGCCAGATTTCCGTGCTGATGGGTCTGTCGGGATCCGGCAAGTCGACGTTGCTGCGGGCGGCCAATGGCCTCAACCGCATCAC CCGCGGCCGGGTGCTGGTCAACGACGGCGAACAGCAGATCGATGTCGCGACGTGCGATGCGGCCACGCTGCGGCGACTGCGACGCGGC ACGATTGCGATGATCTTCCAGCAGTTCGGGCTGTTGCCGTGGCGCACCGTGCGCGAGAACGTCGGACTCGGCCTGGAACTGCGCGGCG AGTCTGCCGTCGAGCGTCGCCGGATCGTCGACGAGAAGCTGCAGCTGGTCGGCCTCGAACGCTGGGCCGACCGCTACGGGCACGAGTT GTCGGGCGGCATGCAACAGCGGGTCGGCCTCGCACGCGCGTTCGCGACCGACGCACCGATCCTGCTGATGGACGAACCGTTCTCGGCG CTCGATCCGCTGATCCGCAACAAGCTGCAGGACGAGCTGCTCGCACTGCAGGCGCGCGTGCGCAAGACGATCCTGTTCGTCACGCACG ACCTGGACGAGGCGCTCAAGCTCGGCAACCAGACCACGGTACTGGAGGGCGGCAGGATCGTGCAGACGGGCACGCCCGAGGACATCGT GCTGCGGCCCGCGAATGCCTATGTCGGCGAGTTCGTGCAGCACATGAACCCGCTGTCGGTCCTGAACGGTCGCATGGTCATGCGCCCC TGGGCCGAACTTGCCGCCGAAGGTCCGCAACGCTGGCTCGACCCGGGTCGGCAGTTCAGTGCGGTCCTGGACGACCAGGGCCGTCTCG TCGCCGCGGCGTTCGAAGGGCAGGCCCTCAGCATCCGCACCTCGCCGTCGACAGGCGAAGGTCTCATCGTTGCCGACGTAGACACGCC GCTGCGACAGCTCATTCAGTGGTGCCGTTCCGGCCATCCCGTGCTGCTCGCCGAAGACGGCGTCGTGCGGGGTGTTTGCGGGCCCACC GACGTCATCCGCGCACTCGCGACCAGCGATGCCCGTGCTCGCGCCGTCAACTGATCGATCTTCACTGCATCGGAGAATTAAATGCGAA TCCGCCACCCGCTGACCCGTGTCGCACGTATGCCAGGATCGATTGCCGGCGCAGTGGCCGCGGCCCTCGCGATTTGCGCACCTGCGCC TGCCATCGCGCAGCAGGCCAGCGCCAGCTCCGGCATCGAGGAAATCGTGGTCACGGCGCAACGCCGCGAAGAGAACCTGCAGGATGTC 
GGCATCGCCGTCACGGCACTCGGCGGTGAACAGNTCACCAACCTGAACATCAACATGGCGACGGACATCACGCGCGCCGTGCCCAGCT TGAAGATGAATGNNTACTCGTCATCACAAGTGGTGTTCAACATCCGGGGCGTGTCGCAGAACGACTATGNCGACCAGNNNNNNNNNNN GGTCGCCGGTGTTACCAGGACGACAGCTACGCGAGCTCGATCAACGTCGCGAGCTTTCCCGTCTTCGACCTGGCCCGTGTCGAAGTGC TGCGCGGACCGCAGGGCACCCTGTTCGGCCGCAATGCGACCGGCGGCGCGATCCAGTTCGTGTCCCGCAAGCCGACCAAGGACTTCGA GGGCTATGCCACGGCCACCGCGGGCAGCTACGGCCAGTTCATCATCGAGGGTGCGCTGTCAGGTCCGCTCGCGGACAACTTCCAGGCG CGCATCGCCGCGATCAGCAACACCGACGACGGGTACATGGAATCGATCGTGCATGGCGTGCCGGATCGCGGCGGCAACGATCACTACG CGTTGCGCGGGCAACTCGCCTGGCAACCTTCCGAGACGACGGACCTCAACCTCATCGTTCGCTACATGAAGGCGGACAAGGAGACGCA GGCCGGCATCTATTCGCAGGAGCCGGCGTGCCCGAACGACCAGTTCCAGGGCGAGTTCACGCGGCCCGACCAGTCGTGCGGCTTCTGG GGGACCGGGCCGGGTGAAGGCGGCACGGGATACCGCAACGACGCCATCACCCCGAGCCGCGGGGGCGATCCGTGGAAGACCGCCGAAA CGCAGCGCTCCTACGTCGATCGTGAAATCACGGGCGCGACGCTGCACTTCGACTGGGACATCGGTGAGCTGCACCTGGTCTCGATCAC CGACTACCAGGACGCGACCAAGTTCTACCTCGAAGGCGGCGACGCGTCGCCCGTCGACGGTGTGCTGTTCTACCAGGGCAGCGACCTC GAGCAGTATTCGCAGGAATTCCGCCTGTCGGGGCAGGCGGGCAGCCACACATGGGTGGCCGGCGTGTACGGCATGAAGGTGGACGGTG ATTACATCGGCAAGTTCGCCACGCCGTTCTATGGTTACGACCCGACCATCGAGATGTCGCAGAAGACGACGTCGTACGCCGTCTTCGC GCAGGACGAGTGGCAGTTCGCCGACGCCTGGAAGTTGATCGTCGGCGCGCGCTACTGGAACGACGAGCGCGAAGGCACTTACTTCGGC ACCGCACCCGAAGTGCCCGGTCTTTCTGCGCCGGTCACGATCATCTTCAACCAACAGGAAGTATTCCCTGGCGGCAGCAGCATAGGGC CGGGCGATGCCAAGAACAGCTTCGATGGCGTCACGGCCCGAGTCCAGCTCGACTGGCAGCCAATGGAGGACCTGCTGCTCTACGCCAG CTTCAACCGCGGCAGCAAGAGCGGCGGCTACACGTTCTCGACCGGCACGCCGTACGATCCCGATGGCAGCCTGACCATTCCGCGCACG TTCCTCGAAGGCATGCCGTTCGACGAGGAGACGCTTGACGCCTACGAACTCGGGCTCAAGTCCACCCTCTGGGACACGACGACGCTCA ACGTGGCCGCGTTCTATTACGACTATTCGGATTACCAGGCATTCGCGCAGTTCGGCCCGGTGCAGACCGTGATCAACCTCGATGCTGA GACTACCGGCCTCGAAGCCGAACTTACGTCGCGGCCCCTCGATGGGCTGACGCTGCAACTGGGAGCGTCGTTTCTCGACACCAAGGTC AAGGACGTCCCGTTGCCGGACGGCGTCACGGTCGAGGATCACGACCTGCCGCAGGCACCCGACGTTTCGCTCAACGCGCTGGCGAGGT ATGAGATCGACCTGGCCGGCGGCGTCGTCGGCATCCAGGGCGACGTGCAGTACTCGAGCGAATTCTGCTTCACGGTGCTATGCGCGCC GGTCGAGGAGGAAGACGCCTATACCGTGGCCAACGTCCGTTTGAGTTACGAGAGTGGTAGCGGCCGCTGGGGCGTGGCGGCTTTCGTC GACAACGTGTTCGAAGAGAAATACCGCGTGTATGCCTTCGACAGCTCGTTGTTCGCAGGTGTAGTGGCGGGCGTCTATGCCAGGCCGC GCTGGTACGGCCTGAGCGCCACCTACCGGTTCGGGTCACTCTGAGCCGAGGCAGGGCTCCTGCGCATCACTTCTGGTGGCGCGCGGGG GCAAGTCGTTGTCGCAAATTGATCAGTCGCCCGCTGGCGGGGCGACCATACTGGCCTCCTCGCAGCCGGGGACGGATCCACCATGTCC AGCATGGAAGAACAGCAGCCCGCCGCCGAAAGGCGCCCCCTTCGCGCCAGCGGTCGTGACGCAAAGCGTGCGGCGCGTGCAGCCCGCG CCGGCGCCTCGATCCCTTACATCACGCGCTCGATCCCGTATTTCGAGGTCCTGACCGACGAGGGCCTGTCGCTCATCGAGCAGAACGC CGAGACGATCCTCGCCGAGTACGGCATCGAATTCCGCGAGGACGCCGAAGCCCTGGCCCTCTGGCGAGCGGCGGGCGCGGACGTCCAG GGTTCGCTGGTGAAATTTCCGCGGGGCATGTGCCGCGAGCTGGTACAGAAGAATGCGCCGCGCGAATTCGTGCAGTACGCGCGCAATC CGGCGCGCAACGTCCGCATCGGCGGCAACTCGACTGTATTCGCCCCGGCCTATGGTTCGCCGTTCATCCTGAATGCGGACGAGGGTCG TCGGTACGCCCGCATCGACGATTTCCGCAATTTCGTCAAGCTCGCCTACATGGCGAATTCGCTGCACCACTCGGGTGGCACGATCTGC GAGCCGGTGGACCTGCCGGTGAACAAGCGCCATCTCGACATGGTGTACAGCCACGTCAAGTACAGCGACAAGGCGTTCATGGGTTCGG TTACCGCGCCCGAGCGCGCGCACGACAGCGTCGAACTTGCGAAGCTCGCCTTCGGTGCCGATGCGGTCGATCCTGCGACCGGCAAACC GCGCACGATGCTGATCAGCCTGATCAACGTGAATTCGCCGATGGTCTACGACGCGACCATGCTCGGCGCGCTCAAGGTTTACGCCCGC GCGAACCAGGCGACGATCATCACGCCGTTCATCCTGTCGGGCGCGATGTCGCCCGTCACGGTAGCGGGCACGGCTGCACAGACACTTG CCGAGGCGCTCGCCGGCATGGCCTTCGCGCAGCTCGTCAATCCGGGCGCGCCGGTGGTGTTCGGCAGCTTTGCCTCGTCGATTTCCAT GCAGTCGGGTGCGCCGACTTTCGGTACGCCTGAGCCGGCCCTGGTGCTCTACACGATGGCGGCACTTGCGCGGCGGCTCGGCGTGCCG TTCCGCTCGGGCGGCAGCCTGTGCGCCTCGAAGGTGCCCGACGCGCAAGCCGCGTTCGAGTCCGCGCAGACGCTGCTGCCGACGTGCC TGGCCGGCGTTAACTTCGTGCTGCACACGGCGGGCTGGCTCGAAGGCGGCCTCGCGATGGGGTACGAGAAATTCATGATGGACGTGGA CCAGGCGGGGATGATGCACACGCTGCTTGCGGGCGTGGACCTCACGCCGAACGGCCAGGCGATGGATGCCATCAAGGAAGTCGGTCCC GGCAATCATTTCCTGGGGTGCGCGCACACGCAGGCCAATTTCGAGAGTGCGTTCTACCGCTCGCCGCTGGCCGACAACAACAGCTTCG AACAGTGGCAGGCGGAAGGGTCGCTCGACATGGCGCAGCGCGCCAATGCGCTGTGGAAGCGTCAGCTCAACGAATACGTGCCGCCGCC GCTCGATCCCGCGGTGGACGACGCGTTGCTCGATTACATCGGTCGGCAGAAGGCTGCGACGCCGGACTCAAACATCTGAGTCTTTCAC CTCTCCCGCGTCTTTGATAGAGATCGCCTGCAGGGCGGCTGAGGGTACGTCTCATGGCCCGCTGGACGGGCTGCCGTGTTCCTCTGCG CTCCGGGGTCTCGCGCGCATCGCAAAGTAATC

\section{Contig 2}

TGCGATGCGCGCGAGACCCCGGAGCGCAGAGGAAGACTGGAACCCGTTCAGCGGGCTTAGTCGGCCACCGACCAGATGAGGACAGGTT CCGATAAACTGCCGGCCGGCGCCGGTATGGCCGGCCGCCGCACCGAATCATCGCTAGCGAGTCCAATCTGATGCGTCATTTCATCGTC CGCGCCTGCACGCTGCTGCTGGCCCTGTCCCTGGTTGCAGGTCTCGCACAGGGCGCCACCGAACCGGCCCGCAGGGCCATCACCCACG AGGACGTCTGGCTGATGCAGCGCCCTGGCGCGCTGGCGGCCAGCCCGGACGGCCGTTGGTTCGTCGCCTCGGTGGCGGCGCCGTCCTA CGACGAGGAGCAGCGGCGCAGCGACCTCTGGATCATGCCAGCCGACGGCAGCAGTCCACCGCGCCGACTTACCTCGAGCCGCGGCTCA GAAGGCGACCCGACCTGGAGCCCGGATTCCACCCGCATAGCTTTCTCGGCCAAGCGCGAAGACGACGAGGCGGCACAGATCTACGTGC TGGACCTCGCGGGCGGCGAGGCGCAGCGCGTGACCAGCTGGCCGGGGGGCGCCAAGTCGCCGCGCTTCAGCCCCGACGGCGGGTCGAT CCTCTTCGTAGGGCCCACGCACCCGGGCGCGGTCACTCTGGAGGACAACCGCAAGGCCGCTGCCGACCGCAAGGCGCGCAAGTACAAC GCCCGCGCCTACGACTCTTTCCCCATTCGCCACTGGGACCGCTGGCTGGACGAGCTGCGCCCGTCGCTGATGGTCCAGCCACTCGACG GCGCCTCGATCGCCCGCGACTTGCTCGCAGGCAGTGCGCTGCGTAAGGAGCGGGGATTCGGTGGTCAGCTCGGCAACGAGGGCGAATC TATCGATGCCGCCTGGACGCCCGATGGCAGCGGCGTGGTGTTCGCCGCAACCACCAACCGGCACGAGGGCGCTCGCGCCCAGGTATTC ATGTCGCTCTGGCACGTGAAGCTGGACGGCGGCGAGCCAAGGCGCCTGACCGCCGACGAGGGGGACTACTCCTCACCCGAGTTCACGC CCGACGGTGCAACGCTGCTTGCCAAGGTGCAACCCGCTTCGAAGCGCTGGGTGTATTCGACTGACCGCCTGGTGCGATGGTCGTGGCC GTCACTCGGTGAGCGCAAGGCGATCACGGAGGGCGTTGCGGAGTCGGTGGGTCAGTACGTACCGGCGCCCGACAGTCGCAGCGTGTTC TTCATTGCGGAGCAGGCTGGACACGACCAGCTGTTCCAGGTGTCGCTCGCGGGCGGGTCGCTGTCACGGGTCGGCGAGCTCAGCGCCG GCACTTACACGCGCTTTACGGTCGGTGGAGCGGCCGCGGCGCCCGTAGTCGGCGCGATCTGGTCGAGCACAGTCAGCCCGCACGAGGT GGGACGCGTGGACCTCGCCACGGGCCGCTGGTCGGCGCTCACGTCGTTCAACACAGCGCGCGCTGCCGCGATCGACTGGCAGCCGGCC GAGACGTTCTGGTTCACCTCGAAGCGCGGCAAGCGCATCCACAACCTGCTGGTGAAGCCGCCCGGCTTCGACCCGACGAAGAAGTACC CCCTGTTCGTGGTGATCCACGGCGGCCCGCACGGCTTGTGGAAGGACGACTTCGTGCTCCGCTGGAACTATCACCTGCTCGCGAGCCC GGGCTACGTAGTGCTGCTCACCAACTACAGTGGCTCGACGGGTTTCGGCGAGGACTTCGCGCGCAGCATCCAGGGAGACCCACTGGCC GGGCCGGCCAACGAAATCAACGAGGCGGCAGACCAGGCCATCGAGCGCTACCGGTTCATCGACGGCAAGCGGCAGGCCGCGGGCGGCG CCAGCTACGGCGGACACCTTGCCAACTGGCTCGCGGTCTCGACCGACCGTTACCGGGCTCTCGTGAGCCACGCGGGCCTGTACGACTT GCGCAGCCAATGGACCACGAGCGACATGGTCTACAACCGCGAACGCAACATCGGTGGCCCGGCCTGGGACCCGATCCCGTTGTGGCGG GAGCAGAGCCCGTTCTATCGCTCGGAAAAGCTGCGCACACCCATCCTGCTCACCTACGGCGAGAAGGACTTCCGCGTGCCGCTCAACA ACGGCCTGGAGTTCTGGGCGGTGCTGCAGCGGCAGGAGGTGCCGAGCCGGCTCGTCGTGTTCCCCGACGAAAATCACTGGGTGCTGAA GGGCGAGAACAGCCGGTATTTCTTCCAGGAGGTCCACGGCTGGCTGGCGAAGTACCTGTAGCGCTGTTGCTGCAGTGGAAGCATTTGA GCGCAGGACAGTGGTTGCGCATGGCCCGCTGCACGGGTCCCGGTTTTCCTCTGCGCTCCGGGGTCTCGCGCGCATCGTGAATCGCGCG 
GAGGAACCGCACGATTCACGGCGAACCTTGCTCGAGCGAGAGCGAAGCGATGGTGGCAGCGCAACAGCGGCACGACGACGGTGCCGCT TCGCTCTTTACGCTCGAGCTGCGGCGCTCGACACGGAGCGCAAAGGAAGACCGGGACCCGTACCGGCGAGCCTGTAATAGTCGCGCTT CACTGAGACCACGCGGAACCTTCCGTGGCAGCGGAGGCGGGAGCCCGCGGTGCAGCATTCACTTGGTCACGCCCACCTCGTTCAGCTT GACCGACCGTGAGCCGAGGCAACGCGCGGCTTCCAGCACGCTGAATGGGTTTCGGTCTTCCTCGGCACTCCGTGTCGAGCGCCGCAGC TCGAACGCAGGTGCGAGGCGGCTTCGTATTTTCCGACCAGACGCTGGCACCATCGCCGAGCACCCGTTCGAGCAAGGTTCGCCGTGAA TCGTGCGGTTCCTCCGCGCGATTCACGATACGCGCGAGACCCCGGAGTGCCGAGGAAGACCGGAACTCGTGCGGCGGGCAACCACCGT CCTGCTTCCCTCGGCTTGCGGTGTGGGTCTACGCGGGTCGCGCTGGGCGTCGATTCCGGCTGCCACGCGACTCGCCCGCCGGCTGTGC CGCCGTCTTGAGTGGCGGCAATTCCACGACCTTGCGCAGGTTGGGGTATTCGGCCGTCTTGTGTGGAATGGCCATGGCTTCGACGAAG TGCTCCTGGAACCGCGGTTCGATGGCGGTCTCGATCTTCTCGACCTTGCCCACCAGCGTTTCGATCGTCTCGCGCGAACGTGAGTCGA GCAAGGCGATGCGTGCGCCCGTGCCTGCCGCGTTACCGGCCGAGGTCACCTTCGAAAGGTCGCAGTCCGGAATCATGCCGAGCACAGT CGCGTACATGACGTCGATGTGCGCACCGAAGGCGCCAGCCAGCCGGATGCGATCGAGCTTGTCGACGCCGAGCCGCTCCATCAACAGG CGGATGCCGGCCATCAGCGCGGCCTTGGCGAGCTGGATGGCGCGCACGTCGTTCTGCGCGATGCAGAGCGTCTGGGCGCCTTCGTGCA GCACGTAGGAGTACGTGCGCCCGGCTGCCACTAC

\subsection{Das Cosmid slc_1f}

\subsubsection{Lage der offenen Leserahmen (ORFs)}

\begin{tabular}{|c|c|c|c|c|}
\hline ORF & Annotation & Start & Stopp & $\begin{array}{l}\text { Orien- } \\
\text { tierung }\end{array}$ \\
\hline 201 & Hypothetisches Protein & 38 & 535 & - \\
\hline 202 & Hypothetisches Protein & 633 & 1418 & - \\
\hline 203 & Hypothetisches Protein & 1736 & 2365 & - \\
\hline 204 & Potentielles integrales Membranprotein (ComEC) & 2425 & 5190 & + \\
\hline 205 & Vorausgesagte ATPase & 5246 & 6610 & - \\
\hline 206 & Hypothetisches Protein & 6634 & 6873 & + \\
\hline 207 & Hypothetisches Membran-durchspannendes Protein & 7043 & 9565 & + \\
\hline 208 & Hypothetisches Membran-assoziiertes Protein & 9645 & 10313 & + \\
\hline 209 & Hypothetisches Membran-assoziiertes Protein & 10338 & 11090 & + \\
\hline 210 & Prolipoprotein-Diacylglyceryl-Transferase (EC 2.4.99.-) & 11122 & 12123 & + \\
\hline 211 & Uncharakterisiertes konserviertes Protein (COG4276) & 12130 & 12690 & - \\
\hline 212 & Vorausgesagte Dehydrogenase und verwandte Proteine (COG0673) & 12723 & 13691 & - \\
\hline 213 & Protein der Subtilase-Familie & 13945 & 16938 & + \\
\hline 214 & Glukosamin-6-phosphat-Isomerase 2 (EC 3.5.99.6) & 17159 & 19120 & + \\
\hline 215 & Konserviertes hypothetisches Protein & 19144 & 20781 & + \\
\hline 216 & Konserviertes Protein & 20787 & 21620 & - \\
\hline 217 & Hypothetisches Protein & 21772 & 23994 & + \\
\hline 218 & Alkalische Phosphatase (EC 3.1.3.1) & 24130 & 26700 & - \\
\hline 219 & Hypothetisches Protein & 26697 & 27170 & - \\
\hline 220 & Hypothetisches Protein & 27188 & 27613 & + \\
\hline 221 & Hypothetisches Membran-assoziiertes Protein & 27722 & 28453 & - \\
\hline 222 & Hypothetisches Membran-assoziiertes Protein & 28629 & 31646 & - \\
\hline 223 & Hypothetisches Membran-durchspannendes Protein & 32024 & 32776 & - \\
\hline 224 & Hypothetisches Protein & 32914 & 33165 & - \\
\hline 225 & Konserviertes Protein & 33228 & 34661 & - \\
\hline 226 & Konserviertes Protein & 34720 & 35898 & + \\
\hline 227 & Konserviertes Protein (hypothetisches Sensor-Protein) & 35991 & 37482 & + \\
\hline
\end{tabular}




\subsubsection{Sequenz des Cosmid slc_1f}

AACCCTCACTAAAGGGATCTGGGCAAGTTTGGGCATGTCACTCTGCTCCCTTCAGAAGTTCGTCTCGACGACGAAGGTGCGTTTCGAC CGCTTCGATTGACTGCTGCACGCTCTTGCCGGCCGAGGCGACCGACGATGGATCCTCGACCGACTCGAGTCCGCGAGCTGCGGTCCCG ACTGCGGTCGCCAGCTCGCGCAGCCTCTCGTCGTGATCGTGAATGTCGGCGAGGACCGCGGCGTCGATCTTCACAGTGTCGAAGAAGC CGCCGTAGCCCTGTGGGGCGTGGCGAATGCGGTCGCTGACGGCGGCGAGACGCCGCCGCAGGGCCTCGAGCGATTCCAGCGAGTCGAA CTTCATCGCCTGGCTGCACAGGGCAATCGCCCGGTCGATACTCCGCTTGGGTTCCTCGAGGAGCCGCACGGTGGCGTCCCGCAGGAGG CGATCGGTGTCGCGGCGGGCTTCCTTGTCGGCGTATCCCTTGTAGCCGGGAATCCAGCCGACGAGCTTCTCGACGATGTTCTGCTTCT GGGCCATGGGAGCTCCCATCCTCTCGCGTCCGCTGCGGTGTGTCGTGAGACGATCGGGCGACAACCGCGGCGGGCATGGTAGTTGGGA AGAGTGGCTCGCGGATTCAGCGCGTGGAGCCGCTCGCTGCATCCGCCTCGGCGTTGAACCGCTGCACCGCCCTGCGATACGCCGCGTC GAGGGCTTCGCGATCGGGAATGAAGGCCAGCGCCTCCACTTCGGCGTGAACCTCCGGCGGCAGGTCGCGATCGAGGTAGCGAAGACCG AAGTCGTAGCGTTCCGGGGAGTGCCGCATCCGCAGCAGTTCGACCAGCGACCGCAGCACGATGGCGTGATAGCGATCGATGGCCTCGC AGAGGTCTCCGCGGCGGATCGCCTTGCCCACGAGATGCTCGAAGAGGCCGAACTTGACGATCAGTTCAGCGCGACGGCGACGCAGGGC TTGGCCGTGGGCGTCGCGGTCGAGCGTCGTGGGAACGGCGACGCCGCAGCGATCGAAGAGGACGATTGCCTTCCCGTGTCGCAGCGGT TCGAGAAACCAGGTCGTCGGATCCGAACTGCGGCGAATCACCACAAGATCGATCATGTGGCACGGGTCCCAGCCTTCGAGTTGAAGGA AGACCTGTGAGTGGCCGTGCCAGGAGGGCTCGGGGACCCGCCAGCGGAGGGCAACCGGAGCCACCTGGGTGATGGCGCTCTCAATCGA CTGAAGCACCGCCTCGACGGCGTCGTCATCCACGAGTGTGACGAGATCGACGTCCGAGAGCGGATCGGTTCGACCGGTCGCATCGCTC CCGCCGAGCCACGCGGCATGAACTCGCTGGTCGGCGGAGCAGACCGCGGTGAGACGATCGATCAGGGGCAATCTGCAATCGGTGGGCG AGAGTGGCATGCCGGCTCCGAGAGGAGTGAGGGTTTCGTCGCAATGTATGGGCGGCGATTGATCCGGATGCGAGACGAGGCGCCCCGC GCGTTGCTCATCGCCACTACTGTCGCTCTGTGCGCGTCCTTTGGCTGATCATCGTTCTTCTCCTCGCGGCAGCGGGTTGGAGCGCTTA CTCGCGGAGCCGCGGGCCGAGCGACGAGTCGTCCACCCCCGGAGCGGAGGCAGGGAACGCAACGGCACTCGCAGATCGTTCAGCCGCA GGCCAGGCCGAGGTTTCATTGGGTGCTGAACCACCGGTGAGCGTCGCACTCGCCCCTGCGGCATCACCGCCGGGTGAGCCTCCGACTT CGGCGACGCCCTCTCCGATCGAGGGTCCGCCCGCGCCGGCAGCGGACGCTCCGATCTCCACGTCCGCGGGTTCGGCAATCAGCGAGGA CGGCGTCACCCGCCTCGACGATCGCTTCATCGTGCGCGGCGCGGGAACACCGGCCGACCCGATGCGGATCACCTGGGACCTTCTGATC TCCGCCAGCGAGACCTATGACCTCGCCAAGAAGAAGACCGAGCTCCCGAGTCGGGTCACGGCGCTCTCGGGTCTCACCGTGGCCATCA CCGGGTACATCGCGGCCGGCATCGTCGAGGACGAGACGAGCGACATTCTGGTGATGTTCAACAAGTGGGACGGTTGCTGCCTCGGGCT TCCGCCGACTCCCTTCGACGCCGTCGAAGTCGATCTCGAAGCGCCGGTCAAGCTGCGCGGACAGCACATGCTCCGCTACGGGACCGTG ACCGGCGAGTTCGAGGTCGAACCCTTCATCGTCGGCGAGTGGCTCGTCGGGCTGTACCGGATCCGAAATGCCCGGCTCGAGTGGGGTG GATGAGTCGAGGAGGGCCGGCGTCGCGGCGAACAGCCTGTGGCGAAGGTCATTCGGGGCTGCGAAGGACGAGTGCACGACGAGGGCGG GAATGAGATTTCACCTGTCGTCGGGCGACCGTCGTTCTCGGGGTGAAGATGCCGGACATGAAGGAACCGTGGGAGGCGGGGGAGGCGT GGGAGTCGAAAGGCGGTTCCGCGGCAGTCGCATCGGCGAGTGCCTTCGCAATTGGCATCACCCTCGGCTGGTCCTTCGGTCCGGGCAT CACGGGGTGGTCGCACTCGGTCGAGGCGGCTGTGATTGCGGCCGTACTCGCCTCGGTGGCGGCACTGTGCGCGCACGCTCGCCAACGA TCCTCGACTGAGGACGGGGCGAGGCCGCACCGAACGGCGCGAACTCGACTCGCCTGGGCGATGACCGCTGCAGCAGCTCTCGGCTTCG CGTGGATCGGGCTTCGTTGCGATCGGGTCCACTCCGACGATCTTCGCCGCGAGCTGGTCGCGGGAGAGCGTCTCACGGAGGACGGCGC GACGAGCTTTCCTGGACCGCGAACCCCGCTTCGAACGGTCCGCGGGATCGTCCTGGACACCCCGACTCTCGCCCCGCGCCGCTCACCT CTGGCACGATTCGATCCTCGCCCTCCGCGCTGGCGATTTCGACTGGCCGTCACGGAACTGTCGCCCGTCGAGGGTGCCGGAGGCGCCG AATCCGGCGCACTGCTCCCCGCGCGCGGTGTGCTCTGGACCAGCGTTTCGGACCCCGAAGCGGATGCTGTCGAGAGCCAGCTCTTCGA GCGTTGGTCTCCTCGGGCGCTCGCACTCATCGACGCCGGGGGCGTTGCGACGGCTCCTCGAACTCCACTGCGCGCCGGCGACTCCATT CTTGCCGTCGGCCGCGTGGAACCCTTCGACGGGCCGGCCAATCCGGGAGAGTTCGATGCCCGCAACTGGGCCCGCGCCGAGGGCCTGG CGGGCGCCCTCTGGGTGGAGGAGCCGACGCTCCTCGAACGAGTCGTCTCGGGGCACCGCGACACGCGATCGTCGCCCGCCGCGGCGCA CGAGTGGCTTGAGCGCCGACACGCGGCGCTTCGAGCCTGGTCGCGGGAGTTCGGTGATCAAGCTCTGGAGCGAGGACTGCCGCGCGAC ATCGATCCTGACATTCTGGCGCTCCTTCGAGCGATGTTCCTGGGTCGGCGTGATGCGGCGCTTGCAGAACTCGAGTCGGCCTTCCGGC GCACCGGGACCATGCATCTGATTGCAATTTCCGGCTTCAATATGGCGGTGCTGGCGGCTGGCGCCACCTGGCTCTTCTCGCGAATCGG CGTCGCCCGGCGCGGTCACGCGCTCGCCGTCGTGCTGGTGATCCTCGGCTACCTCGCCATCGTCGACGCGGCCCCGGCCGTGCTCCGG GCAGGCGTCATGATCCTGGTCGCCGCGGTGGCTCAGGCGTTCGGTCGCGGGTGGAGCCGACAGGGCGTGATTGCCACATCGGCACTCC TTCTCCTCGTCGCCGATCCGGCCCAACTCTTCAATGCGGGATTCCAGCTCTCATTCGCAGTCGTGGCCGCGCTCGCCTTCGTCGCGCC TGCGCTCCGGAGGGACTGGTTCGGACGGCGCACGCCGCACGCCTCGACACTGATCGCGTTCCTCCGAGAGCGTTGGCGCGACGCCATC GCCGCCGCCGGTGCAGCGTGGCTCGCCTCGACGCCCATCGCCGTGTGTCACTTCGGGATCATCTCGCCGCTGGCGGCGCCGCTCTCGT TGATCCTCATGCCGTTGGCCACGCTCCTTCTTCTCGCCGGGTACGTGAAGATGGCAATCACGCCGCTCTCGCCCGTGCTGGCGACCCT GAGTGGATTACCGGTCGAGGCACTCGCAATCGCGTTTGCGGGGCTGGTCCGGGCCGCCGACGGGCTTCCGGGCGCGGTCCTGCATGTC CCGTCACCTGGACCAGTCTGGTGCGCACTTGCCGGCGCGGCGCTGGTCATCGCGGTGCTGGGAGGATCGCGCCGCCGCCGCCGGGCCG GACTGCTCGTCTCGGCAGGCGCGGCCCTCGTCCTCCTCTGGCCGCTGCGCCCGGTCTGGCTCGGGCGCAACACTCCAACACTGCGGCT CGACATGCTCTCGGTCGGTGATGGCACGTGCATCGCCGTTCGCAGCGGTGAGGATGTCGTCCTCTTCGATGCCGGCAGCACCTCGCTC TCCCGCGGCGAGCGCACCATCATCCCGGCGCTGCGGGCGCTCGGCATCAGGTCGATCGACGCCATCGTCGTCAGCCATCCCAATCTCG ATCACTACGCCGCGATTCCCGAACTGATTCAGGAGTTCGAGGTCGGCGAGGTGATTCTCGGCGACTCGTTCCTGCGCGCAGCGGGTGT ACTCCGGGGACCGGCACTCGAGCCCCGGACTGCGGAGACCGCGGTCGCGGCCACCCGCGCCGCCCTGCATCTGGCCGGCGTTCCCCTG ACGCTCGGGCGCGCGGGGCTCGAACGGCGATTCGGCGAGACGAACTGGGAGTGGCTTCATCCCGCGACCAGCTTCCGCGCCCGCCGCA TCAACAGCACGTCGCAGGTGATCCGAATCACGGCCGCAGGGCGTTCAGCTCTTCTCTGCGGCGACATCGAGGAGGAGGCGATTGCAGT TCTCTTGAAGCATTCGCTTCCACCCTGTGACATCCTGGAACTGCCGCACCACGGGAGCTGGCGCGACGCCGCGGGGCACTTGGTCGAG ACCCTCGCGCCTGCGGTCGTCATGCAGTCGACCGGCCCAGCCCGACTGCTCCGAGATCGCTGGCAGACGCAACTTGCCGGCACATCTC GCTTGGTCACCGCACGGGACGGCGCCGTGTGGGTCGAGGTCGATCGAACGGGTGGAATCTCTTATGGAACCTTTCGCCCCCGATGAAG AAGATCTCACGACATTGTGCCTGCTCGCACCGAGCGACACAGTCGCGCAGCGGTCACCCTTCCGAGAGCAGCCACTGGTGCGCCGGCA CGATGCGAGTCTTGGGATGGGAGAGCGAGCGGGCGGACACGGCGTCAAGCACCACCACGGTTCGCTCGGCCTTCGCGTGCTCGCGGTG GGCCGCATCCAAGGCACGCGTCTCACGAGCCCAGACCTCCGACGACCAGGTTCCTGAGTCTGACGCATCGGCGCACACTTGGATGAGC TCCTGCCTCCCATCCGCGTGCCGCGCAAGGAAGTCGACCTCGAATCCCTCGGAGGTCTTCACGTAGGCGATCTCGGCGCCGCGTCGTG AGAGCTCGTTGAAGACGGCGGTCTCGAGCGCGTGGCCGGTGTTCGACCGGCCACTGATGTCGAACGCATGGATCAGCCCGGGATCCAC CGGATACACCTTGCGCGGATTGGTGTTGCGCCGCCGCTCCGACTCGGTGGCCACGGGCACCGCGGCGATCACGAACGCGTCGATGAGG TGGTCCAGCAGGGCGTGGACGGTGTCCTTTGCCACGTTGTGACCTTGCGAATGAAGGTCGGCGTACAGCCTGCTGGCACTAAAGCTGC CGCACGGGTTTCGGAGCGCATGACGAATGATCCAGCGCAGCGCCGCAACCTGCGACACCGCGTGGCGCTCGATGACGTCGCGGAAGAG GACCGTGTCCACGTACCCCTGCAGGAGCGCGATGCGCGTGGGGATATCGAGCGGGCGCCTGCCGGTTCCCTGCACTTCAGGGAAGCCG CCGACGACCAGGAACTCGCGCACGCGCTTCTCCACTGCACTGCGAGACGCGGCCGTGAGCCGGTCGGATCGCCCCTTGGGTTCCTCGC CGCGGTGGCGAAGGGCCTCCCGCACGCTGAACGGGGCAATGACCGTCGCCATGGCGCGGCCGCGGAGGGAGCTGTGGATCTCGCGAGA GAGCATCCGTGCGGACGAACCCGAAACGACGATATCGATCGACTCGGTGTCGAGGACGCGACGGACGAAGCGATCCCACCCTTCCACA AACTGGATCTCGTCGAGGAACCATGCGACACGGCCCTTGCGGCGGATCTCGGGATGGCGTCGAAAGTACTCCTCGAGCAACGCATCGA GTTGTGTCGCGTCAATGCCCGCCAGCCGATCGTCATCGAAACTGAGGTAGATGGAGCGCTCCGGTGGGCCGGACTGCCGGCGGTCGGC 
GAGCAGCTGCCTGAGGAAGCAGGTCTTTCCCGCTCGCCGCATGCCAATGACGGCGTGCGCCTTGCCCGGCACCGCGGGGAGCAAGGCG TCCCTCCGCGTGAGCGAGCTGGATGGCAACGGAAGGAGGGCGTCGTTGAGCTTCTCCCGAAGCGCGTCGAGCAGCGGCATGCCGGAAG GGTACCGCAATCTGTCCTTCCCAGAAGGACAGATTGTCGATAAACTGGCCGTTTGAGAAGGCCAGGAGGGTTGACGGGGAGTTACGTT TGGGGCCACGGCGCACGGCGCCGCCCGACTTTGCACTCGAGCGTCCTGAACGCCGCGGCGTGACAGTCGTCGAGCGTGATGGACATCG TGCCCGGACCGGCGGCGGGAAGCGACTCCGTGTCGTCAAGGGTCCCGCGGTCGGCTCCTGCTCGGATTGTGAAATCTCGCGCCGCCAC TCACAATGACCCGCGCAGCGGGGGGACCGGCGCCCTTCTGGGGGCGCGTCGACCATCGGCTGATCTCTGATGCGGGCTTGTCCCGTCG GTTGCAGTGGCGGGTCCGCGGCCGCGCCGAAGCTGGTCCGGAGGGACGCCATCGCCGCCCGCGCCCATGCCCCCCGGAAGCTGTCCAG CAATGACCGAAGCCCTCCCCATCTTCGAACACCTCCAGACGCTGCACCGACTCGGCGAGGGCGGATGCGGCACGGTCTGGCTGACCCG AAATCTGTCGACCAACGAGCTGGTCGCCGTCAAGATCCCGAGAGCCGACTTCCGCTCGGCTGACGCACTCGCCCGCTTCGAGGACGAG TGCGACCTGCTGCTGCGGCTTCCTCGCCACGAAAACGTCGTGAAGGTCATGCGCTGCTCGGCGGCAATCGAGGGGCGTCTGGCATCCT CCGGGAACCGGACGATTCTGGCCCTCGATGATGCTGCGGCGACCTCGCACGCGCCGGCGGCCATCCGACCAGCACCAGAGCTCTTCAG CGAGACGCCCGCCGTGCATCGGACGGAACCGGGAGTCGGCGAGGTCCGCGTTCCGGCTCTCGAGATGGAATACATCGAGAAGGCCCGC ACCATCCTCGAGTATGCCGATCGTCGGAAGCTCACGCAGCGGGATCGGGTGGCGCTACTCGCCGAGGCGTGCCGCGGCGTCGCCCACC TTCATCTTCACGGGGTGGTGCATCTCGACCTCAAGCCCTCGAACATCCTCGTCGACGATGTCGAAGGGCGCCCCGGTCGACCTCGGGT CATGGATCTCGGCGCCGCCAAGGTGCGCCTTCACCGAGATCGACGAGATCCGCTCTACTCCATCCGCTATGCCAGCCCGGAGCAGCTC ACGACCCGCTCGCCCGAAACCCTGACCCAGGCCAGCGACGTCTATTCGCTGGGCAAGCTGCTCGCGGCGCTGGTCGCGGGGCAGGCCT CGATTGCCCTGCCCAACACCGAATCACGGGACGAACAACTCAAGGCTGCGCTCGACTGGCGGGCGACGCGGGTCCGCGACTTCCTTCC CGACATCGATCCCGATCTCTACGACATCATCGCCCGCGCCACCGACCCCGACCCCCGGGAGCGGGCCCATTCATACGAGAGCGCCAGC GACCTCGGCCGAGCCCTCCGCGAGTGGCTGCTACCGCAGCACACCAAGCTCTTCGAGATTCTCTATCGCGGCGTGAATGCCGTGCCCG GCTCCCTCTGGCGGCTGGCTGCGGTGGCCTGTGCGGCGCTCCTCGCCACCGGAATGTCGATGGCCGTCGGCTACGGGAGCGTGCGGCT CGGCGGGATCGCGGCGATGTACCTGCCCGTCAGAGCACCGACGTACTTCGAACACGTCGTCGTCCTTCAGATCCGGCCGAGCGATACG CCGGAACAAATCAAGGCGGTAGCCGAGTCACTGGGCGCCAAGGGAGTGGACCTGACGAGCAAGGCAAGCGTTCGAGCGTTCTACGCAA AGGTCCTCCCGATGGTTGTCGATGCCGGTGCTCGAGCTGTTGCCTTCGACATCCGGTATCCGGAGAACCTCGCATTCGAGGAGGCGAC GATCGAGTTCTTGAACGCAATCGTCGCGGCAACGGCACAAGGCTGTCACGTGTCGGTGGGCTACAGGGATGTGTGGGCCAACCGGCCT CCTGCGTCTCAACTCGATCCTCGGCTTGAAGCGGTGGTCGACTCCGGGAACTGGGAGTTCCACTTGGAGGAGGGGGAGTCGCGGGCGC TGTTGATCTGGAGTGTGCGGATCTCGGAGCGTCACGGGGACTGCCGGTCTTTCTTCGCAGCCAGCATCGAGGCGCTGCTGGGCGGTCG CCGCGAGGCCGGTCTCTACGTCGATCAGTCACGTGGCCTGCTGCGATTCCGTTGCGTCGGCGGTATGGATGTCCCTCTCTGCCTCATC GAAACGAAGGCGGAGTTCGATCAGCGGATCAAGGGACCGGAGGAGCCCGCAGCGACAGATGCCTCGGGCTCGGCCTCCCAGGCAACCT CCGCGCCTCCTGCACCCGGCGACGACGACCTCGTGGCCCTGATTCGATTTGGATTCGCCGATCGAGCGGCCCTCGAAGCGGCCACCAT CCCGCTGCTCGACTGGCTCCAGCTTGACGAACGCGAACGAGCCGCTCGCATCCGCGGCAAGTTGGTGATCGTCTCCAACAACCTCGAC GGCGAGGACATGCTCGAACTGAAGGACCCCAAGCTGCCAGCGTGGCTCACGGGGCCGGCCGCCTGGGTCCATGCCTGTGCAATCGAGT TGATGCTCCAGGAGGCGACACGAGAGCAGCCCGCCGCCGTCGACACCTCATGGAACGTGTTCGGGCGAATGTTCACGGCTGCGTTCAT CTGCTGCGGGACATTCTGGGTGGCCTCTGAAGTCGGTCTGCTCTCGCGACGGCGACGGTCCGCCGCGGCCGCGGGCGGATCGAACAGG GGGCGCGGAGTCGCCTTGGCGTGGACGGCGGCGATCGTGCTGATCTTGACCGTCTGGACCGGCGCTGCAATCCTTCGCATTCCGTTTC CATTCGTCGCGACCGAGATCGTGCTCGCGGGGATCTTTGGGGCGGTCATCGGGATCACCGGGGCATGGCTGGGGCCGTACATCGCCGC CGAGTGGGAAACACTTCGTCGCTCGAACTTCCGGGAGGTGCCTCGTGTCCAATCGTCTTGACTTCATCCGGGCATTCGTTCTCGTCGC CGCCTTCGCGGCCTGCGCCGGCTGTCAGAATCAGCCTGCGGGACGCCTCGAAATGGCAGAGACGCAGGAGGTCTACTACGACATCAAC GCCTCGCTGCAGATTCTGACCGGAACGGTCTTCGACTTCGCGAGCGAGTTCGTGGTGCGCGATGTCAAGACCGCCTGGAAGACGAATC CGACCAACGGCGACTCGTACCGGTACGTGTACAGCGCGATGTTCCGAGACGGCGCGTCCGCGAGCCTCAACGCCGATGGCACCATCAA TCTGCTCTCGGGCACCGTCTACGTCACCTCCAGGTTCGAGCGCGATCCTTCGGTGACCGGGGCGCTGTCCTGGGCTGGACCAGACTCC GCCACTCCCGAGGTCGGGCTCGAAAGCATGAGCCTCTGGTGGTACCCGATCGTCGTGCATGGACCGATTCAGGCGGGTTCCGATGGAA CGCACTTCATCGTCGAGGCCGCCAAGGATGTGACCGGTCTGCCCATCACCCGCGTCTATCTGACGCGCCCGGTCTGGAGCAGCCGAGT CCACGTCGGCACGACGACTACGGCGCTGACCGTCCTCAAGGGCGGCGAGCGCTACGCGGAGTTCTCCCACGCCAATCCGCTCCCGGTG CCGAATCCCGGCAAGTTCCGCGACGTTCCCGAGCGGAAGGATTTCGCGATCGTGACGATGGGCCGGGCCAAGTACTGGTCGCTGAGGA CTGACGACGGAACGTGAACCCGACGTCGATTTCGGAGGTGCATGATGCAACTGAACCGCATTGGACTGATTCGCTTCGCAAGCGTTGC AGTGGTCGCTTCGTCGATTGTGGCGATGCGCACGCCATCCCCCGCCGATCAACCCGCGGGAGCCGGTCTTGCGCTGGCGTCCCGCGCC GGGGCGGAAGTCGTCCTTCGTCCCAACACGGCCTTCAAGCCCGGTGCCGAGTTCGTCTTGCGGGACATCGACACCGCCTGGAAGGTCG ATCCAGGTGGCGCCAAGTGGTGTCGATACATCTACAGCGCCGCGTTTTCGGCGGATGCCGAGATGAAGCTCCGTGACGATCGCACCGT CGAACTGCTGGCGGGATCGGTCTACATCTCGTCGCGGCTCGAGAGCGATCCGCCCGACGTCGGCGGAGTCGTGGCTCCGGTGGTCGGA CCCGCGGCGGTGGCGCCGTGGTGGTATCCAATCGTGGTCCGAGGCCCGGTTCAGGCAGGAGCGGATGGCACGCATTTCATCGTCGAGG CTGTTCGCACCGCTCCGGATCAGCCGGTCACGATGACGCGGGTGTTTCTCATCGAGCCACTCACCGTCGGCAGCAAGCTGTACACGAC GACGATCCGCCACGGAGCCGCAGTTGCCCTGAACACTCTCACGGGTGAGGAGCTGTCGGTCGAGTATCCCGACGCGAACCCGGTGCTG GTGGCGCCCGTCCCGTTCCGGACGGTTGACACCCTCAATCAGGTCGTGACGGCCTCGGAGGAGCGGGCCAGGCGCTGGCGACTGCGGT AGCACTCCAGCGAGGTTGCTCTATCCTCGCTCCGTGCTGCTGATTGCCGAAAGCTACCTTCATCGCCTCGACCCGTTCGTCCTGCGCT TCACTGAGGACTTCGGCATCCGCTGGTACGGGCTCGCGTACCTGACGGGCTTCCTCGTGGGCTGGCTGATCCTGCGCTGGATGTGCCG GACTGGTCGCGCGGCGCTCTCGGTGTCGCAGCTTGAAGGCTGCCTCACGGCGATGATCCTCGGCGTGCTGCTGGGGGGACGGCTGGGG CATGTCGTCTTCTACGAGCCGCACCTCCTCTACACGTTCACCTCGTCGCCGCCCTGGTGGGAAGTGCTGGCGCTGCATCGCGGCGGCA TGTCGAGTCACGGCGGAATTCTCGGGGTGGTCGTCGCCGCCGTGTGGTTCGGTCGACGTCATCGGATCGATGCCGTCCATCTCCTCGA CCTCATGGCCCTCGCCTGCCCGATCGGACTCGGCCTGGGGCGCGTCGCCAACTTCATCAACGGCGAGCTGTGGGGACGAGCGCTTCCC GAGGCGATGCGGGCCGCGCCACCCTGGTGGAGCATCAAGTACCCGGAGGAAGTGCTTCTCGACTCGTTCGATCCATCGACGCTCGCCC CGATTGCGTTGCTCGTCGATCCGACGCGGCCCCTCGCCGAGGCGGTCCACTCCGCCGTCGTGATCGGGCGCGAGGATGTGATTGCGAA GCTCACCCCGCTCCTGACGCCGCACTACCCCTCGCAGCTCATGCAGGCCGCCACCGACGGCGTCATCCTGATGCTGGTTCTGGCCCTG GTGTGGTGGAAGCCGCGGAAGCCGGGAGCAATCGGCGGTGCATTCCTCATCACCTACGGAGTGCTGCGATTCACCACAGAGCAGTTCC GCGAGCCGGACGAAGGAGTGCTGCGGATCGATTGGCTCACTCTGCCGATGGCCCTGAGCACGGCGATGATCGTGGCGGGAGCCCTCTA CATCTTCTTGACCAATCGGCGCGACGTGCCCGCCCTCGGCGGGTTGTGGAGACGAGCGGGCGCGTAGCGCTGCTCAGCAACGGCCGAG CAGTCGCTGCAGGGCTTCACGTCGATATGCGAAGATCCCCTCGACGTCGCGGTCCACGATCAGTCGATGGGCGATCCGCGCACACGGC GCCCGATAGTGCACTCGATCGCACATCAGCGTGAAGCGGCCGTCACGCTCGAAGGTGTGTTCGTGGTGCCAGAGGCGATATGGGCCGC GAAGCTGCTCGTCGACGAAGCGACGAGAGGGCTCCCACGCTGTGATACGGGTGCGCCAGCGGATCGGAATCACTCGCCAGCGAAGGCG ATAGTCGATGAGCGTGCCAACGCCCATGGCGATCGGTCGCGGGGTGAGGACCGTGAAGCGAAGCCACGGAGGGGTGATCGCTTCAAGA TTGTGGGCGTCGGCGAAGAAGGGGAAGACCTCGTCAGGTGTACCCGGGAGTCGCTGGGTGGCCTGATACAGGGTGGCACATCGAAACC GGGGGTCCGACTCGGCGCGGATGCCGGCGGCCGCGCGTACGGACGCAGTCGTGATCTCGGACATGGGCCAGCAGTTCGCCCCGGTCCC GAGTTCGGATTCCTCCACGCAATCTCCCGAAGGGTCACGGCGCGCCGCGCTCAGCCCATCAGACTCGCCCGCTCCGCCTCGAGGAGCC GGGTGACGGTCAGAGCCTCCTCAAGGGTGGGCAGCCCGCTGCGATTGCCCGAGGCGATTGCGGTCACCGCCGCCGCGACTTCCGCGTC GTATCCGCCAATCGTCGGAAGCTCGACCGGCTCGCTGCGATCACCACGATGGAGCGTGGTCGTCGGCGTGCGGGAGAGATCGAACTCG GCGGTTGCGCTCTCGAAGCAGACCAGATACTGCATGCGGAATCCGGCGCTTGGCGAGAGACTCCAGGCTCCCTCCGCACTGACGTGGG AGGGGCCGTGTCGGTAGCGGTAGAGCGTGGTCAGGTGGGTCGACGTTCCCGTGGTGTGCACGCTGTCCGGAGGTCCGAAGCACCAGGT GACGAAGTCGACATCGTGGATGTGAAGATCGAAGAGGGCTCCGCCGCTGCGAGCTTCATCCGCGTAGAAGCCCGTCCACGAGGGTGCC 
GAGCCCAGCCGTCGAAAGGAGGCGCTGCGCACCGGTCCGAACTCGCCGGTCTCGATCCGGCTCTTGAGCCAGGTCCACCCCGGCCAGA AGCGCATGCACATCGCCGGCATGCACAACCGATCGGTGGCCCGCGCCGCCTGCAGGAGTCGTTCGACGTCGGCGCTGCGCACGGCAAC CGGCTTCTCGACCACGACGTGCTTCCCGGCGGCAAGCGCGGCGATGGCCAGGTCGACGTGGGTGTCGGTCCAGGTGCAGATGTGGACG AGGTCGACGCAGGAATCGGCGAAGAGCTCCGCCGGGGTGAGATGTCCGCGCACCGAGGTTGGATCGAAGAGAGGCTCGCTCCCCGAAG GAATGTTGCCGGTCTTGTCGCCGCTGTGGGGGACTCCGCCGCGGAGTCGCTCCGGATCACCGTCGCAGACCGCCACCAGACGGCAGGG AAGCCCGGCGTGCGCGGCCGCCCGAATCGCCCCGATGTGAAGCCGCCCCATGAAGCCCAGTCCGAGGACCCCGACCCCCAATTGGGCA CGTGAAGAGCCGTGTGAAGCCATAGCGGAGGAGCGTAGCGACGGGCGCCTTGAGTTTCACCGGGCGCTGGCGGCGCCGTTCACGCTTC GTTCATGGACGGGTACACGCTGTGCAGCGTGGTGCGTGCCCGTGACTCATTCTCGACCCGACAACCTCGACCCGACAACTGGGCTCCC AGCGCGATGGTTGCGCTCCGGGCCTCGGGAGGACTCACTCATGCAGCTTCAATTCAGGCACCCCCCATTCAGGCACCCTCGATTCATC GGGGCGGCTTGCCTGGCCGCGTCGATTACTTCGCTTCTCGGCACAACGGCACTCGGCCAAGCGGCCGGCCGCGCCCGTCCCGCCGGCG TCGATGCGGCCGCGCTTCTCGAGCACGGAACGCTCACCCGACGCTACTTCAAGGAGACCGAGACGCGTCCGGTCGACCTCACCCGCGT GGCTGTGATCGCCCGCGACGACAACGCCCGCCGCGCTCTTGACGAGCGCCTCGCCGACCTCGGACTCGGCACCGACTCGGCGACGGCC TTCACCCATGGCGACGTCCATCTCGTCGAACTGCCGGAGGGATTCCGCACTGCTGACGGGGTCGCCACGGCGCTCGAAACCTTCCGGG GCGATCCGCGACTTGCTTTCGTCACCCCGGTGATGCTCGATCAGCATGGTGGGGCGATCATCCCGCTTCCCGAGATCTTCGTCGGGTT CGAAGAGGGCGTGACACTCGCCCAGGCCCAGACCATCGTCGCCGAGCTCGGTGTCGGCGAAATCACCGTCGTCGACCGCCAGCCCGGC AACATCCATCTGGTCACGCCGAAGGCCCGTGATGGCGTCTCGGCCATTGCCGCCGCAGCGGCCCTCTCGATGCACCCGCTGGTCCGCT TCGCCGAGTGCGACGAGATCCTCCGCGCGTACGGGGAGCTCGAACCGAACGATCCTGGCTTCGACGACTGCTGGTACCACTTCAACGA CGGTGCCGACTGGTGGGTTGCCGACATGGACGTGAACAGCCCCGAAGCGTGGGACGTCGAGACCGGAACCTCGTCGATCATCGTGGCG ATCCTCGACAACGGTGTCGAGCAGGACCATCCCGACATCAATCAGGTCGTGCCCGGCGAAGACATGACCATCTTCGGTGGGTTCGGGT GGACCGGTGATCCGATCTTCGAATACGACAATCACGGCACGCCCGTCGCCGGACTCGTCTCGGCGATCATGAACAACGGCCTCGGATC GGTGGGAGTCTGCCCGAGCTGCCGCTCCATCTCGATCAAGATCGCCTACGACGACGACGCGGCGTGGGGTTGGACGACCCAGGGAAGC TGGGTCGCCGACGGCCTCTTCGAAGCGATCAGTCGCAATGCCGACATCACCAATTCGAGCTTCATCATCGGAAGCTCGGCCACGCTGA CCAACGCGTACGCGGCGACATCTCCGGTGCTGCTGCACTTTGGCGCGGCCGGCAACGGCGGCGACGACGACATCGGCGACCCGTCGCT CGACTATCCCTCGAGCCTCTCGAGCGTGCAGGCGGTCGCGGCTCTCGATCAGGACGGAACGCTGACCAGCTTCAGCAACTGGGGCACC GGTCTCGATTTCGCGGCGCCCGGCACGGGCCTGTACACGACCGATCGGACTGGCACTGATGGCTACGCCAGCGGCAACTACACCTACT TTGGCGGCACTTCGGGCGCGTCGCCGATTGCCGCAGGCGTGGCGGGACTGATCTGGTCCGCCAACACTTCGCAGACCCCCGCTCAGGT GCTGGCCCACCTGAAGAACTTCGCCAAGAACCTCGGCGCGGCCGGGTACGACACCACCTACGGCTGGGGCATCCCCCGCGCCGACCAG GCGGTGCTCGAGGTCGCCTTCGGCGACGAGTGCGGCGCCGCCGGCAACTGCTACGACGCTCACGACACCGGAGGCTGTTCAAACACGG AGTGCTGCTTCACGATCTGCGCCCAGGATGCCTACTGCTGCAACAACCAGTGGGACGGAATCTGCGTGAACGATGCCATCACCCTCTG CACCACCTGCGGCGAGGCCTCGGCCGGAAGCTGCTTCTCGACCGGCAACGCTTCGTGCGACGATCTGACCTGCTGCGCCGACGTCTGC GAGGTCGACAGCTTCTGCTGCAACAACTCGTGGGACGGCCTCTGCGTGAGCCGCGCCTGGGACATGTGCGTTCCCGAAAACGACACCT GCTCGAACGCCCTCACGCTGACCACCGGCGTGCCCTTCTTCTTCTCGACGGTCAACGCCACCAGCAGCGGTCCCGATCATGACGACTG CCTGTATTTCGGCAACGACTCGATCAACAACGACATCTGGTTCAACTGGACGGCGACCTGCAACGGCTGGATGACCGTGAGCACCTGC GGCACGGTCGACTTCGACAGCAAGATCGCAATCTACGGGCCGGGCATCCTCGGTTCGCTCTGCCCGGGCGCGACGCTCTTCGCGGCCC AGCTTCTGGGATGTGCCGACGACACCACGGACTGCGACGGCAACACCACCGAACTCTCGGTCGCGGTTTACTCCGGCACGACGTATCG GATCCGGGTCGGTGGCTACAACACCGCGGATGGCGAAGGCACGATCCTCGTCACCTGCGGCATCCCCAACGACACCTGCAGCACGGCG ATGGAGATCTTCGACGGCCTGACCAACTTCTCGACGGTCGGCGCCGCCAGCGAAGGACTCAACGTCACCGACTGCGACGGAGCCGCGA GCTCGACCATCAACCGGGACATCTGGTTCGTCTACGAGGCGACCTGCAGCGGCACGCTGACCGTCAGCACCTGCAACGACGCCGACTA CGACAGCAAGATCGCCGTGTATGGACCCCACTTCTTCAGCGGATCCACTTGCCCCAGTGCAGGTCTGTTCGGCGGGATCCTCCTGGGG TGCAACGATGACAGCGCGTTCTGCAACGACAACACGTCGCATCTCGAAGTCTCGGTGACCGCTGGCAAGTCCTACCGCATCCGCGTCG GGGGCTACAGCAACTTCTCGGGTCACGGCACACTCCTGGTGCAGTGCTCGCTGCCGTGCCCGGGGAATCTCAATGGAGACGGGGTGGT CGATGGCGCCGATCTCGGCCAGCTTCTCACGCAGTGGGGAGGCGACGGGAGCGCCGACTTCGACAACAACAACATCGTCGATGGCGCC GACCTTGGGTTCCTGCTGAGCAACTGGGGGCCGTGCGACTGAGTTGAGTGGCGACCGGGGTCGCCCGACACGCATCGCGTCGCTCCCT CCACGTGGGACGACGCCCGTTCGCAGCCGCGCGGGGTCTTCGGACCCCGCGCGGTCGTTTTGCCCTCGCGGAGAAGCCTTCTCGTGAA GCCGCGCCCGTATCCTGCCGGGAATGACCGCCGTCCCGTCCTTCGACAAGTCATCGGCAGAGCGATCGATTCCGGAACCCCCGATTGT GGTCACGCCCGAAGCGCATCTCCCCGAGCGCCTTCCGGTGGCGGTTCACGCCGACAGCGCCGCCGCCAGCGCCGCAGCGGCGCAGGAG ATCGCCCGCCTCATCCGCGAGCGCGCCGCCCAAGGTCGGCGGGCTGTCCTCGGCCTGGCAACCGGATCGACGCCACAGGGCGTCTACG AGGCCCTGGTCCGGCTGCATCGCGAAGCAGGTCTCTCCTTCCGAAACGTGACCACGTTCAATCTCGACGAGTACTGGCCGATGCGGCC TGATGCCCTCCAGAGCTACCGCCGCTTCATGCAGGAGCATCTCTTCGATCTCGTCGACATCGACCCCGCCGAGACGCATGTGCCGGAT GGCCTGGTCCCGCGCGAGTCGGTCGCAGCATCGGTGGCGGCCTACGACGCGGCAATCGCCCGCAGCGGCGGCATCGACATCCAGCTCC TCGGCATCGGGCGCACCGGTCATGTCGGTTTCAACGAACCCGGATCATCGCGAGAAAGCCGGACGCGACTCATCACGCTCGATCGCGT GACCCGCATGGATGCCGCCAGCGACTTCTTCGGCGAGCGACACGTGCCTCGACAGGCGATCACCATGGGTGTCGGCACCATCCTCGAA GCCCGGCAGATCCTGCTGCTGGCATTCGGAGAACACAAGGCGGCGGTCGTGAGACGGGCGGTCGAAGGCGAGGTGACGCCACTCGTCG CCGCGAGCTTCCTGCAGAAGCATCCCTCGGCGAAGTTCCTGCTCGACCCGGCCTCCGCGGCCGAGCTCACTCGGTTCAAGACGCCGTG GCTTCTCGGGGCAATCGGCCAGTTCGGTCTCGACTGGAACGAGTTCACGACGCGCCGCGCCGTCATCTGGCTGGCGACCATGGTGAAG AAGCCGATCTTGAAGCTCACCGACGAGGACTACAACGAGCACCACCTCCAGGAGCTGGTCGCGGGCCGCGGCGGCGCCTACGAGATCA ATCTTGAGGTGTTCCGCGCCCTTCAGCGGACCATCACTGGCTGGCCAGGTGGCCGGGCACCCGCTGCGGCCGCGGACAGCAACCGCGA CCGCAACGCTTCGGCGGCGCCGGGCGATCCGTTTCCCAAGCGGATCGTCGTCTTCAGTCCTCACCCCGACGATGACGTGATCTCGATG GGTGGCACACTCATCCGTCTCTGCGAACAGGGCCATGAGGTGCACGTCGCATACCAGACGAGCGGCAACATCGCGGTGTGGGACGAGA CCGCGCTGCGGCACGTCGACTTCGTGCAGGAGTTCGCCGACGCATTTCCGCAACTCGGGAGCGAGTTTGCGCAGCATCTCGAAGACAC CATCGAGCACTTCGTGGCCGAAAAGTCGCCAGGGCAGGTCGACAGCCCCGAGCTCCAGCGGGTGAAGACCTTGATCCGCCGCACCGAG GCCCGGGCCGCGGCCCGCTACTCGGGCGTCGACCTCGAGCGAATCCATTTCCTCGATCTGCCCTTTTACGAGACCGGCCGGGTGCGCA AGAAGCCCATCGGTCCCGACGACGTCCGCATCATCCGCAGCCTCCTCGAACAGGTGCGCCCGCAGCAGATCTATGCCGCCGGCGATCT CTCCGACCCGCACGGCACGCACCGCGTCTGCCTGCGAGCGATCTTCGAGGCGATCGCCGAGCTGCGCCGCGCTCCCGGGCAGGAGTGG ATCCGGCACTGCACGCTCTGGCTCTATCGAGGGGCATGGCAGGAGTGGGGACCCGAGGAGATCGAGATGGCCGTGCCGTTGTCGCCTG ACGAAGTGGCCCGCAAGCGCTCGGCGATCTTCAAGCATGAGAGCCAGAAGGACACGGCGCTCTTCCCGGGACCCAGCGACGCCCGCGA GTTCTGGCAGCGGGCCGAGGATCGCAATCGTGCCACCGCCCGCCTGTACGACGCGCTCGGTTTGGCCGAGTACGAGGCCATCGAAGGA TTCGTGCGCTGGCGCGGGGTATGAACCGAACACCGAAGGAATCTTCCATGACTGCTTCACGACGCCTCACCCGCTCACTGGCTGCGCT CACCATCGTGGCGACGGCTGCGGTTCATCACCCTGACCTCGGGCTCTCAGCATGCGCGGCGCCACCGGTGCGTGGCGACGCGCCGGCG GCCGTTGCGCCGACCGCGGCTCCCCCGACCGATCCCGCCGAACGCGCCACGCGGATCAAACGGTTCGTCGGCACGTGGAGCGGCGAGA TCCGCGTGCCCGGACAGGGGCTGGCGGTCTCGATCACGATCGAGGCGGGCGCGGCGACCTCGGGGACCGACCCGGCCCTGCGCGGCAC CATCGACATCCCCGTGCAGGCGGTGCGGGGCGCCCCGCTCGACGTGACTCTGGAACTTGGAGCGGCGCCGGAAGCGGATCGCATCCGC ATGCTGATCAAGGGACTTCCCGGCAACCCCACGTTTCGCGGCTTACTCCGAGATGGTGCTGCCGGAGCGGCGGACGTCGAGGCAATCG AAGGACAGTTCGAGCAGAGCGCCTATCGACTGCCCTTCTCGCTGACCCGCGGAGCCCTCGCACGGAAGGTGCGCCCGCAGGATCCCGT GCCGCCGCTGCCCTACACCGAGGTTGAACTCACGGCGACCCACGGCGAAGGAGACGGCGCTGTCTCGCTCTCCGGCACACTGACTGTT CCCGCCGGGACGGGTCCCTTCCCTTGCGCCATTCTCGTCAGCGGAAGTGGCCAGCAGAACCGCGACGAGGAGCTCTTCGATCATCGAC CCTTCCTGGTGATTGCCGACCATCTCACCCGTGCTGGCGTTGCAGTGCTCCGCTACGACGACCGCGGGGTTTGCAAGTCGACCGGACC 
AGTTCAGGCGGCCACCAGCGCCGACCTTGCGTTCGACACCGAAGCGTGGATCTCGGTCCTCAAAGCCCGTCCCGAGATCGGCGCGGTA GGCATCATCGGCCACAGCGAAGGTGGGCTCATCGCTCCAATCGTGGCGGCACGGAACGCCGACGTCTCGTTCATCGTGCTTCTTGCCG GACCCGGCGTCCCGGGAAGCAAGCTTCTCGCCGCACAGCAACGGGCCCTCGCAGAATCGGGCCATACCGCACCGGAGGTCGCGATGCA GCTCGAGGCGACGTCGCTCACGCTCTACGAGGCGGTGGCGGCCGCGCCACTCGACGAGCCACTCTCCGACAACGTTGCCACGAAGCTC GCGGCCCTGATTGCGGTGCAGCGCGGCACGACCCCGCCCGCGCCCGATGCCGAGGGCAACGCCAGCGTGATCACCAGGGAGGTGGCAG CGGCACTGCAGCAGCTTTCGGTCCCGTGGATGCGGTTCTTCCTGGCGCACGATCCGAGCGGCCCGCTCCGCGCCGTGCGAGTGCCGAT CCTCGCCCTGAACGGCACTCGCGACCTTCAGGTCCTCGCTGATCAGAACCTCCCCGCAATCGAAGCGGCGCTGAAGGAGAGCGGGCAT CCCGACTTCTCCGTGCGCCGCCTCGAAGGGCTCAATCACCTGTTCCAGCCCGCCCATCCGCCGCTCACCGGCGGCCTCGCCGAGTACG GCCAGATCGAGACCACGGTCGATCCGGCGGCACTCGAGGCGGTGCGGGCGTGGATCGCCGAGCGATTCATCCCATCGGCGCCGACTGC GCCGAAGCCCTGAGTCGATCAGCGCCTCGGCGCCGCGGTGATTGCCTCGAGCTTCTGGACCAACTCGTCGACGGTGCGGCGCAGCTCC GCGATCTCCGCCTCGGCGGTGAGTCGCTTGGCATCCAGTTCGCGGATCGCTTCGACGACCAGCGCCGTCGCGCCGCGCTCGGTGATGA ACCGGGTGCCATCGGGCATCGCCTCCACCCAATCGGGAAGCACCGCCTCGACCTCCTGGGCCACGAAGCCGATCTGCCGACCGGGCAG CGCCAGACCCTCCGCGATCCACTCCGGGTTGTACTCGTAGGTGACGCCCTGGAGCGCAAGGAGCGTGGCCAACGCCCCGCGCAGCGGC TGAATGTCATGCTTCGTGCGACGATCGCTGAGTGTCGACCAGCTTCCGCCACCCGGCTTGGCGGCGCTGCCGTTGACGGCGAGCTTGA AGGAGCTGATCGCCGCGGTCCCGATGCCGACGGCCTGAGTGACGTAGACCTTGCCGTTGAAAGTGCCGGCCCACCCGTTCGTGGAACT CGCCCAGAGACCGGTGCCGTTCAGTGATTCGGCCCACACCCCGACGAAGTCGTCGGAGTGCCCACCGATTGCAACCGAGACATCGTTT CGGATCTTGAGGCAGGTCGTTCCCAGAAAGTTGACGTGCTCGTCGATTGGAAGATTGAGCGAGCCGGCGCGAGACGCGTAGATGGCAA ACGGCGTCGGTCGGATCGACTGCCAGGGCATCAGCGAGGTGTAGCTTGCCTCCGAGCGATCGGCGTTGGAGACGCTCCCGGGTCGCAC CGACATCAGCAGGAAGCGCTCGTAGTCGTTGAAGAGAAGCGATCCGAAGTCGAGCTCCACGGTGAAGAGCCCATCCGTCACCTCGATG TCATCGCGATTGATCCTGCGCCATTCCGGGCGCCGTCGCTATAAATGACGGCATCTCCCGGTGGGGCCTGGGACAACAGGGGCCGGGA CAGCCACTCGCATCCAGTTGCTCAGGAGTCGATCGATGACACCACGCACGTCCCGCGTTCCGGCCATGGTTCTGCTGGCGACTCTGCC ACTCATCGCGGTTCCCTCGACTCTGGCCGACGTCAAGAGCTGGAACGTCGGAGATGGGCTCTGGAACACCGCGGCCAACTGGTCCCCG GTCGGCGTGCCGTTTCCCGCCGACTTCGTCCTGATCGGCAACACCGCGGCAGCCCAGAACGAGTGGGTCACGATGAACGTGAGTTCGG TGATTGCGTCCCTCACTGTCACCGACGGCATGGCCGTGGACACCGACGGGGCGCTGCTGGTGGTCAACGGAACCACGACGCTCTCGGG TTCCAACAGCAACGGGCAGCAGATCTATCCGTCGAGGATCATCGTCGACAACGGCGTTCAAGCGGTCGACTACGTCACGCAGGACCTG ACGATGTCGGATGGCGCGAGCCTCCAGATCCAGGGTGGAGCCGTGGTGCAGGTCAACGGGGTCATGACGATCAACGACGAGTCGTCGT GCTTTGGACACGGCGCGTTGAATCTCACCGGCGATGATCCGGTGGTCCTTCTCAAGAACGGCTTCTTCAGCGCCGCGGTCGACGGACT CACGGTCAACCAGCTCGGCGAAGGTCGAATTGATCTCGACGGGACCAGTATCGGCGACATCCTCAACGTCACACTCGGAATGATCGAT GGCAGCGCGTTCTCCTGGCTGACCTTCAACGGCGACGCCCTCACCGACCCGATGGGCGACGGGATCTGGGTCAGCGAGAACAACGTCC TGACGATGAACTTCTCCGAGGGGTGGGCGGTCGACTCGGTCTCCGAGATCTCCTTCTTCAACAACATCAGCTTCCCAGCCCCAGCCGA GATCAATGGAACAGCCCTCGACCTGAGTGCGAACCTCGACCACTTCACGGGAGCCCACGGACAGTTCAATTGCCCCGTGACGCTTCAG GCGCCGATCTTCGCCGACCTCAGCCCGCAGGCTCGGCTCGAGTTCACCGCGACGACGGTCCTCAATGGCGGCGACTACGTGCTCGGCG AAGACGCCAACGTCGACTTCGCCGGCACCACCACCGTCCACGGCGGCACGTTCACGACCTTCAGCAGCTCGGCCTCCGACGGCACCGT CGACTTCCTCGGCAGCACCACCTGGAACGGCGACATCGTCGTCGATGGTGTCGCCCGCCAGATCGGCGACGCGTCGGTCTCCGGGCCG AGCCAGATCGACGCCGACGTCTTCGATTTCGGATTCGGCAACGACTGGAGCATCGGGAACGGACTCGTCGTCAACGCTGACACCATCG GGTCGCTCTTCGCGGGGAGCTCGTTCGCCGACTTCTCGATCACCGGCACATTCCTCGGCAAGCTGACCGTCAATCTCACCGATCCCGG GGACGAGTGGAATCAACTCGGGAATCTGAACCTCGGTGGTGTCGCGGCGATCATGACCACCCGGATCGCGGGTTCACAGCTGCGGCTC GACGGCGACGCAAACATCAGCAATCGCGTGCAGATCACCGCCGACACCGTGCTTGACTCGGGAAGCGCCGTGAACTTTGCGAGCGCCA CCGCGCGGCTTCAGTTCAGCGGCGAGACCTTCGTCGACGACGGCTGCGCCTTCAGCGGGGGCGGGCTTCTTGCCAACGCCGCCAGCGG CGACATGACGCTCGCCCAGGGGACGAACCTCGGTGCCGGAAGCCTCTCGAACGCGGGCACACTGCGCCTCGGCTCGTCGCCCGGACTC GTCTTCACCCAGGGATTCTCGAGTGAACGCACCGCGACGTGGGTGGTCGAACTCGGCGGACCGGCTCCCGGGTTCGAGCACGATCAAC TCTTCGTCACCGGCACTCAGGTCTCGCTGAACGGCCTCCTTGACGCCCGGCTGATCAACCTTGGCGGTGGCTTCTTCGAGCCCGGCCT CGGCGACGAGTTCCTGATCCTGACGTGCGCATCAGCGGTCCCCACCGGCAGCTTCAGCAATCAACCGGTGAGCTTCATCCCAGGCAAG GCCTACGTCTGGACCGTGAACTACCTCACCAACGGCGTGAGTCTCGAAGTCGCCGACATCGTGCCCTGCCCCGCCGATCTCGATGGCG ATGGCAAGGTCGACGGCGCCGATCTCGGGATCCTGCTCTCTGAGTGGGGCGTTTGCGGCGGATGCATCGCCGACCTCACCCTTGATGG CGTCGTCGACGGCGCCGACCTCGGGTTCCTGCTCTCGAACTGGGGACCGTGCCTGTGAAGCCCAGGCGACCGCGCCGTACTCGGCACC CGCGCTCGTGAACGCACAAGCACCCTGTACCTCCGCCTTCGGGTGGGCGGAAGCACAGGGTGCGTTGGTCGAGAGCAATCCAGACGAG CGGTCGTCAGCGAGTGATCAGCGAGCAGGCGGTGCGAAGAGCGCACCGAGGTTGAACAGCCGGGTCTCGCCGCTCGAATCCTCGACAC CGTCATTGTCATTGACGATGAGCGTGGTGCCGTCGGGCAGCACCGCGAGACCCTCGAGCTTCTCGAGGATGACGTCGGCCTCGTAGTC GCCGGAGAGGATGAGATCGCGATCGAGTGTCTTGCTCACGAGCGGCAGTGCCGGTGCAACCGCATTGGGTGCGAAGACGACGCCGTCG ATCGAGAAGGAGTAGACCCGCTTGATGCGGGCGTCGGGACCGGCCTGATTGTCGCGTTCGATCACCACGAACTTCCCGTCGCCCAGTG CGGTGATCTCGGAGAGACCGACCCAACCCCCATTGGGCGACATCGGCATCTGAAGCGGGTAGTAGGCGAAAGTCCACTCGCCGCTGAG GGTGTCGTAGCGACCGATGCGGGCCCGATTGGCCGGATCGGCGGCCCCGCTCCAGCGGCGCTGGAACGCGACGTAAAGCACTTCTGCG CCGTTCTCCTCGACTGCGGCGACGCCCTCGTATCCGAATCGGAACTGATTCAGCGTCAGTTCAAGCGGCGGAAGCACTGCTTCGGTGA TCGTCCCCGTCGCATCGACGCGCAGCAGCAGATTCGGGGAGCGGAACGGCTGGTCCGCCGGATTGCTGACGCCTGCGGCGAGATTGCC TGCGCCTTCGCTGGCGATCCAGAAGCCGCCCCCCATGCCGACGGCGATGCCCTCGGGGTCGAGGTTGACGCTGCCATCGGCGCCGACC AGCGAGTCGGGATCGAACGAGCCGAGATCAGGGAGCGTCGACGCAAGGGCGTCGAGCGCTGCGGCAAGCACGTTGCCGGAGTCGTTCA GCTCGAGTTCCGAAGCGATCGTCGCGGGGCTGGCACTGACGTCGAGGGTGTAGATCCGGCTGCGGAGGTAGTAGCTGTCGTGGATCGA ATACACCGTCTCGGCATCGGCCGGGTCGACGACGAGCCCCGAGAGCGCCGCCCAGGGAATGGGTGAACCATCGGCCCGGTCAGCCGAG ACGATCTGGGGATAGGTCGCCTCGTCTCCGAACTGGTAGATCGAGACGGTGGCGCGGACCAGGTCGGCGCGGGAGTCGACCTCGCTGG CGACAACGAGCAGGTTGCGCTCGGGGATTGCCAGAAGCCCTTCCGGGCTGAGGCCGGTGGGAAGGAGCTGCTGGAACTGCGGTTCGAT TGCGCAGGGGCCCCAGGCGGCCAGCAGCGCGGCGAGGTCGGTTTCGTCGACTGCACCGCTCCCGTCAAGATCGGCGGGCAGGTTGCGA CCCGCGCCCCACGTCGAGAGCAGCTCGCCCAAGTCGGCGCCGTCAACCGATCCGCTTCCGTCGAGATCCGCAGCGCAGATCGGGTTGA GCGTGTAGACCGCAATCGTGCTCGACCGCTCGGAGCCAACGAAGAGGTACGACGTGTCGCCGAACTCGGCGAAAGTGATGCCCTCGGG CTCGTTGCCCTTGTTCTCCGATCGATCCTCGGGGTAGTGGCCGTGGCGGGCGACGATCCGTTCGAGGGTGTTGCCCGCCTCGAAGAGC ACCTCGCCGCCCGTGGAATAGACCGTGAACCCGCGGCTTCCGCCGAAGAGGTCGCCCTCGTCGGCGGTGGCAAAGGTCGTCGACGTGA GCCACGTCACCGCGTCGGCTTCGCGCGGCACGGCGCGGAGCGAGTCGACCTGATTGATCACCCCATCCTCAATCGCATCGATGCCCTC GAGGTCGGCGTTTCCTGCCGAGAAGTCGCCGGTGACGGCGCCGCTCGCCAGATCGATCAGCGCGATGTGGTTGTTCTCCTGGAGCGTC AGGACCAGTTGATTGTCGCTGTTGATGTCGGCGAACTCGGGCTCGGGATCCCCGGGGAAGAGCGTGGGAACGCCGACCAGATCGACCT GTCGGGTGCTCCAGGACGCGGGACTACCGATCAGGTCGACGATCACCACGTAGCCCGGTGGGAACTGCGGTGGCTCGCCTTCGCCAAG ATCCTCGTCGCGCTCGTTCTCGATGACGACGGCGGCGTACTGGCCGTCGGGACTCACCGCGACCGAGTCGGGCTGTCCACCCAGCTCG ATGGTGCGGACGGTTTCGCGAGTGTTGACATCGATCACCAGTAGTCGTCCCGAGACGTTCACGAAGTCGCGGCTGGTGTTGATGGCCA CCAGCGCGAAGTCGTCGACGACGTTCACGGAGGTCGGGTCTCCGCCCAGCTCGACACTGCCGGTTGCCTTCGGAGCGGCGGGGTCGAC GATGTCGATGAACCCGAGCACGCCGGCGGGCCCGTCGGTGTAGACGAGGAGCGTGCCATCGAGCGCCGCGGCGACGATCTCGGCCGAG CTCTCGGTCTCGACGCTGGTGTTGAGGAAGACCGGGATGGTCGAGATGCGGCGGAAGAGGCCGGTCGCGTCGGCCGCGGTGGCGATGA AGAGGGCGCCGGCCGCGGCGAGGCCCGCGACCCGAATCGGGTTGAGAGCGCTGCATCCAGCGATGGGTCGCGGGCGGATATCGTGGTT CAGCGGTCGCGCGGACGGTCGAAAGCGATCGTTCATGAGAATCTCCTGGGATGTGGACCTCTCGGCCTTGCGGGTTCCTGCACAACTC 
GCGCGGGACCCATCGACCCGTCCCCGCCTCCGGGCGTATGTGAATCGAACAGCCGAGGGGGGCGAACGTACGGTCCGCCGCGACGGGA CGGGTCGGGGCTTCGCCAAGGTTTGACGAAGATCGCGCGAAGGGCAAGGTGATCGCGGATCGATGCGATCCCGTCGCCACGATCCGCG ATGTCAACGAGCTGCTCTAGTGCCGCATGCTCACTCGAGTCGCCCCTTGGGCCGAGCCCGATCGACCGAGTGGTCGAACCCGTGACCG ACTCGCCGCCGTGAGCCCGGCATGGCACTCGAGCGGGTTTCCGATGCCGCGAAAGCTCGTTAGGCTTGCCACCCAAGGCGTGATCACT CTGCGACGCCACTCCTGCGGCGTCTCCACGCCCTCTTGCACGTAGCCGCTCATACCTCTGACCCAACTTTGGAGAGAACCCTCATGCG CACGCTCACCCTCGCCGCCGCCCTGATGATCGCCCCGCTCGCCCTTCCGATTGGGATGACTGGTTGTGAATCGACGTCCAGCGTCGGG TCACTGGCCAACCTGAATCCCTCCGAACTCATGTCGGGCTACACCTCGAAGCTCGGCGACCTTGGTGGCCTGCTCTCCGGCGTGAAGG ACTCGCAGAGCGCCGCAACTGCTCTCCCCAAGGCGAAGGACCTCGTCAACAACCTCGGCTCGTACGCGGAGAAGATCAACGCCCTTCC GCCGGGACAGGTCGACTCGTTGATGACGCAGTACGGCGGGCAGCTCGATCCGGCGATGGCCAAGGTCGACGAGCAGATCGCCCGTCTC GCGAATCAGCCGACGTACGGCTCGGCGTTGAGTTCGGCGCTGAAGTCGATCCCGAAGCTCGGCGCGTGAGTGTCCGTCGCCGAGCTGT TTCGGCATCTGGATCGAGTTGAAACACGACAGGCCCCGCCGGAGAACCGGCGGGGCCTGTTCACGTGAAGTGCGCGTCTGCGCGGTCG ATCAGGTCCAGTTGCTCAGCAGAATTCCAAGATCCGCTCCATCGACCTGCAGGTCGCAGTTGAGATCCCCGAGGCACTCCACGTTTGG TGGCAAGCACAGCCCCCAATTGGCCAGCAGGGCGCCGAGATCGGCTCCATCGACGATGCCGTCGTCGTCGAGGTCCCCTGGATAGTTG CCGCTGAACTCATAGAGATCGATGAGCGTCAGCGGACCGATCGGGTCGCCACCGACGGCGCTGATGGTCGTCCCGGGGGTGTTGGCTC GAAACCGGACCACGTCTTCGGCGTCACCGTCGAGAGAGATGAAGAACAGCTCGGCCACCACCGAGTCGCTCGTTGTCGGCAATTGCAG GAGCGGCTGGTTGACTCCTGCTGCCATGTCCAACTCGCCCGGCGGCCCGGCGATTGGAATGATCGGAAGCCCGAACGGCGCTGCGGTG TAGTTCCCGGTGAGATACGCCACCTTGGCGGTGTCGAACTCGATGAAGGCCTGGAATCCGGCCGCCGGAGTGCCGAAGGGGATGTCCG ACATCTCGACGAGCACTCGGAAGACATCACCTGGGGCGAGGCAGACGATTCCATCGGGGAACGCCAGCTCGAGTGTGGTCCCGCCGCC GAGCGCGTCGGTTGACCAGCACAGCGCCGCCGCTGATGCCACGAGCACTGGGACGACGATCACTGGGGCGACACACACCCCGGCGATC GGACGTTGAACTTCTGAAGTGAACCGCATGAATCGAATCCTCTTCCTCGATGTGGTGAAACTTCGCACACGACGCGGCCGGCGCCGCG CTCCATGATCCAACGAATCCAGCTGACCCAACTCGTACCCAGCAACGCTCCGGCGCGAGCTTTCGCCCGCGCCGGAGCAAGGAGACCC TGGAACGCAGAATCTCACAACGTGGACGCTACTGACCAGTCATGAACAGGGCGACATCGGTGGAGTCGACCCATCCATCCGAATTCAG ATCAGCGCTCATGGGATTGGGATATCCCAGGCGACGCAGCTCGGAGACTCGGACCCGATGCCGCGGCTGCGGCTGAACGCCCCCGGCC AGCGGGAGCGGACAGCATCCGGAGGCGTCGAACTCGAAGAACGACACCTGGATGAACGAGAAGTCGAGCACGTCGACATCTGCGTCGC CATTGAAGTCGACGTTGAACCCGACGTGACCGCAGAGCGTGTCGGCACCAGGCGAGGTGTTGTACTGACCGACATACGCACCGAAGTC GAGAATGTCGATGAAGGTGTCGCCGTTGGCGTTTCCACCGATCAGGGCATCGCCCGGATCGCTGATGCTGACCTTCAGGAACGACGTC TCGTACCCGCTGCCACCCACGGAGACCGACGAGGTCGACCGCAGCGTGTGTTTCGGATCACGAGCCGTGACACAGGTGTAGCCGACCG CCGAGCAGGGCACCTCGATCGTGCCGACTCCGATGCCGCTGTTGAACTCCAGCTCGGCGGTGACGATCGTGCCGCAGTCGAGATCAAA CTCGATGCAGCGGGTGAAGGGACCCGGATCGATCCCGCCGAAGAGCTCTACTTCAACGTCGAGGAGCGTGAAGGCGAGAACTTCGACG GTCTGATCGAGGCTCGTCTCGTTGCCGCACTCGTCGGTGGCGGTCCAGGTGATGATCGTCTCGCCGGCCGGGTAGGGATCATTCAGGG CCATCGCGTCGTCACGCACGCCGACGATGGTCGGCGCGGGATCGCAGTTGTCGCTGGCATTCGGCTCCGTCATCGTCGTGAAATTGTC CCAGTGGATGTCGTAGGTGACACCCGCGACGTTGTTGTGACCCTGGAGGATGGTGTTGCCGATCTGGACCGATCCGTTGGCATCGATC GACACCGACAGATCGCCGACGGTGTAGACGACATCGGTGCCGACGATGGCGATCTCGAGGGTGTACCACGCGTCGTAGACGAACCCGG TTGGAAGCCCGAGATCGATCCAGACGCCGTTGTTGTACGCACGGAAGCGGGGAAGTCCGGTGCCCTCGGCATTGCTCGAGAACTCCAT GATCGGGTAGAGCGAGATCGCGTTCCCGATATCGAACGCCGTGCCCCAGAACCCGGCCATGCGCCGACCGGTCGTCGCCCAGTCACCG GGCACATAAAGGTCGATCGACATCGACGCGGAGCCGGGAGTGTCGAACTTCCGCCCCTGGGTGTTGTAGAAGGCGCCGTTGAATCCGC CTGGTCGGCAGGGCTCGCAGTCGGCGGCGTTGATCGAGTGCCTGAGTCGATCGTCACCATCGAAGAAGGCATTGGTGAACCCGAACGG CGGGAATCGGTCCGTGTACCAGGTGCCTGGAGCCTGGAGCGGCCCGATGACCACCGGATCGGTGAACTCCTCGGTCTCCGAGCCGTAG ATGTCGACGACCGCCGAGCACTCGCCCGGGTCGGAGTAGACGGTGATGTCCGCCGGAATCGTGAGCAGCGGATCGGTGGTATCCGAGA CCGTGATGATCTGGTCGCCAGTGGCCTCGTTGCCGCAGTCGTCGGTCGCCGTCCACGTTCGGGTGATCATGTACGACGCGTCGCAGGC GCCGGGCGTGATCACGTCGTCGTAGGTGATGTCCGGAGCGCCGTCGCAGGTGTCAGGGGCGGTCGCGGTTCCGGTGTTGGCCGGAAGC GTGGACTCGTCGCACTCGATCGAATCGTCTGCCGGGACAGCCAGCGCCGGGGCGTCGGAGTCGAACGTGACCGTGGCGAGATCGGTGA GGTCGGGATAGATCGCCGTCGAGAACTCATCGGTCACCGTGGTCGGCAGCAAGGGCGCCACGCTGAAGGAGACGGCGTCAGCGATGCT GCAGGCGCTGTCGTCGATCACCTCGAACGTGATGACGGCCATGGTGGCATCGCCGGTCGTGCCCGGATCGGGCACGGTCAGGCCCACT GCATACTGGAGCAGCCCCGGCACCTGGAACTCGAAGATCTCCAGCGGGAACGGGGCGCCGATCGACGGATCGGGCGTCGCGCTGACGA ATTGGAGAACGTTATCGTCGTACTCCAGGAAGAACTGGCCGCCGACGATCTCGTCGGAGCCGTTGCCGGTGAGTTCGACGGTCACTTC GACCAGCTCGCCCATGCCGCCCGTGTAGCAGGACTGATCGGCGACGAGTTCAAGGGCCTGAAGCGGGAAGTCCTCGAGGTTGACCGTG GCCACCGAGCCGTCCATGAGCTCGATGCGGATGCCGTCGATCCGTCCCTGGAAGCCGTTGGCCCACCCCGTGCCGAGGCCGAGATTGA AGAACGAGATCTCCTGACCTCCGATTGGCGCGTAGGCGCCGTTCAGATTCCATGCCGGAATGGGATAGGTCAGGAGTTGGAAGGCGTC GAGGAAGGGATCGGTGTAGCCGCCGAAGTAGTTGGGCGTGCCCGTGGAGTCGTAGAAGCGCAGACGGTTGTCTCCACCCGCATCGCTC ACCCACTCGTTCCACGTGTTCGCAGGGGCGTTGAGACTGCCTGAGAAGTACGGCTCGGAGTTGATCCGGTGGCCGTACCACGTCGCCC CGCTGGGATCACCCACGTAGTTGTCGGTATAGAACTGGAAGAACCAGTCGACGGATCCTTCAAGGCCAGCCTTCTTCGTGAAGTAGCT GACGCTCGCGAGCTCGGAGACGAGGATGTCGTTTCGTCCGAAGAGGACCATCGGATCGAGGATGATGCTGGTGAAGAGCGGCGGACCA GTCACGTTCGCCTGCCACGCGCCAGTGCCGTAGCCCGACGCGGAGTCGGCGGAGACGCCGAGCGGCAAGGTCCCCTGAAGCCCCGGGT AGTTGGGGTAGTAGGTGAGATTGGTGGTCGTCGCCCCCGCCCAGAGGGGAGCGCAGAGCGCGAGCGCGGACCCGGCGCCCGCAAGAAG CGCGGTACTACAAGATCGACCTGACGTGAATCGTGCGTTCATCAACTGTCTCATCGACTGTCTCCTTGGATTAACGATCGGACCCGGG ATCCTCGATTCCGCACGATCGCCGGATGACTCCTCGCGGCGCACGGCACAACCGCCGCGACGCATGGAGGGCGTCACCGATGACCGTC GAATCGAGCTCCCTTGCCCCACTGAACCAGCTGCGCGCCGGCCAGCTTTGACCGACTGCGCTCCGACCCGTCAAGGCGCCCCATTTCA GGCGCTGCCGAATGGCTTGATGCCCGCCGGCGTTGCACTCCCTCCCGATCTATCCGCACGCGGATGTGCGGAACGGCAGATCGTGTTT GTGGTCCCCAAACCAGCAACTACGCCCGAAACCAAACCCGAACCGTTCGAGACGAACTCCCGCCACCCGATTCCCACCCTCAACCCCA GGCGCTGAGCAGCAGGCCCAGGTCGGCGCCGTCCACGACGCCACTTTCATCAAGATCCGCGTCCTCGTCCGCGGAACCCCACGCGGCG AGCAGAAGCCCGAGGTCTGCCCCGTCGACCGCACCGTCACAGTCGAGGTCGGCGACACTCCCGAGCAGTTGACTTCAACGACACACC CGAGCAGGCCGCCGGTGATCACCAGTCCGGGCACGACGCCTGAAATCACTTTGGTCTGCCCACCGGAATCGACCGGCTCGACCACCGA GACTCGTCCCGGCGCCAGCCCCTTGAATCGCAGCGTGGTCAGCAGGGTTCCACTCGAGCTGGCAAACGTCGTCACGCCGAGCTGTGCG AGCGCGAGGTAGGTCCCGTCACCATCCTGCGGCGGGATCACCTCGTTGTGACCGGTCGGGTCGTTCGCAGGAAAACTGGATGCCAGCA GCGGAATCGCGCCAACATTGGTCAGCCCCTCGAGCTTTACAACAAGCGGGTTCCATTCGAAGACGATCTGGGCAGCCGAGAAGGCCAC GAGTTCGCGGTCGGTGAAGAGGTAGACCCCGACCGACGCAATCTCTCCGACCTCAACCGACTGCATTGCCGGGAGGAAGTGGATGCCA ACCGGCGGAATTCCCCGAGGTGCACCCGCACCGAGGCACGCCGCGCTGAGGCACAGCGAGAGCGAGAAGGCCGCGAAGTCGGGCATCC GAGTGCGATTGTTGAGATTTCGCGTGTCCCCTCGACCCATCCGCACCCCCCGTCGCCGACTTCACTGGTCGCGACGCGGAGAAGCTAC CAATGCTCCTCGGGAGTGGCAAGCCGGCGTTGTTCAGATTGAGCTTCCCTTTGGGTCAGTACCCAGCGGCACTGCCGTGACGTCGTCA CTCAGCGCGCCAGCGTCGATTGATTGCACACTTCAAGCGGCGCACCTCGTCGTGCCTTCGGGCACCGCACGTGAGAGGCGCAACACTC GCGGACTTGGCACCAGGACAAGCATGGTGGACCAATCGATCCGTTGAGCGCCACTCGAGAACGTCCGCTCACGAATGGCCCCGGTGGG ACTCGAACCCACACGTCCGATGAAGGACCGCGGATTTTAAGTCCGCTGCGTCTGCCGATTTCGCCACGGGGCCGCACGACAGCGTCGG CTCGCGGTGCGACGACGTCAACTGTGGCCCACGAAGGCGCGCCGCCCTCGTTCACCCCGCCGGCCGTGCCTTCCACGCCTTGAGCACT TCGGTTTCGCGCTCACGAGTCATACCCGCAGGGCGAAGACGGGCCTTCTCGTCGGGCTTGAGTCCGTCGATCCAGGTGTAGATGCCGC GAATGGTCGCATCAAGAGAACGGAACCGAAGTCCCGCGGCGATTGCCTTATCGACGTTCCACTGATGAAAGCCCGCGCCCTCGCCCTG CGGCGGGATCCAGATGGGCAGATCACCGCCCGGCGAGACTCCGAGGCTCTGGAGGAAATCGGCCGGCACCCACGTCACGGTCGTGTCG 
ACCAGCTTGCTCTCGCTCGAACCAGAACCAGCGGTCTCCTTCGCGACGCGGATGCTCTCGTTGATCACCTGTCCAATCGTGCCCGGCG GCTTGGGACCGGTGGCGCTGAAGAGCCCGACCACCTTCTTCTCGGCGCAGAGCACGATCCACTCGGCGAGATCGCGCACGTCGATCCA CTGCACCGGATCCTCGGGAGTACCGGGGCCAAGCATCTCGCCACCGAGACGGGCACGGAGCGGCCAGTAGCTGAATCGCCCGGTCCAG TCGCCGGGGCCGACGATGAAGCCCGGTCGGATGTTGGCAACGCGACCAGGCATCGCCGCCTCGGCGGCCTGCTCGCAGAGAGCCTTCA GGCCTCCGTAGTTCTTGAAGCCATCACCCATGGTCTCGACCGCCGGATCATCGAGCGTCGCGACGGGGAAGCTCTCGTCGGAATTCGG CGGCGCGCCTTCCTTGAAGGCGCTGATGCTCGAGATGTAGATGTACTGACCGACCTTGCCCGCGAGCAGTTCGGCAGAGGCCTTCACG TGCCGCGGGTAGTAGCCGCTGTTGTCGACGACGACGTCCCACTCGCGCCCTTCGAGCGACTTGAGTCCCTCGTCCTTGTTTGGGTCAC GATCGCCACGCAGCTTCTCGAGGTCGGGGAAGAGCTCGGGACGAGTCTTGCCGCGATTGAAGAGCGTGACGGTATGTCCGCGGGCTTG GGCCGCTTCAACGACCTCCGGGCCGAGGAAGGCCGTGCCGCCGAGGATGAGAAAGCGCAGCGGCTTCGCCGCCTTTTCACGCGCGGCC GGAGCGCTTGCGGCGCCGGGTTTGACCTTCGCGCCGTCCTGCGCCCCGAGGGCGCGGTGACCGAGGGCGAGTCCGGCGGCGCCGGCAG TCGCGAGGGCGACGAATTCACGGCGATGAAGGGGGCGTGGGAGGTGTGACATGAAAGGATGTCTCGTGGCGAAGCGGGGGGGGGGGA AGGACGATCTCGCATTCGGAGCGACGCGTGTCTGGCCGTGACCGTACCCCGCGAGCGGGATCGGCGGAGTCTTTCGTACGTCCTCATG CTGGAGAGGTTGCGGCAGAGATCGCACCGCCGGGCCGTTGCCGTGGGAACGTCCCGGTCGGTGGCCGGTCGGAACACGATGCGAGATC CCGGCGGCAGCCGCCGGATTCGAACAGTCTCCGAGGATACTGCCCCCATGATCGCTATCGCCACACGAATTGCTCCCCCACTGGCCGT GCTCGCCGCGCTCGCGTCATTCGCCTGTCGGGGGCCGTCTCTGCGGGGACCGCTCAGCACCGACTCGACCGAGCCGCGGTCCGAGGTC GCGGCGACCGCCGCAGCAGCGGCTCGTTCTCACCGCCCGTCCGACGAGGCGCCGAACCTCACCGCGATGGAGCGTTCCCAATTCGAAC ATGCGGCACGCTACTCGGAGAGTCACAACGGCCTCAGCCTCCTCGTGATGCGCGATGGCATTGTGATCTACGAGCGCTACCGCGAAGG CGTCGCGCCGAACACGTCTCACGCGCTGGCCAGCGGAACCAAGAGCTTCGCGGGCGCAATGGCCATCGCCGCGGTCGAGGATGGACTG CTGGCACTCGACGAACTCGTCGCCGACACGATCACCGAGTGGAAGGACGATCCGCGTCGCAGTCGCATCACGATCCGGCAGCTCCTCT CCCTGACCAGCGGCATTCCCGGCGGCACCATCGGTCGGCCGCCGGCCTACGCCGCGGCCATTGGGACCGCGGCCAAGGCCGAGCCCGG TGCGAAGTTCCAGTACGGCCCCGCGCCGTTTCAGATCTTCGGCGAAGTCATGCGTCGCAAGCTGGCGGCCAAGGCGACGAGCTCGGCT GCGCCCGAGAGTGTCGAGGGCTATCTCACGCGACGGATTCTCGCGCCCATCGGTCTCGAAGTCGGGGCGTGGCGCGAAGATCGCGATG GAAACATCAACCTGCCCTCGGGAGCGCTGCTGAGCGCCCGGGAGTGGGCGAAGTTCGGAGAGTTGATGCGAATGAAAGGGGCGTGGAA CGGCACACAGATACTCCGTGCCGACCTGGTCGCCGAGCTCCTGGCGCCTTCGCTCGCGAATCCTCGGTACGGGCTGACCTTCTGGCTC AACACCGCCGACGGACGGGGGCTCGATCCGGAAGAGATGCTCTCGCCCGCCGTCGCCGGGACCGACGAGTCGGCCGACTCGGGACCCG CCCCCGCAGCGCACGGCGTCGCTCCCGATCTGTTCATGGCGGCCGGACTCGGAAAGCAGCGCTGCTACGTGATTCCCGCGCGCAATCT CGTGGTCGTGAGACAGGGAACACTCGACCGCCGCAGCTCGTTCAAGGACGACGCGTTCCTTCGCCGCCTGCTCGGGGAGTGAGCGCGG AGAGTCAGGCGCATCGCATCGATCCCGCCACTACCATCGCCCCCATGCACGTCCTCCGCGTGCTCGCTGGCCCGAATCAGGGCGCTGT GATCCGGCTTCCGCCGGATGAACCGCAGCTCATCGGTCGTTCCAGCGAGGCCCTGCCGATCAGCGACACTGCGGTGAGCCGCAGACAT GCCGAACTCACCCCCGACCGCGGCGCGTGGTTCGTGCGCGATCTCGACAGCGCGAACGGAACGTTTGTGAACGGGATCGCCATCGTCT CGCGGACTCGGCTCGTCCCCGGCGACGAACTGCGCGTGGGATCGACGACCTTCCTCTTCTCGGCGGAGGCCGAGCAGGTGGGTGCAAG CCCGATCAAGCTCATCGATCGTGACGAGGGCGACGAGCTCGAAAGCACCATCGCCGCCCGCATCCCCGCGGACCAGCCAATCGGCGCC GCCGGAGACGATCCCACCGACGACGCGATGCGTCTCGCCGGCGAGCATCTTCGGGTGATCTACGCCCTCACCGAGATCACCGCGTCGG CCCTCACCAAGGAAGAGCTGCTGACGCGGGCGCTCGACCTGGTCTTCCACGAGTTCAATCCGGAGCGGGGCTTCATCCTCCTCCAGCC CGAGGGTTCGACGCGCCTGATCCCGGCGGCGGTCCGCCACCGCACGCGCCCCCGCACAGTCGACGAAGGACACATTCCGGTCAGCCGC ACGATCATTCAGCACGTGCTCACCCGCGGCGATGGAATACTCGCGACCAACGCCATGAGCGACGAACGCTTCCGAAGCGGCGACTCGG TGCGCGAGTACGGAATCCGTACCGCAATCTGCGTGCCGCTACGGAGCGGTCGCATCGTGCTGGGGGCCCTTCACATCGACAGTTCAGT CGCGAACTTCCAGTGGGGCGACGCCGAGCTTCGCCTGGCAAACCACGTCGGCCAGCACCTCGGCCTGGCCCTCGAGGGGGTCGAACTG GTCCGTGGAATGATGATGCGCGAACGGCTCGCGGCGATGGGGGAGACCGTGGCGAACCTCAGCCACTCCATCAAGAACATCCTCCAGG GACTTCGCGGGGGCGCCGACGCCGTGGAACTCGCGCTCGAGCGAGACGACCTCGCCGGGGCCCGCGAGGGATGGCCAATCGTCTCCCG AAACCTCGGGAGGATCCTCTCGCTCACCCTCAACATGCTGGCGTGGAGCAAGCCGCGAACACTCGACCTCGAACTCACGTCAGTCCTT CCGCTCTTCGAGGAGATTGCAAGTCTGGTGAGGCCCGAGTGTGACCGTCGCGGGATCCGGCTGACCCTCGACGTCGACGAGTCCATGC CCCCGGTTCCGATGGACGTCAACGCGGTGCATCAGGCGCTCACCAACCTGGTCACCAACGCCATCGACGCGGTGACCGATCGCCGCGG CGCAATCGTGCTTCGGGCCCGCTTCGACGGCGCCCGCGAGTCGGCGGAACTCAGCGTCGCCGACAACGGCTCGGGGGTCCCGCCGGAG ATCCGCGAGGAGATCTTCGAACCCTTCGTGACCAGCAAGGGACAGCGCGGGACCGGACTCGGTCTCGCCGTGACCCGACAGA

\subsection{Das Cosmid slc_1g}

\subsubsection{Lage der offenen Leserahmen (ORFs)}

\begin{tabular}{|c|c|c|c|c|}
\hline ORF & Annotation & Start & Stopp & $\begin{array}{l}\text { Orien- } \\
\text { tierung }\end{array}$ \\
\hline 301 & Potentielle L-sorboson-Dehydrogenase & 3 & 842 & + \\
\hline 302 & Potentielle Transposase & 985 & 2112 & + \\
\hline 303 & Hypothetisches Protein & 2195 & 2560 & + \\
\hline 304 & Potentielles periplasmatisches ATP/GTP-Bindeprotein & 2851 & 3801 & - \\
\hline 305 & Potentielle 6-Phosphoglukonolaktonase (EC 3.1.1.31) & 3811 & 4527 & - \\
\hline 306 & Glukose-6-phosphat-Dehydrogenase (EC 1.1.1.49) & 4599 & 5996 & - \\
\hline
\end{tabular}




\begin{tabular}{|c|c|c|c|c|}
\hline 307 & Hypothetisches Protein & 5983 & 6153 & t+ \\
\hline 308 & Hypothetisches Protein & 6291 & 6695 & - \\
\hline 309 & Pantoat- $\beta$-Alanin-Ligase (EC 6.3.2.1) & 6796 & 7566 & - \\
\hline 310 & Potentielle 3-Methyl-2-oxobutanoat-Hydroxymethyl-Transferase & 7640 & 8371 & - \\
\hline 311 & Aldose-1-Epimerase (EC 5.1.3.3) & 8432 & 9481 & - \\
\hline 312 & Hypothetisches Protein & 9649 & 10317 & + \\
\hline 313 & Hypothetisches Membran-durchspannendes Protein & 10354 & 10764 & - \\
\hline 314 & Hypothetisches Membran-durchspannendes Protein & 10767 & 12047 & - \\
\hline 315 & Hypothetisches Protein & 12031 & 12420 & - \\
\hline 316 & Hypothetisches Membran-assoziiertes Protein & 12595 & 13425 & + \\
\hline 317 & Hypothetisches Protein & 13485 & 14591 & + \\
\hline 318 & Konserviertes hypothetisches Membran-assoziiertes Protein & 14588 & 16123 & + \\
\hline 319 & Potentielle Permease & 16202 & 18631 & - \\
\hline 320 & Hypothetisches Protein & 18883 & 19335 & - \\
\hline 321 & Hypothetisches Membran-assoziiertes Protein & 19439 & 20350 & + \\
\hline 322 & Potentielles Cytochrom P450 (EC 1.14.14.1) & 20433 & 21809 & - \\
\hline 323 & Konserviertes Protein (Protein der Tetratricopeptidrepeat-Familie) & 21818 & 22726 & - \\
\hline 324 & Hypothetisches Protein & 22754 & 23113 & + \\
\hline 325 & Potentielle Histidin-Kinase & 23110 & 24651 & - \\
\hline 326 & Potenteieller "response-regulator receiver"-Domäne & 24779 & 25039 & - \\
\hline 327 & Konserviertes Protein (Protein der “Tetratricopeptide repeat”-Familie) & 25273 & 26034 & - \\
\hline 328 & Konserviertes Protein (Cytochrom P460-Vorläufer) & 26064 & 26666 & - \\
\hline 329 & Konserviertes Membran-durchspannendes Protein & 26715 & 27857 & - \\
\hline 330 & Potentielle Cardiolipin-Synthetase & 27913 & 29412 & + \\
\hline 331 & Hypothetisches Membran-assoziiertes Protein & 29501 & 29989 & - \\
\hline 332 & Hypothetisches Membran-assoziiertes Protein & 29973 & 30161 & - \\
\hline 333 & Konserviertes Protein (uncharakterisiertes Eisen-reguliertes Membranprotein) & 30430 & 31599 & - \\
\hline 334 & Eisen-Aufnahme Faktor & 31607 & 32287 & - \\
\hline 335 & TonB-abhängiger Rezeptor & 32301 & 34853 & - \\
\hline 336 & Hypothetisches Protein & 34811 & 35083 & + \\
\hline 337 & Potentielle Methyltransferase (EC 2.1.1.-) & 35266 & 36078 & + \\
\hline 338 & Mögliche Aminomethyltransferase & 36114 & 37310 & - \\
\hline 339 & Hypothetisches Protein & 37524 & 37820 & - \\
\hline 340 & Potentielle Phytoen-Desaturase & 38395 & 39999 & + \\
\hline 341 & Potentielle Phytoen-Desaturase & 39996 & 41555 & + \\
\hline 342 & Potentieller "resonse-regulator" & 41694 & 42416 & + \\
\hline 343 & Potentielles "outer membrane" Protein & 42518 & 43759 & + \\
\hline
\end{tabular}

\subsubsection{Sequenz des Comides slc_1g}

\section{Contig 1}

ACATGAGAATTCGCGGCCGCATAATACGACTCACTATAGGGATCAACCGCATCCTTCGCTTCGACAACATCGAGTCGAAGCTCGAATC GGCCGGGAGTCCCGCAGTCGTCACCGACAAGTTTCCGAGCGATCGGCATCACGGCTGGAAGTTCATCCGGTTCGGGCCCGACGGCCTG CTCTACGTGCCCGTCGGCGCGCCCTGCAACATCTGCGATCGCGGCGAACCGTACAACACGATCTGGCGTATGAAGGCCGACGGCACGG GCATGGAGATCTTCGCGCGCGGAGTACGGAACACCGTCGGCTTCGACTGGCATCCGACCACCCGCGAGCTGTGGTTTACCGACAACGG GCGCGATAATCTGTCGAACGACACCCCGGCCGACGAGCTGAACCGCGCGCCGAAGGCGGGCATGCACTTCGGCTATCCCTATTGCCAC GAAGGCAGGATTCCCGATCCCGAATTCGGCGCCAAGCGCAGCTGCACGGAGTTCGAGCCGCCCGCGCAGCGACTGCAGCCTCATGCCG 
GCGCGATCGGGATGCGCTTCTACACCGGAACGCAGTTTCCGCAGCAGTATCGCAATCAGATTTTCATCGCCGAGCACGGATCGTGGAA CCGCAGCCCCGGCACGCCATTCACGGGAAATCGCGTATCGCTCGTGCGCTTGCAGGACAACAAGGTCGTCGCGTACGAGCCGTTCGCC GAAGGATGGCTGGGTGGAGCCGACAATCGCCAGCGGTGGGGTCGTCCGGCCGATCTCGAAGTGCTGCCCGACGGATCGATGCTGGTCT CGGACGATATGGCGGGGGTGATTTACCGGATTAGTTACGCGGGAAAGTAAAAAAACAAACAGGAGACAGTATGGAATGACCGGCCCGC TATCGTAACGTCGTAGTGCAGTCGCACTCGACAAGGTGGTCTGAGCCACCGATATCGCGGGTTAACGCCTCGCGGCGTCAGAGCCGCA CAGATAGGAGCCGGTCATGAAACAGGTTACTACGTACGTCGGTATCGATGCGCATAAGCAGGATCTGTTCGTCGCGATGGTGATTGGG GATCAGTCGGTACCCGTCACGTGGCAATTGGCCAACGAGCCGACGGCCGTGCGCCGGTTGGTCCGGAAGCTCGAGCGCGACGCTCCGG GAGCGGTGCGTGTGTGTTACGAAGCCGGGCCGTGCGGGTATGCGCTGCAACGTCAGATGAGCACGACGCGGGTCGCGTGCCAGGTGGT GGCGCCGGGGCTGATTCCCCGGAAGCCTGGCGAGCGGGTCAAGACGAATCGCCGCGATGCGCGCAAATTGGTGGAGTTGCTCCGGGCG GGCTTGCTGACGGAGGTCCGGCCGCCCACCCCGGAAGAGGAAGCCGTCCGCGATCTTTGCCGAGCGCGTGATGATGCTCGCGAAGATC TGCAGCGATGTCGCCATCGGTTGGGCAAATTGTTGTTGCGGCGCGGCCTGCACTTCAGCGGGCGCAATTGGACGAAGGCGCATCGCCG GTGGATCGAGACGCTGTCATGGACGCATATTCCCGAGCGTGTCGTGGTCGACGATTATCTGCTGGCGATCGATCATCTCGAGGCGCGG CTGATTGAGCTCGACGCGCGCCTGACCGACCTGGCACAGACAGACCCGTACCGCGAACCGGTCGGGTGGTTGCGCTGCTTCCGTGGCA TCGACACCTTGACAGCGATCTTACTGCTGGCCGAGCTCCACGACTTTCGCCGATTCCACTCGCCGCGTGCCCTGATGGCGTATGTCGG CTTAGTGCCGGGTGAAGACTCCAGTGGCGAAAAGCATCGACGGGGTCGCATCACGCGAACGGGCAATGCGCTGGTCCGCCGGCTCCTC GTGGAGATGGCCTGGCATTACCAACATCGACCGGGGATCGGCGTCGCGCTCACGCGTCGACGCCACGGCCAACCGCGCCGCGTGATTG CGATTGCCGACAAGGCGCAGCAACGACTGTGTCGTCGCTTCCGACGCTTCGCTGACCACCACAAGCCCGCGCCGAAGATCGCGGTCGC CATCGCGCGCGAATTGGTGGGCTTCTTGTGGGCGGCGCTGCAACCGCCGATGACGATGCGGGAGCCGCGCGGAACGGCCGCCGCGTGA TGGTCGCGTGGTTCGGCTCGGTAACGGACCGCGAAGACGGCAGATGATCAGAGGCACGATTGCGAGGATCGGCGGCCTAATCATGCGA TACGGACCGATGTCCCAACTCGCGACCGGAGACTGCACGTCCTCTCGACGAAGCACCGTCCTGTGTGCTCTGCCGCGGATCCCCGTGG TAACCACCGTATATCAGTGTGACTCGTCGTCGAAGCGCCCTCGATCGTCTGTCGTCTTCGCGGCCCGCGCGCCGGACGAAGCACGTGG CGCACACGGCGTCCAGGGCTTCGCACCCGGCGGGTGGCGCCTTTGGGCGCCCCTGGACCCCGCGCGCGCCACGTGCTTCGAAGCTGCT GATGCGCGCAAGCTGATGCTTGCGCGCCCGTACCAAGCGGCCTTCGCAATCACCGGGCTTGACAGAAGGTCATTCCATATCAGATTAG GAGACTAGGAGATTAGGAGGGTTCGTTCGATCTGCTGACCCTTGCGATCGCGCTCAACGCGTCCGCACCTGGACAACAGCGCAGGCGC TTAGAAAACCTCACAGAAAAACGGAAGAAAGAAGCTGGCAAAAGCCGGGGCGTCGAATTTGAAGGCATGGGCGACTCCAGACGTCGAT GCGAACAGAGCACGCTACCGGCTTTGAAAAGCTCTTCCTGCCTTCTAATCTTCCGTTCTTCTGTAATCGTAAATGTCTATGGTTTCGG TTTTGAAACCACTTCCAGCGTCCTCGTGTCCCGCCTATTTCATCTCGGCGCCGATCTCGTACGCCGCGACCGTGTTCTCGTTCATGTG CGGAACGATGAGCACATCGCCCTGCGCGTACAGAAACGTGTGATCGGCAAGGCCCTGCTTGAACGTGCGCACGACGTGGGAAGAGCCG TCGGGCGCCACCTGGATCACCTTGCCGGCCAGAAAATCCGTCACGAGGAATCCGCCGCGCGCTTCCTGCTCGACCCCGTCGATATTGC CGAGCGGCTGCTTGGTGATGAGCGTCTTCTGCTTTGTCTTCAGATCGAGCATGTAGAGACGCCCGGGCACCTTGGTGCTGAAGTCGGC CTCGGGCTTGCCCCAGCCGCCGACGACGAGACGCTCGCCGTCCACGAACAGGCCGTTCGGATACTCGAGCTGCTCGCCTTCGGCAAAG ATCGTCGCCTTGCCGTCCTTGACGGCGTAAATGCGGTTTCCCATCATGTCCGACACATACACAGTGCCGTCGGCGCCGGTCGCCACGT CGTTGAGGAACTGCGCGCCATCGAGCTTGATGCGCGCGGTCTCTTTGGCGGTCGCGATGTCGATACCCACGACTTCGTCGAGGTCGGC GACCCACAGCACGCCGCCGTAACTCCGAAGACCCTTCGGCGCGTTCAGGGCCGTAAACCAGTCGGCCGTCACGACCGAGCCGTCGAGC CCGATCTTCGAAATGCGCCCCTTTCCATCTTTCTGATTCGGCTGCCCGTCAATCTGCGACACGAAGAGATAGCCGGATCCTTCGTCGA GATACGCGCTTTCCGGCGTGCGCATGTCCGTGACAGTCCAGCCGGCTTTGACGGCCGGCGGCGGGGACGGTGGCGCCGCCGTGACCGC GGGCGCAGGCTGTTGTGCGGGTTCAGTGGTCTCGGCGGGTTCGGGCGATCCGCCGCACGACGCGAGCGTGACGGCAAATGTGAGCGTC AAAAGAAATTTGTACATGCGCCTATATTAATGCGAGGAGGGGCGATCGAGCAGCACCAGGGGCGAACGCGCCTGGCGCAGAAGCTCGC CGACGGGCGTCGAGTCGGCTTCGCCATGCAACGCATCGTGAATAATCTTCGCTTTCGACACGCCGAATCCCGCGAGGATGACGCGACG GGCGCCGGCGAGCGCTGGCAGCGTCATGGTGAGGCGTCGCGGCGGAGGTTTGGGAGCGTCGTAGATGGAAATCACGGGGCAGGGCTGA AGCCCTGCGCTACCGGGAAGCCCTGCGCTACCGGTGAAGATTGACGCCACGTGTCCGTCTTCTCCAACGCCGACGATGACAAGATCCA ACTGCGGCGGATCGCCGGCCACCGCCTTCAACTCGTCCGCGGCGAGACGCGCCGCGTCGTCGAGATCGGCGAGCTCGCCGCGCATCCG ATGCGCCCCCGGCGCCGGGACGCCGGCCGGCTGCAGCCACAAACGCCACGCCAGCCCGTAGTTGGAGTCGGGATGATCCGGCGGAACG GCGCGCTCGTCGATCCAGAAGATGTCCACGCGCGACCAATCGACCGGCAACCCCGCGAGTACGGGAAAGAACGTCGTCGCGACAGAGC CCCCGGGCACCGCGACCACGAATCTTCCGCGGGCGGCGACCGCCGCGGCCGCTGCGCTCGTAAACTCGTCCGCGAACATCCGCTGAAG AGCGGGCATCTCGTCCACGACAACGGCCGGAACAATCATCAATCCCCAATCACCAATCGCCAATCAATCTGCCAATCCGCGAATCTGC GAATCTGCGAATTCCCCAGCCGCTACGCCCATCCGCCACCGACCAGCTGACGGGACTCGGCCGGCCCGAAGCTGCCGCACTCGTAACT GAACACCGGGTTGGGTCGATCGAGCACCGGATCGACGATGGCCCACGCGGCTTCCACGGCGTCCTGTCGCGCGAAGAGCGTCGGATCT CCTTCCATCGCGTCGCCGATGAGCCGCTCGTATGCGTCGAGCCGGCCCGCTCCATCTGGCGTCTGCCGTTCGACCACGGAAAGCTCGA TCGGCTCGCCGAACATGCCTTCGCCGGGGCGCTTCGCGCGCGCACCGAGGGCGATGCTCACCTGGGGAGAAAGCGTGAACCGCACGTG GTTGCCACCATGAAGCCCCGGCTCGGCAAACACGACGCCGGGCGCCGGCTTCAACTTCACGAGCACGTCGGTACGCGTCACGTTGAGA CACTTTCCGGCCGTGATGTGGAACGGCACGCCATACCATCGCCACGAATCGACAAACAGGTGCAGCGCCGCATAGGTCGGCACGTTCG AGCTCTTGCTCACGCCGGGCTCATCCCGATACCCACGGAACTGGCCGAGCACAATCTCGGCGGGCGATAGCGGACGGACCGTTCGCAG CACTTTGGCCTGCTCGTCGCGGAGCGCCTCGCGCCAGGCAGACGAAGGAGGCTCCATGGCCAGGTAGCCCACGATCTGCAGCAGGTGG TTCTGCACCACGTCGCGGATGACGCCGGTCTCTTCGTAGAAACCGCCGCGTCCCTCGACGCCGAACGACTCGGCCATTGTGATGTGCA CGCTCTCGACGTACTGCCGGTTCCAGATGGGCTCGAGGAAGGCGTTGGCAAACCGGAAGTACAGGATGTTCTGCACGGGTTCCTTGCC GAGATAGTGATCGATGCGGAAGATCGCCTCCTCGGAAAACGCCTGATGCAGAGTGGCGTTCAACGCGCGGGCCGACTCGAGATCGCGC CCGAAGGGCTTTTCGATGACGACGCGTGCGCCGCTGGTGCAGCCGGCCTTCGACAGGTGCTCGACGATTCGCGGAAACGCGCTCGGGG GGATGGCGAGATAGAAGATCGGATGCCGCGCCTCTCCGAGCGCCTGCCTGATTTTCGTGAAGGTCTCCAGATCGCCGTAGTCGCCCGA TACATATTGCAGGAGCGACGCGAGCCGCGAGAACGTCTCCTCGTCGATCGGCCCGCGCTCTGCCACGCTCGTGCGCACGCGCTCGATG AGCTGCTCGCGTTCCATCGGCGTCCGCCCGACGCCGACGATCGGCACCTTCAGCTGCCGCCGCTTCACGAGCGACTGCAGTGCCGGGA AAATCTTCTTGTACGCGAGATCGCCCGTCACGCCGAAGACGACGAGCGCATCAGAAACAGGAGCGGATGGTGTGTCGGGTGTGGTCAT GCCCGCCGACACTATATATGCGGCAGGCGCTCCGTCGAGTCACCCCTTCGTGCGAGACCCGCGGCGATCGTTCGAGCGGATGCGAGTC GAGCGCTGCCTCTCCCGCATTTCGAAAGCCGCACACCCGTCTGCGACGAGATATTCCGCCAGGCGTGCGGAGACGTCGTAGACCTCTC CCTCGCGGTAGTAGCGCAAGGACATGCCGTCCACGGTGCCCTTTGGTTCGTGGGTGATCCGAACCCTCATACTCTTGTTAGAGCAGCA AAGGTTCTGCCAGAAAATTGACGGTCTGTAAGTGTCGTGATTTCAGTCAGTCAGCGGTTTCGTCATGACGATGAAGTGGCAGGGACGG CTGGCGCGCTCGGGCGCCGAAAACGGGAGCGTCCCGCGCTCGACGTATCCGAACCGGCGATAGTAGGCAGGCAGTTCCTCGCGCAGGT TGACGATGTGGATGTCCATGAAGCGGCAGCCGCGTTCCCGGGCCCGAGCCTCCACAGCCTCGATGAGCATCCGGCCGAGGCCCTGGCC CTGCCTGGACGGGTCGATTGAGAGCATCCCGAAATACCCCCGGTCCCCGCGGCAGCGCAGATACACGCAGCCAGCCATCTTCCCATCG TCGGCGTCGGCGACGAGAAACTCGCCGCCCTCGTCCATCAACTCGACGAGCTCGTCGGCGCTGGTGCGATCGCCGATCTTGAAGAACG CTTCCACGATGAACGCGTCGTTGATGATCCGCGCCATCGCAGGGGCATCGGCGGGGCTGGCGGTGCGGAGCACACGGACAGTATAGGT TCGGGGGTTCGGGGGTTCGTCAGGCCAATACGTTATCGATAAGCCGGGTGTTTCCCACCCACATCGCACCTGCCACCCGCACAGGCCC GGTGACTTCGGCGACCGGCTGCATCGTTGCGGGATCGACAATCTCGAAGTACTCGAGCCTTACGTCCACATTTTGCGGAATGTGCAGC GTCGCTACGTGGCGAATGGCGCTCGCGTTGCGCTCTCCTCCCGCGATCTGCTTTTTGGCTTCGCGCAGCGCCGCGTACAGAGATGTCG CACGCTCTCGCTCGCCGGCACTCAAGTGGCGGTTGCGCGAGCTCATCGCGAGGCCATCGGGCTCGCGCACCGTGGGGACTTCGACGAT GTCGATCGGCAGATTGAAGTCGGCCACGAGCCGTCTGATGATGGCGAGCTGCTGCGCGTCCTTCTCGCCGAAATAGGCGCAGTGAGGC TGCGCCATCTGAAAGAGCTTCAGCACCACTGTCGCCACTGCGCTGAAGTGGCCGGGCCGGAATTTTCCACAGAGATGATCGGCGAGGC 
GGCCAACCTCGACGCGGCACTCGGGCGGCTGGGGATACACTTCGGCGGCCGATGGGGCAAACACGATGTCGACGCCGAGATCGCCACA GAGCGCCAGGTCGGCCTCGAGCGTACGCGGATAACGCGCGAGATCGTCCTGATTGTTGAACTGCAGCGGGTTGACGAAGATCGACACG ACCACCACACCGCTCTCGCGTCGCGCCTGCCTGATGAGCTCGGCATGTCCGGCGTGCAGGGCGCCCATCGTTGGCACGAGGTTCACGC TGACAGTCGGCGGGTCTTGAGGGACAAGACCCGCCCTACGCCGGAGGCGCTCGCGCAAGCCGGCAACGGTTTCAATCAGTTCGGGCAC GTGAGGGAGATGACGCTCGGACGTCTTCGACGAACGCGCGTGCGGCCTTCGTGATGACGTCGGCAAGATCGGCGTATTTCCGGGCGAA CGGCGGAATCCTGTCGTGCAGGCCCAGGACATCCGAGCTGACGAGCACCTGGCCGTCGCAGTCGGGACCGGCGCCGATGCCGATCGTC GGAATGTCGAGTGCCGTGGTCACGCGGGCCGCCAGATCGTCTGGGACCGACTCGAGCACGACGGCAAATGCCCCCGCCGCCTGCAGCG CCAGCGCGTCGTTGAAGATGATCTCGGCGTCGCGGGGATTGCCGCCGCGCTGACGATAGCCGCTCTGCTGGTTCACGGACTGCGGCGT CACGCCCAGATGGCCCATCACCGGAATGCCAACGTCGACGAGCCGCGCCACCACGTCGGTCACCGAACTGCCGCCTTCCACCTTCACA GCTGCCGCACCCGCATCTTTCAATAGGCGTCCGGCGTTCCGCACCGCTTCCGACGGCGTCACCTGATAGGTCAGAAACGGCATGTCGG CGATGACGAGCGCTCGCTCCGTGCCGCGCACGACGGCGGCGGTGTGATGAATCATCACGTCGAGCGTGACCGGCAGCGTGGTGTCGTA GCCGAGGACCGCCGTGGCAACCGAATCGCCGACGAGCAGCACGTCAACGCCCGCCCGCTCGAGGAGCCGCGCGATGGTGGCGTCGTAC GCCGTCAGCACGGCGAACTTTTCCCGCCGCTCTTTGCGATCTTTCAGATGGGATACGCGAATGCGCATGGTTTACGTACTGAAAGTGT ATCGCGTCAGCGACCGGTAACGCTGCCCCGGCCGCAAGAGGGTTGACGGAAACGCCTGATGGTTGGGCGAGTCTGGATAGTGCTGGGG CTCGAGGCAGAAGCCGCGATGCCCGACCGCCTGGCCCGAGTAGAACTGCAACCCGGGCTCGGTCGTGCTGACCTCGAGCGCCCGGCCG CTCGACGGATCTGACACCCGCGCCGCCAGGGCGAGATCGGCCCCGCCGCGGTTCAGGACGAAGTAGTGATCGTAGCCGCCGCCTCTCG CGAGCTGTTCGTGCCCGGCGCGAAGACGCGCGCCGATGGCAGCCGGCTGCCGGAAGTCGAACGGCGTGTTCGCGACGGGCGCGAGCTC TCCGGTCGGAATCAACTGCTCGTCCACTGGCAGATATGCGCTCGCATCGATCGTGAGACGATGCGCCAGCACATCGCCGCCGCCAGCG AGATTGAAGTAGGAATGCTGGGTGAGGTTCACGTGCGTCGGCGCATCCGTCACGGCCTCGCACGTCATCAAGAAATCGTTGCCGTCGC CGAGTGAATACGTCACGTCCACGTCGAGCGTGCCCGGGTAGCCTTCTTCACCATCGACGCTTCTCCGGCGAAACACCACCGCGTTGGT CCTCGTCGCGGTGTCCGCCTCCCACACGTGCTTGTCGAATCCCTCGAAGCCGCCATGCAGATGGTTCGGGGGCTCGTTCGCCGAAATC ACGTGCACGCGGCCGTCGATCGAAAAGCGCGCGTTCGCGATCCGATTCGCATAGCGGCCCACGAGCGCGCCGAAGTACGGCGAAGATT CGAGGTACGGCTCCAGCCGGTCGTAACCCAGCACGACGTTCTCGACGCGGCCGCGCGCGTCCGGCACACGAAGCGAGACGATGAGGCA GCCGTAGCTGATGACGCCGAGCTCGACGCCGGCCGGGGTGCGGAGCGTAATGAGCTCGATCGCTGTGCCATCGTGCAGCGTGCCGAAC GTGCGGCGTTCAAACGTCTGGGACATTCGTGCTTTATTGAGACAACGCGTGTCAGAACTGCACAAATCAGCATATCCTCAATTGGGTG AGGGAGTTGGGAAGGCTGCAAGAGGCCACTGTGGTCGAAAACGGTAATCAACGGGGATCGGCGCGCCGATAGCGGATTCCCTAAGTCA TTCTCCAGCCGCGAGTTACCTGATCAGCCCCCGCGGCAGCGGGATTGCTGTACCGCGTGCCGGAGAACCGCGTGCTACACCAGCCCCC ATTGCCGCAGTCTGCGTTCGTCATCGCCGGCTCTGCTCACGCCGCGGCCCTTCGCCGACGGCTCGAGCACGATCCGACGATCACGGTG TTCGCCGAATCCGAGTCGCTCGACGCGTTGCGGCTGATTCTCCAGAATCCGCCCAAAGTGCTGGCGCTCGACTCGGCTATCGTCAAGA CGGCTCGCGGCGCGCTGATCGTCGCGCGTTTGAAAGAGCACAAGGGTGTGGATGTCCGGGTCCTGTGCGAGGACGAAGGCCACCTTCC CGTGCTCCTCTCGCAGCAGGACATCGCGCTGCACGCCGCATCGCAGCCCCTCGACGGGTGCGGCACGCGCGGCGCCAAACGGTTCCTG ATGAAAGCCGATATGGTCGTGGTGGTTGACGGCGAGCGCAGCCGTCTGGTGAACCTGTCGATTACGGGGGCGCAACTCGTGTTGCCGG CTCGCGTGCAACCCCGTCAGAGCGTACTGCTGACGCTGCTTGACGACACCGCCGAAAAGCGATTCCGCGCCCTCGTGGCCTGGTCCAC GGTCGAGCTCGCGCAGTCGATGGTGAAGTACCGCGCCGGCGTCAGTTTCGTCGATCCCGACCCCAAGGCCATCGAAGCGTTCTGCCAT CGGAACGCGATGGCGGGGTAGCGCAGGGCTTTAGCCCTGCCCCTCGCCCTGCCTCCCCTACCACCTCAACTTGACGGCAACCCCCTTG GGCCGCGCGTCTTTTGACTTCAACGCATCAACCAGGGCACCGATTCCCACACCTCCGGCAATCGACGGCAGGCCGATGGCCACGCGCA CGATCGTGGCGCATTCGGTGTCGTTCGCACCGCAGAAGGCCGGTGGCGCCACCAACAGGCCCGCGACCGCGCCGATGCCGGCGCCGAT GAGCATGCCGTTGACCAGCGAATCGCGCTGACGGACTGCTCTTTGAAACAGGACGGCGGGCTGTTGAGCGGTCGGCAGCCTTATCGTC GCCTGCGAGAGAGGCCGCGTTGACGCCGGCGTGCTCTGCGCCGCCGCCAGGTTCGGCACCGCGATTCCGGCAAGAAGCACCAACAGGC CGAGTCTGAACGACACGCGATATCGCATACTTATTTCAGAGTGAACGCCATTGCGATCGTCACCTTCACCGCAACGGGCTTTCCGCGA CGCGTGCCCGGCTCGAACTCCCACAACCTGGCCGCATCGAGCGCGGCCTGATCCAGTTCGGGATCAAGCGAGCGGACGATCGTGAAGT CGCGCGGTTTGCCGTCGGTTCCGACGACGCATTCCATGAGAACCTCGCCTTCGATCTTGGCCTTCTTCGCCCGCTCGCTGTAGTGCGG CTTCACCTCTTTGAGGAGCCTCGGCGACTGGACGTCTCCTCCCGGCTGATGCACCTCGGACGGGTCATCATCCTGCGCGCGCGGGATG GCCGGCGCCGCGCCGGCCCGGTCGAGCGCCGGCACCAACAAGAGCGCAACCACTGCGGCGACGAGCACAGCTTTCCTTGCCGTGCCCA GCGGTAGGCCCTGCTCGTTTCGCATGATGCGGCAGATTCTCTTCTTCAGGTCGCCGCCGGTGACGCCAGGAACATTCACGAGCGTCGA CGTGATGCACATCTCGCAGGTCTCGAGGATGCCCGCGGCATAGGACGAAGGGCTCTGGCCGAGCGCCAGTACCTGCTCGTCGCACGCG CGTTCGCGCTCGTCGATCATGCGCGCCCCAATCCACCATACCATCGGGTGAAACCAGCAGGCGGCGCTCACCAGCATCTGTACGACGC CCAGAAGGTTGTCGCGGCGCTTCACGTGAGCGATCTCGTGCGCGAGGATGCCTTCGATGTGCACATCGCGCATGCCGGTGGTGAGGTG AAGCGGCCAGATCAACACGGGCTTCGCCACGCCGAAGACGCCCGGCTCGAGGTGACGCGGCGAGCACACGATCCTGGTGGGCGTCCGT ATGCCAGCCGCGCGCTCGACCCGCCGGAGCAGGTCGTGCACCGGGCCGTCCGTGATTGGCTCGGCCGCGCGAGCGATCGCCGCCACGC GCGTCCATTCCCACGACCACTTCGCCAGCACGATGCACGTCCCGAGGAGCCACACCACCGCGATCGCGCGCGAAAACGGTTCGGCCGC CGACACGATTGCAGGTGAATTGAACACGACGCTCACCGCGGCAATGGCGTCGTTGCCGAGCATCGACGAGCGCGGCCACGGAAGCGCG CTCCCCATGGCGCTGAGGGCGGCAAACGGCATCAGGAACTTCATCGACGCGCCGAACCAGACCCAGTAACGCACTGAGGCCTGGTTGT GTCTGAGCATCAGCGCGAGAGCGGCAGCAAGTCCGGCCACCAACGTCGACTGCCAGATGTGATTAACGATTGCGTCCATCTTTCTTCT CCAGTTCCTCGAGAAGTTGTTCGGCCTCTTTGACGTCTTCGAGCGTGAGGCGTCCGGTCTCGATGAGCCGGGCCATGACCGGCTGCGA CTTGCCGCCGAAAAATCCGAGGAAGTCGTCGATGATCCGGAGCTGCGCGCCGGCTCGGGTAATGGCAGCCTCGAAGATGTGCGCGTTG CCAATCTTCCTGACGCGCCGGAGGGCTTTCTTGGCTTCGAGGCGGTAGACCAGCGTCTGGACGGTCGTGTAGGCCGGGCGGTTCTTTT CGGGAAACGACTCCTGGATCTCGCGAACCGACGCCGGCCCGCTCGACCACAACGCTTCCATGACCTGCATCTCCAGCTTCGTCAGTCT CGGTACGCCCATTCGATCTCCTATGTCCGTCCTCAGATCTACTACATCTGTAGTTTATCGGTCAAGCGACAACCTCCGGGTCCGCAAA ATCGTCAAAAAGGGTTCCGGGATCCTTTTTTCTCTTTTCTCGCAACCTGGAGGCGGTCAGGCCCGTAATACCGCAGAGCGGATTTTCT GGAGGTTCTCATGACAGCAGTGCGGCGGGTTTCTGTTCTTGCGATGTGCCTCATCGGACTCACTGGCTGCGTCAGTGTCGATATCTCG GCACAGAGCGAGCGCGCGCGGGGGGCGTTCGAGCGCACCCTGACGGTCAACGGTCCGGTTGACCTCAGCGTTCGGACCGGATCGGGCG ACATTCAGATCCGCACAGGCAGCGGCGACCGCGTCCAGGTGATTGGGCGCATCAGCGCCAGCCATTCCTGGAACACTTCGGAAAGTCC CGCCGACCGTGTGCGCCGCATCGAAGGGGCGCCGCCGATTACGCAGGACGGCAACGTCATCGGCATCGGCCAGACGCGGGGTGACGAC ACCTACAACAACGTCAGCATCAGCTACGAGCTCGTCGTGCCGGCCAACACGCAAGTGAACGCGAGCACCGGGTCGGGCGACCAGACCA TCGGCAGCCTCGACGGCGCCGTGCGCGCGCGCACCGGGTCGGGCGACATTCGCATCGAGCGGACCGGCGGCGGCCTCAACGCCCAGAC CGGCAGCGGCAGCATCCGCGTTGCATCGGTCGGGGGCGAGGTTCGCGCGCAGACGGGCAGCGGCGACGTGCAGGTGACGCAGATCGGG CGTGCCGACGTCACGGTCCATACCGGCTCGGGCGATGTCACGCTGCAGTTGCCTTCCAATGCCGCGTACACCCTCGACGCCAGCACCG GCTCGGGGTCGATCAACACCGCGCAACCCATCACGATGCAGGGCCGGCTCCGGCGGAATCACATCGAGGGGACGGTGCGCGGTGGGGG CAATTCCGTGCGCGTGAGAACGGGTTCGGGATCGATCGACATTCGGTGAATCGCGCTCTCTGAGCCGGATAACCAACGGTCTGCGCAT TCCTTGCTGGAGTCGCAACCGTGCACCTACGCGCAGCCGCGCTCGTACTTGCCCTGCTCGCAACGGGTCAAACACTCGATGTGGCATT CGCGCAAGCTCCGGCGACAGCCGGCGACGCGCCATCCGCGGCCGCACTGCGAGCGCGAGGACTGGAATACGGCTACAACCTCGATCAC GATGACGCCCTTGCGGCATTCGACGCCGCGATTGCGGCCGACCCGCGCGATCCTGCCGCCTATCGCCTGGCAGCCGCGACCGTCTGGA CGCGAATTGTGTTCGAGCAGGGCGCCATTACCGCAGAGGATTATCTCGGCCAGGCAAAAGCCCGCCATCGGCGCAGCGCTCCACGACC CGAGCTCGCCACGAAATTTCGAACGTACATCGACCAGGCGCTCGCGCTCGGCGAAGAGCGCCTGCGGAATCATCCGGCCGAGGCAGAC GCCTACTTTCAGGTAGGAGCCGCGTTCGGCTGCCTCGCGTCGTACACCGCAACGGTCGAGGGCCGAGTGCGAGACAGCCTCGGTCCGG CTCGCCGCGCCTACAAAGCGCACGAACGCGTGCTGGCGCTCGATCCCACGCGCAAGGACGCGGCGCTCATCGTCGGCATGACACGCCA 
TGCTGTAGCCGCACTCGCTCTACCGCTGCGCCTCATCGCCTATCTCGCCGGCTTCGACGGGAACAGCGCCGCCGGCATTCGGCTCGTC GAAGACGCCGCGCAGTACGCCGGCGAAACGCGCCGAAACGCGCTGTTCACGCTCGTGCTGCTCTACACCCGCGACGAACGGTATGACG CGGCGATGTCGCTCATTCGTGAGCTGCAGGGGCTGTATCCGCGCAACCGCCTGCTATGGCTCGAAGCCGGCAACACGTGGCTGCGCGC GGGCCGGCCGGCCGAAGCCAAGGCTGCGCTCGACGAAGGATTGGCCCGTCTCTCGCGCGACACACGTCCGCGCGCTCCGGGAGAGGAA TCCCGCTGGCGTCTGGCCCTCGGCTCCAGCCTGGCGGCACTGAACGACCCGGCCTCGGCCGAACGCGAGCTGAACGCCGCGCTCGAGG TCGCGACACACGACTGGGTTCGCGACCGCATCCGCGCTGAACGTCGCCGCTTGAATCGAGGACGCAAATGAAACCCTTCGCAACCATC GTTGCCGTTTCGGCGATCTTTCTGATGCTGGCGTTGTGGACGCCTGCGGCCTCGCCGTCTCCATCGCGCGACGCGCTCGAAGATCGGT TCCACGCCGATCTCCGCAACGTGGCGATCGAATGGGACCCAGGCGACCGGCGTCCGGACGCGATTCGCCGGAAGGCCTTGTTCGAATT CGTGTATCAAACCTACGACGCATCCGCGTGGATTCCGCAGTCTCTCTTTGACGGAAACATCGCCACACAGGCGATCGCCGGCGACGTC GAGACGATTGTCGGCAAGAAGGTTGGCCTCACACTGTGGCGCGACAACCCGACGGTGCCCGCCTTTGGAATGGCGCCCAATGCGACCG GACGCGATCCGCGCCGGACGAGCGCGGCGACCGAGCCGCTCCGGTGGACGGTGAATTGCCTCGTCTGTCACACGGCGGAAATCGACGG CGTCGCGTACTTCGGCGCGGGCACCAAGACGTTCGACGATCTATGGCTTGGTGAGGCACTCAAGAAGCTGACGAACGATCGGTGGCGG CCCAGGCTGTTACGAGATCCTCGCGACCACGCTTTTGCAGCAGATGCCAATCGCATTCTTCAGAGCCATCACCACGACAAGATCGACT CGCTCACCCGCGGACGATCGACGGCCTTCGCCGCATCACACGTGGAGATGTTCATGCGCAACCACGGCAACCGGCTGCCGGGCGACGA TGAGGTGGGTCGCGGCGACGTGAAGACGCCGCCGCTGTGGCACACCGCGGCGAAAATGCCGATTGGGCGCTGGTACACCGATGGCAGT TTCCACGGTCCGTTCCCGCTGATGGCCTCGTCCATGGAGCTCGAGAAGGATCGATCGTTCGACGCGCTGACCGAAACGGTCGTTCCCA TCATCAAGGATGAGTTCGATGCTGTGATTCGGCACCTTCGCCCGCCGCGCTATCCATACCCGATCGATCGCGCGCTCGCCTCGCGCGG TCGCGCGCTGTTTGAATCGAGTGCGTCAGGTTGCTCGGCGTGCCACGGGGTGTACGACGGCAGCGGCAGCGTCCGCTGGCCGGGGCGG CACGTCGATGTCGGCACCGACGGATCGCGCCTCGCGATCGTGTCGGGCGGATTCATCGACGCGTTCAACAAGAGCCCGCTCGCCGCCG AAGGGGCGCTCCGAAAGAGTGAAGGCTATGCCGCGACGCCACTGACCGGCGTCTGGGCGAACTTCCCGTACCTGCACAACGGCAGCGT GCCGACGCTGCACGATCTGCTCGGTCCTGTTTCCGAGCGGCCGAGGATCTTTCACGTGATGGCGGCGCGCAGGCTCGATCGGACGCGG GTCGGACAGCTATTGCATGCCAATCCCCGTCACGGACAGCTGGACGAGGCCGAGCTTCTCCGCCGGTTCGGCCGCGATCGCGACTGGT TCAATACCTCGAGGCCCGGATCGGGAAATGGGGGCCACGATGTGTGGGAGAGGATTCGGACCGACGACAATCGCCGCGCATTAATCGA GTATCTCAAGACGTTGTGAGCGATGAGGAAATACAAGAACAGGAGGTTAGGAGGATAGGAGGATCGGAGATAAAACGTGGTCGGGACT CCTTCTTCGTCATTCAACACGGAGAGCGTTCATCGGTTGAATCCGTGCGGCACGACGAGCCGGGAGATAACACGCCATGAGGGATACG GCCGAGAGCAAGGCAAATACTCCGGCATACGTGACGGGATCGGTCGGCGTAATACCGTAAAGTGCCCGGCCCAGAACACGGCCCGCTG CCAGGCTGAGCGCGAACCCAATGAGGACGCCGACGATCGTCAGCGCGAAGCCTTCGCGAATCACGGCGGTCAGCACCTGCCTTGCCGA AGCGCCGAGCGCCATGCGGAGCCCCAGCTCGCGCACTCTTCGCCGCATATCGAACGACACCACCGCGTACTGACCGATGACTGCGATG AAAAGGGAGCCGGCGGCAAATAAAGTGAGCAGCATCGTGAGCATGCGAACCGGAAACACCGCAGCATCGATTTGCGTATCCCACGTTC TCATGTAGGCAATCGCAGCACGGGAGTCCACCTGCTGAAGCGCGCGGCCGATTTCGGGACCCACCGTATCCAGACTCCCGTTGTGCCG GACGTACAGAGCTGACTCGCCAGGCGGGGCCGGGTTGTGGCGGGCCGACATGAACACGAACGGGCGCAAGTCGCGACGGAAACCGCTG TAGTACTTATCCGGTATCACGCCGGCAACTTCCACTTCACTCTCACGTCCACGAGTGGTCACGAGCATCCTCCGCCCGACCGGCGATT GAGCGTGCCAGAGCTGGTCCGCGAGACTCTTGCTGATCATCGCGGCCGGCACATCGCGGCTTCCCACATCGCGCGTGGGATCTCGCCC GGCTGCGAATGACACCCCGATGGTCTCGGCGTAATTCGGGCCAACGTGGTTCATCTCCGCGGGTACTGCGTCCTGTGAACCCGGAATC CGCACTTGGTCGGCGCCCCAGTTTTCGCTCGGCGGCCGACGCGCATAGCTTGCCTGCTGCACGCCATTGACCGCCAGGAGTCTCGTGC GAAACGCCTCAAGAAGCGCGGCGTTCGCTTCCGGGTTGGTGGCGCTCCCGGAGGTGTTCACCGTGACGAGCAGCAACGTTCGAGTGTC GAATCCCGAGTCGAAGCTTCCTATCAGAAACAACGACCGGAACGCGAGACCCGCGCACGCGACGAGGAGCACGGAGAAGGCCATTTGA ACGACAACGAGCACTCGCGACACCTTCGAGCGGCCCGCGATTACCGCCTGCTCGCCGGCTTTCAACGGCGGAAGCAGCGGCTGCCGCC ATGCTCTCATCGCAGGACCGAGAGTACACGCGATGGTGCAGAGCATCGCCAACACGAGCGCATAGCCCAGAACGGACCAATCCGGCGT GAAGTCGGGCATGGGAATGTTGGCGCCCTGGGAGTTCGGCGCAAAATATCCGCTCATCGTGCGCGTGAGCATCCATGCGGTGGCGCAT GCGGCGGCCCACGACACGACCGACAAGGCCAGCCCCTCGGCCATCAGCGCCCGGACGATGCGCAGCCGCGACGCGCCAAGCGATTGCC GGAGAGCGAGCTCGCGCTGGCGGATCACTGCCCGCGCAACCAGAAGATTGGCCACATTCGCACAGACCACCACCAGGGTGATCAATGT GACAACGGAGAAGACGGCGAGAAACTGGGATGACCGGTGATCGATAAGGTTCCCGGTACCTGCGTTCGCGGAATAGCGCCCGACGACC AACCGTGAATTCCGATCGAGCTCCGAACGAGACGTCTGGAGGCGCACCCACAACGCGGACAGCTCGGCCTGTGCCTGCTGGCGCGAGA TGCCAGGCCCGAGTCGGCCCAGCACGCACACATATTCAGCCGACCGGTCGAGAGGCACCCAAAGGTCTGCTGATTCTGGTATCGTCGC GCCGCGAAAGCCCTGCGTCGTCACGCCAACAATCGTGAGCGGACGTCCGCTCAGACTGACGGACGTGCCGATGATGTCGTCGGCTCTC TGAAAATTGTTCTCCCACGTTCGGTAGCTGATGACAGCGGCAGCCTCATCGTGGAGAAATCCGCGCCCCTTGATGATTCCAATGCCCA GCGTCTCGAAGTAATTGGAGCTCACCGCACCGGCACGCACCGCATAGCTGCCGCCCCTGTGACTCAGCGTATGCCGGCCGCCCGTCGA TCCCACGATGCGTTCCAGCGTACGGCTATGTTCCTGAAAGGTCTGGTACGCGAGAGGGGTCGTGCAGGGATTCACCCACCCACGCTCG TCGGTCCAGCCCAGCGTCACAAGTCTGGGGGCCGTGACTCCCTGCGCGGGTTTCGAGATGAACCCGTTGGCAATCGAAAACACAGTCG TATTGCCACCGATGACGAGCGCGATGAGGAGCACCGCGGCGGCGCTGAGGCCTGGCGCGGTCGTCAGGATCCGGCAGCCTGACCGGAC GTCCTGCGTGAGTTGTTCGAGCGCCGTCCACGTCCAGACCGCGCGCGTGTCTTCGCGCGCCAACGCAACGTTTCCGAACGCGCGGCGC GCGCTCAGGTGCGCGTTCTCGGCAGTCTCGCCGCGATCTTCGCGAAGCCGCGCCTCTTCCTTGAGATGAAACTGGATTTCTGCGTCGA GGTCTTCCGAGCGAGGCTTGCGGCGAAACCACGCCATGCGGCCCTCCTTTGGGTCCGGCTAAAGCCGGACACTACGTACCAGGCTAAA GCCGGAGGGTGAGGGTCCGGCTAAAGCCGGACACTACGTACGTGAGACGACTACGCGGGGCCGAGAACGCGGGCAATCGCCTGTGCAA ACCGTGCCCACCGGGTCCGTTCGGACTGCAGCTGCCTCCGGCCAGTTCGAGTGAGCCGGTAATACTTCGCGCGTTGCCTGTTCTCGGT GAGCTTCCACTCAGCGTCGAGCCAACCCTGTTTCTCGAGACGATGCAGCGCCGGGTACAAGGACCCGTGGTCGACCTTCAAGACGTCC TCGGTGCTCGCGGCGATCGCCACTTTGATGCCGTGGCCGTGCTGCGGCCCCCATTGAAGCGTGCGGAGAATGAGCAGGTCGAGCGTGC CTTGCAGAAGGTCCACTGACTCGCGCGCGCGAGGCTTGACCATAGGTAGAAGACAATCTACTACCATGGTAGTCGAATGTCTACTACT ACACGAAGTTCGAGGGTTCGTGAGGTTCGTGGGGTTCGGCTGCCGCACCACGGAGAACGCCATCGGCTCCGTGACGCTCGGCGCCTCG AACCCATGAACCCCACGAACCTACGAACCCCACGAACCTTATGGATCATCGCCGGCCGATTGAGCGTAGGATAAGCCGGTGCGCAGCG CTGTCGGCGCGGTTCTCGTCTCGATCGCGGCAAGCCTCGTGCTCGTCGCGCAGGAGCGCTCCGCCCCATTCCGGTCTGGCGTCGACCT CATCAGCGTCACCGCCACCGTGATTGATGGCGACGGGCATCTGGTGACCGGCCTTCCGCGCGACGCGTTCGAAGTGTACGAGGACGGC GAGCGGCAGGCGATTACACAGTTCACAAACGAGCGCGTTCCCGTGAGCCTGGCGGTGCTGCTCGACGTCAGCGACAGCATGTTCGGCC AGCGCCTCGTCGACGCGCGATCGGCCGTCGAGCGCTTCCTCTTCGACCTGCTCGACGAGAGCGACGAGTTCTCCGTCGTCGCGTTCAA TCACGAACCGCGCCAGCTCACCCCATGGACGCAGGCCCCCGACGTGGTCCGCAGCGCCATGGCGACGCTGAGGCCGTTCGGCTCGACC GCCCTCTACGATGCGGCCCTGACCGTGTTGCCGATGATGAACACGCGGACGAAGCAGCGCGCCTCGGTGCTCATCATTTCCGACGGCG CCGACACCGCCAGCGACGCGACGTTACGCGAGGTCCGCTCGGCCCTCGTGCGCAGCGACGCGTTCGTGTATGCCATCGCCGTCGATCC GCCGGCGAAGCGCGCCATCAACGAGACGGTGAACGTCGGCGCGCTGAACGAGATGACGGGAGGAAGCGGCGGGAACACCGAGCTGGTC CACCAGACGAGCGAAATCGTCGCCGCCACGGCGCGCATCGCCGAAGAGCTCAACAGCCAATACGTGCTGGGCTACCACTCGCCGCGTT CTCCAGACGGCAGCTACCGCAGTATTCGCGTTCGCGTCACCAACCCCGGGTACCGCGTGCGCGCGCGGCGCGGGTACATCGCCGATCC GAAGCAATCCCGGTCACGTTAGCGAAAAACAACGCTCGTCCTTGAACATGAGATCGGGAGATCAGGAGGTTTGCAGGCGCGTTCGGTG ATGATGCCGAACGCTATCAGTGCGGACGTACTTCCATCGGCACGGGTCCTTTCGGACGCATCGTGATCCGTAGATCAATCTCTGGAAA CGCACCGGTCGTGCGGAGCTGCCAGCGCTGGGCGATCGTCGCCAGGAGCAGTACGCCTTCCATCCATCCGAACGACTCGCCGATGCAC GCGCGCGCGCCTGCGCCGAACGGGAAGTACGCGAACCGGGGATGATCGGCGCCGCCCTCCAGCCAGCGCCGGGGATCGAACGCCTGCG GACGTTCGAAGAAGCGCCCGTCCCGGTGAAGCAGATACTGGCTGACCAGGACAATCGTCCCGGCCTGCACCTCACCCTCATCGAAGCG ATGTGATTCAGCCGCGTGGCGCGCAAGCACCCACGCCGGCGGATACAGCCGCAGCGATTCAGCGAGCACGGCCCGCGTATACACAAGA 
ACCCCGACATCAGCGGCTGTCGCATCGCGGCCTGACAGTATCCCCCGCAACTCGTCGCGCATATCGCGCTCGACTTCCGGATGGGCGG CCACGAGGGCGAGCGTCCAGCTGAGCGCGCTCGTGATCGTGTCGTGGCCGGCGACCAGTATCGTGAGCAGGTCGTCGAGACGCTGCTC CGACGACCGGTGGCAGGGCTGAAGCCCTGCGCTACCGCGCGGTGGACGCCCTGCGCTACCGGTGCCTTGGGCATCGTGGGCGTTCAAG AGGGCGAGCAGGCTGCCCTCGGTCGCCTCCTCCGTTGCGCGAGACGCGAGTTCGGCAACCACCGTCCGCAGGCGGCTTTGCGCCCGCC GCACGCGGCGCAGCGGCGCAACCAGCGAGACCAGCGGATCGAGCGAGGCAATCGCCTCCGAAACAGCCTGCTGCACCTGCCGGAACTC CGCATCGACGAGGCCGCCGATGATCGTTTCGCCGACGATGCCGAACGTCAGCTGCCCGATCGCGTCGGCAACGTCAACGACTTCGCCG GCGCGCCAGCGGTCGCACATCGCGTGCGCGCGGCGCACGACGACGGCCGCGCATTCATCCAGACGCTTGCGCGCGAACGCCGGCTGGA TCAGTTTGCGCCGCTCGGCATGCACCTCGCCGTCGGCAGTGAGCAGGCCGTTGCCGAGAAGACGTTTCGACCGCAGATTGGCGCTGCC CTTGTGGAATTTCGCCGCCTCTCCCATGAGCACCGTGGAGACGTAGTCCGGCCGATTCAGCAGCACGGCCGGCCGGCGCGCCAGCATG AACGGCACGAAGTCTCCGCGCGCGGCGAGGGCGTCGAGAAAACCCAGGGGACGATGCAGGCCTGTCCCGAGCGAAGTCGGGGGATCTG CCCCGCGCGACGCTGAGGGCCGGATGCTCCATAGTTTCTGGCCGGGATAGTGGGGGAGATACGAATTGGTCACGGTGCGATTCAATCC GGAGCTTTCAGGCCGCGCGCCGCCAGTTCCCTGGATACCGTGGGGCGCATCGCCGTTGCCACGTCCATATCTTCGGTACCGCTTCTTG TGTTACCCATCGTACGCTTGACGATTCCCCGCCCGTAGAGCGCCGTCGCGGAGCTCGGGTTAATCGTCAGCGCGCGCGCGAAGTCTTC GAGCGCCGTCGCATAGTCGCGCGCACGAAAGTGCAGTGCCGCACGCCGCTCGAAGCCTTCGACCGACCGCGGATCGAGCTCGACGTGC CTCGAAAAATCCTGCAACGCCAGACCGTCGCGGCCCGCCGCTTCGTGGCACACTGCTCTATCCAGGTACGCGATGGCCTGTTCAGGAT TCAGCTCGATGACGCGGGTGAAATCGGCGATGGCTTCGGCGCATCGTGACGTGCCGGCCAATGTGAGCGCGCGGTTGAGCAGGGCCTC TTCGAACTCTGGATTCAGGCGAATCGCCTCGTCGTAGTCGCGAATGGCTGTGTCGTATTGCCCGTTCAGCCGATACATGCCTGCGCGG TCGGCGAAGGCCGTTGACGAGCGCGGTTGGCGCTTCAGGACCTGCGTGAAGTCGTCGATCGCTTTGTCGAAATCCTGCTTCGCGCCGT ACACCGCGCCGCGGTTGGCGAGGGCCCGGACCGATCGCGAATCGAGACGCACGGCCTCGTCAAAATCCTGAAGCGCGCGATCGTAGTC GAGCAGCGTGACATAGGCGATGCCCCGCTCGGTATGCGCCTCCGCCAGGTCGCGGCCCCTGAGGCGGCCCGACTGGATGAGGCCCGAA CAGACGCTGATGGAAATTTCGGGATCCGGATGGCCGCAACGGGGTTGGGCCCTCACGCTGGAGGGCAACAGAGCCGATAGAAGTACGA GCGCGATTACAGTTTTGCGCAACGATTGTCCTCGTTCAGGAGTCATGACATGGCGAATGGCACAGATGTAAGACCGCCGCAGTCCGGA GAGCGTCGCGTGATGGCATGGATCGGGAAAGCCGTCAGGGTGGAAGGCAAAGTCATTGGTGGTGAAGACCTTACCATCGACGGCGACG TGGAAGGGTCGATCGAGCTTGGCGGCCACAGCCTGACCATCGGGCAGGAAGCGAAGATCAAGGCCGACCTGCTCGCCAAGACCGTGTC GATCAGCGGCACGGTCCAGGGCAACGTCAAAGGGGTCGAAAAAGTCGACCTCAGCCCGACGGCCACCGTCCAGGGCGACATTACGGCG CCTCGTTTCAGCATGGCCGACGGCGCGACGGTGACAGGCAAGATCCAGGCAGGCTAGGCGTTCGGCAGGCGGACGATAAACGTCGCCC CCTTCCCTGCGCCGGCACTCACCGCCGCGACAGTGCCTCCGTGCATTTCTGTGACGTGGCGGACAATCGTCAGACCGAGGCCGAGGCC GCCGTGTGCCCGGCTCGTCCGCGCGTCGGCCTGCCGGAAGCGCTCGAAGACGTGCGGAAGAAACTCGGGCGAGATGCCGATGCCCGTG TCGGCGACTACGAGCTCCACGCAGGACTCGGTCACCGCCAGCGCCACGCGGAGCGACCCGCCGTCTGACGTGAACTTGACGCCGTTCG AGAGCAGGTTCCAGACAACCTGCTGAAGGCGCGCGAGGTCGCCGATGATGATCGCCGGATCGTCGTCCAGCTCGAGCGTCACGTGGAT GCTCTTTCCGCCCGCGATCGGCCGGATCAATTCGACGGCCGCCTCGACCACCGGCCGGAACGGGAAGGGTTCCTTCTCCAGCCGCAGT TCGCCCGCGATGATCTTTGACACGTCGAGAATGTCTTCCACGATCGTCTGCTGTAGCTTTGCGTTGCGCTCGATTGTCTCGAGCGCAT GCGCCCGCCGCGCGTCGTCCATGGCCGTGCTGCGAAGCAGCGATGTCCATCCAAGCACGGCATTGAGCGGCGTCCGCAGCTCGTGCGA GACGGTCGCGAGAAATTCGTCTTTCAACTGGTTCGCGATCTCGGCCGACTCGCGCGCTTTGTGCACCGCGTCGAACAGCCGCGCGTTG TCGATCGCAATCGCCGCCTGAGCGGCGAGTCCCGTGATGACCCGTTCGGCGGTCTCCGTAAACACGTCAGGCTCGGGGTGGCCGAAGA AGAGCCCGCCGAGCACCTCGCCCGATCGTGCGCTCGTGACCGGGATCGCGAGATAGCTCCGCACCATCAGGTGGCCGCGCGGTATGCC TTGATGCGGCTCGTTGTGTCCGTAGCGGGGATCCTTCGTGACATCCCCACTCCGGATGATGCCCTCGCCACGGAACGTCGGGCCGAGC AGCGACGTGGCACGCGGCGTCGGAAAGCGCTCGAAATGACGCCGGTCGACACCCGACAGCGTGTAGAGCATGTACGACCCGCCGCCCT CGTCGAGCATGTTGTAGAAGAACGATCCGAACCGGGCGCCGCTCAGCTCGGTCGCCGCGTCGGTGAGCGCCTGGACGAGCTTCCGGAG ATCGAGCTCCGCGGAAAGCACGCGCCCGAACTCGTTGATGCGCTGCAACGCGTCGGCCTTTTCGCGAAGCTGCTGGCGGGTCGCGGTC TGCTCGGTGATGTCCTGCACGATGCCGAGCATCCCCAATACCACGCCGTTTTCGCTGTAAGCGGCATGTCCGCGCGCGGCAACCCAGC GCTCGCCGATTCTCGTCCGGATGCGGTACTCGATGTCGTAGTCCGCGCGCGCGACGATGGCTGTCTCCACGGCGACACGCGCGCGCTC CTGGTCGTCGGGATGCAGTATCTTGCGCATCTCCGTCCAGGTCATGACCGGGCCGGGCGGAATGTCGAAAATCTCCGCGGCGCGTGGA GAGAGCGTCACCAGATCGCTCGCTGCATCCCAGGCCCAGTCGCCCAGGCGTGCAGCGTCGAGCGCCAGGCGGAGACGTTCGGCGTCGG AAAACGAGGCGGAAAGCGGAGAAAGGGAGTCGATGCGGGGATTGTATCAGTCAGACAGAACCTGACGCCGGCAGTCTGGCAAGGGCGC GCTCGAGGGCCTGGTGCAACATCTCGCGGCCAATGGGCTTGACGACGTAGTCGACCGCGCCCTGCTGCCGCATCTTCACGACCGTGCT CATCTCCTGAGCGCCGCTGACCGCCACAATCACGGTTTCCGGCCAGCGCTCCCGAATCTGCTTCGCGAGCCATACCCCGTCATAGACC GGCATGATCACGTCCGAGAAGACGATCTCTGCCGGCGCCTTCGCCATTTCCTCGACGGCCGCCTCGGCGCTGTGAGCCGTCGTAACCT CGTGCCCCCACTGCGTAAGCCGCCTTGTCAGGATGTCCCGAATCGGAGCTTCGTCGTCAACCACGAGAATGCGCGCCATGTGCACAGA ATTTTCCTGCGAACGCACACTTTTATCTATAGGGGTTTCGCCTACGCCGGGAAATGCTTACCGGGGAGGGTTTCCGGGGAGATAGGCA AGGACAACGCCGATTCCTACTTCACGCCGGCGCGCTCCATTTCGGCGGCGATGTTCGCACGGTGATGTCTGGCAAGCGCGACGTCCGC ACCACCACCCGCGAGATCGCCGTTCTTCATCCGGATGATGCCCCGCGCGTAGAGTGCCGGCGCATACTGCGGATTGATGACGATCGCC TCTTCGTAATCGGCGAGCGCCTTGTCCAGCTGATTCATGCGGAAGTAGATGGTGCCGCGCCGTTCGTACCGGAACTCGGCGCGCGGCT CGATTTCGATCGCGGCGGTAATGTCTTCGATGGCGAGCTCGTCGAGCCCGATCATCTCGTAACACAGCCCCCGGTTGTAGTACGCGTA GGCGAGCTTCGGGTACGCATCGACGACGCGCGAGTAATCGGGAATCGCATCGGCGTACCGGCCAAGGATCGTCAGCGTAATTCCGCGA TCACCGTACGCATCGATGAGGTGCGGGTTCGCTTCAATCGCGGCGTTGAGATCCTCGAGCGCGCGCGCGAACAGACTCTTCTGCCGAT ACGCGATCCCCCGCGCATAGTACGCGCTCGCAAGCTCCTCTGGTGCTTCCTTCCCTGCGTCGATGAGGCCTGTACAGGCTGAAAGGCG CGCATCGGCGTCGGTGCCGCGGCACCGCTTCCAGGCTTCGTCGTGGTCCTGCGCCCAGGCAGAAAGGTCACCACAGAGAGCACAGAGG ACACAGAGAACCATTCTCTTCCGAAAAGAAAAGACTCCTCTGTGCGCTCTGCGTTCTCTGTGGTGAAACATCACTTCATGCCGCGCGT TCCGAACGTCGCGCGTCAGTGGCCGGCCGCGGCCTTTGCGAACGACGGCCGCAGGGTGCCCGCCTTCTGTGCCACCTCGAGCAGCGTT GGATAGAACTGGACGAAGGTGTTGTCCACGGCGCCGTTCTCGGAGTGACATGCATAGCAGCGCTCGGTGGGTGGCAGCGCCTGGACCT GCGGCTTCATGTCTCGCCCGAAGTCGAAGTACGCCCATTTGCCAGGGAATCGCGTCTCATCTTTCACCGACGCCTCGATCACCACCAG ATTCGACTGGAAGTGGCCGCCTCTGTTGATCGACCCTTCGCTCGATGACGCCCGAATCTCGAGGATGAACATCGTCTTGTCGGGCCAC TGCCCCGTCCGCATGTACGCGCGATACGACGAAGGATTCACGTAGACGTTGGTGAAGTTGGGAGGACGCGGTGTGCCGCTCTGTTGCG CCGACGGCTGGTTGTAGGTCATGCCGAGGCCGGAGGTGACGAACATCCATTCGCGAAAATCGGCGGGGCGAATCAGCTCGCCGGCCGC GGTGTAACGGGGCTGGTCAGACGGCTGCTGTGCCGAGACGGCGACGAGCCCGAAGAGCACGGCGGCACCGCCCGCAAGGAGATGCTTC ATGCGGGAAATCTACCACGGTCCGGCTAAAGCCGGACACTACGTCCGGTGCTACTCGCCGAGGAACCGTCCGATGGGCTTCAGATCCT CGACGTGGTCGCAGAGAACTTTTATCGACATCATCATCGGCACGGCCAGGAGCAGGCCCCAGACGCCCCACGCCCAGCTCCAGAACAC GAGGCCCACGAAGACCGCCACCCGGTTCATCGACGCGACCTTGCCCATCAGCGTCGGCGTGAGCAGCCAGCCTTCGAGCGATGTGATC GCGAGGGAAGTCCCCGCGACGGTCAGCATCATGTAGAGCGTGCCGAATTGGAGGAACGCCACGAGCGAGAGGCCACCGCTCACAATCA GCGGGCCATAATACGGAATCGAATTGAAGACGCCCGCCAGCAGACCCCACAGCGCGGCTTGCTCGAGGCCCATGTACGCGAGGACGGC CCACGTCGCGACGCCGACGACGACGCTCGTGAAGATCTGCACCAGGAGAAAGCGGCCGATCTGCGACGCGATGTCGTCGATGATTTCG ATCGTCACCTTTTTCTTCGAGAGCGTCGGGCCGGCGAGCTCGACGAACTTCCGCCTGTACAACTTGTCGGACAGGAGGACGAAGTAGG TCAGAAAGAGAATCATGATCAGTTGATTGACGGCGCTGACCGCGCCCATCGAGCCCGACCACAGCAAGCCGGTTGCCGTGATGCGCGG CTCTTCGACCTGCACGCGGACGACGCCAGGCGCCGGCTTCGGCGCATCGGTCTTGGCGAGCGCCGCGGCCGCCTGTTCGACTTTGTCG AGCGGGCCCGGAGCCGATCGGGGCCGCCGTTCGACGAGCGCCGCAATCCGACGGGCGCCGGCAGGCAGCTGGTTGATGACGGTGAGCG CCTCGTCCTGTAGCGCGTACGCGCCACCCAGAATCGTCCCCAACGTCAGCCCGAGCGCCAGCGCTGCGCCAATCCATCGCGGCACGCG 
AATCCGTTCCATCGCATCGACGGCTGGATCGAGCGCATAAAAGAGGAGCATTCCGATTGCGAGGGGTGCGAACAGCGCCTGCATGTAT TGAAGGAGGAACACGCAGACGCCGAAGGCGATGATGACCAGCGCGACCGTACGGGCATCCAGACCGTCGAACGGCGACACATCGGCTG ACGGTTCGGCAGGCGCGTGAGAATTCGACAGTTTGTGTAGCGAGGTCATACAAGTCCCTGCACAGTGCTGGTAGAAGAGCAATACACG TGCCTTGGAACTTTGTTTGCACCCGCCGCCGATCGTGACAAGCGAAACGATGGCACACAGGCTTCCCCGCCGGCGTCCGACGCTACGG ATTCCGCGACACCTTCGCCGCCGCGTTCCCCGGCGCTGGCGTGCCGGCCTGCATCAGCATCCAAAGGTTCGCCGGCAAATCGGGGTGC GAACTGTCTGGGCCAAGGTGCGCCAGATTTTCTTCGCCTGGTGGGTCTGGGGCATCGTCGCGATTCTCGCCCTCATCAACGACAACTG GGGCTGGGCGATCGTCACCGGCCTCATGGCTGCGTTCGCGTTTCTCATCTGGCCGCGCGAAGTGCCGCCGCGCGTCGGACTGGATCAC GAGTTCTCGGTGGACGACGACGAGTTTCTGGCGACGATCGCGGGCTCCACCGGAATCCCGTTTTTCGAAGGCAACAGAATCGAGATTC TGAACAACGGCGACGCGTTCTACCCGGCCATGCTGAAAGCCATCGGACAGGCGCACAACTCCGTCACCATCGAAGCCTACATCTACTG GGCAGGCAGCATCGGGCGGCGGTTTGCCGAGGCGCTGGCCGAGCGCGCAAAGGCTGGCGTATGCGTGAAGATCCTGCTCGACGCTGTG GGCTCGTCGACCATCGGCGACGAGATTCTGGAGATCCTTGAGAAAGGCGGGTGCCAGCTCGCATGGTACAACCCTGCTCGCCCGTACA GCATCGGCCGATTCAATCACCGCACCCACCGCAAGTCGCTCATCATCGACGGCCGCATTGCGTTTACCGGTGGCGCCGGCATCGCCGA TCACTGGATGGGCAACGCGCAGGACGACCAGCACTGGCGCGACATTCAGATTCGGATGGAAGGCCCGGCGGTCGCACCGCTGCAGACC GGCTTCGCGCAGAACTGGATGCAATCGACCGGCGAGGTCCTCACCGGGTTCGAGTTCTATCCCGCCATCGACGAACCGGCCGGCAAGC TCGCGGTGCAGACGATCTTGAGCTCACCCGAGACGGGGGCGTCGACCGCGCGGACGTTCTACTACCTTTCGATCGCCGCCGCACGGCG CAGGATATTTATTGCCAACCCGTACTTCGTCCCGGACCAGGGGGCGATCGATCTGCTCGTCGCGGCGAAAGCCCGTGGCGTGGACGTG CGAATCATGGTCGCGGGCATCCACAACGACAACTGGATGGCGCGGCAGAACAGCGTGCGCCTCTACGGCCCGTTGCTGAAGGCGGGCA TCGACATCTTCGAGTACAACCACACCATGCTCCACCAGAAGACGATGGTCGTCGACGGTCTGTGGGCGACCGTCGGCACGACCAACTT CGACAGCCGCTCCTTCGCGCACAACGAAGAGAATAACGTCTGCGTCTCGGACGCCCATCTTGCGAGAGAGCTCGAAGCGATCTTCATC GCCGACATCAAAGGCTGCGAGCGGGTGACGCTGGAGAAGTGGCAGAAGCGGGGCATGCTCGCGAAGTCGCTGCAAGGCGTGGTGTCGT TGTTCCAGGAACAAGTCTAGGGGCTGCGCACCATTCGAAGAATCGCAGATTGGGAGATTGGGAGATTGATTTTCCAATCTACCAATCT ACGAATCCGCGAATAGTGCGTCAGTTGTTTTCGTAACGGTGATAGTGAGAGCCGTCCCGATCGTAACCGCTGTCGTGCACGTCGAGGT TGAGATCGCTCTGCAGGCGGTAGTTCAGCCGTGTCTCGGCAGGAACCGCGACGCGCCGGCCGCGGGTGAGAATCTGCGCGCCCGCGCC GACCGCCGCCCCCGCCACAGCACCGGCGGCCGCTCCGTCGCCACCGCCGATGACGGCGCCGAGGATTGCGCCGAGCACCGCGCCGCCG CCCACGTTGCGGGCCGTTTCCTTGTTCGCGCCCAGGCCGCTGTCTCGAACGTCGACGCCCGCGGTGCCCACGCGATTTCGCGTCGCGT CGATGCCGTAGCGGCGTCCGTTGATCGTCACCGAATCGAGGTCGAGCACGAGCTCATCGTCGGTCGCGCGGCGAACGACCAGCTCTGC CGTCGCGCCGCGAGGAATCGCCAGGCGGCCGTCCGCATCACGCACGTCATTTTCAACGGGTGCCGGCATAAATCCGGCCGTCCATCGT CCGTGTGTCGATAGCCTCTGTCGTTCTCACCTGAATCGAAGTTCCTGCGGGGATCGGATCGACGAACGTCCACGACTGGGCGCCGGCC GCCGACGGAACACAGAGCATCGCCGCCGCGGCGATGCCCATCACGTCACGAACTACTTCCTGCATGACACCTCCAAATGCACGACATG GTGCAATCAGGAGGCCAAGGCACGAGACTTGCGAGGCGAACACGTCGAGGAGGCTGTATGGTCTTCACTGCAGCGAGTCTGAGTCCCG TTCTGGCAATCGTCTTTGGAGTCTTGATCTTTGTTTTTCCCAAGCTGCTCAACTATCTCGTCGCGACCTACCTCGTGCTGACGGGGCT AATCGGCCTGGGCGTCGTCACGCTCAACGTGTAGCGTGGCTGGACAATCCGCGGAGCCGCTAGATCGAATCAGGCCGCGTTCTGGTAC GTGGCGCGGCCGCGCTTCCGAGACGACCAGAAGTGTCGAAGCGCCAACGCAATGCCCGTCCACACAAGGACCGTCGCTCCAGCCGTGA CGAGGCCGGCGACGGTCTGCCCCGCGATCCCGTAAACCTCGCCCGTATGCGCAAAGCGCAGCCACGTGCGCGCACGCCGTCCCGCGGA CAGGCTCGAATAGGGCTCCGATCGCTCCACTTCGCCCGTGCGCCGATTGACCGTCAGCGTCGTGCGCTTGTGCGGTTGTCCGCCATCG CCGGCGTCGAGCGTGAGAACGACTCGGGGCGCGTTTCCCGGTGGCAGGGCGATGCTGATGGTCTTCCACTCGGGCATCCGCGCCGCCG CTGCCGCAACCATCGCGTCGAGGCGCGCGTCAGCGTTTTCCTCAATCGCGGTCGCACGGGCGCGAGGGCCGTTGCCGCGGCCGGCCTG AGCATTGCCCGGCACAGGCGGTTGCTCTCCGTACGCGCGGTACACCAGGGCTGTCGCCCACGGATACGAGATCACCACGCCGCCGGCG ACGATAATCGCGAGAGGAATCGCCGACCAGAAGCCGATCGTGTTGTGCCAGTTGAAGTCGCGCGCCTTGCCGGTCGGCCCTCTCCGGA ACCACACGATGCTCTTCACCGCCGCCCACGTCCACGTGCGCGGCCACCATAGGAAAAGACCGCTCACGACGATGAACAGAAACATCAG ATTGGACGCGCCCGTGATGGCGCGACCAGTGGGACGGCGCTCGCCCGCCATCGCGACGTACCGATGCCACTCGACCATGCGGCGGAAA AAATTCCGGACGCCCTGCCCGTTGCCTTCTCCCAGCACCGCGCCGGTGTATGGGTTGACGAACACCTGGCGTGCGGCGCCCGCCGCGA GCGATGCCGGCGCGCCGGGATCGGAGCGAAGGACGATCGTTGTCGGCGCGAGGTCGGGGTGTGCGCTCTTGACCTTCGCCACGAGCTC GTCTGCCGTGAGTCTCGCCGAGCCCGGGACTGGTTCGCTCCGATACCCGCGCATGTCGGCCCACGCGGTGATCTGCCGCTGATAGGTC AGCAGCACCCCCGTCACGGACATGATGAGAATCACCGCGCCGGCGACGACACCGCAGGCAAGATGGAGCCAGAACAGAACGGATCTCA GCTTCACGATCGCCTCACATCTCCGCCCACTGGCGGAGCAGGTTGTGATAGACGCCAGTCAGCTGAACCACTGACGGATGCGCCGGCA CGTCCCGCGAGAGCTGTTGAATGGATACGTCGAGATCGAAGAGCAGCGTCCGCCGTCCGTCGTCGCGAATCATGCTTTGAATCCAGAA GAACGACGCGACCCGCGCGCCGCGCGTCACCGCGGTCACGCTGTGCAGGCTGGACGACGGGTAGAGCACCATGTCGCCCGCGGGCAGC TTCACCTTGTGCACGCCGTAGGTGTCTTCAACGGTCAGTTCCCCGCCGTCGTACTCGTCCGGTTCGGCGAGGAACAGCGTCGCGGAAA GGTCCGTGCGAATGCGGTGTCCGGTCGAGCCAATCTGGCGAATCGCGTTGTCCACGTGGTTGCCAAACGCGTGTCCGCCCTGGTAACG GTTGAACAGGGGAGGAAAGACGCGAAGCGGGAGCGCGGCCGAGACGAACAACGCGTTCCGCTGCAGCGCCGTCAGGATCATGTCGCCA ACCGACTCTGCGGCCGCAGAGCCCTCGGCCACCTGCTGGTTGTTCTTCGTGCGGGCCGACTGCGGCCCCGCCGTCACCTTGCCGTCGA TCCATTCGGCCCTGTCGAGGAGCGAGCGCGCGGACTTCACCTGCTCGCTGCTCAGAAGATCGGGAATTGCCAGAAGCATCTCGATCTC CCGGTTAGAACCGCACGCTGGACGTCAGCGTCGCCGCGCGGGGCGTCCCCGGATTGAAGCGGCCGCCGTTGTTGTTGACGTTCCTGAT GTAGACCTTGTCCGTGATGTTCGTCACGTTGAGGCGCAGCGACAGGTGCGCGTTGAGGTCGTACTCGACCATCGCATCGGCAAGCGCG TAACCGGGGACGCGAATCGTGTTCGCCGCGTTCACGAACACATCGTCCATGTACCGCACGCCCCCGCCCAGCGTGAGGCGGCCCGGGA AGTCGTAGGTCGTCCACAGACTGCCCGAGAGCTTGGGTGTCAGCGTCAACCGGTTGCCGTTGTTGATCGGGTTCTGGCTGATCTGCCT GGTATCGAGGTAGCCGAGGCTCGCGAGCACCTGCCATCGCGGCGTGATCCGCCCGAGCGAGCCGATCGTAAAGCCGTTCACCTGCTGC CGGTCGTCCTGGTTGAACACCGGGGGGATGGCCGCCGCATCGACCGTGAAGATGACGTTCTCGTTGTCGGTCCTGAAGGCCGCCAGGC TCAACGACAGCCTGTTGTCGTACAGCCCGATTTTGCCGCCGACTTCGTAGTTCCTCGACTCCTGCGGCTTGACGTTCGGGTTGTTCTG ATTGTTGGGCTGGGCGCTGAGCGTGAAATTCGCGGTGCCGGGGGGCGTCACGGTGGAGCCGTACGAGAGATAGACGTTCGCGGCATCC GTCAGGCGATAGAGCACGCCCGCTTTGCCGCTGAAGAGACCATCATTCGTCGTGAGATCGGTGGTCAGGGCGCCCGTCAGATCGGCAG CCTTGAAGGCGGCGTCGTAGTGCTCCCATCGCAGCCCTCCACTCAGCTGCCACCGTGCGCCGAGCTCGACCGTGTCGAACGCATACAC GCCGACGGTGTTCGTCCGTCCCCGGTTGTAGGCGAGGCTCCGCTGCGGCGCATAGGCGGTGACGGCGTCGAACGGATTCGGCGTGTAG ATACTGACCAGATTCCGCGGCGTGCCCACCCCGGTGAGCGTCGGGGCGAACTGTTCCTCGCTCGAAATCTCGATGCCGGCGTTCGCGG AATGGCGGAGACGGCCAGTCGCGAAGCGCGCCGACAGGCTGGTCTGATTCGACAGAATGTCGTTCTCGCGCTCGTTGCCCTGGCGCGC GATGGTCAACGTCTGCGTGTCCGGAACGAAGCTGGCCGGCGACTGCGCCGTGGAAATGACGGCGGTGCGATGCGTCTGGTTGTAGCGC GTCTGGTTTCTGAGGGAGAGATTGCCGTTGATATCGTGCTCGACGCGCGCGGTGTAGCTTTCCTGCTCGACCTTGTCGAAGTCGTAGC CGACGCTGCCGTAGAAGTTCTCCGTGTCTACCTCATCGGCGGCCACGACCGTCGTCGGCGCGAGCGGATAGTCCCGCCACGCGGATCC CGGAACGCCGTAGTCCGGCACGTTGTCCTGCCGCGTGATCTGCACGGCTCCGGTAACGCGCGTCGATGTGTTCATCCCGAGCGCAATC GAGGGCGCGACCGACTGGTTCTTGCGCGTGACCACATCACGTCCCGGAACACCGCCGTCTTCCCACAGGGCGTTGACACGGATCGCGG TGCTCGCAAGCCAGCTGCCGCTCTCGCCAAGAGGGAGCTCGTGATTCGCGTCGACGGTCGTACGATTCTCGTCGCCGCTGCCATACGC ATAGCTCACGGCGTAGGCCGGCTGTTCGTGCGGCGTCTTGGTCTGCATGTTCACATAGCCGGCGGCGTTGCCACGGCCCACGTCGGAC CCGGTCGGGCCCATGAACACTTCAACCTGCTCGAGATTGAACACGTCACGCGACATCAGCCCGTCATCTCTCACGCCATCGACAAACA GGCTGTTGTTGGCGCTGAACCCGCGCAGGTTGAACATGTCGCCGGACGTGTTGGACGCCCCGCCGCCTTCACCAGCCTGGAGGCTGAT TCCAGGGACGTTGCGCAGCGCGTCGCTCAGCGTCGTGACGCCCTGCGCTTCCATGATTTCGCGCGGAAGGACTTCGACCGTCTGCGGC ACATCGATGAGCGGCTGCGCGTATTTCGGCGACGAGGGACGCGGCTGCGCGGCGACGGCGGTGACCTCCACGGCCTCGGTCGCGAGAC 
GAATCTCGAGCGTCACGCTATCGGGAGCCGTGGCGCGCGAGGTCACGTTCGTGCCCTCGAGCGCGCGCGCGAGCGCCTCCGCGGGCGT AAAGAAGCCGTTCACCCCCGGCGACGCAATCTCGCCGATGACCTCGCTGGCCATCGCGATATGAAGGCCGGTGAGACGTTGAATCTCG GCGAGCACGACGCGCAGTGGACCGGCGGGTATGCCGAAGCGCAACTGCCGCGGGTCGCCACCCGCCGCTTGTGCGCTCCACGCGCGCG CGACGTACGTATCGCCAGGGACGGCAATCCTGAACGCCTCGAGCCGCCGGGTGAGCTCGGCGCCGTCGGCGGGTGTCGCCAGCCTCGG GACCAGCGTCGCCGAGGCGACGAACGCGCCCATGACGGCCCAGTTGGATCGTGACTTCCTGCTATGGTGCTTGTGACGTCGTACGCGA GCCATCGCTTCTCCTGATCCGAACGGCGATGACCGGCGCGACGGCTACAATAGGTGAGCCGGACGCGTCATGCGCCACCCGCGTGATG AAAGGTCTCCAGACCCTCGTTCGGTACGCCCGCCGGGTGTTCGCGCACCCGGCGGGTCCTAGGTTCTTCCGCCCTAAAGTGAGACTGA GTCTCAGTTTCATCAACACTGTATATCCGACCAAATTAGTCGGTCAAGAAAATTCCTGATGTGGGGCGTTCGGCGCTCAGATGCGCGA TCGCGACGCGCGATGCGGCTCGGCGCGCGCGCCGGACAACGCGCTCGCGCGCATCTCGCACTCGCGTGCGGACCTTCCCGTGAAACAC GGACAACCGCAATGGCGTAAGGATGGATATACAATAGCCGGCTTAACCGTCTTAGGAGTCAGCACATGCATGTATTGAAGGTGTTTCG TCTGTCATTCATCACGCTTTTTACAGCCCTTTTCGCAACAGCTGCGCTCGCTCAGACGGCGACACAGGCCAAGCCCACCGGGCAGTTC GAGCCGCGCGTCGGCCAGCCCGGCAAGGACGTCGTGTGGGTGCCGACACCTCAGGCGCTCGTCGATCGGATGCTCGACATCGCGAAGG TGACCCCGAACGATTTCGTGATGGACCTGGGATCGGGCGATGGCCGCACGGTGATCACGGCTGCCAAGCGTGGGGCGACGGCCATGGG CGTCGAATTCAACCCCGACATGGTCGCGTTGTCGAAGGCCGCCGCGCAGAAGGCGGGCGTCGGCAATAAAGCCACCTTTGTCGAGGGC GACCTGTTCAAGGCCGACCTGAGCAAGGCGACCGTCATCACGATGTTCCTGCTTCCGAGCATCAACATGCAGCTCCGGCCGAGCCTGC TGAACCTGAAGCCGGGCACACGCATCGTGGCCAACACCTTCACGATGGAAGACTGGCAGGCCGATCAGACCGAGTCGGTCACCGACAA CTGCTCGAGCTGGTGCACGGCGCTCCTGTGGATCGTGCCGGCAAAAGTGCAGGGCACGTGGAAGACGCCGCAGGGGAACCTGACGCTG ACGCAGGAATTCCAGATGCTCACCGGCAATCTGAGCGGAACGCCCATCACCGGCGGTCGCATGAACGGCGACCAGATCTCGTTCACGG TCGGCGGCACGACCTACAACGGCCGCGTGAACGCCGCGGGCAATGCCATCAGCGGCGGCAATCTGACAGCCTCGAAGTTGAACTGAAA CAAAGGGGTCTGACCCCCGCAAACAGTACGGGGTCAGACCCCAAGCGCCGTTTTTCGAGGCGGGTTGAAAAACGGCGTCGGCACGACC TTCGCACCGGCGCGGTGACGGACGGCTTCGACGGTCACTTCCATTTCCAGCCTGCTGCCCGTCTCGATCGAGCCTCGCTCGACCGTCG CGAGCGCAATCATCTTCTTCAGAACCGGAGACCACGTGGTCGATGTCGCTCTTCCGACCTGAGCGCCATCGCGATATACCGGCACGGC GACGCGCGAAGCGGTCGCGGGCACTTGCGGCGGCATCTCGAGCTTCTCGTATAAGGCTTCCACTTCCTCCCAGTTGATCTCGAGGCCC ACGACCTGGCGCCGAGCGCCGTGTGCCTTCTCCTTCTGCAACGCGGCCTGCCCGACAAACGGTCCCTTGTCGACCTGCACGAGCCGCC CCAGCCCCATCTCGAACGGCGAATACTGCTGGCTCGGGATGAGCGCCTTCCGGCTGCTGAAAAAATCCACCTCGATCAGAAGCAGTCC CGCCTCGATGCGCGCGACATCGAGCGCGAGCATGCCCGCGGGACGAACATCGAATGGCCCGCCCGCCGCAACCAGCGCATCCCACACG TCGATCGCCTGCTCCCACGGCATCCAGATCTCGTAGCCGAGATCGCCCGTGTACCCGGTGCGGGAAATGTCCACTGGAACGCCGGCAA TCCGGCCGCTCGTCACACGGAAGTATTTGAGTGAGGCCACATCGGCCTCGGCGACCTGCCGGAGGAGGGCGCCGGACGTTGGGCCCTG GACGGCGAGCGCCGCGACCGTTTCCGACACATCTTCGATGGCCACGTCCAGCCCGACCGCGTTCTGGACCAGCCAGCGCAGGCTGGGA TCGGCGGCGGTCCAGCGATAACGGTGCTCCCCCAGCCGCGACACCGTGCCATCGTCAATCACCTTTCCCAGCTCGTCGCACCATGGGG TGTAGAACACCTGTCCGACAGCCATCTTCGTCGCGTCGCGGGTGATGATGCGATCGACGAGCCTCGTCGCGTCGCGGCCGGTCAGGAT GTATTTGAACAGCGGCGATACGTCGATGAGCGCCGCCGCGTTTCGGATGGCGTTGTACTCGTGCTCGTGATGCGCCTCGAAGGCACTG ACCGCGTAGTACCCCGCCCAGTCGCGGTAATTCAGGCTCTCACACAACGGCAGCGTGCGGTCGTGAAACGCGGAACCGATGGGCATAG GTAAACTAGAATCTGAAATTCCACGCCGGAGGGCGGGTCTTGAACTCCCACCCTTCCTCAGATCAGCACTATGCCCGTTAATGTAGTC GAGCGTTCATCGCAACGATCTGCCAGAGATCGCGGAGGTACTCATCCGCCTCGACGCGTATCCGGACCTCGTCTCCAATGGACCGGTG GTCATCCTACACACTATCTGGACGCCACTTTTCCCCTACACTTCTCGGTTGTTGCTTCTATCATCTTGCCCCCTCCACGAAACGTCGC CCAGGTACTCCACAGACAATTCAGACCCAACACCGTTCAATGCCCCCCCGGACCCCCGCGACAGACCCCTGCACCCGCCTACTGATCT GTACCCCCGACTCTCAACAAAGTCGGTCACGGTGCCCCACTCCCCAACTTGTCTCTCCTCCCCACCCCCCGTAGTCCTAGCCCTCCTT TTGTCTGCTCGCCTCCAACTTCCTCTTACGCACCTCACTGGCCACCTCCCACTGTCCGTCTCCTCCATAGTTCCTCCTTCCCGCCTCC CCTGCCTTGATTTCCCCGCGGCTCACCCACCAGACCTCCCGTACCTTCTTCCCGCAGCGTCTCCTCCTACGCTGTCCCGCCTCCGTCC TCTCTACGTGCGCCACCTCTTCTGCTTCTACCGTCCGTCCCCCACTCCCATCCTGCCTTT

\section{Contig 2}

CCCCCCGGGGGGAAAAAGAAAGAAGGNGNAAAAGGAGGGGNAGGGAAGGGGAAGAGGAAAGANAAGAGGGGGAAAGGGGNGAGAGAG AGGAAGGGGGGAGGGGGNGAAGGGGAAGGGAAAGNNGAGAANNGGGNNNGGANGNANNNGCACACAGGAAACAGCCANGACCANGA NNACGCCAAGCCNGGNACCGAGCACGGANCCACCAGAAACGGCCGCCAGNGAGCCGGAANGCGGCANCCCGAGACGGCAAAGCCCGGG ACGACCCCACCCGNCGCCGCCGCGCCCCCNCCGCCGGGCCCGCGCGCCNGCACGCCGACGCGCCGCCCCGCGCGNGCCCGNNGGCCCG CGCGCCCGCNGCCTCCAAGACCCGCCCTCCGAGAGATTCTAGATCATAGATTCCATGCGCACCTACGATGTCATCGTGATCGGTGGCG GCCACAATGGCCTCGTGCACGCGGCCTATCTGGCACGCGCCGGCCGTCGCGTCGTCGTGCTCGAGCGCCGGCACGTCGTTGGGGGCGC GGCGGTGACCGAAGAGGTCGTCCCGGGCTTTCACATCTCGGTCTGCTCGTACGTCGTGTCGCTGCTCCGGCCGCAAATCATCCGCGAG CTCGATCTGCCCCGCCACGGCTTCGAGGTGCTGCCGCTCGATGGCACCTTCACGCCCATGCCGAATGGCAATTACCTATGGCGCGTCA ACGATCACGGCCGCACACGCCGCGAAATCCTCCGGCACTCGCGCCTCGATGCAGAGGCCTACGATGAGTACGGCAGGGCGATGATCGA CATGGCGCGGTTCGTGAAACCGACGCTCGACGTGCGTGCGCCCGATCCGCTGTCGCTGTCGCTCCGCGACATGCGAGACCTGCTTCGC CTTGGACGCCGATTCCAGTCGATGTCGCCGGAATCGCGCTATCGGCTCGTGCAGCTGATGACGATGAGCGCGGCCGACTTTCTCGATC AGTGGTTCGAGACCGATGTGTTGAAGGCCACCATGTCGGCGTCCGGCATCATCGGCACCTTTCAGGGCGTGCGCTCGCCCGGCACCGC GTACGTGCTCCTCCACCACTACATGGGAGAAATCGACGGCGCATTCCGGTCGTGGGGCTTTGCGAAAGGCGGGACGGGTGCCATTTCC AACGCCATCGCCGCTGCGGCGCGCGAGGCCGGCGTGGAGATTCGCACGAAAGCCGGCGTCAGCCGGATCATCACCAAACATGGCCGCG CCACGGGCGTCGCACTCGAAAACGGCGACGAGATCGAAGGGACGATGGTGTCCTCCTCGGTCGATCCGCGCCTCACCTTCACGAAGCT TCTCGACACCCGCGAGCTGCCCGCCGAGTTCGTCGAGGAAGTGCGACGCTACAAATTCCGTGGCTCGTCGGGCAAAGTCAACCTCGCG CTCGACGGCCTTCCGAACTTCACCGGCGCACCGGGAGAGATCCGCCACCTGCGGGGCGCCATTTCGATCTCTCCGAGCATCGAATACA TGGAGCGGGCCTACGACGATGCCAAGTACGGCCGCTACTCACGACGGCCGTACATGGACGTCGTCATTCCCAGCCTGACCGATCCGTC GATCGCGCCACCCGGGAAGCACGTCATGACGTGCTTCGTGCAGTACGCGCCGTACCACCTGAAAGACACGACGTGGGACGCCGAACGC GAATCGTTCGGCGACACCGTCATCGAAACATTGTCGGAGTATGCGCCCAATCTGAAATCGCTGATCCTGCACCGGCAGGTCATCACGC CGCTCGATCTCGAGCGCGAGTGGGGTTTGAGCGAGGGCAACATCTTTCAGGGCGAGCTCGCGCTCGAACAGCTGCTGTTCCTCCGGCC GGTCCCCGGCTGGTCGAAATACCGCACTCCGATCGCCAACCTGTACATGTGCGGATCGGCGACGCATCCGGGCGGCGGCATCATGGGC GCGCCGGGCCGGAACGCCGCCTTGGAAATCCTCCGCCCGTCCTTCGCGGCTGCGCCGCTTCGGCGGGGCAAGTGATCGACGCCATCTT CATCGGCGGCGGGCACAACGGGCTGGCGGCGGCAACCCTGCTGGCACGCCGAGGCGTTCAGACGCTCGTGCTCGAGCGGCGGCCGATG GTCGGCGGCGCGGCCATTACGGACGAGCTCCACCCCGGCTTCAAGGTCTCCACTCTCGCGCATGCCGCGTATCCAGCGCCGGCGCTGC TGAACGAGCTTCGTCTCGAGGCCCACGGCCTCGCCCTCGTCGAACCCAATCCGTATCTGTTTGCTCCGCTGCCAGATGGTCGAAGCCT GGTGCTCGAGCACAGCGTGGAAGCCAGCGCGACGAGCATCGGCAGCTTTTCCGCGGCTGACGCCCAACGGTACCCGGAGTTCTGTCAC ACGATCGACCGCATCCGCGCGTTCGCATCGCGCGTCATGTCGAGCACGCCACCGGAAATCGAGCACCCGTCATCGAACGATCTCTGGT CGATGCTGATGATGGGACGCCGGTTTCGAGGCCTCGGGAAGAAAGACGCGTACAGATTGCTTCGCTGGGCGCCGATGTCAGCGGCAGA CTTCGTATCGGAGTGGTTCGAGTCGGAGCCGTTGCGGGCAGCCATTGCGGCCGGCGGCATTTTCGGTACGGCTATGGGCCCGCGCTCG GCCGGGAGCACGGCCGTGCTCCTGCTGCGAATGAGCGCAGGCGACGGCAGGCCGCGACTGGTCCGGGGGGGCCTCGGCGCCTTCACGT 
CGGCGCTGGCCGCCGCGGCCCGTGCAGCCGGTGTGAGCATTCGCGTGGACGCCGGTGTCAATCGCATCGACGTGCGGAATCGCCGGGC GGTCGGCGTAACGTTGGAATCTGGTGAAGTGTTATCGGCCGGAATCGTGGTCTCGAACGCCGATCCGCGACGGACGATGCTTGGGCTC GTCGATCCGGTCGAGCTCGACCCGGGCTACCTCGCACGCATTCGCAACTACCGCGCCGAAGGGCGCGTGCTGAAGATCAACCTGGCGC TGAGCGCACTGCCCAGCTTCACCGGGGCGGCGGGCGATCTGCGCAGGCTTGGCGGGCTCATCCATATCGGTCCCGATCTCGAGTATCT CGAGCGCGCGTTCGACGCGTCGAAATACGGTGATTGGTCGCCGAGGCCGCATCTCGACATCACGATTCCGTCCTTGACCGATCCGACG CTGGCGCCCTCGGGCGCACACGTGATGTCGATCTCGGCACAGTTCGCGCCGTATCGTCTGCGTGGTTCGGACTGGAGCGCAGCCGGTC CGGCGTTTGCGGACGCCGTCATCGACACCCTCGCCGAGTACGCCCCGAATATCAGAGGTCTCATTCTGAAGCGCCAGGTCATCACGCC AGTCGCGATGGAAGCGGAATACGGGCTCACGGGCGGACACATTTTCCATGGCGAACTGGCGCTCGACCAGCTGTTCACCATGCGTCCG CTGCTGGGATGGGCGCGCTATCGCACGCCGATTGACGGGCTGTATCTCTGCGGCGCCGGCACACATCCCGGATACGGCGTGTCGGGCC TGTCCGGCCTGAACGCCGCGCGCGAGATCCTGAAGGATCTGAAGTAACGACTTTCTGGAACTTTTCCTGATTGTCTTGTCACGGCGAC GCGGCGTCTCTGAAAAGAGGACAACCCCCGCCACACATTTTCAACACTTGCCTCGAGAGGGGTCTGGAGGGACCCCTTTCACCATTGG GCACTTCGTTTGCACTCCGGCGGGCGCTTGCCCGAGAGACGACCTCGCGCTCTCATTGCCGACGCCGACCCATCGACGCGACTGCTGC TCTCGCACCATCTCTTTTCCGATGGCTTTGCGATTGACGAATGCGCCGACGGACGAGACGCGCTCGAGCGCCTCACCTCGAACCGCTT CGATCTGATCGTGCTCGAGGCCGCCCTGTCGGGTCTCGACGGCATCGCCTTGTGCCGCGCGATCCGGCACGGCTTGGTCAATCCCCGC GCCGCCATCTTCGTCGTCGCGCGCTCTGCCGCCGAGTCGGACAAAGTGCTCGCGCTCGTCAACGGCGCCGACGACTACCTGACCAAGC CGCTGGGCGTTCGCGAGTTCCTGGCGCGCGTGTCGGCGGTCATGCGAAGAGTCGAACGCGCATACGATCGGCCCGCTCGACATGCCGT CGAGTACGGCGACTTGCGCCTCGACCCTTCCAGGCGGCAGGTGATCGTGCGCGGGCAGGACGTCGCCTGTTCGAGGCAGGAGTTCGAC CTGCTCTACGTGCTCGCCGCGTCGCCGGGCATCGTGTTCAGCCGCGAGGAGCTCGTCATGCGCTACTGGCCGGGCGGCGGCGGCAAGG ATGTGCGGCTGGTCGATCCGATCGTCAGCAGGCTGCGCCGCAAGATCGAGCGACAGCCTGACTCGCCGCAGATGATCCTCACCGTGTG GGGGATCGGGTACAAGTTTGCAGAGTAGGGCGGGTCTTGAACTGCAAGACCCGCCCTACGTGTGTGAAGTCTTGAACTGCAAGACCCG CCCTACACGTGTTGAATATGTGACAGGAGTATTGCCGAAATGTGGCGCATTGCGCGGCACATCGGTTGCAGTTCGCCGCCGCCGTGGC GTCGAAGATTCACCGCTTCGCATATGTCGTCGCGCTGGTCGCGCTCGCTCCCCTTCCCGCTCGCGCGCAGTCGACGACAACTCCTGAC GAGCCCCGCACCGTCTGCAACCTGCCGATTCCACCTCCGGCGAATATGCCGCCGGAGGGCGGCCCGCCCGTTGTCTATCAAATCGTGC CGTGCTTCGAAAAACAGGGCAACGTGTCGATGGTCGATCCCGAGACCTACCTTCACTACATCCAGACGCAGGTCAGCCGGCCGTCGCA GAACGAGTGGGTGAGGTACGGCGACGCCGCCATCGAAACGATCCTGCAGGATTTCAAGCGTCTGTGGGCGACCGGCTTTCTCGACGAC TTGTCGATCGAGACGAGCGACTACGTGTTTGCGAACGGAGCGATCGGCAAGCTCGTCGTCTACCGCATGGAAGAACGCCAGCGGATCA AGCTGGTGAACTACGAAGGGGCGAAGCATCTCGAGCAGAGCAAGCTCGAAGAGAAGCTGCGCGAGCTGGATCTGATGATCAGGATCGA CACGTTCGTCGACCAGACGCGCGTCAAGCGCGTCAAGACCGTCATCGGGGAAATGCTGGCGGAGCTCGGCTTTCCCGAAGCCACAGTG AGCGCCGATCTTCGCCCTTTACCCGGCGGGCCGAAAACGGCACAGCTCATCTACACGATAGACGAGGGACCGCGAATCCGTATCAGGC GCGTCGAGTTCGATGGGAACGCCGCCTTCGATGACGGCCGGCTCGCGTCGGCGATGAAGCACAACCGCTCGAAGCGATGGTTCCCCAT TCCGAACTTCGACAGCACCTACAAGCAGACCGGCTTCGAAGAGGACGCCGATCGCATCGTGAGCTTCTATCGCGACCGCGGCTACCTG AGCGCTCGAGTGGGGCCGCCGACCATCCGCCCGCTCGAGGACACGGCTGACGGCAGCACGCGGTGGGTAGCTTTGAGCATTCCGATCA CCGAAGGCCCTCGGTACCGGATAGGAGAGCTGACGGTGGAAGGCAGCGTCGAGGTTCCGTCCAGCTATCTCCTGTCTCTCTTCAAGAT TCGCCAAGGCGAGCTCTACAGCGAGAAGGACATTCGGGATGGGCTGACCAAGGCGCGGGAGCTGTACGGCGCGCTCGGCCGGTTCGAA TTCACGGCGTATCCCGATCTGCGGCCGCGCGATCCCTTTAGTGAGGGTTAATTGCGGCCGCGAATTCTTGAAGACGAAAGGGCCTCGT GATACGCCTATTTTT

\subsection{Das Cosmid slc_1h}

\subsubsection{Lage der offenen Leserahmen (ORFs)}

\begin{tabular}{|l|l|l|l|l|}
\hline ORF & Annotation & Start & Stopp & $\begin{array}{l}\text { Orien- } \\
\text { tierung }\end{array}$ \\
\hline 401 & Rhizobiozin-Sekretionsprotein RspE & 1 & 947 & - \\
\hline 402 & Rhizobiozin-Sekretionsprotein RspD (ABC-Transporter) & 944 & 2677 & - \\
\hline 403 & VacJ, Oberflächen-Lipoprotein (COG2853) & 2854 & 3633 & + \\
\hline 404 & Potentielles Toluen-Toleranz Protein Ttg2 (pfam05494) & 3623 & 4231 & + \\
\hline 405 & Membran Carboxypeptidadse MrcB (Penicillin-Bindeprotein) (COG0744) & 4326 & 6521 & - \\
\hline 406 & Stickstoff-Regulationsprotein P-II, GlnK (COG0347) & 6783 & 7121 & + \\
\hline 407 & Ammonium-Transporter, AmtB & 7149 & 8633 & + \\
\hline 408 & Amino-Transferase für aromatische Aminosäuren (EC 2.6.1.57) & 8760 & 9941 & - \\
\hline 409 & Rhodanes-verwandte Schwefel-Transferase SseA, (COG2897) & 9945 & 10805 & - \\
\hline 410 & Hypothetisches Protein & 10911 & 11195 & - \\
\hline 411 & tm-RNA-Bindeprotein, SmpB, (COG0691) & 11338 & 11820 & - \\
\hline 412 & Hypothetisches Protein & 11860 & 12156 & + \\
\hline 413 & Dihydrodipicolinat-Synthase/N-Acetylneuraminat-Lyase (EC 4.2.1.51) & 12288 & 13163 & - \\
\hline
\end{tabular}




\begin{tabular}{|c|c|c|c|c|}
\hline 414 & Potentielle lösliche lytische Murein-Transglykosylase & 13322 & 15277 & + \\
\hline 415 & Konserviertes Membran-durchspannendes Protein & 15475 & 16359 & - \\
\hline 416 & Konserviertes Protein & 16356 & 17036 & - \\
\hline 417 & Potentielle Oxidoreduktase; möglicherweise D-Aminosäure-Oxidase-Protein & 17109 & 18155 & + \\
\hline 418 & Hypothetisches Protein & 18206 & 18508 & + \\
\hline 419 & Potentielle Acetyltransferase (EC 2.3.1) & 18696 & 19187 & - \\
\hline 420 & Chromosomen-Teilungs-Protein smc & 19353 & 22808 & + \\
\hline 421 & Membran-gebundene lytische Murein-Transglykosylase B & 23309 & 24478 & - \\
\hline 422 & Cobalamin-Biosynthese Protein CobD/CbiB & 24508 & 25428 & - \\
\hline 423 & CobC-Protein & 25425 & 26390 & - \\
\hline 424 & Hypothetisches Protein & 26380 & 26760 & - \\
\hline 425 & Konserviertes Protein & 27410 & 27760 & + \\
\hline 426 & Konserviertes uncharakterisiertes Protein (COG3034) & 27762 & 28295 & - \\
\hline 427 & $\begin{array}{l}\text { MalY, Bifunktionales PLP-Abhängiges Enzym mit } \beta \text {-Cystathionase und Maltose-Regulon- } \\
\text { Repressor-Aktivität }\end{array}$ & 28292 & 29464 & - \\
\hline 428 & Def, N-Formyl-methionyl-tRNA-Deformylase (COG0242) & 29678 & 30196 & + \\
\hline 429 & Def, N-Formyl-methionyl-tRNA-Deformylase (COG0242) & 30196 & 30699 & + \\
\hline 430 & Methionyl-t-RNA-Formyltransferase (EC 2.1.2.9) & 30696 & 31586 & + \\
\hline 431 & Hypothetisches Protein & 31583 & 31816 & + \\
\hline 432 & Hypothetisches Protein & 32079 & 32519 & - \\
\hline 433 & Ribonuklease HI (EC 3.1.26.4) & 32693 & 33157 & - \\
\hline 434 & LytB, Penicillin-Toleranz-Protein & 33214 & 34164 & - \\
\hline 435 & Konserviertes Protein & 34309 & 34881 & - \\
\hline 436 & FolK, 7,8-Dihydro-6-hydroxymethylpterin-Pyrophosphokinase & 35029 & 35601 & + \\
\hline 437 & Hypothetische DNA-gerichtete RNA-Polymerase omega-Untereinheit (EC 2.7.7.6) & 35695 & 36048 & + \\
\hline 438 & Protein der Familie der Guanosinphosphat-Pyrophosphohydrolasen/Synthetasen & 36079 & 37312 & + \\
\hline
\end{tabular}

\subsubsection{Sequenz des Cosmides slc_1h}

ATCAGGTATAGAACCGGGTCGGCAGGCCGCAGAACCGCGCGCGGCGTCGTCACCGTCAGCCCCAGCACGATGCCCGACACCGGCGCGC GCACATCCAGCCGTTCGATGCGTTCGGCAAGCGCACGGCGACGTTCCGCCAGTTCCAGTTCCTGCGCACCGCTGTCGCGCAGCTGAGT ATTCGCCTCTTCGCGCCGATCCGACGCAAGGCGCAGCACTTCGATTTCAATTTCGGTGATCCGGCCCAAGGCTTGCGCGCGGGTGGCG GCCAGTTCGCCCAATTGGCCGCTTAACCGGGCCGCTTCGCGTTGCAGTCCAAGAACCCGGCTGGCTTCGGCAAGGCCCTTTTCAAGCA ATCCCTGCTGATCCGTCAGTTCTTTCTGCAACAGCTCCAGTTGCGTCTTTAACGCCAGACCTTGCGCATCGATGCCGATAACCTGCTG ATCAATCTGCTCGCGCTGCTTGGTAAACTGCTCGATCTGACTGGTCACGCTATCGCGTCGCGCCTCGAACAACCGGCGTTGACCTTCC ACCTTTTCGGCAATCTCGGCGCGCGCCGATGCCGCATCCAACAGGTCACCATCAAAGCTCAGCGTATCAAGATCATCGCGTTCCGCCT CCAGCCGCCCGCGGCGCGCCAGCGATTCGAACAGCTGGCCTTCGACAATCGCCAATTCAGATCGTATCGACGCGCCATCCAGACTTAG CAGCAGATCACCGCCGGCAACCGTATCGCCTTCGGCCACGTTGATCGTGGCCACAACACCGCCGTCAGGATGCTGCACGACTTGCCGG TTTTGCTCCACCTCGATCTGGCCAGAGGTCACGATGGCCCCCGATATTGTGGTGGCCACGCTCCACCCGCCAAAGCCGAATACCAGTG CCGCCACAGTCAGAAGGCCATAAATCACCGGGCGGCGGGTCGACCAGATTTGCGCTGATTTGGTCATGACACGCCTCCGACCGCGGTG GGTTTGGTAATCTCGGCGGGGTTTTTCACCATTTCACGCAGCACTTGGTCGCGCGGGCCAAAGGCGCGCCGCATCCCGTCTTCCAGCA CCAACAGCAGATCGCATTCCTGAATCGCCGCAGGCCTGTGCGCCATGATCAGCACTGCGCGGCCATCTGCCTTCATCTCGCGAATGGC AAGGTTCAGCGCAAGTGACCCATCATTATCAAGGTTCGAATTCGGCTCATCCAGCACCAAAATTACCGGGTCGCCGTACAGCGCGCGG GCAAGGCCGATGCGCTGTATCTGCCCACCAGACAGCCGCCCACCAAGCGTTGAAACGCGGGTGTCATAGCCATCGGGCAGTTTCACGA TCATCTCATGCGCCGCTGCCTTTTTTGCCGCCTCAACCACTTTTGCCCCATCGGGCGCGTCTTGCAGGCGGGCGATGTTCTGCGCGAT CGTGCCATCAAACAGCGTGATGCGCTGTGGCAGATAGCCAAAATAGCTGCCCAGCACATCAGGATCATACTGATCAAGCGTTGCGCCA TCCAACCGCACCTTGCCGCCCGCTGGCCGCCAAACACCAATCAAGGCGCGCGCCAGTGACGATTTGCCAGACCCGGACGGTCCGATAA TGCCCAAGGCCTGCCCCGGCTCCAGCCGAAAGCTGACTGATCGCAGCACGGGCTGGCTGTCACCCGGCGGCACCACGCTCAGGTTCTG CGCCTCCAATATTGCCTTCGGGCGCGGCAATGCTGTGCGCGGCGGGTCAACCGGGGTGCGGGTCAGCAGATCGGCCAAACGCGCGTGG CCCTCGCGCGCCCGGCTGACCAGCGGCCAACCACCAACGGCCTGCTCAATCGGCGCCAAGGCCCGGCCCATCAGAATTGATCCGGCAA TCATCGCGCCGGAACTCAGCTCACCGCGCAGCACAAGCCACGCCCCTAGTCCCAGCATCGCCGATTGCAAAAACATGCGGAACACTTT GGACACCGATCCAAACACCCCCGTCACATCCGACGCGGCAATGCTTTGACCCAGCGCCAGACTGCGCGCCTTTTGCCAACGATCAAAC CCGGCCCCTGCCATGCCCAGCGCCTGCACCGCCTCGGCCTCGGATTTCAGGTTTTCTGCCATCCGCTCGGCTTGCATCCCGGCTGCGT TGGCGCGGATCAGCGATTGTTCAGAACTGCTTTGGTTCAGCAGCGCCACCACAACCAGAATCAGTCCACCCGCAATCGCCAACAGGCC CAGCCAAGTATGGAACACAAAGATTGCGGCAATGAACAATGGCGTCCACGGAATATCAAACAGTGCCAGCAGCACGGGCGATGCCCAC AACCGCTGCACCGCCTCAAGATCGCGTTGCGCCGCCAAAGCCGCCGGGTCACCGGGGGTTAGCGTCAGACGATGCACTGCCGCCGAAA ACACGCGCCGATCAAGCCGATCCTGCAGCCGCGCCCCAATGCGCGCCATGATCCGAGCGCGGGCATGATCCAGAATGCCCATCGCCAA 
AAACAAAAACGCCACCAGAACCGACAGGGCGACAAGCGTTTCAACCGATCTGCTGCCCAGCACACGGTCATAGACCTGCAACATGTAA AGTGGGGCCGTCAGCATCAGCAGGTTCACAAACACGCTGAACAGGAACACCGCAACCATCGCCATCCGCGATTCCCGTCGCGCAGCAC GCAGTTCGGCCAAACCTCGGATTGTTTTCATCAACACGCGTCCCGTTCGTCCGGATGCTCGTCACCTTGCCCCGGCTTGGGGTCGGCG GAAAACAACCAGTATTGCCTCATTTGCCACGCTTGAATGTTGTCATCCGCCAACAGGCAGCATAAGCCTTGTCGTCCTGCGTGACAGC TTGTGTTATGGCTTCTTATGGGCGGGAACCTAGGAAGATGAACCTTACTAATCCATTGCTTTCTTTCGAACACGCAAAGAATTGCCGC AGCCGGGCACTGTTAGCCACAGTTATCGCAGCAAGTCTCGCAGGTTGTGCGAACAATACCGCGCCGCAAGGCATCACCGACCCGAATG AGGCGGCAAATCGCGAAGTTCACGCGTTCAATCGCGGCGTTGATAAGGTGTTGGTGCGCCCAGCGTCGGGCGCTTACGGGTCTATCCT GCCGGAACCTGTGAAGCGTGGCGTGTCGAACTTTGCCAGCAATCTGGATGCGCCCGGCGATGTGGCGAACAATCTGTTGCAGGGCCGC ATTGGCAATGCCGGGCAAAACACCCTGCGTTTTGCAGTGAACACCATTTTCGGCATCGGCGGCCTGTTTGATACGGCCACCGCCATCG GCCTGCCTGGCAAGCCCACCGATTTCGGCGAAACACTGCATGTCTGGGGTGCGGGCGAGGGCAACTATGTCGAGCTGCCGTTTGTTGG CCCCTCAACCGAGCGCGATCTGGTCGGCATCATCGTTGATGTCGCGCTTAATCCCGTGCGGTTGGCGCTGCCCGAACCCGAAGCATCC TATGCGACCGTCGCGAAATTGGGGTCAAAACTTGGTGATCGGGATCGCTATTCCGATCTCGTCGATGAAGTCTTATATGAATCCGCAG ACAGTTATGCGCAGTCGCGCTTGCTTTATTTGCAGAACCGGCGCTTTGCGCTTGGCCAGACTGCTGGCGATGACACCTTTGTAGACCC GTATGAGGATCCCTATGCGCAATGAACTCAAGCTAACACGCCGCGGCTTTGGTGCGGTATTCGCTGCTGGCGCAGTGACGCTGGCAAT GCCAGGTTCGGCGCAAGCTCTAACGGTTGAAGATGCCCGCGCGCTGGTCGGTCGTGCCATTGATACCGTGAACAGCATCATCAGCTCC GGCAAATCCGAATCCGCGATGTTGCGTGACTTTGAAAAGATGTTCGCCCGCTTTGCCGATGTGCCCGTTATCGCGCGGTCGGCCTTGG GTGTGGCAGCCAAATCTGCCAGCAAGGCGCAGCTGTCCGGCTTTACCAAAGCGTTTCAAGGCTACATCAGCCGCAAATACGGCCGCCG CTTCCGCGAATTCATCGGCGGCCGGATCGAGGTTACCGACGCAAAACCGCTGAAAAGCTATTATGAAGTCGTCTCGATTGCCTACCTG CAGGGCGAGGCACCGTTCGATGTGCGTTGGCATGTGTCGGATAAATCCGGCAAGGATCTGTTCTTCAACATCATCATCGAAGGCGTCA ACATGCTGGCGTCTGAACGTGCCGAAATCGGGGCACTATTGGACAGACGCAAAGGTAATATCGATCAGCTGATCGAAGACCTTAAATC GATTTAAAGCGCATTCCGAAAAGTGTGAAACGGTTTTTGGATAAAATGCGCGACAAGACAAAAGGCTAAAGCGGGGGTTTGATTGTTG TCAAACCCCCGCTTTAATTGCCGTCTGAAATCCCCAGCAAGTTGCGCAGAACTCGCTCCACCGGATCAATATCATCCTGCGGTGCCGG AAAGCGTTCGATCAGCACATCGGGCTGCGCCTGCTGCTGATATTCCGGCTGCGGTGGCAGCTTCGGCTCCGGCACGTCCATCGGCAGC GGCGTTGCGGGCAGGCCGTCTTCGACCCGCACCATCACCTCATGCCATATTTCGGCAGGCAACCCGCCGCCCGTCACACCCTGCAACG GCGTGTTGTCATCATAGCCCATCCAGACGCCCGCCACATAATCAGCAGTAAAGCCGATGAACCACGCATCGCGGCCCGCCGTCGTCGT GCCGGTTTTGCCCGCCGCTTCCCGGTCCGGCAAACGCGCACGGCTGCCGGTGCCCGATGCCACCACCTGCGACATCATGTAGGTCAGA TAGCGCGCCGATTGCTCGGAAATCACCCGCTCGCCAATACCGCCACTGGCCCCCATCAGCGATTCGTCATCACCCTTCACCCGCAGAT CAAGTATCCCGTAAGGCGTCACCGATGATCCGCCATTCAAAATGCCTGCATAAGCCCCGGTCATTTCCAGCAAAGTCGATTCCGACGC CCCAAGCGCCAGCGCCGGCCCCGCCGCAAGATCGCTTTTAATGCCAAAATCACTGGCCACTTGCCGCACCAGATCACGCCCCACCGCT TCGGATATCCGCACCGCGGGTATATTGCGGCTTTCCATCAGGGCTTGGGTCAGCGTGATCATGCCCTTGAATTCATGATCATAATTCG AAGGTGACCATTGGCCTGAACCGGGAATGCTTAGGGTCAGCGGTGTATCCTCAACATAATCCGACGGGCTGTAGCCCAGATCCATCGC TGCGGCATAGACAAACGGCTTGAACGCAGATCCGGTCTGACGGCGGGCTTGCGTGGCCCGGTTGAAAGACCCGGCAACTTCGGTCTTC CGGCCACCAACCATGGCGCGAACCGCCCCATCGGCAGACATCACAACAATCGCCGCTTGCGCGGTGGAGCCATCCTTAACCTTGTTCT CAAAGATATACGTCAGCGCCTCTTCAGCAGCTTTCTGTAAATCCTGATCCAGCGTAGACTTGATCACCACATCTTCGGTCGTCTCTGA CGTCAGAAATGCCGGCGCGCTGTCCATCATCCAATCGGCAAAGAACCCGCCAGATTGAGTTTCCGCCGCCGCTGACAACCGCGCCGGA TTGGCGCGCGCCTCATCCGCCTCATCCTTGGTCAAATAGCCCTGCTCTTCCATCAAGCCGACAATAACCGCACCGCGATCCTGTGCCC GTTGCAGGTTGTTGGTTGGTGCATACCGTGACGGTGCCTTCAACAAACCCGCCAGCATAGCCGCCTCTGCCGGGCCCACCTCGTTGGC AGACTTGCCGAAATACCGTTGCGCCGCTGCCTCGAACCCGCGCGCACCGGCACCCAGATAGGCGCGGTTGAAATAGATTGTCAGAATT TCCTGCTTTGAATACTTGGCTTCCATCGCCATCGCATACGGAATTTCCTTAACCTTGCGCCACACGCCGCCTTGGCGACAATCGGCTT CGTACTCGGTTTCGGATTTCCACAGTGTCGGGTTGTATTCCACACCAAGGCACAACAACTTTGCCACCTGCTGGGTGATGGTCGACCC GCCGTTGCCACTTAGCGGCCCGCGCCCTTCTGACAAGTTGATGCGCACTGCCGATGCAATTCCTCGCGGGCTAATTCCGAAATGCCGG AAAAAGCGCTTGTCCTCAGTCGCCACAACCGCGTTCATCAGATAGGGCGATACAGTATCCGCCGTGATCTGCCCGCCAAACGTCTCGC CACGCCAGGCGAAAACCTTATCGTTGCGATCCAGCATGGTGACAGACCCGCGTGATCGCCCATCCAGCAATTCGGCTACTGGTGGCAG TTGCACATAGAAAAAAAGCACCGCCCCCGCCAGGATCATCCCGAACACAAATCCAACGCGCCAGCCAATCCCCCAAAGAATGCGCCAG ATCAGCCGCACAAAGCCCACCAGCAATGCCATGATCGGGTTGCGACGCGGCCGTCTTGGGCTGGCGCGGCGTGCAGTTTTGGCGGGCC GACGGCCACCGTTGCCACCGCCCTGCGCACCACTGCGCTGCGTTGCATACCGCCGGTCAGCCTTAAGCGGACCATTCCCGTGACGTGT ACCACTCATGCCTGTTCCGCCGTTCTGCCGCGCGACTTGTTTTGCCGCACTGTAGCGCGACCCGTCAGGAATGTGGAGCGGTCGCGAT GATGATTCGCGTTTTCAAGCCGCATAAAAAACAGGCGAACTGCTACGAATGTGCAAAACTTGTGCGTTCATGCCAGTAAGTGGGCAGA TTTGCGCCGCCGATTTCTTGTGCTGCACCTGCGAAAGCCGCTTGCTGGCATCGGGGACAGTCAGCAACCCCAGCCAAAGAGATAGGGG AGCGATGTGAAACTCATCATAGCAGCAATCAAACCGTTCAAGCTTGAAGAGGTCCGCGAAGCGCTGACCGCCATCGGCGTGCGCGGCA TGATGGTAACAGAGATCAAGGGCTTTGGATCCCAGTCCGGCCATACCGAAATTTATCGCGGCGCAGAATATGCCGTGAACTTCGTGCC AAAAGTCCGGCTTGAAATTGTTGTCAGCGACGCGCTGGCCGATCAGGTCGTCGAGACAATTGGTAGAACCGCCAAGACCGGCAAAATC GGTGACGGCAAGGTTTTCGTGCTGGATGTGCAGCATGCATTGCGCGTGCGCACCGGCGAAACAAACGACGAAGCGCTGTAACGCGCAC GGGAAGGGGATCCAAAGATTATGAAGAACTCGATGAAATTTACTGGCTTGGCCACGCTTGCAGCGTCGCTATTTGCCAGCCTGCCCGT CTGGGCACAAGAGGCCCCGGTGGCCTATGAATATGTCAAAGCGGTCGACAAAGGCGATGTCGCCTGGATGTCCATTTCGACGGTGCTG GTGCTGTTGATGACAGTGCCCGGCCTTGCGCTGTTTTACGGCGGCTTGGTGCGCACCAAGAACATGTTGTCGATGCTGACCCAAGTGT TCGCAATCGCGGCTGTAGTCGCAATTATCTGGGTGACCTACGGTTACTCCTTGGCGTTTTCCTATGGCGGTGGCTGGGATGCTTACGT TGGCGGCTTCTCCAAGGCGTTTTTGCGCGGTGTTGATGTAACCACACTGGTGCCCACCTTCACCAACGGGGTCTGGCTGCCGGAGTTC ACCTTCGTCGCCTTCCAGATGACCTTCGCGATGATCACCCCGGCGCTGATAGTCGGTGCCTTTGCCGAACGCATCAAGTTTTCGTCGC TGATGGTCTTTGTTATCCTTTGGGTCACCTTCATCTACTTCCCGATGGCGCATATGGTCTGGTGGTGGGGTGGCCCGGATTTCCTGGC TGAACAGCAAACCCTGAAACTGATCGCCGAAGCCGCAGGCGATACTGCCGGGGCAGAGGTCGCAAGTGCCAATCTGGCCGCCAATGGC CTGCTATGGAACTGGGGTGCCTTGGATTTTGCTGGCGGCACCGTGGTGCACATCAACGCCGGGATCGCGGGTCTTGTCGGTTGCCTGA TGCTGGGCAAACGTGTGGGCTATGGCAAGGAATCCATGGCGCCGCATTCGCTGACCATGACGATGATCGGTGCTGCCTTGCTATGGGT CGGCTGGTTCGGCTTCAACGCCGGGTCCAACTTCGAGTCGAACTCGATCACCTCGCTGGTCATCGTCAACACCTTCATCGCAACGGCG GGTGCTGGCGTGGCGTGGATGTTCGCCGAATGGCTGATGAAGGGAAAACCGTCGCTTCTGGGCTTGGTTTCCGGTGTTGTTACCGGTC TGGTGGCCATCACCCCGGCCTGCGGCTTTGCTGGCCCGATGGGATCGCTGGTCTTGGGCTTGGTCGCTGGCGTCTGCTGCTTCCTGTT TGTGGGTTACATAAAGAACATGTTCAATCTGGACGACAGCCTTGATGTCTTCGGTATCCACGGCCTCGGCGGCATCATCGGCGCTCTT GCCACGGGTATTCTGGTAAACCCAGCCCTCGGTGGCGCAGGCATCCCAGACTACATCAGCCAACCCGGCACGTTGCAGGTGGCCGAAT ACGTGTTCGCCACCGCCTTCATGGCACAGCTAAAAGCCGTGCTGTTCACCATTGTCTTCGTCGGTATCGGATCGGCGATCCTGTACAA ACTGGTCGATCTGGTGATGGGCCTGCGGGTGGTCAACGAGGTTGAACGCGAAGGCCTCGATCTCGCCGAACATGGCGAACGCGCTTAC AACATGTAATCTGCTCGGGCCGGACCACTCCCGGCCCGACACCCCCCACGATGCGCCCAAGGGCCCTCCCCCCCCCAAAGCGCACACG AAGGCGGCCTGCGCGCATGCTCCCCGCGCAGGTCGTTTAATTATTGGCTAACCGATAACGCTGGCAATCGCCGCGGCCAGTATAGGCA CTGTCCGCGCATTCAGCCCGGCAATGTTGATCCGGCTATCGCCCACCATGTAAATCCCATGCTCAACCCGCAACCGTTCAACCTGATC AACCGTCAGCCCGATGCGGGAAAACATGCCGCGATGCTGGGCGACAAAGCCAAACTGGTCTGATCCCGTCACATCGCGCAAAGCATCC GCCAAAGCCTGCCGCAACGACAGCATGCTAAGGCGCACTTCCTCCAGTTCCGCCTGCCAATCGGCAGTCAGCCCCGCGTCCTGCAAAA TAGTCGTCACAATCCGCGCGCCATGATCGGGGGGGAACGAAAAGTTCACCCGGTTCAGATGCGCCAAATTGCCCTGCACCGTTGCCCG CTGACCGGCTGCACACAGCACAATCAAAATCCCCGTCCGTTCGCGGTAGATGCCAAAGTTTTTCGAACAGGACGCCGCAATCAACACT 
TGCGGAAACCGCGCCGCTATCATTCGGGTGGCTTCGGCGTCGTCTTCCAGCCCGTCGCCAAATCCCTGATACGCCAGATCAATGAATG GTATGGCCCCGCGCGCCACCAGCAAATCCGCCACCTGCGCCCATTCGACAGCGTTCAGATTTGCCCCGGTCGGGTTATGGCAACAGCC ATGCAACAGCACGATATCGCCCGGCTTCACCGCGCTCAGGTCGGCGATCAGCCCGGCAAAATCGATGCCCCGCGTTTCGGCATCAAAG TACCGATACGTCGCCGATGGAATGCCCAGATAGCTGATGATCGACAAATGGTTCGGCCACGTCGGGTCCGATACCCAGATCGTCGCCT TCGGGTTCGCCGGCCGGATCAGTTCCATCCCCTGCCGAATCGCCCCGGTGCCCCCGACCGACGCCGCTGATGCCACCCGGTCCAACGG CACGTTATCGCCAAGGATCATCCGTGTTATTGCCGCGTTGAACGCGGCTTCCCCGGCAAGGGCCGTATAGGTCTTGCTAACTTCACTG TCCAAAAGCCGCCGTTCTGCACTTTTGACCGCCCGCATAATCGGCGTCAAACCCGTCTCATCCTTATAAACCCCAACCCCAAGATCAA TCTTGGTGGTGCGCGGATCGTCTTTATACAACTGCATCAGCCGAAGGATCGAATCGGCAGGCTGCGGCGCCAGATTCTCAAGCATTAT CTAACCCTTCGCGACCTGCAGGTCGTCATACATGCCCCATTCCGCCCATGATCCATCATAAAGTGCGTGGTTGCGGTGCCCAATCCGT TCAAGCGCCAGACTTAGGATCGCCGCTGTAATGCCGGACCCGCAAGTGGTGATTGCCGGCTTCGATAAATCAGCACCGGCATCGGCAA ACACCGTAGCCAGATCCTTCGGTGCCTTCATCGTGCCATCCGCATTCAGCAGCGTGCCGAACGGCACATTCTTCGACCCTGGAATATG CCCTGATCGCAGCCCCGGCCGAGGCTCCGCCGCCTCGCCCTTGAACCGCGCCGCAGACCGCGCATCCAGAATTTCCGCCTCGCCCAGC TTCGATGAATGCGCCACTTGCGTCACATCCTTCACCAGCCCGGCCTGCCGTTGCACAGTCATATGCCGGTCCCGCAGCACTGGTGGCA TGTCTTCAACAGCGCGCCCTTCGGCCTGCCATTTCGGAAATCCACCGTCCAGCACGGCCACATCCGTCTTGCCCATCAACCGGAACGT CCACCAGACTCGGGCCGCAGACAGCAGGCCAGACCCATCATAAACCACCACCTGATGACCATCGCCCACCCCCATCGCCCGCATCCGG CTGATGAATTTCTCAGTTGGCGGTGCCATGTGCGGCAGCGGCGAACGCTGATCGGAAATCTCGTCAATATCGAAAAACCGCGCACCGG GAATGTGCGCCGCACTATATTCCGCCCGCGCATCGCGACCACTATCCGGCATGTACCAAGACGCATCCAGCACCCGCAAATCCGGGTC CGCCAAATGCGCGGCCAGCCAGGTGGTCGAAACCAGCGTCTTCGGGTCATCCATTGGCGAGGGGGTCATTTTACGCTCCGTGCGGCTC ATGTTCCGGATTAGTCGGACATCGGCATCGAAGCAAGGGTGCTGGGTTGGCCCGGGCGCAACAAAGCACGCCCGGGCCGGGGTTAATT ACTTCGCCATCATGCCTTTCAGCGCGCCGACGATAGCAAGCAAGACACCCCCGCCAACGCCACCCGAGGCGATGGAAGAGATGATCGA GCCAATGTCCAAGCCACCTGCCGCCGCAGCTGGATCAACGGGCGCACCCATCATCCCCAGAAGGTAGGTGCCAATGCCACCGCCAAGA AGGCCGACAATCGAATTGCCAAGCGTCCCGAGGCTGAAGTTTTTCATAATTGCGCCCGCGCCGTTACCGCCCAGTGCGCCTGCAATCA GACTGATGATCAGTTCCATGATACTCGTATTCCTTCCCTAACTCTGTTTCGGTTCCCGTCGGGATTTGCCGAATTACCCAAGCTCTTT CACACCGAAAGGTGCTGGCCCGGTGGACAAAGTGTCGCAGACTGTCGCCAATCGGGCAACTGAGATTGAATTTTTAGAAAGACTTAGT GCTTTGCCGCAACAGCCGACCCTTTTCGCGGTCCCAGTCTTTTTTGGCCTCTGACGCGCGTTTGTCGGCCAGCTTCTTGCCTTTGGCG ATGCCGATCTTCAGCTTCACGATGCCACGGTCGTTGAAGTACATCTTCATCGGCACAATGGTCATGCCTTCGCGTGCAGTGGCGTTCC ACAGCCGCGACATCTCTTTCTTATTGACCAGCAGCTTGCGGCGGCGGCGCTCTTCGTGGCCCCATGTCTTGGCTTGCATGTAGGGCGC GATGTAACCGTTGATCAGCCACAACTCGCCGCCTTCAACCGACGCATAGCTTTCGGCAATGTTCGATCCGCCCTTGCGAAGTGACTTC ACTTCAGACCCAAGCAGCATGATCCCAGCCTCGATATCGGCCTCGATATGATAGTCGAACCGCGCGCGCCTATTTTCGGCAATCAGCT TGGAATTGGGATCAGATTTTTCGACCATGATCCGCCCGAGATAGGCGATAGGGGCAGCCAAGTCCAGATGCGGCCCTCGCCAATCTTG GCATCAGATCGGTATGCACGGGGGGTGTACAGGGGGTGCACAGCAGGTGACGTGCCAAAAAGCGGCCGTTTTGCCCCGACCAAACCAC CGCTAATCGACACCCGCTGCGGATCAAAGCGAACACCGACCTGGTATAGCGGAGCGGCGCAACCATCGATTCATCCCCCATCCGCACG GCCGCCGTCACGGCACAATAAGCGCCCCATCAGCTCAAAAACCGCCCGAATGGCATTCTGGCGGGTCAGACTCGCGGGGCGAAAACCG ATCTCCGCGTAGCTTGGTCAGGATGGCAAATGCCACAATTCCACCCCGAGTCAAACATCATCAGAAGCTGCCCGGCCGGCAAACTGCG GGCGGCAAATTTCAGAAACATATCCTCGACATCAAAGCCAAGCATCTGTTTTGGCTTAGTTTATCAACCCGGCATGGCGCATCGCTGC ATCGATCCGCGCCTTGGTGCCATCGGTCAGGCCAACCAACGGCAAGCGCACGTCGGGGCTGCAGAGATTCAGCTTTGACAGGCCATAT TTCGCCCCTGCAAGACCCGGCTCGATGAAAATCGCCTCATGCAGCGGCATAAGTCGGTCCTGATATTGCAGCGCCTTTGCGTAATCCC CACTCAGCGTCGCGGCCTGAAATTCGGCGCAAAGCCGCGGCGCCACATTCGCCGTCACCGAGATACATCCGACCCCACCATGGGCATT AAATCCCAGCGCAGTGGCATCCTCGCCCGACAATTGGATGAAGTCGGCGCCGCAGCTAATGCGCTGTTGGCTGACCCGTTCAATCCTG CCAGTAGCGTCTTTGACACCAATGATCCGCGGCAGTTTTGCCAGAATACCCATGGTTTCCGGGGTCATATCAACCACCGATCGACCCG GAATATTGTAGATGATGATCGGCAGATCGCAGCAATTATGCAGGGCAGTGTAATGCGCGATCAACCCAGCCTGCGTAGGCTTGTTGTA ATAGGGCGTCACCACCAATGCCGCATCCGCCCCAACCTTGGCCGCGTGGCGGATCAGCCGCATCCCCTCGACCGTGTTGTTGGACCCA GCCCCGGCAATCACCGGCACCCGGCCTCCGGCAGCTTTCACAACCACCTCGATCACCGTTTCATGTTCGTCGTGGCTAAGCGTCGGGC TTTCACCAGTGGTTCCTACAGGCACCAACCCGGTCGATCCTTCGGCAATATGCCAATCGACCAAGGATTTGAGCGTATCAAGATCAAT GGCACCGTTCTTGAACGGCGTCACCAAGGCTGGAATGGACCCTGTGATCATGGCGCGTCTCCTATCCTTTGGGCGGCGATTGCTTAGA CTCGCCCGTTGCAAACGCGCCCTTCCTAGCGCCGCTGCGGCCCATTGCCAAGCGGCGCTGACGCCCGTGCTGGCGATGATGTGAGTTG CACCCAGCCACCGTCTAAGGCACCACTGCGGGTATGATCCGATTTGCCTCCCTGCTCCGCCACGCCATCGCCCTCACTTGCCTTGGAT TTCTGATGCTTTTGGCTGGCTTACCGGCGCGTGCTGACGAAGTGTCAGCCCTACGCGCGGCCCTCGACCGTGCGTCGCTCGAAGATTG GGCTGGCGCGCAGGTCACTGCGGATGGGGCGCTTGCCCAGGACATTGTTGAATGGCTGCGCCTTCGGTCAGGGGATGGCAAGCTTGGC GAATACGAGGCATTTCTTGCGCGTCGCACCGATTGGCCCGGTTTGGCCTTGCTGCGCGAAAAGGGTGAAGAGGCCGTTGCGCGGTCTG CCGACCCCGACCGTGTGCTGGCTTACTTTCGCGATGCCAAGCCCAGAGTGCCAGTGGGGTCGTTGGCACTTGTGAAGGCCTATCTGGC CCTTGGTCGGGCCGCAGATGCCGAAACCGAAGCTATTCGCGCGTGGACAGAACTGGAATTTACCGCACCCGAAGAAGACGCTCTTATG GCCCTGATGCCTGACGCCCTTTCGGTGGCCCATGAAGTGCGCCTTGATCGGGTTTTGTGGGCGGATCGCGCCCCAGAAGCGCGCCGCA TGTTGCCCCGCGTTGGCAATGATTGGCGCAAGCTGGCAGAGGCGCGATTGGCGCTGCGCGCGCAGACCAATGGGGCCAGCGGGCTGGT TGATGCGGTGCCAAAAGCGGTGGCCGGCGACGCTGGTCTGGCGTTTGAGCGGTTCTTGTGGCGGATGAAGAAAGACCGCACAGCCGAC GCGACAGCTCTGATACTGGAGCGTAGCGAGACTGCCGCAAGTCTGGGCGACCCCACTGCATGGGCTGAACGACGGGCTAGCCTTGCCC GCGCCATGATGCGGGCGGGGCAGCCGCGCGACGCCTACCGTATTGCAGCACGCAACCGGTTGGCCCAAGGCCAAGACTACGCCGATCT CGAATTTCTGGCAGGGTTTATCGCGCTGCGGAAGCTGGGTGATGCCGATACTGCGCTAAAGCATTTCGTCAATCTGAAAGCGGCGGTG GAAACGCCGATTTCGCTGTCACGCGCGATGTATTGGCAGGGCCGTGCATTGGAAGCAAAGGGCGATGCGGCGGCGGCCAAGACCGCCT ATACAGATGCTGCACGAAATCAAACGGCATATTACGGGCTGCTGGCTGCAGAACGGCTGGAACTGACACTGGATGCTGGACTGCTGTC TGACACCCGCCCATCAGATTGGCGCAAGTCCAGCTTTGCGGGATCGTCAGTCTTTCAGGCAGCGCGTCTTTTGGTGCGGGCGGGGGAT CGCGGCCTTGGAAAACGCTTTGTTCTGCACCTCGCAGAAGGATTGTCGCCGGGCGAGTTGGACCAACTCGCCGACTATGCACTGGAAG CCGACGAGCCGCACATCGCTGTGCTGATTGCCAAGCAGGCCGCAGAACGCGGCATTATCCTGCCCCGCGCCTATTTCCCAGTGACCGA TATGGTACCGGATGATCTGCCCGTCAGCCGCGCCCTTGCGCTGTCAATCGCAAGACGCGAAAGTGAATTTGATGCCGCCGTGATCAGC CCTGCCGGTGCGCGGGGCTTGATGCAGGTGATGCCGGGAACGGCCAAGCAAATCGCCCCCAAGGCAGGTCTGCCGTACAACCCCGGTC GGCTAACCTCCGATCCTGCTTATAACATTTCCTTGGGCTCTACCTACTTACGTCAGTTGGTTGATGAATTTGGACCGGCGATTGCTCT TGTCGCGTCAGGCTACAATGCCGGCCCCGGCAGGCCCCGGCGCTGGATTGCCGAGTTTGGCGATCCTAGACTTGATAGTGTCGATGTT GTGGATTGGGTGGAAACCATACCTTTCACAGAAACTCGCACCTATGTGATGCGGGTGGTGGAAAGCGTTGTGATTTACCGCGCCAAAT TGAAAGGGACCGTCGGCCCAGTGCGTGTTATAGCGGAATTGACGGGGAATTGACGGCCAGTGCTCTGGCGTCTGTCTGTGCCCGTACA CGGCTGCCGCCGCGACGATTGCTGCAAAGAACCGGTAGCGGAAAATCTCAACCACGTCGGCGTTATATTGCCCGGCCAGATGCTGCAC TAAGCCGTCTTCAATGGCGAAAACCAAGATCGCGCCAATCATCAGCCCAATGCCAAGGTGCGTGTTCTGATCGGTCACTGTGGTAGGC CAAGCTCGGTTTTGCCGCGGGTTTGCAGCAGGGCGAACAGACCGGCTGCGACAACAATCGAACCTCCGATGATCACGGGCATGCGCAG CACCTCGCCATAAACCGCGATGCCGATCAGGCTGACCAGTACGATTTGCAGGTAGGCGAATGGCTGCACTGAACTTGCCTCGGCAACT TCGTAGCAGCGGATCAGCAGCCAGTTGCCCAGCAATGCAAGTAGCGCGTACAGCGTCATCCAGAGCCAATCTTCGCCAGTCATCGGTT CCCAATTCGGCAAGCCGATTGCAGTGACCAAGACGGCGCCAATGATGCCGGACCAGAACAAGGCCACAAACGCAGGTTCATCCCGCGT CGTCAGGCGGGTCAGCAGGCTGTAGACCGCGAACATCAAAGCGGCGACGAAGGGCAGTAGTGAGGCGATGGAGAAGACGCCCGATCCC GGCTGCAAAATGATCAGCACGCCGGCAAGACCGGCCCCGATGGCAGCCCACCGTTGCCATGGAATACGCTCACCCAGTAGCGGCACCG 
CCAACCCCGCTACCAAAAGGGGGCAGACGGCAAAGATGGCATGGCTGTTGATCAGCCCGATCAGGGTATAGCCCTGCACAATGGCGCA AACCTCGGCGATCAGCAGGCTGGCGCGCAGTAGGTGCAGCCAGGGGTGTCGGGTGTGAATAACGGCGCGAAACCCTTGCGGTTGGCGC AGGGCCAAGGCCACTACAAATCCCGCGAAGAACCAATAGCGGATCATGATCACCATGAAGGTGTTGTAGGTTTCCGCCAGATGTCGCG AAAAGCCGTCCTGCGCCGCAAAGACAGTAACGGCGGCTATCATCAGCCAGATGCCGCGCTTGGCGTCTTTGTCGGTCATGCTTGAAGT ACCCCGGTAGACATGTGGCGTTTTGTGCCGTAGCCGACGCGACGTTCAACTGCAAAGCCCGCGGCGGCTAGTGCCCTGCGCACATGGC CTGCGGCAGTGAAAGTGGCGAACGTGCCGCCCGGTCTGGTATGGTCGGCGACGCTGTGCAGCAGATCGTCCGCCCATAGATCGGGGTT CTTGGCAGGTGAGAAGCCATCCAGATACCAGGCATCAGCAGCAGCATTCCATGCGGGTAGTGTCACGGTTGCGTCACCGATGATGATG GTTGCCTTTAGGTCGGGCAAGGCAATCTCGGTCTGTCCAGCCGCCCATTGTTCAAGGATCGGGCCAGCCAAACTCACCGCTTCGGGGA ATGCTGCAAGAGCGCGAGCCATATCGGGGCCGGCCATCGGATATGCCTCAAACGAGGTGTATCGGAGTACGCCTGACCCGCCCGCCGC CCGCCAGGCGATCAGCGTGGCAAGCATGTTCAACCCCGTGCCAAATCCTAGTTCCGCCACATGAAAGCCGGGGGCAAAGCGGGCGGGC AGGTCATTGCCGGCCAAGAACACGTGTCGAGTTTCTGCCAAACCGCCAGCAAGCGAGAAATAGGGGTCATCAAACCGGGTCGACACCG GGATAACATCGTCTCGCCAGTTCAGTGTGGCAGTCTGGCGGGGGGAAGTCATATGCCGTAAACCCTTGATCGCGGGCAGGGATCACCA CGACGGTCGGTCGAACAATGGGCAAGGACGCGACGAATGGCAAGACCGGATCTGACCGTTATGGGCGCTGGGATCTTTGGCTTGTCCA TCGCCTGGGCGGCAACCCTTCGTGGCGCGAAAGTACGGGTGATTGAGGCGGGCGGCGTAGGAGCAGGGTCCAGCGGCGGCCCGGTCGG GGCGCTATCGCCACATGTGCCAGAGGCCTGGAATGCGAAAAAGGCGTTTCAGCTTGATAGCCTGCTGATGGCTCGAGATTGGTGGAAT GCAGTATCCGAAACCTCCGGTCTGCCGAATGGCTATGGCCGCACCGGGCGGCTGCAACCGTTGGCCGACGAGCGCGCGATAGACATCG CGCGGGCCCGTCAACGCGAGGCGCAGGTGCTGTGGCGAGGCTTGGCTGCCTGGCAAGTTGTGCAAGTCGGCGGTGCCGCGTGGCAGCC GCATAGTCCGACAAGTTGGCTGGTGCATGATACCTTAAGTGCAAGGGTGAACCCGACGCAGGCTTTGGCGGCTTTGGCGACGGCGATC ATCGCGCGAGGAGGCGAGATTATCATCGGTAACGCTGCCCCGAAGGGCCCGATTGTCTGGGCGACGGGCACCGATGGCTTGGCCGATC TGTCGGCTGATCTGGCGCAGCCCGTAGGCAACGGCGTCAAAGGTCAGGCGCTGCTTTTGCGCCATGATGCCGGTGATTTGCCGCAACT GTTTGTTGATGGCCTGCACATCGTGCCCCATGCCGATGGGACGGTGGCTGTTGGGTCCACCTCGGAAAACCAGTGGCAAGACCCCAAC TCCACAGATGGTCGGCTTGATGCCTTACTCCGAAAAGCCATTGCCGCTTGCCCGGCTCTTGCCGACGCCCCGGTCATATCGCGCTGGG CTGGGCTACGCCCACGTGCGAAGTCACGCGCGCCGGTGCTGGGGATATGGCCGGGGCGGGAGAAGCATTTCATTGCCAACGGTGGTTT CAAGATCGGCTTCGGCATGGCCCCGAAAGTGGCCGAGGTGATGATTGATTTGGTGCTTGAGGGCCGCGATACCATACCACGCGAGTTT CGGGTTGCGGCTAGCCTGACCCGCTAGGCTATCGCATTGCTTCGGCACGAAGGGACTGCATCAGTTCGGTCAGCACCTTGACCGTAAC AGGATCAAGCAAGCGCCCGTTCGTATCAAATGCCTTCCGCGACGAAGCAACCATAACCTCTGGCCCTGCCAACAGTCTTGGTCGAAAC GCCACCATGCAAAGCCGCAATGCAAACTGCGCCCTGTCGCCGCCACCGCGACCATCCGCCGCCGATACAATCGCCACCGGCCGATCAC GCCAAGCGGACCCCGGCACACGGCTAACCCAGTCCAACGCGTTCTTCAGCACGCCGGACAGGGATTTGTTGTATTCCGGGGTCGAGAT AACCACTGCATCGGCGTTCCGAATTTGATCGGCAAGCCGCTGAACCTCGGGTGGAATGCCGGACGCATCTTCCAGATCATTGTCATAA AGCGGCAGTCGCAGATTGGCATCTACCACGTTTGCCGGACCAAAGGCACACGAAGCCTCTGCCAGCAGCAGCCGATTTGTCGATCCGG CGCGCAAAGCACCGCAGATGGTCAGCAGGGTCAGGTCAGTCATGATCGTCCTTTGGGTCGGGCGGTTTGTTGTAGAGTTTTGGTGAAG ACAAGCGTGGTCGGACGATCAAAGCCAGCATGGGTACTGCTGGCGGTTTGCACAAAGCCCAAGGCTTTGAATGTGGCGTGGTTTTCCA CAAGTTCAATGCGGGTCGACAGTTCTAATGCTGGCAAGCCAAGCTGCCGGGCGCGGTCTTCTGCCATGGCAATCAGCGCACGACCATA GCCCTTGCGGTGGTGCGCCGGATCCACCGCCAGTTTTCCCAGATACAGCGCATGCGGCAGGGTCGTTAGAAACACGCAGGCAACGGCG GGTGTGCCAATCGCCCAAACCTCGCCTTCAATGGCCTGTTTGGCAATATCGAGCGCGGTCAAATGATGCAGCGATGACGGCGGGTCAA TGCGCCCCTCCATCCCGGCAAAGGCACGTGCGATCAGATCGCGCAGGGCCTGCCAGTCATAGGGATCAACCGCGCGAAACGGGGTGGT CATGGCAGCTCCTTTCCGGCATTTGGCTTTTCGCCGCCCAACACGTCAAGACAGGCAATATATTGGGGATAACCCGCCGATATGCTCT ATATAGGGTGGCGTAGCGGTTGACAGCCCGCCGCCTTCGCCAGACGATAGGCGACTGTCGGAATCACCCTGGGTACTCGGTTGCGCTT TTCTCGCCTTCGCCTTAACGGCTTCAAAAGCTTTGTCGACCCGACGGATCTGGTGATCCATCAGGGTCTTACCGGCGTGGTTGGGCCA AATGGCTGTGGCAAATCAAACCTGCTTGAGGCTCTGCGTTGGGTGATGGGCGAAAACCGCCCTACCGCGATGCGCGGCGGCGAGATGG AAGATGTGATCTTTGCTGGTGCCGCCACGCGCCCCGCCCGCAACTTTGCCGAAGTGGCGCTGGTGATCGACAATGCCGAACGATTGGC GCCATCGGGGTTCAACGAGGCGGATCAGATCGAAATCGTCCGCCGCATTACGCGGGATGCCGGGTCGGCCTACAAGGCCAATACCAAA GACGTGCGCGCCCGCGATATCCAGATGCTGTTTGCCGATGCCTCCACCGGGTCGCATTCGCCCGCCTTGGTGCGGCAGGGGCAGATTT CGGAACTGATCAACGCCAAGCCAAAAAGCCGACGGCGCATTCTGGAGGAAGCCGCTGGCATATCGGGTCTCTATCAGCGTCGGCACGA GGCTGAGCTGCGCCTTACTGCCACGGAAACCAATCTGGCGCGCCTTGATGATGTGCTAGAGGCGCTTGCCACGCAGCTGGCGACCCTA GCGCGCCAAGCCCGCCAAGCCGCCCGGTACCGCGAAATAGGCGAGGAATTGCGCCGTGCCGAGGGCATGCTGCTGTACCGTCGTTGGC GCGAAGCAGATGCGGCCCGGCTGGAGGCCGATGCCAATTTGCGTGACAGGGTTGTTGCCGCAGGCAAGGCCGAACAGGCGGCGACGGT GGCCACCGGACAGCGCGCTGCCGCCGATGAAGCGCTGCCCGCAAAGCGCGAGGAAGAAGCAATTGCAGCGGCGGTTCTGCAGCGTCTG TCCGTGCAGCGCGATACGCTGGCTGATCAAGAAGCCCGCGCGCAAGCCTTGATCGAAACTCTGCGCGCGCGGTCCGATCAACTGGGCC ATGATATAGAACGCGAGGCTGGCCTTAATCGTGATGCGGTTGAAACCATCACGCGGCTGGAGTGGGAACTTGATCAAGTTGCCCGCGC CCAGGAAGGCCATGAAGATCGGCTAGCTGACGCGGTAGAGGCGGCGCGCCTTGCGGCAACCGCCCTGACAGACCATGAAACTGTGCAG TCGCAAGCCACCGAAGATGCGGCGCGGCTTGCAGCGCGTCACCAATCCGCACAACGGTTGCTATTGGATACCCGAACCACGGTTGAGC GGACCGAAGCCGAAGCCGCCAGTGCAAACGCCGCTGTTGGCGCTGCGGAGGCTGCCCTTGCCACTGCTGCTACCGCATTCGAGATGGC CGAAGAAGCTACTTGTGCCGCCGCTGCATTGGCCGAAGCCGCGGATGAGGCTTTGGCCAGCACCGAAGTCGCCCGCGCCGATGTTCAG GGACGCGAAGCCGAGGCGCGTGCGGCAAGGTCCAGTGCGGAAGGCGAGGCGAACGCGCTGCGTGCCGAAGTCGCCGCCTTGGCGCGTT TGGTGGAGCGTGAAGCCCTTGCCGGATCGCAGATCATGGATCTGTTGCAGGTGACACCGGGTTATGAAGCGGCCTTGGGTGCCGCCTT GGCCGACGATTTGCGCGCACCTGAAGTGACCAAGGATCGCCGGTCTGGCTGGGCCCTTTTAGCCGACTACGCATCGCCGCAGCCCCTT CCCGACGGTGCGCAGCCATTGTCAGTATGGGTCAAGGCGCCTGCCGTTCTTGCCCGTCGCCTTGGCCAAACCGGCCTTGTGTCGCGCG CTGACGGCCAGCGTTTGCAAGCCGACCTGTCGCCGGGGCAGCGGTTGGTCAGCCTCGAAGGCGACCTTTGGCGGTGGGATGGGCTGCG CGCCGCCGCCGAAGACGCGCCGTCCGCTGCTGCGCTGCGACTGCAACAGCTGAACCGCTTGGTCCTGCTAAAGCGTGATCTGGAAGAA GTGGCGGCCCGAGCCGAAGGCGCGCGCCAGGCCCATGACGCATTGCATCAGCGCCTTGCCGATCTGGCCCGCGCCGATCAGCTTGCCC GTGATGCCCGTCGTGCCGCCGACGCACGGGTGACCGAAGCCAGCCGAACCGCTGCACGGGCCGAGGCCGACAGATCCATCGCTGGTGG CAAACTAGAGGCCGCTCGCCTTGCCGTAAGTCGGTTCGAAGACGAAGCGATGGCCGCCCGCAGCCGCCTGCGCGAGGCCGAAACGGCG GTACTTGGCCTGCCCGATCTTGATGCTGCCCGCGCCGCTGGCGAAGCCGCGAAATTCGCGGTCGAGGCGGCCCGCATTACCATGCTGA CGCGCCGTTCAGCCCATGATGAATTGCGCCGCGAAGGCGAGGCCCGCACCAAGCGTCGGCAAGACGCCACCAAGGAACTGTCAGGCTG GCGGCACCGGCTTGAGACGGCAGAAAAGCGGTCCAGCGAACTTGCTGATCGCAAAGCCACCACCGAGGACGCGCTGGCCGAAGCAGTT GCCGCCCCGGAAGACATCGCCGCCATGCGCGAAGATCTGAACGATGCGATGGACGCCGCCGAGGCCCGCCGTCGCACCGCTGCCGATG CATTGGCCACCGCAGAAGCCGCTGCGCGCGACGCACATCTTTCTGAACGCGACGCCGAGCGCGCTGCAGGCGAAGCCCGCGAAGACCG CGCCCGTGCCGAAGCCCGCGCCGAGGCTGCACAGGAAACGGTTGTTCTGACCGAGGCGCGGATCGCCGAGGAAACCGAAGCAACGCCA ACTGACCTGCTGGAAAGCTTGGCTTCTGACCCCGAGACCATGCCTGATGCTGAAACCTTGGAAACCGATGTAAACCGCCTGAAACGGC AGCGCGAGGCGTTGGGTGCCGTGAACCTGCGCGCCGAAGAAGATGCGAAATCGGTGCAGGAAGAACATGACACTTTGCTGCAGGAAAA GACCGACCTTGAAGAGGCGGTGAAAAAGCTTCGCTCGGGCATTTCGGCCCTAAACCGCGAAGGCCGCGAACGGCTGCTGACTGCATTT GAACAAGTGAACGCCAATTTTGCCACGCTGTTTACCCATCTTTTCGGCGGAGGCGAGGCGCGCTTGGTGCTGGTGGAAAGCGATGATC CGCTTGAGGCAGGGCTGGAGATCATGTGCCAACCGCCGGGCAAAAAACTGGCAACCATGTCGCTGCTATCGGGGGGTGAGCAAACGCT GACCGCCCTTGCCCTGATCTTCGGCGTGTTCCTGGCAAACCCGGCCCCGATCTGTGTCCTGGACGAGGTTGATGCGCCGCTTGATGAT GCCAACGTCACACGCTTCTGCGATCTGCTGGATGAAATGACCCGCCGCACGGATACGCGTTTCCTGATCATCACTCACCACGCCGTCA CGATGGCACGGATGGACCGGCTGTTCGGTGTGACGATGGCCGAGCAGGGGGTCAGTCAGTTGGTGTCAGTGGACTTGAAAAAGGCCGA 
GGCGTTGGTGGCTTGAGTGGCGGCGTTTCCTGATAAATTACCCACTCAGATATCGCATTTCGTTAACCAGCACAGCCTACCCCTGTCC CTGCTGCGACCCTTCGCAGTGGCAGGAGGTGAGGAAACTGAATGAAGTGAGCTATCGGAAATGGATGGTGGTTATCGGGGCAGCAATG CTTCTGATTGCGATCATTCGCCTTTGGATCGGGATCTGATCCCGAATAAAAAGGTGACCCGGCAGAGTGGTAGCTCTGCTGGGTCGTT TTATTGATGAGAAAGCTGAAAGTTGAACTACCGATACTCAGTATCGTAGAGATATCTTAAGCCTTCGTAAAGCGTGCCGTGGCCCTAT GGTTAACGCCGCACCATAATCCGGTCCGTCGCCCTGACCTCGCCGTCCTGCTCAATCGAACACTTCACCGCAATAGGCGCATCGATTT TGGTTGCTGCCAGCACATGTGGCATGCCATGGCCATCGTCATCTGCAGCGGCGCGCGGTACTTTCGGGCCAGTCATCTAAAGCCTATC CAACAGCTCCGCCGTCGGCCAGGCATCGGCAGGCAACCCAAGACGCGCTTGTTCTTTTTGCGCGGCGATGCGGGTTTGTGCCCCAAGA ATGCCGTCGATCTTGCCGACCTCATGCCCCATGGCGGCCAGCTTTTGCTGCAACACCATCATTTGGTCCAACGACAGGGCCGGGTCCG GATCGCCAGAAACATAGACATCGGCACCTTGCAGCCGCGTGGCGAAATAGGCGGCGGTGGTTACGTAGACGAAGCTTTTGTTCCACTC AAACAGCACCCTAAAATTTGGATAGGCCAGAAACGCGGGTCCGTTACGACCTTGCGGCAACAAGACCGACGCCGTTATTCGACCCTGT GGTAGTTCCGTGCCACGCGCTGCCACGCCCATCGCCGCCCAATCTGCCACGGAAAGCTGCGTCTCCAGCCCGGTTTTGGCCCAATCAA GATCCTCTGGCAAGGTTACCTCTTGCAACCACGGCTCGCCGGAACGCCAGCCCAATGATTGCAGCATGTTAGCCGCTGACAACAAGGC ATCTGGCGCAGACGTTTTCAGGCTGATCACGCCGTCACCATCGCCGTCAACGCCACGTTCCAGAATATCTTTTGGCAACATTTGCACC ATGCCAATTTCGCCCGCCCATGCGCCGATGGTGTTGGCGGGGTCGAACATGCCTCGGCCCGTCAGATCAATCGCTGCGAAGATTTGCG GCTGAAACAGCTCTGGCCGCCTGCAATCTTGCGCCAACGTGACCAGCGCGTTGCGCGTGTTGAAATCACCCTGCACGGTGCCGAAGTC CGTCTCGAACGCCCAGAACGCCAGCAATATACCGCGCGGCACACCAAACTCGGCCGCCGCTCTGTTGAACACGCTGTCCCATTTTTGC GCCAAAGCTGCACCGTTGCTGATCCGGCTTTGGCTGATCAGCGCTTTTGAAAACTCAAGGAAAGTCTTGGGAAAGACCCCTTGCGATC GGTCTGCTTTCAGAACCTTCGCATCCACCGCAGCCCCGTCAAAAAACGCGTCAATGTCCGGTTCTGCCAGCCCCTTCGCCAAAGCTTC GGCCTTCATCGCCGATACGAAGTCGGAAAATTCAGCACCACACGGCGCACCAGCGACGGGCGAGGCCAATAGCAAACACAGCAACACC AAACCTAATCGCATTAACGTTTCCTTCAGCTGTCTTAGGACAATCAGATCAGACTAGTCAGGGCGATCACTGCGGTGCCAATAAAAAT CACAACCCAGCTGCGCCAAAGTGCTTTCACGCTGGCATCTACGTCATCCGGCCCTGCGTCGCGCCGGCCTTCGGGATAGACAAACGAA AAATCCGTCATCACGCCGTTGTAGCTCCGCGGGCCAGACAGCGACAGGTTCAGCACGACGGCCATCGCTGCCTCTGGCCAGCCGGCAT TGGGCGACCGATGCAGGGCCGCATCGCGGAGGATGGGCTTCGCTGTATCCCACCGCCCATGGGCCAAAACGATGATCAGCGCAGTCAG CCGCGCGGGCACCCAGTTCAGAAGGTCGTCTAATCGGGCGGCGGCCAGCCGAACTGTTCATAGCGCGGCGTACGATGGCCAATCATG CTGTCGGCGGTATTGGTGATCTTGTACAGCATCAGCCCCGGCAAGCCGCCGATCAGAAACCAGAACGCAGGCGCAATCACCCCGTCCG ACAGGTTTTCCGAGGCGCTTTCGATCGCTGCGCGGGCAACCGCCGCCTCATCCATCGCGTCGGTATCGCGGCCAACGATCATCGCCAC GGCCCGCCTTCCATCGCCCAAAGATATCCGCAGCGCATCGGCGACGGTCTGCACATGCTGCACCAAACTGCGCTGCGCCAACAACATC GCGGCGGCGATCACTTCCAGCGCCCCGAAATCCGGCACCAGATGGATCAGCCAACCCAGCAGCACCGCCACGATGGCAAGACCAACCA TCGCCACCAAGCCCTTTAGCTTTCTTTGCGCTCCGCTATTCAAGCGCTCGTCGGCAAATGCGACTGACCGCCCCATCAGAACCGCTGG ATGCGGCAGGCGCGACCATAGCCATTTCGGCTCGCCCAGCGCGGCATCCATGGCCAGCGCGGGCAACAGCAACATGGCACTCATCGCC CTGTCTCCAGATGCTCAAGCGCGTTGGCAAGCCGCGCCCAGTCGTTGGCTGATCCAGGCAGGCCAAGCCGCAACCAGCCTTTGGAGTA TGGGAAAATCCGCGTCCATATTTGATGACGTGCCAGACTATCCTGCCACCGCGCAGCATCTTCAGTATAGTATAATCGAAACAGGTTG GTGCCGCCTACAAGTTTCGCCCCAACTGACGTGACCAACCCGTCCAGCCGCCCTGCGTCGACCTGCAGCCGTCCTCGGGTTCGCTCGG CCCAGCCCGTATCAGTCAAAGCGGTCACCCCAATCCTTAGGGCCGGGCCAGACACAGGCCACGGACCCAGCATCTGTGACAATCGCGC AATCAACGCAGCATCGCCGATTGCAAAGCCAAGCCGAAGGCCTGCCAGACCCCAGAACTTGCCAAAGCTTTTCAGCACGATCACACCG GGCCGGGCTGCCGCAGAAATCAGGCTTTGGCCGGGCATCACATCGCAAAAGCTTTCATCGATGACGCATAGGTCGCCCGTTACATCAG AGTCCGCCCAGACCCGCCCATCAGGATTGTTCGGGTGCACCAGCACCGCTGCGTTGCCAATTTGGTTTGGCTGCACATCCCATCCCGC CGCCGAAAATGCGCGGCTATGCTCGTTATAAGTCGGATCCGGTATCCGCACTCTTCCGGGGTTCTGTAGAGCCGGAATGCGGGCAATC AAGGCAGATGCACCGGGGGCGGCAAGCACTGCGGCACCATGGGGCACGTGCCAAAACTGCCGCGCCGCTTGTATCAGGGCATCTTGCG CTACGGCGTCGGGCAGGGTGCACCAATCCTTGGGCGAAAGCTCCGGCACCCGGTAGGCAACCGGATTGATCCCGGTCGATAGATCAAC CCAAGCATCGCTGCTACCGCCGTACAGCCGCACTGCCGCATCAACTCCACCGCCGTGATCAGGTGCCTCAGCTTCCACGATTTGCCCT CGTTTCCGCGAATCGGAAGGGACGATTCGCGATCCCAGCCATTAGTTCTTCAGCGTGAAAAATATTCTGGTGTGTTTCTGCGTCCCCA ATGGCCTGCGCAGCTCCGTCGTTCAAAACGCCATTCGTTGTTGGTGATTTCCGACCGTCGCGTTGGCGATCACTGCGCCCCAAAGGGC GCTCGGATGTCGCCGTTTCTCGCAAGAAATACCTGCCGGTCCACACGCACGCATAGGGACATCTGCCTATTGGACACTCAACCTCTAC CATATCTTTGGAAGGGATGTTTGGACCGCATAAGCGGTTGCCGGACGCCAAAATTGCCGGCATTGCAGCGGGGGGGCTGTTGGGCAAA TGGGTCATCAATTCGCGCGCTCCGGTTTGGCGATCAAAGACCCTATTCTTGCGCTTAGCGCAACCAAACTGGCGCTACACTGCGGACG TTTTTGGCCGACACCGCGGCATGTTCGCTGCTACATCGCGCAATCCTGCCACCCAACGTTTCACAAGCCCAAACAATCACCAGCTATG TAGCTGGATTATCTTCATTTTGATATCAACGCCCTGACGGTGTGGTCTGCGTGCCAACCTCAGCCCGACTTCATCGCAATCACGGCCT CGCAGCCACGCAAGGTAAGTGATGCGCCTAACCCAAGCAAACCGATGTCCCAACGAGGGAGCAGATACTGCAACAGCAGACACCGTTC GCAATGCCTCTCAACCCAAATTAGCTGCCTTGCCCAAGACGCCGGAGCGATCAAAACCAAGTGGGAGGAAATGTCGCTTTTGATGGCC AGCGAGGGCTAGAGGCGGACAACTCTGGCCTTACGACATGCCGCGAGAGGCGGCCAATCTGCCCGGCGCAGAGCCCGATCAAATACAG ATCTTTTCGCAGGGCCCCAACGCCGCCCGACGTGACTTTTTCGGCACGCATCAGCCTGTTTCAAAAACCGTTTATTCTCTGCCTTGAT TTTAACCATTTGCGGTTCACACTTCGGATCAGGAGACTGCCATGTTGGAATTTTTCTCGAAGGAACTGCGTGAAGGGTTTGAGGCGGC GCGCAAGCGGCAAGACGCCAAAAAATCTCGTTTGCGGCTGCAAATTGGTGCCGAGGTTTATCCTATTCTGCGCATCTGGGATGATGGT TTGGCCGTCGACGCCGACCATATCTCGCACCTGCGCGGGTTGGTCGACGTCTACGATGGCGCGCGGCATCTTTCGCAATGTCTGATCG TGGCGTCCACTGTCGAAAATGGCCAACTGATTTGTGATTTCAAGCGATCAACGCTGGTCACAGATCGCGCTCCGCTAGATTTCTGGCG TGACGAAAACGCGCCTGTCGGGTATCTGCCCAGCAGCTGACCTATGGCCGCACATCCACCACTGCGCCACTAGCGGTAGCGGCAAAAA TCTCCCGTATCTCGACATTTGAAACGGCGATGCATCCAGCCGTCCAGTCGCCCTTCAAAATCATGTCATCTGGCAGCGCGTTGGGCTG GCCATGGATGAAGATATCCCCGCCCGGATCATAGCCGCCCGCCGAAGCACGCTGCGCGTCAGCTGCTTGCGGATAATCAAGCCCAAGT GACAGATGATAGCTGCTTTGCGCATTCAACCTGTCGACGCGAAACCGCCCCTCCGGCGTCTTGCCATCGCCTTGGCGCATCTTCGCCC CCTTGGGTGAAAACCCCAAGGCAATGCGGTATTCACGCAGCGCTTTTCCGTCGCGGTAAACCACCATGCGCCGGGCGGATTTTTCAAC CACGATCCGGTCAATAGGCCCGACCAATGGCGGCAAAACCGGCGTAGGCGCGGTATCTGGACGCTGCAACAACAGCGCCGCACCCGCC CCGATCAGAGCAAAGAATATCAGCTTTCGGCGCAGCCATCGGATCATTGCAGATCGGCAAATGCCGCTTGCATCCGCGCCACGGCATC AATGACGTTGGCCCGTGTCGTCGCGATGTTGAAGCGCAGAAAGGTATCACCGCCCGCCCCGAACGTCGGCCCGTAGTTGGTCGCAATT CCAGCAGTCTTTTCGACCCGAGCGATGAATTCATGTGCCGTCATTCCAGCACCGGCAAAATCGACCCATGCCAGATAGGTCGCATCCA GCGTCATCGACCGCAGCCCCGGAATGGCATTGATCCCGGCATCGAAAATCTGCCGGTTGGTTTCCAGATAGCCCATTAAACCGTCCAG CCATTCTGCGCCTTCCGGCGAATAGGCGGCGGTCACCATGTGCATTCCGAACGAATTCGGCGAAAGGCCAAGAGCATTCACTCTTGCG GCGAACGTTGCCCGAAGTTTAGCGTCCGCGATAATCACATTGCCGGTATGGCAGCCCGCAATGTTGAAGGTTTTTGTCGCTGCCGTCA TCATCACCAATCTATCAGATATGCCCGGCGCGACATTCGCCATGACGTAATGTTTTTGGCCGGGGAACACCAGATCATGGTGTATCTC GTCCGACACCAAGATCAGATCATGGCGCTGGCAGAAATCTGCGACACCCTGCAATTCGGCTTCGGTCCAGACGCGCCCGCCCGGATTA TGCGGCGAGCACAGAACCAGCATCTTTTCACGCCCCGTTATCTGGGCGTCCCAAGTTGCAAAATCCATCTCATACCGACCGGCGTTTT GCGCCAGCTTGCACTCTACTACCGCGCGCCCACCTCCCTTAATGACACGGGCAAAAGCATGGTAAACCGGGGTCATCAGGATCACCCC GTCGCCTGGCGCGGTAAACGCATCAATACAAAGTGCTATGCCATTGACCAAGCCATGGGTGGTAAAGATCGTCTCCTTAGCCACATCC CAGCCATGCCGAGCCTCCATCCACCATTGGATGGCCGCGATATACTTCGAATCATCGCCGAAATAGCCGTAAAGCCCGTGTGCGGCCA TCGCCTCGACCGCTTGCTGCACAACCTGCGGTGGCCGAAAGTCCATATCCGCAACCCACATGGCAAGCCCGGTCTGTGGCGAAACACC GTATAGCTTCTCCATCATGTCCCATTTTGAGCAATGGGTGCCTACGCGGTTGATCGGTTCGTCGAAGCTCATGGTCTGTCTGCCTATC TGTCGCACGATCTGGTGTTCCGTTGGATGTAAGACTTCTGGAATATCATTCTGACTAACTGATCTCAAGCCATACAATGTTCTGATAA 
ATCGGCAAAACACGGTACATCATCCTGAAGTGCTGCCGATCCTACCTACCATCAATAACTGTCTGCCTTGCACTTGCAACATTGTCCC CTGCGCCGTAAATCGGAAAATATGATCCGATCCATCCTGATCCACCCCGATCCGCGTCTTAAACGGCTTTCCGATCCAGTGACCGAAA TTTCGGCAGAGATGGGAAGGCTGGCCGAAGATATGCTTGCAACCATGTATGATGCGCCCGGCATTGGCCTTGCGGCACCGCAGGTTGG CGTTAACAAGCGCATGATCGTGATGGATTGTGTGAAAGACCCTGATCTTGCGCCGCGCCCCCTAGTGTTGATCAATCCCGAAATTACC TGGGCTTCCGAAGACCTTGCCACCTACGAAGAGGGCTGCCTTTCCATCCCCGATCAATACGCCGATGTCGAACGGCCTGCCGAAGTTG CGGTGCGGTGGACAGGGCTTGACGGCAAACCCTACGAGGAGCAGTTCGCCGGCCTGTGGGCAACCTGCGTGCAGCATGAAATCGACCA TCTGAATGGTAAGTTGTTCATTGATTACCTGCGCCCACTGAAGCGCCAGATGATCACCCGCAAGATGGAAAAGCTTAAGCGCGAACTG GCGCGCGGCTGATGCCCACACGCGCGTTCTTGCAGTGGCCGCACGCCTGCCTTTCGACCGCTGCGGTTCCAATTACCACAATCACCGA TGACGTTCGCGCCATATGGGCCGATATGGTCGACATCATGGACGCGATGCCCGGCTATGGCCTTGCCGCACCGCAAATCGGCGTGTCG CTGCGTCTTGCCGTCGTCGATTGTTCGGATGACCGTGGCCAGGCGATCCTGATGGCCAACCCCAAGGTTTTGCATGCCAGCGGTCAGT TGCGCGAGCATGACGAAGCCTCGCCCAACTTGCCCGGTGTGTCTGCTGTTATCCTGCGACCACGCGCCGTCACCGTGCGGTATTTGAA CGCGGACGGGGTGATCGAAGATCGTGATCTGGTCAACCTTTGGGCCACGTCAGTGCAGCATCAGATCGACCATCTGAACGGCCACATG TATTTCGACCGCCTGTCGCCGCTAAAGCGCAAGATGCTGATTGCAAAGGCGGAAAAGTTGCGGAGGCGGACATGAGGATTGTCTTCAT GGGCACCCCCGATTTTGCCGTGCCGATCCTTGAAGCGCTTGCTGCCCACCATGATGTGGTCTGCGTTTACTCCCAACCGCCGCGTCCC GCTGGCCGTGGCAAGCAGGATCGGCCCAGTCCGGTGCAATTGCGGGCACAGGCCTTGGGTATTCCGACACGGCATCCTACCAGCTTGC GAACCCCCGAAGTGATCGCCGATTTCACCGCCCTGAATGCCGATATCGCCGTTGTGGTCGCTTACGGTTTGATCCTGCCGCAGGCCAT TCTGCATGCCCCCGCGAGGGGCTGCCTGAACATCCACGCCTCGCTTTTGCCGCGTTGGCGTGGTGCTGCCCCGATCCACCGCGCAATC ATGGCTGGCGATACAGAGACGGGAATTTGCATCATGCAGATGGAGGCGGGTCTGGATACCGGCCCTGTTATGCTGCGCCGGTCGATCC CGATCAGGGCCGATGATACCACCGCCGATCTGCACGACCGGCTTGCGACGCTTGGTGCGACGTTGATCATAGAGGCGCTGGAAACGCT GCCCGAACCACTGCTGCAATCGGCCGACGGCGTGACTTATGCCAACAAGATTGACAAGGCAGAGGCGCGCGTTGACTGGACTCAGACC GCAGTGCAGGTTGATCGCCAAATTCGCGGCCTCTCGCCATTTCCCGGCGCATGGTGCGACGTGGCGGGTGAACGGCTAAAGCTGCTCC GTTCGTGTGTTGTGGATGGTGAAGGTGCGCCGGGACAGGTTTTGCACGGTCTGACCATCGCGTGCGGGACGGGTGCGGTTGAAATCAC CCTCGCGCAGCGCGAAGGCAAACGCCCGATGCTGCCCGAAGATTTGCTGCGCGGATGGGTTCTGCCGGATCGGCTTTCTTGACGGAAA CTTGCAGGTGCGCGTCACAGAGCGGTCGGCGATGTGGGTTGGCTGGATACCACGCCCACACCAATCCGCGATCTGTTGTAAAACATCG ATCTGACACCGAGGCAATGAAACCGGGATTGCAGATCGGACTGAGGAAGAGCGCGTCGGGTGACTTCGCCACCATCGGGCAGGCGATG CTGGCGAATCTGCGCCATGACATTGCAAGCCAACGCGTCATTACCTAAGTCTGTTGCCAGAGCGGATCGGAGAGAGTGATGCCTAGCC TCATTTTGGTTGCAATCATCGGTGCTGCGGCGGGCTTTTTTGCCACCCGGTTTATGCGGGTGCAAACTGACGTGCCAACAACAGTGGT GATCGGTATTGTGGGGGCGGTCATCGGCTCGACCATCTTGCGGTTCTTGGTCACGGTCACCGGCATTACCGCTTATTTTATTGGCGCG ATCCTTGGGGCTATGGTGCTGATATGGGCATGGCGGACCTATATCTCTAAGTAAGCTGCTTCACCGCATCTTTGATCTTAAAGCTTTT GCCACCCGCAATTTGCCACAGAAGTTGGCCCTGCCAAGCGGCAAACAGCATCGCCGCTTTTGCGCGCGCCTTTGTACCACGACCAAGC TGTGAACCCAACGTCGCTTCAACTGTTTGACGCCAGGCTTCAGCCCGCTTTCGCAAGACTGCATCACGAAAGTCCATCGACAGGACGG CAAGGTCAAGCGGCTCTGCCTGATCACCACTCAATGATTTCAATAGATTATGCGCGCCCTTGGCTGAGAATTCAGCACTTGCAATCGC TGCTGCAGTCGCCGCATCCAGCGCATCCCATCCCGCTAGATGCGCCGCACGGATCATACCCGCACGCGAGCCAAATCGTTGCACCAAG GTTGGTCCGGCAAGCCCTGTAGCCTGCGCCACGGATGCAAATGCCACGGCCTTTTCGCCACCAGCAAGCAACAATCTGCGGATTGTGA GGAAGATTTCTGCATCGGAAACAGTTCTTGAACGGCCCATTACAAATATGTAAACGAACGTAAGTTTATATTCAAGTTCTTGAAAATC TGATGCCCAATTATGTGCTAGGGTGGCGTCGAAAACTCCAACCCTCAGTCCACTTTCACTGTTTTGAACGGTGCCATGCCGGCTCGCG CCAATTCATCTGCACGCTCATTTTCAACGTGCCCCGCATGTCCCTTGATCCATTTCCAGATCACCGAATGCCTCCCCCGCGCCGCATC GAGCCTCTGCCACAGATCGACATTCTTTACCGGCGGCCCACCCGCCGTGCGCCAGCCCTTACGCTTCCAGCCATCCATCCATTCGGTG ATGCCGTTCTTCACATAGGCACTGTCCGTCACGATGGTGATCTCTGATGGCTTCGACAGCGCTTCTAGCGCCGAAATCGCCGCCATCA GCTCCATCCGGTTGTTGGTGGTCAGCGCCTCGCCACCCTGAAGGGTGCGCTCTTTCACCACCGCCCCACCCTCACGCGCCAGCATCAA AACACCCCAACCACCGGGGCCGGGGTTGCCTGAACAGGCTCCGTCAGTATAGGCAAATAGGTCTGGCATCGTTCTCCTTTGTCCAAAT ACTAAATCAACGGATGCCAGATGGCCCGACGAAACGGTCAAGCAAGTTCCCGCAGCACACGGGGCACTTTAAATTCCACCGCTTCACG CGCGGTTTCGACCAGTTCGACGGTCACGTCATGCCTTGCACGAAAAGCCTCGATTACCTCGTTCACCAACACCTCGGGCGCTGACGCC CCTGCGGTGATGCCAACTGCGCCAATCCCGTCCAGCGCCCGCCAGTCGATATCTGTCGCGCGCTGCACCAGTTGCGCGTAAGGGCAGC CCGCGGCGCGCCCGACTTCGACCAGGCGCTGCGAATTTGACGAATTCGGCGCGCCGATCACCAGCAGGGCGTCGATCTTGCCCGCGAT TGCCTTTACCGATGCCTGCCGGTTCGTTGTTGCATAGCAGATGTCTTCCTTATGCGGCCCGACGATGGCGGGGAACCGGGCTTGCAGC GCTGTGACGATCCCTGCCGTGTCATCCACCGAAAGCGTGGTCTGGGTGACATAGGCAAGCCGCCCTTCATCGCGCACCACAAGGCGCG CCACATCACCTTCGGTTTCCACCAACAAGACCTCGCCTGGCGGTAGCTGCCCCATGGTGCCGATGGTTTCGGGATGGCCCTGATGGCC GATCATCACCATCTGCAGGCCGTTCTCAAAATGCCGTTCGGCCTCCACATGTACTTTGCTGACCAAGGGGCAGGTCGCATCAACAAAT ACCATCTCACGCCTTACTGCTTCCGCCGGCACCGCCTTTGGCACGCCATGGGCCGAAAAAATCACCGGCCGTCCTTCGGGCACGTCAT CCAGTTCTTCGACGAAAATCGCACCCAGCGCGCGCAACCCGTCGACTACAAATTTGTTATGAACAATCTCATGGCGCACATATACCGG CGCACCCCACTTCACGATTGCCATCTCGACAATCTTGATCGCCCGATCAACGCCAGCGCAGAACCCGCGTGGCGCAGCAAGATAAAGT TTAAGCGGTGAACGGGTCATCATGGCCTCGACAGACTTTCCCAAGACCTAGTGCCAAGCATTCCTCAGGTCTACCCCCGACGGCATCA CCTTGGCCGACAAACAGACAAGAAAAAACCGGGAAGCGTTTCCGCAACCCGGCAGGTCAGTCGTGTCGGCAAGGTCTTACTTCGCCTC GATCGACATCTCTTCACGCTCCAGCCTTGGCTCGCGCGGAGGGCGACCAATCACGTCACGCAATTCATCCAATTCGATAAAGTTATCG GCTTGGCGGCGCAGCTCGTCGGCAATCATCGGTGGTTGGCTGCGGATGGTTGATACCACCGAAACACGCACGCCTTGACGCTGCAGGC TTTCAATCAACGGACGAAAATCCCCGTCGCCCGAGAAGATCACAATATGATCGACGCGCGGCGCAAGTTCCATGGCATCGACCGCAAG TTCGATGTCCATGTTGCCCTTGACCTTACGTCGCCCTTGGCTGTCGGTGTATTCCTTCGCCGGTTTGGTCACCATGGTGAAGCCGTTG TAATTCAACCAATCCACAAGCGGGCGAATCGGGGAGTACTCGTCATTTTCCAGCAAAGCAGTATAGTAAAATGCACGCAGAAGCTTGC CTCTGCGCATGAACTCGGAACGTAACAGCTTGTAGTCTATGTCAAATCCCAACGCCTTTGCAGCGGCGTACAGGTTTGATCCATCAAT GAACAGCGCAAGCCGTTCGTCCTTGTAAAACATACCCCAGTCCCTTCAAAATACTGCTCTCCAATCGATTTTCCGTGAGCGGACTACG TTAATGTAGTTAAATGCGATGGCGAACAAAGGGGAATATCGCCCAAATATTCCCCATGGCAAGCGTTTCTATACGGAAGTGTAACACT TAAGATGGTTCAATTACAGGCTGCCCTTCTTGCGTTTGGCGCTAACCTGCCTTTTGGCCGACCTGATGCCCATTCAAACACTGCATTTG GCAATAACCAGTTTCCCTGACGTCAATTTGCCATTGCCACAGGTCAGTCGGTTTTTCGCAACACCCTGTTTTCCCGCCGGCGCCGGGC CAGATTACGTCAATGCTGCTGCTATACTTCAGGTTGCAAAAGATATGTCACCGACTGAACTGCTGTCCCGGCTTCACAAGATTGAGGC CAACTTTGGCCGCCAGCGGACGCAGCGTTGGGGGATGCGGACGCTTGATATTGATCTTCTGGCACTGGGCGACGCCGTTCTGCCCGAT GCGGCAACCCAAACCCGCTGGCGCAATCTTGATCCACGCCTGCAGGCCACCCAAACACCGACTGATCTGATCCTGCCGCATCCCCGCA TGCAAGATCGGGCTTTTGTTCTGGTGCCCTTGGCCGATGTGGCCCCAGAATGGCGGCATCCGCTGTTGCACCTGACAGTCACTGAAAT GCTGGCGGCCCTCCCTGCTACCGATGTCGCTGAAATGCGCCCACTTTAGCCGTGGTAACCTGCCCCGATTCAAGACTTGTCAAGCCAT TAGTCAGCGCTTACATAGGCCGCTCCATATCCATAGCCTGCATTGGAGTATCCCATGGCCCGCGTGACGGTCGAAGATTGCGTTGACA AAGTCCCGAACCGGTTCGAACTGGTGATGCTCGCCGCGCATCGCGCGCGTGAAATTCAAGCAGGTTCTGCGGTGACAGTTGACCGCGA CAATGACAAGAATCCGGTTGTGTCGCTGCGCGAGATTGCCGACGAAACCCAAGGTGCCGAAGATCTGCGCGAGCGGATGATCGAAAGC TATCAAACTCAGATCGAGGTTGATGAGCCTGAAGAAGATCAGATGGCGCTGCTGATGGGTGGCGAAGTTGACCGTCCGATGACGGATG ATATGTCCGAAGAAAAGCTGTTGCGCGCATTGATGGAAGCGCAAGGCGATAACTAAGACCGGGATGCCCGGCAGGATGCGACGAGGAT GATCGACGTAGAAGACCTGATCGCCCTCGTCCGCAACTACAACCCGCGCACCAATGTCGATCTGATCCGCCGGGCTTACGCGTATGGC CTGAAGATGCACGAAGGTCAGCTGCGCCATTCAGGCGAGCCCTACTTTACACATCCCATCGCCGTTGCCGCCATTCTGACGGAACAGC GGCTGGATGATGCAACCATCATCACCGCGCTGCTGCACGACACCATCGAAGATACCAAATCGACCTATACCGAAGTCGCCCGCATGTT 
TGGTGACGAGGTCGCAAAGCTGGTCGATGGCGTGACCAAGCTGACCAACTTGCAACTATCATCGGCCCAAAGTCAGCAAGCGGAAAAC TTTCGCAAGCTGTTCATGGCGATGTCCGAAGATTTGCGGGTGATCTTGGTCAAGCTGGCCGACCGTCTGCACAACATGCGCACCATAA AATCCATGCGCCCCGAAAAGCAGGCACAAAAAGCCCGCGAGACGATGGAAATCTTTGCCCCGCTTGCTGGTCGCATGGGTATGCAGTG GATGCGCGAAGAGCTGGAAGACCTGGCCTTCAAGGTGCTGAACCCCGAGGCGCGCAATTCCATCATCCGCCGCTTCATCACGTTGCAA CGTGAAACGGGCGATGTGGTTCACAAGATTACCGCCGATATCCGCGCCGAGTTGGAAAAAGCCAAGATTGACGCCGATGTGTTCGGTC GCGCGAAAAAGCCCTATTCCGTCTGGCGCAAGATGCAGGAAAAGGATCTCGCCTTTTCGCGACTGTCCGACATCTACGGCTTTCGCAT CATCGCGGCGTCTGAGGCGGATTGTTACCGCATCCTTGGCGTCATCCACCAACGCTGGCGCGCGGTGCCGGGCCGGTTTAAAGACTAT ATCAGCCAGCCAAAGAACAACGGCTATAGGTCCATTCATACCACCGTCTCAGGTCGTGATGGCAAACGGGTCGAGGTGCAGATCAGAA CACGCCAGATGCACGAAGTGGCCGAGGCGGGCGTCGCCGCTCATTGGTCATACCGCGAAGGTGTGCGCGCAAAGAACCCGTTTGCGGT AGATCCGGCAAAATGGATTGCCACCCTGACGGAACGCTTTGAAGAAGGCGATCACGACGAATTTCTAGAACACGTGAAACTGGAAATG TATTCTGATCAGGTGTTTTGCTTCACCCCAAAGGGCGATGTCATTCAGCTGCCGCGTGGTGCCACGCCGCTTGACTACGCCTATTCGA

\subsection{Das Cosmid slc_1p}

\subsubsection{Lage der offenen Leserahmen (ORFs)}

\begin{tabular}{|c|c|c|c|c|}
\hline ORF & Annotation & Start & Stopp & $\begin{array}{l}\text { Orien- } \\
\text { tierung }\end{array}$ \\
\hline 501 & COG0205: 6-Phosphofruktokinase (EC 2.7.1.11) & 83 & 1279 & - \\
\hline 502 & Hypothetisches Protein & 1289 & 1744 & - \\
\hline 503 & Uncharakterisiertes Protein mit unbekannter Funktion (COG4198) & 1897 & 3198 & - \\
\hline 504 & Konserviertes Protein mit unbekannter Funktion (DUF820) & 3302 & 3931 & - \\
\hline 505 & Adenosylhomocysteinase 1 (EC 3.3.1.1) & 3948 & 5261 & - \\
\hline 506 & N-(5'phosphoribosyl)anthranilat-Isomerase (EC 5.3.1.24) & 5419 & 6096 & - \\
\hline 507 & Hypothetisches Membran-assoziiertes Protein & 6099 & 7604 & + \\
\hline 508 & Potentielles Protein A eines generellen Sekretionsweges & 7624 & 9078 & + \\
\hline 509 & Potentielles ATP-Bindeprotein & 9099 & 10343 & + \\
\hline 510 & Hypothetisches Membran-durchspannendes Protein & 10364 & 11691 & - \\
\hline 511 & Dolicholphosphat-Mannosyltransferase (KOG2978) & 11773 & 12585 & + \\
\hline 512 & Potentielle Transposase & 12700 & 13374 & - \\
\hline 513 & Hypothetische Transposase & 13367 & 13948 & - \\
\hline 514 & $\begin{array}{l}\text { Potentielle Acetylhydrolase (ähnlich zu "Platelet"-Aktivierungsfaktor-Acetylhydrolase IB } \gamma \text { - } \\
\text { Untereinheit (EC 3.1.1.47)) }\end{array}$ & -14070 & 14701 & - \\
\hline 515 & Uracil-DNA-Glykosylase (COG1573) & 14966 & 15665 & - \\
\hline 516 & Konserviertes Membran- assoziiertes Protein, & 15667 & 17373 & - \\
\hline 517 & Hypothetisches Membran-assoziiertes Protein & 17379 & 20315 & - \\
\hline 518 & Hypothetisches Membran-assoziiertes Protein & 20305 & 21309 & - \\
\hline 519 & Hypothetisches Protein & 20365 & 21162 & + \\
\hline 520 & Hypothetisches Membran-assoziiertes Protein & 21323 & 21784 & - \\
\hline 521 & Hypothetisches Biopolymer-Transport-Protein exbD & 21839 & 22303 & - \\
\hline 522 & TolQ, Biopolymer-Transport-Protein (COG0811) & 22380 & 23243 & - \\
\hline 523 & TolQ, Biopolymer Transport-Protein (COG0811) & 23629 & 24258 & + \\
\hline 524 & Hypothetisches Membran-assoziiertes Protein & 24276 & 24764 & + \\
\hline 525 & Hypothetisches Membran-assoziiertes Protein & 24773 & 25393 & + \\
\hline 526 & Hypothetisches Membran-assoziiertes Protein & 25523 & 26620 & + \\
\hline 527 & Hypothetisches Membran-assoziiertes Protein & 26647 & 27294 & - \\
\hline 528 & Transkriptionsregulator KdpE des KDP-Operons & 27389 & 28096 & - \\
\hline 529 & Sensor-Histidin-Kinase KdpD eines 2-Komponenten-System (EC 2.7.3.-) (COG2205) & 28101 & 29399 & - \\
\hline 530 & Hypothetisches Protein & 29437 & 29811 & - \\
\hline
\end{tabular}




\begin{tabular}{|l|l|l|l|l|}
\hline 531 & Hypothetisches Protein & 29862 & 30542 & - \\
\hline 532 & $\begin{array}{l}\text { Insertions Element IS630 hypothetisches 39 kDa Protein (pfam00665, rve, Integrase Kern- } \\
\text { Domäne) }\end{array}$ & 30755 & 31849 & - \\
\hline 533 & Transposase & 32173 & 34041 & - \\
\hline 534 & Serin/Threonin-Protein-Kinase (smart00220) & 34303 & 37155 & - \\
\hline 535 & Hypothetisches Protein & 37171 & 37596 & - \\
\hline
\end{tabular}

\subsubsection{Sequenz des Cosmides slc_1p}

TCATCCCTGTTGAGTATCGCGGCGGACCCTCACCCCGACCCTCTCCTGGAGTACCGGGAGAGGGAGAACGCAATCGGGCCGATCACAC GTTGGCCATCGCCGGCTCTCGACTCTCGTCGCTAAGCGCTCGCGGCTCTTGCTGTTCCGATGGCGGCAGCGGCTCTGAGAACGGGCTC TCCGCCGCGGGCCGGTCGCCGAAGCTGATGCCCAGCGCCCGCGCCGCTTGCACGGCGGCGCCGTTGGGGTCAACTCGCGACAGCCGCG AGACCGCGTCGCAGATCGGCACGCTGTTGAAGTTCGGCGGCTGGTAGCAGATCATCTCGCCGAACCGACGGTGATGCACGAGCCGCAC CGCATGCGCGCCGAACTGGGTGGCGAGCACGCGGTCGAACGTCGTCGGCGGGCCGCCGCGTTGCAAATGCCCCAGCACCACGCAGCGG GTCTCGCGGTGCAATCGCTCCTCAATCTCGGCACAGATCACGTTGCCGATGCCGCCCAGCCGCACCTGCCGGTCTTCGTGACGGCGCT CGACCAGCACCATGCCGCGCTCCGGCAGCTCAGCTCCTTCGGCAACGATGATCAGCGTGAATCGCTTGCCGCTGGTTTCGCGATCCAG AATCTTGTGGCATATCTGTTCAAATGTCCAAGGGATCTCCGGGATCAGGATCACATCGCCGCCGCCGGCAATTCCGGCGTGCAACGCG ATCCAGCCTGCGTGCCGGCCCATGACTTCGAGCACCATGATCCGCTCGTGACTGGCGGCCGTGGTGTGCAGCCGGTCGAGGGCGTCGG TCGCGCACGCGACGGCGCTGTCGAAGCCGAAGGTGTACGCGGTCGCCGACAGGTCGTTGTCGATCGTCTTCGGGACGCCAACCACCGG AATGCCGAACTCATGGAACTGCTGCGCAACCGCCAGCGACCCATCACCCCCGATGCAGATCAGGCCGCACAGGTTGAGCTGCTCGACG GTGGTCTGCACCGCGGCCAGCAGCTCGATGTCCAAGTCGAGCCGGTCGTCGATTTCGCAGCGGGCGGCGAATCGCCCCTTGTTGGTCG AGCCAAGGATCGTGCCTCCTTGGGTCAGAATACCCGTGGTGTTCTTCTGGTTCAGAGGAACATACGTGACAGGGTCGACCAGCCCCTC GTAGCCCTTCAAGAAACCCACGCACTCGTAGCCCAACTGGCCGGCCGCTTTGACGACGCCGCGGATCACGGCGTTCAAGCCAGGACAA TCTCCTCCACTGGTCAGCACCCCCAGACGTTTGGCAGCATGGCTCATTGCGCAACCCTATCGGTGGAACCTAGAAACAGAAACGGCGC GACGGAGGGCGTGAACGGCCGCGCCACCGTGGGGGAGTGCGAGGTGGTCCGGCAATTGTAGGTTACGGAACGGGGGCTGGTCGAGGAA AAACCCGCGTCGTTCCACGTGAAACGGGACGCGAATCCGGCTTCTGTAGATCGCCGTGGCGCAAGCCGGCAATGGCTGCATGACGGGC CACTCGCACGGCGGCGATGAGCTCGGCGATGCCCCAACGGGGCAACATCTCAGAGCCCAGGGCAACGCCCTGGGAAACGTGCTTTGAG ATGCAACCGCGTTGCGGTAACCAGACGGGCGAAATGAACCGCGGCCGTTCCGAGCCGTAGGCCGCATCCCTGAGCATATCGCGTTGGG CGTGAAAGAAGCGGAAATTCGGGTCGCGGGTTTCACGTGAAACGGGCTGGGTAGGCCGGCAAACCGCGCCAAACCCCGACAGCGGGTT TCACGAGAACTCTTGTGGAACCCCGTTGGGGTTCATAGGCGATTTCCTTGATGGCACTACCCAGGGTGGCGCGGCGTTCCGCCGCTCA CCCTGGGCTGTGATGTTTAACGCCTTCGGCGTATCAGCCCTTTCCTTCTCACTCCAGCGGATTGATTACCAGCCCGCTGAGGAGCTTG GGATAGAAGTAGGTGCTCTTGGCCGGCATCCGCTCCTGGTGTTGGCTGATCTGGCGGATGTGATCGACGGTCGCCGGCATGACCAATG CTGCCAGCGGGTACTCGCCCGTGTCGAGCCCGTCGATGACCTCCTGCACCAGGTGCACATAGGTCGGCTTGGGCAGGTCCTTGCCTGC TAGCAGCGTTTCAATCAGCAGCCGGTGGAGAATGCTGACGCCGAGCCCCTGCCAATCTGCGCTGTGTTCTGACGCGGCCTCGGCCATC CGCTGGCGGCCGGCGTCGGTGATCCGAGCGACCACCCAGCGTTCGTCCTGGGCGGTGAAGAGTCCGAGCTTCCCTTGCTCGTCGTCGA CCTCCAGCTCTTCCCAGATCGTTGTCGCCAGGTCGCTCCCCTCGCCGGCCACTCGGCAGGTGAAGGCGTCCCCCAGCTTCTTGATCAG GTCAGCCGACGACATGGCCGGCAGCCCGCGGAACAGCCGGTGCGTGGGCAGGACCACCATGCCGGGATCGTTCATTCCCACGCACATC ATCAGCACGGAGTTAGCCGGATGGTTGGGCGTCAACTTGCCCCCGGCGGCCAACTCGTCGCGGTAGTTGCAGGCCGTCTCGTAGCGAT GATGGCCGTCGGCGATGAACACCGGCCGGCCGGCCATCGCCTGCGCGACAGCGCCAATCACCGACACATCGGTCACCGGCCACATCCG GTGGACGACGCCCAGGTGGTCGGTTGCCACGACCGGCGCCTTCTCGGCGATGGCCGCTTCGAGCAGGTCCTGGGCCTGGTTCTCGGGG TCTGGGTACAGGCCAAAGATCTGGCTCAGGTTGGCTCGGCAGGCACGGGTGAGCAATAGTCGGTCCTGCTTTGGGCCGGACATCGTCT CCTCATGCGGGTAGATGTTCCCCTCGCCAAACCGCTCGAGCCGCACGCGGCACATGAAGCCGCGGCGCGTCAGCAGACGCCCGGCGTA CCGAAACTCCTGGTGGTAGACATAGACGGCCGGGTCCGACTCGGCGTACAGTAGCCCTTCGGAACGCCAATTCCGCAAGAACCGCGCG GCCCGCGAATAGCGGTTGTTGCCGTCGTCATCCCCCGGCTCATCGCGGTTCAGGATCAATCGCACCACGTTCGCCGGATGCTGCTTGT AGAGCTGCTCCTGAAGTTCCGGCCCGATCACGTCATAGGGCGGGGCGATCACGTCGCTCAACGAGCCGACGTGGCCCAGGTCGTAGCG GATTCCGCGAAAGGCTTGGATGTCAGGCATGGGAGTGAGGGATCGGGAATCGGGTATCGGGTATCGGCAAAAGCAAAGGGCTTCGGGT GTTTATCCCCGAAGCCCTGGAGAGTTGTCAAACGAGGCGACCGTGTCAGGAGTCGCTGGTTCGGCGGCCCCAAGTGTCGGCGAAGGAG AGTAATCTGGCCAGCGGCAACTCGAAGCCTGGCAGCAACTCGGGACGATAGACCTCGGACGCACCGATCGTCAGCTCGATGACCTTCC GCTTGGCTTTTCGAAAGACCGTCATGTTCCGCTCGAAGCGGTTGATGATCCAGTACTCCGCGATGCCAAGGGCCATGTACTCGTCCCG CTTCTCGATGTAGTCGCGCATCCAACTTCGCCGGCCGGCGGAAACGAACTCGATTGCGATCGTCGGTACATCCTTAGGTGGATCGGGA TGGCGTTTGAGTCCCACCCAGATCACCCGATCGGCACGACGGCGGCTGTGCGGCAAGCAAATGTACCGTTCGCTGAGAGTCGCGTTGA GCAATGAGCCCTGCGGGTGATGGTCTCGCCAGTTTCGGATCCAGTGTCCGAGCTCCTCGTTCGGATCGCACTCTTCTTCCGAGGGAT CGGATTCACGATCAACACCCCGTCAATTAGCTCGTACCGGTAGTCGTCGTCGTACTCCGTAACCGCGTCGAACTCGTCGACGGTCATC CGAATCCCGTTGAGTTCCGGGCCGAGCACAAGCGATTCGGTTGGCGCGAGGACAATCATCAAAGCCTCCCCGGCATCAATACCGGTAG TGATCGGGCTTGAATGGACCTTCAACCGGGTACCCGATGTACTCGGCCTGCGAAGGCGTGAGCCGGGTCAACTTGACTCCCAGCTTCG CCAAGTGCAGCCGGGCGACTTCTTCGTCGAGCTTCTTGGGCAGGACATGTACGCCAACCGGGTATTTCTCCTGGTTCGTCCACAGCTC GAGCTGGGCGATCACCTGATTGGTGAACGACGTGGACATCACGAACGACGGATGGCCCGTCGCGCAACCGAGATTCACCAGCCGGCCT TCGGCCAGGATGATGATCGAACGTCCACTAGAGAAAGTGTATCGGTCCACCTGCGGCTTGATGACCACCTTCTTCACGTTCTTCTGCG CCGTGAGCCAGGCGATGTCGATCTCAAGGTCGAAGTGGCCGATGTTGCAGACGATGGCGTCGTTGGGCATGACGCTCAGGTGCTCGCC GCGGATGATATCGCGATTGCCCGTGGCGGTGACGAAGATGTTGCCGCGCGGGGCCGCGTCCTCCATCGTCGTGACCTCAAAACCCTCC ATCGCCGCTTGCAGGGCGTTGATGGGGTCTATCTCGGTGACAATCACGCGCGCCCCCAGCGACCGCATCGAGTGGGCACACCCCTTGC CGACGTCGCCATAGCCGGCGATAACGACGACCTTGCCGGCCACCATCACGTCGGTGGCCCGCTTGATCCCGTCGGCCAGCGACTCGCG GCAGCCGTAGAGGTTGTCGAACTTGCTCTTGGTGACCGAGTCGTTGACGTTGATGGCGGGCACCCGCAGCTCGCCCCGCTGGTGCATC TGGTACAGCCGGTGAACGCCCGTAGTCGTCTCTTCCGACAGTCCGCGGATGCCGCCGAGCAGCTCGGGGTACCGCTGATGGACCATCG CGGTCAGGTCGCCGCCGTCGTCCAGAATCATGTTCAGCGGCTGGCCATCGGGGAAAAACAGCGTCTGCTCGATGCACCAGTCAAACTC CTCCGCCGTTTCCTCTTTCCACGCAAACACGGGGAATCCCGCGGCGGCAATGGCGGCGGCCGCATGGTCCTGCGTGGAGAAGATATTG CAACTGCTCCAGGTGACGTCGGCGCCCAGCGCCTTGAGGGTTTCAATGAGCACTGCCGTCTCGATCGTCATGTGCAAGCAGCCGGCGA 
TCCGCGCTCCCGCGAGCGGCTTGGACTTGCCGTAACGCTCCCGCAAGGACATCAAACCGGGCATCTCGTTCTCGGCGAGCATGATCGA CTTGCGGCCCCAATCGGCCAATGAGAGATCGGCCACCTTATAGGGCAGTTTGGTTTCGACTTGCGACACAGAAGGCTCCTGAATAGTG GTTGGTTGCTGGTGGTTAACATTAACCCGACGCGTCAGCGAGGGCTGGACCGCGGTTCACCCTCGCTTACGCATTCGGGTTAGTATTG TCGGGCACATCTTATGGACGCGTGTGTGAAGGTGACAAGGACAAGCCGAGCTACGACATAGATCCGCCGAGCGACGCAAACGTGGCCC TGGCCGCCTGGACAAAGCCAAGGATGCGGCCTGGATCCTTGATCCCCGGCTGGACCTCGACGCCGCTGGCGGTGTCCACTGCCGCGGG CCGAGCAATGCGGATCGCCTCGGCGACATTCTCGGGTAATAGCCCCCCCGCAAGGACTAGTGGCGGCACTCCAGCGGCCTTATTGTAG TTGCCGACCGCATTCCAGTCGATCACCTTTCCCGTGCCGCCATAGGCGCCTGGCTTGGATGCATCGCACAGGACCATGCGGGGCATCC AGCCGATCTCGGCGCAGCGAGCCAGATACGCGTGGATCGGCGCCAGGCCTTGTGGACCGCAACGGAACGCCCGCATCACGGGCAACCC GCCGAGCTCCGCCAGGAATTCGGGCGGTTCATCCCCGTGGAGTTGCACCAGGTCGAGCCCCAGCCGATGCACCGTCGCCGAAACGGAG CAGCTCGTCGCATTGACAAACACGCCCACTTTGACGAGCCCAGCAGGGAGCACAGCCAGTATGGCCTGGGCCTGGTCGAGCGATACAA ACCGAGGACTCTGGGGATAGAAGTTGAGTCCAATGGCGTCCGCTCCAGCCTCGACCGCCGCGAGTGCATCCTCAGGCCGCGTAATGCC GCAGATTTTGACGGAGAACGTCATTTGTGGTTAGAAGCTGCCACGACGTGTTCTCTACATTGTATCACGGCTTGGCATCAAGCGGCCC ACTGCCGCTGGTCGAATACCAGATCATGTACCCTTCAAGCAGCACTGCGCGCTGGCGGCACCGAACGTACCTGTTCGGCGTGACGGCG CTGGCGATCCTGCTGGTTGGCAACCTGTCGTCACGAGCCGTCTCGGTCAAGGCAACGGCGTACCGGGCGACGGCCGTTGTGAAGGGGC GGGAGTCGGGTTCGGATGCACCTCAAGCAGACGAATTGCTGGCGCGGCGGGCGACGCTGCCCTTTCCGGCGGATGTCATTGAACGCCT CAAGATCACCACGGCGGCAGACCGCGACGGTGCGGCGCTGCTGAGCATCTCGTCGACCGCGACCAGCCCCGACGAGGCAATCCGCGTG GCAAATGGTGCTGCGGCGTACATCGCTGCGCCGGTGGACGGGGTAGCACAGCCCGAGTTTCAAGAGGCGATTGCGCAAGCACAAGCCG CAACAGCGCTGGCGAGAGAAGAGATCGCCGCCGTGCGGCAGGCGATCACGTCGCTGGTCGCATCGCCTCCTGCACTGCCGGACAGCCG ATTGCAGCTCTCTGCGGCCAGTCCCCCAGCAGCCGGCCTATCTTCCTCTCCGCCGCCTGCCACCGTCGACAATCCACCGCCAAGCGAC GAGTCGCCAGCCAATTCGGCCTGGCAAGCTTTGCACCGTGAACTCAGCGCACTCGAGGCAAAGCGTGAGGAACGGCTGCAGCACATGA CCGATGCTCACCCCACCGTTCAGCGAATTGACCAAGAAATCAGCGCGTTGACGGCACGCTTGCTCGCTCTGCCGCGGCCAACGGGGGG GGACGAGCGGAACAACTCTACGCCTGCGCTAGCAGCACCCAGCAGCCCAAGCCACGAAGAGTCGCAACAAGACGCGACTGCTCCCTGC CCAGATCCCGCAGTTCTCGAAACGCTGCGACAGCAGCAGGAAGACTTTGCACAGTCGCTGACCAGGCAAATGCAGAATTTGCACCAGG CTGAGGGCCGTTTGGAAGAATGCCTCGCCGCCGAACGCGCCTTGGCTGATCAAGCACAGCGGCCGTCGGACCGTCCGCAATGGCAGGT CTTGCCCGCGCACCATGCCCAGCTTGTTGCCGCTTCGGCCCCCGGTCGGTCCGGAAGCGTGACAATGTCGCTGGCGCTCGTTGCCGGA ATGGCGATGGCGTTGATCGGAAGCCGTCAAACCGCGACGCTTGCCACGCGGCGCGAAGCAGAGCGCTGGCTGCCGATTCCTGTGCTCG GGCTGCTCGAATCGCCCGAGTCGCAGACTTCTGGCCTTTCGAAACTGTTCGGGCTTTCGGTGCGGGGAGTCAAACGCACGTGCGAAGC GGCATTGGCCGGCGCCCTGTTGGCAAGTATTCTTCTCAGCGTCTCTGATTTTCGGGCGGGAGGCACCACCGATCAGGCGCTCCGCTGG GGTTGGCAAACGCTCGAATCTCTGACCAGAGGATGAGGCCCAGGGGACTTGCGAGATGTACGAAGCACTGTTCAACCTGCAACAGCGG CCATTTGCGGCCGCGCCGCAGGTCGATCGCTACTTTCCGGCCGCGGCCATCGAACAGGCCCGCCAGGTCCTCGTCCGCTGCATCCAGC GGGCCGAAGGCGCCAGCCTGGTGATTGGCCCGTCGGGCACGGGAAAGACACTGCTCTGCCAGGTCCTGGCCGAACAGCACCGTCTACC ATTCGAGGTGGCGCTGCTGCCTGGGGCCAATCTACAAACCTGCCGCGCCTTGCTGCAGGCAATCTTGTTCGAGCTTGGGCTCCCGTAT CGGCGATTGGACGATGGCGAACTGCGGTTATCGCTCAACGATCATCTGCTCCGCCGAGGTGCCGAGGGACTCGAAGGGTTGGTGCTCA TCGTCGACGAAGCGCACACGCTGCCGCTGCGGCTGCTGGAAGAGGTGCGGCTGCTGACGAACCTGGCCCGCGGAGGAAGGCCCTGCGT GCGGCTGATTCTCGTGGGGAGCCCCCTGCTGGAGGAACGGCTGGCAAATCCGAAGCTCGAATCGCTTAGCCAGCGGCTCTCGGCCCGC TGTTACTTGGAGCCGCTGACGCACGATGAAACGGCGGCCTATATCAAAGCGCAGATCACGTCCGCAGGAGGGGACCCTGATGCGATGT TGGAACAGGAGGCGCTCGGGGCGGTCCATCGGGCAACCGAAGGCATTCCACGGCTGATCAATCAGCTTTGCGACCATGCCTTGCTGCT CGCGTTCGCCGATGGCGAGGCCCGAGTCAACGCAGGCGATATTGAGCAAGCATGGGCCGATTTGCAGCAACTTCCGACGCCTTGGGGA GAATCGCGGACGAGGACCCGCGTGGACGGCGCCCATCGAATGCCGGGCGTGATCGAGTTTGGCAGGCTGGCGGAGGAGAACGACGACC CTGTTGGCCCTGAGTTCGAAAGCCGCCCGCTAGGTATCGTCGGGGCACCGGCGACCGACGAAGAAGCCGAGGCAAACGACCGCTTGGA GGTGATTGAGCGGCACCTGACAATCCTCGAAGCCGAGTTCGGACCGACGACTGCGATCGAGTTGCCGGCGGCCGCTCATGGCGACCCG TTTGGGGAGCAGTTTGCTGAAGACGAAGTGGTGATCGATCGCTATGCCTCGCTCGACGCCGGCGGATCGCAGCAGCGGCCGCACGTCT TTTGCCAAGAAGGAGACGTGCTCACTCGGCTGCTGCAACAGGCCGCGCCGTCGGAGCCTCTGGAGATCGTCGCACGGCAGCCGGTCGA GCCACAACCTGCACCGCCCGTTGCCGCTCCCCAGCTTGCAACTCAGCCATCCGAACTCCACGTTGACGAGATCGACTCGGACCAGGTC GTGATCGAAGAAGATCCGAAAGTGCTGCCTGTTACGGCCCGGCGTCCGCCGGTGCGGCGCGAGGAGTATCGCAACCTGTTCGCAAAGC TGCGGCGGGGATAGTCGCCAGAGGTTGAAAGCCGATGGGTAGCATTCTCGATGCTCTGAAGCGCCTGGAGGAGAAGGCGGAGCATCCG CCGGCACCTGCTGCGCCGAGTCGAGCAACGACCAACAAAGAGCCTGCCGGGATTGGTGTTTCTGGCGATCCTGCGGAAGATGCCTTAA CGCCGCGAGTCGAAGACCCATACACCCCAGGCGGCGTGCCGACGGTTCCGCTCGATCAGCTAGTTTCTCCGAACGTCGCACCCGCAGT GGAGATTTCGGAAAGCGTTACAGGCACGGTTCCAGTCAGCGAGCTTTGGAGTCGCCCGGCCGCAACTCCCACGGAATTCCAAGCAGAT CCTTCCCCCCTGCAGGCGCTCGAAGCCGCGGAACAGGCGATTGCATCGGAACTGGCGCCCACAGCCGCACCACCGGAACCTCCGCCCG AAACTGCTCCATCGGCTTCCAGTCCGGAAGCCGCGGCGTCCGACTGGTTCGAATCCTATCTGCCGAACCGGGATTCCTTGGTGCCTTC GCCGCTAGAGCCCTCTCTGTTTGGTGTTTTGCCCGACGCGCCTGACGTTGCGAAGGAAATCCCCCACCAACCGGACAAAGCTCCCGCG ATGCAAGTCGCGGACCGAGCGCGGCCGTTGGCGGACCGGCGACGGGCGACGGGCGAGGCCCGGCAGCATCCTGCTCGGGGTGGATCGC TGCGCGCAGACCTGAATGAGCTGTGCGAGAGGCTCCGAGCACAGCTTACGCCTGGCGTTCCTCAGATCCTTCTGTTGACGGCCACGGA CCCGGCAATGGGCGCGACCGGCGTGCTGGTTCAGCTCGCAGAGGCATTGGCGGCAAGTGGCGGGATCGAGCTGCTGGCTGTCGACGCC GACCTACGGCGCCACGATCTGTCGCGCGCCTTCAAGGCAGACAAGACGGCCGGCCTGTCCGAGATGCTGCCCAAGGGCCGGACACGCG GCGACCTGGTCGTGCACACGCCGGTCAAGGGCCTGCACCTGCTGCCGGCTGGGCTGGCGCGCGATTACGGCTGGGACGGCACCGCCGA GGCAAACCTCGCCCTGGTGTTGAGCGACCTCAAGCAACAGTATGACTTGATCCTGATCGATGGGCCTGCCGTCTCCTCGCCCGAGACC TGCGCCATCTCGCGGTGCTGCAACGCCACCTACCTGGTGATCCGGCTCGGCACGCCGCGGTGGGACGCCACCGATGCCGTCCGCCACC TCCAAGACTCCGGCGGCCGCGCGACGGGAGCGGTTCTGATTCGCTAGGCCGCGAGCTCGTCGTTTCGTTACCTTCTCTCGCCCGGGCG GCTGACCCCGCCGCGGCTGCACGCAAAAACCACGGCAACCATGGCCATCATGCTTGCCACGAAGACGAACATCGTGGGATAGGAGCCA GTGTAATCCAGCAGCTTGCCGGTGATCGGCGCTCCCACGAGATTGCCGAGATCGAACGTGGCGAGCATCAACGTTGTTCCCAGTCCCC GGTATCTGCCGGGAAAGACCGAACTGCCCCCGGCGACCACCGATGGAAACAACATGGCGTGCGCGATCCCCATGAACGTGGCGGGAAT CGCGAGCTGCCATTCGTGCTCTACGACCAGGAACAGCAGAATGCTGAAGATCAGGCTGGCCAGCCCCACCAGCGCCGTCGGTCGCACG CCGATCCGCTCCGGCAACCGCCGCATGCAAATCCGAGTCAGGAACGCCACCGGCGCGTAGACGGCGAAGAACACGCTGATCCTCGCAA TCCCGAGATTCGCCGCAAAGGTCCTGAGGAACGTGGACGGCAACCCCACGCCGAACCCGGTGGCGATGCCAACGATCAGAATCGCCCC CGGATGGTAACGCCGCAACAACGGCCACATCGGGAGCCGGCGACGGCGCCGCACGGGTGGCGCTATGCCCGCGGTCGCCAGCGCCGCA AACAACAATCCGACGCAGCCCAGCGCGGCAGCAACCAGGAACATGCGATCCAGGTTAGACCGCGTGATGGTCGCCGAACCGAGCAGGA AGTCACCAATCAGCGTGCCCGCCACCATTCCCACAAAGCCCGACGTTCCCAGTGTGCCCAACACCTCGGCCAGCCTGGCTACCGGCGA CTTCAACGAAATATAGGTGATCGCCGCTCCGAAGGCCCCGGCCATGCTAGTGCTGAGCAGGGTGCGCAGCACGAACACCGGCGGCGAG TCCACTCGCACGACCCACAGGTGTCCCAAGCAGCTTGCGATAAACAACACAATCGACCACAGCCAAACCTGGCGCGGCCCGTACAGGT CGATCGCATTGCCCTGGACCAGCCGCATCAGCAGGCTGCCGCCCATGCCAATTCCGACGATCAGGCCCAGGTCGAATTCCGTCCCTCT CAGGTACGTGACAAAATCCGCATACCGATACAGCAAACTGATCGCTAGCATAAGCGAAGTGTTCGCCAGGTACGTGTACCAGAAGGGA GGGCCGTAGGAGGAGGGTTGCGAGTCGAGGGTTGAGGGCTGAGAGACGGGAGCGGACGCCGTGCCTGGACGATCGGCACGATGCTCTG TCTCGTCACCCGCGGCGTCGGAAGGGGCAGTTAATTTGCCAGCGGCGTGTGAAGACGGCTCCGCGCGGCGCAGCATGGTGGGGTAGAG TGTAGGTGGCAGGCTGGTTCCCTCAGTATACTCCGCACTACCCAGGTTGAGATGGCCTAAAGGACCCTATGCCCGGCAAGACCCTGGT TATCCTCGCTACGTACAACGAGATTGAGAGCTTGCCGCGATTGGTCGAGCAAGTCTTCCAGCGCTTGCCCCAGGCCGATCTGCTGGTG 
ATCGACGACAATTCGCCGGACGGCACCGGCCAATGGTGCGACACCAAGGCCCAGTCCGATTCACGCCTCAAGTGCCTGCACCGCAGCG GCAAGGAGGGCCTCGGCACTGCAATCCTAGCGGGGATGCGGTACTCGATTCAGCACGGGTATGACTATGTGCTGAACATGGACGCCGA TTTCAGCCATGACCCACAGTACCTGCCGGACCTTGTCGCCGGCATGGACCGGCCAGGCCAGCGTCCGGTCGACGTGATGATCGGCTCG CGCTACATTCCCGGCGGAGGGATCAAGGGTTGGCCGCTCAAACGGCACCTGATGAGCCGCGGGATCAATTGGTACTCGCGCTGGCTGC TGGGGTTGCGGCCCAAAGACTGCAGCGGCGGCTACCGTTGTTATCGCACCGCGGCCCTGGCGCGGCTCGACTTTGAACAACTCCGTTC CCGCGGCTACTCCTTTCAGGAAGAGGTGCTGTGGCGGCTCAAGCGGCTAGGCTGCCGCTTTGACGAGACCCCCATCGTGTTTGTCGAC CGCGTCCACGGCAGCTCGAAGATTAACCCGCGTGAAGCCCGCTCGGCACTCCGGATCATCCTTCGGCTTGGACTGGAAGAATGGGGCA TCGGGAGGCGGGAATCGGGAATCGGGAATCGGGAATCGGCCGCGGCGGAGCAAGACACCGGCAGCCGTCAGCCGAATGCAAAAGTCTA GCGCGTGGCACGGGCATCCTGCCCGTGTCTTCCACGGGCAAGATGCCCCCACGCATCGATCACTAGTACCGCCCCGCTGAGTTGAGCG TCCTTGGGGGGACGAGGTTGTCCAGGGTCAGAGGTTGAGCGGTCGGCCAGTGTAGGTCCATTTGAAGGGTTTGGCCAGCGTACGATTG AAGTAGTCAATAAAGGCCAGCAGGCGATCGCGAAGGTCCTTCGTACTGCGGAAGGTTCCGCGGCGGAGCACGCGACGCATGAGGATGC TGAACCAGATTTCGATTTGGTTCAACCAGGACGTGTGGCGTGGCGTGTACACAAAGCGGATGCGGTGGCTCTTGTCCTCCAGGAACGC TTTGCGCGTCGCTCGCGATTTCAGCACGCCGCGCCGGCCCTTGATCCCCAGGTCATCGGGCAGTTGGCACTGTTGGGCCACGTAATGC ACCAAGCCTTTGGACCAGTGAATGTTCAACTGGTCGCAGACGACGATCCACTCCGCGTCAGGGTCGGTAGCCACGGTGCGGGCCACGT GGTCCACAAAGTCAGGTTCGGTCCGCGTGGCCTGTATGGTCGGGCTGACGACCTCGCCCGTCACCACGTCCAGGTTGGCGATCAGGCA TTGCGTGCCGTGACGTGCGTACTCGAATTCGCGGCGTTCGACTTGGCCGGGAGCAGTGGGCTTGGTGGGGGCAATGCGTTCCAGCGCC TGGATGCTGGTCATTTCGTCGGTGCTGATCGTGTGGGCGCCGTGTTCCGTCCGTCGCTGTGGAGCCTCCAGATACGTGTCACACACGG CTTGCACCCGCGCGTCGAATTGCGGGTCGGCCTGTTTGTCCGGCGAGTTGAGCCAGTACCGCGTGCGATGCGGCTTCAGGTCGCCCGC CTTTTAAAAAACGCCCCACCTGGCGGTCGGAAATCGAAGGGACGATTCCTCGTTTGATCACTTCCTCGGCCAGTTCTGTGGGAGTCCA GTGTGTGACCGGCCGTCCCGATTCTTCCGGCGACTCGCAGGCCACGGCCAGAATGTCGGTGATTTGCTCCGGCGTGAAGGTCGGCGGC ACCCCAGGCCGCGGCTCATCCGACAGCACCTCGATCACCGCGGCGCGGAAATCCGCCGAGGTCTCGCAACACTCGACGATCGCCAATC GCTTCCAGACTTGCTGCCACCGCAGACGCCAAACGCCGACCTGGTGCCGCCCCAATCCGATCTCGGCAGCGATCTCCTCGTTGTTCCA CCCCTCGAATGCCAGGAGGATGATCCTTGCCCGCCGCGCCACCCCTTGCGAGCACGTCGAACTTCGAGCCAGCGTCCGCAATAACTCC TGCTGCCGCTCCGTAATCACCACCTTCCGCGCCGTCCCTGGCATGGTTTTCCTCCCACGATCAGACATCCTTAAAATCTGGGAACTTC GCCTGATCTTGGCGATTCGCCCGATTCCGTGGAAGATCAACTCGGCGGGGCGGTACTAGGGGGATCTTCGCCGTTCTTCAACCTCCCC CCAGCAGTTCCTTCACCTTCGGCTCGATCGCTTCAGCCCAAATCGCGTAGCCCTTGGGGCTAAGGTGCAGCAAGTCCGGCATGATCTC GCGGCTGAGCGTGCCGTCGGCTTCGAGGAACTTGGGGCCGATGTCCAGATAGTGGACCATCTTGCCATCGGCTGCCTGCGAGGCCAGC TCGCTCGCGCGGGCGTTCTTTTCGCGCTGTGGATTGGGCTTTTCTCCGCGCGGGAAGACGGCCAGCAGCAGGACCTTGGTCTCGGGCA GCTTTTGGCGGAGCTTGTTGACGATCGCCTTGATCCCGTCCGCGATCTGTTCGGCCGTGTTGTCCATTCCGTTCGAGTTGTTGGTGCC GATCATCAGCACGACCAGCTTGGGCGAGATGCCGTCGATGTTGCCGTGATCAAGCCTCCACAAGACGTGCTGCGTGCGGTCGCCGCCG ATCCCCATGTTGGCCGCTTTGCGCGAGGCGTAGTGCTTGTCCCACACGTCCTTGCCATTGGTTTCCCAGCCTTGGGTGATCGAGTCTC CCAGGAGAATCAGGTCGATATTGCCTTGCTTGGCCCGCTCGTTGAACTTTTCGTGTCGTTCCATCTGCCGCGGCTGGTCGCGCGGAAC CGGCTTGACCGCCGAGTGCTGCGGCTCCTGGCCGGGGGCCGCCATAGCCGAGATCAACGTCAGGGCCAAGGTCAGTGATCCGAGAGTC CATCGCGGGGTGCGCATCGTCGTTCTCCGGGTGGCAACTTGCTTTCAATTGAAAACCGATGACGCCAGAATACTGTGCGGGCGGCGCG GAGAAAAGCGGCTGAGGCATGGTCCGGGCTGTTCGGCGGGTCACCAGCCCCGGCGGTGGATTCTCTAAGCTAAGGCATCTGCAAATGC GGAAGTTACTCTTCGGCCGGGCCCAACAGCCTCCGCACCGTGTGAAACAATTCCGCCAGCATCTCGCGCGTCAGCCGTCCGGTGAACG TGTTCTGCTGGCTCGGGTGATAGCTCCCGACCAGGTAACGCCCTCCGGACAACGGGACCACCGCCTGGTGGGCGAACTTGGGAAGCGG CCCCGCAAACCAACCGCGTTCCCGTGCCAGATCGACCACGGCTCTCCACCCGATCTGACCCAACGCCAGGAACACGCGGACCGGCAGA ATGTCGACCGTGTTCAATAGAAATCCGCGACAGGCCGCCAACTCGTCCGGCAACGGTTTGTTGTCAGGCGGAGCACAATGGCACGCGG CGGTGATCGCACAGTCGGTGAGGCTCAAGCCGTCGTCAACTGCCGTGGACGTCGGCTGGTTGGCAAAGCCGGCCTCGCGCAGCGCAAG ATACAGCCATTCGCCGCTACGGTCACCGGTGAACATCCGCCCGGTGCGGTTCGCGCCATGGGCGGCCGGCGCCAAGCCGACGATCAGC AGGCGTGCCTGCGGATCGCCGAAATTCGGCACCGGCCTTCCCCAGTATGTCTCGTCACGGAACGCCTTTCGCCGCACCTGGGCGACCT CGCGGCAATAGCCTCGCAGCCGGCCGCATCGCTCACAGTCGACAATTTGATGGTTCAGCCGTTCCCAAGGAGTCATCGAGACTATAAC AGCTAGCGGCTACGTTTGACCGACACTTGCTCAGTCGCCGCCGCAGCCTGCTTTCGCTTGAGCTTGGCCGGGATATCCAACTGATAGA GTGGCAAATAGCGGTAGTAGACTTCCAACGTCAGCGCTGACAGGCTGGTCATCATCAGCCTTCCGCCTGCACCTCCCCAGGCGTCGGC CATCGGCTTGTCCGGGTCCCAGCTCCCTGCCGCGCAGCCCTCTTTGATCTGCGTTTCGATCAGCGTGCGGCGCATGTTGCGGTTCCAG GTGTCCCAATCGGGGCCGGGAACGTTGTGCATCACTTGCGTGGCGTAGTACCAGTAGTACGTGTCGCGCTCGGCAAGCGCCGGCGGGT GGTCCATCAGGTAGGCCATGCCTTCGATCATCGACGGCGCGTCCGGGCGCGTTCCCAGGTATTGGCTGCACAGCAGGCCCACCGCCGT CATCGACGGAGTTTCCTGACGTTCTCCCAAGTAGCAATACAGCCCCTTGTCTTTTCCAGACGCAACGGATTGCAGCCAGCGTTCGGCC GCCTGGAACGTCTCGTAGTTGACCTGCAAGCCCGCCATCTGAGCGCTCTTGAGGGCCATGAGCTGCCAACCAAACACGGACGTGTCAC CGGGCTGACCAGGCACATAGCGCCAGCCGCCGGTGCGCTTGTTTTGTGCGCGTTCAATAAACCGGATCGCGGCCTGCGCGGCCCTGCC CGTCGCGGTGTCGCGCGTCATGCCGTAGGCTTCGCAGAGCATGATCGTCGCGAGGCCGTGCGAGTACATCACCTGGCCCGAGCCTGCT GACAGGTCGCCGGTCATCTCGCCGCTTTTCACTTGGTGCGAGAGCATCCAGGCGATGCCGGCTCGAATGTTCTTCTGATAGGGGCCGT CGGTGTCGCTGGTCTGGCCGGCGGCGAGGAATGGCAGCAGGGCCAAAGCGGTCGCTCCCGCGTCGGACTCGGTCGAACCGGGACCGGT ACAGGTTTTGTCCTTGCAGCGATACTGGTGATCGAGGCTCCAGCTTCCGTTCGCGTTCTGATGGCGCGCCAGCCAGTGCAGCGCGGCG GCCACTGAGCGCTCCGACGCCTTGGTCCCGCCGGTCCCCAGCAACGCCTCGCGCATTCCCTTTCCGCGGCTGCCGAAGCCGATGCCCG CGCCGCCGCTGCCGCCGCTGGTCGATTCTCCGATACCCGCTCCGACGCCGCCGGCGCCCTGCGTCGCCGCTCCTGCGCCCAGCGCGCC GGTGTCAAACCCTCCCAGCCCGCCAAACGGCAACGAATCGAGCGCCGTCGCGTTGCCTCCGCCGGCCGCCTCGAAGACTTTAGAATCG TCATTGTACTGTGCGCTCTGGGCCGGCGGCTCGGTCAACAGAAGCGTGTCGGTGCCGAGCTCGGTCGGGTCGAGCGGCGCTGTCTCAA GATTGAAGTCCAACTGTGCCAACTCGGGGACCGTATTGTCAAAGCCCTCGAACGTGGGAGGGGCGGTGCGAAGCGGCAACGTGACGGC GCTGAGGATCAGCATGATCACGATCAGGCCCACCGCGTGTCCGCACAGGCTGACGCCCCACCACCGCCAATTCATTCGCAGCCAATCG ACTGTTTGCCGCCTCAGCTCCGCGGGCGCGGGAAACCGGATGCTGGCGATCAGCTTCTGCAGATCGCGGATCAGCGACGACTGCTGTC CATCGGGCGGCAACGAGTCCGGCTGTCGATTGAACATCGGCGCTACTGCTTTCTTGGCTCCGCTGTCCGGCCCTGGGCGACGAGACAC TTATCGAGCAGAGTTTGATACTGAGCGACCATCTCCGGCCCGCTCAGCTCCGCGCTCAAGACCAAGGCGGCCTTTAATACTTGCTCCG CCTGGTGGGCCTGAGCCGGGTCCTTAGTGCGCATGCTCTGTTCGGTCAGGCACTCGGCCACATTGTAAACGACTTCATAGTATTCCAG CGGTTTTTTCGGCAAGCGTTGCAGCAAGCTCCTGAGCCGCGTCCAGTGAGAGACTGCTGCCGGGTAGCGCTCCGGATCAGTTCGCGCC CACGATTGCAGTATCCGTCCGCGCTGCATCAGCGCCGCAAAATCATGCGGCGCGCGCGCGAGCAGCTCGTCGACCTCGGCAAGCGCGG CTTGAAATTCCCCATCGGCCAGCAGCAGGTTGCTGAGTTGTGCACGTGCCCTGTTGAGCGCCGCCTGATGACTAACGAGCAGTGTCGG GTTCTGCTGGCAAGCCTGGACCACCAGTCTGTACTGCTCACGCGCCGGCTCCTTCGAGCCAAATTCCAGGTAGACGTCCGCAATAAAT AGCCTGCCGCTGGGCGAAATGGCCTGACGCGGGCGAAGCTGGTCCAGCAGCTTGGTGAGCAGCTCCTTCTCGGCGGCGGCCTCGGGGT CCGACGCCTGTGGAAAACCCTGCGATGACTTGGCCGCCGCCTCGATGGTCTGGCGCCACTCGGCGTGCAGCGTCTTGGCCAGCTCGAT GAGCGCAAGATTTGCCTGGCTATCGTCTGCCGCGCCTTCCAGCGTGCTGAGCGTTAGCCGGCGCGCGCCGTCACGGTCGTTGAGTGCG ATCGACGCGCGGGCCAGCAGCGCAGCGGCCCGCAGCGAGGCGGAATTGGTGCGGGCCCGCTGCGGTTCGTTCGCGGAATTGACAATCG GTTCCAGGATCTCGGCGGCCTGGCGAGGCTCGTCCTCAAGACGCGCTTCCGCCAGCAAGAGACGGCACTCGAGCTCTAGATCGGGCGC CGCCGTGCCGGCCGGCCGGCTTGATTGCGCAGCCAGCGTATCGGTCAATAGTTGCACTGCCTTCTCGCGCAGAACAGCGGCTTGGCCC TGAGCGGCGGCGCCCGAGCGGTGTTTCTCGCCCAGGTATTCGCGCCAGGCGACTTGCGCCGCCAGGAATAGAGCTTCCGGCCGGCGGT CGGACGCGGGATCGACGGTTTCGAGCAATTTGATGGCTGCGTCCGTTTCGCGGCGGCCGACGTGGAGCGTCGCCAGCATGAGCCGCGC 
CTGATCGGCTTCGGCCTGTTGCGGCCAGCGCGCGATCACAAGCTTTCCGAGATCGAACAGCTTGGTTTCGGCGGCCGCTTTGTCCTTG GCGGTCGACTGCAGCTTCGTCGCCGCGGCGATCGCCAAGCTCGCTGCCGCCGGGGACTGTGCGCTCGAAGGCTGGTCTCGCGCCAGCG CTTCGGCGGTGGCCAGCGCGTCGGCCATTTGACCGGCGTTGAATTGCGTTCGCGCCAGCTTGAATCGTGTGAGCGGCGTCTGCTCCGT TTGGTTGGCGCTGGATGCCAGCTCGACGGCCCGCTCGTAGGCCGCAATCGCTTCGTCCCACAACCCCTCGGCCGCCGCGACATCACCG AGGCTCAGTGCTTCGTCCAGCGTCCGCGGGTTCCAGCCTGACTGGGGAGCGTGCTGCCGGCGGAGCAGAATTGCTTGCGCTTGGTATG GGCTTTCGACCAGAGCCATGTCGGTCAGGATGGCGATGGCGGACTGGGCCAGTTTTCGCTGCGCATCGCCGTCGCCAGATTGCGACCG GGCAACCTGCGCCTTGGCCAACTCCAAGGCGATGCCCTGAAAGCCCTCGGTCTCGCGCGCGGACTTGTTCTGCCGGAGCCAGTCGCCG GCCTCGGTGAGCAGTGTCTCGTAATCTTCGAGGGCCGCCAGGACCTGCAGCCGGCAACGCTGCGCCTCGGCAAACACGGGCAGCAAGT CGGCATCGGCCGGTTGCTCGCCGGGGTCGGGCGCGTTCGCGAGCACCTCGTCAAACACGTCCAGCGCCGTTTGTGACTCGCCTAGCTC CGCGAGCGCTTTGCCATGCCACAGATGTGCATAAACGCCCAGTTGCGAGAGCCGATATTCTTGAAAGAGCTCGTCGAAGGCGTTCGCG GCGTCGCGCAGGGATTGGTCCCGGCCGGGCTCCGCCGAGTCTCCGTACGTTTGCGCCGTGTAGTACGCCGCCAGCGCCGACTGCAAGC GCGCTTCGGACCAATGTTCCTCCAGATCGTCTACCTCGGCCGTCTTTTCTCGCGGTTGCGCTACCGGCTCTTGCTTCTTCTTCTTCTT GGTCGTGGCGGTGGGCAATCGTGTCCGCCGGGGACGCTTGACGACCGGGGCAGATGGTTCAGGCGCCACCTTCAACAACTGCGACTGA TAGGCGGCAGCGGCTTGGCCAAAGCGAAGCTGCGCCTCTTCCAGCGCCTCGCGCGCCTGCTGGTTGATGCTGGCGCGAGACGATCGGT CGGGCGTCGACGATGCTTCCTTCCACAATGCTTGGCCGCGGTTCATCGCGATTCGCCCGACCTCGCCAAGCGCCGCCCCGGCGCGTGG ATGGTCGGGCTGCTGTTCAGCAAACGTGTCGAGACGCGTCTCAGCTTCCGCAACACGCTCGGCGGAGAGGGCAGGATTGCGCGTTTCA GCGGCGGCGATCCGCAGGCTGTGCGCAAGTTCCAGGTCGAGGACCGCGCGCACGTCGTCGGGCAAGTCAGTTCGGTCATGAATCGACT TCAGATAGACGACGGCCAACTCGCCGTAGCCGCGGTCTTGCAGTCCATGCACAAAGTCCAAGTATCGCTCGGCGGCGAAAGATCGCGC GGCGACAAACGACAGCAGCGTCAGGCCCAGCGCCATCACTCGCCGCATGTGGCGTCTGCGACGATCACGCCTCATCGTCGGCCTCCTC CTCGCGCTGCGGCGATTCCCAGGGAATTGCCCGCTGGTGATGACTGCCATTGGATGGGGGCGACGGTTCAGCGGGGAGTGGGGATTGC TCGATCTCGCCGAGCCAACGCTCGACGTCGGCGGCCCTTTGTGCGGCGAGCGGGGCGGCGCGTCGGGTGGCCGCAAGTCCGCTGCGCA ACCACCACCGGCCGACCGCGCCCGCCAAGATCAAAGCGCCGATGCTGAATGTCACCCAAAAGTAATCGTCACCCGTTTGGGCCATGCC GCGTGTTTGCGATGGATGCCAGCGCAGGCGTCCGATCAGCAGCGGCGCGGCGCGAGGCTTGTCGAACGCCTGATAGGCCATCAGCTTC AGAAAATAGCCCACGAACGTGGCTTCTTCGTAAATCTCGGCCCCCAGCGGCATGCCCTCCGGCAGCTCGCTGAACACAACCAAGTAGG GGAACGACTGCGACTCGTCGGTCGCGCCCCAGGCCTCGTACACTTGTTCTACTCCGGCGGAATTCTCCACAGCGCGATGGGTGAGCGC GCGGCGGAGGTGCAGCCGCAGCTCAATCACCTTGCCGCGGAACCGATCGGGCTCGTCCCAAACTTGCGTGTACAAGAGGCTTTGCTGG CCGCGGCCTCGCAGCTCGTCGAAGCTCTGAGCGCGGCTCCAGCTCATCAGCCGCCAATACGCGGGCATCTCCTCGGCAGCGAGCGGCG CGCGATCAACGACCGCTTGAAAATCGGACTCGGCCGCCTGCGCCTCGTCGGGGTCAGCGCTCGTTGGTCCGGTCACGATCACTTCTTT TGCGGGCGCGGCAACGGGCGATGGGGCATCCGCTGCCGTTGATTGATCGCCGGCCAGCCAGCGCCAGGTCTGCGGCTCCTTGGCCCTG CTGATCAGCATCCACAGCACGGCAAGCAGGGCGATCATGGTCAACAGGCGCGGCAGCTCGCGGCCGTGAAACATCGACGGTGAGTGGC TGCGGCGCGTCATACTGGGCCGACCTTTACGTCCCTGCTGCCGGCATCTCCGGCAGTTCCACGAAACTCAGTCTCGAAAGCTTCTTTC CGTCCGGCAGCTTCTGCCGCGTGCAGACGTCGATGACCTCCATCAGCGCGTTATAACGCAGCGTCGAGCCGGCCTGGATCAATACCTG GTCGAACGGATTTCCCGGATCGGCCAGCACGGTCGCCAACCGTTCGTCCAAATCCTTGAGCGAATCCACGGCCCCATCTCCGATGGCC AACGAGTCGATCGCCCCCGCCGGATTGGGAAACACACTAATCACCAACGTGTTCAGCCCGGCCACAGGGTCGGGATTCGACTGGTCCG ATCCGGCCGGCTGCTCGGCGCGCACGTCGGTGACCGATTGCGGCGGCGGCAAGTGCAACGAAATCTCGCCTTCGATCGGCGAGGGCTT AAACGTCAGGATGAAGAAGGCCAGCAACTGGAACGCCATGTCGAGCATGGCTGCCAGGTTCAGCTCGACGTCCCCTTGTGATCGCCGG CGGCGGCGTTTCATCTACGCCTCCCCTGCGCGGTTCATCGCCTTGAGCGAATACCGGCGGAAGCCGTGCCTTTGGCAGACCTTGATCA CGTGGTTGAGCAGGTTGAACGGAGTCGCCTGGTCGGCCCGAATCACGACGCTCGTGGGCAGCTCATCGCCCGGCTGTAGCTTGGGGTT GGCGGTCCTCGCCGTCCGGAGTGCGGCCTGGGCCTCGCCGGCGATATACGTTTCGACGTCCTTGCTGACTCCATACACCAGCAGCCGG CCGCGATTGTCGACGTTGAGGATCAGCGGGTCCTCGACCTTGGCGTCTTCCAGCGGTCGAGCCGAGCCGATCACCGGCAATTTCAGCG AGAGATCCATCGACGCGCTCTTGAAGCTGATCACCAACATGAAGAACGTGATCAGTTGAAAGACCATGTCCAATATTGGAGTCAGGTT GGGATCGGCGATCGCTTTGTCCGACATCGAAGCCGACATGTGTAGGTCAGGCTTTCCAGCCTGACTCCGTGGTTTCCGACGGTTCTCC CTCTTCTGTCAGGCTGGAAAGCCTGACCTACAACGAATTGCCGCGCGACGCGGCCGTCGGCGCGGCGGTAACCACCTGTGCAACGGGG GCCGTTGACGGTGCAAGCGCCGGCTTGCCGCGCGCCGCCTTGGCCATCCGCCGCACGAATTCGTCCGCCTCGAGCAGCGTCGCCGAGC TGAGGTGCGCGACTCGGTTGCGGAACAGCGCGAAGAAATAAATGGCTGGGACGGACAAGGCCACTCCCTCGAACGTCAACAATAGTGC TTCCGAAATGCCGCCGGCGACCTCGCTTGCTCTGAGCTGCGTATCGGACAAGGCGATCACGCTGAAGCTGGAAATCATTCCCTTGAGC GTTCCCAACAGCCCGATCATCGGACCCAACGTGCCCAGGACGGCCAGCATGCTGATCTTCTTTTCCATCTCGACCGTGATCACGTCGG CCACGCGCTCCATCGCTTCGCGGGCCTTGGTGACGCCTTCCGAAAGCTCCGTCAGGCCGGACGAGACGATCACCGAAAACGGCGAGTC GTCGCGCTGCACGGCCGCGAAGACGCCGCGAAAGTCGCCCGCCTCGACCAGCGTGTTGCACTCCTGCAGGACCTCGGGCGGCATCACC ACCTGCGGCCGCAGCTCGACAAACAGCCGCGAGACGGTGGCGATAAAATAGATCGAAAGCAGCAGGATCAGCGCGCCGATCCAGCCGG AAGACGCCAGAAACCACGCACTCCGGCTGCGCGGCTGCGCGGCCGGGGGCTGCTGGCCCTCGGCGGCGGGCGGACCGTCGTATGCCTG GCAAGGATCAGGCACCGCGCCGGATAACGCCAGCGCCACGAACAGTAGCTGCAATGCGTGCTGTATTCCGGAGGCGCCCGCGATCGTG CGCAGCGTCATTGATCTGTTCCTGGGCAGAGAGTGTTGCGATGTGAAGACATGAACCGCCGCAAGCCGACCGCTTGCTTCAGAGCGGC AAACCTTGCGAAAGCTGACGAATGCAGCGTCATCGCATGTTCTTGAGACGGCCTGTTCCTCGACGTCCCTGGCGTGTGAGCCACTGCT ATCGATCGTAGGCTCAGTGAAGGCCGCTTGTCAAGCACGCCGCAGTTGCGCGGACGTGCATCGTTCTCGCAGTCGAACATCACACCGT TACAGTAGGACCGCCGATGCAAGTGCCGCATAAACATTTGAGTTTGTTACATAACATTTTCATAAAGGAACGACGACCTGCAAACTTA ACTGCACTTTCCACACGGCGAGTGCACGCTAAAATACCAGACACATGAAAGTCAATGACCTCGCCAAGTTGCTCGGCGACGCGTGCTA CTTGTTTCTCGCGGTCAACGCCCTGTGGGGCGGGTTCTGCCTGATTGTCGTCTGGCGCCGGCTGATGCAGTTGCGGTTTCGCAGCCAG CAGCAGCAAGCCGAGTTCTTGAACGAAGTCGAGCGGCACGTCGAACGCCGCGATTTTGACGGGGCGGCCCAACTCTGCGAAGACGATC CGCGAGCCGTGCCCCAATTGGTGCAGCTTGCCCTCCTCAACCGCGAGTTGGGTTACGCCAAGGTCCGACAGCTTGTCTCGGACCAGTT CCACAGCGACGTCCTGGCCGACCTTGAGTATCGCGTGAGCTGGGTATCGACCGTGATCAAGAGCGGCCCCCTGCTCGGGCTGTTCGGC ACGGTGCTGGGAATGATGGCCGCGTTTGGCCGAATCGGCACGGGCGAGAAGGTCGAGCCTTCGCAGATTGCCGATGAAATCAGCATTG CGCTGGTCTGCACCGCGATGGGATTGGGGACGGCAATCCCCTTCAACTTCATGGTGGCCGCCGTCAACATCCGCATCCGCAAGCTCCA GGAGACGGTCAACCTGGCGTTGTCGCGGTTCATGGATGTCCTGAAAACCGTCATTTAATAAAGGTCGTTTCGCGCGTGGCAACAGGAA CCGCCGTTGGTGGATTCGCGGCCGGCCGCGATGAGGACGGACCGCTGATCGTCCGCAAGCCTCTCACGGAGGGGAGCGAGATCGACAT GACGGCGATGATCGACCTGGTGTTCATGATGAACATCTTCTTTCTCGTCACCACGCTCACGCAGACGCTGGCCGAGGTGGACCTGCCT GTCGCCAAACGCGTGGTGGCCGCCGACCTCGAAAAGTCGGTGATCATCACGTTGGTGGCGGCCGGACCGAACCAGGCCTCGGTCTACC TAGGCGACGGCGCCAAGGGGCGACCGCTCGTTGACAAGACGCTGGACCAGGCGGTCCGCGAGGCGGTCGAACGGGGGGCGGCAGAGGG CAAGAACACGGTGCTGATCAAGGCCGAAAAGGCGGTCGTGCATCGAGACGTCAATCGCGTGGCCGTGGTCGCCGCTGCCATCGAAGGA ATGAAGTTGAACCTGGCGGTCGCCGAACGGGATTAGCCAATCGCATGTTCCGGTTTTCGTGCATCCATTGTGGCCGACGGCTAAAAGT CTCCGCCGAGCTCGCCGGAAGAAAGGTGCAATGTTCCGGCTGCCGGCGGGTGCTGGTGGTCCCGTTTCCGGAAGGCGCGGGCGATGCC AGCCAGCTCGCGGTGCAGCGCGACCAAGCGGCAGCCGAGCCGATCATTCGGCCTCCCCAGGCACTGGCCGAAGGCGAAGGGATTGATA TGACGGCGATGGTCGACATCGTCTTCTTCTTACTGATCTTCTTCCTGGTTACCTCCATGCACAGCTTGCAAGCGTCGATGGAGCTGCC GCCGCCCGAGGCGCAGCAGGGATCGTCGGCCGGGCGAAGCGTGGCGGACTACGAGCAGGATCAGGAATACGTGATCGTCCGGATTGAC AACGACGACACCGTGTGGGTCGAAGACTCCGAAGCGCCCAGCCCCCAGGAGGTGCTTGCCAAGCTGCGCGAGGGGCGAAAGGACCGGG CCGCCGCCGGCAAGTCGACCAAGCTGCTGGTGCTGGCCAGCGCCGACGCACATCACGGCACGATTGTCAGCGTGCTGGACGCGGGCAA CGAAGCAGGCATGGATGGCCTGCGGCTGGCGATGGAAGATGACCAATAAGGGCAAAGTCCACAAGGCGGGCGGCTCGTTAGGGCGTAA 
TCGAAGCAGATATTTCGCATCACGCCTGTTTTCGCTACAAGCTGTCTACCGCACTCCCCAAGTTAAATAAACGAGGCTGCGAAGGCTC ACATGGTCATCTCTTTCGTTAAGCGGTTCGCTAAGTCGTTGGATGGGCCGATTCTTCTAGCTGCTTTCATCACTGCCGGCTTCTACGC GGTGATGGGCCTCGACGGCATGCAGCATACGTTGGTCCACAAGTACACGACGGAACACGCTACGGAATACGTGATCGTAGCCATGCTC TCCTGGGGGCTGTCGGACCTCGCGCTGCGGTGCGTGCGTTTTCGCCGCGAGAATTTGGCGTTCAAGCACCACTGGCTGCCTCCCCGAC GCGGTCCGGAAAGGGCGAGCAGGGCCAGCGAGTTCCATGCCGCCCTGGATGCTCAACCACAGTGGCTGCAACAGACGAGACTTGGCGC TCGGCTGCGGCAAGCCCTCTTGTATGTGCATCAGAAGCAATCGGCGGAAGGTTTCGACGATCACCTGCGAGACTTGTCCGAACGAGAC TCCCACCGCACGCACGCCAACTACGCCGTCGCCCGGTTCGTCGTGTGGGTTTCGCCGGTGCTCGGCTTTCTGGGGACCGTCGTGCATT TTGGCACCGCGCTCGGCGGCTTTTCGAGCAATGACCTCGCCGCGAAGCTGCCGATCGTCACCGCCGAAATGGGGACGGCCTTTAACAC CACCACGATGGCGCTCGGCACATCGACCGTGATCATGTTGTGCATGTTCCTCGTTGAACGGGCGGAGCAGGGACTTGTTCAGGAGGTC GACGCGCGCGTGGACCGCGAGTTGTCGAACCGGTTCCTGGTCGAGAGCACAGAGCTGACCCCCGTGCTCTCCGCAATCGAATCTTCCC ATCGCGATCTGCTCGGCGCGATCGCCGAGCTAGCTCGACGCCAGGTGCAGGCCTGGCCCGAAATGCTGGCGATGCTGCACAAGAGCCA GCAAGACTGGCAACGCCAGCAGATGCAGGGGTGGGAAACGATTGTCGATCGCCAACAGCATCGTGAGCTCCTGGATTTGCAGAGCAGC TTGGCCGACAACCTGCAATTGCTGCAGCAGACTCGTGGCTTCGACGAGGCCGTCCAAGGGCTAACGGCGGCCATTCATTTGTTAACCG CGCGTCATCAAGGGCCGTCCCTGTCCAGTCCCAAGGCCGCATAGCGTGGTCCACGCTTTCGAAGACAGCGTTACCTTTCGGACTTCAA CTTTGACACGTCAACATAGACGTATTTGCCGCGATTCTCGCGCGCCAGACGCGTCAAGAAGCTGCCGCCCGCGGCTTGTTTTCCGGTC CCGAACTCAATCACCATGATCATCGATAGTCCGCCGTTCATGCGTTTGATGCGGGCCAACTGCGCGTCGGACATCGGGGGCTCGGTGC CGTCGGTCAGGAAGAAGATCGCGTCGGGCTCCATCCGCAGCCCCGTCACCAAGGCCGCTTCGTGATTCGTGCCCCCGTCGGCAGTGAT GCTGTTGACGAACCTCTTCGCGTGCTCTTTCGTCGAATCGCTGCCGAAGGCGAGCCGGCCCGGCTGACCGTACAAGGCGAAGGTCCGC GGGCGATGGTTGTAGAAGATGATCTGAAACTGCTGCGCCTGGTCCAAGAGTTCCAAGCTCGAAAGCAGTTCGCTCTTCGCCGCGCGCA GCGGGGCGCCGCCGCCTTCGCCCATGCTGGCCGAGCGATCGAAGATATAGACGAACTTAGAGCCTTCGGCCTCGACGCCGAACACACT GGTCCGCGTTCGTCCGTCGAGCGGTCGAGGCCGGCTCGGTCCACTCTGCATCCCGCTGCCGGCCAGGACCGCGACAATCAACAACAGC CAAGCTGCTTTCATTGCGGAAATCGTAGCCCGAAGCAACCGGGAAGAACAAGCTTGTGCCGCGATGCCCGTTGATACTTTCTTTATAT CTCGGCCCAGGGCGACGTTGTCAGTCGCAGATGAGACGGTAGCCGACCCCTTGCTCGGTCAAGATGTGGCGCGGCTGGGCTGGGTCGG CCTCGATCTTGCGGCGGAGACCCGCCATGAAGACCCGCAGGTGCTGCGTCTTCTGCACCTGCTGTTTCCCCCACACCTCTTCGAGCAA GAAGGCGTGCGTCAGCACCCGGCCCGCATGACGGACCAGGGTGGTCAGCAACTTGTATTCAATCCGCGTCAAGTGGACTTCGGCGCCC CGCGCAAAGACGCGTCGAGCCGCCAGGTCGATCTTCAATTCACCCGCTTCAAATACTGGGATATCGGCGCCTGCTTGCGCGCCTGCCG CATGCCGCCGCGCCACTTGAATCCGAGCGAGCAGTTCGCCGGTGCTGAAAGGTTTTGTCAGGTAGTCGTCGGCGCCGTGTGTCAAGGC TGTGATCTTCTGCGCATCCTGATTGCGAACCGACAGCACGATGATCGGCGCCTTCGACCACTCGCGCAGCTTGACGAGGACTTCTTGG CCATCCATGTCCGGCAGGCCGAGATCGAGCAGCACGACGTCAGGACGGCACTGCGCGGCCAACAACAGCGCTTGCTGGCCTGTACCCG CCTCCTCGATCCGAAAGCCGGCGCCCGACAAGAACGCGCGCAGGAACCGGCGCATCGGAACTTCATCTTCAATGACCAGCACGACCGG TGCGGCAGTAGACGCGAGCGACATGATTTCAAAGCAGTGCTGTGGCCGCGGTTTCGTCCAAGGCAGGTGGCAAGCCAGGCGGCGGACA AGGCAACGCAATCACAAACCCAGCACCGCCGGCGGGACGGTTGGCCGCGATGATCCGGCCGCCATGCGCTCGCGCAATGGCCTGGCAA ATCGCCAGTCCCAACCCGACGCCTCGCTGGCCGTCGGCGACCACGGTCTTGGCCCGAAAGAATTTGTCGAACACCTTCGCCTCGCTTC CCGCCGGCAAGCCTGGACCATTGTCGGCGACCCTGATTTCAGCCTGTTCACCCGAGTACGCGGCGGTGATCTCGATCCGGCTGCCCGG GGGCGTGTAACGGATCGCGTTTTCCAACAAGTTGACGAACATCTGTTCGATCAGGTCATCCGCGACCCACAGCAGCGGGAACTCACTC GGGATCGAGACCTGCACCACGTGTCCGTCTAGTTCCCTCCGCAAACGCGCCAGGGCCACGCCGACCAACTCCTCCAGCACGTGCCAAT CTCGATTCAACACCGGAGCGCCTGCATCGAGCCGCGCCATGTCGAGAAGGTTGTCGACTTGGCGCGCCAAGCGGTGTGATTCATCGAC CACCGTCTGCAGCATCTCCCGTTTTTCGGGTCGGATCTGCTCCGCGTCCTCGAGCAAGCTGCAAGCGGTCACCGCGATCATCGCCAGG GGAGTGCGCAGGTCGTGCGAAACAGTGCTGAGCAACGAGTTGCGCAGTTGCTCCTCTTGGACTTGGACTTGGGCTTGCTGGACCTCCA GCAGTTGCTGCTGCGACAACTGAAACAACTGCGCCGTGCGCTGTTCTTGTTGCTGCGATACCTCGACCTGCTTCTGCAGTCGCGCCAT GAGTTCGCTGATCAACAGGCCGATTCCCAGCATGACGCTCAAGGTCAGGAAATACTGTGCGTCACTCGGATTGAAGCCAAAGATCGGC TTCACAAAAAAGAAATCGAACACCAGTACGCCCAGCACCGCGGCGGCGACCGCCGGGCCATGCCCAAGCCGCGCGGCTACCAGAGCCA CCCCCGCCAGGAAGATCATCACGATGTTGGCTTCCGTGAGGCCGAGGCTATGACTTAGCCAGCTCACGATACCGCACAGCGCGACGAC GCTGGCCGCCGCCAAGTAGGCTTCCCATGCAGCCCCTACCCGGCGACGAACCGGTTCGCCCGACGGCGGCGCGGTGTCGCCATCAATC TTCGAGCGCTGAAGATCTCCAGCACGGCCAACCGCGTTCCGCTTCGGGTCGTCGCGACCTATTGAGCGATCGATAGTACGGCGGTCGT TGACCATAGGCGAACGGCAAGAGTTTCCTCGATGGCGTGCCCTGCTAGCGTTTGAGAGGATGCGTTGTCAAGGGAAAGTCGATCGTGT TTTCGCCTGGTTTGACATCGGCAGTCAACGTCGTATTGGTGTTGTAGTGCGCGGGGACGAGTTCCCTGAAGTTAGGCACTTCGCCACC TGACTCATCTTCCCGCGGCGTTGTGATCGTGACGGTGTGCTGGCCGACTTTTGCTCCAGGCGTATCGAACAGGTAATCCAGCTTGTAG CGACCATCCCTGTCCGTCAAAGCCATCGAAGAACGACCGTTTTGCGGCGCAAATCCCACCCAGACATTGGCCAGCGGCCTGCCATCCA GGGTTACGGTTCCCGTGACTAACCCCAATTCGGGCTGATCGCTAGGCGTGCAACTGCACCCGAGCACCAGCAGCAACGCCCCGATGGT GCAGAAGGTCCGTTCCAATCGTATGCTCATCACTCAAGGAGCTCGGCCACTTGGCCATCATTGAAGGTCCCCATATCCGCAATCGTCT TCTGGTTCGCGTTCTCACTGACGAATCGAACGCTCCCATCGGTGAGGGCAAACTGGGCGCCCCCCGGATGTCGGCTGGCGAATGCATT GATTGAGGCGCCATTGATCGCAAAGGTTGACGGTGGCAACGCAAGTTGCATGACCGTATTCGCAATTTGCGTATCGGGCGCAACCCCC AACCAAAAGCCTCCCGTGTATTCGCCGGGACTGAAGGTTTGCCGAACGCCATCGAGATCACGTCGATATTTTTCGCCCACCAGAAACG TGGAGCTCGTGCCGTCCTTGACATCGCGCAACGCTGTCTTAAACAGCATTCCATTCACAAAGATTCCCTTGCGTCCCGTGGCAGCCGC GACACCCGAAAAATCCGTGCCCGACACGCCGACATAGTTCGACTTCGCGTGCGAGCCGGGAGTCGCCGGGGCGGCTGGGAGTCGCGTG TCATTGAGATCCATGTCGCCAGCGCTGGGACAGATGTAAAAGGTCAGTCTCGTCTTCTGCAAAGCTTCGCTCCCGACAGCCGGACTGG CCTGCGCTCCGGTAGGTATTCCGCAGACGGTTTGCTTGGAAACGGGTGCGAGGGCAGCGTGAAGGCTCGACTGCTCCGTATACGGCAG GATCAATGCGCCCCAGCCCCACCCTCGAGGTTGCGCAGCGGCGCCGCTATTGACGGTCGAACAATTCGCGGGAGGTTGGCCAAGATAA CCAGGCGGGAAGACGTGGAACACATCGGCATACGTGTGAATCGCCAGGGCCATTTGCTTCAAGTTATTGACACACTGCGTGCGCCGCG CCGCCTCGCGTGCCGCCTGCACAGCGGGCAGGAGCAATGCGACTAAACGACCGTGCATGAATCTGGGACAGGGCCACAGGCCGTTGCG ACGTAACGGTGCGTGCCAGTGCGACGGCGTTGGGTTAGGTAGTCGTGGACGCGCTGCATCAGTTGATCGATGGTGATGCACGTATGGT TGCGAGTCACATTGTCGTGCAGGTCTCTCCACAGCCGTTCGATGCGGTTGTGATCCGGGCAGTATGGCGGCAGGAAGTGCAACTTCAC GCGATCGCCCCAGCGGGCCATCGCTGCTTGCACGGCGCGGCTGGTGTGAATCCGGAAATTGTCCAGCACGAGATGGATGGTTCTCGCG GAGGCGTACGCGCGGCTGACCAGATGATCCACCAAGCCCACAAACAGCGCGCTGGTTTTGCGAAGTCCTTCGACCCAGGCGATTCGTC CGCTGACGGCGTTGAGCGCTCCGGCCAAGTAGCGTTTCTCGTTTTGTCCCGGCGTCAGCACTTCCTTCTGTTGGCCACGCAGCATCCA GTCATCGCCGATCTTGGGGTTGAGGTGGATGTCCACCTCATCCACATACAGCATCACTTCGTCGGGCGGCAGTTGTTTCCGCAAACGG CGAATCGCGTTCAAACGCCGCGTTTTCTTGTGTTTCGACCAGGGGCACGCCACCATCGGCTTGGGACGGCCGCGACGTACGCCGTGCC GCGCCAGCAGCCGGCTCATGGTGGTTGTGCTGATGCAGATGTTGGTTTGGTTGGCTGCCACGACGACCAGCAACTCCTGCGTCCATGT TGGTCGCTGAAAGCCGTATTGCTGCGGCGACAGGGCCACCGCGACGAGAACGCACCATTCGTACTCTTCGGTCACCTTCGGCTGGCCG TTCTCTTCGCGTTGATCGACCAACCCTGCAGGCCCATCCGTCAGGAACCGTTTTGCAACGCGATACACTTGCGAACGGCCGCAACCCA GAATCGACGCGATCCTCCTGGGCAGTTCACCGCGCGCGAGATTCCGCACAATCTTGCAACGCACCATCCAACCAGCATTCGCGGAATG CATCGAATCCGAAATCAACCAGCGACGCTCTGTTTTCAATAGCCGCTTCCAAGCTTCCATCACTTGCTGCACAATACGCATGGGAACT CCTTTCACTTGCTGCGAACTGATCCTCAACGCAAGTGTTTGCGAGTTCCCGTTTTATCTATTCGTCCCAGGTTCGCGCAAGCCTATTT AGAATGCCAATGATGGCGATCACCACCAGCAGCTCGACCAATGTAAAGCCGGGTCGTTTCACGTCACTCCTCGCGTGCAATGATGGCC AGCCGAAATGAGTGCAGTCCGCCGAAATGAATGCAGTCCAAGGCGCAGAGCGTTCAAACAGTCTAGCCCAGGTTGCGCACTTGGGAGG CCGGAGTATCATATTCGCCGGAGAATCCGCAGGTCGAGGCCGCGAGTCTTCACTACAAGAGGCGGTCGGGACTGAGCCGTTCCGGAAG 
TTCCAGCTTCAAGGAGGCCAGGATACGGGCTTGCTCCGGCGTGGGGCGAGCGACGCGGCGGAGGGCGAGCTGCCGGCCGTCAACCGTC TTCAGCAGAATGTCCCCAATCTGCACCTGAGCGAGCTCTCTCAAAATGGTCTCCGGGGTCATGGGGCGTGGCTTCGGCGAGGCGGTCG GTCGATCCATGTCCGGCTTGCGGATCAGTGTCTGTAAGCCCGCTTGCTGGGCCAGGTGATCCAGCGTCTTCCAAAGGGCATAGGCCAG GACGCAGACCATCACATGCGCCTGGGTGCGCCCGTCGTAGTGGTGCCAGATGGGCCGAATCAAAAGCTCGCTTTTCAACACGCGGAAG GCGCGCTCCGCCACGGTTAACTGCATATAGCTCTCCCAGAATTCTTCGGGCGGCCAGTCGGCGTAGTTGCTCTTCAGCAGGTAGGCGC CGTCGCGAGCGAAAGCTGCCCGAAGCAGATCCCGCTGCCATTGCCAAGCGACTTCCGGCTTTCCCTGCCGGGCGACTGTGATCTGCAC CAGTCGCGCCGCCTTGGGAAAGCGTTCCTTCAAACGTCCCACTCGCTCGATGATCTTATCGCGCGCCTTCAGTTTGCCCTGTGCCACG CGGCGACTCAGTCGCTTCAGAGCATCACGCAAACCTCGCGTGTGGCGGCGACGCATCGCGCGCTCCTTTGCGCGGCGCTGGGAACTGC GCGCCAGTAGGTAAGCGATGCCATCCCGCTGCACCGGCTTGACTTGCACATCCTCGCGAATATCCAGCCAGCCGGGCTTCGCCAACTC CTCTTGGAACTGGGCCAACTCGCTGCGCAGGGTACCGATCAGATACTGACGCGGTGACTGGCTGAGAAACTTCAGATTGTCTTCACTC ATCATGCCGCGATCCATGACCCAGATCCGCCGGCTCGCGCCAAAGCGTCTTTCGATGGCCGTCACGATGGTTTCCACGGTCTTCACAT CGCGCGTGTTGCCGGCCAGCGTGTCATGCGCCAACGGGAAGCCTTCGCGCGTCACGACCAGAGCCAGGATGATTTGTTTGCAGTCCCC ACGATGGTCGCGAGAGTAGCCGCGCTTGGCCAACGTGTTCTCCTCCGCCAGGCCCTCGAAGTAACTGCTGGTGAGGTCATACAGCAGC ACGTCGTAGTCCAACTTGAACAACGTTCCTAGCCGATCCTTCAGATCGTTCTCGATGGCGTCTTTGGCGGCCAGCAATTCGTCCAAGA TGCGATACAAGCGGTCCTTCGTGATCTCGCTGTCCGGCACACCGAGCAGGTCCTCGAGCCCTGTCGAGGCGTACCAATGTTCCGCCAA AGCAAACTCACTGCACGGCGCGCACAGTCGATTGATGACTTCGATCGCCACCACATCAGCCGGCGCCACCGTGTGACGGCCCAGCGGC AGATGCTGCGCAACAATTTCATCCAGCTTCAGCAGCCGCCAGAGCCAAAGTGCCAACCAGACGTTGCCGAAGGCACGTGCATTGGTCC AGCCTGTCGCTCCCAACCGCACGCGAACCACATCCGGTTCGTCGGGGAGCGAGACGTTCGCCTCGTCGGCAAACAGTCGCAGTTGTTG GACCTCACCGTGGCGGTTGTAGAACGACACGGTCCGCTGCCAGCGTCGCTGCTCGCCAGTGTTCAGTTCGCCGAGGTGCGCCACCACG CGCTGTCGCGGACCCGCATCGGTGCGAACGCTCTCGACCAAGGCGTAGTACGTGAACGCCTTGCCGGCTGCCTTGCGGGTGTATCGCC GCAGAAACATCCGTGCCTCCTGGCGCACCAGCATGGCAGCCGGTACGGCGAAGGCAAGGCAGTAGGTTTCCACTACATCGCCCCGCGA CGGTTTCCACCACCATCAGCTCTCGACTTACGTCAAAAATGGGGCGCAAAAAGGCCGAAAATCGACAGACTTTTCTTCGAAGTGCGCA AGATGGGCTAGTCAAAAATAATCGCGGGAAAAAGGAGCACGCGGCGCACTTCATGTCGCCCGAGGCGCTGGTAGCGGCGGGCCGGGAA ACTCAACGTGTCGGATGGATGCCAAGGTCATGGATGAAGGCGACCGCCAGCGGTTGCTGGGCCGCCAGCATCACGGTGTGCCTAGCCG CTCGACCGTCGAATCGGCTTGAGCGAGCAGCGACTTGAAGTCATCGCGCTGGCGGAGCGGGTTCAGGTCCGGCTCCGATTCGAGATAA ACGGCGTCGCGGTAATCTCGCGCGATTGCGGCCCTGAGCGCGGCGATTGCCGTTTCGGCGTAACCTTTTTGCAACTCGCGATCGGCGG CGGCGCCGGAACACTGGGCGAAGCAGCGAGCCACATCGATCAGCAGTTCGTTGTCGGGCGACTTGCTCCGGCGGTACTTTTCAGCGAT GGCCGCGGCCTGCTCGTGTTCCCCGCAGTGGACCAGCGCGAGCATAAGTTCCATCTGGCGGCGATCACTTGATTTGTCTCGGAGAACG AGCGCTTCACGGATCGCGCGGCACTTCTCGAAATGCGCTTTCGCCGCGGCCGGATCGTGATTGCTGAGGGAATGGTTGGCGAGCCTGT AGTGGGCCAGGCCCAGCTCGCGCTGAAACACAGCCTCGTAAGGATCGTCCGCGACCAATTCGTTGAGCAGCGTCCGAGCCCTCTCGAA GTGTTCCGCAGCCGAGTCCCAGCTTCGGCGGTGCAAATAGATGTCTCCGAAATTGCCGTGCGCGCCGGCGCATTGCAGCTTGAAGCCG CGGTTCTTCGGGTTCTTCGCGAGCAGGTCTTCCCGCGCGGCCACTCCTTCGCCGTAGAGTTTGATCGCGGCCTCCGGGTCATTCGCGC GATGCTTCATCTCGCCCTCGGCGAGGATTGACGTAGCGAGCGCTTGCTGCAACGTGCTGAGTGCCGGCCGCCGCGCGTCGTTGGGCTG CAGTGCGGCGACTGCGGGATCGCTGGAGACCGTTTCCACCAGTTCCCGGCGTATCTCGTAGGCACGATGGAAGTGTCTCGCGGCCGCG GCCGGATCGCCTTGCCGGAAAATCGTGGCGGCCACGCGGGCCTCGTCCTCGGACGACTCTACGCGGACAAGAAACGGAATCGCCGCAT TGCCGTCGCCCGGATGGGGATGGTCGAGGACGTCCTGACGAATTGCCAACGCCTCGCGGTAGTACTCGAGCGCCTGGGGCAAGTCGCG GCCGACCTCGAGCGTCGCACCCCCCAATTCTCGCAACGTCAGCGCCAGATTGCTTCGCGAGCTGTCACTATGTTCTTTGATCACGACG CGTTTCCGCGCGATCGTCAGCGCATTTGAGAACTGCTCGTGTGCCTTGGCCCACTCGCCCATTTGTTTGAAGAGCACGCCAAATTGAA TGAAGGTAGCCCACTCGGTGACGCCGATGGACGTTGAGGAATCGACCTTGTCGGCGACTTCTTTGAGGCCCTGTGCCGCGATTTGCAA CACCGCTCGCCGTGCCTCTTGCGTCTGCGGCGCCTCTTTCAGCCGCTGTTGCACTTCGAGGATGAGTTTTTTGATCGTCCTGACCGCA AGCGTCGATTGTTCGGTGGCTGTTTTTGCGTTCGCATCGGCGATCTCACGAGCCGCGTCGGCCTTTCGTGCTTCTTCTTTGGCGATCG CTTGCTGCTCCACGGCGTTCTTGGCCTCGCGTTGAGCGGCGCCCCGGGCCTCGATCGCCGCCGCCTTTTCATTCGCGATCGTCGTGTT TCTTGCCTTCAACGTCACCGCAAACGAAAGTGAAACGATCGCGGTCGTGACCAAGAGCAAGATCGCGGTGGCACTGGCCAGCGCGATG CCGGGGTTGCGGCAGCTCCAGCGCCAAAGTCGCTCGCCGGTGGAGACCGGCCGGGCCAAGATCGCTTCGCCTTGTTGGAATCGCCGCA AATCGTCGGCGAGGGCCTCCGCCGTTGGATAGCGTTTTTGTGGGTCCTTTTGCAGGCACTTGAGGCAAATCGTTTCGAGATCGCGAGG CACCTTTGGTTCAAGGCGGCTCGGCGGGACCGGTTCAGCCTTCACGACCTGTTGGATCGTGTCGATGGCGCTGGCGGCGAGGAACGGC GGCCGGCCGGTGAGCATTTCGTACAGGATCGTGCCGGTGGCGTACACATCGGCGAGTGGCCCGACGTCGTGCACGTCGCCGCGAGCTT GCTCGGGGGCCATGTAGCTGGGCGAGCCTATGATTGAGCCGCTGCGCGTCTGGCCCGAATCGAATTCGAGGCGTTTCGCCAGACCGAA GTCGCTGATCTTGGGAATCGCGTTGCGCAGCGGGCCTTCCGTGAGCAGCTTCTGTTTCACGCGGTCGAGGCTCGTGGCCGACGAATGG TCGCTGAACGCAAGCAAAATGTTCGCCGGCTTCAGGTCACGGTGGACGATGCCGAGTTGGTGTGCGCAGTGCATCGCCCGAGCGATCG TTTCCAGCAGCCGCGCGGAATCGATCGGCGGCTGCGGCTTGCCGGAGATCTTTTGAGAGAGACTGCCGCCAGGCACGAACTCCAGCGA GAAGAAGGGCAACCCCTTGTGCTCGCCGACCTCGTAGATTTGCACGATGTTCGGATGTTGCAGGCTCGCGACCGCCTGGGCCTCGGTC TGAAACCGCGCCAAGTGGTCTGCGCCCGCATGCTCGCCGGCCAGCATCATCTTGATGGCGACCCAGCGATCGAGCCCTTTCTGCCGGG CCTGATAGACTACGCCCATGCCGCCGTGGCCGAGCACGCCGATGATCGTATAGCCGGGGATCTCCGGCCGTTCTCGCTTCAATTCGGA CACAGACCTATCAAGGCGCGAATCGTGAGCCGGCGTCGCATACTCACCCGTGGGCGCAACCATGTCTCCGGTGTTCTCGTTCGCAAAC TCGACGGTCGGCGCTGGCACAGCCGCGGGCTTCGACTCGCCCGGCGTCGTGCGAGTGCCGCCCAGCGCAACTTGATCTCCAGATTTGG AATCACGTGATGCGTTCATGTGCAAGCCTCGTGGCTAAATCCCCGCGATGAAGTCGATGTCGTCGGCAAACTCATTCGCTTGCAGGTC AGTCACCTTGTCCTTCAGCGCGTTCGAGCCGTCGCCGTCTTGATTGAACAGGAACCAGTCCTGGCCGGAGCTTCCGGTAAGGATATCC TGGATCAGGTCGTCGCTCACAGTAGCACCGGCGTCATCGGTTTGGAGGAAGACGCTGCCGTTCAATCGTGCTGCGAAGGTCGCGCCGC TGCCGGTGCCCTTCAGATTCGCGACGCGGTCGGCGTAGCTGCGCGCGGAATTCCATTCGGCCATGATCGAGCGGAGCGCCGCGTCAAC GGCGTCATGTGACGTGTGGCCGGCGATCAAGATATCGTCATCGGCGTTGCCCACCATGCGGTCGCTGCCGTGGCCACCGATCATCACG TCGCGTCCGTTGCCGCCCACGAGCAGA 


\subsection{Das Cosmid slc_1q}

\subsubsection{Festlegung der Gene über “Genemark”}

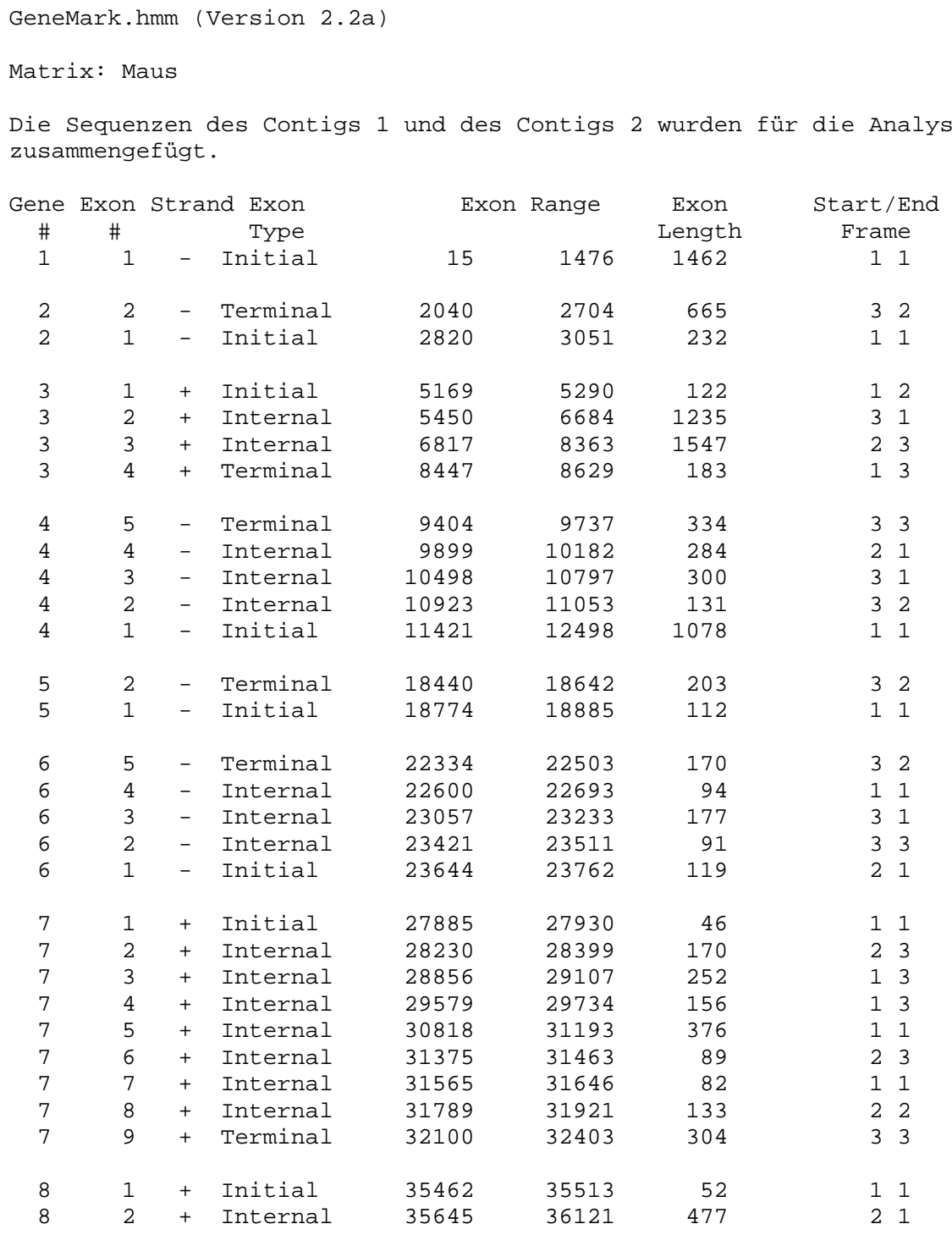

\subsubsection{Aminosäuresequenzen der übersetzten cDNA}

1|GeneMark.hmm|gene 1|487 aa

MASSSSPPHYSCRRRRHRTSAKKKLSSRDERDQLAFLILNGLEYSEERHSVNIVMLYNSLFATYYDENKSKQMSMDVESTYRGLTLDD ADYNESTFRQLLDSFGADRRLHAKYALEMFERVKELLKPMANVRSFDLSSRESTNEDDDADDDDDDDDDEKREPSTCIVCGDLHGHFD DLLNIVNRFSTPGKSCYFVFNGDWVDRGSKQIECLLTLFYAFVMYPHRVFLNRGNHEDRAQNSLKAYSPCLKMAALSYFGKYGLVVYN KLNEVFRHVPIAVI IGNPGTGQRYFVVHGGLNDAIDLDELQRGDRSRLTSLCRRPTGTGPSDEYERFRATVTDLLWSDPMAKNGLKYN ANRNIGKLFGPDVTARFLAKNQFTRLIRSHECKQNGYEIMHNSKLITVFSASNYTLQNRASVLKIVYGRPKIDILTYNSTSKSSGSSS SSSSTKPTPNHMVDSCHDDDDDEDGLDHLSRAIKSLKAVI YRSKDPF 
_2|GeneMark.hmm|gene 2|298_aa

MLERILLLCIFVAVAVALLPSNLDHVLKESGSLLLDARQIEACAATNNQLDASGAYTDELVQRPRPEGQRKRTRSDQNDDYDDDDDDD DSFHFDFVRLRRARCHYGHNAGLRCPWMNEYIFGTRIDTDIIDLEKTATLLHQALNFIAHVTFRGGI IMFVSRQAQSIPVVERMTMNV NEYSMCKPWPSGLFTDSTRQFGSVIRLPDTVVFLQTQSSLNEQHPAINEAAKMLIPTVAVCDTDSDPSLVSYPIPGNDDSIVSIHYYC SLFERTILGAKQKRSKLESQGYQFQYGVKQQSSS

_3|GeneMark.hmm|gene 3|1028_aa

MKTFTFDKVFGVTSKOSEVYSOVVRPVVLEVIEGYNCTIFAYGOTGTGKTFTMEGDRTPSADDCVSWDDDPLVGIIPRSVNHLFTALS MTNCEYSVKISYIELYNEEVSDLLSDSIENSEAKLRIFDDANRKGSVIIPGLEEVVVKNRNEVYKIMQKGADKRQKASTLMNAQSSRS HSIFTVTVFIKEKSIEGEETIKVGKLNLVDLAGSENIERSGATGRRAAEAGKINKSLTTLGRVITALVEHRDHVPYRESNLTRLLQDS LGGRTKTTIIATISPAQCNFEETLSTLDYAHKAKSIRNKPEINQKLVKKALIKEYTEEIDKLKRELLSSREKNGIYLPEDIYQEMASK VDTQKEEIRENLVKIAGLNEEIEKLNDLFHETKIHLDEKCVMLADTNKKLSETERTLDSTKRECDETKYVLDIQVKSEEKLFDQAQYL LKLSNETKDDCQGLHSKLERLYLMTEKNQCLTTMFSKEIIETFVRMIESSSNHTKTNSSKLCTVCDLLQKAFAKLGMLKEEMLQQLTF FDEKQTSWLMQQESFVRKQIEASFLQFYENFFKTSNEHHEKNVEFVADLEMLCLEHKHELSEIERKQAVSLSKIDARAGEFELDLESR AEQFLTSNKVQLVDVNETRYAEKLTSLSQTVDSMQREVKEMNRATACWSKELGETLFSFEQMIKSFSTGISHKLSYMHAKFEQLSSQS EOTLAELGOLKLDIASNNAAFVDESRKRFHADIYATASEFVEATRHEVSECOLTNAIFKERNACLNEKLCGELGSFKIAOSDNNTALN TFVTMKLNELDKDCKHLQANFKSYSRQSADHLSEYLVHPLEQETASLAGLLDESARLVKSSNNSIEMFGAQTTQVHENNIKCVEQFCE SEYLSDAPTGQTPRDSKVYKTDVSLSKTKAHQLLLDEYRSMQATSRAAESPLELTPTPSSSSSSVSLQSSTSPKSLAKSKSQARLNPD VLPSQQLKRQFNDKENNNNNNNNENERVMNVPKLIVTGPKAATLQKNSAPPSKKAFHEKN

4|GeneMark.hmm|gene 4|708_aa

MNPSKCVKYMRNVFLILKFLVQSRRALVKKILVGTGLSVTLLFVLAKLVRRHLAKFASSNKLHILSKLSTPSNETTSKSSRNPGLDRQ FLAEMKYLLSIMFPSLVSKQSALLAMHTLTLVCRTFLSIYVAKLEGSLVKNIVQKSPKTFAKNLLYWLLIALPATTCNSLIRYLESNL DLQLKSRLVDKSLERYFKDRTYYRIALSMNENVQIDQNLSEDTEKLTHLLVHLYSHLTKPILDIVLITASL ISMAKSQDFNYMLPSAI GFGVMGATAMLMRAISPRFGQLAAEEAKRKGYLRFLYSRIQANSEEIAFYSGEKIEVNMIKKSYRFLKEQLEFIYFNKLWFIIIEQFF MKYIWSANPNASEVSAADQDLLTRTEQFTIAKHLLVSSADAFERIMTSYKEVIELTGLVRRVYEMYQI

FDACSQTIEQDPNNNDKNLNYFMSMPKLKLQSAENNETNGQLLALAESAGQIYESNEQNSI IVESISVITPNGDVIVPSLTLKSGVIY RPKLNEMFYIPQKPYLPIGTLRDQIIYPDSLDDMRRKSIRDEDLMSILDIVNLQNVVIREGGLNTIADWKDVLSGGEKQRIGLSRLFY HKPKFAFLDECTSAVSIDVEGKIYLSAKNDYNITLLTIAHRATLWQYHDYILQFDGHGKWKFEELNKNLTERLNLKQEKENLEKSLLS IANSKLRLKELCELLGEDSVVLDD

_5|GeneMark.hmm|gene 5|104_aa

MRKKVLLMGKSGSGKTSMRSIIFANYIARDTRRLGATIDVEQSYVRFLGNLVLNLWDCGGQEAFMEHYFTAQRDNIFRNVEVLIYVFD VESREIDKDIHYYQSW

_6|GeneMark.hmm|gene 6|216_aa

MQQYFTTQREYVFKKVEMLIYVFDMDSKDLEKDIFYFRCCLQAMLMHSPKAKMFCLINKMDLVAEENKETPLNCVYFGTSLWNESMYK AWSNIVNELIPNGAYLKKSLKQFADVIEADEILLFEKTTFLSIEIKNANYTIVLDQFTPNSYIMVIISDQRITPALATHNIKYAQKHF ENLETLTTKTPASTTGNSNNVTATIVNNNQNSFRRNLPGI

_7|GeneMark.hmm|gene 7|535_aa

MMKGISVNEFGGPEKSGVISKLGKNVKNFSVGDRVFTVNSDSGTYAEYALCSPLYTFKLSDKLTFEEGSGIGVGIAATQLAKAHGMKV IGTAGSVAGLNLVKAQGADYVFNHKDTDYMEKIRSINPDGLDLIIEMIANINLNHDIHILKWKRGRVVDDLHLMYSHINQMIEMGSIK PIVGHSYPLEEASKAQNDVINNAGSTGRLTLSVRSLESERHFVGHEQWRSLYKAVVLSDDRREWRNDSNQREEQMEVHRHARRRTHAH RALDQLVAVROOAGVGKLRRLHNHMEAOCDDTVVRVDRSLGRTRERGOVHGMVLRRRLFGLMLERSORLVSDGDDMECSSVLTIHDOD VKHVLWHPHKNLLVSSSYDDTIKFSAPDIDDWSCVATLASHNSTVWSCDFNVDGDRLVSASDDKTLKVWKEIDHPDQKTKNGTVKWSK LNNLIATACADNSIHIFREADDTNAPEESDELLRAHRTSLKLVHHEQNAHAQDCNCVDWHPKQSNVLASCSDDGSIKIWMLDLLTADA DSVAGTL

_8|GeneMark.hmm|gene 8|176_aa

MTDEVHNGNKLDDEDLKSNKSESSKHAENVTPSQRVADGTGSKSSASSSLSLADNLQSLLKQLQQQSMASVIESDEDEASMHQRLLES VYMQQKQLAKSSHQHESAKANVMASTSSSSSSSTLISNNWNSWISNLNGNNNGQQHDSMFNSTTQLLKANSIASLASALVRTGLAKFM

\subsubsection{Sequenz des Cosmides slc_1q}

\section{Contig 1}

CAATTAACCCTCACTAAAGGGATCTTTCGATCGATAAATCACTGCCTTGAGACTCTTGATCGCTCTACTCAGATGATCTAGGCCGTCT TCGTCGTCGTCGTCGTCGTGACACGAATCTACCATATGATTCGGCGTCGGTTTTGTACTACTACTACTACTGCTACTACCACTACTCT TGCTCGTCGAGTTGTAAGTGAGTATATCGATTTTTGGGCGTCCATAGACAATCTTGAGAACGCTGGCTCGATTCTGGAGCGTGTAGTT GGACGCGCTAAATACGGTGATGAGCTTGGAATTGTGCATGATCTCGTATCCGTTCTGCTTGCATTCGTGCGATCTAATGAGCCGAGTG AACTGGTTCTTGGCTAGAAATCGCGCTGTGACGTCGGGACCGAACAGCTTGCCGATGTTGCGATTCGCGTTGTACTTGAGACCGTTCT TGGCCATGGGATCACTCCACAAGAGATCGGTGACAGTGGCGCGAAAGCGCTCGTACTCGTCGCTTGGCCCCGTGCCCGTCGGCCGCCG ACAAAGACTCGTCAGCCGAGAGCGATCGCCGCGCTGCAACTCGTCCAGATCGATGGCGTCATTTAGGCCACCGTGCACGACAAAGTAG CGCTGCCCGGTGCCCGGATTGCCTATGATGACGGCGATGGGCACGTGGCGAAAGACTTCGTTCAGCTTGTTGTAGACGACGAGGCCGT ACTTGCCAAAGTAGCTCAGCGCGGCCATCTTCAGGCATGGGCTGTAGGCTTTCAGGCTATTCTGGGCTCGGTCCTCGTGATTGCCGCG ATTGAGGAAGACGCGGTGCGGATACATGACGAACGCGTAGAAGAGAGTGAGCAGACACTCGATCTGCTTGCTGCCTCGGTCCACCCAG TCGCCGTTGAACACGAAATAGCAGGACTTGCCGGGCGTCGAGAATCGGTTAACGATGTTGAGCAAGTCGTCGAAGTGACCGTGCAAAT CGCCGCACACGATACACGTGCTCGGTTCTCTCTTCTCATCATCATCATCATCATCATCATCATCAGCATCATCATCTTCATTCGTGCT TTCGCGCGAGCTCAAGTCAAACGAGCGCACATTGGCCATGGGCTTGAGAAGCTCTTTGACGCGCTCGAACATCTCGAGGGCATATTTG 
GCGTGCAGGCGGCGATCGGCGCCGAACGAGTCAAGCAGCTGCCTGAACGTGCTCTCATTGTAGTCGGCGTCATCGAGCGTGAGGCCTC TATACGTACTCTCCACGTCCATACTCATCTGCTTGCTCTTGTTCTCGTCATAGTAAGTGGCAAACAAGCTATTGTACAGCATGACAAT ATTGACCGAGTGTCGCTCCTCGGAGTACTCGAGGCCATTGAGTATGAGAAAAGCGAGCTGGTCTCTCTCGTCTCGGCTGCTCAGCTTC TTCTTGGCACTTGTTCTGTGTCGTCGTCTACGACACGAGTAATGCGGCGGCGATGACGACGACGCCATCTTCTTTTCTATTTTACGAA CTTGTCTCGCAAAATGAGTCAAAATGATCAAATGCAAATGCAAATGAGCGCGGCGAATTCGAGCAAGAAAGAAAGAATGAAAGAAAGA GAGCGAGCGAGAGTGAGAGAGAGAGAGTTTCATTTTCTCTCGTCGCCATTTTCTTAATTCAATTTAAAGCGAACAACAACAACAACAA CAACAAAAGCTACACAAATTAAATTATAATGATGGTTGGTGGTTGCTAATTCGAAATTTGGTAACCATAATAAGGCTCTACATATACG ACCACGACCACATAACTTAGTTACGTGTTCTCATCTTCGTTTCGTCTTCTTTATTTATTAGTTGGAATTTGCCACACATGCCATAATA CTTATATATAGCTATAGCTATGCGGCTATTTATTTATTGCGAACAAGAAAATAATAATAAAGGAAGAGAAAAAAACCTCCACACAGCT ATAGTAGAAGTCAGTCAAATAATGGAAAGTGAATGAAGGCTACGCGTTGTGAGTTGAGTTGCTTGATCGTGCTGGTTAAAAGTTAGCG TAGTAGGCGTCGTGCTCAGCTCGACGACTGCTGCTTGACGCCATACTGAAACTGGTAGCCTTGACTCTCGAGCTTACTTCGCTTCTGC TTGGCGCCTAGAATGGTCCGCTCGAAGAGACTGCAATAGTAGTGAATGGAGACGATGGAGTCGTCGTTGCCCGGTATGGGATAGCTGA CGAGACTCGGGTCCGAGTCCGTGTCGCACACGGCTACGGTCGGTATGAGCATTTTGGCTGCCTCGTTGATGGCCGGATGCTGCTCGTT GAGCGACGACTGCGTCTGCAGGAACACGACCGTGTCGGGCAGCCGAATCACCGAGCCGAACTGACGCGTCGAGTCGGTGAACAAGCCG CTCGGCCATGGCTTGCACATGGAGTACTCGTTCACATTCATGGTCATGCGCTCGACGACGGGTATGCTTTGGGCTTGGCGGCTCACGA ACATGATGATGCCGCCGCGGAAGGTCACGTGAGCTATGAAGTTGAGCGCCTGGTGCAGCAACGTCGCCGTCTTCTCCAAGTCAATGAT GTCCGTGTCGATGCGCGTGCCAAATATGTACTCGTTCATCCATGGACATCGCAGGCCTGCATTGTGTCCATAGTGGCATCTTGCTCTT CGTAATCGAACGAAATCGAAATGAAACGAATCATCATCATCATCATCATCATCATAATCATCATCTATGAACAACAGTACAGTACGTA ATGATTATTTTTCGGCTTACTTGAAAAGATCGTCGAGTCGAATGAGATCTTTGAGGCCAAAAAAGTCGGGATCGTGCAAAGGACTAAT TACTTTGGTCGCTTCGGGTTCGTTTGCGCTGGCCTTCTGGTCGCGGGCGTTGAACGAGCTCGTCGGTATATGCGCCGCTCGCGTCGAG CTGATTATTGGTAGCAGCACATGCTTCGATTTGACGAGCGTCGAGCAGCAGAGAACCACTTTCCTTGAGAACATGATCTAAGTTAGAT GGTAGAAGAGCAACAGCAACAGCAACAAAGATACATAGTAACAAGATTCTTTCGAGCATGATTGCCTACTCATACTCATATAGTCTAG CATTCGAGCGAGTTGAGGTAAATAATATCGTATTAGAATCGTTTTTAATGTTTTTAACCTTTAAAAACACGAAATCAAAACAACTCAA TAAACAAATTTATTTACCATACCATATAACTACATACATATACTGCTCTGCATTCACACACACATCACATCTTATGTGATGCTGCTGT ATAACACGGTATCTAGCTATAATTATTTCAAATAAAAACTCAAAAGTGCATCATATAGCATCACACCGCATCATACACAAATACTAAA TCAAAATACGCAGCATAGTACATATATAAAAATTCAACTATATACGTACATCAAACGTACGTTGCAAGCTGATGTGCTGTCTGAGAGA TGACGATGATTTGATACCATGATCTCATATATAGATAGACGTATATAGAGACTAAAGAAATGCATTCAAATAAACTGAAAATACTATA CATACACAGCAGCAGAAGTTTTGTATGTTAAGTTAGTTTTGACACGTGATGCTTGATATTTCTGGAGCGCGTAAAAGACTGACCATAG CAATATATGCTGCTATGTATACAATGTGTGCTGTGTGCATAAAAGGGACGTTAAAAGTAAATATGATTAACATGTACATATATATATA TACTGATGTATATATGTATATGAATAATATAACGAACAGCATAACATGATGCATCATCATCGCTCATATAATTTAAGCCCCTTTTTGA ATATTCTGGCGGTTATTTGTTTATATATATGCTGTGTGTTGTATATTTATAGAAAAAGTTCGTTAAGGCTGATGCGCGATCTAATATA TATAGCTTTAACTTTAACCGACATTCTTCATTCAATCGATTCAACTGCTGGCGATTAAATATAGACTATAGATAAGTTACAAGTGCTG AATCTGCTCTATTGACACTATATATACAGTATATATGTATAACTACTGTAAATCCTTGATAATATGACCCATGGTCTTATTTTCAACG TCTCGTAAATAAGACCATGGTCTTGGATATTTTTTATTTTTTTATTTTTCTGCCATAAAAAAAACATGGTACTATGGTTTTTATTGTCA TATTATCAAGGATTTACAGTATATTTGGCAATATTCAACAACAACATAAATGGTCTCACTATATATATATATATATATATATACATAT ATACGTATAGAGGAAAAAACGTAACCATATCGATTCGTTTGATGATCGGGCGCCGTTTTTTCGCAACATTTGGACAAAACCATCAATC ATTGATCCTTTCTTGTTTGTTTCATTTGTTCATATGTTTATTTTATTTTATAGATACTCAATAATTTATTAGATTTTCAGCAACACAT AACACAACACATCACAAATCATTTGAAAAAAAAACAAACAAACAAACAAGTAAAGACATTTAAAATTATATTTGCTGCTGGTAGCTTTT TGTGTTTCCCTTTTCTCTTTTTTCCTATAATCTTGATTAATAATCTTTTATTGTTCTTTGTAGAAATAAAGTAGAGATTTAGCGTCGTG TTTGATTGGCTTTTATCTAGACCTTTGAACGCGAATCTATATATCTGTTTATCTATCTATCTATCTATCTATCGTAGAAGTAGTAGTA GTAGTAGTAGTCGTATTAGTCGTAGTAGTCGCTACTTAGTGGTTATTTTACTTCTTTTTGTTTGTTTGTTTTGGTTTAAATTTCGATT TCAGAAGTTTAAACGACAAAGAAAGAACAAAGACCTAGATTTTCAGTCAGCTTTATTTAAAACGAATATTTATTTTTCTAATTATTGA ATCTAACAACAACAACAACAACAACAAACTCAAACTCCAACACTCACTAGTGAACAGACTCAACAAGACAGGAAACATGGCGCAAAGT TCACAATACATTCAAGTGGCTGTCAGATGTCGGTGAGTAGCGATGAAATTCACTTCTTTCTTTTTTTAAAATGCTGTTTCGTGCTGTTC GTGACCACTTATTTTTGCCAATATACCATATACCATATGGCTAAAGGCCGCTGAATGATCGCGAGAAGAAAGCGAACAGCGTGTCCGT GTGCGAATGCAACGAGAAGCGCAAAGAAATCAATGTCTATGACAAAACGTCAAGTGTGGCGTCCATGAAGACGTTCACCTTCGACAAA GTGTTCGGCGTCACGTCAAAGCAAAGCGAAGTCTATAGCCAAGTGGTTCGACCCGTTGTCCTCGAAGTAATCGAAGGCTACAATTGCA CAATCTTCGCGTATGTTTAGTTTTATATGCGTATATGTATATGCGTATATGTATATATATGTATATTTGTATAGATATACGTATACAT AAGTGTACTATAGTTACTTCTGTCTTCTGAGTTGAAATTGAATTCGTGTCGTGCTCGTCGTTGTTTGTCGCTCATTTCTAGCTACGGT CAAACCGGCACGGGCAAAACGTTTACAATGGAGGGCGATCGCACGCCAAGCGCCGACGACTGCGTGTCGTGGGACGACGATCCGCTCG TTGGCATAATACCGCGCTCGGTCAACCACTTGTTCACGGCATTGTCCATGACCAACTGCGAGTATTCGGTGAAGATCAGCTACATAGA GCTGTACAACGAAGAGGTGAGCGACCTGCTCAGCGACTCGATCGAAAACAGCGAGGCCAAGCTGCGAATCTTCGACGACGCCAATCGC AAGGGCTCCGTCATCATACCTGGCCTCGAGGAAGTGGTCGTCAAGAACCGTAACGAGGTCTACAAGATCATGCAGAAAGGCGCCGACA AGCGCCAGAAGGCGTCGACGCTCATGAACGCTCAGTCGAGTCGCTCGCATTCGATATTCACGGTCACCGTGTTCATCAAGGAGAAGTC GATCGAAGGCGAGGAGACGATCAAGGTGGGCAAGCTCAATCTCGTCGACTTGGCGGGCAGCGAGAACATCGAGCGCTCGGGCGCCACG GGTCGACGAGCTGCCGAGGCGGGCAAGATCAACAAGAGCTTGACGACGCTCGGCCGCGTCATAACGGCTCTCGTCGAGCATCGCGACC ACGTGCCCTATCGCGAGTCCAATCTCACTCGGCTGCTGCAAGACTCGCTCGGCGGCCGCACCAAGACCACCATCATAGCGACGATCAG TCCGGCTCAGTGCAACTTCGAGGAGACGCTGAGCACGCTCGACTATGCTCACAAGGCCAAGTCGATACGAAACAAGCCCGAGATCAAT CAGAAGCTCGTCAAGAAGGCGCTCATCAAGGAGTACACGGAGGAAATAGACAAGCTGAAGCGAGAGCTGCTGTCGTCGCGCGAAAAGA ACGGCATCTATTTGCCCGAGGACATCTACCAGGAGATGGCGTCCAAGGTGGACACGCAGAAAGAGGAGATACGCGAGAATCTAGTCAA AATAGCGGGCCTCAACGAGGAGATCGAGAAGCTCAACGATCTTTTCCACGAGACCAAGATTCATTTGGACGAGAAGTGTGTCATGCTG GCCGACACCAACAAGAAGCTGAGCGAGACCGAGCGGACGCTCGACTCGACGAAGAGAGAGTGCGACGAGACCAAGTATGTGCTGGACA TTCAGGTGAAGAGCGAAGAGAAGCTATTCGATCAGGCTCAATATTTGCTCAAATTGAGCAATGAGACCAAAGACGATTGCCAAGGTAA GATCTATATTACATAACACCAGTTCAATCGGACTTCATTGCTCGCGTCATTTCATTTTGAATAAGTAAACAAAACAAAAAATAATCAT GGTCATTCAATTCAATTCATTCAATTCATTCGATCATTAGGGCTGCACTCCAAACTCGAGCGACTGTACTTGATGACGGAGAAGAATC AATGTCTGACGACCATGTTCTCGAAAGAGATCATCGAGACGTTCGTGCGCATGATCGAGTCGTCGTCGAATCATACCAAGACGAATTC GTCGAAGCTGTGCACGGTGTGCGACCTGTTGCAGAAGGCGTTTGCCAAGCTGGGCATGCTGAAAGAGGAGATGCTGCAGCAGTTGACC TTCTTCGACGAGAAGCAGACGAGCTGGCTCATGCAGCAGGAGAGCTTCGTGCGCAAGCAAATCGAGGCGAGCTTTCTTCAGTTCTACG AGAACTTCTTCAAGACGAGCAACGAGCACCACGAGAAGAATGTGGAGTTCGTGGCCGACTTGGAGATGCTCTGCCTCGAGCACAAGCA CGAGCTGAGCGAGATCGAGCGAAAGCAAGCGGTCAGCTTGAGCAAAATCGACGCCAGAGCCGGCGAGTTCGAGCTCGACTTGGAGTCG CGAGCCGAGCAATTCTTGACGAGCAACAAAGTCCAATTGGTCGACGTCAACGAGACTCGATATGCTGAGAAGCTCACCAGCCTGAGTC AAACGGTCGACAGCATGCAGCGAGAAGTGAAAGAAATGAATAGAGCGACCGCTTGCTGGTCGAAAGAGCTCGGCGAGACGCTGTTCTC GTTCGAGCAAATGATCAAGTCGTTCTCGACGGGCATCAGCCACAAGCTCAGCTACATGCACGCCAAATTCGAGCAGCTATCCAGCCAG AGCGAGCAGACGCTGGCCGAACTTGGCCAATTGAAGCTGGACATCGCCAGCAACAACGCCGCGTTTGTGGACGAGTCGCGCAAGCGAT TCCACGCCGACATCTACGCAACGGCCAGCGAGTTCGTCGAGGCGACGCGTCACGAAGTGAGCGAGTGTCAGCTGACCAACGCCATCTT CAAGGAGCGCAATGCGTGCCTGAACGAGAAGCTGTGCGGCGAGCTAGGCTCGTTCAAGATAGCCCAGTCGGACAACAATACCGCGCTG AACACGTTCGTGACCATGAAGCTGAACGAGTTGGACAAGGACTGCAAGCACTTGCAGGCCAACTTCAAGAGCTACTCGCGCCAGAGTG 
CAGACCACTTGAGCGAGTATCTCGTGCATCCGCTCGAGCAAGAGACCGCCAGTCTGGCTGGCCTGCTCGACGAGAGCGCGCGTCTCGT CAAGTCGTCCAACAACTCGATCGAGATGTTCGGCGCGCAGACCACTCAAGTGCACGAGAACAACATCAAGTGCGTCGAGCAGTTCTGC GAGAGCGAGTATCTGAGCGACGCGCCGACAGGTCAGACGCCTCGAGACAGCAAGGTGTACAAGACGGACGTGAGCTTGTCGAAGACGA AGGCGCATCAGCTCTTGCTCGACGAGTACAGAAGCATGCAGGCCACGAGTCGGGCGGCCGAGTCGCCACTCGAGTTGACGCCCACTCC CTCGTCCTCATCGTCAAGCGTCTCGCTTCAATCCTCCACAAGTCCAAAGTCGTTGGCCAAGTCCAAGAGCCAAGCGCGCCTCAACCCT GACGTAAGTGTATTATTTTCTCCTTCTCCTGATCATTCGGATCTGAGTGTGCGTAATGCGAAATCCTATTAACTTATTTCTAAAAGGT TCTTCCGTCTCAACAACTCAAGCGACAATTCAATGACAAAGAGAACAACAACAACAACAACAACAATGAGAATGAGCGAGTCATGAAT GTGCCCAAGCTCATTGTGACCGGGCCAAAGGCTGCAACTTTGCAAAAGAACTCGGCGCCGCCCAGCAAGAAAGCGTTTCACGAGAAGA ATTAACTTCTACGTCTTCTACTACTACTTCAACTACTGCTAGTTGGTAAATAGTAAATAGAGTGAGATAGAAGAATGACAATAAGCGC TCTTATACGTATATATATATATATAGACAAAATGATACTTTTATCAAATTACAATAGCAATTGCCATGAATTTTTATTCTAATTAAAT TCAAAATTCTTCTTCTTCGTCGTCTATTTTGTTTGTTGTTGTATTGAACAAACCTTTAATTTAATTTCTCATTCTAAACTTTTTAGAA GTTCAAGAACAAGTTAGTTAAAGCGTAATTTTTGTGGATTAAATCTGGAGTTGAATGTATGTAAATAGAAACAAAATAATAATATATA ATATATATATATATAGTTATAATAATAATAATCATAAACAAAGCACAAACAATAAATGTCTCAATGTTTCAATTAGAAAGGAAAAAAG ATAGTTCGATTTCTCAACCTATTAGATGTAACTAACAAAAAAAAAACAATAATAATAATGTAATAAATTCTTTTAAATTAAAAAAAAA GAAGGTGACTAGTCATTTAAATGAAATGAAGTTAAAGTATTCGTTATTAGCTTGTTTTTTGTTTTGTTTCTCAGAATAAATAAAGACTT GTGTTAAGTTCAGGAATATGACCTAGTTAATATATAGTATGTTCAATGTTAACAAAGAGGTTTGTTGCTTGGGGGCTCGGAACACTAA ATAAAACTCATTTCTAAAGAATGAAGAGCAGAGCAGAGCAAATCATTAGTATTATTATAACATAGCACGAGGAGTTTAATCGTCGAGA ACCACCGAATCTTCACCGAGTAGTTCACACAGCTCTTTCAAGCGAAGCTTCGAGTTCGCTATGCTCAACAGCGACTTCTCCAAGTTCT CCTTCTCTTGCTTCAAGTTGAGACGCTCGGTCAGGTTCTTGTTGAGCTCTTCGAACTTCCACTTGCCGTGCCCATCGAACTGAAGTAT GTAGTCGTGATACTGCCACAGAGTGGCTCGATGTGCGATGGTGAGCAAGGTGATGTTGTAGTCGTTCTTGGCGCTCAAGTAAATCTTG CCCTCCACATCGATCGACACGGCCGACGTACACTCATCCAGGAATGCAAATTTGGGTCTAAGATTTAGATTTGAGAGTGAACGAGAAG AAGAAGAAAAAAAATGGAATTCAAACGGTGAATATGTTGATTCAGTAATCATATAGTAGCTAATCAGCTTTAGCTAGCTGTGTGTGTG TGTGTGGTTTCGACTCGTTCGTCGTATTTGTGACTGACTCACTTGTGATAGAAGAGACGACTGAGACCGATGCGCTGCTTTTCGCCGC CCGACAAAACGTCCTTCCAGTCGGCGATCGTGTTGAGACCGCCTTCGCGTATCACGACATTCTGTAGATTGACAATGTCGAGTATACT CATCAAGTCCTCGTCGCGTATCGATTTTCTTCTCATGTCGTCGAGGCTGTCCGGATAGATGATCTGATCTCGCAATGTGCCAATGGGC AAGTAAGGCTTTTGCGGTATGTAGAACATTTCGTTTAGCTTCGGCCTATAGATGACTCCCGACTTCAACGGCCAAAGGCCAGAGATGA TTCGGAATCTAATAGTAATTGAATCACATCAACAATGAGAATCTGCACATGTGATTCAGATTCTGGGCCGATGAAGCTGATAAGTGAA CAACAACAATAAGTGACTTACAATGATGACTTGCCGCATCCATTAGGACCAGTTATCAGAAGATTCATTCCTCGTTCGATCTGTTTTT TTTTTAAATTTCACATATTATGCATAATGCATCAAGATCACGAATAAAGCAAGCACTAACAAGAGTCGATGTAAGTCCATATCATATA GGGTAAGCCAAGCCAATGTACTTACTTTGAGAGTGAGCGAAGGAACTATGACGTCACCGTTCGGCGTAATTACACTTATCGATTCGAC AATAATGCTGTTTTGCTCATTCGACTCATAAATTTGACCTGCCGACTCGGCCAGTGCGAGCAGTTGACCATTCGTCTCGTTGTTCTCG GCACTTTGCAGCTTGAGCTTGGGCATGCTCATGAAATAGTTAAGATTTTTGTCGTTGTTGTTCGGATCTTGTTCGATGGTCTGGCTAC ACGCGTCGAATATTTGATACATCTCGTAGACTCGTCTAACTAGGCCTGTCAACTCGATGACCTTCGTCGCAATGAAATCAATTCGTAG CGATTAATAAGCGGCAAAAAGTCAAGAGAGCTGACAATTGTGTTGGTCGTCGTTGGGACAAAGAAGAAGAATCTCAAGTAAAACAGAA ATTCGCTTACCTCTTTGTAAGAAGTCATTATTCTCTCGAAAGCGTCGGCCGATGAGACGAGAAGATGCTTTGCTATCGTAAACTGTTC GGTTCTCGTCAACAGATCCTGATCGGCAGCACTAACTTCCGACGCGTTCGGATCTGGTGGCGATAGCTGCTTCAAAGACGATTCTGTA CGTTGTTTGTTGTTGTTGTTGGAGAAAAAAAAACATTTTAAAATTAATCAGCTAAAGTTATCAACTGAGTACGGCAAAGCCTAACGAG AAATAGAACCAGCTCTCTCTCTCTCTCTATATATATATATATATATAACTTATGTGTATTATATTACCTTTAGCAAGCAACACCGGTA TAGAAATCATGGAAAGTCCAGCTATTTTTTGTTGTTGTTCCCCCATAAAATTAATTTAAGAGATTCGATTCATTTACATAGATATTTT GGCAACGCTAAATCGGAATCAATCGGTGAATAGAAGTTGGCAACAGCAACTAGGCGTTTGCTACTTACTCGCGCTCCAAATGTATTTC ATGAAGAACTGCTCGATTATGATGAACCAGAGCTTGTTGAAATAGATGAACTCGAGTTGCTCCTTTAGGAATCGATAGCTCTTCTTGA TCATGTTGACCTCGATCTTCTCGCCCGAATAGAAAGCGATCTCCTCGCTATTGGCTTGTATGCGCGAGTACAAGAAGCGAAGATAGCC CTTGCGCTTGGCCTCTTCGGCCGCCAGCTGGCCGAAGCGAGGCGATATGGCGCGCATGAGCATGGCCGTGGCGCCCATTACGCCGAAG CCGATCGCCGACGGCAGCATGTAGTTGAAGTCCTGAGACTTGGCCATGGAGATGAGCGAGGCCGTGATGAGCACGATGTCGAGTATGG GCTTGGTCAGATGCGAGTAGAGGTGAACGAGCAGATGCGTGAGCTTTTCCGTGTCCTCGCTCAGATTCTGATCGATTTGCACGTTCTC GTTCATGCTGAGCGCTATGCGATAGTAGGTGCGATCCTTGAAGTAGCGCTCGAGCGACTTGTCGACGAGGCGACTCTTGAGCTGCAAG TCCAAGTTGGACTCCAAGTAGCGTATGAGGCTGTTGCACGTGGTCGCCGGCAAGGCGATGAGCAGCCAGTAGAGCAGGTTCTTGGCGA ACGTCTTGGGACTCTTTTGCACGATGTTCTTGACGAGCGAGCCTTCCAGCTTGGCCACGTAGATGGAGAGGAACGTGCGACACACGAG CGTGAGCGTGTGCATGGCGAGCAGCGCCGACTGCTTGGACACGAGCGACGGAAACATGATGCTGAGCAGGTATTTCATCTCGGCGAGA AATTGTCGATCGAGGCCCGGATTGCGGCTGCTCTTCGACGTCGTCTCGTTACTCGGCGTGCTCAGCTTGCTGAGTATGTGGAGCTTGT TGCTCGAGGCGAACTTGGCCAGGTGACGTCGCACGAGCTTGGCGAGAACGAACAGGAGCGTGACGGAGAGGCCGGTGCCAACGAGTAT CTTTTTCACGAGCGCTCGTCGGCTTTGCACGAGAAATTTCAAGATCAAGAACACATTTCTCATGTATTTCACACATTTGCTCGGATTC ATGGCAATCGAACTTTGTTATTGCCAAATGCTTATCTTGCAAAAGAAACACAGAAACAAAATCAATCAATCAATCAATCAATCAAACG CACGAACATATGATTTACAGTAGTAGAAGAAGTCATATAGATACTAATAGTAACTTAGTAGTAGTATTCTATATATATAATACATCAT GAAGAAGCTGAAAGCTGAGCAATATCGATAAGCAAACAAATAGAATAAAGAAGTCTACATTACATACAGTATATAGTTAAATATACAT ATCTCTCTCTCTCTCTCTCTCTATATATATATATATATATATATATATATATATATATATATATATATATATATATATATATATATAT AAATATATTTCAAACTCGATAGTGTTATAAACAGACATAATAATTATAATAATTTATATTGAAATGAATCGAGAAGTATATTTCTCTA TTGAGAAATTCAATTGAATTCATACAAATAGAACGGATGATGATACATATTGGCATATATTATTATCGGACTCATTATCGTGTACGTG AATCGATTTGCTGTTGTTATCAGCTTATCGAATAGCAAGATTTGTAAGCTTTACTCTAACTACTAAACGAGAAGAGAGTAAATAAATA CTAAGCTCACACACACACACAACTCTACAGTAGTTTGAATTCTCATGTCTGGATTATCAGGTGATATCTCAACAATAAAACAAAGAAG GTTTAATTCATTCATTCCTTCCTTCCCTCTGTCAGGTCATCAGTAGTCTATATGATGATTTCAAGTCGTTGCTGCTGCAAACAACATA CAGTATGATCAACTCCTTTCTCTCTCTCTCTCTCTTTCTCGTCTCGTGGTGTGTTTAACCTATCTAACGAAAATCACGACGAAAGCAG CAACAACAAACAAACAAACCAACAAACAATAGCAAGCTAATTTGATATATGTACATACATAGAGTATAATGGAACATAAAAAGGCAAA TAACTATTGTATGCACATTATAGAGTATATAGTAAACATTACTGACGTGAAAGAGAGCGAGAGAGAGAGAGAGAGAGAGAGAGAGCAA ACAACTTCATGATAGAGAAGATAACTGAGTAGAGTAGAGTGCTATTTTAGACATAATTATAATAGCGCAAATAGCGATGAGTATTATA CAGTATATATGAGTTACATTCTAAAGAAATAATTCGCATATTTACGTTTTTTATTTTTTATTTCAAATCATTTGCTCTTTTCTCTATAAT ATAAGTTACCATGTACTATAAGCTGTAAATTATGCGCATATAATATACGTAAATAAAGATAAAAGCAAATTAGTGATGTCGACAAGAC AATCGAAATATTTAATGATGAGCAATACGAGTAGAACAACTGAAACAAATTAAGATTTAGGAATCTTGGAGCCATAAGTCATCATCAC TCGCTTAGTTATAGCAGAATAAATACACCTATACTGTATATATATAGATGGCTTTTTGTGAAGAAATAAGAAGAAGATGCAGTAAGCT GAGCTATAATGCTATCTCACTTGCGTTTACTACTTAATATTCATCTCAAGAAAGAAAAGAATACATATAAGAGAGAGAGAGAGAGAGA GATTGAGATAAAGTTGTTAGTTTCTTCGCTCTTCTTCAACTTCTTCAACTAAATTTGTTATTTATGATATACTAGAATACTCACGACA ACAAAAGTTAACAAAAACAAAATGACGTATCAAAGATCTTCTAACAAGCAAGCAAGCAAGCAGCCTTATACTTCAAACTGAGATAAGA CGACTAGGTAACTTATAATATCGTCGTGTCCTCCAACCTACTCATGTAACTACTATGAATATACTGTATATATATATATATATATATA TATATATACCGTATTTATTTATTAATTTATATGGATTATACTGTATGTAGCTCTCCTTTTGTATGATAGAGTTAATTGATATCAACTC AAAATAGCTGAGTATGTGCCTTCTTAATACTGTATGATGACGGTACTTTTCTCTGGCTAAATATAATTATTTAAATGCGATGATTCAT TTGACATTATGTATAGTTAGCTATAGTTAGCTATAGTTAGCTATAGTTAGCTATAGTTAGTTTTATGAGGAGTTCACATATATGTATA TAATTCAGGTTATTAGTTATTTTGATAACTATACAGTATATGCTGTAATAAGTTAGAGAGGAAAACACGATAAGAGACATTACCTAGG 
GAGAAAAGAACGAGTAAATCATCACAACTAACTTATAACAAATAAATCCGATGGTTCGACATCGCGTTTATAATCTTTATTTATAGAG AGTCGAGTCAAAATATACATACAGTACTACTAAGTAATTCTTCAGTAGAACTCGTTTTATTTGAATTTATATAACTCGAGAAAACATC TTTCATAAGTTACTTACGATTGCAATATAGTTATTATAAGAACGAAATTCTCTCGAACGAATTTTCCTCCTTCATTTCCAAAATCAAA TCGTTGAAACACTAATTGTAAGCGATTATTTCTTTCAACAGTCATCACCCATTCACCTCGTCATCCACTGACTAAGGACTCAAATAAA CACACACATCAGTCCAATTTTAGAACAAAACAACAGGCACACATCAGTTGCAACTCTGGTGTCATCACTTCTGCACGAATAATTGCTA ATTATACATATAAGTAAGGGCAAACAATTAAGTCGTTCGAGAAAAGAAATTTGCCCTTTATTTATAAATGCAAAAACGAAAAATATAC CTCAAGCTGATAGCAAATTATTACAAGCATAAAAAATATAAAAAAGATACAATTTTTAGATAAGTAAGAGTTGCCTATCTATCATTAGA CCTACCTATAACTATACTGAATAAACGCATATACTGTAATCGTATGTACCTATTTTATATATACGTTCAACGGATTATATAGTACTCA TTCTCATATACATATATATATATACAAGCAAGCGAGTCTAGAAGCCATTCTAGAAAATGCGTTATATAAAATGAAGAATTGTTATTTC AAGAGAAGTAAATGCAACTATACGTTCATATATCCGATCGGCCAAAAATTGAGAATAAGAGAGAGAGAGAGAGAGAGAGAATCCTATT TCTATATTGGATGAGCACTTATACGATAAAATATGCTGTGAAAAATACCTATTTTTGTTGTTGTTGTTGTTTTGAAACTAATAAACGC CATAAAAGAGTCTCAGCATAATATTGTCTATTTCAATTTCTATTTTAATTAGCGTCTAAATTGTGCTATTGAGAAATTATAGAGGATG ATGTGAGTGTCGCAGAACTCACTCACTTTTGTCATCGATTTTTCCTTCTCGTTCCGATTGCCTGATGCGAATGAATGAATGAATGAAT GAATCCGAGACTTCTTCTTCTTCTTTATTCTCTAACATAATCCAATAATATAGATTGCGCTAGTGACATCACTCAACGCAACGAACGA GAGGAGATCTAGTTTTATTTCGTTTTCAAAATGAGAATTAATTTAAAAATAATTGCATATTATTACTTAAGTATTATTATTATTATGA TTTGTTGTTGTTGTTGTTGTTTTTGTAGAAGTTGTTATAACTTATATCTGGTTCTTTTTCATTTGACACCATTTGAAATTCACTGCTT CAAATGCTTTTGCTTCAGAATACGATGCGATAAATTAAGATGAAAATTTTCTTTCATTTATGTTGTTTTGCTTTATTATATAATAATA ATAATAATAACATAGTAATCATTTGTATATTTGTGTGTGTGTGTGTTTTTTTATTTGATATAACTTAATAATTATGTTTATATAAAGAT AGAGAGAGAGAGAGAGAGAGAGAGAGAGAGAGAGAATCTGCCTTCATAAAGAGAATAGGAAAACGAAAGGCAAAAATTTTACAACAAC TTTTCTTTTTTTTTAAACCAAGCATCCATATAAGAACGGATAATCGACTCACACACACACACGCATATAGTACAGCCAAGCTCAATTAT TACGCCAATATAATGCAATAAAAAGTGATTTTCAATTTCGAATCATTTCTGCTGGTTTTCCTTTTAATATTTGTTCCAAACAATGGCTT TTCAGGTCGAATGTGAAGTTGTTGCTGTTGTTGCTGTTGTTGTTGTTGTTGTTGTTCAAAGTATAACGACGATATGAAGAGAAGAACT TTTGTTGTTGTGTCATATAGAAAACAACATGCTACGAATATATTTAGTCTAGAAATCATGTTTAAGTATTTGAATTTTATTTTATTTT TTCTTTAAATCAGTTGGTGCTGTTGTTGCTGTTTCATGATGGTAGTAACAATGGATGATGCTGATATCTCATTCATGCATTCATGCAT TCTTTAATTCATTCATTCATTTATTCATTCGTTATCGTGACTATGAATCGGAATTGAATGAATGTGTGCGTGCGCTCATATATATATA TAACGAGGGACAGTGTCGCTGCGGCGTTTTGAGTTTAGCCGCGAAAGTTTTGCATTTGCTGTTGCTGTTGCATTTGTTGCTCTTGCTG TGACAAGGTTTCCAGATTTTCGAAATGCTTTTGCGCATACTTGATGTTGTAATTGGTGAGTGCCGGTGCTTTTAAATCGCAGATAACA AAAAAGACAAGCAACAAAATAAATCACTTAGGAGACGATAGAAGACGATTGATATGAGTAAGAGACTTATGAGATGTATGATAGAGAT AGAGAGAGAGAGATAGAGAGAGAGAGAGAGTTTTAAATTAGTATTATGTAACTTACTTATTCGTTGATCGGAAACGATAACCATGATC TTAAAGTCAGAATCAGTTCGAGTCGTTCGATTCGAGACGGATCGATCGATTAATTAGTGTTATTCGTACAACGTAACGGTTTTAGTGC TTCGTATTTCAAGTGTTTCGTAAATAAAGCTTGCCAAATGAATTTAAAACAAAATACGTACATATGTGTTCGGTGTAAATAAGTCGAT AATGATCGTGTAGTTGGCGTTTTTAATCTCGACCGACTGAAAAGAGGTGTCAAATTTGCTGCAGCTAAGCTTGAACTGTTTGATTATA TTGCTTATTTTCTCGAACCGCTGCAAGTCATTGTGATCTTTTTTGAGGCAATGTGACACGACCTAGTTATTCGGCAAGTCAAACAAAT GAAATAGACACGTCATATTAACTTAATGGCTCGATCTTATCGACGACCGAGAATCCTATGGACAGATTCACTCGATTCTCATTGCTCA TTCATTATGTGTAATGTCGCCAATTCGATGGACTCAAGCATAGAGAGCAGGGCAACGTCGTCGAGTACATGTTGATGGATGAGAAGCC ATGACAACTTACCAGAAATGTGGTCTTTTCAAACAGCAAGATCTCGTCGGCTTCTATGACGTCTGCGAAATCCTTCAAGCTCTTTTCC AACTGAACAGCATTCGGTATTAATTCGTGCACAATTTGGGACCAGGCCTTTTGAGAGTTTGTTTGATATAGCATAGCATCAATGAGAT TCTCATACTAGCACATGCATTGGGAGAGCTAAACAACACTCAACAACAACAACAACAACAACAAAGAAAAAAAAAGATGGCTTACTTT GTATAAAGTTTCGTCCCAAATCGATGTTTGAAAACAATGGCAACTTAGAGGCTTCGAATAAGTCACCAATTCTTCAACGCGTCTATTG TAAATCTGTTGGTGTTGATTATTTCGTTTGTTTTAAAATTGTCGCATGAATAAAAGAGCTGCTATGCTGAGAATCAAACTAAGAGTAT ATATGACAATTTGAAATGTATCGCATTGTGTTGGACTTACGGCTTCGCGCTGATTGTCAGCGACCAAGTCCATTTTGTGAATGAGGCA AAAGATTTTGGCTTTCGGCGAATGCATTGCCATCGATTCAAGGCTAAACGTTTTTTTTTTTAAATAAAGTAAGTGGATAGAGAGAGAGA GAGAGAGAGAGAGAGATGGAGAGGGGGGATGTTATATGAATGGTTGCCTACCAGCTCTGATAGTAGTGAATGTCTTTGTCGATCTCGC GACTCTCAACATCGAATACGTAGATGAGTACTTCGACATTTCTGAATATGTTGTCGCGTTGCGCCGTGAAATAATGCTCCATGAATGC CTCTTGGCCGCCGCAGTCCCATAGGTTGAGAACCAGATTGCCCAAAAATCTCACGTACGATTGTTCGACGTCAACTAGACAGACGAAT ATTTGAATAATAAGCAGCAAACGAAGAGATAATGAGAGAGAGAGAGAGAGTATATATAGCAACTAATAAATGCATAGAAGATGATGAT TGATCGCTGATCGTTGTTTGTCGCCTTACTTGTGGCGCCTAGACGCCTCGTGTCTCGGGCTATGTAGTTGGCAAATATGATTGAGCGC ATGGAAGTCTTGCCACTTCCGCTCTTGCCCATCAAAAGCACTTTTTTACGCATTGTTTTTGTTTTCCTGATATATAGTTATATATATA TATATATACTTGACGCAACGAAACAGATCTACTCTAGTCTGATTAAATGAACAGCAGCGAAAAATGAAAAGAAAAGAACATTTGGAGT CAAATAATAAATAGCGAAACGAAAAGAAACAACTACTGTATATAGCCTTATATATAGCTGAGATTGCATGTTGAACTCGAACTAAAAT ATAAGATGCCAAATAATATTATTGTTATTTCAATATAAATTAATATCATTATCTTAGAGTTTCGACAAGTGAAAAAAATGAAAGAAAA GCTATAAATAGAAAATTCTCATCATATTAAAAAAGAAACTGAAAAGAATGAAGCAACTAAAAGATGCGTTTCTCTCTCTTTCTATCTC TCTCTCTCTCTCTGTCTTCTAAGTATATTAGTAGTAACTTATTACTACAGTAATTCACGAGGATAGCTTACTCTTATGTAAAAAAAAA GAATAAAATAAGTATGAGTATGATAAGAAAGAAAGATGGAAAACAACATAAGAGCACGCACTCTCAAGTTGATAGTCTGGCCGCAGTT ATCTAGGCACACCATCACACTCCCTTTATTCATCTTCTCTTTGTTATGTAAATGAACATGCAAGTTAAATATATAACTTATATATATA TATATAGAGAGAGAGAGATAGATATGTGTAGTTTAGCTTTCAAAGCTCACAACATCTAACAGACACAAATTTATTATAGTATGTCGAT ACAAATAACATTGCAAATATGTATGCTATTTAATAATAATATGTAATAATATGTTAGTGTTATTGTTATTACTTAGTTTATTATAATT ATTAGTATTATTTGCATTATTATTATTATGGGATGTATATATAGACGGAACGTTCGCATATAATGATGGGGAGGAGGAGGATGCTGCC TTTATATACTACTCACAATTTTAAGGGTGTCAACCTCGGCTTCATGTCCCCCTCATCAAGTCGCCCGCCGTTCTCACCGGGGGGGGG GCTCGACTACAACAAACCGACACCTCCCACGCGCACATAACCAAAACTCACACGTCTAGTTAATGTGCCACCCCCTCCGCGGGGGGCG GGCC

\section{Contig 2}

CATACATACACACACACACACGCAACATATACACACACACACACACAACATACACACACACACACACACACACAACATACACACAGTT GATAAATAATTAAATTATCATAATGTGTCTGGATTGCAAATAAATCATAATACATAGGAAAGAAAATCGAAAGATCTAGACTGTTGTT GTTGTTTCTTTCATTAATTTTTATTATAAAAGTATTTGTTTTGGAGAATAAAAGATAATCGCATTAGCAAAACGAAACATAACTTTTGT TAGATTAGATGGATTCAATTCAAGAGTTGATTTGAAGGGAAAAAAATAAGTTGAAAAAGCACTTTATTTTTTTTATAAGTTACTTAACA AAGTAGAAGAGAATGAGAGAGAGAGAGAGAGAGAGAGAGAGAGAGATTCCTAAATCATACTTTAATTCTGACTGAAAATAACTATACT TGCTAGGCATTTAGAATTCATTTTGCACTTAGGTTTTTAAATAAGACTTATTATTTTTCATTTCAGTTTAATGATAGCTTGTTGAAGA AAAAAGAGTACTAGTAGAGAAACACCAGATGTGCTGGATTTTATGGTCGTAAAGTGCGTTTATAAGTTAATGCAAGTAGTTTATGCTG ATGCGGCGAAACGTATGTCGATGAAAATTCTAAAAGTTCCCAGAAACTTATGTTCCAAGTCGAATGAGGCAAATCGAATTATAAGTAG TCTACATATATAGATCTCTTTTTCTTATTTTCGTTCACACGAGTTCGAGTTCTTCTAGAGTTATTCAAACAACAACAACAAACATCTT GAAGTGTGAGAGCAAATAAAGATTACTAGAATATAGTGGTGCCATAGGTAACTAACTAGATGCGCAATATGATTCTATCTAACTATCA GTATTCAAATTGAGTCTCTTTTGATGGAGGCCAACTATATTCGTTTAATTAAGTTTTAGTATTATATAAACGCCAAGTGAATCGAACT AGCTAGACGATTTCAATTATTGCTATTTTTGTATCAGTAGAGTTCACTTCATTACAGTTATTGAGAACTCTACTTGGATTCTTTCAAA 
TTGACGGGCTCAAGTATTTACAGTTATTAGGCTTAGAATTGGCACTATTGTGGGACTCGTCATCCATTGCTTCTCCACACACACACAT AAACCATTTCTTCAATCAATCAATCAACTACTACCAATCGAGTGGAATTGGCCGCATTCCTCATAAACGACCGTCATTATAAGTTTTC TATGCGTTCTACTATATCTAATTGAAATGGTTTGGGGTTTGAGTTTGAGATTTAGTTTGAGAGTTTGTTTTATTATTAGAATATATTT TCCAGAATTGATTTTTTTTTTAAATTATATAGAATAAAACATGTGTGCTATGTATATCTTATCATATAAGTGTTTCATTCGGAATATA TAAATAAATACTATGACGTAACTATGACGAATAAATAAATATAATGTATATATATATATATGTATGTATAATAAGTTAAGTTTAAACA GCAACAACAGCATAAATCAAAAGCATAAATGCTCAATTCAAATTGTTTACGCAATTATCATCCATCAATTTGAAGCGAATATTTTTTT AACTAAAAAATTACTCAACACGTTTTAAAGGTTTTAATTTGGTTTCCTTAAATATTTCTTTTGTATTCAGAAACACACAAGTTTTTACAA GTTTTCTTTTCTCTTCGCTTCATTTAGGTTCGTTCGAGAAAAAAGTGACAAACAAACAAACAAACAAACTTAAAACAAAACAAAACAA AACAAAACAAAAAAACGTTAAATAAATTAAACTTAAGAATATATATCGCTGAAAGGCGTCGCTGTCTCAATGAGTTGATTTTCTTCTT GTGTCTGTGTGTCTGTGTGTTTTGGATTTTTTCTTTCTTTTGTCTTCTAAATTTTGAAATCAAGTCCAGAACAAAGGACATCATGTTT TAAAAAAAAAATTCTTTTTCAAATAATATCAAAATTCTAAATCATCGGAAATGTAATGTAAGTGATGGAATATAAGTGAAGTTTCTTC ATCAAGTATATACTGTACAATCGTAAGTCATTGAGTCGTCGTCGTCGTCGTCGTCGTCGTCGTCGTCGTCATTGGGTTCTGTTTGTTT GCTTTTAGTAACTATTCTGTCAGCTCAATCGAAATTTTATTCGATTTGGTTATACAGTTTATTCTAACCGTTAATACTTCGATATAAA TAAGGCCATGCGCTAAATGTACAACTATTTCATTTTATGTTGGTTGGTTGATTTGTTGATTGGTTGATTGGTTATCTATGATCACCGG ATTTCTGAAAGAAATTATATTAAAAAATGCTTTTGTGTGATTTCACGAAAACATTGGTTTCATCAAATGCCAGGCAAGTTTCGTCGAA ATGAGTTTTGATTGTTGTTCACAATGGTAGCCGTGACATTGTTACTATTGCCGGTCGTGCTAGCAGGCGTCTTAGTGGTCAATGTCTC GAGATTCTCGAAATGTTTTTGAGCATACTTTATGTTGTGCGTCGCTAATGCTGGTGCTATGTAAGAAGAGAAAATGTGATATAACTTA GAGCAAATGAATGCGATAAGGCCAACGTCGACATAATAAAAGTGCCTCTCTCTCTCTCATTTACTTATTCGCTGATCGGATATAATGA CCATGATGTACGAGTTGGGCGTAAACTGGTCGAGCACGATTGTGTAGTTGGCGTTTTTTATTTCAATCGACTGAAACGACTTGTCGAG TTGACTTTTGATCATCATTTACGGTGAGCGACGCGACGCCAAAGAGGAGAATGAACAAATAATAAGAAGCAATAATAGAAGAACGCGC GCTGGAAGAAGGAGAGAGGCGGTCATTTAGTTACTTGCAGCGATGCCGATATTGTTTTATGATACTGCTTATCTTTTCGAATCGTGCC TGATCGTAGTTGTTCTTTTTAATGCAATGCGAAACGAGCTTGACAACGATTTGACAACAAAGAGATTAAAGTAAGTATAAGTTGAGCA AAAACGTGGCCGAACGTCTTTCATGAAGAAGAGGAGAAAAGCATGCTTTTGAGCTCTCTCTCTCTCTCTCTCTCTATTTACCAGAAAT GTGGTCTTCTCGAAAAGTAAAATCTCGTCGGCTTCGATCACATCGGCGAATTGCTTGAGACTCTTCTTCAAATAGGCGCCGTTCGGTA TGAGCTCGTTGACTATATTCGACCAGGCCTTGTACATGCTCTCGTTCCAGAGGGACGTGCCAAAGTAAACGCAATTCAGCGGCTGCGA AAGGCCCATGAGCTGCTCTTTTTTCCACTCGAAAGCCTAAGTTCACATTCATTTTCGTAGAAGAAGAAGACGAAGAAGAAGAACGCTC GAACGTCATTTTATTTGAGCATTTACCGTATGTATTAACTTATGACTGAGTGTGTGTGTGTGTGTGTGCTGTGCTGTGTGAGAGAGTG CTTACTGTTTCTTTATTTTCTTCGGCAACAAGATCCATTTTGTTAATCAAGCAGAACATTTTTGCTTTTGGCGAATGCATGAGCATCG CTTGAAGGCTTTGAAAGAAGAGCAGACATATCAAAGCAAACCGTTCTAATCTAAAGCCCGTATATGTGTAGTCGAATCGATCTAATAT TCGATTCGATTCGAAGAGAGAGAGAGAGAGAGAGAGAGAGAGTCAATATTACCAGCATCGAAAGTAGAAAATGTCTTTCTCGAGGTCC TTGCTGTCCATGTCGAATACGTAGATGAGCATCTCGACCTTCTTGAACACGTACTCTCGCTGCGTCGTGAAGTACTGCTGCATGAATG CGTCCTGGCCGCCGCAATCCCATAAATTTATGACTACCGAGCCCAAAAATCGTATGTACGTTTGCTCGATTTCGACTTCAACAGCGTT TAAACATTTAGAGTATTTAGCGTGCAAGCAAATGTCAATCCGACAAACAAATAAAACACATGATAGCAAAGATAGAAGGCGTGTCGCA TTTACTTGTGGCACCCAGACTCTTAATGTCGTTCGGTATGTAGTTGGAGAATATGAACGAGCGCATTGACGTTTTTCCGCTGCCGTTT TTACCCATTAGGAGAACCTTGTGATAATGATTATTAAATAACAAGAGCAATAAGGAGACGAAGAAGAAGAAGTAGAAGTAGAAGAAGA AGAAGAATTGGAAACATGAACATGATTACGTAACATGTAGCATGCGCCTTCTTCTATATCATATCATATAGATATACATATACATACT AAGTAAAGCACATGGCAATATTTGAGTATCTATTTCAAATCAAATTCGACTGTCGAGTCGAGTTGATAAGTTCATTCTAACTTAATTT ATCATATGCGCTTGAGTATCAATCGACTATTTGACACACACACACACACACACACATCCAAACACACACACACCCAAACACATGTGTA AATAAGCATCTAACTTCTAATTCACTTACTTTTTTTACCCATTGCAATGGCTCTGCTTGATTTAGATTTGGAATTTCGTTTGTTTCCTC TATTTTCTTCTTCTTCTTATTCTTATTGTTGTTGCTTGTTGTTTGTTGTTTGCCTTCGCATATATATGAATTTTGTTTTGTTTTGTTT TCAATTCTTTCTTATTTCAAGTTGTTTGAAGTGTGATGATGTATCTTTTCAAAAGAAGAGAAGAAAAAAAACAAACTCTTAACACTTG TTTTATTTCATTTTTAACAATGAAAGATGAGGAAAAAAACAAATTAAGAAATTAAAAAAAAAAATCTCTATAAAACTGCGCAATTATT TTTGTTGCTTCAAATATACAGCATGCGAATACATGCTTTATTAATATGAAAATAGAAATTGAAATCTGAACAATAACATTGATTAGAA ATTATGTAAAACGACACATACGCAGCACACACACACACACACACACACGCACACACGCATAGAGAGAGAGAGAGAGAGCGAGAGAGAG AGAGAGAGAACGAGAGCATATTAACAATAAAAAGAAATTCATGTAAATGTATTATTAATAATAATGTAGCTTAATATGTATGCAAATA ATAAACTATAATATAGTATTATATACGAATATATATATAGTTTCTTCTTCTTATTTTTTTTTCTACTTCTTCTTAATGTGTAATAAAAA TTGCGCAGTTGAATTTGTTTTTTCTTCTTTTATTTATTTTAAAAAAGAATTTTTTTTTATTATAGCTATTTATAATACTTGATATATAT ATTCTTAACTATAATGTTGTCATTTGCTCGGTTCCTAGAGATTCTCTCTCTCTCTATATATATATATATATATAAACCTACATATTAA GCTATATTGCTACATTTCTACATTATTCATGAAATGTAGTTGTTGTTTTTTGTTGTTGTTGTTTGCTTGCTTGTGAAACATGCAAGTA TATAGTTATGCGCATATTCTCATGTTTCCAAACTGAATGAACTAATAAAATAATATATTGAAATGAAAGCATTGCAATTTGAATATAT ACATACTCTATAGTATATTATATGTGTATGTATACACACATCAGAGTCTATATAACGTGTTCGAAAGCGCTAAACTGGCGCTACACAA CAACAAGTGGAAATAAATGGAGGAGACAAATGCTATTTTGTTGTGGGAGTATGTTAAAATGATGAAGAAGAAGAAACGAACCAATTAG AACTCGACATGAGAACAGATATTTGAGTCTCATAATGCCATTAATTATAATAATAGGAATAGTATTACGTATTTACTCCTCTTTTTTT TTTAATTTTCTTCACAAGTTCATTTTTTTTTTTACTTTCATGTGTTGCAGGCAGTTCGCCATTATTGTTTTACATCTAATATTATAGCT TTCAATCTATATTATTATAGTTTACTTCGATTTCATAATTTATTTTCCCTTATCGCCACGAATTTGTTTGTATCGAATACTTTCAAAG GAGTTATTGCTATATATGGATTTTTTAGGTTAAACTAAAAAATCGCAACGAAAAAAGAAGGGAAATTTGAAACGAATTCCATGAAGAG ATTAACTTATTTGAGAGATGAAGAGATGGAGGAAGGGAGAGATGAAGAGAGGGAGGAAGGGAGAGATGAAGAGAGGGCGGAAAGGAGA ACGTAAAAGAAGAGAAGTTAAAAGTTTAAAGATTATTTTTAAACGAAAAGTGCGCAATTTATTCTATTATAATGTTGCTCAATGCTTT ATAGTTACCTTGTTATTCTCCTCTTATGTGTATTATTTGATTTAACATAGTTTTGTTTTATCCTTCTCTTTTTTAATCAGATGAGTGA AAATTCGCTTCTCACTTCTTTAAACGATCGTATTCATTCGCCAGTAGATATCAAATTTTTCTATTTCAAATGCATGCTGCTTGCTTTT CTTCTTCTAATAAGTTTAATTGTGCATAATTAACTTATTGTTTGTTTTTAGCACGCAGTCGAATTTACTGATGTGTGTAGGTTCATGC GTTGCAAATGTAACCTAACGATAGCATAGCAAACGAGTCAGTCGGTGAGAGAGGCAATAAAACTAGTTTCAACTTTTCCAGTCAAATA ATCAAATGGAATAAAAGACCTTTGTTCTTTCTTTCTTTCTTTCTTTCTTTGTTCAAGTCAAATCAAAAACATGTGTTGTATGCTGGAG CCATATTTGGCCGCCTACTATAAATAGCATGCTCGTTTTGATGAGGTTTTTCTTTTTTTTTGTGTTGTTGTTGTCAAATATAATTTGGA AAATGAAAATGAAAGAGAACTTTGAAACAAACAAACAAACAAACAAAAAAATTTAAACATGAACAAGTAAATAAATCACTTTTCAATT TAAACGCCGTCTGCACATCTAGCTCGCTAGCCAGCCAGCCAGCCAGCCAGTCAGTCGACAATTAAAGTAGTCTATACATGTACTCTCA ATCAACACACATTCTATAAATAGCTTTTATAAAAAAAAAGAAAAGAAATAAATTATACTTATACACCTAAAATGCTCTCATTTCATCG TCTCGTGTACACATATATATATGTATAAGCTCCTATATGTAAATACGCATATAAACCTATATAGAGTTGTATCGCGCCTATACTTAAA TATAAAAAAACGACAAAATGCAAAACGTCGTCTTGCAATATTGAAAGAACTATAATAAATAGACTTTATTAATATGCTGTATATATGT ATAGCTCCAAACTAACTCTATGATGCAGTTCCATATGAAATAGAAAGTATACATTGACTATATATGTATAGTGGTGTGCATAGTATTG CCTTCTACCTCACTCACTCACTCACTCGTTCAATCATTGTTCGCTCACTCAGCAGTCACTATTAGAATTTTGTTGTTGATGAGAGGTC AAAATCTTTAATTCATTCGTTCAATGATCCATATAATGAAGTTTTAGTTGTATAGTTTGAGCGTGCTAGCGTCCATATAGCTTAGTTA GTTCATACATATTGCACTTGAGCGTTGTGATCGCAATTACTTGAAGTGAACTTGTATCGATCAGAGCAACTTCATTCTACTCAACTCG TATAAATATCTTTATTAAGAAATCATCGATACATAATGCAGTACGTAATAACTTAATTATAAAAAGGCTTCGAGGAATTCCTCGATCA TATTTTGCTAGGTTGATTGGTCGCGGTCTAGTCTCGTTACCAATGGCAACACAACAGAAGAGAGTCAATTATGCGTTGTTTTCTATGG TTTGTACCATTGTAGATGCTTCTGCTGAGTTTTTTTTTCTTCTTTTGTTCTACTTTAACAAAAAGTTTGCATTATTATATGAATATAC GACGATGACGACTTGGTTTAAAAAATCAACTACACATAAGTTACTCACAAATATTTTCATTCGTATTCGAATTTTTCATCAAGCAATT 
AGAACGAATTATAACTTGTATAGATCTTAGCAATCAGAGGAGCAAGATATTTGGAATAGAGTAGAAAAAATGATGAAAGGAATTAGTG TGAACGAGTTTGGCGGTCCTGAAAAGTGTACGTATTCGTCTAGCCTTCCCATACCAGAGCCAAACGACAATCAGATTCAAATCAAAGT TCACGCGGCCGGCGTCAATCCTGTCGATACGGTAGAGACAGACTCTATATTTCAACGCTTCTTTGTTGCTCTTATAAGTTATATAGAA TAGGACATGGCTCAGCTTATAGAGATTAATTCAAGAATGCTTTACTCTTTGTTGTGCTGTGCTGTATATGTCTTATGATATGAAAGTA TATTCGTTCGGGCACGCATAGTCGACAGCCCAAGTTGCCGTATACGCCGGGCTTAGACTCAGCCGGCGTCATAAGCAAGCTTGGCAAG AACGTGAAGAACTTCTCGGTTGGCGACCGAGTCTTCACGGTCAATTCGGATTCGGGCACGTACGCCGAGTACGCTCTATGCTCGCCAC TCTACACGTTCAAGCTAAGCGACAAGCTCACTTTCGAAGAAGGATCTGGCATTGGCGTAAGTAGTAGTAGTAGTAGTTGGCGTTCTTA CGCAAACATAAACATATCTTGTAAGTTAAACAATGTAGTGTAGCGTATATATTTATATATATATATTACTACAAACGAAACGCAAACT CCCAGGTGCCTTATTTCACAGCTTATAGAGCCTTGTTTCTCAAGTAAGCGTGCATACGTGCTGATCAAAATTCATTCATGTATTAAAA CTTATTTTCGTCATGTTTGCTTCATTTCAAAAATGTTTGTGTGTTTGTTTGTTTATTTCTTTTGTTAACACGATCTAAAGAGGTCACG CCAAACCGGGAGAAACCGTTTTGGTTCATGGAGCTTCTGGAGCGGTACTTCTTCTTTCTTTCTTTCTTTTTTTCTCTGAACTGAAACT CAATTTCACTTGTCACAACGACTGCCGCTGAGCTGCTGTATCCTTCCTTCCTTCCTTCCTTCCATCTAACAGGTAGGAATAGCGGCCA CTCAACTGGCCAAAGCACACGGCATGAAAGTGATCGGCACAGCCGGCAGTGTCGCAGGCCTGAATCTAGTTAAGGCACAAGGCGCCGA CTACGTTTTCAATCACAAGGACACCGACTACATGGAGAAAATACGCAGCATAAATCCGGACGGACTCGATTTGATCATTGAAATGATT GCCAACATCAATTTGAATCATGACATTCACATTCTCAAATGGAAGCGAGGCCGCGTCGTTGTAAGAATCATTATGCTCACTCGTTTAT CATTTAGCAAATACGACGTTTAATGAACGATTCTTGTTGAATGCACATTCGAATCCATTATTAGTAGCAGTAATTAATTTAATTGTCG ATATGTTCACTTTTGTCCAAGGTCATTGGTAATCGTGGAACAGTAGAGGTAAAGAAATTTCTTCTGGTTGTCGTCTTATAACTAACTA CGCATGCGAAATTGCGAATGGGAGATGTCTGACTCATGCTTCTATGTATTATGGCCAACTCGAATAGATAAATCCACGCATGTTAATG GCCAAAGAGACGTCGATAACGGGCGTCACTTTGTTCACATCGGACGAGGTAAATGAGCGAATATAACTTACATTAATTTTATATATAC TTATAAGCAATCTTAAATAAAGCTTATACATATAGACATGCACAGACGCCGCAGCTATACTTCTGATGTTGTTTCACTTCTCATTCAA TAGGACGATTTGCATTTGATGTACAGCCACATAAATCAGATGATCGAGATGGGCTCAATAAAGCCAATTGTTGGCCATTCTTATCCGT TGGAGGAGGCGTCTAAGGCTCAAAACGATGTCATTAATAACGCCGGCTCCACTGGCCGTCTTACTCTAAGCGTGTGATTAAGTCTTGC TCGACTCGATCGATTTGATGGCACCCACAACCAGAGCATTTTTATTTGTACTAGAGTGGATGGATGAGCGAAAGGAAAACCAAAAGGG CCAAAAAATCACAGAGACAGACTTTTCATTGATTAGTTTACATTAACAAAACAAAAACTTTTGATAAGTATTATAGATTTCTTAGTTT GCATGCATGACTTTTAAATTTCCTATTTAATAGAGACACATTGAATAAACGCCTATCATTTGAGAAATACAATTCTCTATCCCCAACC ATTTCAATTGGTTGCTATAAAAGCGTCTTATTTAGATTCTAAGCAAAACAAACAAGATGGCTTTCGTGCAACAATCATGACTAAATGA AAACTAAAATCGGCCAGCTGAGAATAGTTCGTTGAAATTGCTCTATGTTCAGTATAGAGATGATTGTTGAGAGTTGATTTTTCAGCAT TTTACACATAACATGTTTTTGTGTTGTCTAATAAAATAGTAATAATAAATTGCAACGTTCAAGACTTCTTATATTATTTGTGTTTGTG TTGTGCGTAGATCGACACAAATATACTGAGTATATGCGCGTATACATGGTGAGGTACGCTTACGCAATTATATATATATATATAGAAT AAATGTGTGACTAGAAAAGTAATAAACAAAACACACTATTAAAATACTTTTTTTTTTCATAGCAAATGATCATTTTATTAAATAATAAG GAATATATTTCATTTTATCTTTCTTTCTTTCTTTATTCAATACAATATTATCAAAACAACTCAAACTGTTATTTTTCAAAAATTGCTC ACTATTATTAGTTAAATTTCTTCGATTATTAGAGTTCATTCTCTCAACAACAACAACAACAACAACAACAACGACGACAAAAATGCTT AAATCGGTTGCCACTCTTTATGGTCACGACGACCGAGTTTGGTAAGCTGATTGGTTTCATTTTAGTTTAGTTGAATTGAATGTAACTT AGTTGCCTCCTCCTCCTCCCCGTTCATCATGATGTCATTCTCGAATGTTTTCTCTCTCTCACTCTCTCTCTCTCTCTCTCTCTCTCTC TCTCGTCTAGGTGCGTAGCTTGGAATCCGAAAGGCACTTTGTTGGCCACGAGCAGTGGCGATCGCTCTATAAAGCTGTGGTCTTGTCA GACGACCGCCGAGAATGGCGAAACGACTCAAATCAGCGAGAAGAGCAAATGGAAGTGCATCGACACGCTCGTCGACGGACACACGCGC ACCGTGCGCTGGATCAGCTGGTCGCCGTGCGGCAACAAGCTGGCGTCGGCAAGCTTCGACGCCTCCATAATCATATGGAAGCGCAATG CGACGACACAGTCGTTCGAGTCGATCGCTCACTTGGAAGGACACGAGAACGAGGTCAAGTGCACGGCATGGTCCTACGACGGCGCCTA TTTGGCCTCATGCTCGAGAGATCGCAGCGTTTGGGTGTGGGATGGTAAGCAAGCGGGCGGTCGAACGAATGAGTCACTTCGGACTTAA GCGACTATAAGTTCATTCGTTCATTCGTTTGCCTTATTCCTCTCTCTCTCTCTCTCTCTCTTCTCTCTCTCTCTCTCTTTGGCTCGCT CGCTCGCTCTTTTGACTTGCTGGCCGCTTTGCTTACTAGTAAGCGATGGCGACGACATGGAGTGCAGCTCGGTGCTAACCATACACGA TCAAGACGTCAAGCATGTTCTCTGGCATCCGCACAAGAACGTAAGGCGCATACTCATTCGAATTGAATACTAAATAACTAGCATTCTA CAGTATATGCATTCTCTCACAACCACGTCTCCCATTCAATTCGTATCATTTAGCTGCTTGTCTCGTCGAGTTATGACGACACCATAAA ATTCTCGGCGCCCGATATTGACGATTGGTCATGCGTGGCTACTCTAGGTAGCTAGCTGCAACACGCTCACGAACACGAACATCAGCGA TATTAGATGCTGCTAGTCAGTCATCTTTGTGTTATCATTTGTGTTTTCTTCTTCTATTTTCTCGTTTCGTTTCGTTTCGTTTCAATTT GACTCGTCGAAAGCGTCGCACAACTCGACCGTGTGGAGTTGCGATTTCAATGTCGACGGCGATCGACTTGTCTCGGCTAGCGACGACA AGACGCTGAAAGTATGGAAAGAAATCGATCATCCGGACCAGAAGACTAAGAATGGTACGTGCGTCGTGCTTGACTTATTTACACACAC ACACACACGTGATTGGACGCGTGACACTGACAATCATGCTTTCAACAACAACAACAACAACAAAAATAGGAACTCGTGGCGACGGCGA CGACATGAACTGGAAATGCATATGCACGACGAGCAGCTATCACTCGCGAGCGATCTACAGCGTCAAGTGGTCGAAGCTAAACAACCTG ATTGCCACGGCGTGCGCCGACAACTCCATTCACATATTCAGAGAGGCCGACGACACGAACGCGCCCGAAGAGAGCGACGAGCTGCTGC GAGCTCATCGAACGTCGCTCAAGCTCGTCCATCATGAACAGAATGCTCATGCACAAGACTGCAATTGCGTCGACTGGCATCCCAAGCA GTCGAACGTACTTGCCTCGTGCAGCGATGACGGCTCGATCAAGATCTGGATGCTTGATCTGCTGACCGCTGACGCAGACAGCGTCGCG GGCACTCTATGAGCCGTGAAAGGGGTCTTCTTATAATTTTCGTTTTCTTTTTAGAATAAAGTTTAATCGTCAGTTATATATATAACTTA TATTTTTTGGTCGTATTTTCTTCTTCTTGTTTCTATACAGTACCTATAAACACTCTTCTAACCGAAACTCCCGATCATACGGACGACA TGTGTCATGAGCGAGCGAAAATTGATATGAGGACGCTCAAAAATACCATATAAATACACATACACATGCTGCCGTATTGGCGTTTATA TGGTACTTTTGAGCGCCCTCGTATCAATTTTCTCTAATACACCGACATGTCGATAGTATAGTTATTTATGGGAGAATATCCGCTATAC TTACATGCAGCATATCTACATCTCTATATATAAACTATACTCTCTCTCTCTCTCTCTAACTTATCGTGCTATGCTTTATAGCTTTCTA CGACTCTTCTGTTCACTACAATAATAAATGATTCACAAAATGCTTGTTTTTTTTTTTCTTCATGTTTCAAGAGGTTTATTGCTTTTTTT GTTAGTTCGATTTCCTCGTCTCAACATAAGTATGTTGTTAAACCAATTGTGCGATTGTCAAATCGTTTTTCTATTAATTAATAGAGTT CTAAAAATAGACCTTCGTCTTTTCGTTGTTGTTGTTGTTGTTGTTGACGCTGTTGATTGTTCACCTCTATAACTGCATGCACGTATGA TGATGACTGCATTGACTTACCCATTTGAACTGACCGTCAAAACCGTATAATTGTATGCATATATAAATATACAGTATACTCATAACTT ATGAGTCTTAGGAGATCGATCAAAATCGATCGATCGATCGATCGATCGATAGAACGAAATCAACTGCCATTCTGTATATCTATATATA CAGTACAATCATCATATTTAGTAAACATATTTTATTTATTACTCTATACTTTACTGTACTATTTGTATAAATTTATATTTATGCACTC ACACCATAGTCTACTCACACATGCACACACATACAAGTACTGTGTACTATATAGTCTAGGTCTACACATAGTAGATATTGATGTGCAT CATATATCGATATAGGATCGTACAGGAAATAAACTCTCAACTCTATACAGCATCTAGTAAGTATAGATCCTATATAGACTATGAGCAT ATTGGCAGCATGCATCAGCCCCATCACATAACTACAAAGGCCAGCATCAGCTTAATAGCTCGACATTTATCGTCAGTCTCATCAATAA ATCAATATGCAGAATTCAAAGTTAATTTCATTTGATATCAAGTTTTTGTTGTTGTTGCTTTTTTGTGTTTACCGTCGTATAACTTATGT CAAAAATCGATCGATCGATCAATCAAGGATTTCATGAAATCACCCTTTAAAAGCTGCTGATGATGGCTGAGTTGCCAGCATGTTCAAT AGATAGCTTCTATGAATATGAATGCTACGCGCCGCGTTAGGTCTATATGTGATATAGTGTATATATATATATCTATATGAGAGAGATT GAGCCGCATAGATTATATAGGTATAGTTAAGTTATGAGAGACGATTTTACTTGGACTATAGACTATAGAGCTATACTAACTTAGATAA CTAACTAGATATCTATACTTGTTCATACGCATATATAGATTAAGCATGATGCATGCCAACATTTCCCCCCTCTCTCTATATATAATAT AACTCGCCGCGCGTTTATTTTAAATTTTGCTCTAACTCGTTATTTCATTTGCATGTCTATATAGTTACACGCACGCTATATAGTTTAG TGCCGCGGCATCACTAAACTCGTTTGATTTGGTTTAGTTTGTATATAAATGCTGTTGTGATATATACGTTAATTTGTTTGTTTGCGCA ACTATGTATGTTTGTGTGCGTGCATGTGCGCATAGACAGACTCAAACTAAAAGTAAATTGTACAATATAGATAGTCTATAAGCTCATA ACTCACCAACTATGCATAGCAGCATATTGTATTGTACATAAGCACTGGAGCGCAGAAAAAACACAAAGGCGTTCAAAACTACCATATA AATAGACATGCTGCAGTATGTATATTTATATGGTAGCTTTGAACGCCTTTGTAAATTTCTATGTATATATGCACAGTATATATATATA TGTGCTGTGATAGTTCATCTAAATATAGTTTCTTGAATTGTGCGAAAACATGCAAATTGAAATGTACATTTTTCTTCCACCCCACTTC 
TCTCTATCTCTCTCTCTCTCTCTCTCTCTCTCTCTGTTCTCGTTCTCGGTTTTGTTGTTGTTGTTGTTGTTGTTGTTGTTCTATTCAT TCTCATATTTTCTGTTTCTCGAGAACATGCTTTTTTTTTGTAATTCATTTATACCTTTATTGAAAACAACAAAACATATTTTTCGTCA ACTTACTTCTCTTATCTAAGCGATAGCATATCTTCTTAGCGTAGATATGATGAGATGGCCATGATTCATCATCTTATTCTTCTATTCA TTTTATTCGAGCCCCCCTCTCTCTCTCTCGTTTAATGTTGTATTTCAATTTTTTTTCCCCCACTAAACGCACATCTTTAAAAAATATAC AGCATATAATTTTTACATGGACTATGCATGTCTGTGCTTATTGTTTGTTTGTTTTGTTTCTTGTTTAAACAAGTGTGCATTGCGTGCA TGTCTCATTTTGCGAATGTGTACACGTGTTTGTATAAAAGTTGTTGTTCTTCTTCTTCTTCTTTATTAGTATCATCATCATCATCATT ATTATTGCTATTGTTATTATTATTAATATTTTTTTATTATGTTATCTTGTTTTTATTACATAACGAGAACATATTTCAAGCAGTCGTTTT GTTGTTTCTGTTGTTTTTATGAATTCAGTTGCTTGTATTTGTATGAATGAAGTCAGTCACTTACAACAAAAAACAACAACAAAAAAAC TAATATTTTTTTAATATTAATAATACATTTTTGTTACCGGCTAGCTCTAGTTGAGGTCATTTATACATCATCATTTCAATTTGAAAGCT AATATTTAGATTAATATACATAATAATATATAAGAGGAATTTTTTTTTTTATAACCATTAAAAAACATACAATTCAAAAATGACTGACG AAGTTCATAACGGAAACAAATTAGACGACGAGGACTTAAAATGTAAATCGTTAAAAGAGATTTTAGTAGTTTAATATTGTTGTTATTT GAGAAGTTCTTGTGGATTGTTTGATATATTAGCGCCGCTCTTATTGAAATGGTGTCTGATTGAATTTTTGTTTTGTTTGTTGTAGCTA ACAAGAGCGAGTCGAGCAAGCATGCTGAGAATGTGACGCCGAGTCAACGAGTCGCCGATGGCACTGGCAGCAAGTCATCGGCCTCGTC TAGCCTCTCGCTTGCGGACAACTTGCAAAGTCTGCTCAAGCAACTGCAGCAGCAGAGCATGGCGTCCGTCATCGAGTCGGACGAGGAC GAGGCGAGCATGCACCAGCGCCTACTCGAAAGCGTCTACATGCAACAGAAGCAACTAGCCAAGTCAAGCCATCAGCATGAGAGCGCCA AAGCGAATGTCATGGCATCGACGTCGTCGTCGTCGTCGTCGTCGACGCTCATATCCAACAACTGGAATAGCTGGATCAGCAATTTGAA TGGCAACAACAACGGTCAACAGCACGATAGCATGTTCAACTCGACTACTCAGCTGCTCAAAGCGAACAGCATTGCCTCGTTGGCCTCA GCGCTCGTACGAACCGGTCTGGCCAAGTTTATGGGTAAGAATTTTCACTGATTGTTTCATTTCATTGATAGCTTTCATCTCACTCTCA ATCGAATTCCATTCAAATTTATTGACAGACGATACTCCGGCTTCGTTCAGCAATCAACTTATCGAGTTGA

\subsection{Das Cosmid slc_1s}

\subsubsection{Lage der offenen Leserahmen (ORFs)}

\begin{tabular}{|c|c|c|c|c|}
\hline ORF & Annotation & Start & Stopp & $\begin{array}{l}\text { Orien- } \\
\text { tierung }\end{array}$ \\
\hline 701 & Hypothetischer ABC-Typ Nitrat/Sulfit/Bicarbonat-Transportsystem, Permease-Komponente & 1 & 229 & - \\
\hline 702 & $\begin{array}{l}\text { Hypothetischer ABC-Typ } \quad \text { Nitrat/Sulfit/Bicarbonat-Transportsystem, periplasmatische } \\
\text { Komponente }\end{array}$ & 386 & 1969 & - \\
\hline 703 & Hypothetisches Protein & 2208 & 2969 & - \\
\hline 704 & Hypothetisches Membran-assoziiertes Protein & 3129 & 3893 & - \\
\hline 705 & $\begin{array}{l}\text { Konserviertes Protein (hypothetische Dihydrodipicolinat-Synthase/N-Acetylneuraminat- } \\
\text { Lyase) }\end{array}$ & 3987 & 5045 & - \\
\hline 706 & Konserviertes Protein & 5032 & 6018 & - \\
\hline 707 & Konserviertes Protein & 6087 & 6752 & - \\
\hline 708 & Hypothetische Serin/Threonin-Protein-Kinase (katalytische Domäne) & 6803 & 7651 & - \\
\hline 709 & Potentielle Serin/Threonin-Protein-Kinase (mit Membran-durchspannender Domäne) & 7629 & 10550 & - \\
\hline 710 & Konserviertes Protein (potentielle Phospholipase/Lecithinase/Hämolysin; COG3240 & 10705 & 11649 & + \\
\hline 711 & Potentielles AslA (Arylsulfatase A und verwandte Enzyme) & 11777 & 13924 & - \\
\hline 712 & Potentielles OmpA-verwandtes Protein & 14115 & 17522 & + \\
\hline 713 & Hypothetische Imidazolen-Propionase oder verwandte Amidohydrolasen & 17623 & 18954 & - \\
\hline 714 & Hypothetisches Membran-assoziiertes Protein & 18971 & 19759 & - \\
\hline 715 & Alkohol-Dehydrogenase, Klasse IV & 19867 & 21150 & - \\
\hline 716 & Hypothetisches Membran-assoziiertes Protein & 21204 & 23006 & + \\
\hline 717 & OmpA-verwandtes Protein & 23107 & 26478 & - \\
\hline 718 & Hypothetisches Protein & 26540 & 27166 & + \\
\hline 719 & Hypothetisches Protein & 27238 & 27528 & + \\
\hline 720 & Hypothetisches Membran-assoziiertes Protein & 27529 & 28300 & - \\
\hline 721 & Hypothetisches Protein & 28381 & 28728 & - \\
\hline 722 & 1,4- $\alpha$-Glukan verzweigendes Enzym (EC 2.4.1.18) & 28813 & 31068 & + \\
\hline 723 & ATPase-Komponente eines ATP-Transporters mit verdoppelter ATPase-Domäne & 31508 & 33145 & - \\
\hline
\end{tabular}




\begin{tabular}{|l|l|l|l|l|}
\hline 724 & Uncharakterisiertes konserviertes Protein (COG2947) & 33147 & 33578 & - \\
\hline 725 & Serin/Threonin Protein-Kinase, katalytische Untereinheit & 33642 & 34640 & + \\
\hline
\end{tabular}

\subsubsection{Sequenz des Cosmides slc_1s}

TCAGCGCGGCGACCGGCAGGTTTCGGCCGAAGAGCGCGATCGGCGCTCCCGCTGCTTCGATCGCCCGCCACGATGCGGCCACGATCCC GAGCGGCACGCCAACGAGGATGGCGAGACCGAACCCGATCAGCACGCGCCGCAACGTTGCGGCGATGCTTTGCAGCAGTGCCCGATCG TTGAGCAGGCTCGGGAAGCTGGCGAGCACCTCGCGTGGGCTCGGCAGAATCACCGGCGAGATGAGGCGGTCCTCGGGTGCACCACCGC TGGTGGCGAGCCACCAGAGCAGAACGACGAACGCCACCATCGCCGCGCCGAGCAGCCGGCGCACCATCCGCGGCGGCGGGACGCGAAG CGAGAACAGCGGCGGCCTGGCTTCGCGCACCATCTACTTGGGGGTCGTCGCCTCAGCCGGATAGACCTTGACCTCGACCCGCCTGTTC TTCGCGTGGTTCTCCGGATCCGTCGTTTCGGCCGGCCGGTCCCAGCCGATGCCGGAGCTGGCGAACTGATTCGGCTGCAGCGAGGGGA ACTTTCGCAGGATCGCCTCTTTGACCGAGTTGGCGCGGTGCAGCGACAGCTCCTGCACCAGGCTCTTCGGCACGGTCCCGCGCATCGA ACCGTCGGTATGTCCCTCGATCACGATGCGCGCCGCGCCGTACTGGCCGGCGAGCTTACCGACTTCCTCGACGATGAATCCGACGTTG GGATCGTAGAGTTCCTCTACATCCTTGCCGTCCATGGTCTTGGTGACCTTCTTGTTGAGGTCCCAGGAGTTCGGGAAGAAGTGGATGA CGACCGTTTTGGTGAGGATCTCGTCCTTCTCGCCCTGGATGGAGCCGGCAGTGGCCGGCGCAAACTGCACGTCGTACTCGTTCTTCTG GCTCGCATATTTCGGTTCGGAGCTCAGCTTCTGGATGACCGAGAAGTCCATCACCTGATCGAACGGCGTCTGCTGCGTCACGGCGTTG ATCTTCTTGTAGAGGAAATACGCCGTGTTCCACGTGCGCTCGAAACTGGTGGGGTTGTTCTGGTTCAGGAAGAAGTCACGGTTCTCGG CGTAGTTGGTCGAATGCGCGTCGCCCAGCATGCCGAGCGCGTCGCTTTCCGGAATCGAGTAGCCGGCGGCCATCAGCTTGGCGACCTT CTGCTTCGCCTCCTGAGTCTTCAGCTCCTGCATGGCGTCGAAGATGCCGCGCACCATGCCTTCCATGATGTCCGGGTTGTCCTTGGCA AAGTCGGCACGCGAGAACCACACGTCGGCGATCAACTTGTTGGCGGTCGCCGTGGTGACGATGAGACGGTTGCCCTTGACCTTTTCGA GGTTGTAGATGTCCGGTGCCCAGGTGACGGCGCCGGCCATGCGCTTGTCGGCATTGAAGGCGGCGGCCGCCTGGAAGGCATCCTGCGT GAACTTGAACTCGACTTCCGCCGGCTGCACGCCGGCATTGATCAGGGCGTTCAGGGCGAAGAAATGCGACGGCGAGTTCTGGGCGAGG ACAATCGTCTTGCCTCGCAGATCGGACATCGTCTTGATGGCTTCGCGCACCACGATTCCGTCGCCGCCGTTCGACCAGTCGACCTGCT GGTAGATGCGTGGCATCACCCGTGAGTCTTTGCGCAAGCCTTCGAGGAAGAGCGGCACCATGTCGAGCGTGGCCCAGCCGACGTGCAA CGTGCCGGCGGCGTAGGCGTCGCGCATGGCCACCGGGTCGTCAATCAGGACGAGCTCGAGCTTGAAGTCTTTACCGCCCGGAGTCTTC CACATCTTGCCGGCCTTGAAGCCATTGTTCGCGTAGATGATCGGCCCCCACCCGGCCCAGACGTTGATCGCGAACCGCACGGTGCGAT CGGCCATCGGCTGGTAGCTGGAGATTCCCTTGACCTCTGGCAGCTTGGCGCTCGGGACGTAGTTGTATTCCTTGACCGTCGTGATGCC CGAGTTGTCCGGCTTCTCCGCGCTGCCGGCCATCTGCTTCATTTCTTCGCTCGAGAACTGGCCGCCGGATCCGCCCGGTGCCTGGCTG CTGTAGCGCCAGACCGCCAGGCCGACGAGGCCCAGAACGACGAGCAGGACGGCAGCGTAGAAAGCGCGTGTCGGTTGTCCGTTCGCCA TAGCTCCCCTCAGGAAGGGAAGAAGGATGAAGGAAGAAGGATGAAGGATCGATGTTTTCCTTCTTCCCTTCCTCCTTCCTTCTTCTTC CTTTCTTCTAGTTCGTCTGCTTCTGTACCGGCTTGTCCGTGGTCGCCGGGCCCAGGTCCTTGGCCGCCTGCGCCACCGGCGTGGTTTC AGGCGACTTCAGACCCAGTTCCACCTCGAAGTTCGTCAGCGCCTGTTCCGCCAGCTCCGCCTCCATGCGTTCTTCGGCCTGAATCTCG GCGATGCCTTTCGAGGACAGATCGGCGGCGACGCGAACGCGGCCGCGGTTCTGGTCGATCTTCTGCTGAATCACCGCTTCGATCTGTC CGAAGTCCGTCGTCAGGTTCATGTCGAAGCTCTCGGCGAGCTTGGCAATCTCCGCTTCCGCCGCGCTCATCTTCAGCTCGGCGTCGTA CTTCTGGATTTTCTGGCGCAGCTCGATCAGCTTGTCGTTCGCATGCTTGATTTTCTTCAGGTTGTTCCCGTACGCCGTTTCGTGCATC TGCAGCTGCTGATCGTTGGCGGCGAGCTCCCCCTTCGCCTTCTGCAGCTCCAGCGCGAACTTCGCCGCCGTCGCCCGATCGCCGGCTT TCAAATAGGCCTTGGTCTCCGCCTCGAGCTTCTGCACGTGCGAGCGATTCGCCAAAACCTGCCGCGTCACGCGCTCGACCAGGCCGCG ATACTGCTCGAGCCCGACGCGACCCTCCTTCAGCTGCTCGACCGAACGGTCGTACTCATATTGCATCTGCGCAATGGGGTCGGCCTCC CAGAAGATATTGGCAATCTTGTTGATTTGCGCGACGAACGCAGACCAGAATTTTTGGACAATCACAGACGTCTCCTCAGGATGAATGC CGTGAGGTGATAACTCCCAACTTCCAAATCCCAACTCCCAAACGGGCGTTCCGAATCAGCGGGGTGAAAACCACGCGAGCGACTCGTG TTGGAAGTTGGCAGTTGGGAGTTGGAAGTTGACACGTATGCATCTCAGCTACTTGCGCTCCCCCGCGTCGACCGCCTCGGCGAGGATG CGTCCCTTGTAGATATCGTCGAGCGCCGCCCGAAGCTCCGCGCCGTTGCCGGCGCCGATGACGTCCCCTCCCACCTCCTTCAGGAATG CGAACTTCTCGGGGCTCGTGTCGAACGCGACGAAGTAGGTCTGCACGGCTCCCTCGCTCTTCCTGAAGATATCGCGGGCGACGGTGTT CGGACTTCGCCCGGCGGTGTTCTCGCCGTCGGTCACGACGAGCAGGTATTTGCGGAAAACGCCGGCGCGGTAGAGATCGGGACGGGCG TTGCGCATCGCTTCGCCGATTGCCGTGCCGCCGCCTGGACTCGGCAATCGATTCAATGCCTCGCGGACGATCGCCCGATCGTACTTCT GGAGAGGCAACACGTTCGAGACGCCGCTCGAAAAGCTGTACACACCTATCTTGATGGGGAAGTCCGGATGGCTCGCGACGAAGCCGTC GGTGGCATCCAGCGTGGCCTCGAGCGCCTCTCGGGCGATGACGTACTTCGGCCGGGATTCGCCGGGGGCCGTTTCTTTCATCGAGCCG GACGTGTCGACGAGGATTGCGACTGCCGCGCCAAGTCCTTCTTCGACTTCTGCCTGGTAGGGTGCGGAAGGTTCAGCATCGTCGGCTG GCTGCGCGCTCCCGCCGGAGCCCGAGCCGCGACCGGAATCGCAGGCCACTGTGGCCATGAGCAGAGCGCAAACAGCGAGCTCGGCCGC CAACTTGAGACAAGGCCGCAAACGCGTGGGCCTCGAGTTCATGTGCGCCAAGGAATCATGTAGATCGACGAGGGAGTGTACCGTTCGG TTCCGGAAGGATGCAAGACGAGCCGGCTACCTGAGCCACAGATCCCGGCGCTCCGCGACAAATGCGTCATCGGTCAGGTGTGGATATT TTGACAGCACCCGATCGATCTCTGCCATCTGCCCTGTGCTCAGCTCCTCGTGCGGATCGAGGCACCCGCGTCCGGCCAGAAGTCCTTG CCGCCGCAGGACTTCGTGAATTCCAGGGATGCAGCCGGCAAAACCGTGCGCCGGATCGAACAGTGCAGCATTGGCGTCGGTGAGCTCG GCGCCGAGCGCCAGGAGGGCCGACACCTCGTCGCCTGCCGCCACCTTGCAGCGCTGAAGCAGGCCGACCGCTTTGCTCGTCCAGACCG CCCACTGCCCGAGCAGGCCACCCGAAAAGCGCAGTCGCGGCTGCCCGTCGCCCGCGGCGTACCCGGTCAGCAGATCCGCCACGATCGC GTCGTCATTTCCCGTGTAGAGGGCCACGTCCGTTCGGCCGCTCTCCGCGAGTGCGTTCACGACGTCCAGCGTGCGGTAGCGATCGAAC GGCGCGACTTTGATCGCGACGACGCGGTCGATGTCCAGAAACGCCCGCCAGAATGCGCGATCGAGTACCCGTCCGCCGACGGCGGGTT GCAGGTAGAAGCCGACCACGGGAATCACGTCCGCCACGCGCGCACAGTGATCGAGAACCACGCTGTTGCTCGCGTCACGAAGGGCGCC GAGGCTCAACAAAGCCGCCTCGTAGCCGAGCGACACGGCCAGTTCCGCCTCCTGTAGCGCCTGCGCCGTCGGTCCTACGACACCTGCG ACCATCACGGGCCGTCGCTCGCGTCTGGCGCACCACGTGCGCACGGTGTCGCTGGCGAGCGCGAGAACCGGCTCCAGGAGGCCGATCG TCGGATCGCGGATCGCGAATTGCGTCGTGTGCACGCCGACCGCAATCCCTCCCGCGTCGGCGTCGCAGTAGTACCGGGTCAGCGCCAC CTGCCGGCGCTCATCGAGCCGGCGCTCGGCCGTGAGCGCCAGCGGGTGGGCCGGGATTACGACGCCGCGCAGAAGCGTCTGGCGCAGG CTCGACAAACGTTCGTCAGAAGCGGCCATCCGTGACCTCGAAGTGGGTTGGCTTGTTCAGCGAGGCACCGCCTGCCTGCACCCAGTGC GCGACCCATTGCTGCAGGACTGTCAGGGGGACCTCGGGTTCGCCCAATTGCGCACGACAGCGGCTGGCATCGCTCAGGAGTGCAACCG GTCCTTCGGTGCCGACGAAGCGGGGCTCGCGGCCGAACATGGAGCCGAACCATCGCGCGATCTCTCTGACCGAGATGCGTTCGGCGCC GGTGACGTTCAATATCGTTGGCGGTGATGCGCAGAGATCGAGGCAGCGCAGCGCATAGCTGTTGGCGTCACCCTGCCAGATGGCGTTG AAGTAGCCGACGGTCAGGTCGACAGGTTCCCCGGCAAAAACCTTCCGCGCGATGTCCACCAGCGTGCCGTAGCGGAGATCGACCGCGT AGTTCAATCTGTACAAGAGCGATGACGCGGTTCGTTCGTGCGACACGAACTCTACGACTCGTTCGCGCCCAAGGCAGGACTGCGCGTA TTCGCCGACCGGCGCCGGCGTATCACTTTCTCTCGAGGCTGGCCCGTCGATCGGCACGAGGGGATACACATTGCCGGTTGAGAACACC ACGAGCCTGGACCGGGCGAAGTGTTCGGCGACTTGCGCCGGCACTACAGTGTTGGTGACCCAGGTCAGGTCGGTTCGATCCAGCGTTC CGAACTTCCGCCCGGCGAGAAACAGCACGTTCTCAGCGCGAGGCAGCGCGGCGATCTGCGCGGGCTCGAGCAGGTCGCACGCCAGGGT 
CTGGATGTCGTCCGCTTCCAGTCGGCCGCGGGCTTCGGCCGAAGAAAATCGCGACGCCGCCATTACGCGATAACGGCTGCCAACACGC GAGAGAGCCCGGTAGATCCGGCGGGCCAGCGAAGGCCCCATCTTGCCGCCGGCACCGACAATCAGCACGTCGCCATCGAGACGCCGCG CGAATTCAACGTCCGCCTCGGCCGGGCGCGCCAATACGTCCTCGAGTTCGGTTTCGGTGCGAATTTGTGCCGGTAGGTTCATGGTAGC GAAGCGAACGGCGATCAGCGCGCTATGACGCCCAACAGATAGCGTAGCTCATCGTCGATTTCCTGCGGACTGTCGACGGTCTCGGCGA TGGTCTCTCTCAGAGCGGCAGCGAACTGTTTTCGCAGCCTGTGGACGGCGACGCGGACCGCACCCTCGCTGGTGCCGAATTCCCGGGC CAGGTCCGGATACGACAGCGTATCGTTTCCGGTAAGCGTTGACCTCAGCTGCTTGAACAGCGCCTCCCGGCCGGACCGAACGTGTGTT TCAGCGACGCGGATCAATGCCTCGTCTAGGACCTGCAGCGCCCATCGCCGCTCGTAGATCCGCTCCGGCGTCAGGTCGCTCGAGGGCT CCAGCTGGTAGCGGCGTTCGCCGTCGTCGAAGTCCAGCGGAACGTGAAGCAGCCCGCCACCGCGTTTCAGCGTACGTGCCCAGTCCCG TTCGTTCGACAGGAAGTGCCGGAGCGAGCCGAGGAGGAATGATCGGAAGCGGCCGCGGACGGGGGTTGCCGACTTCAAGTAACCCTTC TCGATTACCCTGGCAAAAAACGCCTGCGTCAGGTCTGCCGCGTCGTCGGTCGCCGCACCGCTCCTGCGAACGAAGGCGTAAACCGGAA ACCAGTATCGCTCACAAAGCTCGGCCAGCGCCGCGTCAGCGTCCGTGGTGGAGCTTCCGGCCATGATGACCAGGCTCCAACGGGTGGT CGCGAAGCGATGCCGGCTCCGCTCCGTCAGTTTCGAACTCCCTGCATATGTCCGAGCGCCGATTTCAGGTCGGTCGCCACATCCTCGG CTGTCTGCCAATTTGCGCCACGGGCATCCGGCCAGATGTTGTCGCAGACCGATGCGATGTCCGTTCGACACTTGAGCAGGCTGGAGAT GAGGTCACGCAGATCGTCGACGTCGGCGCGTCGGTTGTGTTCTCCGAAAACCTCCCCAGGTCGATCCGAATCCCGGCGCCCAGCTCGG CGGCTGATCCACGAAGCTTCTATGGTCGGCCGCATTCCCATATCGAGCAACGCTGGCATACATCCGTTCGATGAAGCCACGATGATCA CGTTGTGTGCCTTGATCGACCCGTGTGCCAGGCGACATCGGTGCAGCTCAGCGACACGTTCGCAGATGTCAACGAGGACTTCGAGCCG CTCCCGGGATGGTCCGGACGCCGCGAAATACTGGTCGAGGCAAACGCCAGCGGCGTACTCGGCGCACACGCAGGCGCGGCCTTCAGTC GTAACTGCCGTGCCGATGAGCCGACCAGCACCCGGCGCGCGGGCATCGACGGGCAAGCGATGGAGGAGATCGCGCATGAGCGCCAGGA ATAATTCGACGTCGACGGGCTGTTCGATGACCTTGACCGTTATGAAACGCCGGGGCTGGCGGACACGGCAGCCCAGGTAGACCGTGCC GTTCGGCCCACGGCCGATTGGTCCCAGCACGCGGTGTGGTTCATTCTCGATGACGACGCCAGGGCCCGCCGCAACCGGTTCGAGACCC AACCGTAGAAGACACGCGGCGCACAACGGCGGCCCCTCCGACGTCGCCACCATCGTGGACTCACAGTGCGCGCACGGCTTCATGACGC CCTGCTGGTGGTTTGGCGCCCATCGCGCTGTCGGCGCGAAGTGCGCGTTCGAACTGGCTGTAGAACGCCAGCGCGTCGGACGGCCTCT GTGAGCGGTCGATCGCCAGCGCACGGTCGAAGAACTGCGCGCAGTGAGGCCACACCGGCCGGAAGATTTCACCCGGCTCCCAGTTCAC GCTGCGCATCAGCGCTCCATGCGGATCCCATGGCGTATTGACGGCGATCAGAGCAAGGCTCCCGCTCAGCATTTCGCGGGCGATCACC GCGAGGCTCCAGATATCCCAAGCGGGCGCGGGCTGCTCGCCACGGAGATGTTCGGGCGCCATGTATTCGGGGGTACCGAGCAGCACCC CTGGACGCGTGTCGCTTCGAGTCGCCACCATCCCCCCCGAAGAGAGGAGTGGCTTTGCCACGCCGAAGTCGAGGACCTTGGGGGTGGG TGCCGCTTTTCCTTTTACGAGAAAAATGTTCTCGGGCTTCAAGTCCCTGTGAACGAGCCGGACGCGGTGCGCGGCATCAACGGCCGCA CACACACCGTTGAGAATCAGGAGCACCGCATCCGGCGCCAATTCTCCGCCGACCTCGATTTCGTGGCGGAGGGTCCGGCCAACCAAGC GTTCCATGACGAGAAACGGCTGTCGATCACCGACAACACCGAAGTCGTGGACGGTGACGACGTTGGGGTGCACGAGACGGGCAGCCAG CTTGGCCTCGTCGAAGAATCGCTCGACCGCACCATCGGCGCGCGCCAGATCTTCGCGAACCACTTTGGCCGCAACCGTGCGATCGAGG GCGATGTCGTGCGCTTCGTAGATCGTCCCCATTCCCCCTGCGGCCAGGCGTCTGTCGAGCCTGTACCGGCCCGCGAGTGTGCGCGGCA GGTCCCGGACCGCCAGAGGCCGCGCGTCGCGAGCGCACGTTCGACTGCCGCCATCGAAGCAATCGCCACATTCGGGGCATTCTTCGAG GGTAGGCACGTCCCGCTGTGCAGAGGCAGTCGCCGGAAGCAGCGCGATGTTGTCCGCGATGGTGACCAGGACATCCCGGTCATCCGCC GAATAGGGCTCCTCGGATCGCTTCACGCCGAGCGCGAGCAGGGCCGTAAGGGTGCCGCTCGATCCGATCACCGGAACAATGAGGTCGA TGCCACCGGCGATGACATAGTCGATGTCGGCGTCGGTCAGGTGACGAACCTGCGATCGGTCCGCGTCCACCGAGGTCTCGAGCGGTTG TTCGAGCACGCGCACGAGCGCGACGAGTTTCGCTTCGGCATGGAGGTCGGCGAGCGCATGTGCCGCCGGAGTCGCCGCGATCGTGCGG TAAACGGGTTCGTGATCGTCTCGCGCCAGCAATACCGCAAACTGCGGGTGCATCGCGGCCTCGATTTTGGCGACGACGAGCGGAGCGA CGCTCTCGAGGCTGCCTCCTCGACGCACGTGTTGAGCCACCTCGCGCAGCACGACGTATCCGTCATGTCGCTCCCTGAAAAAGCGACG GTCGATAGCGTCGAGCCATCGCTGTCTCCAGGCGTACGCGGCAGTGGCGACTAGCGCGACCGCAAGATACGTCGTCCCATGACGCTGC AGCACGGCGCTGATCGTCTCGTGACGGTGACGCAGCAGGTCCACAGCGAGACTTGTCGCCAGTACGGGCGGAACCGACATGGCGGTCC AACGGGCCAGCGCATACCTGAGCCACTGTCGGATGATGAAACTGACGTCGAAGAGCCGATGCCGCAGGACAGCGTAGGTAATCGAAAG CGGTGCGGCCAGCATCGCGACTGCAGCGAACGCGATGGCTGGCGATTCGAACAGAGATGTCTTGAGGTCCGCGCGCGGTGTGAGCCAG TGATACGCGAACATCGGGAATGCCGGAAGAACGCCCGTAGCAATCCCAGCGACAACCGCTCGAAGCCGCCGCCGCTCGTTCACGTCAT CGATGCGCTGATAGTTGAAGACGACGATGACTACCGCTGCCGCCAGCGAAACGATGGTGACGGCGAAAAGCGGCCCCGTTCCTGGCCC TACGCTCCTTAGCGTCTTCCCACCATAGACGACGGCTGCGAAGTTGTACAGAGGCACAGCTAGCGCGCCGGACGCTGCGGTCCAGATC GCTGCCTGGATGCGTCCCGCGCCCGGCATGCGCCGCGGAAACGACGCCACGAACGTCAGCAACACCGGTCCGATGGCCAGGCTGCTCG CGTACGGCAGCCAGATCAGCGCGCCGAGCGGTGCGGGCAGCTCGCGCCACACGGAAGCCAGCCGCATCGGCAGGGAGATCGTGAAGGT GGCGCACGCCAGCAGGAACCAGGCGCCCGTCAGCGCAACGGGGTCCCGCGGCAGCCGCCACGCCACGAACAGCCCGGCGACGAGCGTC AGCAGTTGCGCCCCGAGGGTGACGACCAGAATGATGCCTGCCTGGGTTCGCCAATATCGCATTGGCGTCGGACCGAGCTGCAGTGGCA ACGTCAGTCGCTCGTTCCCTCGCGCAACGACCACTGGCATCGGTATTCCCGTTTTAGTGATCGTGCCAAACTCGCCGCTGGAATCACG CCCGGCAATCGCGACGTCGTTGAAGACGAGGATCCTGTCACCTTGCTTCAGTCCCGCCCGTTCCGCCGGCGATCCAGCAGCCACGTCG GCGACCAGGACGCCTGGCTCCACCCCGCTCCTATCGGCGACGAACCCGGCATTCTCCGGACGCGTCACGTCGCAATAAACCAGGAGCA AAAAGTACGCGCAGAACGAACTGGCGGCAACGACCAACCACGGCGGCGGCCAGCCGGCGCGTACGGCCGATTTTCGACGGATTTGTCG AGGAATCACCGACAGGGTCACCTCCGCAAGTGACGCAGCCTGACTCGCGATGGCGACGTGTATCGAGGACGGCAACATTATAGCCCAG CTAGCGGCCAGCCTCCTTCACCCTTACTGAAGCAACCGCACCAATTTGTTACCGGTAACGTTCCACCTCCAATCCTTCAGGAGAACTC CGAGCCCCGCCTCGTTGCGCGGCGCGTCAACACGTCCTCTAAATCAGGAGATTGGTATGCACATCGCCTTTCGCATCATGCTGACGCT GGTTCTTGTTCTCTGCGGGTTGACTGCGGGTACGCGGACATTAAGCGCCGCAGATACATTTCGCGTCGTTGTCTTCGGGGATAGCTTG TCCGACTCGGGCGGCAATCCTGCTCCTTCGCCGCCGTACTTCGGGGGCCGCTGGTCGAACGGTCATACATACGCCGATGGCCTTGCGC CACGCTACGGTCTCGGTGACGCGCTCCAGCCTTCCTCAATCGCTGGCGGGACGAACTATGCGCGCGCCGGCGCCCGCGTCACCGGCGC GAGCGGTGTCGTCGAACAGATCGCTTCTTACCTGCGCGACGTGCAGTGGAACGCGGACAAGCACACGCTGTACGTGGTGTTCATCGGT GGAAACGACATCAGGGACGGGCTGTTCAGCGCGTTTACGGATCCGTCATTCAATCCGGCAGCGTTCGTGGACAGCCGGCTTGCGGCGT TAGCCGTCACGCTGAACGGACTCTCGGTGCTGGGCGGGCGCAACATCGCCGTGCTCGGTCTGCCGGATCTGTCGAAGCTGCCGGGACT GCCGCCCCAGGCGGCGCCTCTTGCCACGTTCATGACTGTTCGGTTCAATGCCGGGCTGGCACAGATTGTCAGAGGTCTCGAGGAAGGC CGCGGACATGGGTATCTCGTCGACGTGTCAGCGCTCTTCGGTGAGATATTGACGGATGCCGCCGGTGGCGGCGCGCGTTTCGGGATCA CGAACGTGACGCAGCCCTGCCTCGTCGTATCAAACGGAGTTGTGATCGCCCAGTGTCCAAATCCCGATGCGTACCTCTTCTGGGATCC CATCCATCCGACAGCCCGCGTTCACGAAATCCTCGCTGACTACGTCGTCGAATCTGTTGCCGAAGCTCGTGAGGACGAAGAGAACGAC GAGGAGGAGACGAACAGCCAACAGCGACCGTAGTTGAACTCTGTGAGCAAGGCGTGAGGGAGTCGCCGGCGGGCGGCTCCCAAACGTT TCAAAATCTGCAAATGGGGACACTCAACATTTTTGCGGGACTGTCCGATTTCGAAAAAGGTGAGTGTCCCTTTTCATGGGCGGAGCTCG GCGAGCGTGCGCGCGATGTCCTCTTGCTTCGGATCGAGCCGTAGCGACTGGCGGAAAGCGGTGACCGCCCCGGCCTTGTCGCCCACGG CCAATCGCGTCAGGCCCAGCCCGTTCAGCGCCATCGTCGACGCTGGATCGGCGTTGATCGCACGTTCGAAGTAGGGCAGAGCGTCGGT GGGGCGACCGGCCGACGCCAGCGCGCCGGCGAGATACAAGAGGGCTTCCGAATTCGACGGGTCGCGCTCGATCGCCTGCCGGAACAGC GTCATCGCCTCGTCTCGACGACCGCCACGCATCCGAATCACTCCAAGCTTGGTCATAGCCGATACGTCGCCGGCGTCCAGTTCGACGA TGCGTGCGTAGCGGCCGCCTGCGGCGTCGAGATCCTCGCGAAGCAAGGCGAGGTCGCCCAGACGGCGAATCGCCTCGATGTGATCGGG GACGAGCTTCAGCACCCGTTCGCACAGGGCCGAGGCTTCATCGTATTTGCGTTCCTGGATGCGAACCTCGGCCAGCGAGATGAGTGGC TGCGGGAACGTCGGATTTTCACGCTGCGCGCGTTCGAGGATCAGGCTCGCTTCCTCGAATCGTCCTGCCGATCGCAGGTTGTCGCCGA GCACGATTGCGTCTTCAGGCGTCAGCTGTCCTTCCTTGTCGAGCGCGCGAAGGTCGGCGATGGCGAGATCGTGACGTCCGGCAGCCGC GTAGGCGACAGCACGCGTCCGCCTCGCCATGAACAGCCCGGGATCCTCCTGCAGCGCCGACGTCAGTTCGCGGATAGCGAGCTCCGGC 
TCCGTTCGTGCCGCCGACATGCCGCGGTTGAGTCGTGGCAAGAGCCGAATCCCATCCTTCGGGTCGCGCAAGGCTGTCCCAGGGCGAC GTACCGCACGACCACCGCTCGCGTAGCCGAGTGCACGCAGGCGCTCCGCTGCTTCGGGATCGACGGCTGGCGCTGCTGTGGCGGTCGG CGTGGGACGGCGCAACGCTACCTCGAGCTTGCCGCCCAAATCCTCTGCACGCGCCCGTTCATCCGCAGCGCGGTTCGTGGTCTCCGAA GGGTCCTTCTCCATGTCGTATAACTCTGGCTTCGGCGCCTTGATGAACTTGAAGCCAGACGCCCGCCACGCGTGCAACGGCGCCCATC CCAGCTCTACCTCGGAATAGAGAGATTCGGCGTACGTCGGCGCCTCTCCCATCTCGTGCCCGTCAATTGCGGGCTTGAGAGAACGTCC CTCCAAATCAGTGCGTTGCGGAAGGCCAGCGAGATCGGCAAGCGTCGGCAGCACGTCGATGGAGCGGGCGACCGTCTTCGACACGCGA CCGGCCGGGATGAGCGGTCCGGCCATGACCCACGGCACGCGAATGGTCGCGTCATAGATGAAGATGCCGTGCGTGCCCTCGCCGTGTT CGCCAAGACTCTCGCCGTGGTCGGCGGTCACCAGCACCACGGTGCGCCCGGTTTCGTTCCGCTCATCGAGCGAGCGCATCAGGCGTCC GAGCTGCAGGTCCACGAACGCGATCTCTCCATCGTAAGGCGCCCGCTCGAAACGCTTGGCGAGGTCGCCCGGCGGCTCGTATGGCGCA TGGGGATCGTAGTAGTGCACCCACAGAAACCAGGGAGCGGGCTGTCCGGCGGTGGGATTCGGAGATGCCAGCCAATGCAGCACGGCAT CGGTCGTTGCATCCGCGAACCGCTCGACATACGGAGTGCGACGCCGGTCGTTTCCCTTGGGCAGACGGTCGTCGTACTTGTCGAATCC GCGATCGAACCCGAACCGGCGATCGAGCGGGAACCCCGAGACGAACGCTGCAGTTCGATAGCCCGCCTGCCGAAAATCCTCTGCAGCC GTGCGTACTTGCGGTGTCAGGACGAATCCGCTGTTGTTGCGAAAGCCGTGGCCGAGCGGCGTCTGGCCGGTAAGAATCGAGGCGTGCG ACGGTCCGGTCAAGGGCGCGTGAACGAGGGCTGTCTCGAAACGTATCCCACGGCCGGCCAGCGCGTCGATGGTCGCTGTCGACGCGGC TTTGTAGCCGTAGGAGCCGACGCGGTCGGCGCGCAACGTATCGATCGTGACGAGCAGGACGTTGGGCTGGGCCGTGGTTCGTGCGGTC GGGGTCTGCGATTCGGACACGCTCCGCCGGCATCCGGGAGTCACGGTCAGCAGCGCCACGAGGATGATTGAAGAACTGAGCCGCATCA GGTAATCGTTCGAAGCGTATCGGCAAACCACCACCAGCTCAAGCCGACGCGGAAAAACCGGTTGACAGCAGCCAAATTAAAGAAGGAA AGTCAGTTACTTCGGAGTCCATTAGAGGAGCACGATGCTGAAGAATGTGTTCGACATGACGCCGCGGTTGCGACGGGCTCTTGGTCGC ACTCTCGCCCTTTGCACGATCCTTATCGCGTCTGCCTTCACCACCGCAGCGTGGGGGCAGTCGTTCCTAGGCACGATTCGCGGCACCG TCGCCGATCCGCAGGGACAAGTCGTGCAGGGCGCCGCCGTTCTCATCATCGATGAGTCGACTGGTGTCACCCGTACGGTCGACACCGA TGCCGAGGGTCGCTACGAAGCGTCTAACCTGAGGCCAGGCACCTATCGCGTCGAGGTTGCGACGACGAACTTCAAGAAGTTCGAGCGG ACGGGCGTCGTTCTACGGGCGGCGGGTACGGCTCTCGTCGACGTCACGCTCGACGTTGGGAACATCAACGAGACGGTAACCGTTGCGG CGGACGCGCTCAACAACATCACGCTCGAGAGCCAGGCGATTGCCCGCGGCCTCGATGAGCAGCAGCTCCACGATCTTCCACGCAACAG CCGCGACATTCAGTCGTTTCTGCTGCTCAATCCGAACGTCGTCGGCGGCGCCGACGACATGCAGTTCCTCGGCGGCAAGACCTACGGC GTGTCGTACATCCAGGATGGTCAGGCGTCGACGAACGCGATTTTCGGTACCGTCGGCAACTCGGCGCCTGGCCTCGATGCCATCTCGG AAGTCACCGTGCTCTCCAATTCGTATAGCGCCGAGTACGGCGGCCTGGCGGGAGTCGTCGTGACTACCAAAAGCGGCGCGAGCAGTTA CCGCGGGACGACCTTCTACGACTTCAACAACAGCGCGCTGAACGCGTTGACCTACAACCAGACGCTGGCCGGTGTCCAGCGTGGCGAT CCTAACGCCGACACACACGAACACCGGTGGGGTGGAAGCATCGGTGGCCCATTGATCGGCAGCAACCTGTTCTTCTATGGAAACTACG AGGGCTCCAACAACAAGTCCATATTCGGCGGCGGAATCGCGACGGTGCCCACAGCCGCAATGCGGAACGGCGACTTCCGCGGCACGGC AATCGCGCCAATCGATCCGCAAACCGGCGTGGCTTTTCCGGATCGAGTGATTCCCACTGGCCGCATCGACGCGGCCGCGCGGACCATT ATGGACTTCTTCTATCCGTTACCCAATCAAGGTACGTTTGCCAACGGATATGGGCGCTACCAGCAGTTCGTTCCCAAAGTCCGCGAAC GCCACCGCGGCGATCTCCGAATCGATTATCAGCCCAGCAGCAACGATTCCGTGTTTGCCCGCGGGAGCTATCAACACCGCAATCCGAA CAGCATCATTTTTGAGGCCGGCAATGCTCTGACGAATATGCCGAGTCTGAATACCAAACTCAATACCGCGTCACTGATCGGTGGCTGG ACCAAGGTTTTCTCGGCGACGCTTGTCAACGAGTTCCGGGGGGGGTTCAACTACGACAATTCAGAGCGTGCGAGCACGTTCACCGCGA CGGAGGTGACCAGGCAGCTAGGCATCGAGAACGCGCCCAGTCTCGCGCCGGATAGGCGCGGATTCCCTCAGTTCCAGTTCACGGCGGG CACGAACCGGCCCACCAATATCAGCGATGCTGGACGCAACGTGGATCGCACGCTTCGTCAGAACGCATTCTCGGTGAGCAACAACCTC ACGTGGATCAAGGGTGGCCACACATTGAAAGGTGGCGGACTCTGGACGCACAACACCGCGCGCGACGGGTTCGGGTTCGGCGTCAACT ACCGCGGCCGATACCGCTTCCGAGGAACGTCGACGGGCAATGCGTTCACGGACTTTCTGTTGGGTCTGCCGACCGATGTGGGTGATCA CATCAGCAATCGCGGCCCGCTCGAGGGCCACTCCAATGACATTGCCGGCTTCGTGCAGGACGACTGGCGGGCCAGCAAGAGCCTGACC GTTTTTCTCGGCGTGCGCTACGAGGTGGTGGGGACCTGGCACGAGAACTCACTGGCCCTCGCGAACTTTGTACCCCTCGAAGGCGGCT ACCACGTGGTGCCCAACGATCAGATCGCTGCCTTGCTGCCGCCCGGCCTGATCGCACTCGGCCGCACTCGTACGGCAGACGAAGTGGG CCTCCCGGAGACATTGCTCAACGCGGACAAGAACAACTTCAGTCCGCGTGGAGGCCTGGCATGGCGCCTCGACGAGAGCAACAAGACC GTTCTGAGGGCAGGTGTTGGCTTGTTTCACCCAACCGTGGCGGTCCAGGGCATTCGCGATCTGATGGCGACAAACGAGTTCCGCTACG GCAACTTGCGACGCGGGGGAGGGCTGCGCAACGGCTTCTCCGGGGGACGCCGTTCGTGGATCTCACCGACTTCGGCAACCAGGGGAT CGATCCAAACCTCGAGAGTCCCGACATCTATCAATACAACCTCACGCTCGAGCGCGAGCTGGGCGGCCAGCTTGGGTTGCGTGCGAGC TACATCGGTTCGACGATGCGCAAGCTGCTGGTGGATCGTGACCACAACACGCTGCCGGTGAGCACCGTTCCCTTCGATCCTGAAAATC CGGCGGACTACGCGCGGCTGCCGTTCCCCCAGTACGGCTATTACATGGACAACGTGTCGAACGCAGGGAGCGGCCAGTTCCATTCGGC GCAGTTCGAGGTGCTCCGTCGCTGGCGCAACGGTTTGGCCTTCAACGCCGCGTACACGTTGGCCCACTCCGACAGCAACGCCCCGGAT ACCGGGAACAGCACGATCGGTCCGGTGCAGTTCGATCCCTACGACATCGAGAAGGACCGCGGACCGGATCCAAACGTGGTCAAGCACC GCGTCGTCGCCAACGCGACATGGGATATTCCCGTCGGCCGCGGCCGGCCGCACGGCGCGAACATGGCGAAGTGGGCCGACGCGTTGTT CGGCGGCTGGACGGTGTCGTCGATCTTCCAGGCGCGCAGCGGACAGAACCTGACGCCGTTCTTTACAGGGTTCTACACGACCAGCCCC TGGAATACGGGAAAACCGCTGGACGGCCTCGGCAACTTCTTCGCCAACGCGTGGCGGCCGGACCAGCTTCGCGATCCGAACAGTGGCG GATCGCGCGAACAGTTCTTCGATCAGACCGCCTACGCCATTCCGGCGCCGGGACAGCTTGGCAATGCCAAGAAGGGCAGCCTCAAGGG TCCCGGAACCTGGGTCGTGAACTTCGGCTTCTACAAGGACATCGTCGCGCAGGGGGACTTCCGACTGCAGTTCTCGGCCTTGCTCGAC AACGCGTTCAATCATCCGCAATTCTTCCCGACCTATGGGAGCGGCTTCGTCGATCTCACGTCGTACCTGATTGATGGGGATCCCGCCA ACGGTGAAACGGGCGTGCTGGGGGCCGGGGCCATAGGTAACGCCGAAGGGTTTGCGCCTGGACGGGTCGTACGACTGGGCATAAGAGC GGTGTTCTGAACTAACTCCCAACTACCAACTTCCAACTCCCGAAGTTCTCGGAGCTATCTGGCCGAGTTCTTTGGAAGTTGGGAGTTG GAGGTTGGGAGTTATCGGTGCTCTAATACTTGCGGTACCTCCCCACGTCCACCCACTTTCCTTGGACCATCACCCGCTCTACCGTGCG AATCGCAGATATGTTCCGCAGTACGTCTCCCCGGACGACGATCAGATCCGCCTGAAATCCTGGACGTAGACTTCCGAGATCTTCACTG CGATAGATGAACCCCGCCGCGGTGCTCGTTGCCGCGGTGATGGCCTCGAGCGGTGTGAAGCCGCTTTCGACGAGCAGTTCGAGCTCTC GCCACGGCGCCTCGCCGCGGTCGGCAAACGGCACCGTCGAATGCCCGCCCATGACCACGCGCCCGCCTTCGCGCGCGGCACGCCGGGT CAATTGCTTCATCTTGTCGAATCCCGCAGCGAACAGCTTTGCCTGCGCGGCTGTCGCTTTCTCCGGGGGTCGATCGCTTCGACGTTCG AAAACCGCCAGCGTCGGGTCGAGCCAGGGCTTCTTCGTTCGCAGAACGGCGTAGAGCGCCTGCGCTTCCGGTCCGTCGAGATCCAGCT CGGAGAACATCGTGTACCGTCCGTCCCGCCGTGCGTCGCTGTTTGCCAAAACAGCCTGCCGATACGCCTCCGCCTTCATCCGGGTCAT CAAACCAAAACCGAGAGACGTGATGTGCTCGATGCCATTCAGACCCGCGTCGAACAGATCTTTGGCGTCGAGGATCTCGAGGTGGGCA GTGCAAGGCACGCGACGCGCCTCGCACACGCCAATCACGGCCTTGGCACTGTCGAATGGAAGCCGGAAGTAGATCTTCAGCGCCGAGG CGCCCTGCCGAAGGTTGCGCTCCGCCAGTCGCCTCGCCTCTTCGGGATCGCGAGCGACAACGGCATCGCGGGGATAGGCGGGGTGTTC ACCGTCGATATGAGGGCCGGCGGTGAAGATACGTGGCCCGGGCAGCCGGTCGGCCTCGACCAGACGCCGCAGCTCCGTGAACCGCTCT TCCCACTGTCCCGGGTCGCGAAAACTGGTGACCCCGTTGCTCAATTGACGAAGCGCGAGCTTCGGATCGTCCTCGATGTGGAAATGAA GATCGATAAGGCCAGGCAGGACGGTCCGGCCGGCCAGATCCATGGTCTCTGCGCCGGAGGGAGCAGGGACCCGGTCGACGGGCCCGAG TCGCGAAATGCGTCCGCCTTCGATGACGATCCGGCCGCGCTCGACCGGCGTGCCGCCGCTGCCGTCGATGATGCGTACGTTGTCCAGC AGCAGCGTCGGCGACTGGCCGTGGACCGCGAACGCGGCCATGACCACGAGCGAAGCCGCGCCGAAGCGCTTCGCGCGAAGGCGGGCGC CCAGCACCGCCGTCGCACATCGAAACGCCCGCATCTAAACTCCTTTGTCCTTACGCGAACTCCGGCCCGAAGATCGCAAATTCCTTGA TGCCATCGCGGCTGCCTGCCGCTCGAGCAGCCGACGTCGCGCCGGGACGGCACATGCGGTACAACGGGCGCTCGGCACGGAAGCCGCA CCTGCGCAGCCAGTCGGCAAAGCTTTTGTGCTCGTCGAAGGCGTCGACGACAACCGGACGCTCACCAGCCGCAGGCATTGCCGCCATC AACAGCGCCCGCGCGCGGTCGCCATCCTGCGCCACGATCGGCCCGATCTGATCGAACAGACGGCCCTGCCTGCCGAAGCAATACTGCG GCGGCGAGGAGGTCGTTCGCACCACGCGCGCGTAGTGAGGCGCGCTCGTCAGCGCCCATTCGAGTACGCCGCGCCGGTTCCCACCAAA 
GATGTTGCGATCGTGACCGGCAATCGCCTCGACATCCGGGCCCGCCATGGGTTGCACGTCATCGAGACGAGCGGCGGCGCGGTCGTCG ACCGATCGACGATCTGCGGCCGCGGCAACATGCCGCGTCAGCACGGTCTCGTCGACGAAGCCGAATCGCTGGTAGAGCGGCCGCCCCA TCGGCGTTGCGTCCAGGCGGATCGGCATTCCGGCCGGCAATGCGTTCATCGCGGCGTCGAGCAGACGCGCCCCGAGCCCTCGACTACG GTAGGCCGGGTCGACCAGCATCATGGCAATCCAGCCAAAGCTGCCGTAATCGATGCCAATCGCCGTACCGACGATCTGCCCGCTGCTC TCGTCGATGGCGCCGAAGCTGCCAGTCGGTGCAATCGTCAACAGCATCTGCCAGTCGGCGCGCTGCTGATTCCAGCCCGCCGTCGAGC TCAGACGGAAAGAGTCATCGAGATCATCGAGCGTGAGATGCCGGATGGCGGGGGTGGGCCCCTCGATCACCATGCGACCATGGCGTCT TCGAAGAGCGCGCTCAGATCGTCGGGTCCGGCCGGCCGCGGCGACAATTGCGTCACGCGATGCTGCGGTAGCGTTCCTTCCACCAGCG ACGGAATATCCGACGACGAGTAGTCGAGGGCCCGCAGTCCGTTCGGCGTCTTCAGACGTTGCATGAACCAGGTGATCCGATCGGCGAG CACCTTGCCGGCATCTTGATGCTGAACACCGGATACGTCCGCCCCGAGTGCCTCCGCGGCCTGAAGATGACGCTCCGGGTTGGCGCTT GCCGTATACCTGAAGACGGCGGGCGCATTCAGGATTACGGAGATGCCGTGCGGCACCAGCGGATGGTCCGTCTCGTACCCTGGTGCCC GATAGTTTTTCACGCCACCAGATACCGGATACGACATGCCATGCGGCAGATGCACGCCGGCGTTGCCAAAACCAATGCCCGCGTAAGA CGCCGCGAGGAGCATTTCCGCACGCGCCTTGTCGTCCGACGGGTCGTCAACGGCGCGAACGAGCGACCGGGTAACCATTCGGAGCGCC TGCATAGACCAAATGTCGCTGATAGGGTTCGAGCCCTGGTATGCGGGGCGCAGCGCCGGACGTTCGGGCCGGCGCCGCTGGTCGAACG GCAGGGCCGTGAACGACTCGAGGGCGTGGCTGAGGATGTCCAGACCTGCAGAGGCGGCGACCTCGCGGGGAACCGTGCGGGTGTTCTC AGGGTCGAGGTAGCCGAGGGTCGGCTTCAGGCGCCGATTGGCGATACCGGTTTTCGCGTGCATCCGCTGCAGATCGAAGATCGCCACT CCGGTCGTCTCACTGCCGGTTCCGGCGGTCGTCGGGATAGCCATCAGCGGCTTCAGCGGTCCGGGGATGGGCAGCCCCTTCCCGATCG GTGGATTGACGTAATCGAGGAAGTCTGCGGGTGGCCAGCTCGTGTAAAGGTTCGCCGCCTTCGCTGTGTCTATTGTCGAGCCGCCGCC GACAGCGACGAACGCGTCGTACGGCCGCGCCCGGGCAAACTCGATGGCGTCGAGAAACGATTGGTCGCTTGGCTCGATTCGAACGCGG TCGTAAACGACGTACTCCAGGCCATTCTGCTCCAGCGATTCGACCACGGCCTGGGCTGGGGGGAGGCGGCTTACGATGGGATCGGTGA AGACCAGCACGAGGCGGGCTCCCATTTCCTTCAGGTCGGCGCCAACCTCGCGTGTGACACCAACGCCAAACCGGACGTTGGAGACCGC CATCTCGAACGCATAGTCCCTATCTGCCATTCCCCCTCACCCACACAGTTTCGCGTGGAATTTACCCAAGATAGTCTACATTTGTGCA GCGGGCTTCCGAATGTCCCGCATATGTCATGGTCCGGCTAATACTGGTCTTCGCCCTCCTGCTGCTTGGCATCGACGCACAGGCTGAT GTGCGTCGGGTGTGGGCCGTCGGCGACGGCGACAAGGTTGAGCGCGACGAACAGAATCATCCCGCGAGCGCCCGCAATGCGGTGTGGG ATGGGCGCGTCGTCCGTCTGTTCGCCGCCCGCAACGAGATCATCGCCTTCCAGGTGATCGTCGAAGCCGACGGCGATGGCATCGGCCA ACTTTCTGTACGCCTGCCCGAGCTCGTTTCGGCCACCGACCGGATCACCTACCAGCCGCCGGGAGCGGATCCCACCAACTCGGTGGGC CGGCCGATCCAGATCTTCACCACGAACTACATGCTCGTCTCGGACGCCTCCAATGCGCCCTGGGTCTTCGAGCGCGGATCACCGGCTG CGCCCTCCGATCCGACCGGCTGGAAGCCGGTCCAGCTCATTCCCGAAAACGCCAGACGCGGGCGGGGGGGCATGCCGGTCTCGATCAA GAAGAATGAGAATCAGGCCGTCTGGATCGAAATCTACGTCGAGACGGCGCGCGCGCCCGGCATCTACCGCGGCACGATTTCGGTGCAG ACCGACCACACGCGGCGGAGTCTGCCGGTCGAACTGCAGGTTTTCGATTTTGCCTTGCCGGACGAGAACAGCATGCACGCGATGCTGT TTTACATGAGCGAACAGGCCGAGCTCTACCACGGTCGCAACATGGATGCGGAGTACAACCGACTCGCGCACCGCCATCGCGTCGAGCT CGTGCACGCCTACGACGAGAAACGCGTTCAGGAAACCTGGGGACGATTTTCCGGCTCGGATTTCACAAAGGCTTCGGGGTACGAGGGT CCCGGAACCGGTGTGGGCAACGTCATTGTCCCGCGGACGTTCTACGGCCCCGGCTCCGACTTCGACGACCGCGCCTCAGCCTGGTCGG TGAGCGATTCATGGATGACGTTTCTGCGTGAAAAACTGCCGGCGGCAATCACGTTCCTCTACATGCCGGACGAACCGGATCCCGATCA ATATCCGCGCATCGTGGCGCTGGCCGACAACGTTCACTCGAATCCCGGGCCTGGTCGGGCTCTGCCGATTTTTGTCACCAGTCGGTAT GTTGAAGCCCTCGACGCCTCGATCGATATCTGGGATACCGGCCCGAAAGGCTTCCTCCTGGATCGCGTGGCCAGCGAGCGTGCCCGCG GGCGTCAGTACTGGTTCTACAACGGCGGTCGCCCGGCAGCTGGAGCCATCACCATCGATGCGCCGGCAACCGACGCGCGCGCGACGAT CTGGGCGGCCTTCAAGCACGACGTCCGCGTGTACTTTTATTGGCACTCCGTCCACTGGCGGCACAACTCGCAGAAGCAGGGGGACGG AACCAGAACGTGTGGGCGGAGAGCATCACGTTCGACAACCGCAAGCAGCCGCAACGGTCTGCCGACGATCAGGGTTTCATCAATGGGG ACGGCGTGCTGATTTATCCGGGCCAGGATCGCCTGCACACGGACCAGGATCGTGGCGTTGTCGGCCCGGTGGCGACGGTGCAACTGGC GAACTTCCGGCGCGGCCTGCAGGACCACCAATACTTGACGCTCGCCGCGAAGCTGGGCCTCAAGCCTCTCGTCGACGAAGTGCTTGCG GCCATCGTCCCGCGCGTGTTCTCGGATGCGACCGAACGCGTCAGCTTTCCAGAGACGGGCGATCCCTACGAGGCAGCGCGGCTCAAGC TCGCGCGCGCGATCGAAGCGGCGCAGCCCAAGCGCTAACGATAACTCCCAACTTCCCAACCTCCAACTCCCAATTCTCAAAGTCGAAC GACTGAGAGTGTTTTGGGAGTTGGGAGTTGGGCCTTGGGAGTTGTCGTAATCAGAAATAGAACTTCAACCCGAATTGAATGATGCGCC CGTTGCCGGCGGTCAGGATCTGCCCGAAGCCGCTCGACTCGCGTGCGATGTTCGGCGGACCGAAGTTCGCGTGATTGAAGGCGTTGAA CAACTCGGTGCGGAACTGGAAGTAGCGTCGGTCGCCGACGTTGAAATTCTTCGCCAGCGTGAAGTCGAAGTTCGCCAGGCCCGGGCCG CGCATGATGCCGACGCCGGCGTTGCCGAACGCCTGGGGAGACGGGCTGAATGCCGTCGCAAACGCGTCGGTATTGAACCAGCGCGCGA CCGTGCGCTCCGATTCGGGCAACTCCGGATCGCCGATGAGGTTTGGCCGCGCGCGCCGCTCGCCGCCGAGGTTGAGCACCGAGGATCC CCCGAGCGTCGCCGTCAGAGCGAAGCCGCTCTGGAGCACGTGAATGCCGGTGACCTGCCAGCCGCCAAACGCGAAATCCATCGCCCGG TTCCAACCGTCGCCGTAGCGCCGGCCGCGGCCGAACGGCAGTTCCCAGATGTAGCTGGCCACGAACCGGTGCCTTATGTCGAACTCCG TCGGTCCACGTTCCGCGCGCAGATTGTTACCGTCCTGCGGCTCGCGGAACACTCCGGTGTCGATACCCGCGCCGCCGCCGCTGGTTGA GATGTGATCCGGCGCATCGGCGATCGCTTCGCCGAGTGTGTAGCTGATCATGCCGCTGAGCCCCTTCGAGAAGCGTTTGTCGAGGCGC ATTTGCAGGGACTTGTAGTTGGAGGCGACGCGATTCTCCATCCACTGGATGTCGCCGAAGGCCGGATACGGCCGCGCGCCCGCCGTTT GTGAGCCATCCGGGTTGGTAATCACCGCGCGTTGATTCAGGTTGCGGAAGCCGTTCAGCTTCGTGCCCTTGTTGCCGACATACGCGAT GTCGAGCACGACGTCGGGCCCCAGCTCATACTGCATGCCGACGTTGAACTGCTGGATGTACGGCGTCCGCTGGTTGGCATCCTGGGCG CGGCGGAGAACCGTCGGCGTCAGCGCATTCGGATCGAGGAGACCCGACGGGTAACCGTCGACGAGGCGGAATGGCGCCGCCGACGAAA TGGCTGCCGCGCCGCTGACGCTCGTCTGCAGCAGGTTGTCGACCAGGTACGGAGGATTGAAACCGAGCAATCCTTCACGCCCTTGCCG GACCGTGTGGGTGTAGAACACTCCATACCCGCCGCGCACGACCATCTTCGTCCACGGTGTGTAGGCAAAGCCGATGCGCGGAGCAAAG TTGTTGCGATCCGGGTGAATCAGGGCGCGCTCGAACGTACTCCCGTCGGCGGCAAAGATCATCGTGCCGGTCGCCGGATCGAAGTTCG AGAACTGGTTGTCCTTTTCGACCGGCGGCGTCGCGTACTCGTAACGGATACCGACGTTCGCCGTGAGCTTCGGGCTGATGCGATAGTC ATCCTGCACGAAGTAGAACTGCATGTCCTGACCCTGGTCCATGACCGTGTAGCTGGTCAGCGCCAGTTGCGACGGCAGGCCGAGCAGC AGATCGCCGACTGCACGGTTCGTGAACCGATTCTCGAAGTTCATGCGTCCGACCGTGGCATTGAGGTCGTTGATCCTCGTCTCGACGT GCAGGAACTCGCCGCCGAACTTGATGAAATGCGCGCCGCGGTTGTAACTGAACGTCGCCCGTGGATTCCACGACCGGGGCGTCTGGAA CTGCGGCGTGGACGTGTGGCGTCCAACCGCGTCGAATCCCTGGACGTTGACCTTGGGCACGCCGCCGACAATCAACGGATCGTTCGGC ACGTTTTTCAGACCGACTTGCACCGCACCGTCGACGCCGAAGTTGGGCGGATAGGTGTAATAGTCACCTCTCGCATAACCAAAGCGCA GATCCCCAACAAGATTGGGCGACATCGTCCAGGTCAAGCCGAGCGCCAGCCCCTGCGAGCGGTTGTCGTTGGAGCCAAACGCGTCGTT GAACGAACCTTCCGCCAGGCCGGGCAGCGGCGCCGGCCGGAACGTCAGGGTGTCCACGAAACTGTAACGCCCGAAGAACGTCATGCTC GGCTTGAACTGATGATCGATGCGGATGTCGAACTGATCCTGCGTGGTGTCGGTCACCGGCGTCGAGGCGTAGATGGTCGAGTTGGGAA CGTTCGGATCGGGAATCAGCGCGACGATGTTGGCGCCGACCGGATCCCAACGATCACGCGGGATGACCCACTGGCCTTGAGCGTTCTG GCTGAAAGCCGGGCGTCCCGCGGCGAACGGGTCGTTCACCACGCTGCTGAAAAGGCCGGCCTTTTCCGCCGCCGTCGGCACCAGCCGC ACGCGCGGCACGCCTTCCTGATCGCGCAGCCCCTCGTAGTCGCCGAACCAAAACGTCCGGTTGCGGACGAGCGGGCCGCCGACCGCCA CTCCGAACTGGTTACGCTCGCGTTTCGGCTTGGGCGCATTCAGCGCGTTCGAGAAGAAGTTGTTGGCATCGAGCTTGTCGTTGCGCAG GAACTCGTAGACGCTGCCTCTCACCATGTTCGTGCCGGACTTGATTGTGGCATTGACGACGGCGCCCGAGCTGCGGCCGTATTCCGCC GAATAGGCGTTCGTCTGGATCTTGAACTCCTGCAGGGCCTCGATCGAGGGCTGCACGAGTTGCACGTTCTCACCACGGAAGGAGTTCG AGTACGAGATATTGTCCACGCCGTCGAGCAGGAACACGTTGTTGAACGTGCGGTTACCGTTGACGTTGAGCACGCCTTTGAAATTCAC GCTCGCCAGCCGCGGAGTGCCCGGCAGCACGCCGGGAGAGAGCAGGGCGAGCTGGTTGTAATCGCGGCCGTTCAGCGGCAGGTCCACG ATTTGTTTCTGGTCGATGACCAGTCCGCGCGAAGACGTCTGCGTGTCGAGCAGCGGCGTTGCGCCGACGACCTCGACCGTCTCGGTCA GCTGACCCGACTGAAGCGTCACGTCGATCCGAGCCACCTGGGCGACCTGGAGGGTGACGCCGGTTCGTACCATCTTCGGAAAACCGCT 
GCTCTCGGCCGCTACTGAATACTCGCCTGGCCTCAGGCTCGGAATGACATAGGCGCCCTCACCGTCGGTCTCGGTTTTGACGCTGATA TTCGTTTGCACGTTCGTCACCGTCACGGTCGCCTTCGGCACGACGGCGCCGGATGCGTCGCGGACGATGCCGGTGATGGTTGCAGTTT CTTGTTGGGCGGAGGCCGGCGAGCAGAACAGCAGACACGTAAAGAGAAACAGAGCCGTCAGCGGTCGTCTGTGCATGACAGATCTCCT GGCGATATGGACATCCCGACGAGTGTGCAGCATCGTACCCCCGTTTGTGCTCAAAGCGAATGAGTTTTTTGCCCTGCAAAATGCCCTCA TTTCCTAATGGAGCTGTAAAGTTGGGGCGACGCGATCGGGCGGAGGTGTGAATGGTCGTTCGGATGGTGGTCGGGATGTTGCTGCTAA CGTCGATCGCCTTTGGCACGTGGCAGTCGCGGGCCGGACGCAGCGACGGCGACTGGCAGTCGTTTGGCCGCGATCCAGGCGCGCGTCG TTATTCCCCTCTCACCCAGATCAACACGAAGAACCTGGCCTCGCTGGTCGAGGCCTGGACCTTCGATACTGGCGTCCAGGATCTCGTC TTCATCGGCGCGACCATCGATCGACGGTTCCGCGCTTTCGACGCTCAGACCGGCGCCACGCTTTGGGAGACGATGCTCGAGGCCAGCG CGCACGCGACGCCGATAACCTTCATGGGGCGGAACCCGCAGAGGCACGAGGGATGGCTCGTTGCAGCTGTCGGGCTGGCGTGCGGCGC ACGCCAGCCCGCGACGAACCACCCCGGACGTCTCTCGCCCTTTGCGCTCCCCGCGTTGGAGCTCTTCGACAAGTCACTGGCGTTTCCT GAAGCGGCTGCTGCTCGCGTCTTCGTGCTAAGAGCACGCGGGTCGCAGGCGCTGTCAAGAGAAGAACGACGCCGATTACAGAATTCGC TCATCCGATCACTGCGAGTGACGCGGAAATTTGGATCTGAGCTCGGATCGATCGCAGGTTGATCGTGCACAGGGCGGATACGGCTTAG CTTGAAGCGCATCTCCCGGCAGGATAGGGTAGGCAGAATTCTTCGATGAGCGTCACGGTGAGCTGTCCTCAACTTGGAGATGCGGCAC TGCGCTCGCAGCTGCACGACCAGGTCAGGGAAGTCGTGCGGCGGTGGCGTCCTTCCTTCGAATACTGGCGTCTCTCGATTTTCAAATC GCAGTCTGGATCGGGGTGGGATCTGGCGATGAGCGGACCGCGGTTCCGCAAAGTCTTCACGTTGTATGGGCCCGCCGACGATCTTCCC GGGCTCGTGAGCGCATACGTCGACGCCATCCTCGCGGAGAAAAGCGTTCCGTCACCAGCGTCGCGATCATAGTCACCAGTAGCCAGTA GCCAGTAGCCAGTAGCCAGTAGCCAGTAGCCAGTAGCCTGGAAACTGGGAACTGGGAACTGGTAACTGGTAACTGGCAACTGGTAACT GGCAACTGATTGCTAGCTCAGCTTGCATCCATCGCCAACTAATCCATAAGCTCAGGCCATGGGATTCGCGCAGTGGATGCGTGTGATC GAGACGGTGGGCAATCTCGTCCAGCTCACTGGTCGCGTACGGCAGCCGCCGGAGTCGCCGGCCGGTCCGCTGGCCACAGGCGGCGCGA TCGGTCAGCTCGAAACACGGCTCGCCGGCGTGGTCGTGGCCGCGCTGAAGGAGGCGTTCGACCGCGATCGCGTGCGCATGGACCTCGA ACGCGCGCAGATGGAGTCGGAGCGCCAGCGCGCGGAGGAGGCCCTGCGCGCCGAGCTGCGACGCCAGGCGGCCGAACGCATGCTGGGT CAGCTGCGCCTGGTGGCGGTAATGGCGATCGCCATCTGGATGCTGTCGGCGGCGCTGGGCGCCTTTCTGCCGGGGATGCAAGAAGGAG CGGCCCGTCTGCTCATGGCCACGGGTTGGGCACTCACGATTGCGGCGCTTGGCTGCGCGTTCGGAGCCTGGCAGCATGTGTCGACGTG GTCGGCGGATGCGCGAGTGGGCGGCGAAACGCCGTATCATCCGGCCGCAGTGGCCGCCCAGTGGCTGCTCCTGCTGGCGCTCGCGGTG ACCGGAAGCGCTCTGCTGGTTGCCATTTAGCGTTCCGCGATTCCGTGCGGCGGGAGTTGACGCGTTGATCAAGGTTTTCGGGACAGAT TGGTGCTCGGACACCCGCCGCTCGCTGCGGCACTTGCGGCGGCTTCACGTTCCGCACCAATACATCAACATCGATGACAGTCTGGACG GCCTCGCCCGCGCCAAGCAGCTGACCGGCGCGAAGCGCTGCACCCCCATCGTCGATCTGGCGATGGGTGGCCAGGCGCTGGTCGAGCC GTCGAACGACACCTTGACGGGCGCGCTGGTCGAACTGGCCATGCTCACGCAGGATGAGGCATACGATCGACTGGCCGTGCAGAACGTC GGAGATATCGAGCGTGCCGTGCGCATGAGCGTCGGCGGCGCCATCCTGGCGACGGCAGCGGCGTTGCCGCGCGCGAGCCGCTGGCCGT TCGCCCTGCTCGGCCTGTTCGCCGCAACGACCGGGCTCACTGGTTGGTGCCCGGCTTACCACAGGGCTGGTGTGACCTCGCTCGGTGG TCCGGGCGATCGTCCCAGCGAATCAGAGCGCGAGGCGTGGGTTTCACGACGCTCGGTCGCTTCCCCTCGCCTCGTCACCGCCGGGACC GAAGCATGACGCCACCCACCGGCGTTCGGCGGATCGACTTCGACGCGCTGGCCGAGGCGCGGCATCACGACCCCTTTTCGATACTCGG GCCGCACGTCGTGGACGAAGGCGTGGTTATTCGCGCGTTCCTGCCACAGGCCGAACTGGTCAGCATCATCCGGCCCGGTGGCGATGCT GTGCCGATGCAGAAACGCCATGACGCGGGAATTTTCGAAGGACTACTCGCTGGCCTCACCACGATTCCCGATTACGCGCTGCGCGTCA CCCACCCCGGCGGCGATACCGATAACGTCGACGATCCGTATCGCTACGGGCGAGTCCTCGGTGACTACGATTTGTATCTCTTCGGCGA AGGCAATCACACGCGGATCTACGAAAAGCTCGGCGCCCATCCGATGCGCATCGGCTCGGCTGACGGCGTGCACTTTGCGGTGTGGGCG CCCAACGCCGTCCGCGCCAGCGTCGTCGGCGACTTCAACCGCTGGGACGGTCGCGCTCACCCGATGCGTTCGCTCGGCGCGAGCGGCG TCTGGGAGATCTTTCTTCCTGCCGCGACGGTCGGCCATCGCTACAAGTTCGAGATCAAGGCACGCAACAAGAACGTTCTGCTGAAAGC CGATCCTTACGGTCGGGCGTTCGAGATCCCGCCGCTGTCGGCGTCAATCGTGACCCGCCTCGACTACGACTGGCAGGACGATGAGTGG ATGCGAGACCGGCCGAGACGTGAGTCCTGGCTCAATCGGCCGATGGCCAACTACGAAGTGCACCTGGGATCCTGGATGCGGATTCCCG AGGAGAAGGATCGTTACCTGACCTACGACGAGCTTGCGGCGTGGCTCATTCCGTACGTGCGCGACATGGGTTACACGCACATCGAGCT GCTCCCGGTCATGGAACATCCGTTCTCGGGATCCTGGGGATACCAGGTGACGGGCTTCTATGCACCGACGAGCCGCTTCGGAACGCCG CGTGAGTTCAAAGGGTTCGTCGATGCCTGCCACCGTGCCGGCATTGGCGTCATCCTCGACTGGGTTCCCGGCCACTTCCCCAAAGACG CTCACGGGCTGGCGCAGTTCGACGGCACTTCACTCTACGAGCACGCCGACCCCCGGCAGGGTGAGCACAGCGACTGGGGCACGCTCAT CTTCAACTACGGCCGCAACGAAGTACGCAATTTCCTGCTCGCCAACGCTCTCTTCTGGCTGCACGAGTACCACGCCGATGGCCTGCGC GTCGACGCGGTCGCGTCGATGATCTACCTCGATTACTCGCGGCGGGAAGGGGAGTGGGTGCCGAACCGTTACGGCGGCCGGGAAAATC TGGAGGCGATCGAGTTTCTCCGCCAGATGAACATGCTGACGCACGCCGAGCAGCCGGGATCGATCACCATCGCGGAGGAGTCAACGGC CTTTCCGTCGGTGAGCCGTCCGACCTATCTCGGCGGCCTGGGTTTCACTTACAAGTGGAACATGGGCTGGATGAACGACATTCTCGAG TACGTCAAGAAGGATCCGGTCTACCGGCGATGGGATCACACACACCTGACGTTCTCCCTGCTCTATGCCTTCACCGAGAACTTCATCC TGCCGTTCTCGCACGACGAAGTGGTACACGGCAAGCGGTCGATGTTCGGCAAGATTCCCGGTGACGACTGGCGGAAGGCGGCCACGCT GCGGGCGCTTTACGGCTTCCTGTACGCGCACCCGGGCAAGAAGCTGATGTTCATGGGCTGCGAGTTCGGCCAGACTCGCGAATGGAAC TACGATCAGAGCCTCGACTGGCACGCGCTCGACGACCCGCTTCACTCCGGCCTGCGGCATTTCGTTACCGATCTCAATCGGACCTACA CGAGCGAGCCGGCCATGCACCAGGTCGATTTCGATCCGCACGGGTTTCACTGGATCGATTGCAACGACAACGAAAACAGCGTGGTCTC GTTAATCCGCCGGGCACAGAATCCCGATGACTTCGTGGTGGCGCTCCTGAACTTTACGCCCGTGCCCCGCGAGGGCTACCGCATCGGC GTCCCCAGGGACGGCGGCTACATCGAGCTGCTCAACAGCGATGCCCAAGCCTACGGCGGCAGCAACTGCGGCAACGGCGGCATCGTGT TCACCGAACCGATCGCCTCGCACGGGTACAACGTGTCGCTGAGCCTGCGCATCCCTCCGCTCGGTTTCCTCCTGCTGAAGCCCGCGGT GTAAGATCGTTCGTTTCCATGGCTCGCCGTTGACGGCGCCGCATCAAGGAGTTCGAGGAATGTCTCAGAGAAACGGCGAGAAGTCGCG CTTCCAGATCAATCGCAAACGCGGAGTACTCCGGCGCGCCAAGATTCGCGAGCTGCTGGCAGCTCCGGCGGCGGAGAAGCGACCGGCG CACGCCAAGCCGCGCCGAGGCAAGTAATAAGCTGTCGACGAGCATCTTTTCTCAGCGCTCGCGGGGCCCCACCCCCGCTCGCTCTCGC TCGCGCATTCGCGCTCGCTCGGGCCGCAGGCGCTCCCCGAGCTCCCGAGCCCCCGAGTCCCCGAGCCCCCGAGCCCCCGAGCCCCCGA GCCCCCGAGCTCCCGAGTCCCCGAGTCCCCGAGCCCCCGAGCCCCCGAGCTCCCGAGCTCCCGAGCTCCCGAGCTCCCGAGCTCCCGA GTGTTACCCGTGTACCCCCGGCGCTTCGTGCCCCGTGCGCTCGACGTATTCCACGTAGGAACCCGGGTAGGCGTGCGGTTCGGCGTCG GTGCCCGACTCTCCCCCGAGCTCGAGAACGCGGGTGCTCAGCCCGCGCAGGAACGCCCGGTCGTGCGATACGAACATCATCGTTCCCT CGTATGACGACAGTGACGCGACGAGCATTTCCTTGGTGGCGAGATCGAGGTGGTTCGTCGGTTCGTCCAGCACCAGGAAGTTTGGCGG GTCGAGCAGCATCCGCGCCAGGACGAGTCGGGTCTTTTCGCCACCCGAGAGGGCGCGTATTTTCTTTTCCACCTCATCGCCAGAAAAC TGGAACGCTCCGAGCAGGTTGCGCAGCACGCCGGTCGACTCGTGCGGAAAATCCCGCTCGATCTGTTCCCACACGGTGAACTCGGGAT CGAGCAGATCGAGAGCCTGCTGTGCGAAGTATCCCATCCTGACGCTGACACCGATACGCACGTCGCCGCTGTCCGGTGGCAGGACGCC GGCGACCATCCGCAGCAGCGTGGTCTTTCCCGCGCCATTCCGCCCCATCACGCACCAGCGCTCGCCGCGCCGGACAGTCAGGTTGACA CCGTCGTGGACGATGCGACGGCCGTAGGCCTTGCTGACGCCTTCGAGCACCGCGACCTGTTCGCCGGAGCGCTGCGGCTGCCGGAAAT CGAACTGCACGACGCGGCGTTTCTTCGGAAGCTCGATCTTTTCAATCTTTTCGAGGGCCTTGACGCGGCTTTGCACCTGCGCGGCCTT CGCCGCATGCGCCGCGAAGCGGTCGATGAACCGCTGCTCCTTGGCGAGCATCGCCTGCTGGCGCGCATATGCCGCCTCGCGATTCGCT TCGCGAATCGCCCGCTCCCGTTCGTAGAAGTCGTAATTACCCGAGTACGTCGTGATCTCGCCGCCGTCGATCTCCGCGACGCGACTGA CCACCCGATTCATGAAATCGCGATCGTGGGAGGTCATGACGAGCGCCCCGGGAAGCGACTTCAGGAACGCCTCGAGCCAGATGATCGA TTCGATGTCCAGATGGTTGGTCGGTTCGTCCATGAGCAGGACGTCCGGGCGGCCGAGCAGCACGCGGGCCATGGCGACCCGCATCTTC CATCCCCCTGACAACGCCCCGACGTCTCTGTCGATTTGTTCATCGTCGAATCCGAGGCCGTGCAGGACCTCGCGCGCCTGGCTCTCGA GGGCGTAACCGCCGAGATGTTCGTATTCCTCCTGAACCTCGCCGAACCGCGCGAGGATTCGGTCCATGCCTCCGCCGCTGGCCGGGTC GGACATCGCGCGCTGCAGCGCGTCGAGCTCGTGGTGCAGCACGCCGGTGCGGCCACTGCCGGCGATCGCCTCGTCCAGCACGCTGCGC 
CCTGACATCCCTTCCACGTCCTGCCTGAAGTAGCCGACCGTCACTTTCTTCGGAACGGACACTTCGCCGTCGTCGGGCGTCTCTTCGC CCACGACCATACGGAACACAGTCGTCTTGCCGGCGCCGTTGGGCCCGACGAGGCCGACTTTTTCGCCGGGATTCAGTTGGAAGGAAGC GTCGACGAACAGTATCTGGCGGCCGTACTGCTTGCTGACCCGGGAGAACGTGATCACGTCAGCGCGACCTCCCGCCGGGAGGCCGCCC TTCGCCTGCCATCGACTCGATCCGTCTCCACTCGACGTCGGTCACCGGCATGACGGACAAACGCGACATTCGGACGAGAAGAAACGTG GCGAACGCCTTGTCGGCTTTGATCGCCGCCAGGGTGACCGCTGACGCGAGCTTTTTGACAGGCTCTACGTCAACCGCGTAGAGCTTTC CCGTCTTGTCGGCCGGGTCCGGATAGGCTGCGCCCGACGCGCGGGCGATGCCAACGACCGCCTTTTCGTTCCCAGTGTGATAGAAAAA GATGCGATCGCCATCGCGGATGCTCCGGAGGTGCTTTTGCGCCAATGGATTTCTCACACCGGTCCACGAGGTGCGGCCATCGCGCGCG AGGTCGTCATAGCTGTAGTTCGACGGTTCTTCTTTCATCAGCCAGTTCATCAGCGGGCTCCGAGGCAATCGGGTATGTCGGTTTTTGC GTTCTTGTCTGGATTATAAACAGCCGTGACACGCCAGCACATCGGTCGCTACAGGATCACGGGAACGCTCGGCGAGGGCGGCATGGGG ATCGTCTATTCCGCGGTCGATCCCAAGCTCGAGCGTCCGGTCGCCATAAAAACATTGCGCGGAGCCTCTCCGGATCCGGTTGCCCGGG AGCGACTGGCGCGCGAGGCACGCACTGCCGCCGCCATCAACCACCCCGCGATCTGCCAGCTCTATGAAATCGGAGAGGACAACGGCGA GCTGTACCTGGCGATGGAGCTGCTGGAGGGAGAGTCCCTCGCCACCCGCATCGGGCGCGGCCGGCTGACGACGTCGGAAGCGGTTTCA CTCGCGCTCAGCATGCTCGCCGGGATCGATGCGCTGCATCGTCATGGCGTTGTGCACCGGGATCTGAAACCCTCGAACGTGTTCCTGA CGGCGCACGGCGTCAAGCTCCTGGATTTCGGTGTCGCCGCCGCCACCGGCGCCGACGCCGCGGCAACGTCGACGCGGCTCACTTCCCC GGGCATGCTGATTGGCACGCCGCAATACTGTGCGCCGGAGCAGATCCGGGGGGAGCCGGCCGATGCTCGAACGGACATCTTTGCCGCG GGCGCGATCGTTTACGAGATGGTGGCCGGGCAAACGCCGTACGGCGGCCACACCACTGTCGAAGTCATCCACAACATCATGTACGACG AGCCACCGGTGCTGACGGGTGGGCCTGCCGTGTCAGCGCTCGATCGCGTCATCAACAAGGCGCTCGCCAAACAACGCGACGATCGCTA CCAGACCGCCGACGCCTTCGCACAGGAGCTCCGCTCGTCGCTGCTCCTCGCGGATACGCAACCGGTTGCCGCCCGCGCCGCCACACGT CTCATCGTCCTGCCATTTCGCATCCTCCGACCGGATGCCGAAACGGACTTTCTCGCGTTCAGCCTCGCCGATGCCATCACCAGTTCGC TCTCGACGCTGCAGCCGCTCGTCGTGCGATCGAGCGTCGTCGCCGGGCGGTTTGGA

\subsection{Das Cosmid slc_1t}

\subsubsection{Lage der offenen Leserahmen (ORFs)}

\begin{tabular}{|c|c|c|c|c|}
\hline ORF & Annotation & Start & Stopp & $\begin{array}{l}\text { Orien- } \\
\text { tierung }\end{array}$ \\
\hline 801 & Kalium-Aufnahme-Protein & 1 & 646 & - \\
\hline 802 & Mit GGDEF-Motiv gekoppelte “response regulator receiver"-Donäne & 871 & 2259 & - \\
\hline 803 & Hypothetisches Protein & 2371 & 2649 & + \\
\hline 804 & Hypothetisches Protein & 2646 & 3056 & - \\
\hline 805 & Potentielle Halogensäuren Dehalogenase-artige Hydrolase & 3205 & 3903 & + \\
\hline 806 & Trimethylamin-Methyltransferase (MTTB) & 3983 & 5542 & + \\
\hline 807 & Hypothetisches Protein & 5559 & 6047 & + \\
\hline 808 & Hypothetisches Membran-assoziiertes Protein & 6123 & 6680 & + \\
\hline 809 & Kationen-Transport-Protein & 6698 & 7669 & + \\
\hline 810 & Konserviertes Membran-assoziiertes Protein & 7714 & 8379 & - \\
\hline 811 & UDP-N-acetylmuramoylalanin-D-Glutamat-Ligase (EC 6.3.2.9) & 8450 & 9853 & - \\
\hline 812 & Hypothetisches Protein & 10148 & 10360 & + \\
\hline 813 & Hypothetical Membrane Associated Protein & 10384 & 10659 & - \\
\hline 814 & Uncharakterisiserte Protein-Familie (UPF0156) & 10874 & 11131 & + \\
\hline 815 & Hypothetical protein (COG3668, ParE (Plasmid stabilization system protein )) & 11121 & 11435 & + \\
\hline 816 & MiaB, 2-Methylthioadenin-Synthetase (COG0621) & 11758 & 13104 & - \\
\hline 817 & Konserviertes Protein (hypothetische Tyrosin/Serin-Phosphatase, COG2365) & 13261 & 13959 & + \\
\hline 818 & SUL1, Sulfat-Permease und verwandte Transporter (MFS-Superfamilie) (COG0659) & 14025 & 15695 & + \\
\hline 819 & N-MethylhydantoinaseA/ Aceton-Carboxylase, $\beta$-Untereinheit, HyuA (COG0145) & 15692 & 17689 & + \\
\hline 820 & CsdB, Selenocystein-Lyase (COG0520) & 17686 & 18909 & - \\
\hline 821 & NodQ, bifunktionales Enzym (Nodulationsprotein) & 19058 & 20074 & + \\
\hline 822 & Potentielles Kälteschock-Protein & 20153 & 20362 & - \\
\hline 823 & Hypothetisches Protein & 20482 & 21225 & + \\
\hline 824 & 4-Hydroxyphenylpyruvat-Dioxygenase & 21368 & 22441 & + \\
\hline
\end{tabular}




\begin{tabular}{|c|c|c|c|c|}
\hline 825 & Konserviertes Protein (COG3791) & 22438 & 22893 & + \\
\hline 826 & Maleylacetoacetat-Isomerase (EC 5.2.1.2) & 22880 & 23551 & + \\
\hline 827 & Homogentisat 1,2-Dioxygenase (EC 1.13.11.5) & 23551 & 24693 & + \\
\hline 828 & Hypothetisches Protein & 24697 & 25572 & + \\
\hline 829 & Hypothetisches Membran-assoziiertes Protein & 25846 & 26259 & + \\
\hline 830 & Protein der Fumarylacetoacetat-Hydrolase-Familie & 26516 & 27478 & + \\
\hline 831 & Hypothetisches Protein & 27475 & 28014 & + \\
\hline 832 & Acyl-CoA:Acetate/3-Ketosäure-CoA-Transferase, Untereinheit A, AtoD (EC 2.8.3.5) & 28032 & 28733 & + \\
\hline 833 & Potentielles Phospholipid-Bindeprotein (COG1881) & 28745 & 29392 & + \\
\hline 834 & Acyl-CoA:Acetat/3-Ketosäure-CoA-Transferase, Untereinheit B, AtoA (EC 2.8.3.5) & 29405 & 30034 & + \\
\hline 835 & Hypothetisches Membran-assoziiertes Protein & 30182 & 30613 & + \\
\hline 836 & Hypothetisches Membran-durchspannendes Protein & 30619 & 30885 & - \\
\hline 837 & Konserviertes Protein (COG5361) & 31024 & 32454 & - \\
\hline 838 & Peroxidase/Katalase (EC 1.11.1.6) & 32531 & 34726 & - \\
\hline 839 & Konserviertes Protein (DUF1080) & 34981 & 35556 & + \\
\hline 840 & Cytochrom P450 & 35751 & 37124 & - \\
\hline 841 & Hypothetisches Protein & 37192 & 37731 & + \\
\hline 842 & Potentielle Kynureninase & 38355 & 39005 & - \\
\hline
\end{tabular}

\subsubsection{Sequenz des Cosmides slc_1t}

TCGGGCCAAAAAACTTGGCAACCGCTTCGGTTCCGCGTGATTGCACGGCAAATAGCGCGATCAGAATTCCCACCGCGATTGGCAAAAT GAATCGCTCAAATCCCGGATGCACAAGCCGCAGGCCTTCAACCGCCGAAAGCACGGAAATCGCCGGCGTAATGATCGCATCGCCCAGA AACAGCGATGCCCCGAATATGGCCAGAATTGTCAGGCCGGTCAGTTTTTTCGCCCCCGGTTTGCGCACCAACGTCAGCAATGACAGGA TACCGCCCTCGCCCTTGTTATCGGCTCGCAGCAAAAAAGTGACGTATTTGATCGTCAATATCAGGATCAATGCCCACAGCAGCAACGA AGTAACGCCAAGCACTTCCTCGCGTGACAGGCCATCGCCCGCCACAACTTTCAACGATTCCCGCATCGCATACAGCGGGCTGGTGCCG ATGTCGCCGTAAACGACACCAACCGAGCCAAGCGCCAGCGCAAACAGTTTCTTGTTCGAGCTGACTGAATGGCCGTTACCGTTGCCAC CGCCGTCCGCTTTTTCCGGGTCAATAGATATGTTCATGGTGCAAGGGGGTGGAGGCTGGCCGATTTCGGGCAAATACCCTGGCGCTGC GTTCCTGACCGATTTCTTTCCGATCCACACTGAGTCGACCTCAGCGGCGCGGAACCTAACACTTTGGCTTTGGCAGCACAATGCGCTA TTGTGCGCCGCAACATGGATTGAAAAATGTCTACTTTTTCAAACAATTACAATTGGTTATATTCATTCTCGCTCGTGCGTTTGCCCTC GAGGCAAGGTGATCGCAATAGATCAAACCCTTTTCCCGGTCCGCGGACGCCTTCCCTCTGGCACCCGAATTTTTTCAGTTATGCCGCG ATCCTGGCAAAGCAGACACGGTTGCGACCCTGCGCCTTGGATGCATATAGCGCCTCGTCGGCATGCCGTATCAGGCTGTCGGCGGTGG CGGACGAATCCCCCGACATCACAGCGCCAATACTGACTGTCACGTTGGTGGTGCCTTCACCCTGGCGCAGAGTAAATGGAACCAGTTC GACGGCCCGCCGCACTCTCTCCGCCGCTGCGGCGGCCGCCATGCTGCTGGTGTCGGGCATGACCAACAAAAATTCCTCACCCCCCAAG CGCGCAACAAGGTCAACGCCGCGCACATTTTCGCGCAAACGTCGCGAAAACTCGGTCAGCACCGCGTCACCGGCATCGTGCCCCCAGC GGTCGTTGATGGATTTGAAACGGTCCAGATCCATTATCATAACGGCAAAAGGCAAGCCGCCGGTCTTGGCGCGCTCAATGATTGTACT CATGTGCTGTGTGGCATAGCGACGGTTGAATAACCCGGTCAACGGGTCGATCACCGCCATTTTCAAACCGTCGCGCATATTGGTCCGC AGTTGGTCAGACAATTGCTTGCGTCGCATCTGTGAACGCAACCGCGCCACCAGTTCGTTCATGTCAAAGGGTTCCATGATGTAATCAC TTGCACCCAGTTCCAGCCCCTGTGCCGCCACCGCCAGGCAATTTGGCCCGACGATCAGGATAATAGCTGAATGTCGCGTTTCCGTCCT TGCCCGCAGCGCCGAAACCAATCGCAAACCGTCGCCGCCTTCGGCCAGCGAATGATGCACGACAAAGACGTCGGGCCTTTCCAGCAGG CCCAGATTGGTGGCTTCGCGCTCGCTGTTGGTTTCAATCACCTGTACGTGCAGCGACTTATCCAGTTTTGTCCGCCATTTGTGGCCAG TTTCAACATCAGGCGGTGCCAGCATGACCGTTCCCGGCGTCTGGCATTGCGCCGACAAACCACTAAGGAACGCGCCCAGACCCAATTC GCGCGACGTCGAATCGCGCATCCGCAACTCGTCAAACATGACTTTGGTGCGCATCAGGTTTTTGACCCGGGCAAACAACGCCAAATCA TTCACCGGCTTGGTCAGAAAATCGTCTGCTCCAGCCTCAAGGCCCTTCAGGCGTTCTTCGGCAGAGTTGGTACCGGTCACCATGATCA CCGGAATATGGGCAAGTTCGCTGTCTTGCTTCAAAATGTGACAGACCTCGTGCCCGTCCATGTCGGGCATCATCACATCCAAAAGGAT GATGTCAGGTTGTTCGCGACGTGCCAACTCCAAAGCCTGAACGCCATTTTCTGCCAGCAAGACATCATAATAGGCCGACGACAGTTTC GCCCGCAAAATCAGCCGGTTGGATGCCGTGTCATCAACAACCAGAATTCGCCCCGACATACAAAACCTCCGCGTTCGCCGACTAATGT CCGCTTCCCGCTTGGCAGTTTGCCGCAAACCTCTTAACGAAAGCTAAAGCCCGTTACTTTATCCCACGTCAGGATGAACCCGATGCAA ACCGACCGTGCCCAAACCATCGCGCTGCTGGCGCTTGCCTATTTGGCACAGGATGAGGATCAGATTGGCGCGTTTCTCAACGCCAGCG GTGCTGCGCCCGATGACTTGCGTCAAAGGGCACAAGACGGCGATTTTCTGGGTTTCGTGTTGGATTTCATCATGGGTGAGGAATCGCT AGCCCGCGGTTTTTGCGAAGCCGAAAATATTGCTGCCCAGACATTGCACAGCGCACGCGCGGCGCTTCCCGGTGGTCAGATTCCAGAT TGGACCTAACCAGCTTTTTCAGCAAAATCCTTGAAACTGTTCATCATTTTTTCGGTCTGCTTGCGAAACATGCCCGGCATCAACCAGC CCAATATCATCAGAAACCCGCTCATCTTGAATTCGGTTTCCAGCGTCCAGCGGGTTTTTTCCCCCAATTCTTCGAATCGGTTCACTAC CGAATTCCACACACCCTTGGTTTCATAGACCCCCGAAAACTCGCGCGGCAGGTCGCGTTTGGTAATGGTTTCAACCAGATCAACCCGG CGTTTTCCCATCAGAAACACCAAATTGGATTTCGCGCCTACCTGCCCCGGCGTGCCGGAAATCGGCGTAAAACTTTGCAGTCCCTCCT GCCATTTCGGCAGATTGGCCGGGTCATCGAACAGTTCGATAAACCTTGGCCGCGAAACATTCACATCAATCGAACTGGTATATTTCAA AACCAACCCTCCCGCGCAATGTCAGATCAGCCTGTCAGAAAACGTCGAATCTGGCAACCGCCGCGCATTGGCCTTGTCACAATCCTGC GGTATTCTTGATGGTCTCGAATTCAAAGGAATCCCCTTGCGCAACCAGATCAAAGGCCTGCTTTTTGATAAAGACGGCACCCTTTTCG ACTTTAACCTGACTTGGGCCAAGTGGTGCAGTGACTTCATCTTGCACATGGCCAACGGTAACGGCGAAATCGAAAATCGACTGGCACA AGCGTTGTTGTTTGACATGCAATCGCTGACCTTTGCCCCCGGCAGCCCGATTATTGCCCATACGCTGTCGGAAATCGCCGAAGTCGTC TTTGCCGCCTTGCCCGAACAAGACCCCGAATTGGTTCTGGCGCATATGCGGCAGTCGGCAACCATAGCTCAACAAACCCCAGCTGTGC CATTGCGACCACTTCTCGACGGCTTTCTTGCCCAAGGACTAAAACTTGGCCTCGCCACCAACGATGGCGAAGCCCCGGCGCGCGCGCA 
TTTGACCGGTGCCGGAATCCTTGACCATTTCCATTTTGTTGCCGGCTACGACTCCGGTTTCGGGGCCAAACCGGAAACCGGTATGCAA AAGGCTTTTCTGGCGGCCACCGGTCTGCAACCACAGCAGGTCGCCATGATCGGCGACTCGGCGCATGATCTTCATTCAGGTCGCGCCG CCGGAATGCACACAGTCGGTGTCCTCACCGGCCCCGCCACCGCCGCCGATCTGGCACCCTTGGCTGATGTGGTGTTGAAAGACATCGG CGAAATCCCGAAATGGCTTGGGCACGAATAAAACGGTAAAACCGACCACTTTGCGTCGCAAACCCCTAAGCAATCTTGGCCTGTAACC CCTTTTTATACCCAAAAGGGGAATGACGATGTCAGAACGCAAAAGACGAACTGGTGGCCATTCGGCAAATCGGCGCGGCGCCGGCGGC GTTGCCATCCATCAGTCGCCATGGACCAACCCGGTCAACCCCGACCGCCCGACCGAACCCCTGTCGGAAGAAGGTGTGCAGGCGATCC ACAATGGCGCTATGCGCGTGCTGGAAGAAATCGGCATCCACTTCCTCAACGACGAAGCCCGCGCCTATCTCAAGGCCGCCGGCTGCTG GGTTGACCCCGATTCACCAAATGTCAAATTCGACCGTGCCTGGATCATGGAAATGGTCGGCAAAGCGCCGCGCCAATTTGATATCACC CCGCGCAACCCCGATCACAAAATAACCATTGGCGGCAAGAACATGGTGTTTGTGAATGTCTCCTCCCCGCCAAATGCCATGGACTTGG ACCGCGGCCGCAGGGTTGGCGATTTCAGCAGTTTCAAAGACTTCATGAAACTGACCCAATATTTCAACTGCATCCATGTCGCAGGCGG CTATCCGGTGGAACCCGTGGATATCCACGCCTCGGTTCGTCATCTGGATTGCGTGTTTGAAAAGCTGACCCTGACCGACAAGGTCATT CACGCCTATTCGCTGGGATCGGCCCGCGTCGAAGATGTCATCGAAATGGCTCGCATCGCTTCGGGTCTGACGGCGGACGAATTCTTTT CCAAACCGCGCCTCTATACCAACATCAACTCTTCCAGCCCGTTAAAGCACGACCTGCACATGCTGGACGGCTCGATGCGGTTCGCCAA ACGCGGCCAACCCGTGATCGTCACCCCTTTCACGCTTGCCGGTGCCATGGCCCCGGTCACCATGGCGGGCGCGGTGATGCAATCCCTA GCCGAAGGTCTGGCCACCATCGCGCTTTACCAGTTCATCAATCCCGGCACCCCGGTGGTCTTTGGCACCTTCACCTCGAACGTTGACA TGAAATCCGGCGCACCGGCATTCGGCACCCCCGAATATATGCGCGCCACCCAGATGACCGGCCAAATGGCCCGTTTCTACGGTCTGCC GCTTCGCGCTTCCAATGCCTGCGCCGCCAATGTCCCCGATGCGCAAGCCATGTGGGAAAGCTGCAATTCGCTTTGGGCTGCGGTAACG TCCGGCGTCAATGTCGTCTATCACGCCGCCGGGTGGCTGGAAGGCGGGCTGATCGCCTCCTACGAAAAGTTCGTCATGGATTGCGAAG TGCTGCAACAGGTTCAACGTTATTTTGAACCTGAAACCTTTGCCGCCGATCCAATATCGGTTGCCTTTGACGCCATCAAGGATGTCGG CCACCACGGCAACTTCTTTGACACCCCGCATACCCAGGAACGTTATGAAACTGCGTTTTACTCGCCCTTCCTCTCGGATTGGCGCAAT TATGAAGCCTGGCAGGAGGCCGGTTCGGAATGGACGGCGCAGCGCGCAAACCGCGTGTGGAAAAACATCCTTGCCGAATACGAACCCC CGCCCATGGATATTGCAATCAAGGAAGAACTGACCGAATTTGTCGCTCGCCGCAAACGTGAAGGCGGCGCACCGACAGATTTCTAGGT CCGGAACTTGCTCCATGCTCAAACTTGCCACCATCGCAGCCTTGTTTGCCACGCCGATACTGGCGGATGAAACGCTTTATACCGAAGG CAACTGGACACTGGTCAAATACGAATTCGACGACGGCACCATTTCCTGCGCCACAGAAACACTCAACGACGACGGCACCACCCTGCGT TTCGAATCATGGCCTACCGGTATTGCCGCCATCAGCCTGTCAGACGGCGATTGGCAATTCCCGGCGGAACAGGTCGATGAATCATTTG GTTTGCGCGTCAATGGCGGCGATTTGTGGACCGGTCAGGGATCGAAATTTGGCAATACCGTTCAGGCCAGCCTGCCAGCCGAGGACGC CAGCCTGAATGACTTGCTCGAACGCATGACCAACGGCACCGCCTTGGATGTCGAAAGCGCCAAGGGCACACATATCACACATTTCAGC CTTGCCGGTGCCGCTGCCACGCTGGAACACCATTTTGAATGCGAAATCGGCTTCGCGGGCTAACGCCAAAATCCCTCTTTGAAACGCC ACATTCTCGAAATAAGTTTGCCTGACCCAAGTCTCGAAAGGATGAGTTCCATGTTGAAATGGGTCGCAGTCGCAATTCTCGTCGCTGG CTCCGCCTTGGCCGAGGGTATCAACGACTGGGAAACCGTGTTTGAACAAGACAACTGGCGCCTAGACGTCAACACCTGGGAAGATGGC AGTCTTTCCTGTGAAACGCGCTCGATCAGTCAGGAAGGCACCTTGTTCAGTGTCGAAAGCTGGCCCGACGGCACATTCAGCATCACAC TTTACAATGAAGCTTGGCGGTTTCCAGAACAAGCGGTTGAAGAAACCTTTGTCGTTCGCATCGACGGCGGTAGTCCTTGGGACATCAC AGCCGAAAAATACGCCTCCTACGTCACCTCTTATCTTGATCGCACAGAACCCGCGACTCAGCGGTTTCTGACCGCTTTCTACAGCGGT TCCGCTATGTTGATCGAAAGCGTCAAGGGGACAGCGATCGCGCATTTTGCCCTGTCGGGATCAGGCCCGACAATGGACCACCACTCCG AATGTGAAGATTTGATCGGCACAGTGTCCGCCACGATCGAAGCCGACCCCGACGCCAAATTAGCCAAGGAGACTTTCTGATTTCCGAC CGGCACGCATTGGCAAAAGCAGACGACCATATTCTGCTGTCCTATTCACTGGCCACAGGCCAGCCAGTGCCATTTGACCAATTGTCCG CCGAACTGCGCGCTGACGCCCCAAATTGGGTGCATCTGGACCGCAACCATTCCGCCACCCGACCTTGGCTGGAACACGCTATTTCCTT CCTTGATCCCACCATTATTGACGCCCTGCTGGAAGAAGAAACACGCCCTCGCATCGTCGTGATCGGCGACGGGGCCATCATCATCCTG CGCGCCATCAACCATAATCCAGGGGCAGAACCCGAAGACATGGTGTCCTTCCGCCTTTGGATCGATTCTAAACGCATCATCAGCCTGC AAGGCCGACCAATTCGGGCTTTGGATGATTTCGTCAAGCTGATGAAAGGCAAGTCATGCCCCCGCAACGCAGGTGAGTTTCTGACCTT GCTGCTCGAATGTCTGCTCGACCCGATGCAACCGGTGCTTTCGGAAATCGAAGACAATATCGACTCCACCGAAGAATCCATGATGTCC CGGCCCAGCCATAACCTGTCCAAGGAACTCACCGATATTCGTCGCTCGGCAATTTTGCTTCGCCGTTATATCGCGCCTCAACGCGAAG TTTTTGGTCAACTTCTGGCGTCCGAATTGGTTTGGCTGTCCAAACACGATCGCCGCCATTTGCAGGAAAGCCAGCACAACGTCATCCG CTACACCGAGGATCTGGACCTGATCCGTGAACGCGCTCAGGTCGTCAAAGACGAACTGCAAAGCGCCTTTGCCGCAAAACTTGGTCGC AATACATTCCTGTTTTCCGTACTGACCGCAATCTTTCTGCCGTTAACTTTTGTCACCGGACTGCTTGGCATCAATGTCGGCGGCATCC CCGGGGCCGAGCATGGCAACGCTTTTTGGGCCATCACCGGCATTTTGCTGATAATCATGGCGCTGGAAATTATCATTTTCCGGTGGTT AAAGTGGTTTTGACATTCGCCGCACGATGGGCGTCCGCACCTATCACATAATGTCCGTCACTTGCGCCCGAACCACCCTTTGACGCGA TCCAAAGCTCCACGACCAACCTCACCTGCATCCTCAACTTTATCACTTAAGGCTTCGTAACTATTACCTAAATCTTCGCCGATCTCTG CCACAACCGGGTCTATCCTTCGCTTGCGCCAATTGATGAACAAGCGACGGAAGGTCAACCAGGCCAAGCCCAGCAGAACAAAGAAAAC GATGTTGAACCACGGAATTATTCTTGCATCCGGCCCTTCAACAACCTTCATCGACAGCGCGTTTGGATATATCGAAAACCAAGTGCTG CGCCAGCCGTAATGGCGGATAGAAACCCAAATCGGTGCGGTCGCGGTTGATACTTCATTGGCGGCCTGTGCGGCCAGATCAGCCGAAC CAAATTTGAAATAGGGCGGCCAACCCCATTGCGTGTCTTCATTACGATACACCAGCGTATTGCCATTGGTCCGCACCGTATTGATGAA ACGAACATCGCGCGACTGGTTGTCGCCGGTGCCGGTGTCGGTGCCTGCCCAAAACCACCCCGAACCAATGTCGGTTCGCTTCACCTCG GTTCCAACCACCCGCACGATAGTGTGCTGGGGCAAAGTGTAATGGAAAAACAAAACGAGAATCAGGATGACCGTCGTCAATGTTCCCC ATTTCAAATATCGCCACATGATTCGCACCTATCGCTTGGTTATTGTCAGATTTGGGTATTCTTAACCGAAAATGCCAGCCGTTGCGTT TTTACGGTTGCAGCGCGCGCACCGCAGCCTCAAAAGCCTCACCCCTGTGTTCAAAACTTTTGAATTGGTCGAAACTCGCACAGGCCGG TGCCAGCAAAACCACGTCGCCCGGCCTTGCTTCGGCTTTTGCATGCGCCAACGCCATGTCCAATGTGCCCGAAATCTCATGCTGCACG TCACCCAGCGTCGTCGAAAACGCCGCCGCAGCTTCGCCAATCAAATAGGCTTTCGCGACACGGCCAAACAGCGGCCGCAAACTGTCGA TGCCACCTTCCTTTGCCTGGCCGCCGACAATCCAGCGTATATTGTCAAATGATTGCAAAGACTTGCCAGCCGAGTCTGCATTTGTGGC TTTGCTGTCGTTGACAAATCGAACGCCACCAATCTCAGCGATTGTCTGACAGCGATGCCGCAGCCCCGGATAATCTTTCAACCCATCC TCAATCACCTTGGGTGCCAGCCCCAGTGACCGACAGACCGCCCAAGCAGCACAGGCATTCTGATGGTTATGCGCCCCTGTCAAATTGA CAAATCCGCGCAAATCCACGCTTGCAACCTGCTTGCCACGCCGCCATTCCGCCAAGAACCCTTTGCGGGCAAAAACCGTCCAGCCTCC ATCTTGCAGCTTGTGCGCTGCGGAAATCCGGATAACCGGCTCGCCGTTACCCGCTTCTTCGCGCATGGTATTGGCCAGAAACCGCCCT TCGTTTTCATCAATGCCAATCACCATCCGCTCCGGCCCGCCAAGGCTGAACAAACGCGCTTTGGCGGCAAAATAGCCACCCATCCCGC CGTGTCGGTCCAGATGATCGGGCGACAGATTCAAGAACACCGCAATGTCGGGCTGCAAAGACCGCGCCAGTTCAATCTGGTAACTCGA CAGTTCCATCACGATGATCGACCCGTTTACCGCTGGTTCCAGATCCAAAACCCCGCGCCCTATATTACCGCCCAGTTGCGAAGGTCGC CCGGCCTCAGTCAGAATATGATGAATCAGTGCCGAGGTCGTCGATTTCCCGTTCGATCCGGTAATGCAAACCACCTTTGGCAACACCG CCAATTGGTCCCATTCCGGCCCGGCAAACGACCGGAAAAACAGCCCGATGTCATTGTCCACCGCCACGCCAAGTTCCCAAGCCTTGGC CACAATCGGGTGCGGTGCCGGGTAAAGATGCGGTATTCCCGGTGACAAAACCAAGGTCGCCACCCCGTCCCAGGCCTTGGCGCGGCCC AAATCCGCAATCTCGAACCCCGCCGCTTCCGCCGCCTCGCGCGCTTCAAATCCGTCGTCCCAGCACACTGGCGTGGCTCCGCCAGCCC GCAATGCCGCAGCGGTTGCCAGCCCCGAACGGCCCAAGCCCAGCACCGCCACGCGATGCCCCTTGTATCCTCGAACCGGAATCATCCA ACGCCCTCACGCCAAGCCAACAATCCCCCCTAGTCCAACCCCACCAACAAGCCAATATCATTTTCCGGATGGTTCAAATATCCTGGGG TCTGGGGCAAAGCCCCGCTCCGATCCCAACCGAAAGTCAAAACCATGCAACTCGGTGCCTTTTCCGTCAGCCTTGCGGTCAAAGACCT CGCCGCCTCGCAGGCGTTCTACGAAAAACTGGGGTTCAGCCAATTCACCGGCCACCCGACCCAAGGCTATGTCATCCTGCAAAACGCC GGCACCACGATCGGGCTGTTTCAAGGCATGTTTGAAGGCAATATTCTGACCTTCAACCCCGGTTGGGATGCAAAGGCCCAGGCGCTTG TCGCATTCACAGATATCAGGGATTTGCAGAAATCCCTCAAATCCCAAGGTATCGCTTTAATGTCCGAAGCTGACGAGGCCAGCAATGG CCCCGCCAGCTTCATGCTAACCGATCCGGACGGGAATGTAATTCTGGTCGATCAACACGTGTGAAAAAAGGGCCTAAGCCCCCCAGTT 
CACTGCATCATCATAGCGTCCATTGCCATGGTATCGGGCTTGCCTGCGCACATTTCCATCGTGTGCTTCATCGCCATTTCAGCGCCAG CCTCGTCCATCGCCATCGCCGCATCCGGCCCGGCCATATGCATGGCATCGGTCGCCGCCATCATGCCTTCCATATCCATCGCGCCAAA TTCGGCACAGGTCATTTTCATCGGATCCATATCCTCGGCCAAGGCCAGGTTAGGCAGGGCAATGGCGCTCAGAACGGCAAGTTGCAAA AGATATTTCATCGGTATTCCTCACTTTTGAAGGGGCCGGAAACCCGGCCATTTAAGTGCGAAAACCCCTAGCACCCCCCCAATTCACG CCCCCCACACGTTCCCGCGAGCGCACATAAGGTTGAGGATTGTTGCAAGTGACGCGTCCGTGGTCACCGGAATCAGGTTTGATTGCCG TCAACATTTCCGTTACCATTTATTGGTATCCATTGGTAAAGGAGGCATCATGGCCAAGAACACATCCATCGCACTCAGCGATCATTTC AACGATTTTTTAACCAAGCAGGTTCAAGCAGGCCACTACGGCTCGGCCAGCGAAGTGGTGCGCGCTGGTTTGCGGTTGCTGGAAGAAC AGGAAGCGAAGATGGAAAGGTTGCGGGCAGAAATTCAGAAAGGGCTGGACAGCGGCGATCCGCAAGAGATGGATTGGGATGCATTCTA TGCGGAAAAGCACGCCAAAGCCGGGGTGAAGCGTGCGGGTTAGATATCTGGTGCAAGCCCGTACCGATATCGACGAAATCTGGGATTA TTCTCTAAAAAAATGGTCGCTCGCCAAGGCTCACGCCTATGTTGAGACACTGCGCAGGGCGTGTGAGCAGGTGGCCGATGGCCGCAAG CCGGCCCGCAAAGCCGACACAATCAAGGCTGGGCTTTGGCAGATGACTCAGGGTCGGCACGTGGTTTATCTGCGCAAAGAGCCCGGGG AAATCGTCATCGTCCGCATCTTGCACCAGAGCATGGATGCGAAGGGACGGATTGTCCAGCAAGAGCGGAAACCATTGGAATGATGGGT GAAATCACCCATCCTACAAGTTTGCATGGCATCGTCGCAAATCCCTTGCAGGCGCGACCGAACCAAGCTTTGAGCGTGTTACTGACTC GCTAGGCGCCCAGCCCATTCTGGAAACCAATAGGCAAACATCAACGCCAAGATCAACGCCAACATACCCAACCGCATGAGGATGGTTC GAATTACGCTCGGCCATTGGCTGCGTTTCCAAGGAACTTGTTGGCTTTCAGTTTTCGATGCCCGTGGATTTGCATAGATAGCATCAAG CATTTTGCGTTCTTTTCTCGCTCGTCGCTGCGCCAGAATGTCGGCAAACCACCTCACCCCGCCCTCCCCCACAAATCATATTCCCCCG CCTCATCAACCACCACCTCAACCACATCCCCCACCGACAACCCTTCGAACCCTTCGTCGATAAACAGGTTCCCGTCGATCTCAGGTGC ATCCGCCATGGTGCGGCAAGTCGCCCCCTCACCGTCCACATCATCGACAATCACCGCCAGGCGCATCCCCACCTTGGCCGCCAGTTTG GCCTCGGAAATCGCCTGGGCCTTTTCCATGAAGCGGTCCCATCTCTCCTGCTTAACCGCTGAGTCCACATGGTCGGGCAAAGCATTCG AACTTGCCCCATCGACGTTTTCGTATTGAAAACACCCCACCCTATCCAACTGCGCTTCGTCCAACCAATCCAGCAGGTGCTGGAATTC GGCCTCGGTTTCCCCCGGATAGCCAACGATGAACGTCGAACGCAGCGTGATATCCGGGCAGGTCGAACGCCAGTTTGCAATTTCCTCC AAGGTCCGGGCGCTGGTCGCCGGGCGGGCCATGCGTTTCAGCACATCGGGATGCGAATGTTGGAACGGCACGTCCAGATAGGGCAGCA CCAACCCGTCTGCCATCAGCGGAATTAGGTCGCGCACATGCGGATAGGGATAGACGTAATGCAGCCGCACCCAGGCCCCCAGCGACCC CAGATCGCGCGCCAGATCAACAATATGCGCCCGATGCCCGCGCTCCTCCTTATAGGCCAGATCCAACCCATAGGCCGAGGTGTCCTGC GAAATCACCAACAGTTCTTTCACCCCTGCCGCCACCAGCTTTTCCGCCTCGCGCATCACCGCATGGGCCGGGCGGCTTTGCAGGCGGC CGCGCATGTCGGGAATGATGCAGAACTTGCACTTGTGGTTACAGCCTTCCGAGATTTTCAGATAGGAATAATGCCGTGGCGTCAGGCT TACCCCGGTGGCGGGCAGCAGGTCGATGAACGGGTCGGGTGCCGGTGGAGCAGCCTTGTGAACCGCGTCCAGCACCGCTTCATATTGC TGCGGCCCTGTTACCGCCAAAACCTTTGGATGCGCCCCGGTAATGAATTCGGGGTTCGCCCCCAGACAGCCGGTGACAATGACCTTGC CATTGGCATTCAGCGCCTCGCCAATCGCCTCCAGACTTTCGGCCTTGGCTGAATCGAGGAAACCGCAAGTATTGACGATCACCGCCTC GGCCCCTTCATAATCGGGCGAAATCGCATAGCCTTCGGCGCGCAACCGAGTCAGAATGCGTTCACTGTCCACCAAAGCCTTGGGACAA CCCAAGCTTACCATGCCGATTTTCGGCTGGCCGGGACGGGCCACATCGGGGATGTGGGAACGGGCAAGATCGGGACGCAAATTCGGCG GGTTCTGGGTCATCCGCGCGGTATAATGCGGCTTTCACGCGGTTAGAAGCACGTAATTGCACCACAGGGCGCTGATATGGCGCAGTCG CAATGCTTTCCAGAACCCCCATTTTCTGCGAAAGACGCGCGCAAGTAATCGGAGAAACCCTTGTTCAACCTGCGAAATCGTTGGGCCA AAATGATGACGGGCTGGCGTTCGGGGTTTCAGTCCCTTGATGGAGGCTGGCAACGGGCGCAGGCCTATTTCGACCTGTACTGGATTGA CCACGGGTTTTTGCGAGCCATTTACGGCAACCAATATCAAATCGGCACCGGCCTGTTTCGTCGGGCGCAACCATCGCCAAAAGACATC CGCAATTTTGCGGCAAGCGGCGGCAAAACCATCGTCAACCTGCGCGGCACCGGGCGCGGCGGGCCGTATCTGCTGGAACGCGAGGCTT GTGCCGCCAACGACGTTTGCATGATCGACGTGCGCACCTCCTCGCGCAACCTGCCAAAGGCCGAGGTCATTCTGGAATTGGCCCATAT CCACGCCAATGCAGCGCGACCCTTGATGTTCCATTGCAAATCCGGTGCCGATCGCGCCGGCATGGTGGCGGGCTTGTTCGTCTTGTTT GACGGCGGCAACATTGACCAGGCCAAGGCGCAACTCAGCGCGAAATATCTGCACTTTCGCAGTTCACCAACCGGCGTGCTGGATCAGT TGCTGGTCGAATTTGAACGCAGCGGCAAAGCTGATTTCCTGCAATGGGTTAGGGACGACTACGATCCAAAGGCAATCGAGGCGCATTT CCACGCCAATCGTTGGGGATCGGTGTTTGTCGATTGGATATTGCGCCGCGAATAGGCACACCCCCTTGCGTCCAAGTTGTGGCTTTGA TTGAGTGCGGAAACTGAATTTCCGGGAACCGCATGTCAGCAACCTTTGCCCAGCTATACACACCCAAACTGGTGACTGTGCTGCGCGA AGGCTATCGACTGGCACAGTTCCGCGCTGATGCCTTTGCCGGGCTGACTGTGGCTATCGTCGCATTGCCATTGTCGATGGCCATTGCC ATTGCCTCGGGTGTTGAACCGGAACGCGGCTTGTACACCGCCATCATCGGCGGGTTTCTGGTCTCGGCATTAGGGGGCAGCCGCTATC AGGTTGGCGGGCCGGCCGGGGCATTCATCGTGCTGGTTGCAGCCACCGTTGCCCAGCACGGCGTTGACGGTCTGATCCTTGCCACCAT CATGTCGGGGCTGTTCCTGATGGCGGCAGGCTGGCTAAGGCTGGGCATTTTCGTCAAGTTCATCCCCTATCCTGTTACCGTTGGCTTC ACTTCGGGCATCGCCGTCATCATTTTCGCCAGCCAGATCGTGCCGCTGTTTGGCCTGGTCTTGCAACAATCCGAACCCGGACCTCTGG CGGAAAAGCTGCCGGTATTGTGGCGTGCCTTGCCGACTTTCGATTTTGCGGCGTTTTCGATGGCTTTGGTCAGTCTGGCGGTGATCAT TTTCTTGCGCAAACAATGGCCAAAAGCGCCGGGAATGTTGGTGGCTGTCGGATTGGCGGGCCTGGCTACTTGGGCCTTTGCCTTGCCG ATTGAAACCATCGGGTCGCGTTTCGGCGGCATCCCGGGCGGCATGCCTTTGCCCGCAATGCCGGTGGTAACCTTTGCCAAACTGCGGG CAGTCTTGCCAGATGCCCTGTCCTTCGCCCTGCTTGGCGCCATCGAATCTTTGCTGTCCGCCGTGGTGGCAGACAGCATGACCGGGCG TCGCCATCGCTCAAATTGCGAATTGGTGGCACAGGGATTTGCCAATGTCGCCAGCGGGTTTTTTTGGAGGGTTTTGCGTCACCGGAACC ATCGCCCGCACCGCCACAAACGTCCGTTCTGGTGCGCATGGACCGGTGGCGGGCATGTTGCATTCGGCGTTTCTTTTGGCCTTCATCC TGCTTGCCGCTCCATTAGCATTCAACATTCCGCTGGCGGCTTTGGCTGCGGTTCTAGCTTTCGTTTCGTGGAACATGTTCGAACGGCA CGCCTTTGCCGCCTTTATCCGTGGGCGCAGCGGCGAAGCGGTCGTACTGTTGGCGACTTTCCTGCTCACCATTTTCCGCGACCTGACC GAAGCGATAATTGTCGGTTTCGCCTTGGGGGCAATTCTGTTCATCTATCGGATGAGCAAGCTGGCCGAGGTGCAGTCGCTGTCATCCT TTGCCAGTGAAGACGTCGCCGACAGCGAAAATGGCCGCTCCGACCTTGGCGGCGCCGACCCCGATGTTGTCGTCCACCGAGTGCGCGG TGCGTTCTTTTTTGGCGCAACGGGGCTGATGGATTCGGTTTTGGACAGGGTTGGTGACACCCATCGCGCCTTGGTGCTGGATTTCGAC GGCACCCCCTTCCTCGATTCCTCGGCGGTACATGCTGTTGCCTCGGTGGTCAGCAAGGCACGCAAACAAGGCGTGCGGATTTATATCA CCGGCACTAGCAAGCAAGAACGGCGCGAGATGACCTTGCACGGCATTGCGCCACGCGACGTTACCTTCAAGACTACCGCCGAAGCGGC GCTGGCGCATTGGGCCAAAGTCGCACCATGAGCTTGAGTCTGGGCGTCGATACCGGCGGTACCTATACCGATGCCGTGCTGATCGAGG GCGACAAAACTTTGGTCGCCAAGGCAAAATCGCTGACAACCCGGCACGATCTGGCTTTGGGCATCGGGCGGGCCATTGATGCCGTGCT CGCAGACACGGCCCCAGAAAAAATAACGCTGGTATCGCTGTCCACCACCCTGGCAACCAATGCGTTGGTCGAGGGGCAAGGTGGGCGA GTTTGTCTGATTTCAATCGGCTTTGAACCAAAGGATCTGGAGCGCGCCGGCCTGACCGCCGCCCTGAAAGGCGACCCGGTGGTTGCAA TTTCTGGTGGACATTCACATTCCGGCAATGAAACCCAGCCCTTGGATATCGAGGCCCTGAAAGCCGGGATTTTGGCGCATGTCGCCGA AGTTGGTGCGTTTGCCATTGCCGGACATTTTGCTGTGCGCAATCCGACCCATGAAATTGCAGCCCGCGATCTGGTGCGCGAATTGACG GGCAAACCAGTGACCTGTTCGCACGAATTGACTGCCCGCCTCAACGGCCCGAAACGGGCATTGACTGCGGTCTTGAATGCGCGGCTGA TCGGTTTGATCGGGCGGTTGATCGAGGCATCGCAAGCCTTGCTAAGCGAACGCAAAATCAACGCGCCTTTGATGGTGGTGCGCGGCGA TGGTGCCTTGGTTTCAGCCGATTTTGCCCGCACCAAACCGATTGAAACCATCTTGTCCGGCCCGGCGGCCTCACTGGTCGGTGCTGTC TGGTTGACCGGAGCGGCAAACGCGATTGTCTCTGATATCGGTGGCACCACCACGGATGTCGCGATCTTAGCCGAAGGTCGCCCGAAAA TCGACCCCGAAGGTGCCATGGTCGGCGGCCATCGCACCATGGTCGAGGCGGTCGCCATGCGCACAACCGGCCTTGGTGGCGACAGCGA AGTGCAACTCTTGGCCCATGGTTTGGCGGGCAGCCTGGTTTTGGGGCCACGTCGGCGCGTTCCTTTGGCCCTGTTGGCCATGGACTGG CCCGACATGGTCCATGCGGCGCTTGATGCACAAATCGCCACCGAGCGGACATCGGAAACCGATGCCAGTTTTGTGGTTCCGGTCTTGC GAAAGGGGCGGAACCTCAGCGGGCTTAGCGAACGCGAACGCGCCTTGATAAGCCGACTTGGCGAGTTGGCGCTGCCGACCGGAAAATT GATCCGTTCCCGCGTTGAAATCGGTGCCTTGGAACGATTGGTGTCGCGCGGCTTGGTGCAGATATCCGGCTTTACCCCCAGCGATGCC GCGCATGTTCTGGGTCGGCAAACCGGTTGGGACAGGGCCGCAGCGGTCAAGGGCGCTATCTTGTTCGCCCGGCAAAAAACCGGCTCGG GCGAGGTGATTGCAACCGATGCCGAGTCGGTTTCACAATTGGTCATCGACCAGTTGACGCAGCAGACCTGCGAGATCCTGCTGGAAC 
CGCTTTCGCCGAAGATAGCTTTGATCATCCTGAAAAACTGGCGCGTCATGTCCTCTCCAACGTGGGAACGCGCGCGCATCGCGGCGCT GCCAAGGTCAACATCGGGCTGGGATTGCCGCTCATCGGCTTGGGCGCATCCGCCCCCACCTACTACGGCGCGGTAGCGCAACGCTTGG GCTGCGAGGCGATCTTGCCAAACGATGCTGGCGTGGCCAATGCCATTGGTGCTGTGGTGGGGCAGGTTCGGGTGACGCGCCGCGTTGC TGTTACCAGCCCGGCAGAGGGTAAGTTTCGCGTGCACCTTTTGGCCGGCCCAAGGGACTTTGCCGCGCTAGAGGCCGCTCTGACCTGT GCCGAAGACGCAGTGCTGTCGTCGGCATCCGACGAAGCGACGGCCTCGGGCGTGCAGGAAATCAGGGTCGATGTCGAACGACAGGTGC AAAATGTAACGGTCGAAGGCCGCGAAACCTTTGTCGAAGCGCAGGTTCAGGCCATAGCCAGCGGCAGACCCGGCATCGCGCTGGCCTA GTCAGCAAACAATTCCCGGCAAGTCTCCAGCGCCGCCACCAGCACGTCAACCTCGGCCTTGGTGTTATACAGGGCAAACGACGCGCGG CAGGTGGCGTTGACGCCCAGATGCGCCATCAGCGGTTGCGCGCAATGATGTCCGGCCCGAATGGCGACGCCTTTTCGATCAACGATGG TTGAAACATCATGCGGATGCGCCCCACCCTGCATCGTGAACGAGAAGATCGCCCCCTTTTCCGGCGCATTTCCTTGGATATTCAACCA GTTAAAGGCCGAAAGCCGCGATTGGGCATAGTCGCGCAACTCGCGTTCATGGCCAGCGATATTCGCCATGCCCAAACCGTTCAGATAG TCAATCGCCGCCCCAAGCCCGATCATCTGGGCGATTCCGGGTGTTCCCGCCTCAAATTTGTGCGGCGCGTCGTTGTAGGTAATCGCGT CTTTGGCAACGGTGCGGATCATGTCGCCGCCACCAAAGAACGGGCGCATTTCGGCAAATCGGTTTTGGCGCACATACAATGCGCCCGA AGCCGTCGGGCCATATAACTTGTGCCCTGTAACCGCATAAAAATCGCAGCCGATTTCCGCCACGTTGACGGGCATGTGCACCGCCGCT TGTGAGCCATCGACACAGACCGCAATGCCTTTGTCGCGCGCGGCGCGGCAAATGGTTTTTACATCGACAACCGTTCCCAGAACGTTGG ACATATGGCTGATAGCGATCATCTTGGTGCGCGGGCCAATGGCGTCGATCACGGCGTGCGCATCCAGCGAACCATCAGGTTCGATATC GACCCATTTCAACACCACGCCCTGCCGTTCCCGCAGAAAATGCCACGGCACAATGTTGGCATGATGTTCCATGACGGAAAGGACAATT TCGTCACCCGCCTGCAAATTCGGCATGGCCCAGGCATAGGACACAAGGTTCAGTCCTTGTGTCGAACCGGTGGTAAAGATGATTTCGC TGTCAAGTTGAGCGCCCAGAAATCGCCGCAAGGTTTCGCGGACCGCTTCATATTTGTCGGTTGCGTGGTTGGAAAGGTAATGCAGGCC GCGATGCACATTGGCGTATTCTTCGGCATAGAAACGGCTGATCGTGTCGATCACCACCTGCGGCTTTTGCGCCGAGGCGCCGTTGTCC AGATAGACCAGCGGCTTGTCCCATACTTTTTGGGCCAGTATCGGGAAATCCTGACGAACGGCGGCGACATCAAACATCTACATCGCTC CCGGCGGCACAAAGCCCGCCATGATCGCCAGATAATTGACCAGAAAGACGAATCCGACAAAAAGCACGATCATTGTTGCGATCGTCAC CGCCGATGGCGACTTGCCGCGCGCCGCTGCGGGCGATGCCGTAACTCTGGTGATCGAGGATGAGATCGACGCCTCTCGGGGCGACGTC TTCGCTGCCGCCGAAGCCCGCCCGGAAGTCTCCAACCAGTTCACCGCCAACGTCCTCTGGATGACGGAAGACGAACTGACCGCCGGCC ACGCCTACCTGCTCAAGATCGGCTCGCAGACCGTGCAGGCCACGATCACCGGCATCCGGCACAAGATCGACATCAACACGCTCGACAA GACGCAGGGCCACGCCCTCGGCCTCAACGAAATTGGCTTCTGCAACGTCACTACCAACCAGCCGATCGCCTTCGACCCCTATCGCTTC ATTCGCGAATCCGGCGCTTTCATCCTGATCGACCGCTTCACCAACCAGACGGTCGGCGCGGGCATGATCGAATTCTCGCTGATGCGCG CCACCAATGTGCATCGCCACGCGATGGACGTAACGAAGGCTTCCCGCTCACTGCTGAAGGGCCACCGTCCGGCGATCCTCTGGTTCAC CGGCCTCTCGGGCGCTGGCAAGTCCACTATCGCCAACCTGGTCGAACGGCGCCTCGCAGACATGGGCGCGCATACTTACTCGCTGGAC GGCGACAACATCCGCCAGGGCCTCAACAAGGATCTCGGCTTCACCGACGCCGATCGCGTTGAGAACATTCGCCGCATCGGCGAGGTTG CGAAGCTATTCGTCGACAGTGGGCTCATCGTCACCGCGAGCTTCATCTCGCCCTTCCGCGCCGAGCGCGACATGGTTCGCGGCCTTGT CGAGACCGGCGAATTCATCGAGGTGTTCGTCGATGCGCCGCTTGAGATTGCTGAGAGGCGCGATCCGAAGGGGCTCTACAAGAAAGCT CGCGCGGGCCAGATCCGCAACTTCACCGGCATCGATAGTCCGTATGAAGCACCTGTCGCGCCAGAACTACGTCTCGACACGTCGATCG CGACTGCCGAGGCGCTGGCTGATCAGGTGATCGAACACCTGCGCAAGGCCGGTATCATCGGATCATCAGCCGACCAGGCGCTCGACTT CAGCATCTGACCAGAAATAGAAAGGCCGCGCACTGGCGATTGCTTGAAGCGGATCGCCAGTGCGCAGCCTAATTTTGTCGCCGCGGTT CTAGAGCGCTTTGAGCTGCGTCGCGGACATCTTGCCCGAGCGTTTGTCTTTCTCGAGTTCGAAGCTGACGCGCTGATTTTCTTTCAAG CTGTGCATGCCTGCAGCTTGAACGGCAGAGATGTGGACGAACACGTCGCCCCCGCCCGATTCCGGCTGAATGAAGCCGTAGCCTTTTT GTTCGTTGAACCACTTCACAGTGCCGGTAGCCATAGAGGTGTAGCCTTTCAGTTTTTCGTCGAAGGGCGGCACTATAGCTGCGAACGG TCGCGGCGCCTAAGGAAACGATTCGGCCAGGCCAAGAATGTTTTGCAGGCACTAGGCGGAACAAAGTGTCCCGTAAGGGGACATTGCG CTTCCAATGTTATTGTGTAACACAGGCGGCGGCCGTTCCGGCCAAGCTTGGATCGGCAATGTCGGGCGAAGAAGCAGCAATTGTTCTG GGCGCCGCAGCGCTTTCAGTCGCGGGAGTTGCCTTTGCGCTGTTGGCTGCCGCTGTCGCACGGCGGGTCGCGGACCTGGTTGGCCTCG CTGGCGGAATAGTCATTCTTCTTGTCGCCGTCTTTCATCTCGCGCCCGAAGCCATCGCTGCGGGCGGCACGGAGCGCATTTTCCTGCT GGCCGGGGCCGGCGTCGGCGTAAGTCTCGAGATTCTTTTCCGCGCCCGCGCCGACCCTGCTCCGGCCACCCTCCGGATAGGCGCCTGG CTCGGCGTTCTCGTCCTGGCGATCCATTCCACGCTCGATGGCGCGGTCTACAACGCCGTCATCTGGCACGGGGACGGCGTCGGATTGC TGGCCTCGATGGGCCTCATTCTCCACGAGGCGCCCGAGGGGGTCGTTGCAATGATGCTGGCGCTGCAGGCAGGCCTGAAGCCCGCGCC CGCCGCCGGGATCGCGGTTGCGGCGTCCTCCATCACCACGCCGCTCGGCTGGCTGCTCGCCCATCTCATCGGCGAATCAGCGCAAGGC GCGATGCAGGCGATGTTCGCCGCCTCGGCCGGCCTGCTGCTCTATGTCGGCTGGCATCTCATCGCCGGCGGCTGGAAAGCCCTGCGCG CCAGAAGCGAACCCTGAGGCGCAGCGACCCTGCATAAAATCGGGCCAAACCAGCCTGATCACGCACAACTCTTTCAAAGATTGATCCG TGGGGCGCCACGGGCTCGCTTCTTTCGTCCCGCACACAGGCATATATCTTCGCCTAAGTACGGAGAGCGACATGGCCGACCTTTTTGA AAACCCGCTGGGCACTGACGGATTCGAGTTCGTCGAATTCACTTCGCCCGACCCGCTGGTCCTGGCGAAGCTGTTCGAGACGCTGGGC TTCACGCCCGTCTCCCGCCATCGCTCCAAGAACGTGATCCGCTTCAAGCAGGGCGACATCAACTTCATCCTCAACATGGAGCCTGCAG GCCAGCCCGCAGAATTCCGCGGCCAGCACGGTCAGGGCGCCAACGCCATGGCCTTCCGCGTCAAGGACGCCGCGAAGGCCTACGCCGA AGCGCTCAAGCGTGGCGCGGAGCCCGCCTTCGGCCAGGTCGGCCCGATGGAGCTCAACATTCCCGCCATCAAGGCGATCGGTGGCGCC TACATCTATCTCGTCGATCGCTACGGCGCCCACGGTATCTACGACATCGACTTCACGCCCATCCCCGGCGCAGATGAAGCGGAGAAGA AGAACTCCGTCGGCCTCACCTATCTCGACCACCTCACCCACAACCTGTTCCGCGGCAATATGGACAAGTGGGCGAGTTACTATGAGAC CATCTTCAACTTCCGCGAGATCCGCTACTTCGACATCGAGGGCAAGCAGACCGGCCTCATCTCGAAAGCGATGACATCCCCATGCGGC AAGATCCGCATCCCGCTCAACGAAAGTCGCGACGACAAGAGCCAGATCGAGGAATTCCTCAAGGACTATGGCGGCGAAGGCATCCAGC ACATCGCGCTCGGCACGGACAACATCTACGACAGCGTCGAAGCGCTCCGCAAACAAGGCATCCCGTTCCAGACCGTGCCCGACACCTA CTATGAAGGCATCGGCCAGCGCATCGGCAATCACGGCGAAGACGTGCCGCGCCTGCACAAGAACCAGATCCTGATCGACGGCGCGCCG ACCAAGGGGCAGGGCCTGCTGCTGCAGATCTTCACCGCCAACCAGATCGGCCCGATCTTCTTCGAGCTGATCCAGCGCAAGGGCAATG AAGGCTTCGGCGAGGGCAATTTCCGCGCTCTCTTCGAGAGCATCGAAGCCGATCAAATCCGCCGCGGCGTGCTGAAGGCGGAAGCGTG AGCGTCGCGCTGCCAGTCGAAGGCGGCTGCATCTGCGGTGAATCGCGTCTGCGCGTCAGCGTCCCGCCGATCATCACCATGGCCTGCC ACTGCAAGGGCTGCCAGAAGATGAGCGCCAGCGCCTTCTCGCTGACGGCGATGGTCCCGGCGCAGGGCTTCGAGGTCGTCAAAGGCAA GCCGCAGGTCGGTGCGCTGCACGGGGAGTCGGGCTATCACTTCTGTCCGAAATGTCTCAACTGGCTCTACACCACGCCGGCCGGCAAT CCCTTCGTCAATATCCGCCCGTCGCTGTTCGAGATTCCGCTCTGGTCCACGCCCTTCATCGAAACCTTCGTCGACGAAAAACTGCCCT GGGCTATGACAGGCGCGCGCTACGGCTTCAGGAAGTATCCGCCGCCGCACGATTACGGAAAACTGGTGGAGGAATACGCCGAATGGAG TGCCCGGTTTTGAGCAGGGCCGCGCCATGAGCAAGACCATCCTCTACGGCTACTGGCGCTCCTCCGCGACCTACCGCACCCGCATCGC GCTGAACCTCAAGGGCGTCAGCTACACGACCGTCGGCGTCCATCTCCTGAAGGACGAGCACACGCAGCCAACGCATCTCGCACGCCAC CCCTCGGGCCGCGTACCGATCCTCGAGATCGACGGCCACCGCATCGGCCAGTCCATGGCGATGATCGACTATCTCGACGAGACCCGCC CCGACCCGCCTCTGCTCCCGCGCGATCCCGCGACACGCGCCCACGTCCGCGACCTCAAGGACCAGATCGTCGCTGACATTCACCCGCT CAATAACACCTCCACGCTGGCCCGCCTGCGCTCCCAGTTCGGCGCAGACGATGCAGCCATCGCAAGCTGGTACGAGCACTGGATCGTC CGCGGCTTCAACGTGCTGGAACAGATGCTCCCATCCACCGGAAATTTCTGCGTCGGCGATAGCCCGACGCTCGCCGACATCGTCCTCG TGCCCCAGGTGACGAACGCACGCCGATACCCGCAGATCGTCCTCAACCAGTTTCCCAACATCCTGCGCATCGACACAGCGCTGCGCCA GATCAAGGCGTTCCGAGACGCGGCGCCCGAACAACAGCCGGAGGCGAAGCAGTAATGACCAAGGGCAAATGGATACCCGTGCAAGGCG CCGAGGGCAGGCACTCGAAGCAGGCCCATGCCGACATGCCGGAAGGCACCTTCGAGCGCGAAATGTCGAAAGAGGGCTTCTTCGGCCC CGCCGCTTTCTTCCACCACCCGAAGCCGCCGACCGGCTGGATAACCTTCGAAGGTCCACTCCGCCCGCGCGCATTTGATCTCACCAAG ACCTCGACCAGGGGCGAAGGCGCAGGTCCGTGGCATGCCCCGGTGATCCTTTCGAACAAGGCTGTCGAGGTTCGTTACTGGAAGCTCG GTGGGCCGATGACGAAGCTGTCCCGCAATGGCGATGGCGATACGCTGCTCTTCATCCACGCTGGAACTGCCGACTTCTACAGCGACTG 
GGGACACTATTCCGCCGTCCCGGGCGATTACATCTACATCCCGCGCGGCGGCATGTTCTTCCTGAAGCCTGGCGGCCCGCTCGATGCG CTGGTGATCGAAGCGACCAACACGCACTTCACCCTGCCGGATCGCGGCCTGCTAGGTCCGCACGCTTTCTTCGATCCCGCCATGCTGG AAACGCCGAAGATCGACGCCGCCTTCCTCGATCATCAGAAGGCCAGCGGCCAATGGCAGGTCGAGGTGAAGAAGCGAGGCGCAATTTC AATAGTCACCTATCCGCAGACGCCGCTGGATGCCGTCGGCTGGCACGGCGACCTCGCGCCGGTGAAGATCAACGTGAAGGACCTGCGC CCCGTCGTCAGCCACCGCTACCACCTGCCGCCATCGGTTCACGCGACATTCCTGAGTGACCGCTTCGTCGTCTGCACCTTCTGTCCGC GCCCGTTCGAGACCGATCCCGGCGCGCTGAAAGTGCCGTTCTTCCACAACAACGACGATTTCGACGAAGTCCTCTTCTACCATGCCGG CGACTTCTTCAGCCGTGACAACATCGAGGCCGGCATGATGACTTTCCACCCCTCCGGCTTCACCCACGGCCCGCACCCTAAGGCGCTG AAGAAGATGCTCGTCCAGGACAAGCCAATGACCGACGAGTACGCCGTCATGATCGACACCCGCGACCCCCTTGATGTGGGCGAGGCGG CTGCAGCCGTCGAGAGCACCGCCTACGTCGACTCCTGGAAGACGAGCGAATAGCGGGTGAGTTACGAACTCCTTATCTATCCGAAATC CTACGACGCCCAATCTGTTCGCCACCATTTCACCGTCCGGCCGAACTATACGATGTTCAGTGGGCAGGCGGCCTACGGCAATGAAGAC ACTGGCGTCGGCTTCACGTTCGACTTCAGCGAAGGCAGCAGTGAAAGCGAGCCCGCCGTCTTTTTCAATCTTTCATACTTTCGCTCGC GCGTGTTTGGTATCGAAGCCGCGCAGGAACTCTCAATATTTCTGGACGCGTTCGACAGCCGCATTGTCGATCCGCAGCAATTGGAAAG CATGGGCGTGGGGCCATATACCAGCGACGGCTTTCTGCGGAGCTGGAATGCCAACAACCAGTTCTGCTTCGAGTCCTTTTCTGGTGCG AAGCTCGAACGGCTGATCTGGCCCGCCGATCCTGCCCTGGTCGAGGCGATCTGGCGTTGGAACCTGAAGCGTGAGGAACGTCAGCAAC GCATCGGCGACCGCATGTTCGTGCCTAAGGTTCGTTGGGCCGTCGTCGATAATGGCGAACCTGTATCCTGTGTCGCCTGGACCGAGGG CGTGCCCACATTGATCCCGCGCGATCTCGTCACGCACGTCATCCTCGTGCGCCAACCACGCCCGTCGGTAAAGTCGATGTTCGGCGCT ATTGCTGGAAGCGGCCCGAAACCCGAGATGAAAATGGTCGGCCTCAGGGCCGTCGCCGCGTCCCACGAAGTGGTGGAAACCGAATTCG ACGGCGAGAGGATCGTTCAGACGCCTCAGGCGACAGGCATCATTTCCACGCCTGGCGTGTGGCCGAGGACGAGCATACGCATCCTGCC GCCGGAAGAAATCTGCGACAGCGATCTGATCGATCTGATGAAGAAACTCTAGCGCCGCGTGTTGGCGTAGTTGAGCCCGGCGACGAGA ACCGACACAGGCATGAGGTAGGCGCACACGGCGGCATAGAAGCAGGCGCGGGTGAAATACATGGCTCGAAACTCCGAAACTGCTTCAG GCGCGGCATGCGCAGGCGGTCGGAAGTGAACTCTGGTACGCTGGCGTCAGGATGCGCGCCCTTCGTTAACGAGGTATGCATGTTGCCG GGCGGGGCAGGCGGCCTAGTTTTTTGGCAGACGTTTTCGTTGCTTTTCGAAGGAGACTCTCATGGCGCGTCTGACGATTGCAGTTGCG GTTTCCGCGCTCTTCGCCGTCTCCTGCACGCCGAATGCAGATGTCCCCGCCGCGCCCGCCGCTGACACGACCGCCGCCAGCGAGCCCG CGCCGGCCGAAGCCGCCACGCCTGCGCCCGATGCCCGCGTGGTCGCGATGAACCTGATGTGCCGTGGCGAAAGCTTCCGCGTCGCCTT CCTCGAAACAAGCGCCACCGTCGTCAACGCCGACGGCAGCAACACGAATCTACCGTCTCTTGCGCCCGACGCCAATGCTGCGCCCGGC GTTTCAACCTACACTAACGGCACAATGACGTTCGCCAAGACAGGTGGCGGCGCCACCCCCACGGTCATCCGCTTCGCCCGCGGCCGCA TGGCTTTCCAGGATTGCGCCATCGCGCAGAACTGATTCCCTGATCTGTCCAATCGCGGTGTCATTCCGGGCGAAGCGGCGAAGCTGCG CAGACCCGGAACCCAGGGGCCGTAAGCACAACTGTTTCGGAATGTCGTTCCAGCAGCGATTTCCGCCCCTGGGTTCCGGATAACGCCT TCGGCGTTTCGGAATGACACCGGCAGGAACTCTGCGAATTGCGTCCGGCCTCAGCGCGTTCTAGAAACGCTCCATGAAACTTGCCTCT CTAAAAGCCGGTCGCGATGGACGACTGGTGGTCGTCTCCCACGACCTCACCAAGATGGCCGACGCCAGCCACATCGCGCCGACGCTCC AGTCTGCGCTCGATAGCTGGAAACGCGCCGCGCCACGTCTCCAGTCTCTCGCTGGCGAACTCGAACTCGGCTCTATTCCCAGCGAACG CTTCCACGAACACGACTGCGCGTCCCCGCTGCCGCGCGCCTATCAGTGGGCCGACGGCTCGGCTTACGTGAACCACGTCCAGCTCGTG CGCCAGGCGCGCAAGGCGGAAATGCCGGAGACGTTCTGGACCGACCCGCTGATGTACCAGGGCGGCTCGGACTCGTTCCTCGGTCCGC GCGATCCCATCCCGCTGGCCGATCCCGAATGGGGATGCGACATGGAAGGCGAGATCGCCGTCATCACCGGCGACGTTCGCGCCGGCGC CACCCAGGAGGAGGCGCAACACGCCATCCGCCTCGTCATGCTCGCCAACGACGTCTCGCTCCGCAATCTCATCCCCAACGAACTCGGC AAGGGCTTCGGCTTCTTCCAGTCGAAGCCATCCAGCGCTTTCTCGCCCGTCGCCGTCACGCCCGACGAACTGGACGGCATGTGGGACG GGCGTCGTCTCCATGGCGCGCTGCAGGTCCGTCTCAACGGCGAAACCTTCGGCTGCGCGCAGACCGCCGTCGACATGACGTTCGATTT CCCGACGCTGATTGCCCACGCCGCGAAGACACGCGCGCTGTCCGCCGGCTCGATCATCGGCTCCGGTACGGTCTCCAACCGCGGCGCC GATGGCGGCCCCGGCAAGGCGGTCAAGGATGGCGGTGTCGGTTATTCCTGCATCGCCGAACTGCGGATGGTCGAAACCATCACCGCTG GCGCGCCGAAGACCGGATTCCTCAAGCGCGGCGACCGCGTCGAGATAGAAATGCCGGACAGCAAGGGCCGTTCGATCTTCGGGCGAAT CGACCAGACGGTGGAATCGTGAGCAGCAAGCAGATCCGTGCACGCGTGACCGAGTGCGATCTGCCAACCGGCAGCGCGTTGAACGGCG CCTTTGCCGGCATCGACTTCCACGACTCGTATCGGGCGCCGCTGGCCCACCCTGATCTTGGCCCGCCTCACATCTTCCATGGCATATT CAGCCACACTCCGGTCTGGATGAGAGCGGCGCTGATCCTCCGCAACCAGTTCGCTAGGCTTGCTGGCCTCGAAGTGCCGCGTACGTTT GAAATCGTCGGTTCTCGCCCTCGCGAGCGCTATCAGGTCGGCGAGAAGATAGGGCCATGGCCGATCTTCTCCCTCTCGGGCACCGAAC TGGTAGCCGGCCGAAATAATCTGCACATGGATTTCCGCGTCTCGATCATGAAGGTGCGCGATGGCGGCGGGGCCGGCGTCGTCGTCTC CACCATCTGCAAGGTTCACAACACCTTCGGGCGGGTCTACCTGTCTTGCGTGATTCCGTTTCACAAGTTCGGCGTACGCAAGTTGATG GCGCGCGCTCTCCTCGCACAGCGCCTCTAGGTTCCAAGGAGCCCACGATGACGACTAAGGTCTATCCTGATGCTCAAGCAGCTCTTGC AGGCCAGCTCTTCGACGGCATGACTATCATGGCCGGCGGCTTCGGCCTCTGCGGTATCCCGGAAAATCTGATCGCCGAGATCAAGCGC GCGGGCGTCAAGGGCCTCACCGTCATCTCGAACAACGCCGGCGTCGATGGCTTCGGCCTCGGCGTCCTTCTCAACACCAAGCAGGTAA AGAAGATGATCTCGTCCTACGTCGGCGAGAACAAGGAATTCGAGCGCCAGTATCTCTCCGGCGAACTCGAACTTGAATTCAACCCGCA GGGCACGCTGGCCGAACGCTGCCGCGCGGGTGGCGCAGGCATTCCGGGCTTCTACACAAAGACCGGCGTCGGCACGATCGTCGCCGAC GGCAAGGAGCACCGCGACTTCAACGGCGAGACATTCATCCTCGAAACCGCACTGCGTTCGGATCTTTCGATCGTGAAAGCGTGGAAGG GCGACGCCCAAGGTAACCTCATCTTCCGCAAGACGGCCCGCAACTTCAACCCCGACATGGCGACGGCCGGCAAGTTCTGTGTCGCCGA AGTGGAAGAAATCGTCCCCGTCGGCTCTATCGACCCCGACCACATACATCTCGCCGGCATTTTCGTGAACCGCGTCATCCCGGGCAGG TTCGAGAAGCGCATCGAACAGCGCACCGTCCGCAAGAGAGCCTGAGAAAGCAGGCAGTGAACCCGGGGCTCGCCGAGCCCGCACAGTT CCACCACCGCGCCGAACTCGGTCAGGGAGATCGACGCGGACTTCAAGCAGCTGCTCAACACAGAATGGGAGTCGCCATGAATACCGCA GCAATCCTGATCGCCACGACCGCCATCATCCTCGCGTCTGCCGCACCGGCCAGCGCGCTCAAGCTGACCAGTCCGGACCATGCCAACG GCGCATCCATCGCCACCGATCACATGTATCCACGCTGCGGCGGCAAGAACACTGCGCCCGCGCTCAACTGGACCAGCGCGCCCAAGGG CACGAAGTCCTTCGCGCTTACCTTCGTCGACACCAGCGTCCTGCCGCTCGCCTGGTCGCACTGGATTGTTGTCAACATCCCCGCCGAC GCGACCTCGTTGCCGAAGGGCGGTGCGCTTCCTGCCGGCGCCGAAGGCCTCAAGAGCAATTTCGGCGATGAAGTTTACGCCGGCCCGT GCCCGCCCGCCGGCACCGGCATCCATAAGTACGAATTCACGCTCTACGCACTGCCCACGCGCGCGCCCGCCATCGTCAGCGAGTCGAG CGCCAAGAATCTTGTCGAAAGCCTCGGAAAACTTGCCCTCGCCAAGGCGACCCTCAAGGGTGTCGCCGCCGCGGCCGACCCGAACTGA AAGGACCGAACCATGCCTTGGGATCGCGATCAAATGGCGGCGCGCGCCGCCAAAGAGCTGGAGGATGGCTTCTACGTCAACCTCGGTA TCGGCATTCCGACGCTGGTCGCGAACCACATCCCGGCCGGCGTCGATGTCACGCTGCAGTCGGAAAACGGCATGCTCGGCATGGGCCC GTTCCCGTTCGAGGGCGAGGAAGACCCCGACCTCATCAACGCCGGCAAACAGACGATCACCGAGCTTGATCGGTCGGTGTATTTCTCC TCCTCCCAGTCCTTCGGCATGATCCGCGGCGGCCACATCGATCTCGCCATCCTCGGCGCGATGGAGGTCTCCGAAAAAGGCGACCTCG CCAACTGGATGATCCCGGGCAAGCTGGTGAAGGGCATGGGCGGCGCGATGGATCTCGTCGCCGGCGTCAAGCGCGTCGTCGTCATCAT GGACCACGCCAGCAAGGCCGGTGAAACCAAGCTGCTGCACGAATGCTCCCTGCCGCTCACCGGCAAGGGCGTCGTCGACCGCATCATC ACCAATCTCGGCGTCTTCGATGTCGTCCAGGGCGGCCTGAAACTGGTGGAGACCGCCCCCGGCGTGACGCGCGAGGAGATCGCGGCAA ACACGCAGGCGAAACTGGTCAACTGACGCGCCGTCTTGCCTCCCCCACTTGCGTTGCAAGTGAGGGAGGTAAGAGGCGCCCGGCGCTC TCCACGTCCCCGGTCCGTCGCTCCTAAAACAAACTCCTGCCCCAAACGCAGCGCACCGCTCAAGCGATTTCTTAGGGGATTAGCCGTG ATCCGCTTCGCCCTCGCAAACATCGCCGTTGCCAGCGCGCTGTTTCTCTCCGCCGCCCACGCGCAGACGCCGCCCTCCGTCACGGGCG AATGGATCGGCAAATACATCTGCACGCAGGGCGTCACATCGCTCAATCTCACCGTCACGAAGGGCGACGGCGCCGCCATCAAGGCGAC CTTCAGTTTCGGCCCGCTGCCTGAAAATCCCGAAGTTCCGAAAGGCGCCTACCAGATGCGCTGCACATACGATCCCGCGACGCGCAGC GTGAAGCTCGACGGCGTCAAATGGATCGACGCGCCGCTTGGCTACGTCATGGTCGGTCTCGACGGCCACATGACGCCGTCAGGCCAGA AGATCGCCGGTCATGTGCCGGATCTTCCCGGCTGCACCGGCTTCGAAGTATGGCGGCCGGTGGAGCTGATCGGCTGAAACCGTCAGGC CGCGCCGCGCCGGATCAGCGACAGCAGCGCCAGCACCACGACCGCGCCGATGGTCGCGTAGAGGATGCTGGTGATCAGCGGATTACCG 
ACCGAGAACGCGATGCCGAGCTGCGGCAGCAGCCACGCTGCGACGAACGCTCCGACGACGCCGACGATGATGTTGCCGACGAGGCCAA ATCCGGCCCCCTTCATGATGAGTCCGGCCAACCAGCCGGCAATGGCGCCGACGAGCAGCACGACCAGAATTGCCTCGACTGTCATTTG ATTTGTTCCTGAGCGGCGCGCCCGCACGGCGATCCAAGTTGAATCAATGCGCAGGCAGCCGCGATGTTCCGCGACGTTTGCTGGATCG CTCTTGATCCGCGCAGCTCTTCCCTAGCGCTATGCGCAGGGGAAGTGTCACATCTTCTTGACCGGCGGCGCTTTCCACGTCCGGTCGA GCAGCTCCCGCTTCGGCAGGTAGGCGCGCAGCGACATGCGCATCGCTCCAGCCGCCGCCGGCAGCCAGTTCGCCGCCAGCGGACCCGT GGGCGCCTCGCGCTGAATGAGGATGTCTATCGACCCGTCCGCATTCCTTACCAGCCCCTTGGTCCGGTCGCCCACCGAGAACCGGTTG ATCGGGTTCTGCACCAGGAACGAACGGCCATCGGCCTCTTCCTGATACATGGTCAGCGACCAGAACGCCTCGGCCGGCACGCCGCCCG GCGGCACGCGCCAGACATATCTGCTGGCCCCATTCAGCATCGCCCCCGCCTCGTCGCGCGTGGCCTGGAAATACATCGCTTCGTTCTC AGGCAGCGCCGCAAGCCCGCCCAGCGCAATCGCTGCGCGCAGGTAGTCGCTCGCCGACGCTTCGCCGACGCCTTTCTCCTGATAGCCC CACCCGTTCACGATCAGGTCGCGGAACTGGAACTTGTCCCTCAGCTTGGCGAGCCCCTTGGGCAGGTAGGCGCGCCACGCCGCGATCA TCTCGGGGGTCGCCGTTGCATTAGCTCCGATGCCCAGGCTGGCAAACCTGTTCGCCCGAGCCGTCTGTCCCTTGCCGCCTGGCGACCG CCTCAGCATGTCGTTCACCACGCCAAGGAAATTCTCCGGATCCTCGACACTCGTCGCCTTCACGCCAAGAGCTCGCGCCGGCTTGTCC GTCACCGGCTTCAGCGTGATCTGCTGCTGCAGCGCCCGCGCCGCCGGCAAATCCTCCGGCCCTTCCACCACGATACGCCCCAGCATCC ACACATCGTTGGTCGATGACCGGATAAGCTGGACGCCTGCCGGCGCCGCGCCGGTCCACTCCGGCCCCACCACCCAGAACTTGCCGCC CTGGCCCCTAGTCAGTCGCGTGCCGATCCCAGAGAAATTGTCGGTGAAGGCGTCCATGAACGTGATGTTGAAATAGCGCTGCGTGTCC GTCGGCGAGACCACTTCCATCGGCCCGCCGGAAAGCTCGAGCTGCGCGGAGGAATAGACCGTGTCGTTGTTCGGCGCCGTGATCTGCC GCGACGTATGATCGGCCAGCACCGCGCGGTGTCCGAGCGTGTTCAGCCCCGGCGCCGCAGCGCGGTTCTGCCCGGTGCGCGCGATCTC GTAGAGCGGGAACGCATAGAAGAACGCCGCATCAAGATTTGCCTCGCCGCTTGGCTGCGCCGCGCTATGGCAACCCACGGCGCCGAAC AGTCCAAGCCCAGCCAGCCCAGGCATCACATCGCGGCGCCGCATCTGCTTCTCCGTGCGATACTGATCAGTACCATTCTGGTTTACTG GTTCGGCATCGCCCTGGCAACGGCGCAAAAAACCCCCGGACTTTTGGGGTCCGGGGGAGTTTCTCTCCAAGTCCTCTCCCCAAAACGC ATTGGAAGAGAGATCATAAAACGTCGAGTCCGGCCGCGGGTTGCGCGGCCGGAACGGGTCATGTCTTCAAGTCGAAGCGATCCAGCTC CATCACCTTGGCCCAGGCAGCGACGAAGTCCTTCACGAACTTCTCCTTGGCGTCGCTGGCCCCGTAGACTTCCGCAAGAGCGCGGAGC TGCGAGTGCGAGCCGAAGATCAGGTCGGCGCGCGTACCGGTCCATTTCACGGCGTTCGTCTTGCGGTCGCGGCCTTCGAACACCTCGT CGGATGCATCGACCGCTTTCCACTTCACGCCCATGTCAAGCAGGTTGACGAAGTAGTCGTTCGTCAGCGTCTCGGGCCGGTTGGTCAG CACGCCATGCTTGGGCGAGCCGACGTTGAGCACCCGCAGGCCGCCGACGAGCACGGTCATTTCCGGGCCGGTCAGCTCCAGCAGTTGC GCCCGGTCAGCGAGGTGCTCCTCGATCGTCATGATCGGCTTGCGCACATAATTGCGGAAGCCGTCTGCCTTCGGCTCGAGCCAGGCGA ACGACTCGATCTCGGTCTCCTCCTGCGATGCGTCCATGCGCCCCGGCGTGAAGGGGACCTTCACAGCATAACCGCCGGCCTTCGCAGC CTTCTCGACGGCCGCGCCGCCGGCGAGAACGATCAGGTCGGCGATAGATACCTTCTTGCCGCCAGTGGCAGACGCGTTGAACTCCTTC TGGACGCCTTCGAGCGCCGACAACACTTTCGCCAGTTCAGGCGGATTGTTCACTTCCCAGTTCTTCTGCGGCGCAAGGCGTACGCGCG CGCCATTGGCGCCGCCCCGCTTGTCCGACTCGCGGAACGTCGAGGCCGAGGCCCACGCCGCCGAAGCGAGTTGCGAGACCGAAAGGCC CGTCGCGAGGATCTTCGCCTTGAGCGCCTCGATCTCGGCGTTGCCGATCAGCGGGTGGTTCACCGCCGGAATCGGGTCCTGCCAGATC AGTGGCTGCTTCGGCACGAGCTTGCCGCGATAGAGCGTGATCGGCCCCATGTCGCGGTGTGTGAGCTTGTACCAGGCCTTCGCGAACG CTTCCGCGAACTCTTTCGGGTTCTGCTGATAGCGGCGTGCGATCTTCCCGTAGATTGGGTCGACACGCATAGCCAAGTCGGCGGTCGT CATCATCGGCTGGTGCTTCTTGTTGGGATCGTGCGCATCGACCACCGTGTCCTTGCCGGCGTCACCCTTCGGCTTCCACTGGTGGGCG CCCGCGGGGCTCTTGGTCAGCTCCCACTCATAGCCGAACAGCGTGTCGAGATAGCCATTGTCCCACTTGGTCGGGTTCGGCTTCCAGG CGCCTTCGAGCCCGCTGGTGATGGTGTGGCCGGCCATGCCGCTCTCGAACGTGCTGCTCCAGCCAAGCCCCTGTTCGGAGATGTGGGC GCCTTCCGGCTCCTTGCCCACATGACTTTCCAGGCCTGCGCCGTGCGCCTTGCCGAAGGTGTGGCCGCCGGCGACCAGCGCCACGGTC TCTTCGTCATTCATCGCCATGCGCCCGAAAGTCTCGCGAATGTCGCGCGCGGATGCAGCCGGATCGGGATTGCCGTCCGGGCCCTGCG GGTTCACGTAGATAAGGCCCATCTGCACCGCGCCGAGATTGCCGTGCAGGTCGCGATCGCCGGAATAGCGGCTGTTGGGCGCCTTGCT GTTGGCGAGCCAGGCCTCTTCCGTGCCCCAGTTCACATGTTCTTCCGGCTCCCACACATCGGCGCGGCCGCCGCCGAAGCCGTAGGTC TTGAAGCCCATCGACTCGAGCGCGACGTTGCCGGTGAGGATCAAGAGGTCGGCCCACGAAATCTTGGCGCCGTATTTCTGCTTGATAG GCCAGAGCAGGCGGCGCGCCTTGTCGAGGTTGCCGTTGTCCGGCCAGGAGTTGAGCGGCGCAAAGCGCTGCTGCCCGCGTCCGCCGCC GCCGCGGCCATCGCCCGTGCGATACGTGCCGGCCGCATGCCAGGTCATGCGGATGAAGAAGGGGCCGTAGTGGCCGTAGTCGGCCGGC CACCACGACTGCGAGTCCGTCATCAGCGCGGTAAGATCTTTCACCAACGCATCGAGGTCGAGGCTGTCGAATTCCTTGGCATAGTCGA AGTCAGCGCCCATCGGGTTGCTGTCAGACGTGTTCTGGTGGAGCGCGCCGATGTTCAACTGGTTGGGCCACCAGTCGCGATTCAGCCG GCCCCGCGAGTGCGGCACAGGGCACTTGCCGTCACCGCTTCCATTGCCATCCATGTCCCACTCCGTTTGCTAGTGTTGGTGATAGGCG CGCCTGGGAGGCTGCCTGAGCCAGACAAACTTAGAACCGTTCTAATATTAGGGCAATGCCGGGGTTGAACAATTCTAGGGTAGATGCA GCGCTTTGTTTTCGAACGAAAAGGGAGTCGCACCTCCGCCAAGCCGATTAGATTCAAGGCACAGGACTAGCGGCGTCGGATTGCTCGG TCACGTCCGGCGGTGTCTGCTGCCGCCAGTCCCGGGGGGAATGCATGATCTCGCAATTGAAGGCCATCTGTGCGGCGGCGTTGCTCGC ATCCGCCTGCGCCAGCACGGGCGGCGGCGCCATCGATCTTCTCGCGAAAGGCCTCGACGGCTTCACCGTCGCGAACACCGCCAACTGG AATTACGCGGACGGCGTCATGCAGGCGAACGCCGGCGGCGCCCAGCCCAGCGTCCTCGTCACAAAGGACGACTACCAGGACTTCGAAC TCACGCTCGAAGTCTATGTCAGCGAGGATCACAACAGCGGCGTCTTCATCCGCTGCAGCGACCGCAACAACATCCAGGCCACCAACTG CTACGAGATCAACATCTTCGATGAACGCCCCGACCAGTCCGGCCGCACCGGCGGCGCCCCCGGCTTCTTCAAGCCGCTCGCCCACGTC GACGCCGCCGGCAAGTGGAACACGATCAAGATCCACGCCGAGGGCCCGCACATCCTCGTGGTCATGAATGGCGTGATCACCATCGACA GCGACGGCCCGCTGATGTCGAACGGCCCTATCGCCCTGCAGTGGGGCGCCGGCGAGGTGATGTTCCGCAACGTGCGCGTGAGGCGCCT CTAGCAAGCCTGCCCCAATGGCGAGCAGCCGCCGAAGGCGCGATTTGGTCCAGTGGCCCTTATGCCGATGCCGGCATAATGGTCATAG TGCCGAGCGCCGGATTATGGATCCTGCCCCGGTTTTGTGGACGCCCATGCTAAGCTCGGAAGGGCTTGGAGAGGCGTTCAGTGCGATT TGGGCTGAGAACGCCTCTCGGATCACACAGCTGAGCTGGTCATTGCCATCGGCATGCCGTTCCTGGGGTGAAGGGCCATACCCGTCTG CGGCCAGACGATCTCCCGTGGTGGCGGCTCGAACTGCGTCGAGCGGACTAGAGTTGTGAGAACCGTCACGGCTTCCGCCATCGCGAAA GCCCCGCCGATACAGATGCGTGGGCCGCCGCCGAAGGGCATGTAGGCAAAGCGCGATGGCGGCTCGCGCCCTGGCTCAAATCTGTCGG GATCGAACGCGTGCGGGTCGTTCCATACGCTGGCGCGGCGATGAATGGCGTAGATCGGAATGTTGACCCGCTGCCCCGCCTTGAGCCG ATGCCCTGCCAGCGCCGTATCACGCGTCGACACGCGGGTTAGCAGAAACGCGGGCGGATAAAGTCGCATCGCTTCCGAGATCACCTGA CGAGCAAATATCAACTGCGGGAGTGTATCCGGCGTGACGTCACCCGCGCCCAAGACCGCAGTCGCTTCCGCCGTCAGCCTGTCACGCG TTGGTGGATGAGCGGCGACCAAGTACAGCGTCCACGTCAAGGCGACTGCTGTCGTCTCGTGACCCGCAAGGATAAAGCCGAGAATATT GTCGGCGAGCTGTTCATCGCTCAATCCCAGACCGGTTTCGGTATCTCGCGCCGCCATCAGGAAGTCGACAAGGTCGCCACGCGGCGCT GAAGTCCGGCGGGCAGCGACAAGACGCGCAATGTGCGCGACCAACGGTCCGCGATGGCGCGAGGCCGTCTGGGGACGCCGTTCATGAT ACGCGTCCTGCCGGAAGAAGTAGCTGAGGCGCATGCGGTTGATGTCGGCGAAGAAGTCCTTGGCGCTGTGGCGGATTGTTTCGCGATC AAATGCCTCGGCGCCGGAAAGCATGGTGTCGAGGATGACGTCGAACGTGATCCGCTTCATCTCCTCCAGAGCATCGATCCGACCACCG GGAAGATCCGCCCAGCGCGCTAACGCCGTGCGCGTTGCCTGCACAAAGAAGGGCGCCAACTTCGCGACATCGCCGGCACGGAAGGCCT GAGCGCAAGCGCGTCGCTGGGTCTGCCAGGCTTCGCCCTGTGACAGGAGCAGCCCCTTTCCCCACACGGGCCGCATGATCCTTTCAAA CAGCGCGCCATGCGGGTAGTGCTCGGCCTCGGTAAGCAGCACCGTCTGGATCGCATCAGATGACATGATGAACAGCGGCATGCCCGGC AATGGTGGTTTCCAAGCGTCCTCCTCGAACACCTCTCGCGGTAGGCCTTCGATTTGTGATCGGAATGTCCGCAGCACGAGCGCCAGAT TGGTTTTGGTCTCTGGGCCCGGGAAAGGGGCCGGCGGGCGAAAGACGTCCGTGTCACGTCCGCGTTGTGCCATCACCTCTCGACCTCC GCACCGCTTCCATGCTACAGACCATACCACATGGTATGTGGTCAAGGGTTGAGAAGTGAGCCGTTTCAACAAGGAAGACTGGCTATCT CTCGGGGCAGACCTTCTCGGAAAGGAAGGGCCAGACGCGCTGACGCTGGAACGTCTGACCAAGGCGGCCGGCCGCACGCGAGGGAGCT TCTACCACCACTTCGCGAACCGAGAGGCCTTCCTTACCGGGCTGATGGACTGGTGGCGTCAGCGGGCAATCGACAGTCTCGCAGCGCG TATCCAATCCGCGCCGGGCCCAGAAACACTGCGCTCCATTCTCCGCGCTGTGCCGTCGGAATGGAATGCTGCGTTCGAACGCGGGATA 
AGACGGTTGGCTGTCTCGGAGCCGGTGGTAAAGGACGCTCTCATCAGCATCGACGAGACACGCATCGCCGGTCTCGCCGCAACCATCG CCCTCCTGCGACCTGACGTTGAAGATCCACGCTCACTCGCCTTCATCCAGTACGCCGCGGTAATCGGCGGCCAATGGCTGCTCGAGTC TCCAGATGATCCGCGCATTCCCGCCATCAAGTTGGCCGGGAACGCGCTGTTTGGCTTGCTCGACTGAGGAACGGCGAAGCCATTCATA TGCCGACTTGCTGCGCGGCCGGGAGTTGCTGCAAAAAGCGTTCGCGGCAGCCGAGCGGCAAAATCCGGCGCTCGGCATTATGGACCAA ATCGAGGAGCGAACGCCCGCGGCAGGGGCCGGCGGGCAAGACGTCGCCGCGTGTCATTCCTCGCGAAGGCGCGCAGCGCCGAAGGCCA GGAGGCCAGTGCTGCGAGCTCCTTACCAGCCTCCTGGCTTCCGGATAACGCCTGCGGCGGTCAAACGCATGGGTTTGCAATGACAGCG CATCCCAGGGTTTTCCCTGAGCGCAATCCAGCATGCTTCGAAGGCCTCCAACGCCAATCTTTCGTGTCGTTTCAAGTCGCTAGGAAAA AACATCCGGAAAGTTATCCTCACCCCTCCGGACCGGGCCGATACTCCACACATGACAAACCGTTCTCACGCGCCCGCAGCCGCGATCA CACCCTCATGTCTGGCCCCAACGCAGGTCGGCCGTGAACGCTTGTTGTTGTTGTTGTTGTTGTTAGCGGAATCGCCCGAGCGCGACGT TCGAGCGAAACTCGAAAGCCGCCGACGACGACGATTCTGAAAATCAACCAAAATCGTCGGATCGATCGGCAGCCTCACGTGACCGCAG CGCGCTTCCTGAACTCGGGCCTGTCCCACGCGCCGCTCGCGAGCACGTCGCCAAGCGCATCCATGGCGTCCCACACATCCACATACCG CACGAACAACGGCGACACGCCGAACCGCATCGCATCCGGCGCCCTGAAATCCGCGATCACGCCGCGCGCGATCAGCGCCTGCACCACA GCGTAGCCCTCCGCATGACGCACACTCACATGACCGCCGCGATGCGCCGCATCCAGAGGCGAGATCACCTCGAGCCCCAGCGCCTGCG TCCGCGCAATCGCCAGATCGCCCAACCGCTGCGCCTTCTGCGCCGCCATGCGCATGTCGACGCCGTCGAACGCACTCAGCGCTCCCTC CAGCGCCGCCAGCGACAGGATCCCCGGCGTGCCCGACGCGAACCGCGCCACGCCCAGCCTCGGCGTGTACCCGCCGTCGAACGCGAAG GGCCGGGCATGCCCCATCCAGCCCGAGATCGGCGAGTCCAGTCTCACTGCCAGGTCGCCACGCACATATACGTACGCCGGCGCGCCCG GCCCGCCATTGAGAAACTTGTACGTGCACCCTGCCGCCATCCACGCGCCCGACGCCGTCAGGTCGAGATCGATCGCGCCTGCCGCATG AGACAGATCCCACACCACCACGCCGCCGCCCGCCTTGGCCGCTTCCTCGTGCGCCGCGATGTCCGCAATCCGCGCGGTCCGGTAGTTG ACGACGCTCTTG

\subsection{Das Cosmid slc_1u}

\subsubsection{Lage der offenen Leserahmen (ORFs)}

\begin{tabular}{|c|c|c|c|c|}
\hline ORF & Annotation & Start & Stopp & $\begin{array}{l}\text { Orien- } \\
\text { tierung }\end{array}$ \\
\hline 901 & $\begin{array}{l}\text { Potentielles Typ I Restriktions-modifikationssystem, Restrik-tionsuntereinheit } \mathrm{R} \text { und ver- } \\
\text { wandte Helikasen (EC 3.1.21.3) }\end{array}$ & 1 & 3022 & - \\
\hline 902 & Konserviertes hypothetisches Protein & 3019 & 3543 & - \\
\hline 903 & Konserviertes hypothetisches Protein & 3540 & 4691 & - \\
\hline 904 & Konserviertes Protein & 4846 & 6279 & - \\
\hline 905 & Konserviertes hypothetisches Protein & 6272 & 7972 & - \\
\hline 906 & Potentielles Typ I Restriktions-modifikationssystem, Spezifitätsuntereinheit & 7969 & 9243 & - \\
\hline 907 & Konserviertes Protein & 9240 & 10412 & - \\
\hline 908 & Potentielle Serin-Protease DO-like & 10565 & 11782 & + \\
\hline 909 & Hypothetisches Protein & 11733 & 13895 & - \\
\hline 910 & Hypothetisches Protein & 13894 & 14868 & + \\
\hline 911 & Konserviertes Protein (Hypothetische Peptidase) & 14871 & 16136 & + \\
\hline 912 & Hypothetisches Lantibiotin modifizierendes Enzym & 16133 & 17365 & + \\
\hline 913 & Hypothetisches Protein & 17362 & 20235 & + \\
\hline 914 & Hypothetisches Protein & 20307 & 20999 & + \\
\hline 915 & Hypothetisches Prolipoprotein-Diacyglyceryl-Transferase (LGT) & 21092 & 21691 & + \\
\hline 916 & Hypothetisches Protein & 21835 & 22719 & + \\
\hline 917 & Konserviertes Protein (Vorausgesagte Glyceryl-Transferase) & 22689 & 23741 & + \\
\hline 918 & Konserviertes Protein (hypothetisches "death-on-curing” Protein) & 23725 & 24126 & - \\
\hline 919 & Hypothetisches Protein & 24439 & 25821 & - \\
\hline 920 & Hypothetical Membrane Spanning Protein & 25919 & 26797 & - \\
\hline 921 & Hypothetisches Protein & 26880 & 27230 & - \\
\hline 922 & Hypothetisches Protein & 27249 & 28307 & - \\
\hline 923 & Hypothetisches Protein & 28304 & 29365 & - \\
\hline 924 & Hypothetisches Protein & 29335 & 30225 & - \\
\hline 925 & 3-Isopropylmalat-Dehydrogenase (EC 1.1.1.85) & 30345 & 31445 & + \\
\hline 926 & Aldehyd-Dehydrogenase (thermostabil) (EC 1.2.1.3) & 31574 & 33295 & + \\
\hline
\end{tabular}




\subsubsection{Die Sequenz des Cosmides slc_1u}

TCGCCTCGCTGGCGCGCAGTCTCCGATACGCCTCGCCGGCCATCCAGGAGGTCACTACCTTCTGGAACGGCGCGTCGTTCATGAACCG AACGAAGATCTCCTCGTTCTGATCCATGCGCTCCACGAACAGGCTTTCGAGCAGGTTCTTGAAGACCAGCTCGAACTTGTCGTCCGGA TTGACCGCCGCGGCCTGCTGGAGGCCCGCGTCGGCCATTGCTGCCTCCACGATCTGATCGAAGAAGAACTGGTCCGCCTGGTTGAAGT CGGTTCCGAAGCGCTCGTTGACGATGTCGATGAGCTGCGACAGCGGGACCGGGCGCTCCCGCACGAGCGCGCTCCCCACCTCGGTTGG GCCATCGAGCTTCTGAGCATCGCCCTCGTGCAGCGAGATCGAACCCTCGCTGATCTTCTGAAGACGGTAGTACTCGAGCCGGATCTCG TCGTCGAACTGGTACGCGGGTCCGCCCTTGCGCCGGGGAAGCTTCGCGCTGAGGTGTCGCAGGAAGACATAGAGCCGCTCGAGGTCCG AGTCCTGGTAGGGGATGACCTGGCTCAGGAAGCCGTAGAGATTGAGGAAGGCCTGAGCCTTCCCGCGCCAGAGCTCGGTCTCTTCCTC GTTCTCCTGCTGGCGGGCAGTGAAGCGGGAAACGGCCGGGTCGAGCGCGGCGTTCAACGCCTGGTGATCGCTCGGGCTCTGTTTCGCC TTGGGCTTGAAGTAGACGGCGCAGAAGCGCTCGAGTTCCTCGGCCACGTAGACGCCGCTCGCATCGAGCTCGCCGCGGATCTGGTACA TCCGTGCGGGATCCACCTGCTCGCCCATCTCGGCGCCTTCGAAGTACGTCTTGAACGCCTCGCGGATCTCGTCCCGGTCGTTGACGAA ATCGAGGACGAAGGTGTCCTCCTTGAGCGGGTGGATCCGGTTCAGGCGAGAGAGCGTCTGCACGGCCTGGATCCCTGCCAGCCGGCGA TCGACGTACATCGTGTGGAGGAGTGGCTGGTCGAACCCGGTCTGGTACTTCTCGGCCACGAGCAGGACCTGGTATTCCTGGGACGAGA ACTTCTCCGGCAGCTCTCTCTCCCGGACTCCCGGGTTCATCCCCTCCTCGGTGTAGGTCACGCCGTCGACCTTGTCGTCCTGAACGGT TCCGGAGAAGGCCACGAGCGTTCGGATCGGGTACCCCTTCTCCTGGATGTAGCGGTCGAAGCTCTGCTTGTAGCGCACCGCCTCGAGC CGTGAGCTCGTGACCACCATCGCCTTCGCGCGCCCGCCGATCTTGTGCCGGGTGAAGGCGTTGAAGTGCTCCACCATCACCTCGGTCT TCTGGGCGATGTTGTGCGGGTGGAGCTTGAGAAACCGGGCCAGCGCGCGCGCCGCCTTCTTGCGCTCGACGTTGGGATCGTCCTCGCA AGCCTTAAGGAGGCGGTAGTAAGTGGCGTAACTCGTGTAATGGGCGAGAACATCGAGGATGAACTCTTCCTCGATCGCCTGGCGCATG GTGTAGCGATGAGTCGGCTCGCCGTTCCGGCCGAAGACAGCCAGGGTCTTGTGCTTCGGCGTAGCCGTGAAGGCGAAAAAGCTCAGGT TCGCTTGCCGCCCCCGCTTGGCCATGCTCCGGAACATCTCGTCGAGGTCGTCGAGCCCCTCCTCGGTGGCCCGCTTCTTGGCCTCTTC GCGAAGGCCCTGGCCGCCGAGCACGGCCTTTAGCTCAGTGGCCGCCTCGCCCCCCTGGGAGCTGTGCGCTTCGTCGACGATGACCGCG AAACTCCGGCGCGGGAGGTCGGGCACCCCCTCGTCTCCTCGCTCCTGGGCCATCTCGAGGAGGTGATCGGAGACGAAAGGGAACTTCT GCAAGGTGGTGATAATGATCGGGACGCCGCTGTCGAGCGCCGCCGCAAGCTGCTTCGAGTGCTCGTCGATCTTCTCGACCACGCCCCG CTTGTGCTCGAACTGGTAAATCGTGTCCTGGAGCTGCTGATCGAGCACGACGCGGTCGGTCACGACCACGACGCTGTCGAAGACTCTC CGGTTCGATGCGTCGTGAAGTGACGCCAGGCGGTGCGCGAGCCAACCGATGGTGTTGCTCTTCCCGCTGCCGGCCGAGTGCTCCACAA GGTAGTTGTGGCCTGGCCCCTCGCTGCGCGCGGCCGCGGTGAGCTTCCGCACCGCCTCGAGCTGGTGGTAGCGCGGGAAGATCATCGA CTCGGTTCGGACCTTGCGGCCCTGGTCGTCCCGCCTCTCGTCGACCTGGAGATGGATGAAGCGGGCGAGGAGATCGAGAACGCTGTGT CGCTCGAGGATCTCTTCCCACAGGTAGGCCGTCCGGTAGGTCCGCCCGGATGGGTCGGTCGGGTTGCCGGCCCCACCGTCGCAGCCGC GGTTGAACGGCAGGAAGTGCGTTGCGGTGCCTCCAAGTCGGGTGGTCATCAGCACCGACTCGGTGTCGACCGCGAAGTGCACGAGCGT GCGGCGCTTGAACTCGAAGATCGGCTCGTGGGCGTCCCGGTCGCTCTTGTACTGCGCTCGGGCGTTCTCGACGGTCTGTCCGGTGAGC GGATTCTTGAGCTCGAGCGTGGCGAACGGGATGCCGTTGAGGCTCAAGGTGACGTCGAGGGAATTCTCGGAGCGCGCGGAGTACCGGA GCTGCCGCGTGAGGCCGAGCCGGTTCGCGGCGTAGCGCGCCTCGAGCTCGGGGTTTAGCTCGTGCGCCGCTCGGAAGTAGGCGACTTG AAGCGTCCGCCCGTAGCACTTGAAGCCGTGCCGGAGGGTGGCCAGCGCGCCGTTCGCGTCCATCCACTTGCAGAGGTCGCCGAGAACT TGATCCCCGGTCTGCTCGCCGTGCAGCGATTCGAGTCGCGCCCACTCCTTGGGCTGGGTCGCTTGGATGAACGCCAAGACCTCGCCCG GGAAGATCGCGCGCGCCTTGTCGAACGCTTCCGGCTTGACGGAGACGTACCCATGCCCCAGGAGGTGCGCTTCGATGACCGTCTCGAA GGCTGCCTCCGAGTGCCTGCTGGCCTTCAAGGTGCACCCACGAGATCGAGCTGGACCTTCAGCTCCCTTAGCATGAAGAATGTGTCCT TGGGGAGCACGTTGAACTGCTTGCAGACGTCGGGCAGCAGCACGCGGTTTCGCGAATCCGGACGGGGCTGCTCGTTGGTCACGACCAC CGTGCCGTGGACCATCGAGTACGCGACCAGCCAGCCATCCGCCTCGGTCGCGAACTTCGCCTTGGCGCGGTCGAAATACTGGGGGTTC CGCTGAACCCAGAGCATCACTTCGGCATACGCCGAGCTCACATCTTCGGCGTTCGAATCGAGGAAGAAAGCCGCTGGGACGTCGTTCT TTACCCACTGCACGAGGTCTTCCTCTTTCCTCCCGGTAAGCAGCTCGTTTCGGATGCGATCGAGGCTGCGAGCCCTGCCCAAGTGGTG CGCCTGGAGAACGGCTTTCCAGAAACCCGGACAGATCTCGAAGGCGTAGTAGGCATTCTTGGCGGCGATGAAGACGTCCGAATCCAGC AGGAACAAGGGAGCCTTGCTCATGGCAGGTCGACCCCCAGCCGGCGCGCGTACTCCTGGAACGCGCCGCCGCGCAGGCCTGTTAGGTC GTAGGCCTCTCTGAAGCTCAGGCGGCCCTCCAGGGCAGCGTAGATGACGCTCGTCGCGAACTTCGCGCCGACGCGCGTATTCTGGTTG TTGTAGAAATCGCCGCCAGAAGCGCGCTTTGCCTGCAGGCGCTCTCTCCGCGTGTAGGTCTCGTAGAACTCGAAGAACGTCTTCCGCC CGACGAGCCCAAGATCCATGGCTCGCCGGCCGGCCACGATGGGGCTGACCTTGAAGTGCCTGGCAATCTGCTCGAAGGCATCCGCAGC GCCCTTCACTGCGCGCCAGAGCTCCTTGAGCTCGCTCGCCGGCACGAGGAACTCGGCCGCCGCCTGATCGCAAAACGTCTCGACCCTG GTGTTGCCGGGAAAGATGCCGTCGAATCCCGAGAGGCCCTCGCCTTCGGAGCCGAGCCATACGTGGGCGAGCTCGTGAGCCAATGTGA ACATCTGAGCCGATTTCGCGTCGGCACCATTGACGAAGACGACCGGGGCGTACGGGTCGGTCAGCGCGAAGCCGCGGAACTCGTCCAC GTCGAGCTTGCGATGGGTGTTGTTCCCGACGACGCCGTTGATGATCGCCAATACGCCGAGTTGCTCGATGCGACGGCGCAGCTCGTTC ACCGCCTCCTGCCAAGTCGAGACAGCCGAGGCCCACCCGTCGACGAGCGCGAGCATTCGTCGGATCTCCCGCCCGACCGCCGCGGGTT CGTCGCTGAGCCGTGCGCTGCCCACGAACTCCAGAGGCCCCGCCTCGCTTTCGAGGCGCTCCTCCCGCAGCCAGTCCTGGCGCCGTTG CATGGCGTAGATGGTGTCGAGGAGATCGGCGCTCGGCCGCTCGGGACCGCGGACGACCGTCCTGAGGTCGCGAATCGGCAGTCGCTCG ACGGGTGGCTCGGGAAGGAGCAGGAATCCCAGCGGCGTGCGCGTCGCCTTGGAGAAGGTCTCCAGTTGCTTCAGAGTCGGGCGCAGCT CCTGCCGCTCCCACGCGTCGAGCTGCGGAAAGCGCGCCGACAGGTCGAGCACGTCGACGCGCGACCGCTCGACCGCCCACCGCAGCAG CTCCGGCTTGACCTCGACGCGCAACATGGAGATGCCCCGCCCCCTCTCGGATGGACCGAAGGAAGTCTAGTCCTGCGTTGCCGCCGCC TCCAACTCGCCGGTCACCGGCAAGCGAGGTTCATCCGCTCGGCGTCGGCCCCGCCACCGGAGCAGATCTAATCATCTAGGAAACGTTG AGTAGTCAGGACCCCTTGGGGATGAGCCTGCGGGATCTCGACACGATGGTCAGCGACTTCGAGGCGCGCGTGAGCGCAACGTAGAGCT CTTGCACGGAGAGGTGGTGCGGCTCCCAGAGAAGCACTGTGTGATCGAACTCGAGGCCCTTCACGAGCAACGGTGTGCCGATAGTGCG CAATTGGAGGTTCCGGCCACGATGGCGCGCGCGTGTTCGCGCTGCAGCCACCAGTTCTGGCAGCTCGGAGAATGTGTCGCCGCTACAG TGACGGAGCGCCTCGCGAAGCTGGAATGCGCATTCGGGTCGATAGAGCCACCAGTCACCTCGGCGGGCGAGGACCGTTTCGAGCCACG CGAGCGCGTTCGCCGGCGTTGAAGCGTTCGCGAGCGCGTTGAGCTGGTCGGCCTGCTCACGGTTCTTGGTGATTCGCGAGGTGCCGCG GCCAGCCGTGATGGCTTCGACAGCAGTCCTCAGCGCCGGACCTATGCCCGTCATCCGCTCGGATACGAACTCCACCAGCTGGGCGACG ACTGTCGGGCCATCAGCGGCGACAAGCCTCGCGCCAAGATTCAGCAGATCCGGGTCATCGAACCTCTCGACGACAGGCCAGCGCCCAC CCATGCGCTTCGCCAACTCCTTGCACTCATTGGGCCACTTGAGGATTGCGACGACCGTCTCTTTCGCGGAGGCGACTACCTTCCGGCA TGTGGAAGCCCACGCCTGTGGCGCTTCAATGTCGGTAGGGTGCTGTACCCATGTGACCGGTGCATCATCGGCGATCGCGAGGCTTCCA GTTGCCTTGAGCTGAGTTCGAGCCGCAGCGAGCCATTCTCCAAGCCGTCCATTGCATCCCTCACGACGCCAGCGCCACGGCTCGGTAA GTACGTCGTCGATCACTTCGAAATCAGCAGTGATGGTGCCCCATGGCACGACTGGATCGTCGCGAAAGCCGAAAACGGTCTGGAGTGG ATCTCCAACGCCTCGGCACGGGACGCACTCCGCGAGCGCTCGTATGAGTGCGTGCTGGTTCAGGGAACAGTCCTGATACTCGTCGACA AGCACGCCGTCATAGCTCTCGCGCACGACGCGCCTTCCAAGGGCCGTACGGCAGACTTTCTCGGCTCCAGGGTACGCCGCCACCCAAT CCGGATCGGCCTCGGCGCCCGGTCGGAAGCCGGAGATTGCAGGGTATGCAGCGCCATATCGAAGGCACCACCCCGCGATGGTGCCGAG 
GTGGAACTTGTCGCTAGACACGCCCTTGTCAACGAGGCGCTTCTTTATGGCCGCCACACCGGCGTGCGTGTGGGTCAAGACGAGCTGA CGACCCAAGCGCTGATCGGCTACGAGTTGTCCAAGCAGCTCCGTCTTCCCGCAGCCAGCGGCGGCGACGGCGAAGGCTCGTGGCGAGC CGAGCATCGCCTCGACCGCCGCGTTAGCCATGCGCGAAACTTCTGAGCGTTCCGATCACGTCGTGAGTCGGCGTGCCAGAAATTGCGC TCCAGTGATCCGCGACAAGGGAGCCCAGGAGCTCACCCTGCTCACGGGTCTTGAACCATGAGTGGTTCCTCGTCTTCGCGAGGTCACC GAATGCTTTGCGGAACGCAGCAACGCCATTTGCCGTGAGCCACGACGCCGGATCTCCCTCTATCAACGCTGACCGGGCCGCTCCGAGC TGGTCGGCGAGCGCTTCGCGAACGCCTCGTCCGCCGCGTTCATCAGCCCGAGCGGCCATCTGGGTAATGGCGGCTTCGGGCAGATCAT TCGCAAGGCACTGCTCGGTGCACAGCCCTTGGGGCCATGCCAGGACCGTCGCACCCACAGCCTTGCTCACCTTCGCTTTCGCATCGGC GTCGATCAGCAGAGCCACCTCGTAGCCGAGTGTCGCGAGGTGCCCGGAGATTTCGGCGGGCTGTGTGCCACCCCTGCCGTCGACCACA ACCACCCCTCGGTATCCGAAGCTCCCCCCGGTTTCGGCTGTCCAGGCTTCATCGAGCGCCTGGCAGAGGCCCATCTCGGTCGCTCCCT CAGCGACAATAACCTTGCGGGCTAGGAGCGCTTGGGGCGTCCTCTTGAGGATGTACTCGACGGCCCCTGGAAGGCTGCGAACCGTCAC AGTCCCATCGGCGGCTCGCCTCGTCACGGCAACCTCAGCGGCCTCCAATTCCTGAAGGACCGCCGGCGAGTGAGTGGTGAGAATGAGC TGCCCATTCGCGAGTCCGTCGCCCTCGGGACGGCGCCCGCGAAGGACGCGCAAGAGGCGCCGAATGCGATGCGGTTCGAGTCCCTGCT CGAATTCATCAATGATGGTGAGCCCGGATTGCGCTGCGGCCTCACGCTGCATGGCGATTGCAAGGAGGCGTCGCGTGCCGAGGCCCGC ACGCCGAGTCGGGACCTTCCCATCATGCAGCGAGAGCGCTCCGGCAGTCACCGAGAGCGACGCTGCGTCGAGGTGAGGCACGAGCGCG TTCGTGAGCGCGACGCCGAGACTCTTGGCTAAGGCTTCGACTTTTTGCGCGGCCGCCGCGAGTTTCTCGAGGCCATCGGTCTTGAGGC CCGATCGCGCCTGGCGTGTCGCCTCGGCGAGAACCGCCCCTACAGAATCACCGCTGTCAGTGAGGCGCGTAAGTACGGAGCCCCGGCT CCATCCGAGGTGTTGGTCTACGTAACCCCCCACGCGGAGCATTCCGAGAGCTTCGCGGTCGCGTGCCATGAAGGGGCTCCTCCCGCCC TCGGAGTCGAGGACGCTCCACACGGGCTCGAGACTCGCGTCGACGCAGAGCTCGACGACGAGCGCGTTCTCCTCTTGCTCCTCACCGG ATGCTCGGACAGCTTCGCCCTTGTCCTTGTCGAAGCCGTGGAGGAGTAGACCGAACTTCGAGTCCCGGTAGAAGCTCGGCGCGAGGCC GGTGATGGTTGCACGGATGACAATTGCCTCGCCGGTGTGAAGGTCCCAGAAGTCGGTGTCGTCGAAGGGGACATTCCACTTCGGCGAG AGCACGCGCTCGATGGCGTCAAGGATCGTCGACTTCCCCGAGTCCCCTGGACCAACGAGCGCGGCGGTCTCGGCGATGTGCCGCCAGT CCAGGGACTTCACTCCTCTGAAGTTCTCGATCTCGAGCCGACGCAGCTTCACGCACCCAACTCCTTCAGCGCGCTACGCAGCTGAATC ACGGTGTTTGGGGCGCCAACAATCTCTCCTGACCTCGATAGGCTGATATCGAGCTGTCCTGTGACCGTCACGGCGATGAGGGCGTGGC GGCGCTCCTTGAGCAACGCGACGGTTCGCTCGGTCGCGGCGCGCACGGCGTCGAGCTTCGCGGTCTCGCGCGCAATGTGCTCGACAAT CCTCTTCTGCTCAGCAACTTGTGGAAGGAACACGGGGACGTTCAAGAGCCTCTCGGGCTCGATTCGCCACTGATTGATGCGAATGCCA TTGGAGCTAGACATGTACACGGTCGTAAGTTGGGGTGTCCTGAGCATGAAGTGCAAAAACTTGGGGAGCTCTGCATGGGTCGGCCGAA ACACGACGTAGTCGGGACTCGTGATGCCACGAAGGTCAGAAATCCCGAGCGATCCCTGCCAAGCCTTCATCTTGTTGACGACAAGATC GCCAGCCTCGACGAGTTGGTACTTAGTAAGGTTGTCAGGCAGCACGTTCGCATTGTCATCGCGCGAAGACCGTTCGATTACGCCGTAC TCGCGATAGACGGAAAGTACCGTCAAGTCTGGAAATCCGAGAATCTTCGACTGACGAAAGAGCCTGCCAACGCGACTTTGGCGCCAAT GCGCTGGCGCCTCCGGAATCCACTCCACGCCGGTGGGGGCCATTCGTGTCTCGGGGTCGAGTCCGCACGTGACGGCCGTGGCGATCAT CGTTCTGCGCTTTTCTGAGAGCAGGTCGAGAAGCCGCTGCTTTGCTATGACGAGCGCATCGAGCCGCGCTGTCTCGCGGGTGAGGTAG CCGGCGATAGCACGTTGCTCGTGGACTGGCGGGACAGGGATCTCCAGGTTCGCGATGACATCGACTGCGATTCCGGGTTGGGCAGCTG ACTGGGAGTGCTGGTTGAGGTTCATCGCTCGAAGGAGCTCACCAAGCCAGGTAATGTCCACCTCGCTCTTGGCCTCGACCACTACGGC GTGTTCCGAGGCCCAGAAACATCCCGAGGCGTAGTTGATGTTGCCGCACAGGGCGCCTTGGCGGCCGACGAGCGCGTAGTTCCCGCAA TGGGTGTAAGCCGATGTGTAGCCGCGGACTCCGTTTCCTCCAAACACGGGATACTCCCCATCTTCAGCAATTGAGTCAGACGTAATGG AGTCTCCGCTCCTCAGCGACGCCACATACTTGAGCCGCTTCCTGGCCCAGTGTGCCGGGATCTGGTCCAGCCAGGTGGACGGCTCCCT CACGAGACAACCTCGCGAAGTAGCCGCATGACTACTTCTTCCGCGTTCTTCAGCTCCTCGTCGATCGCCTCGAGCGGGCGCGGCGGCG TAAACCTGTAGAAATGACGGTTGAAGCTGATCTCATAGCCGACCTTGTCCTTCGTCCGGTCCATCCAGGCGTCGGGAACGTGGGGTCG CACCTCACGTTCGACAAACGCCTCGACATCCTCTTCCAGCGGTACGTTCTCGAAGTCGCGAAGGTCTGGGTCCGGTTCGAGGTCGCCA CCCGCCCTTGGAACTGGGTGCGCATCCGGCGACACCTCGGTGAAGGTGCTTCTGAACGCCTTCATAGCCGGTGCCTTCCACGGGGTCT TCCGCTTGTGAAGGATCTCGTCGACTCGCTGCGAAACGGCGTTCCAGTCGAAGTGTGGCTCGCGGCCAAGGCTCGTCGTGATGGCTTC GAGATCTGTAAGCAGAGCAGGGTACTGGGCCACGAATAGAGCGGTGCGTTCCTCGGTGATCGTCGCCTCGGGCGGCGACGAGCCGTCG GGCAGGAGGACGTCGAACGTGACCTCGACGACCGGCTCGGCGGTGAAGTCGACCGTCGCGCCCGGCTTCACCTCCCAAACGTTGGAAC CGCGCGCCGGCGCGACCCGGAAGCCTGCGCGGTAGCCGGCGAGGCTGTACGACCCGTCAGCGAGTCCCGACGCCGTGTACCGCCCGTC GGCGTCCGTCACCGCGTCCACTTGGCTCATCTGCTGCCGCTGGAGGCTCGTGACGAGCTTTCGCACCTCCTCCTCGATGTCGGGCGGC GGCGGCGCGCCCTCGGCCCGCTCGCGCCAGCTGGACGCCTGCCGGTAGATCGCCCGCACGGTCACGCCGCGGACGGGCGTCCCGTCGG GGCGCGTCACGCGGCCGGAGATCGCGCCGGTGCCGCGCTCCACCTGCGGCAGAGGCAGGTCGCGGAGCGCCTTCGCGAGCCAGGTATC GCCCTGCGGTCGCACTTCCGGCGGAGGCTCGTGCGACGGGGCGGCGGGAACGTGCCCGGCGCGGGCGGGCGCGGGGCGCTCCTTCGAC GCGCCGAGCAGGTACCCGACCGCGAGCCCCACGCCCAGCGCGAGCAGGAGGGCGATCCCGCGGCGCATGCCTTCGAGTGTAGCGCCTC CGCGGGCCCCCGCGCCCCCCCCTTTCATGCAACAATGCGCCTCGCATGCCCAGAAGACGCCTTGCTCTCCTTCTGCTCCTCGCGGCCG CGGCGCGTGCCGGCGACGATACCGGGACGCGGCCGGACTTCCGCGCCGTCGTCCGCCACGCGACGGACAAGGTCTTTCCGGCCGTCGT CTACGTGAAGTGCATCCGCGAGTCCCACGAGGAGGGGAAGAAGGAGGCGCAGGAGGTCTCCGGCAGCGGCGTCCTCATCTCGCCCGAG GGCGAGCTCGTGACCAACTGGCACGTCGTCGACAAGGCGGTCGAGGTCCGCTGCCTTCTCCAGGACGGGACGCCGTATCCCGCGGAGG TGCTGGGCTCGGACAAGGACACCGACCTCGCGCTGATCCGGCTGAAGCGTGCGGCCGGCGCGCCGCCGCTCCCGTACGCGGACTTCGG CGACTCCGCGGCGCTCCGCGAGGGCGACTTCGTCATGGCGATGGGGGCGCCGTGGGGGATGGCCCGCTCGGTCACGATCGGGATCATC GCGGCCACGAACCGCTACCTGCCCGACCACAGCGAGTACAGCCTCTGGCTCCAGACGGACGCGTCGATCAGCCCCGGCAACTCGGGCG GCCCGCTCGTGGACACGGACGGGCGGGTGATCGGGATCAACACGCGGGGCGTGATGTACGGCGGCGACATCGGCTTCTCGATCCCCGC GGAGACGATCCGGATCACCGTCGATCTCATCCGGAAGCACGGGAGCGTGAAGTGGAGCTGGACGGGGATCGAGCTCCAGCCGCTGCGC GACTTCGACCGGAACATCTACTTCGACGCGACCGAGGGGGTGATCGTCTCGGGCACGGAGCCGGAAAGCCCCGGCCGCCGCGCGGGGC TCGAGCCGCGCGACCGGATCACGAGGATCGGCGACACGAGCGTCACCGCGACGACCCACGCAGACCTGCCGGCGCTGCGGCGCCGGCT CGGGATGCTCGAGGTGGGGAAGCCGGTGAAGCTCGGCCTCGTGCGCGGCGAGAAGACGCTCGAGGTCGAGCTCACGCCGCTCGAGAAG GGCAAGGTCGAGGGCGACGAGCTCGACTGCCCGCGCTGGGACTTCACGGCGAAGACGATCAACCGCTTCGACAACCCCGACCTCTTCT TCCACCGGGCCGAGGGGCTGTTCGTGTTCGGCGTCCGCGAGCCCGGGAACGCCGGGGACGCAGGTCTTCGGAAGAACGACATCGTGCT CAAGGTGGACGACGCGGACGTGAAGACGCTCGCGGACCTGAAAAAACTCCACGACGAGGCGATCCGGGGCCTCGCGACGAAGCACCGC GTCGTCCTGACCGTGCTCCGGAACGGGCTCATGCGCCGCGTCGTGCTCGATTTCTCACGGGACCACGAGAAGGAGTAGGAACATGCGC CGGATCCTGATCCTCGCCATCGTCGCGCTCGCGGCGGCCGCACGCGCGGAGGAGTCGACGGCCGCCGACATGGCGAAGATCGCGGACG CGATCGAGCCCTCCTCCGTCGTCGTCGAGTACTGGCTCCGCTTCGACCGCGGCGAGGCGCCGCGCGCCCTCTCCTCGCGGGGGGACGA CGAGCAGCTCGTCCGGAACGAGCGGCCTCTCGTGCGCGCGGGCCTCGTCGTGGCCCCGGGACTCGTGATCACGACCGACCCGATGATC CACCCCCGGTTCGTGGACCGCGTGGAAGTCCGTCGCGGCGACCGGACCGTGCACGCCGCCCCCTCCTCGTATCTCCAGCGCGGGACG GCCTCCTGCTCAAGCTCGAGGGCCCCTTGGAGGGCGCCCGCCCGCTCGTGTTCGACGCGAAAGCCGAGCCCGCGTTCCGCGCGCGGAT GCACCTCCGCGACGAGGCGTGGGGCATCTCCGTCTGGCGGTTCTCGACCGTCGTCGCGCGCGAGGACCGGAGGGCCTTCGCGCTCGCG GACACGCCCCTCGACATGGCCGTCGCGACCGGCGGCACGGTCACGGGCATCCAGTTCTTCGACGAGCTTCCGCTCGACGACTCGTGGA AGGGCTCGCCGGTCGACCTCCCCGCGGTGCCCGCGGACCGCATGACGGCCCTGCTCGCGGAGACGGCTGCGCGGGCGGCGAGCGGCCT GCCGCGGGTCTCGCTCTCCTTCCGCAGCGGGAAGGCGAAGGGCGGCGGCAGCCGGTTCTCCTTCTTCGAGCGGGAGCAGGAGGGCGAA AACGCGACCGAGATGCACGCCGTGGGCGTGGTCCTCGACGGGAAGAGGGTGCTCGTCCTCGCCGACCTGAAGCCCAAGGTGACGGCGC GGCTCGAGGGGATCCTCGTCCACATGCCGGAGGGCGAGCCCGTCCCCGCCGACTTCCGCTTCTCGCTGAAGCGCCTCGGCGCGTTCGT CGCCGAGACCCGGTCCCCCCTCCCCGCGCCCCTCCCCCTCCCCGCCGAGGGGATCCGCGCCTCGCGGGGGAAGCCTCTCGTCGCCGCC 
GAAGTCGTCGTCAGCGGCGAGGAGCGCACCTCCTACGTCTACCCGGCGCGGTTCGACTCGATCCGTCGCGGCTGGCGCGACGAGATCG ATCCGGGAGCCGACGGCGACGAGACGAACCTCTTCCTCTTCGACCCCTCGGGGGCGCTTTTCGCGCTGCCGGCGGTCCGGCGCGACCT CGACACGCCGCAGGAACGGTGGAGCTCGCGCGCTTCGGCCTGGCTCCTCGCGGCCGTCAACCTGAAGGAGCACCTCGCGGACACCGAT CCCGCGAACGTCCCGCTGTCCGAGGAGGAGGAGAACCGGCTCGCGTGGATGGGGGTGGTCCTCCAGCCGCTCGACGAGGAGCTGGCGA AGGAGAACAAGGTCTCCGAGCTGACGAAGGGGGGGGACGTGGGGGGGTTCGTGGCCTACGTCTATCCCGGCTCGCCCGCCGCGCGCGC GGGCGTCGAGGCGGGCGACATCCTCCTGCGCATCCACGCCGAGGGCGTGCCGAGGCCGCTCGACGTGAAGGTCGACGAGAACCCGTTC GCCGAGTTCGACCTGCCCGTGGACATCCCGGAGGAGATGCTCGACCAGCTCGGGGACCTGCCGCCGCCGTGGCCGCCGGCGGAGAGCA CGCTCGCCCGGATGCTCACCGACCTCGGCGCCGGCCGGAAGTACGAGGCGGAGTTCTTCCGCGGCGGCAAGCTCGAGAGGAAACCGAT GGTCGTGGAGTGGGGCCCCACGCACTACGACTCGGCGAAGCGGTTCAAGTCGGACGCGCTCGGGCTCACCGTGCGCGACCTCACGTAC GAGGTGCGGCAGCACTACCAGTTGGGCCCCGATGAGAAGGGCGTCGTCGTCTCGAAGGTCGAGAAGGGGAAGAAGGCGGGGGTCGCGG GGGTCCGCGTCTTCGAGATCGTCACGCAGGTGGACGAGAAGCCGGTCGAGTCGGCCGAGGCGTTCGGGAAGGCGGTCGCGGAGGCCGG CGAGCACCGGCTCACGCTCAAGTACAAGGCGAAGACCCGCGTCGTGAAGGTCCTGAGCGAGTCGCGTTAGAAACCGCATGCGGACGGC GGGACTCCTCCTCCTTCTCGCGCTCCTCGCCGGCGCCGGGGAGGAGAACCTGCTCGGGAACGGCGGGTTCGAGGGGGGCGAGGAGGGG TGGATCTTCCACCAGTTCGGGGGCGGCGACGCGCACGAGGTCGACGACAAGGTCAAGTCCGGGGGGAAGAGCGCGCTCCACGTCACCA AGGCGGCGAAGTCGACGGCACCCGCGATGATCTGGACGGACTACAAGCTCGATCCGGGCCAGGAAGGGACGCTCGCCTTCTCGATCCG GGCGAGAGGGAAGAAGCTCGGCAGGACGCGGGTGTTCTTCATCGTCTGGGACGACAAGGGGGAGTCGGCCGCGCAGGAGATCGCCCAC GACGGAGACCTCGGCGCCAAGTGGCAGACGATCGAGAGGAGGATCGAGATCCCCGGTCCGGCGATGGGCGGGCGCATCCTCGTCCACC TCTTCGAGCCGGGCGAGCTCTGGCTCGATGATGCGCAGGTGGTCCTCGAGGGCGGCGACGCGGCCGATACGGTTCCGTCGGTGGCGGA CGGCCCCAAAGCGAAGGTCCGCAAGGATGCCACGGGTGTCCGTAACGGCGACTTCGACAAGTCGAAGGACGGCTGGGAGATGCTGCCC GGTTCGGAGGATCTCAAGGTCTCGCTGGACGGCAAGGAGCTGCGCCTAGAGCGCGGCGGCCACCGGCTCTACCCCGAGACGGGCGTCC AGCAGGTCGTGAAGCCCAGCGGCAGGAAGAAGCAGGTGACGCTCAGGTGCCGCGCCCGCGCCGAGGGGTCCGCGCGAGCCTGCGTCGC CCTCCTCGCGGAGACGGCGGATGGCGCGCTCGTCGCCTTTGCCCGTGCCGACGCGCAGGGCGAGGTCGCGCTCCCGCTCGCGCTCGGG CCCTCCGTGAAGCAGCTCCGGATCATCCTCGCGATCCGCGGCCCGGGCGACGCCTGGTTCGACGACGTGCGGCTCGAGGGGTGACGAT GCGTCTCGTCGTCTTGCTCGCGCTCGCAGGCCTCTGCGCGGCGGCGCCGGACGAGAAGCGGATCCGGACCGCGCTCTACGACCTGCTC GCGCAGCCGAAGGAGGCGGAGCGGAAGAGGATCATCGCCTCGCTCGCGGACGCAGGGCCGCTGGAGGAGGTCGAGCAGGTGATCCGGA AGGGCCCGCTCTACCCGCGCGACGCCGCGGAAGGGAAGGGCCTCGTGAAGATCGGGGGGGCCGTGGGGGGGTACGGCTTCGAGTACGA CGGTCGCACGTACGGCTACGCAGTCCACGTCCCGAGCGGCTACGACCCGGACAAGGGGAGCGCGCTCCTGCTCGATCCGGGCCACGGC TCGTGGGCGAAGGATCCGATCGAGAAGAAGCTCGAGGGGTTCGGGTTCTTCCGCGGCGAGGCGGACGAGGCGGGCGGCCGCGACTGGC TGATCGTGCGCACGGAGATCGTCGAGCAGATCGGGTCCGACGCGCGAGGCCTCCCGGAGGAGGAAGGGAACCGCATCTTCCAGGAGAT GTTCAAGGACCTCGCGACGCGCTACCACTTCGACCCGGACCGGATCTACGTGTCCGGCCTCTCCCAGACGGGGTTCTGGGCGTGGGAG CTGGGCTGCACCCGCGCCGACCGGTACGCGGGCATCGTGCCGATGAGCGCCGTGACCTGGGAGACGAACGGGCTCCACGCGAACCTCC TCGCGCTCCCGGTCCACGTGCTCCACGGCGCGAAGGACAAGGTCTGCCCCGTCCGGCAGCCGCGCGAGACGTGCGGCGAGCTGGCGCG GATCGGCGTGGACGTCCGCTACCAGGAGTTCGCGGGCGCCGGCCACGACGGCGTCGTCTGGGGCGCGATGTCAAACGCGCTCGAGGGC ATGAAGGAGCGCCCCCGCGAACGGTACCCGAAGCGCGTGAGCAAGAGCCTCCAGACGACGCAGGACGGCTGGTGCTACTGGATCCGGA TCGACAAACTCGACGACGAGGGCACGGGCAAGGCGGGCGAGAAGCCGAAGGCGGGCATCGACGGGGAGATCGACGGCCAGACGATCCG CCTCTTCTCCGAGGGGGTCGCCCGCGTCACGCTCTGCCTCGCGTCCGAGATGGTCGATCTCGCGAAGCCTGTTTCCGTGATCTGGAAC GGGAAGACGGTCTTCGAGGGGACCGCCGAGCGGAGCCTCGCGACGATGCTCGACCTCGTCTACGGAAAGACCGACTGGAAGGAGACGT TCGAGGCCGCCATGGAACTGAAGGCGCCGTGACGGCCCCCGGACCCCCTCGATTCCGCGCACTGAACCGCGCCGCCGTGCTGCTGTTC GCTCTCGCGGCCGCGGGCGGCGAGGAGGCGAACCCCGTCCAGCCGGCGGCCGCGGAGCTCCTCCGCGACCGCGCGGCCTGCGTGAGAC TCGCCGAGGAGGCGGGCCGCGCGCTCTTGGCCCGCCCGTGCGAGGACGGCTCCGTCTACTCCGGCGACGCGGGCGTCGCGATCCTGTT CGTGGGCCTTTACCGCACGACGCGCAAGCGGGAATGGCTCGACGCGGCGCGCGCGAGGCTCGACGCGCGCCCGGGCGACGACGCGGGG CTCTACACCGGTCGCGCCGGGCTCGGCCAGGTCTGCCTCGACGCCTACCGCGCGAGCGGCGAGGAGGGGTTCCTCGCGAAGGCAAAGG AGTGCGCGAAGGGCCTCGGCGAGCCGCAGGCGACCGACATCATCGGCGGCGCGGCGGGGATCGGCATCTTCCAGCTCAACCTGCACGC CGTCACCCGGGCGAAGGAGGACCTCGACGCCGCGCGCCGCACCGGAGAGTGGCTCGGGAAGCGCGCGATCCGCAAGGACGGCACGGCG AGCTGGCACGTCGGCGCGGACGAGACCTCGCGCGTCTACACCGGGTTCGCGCACGGCGCGGCGGGGATCGGCTGCTTCCTCCTCGAGC TCGGGCGCGCGACCGGCGACAAGTCGTTCGTGGCGCTCGCGGAGGAGGCGGCGCGGTTCGTCGTCCGCCACGCGATGGCCGAGGGCGA GGACGGCTGGCTCTGGTACCGGACCGTGCCGCCGGACATGGAGGAGGAGATCCGGATCCAGTGGTGCCACGGCCCGCCGGGGAACGGC CTCCTCTTCCTCGCGCTCGTCCGCGAGGGGCGCGAGGAGTTTCGCCCGGCGCTCGAGCGGTGCCTCGCGACGACCCGGCGGCGCGGGC GGACGGCGCGCGCGGGCGGCTGCCAGTGCCACGGCGGCGCGGGCAACGCGGAGCTTCTCCTCGAGGCGTACCGTCTCACGAAGGACGA GGCGCTCCTCGACGAGGCGCGCCGCTCCGGAAGCGCGCTGCTCGTGACCAGCGGCGACGGGTTCGCCGTCGAGACAGGTTACGATCCC TCGTACATGCTCGGCCTCGCCGGGATCGGCCACTTCTTCCTGCGGCTCTCGGACCCCGCAGGAACGCCCCTGCCGCTGATGGTGGTGG ATGGGCCCCGGGAAGGAGGAGGGAAATGAGGCGTCTTCTCCTGCTCGCGCTGCTCGTCCCCGCGTCGGCCGGCGACATTCTCGAGAAC GGCGGCATCGGCAAGGGCGACGGCTGGAACCACACGCCGGGGGCGCCGTCGGTGACGTTCGAGCTCGACCGGAAGGAGGGCGCGAAGA AGGACGGCTGCCTCTCCATCGCGAACACGGACGCGGAGGACGACGCGGCGCACAACTGGTACGCGCGGTTCGACGTGCCGCGGGGCGC GCCGTACCGGCTGAAGCTCACCGTGCAGGCGAAGACGGAAGGCCTCGCCGAGGGCGCGGAAGCGAACGTCATGGTGCAGATCTACCCC GCGAAGGGGAACGCGGTCGGCTACGCGTGGTGCGGCGCCGTCACGAAGGACCACGACTGGCAGGAGATCAAGGCGGTCTTCGAGGTGC CGAAGGAGGCCGCGTACGTCCGGATCCTTGCCTACTTCGTGGGCAAGGGGCACGTCCTCTACGACGACTTCTCCGTCACGAGGACGGA GGAGCCGGTCACTCCGCCGCCGCCGTCGAAGCCGCGGCGGGTGAAGGACGACCCGATGTGGAAGCTCGTCCGCTCGGCGGCGGAGGAG ATCCCTTGGATGTTCGACGCGGCCGCGGCGCGCGCGTTGGCGGCGAAGGAGGAGCGCCCGCTCCTGCTCTACGTGCGCTGCGTGGACA ACTCGGACGTGTTCGCGGCCGCGCGGACGACGCTCCGGGCCGAGGGGATCGCCTCCTACGACGACGGCCTGAAGAAGGACATTCTCTT CCGCGCGGGGCCGCTCTCCGACCCGGATGTCTCCGAGCTGATCCGGCGCCGCTTCGTCCCGCTGCTCCTCACCTACCACCTCGGCGTG CACGGCGTCGCAGGGGGGGCGCTGTCGCCCTGGTACGGCGACGGCGGGGGTGAGGGGTCGACGGTGGAGATCGACGCCGCCGAGGGCG CGCACGAGAAGGGCTCGCTCTTCATCCGCAATACCGCCAACGGACCGCTCCACCAGTGGTCGCAGTCGGTCGAGGCGCCGGCGGAACG GCCGTGCAAGGTGCGCATGGAGGCCGCCTTCCGCGCGAAGGGGTTCGCGGAGGGTTCGGAGGCGTGCGTGATGGTCCAGTGCCGTGCG GCGGACGGCACGGTGCCCCTCTACGCGCGGATCCGGGAAGTGCGGGAGAACCGCGAGTGGAAACGGGACGATGTCGAGTTCGAGGTGC CCCTCGCCTGCACGCAGATCGTGCTGATTGCCTACCTGAAGGGCGAGGGCGAGGTTTGGTTCGACGACATCCGGATCGAGCGGGTCGC GGGGAAGGACCGCGACAACCTCGTCCGCAGCGGCGGAATCGACCCCCTGGAGGGCGTGGACCCGCTCCGGGAGTTCGGCGCCAGCGCG ACGGGGATCGTGACGCCCGCGCTGGTCGTCGTCGACGGCAAATCCACGCGAAAACTCCACCGGATCGGCACGATGTCCGCGGACCTCG TCGACACCTGGCTCCGTGAGGGACTTCCGCCGTCGCACGCGACGGATCCGGAGGACCAACTCGCGGAAGGCGACCTCGACAAGGCGGC GCGGAAAGGAGGCGTGGTCGGCGCCAGGGCGCTCCTCCGCCGCGGCGACCTCGACGAGGCCGCTCGCGCGATCGAGAAGACGAAGTCG CCCGAGGCCGCGCTCGTCCGGGGCACGATCGCGCTCCGCCGCGACGCGTGGGGCGACGCGCTGGCTGCATTCCTCGATGCCGGCGACA CGGAGGAGGCCCGCTTCTGGCAGGCGTGGTGCCTCCACTTCATGGGGAAGCAGGAGGAGGCGGAGAAGGAGTGGAGGGCGCTCGCGGG CCCCACTCGGTTCGGCCGTCGCGCGGCCGCGTGCGTCCTTCCGAACGGCCCGCGCCTCTGGCTCTCGATGACCGAGCGCCTCTGGCCG CGCGGCCGCGCGCTGCCCGAGCAGACGGAGGGATACGGGGACGCGTTCGACGGCGCCGAGAGCGTGCGCGCGCTCCTCGAGCTCCAGA ACGGCGACGGCTCCTTCGGCGGCCACGACGGCGCGCCCGGCCAGGGTTACCACGACGGCGCGATCACGGCGCTCGCGTCGGAGGCGCT CGCCCTCTGGAGCCGGCAGGTGCCCAAGGCGCTCGGCAGTGACGCCGCGCGCGAGCGAGCCCTCGACTGGCTCGAGCAGTGGTCCCGG CGCGAGAACGGGCCGACCGACGCGTTCAACAACCCCTACGTGCTCATGGAGCTTCTCCGCGCGCGAAGGGAGGGGGCTTCGGGGGCCG 
TGATCGCGCGCATCGCGCAGAACCAGCTCGAGGACGGCAACTGGACGGTCTACCAGGCGGCGCGGCCCGCGTCGTTCAACACGGCGCT GAACGTCCTCGCCCTCGCGCGCGCGAAGGAGGCGGGGGTCAAGGTGCCGGCGGACGTCCTCGACCGCGGCGTCAAGGCGCTCGCGGCG ATGCGGCAGAAGGACGACCTCTTCCCCTACTCCACGATGACCGGCCACGAGTGGATGACGACGGAGCACGGCTCGATCGCCCGCGACG CCCTCTGCGAGCACGCGCTCCTCGAGAACGGCAAGGGGGACGCGAAGATGCTCAAGGCGGCGCTGGGGCGGTTCGAGACGTTCGCCCC CGAGCTGCGGCTGCCCACGAAGAAGCTCTACGACTACTTCAACTCGCGCGGTCACGGCGGCTACTACTTCTTCTTCGCCCACCGGAAC GCGTTCGACGCGGCGGCACTCCTCGACGGGAAGACCCGCGACCACGTGCGCGGGCTCGTCCGGAAGGCCGTGCTCGACGCCCGGGAGG GCGACGGCACGTTCATGGACCACCAGATGATCGGCCGCGCCTACGCGACCGCCCAGGCGCTCTCGATCCTCGCCCCGCGGTGACCTCC GGCCCCCGGAGCCCCCCCCGACCTTCCTGTCGGCACGGATCCTCGTCTCGCAGTTGATCCGGGGAGATGATGACCCCGGAGGTCTTCG CCATGTCGTCCAGGAAGTGGATCCTGCCCCTGCTCCTCTCGCTGCCGCTCGCCGCGATCGTCCTCTTCCTCGGCGGCTGCCTGCCCGT CGGGGTCGGCGACCCGGAGACGAGCAAGGTCGACCCGAAGCTCACGGGCGTCTGGGAGGAGCTCAAGGAGGACGGCTCGCCCAAGGGC TCCCTCGTCGTCCTCGTGCCGTTCGACGGCCGCGCCTACCTGCTCCGCACCGTGGAGATCGAGCGGAGCGCGGACGGCGTCAAGGTGA AGCCCGGCGACGGCCACTACAAGGCGTGGCTGACGGCGATCGAGGGGCGCACGTTCGTCACGGCGCAGCCGCTCTACCTCAAGGAGGC GGTGACCGAGGGCGACAAGCTCCCGGGATTCCTGGTCGCCCGCATCGAGCCGTCGGAGGACAGGAAGAAACTCAAGGCCACGGCCGTC GACCCCGACTTCAAGGCCCTCGAGCCGCTGAGGATGCTCCCGGGCCACATGAGCTACGAGCCGCCGGCGGCGGGCGAGAAGGCGCCGT CGGAGGATGAGGCGCGCGCGCTCCTCCGCCGCGTCATCGCCGAGAACGTGGACAGGAAGGAGCTCTACGGCGACTCCGTGACGTACGA GCGCGTAACGGACAAGGCCGTGCTCAAGGCGGTCTTCGAGAGCGTGATCGGGTGACCGCCTACGGCGCGTGCCTCCTCGCGGCGCTCG TCGCCGGCTGGTGGGTCGCGCGCCGGCACAGGGAGATCGATCCCGTCCACGTCGATCGGATGGCGCCGCTGCTCGTGGCCGCAGGTCT TCTAGGCGCGTGGCTGCTCGGATGGATCGGAGGGGGGCTGGGGGGCAGCCGGGCGCTCTTCGGCGCCCTGTTCCTCGCGGTCGGCGCG GGGATCGGCTACTGCGTGGTGCAGCGGCTGGTCCTCGGCCCGGTCGGCGACACCTTCGCGCCGTCGATGGCGCTCGGCGTCGCGATCG GCCGCGTCGGCTGCTTCTTCGCCGGCTGCTGCTACGGCACGCCGACCGACCTGCCGTGGGCTTTCCACGGCCGCCATCCCGCCCAGCT CTACGAGTCCTTGGGCGCGCTGCTCCTCTTCGGCCTCGTACTCGCGGCGCGCAGCCATCGCCGCGTGCCGGGCGAGGCGTTCCTCGCC TTCGGGGTCGGCTACGGCATTTTGCGCTTCGCACTCGAATTCCTGCGCGGCGACAACGCGCCCGTCTCCTTGGGCCTCACGGTCCATC AGTGGATCTCGGCCGCGGCCGTCCTCGCGTGCGTCGTGCTCTTCGCCGCCCGCCGAAGGCTCTACGGCCCGGCGAGTGCGCGGTCGAG GATCATCCGCCGCAGCAGCGAATCGCCCGGCTTCACCGGGTAGCGCATCCGGCGGTCCCGGGTCGCCGGATCCTCGAGCGGCACGTCG CTCTCCTTGCGCAGGAGGTCGGTGAAGTCGGTGCGGCGGACCGAGACGTAGGCGTACATCATCAGGTAGCGCGGCGTCACGCAGTCGC GGCTCCCGTAGTGGAAGCAGCGGCTGCTGTCGAGGAAGAGGACCGTGCCCGCGGGATACGCGAACTCGACGAGCTCCTTCCGGTCCAC GGCGCCGAAGATCCCGTCGTCCGACACGCGGTACGGGTGGCCGCGCCGGTGGTAGCCGAGCGCCGCCCGCGCGCGGTCCGACGCCGAC GCGGGCAGGAACGAGAAGGGCCCCGACTCGCGGGTCACGTCGCGCAGGCAGACGATCACGTACACCATCGGCGAGTCGTGGTAGTCGC AGTGGAAGAGCTGGCTCGCCCGGTACTTCCCGTCCCAGTCGGGGACGAACCGCTGGTCCGACTCCGCGAGCCGGACGCCCAGGGGCTT CGCGGCCGAGAGCGTCGGGACAAACCTCAGGTACCGGATCGCGGGGAGGAGCACCTCCGACGACGTCGCGAAGTCGAGCACCGACGGG TATCGCGCGATGTGCTCGTCCGTGATGATCTGCTGGAAGAACTCGCGGCTGCCGCCGCCGCGGACGACCCCGCCGCGCTCCTCGATGA TCCCCTGCGACTCCGCGAGCAGCCGGTCGAGGTGGGGGAGGGACCGCGACGTGTCGATCGCCCATCCGTCGCGCAGCTCGACGAGCGG ACCTTTCGGCGCGCCGTTCTCGCGGATGAGGTCGTCGAGCCTCCGGAACTGCTCCTCGCGGAAACGCACGCAGCGGCGGTTCTTCACG CCGTTGAACGCGCGCGCGATGCGCATCGTGGCCCGCGAGCCGAGCAGCCGGTTGTGGTCGTCCTCGAGCTTCGAGGCGACCCAGCGCG TCACCCGGTTGTCGAGCATGCGCACCTTCTACCAACGGCCCCCGCGCCCCCTCAAGCTGATACCCTGCGACCGTGCGCGCGGTCCTCT ACTGCCAGCCGTTGACCGGCCTTGGCCACTACGTGCGCACCTTGTCGATCGCCCGCGAGCTCGCGCCGGGGCACGAGGTCCACCTAGT CGCCGGCGGCCGGCCGTTCCCGGGCTCGCGCGACACGCCGGGCGTCCGGTTCATCGACCTGCCGCCGCTTTGGCGCGAGGGCGGTCGG GTGGTCGGCGCGTCGCTCGACGAACGGAAACGCCTGCTCGCCGAAGCGGTCCAGGGGATCGCGCCGGACGTCCTCGTGATCGAGCACT TCCCGTTCAGCAAGTGGGAACTCGCCGACGAGGCGCTGGCCGCGATCGAGGCGGCGAAGGGCGCGAAGATCGTCTGCTCGCACAGGGA CATCGCGCTCAAGAGCGACCCGCGCGCGTGCGCGGCGCTCGGCGAGCACTTCGACGCGCTCCTCGTGCACGGCGATCCGAGCGTGACC CGCCTCGAGGAGCAGCTGCCGTGGGCGGCCGACATCCCGGTGCCGGTTTCGTACACCGGCTATGTGTGTGGGAGGGCTCCGGGAACCC AGGCAGCCGCGCGGCGCATCCTCGTGAGCGCGGGAGGCGGCGTCGAGGCGGAGGCGCTCCTTGCCCCGTGCGTCGAGGCGTGGCGGCT CCTGCGCGAGGACCGGTCGCTCGTGGCGTTCACGGGGCCGTTCCTGCCGGAAGAGTCCTTCGCGCGGCTCCAGGCGCTCGCGGACGTG CGCCGGTTCACGCCCGACCTCGCGGGGTGGATGGCCGCATCCGACCTCTCGATCAGCCGCGGCGGCTATAACACCTGCGCGGACATCC TCCTGTCGCGCGCGCGGGCGCTGGTCGTCCCGTCGCCGCTGATGTCGGACCAGCGCCTCCGCGCCCGTCGGCTCGCGGAGCTGGGCGT GGTCGAGACGCTCGCGCCCGAGGAGCTGTCGCCCGAGTCGCTCGCCGACGCGATCCGCCGCGCGCTCGCCCGCCCGAGACCCACGCAC ACGATCGCGCTCGACGGCGCGCGGCGGACCCGTGCGCTGCTGGAGGAGATCGTCAACGATCGTCCTTGACCGCGTGCTTGACGAAAAA AGCGGTCGTCTCGTCCTTCGTGATCCGGCTTGCCGCCACCCCTAGGGTCAGGTCCTCCAGTTCCTTGTTGCTGGCCCCCAATCGCATG CCGTTGACCAGCAGGAAAACCTCGGCCGAGGCGAGAGCCGTTCGCTTGTTGCCGTCCACGAAAGCGTGGTTCTTGCACAGGTGGAAGA GGTACGCCGCGGCCATGGCAGGGAGCCCGTCGTGGAGGTAGTCTCCTCCGAACCGTGCCGCGGGCATCATCACGGCGGATTCCAGCAG TCCTTGGTCCCGGACGGCAGGATCGCCGCCGAACTCCTCGATCGACCGGCCGTGGATCGCAAGGACGTGCTCGATCGTGAGGAACGCG GGCGACTGGGTCATTCGGCCAGCCTGCGCAGGACCTCGCGACGTTCGGTCATGACGCGCTTCAGCGCATCGTCGAAGCGCTTCTTGTC GATGGGCTGAGGGTTCGTCGGTGTGATGACGATCGCCCCGTCGTGGACTGTGAGCTGGACCTCGCCACCCTCCTCCAATCCGACCAGC TCCAGGATGGCCTTGTCGAGGAAGAGGGCGTTGCCGTTGCCGATCTTCTTGATCTGCTTGATCATGGGCGCGCCTCCATGTGTTTATA CTATGGTATAACGCTTGTCGCGGGCGTCAAGGCGGGGCGAGGCGCTGAAAGGGCGGCATCCGTCAATCAGCCAACCTCTTGAGGGCCT TGCCGAACTTCCGGTTCGCCTCCTTGAGCGCGGCCTCGAATGCCCGTCGGCGCTTCGCGTCGCGGACTGGCGCCACCACGAGACAAGT TCCGTCGGTCGTGATCGACAAGGGGGTGTCCGCGTCGATCTCAAGCAGCTTGAGCACCGCGCGGTCGATGACAAGAGCCAGGCTGTTG CCGTGCCTCGTGAGCCGCTTGATCATGGGTCCTCCTTGCGGTAACCCGACGTTAGAACATCGTATCACCGCATGCGCCGGACGCCGGT CCGCTAGAATGGCCCGCCCGTGACGGAGCACGAGAACGAACTGTTGACGCGCGTGGGTCCCGGCACGCCGATGGGGGAGCTGCTGCGT CGCTACTGGCAGCCGGTCGCGGCGGCGAGCGAGATCGATGCCCGCCCGACGAAGCGGATGCGGATCCTCGGCGAGGATCTCGTCGTCT TCCGCCACGCCAAGGGCTACGGCGTCGTCGCCGAGCACTGCCCGCACCGCGGCGCGTCGCTCGCGTACGGCATCTGCGAGCCGGACGG GATCCGTTGCGCGTACCACGGCTGGAAGTTCGCGCCCGACGGGAAGTGCCTCGAGGTGCCCCCGGAGCCCCCTCTTTCCCCTCTGCTG CGGCGCGTGCGCGCTTTGGCCTATCCCGCGCAGGAGCTCGGCGGCCTTGTCTTCGCGTACCTGGGCCCCGGGCCCGTGCCTCTCCTGC CGCGCTGGGACGTGCTCGCGTGGGACGACGCGCTGCGCGACATCGGGCAGGCCCTTCTCCCCTGCAACTGGCTCCAGATCATGGAGAA CAGCGTCGACCCGCACCACACGGAGTGGCTCCACGGCCACCACCTCTCGCACGTGACGGAGGGCGGGCCGCCGCAGTACCTGCGCCGG CACGAGAAGGTCGGCTTCGACGTGTTCGAGCACGGGATCGTGAAGCGGAGGGTGCTCGAGGGGGGGTCGGAATCGGACGACGACTGGG CCGTCGGCCACCCGCTCCTCTTCCCGAACACGCTGCGGGTGGGCGAGCACGGGAGGTCGCGGCTGCAGATCCGCGTGCCGGTCGACGA CACGCACACGTGGCACCTCTGGGTCTCGTGCTACCGGTTCCCTGGCGTCGCGATGCCCCGGCAGGAGCAGGTCCCGCTCTACGACGTG CCTTGGCGCGACGAGCGCGGTGAGTTCATCGTCGACTTCGTGGACGGCGGCGACATCATGGCGTGGGTCACGCAGGGAGAGATCGCCG ATCGCACCCGGGAGACGCTCGGCGCGTCCGATCAGGGCATCGCGCTCTACCGGCGATTGCTCCTGGAGCAGGTGGAGAGGGTGCGCGC GGGGGAGGAGCCCTTGGGCGTGGTCCGCAAGGAGCACGCGATCCTCGAGCTGCCGCAGGAGAGGAACAAGTTCGGCGGCGGCGCGGAG TTCCTCCTGCGCTCGATCGAGAACGGCCACGGCCGCCACTCGCCGCTCAAGGAGCAGGTGCGGGCGTTGCTGCGCCGCGGCGGCCCGT AGCAGCGTGTAGGCGGACCCGGTCCCACGGCACCCAGGCGAGGCTCAGGAGCGCGAACGCGGTGAACCGCGGCCCGATGAGCAGGGCG AACGCCGCGAGCATGAGAAGGGACGCCGGGACGAGGAGCATGCGGGCGCGTACGCTCACGAGCGCGAGCGGGTAGAGAAGCTCTGTGG CGACGGTGGCCGCGGCGAGCGCGTGGCAGAGGAGCGGGGACCGCGGGAGCCCGAGGCTGAGGGTCCGGGGGGGGAGAAGCCCGTACCT CCGCTCGATCAGGAGCAGCCGCAGGTTGTCGGTCGTGATCCAGTCGAACCCCGAGTGGCGGAGCTTCGCCACGCCCGCCGCGAAGAAC GCCGTCGCCAGGAGGACCTGGATCGCGCGCAGCGGCCAACGGTACTCGCCGCTCGGCGGCGCGGGTGCGGGGCGCCGGGCCGCATCGA 
CGGAGAAGGCGTCGCCGGCCCGGCTCGCGGCCATGACGCCGAGCATGATCGCCACGGGAAGGTCGCTGTGGTGGGCGACGCCGAAGCT GCTGTCGATGCAGAGCAGGTAGGCGCCGAGGACGAAGGCGGCCACCGTCGCGGCGCGGGTGAACAGCCCGATTGCGGACAGGGCGAGC GACGCGAGGAAGATCCACTTCGCCGCGAGCAGCCATCCTTCGGGCGCCACGGGCAGCGGCAGGTCGCGCGGCAGGTAGAAGACGCGGG GGGCGGACCCCCAGGCGGCGAAGTCGCACGGCGCGTAGAGCGCGAGCAGACCCGCGAAGACGAGCGCCCGCGTGATGCCGAGGCCTCT CGGCCCCGAGGGCGCGAACCAGAACCGGTTCCAGGCTCCGGTCATCGCGCCTCCGCCCGGGCCTCGCCCAGGAGTTCGCGCGCGCGCG GGCGGTCGCGGTTTCTGGCGTCGGGGTCGACTTCCCACGTCATCCGGTAGAGGCGAAGGCCTGCGAGCGCCGGGCCTGCATGCCGCCC CGCGCGGCGGCGGGCCTCGTAGCGCGCGAGCAGCTCCGGGAGGGCTTCGCGCAGCCGCGGTTCGTCCATGCGGCCGAGCACGCGCTCG AGCTGGACGACCCGGAAGGGATGGAAGCCGCCGTGCTCGGAGAGAGGGGCCTCGGCGCCGCCGACCGACACTCCGTAGAGCCAGAGTC GCGTGACGTCGGGACCGCTGCGGAGGTCCGAGTACATCGCGTAGGACGAGAACGGCCAGCTCTCCCGGTCGAGGAGGATCGCGGCCGC CTGGCCGGCGAGGACCGCGAGCACGATCGCGTTCGCAAGCAGCCGGCGCCCGCGGGTCATGCCGGCCCCCGGCCATGGGTCGGCAGCC GCCAGCTGCGGTAGGTCAGTTTTCGCACGGGCATCGACAGGAGCCACCAGGCGAGCGATCGCGCCGCGGAGCAGTCGTAGAGCCGAAG CGCGAAGAGGCGGTTCGGGAGCGCGAAACGCGGGGGCCTGAGGAGCCCCGGCCATGTGCCGGCGGTCAAGTGCACGTCCTCCCGTGCC GCGTCGACGGCCCGGGCGACGGCAGGCAGCGCCCCCCGCGCGTCGAGGGCGAGGAGGAGGAGCGCGAAGACGTTGACCGTGATCCGGT ACGTCCCCTCGGCGCGGCGGCGCGCGAGGAACGCGGGCCAATCGAGCGCGGGACACGCGGCGGCGATGCGGTAGAGATCGACCAGCGC CCGGGCCCGGAGCGCGCCACGCTGGAGGTCCCGGAAGATGCCGAGCGCGCAGAGCGCGAGCGCATCCTCGTCGGAGAGCTCGTCCACT CGCACGTCGCCGATCGTGCGCGCTTCCCGCCGCCCCCGGAGCCCCCCGAGATCGAACCGGAACGAAGGGTGCCGGGCGAGAGTCCAGT GCAGGTCCACGGTGGCGCCTTCCCCCACGTAGTCGAACGCATGGGTGAACCTGAGCGCGAGGCGCCGCACGGGCACGACCGACGCGCG GCGGAAGCCCGCGCCCTCGAGGGCCCGTTCGGCCGCGCGGAGGTCCCCCTCCGGGACCAGAAGGTCGAGGTCCCGCGTCGCGCGCCGG TCGAGGCCGCCGTAGAACCGGGCGCCGAGGCCGAGCCCCTTGAGCGAGATGGCCTCGATGCCCGCGGCGCGGAGCGCCGGCACGATGC GTCCGAGCGCGCCGAGCAGCCGCGCGCTGCGCTCCGCCTGCGCGCGGCGCGCCGCGTGGAACGCCTCGAGCGTGTCCTCCGGCACCCG CGCACGGAGCGGCGAGCGCTCGAGGAGCCAGTCGAGGATCTCGCCGACGCTCTCCCGGCGGGCGAAGGCTTTGAGGTCGGGCCCCGGC TCCGCCTCCCTCCCCTGGAGCGCGGCGGCGACGAAGGCGAGGTTCCCGGCCTGCGTCACGGGACCTGCTTCCGGATCGCGTCCCAGAC GGCGGGGCCGTCGTACGCGCGCCGCCCGAGGCCCACCGCGAAGCATGCGAGCCGCGGCGCGAGATCGCCGCAGAGCCGGTCGAGCGCC GCGCCGTCGCGCACCGCCGCGTCGCTCCCGGCGAAGGCCGCCGCCGCGTGCTCCGGGAGCGCAGCGAGGAAGACGCTCCGCCGGAGCC GGGCCGCGGCCTCGGGCACGGGGAGCGCTCGCAGCTCGAAGCGGTCCACGTCGGGAGCGACCGCCGGGAAGACCACGGCGCGGAGCGC TCCCTCGCGGCTCGCGTCCGCCCGGGCCAGCGCGCGGAGCTGCACGGGCGTCAGGTTCGGGCTCGATCCCGTCGCGTGCGCCGCCTCG GCGAGCGTGCGGTGGCGGGCGTACGCGCTCTCCCGGAGCCGCTGCGCGAAGCCGGGGAAGCGCGCGAGCGCCTCCTCCCGCAGGCTGA CGATCGTCGGCATCCCGCGGGCCACGGGCGGATCGCCGCGGACGTCGACGAACAGCCGGTCGTTGGTCAGGTAGCGGACGCCCCCGCC GAGGAGCGCGTGGAGCAGGAGCGTCGTCTTGCCCGAGCCGCGCGGCCCGGCGATCGCGACGACGCCGCGCGGGACCTCGACCGCGGCC GCGTGGAGGTGCAGCTGCCCCTCGCGAAGCGCGTGAGCGGTAAAGAGTTCGCGGGCGACGCGGAGGAGCGCGAGCCGCGAAGCGGGCC CGTCCGCCGGGGCGAGGATCGACACGTCGGCGCCCCGCACGAGGTAGAGGATGCCCTCGCCCGCGTCGCGGATCTCGAGCGCGCCGTC GGGGAGCCGCCGCGCCGGGAGCCTCGCGAAGCTCCCGTCGAGAGTGAAGCACTCGATCTCCCGGGACGGGCCCTCGCCGCCGGGCGGC ATCGGCCCGAAGGCGACCGTCACGCGGTGATGAGGGGGTGCGGAGGGGGACGGGGTCTCGAAGCCCAGGAACTCCGCGAGCCAGAGGA GCGGCCCCGGCTGCGCGCACTCGACCGCGATCACGAGCGGGCCGTAGGCGATGCGGAGCATGGAACCTGGCTGTCGGGATGCGCGGCG CCCTCCTCGTCGAGCTGGGCGAGCAGCCGCCGGAGCGGGACGTCCGCGCCCGCGTAGCCCCGGGACCCGCGCACCCACGTCGCGTGGG CGAGCGCGGCGATCATCCAGAAGCGGCTGTGCTCGACGAACCCGCGCGGGTCGCGGAAGGCGCCGTACGCCGCGAGGAAGATCTCGCG CGCCGGGGCGTCGAGCGGCCACCGGTAGCAGGTGCGCGCGAGATCCTCGTCGGCGGCACCGACCCGCGCCCCCGCGTTGTCGACGGAG AAGAGTCGCCCGGAGGGGTCGACGACGATGTTCTCGGGACAGAGATCGCGATGGATGATCGTCAGGTCGACGGCGCGGGGCGCGTTCG CGCTCGCGAGCTCCTCGAGGCGCCAGGCCGCGGTGTCCGCAAGCGCGCCCATGTCGACGAGCCGCCGCAGCTGGCGCGAGAGGATCTC CCGCCGCGCGCGCAACCAGTGGCGGCGGCTCCGCGCCGGGAGCGTCCCGTGCACGTCGCCGAGGGTCTCCGCCGCCCAGCGGAGATGG CCCCCGTCAACCGCTTCGCTGTCGAGCGTGTCCCCCGGGATCCAGGCCTCGAGCAGCGCGGCGCCATGCCGGCCGATGACGCGCGGGA ACCTCCCCGGGTCCAGCCGCGCGACGATCGCCTCGATCCGGGCGGCGACGCCACGCGAAGGCAGGCGCCGCCCCTTCAGGGTCACGCC GTCGGCGAAGTCGAGCCGGAAGGTGTCCCGGGACCGGCGAGCGGCCCCGTGCCGGGAGATGCTCTGGTAGCCGACGAGTCGCGAGGAA CGCTCATGCACGAGAGTCTCGAGGTCGGAGCCCAGGCGCACGGAAACCCCCACGGCCGGCCGTTTATACCGCGGGCGGCAGGGCGCCG TCCAAGGCGCGCTTGACGGTGCGCCGCTCGCCGCGATACCATGCCGCTTCCGCAGGGGCAAAGAGCCGCATCGTGTCGCGCCTCCTCG ACCGCATCTTCGGGTCTCCGTGCCCTGACCGGGCCCCGTGCGTCCTTGGCGTCCTCGAGGGCGAGGGGATCGGCCCCGAGGTCGTCCG TGTCGCGCTGCAGGCGATCGCGGCCCTCGAAGCGGCCGGCGTCGCAAGCGTCGAGGTCCGGATCGCGCGCCCGGCGTGCCCCGGCTTC GAGGAAGCCGCCGCCTTCTGCGAGGCCACGTTCGCCGCCAAAGGCGCGATCCTCACGGGGCCCTTCGGCGGCCGGTTCGTCTACGACC TCCGCCGGCGCCTCGACCTCTTCTGCAAGTTGACCCCCTTGAAGCCGTCGCCCGCGCTGCGCACGGCGTCGCGGCTCAAGCACGAGTT CCTCGAGGGGGTCGACATCCTCGTCGTCCGCGAGAACGCGGGCGGCATCTACCAGGGACGGTGGGCCGAGAAGGCGACGCCCGGAGGC CGCATCGCGGAGCACGCGTTCTCGTACGGGGAGAAGGACGTCCGCCGGATCCTCGCCGTCGGCGCGACGCTCGCGGCGGCGAGACGCG GGAAGATGGCGGTCGTCGTGAAGGCGGGCGGCATCCCGTCGGTGAGCCGGCTCTGGTGCGACTGCGCGGCGGATGTCCCCCGTGACGC GGGCGTCGAGGTCTCGACCGTCGACGCCGACTACGCGGCCTATCGCCTCGTCCAGCACGCCCGCGACTTCGACGTGATCGTCGCGCCG AACATGCTCGGCGACATCCTCAACGACCTCGGCGCGGTGCTCCTCTCGTCGCGCGGGGTCTCCTTCTCGGGGAACTTCTCGGCGACGG GCGGCGCCGTCTACCAGACGAACCACGGCGGCGCGAAGGACCTCGCGGGGAGCGGGCGCGCCAACCCCGCGGGGCAGCTGCTTGCCCT CGCGCTGCTCCTCCGGGAGAGCTTCGGCCAGGGCGAGGCGGCTTCGCTCCTCGAGGCGGCGCTCGAGGAGACGTGGCTCCGCGGTTTC CGGACGTTCGACGTGGCCGCGCCCGGCACGAGGGTCGTCGGCACCGCGGAGACGGGCGACCGGATCGCCGAGGCCATCGCGCGGTTGG CCGCCGCCCACCCGGCGTTCGCGCGATGAGACCTGCCCTCCTCCTCGTCGACCTCCAGAACGACTTCCTGCGCGCGCCGGGGCTCGAG CCTCCCGCGGGCGAGGTGGTGGCGCGCGCGCGGACGCTGCTCGAGGGCTGCCGCGCCCGCGGCGTCGCCGTGCTCCACGTACGGACGA CCGTCGGGCGCGGCGCGCCGCCGATGCCGCACTGGGATCGTGCCGGCACGAGGTCGTGCATCGAGGGAACCGAGGGCCACGCGCCGCC CGTGACGCTCGCGCCGGCGCCGGGCGAGCCCGTCTTCGACAAGACCTTCTTCAGCGCCTTCGGCGTCCCGGCGGTCGAGGAGGCGCTG CGCGCGCAGCGGATCGACACGGTCGTCGTCGCCGGCGTCCACCTCCACGGCTGCGTCCGGGCGACCGTGCTGGACGCCTACCAGCGCG GGCTCGCCGTGGTGATCGCGGAGGATGCCGTCGGAAGCCACGATCCGGTGCACGCCGCGGCCACGCGCCGCTGGCTTACGGATCGCGC GGCGCGCTTCGTTCCGGTCGAGGGGATCCTCGTGGAGCTTTCCGGGGGGGTCGGGGGGGCCGTGGAGCGGCCCGGCGCCCGGGCGGTC GACGCGGCGCAAGAGGCGTGGCCGGCATGGCGGCGGACATCGCACGCGGAGCGCGCGGCGCTGCTCGAGAGGGTCGCGGGCTTTGTCG AGGCCGAGGCGACGTCGCTCGCGGCGCAGATGGCCCGGGAGACCCGGAAGCCGGTGCGCTACGGGCGTGCCGAGGCGACGCGCGCGGT CGCGCTCCTCCGCGGGACGGCCCGGCGCGCCGGGGTCGCCGAGGAGCTGCGCGGCCCGGGCGAGCACGCCCGACGCCGTCCCCACGGC GTCGTCGCGCTCGTGACGCCGTGGAACAGCCCGGTCGCGATCCCGCTCGGCAAGATCGGGCCTGCGGTCGCGTGCAGGAACACGGTCG TCTGGAAGCCCGCGCCCGCCGCCGCGGCGATCGCAACACGGCTTGTCGAGCTCTTCGTGCGTGCCGGCGCGCCGCGGGGCGTCCTCGG CCTTCTGTCGGGCGATGCCGCGGCGGCGCGGTCGCTCCTGGAGGACGAACGCGTGCGCGCGGTGTCGCTCACCGGCTCCCCCGCGGCG GGCCATGCGGCGCAGGAGATCGCGGCTCGCCGGAACATCCCCCTCCAGGCGGAGCTCGGCGGGAACAACGCGGCGATCGTCTGGTCGG ACGCGGACCTGCGACGCGCGGCGGAGAGGATCGCCGAGGGCGCCTTCGGCCAGGCGGGCCAGCGCTGCACCGCCAACCGGCGGGTCAT CGTCGACGCCCGGTGCGAGGCCGACTTCGTCGCCTGCCTCACAAGCGCGACCGCGCAGCTCGCGGTCGGCGATCCCCTCGACCCCTCG ACCCATGTCGGGCCGCTCGTCTCGGCGGAGGCGCGTGCGCGCGTCGCCGGGTCGATCGAGCGTGCGCGCGCCGTGGCGCGGGAGGTGA TCGTCCCGCACGCGTCGCTGCCCCCCGGCGACTTCGTCGCGCCGACGATCGTCTTCTGCGACGACGCTTCCGCCGAGATCGTGCAGGA GGAGACGTTCGGACCCGTCCTCGTCGTCCAGCGCGCCGGGAGCTTCGCCGAGGCGGTCGCGCTGCTGAACGGCGTGCGGCAGGGGCTC GTCGCGGCGCTCTTCTCGCCGTCGCCGGAACTCAGGGCACGCTTCCTCGAGGAGGCGGAGGCGGGAATCCTGAAGCTCGACGAGGCGA 
CCGCCGACGCGGGCGTCGAGGCCCCCTTCGGCGGCTGGAAGGCGTCCGGCGTCGGCCCGCCGGAGCATGGCCACTCCGACGTGGAGTT CTACACCCGGGCGCAGGCGCTCTACGATTGAGCGCTTCGAGCCCGGAGGGGAGGGCGACATCCGCTTCGTTCGCTCATGATCGTCGTC ACCTACGCCACGGACCGGAACCACCCGGCGCTCCGGCGGTTCCTCGCCCCCTCGTGCGCGCGCTTCGGCCTCGACCTCGTCGTCCTCC CCCCGCGCCCCCCTCGAAAGCTGCGGACTTTCCGGATGAAGGACCGATGGCTCCTCCGGTTCCTCCGCGGCGTCCCGGAGGACGAGAT CGTCTTCTCGACCGACGGCTACGACGCCTTCCTCCTCGCCGGGCCGGAGGAGATCATCGCGAAGTACCGGTCGTTCGGGCGCCCGCTC GTGTTCTCCGCGGAGCAGAACTGCTGGCCGCGCCCGGCGCTCGCGGCGCGCTATCCGCCGTCGCCCACGCCGGCCCGCTACCTGAACG CCGGCGGCTTCGTCGGCCCCG

\subsection{Das Cosmid slc_1x}

\subsubsection{Lage der offenen Leserahmen (ORFs)}

\begin{tabular}{|c|c|c|c|c|}
\hline ORF & Annotation & Start & Stopp & $\begin{array}{l}\text { Orien- } \\
\text { tierung }\end{array}$ \\
\hline 1001 & 4-Hydroxy-2-oxovalerat-Aldolase (EC 4.1.2.-) & 259 & 1044 & + \\
\hline 1002 & Aminotransferase (EC 2.6.1.-) & 1270 & 2499 & + \\
\hline 1003 & Extrazelluläres Bindeprotein (Familie 3) & 2569 & 3366 & + \\
\hline 1004 & ABC-Transporter-Permease & 3439 & 4113 & + \\
\hline 1005 & Potentielle Aminotransferase & 4149 & 5429 & + \\
\hline 1006 & Aldehyd-Dehydrogenase (EC 1.2.1.3) & 5499 & 6925 & - \\
\hline 1007 & Potentielle Metall-abhängige Hydrolase (COG3618) & 7043 & 7930 & - \\
\hline 1008 & CoxE, Protein mit von Willebrand Faktor Typ A (COG3552) & 7930 & 9060 & - \\
\hline 1009 & CoxD (MoxR-ähnliche ATPase, COG0714) & 9057 & 9935 & - \\
\hline 1010 & CoxL & 10097 & 11101 & - \\
\hline 1011 & CoxL & 11105 & 12475 & - \\
\hline 1012 & CoxS (COG2080) & 12480 & 12962 & - \\
\hline 1013 & CoxM (COG1319) & 13010 & 13807 & - \\
\hline 1014 & Konserviertes Protein & 13824 & 14267 & - \\
\hline 1015 & Potentieller Transkriptionsregulator, AraC-Familie & 14373 & 15197 & - \\
\hline 1016 & ABC-Transporter, periplasmatisches Substrat-bindendes Protein, UgpB (COG1653) & 15474 & 16805 & + \\
\hline 1017 & ABC-Transporter, Permease, UgpA (COG1175,) & 16868 & 17866 & + \\
\hline 1018 & ABC-Transporter, Permease, UgpE (COG0395) & 17863 & 18810 & + \\
\hline 1019 & Hypothetisches Protein & 18807 & 19013 & + \\
\hline 1020 & ABC-Transporter, ATPase-Komponente, MalK (COG3839) & 19017 & 20126 & + \\
\hline 1021 & ABC-Transporter, ATPase-Komponente, MalK (COG3839) & 20119 & 21135 & + \\
\hline 1022 & Dak2 & 21150 & 21752 & + \\
\hline 1023 & EIIA-man, PTS & 21749 & 22138 & + \\
\hline 1024 & HPr-verwandtes Protein, PTS (COG1925) & 22151 & 22462 & + \\
\hline 1025 & EI, PTS (Phosphoenolpyruvat-Protein-Kinase) & 22467 & 24068 & + \\
\hline 1026 & Konserviertes Protein & 24070 & 24504 & + \\
\hline 1027 & $\begin{array}{l}\text { Dihydroxyacetonkinase, } \\
\text { Dak1 (COG2376) }\end{array}$ & 24541 & 25527 & + \\
\hline 1028 & Potentielles universelles Stress-Protein UspA & 25540 & 26376 & - \\
\hline 1029 & Sensor-Protein FixL (EC 2.7.3.-) & 26523 & 28106 & + \\
\hline 1030 & 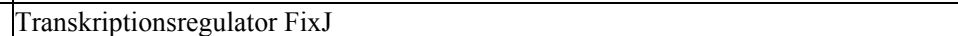 & 28093 & 28716 & + \\
\hline
\end{tabular}




\begin{tabular}{|c|c|c|c|c|}
\hline 1031 & Hypothetisches Protein (potentieller Transkriptions-regulator FixT2) & 28796 & 29161 & + \\
\hline 1032 & Regulationsprotein bei der Stickstofffixierung, FixK & 29246 & 29896 & + \\
\hline 1033 & Konserviertes Protein & 29862 & 31199 & - \\
\hline 1034 & Dienlacton-Hydrolase und verwandte Enzyme (COG0412) & 31567 & 32454 & + \\
\hline 1035 & $\begin{array}{l}\text { Uncharakterisiertes, in den Propionat-Katabolismus involviertes Protein } \\
\text { (COG2079, PrpD) }\end{array}$ & 32693 & 34168 & - \\
\hline 1036 & COG1804, Vorausgesagte Acyl-CoA-Transferase/Carnitin-Dehydratase, CaiB & 34198 & 35319 & - \\
\hline 1037 & Acyl-CoA- Dehydrogenase, CaiA (EC 1.3.99.3), (COG1960) & 35332 & 36510 & - \\
\hline 1038 & $\begin{array}{l}\text { L-Alanin-DL-Glutamat-Epimerase und verwandte Enzyme der Enolase-Superfamilie } \\
\text { (COG4948) }\end{array}$ & 36534 & 37703 & - \\
\hline 1039 & Hypothetisches Protein & 37700 & 38032 & - \\
\hline
\end{tabular}

\subsubsection{Sequenz des Cosmides slc_1x}

CTGCGCCGCGGTCAGATTGTCGTCCCAGCTTGCCAGCCAGCGCTCGGGAACATCGGTGATCGCCAGCCCGCCATCGGCGTTGGTCGAG AAGATGCCGAGCTTCAGCCGGTTCGGTCCTTTGAGCGGGTGTGGTCTGATCATGCTGGTCCTCCCGACCGTCCACGCTAAGAGCGTCG CCAGATATTTCAAGCATGAAACAGCACTTCGCAGGCACCCAGTTTGCGGCTAAGGCTTGAGCCACCGATCCGGGAGGAGCACATGAAG AACTTTCGCGACAGGACCGTTGCCGGAACGCCGCTGGTCGGCACTTTCGCCGAGATCCCGCATCCGGTGGCGATCGAGGTGACCGCGC AGGCAGGGCCTGATTTCATCTGCATCGACTGGGAACACGGTCAGATCGCCCGCGACCAGATCGAAAATCTCGTGCGTGCCTGCGACGT GAGGAATGTCCCGGCGATGGTCCGGGTGCCCGGCCATGCTCCCGAGGCAATCGCCGCGGCGCTGGACAGCGGCGCGCAGGGCGTCCTG GCGCCGCGCGTGTCGACGGCCGCGCAGGCGGCCGCCGTGGTGAAGGCGGCACGCTACCCGCCTTCGGGCGAGCGCGGCGTCGGGCCCG GCCGCGCGAGCGGCTATGGCTACCGCATCTTCGACTATCTCGCGGAAGCAAATGACTCCATTGTCGTCGCCGTGCAGGTTGAGACCGC CGAAGGGCTCGCCAATGCCGGCGCCATCGCCGCAACCGACGGCGTCGACCTCGTCTTCGTCGGACCCGGCGACCTCTCCGTTTCGCTC GATGCCTATCGGCCGGACGGTGCGCTGAAACTCGCCAGGGCGATCGAAAAGATCATCGCCGCGACGCTGAAGCGGGGCAAGACCGCCG GCATCTTCTGCGGCAGGCCGGACGACGTTGCCCGCTGGACCGACAAGGGAGCAAGCTTCTTCATCCTGGCCAGCGATACGATGTTCCT GGGCGCCAGCACGGCATCCGGCCTTGCCGAAGCACGGGCGACGCCAGCGAAGGCACGGGCACGAGGCAAGCGCTGACTTTTTAAGCTT AAAACTTTTGCCTTGAAAAGCGCCCCGGTTCGGATAGCATTCGCTGCTATAACTTGCGCGCGACATTGGCCTGGACATCGGCTTGGGG GGCCGTCGCACGCCGCGTAACCCGAGTGTGCGCAAAGGGTCCCGGTATTGTCGTTCCTTCCACCCCAGTCGTCCGCCGCGGCACCGCA TCGGCCCGAAAATCGGGATCGATTTTCGGAAAGCACGATGCAGAATTTCAAAGACCTAGAGCGTCCTTTGCGCGTCCAAGAGGACGCG CGGCGCTCTAGCGCGCGTTACGCTTTCGAAGGCATCCGCGCGCAGATCCGCGACCTCCACACCGAGAACATCGCCAACCTTGCCGTGC GCGCCCGTGAGCTCGGCGATGTGATCGCTCTCTGGTACGGCGAAGGCGACCTCGTGACGCCTGACTTCATTCGCGAGGCCGCCAAGGC AGCCTTCGACGAAGGCCAGACCTTCTACATTCCCAACATGCGCGGCTACGCGCCGCTGACCGAGGCGCTGTCGGCTTATCAGTCGCGG CTGCATGGCAAGCCGATCGGGATCGACCGCACCACCGTGACGCCCAGCGGCATGCAGGCCCTCTACATGGCGCTTGAGCTGCTCGTCG ATGTCGGCACGAACGTCGTCTATGTCGCGCCCCAATGGCCCAACATCCACAACGCCATCCACCTGATCGGCGGCGAACCGCGCCCCTT CGCGCTCGATTTCGACGGCGACTGGAAGCTCGACCTCGACCGGCTTTTCGCGACTTGCGATGCGCGCACGCGGGCCATCTTCCTGTCG ACCCCGTCCAATCCGACCGGCTGGACGGCAACGCGTGCCGAGATGGAGGCGCTGCTTGAATTCAGCCGCCGCACCGGCATCTGGATCA TTTCCGACGAGGTCTACAACCGTCTCTACCTGGACGGCGACTCTGCACCTTCGATCCTGCAGATAGCGGAGGACGGCGACCGCGTACT CTCCGTCAACAGCTTCTCCAAGGCATGGGCGATGACCGGCTGGCGCGTCGGCTGGCTGACCCATCCCTCGGGGATAGCGGACCAGCTT GCCGCAATGACGCAATACGTCAACAGCGGCACCGCCGGCCCCCTCCAGGCAGGTGCCGCCGCGGCCATCACAAAGGGCGAACCGCTGG TCGAGGAAATCCGGCAGCGCATCAAGACCGGGCTGGACCTGGCCTATGACCGGCTGGCGCATTTTCCTGGAATCATACTTCCGACGAA GCCACGCGGCGGCATGTACGCATTCTTCGCGGTGGAAGGCGAAAGCGACTCGCGTCGCCTGTGCGCCGACATCCTGGAAAAGACACGC GTCGGGCTGGCGCCGGGGTACCTGTTCGGCAGTTCGGCCAATGCCTTCGTGCGCATGTGCGTCTATCGCGAGGCCAGCCAGCTCGAAA CGGCGCTTGGCCGAATGCTCGAATTCAAGAATTGACGCCGCGCAACGCGGCGCCAACCACACCGGCGGGGAGGACTCGTCCGGACCAA CCAGAGGGAAAGAAAGATGAATTTCACCCGTCGCAACCTGCTCATGATCGCCGCAGTGGCCGGCTTTGCCGGGGCGCCCATGGCCGCC TCCGCCGAAGGCGTGCTGAACGTCGGCTCCTATCCGAACAACCCGCCCTTCGAATACAAGGCCGAGAGCGGCAATTTCGAGGGTTTCG AGGTCGACATCGTGACCGAGGCGGCCAAGCGCGCCGGCATGACCGTCAACATCGAAGGCTATGACTTCCAGCCGCTGTTCGCCGCGAC AAGCTCGGGCCGCATCGACGCCGCGATCTCCTCGATCACCATCACGCCCGAGCGGCTGGGCTCGCAGTCGTTCACGCAGCCCTACTAC GATTCCGACATGGGTATCGCGGCCAAGACCGACGGCGCGGTGAAGAGCCTCGCCGACCTCAAGGGCAAGATCGTCGGCGTGCTGTCCG GCTCGACCGGCGAGAAATATGCCAACGACAACAAGGACGCCCAGGGCTTTGCCGAAGTGAAGGGCTACAATACCCAGCAGGACGTGCT GCTTGACCTGGCGGCCGGCCGCGTGGATGGCGTGGTCAGCGACGTGCCGGGCATGGAATACGCCTTCACCAAGATGCAGGGCCTTGCC GTCGTCGACCGCATCAAGACGGGCGAGCAGTACGGCCTGATGATGACCAAGGACTCTCCGCATCTGGCCAAGATCAACGACGCGTTGA CCGAAATGAAGAAGGACGGCACGCTGCAGGCAATCCACAAGAAGTGGTTCGGCACCGACGCGCCGGCCGACTCCTCGACGGCCAAAGA GGCGCCGCTTCCGAAGGCCTGATATAACAGCATCGTTGCGACTGATTGTGCCGGCGCAAAGCCGGCACAATTCTTTGTATGCGGGGGA CTGCACATGACGTTGCTCGACACGTTCTTCAACAGCCAGGTCATGCTGTCGGCGCTGCCGGCCCTGATGCGAGGATTCATCAACACGC TGAAGCTTGGGCTGCTCGCCATCGGTATCGGAATTCCGGTGGGCTTGCTGATCGCCCTCGTGCGCCTCTACGCGCCAAAGCCGTTTCG CTGGCTCGCCATCGGCTATATCGACATCTTCCGCGCCATGCCGGTGCTGGTCGTCCTCATCCTGATCTACTACGCGCTTCCCTTTGTC GGCATCCGCCTCTCGTCATGGGTTTCGGCGACGCTGGCCTTCACCTTCATCATGTCGGCCTACTCGGCGGAAGTGTTCCGCTCGGGCA TCGAGAGCATTCCGCAGGGCCAGTTCGAGGCGGCGCACGCGCTCGGGCTGCCGTTCCTGCTGACGCTGCGCAAGGTCATCCTGCCCCA GGCGGTGCGTGTCGTCATTCCTCCTGCGACCAGCAACTGCGTGTCGATGTTCAAGGATACGTCGCTGGCCTCGGTGGTCGCCTTGCCC GAACTTCTCAAGGAGGCCAACAACGCGCAGGCGCTTTACGCAAATCCGTCGCCGCTGATCGGAGCCGCCCTGATCTACCTGATCTTCC TTTGGCCGATGGTGCGCCTGGTGGGCCTGCTCGAACGCAAGTTCAAGGTCGAGAAGACACGCTGATCCCCCGACTCCAAAGCTTCCTT TGAGGACTTCACGTGAACCAGCATCCATCCGCCGCGTCCGCAGAAACTTTTCCTGTCGAGAAGATCAGGGAGATGTTCCCAGCGCTCC GGAAAGCCGGCGACTTCATTTTCCTCGACAACGCCGCCGGAGCGCAGATCCCACAGAGCGTGCTCGACGCAGTGACCGACCATCTGGT TTCACACAACGTGCAGCGCGGCGGCCGCTATGGCCGCAGCGTGACGGTGGACAAGGGTGTGGCCGACGCGCGCGAGAGCGTGGCTCTC CTGATCAACGCCCCGAACCCATCCGAGATCTGCTTCGGCATGAACGCCACATCGTTCATCAGGCTGGTCAGCCTCGGTATCGGCCAGA TGATTGCCCGCGACGGCAGCCGCGACGAGATCGTCGTCACCGACATGGACCACGACGCCAACATCGCGACGTGGCACGCGCTGGAACA GTCCGGTGCGAAGATCGTGTGGTGGCGGATGCGCGAAAACGGCAATCTGCACGTCGACGACCTGAAGCCGCTGGTCAACAGCCGCACG 
CGGCTCGTCGCCTGCACGGTAACGGCGCATTCGATCGGCTCGATCGTCGACGTCGCGTCGGTGGCGAAAATCGCGCACGCCGCCGGCG CCGAGGTCTTCCTGGACTGCGTGCATTATGGGCCGCATGGCCTGATGGACGTGCAGGCCTGGGACTGCGACTACCTTATCTGCTCGGG CTACAAGAATTTCTCGCCGCACATGGGGTTCCTGTGGGGCCGCTTCGAGCTGCTGAAGCGGCTGCCGACCTTCCGCGAGGATTTCATC CCGGACGAGCCGCCCTACAAGGTAGAGGCCGGCACTTTCGTCTACGAGAATGTCGCCGGCATGGACGCCGCGGTGCGCTATCTGGAAT CGATCGGCCGCAACTTCGCGCCATCGAACAACCGCACGCGGCGCCAGAACATCGTCGCTGGCATGGGCGCGATCCGACAGTACGAACT GGTGCTGGCGCGGGCGATGATGAAGGTGCTGAAAGAGTGCGGCGCGACCATCTATGGCGTCGCCGACGAGGCGCGCATCGACGAGCGC GTGCCGACCTTCTGCTTCAACATCGGCACGCTGTCGCCGCAGGCGATCGTGGAGGAGATGGCGAAGCGCGAGATCGGCATCCGCGACG GCCACATGTATGCGCCACGCCTGATGAAGCGGCTCAACCTGTCGATGGATTCGGGCGCAATCCGCGCTTCGCTCGTCCACTACAACAC GCTGGACGAGGTGCGCCGTTTTGGCGACGCGCTGAAGGGTGTGATCGCCAGGCTGGCGTGAGCGCGGAGACGCCGTGAACCGGCGCCT CTTCCCCACCTTGGCGGGGAAGAGGAATGGGCCGGACGAGGTTACTCCCCGTAGCCGATGATGCCCTTGATCTCTAGGAAGTCGTGGA TCGCCCAGTCGGCGTATTCGCGGCCGTTGCCGGACTGCTTGTAGCCGCCGAAGGGCGCGTAAAGATCCCATTCCGGATAGTTGATCGA GACCTGGCCGGCGCGCATGCGCGCAGCTATGGCGCGGGCGTGCTCGATGTTCTTGGACTGCACGTAGGCGGCGAGCCCATAGACTGTG TCGTTGGCGATCCTGACAGCGTCTTCCTCGTCGTCATAAGAGATAACCGAGAGGACCGGTCCGAAGATTTCTTCCTTCTCAATGCTCA TGCCCGGCTTCACGTGGCCGAAGACGGTCGGGCGGATGTAGTAGCCGCGATTGAGGTGTTCAGGACGGCCAAGGCCGCCGGTGACGAG CGTAGCGCCCTCGTTTATGCCCTTCTCGATCAGACCCTGGATCTTGTCGTACTGGATCTTGCTGACGACCGGACCGAGGTGCGGACCT TCCAGGCGCGGGTCGTTGACCTTGTGCGCCTCTGCGGCCTTCTTGGCGATCTCGAGCGCCTCGTCGTGACGGGCGGCCGGCACCAGCA TGCGGGTCGGCGCGTCGCAGGACTGGCCGCTGTTGCCGAAGCAGCCCTTCACACCCTTCTTAACCGCCCGCTCGAAATCGGCGTCCGG CAGGATGATGTTCGCCGACTTGCCGCCAAGCTCCTGGCACACGCGCTTCACCGTCTTCGCCGCCGTCTCTGCAACGATGATGCCGGCG CGGGTCGAGCCGGTGAAGGAGACCATATCCACGTCGGGATGGCCGGCCATGAACTGGCCGACGTCAGGACCCGTGCCGTTGATCATGT TGTACACACCCTTCGGAACGCCGGCGGCATGCATGACCTCGGAGAAGATGATGCCTGAAATCGGCGCGATCTCCGATGGCTTCAGCAC GACCGTGCAGCCGGCTGCGATCGCCGGGGCGACTTTGCAGACGATCTGGTTGAGCGGCCAGTTCCATGGGGTGATGAGCGCGCAGACG CCGATCGGCTCCTTGACGACCATGGTGGTGCCGCGGCGCTCGGTGAGTTCGTAATCCTCGAAGGACTTGATGGTGGATTCCATATGCC CGCGCCCGGCCGCGGCCTGCGCGTCGCGCGCCCAGGTGATGGGCGAACCGTTTTCGTGGCTGATCGCCTGTGCGAAGTCCTCGAAGCG CTCGTTGTAGACTTCAAGGATGCGCCTCAGCAGCGCCAGCCGTTCAGCCTTGCTGGTGAGGGAGAAGGCCGGAAACGCTGCCTTGGCA GCGGCAACCGCGCGATCGACGTCGGCTTTCGATCCGACGGAGATCTGCGTATAGGCCTCTTCCGTCGAGGGGTCGATGACGTCCAGAA CCGCCGGAACCGCCGGATCGACCCACTTGCCATCAATGTAGAATTTAAGGTGGTTGCTCATGGTCTACCTGTCTCTTCGAATTTTGTG ATGGAACGGAATAGCACAAAGACGCGGCTGTTAGGCAACATCCGCGTCCGCGCCATGTCGCCAGTGCGACAATTCCGCCGGCAGCGCG CCTTACACTGGCCGATAGATGCGTTCGGCGGTGTTCCAGAAGATGTCGGCCTCGGCCTTGGCGCCGTGTCTCGAGACCGCCGCGCGAT GGGCGGCTATCAAATCGGCGTGACTGGTCCACAGCTTTTCGATCGGAAAATTAGAGCCGAACATCAGCCGGTCGCTGCCAAGAATCTC TATCGCGTTGTCCACCACCGTGCCGATGACCTGCGGGTCGTTTTGGTGGACGAAGGTGCCTAGGCCGGAAAGTTTTGCGTAGAAGTTG GGCGCCTGCGCAAGCGTGCGCAGGCCGGCCTTCCACTCCTCGACCACCGGTTCGGCAAGACCGGTCAGCATCCCGGTATGAGTCAGGA TGAAATTGGTCTGCGGATTCTCGCCGACAAGCTCAAGCCCATCCTTCATCTGGGCGGGGAAAAGCTGCAGATCGAAGGATAGGCCATA GTCCTTCAGCCTCGCAACGTTCTTCTTGACGACAGGGTCGATGACCTGGTCGGCCGATCTGGCGAAGCGGAAGGCCGGCGTCTCGTGC CAGTGAAGCTGCATCCGCACGCCGCGCAGCAGCGGATATTTCTTCAGCCGGTCGATCTGCTGACGCACGTCGTCCACGGTCATGTCTG CATAGCCGACGATGGCGTGCGGCCAGCCACTTCGCTTCGCCGTCTCCGTGAGAAACGCGACTTCGTTCTCGAAATCCTCCTTGGCCCA GTTGGTCTGGACATAGACCGCTTTTCCCACGCCCGATCCGGCCTGATCGGCGAGAAATTCCTCGATCGGATAGTCGCGCCGGATCGGC TCGTAGGGTCCGAAGATGCGCGGCACCATCGGCCCGACCAGCCAGGGCTGGTCCTTCTGCCGCCAGATGTGGAAATGCGAATCGATGG CCTTTTGCATCAGAGGGTTCTCCTCCACACGGTTGCGGCCGGGGGTGCGGCCCGACCGAGCGTCAGCATGAACTCGGCGAGACCTGAA AGCGACGAGCCGTCGACCAGATCGTCGAGGCAGGGCAGGATCGCCTGCAGCGCGGCCGTCTTCGGCGAGAAGCGCGGATCGCCGGCCA GCGGCGTGGCGAGTGACAGACGGAAGGCGCGCGCGCCGAGGCGGCGCATGGCGGTCTCCATCTCGGCATGGTCGCCCCGCTCCAGCCC GTCCGACAGGAGCAGGATCGCCGCGCCCCGCGCGAAGGCGGCAAAGCGCGGTATGGCGAGGAAGGCGAGCAGCGTCGGACCGATGCGC GTACCCCCGTCCCAGTCGTCGACCAGGGCAGCCGACCGCTCCAGCGCCGCATCGAGGTCGCGAACTTTCAGCGCGCGCGTGACGCGGG TCAGCCGCGTGCCGAGCGTGAACACCTCGACGCGATCGGCGGATTGCACGGCGGTGTGCGCGAGCTTCAGATAATCGCCGGTGTGCAG CTTCATCGAGCCGGAAATGTCGATCAGGATCAGCAGCCGGCGTGACACGGTCGGACGGCGACGCAGCGGCGGCGCGGGCACGTCGCCG TCGGAACGCACGATCGAACGCAGCGCGCGGCGCAGATCGAGCTTGCCGCGCGAATTGGTGCGGACGGACCGGAAGGAGCGGCGCTGAG GCAAGGCCTTGGGCAGAGCGCGGCGGAAATCCGCCAACGCCTGGCGTTCGGCCTGGAACGAGCGGATGCCGAGCCGCTCTACGGCGGA AGCGGACTCGCCGCTCTCCTCCTGCCTGAGCTCCGGCTGTTCGCCCTCTTGCTCGACGCCGTTGTCGTCCTTGACCTCGGTGTCCTCG TCGCTTTCGCCATCCACAGTGACGGTCGCCTCGCCATAGAAGAAGCCACGAAACAGCGCCTCGAATTCCGCCTGTCGGTCGTGCGGTG GAGCAAGCGTTGCAAGCGCCGCCTGGTGGATATCCTCCATGGAACGGGGACCGAGCAGCGTCACGCCCTGCATGAACGCGATCGCCTG CTCGGCGGCGACCGGGAAACCAAAGCGGCGCAGATGCCTGGCAAAATCGGCAAACGGTCGCGCGGAGCGGGGGAGAGCCGTCACGCCA TCGCCCTTTCGAGGATGCGGTCGAGTTCGGGATTGAGGAAGCTCATGTCTTCCTCGTCCTTGATCAGAACGCCGAGCGCGCGGCGGAA GGCTTCAGGCCACGGGCTGCCGCCCTTTTCCAGTATGGTCGCGGCGTTCGCCCATTCGACCGCCTCCGCGATCCCAGGCGGCTTGGCG AGCGGTTTTGCACGGATTTCGCCGACCGCTTTGGCGACCGCGCGGGCGGTGGCTTCGGCGACGTCGCCGGCGCGCAGCATGATGATCG CCGCCTCGCGTTCCGCGTCTGGATAGGCGATCCAGTGGTAGACGCAGCGGCGGCGCAGCGCTTCGGCAAGCTCGCGGGTGCGGTTGGA CGTCAGGATCACCAGCGGCTGGCTTGGCGCGCGGATGGTCCCTCGCTCCGGGATGGTGATCTGGAAATCGGACAGGAATTCAAGCAGC AATGCCTCGAATTCGTGATCCGACCTGTCGATCTCGTCAACCAGCAGCATTCTTTGCTCGGGCTGCTGCAACACCTGCAACAGGGGAC GCGCGATCAGGAAGCGGTCGTCATAGATGTCGACCTCTCGCTCGCCAGCCTGCCGAATGGCGAGAAGCTGGCGCTGATAGTTCCACTC ATAAAGCGCGTGGGCGGCGTCGATGCCCTCGTAGCATTGCAGCCGGACGAGGTCGCGCGAGGTGAGCGCGGCGATCGCCTTGGCGGCT TCCGTCTTGCCGACGCCCGGCGCGCCTTCGAGCAGCAGCGGCTTGCCGAGCCGGATGGCGAGGAAGATCGCGGTAGCAAGCCCCTCAT CGGCCAGGTAGCGCATGCCGGCGAGGCCGGAAGCTAGGGACTCGGGGGAGGCGGCGATATCGTCTAAGGGGCGGATCATCGAAAGCTG CGCGCCCCCTCCACCACGCTTCGCGTGGTCCACCTCCCCCGCTGCGCAGGGGAGGAACAGGCGGCGCGGCCATCACCGATCTTGATCC TCCCCCGTTTACGGGGGAGGGGGACCGCCGAAGGCGGTGGAGGGGGCGATGGCTGCTGCATAGCCTAAGCCGCCCGCTGTTCCTTCAA CGCCCGGAGAATCCGCTCGGGCGTGATCGGCATCATGTCGATGCGCACGCCGACCGCGTCGAACACCGCGTTGGCGACCGCCGGGATC TGCGGATTGGCGCACATTTCGCCCGGCCCCTTGGCCCCGTATGGACCATCGGCCGCGGGGCGCTCCAGCACGACGATTTCCGTGTCGG CGAGATCGCCCGGACCTGGCATCAGATATTCGTTGAAGTCGGTGCCGCCATGGTCGCGCGCCGGATAATAGGGCTCGGTCGTCTCGTA GAGCGCGTGCGAAATGCCCATCCACGAACCGCCGACGAGCTGCTGCTCCACCATCTTCGGGTTGAGCGCGCGGCCGATCTCGAAGACG TTCTTGACGGAGACGACGGTGACTTCGCCGGTCTCGTCGTCGACATCGACCTCGGCGACCGTGCAGGCATGGGCGTAGCAGGTCGCGG GCTTCATGGCGCCCGTTTCGACCTCCGGATAAGAGCGCGGCACCAGGAACATGCCACGCCCGGAAATCGAGCGGCCAAGCTTGAAATG CGCCATCAGCGCAGTGTCGAAGATCGAGATTGACTTCTGCGGCGCGCCCTTGACGTGGATGTTGCCCTCCCCGTCTGTATCGAGGTCG GCGGCGTTGACCTCCAGCGCCTCGGCGGCGACTTCGAGCATCACCTGCCGCGCCTCCTGCGCCGCCTGGATGACCGCATTGCCGATGC GGTGCGTGCCGCGCGATGCAAACGTGCCCATGCAGTGTGGCCCTGTGTCGGTATCCGCCGTGTCGATGGTGACCTGCTCGGTCTTCAC GCCGATCGTCTCGGCGCAGATCTGCGCCATGACCTGCTTCAGCCCCTGCCCCAGGTCGACCGACGACAGCGTCACCATGAAGTTGCCG GTCGGCGTCGAATGCACGAGCGCCTGGCTCGGATCGCCACCGAGGTTCATGCCGGTCGGATAGTTGATCGCCGCAACGCCGCGGCCGC GCCGGATCGCCATGGCTCAGGCCTCCTTGTAGGATGACATCTTGAGGTACTTCTCCGCCACCGGCCAGTTGGCCAGGCGCGACGCTTC CTGCATGCATTCGATGAGTGCTGCGCCCGTCGTGGGCTGGCGATGCGCCTTCATGTCGCCGTCGCGGTAGGCGTTGATAAAGCGGAAC TCGAGCGGATCCATGCCAATCACCCGCGCCAGCTTGTCCATCTGCACTTCCAGCGCGAAGTCGGCGATGGTGACGCCGAAACCCCGCA TCGCGGACGACGGCGTGCGGTTGGTGTAGACGCAGTATGTGTCGACTGACACGTTCGGCACCGTATAGGGGCCGGGATAATGCGCGGC 
GCCCTTCTGCGCACCATAGGGCGAATGGCGCGAATAGGCGCCGGCGTCGGTGTAGCCGGTCACCTGGCGGGCAATCAGCCGGCCGTCC TTCATCACGCCGTCCTTGAGCACGATCTTCTCGGCCGCACGCGGCGAGGAAATCTGCATCTCCTCATGGCGGCTGTAGATGAAGGATA CGGGGCGACCGGTGAGCTTGGCCGCGAGGATGGCGATCGGCTCGACGGTGACATCGACCTTGCCGCCGAAACCGCCGCCCACGGTGCC GCCGACCATGTGCAGCTTGTGGCCGGGCATCTGCAGGATGATGGACGTGTTGTCGAGCGTGAAGAACATCGCCTGCGTGTTGGTGTAG CAGGTGAAGCGATCGTTGCCGTCGGGCGTGACGATACAGCCCGTCGTCTCGGTCGGCGCCTGCTCGATGGGCGACGAGAAATAGGTCT GTTCGAGGATATGGTCGGCCTCGGCGAACCCCTTCTCGACATCGCCGAAGCGTACTTTTCGGGAGGCACCGCTGTCGTACATGTAGTG GTTCTGGCCATGGTATTCGTTGACCAGAGGCGCGCCCGGCTTCAGCGCTTCTTCCATGTCGAAGACAGCCGGCAGGACCTCGTAGTCC ACCTTCACCTTGGCGGCGGCTTCCTCGGCGGCGCGCTGGCTGTCGGCAAGCACGGCGACCACCGCCTCGCCCTTCCAGCGTACCTTGT CCTCGGCAAGCACCTGCTCGTCCTCGGGGCCGACCTGGATGAGGATCAGGATCGTGTAGACGTTGTGCGGCACGTCCTTGTGGGTGAT GACCCGCGCGACGCCCGGATGTTTTTCAGCCTCGGAGGTGTCGATCTTCCTGATGCGGGCGTGGTGGTGCGGGCTGCGCACCATCTTC AGGTAGAGCATGCCCGGAAAATGACGGTCGGCGAAATAGGTCGTCTTGCCGGTCACGTGGCCCGGCACGTCCGAGCGCTGCAGGCCCT GGCCAAGCTCCTTGAGATCGTCCTTGCGCTCGTCGGCGAAATAGCTCTTGGCGAGTTCCATGACCATGACCTCAGGCAGCGTTCTGCG AGTTGGCGCGCGCCGCCGTCAGCACGGCGCGAATGATCGGCTCGTAACCGGTGCAGCGGCAGATGTTGCCCGACAGCGCCTCGACGAC ATCGTCGCGCGACGGGTTTGGCGTGCGGTCGAGCAACGCCTTGGCGGCCATGATCATGCCGGGCGTGCAGAAGCCGCACTGTGCAGCG AATTCATCGACGAATGCGCGTTGCAGCGGATGAAGAACGCCATCCGTGGCGAGGCCGCCTGTGGTGAGGATGTTGGCTCCCTCGCACG TCTCCGCCAGCGTCAGGCAGGACAGCGTAAGTTCGCCGTCGATCAAGACCGAACATGCGCCGCATGTGCCCTGGCTGCAGCCGCCCTT GGGCGAGGTGTCGCCGAGCTTGTCGCGCAGCACCTTGAGCAAGGTCGCGCCGCTGTCGACGAACTCGGCCTTTTCCTCGCCGTTGAGC GTGAACTGAACTGGAACCTTCGCCATTCTTCCTCCCTATGGCACCGGCTGTCGGTAGAAGAGACTGTCTTCGCCTATCCTCCGGCTTG ACCGAGCAGCAGCCGGCGGAAATGCACCGGCAGCACTTCGCCGCGATACCAGGCGCTCGCAATGGCGTCGGTGATCGGTTCTGTCCCC TCCCCGACCGCGGCCACCGCGGATGCAACACCTGCCTCGTCGAGGGTTGCCCCAATGAGCGCCCTCTCGGCGGCCTTGGCGCGAACCG GCCGGTCGGCCATGCAGCCGAGCGCGATTCTCGCGCTCTTCACCTTGCCGGCATCAGTGTCGATGACGGCGGCGATGCTGAGCACCGA GACACCCTTCGGCTTGATGCGCGACACCTTCAGGAACCGGAATTTCCGGGCGTCAGGAACAGCGAAGCTCACCGCCGCGACGACCTTG CCGTCGCGGTCGGCGAGAAAGTCGTCGATGGCCATCTGGCCGGCGGTGGTGTGCACGGTCGCATCCAGCGCCAGCAACGCCACCGCGA AATCTCCATAGGGCGCCGCAGCGAAAAGATTGCCGCCGACCGTCGCCATGTTGCGTATCGCCGGCCCGCCGACCGCCTTCGCCGCCTT GGCGATGGCCGTGAGCCCGGGATGGCGGGCAATGGCCGACATGGTGACGGAAGCGCCGAGCGTGGCGCGACCGCCTTCGACCTCTATC GCGGTGAGCGCCGGGTCGGTGGAGCGCACGAAGGTCGACAGCGAGAGGTCGCCTTCGTTGGCAGCGCGAACGACAAGCGTTCCGCCGC CGAGATAGCGCGCGCCTTCGCCCTTGAGCGCTGACCCCGCCTCGGCAATCGTCGGATATGTCTTCAGGGCAAGCGGCATCGCGTGCTC CTATGGATCAGCTCTTGGCCGAAAAATGGCTCTTCAGCGCGTTGAAGCCACCCTGAAAGACGTTCTCGCCCATGCCCTTGGCCATCTC TTCGGCCTTTTCAGCCGGTGCATCGAATTCCGAGGTCCAGACCGCATAGGTCCTGTCGCCGTCAGTGATGCGCTCGAGCTTCAGTGTT GCCGTGTGGTTGGTGATCGGCGCCGGGTGTTCGACGATGGCGTAGGTGGTCAGGAACTCATCGTCGGAAAATGCGTCGAGCCGTTCGC GGACGATCGGACCGGACGCCAGCTTGAACTTGCGTACGGCGCCGATGTCGGTCGCCTTCTTGCCGTCCTCGATCTCGCTTTCGACCAT GCGCGGATGCCAGCCGGGCAATCCGTTGAAATCACGAATGCGCGCCCAGACCTTTTCGACCGGCGCGTCGATGACGCTCGAAATCCTG ATTTTCGGCACGAAATCCTCCCTCGATGTTGCCGGGACGATAACGCCAGACCGCGCAGCGCGCTTATCAATCAGTCGGGATCGCTTAT CGATCCGTCTGAAATTCTCGCCCCCGGCTCAGGCAGCGCTCTGGATGGCGTCGCGATAGACGGTCGGCGGCACGCCTGCATGATCGCG GAAGAAGCGCGTAAAATTGCCCTGCGTCGTAAAGCCGAGGTTCCAGGCGACTGACGTCAGCGGCTCGCGCGACCACTGCAACTGGCGC AGCGCCTCCTGCATCCGCAACGTATTCCAGTAGACGTTGGGCGTGAGGCTGGTCTGCTCCTTGAACAGCGCGAAGAAATGCGGCCGCG ACAGGCCGACGCTTCTGGCGACGTCGTCGAAGCAGATGCGCTCGCTGACATTCGCCTTCATCAGGTCGATGGCCTTAAGCACGCGGAA GTCGATGCCGTCATTGCCGACCGAAGCTGCGCGGCGCGGACGAACCGATTGGGCCGCGTCCGCCAGGCAGTCGATCAGGCGCTCGACC TCGTAGAGCGCGAGTTCATCGATCTCGCCGCTGCTCAGTTCTTCGTAGAGCAAGACGGCTGCGCGGTGCAGCCACGAATCAACAGGGA TGGATGGCGCCTGGAAGATGGTCTGCTTGGCCGGAACGCCGCGGCGGCGGTGGAACCATTCGGGATCGATGTAGAAGGCGAGGAACTG TCCCGCCCTGCCGTCGGCCGAAAGCGCGTGGCTGTGCGGCTGGAAGGAATTGATTCCGGCCGCGACCGTCGGACCGAGCTCGACCTTC GTGCCGCCTACCGTCATCTCTCCCGCGGCGCCGTCGAGCCACAGGATGATGTGCGCCTCGGAGTGGGCGTGGGTGACGAAATCGCTGG CGATGTTGAGCACCGAGACATGCCCGAATGCCCCGCGTACGAGCCTGATCGAGGTGGCCATTCTGCTTCCTCCCCGGGGCTTCGTAGA TCGTGCGCATGCGTGGCCCCGCTGCTCAAAATAGTGATGCTCCGGCGGTAGATCGTCAACACGAAACAGCCGGCCATGCGCTCGCCGT CATTGTGCAGCGCAGCACATTTTCCCTCTTGCGTGTTTAGTAAATTCTGTTTCAACTAAACAAATTACTCAACATCGCGGACGTGATG TCGAGGCCCCCGAGGAGAGGGGTTCACGGTTCTGAGGCCGTCATCCAGACGGTCTCGCTAATGGGAGGTAGGCATGAAATCGACATTG AAAGTGTCGCTCGGCCTGGCTGCGGGGCTTGCCGCCTCGACTGCCATGACGGGCGCTTCGCAGGCCGAAGACCTGACGCTCTGCTGGG CCGCTTGGGACCCGGCGAACGCGCTGGTTGAGCTTTCGAAGGACTTTACGACGCAGACCGGCATCGGCATGAAATTCGAGTTCGTTCC GTGGACGAACTACGCCGACCGCTTCCTCAACGAGCTGAACTCCAAGGGCAAGCTCTGCGACCTGATCATCGGCGACAGCCAGTGGATC GGCGGCTCGGCCGAGAACGGCCACTACGTCAAGCTCAACGATTTCTTCGACAAGGAAGGAATCAAGATGAGCGACTTCGTCGACGCGA CGGTCGTCGGCTATTCGGAATGGCCGAAGAACACGCCGAACTACTGGTCGCTGCCGGCGTTTGGCGACGTGGTCGGCTGGACCTATCG CAAGGATTGGTTCGCCAAGCCCGAACTGCAGGCGGAATTCAAGGCAAAATACGGCCGTGACCTGGGCGTACCGGCGACCTTTGCCGAG TTGAAGGACATCGCGGAATTCTTCCAGAATCGCGACATCGACGGCAAGAAGGTCTACGGCGCGTCGATCTACACCGAGCGTGGCTCCG AAGGCGTCACCATGGGCGTCATGGACGTGCTTTATTCCTACGGCTTCAAGTACGACAACCCGGACAAGCCCTACGACATGCAGGGCTT CGTCAACTCCGACAAGTCGGTGGCCGGCCTCGAGTTCTACAAGTCTCTCTATGACTGCTGCACGCCGCCCGGCGCATCGAACAGCTAC ATGGGCGAAGGCATCGATGCCTTCAAATCTGGCCAGGTGGCGATGCACATGAACTTCGCCTTCACATGGCCTGGCTTGCAGAAGGACG AGTCTGTCGGCGGCGACAAGGTCGGCTTCTTTGCCAACCCGGCCGGACCGGACGGCGAGAAGTTCGCACAGCTCGGCGGCCAGGGCAT CTCGGTCGTTTCCTATTCCGACCAGCAGGACGCCGCGTTGCAGTACATCAAGTGGTTCGCCACGACCGATGTGCAGAAGAAGTGGTGG TCGCTCGGCGGCTTCTCGTGCCTGAAGTCGGTCGTCGAAGACCCGACCTTCGAGGCCAGCCAGCCGTACGCGAAGACCTTCCTCGACT CGATGGCGATCGTGAAGGACTTCTGGGCCGAGCCGAGCTACGCCTCGTTGCTGCAGGCTTCGCAGAAGCGCTTCCATGACTACGTGGT GGCCGGTCAGGGCACTGCCAAGGAAGCTCTGGACGGCCTCGTGGCCGACTGGACCGAAATCTTCCAGGACGAAGGAAAGATCTAAGTT CGTCCTCCCAAGCCCGCCCCGCGCAATATAGTATGCGCGGGGCGGAGACCCCCGAGACCATGCAAGACTTGCCCAGCGGAAAACCTGT CGTGACCGACACCACCTCGTCGATACTGGATCGGGCGGCGGAAGCTGCCGTGCGGGCGACGCCGGACACCCTCGCCACGCGGGTGCGC GGCCTCTCCGACCGGATGGTCGCCTGGATCTTCATCGCGCCGACGATGCTGCTTCTGCTGGCGATCAACATCTTCCCGCTGATCTGGG CAATCCAGCTTTCGTTCACCAACTACCGCGCCAACCGGCCGAACGAAGAGATCAAGAACGTCGGCCTGCAGAACTATTCGCGCATCCT GAACGATGCCGACACCTGGATCGCCATGCAGGCGACGGCGCATTTCGTGCTTTGGACGATCGTCCTGCAGACGCTGATCGGTTTCTCG CTCGCCTATCTCATCGACCGCAAGTTTCGCGGCCACGCCTTCTGGACGACCATCATCCTGGTTCCGATGATGCTGTCGCCGGCGGTGG TCGGCAATTTCTGGCGCTTCCTCTACGAGCCGCAGATCGGGCTCTTCGCCTATGTCGTCTCGTTCTTTACCGGCATCCCGCCGACAGA GATCCTGATGCTGTCCTCGGTGAAGCTTGCACCCTGGGCGATCATCATCGTCGACACCTGGATGTGGACGCCCTACGTGATGCTGATC TGCCTGGCCGGCCTGCGCTCCATCCCCGACTACATCTACGAGGCGGCCGAGGTCGACCGCGCGTCAAACTGGCGGCAGTTCTGGTCGA TCACGCTGCCGATGGCGCTGCCCTTCATCATGCTGGCGGTGCTCTTCCGCGGCATCGAGAACTTCAAGATGTTCGACATGGTGAACCT GCTGACCGGCGGCGGGCCTGGCTCTACCACCGAGGTCGCCTCGATCACGCTGAAGCGCGAGGCGTTCGAGAAGTGGCGCACCGGCTTC TCGTCTGCCTTCGCCATCATCCTGTTCGTCGCCGTCTTCGGACTGGCCAACATCTACGTCAAAGTGCTGAACAGGGTGAAGAGCCGAT GAGCGCCACCGCTCACTCCGTCGTCGAGCCGAGCACGACATCGAAGCGCGTGGCCGCGACGCTTGTCGTGGTCTATGCGCTAATCTCG ATGATCCCGCTGTTCTGGATCTTCGCGACCAGCTTCAAAACGCCACCCGATTCGATCGCCTATCCGCCGAAGGTGCTGTTCACGCCGT CGATCGAAGGCTACTGCAACCTGTTCACGACGCGCACAAGGCAGACCGCCGAATACATCAACTCGCTGCCGCCGGCGACGAGCTTCTG CGACGAGACCACGCGCAAGCGCAACATGGTGATCGCGGGGCAGTCGAACTTCCTGCCGCGCTTCGTCAACTCGCTGATCATCGCCTTC 
GGCTCGACCTTCTGCGCGGTGTTCCTCGGCACGCTCGCCGCCTATGGCTTCTCGCGCTTCAAGGTGCCGCTGGCCGACGATCTCCTGT TCTTCATCCTGTCGACGCGCATGATGCCGCCGATCGCGGTGGCGATCCCGATCTACCTGATGTACCGCGAGTTGGGCCTGTCGGATAC CGCGCTCGGCATGATCCTGCTCTACACGGCGGTCAACGTATCGCTGGCGGTGTGGCTGCTCAAGGGCTTCATCGACGAGATTCCCCGG GAGTATGAGGAAGCCGCGATGATCGACGGCTACACGCGGCTGCAGGCGTTCCGCAAGGTGGTTCTGCCGCAGGCGACCACCGGCATTG CGGCGACCGCGATCTTCTGCCTGATCTTCGCCTGGAACGAATACGCCTTCGCCTCGCTGCTGACATCGGGCACGGCGCAGACCGCGCC GCCCTTCATCCCGACCATCATCGGCGAAGGCGGCCAGGACTGGCCGGCCGTGGCTGCGGGAACGACCGTCTTCCTGGTGCCGATCCTG GTCTTCACGATCCTCCTCAGGAAACAGCTGCTGCGCGGCATCACCTTCGGGGCGGTACGCAAATGAGCGCGGGACAGACAAGGAAGCG CCGTTCGAACTGGCCCCGCGCACTGCGCCGCGGGCTGCTCGAAAACATCGCCACGGCGATCATCGGCATCGGTTTCCTGATGCTGTTC CAGCCCTTCGCGCTGTCGCTCTACACATGGTCGTTCGTGACCATGTTGTTCGGCACGGCGATGTTCATCATCGTCTCGAAGTTCCCGG AGTAGACGATGGCCGAGATACGCGTCCAAAACCTCAGGAAGGAATTCGGATCGTTCGTGGCGGTCCAGGATTCCAACTTCGTGGTCAA CGATGGCGAGTTCTTCGTCATGCTCGGGCCGTCGGGCTGCGGCAAGACGACGACGCTGCGCATGATCGCCGGCCTTGAACTGCCGACC GGCGGACAGATCCTGCTCGGCGGCGACGACGTCACGATGCTGAGGGCGCGCGAGCGCGACATCGCCTTCGTGTTCCAGCTTTTCGCGC TCTATCCGCATATGAACGTGCGCAAGAATATGGGTTTCCCGCTCTTGGCGCAGGGCATGCCGAAGGCCGAGATCAGGGCGCGTGTCGA GGAGACCGCGAAGCTTCTGCGGATCGACCATCTGCTCGACCGCCCGGTGTCCGGGCTCGCCGGCGGCGACCGCCAGCGCGTGGCGCTC GGCCGCGCGATCGTCAGGCGGCCGAAATGTTTCCTGATGGACGAGCCGCTCGGAACGCTCGACGCGGAGTTCCGCGATCTGATGGTCC ACGAACTGCGCGAGCTGCATAATCGCATCCACGCGACGACGGTCTATGTGACGCACGACCAGCTGGAAGCGATGTCGATGGCCGACAA GATCGCGGTGATGAACCACGGCGTCATCGAGCAGTTCGGCACGCCGAAGGAGATCTACGATCACCCTGCAACGATGTTCGTCGCCGAC TTCATCGGTTCGCCGCCAATGAATTTCCTGAAGTTCGGCGGCGCCCTGCAGAAGGGTGCGAAGGAGATCGTGGTGCAAGGAGCGAATG TCCCGGTGCCGGAGGTGCGCGAGGCGTTCGCGGCAGCCGATTTCGCGCTTGGCGTAAGGCCCGAGCACATCCGCTTCGACGATGCATC GAAGCTGCGCGGCTCGATCTACGGCACGGAATATCTCGGCACCACGCAGATCGTCGCCGTGGAGACGGCTGACGGCATGCTGAAGGCG CGCGTTCCCGCCGACATCAAGCTGCGCATGGGCGAGCCTGTCGGGCTGTCGTTCAACCCGCAACGCCTGTCGCTGTTCGAGAAGGCGT CTGGCCGCGCGGTCCACACAAGCGCCCGGGAACCCGTGGCGACGGGAGCGGCGCATGGCTGACGTTTCGCTGCGCGGCGTATCCAAGG CATTCGGCGACACGCAGGCGGTCGACGACCTCACGCTGACCATCAAGGACGGCGAATTCATCGTGCTGCTCGGGCCGACCGGCGCCGG CAAGACGACGACGCTACGGCTCGTCGCGGGGCTCGAACGGCCCGACAGCGGCTCGATCGTGATCGACGGCCGCGACGTCACCAAGGTC GCGCCGGCGGCGCGCGACGTGGCCTTCGTGTTCCAGCAATATTCGCTCTACCCGCATTTGACCGTGTTCGAGAACCTCGCCTTCCCGC TCCGCTCGCCGGCGCGCAATGTGGGCAAGCAGGAGATCGAACGCCGGGTCGCCGAGGTGGCGAAGCTGGTGCGCATCGACCACAAGCT GGCGAACAAGTCGACTCGGCTCTCCGGCGGCGAGATGCAGCGCGTTGCGATCGGCCGCGCGCTGGTGCGCAAGCCGTCCATCTACCTG ATGGACGAGCCGCTGTCGTCGCTCGACGCCAAGCTGCGCGGCGATCTCAGGCTCGAGCTCAAGCGCATCCAGGCCGAACTCGGCTCGA CCATGCTCTATGTCACGCACGACCAGATCGAGGCGATGACCATGGCCGACCGCATCGGCATCCTCGCCGAAGGACGGATGGTGCAGAT CGGCACGCCGAGGGAGATCTACACCGAACCGGCGAACCTGCATGTCGCCGCACGCCTCGGTCAGCCGGCGATCAATCTCCTGCCGCCC GACCTGCTGCCCGAGACCTCGGCGCCGGCGGGCACCAGGACCATCGGCGCGCGCACGGAACACCTGACCATCCAGAAGGCGACGAACG GCCATTCGGACGGAACGATCGACTGGATCGAGCATCTCGGCGACCAGAACCACCTGCACGTGACCGTTGGCAGCCGCAAACTGGTGAC GCTGACCGATCCGGACACGCTGTTCGAAAGGGGCGACCGCGTGACGATCCGCTTCAAGGCGCCGCTCTATTTTGACGGCGCTGGCAAC AGGATAGCCGGGTGATGGAGGCCGCCACCATGACCAGACCGGATCTCAAGGCCCTGATCGCCGCGGTCGCGGACGCGATCGTCGGTCA TGCGGAAGAACTCACAACGCTCGACCAGGCGATCGGCGACGGCGACCACGGCCTCAACATGAAGCGCGGCTTCGAGGCTGTAAGAGGT GATGCGGCGACACTTGCCGAGAAGCCTTTCCCGGAAGCACTGAAGGCGATCGGCACCAAGCTGGTGATGACCGTGGGCGGCGCATCGG GACCGCTGTTCGGGACGTTGTTCATGACGCTCGGCAAGGAGATTTCCGCCGAACCCGGCCGCGCCGATTTCGCCGCCGCGCTGGCGAA GTCCATCGACGCAGTCGCGGCGCGCGGCAAGTCGCAGCCCGGACAGAAGACCATGCTCGATGTGCTCTACCCGGTGCAGGCTGCCGTT GCGGCGGGCAAGAGCCCGCCCGAAATCGCGGACATCGCCGACGCTGCCGCCGAAGCGACGAAGCCGCTGAAAGCTATCCGCGGACGCG CGTCCTTTCTCGGCGACCGCTCGATCGGCCATATGGATGCCGGAGCGCGCTCGACCGCGTTGATCGTCCGGGCAATCGCCGAAACTCT GGAGACCGACGCGTGAAGAATGTCGGCATCGTCATCGTATCGCACTCGTCCAAGGTTGCCGAAGGCACCGCCGACATGGTGCGCCAGA TGGTCGGCGAAGAGGTGCCGCTGGCGTGGTGCGGCGGCAACGCCGACGGCGGGCTGGGCACGCAGGTCGGCGCGATCATGGAGGCAAT CGACAAAGCTTGGTCGGAGGCCGGCGTCGCAATCCTCGTCGATCTCGGTGGCGCCGAGACGAACAGCGAAATGGCAGTCGAAATGATC GGCGAGCCGCGCTCGCAGAAGATCGTCATCTGCAACGCCCCGATCGTCGAGGGTGCGGTGATGGCCGCCACGGAAGCATCAGGCGGCG CATCGCTCAAGGATGTAGTCGCCACCGCGCACGAACTCGCGCCGGCATAGGACAAGATCGAGATGTCGGCGACAGCATCGGCAAAGAT CGAGATCACGCACGCGGTGGGCCTGCATGCCCGTCCGTCCGTGAAATTCACCAAGCTGGCGAAAACCTTTCCAGCTTCGGTGGAAATG GCGCTGTCGGAAGCCGGCCCCTGGATCGACGCGAAGTCGATCGTGAAGGTGATGGCCGCCAAGGCGCCGAAGGGCACCACGCTCTATT TGCGCGCCAGCGGCGAAGGAGCTGCGCAAGCAGTCGAGGCGCTGGTGGCGCTGGTCACCCGCGATTTCGACGAAGCCAGCGAGGGCGA GGCGCATGTCAGGAGCGCCTGACAGGGTGCTGCGCGCGAAACCGGCCCTGACATTCAGCGGCGCCGCCGCATCGCCGGGCTACGCGCA AGGGCGCGTCCACCGGTTGGACACCAAGGCGTCTCATTACGAACGAAAGGCGTCTCCAGCGCTGGAAGCCGAAGCGCTCAAGGCGGCC ATCGAGACATCAGCCAAACGCCTTGCCGACCTCGTCTCGAAAACCACCGGCGAGGCCGCTGACATGCTGGAGTTCCAGATCGCGATGC TGGCCGACGACTCGCTTTTCGGGCCGGCCCTCGACGCTATCGAGAGCGGAACGGCAGCCGACGAGGCATGGTCGGCCGCACTGCAAGC CGAAATCGACGGATATGAGACGGCCGACGACGAGTATTTCCGCGCACGCGCGGCCGACCTCAAGGACATCCGCCAGCAGGTGCTGGAC GTGCTGGGGCATGCAGGCTCGCTGGACGCTCCCGCAGGCGCGATCCTGGTCGGCGAAGACATCGCGCCGACGCGCTTCCTCGCCACCG ACTGGACGCAAGGCGGCGGCATCGCGCTGACGGCAGGCAGTTCGGCCAGCCACGTCGCGATGCTTGCCCGCTCGCGCGGCGTGCCGAT GGTCGTCGGGCTTGGTCCGGTGCCGGTGGAATTCGACGGGGTCGCCTTGCTCGACGCGGAACACGGAAGCCTTCTGCTTGGCGCGGAG GGCGAAGCGGCGGCGCTTTTCAGATCCAATGCCGACGCCTTCGCCGCAAGCCGGCGCATGGCCGAGACCCATCTGCATCGGCCCGCCG TGACCGCCAACGGCACGCCGGTGACCATGCTGATGAACGTCGCCGATCCCGAAGATGTCGACGGCATCGATATCGCAACCTGCGACGG CGTCGGACTTATGCGAACGGAGTTCCTGTTCGGAGGGTCAAGCGGCTTGCCCGACGAGGAAACGCAGTACCGCGCCTATCGCAAGGTG CTCGAATGGGCCGCCGGCAAGCCAGTGACGATCAGGACCGTCGATGCCGGCGGCGACAAGCCGGTGGCGGGATTTACGGTCGAGGAGA CCAATCCGTTCCTGGGGTTGCGCGGCATACGCCTGGCGCTGGCGCGGCCGGATGTGTTCCGCATCCAGATCAGGGCGTTGCTCAGGGC GGCCGTTCACGGCAATCTGAAGGTCATGTTCCCGATGATCGCAGTGCCGGAAGAATATCAGCGTGCAAAAGCGATGTTCGCCGAGGAA GCCGGACGGCTTGGCGACACCGGCATCCCCTTCGCAATGCCGCCGCTGGGCATCATGGTCGAGGTGCCCAGTGTGGCGGTTGCGCCCG AGCTTTTCTCCGAAGCGGCGTTCTTCTCGATCGGCTCCAACGATCTGACGCAATATGTGATGGCGGCGGCGCGCGACAATGCATCTGT CGCGGCGCTCAACGCGGTGACGAACCCGGCGGTGCTTCGGCTGATCGAGGCGGTGGCCAGCTTCGGACGGGATCGCGGCATTCCGGTC AGCCTGTGCGGCGACGCCGGCGGCGATCCCCTGGCGATCCCGCACCTGCTCAAGGCGGGACTGCGCGACCTTTCGGTGGTGCCGGCGC AGCTTGCCCGGGCGAAGGCGGCCGTCGCCGCGGCCACGGCCTGACATGGCCAGGAAGCCGCCACCATCAGCCGCCCCGCCGGATGCCG ACGCCGCGATCCGCGCCTACAAGAGCGTGCTATCGACCGTCATCGAGCAGCGCCCTTCCGGCACCCGGCAGCGCCTTGCCGACGCGCT CGGCAAGCACCGCAGCTTCGTCACCCAGATCACCAGCCCGACCTATTCGACGCCGATTCCGTCGAAACATCTGCCGGCGATCTTTTCC GTCTGCCATTTCAGCCCGCAGGAGCGCGAAGCGTTCGTCGCGGCCTACAGGGTGGCGCATCCGGGCAAGGCCTCGATGGACGGCGAGT TGCGCCGTAGCAGGCATATCGCCCTGACAGTGCCCGATATGGGCGACGCAAAGCAGAACGCGGCGCTCGACCGCGCCATCAACGAGTT CATACACAGGATCACGAGCATCGCCGGCAAAGGCGGCTAGCGGTCTGACCGCTGAGCGAAAAAGGGGAGCTGGACCATGAAGAAGTTC ATCAATGCGGTCGAGGACGTGCTGACCGAAAGCCTCGACGGCATCGTCGCGGCGCATTCCGACATCCTGACGCTTGGCGGCGGCCACA AGTTCATCCGCCGCAAGGTGCTGAAGCCGGGCAAGGTCGCGCTTATCTCGGGCGGCGGCTCCGGCCATGAGCCATTGCACGGCGGCCT GGTCGGGCATGGCATGCTCGACGCCGCTTGCCCGGGCCAGGTCTTCACCTCGCCGACGCCGGACCAGATGATGGAGGCGGTGGCCGAC GTGGACACCGGCGCCGGCTGCCTGTTCATCGTCAAGAACTACGAAGGCGACGTGATGAATTTCGACATGGCCGCGGAGATGTCGGACG GCGTGCTGCAGGTCGTCATCAATGACGACGTGGCAGTGGAGGACTCTCTCTTCACGACAGGCCGGCGCGGCGTGGCCGGCACCCTGGT 
GGTGGAGAAAGTCCTGGGCGCCGCCGCAGAAGAGGGGCGCCCGCTCGCCGCGCTGAAGACGCTCGGCGACAAGGTGAACCGCGCGACG CGCTCGATGGGCGTGGCGCTGACCTCCTGCATCGTCCCGGCGGCGGGCAAGCCCAATTTCGAGATCGCGGACGACGAAATGGAATTCG GCGTTGGCATCCATGGCGAACCGGGCCGCCGGCGCGCCAAGCTCCTGCCGGCGGATGCGATCGCGGAGGAAATCTGCGCCGCGATCGT CGGCGACCTCGGAGCGGCGGCCAGGGACAACGCCCTGCTGTTCGTCAACGGCTTCGGCGGCACACCGTCGATGGAGCTTTACCTGATG TACAACAGCGCGCGAAAGATGCTGGAACGGCATGGCGTGACGATCGCGCGCTCGCTGGTCGGCAGCTATGTAACCTCGCTTGAGATGG CGGGCTGCTCGATTACGCTGACCATGCTCGACGATGAGACCGCGCGGCTGTGGGACGCACCGGTTCACACCGCCGCGCTGCGCTGGGG CATGTGAAGCCGTCGTCGGTCAGTGCGAGAGCAGCACCGGCAAACGAAGATCCGAAAGAACGCCGGCCGTCGCGCCGCCGAGCACGAA ATCGCGCAGCCGCGAATGGCCATAACCACCCATCACCAGCAGGTTGACGTCACGCTCCAGCGCGCCAAGTTGAAGAGTCTCGGCGATC GGACAGTCCTCCAGATCGAGCACAACTGCCTGCGCCGGCAGACCCGACTCGCGGAGCGCCGCCGCGAGGCGTTCGCCGGCATCCTTTT CCTTGATCGGCTTCTCGTCATAGACCGTGAGAACGGAAATTCTCTTGGCGTGCTGCAGAAAAGCGCGGGCATCGGCGACAGCCCGCGC AGCCGCGCGGCTGCCATCCCAGGCGATCGCCACATGGTCGAAGGCGGATGGCTTGAGCCTGTCGGGCACGAGAAGCACCGGCCGGCCC GAGCCGAACACGACGACCTCCGCCATCATGCGGCTGGTTTCGTTGCCAAATTCAACAGGGACCAGGCTCAAGTCGAGGTAGCGGGCAT GCACCGCCGCCACATCGGCGAGCGCGGCGATCGGCGCGGTCACCGATACGGCCGAGACTTCGACGCCAATCGCGGTGGCCTTGGCCTC TACAAGATGCGCCAGCCGGTCGCCCTCGATGCGGCTCTTGGTCTCCGCGTCGCGGATCAATTGCGGCGTGTCGAGGAGAAATTTCGAC AGCGCATTCGAGACGTCGGGAATGTCGGCCTTGATCGCAACGACGCGCAAGCTCGCGCCAATTTTTGGCGGCGATCTCGACGGCGTTGC CGAGCGCGGCCTCGCCGATCGTCTCGGGATAGGTGGCGATGGGCAGAAATGCGTGTGTCTTCATGACGTTTCCTCCCTTTCTCCGCGC GTTGGCGGTTGGGGCATGATGCCGGATTTTCCGAGGTGTAACAGACAACTCCGCGCGATTACTTGATCCCGGTCAAGGGACGGCATCG ACGGAATGGATAGGAGCTATCCCTGTCGGTCCCGATGCGCGCGATTGCCGGCCCGGCTTTGTCGCACTACAAGAGACCCCTCAGAGTT AAAGGCACTCTCCAACCCTTCCGGCACATGAAAGATTTCAACGACCGTCTGCAGGCAGCGATCATTTCCCGCCGCTTCGAGGGAGCGA GCGGCTATACGTTTGCGCTTGTCGCCTGCGCCCTCTCCTTCGGGCTGGCCTTTCTTCTGAACGGGCTGCTGGCGGGCGGCGCACTGCT GCTCTTCGTTCCGGCGGTGCTGGCCGCAGCGCTGATCGGCGGCGGCGGTCCCGGGCTTTTCGCAACCGTTCTGTCCATCGCCGGCGGC GCGTATCTGGGCGACCCGCCCGCGCCGCTTCTGATATTCGCCGCCGTCTCGCTGGCGATGGCCTGGGCGGGAGGGATGCTCCACCGCG ACCGCCGCACGATCGCGGAAACGGAGACCGCATTGCGGGCGCGCGAGGCGCATCTGAGATCTATCCTCGACACCGTGCCCGACGCCAC CGTGGTCATCGACACGAAGGGCACCATCGTCTCCTTCAGCGCGGCGGCGGTGCGGCAGTTCGGCTATGCCGAGCAGGAGGCGGTCGGG CACAACGTGCATATGCTGATGCCGGAACCCTACCATGCCGAGCACGACGGCTATCTCGCCCGATATATGACCACGCGCGAGCCGCGCA TCATCGGTATTGACCGCGTCGTCGTCGGGCGGCGCAAGGACGGCTCGACCTTTCCGATGAAGCTCGCCGTCGGCGAGATGAAATCTGG CACCAAAACCTATTTTACAGGCTTCATCCGCGACCTCACCGAACGGCAGGAATCGGCGGCCAGGCTCGAGGAGATACAGGGCGAACTC GCCCGGCTGGCGCGCCTGAACGAGCTTGGCGAAATGGCGTCGACCCTGGCGCATGAACTGAACCAGCCGTTGGCCACGATCGCAAACT ACACGCAGGGCTGCGTGCGCCTGTTGCGCGACATGGACGACGCGGTTGCGGATCGGATGCGCGAGGCGCTGGAGGAAACCGCCAGGCA ATCGCTGCGCGCGGGCGGCATCATCCGGCACCTGCGCGAATTCGTGACGCGCGGCGAGACCGAAAAGTCACCGCACGATATCCGCAAG CTGATCGAGGAGGCCGGTGCATTGGCTCTGGTGGGCTCGCGCGAACGCGGCGTCAGGAGCACATTCGACTTCGGGCAGGGCGACGCTA CCGTCATGGTCGACCGCATCCAGATCCAGCAGGTCCTGATCAACTTGATCCGCAACGGCATGGAAGCCATGCGGGACAGCAGACATCG CGACCTGACGATACGCACGCGCCCGGAAGGGGCGACATCGATAAGGGTCGACGTTTCAGACACGGGCCCGGGCATACCCGAAGACATC GCCGCCCGGCTTTTCCAGCCCTTCGTCACCAACAAGCCGGGGGGCATGGGAATCGGACTTTCGATCTCCAAACGCATCATCGAGGCGC ATGGCGGTGAATTGTCGACTAGCCCTAACCTTTCAGGTGGTGCAACCTTCAGTTTCTCGCTGCCCGTCGCCACCCTGCCGGCGCCGGC AGCCGGCAAAGAGGAGAGCGATGCTGACCGGTGACTATGTCGTTCATATCGTCGATGACGAGGAGCCGGTGCGCAAGTCGCTGGCTTT CCTCTTGTCGATGGCCGGCTTCGCCGTGCGGGTGCACGACTCCGCGACCAGCTTCCTGGCCTGTGCTCCCGGCCTCAGCAAGGGATGT CTGGTGACCGATCTCAGGATGCCGGACATGAGCGGTGTGGAACTGCTCGAGCAACTGGCGACGGCGAAGGCGTTGATGCCGGCGATCG TCATCACCGGCCATGGCGACGTGCCGATGGCTGTCTCTGCCATGAAGGCCGGAGCTCTCGACTTCATCGAGAAACCCTTTGAGGACAA AGTCCTGATCGAGGCCATTCGCCGTGCTGCGGAACGTATTCCGGCCCCGCATTCGGCATCGGATGACGCGGATGCGATCCGTGCCCGG ATCGAACAGCTCAGCGAGCGGGAGCGGCAGGTGCTCGGAGCCGTCGTGGCCGGCCTGCCGAACAAGACAATCGCCTACGACCTGAATA TCAGTCCACGCACGGTGGAGGTCCATCGCGCCAGCGTGATGGCAAAGATGCAGGCCAAAAGCCTGCCCGAGCTCGTGCGCATGTCGCT GCTGACAGAAGCCGCCGACCATATTTGATCTGGCGCAATGCCAGGCATGCCGCTCCGCCGTAGCAATAGGGATCAACCGCATCGCACA GCGGCCGGAGACCTTTCGCTTGACAACGGCCCCGCTCGTCATTGTTGTCGCGCCAGACCGAGCCTTCCGGCGCTCGCTCGAGTTCGCG TTGCAGACGGAAGGGTTTTCGGTCGAGTCCCATCCCGAGATCGGGCTGGCAATCGCAACGCCGGGTGCGCTGCACGCAAGCTGCGCGA TCGTCGACGACAGGGCCGTCGAGAACTGGGCCGAAGCCATCGTCACGTTTGCGACGTTCGGTCGGCCAGTGATCTTTCTGGCGGGCGA GAAGTCCATGCCCCCTGCCCTGCCGACGCTGACGGTGCTGACAAAGCCTTTTCTGGGACGACCGCTGATCGACGCCGTCCATGCGATC GCCCGGCAAACGCCCGGCAAGGTCCCTACGTAGATTCCCTAAGCAGATAACCGAATTTCAATGCGGCTGCCCTTGCGCCACTGCTTGC GTATCGAGAACCGATGCGGGAGAAGACGGATGACGCTGCGCCAGACCTTTACAGCCCCGGATTCGATCTCCGGAAACTGGACGCCGCC GCAATCCGTGCCCTCCGTATTGCAGGATCCGCACCCGCCGACCTTCTATCCGGCCGGAGCGGAGATTTACGCGCAGGGCGAAATCGCC GGCAAACTCTTCCGGGTCGAGTTCGGCGCCGTTCGCGTCTACCGCCTGCTTGCCGACGGACGCCGCCAGATCTCGGCGTTCCACCTCG CCGGAGAAGTTTTCGGCTTCGAAGCCGGGAGCATCCATCATTTCTTCGCCGAGACGATCGCCGCTTCCGGCATTCACGTGATGCGGCC GGCGCGCGGCCGCAGCCTTGCCGACGAACTGATGCCTATCGCACTCCAGGTTCTGGTCCGGGCCCAGGAACATCTCCTCGTGCTCGGC CGGCAAGCGGCCGAGGAACGTTTGGCCGCGTTTCTGGTCGATATGGCGGAACGGCAAGGTGATCTGATGCAGGTGGACCTGCCGATGT CGCGGACCGACATTGGCGACTATCTTGGTCTGACGATCGAGACAGTGTCGCGCGTGTTGAGTCGCCTCAAGCAGAAAGGCGTGATCCG GCTGCCCAATCTCAGAAGCGTCGAGATCCTCAAGCCGCAGGCACTGCGCGCCCTGGCGTTCTGACTGCTTCGTCGGCGACCAGGCGAT CGGCGAGCTTCTCGACCTGCAGGCGGATGTCCGGGACGGCGACGATCTCCCAGAACGCACCGACCGTCGCGGGACCGACGGCGAAGAC GCGGCGCGACGCCTTGCCCTGCGCATCGAGCGTCGCACAGTCGCCGGTGACGTCAACGGCGAGGCGCAGCGGATCCGGCCTCAGCCGG CCGTCGGCAAACAGCGCGCGCAGCAGCGGATTGCCCGTCGACTGCGAATCGGGGCTGTGGCCTCGGCAGTCGATCACATAGTCCGCCT CGATGGTCCGTTCCGCACCGGTTCCTCGCGGGACAAACCGCACTTTCGCCCCGGCGCCGCTTTCCTCGATGGCGGCCAGCCGCGCGGC AAAAACCGCGAGTTGTCCCGAAGCCTTCGCCGCCTCGATGCGATCATGTATCTCCGGCGCCATTCGATGCCGATGGACATCCCACCAG GGGCGCGCATGGCGCAGGAAACGGCGCTTCTCGACGGCGGGTAGGCTGCGCCAGATTTCCTGGCTATAGGGACGCAGGCTGTCGACGA CCGAGCGCCAGTCTCCCTGGCCGTCGCGCTCGACCTGCCGCACACGGTCGCGCACCCATCGACAGAGCCGCGACACCGACGCTTCGGC AGGCACGTCGGAGTTTTCGAGCGGCGCACGGCGCGCGGCGTTGTCGTGCGGCCTTGGCACAAGGCCGCGCCGCGAAATCGCGGCGATC GGGCCGCTGTGGCCTTTGTTGAGGAGCGACATGACGCTGTCGACCATGGACAGACCGGTGCCGACCACCACAACCGAGGCGTCAGGGG GAATGTCGAAACCGGATGGGCTCGACCAATAATCGCGCCGCCACGCGGCAGCCTTGCCGCCGGGGCTCTCGTTGCCGGTCGCAAGCAC CGCGCCATCCGCGCGATAGCGTGACCCGTCGGAGGCGACGAGTTCCACGCCATCCGGGCGCTCGACGAGATCGACGACCTGCTTTCGG TGGAGTTGAAGCCGTCCGCTGGCAACGTACGGCTCGACCAGGCTAGCCAGATAGTCTCGATAGAGCCGGCGCGGCACGAAGGATCGCG GCGTCCAGCCTCCGTCGGGCATCCATTTCGGAACGTCCTTGACCCATTCCACGAAATCGTCGGGCTGGTCGGCGAACGCGCTCATGCC CTTGGCAGCGACATTCAGCAGATGCACCGGATTTTCCGTGGCGTAGGCAATGCCTGCGGCAAGGTCTGCGCCCGGTTCGAAAAGGTCG ACCCGCTGCGTCGAGGCATGTTTCAGCAGGTGAGCGGCCGCAAGCACGCCGCTTGCCCCGCCTCCGACAATCGCGAACGTCTTCAGCT GCGTTCTCCGCTCGGCTGGTTTTGGGGCATCAGTTTGCGTCCGGAAGCGAGAATAGAGAAAACCATTCCCGATCTGATTGGCCTATCC GCCGGATCAGATCAACGCACTATGTCGACAGTGTCCAAGAAAATTGCGACGCGGGGATGGTTCACTTACGTGGACCCGGCGGCGGCAG ACCGCTGGAAATCAACTGTCGGTGACGCAAAGGTGAAACGCGTCCCTCAAGTCTTGCTGCGATATCCGGTCTATGATGGTGGTCGCCG GTGGCAGACCGTGCCGGCGGGGGCTGATCGCACCGGCGTCTTTAAATCCAGAGGAAAACCCCATGACCAGACTGACCGCCAAGGACTT TCCGCAGGAACTGCTGGAACTCTACGATTATTACGCGCACGGAAAAATCACCAAGCGCGAGTTCCTTGATCGTGCCGCCAAATTCGCG GTCGGGGGCGTGACCGCCGCGGCGCTCGTGGCGTCGCTGTCGCCCGATTATGCGCTGGCCCAGCAGGTCGAATTCACCGATCCCGACA 
TTCTCCCCGAATACATCACCTATCCGTCGCCAAAGGGGCATGGCGAGGTGCGCGGCTATCTGGTGCTGCCTGCCAAGCTCGACGGCAA GGCGCCGGCCGTTGTCGTCGTTCACGAAAACCGTGGCCTCAACCCCTACATCGAGGACGTCGCGCGGCGCGTCGCCAAGGCAGGCTTC ATTGCGCTTGCGCCGGACGGGCTGACCTCGGTCGGTGGCTATCCGGGCAATGACGAAAAAGGCCGCGAGCTTCAAGCAAAGGTCGACC CGGAAAAGCTGATGAACGACTTCTTCGCCGCCATCGAATTCATGATGGCGCACGAAAAATCGACCGGCAAGGTTGGCATCACCGGCTT CTGCTACGGCGGCGGCGTGTCAAATGCGGCAGCGGTGGCCTATCCGGAACTGGCAGCCGCCGTTCCTTTCTACGGCCGCCAGGCGCCG GTCGAGGACGTGCCGCGCATCAAGGCGCCGCTTCTCCTTCATTTCGGCGAACTCGACACCCGCATCAACGAAGGCTGGCCGGCCTACG AGGCCGCTCTGAAGGCCAACAACAAGGTCTACGAGGGCTACGTGTATCCAGGCGTCAACCACGGCTTCCACAACGATTCCACGCCACG CTACGACGAAGCTGCGGCAAAGCTCGCCTGGGACCGCACGATCGCCTGGTTCAAGAAGTATCTGGCCTGATCACCAGAGGGCGCGCCG CGCCCGAAGCGGCGTCCGGTGGGCCGCAAGAACCGGTTGCGAACCACCTGATTGCAAAACCCCACCGCCGGCGCCGTCGAGATCGAGC GTCGCGGCCAGAGCCTCGACGCGATCCGCCGCAATCCTGGCGCTTTTGCGCTCGATCCGGCCGATGGCATGCGACCCGGTCCCGTGCG TTTGCGATGACACGGCCGTTCCTTCGTCGATTCCCTAAAGGGCGCTACGCCGGCGCTCCCACCTGCCAATCCAGCAACTCAAAAATCT GGCCGACATCGTTCGCCGCCTCTAGTGACCAGACGAAATCGAAGACCTTTTGCATGCGCACAGCATCGATCAGGCCCTCGGCGCAATC GCGGAACTTCCCTTCAAGCTCGGAGTCGGAAAGCGGATTGTGCGGGCTGCCGCGATAGTTCTCGTCGGCCCAGCGCTCGATATGCCGG CCGTCCCTCGTCGTCACCTCGATCTTCGAGCGGATGCGGTCCCAGCCCATGTCCTCGATCGACTGGTCGAACGCGGTCTCGATGCGTC GCTGCATGTCCTGCGAAGCCGGCGAGGAGACGAAATCGTCGGTGAATTCCATCTTGCCGGCGCGCCCGGCCAGAATGATCGCCGTCAG CAGGAAGGCGAAAGAGAATTTCCCCTCGAGCTCCGTCGTCGCGATGCGGAAGCGGATGGGACCGAGCACGTTGCTGCCAGCCTTCAGC GTCACCGACGCGATGTCGTCGGCCGTCAGTCCGTTCTCCCGCATCAGGAAGAGCATCGCGTCCATGCTCGGATGGGTGAGCACACCGG ACGGATAGGGTTTGATCGAGACGCCGGGGCTTCTCATCGCGTGCGGCTTGCCGAAGCGGTCGCGCACGAGAGCCGGCTCCCCGCCGGG ACCGGCGATCGCCAGATAGCCCCATCGGCCGTCGAGCGCTTCCAGATTCGCGGAGAGGCCGTGGCGTGCCAGCAGCGCCGCCGTCACG CCGCTTTCCGCCGCGCGGCCGACATGCATCGGCTTGGTCATCGTGCCGAAGCCGGCGCGGATGCCGGACGCCATCGAGGCGGCAAGGC CGAGCGCCTGCGCGACGCCCCCCGCATTGAGGCCGAGCATCTTTGCCGCCGCTGCCGCGGCCGCAAAGGTGCCGATTGTGCCGGAGGT GTGGAAGCCGCTCATGTAGTGGTCCGGATTGATCGCCTCGGCCACCTTGCAGCCCACCTCGAAACCCGCCGAAAATGCCGTCAGGAAC CGTTTGCCGTCGACCGGCCGTCCCGTCTCCGCGACAACGAGATCCGACATCGTCAGCGCCGCGATCAGCGGCGGCATGGTCGGGTGCA TCAAGAGGCCGTAGGGGCGGCCCGGTCCTTCGGCGAGTTGCGTGTCGTCCCAGTCCATCGCGTGGCCGGCCGTTCCGCCCCAGAGCGC GGCGAGATGCGCCGGCACCCGGCGTCCGGCCTTGCCGATGAGACGCGCCTGCGGCGTACCGCCGAGACTCTCGATGTAAGCCCCAATC GGCCTCATTCCCGGGTGATCGGACCCGGCGAGCGCGACGGCGAGACCATCGAGCACGCAGCGCCGCGCGAGTGCAAGCGTCTCTCGGT CAAGGTCGCCGAATTCGAGATCAGCGACGAAGGTTGAGGCCGCCTTGGTCAGGCCGGTCAGATGCGCATGCGGGTCGGCGGTTGCGGC GGGTGTGTTCGGATGTTGGCTCACGGCGCTTTCCAATCGCATGTTTATGCGGCTCAGCCGAATTCCTGGCGGATGGCCGCCCCATCGG CATCGATGGACGGCACGGCGCCGCAGGCCGGGACGCTGCCCCGTCTCCGTGCCGGCGGGGCGGGCACGGCGACCACGTCGCCGTTCGT CGCGATATCCACCCGTCTCAGATGGGGATGCGCCGCCAGATCGAGCGGCGTGTTGACCATCGCATAAGCGATGCCTGCGGCGTCGAGC CGCGCGATCATCACCTCGTGCGGCGCGAGTTTGAAAAAGGCCCCGATCCGACCGTCCATTTCGGCGCGGTTCTCGATCCGCCGGAATG CGTCGGCGAAGCGTGGATCGGTCGCGAACGCGGCGTCGCCCATCACGCCGGCGCAGAAGGAATGCCATTCGCGTTCGTTCTGGATGGA GATCAGCACGCCCCGACCGTCGGCGCAGGCGAAGACGCCGTAGGGTGCGATCGTCGGGTGGCGCAGTCCCATGCGCGGCGGGTTCCTG CCCGATCCCTCGGCTTGCAGCAGCGGCACTGTCATCCAGTCGGCCATGGCATCGAACATCGCGATGTCGACGACGGCGCCGCGCCCTG TAAACTGCCGTTCGATCAATGCTTCGAGGATCGCGGCATGGGCATACATGCCGGTGCCGATATCGCAGACCGAGATGCCGACGCGCGT CGCCTCCTCCGGCGTTCCGGTCACCGAGGCAAGCCCGCTTTCCGCCTGGATCAGCAGGTCATAGGCCTTGCGATCGCGATGGGGGCCG TGGTCGCCGTAGCCAGAAATGTGGCACTGGATGAGCGCCGGGTTCAACTCTTCCAGCACGTCCACGCCGAGCCCGAGACGCGCCACTG CACCGGGCGTGAGATTTTCCACGAAGACGTCCGCCTTCGCCAGCATCGCCTTCAGAAGCGCCAGGTCGCCTGCCTGCTTCAGGTCGAG CGCGATCGACTGCTTGCCGCGGTTCAGCCAGATGAAATAGGTGGACTGCCCCTTGGCAAGCTGGTCGTATTGGCGCGCGAAATCTCCC TCCAGCCGCTCAACCTTGATCACGCGCGCCCCGGCATCCGCCAGCCGCGAGGTGCAGAAGGGGGCGGCCACTGCCTGTTCCAGCGAGA CGACAAGCAATCCATGCAGCGGTCCGGCCATCGCTCCGGTTCCTCAATAGGAACGGGGCATGCCGAGAACATGCTCGGACAGATAGGC AAGGATGAGGTTCGTCGAGATCGGCGCCACCTGGTAGAGCCGCGTTTCGCGGAACTTGCGCTCGACGTCGTATTCCTCGGCGAAGCCG AAGCCGCCATGGGTCTGCAGGCAGGTATCGGCCGCCTGCCAGGAGGCCTCGGAAGCGAGCAGCTTGGCCATGTTGGCCTCCGGGCCGC AGGCCTCGCCCCGATCGAAGCGTTCCGCCGCCCGGTAGACCATCAGCTTCGCCGCCTCCGCTGCCGCATAGGCGCGCGCGATCGGGAA CTGAACGCCCTGGTTCTGGCCGATCGGCCGGCCGAAGACGATGCGCTCGTTGGCGTAGCGCGCAGCGGTTTTCGTGAACCACGCCGCA TCGCCGATGCATTCGGCGGCGATCAGGATGCGCTCGGCATTCATCCCATCGAGGATGTAGCCAAAACCCTTGCCCTCCTCGCCGATCA GGCTGTCCGCCGGGATTTCCAGATTGTCGAAGAAGACCTCGGTCGTCGCATGATTCAGCATGGCGCGGATCGGCTTAATCGAGAGCCC GTTGCCGAGTGCTGCCTTCATGTCGACGAGGAAGACGGAGAGCCCGTCGCGATTCTTCGCCACCTTGTCCTTCGGTGTGGTGCGGGCA AGCAGGATCATCAGGTCGGAATGTTCGGCCCGCGAGGTCCAGACCTTCTGGCCGTTGATCACATAGGTCTCGCCGCGCTTCTCCGCAA AAGTGCGGATCGATGTCGTGTCGGTGCCGGCCGCCGGCTCTGTGACGCCGAAGGCCTGAAGGCGGGTCTTGCCGCTGGCGATCTTCGG CAGCCACAGCGTCTTCTGCACCTCGCTTCCGTGACGCAGCAGCGTGCCCATCGTGTACATCTGCGCATGGAGCGCGGCGGCATTGCAG CCCTGTGCATGGACTTCTTCCAGAATGTTGGCGGCGACCGCGATGCCCTGCCCGCTGCCTCCATACGCCTCCGGAATCAGCACGCCGA GAAAGCCACCTTCGGTCATCGCGTGGACGAAGGCCGTCGGATAGGCCTTTTCCCGGTCGAGCGCGCGCCAGTATTCGCCCGGAAAGGC GGCGCAAAGGGCCGCGACCGACTGGCGGATTTCGCGGATCATGTCGGCGTCGGCCGTGACTGGCTGCTCCTCGTTCATGGCTACTCCT CTCCGTCCGCCTCTCAGGTGCTGGTCGCCTCGCGCATCGCCCTGATCAGCGCGGAATTCTGCTCGAAGCCGATGCCCGGCGCATCGGG CAGGCCGACGCGACCGTTCTCGATGCGGTTGCCATCGGCGAAACCGCAGAACGGCTTGAAGACTTCCGGATAGGATTCGTTGCCGCCA AGCTTCAGGCCGGCGGCGATGTTCAGCGACAGCTGGTGCCCGCCATGGGGAATGCAGTTGCGGCTGGAAAAGCCCTCCTTGCCGATCG CCTTCAGCGTGCGCAGATATTCGACCAGCCCGTAGGAGAGCGCGCAATCGAACTGCAGCCAATCTCGATCCGGCCGCATGCCGCCGTA GCGCGCAAGATTGCGGGCATCCTGATGCGAAAACAGGTTCTCGCCGGTCGCCATCGGCCCCGGATAGACCTTCGCCAGTTCCGCCTGG ATATGGTAGTCGAGCGGATCGCCGGCCTCCTCGTACCAGAAGAGATTGTAGGGCTTCATCGCCTCGGCATAGGCGAGCGCGGTTTCGA GGTCAAAGCGGCCGTTGGCGTCGACGGCGAGACACTTGCCCTCGCCCACCACATCCAGCACCGCTTCGATGCGGCGGATGTCCTCGTC GAGCGGCGCGCCGCCGATCTTCATCTTGACGACTTCGTAGCCCATGGCGCGATAGCGCCGCATCTCGTCCTGGAGCTGGCTGTCGTCC TTGCCCGGATAGTAGTAGCCGCCGGCGGCATAGACAAACACCGACGTGTCGTGGCTGCCATCACCATAGGTATCGGCCAGATGCTTGT AGAGCGGCACGCCGGCGATCTTGGCGACGGCGTCCCAGACCGCCATGTCGACGACGCCGACGGCGACCGACCGCTCGCCATGACCGCC CGGCTTCTCGTTGACCATCATCGCCGCCCAGATCCTGTGCGGATCGAGGTTGTCGCCGGCGTCGTTGACGAAGCTCTCCGGCTTCGCC TCGCGCAGGCGCGGCAGGAAGCGTTCGTTCAGCAGCCCGCTCGCCGCATAACGGCCGTTCGAATTGAAGCCGTAGCCGATCACCGGCT TGCCGTCCTTCACCTGATCGGTCACGACCGCCACGACGCTCGCGGTCATCTTCGAGAAATCGATGAAGGCGTTGCGGATGGGCGACGA GATCGAGACCACGGCCTCTCGAATGTCGACGATTTTCATGGGCTCTTGCCTTTTGGACCGGCCGCGAATCGCACGAGCAGCGGCGGCG CGATGATGTTGGTGAGGAAGGAACGGGTGAACTGGAAACCGGCGACGATTGCCGCGGCGGCGCCGAGCGCCTTGGCCGAAGCGATCAT CTCGCCGAGACCGCCGGGGGCGACCCCGAGCGCCAGCGAGACGGGCGCGACATCCACGAAAAGGCGGAGCACCGGCACGAAGCCGAAG ACCATGAAGAGGATGAGGCCGCCGCTGCAGATGACGGCGGCGAACGCCGCTCGCGGCACGCGCGCGAAATCTTCCTTCTTCAGCCGTG CGCCGAGCGAGAAGCCGA 


\subsection{Das Cosmid slc_2g}

\subsubsection{Lage der offenen Leserahmen (ORFs)}

\begin{tabular}{|c|c|c|c|c|}
\hline ORF & Annotation & Start & Stopp & $\begin{array}{l}\text { Orien- } \\
\text { tierung }\end{array}$ \\
\hline 1101 & Potentielle Protease & 1 & 633 & - \\
\hline 1102 & Hypothetisches Protein & 704 & 1066 & - \\
\hline 1103 & Potentielle Protease $y u x L$ (EC 3.4.21.-) & 1332 & 3548 & + \\
\hline 1104 & Konserviertes Protein & 3711 & 7052 & - \\
\hline 1105 & Hypothetisches Membran-assoziiertes Protein & 7244 & 7813 & - \\
\hline 1106 & Konserviertes Protein & 7889 & 8299 & - \\
\hline 1107 & Konserviertes Protein (pfam04412) & 8299 & 9570 & - \\
\hline 1108 & Konserviertes Membran-assoziiertes Protein & 9656 & 10438 & - \\
\hline 1109 & Threonin-Dehydratase (EC 4.2.1.16) & 10671 & 11711 & + \\
\hline 1110 & Potentielles osmotisch induzierbares Protein & 11942 & 12385 & - \\
\hline 1111 & Hypothetisches Membran-assoziiertes Protein & 12479 & 13471 & - \\
\hline 1112 & $\gamma$-Glutamyl-Transpeptidase & 13512 & 15179 & - \\
\hline 1113 & Glutamin-Synthetase & 15464 & 17668 & + \\
\hline 1114 & Hypothetisches Membran-durchspannendes Protein & 17787 & 21014 & + \\
\hline 1115 & Hypothetisches Membran-durchspannendes Protein & 21122 & 23632 & + \\
\hline 1116 & Potentielle Threonin-Dehydratase (EC 4.2.1.16) & 24062 & 25039 & - \\
\hline 1117 & COG2989, Uncharakterisiertes in Bakterien konserviertes Protein & 25023 & 26792 & + \\
\hline 1118 & Glutamin-Synthetase & 26935 & 28239 & - \\
\hline 1119 & Hypothetisches Membran-assoziiertes Protein & 28291 & 29256 & + \\
\hline 1120 & Konserviertes Protein (COG2107) & 29330 & 30178 & + \\
\hline 1121 & Potentielles Sensor-Protein AtoS (EC 2.7.3.-) & 30203 & 33358 & + \\
\hline 1122 & Hypothetisches Protein & 33585 & 34253 & + \\
\hline 1123 & Potentielle Sensor-Hisidin-Kinase & 34278 & 35867 & + \\
\hline 1124 & Hypothetisches “„response-regulator-receiver“ Protein & 36001 & 36357 & + \\
\hline 1125 & Hypothetisches Protein & 36490 & 37011 & + \\
\hline 1126 & Potentielle Kurzketten-Dehydrogenase/Reduktase & 37008 & 37727 & + \\
\hline 1127 & Hypothetisches Protein & 37724 & 38617 & + \\
\hline 1128 & Hypothetisches Protein & 38895 & 39068 & + \\
\hline
\end{tabular}

\subsubsection{Die Sequenz des Cosmides slc_2g}

CGCCGTCGGGGCTGGGCTCGCGAATACGCCGTCAGCCAGCATGGCGTTCGCGCCGGTCGCCCGCTCCTCGGCGGGCTGGAAGACAAAC ACGACTGTGCCGGCGAGCGAGTCGCGCACCTGGTGCAGCATCGTCGCGAGCGCGACGCCGATCGTGGTGTGGACGTCATGCCCGCAGA TGTGCCGGATCCCGGGGACGACCGAACGGAACTCCACGGGATCCGGAGCCGTCGACGCGACCGCGTCCATGTCGGCTCGGTAGGCAAC CACCGGACCCGGGCGCCGCCCACGCAGGATCGCGACCACACCGTGGCCTCCAACGCCCGTGCGCACCTCCAGGCCCAGCTGCCGCATC GCCGCAGCGACGACCCCGGCCGTGCGCTGCTCGAATCCGGAGACTTCCGGATGGCGGTGCAGGTCGCGTCGAAATTCCACCATGCGCG CCGAGTCGCGGACAAGTACCGATCGTAACTGCTCGGCGACGGGCCCGGGTGGAATCGGTGCGAACGACGCTCCTCCCGGCGACTGCCG GCAGGCGATGGTGGCGACGAAGCAGAGAGTGAGCGTGCGGACGATGGGCATCGAGGCGAATCGGCAGTATGACCAACCTAGGTCCGCC CGGACACCCAACGACACTCGCCGATGACAGAACGTCCGGCCCGCGTGGCAGGCCGGACGCTGGGTCCGTGGTGTTCGACGCTCCCGGT CAGAACGGAGGGATGAACAGGTTGACCTTCTCCCCCGCCACGACCGTGATCTCGTCGCTGACCTGGTTGCCGCGCGCCCCGATCGGGT GCACCGCGAATCGCAGCGACGCGCCACTGAACAGCAGGTCGCGGGGGATCGTGAGCTTGCCGACGGTCAGCCCGGTCACCGTTCCCAG CCGCTGTACCCGCAGGCCGTGCACGGCATAGATGACCGCGTCGTTGAACGCCGTGTTCTCGACTTCGAGGACGGTGCGACCCTGCTTC 
AGGGTCGCCTCGTCGGTCGGATATCGATACGCGACGGGCTTCCCCAACCCCGTCACCAGCGCTGCGCCCAGCGCAAAGTGCATCATCA TCGCCCGCATGTGTTCCTCACAGAGAGAGTACGTCGCTCTCTACACGCACCGTGACGGGCGTTCCCGGGTTCCGCGTCGCCGTTGTCC GAACCTCGACCTGCCGGTTGGCGGGTCGGCGCCCGCGACGGCGAGGGCTGGCGACCCCGGAAGCCGCCCGGACCGGGTCGGAGCCTTG ACCGCGGGTGAACGCGCGCAACTATTGATGCGTACTGGATTTGGCCCGTCGCTCCCCCACCGGGCGTCCCCCGGATTCTGCACCCCTC GAGGTCCTCACATGCGCAGGTCTCTGTTCGCCCTCGTCCCGCTCCTCGCCCCCTTGGGTCTCGCGGCCCAGGCGCCGCGCCCCATGAC CTTCCTCGACCAGCAGCTGATGAAGCAGGCAGGGTCGCCGGCGCTGAGCCCCGACGGGTCGCGGATGCTCTACACGATCTCGGTGCCT AACTGGAAGGAAGCGAGGCGCGCCACGGACGTCTTCGTGGTGAACACCACGGGGGGCTTGGCCACCACGCGGCAACTCACCTTCACCA AGGACAAGAACGAGAACACCCCGCGCTGGTCGCGTGACGGCCAGTGGTTCGTCTTCTCGTCCAATCGTGATGGCGCGACGAACCAGCT CTACGTGATGTCGCCGGACGGCGGCGAAGCGCAGAAGATCACCGATGCGAAAGATGGTGTCGGCAACTACGGCTTCACGCGCGACGGC AAGTCGCTCGTGTTCGCCGCCGGCAAGCAGGACGAGCAGCAGCTCTGGATCATGCCGGTGGCGGGCATCGCTGAGGCAAAGGCGACGC CGCTCACGAAGCATGCGACGCCTATCGGGACCTGGCAGATCTCGGTCGACTCGCGACGCGTCTTCTTCCTCTCCCCGGACTCGGTGGA CAAGGCCAACAAGGAACGCATGGAGAAGAAGTTCGACGTGCGCATCCGCAACCTGGACGTCCCGCTCAACCACCTGTGGATGGTGGAC CTCGCCAGCGGCCAGGAGAAGCGCCTCACGCAGAGCAGCGACTTCTCCGCCGAGGGCTTCTCGCTCTCCGACGACGGCAAGTGGGCCG GGGTGCGCGGCCAGCCGAACGACCGCTTCGTGCGCACGACCAACGAAGCCAACAACAGCGGGGAGCTCTACCTCCTCAACATCGACTC CGGCAACCTCGAGCGCCTGACGAACAACAAGGAGATCTCGGAGAGCAACCTCTCCTTTGCGCCCGATGGCCGCACGATCGCCTTCTCG GCGTCCGACGACTTCGTCTACTTCAAGTCCAACAAGGTCTACACGCGCGCGATCGATGCCGTGAACGGCCGGTGGACGAAGCTCGGTG GCAGCTATGACGGCAACGTGACCATCGGCTGGTGGAGCCCGGACTCCAGGACGATCTACTACGGCGACGGCGTGCGGGCGACCAACCA GGTGATGGCGCTGGATATTGCCGCGAACACGGTGAAGCCCGTCACGGACTTCAAGGCCGCCGTGAACGCCAACCTCGACGAGGTGAGC GGCAAGATCCTCATCACGTACGCCGACCCGAAGACGCCGCCGGTCCATTTCGTGGTCGACAACATCGGCCAGGTCGCCAGCAAGTCGG CGTGGCGCCAGGTCACGAACGCCAATCCGCAGGTAGCGAACTTCCAGCTCGGCGAGGAGGAGGAGATCTGCTGGGCCTCGGTCGACAA GAAGCAGACGTGCGGCATCCTCGTAAAGCCGGTCGGCTACGAGGCCGGCAAGCGATATCCGCTCATCGTCGCGATCCACGGCGGCCCG CAGTCGGCCGACGTCCTTGGCTTCAACGGCGGCTACGGCGCCCAGGCTTACGCCGGCGACGGCTACATGGTGCTCAAGCCGAACTACC GTGGCTCCACGAACTACGGCGAGGCCCACAAGTGGGGCATCGTGAACGACTACTTCAAGAAGGGCTACGAAGACATCATGACGGGCGT GGACCAGCTCATCGCCAAGGGCATGGTCGACGGTGACAAGATGGGGGTGCTCGGCTGGTCCGCCGGTGGCCACTGGACCAACTGGATC ATCACGCACAACACGCGCTTCAAGGCCGCCTCGTCAGGCGCCGGCACCGTCAACTGGATCTCGATGTACGCCCAGTCCGACATGCAGT ACGTGCGCATGCACTACCTCGGCAACAAGCTCCCCTATGGTGACTTCGAGCCGTACTGGAAGCAGTCGCCGATCCGCTACATTTCGGC AGCGAAGACGCCGACGATGATCCACGTCGTCGACGGCGACCCGCGCGTGCCGCGTCCGCAGAGCGAAGAGCTGCACATGGCCCTCAAG AAGCTCGGCGTGCCGACGGAACTGTTCGTGTACCCCGGCATGACCCACGGCATCACCGAACCGCGCAACCAACTCCTCAAGGCCGTCG CCGAAAAGGCCTGGATGGACCACTACATCCTCGGGAAGGGCGGCTTCAAGTGGCAGGACGTGCTGAAGACGCTCGAGGAAGGGGAGAC GAAGGCCGTTACAACCACGAGCCCGTAGGGCTCGTGGTTGTAAACGAGTGGACGAGATAGACGAGTAGACGACACACAACTGCTTTGA ACAACGCCGGGTCCCTGAAGGGGCCCGGCGTTTCATTTCGTTAACCTCGTCCATCCGTCCGCTACGTCCATCCCGTCTACCCCGTCCA CCCGTCCCGCGTCGCTACTGACTCCCGCCGCCGATCTTCACGGCGTCCCCCTTGAGCGCATCACGATGAACCCACCAATGCACCCCGA ACGGCGTCTTTGCCGGCCACACCTCGTCCAGCGAGTTGCCATCGTACATCACCCCGCCCTTCATCACGTACCGGATGTTGCGCGTTTG ACGGATATCCTCCAGCGGGTTCCCATCGAGCACGAGCAGGTCGCCGAGCTTGCCGACCGCGAGCGACCCCGTCTCCTTCTCGATCCCG ATGAACTTCGCCCCGTGGATCGTCCCGACCTCGAGCGCACCCAGGGGGCCTAACGCGGACGCCGCCATCCAGACTTCCCAGTGCGAAC CCAGGCCATGCTGCTGCCCGTGCGAGCCGATCGCGCCGAACCCACCCTCCGCGATGATGTCGCCGAGCCCTCGCGCGAGCAGCGGAAA GCTGTAGTCGGTCTTCGGCCGGAGCATGCGCCGGCGCGTTTGCGGAATCAGCATCTGCCACGGCAACCATGACTGCAGCTTCGGATCC TTGAAGACGTCGCTCTCCGCGTACCAGTAGTCCTCGTTCCACGACGATGTCCCACCCACGGCAAACGTCGGGCTGTAGAAGGCGCCGG CCTTGCCGAAGAACTTCGCGACGTCGCCATAGATCGGGACGTAACCCCACGGATGCTCCCATCCCGTCTGGCCGTCCATGATCATCGA CATGTTGAACTCGATGTCGCCCCCTTCCGCGGTGACCCGGAGCCCGTGCTTGCGTGCGACGTCGCTCACCCACTGACGCTGGTCGCGG CGCGGCTGCGAGTACTGCTTCATCGTCACCGCGCCCCAGCTCTGCAGGCGCTTGATGTTCTGCTCCGCTGCCGTATACGAGGCCAGGT CGTTCTGGCGCTGCGCATCGCCGGCGTACAGCGGATCGCCGGAACTGTACGTGCGCGGGCCGATCATCATCCCCGCCTCGACCATCTG CGCCGTCGGGAAGACGTTGCCACTCCACATGGAGTTGTCGAGCGTGGTCGTCACGCCATACGCCATGTAGATCGCGGACTCCCAGTTC TTCCTCGGCAACACGCCTTCATGATCGCGATGATGGTGGGCGTGCAGGTCGACCAGACCAGGCATGATCGTCTTGCCCGACGCGTCGA TCACCTGCGCTCCTTGCGTTGTACACACGCCAACGCAGTGAATGCGACCATTCCGCACCACCACCGTTCCCCGCGCAATCACCGTTCG GTTCTCCATCGTGATGATCCGCGCATTGGTCAGCGCGATCGATCCTGCCGGCACGCGCTTGGGCACCTTGAGCGTGATGGTCACCGTG TCGGCCTTGTTGGTCCGCACGTCCATCGCGATGATGCGATTGGCGCTCGCAAACTCCGCGGTCACGCTGTCACGCCAGTGGGGAAAGA GCCCACCCTCCAGCGACAGCTGGCGCGCCGGCAGGCGCCCGGTGCGTCCATGCTCGATCCGTGGGGCCACATCGCCGGTGCCGGCGAG GGGGAATGAGATCAGGTACGCGTTGTCGCCCTCCTGGTACAGCAGCCACTTGCCGTCCGGCGAGATCGCGGCCTCGTCGACGAATGGG AACGTCAGGTGAACCTTGCGATCGCCACCATCGCGATTGATCGATACGTAGTCGGTGCCCGCGGGCTCCGCGGGGGCGCCGGCTTGCG CAGCCTCCGCGCCATGCGTCTCCGGGAAGTAGATCCTGCCGCCAGGACCATAGTGCGCCTGCACGATGGGTCGCCGAGGCATGCCGGG GCGACTCGCGGAGAAGGGTCGATTCACTTCGGTGATCATCCGCTCCGTCGCCCCATCCGCCGAGATGCGTCGCAGCTCGTACCACGTG TTGTTCGAGACGGAGTGCTGCCGCAGGAAGCCGCCGTTTCCTCGCGTGACGATCAGCTCGCTGCCGTCGGGTGCCCACACGGGCTGCA GGTACTCGCCCGCGACCTTCGTGAGTCGCACCGGCTCACCGCCAGTGGCGCGCACCTTCCACAGGTGCCCGAGCTTCTCGTCGTCGAA CGTCGTGAACGCGATCCACTGGCCGTCGGGCGACCACGCCGGCGACAGCTCGACGGACGTGAATGACGCCGGTGCCAGGCGCTTCGGT GTCCCGTTAGGCACGTCGGTGACCCACACCTTGCCGGCGCCTTCGAACGCCGCGCGCTTCCCGTCCGGCGAACGCGACGCCCAACGCA GGTACTGCACGTCGAGCGTGTCGTCGCGCACCGATCGCGACACGAGCGCCTGCTCCGAGATCGTGCGCTGCACCCGCGCCGTGAACGG AATCTCGGCCACGTGTCCACTCGCGACCTCGAGACGGCGAATCTTCCCGCCCTGCGAGATGATGATCCCCCTCCCATCCGGCGTCCAC GCGTAGCCCGGTAGCACGCGGGAGATCTTTCCGCCCTCGGCCATGTCGACCTCGATCGGGTCCATGATCACGCGCTCGGTGCCCGTCT CCATGTCGCGTAACCAGAGGGCCGTGCGCGGCCCGAACTCGAGTCCCTTGAACTCGATGGTCCCGTTGGGTATGCGTCGACCGAACGC CACCCACTTGCCGTCGGGCGAGACCTGCGGGGCGACCGCACCACCGCTCGATCCCTGGTACTGCTGCTCCGAGAGCCCATCGGTCACC ATCAATACGCGACCCGTCGCGAGTTCGAGCCGACGGAGTTGCCGCGATCCCTGGGTGACGTCGTTCTTGCCTGACGCGATGCCTTCGG TGATCGCGACCTGGTAGTAGAGGTACTTGCCGTCCTTCGAGAGCGCGGGTGATTCGGGGCGCGATTGCGTGACCAGAGCGATGCCGGT GCCACCGTCCTTGCTGTACATCCACAGGCCACCACCCCCACCGCCTCCACCACCCGTGGCCGACCGCCTGACGACGATGAAGTTTCCA TCCGCGGTCCATGCCGGCTCGGCCGCGCGCACGTTGGGGTCGGTGAACACCGGACGCGGGTTCGAGCCATCGGCGTTCATCACCCAGA GGTTGTTCTGTCCGCGCCGGTCGCTGATGAACGCGATCAACGAGCCGTCGGGTGAGATGCGCGGGTGGAAGTTGACCGCGACGCCGCT GTTCTGCGTCAGCGTGGTGGCTTCACCACCTGCCGCCGGCATCCGATAGACATGCCCGAGCAGGTCGAAGACGATCCATGACGCGTCG GGCGAGATGTCGACCGACATCCACGTGCCTTCATTCGTCGTGAAGTTGATGTCGCGCGTCTTGCCGCGCGCCAGCGTGACGTCCCAGA CCGAGGGGGAGCTGGCAGGTGGCGCGGCGGCCTGGCCTTCGAGCGACGAAGCGAAGGCGGTGAGAAGGACGAGCGCGAAGGTCGGTCG GCGCAGGCGCATGGCAGTTCACGGTGTCGAGGAGGACGACACCATGCGCCGGGGGCACGAGCACCGCAATGCGGTGGAGCGGACGGGT TGACGGGTGGACGGGTGGACGCGTGGACGGAATGAAGAAGGCGGGTGGTCGAAGGGCACGAAGCCCAGCACCACCCGCCTACCCGCCT ACCCGCCTACCCGCCCACCCGCCCGAACTACCGACACCTCGTCGCCGCCGCGACCTCGAACGCGAGTGTGCTCGCGCGATTGTATCGG AGGATCTTCTGTACCGAGGCCGGTGGGTTGAGCGCGACGGCACGGGCGTACCGCTCCGCCGTGGCCGTCTCCGCCTCGACCGCCACCT CACACGCCCCGGCCACCGAGGCGTAGCGCTCCATGTACTGCGGGCCCCCAAACGGGTTCGGCGGCGGGAAGGCCGGGTACTGTCGGTA GATCTGCATCAGCGTCTCGACGCGCGCCGCCTGCACCGGCTCCATCTCCTTGAACGGCGAAACGGTGCCGAAAGCCTGCATCACCTGT TGGTACCGCGCAGCGGCCCGGTACTCGTCGACGACGAGGGAATCGAGGATCGCGCTCACGGCGTGTGGCAGGCGTTCCGCAGGTGTGA GGGCATCGCCACTCCCTGCGCAGGCAACAGCAGAGAGCGCAAAGGCGCCGATCACGGCGGCGTGGCGAACGCGGGACGGGCTGTAGCG 
GCGTGTCATCGTGACTGACCATACAAGCCAGTCGCGTGCCAGCGCAGGTGACTTTCGCCACATCGGCACCGTGACTTCCCGGCATCGC GACCGTATCGGTCAGGGTGACGCAAATCGGCATGAGCGATCATGCCCTGCACACCCTCATTGGACCACGTTCACCTGCCCAGACGCCA GCACCTCGAGCTCGCGCGCCGATGCAGAGAGTGCGTAGTCTGCCGGCGAGAGTACCACGATCGGGACCACCGTCCCATACAGCGCCTC CGCCACGAGCGCGCCGATCACCAGGATCGGGTCGGCCGTCGCGAGCACGATCGCGGCAGGGCCCACGCCCGCCCGGATCACTTCCGCG AGCACGCTCGAACTCGAGCTCGACCCGCGACCGCTCGGCATCACGAGCACACGGCCGGCGATCGAGGCGCCATGCTGCGGATGGTGCA CGTCGATGACCGTGCCTTCGCGCTCATGCACGCCGCCCCAGAAGCTCAATGGCTCACTGAGTGCGACCACCGCGCCGCGCGCCTCACC CGCTACAAGCACTTCGCGCGCCTGCATCATGCCTCGATCAACGCGCGCAGCGCGTCATCGCGCCACACGTCCCCTCGCACGGCCGACT CCACGCATTCCTCCAGGGTCCCGAACACCACCTCGTACCCGAGGTTGCCGGGAGCATACCACGCCCACTTCGCCGAGTTTGTCATCAC GGCGCCGGGCCGCGGCGCGAGGATGGGCGTGAGGTACGTGCACGTGTCCGTCACGATCTTCACGCCGAGGCGTCGCAACTCGACTTCC CATCCGCGATCGGCCACGGCCTGCAGCACCTCACGCCCCGTCGACACGTAGAACGCAATCGCCTCGTTCACGGGGCGCCCCGCGAATA GTGCGTGCAATCGCTCGAACTCGGTGAGCGAGAAGTGCGGCGTGCCAACGCTCACGGCCCCCAGGCGCTGCGAACGCGTCGACGACAG CGCGGCCATGCCCTCCGCCATGTCGCGGGCACCGAACGTCACCGTGCGCTCGGGAGCCCGGCCACCAAGCGCGGCGTCGAGCGTCGGG GCCTCGGGCGTGACGCCAACGACGTGAAACATCGCCACGGCGCCAGCCGATGCCGCTGCTGCACCGAGGGCTTTGAGCTGGTCTTCCG TCGCGGTGGGCACGCCGATGATGGCGGGGATCACGCCCGCGACGTTCGCGCCGACGAAGTGGCCCAGCGTGGCGAAGAAGACGTCGCG CTCCTGCACCGCTGTCGGAATCCCCTCAACGGATACGACCACGCGCGCCCGCCGACCGGCATCGGTGTGCAGTCCCGTCGCCGGCACC CATCCCGTGAGCGCGGCCGCGATGTCCATGAAGTCGCCGTAGCGCTCGGTGCGCGCACCGAGCACGCTGTTGCAGAACACGATCGCGT TGGATTCGGCCCACGCGACCTGCTCGCCGAGGTGGGGGCGATCGACGAGTTGGTACGGCGCACAGGTCCACGTTTGCCGGCATCCCAT CGCCCGGTAGTACCGCATCATATCGCGACCCGCCGCCGCCACCTCTGGAGGGCCGCGAAAGAGCTCGGGGTGCAACAGGTCCACGATG CCCACGTTGAGCGTCGTCGGTACGCGCACTACGCCCCCACCGTCCGCGAGCGTCCGCGCGAAGTCGAGGCTCACCTGCCCGTGGTACA GGCACCCGTCTACGTGTGCGCGAGTGATCGGCAGCAGCGACACGGCGCTGGTCACGGCCGCCATGCGCGTCACGAGCCGCATTGCGAG CTGGACGGCGGGGCCGCTCGCACCCGCCAGGAGTGCCTGCTGGTCGTCGGTGAGCCGCAGGGTCACGTCGCTGTCATCCCGGTCCGGT GAGCGGAGCGAGCCGAGAACCGGGACCCAGCGTCGTCTTGTCCGGGATGACCGGGACTTGCTGTCATCGCGTGACGCGCACGATCACG CTACGCGCCGTGAGCATGCCCGGGCTCCGCATCGCCGCCATCACGTCGGCGTTCTCGTCGTGCACCTTGCCATCCTTGCGCCGCAGCT TCGATCGGAACAACAGTCCACCGAGGAACAGCAGCGGCCAGGTGAGGAGCAGCAGTCCCATCGCCGAGCGCTTGTGCCGATCGTACGA GACGGAGACGTTGGAGGCCCCAGCGCGCAGGAAGGCGACGACGATGTAGTAGTAGCTCACCGGATGGATGTGCCCCGAGGTGTGCACC ACGTCGACGCGCGAGAGCGGCAGCGGATTGAACAACGTGAAGAACCCCGAATGCAGGTACCGCCACCGGGAGTTGAGGTTGAGCACGT TCGGCGTGCTGATGATCGCCACGCCGCCGGGCTTGAGCACCCGCATCACTTCCCGGCTGTAGGCAAACTGGTCCTCCACATGCTCGAG CACCTCGAGGCTGCACACCACATCGAACGTCGCGTCGGCATATGGCAACCGACCATCCATTGAGAGCCGCTCGCAGGCAACGGCGGGA TAGCGGTAGATCTCGGGCGTCACGTCGCAGGCACTCAGTATGGTCGCGGGCGCGACGCCGAGCGTTTCCTCACAGAAGCGGCCCACGA CCCCGGAGAAGTACCCTTCGCCGGCACCGAGGTCGAGCATGCGAATGCCGGGGGCGAGCAGCGGCCGCACCATCGCGAAGACCTGGTC GTTCGTGCTCTGGTGCGAGAGCGGCCGCGCCGCCTCCTGCGACATGCCTGGCACGAGGGCCTCGGGGTGAAGGAATCGCCGACGACGC CCAACCTGTGGTGCCCGGTCCGCACGCGGAAGGCTCGCGCGACGTGACCGCATGGAACGAAGAGGCGCCGGCCGGAATCGAACCGGCG AATAACGGTTTTGCAGACCGCTGCCTTACCACTTGGCTACGGCGCCGTGGGGAGGGAAGCTAGTCCGGCGAGCGACGTCGCTCAAGGC GGAGGTCGCGTGGAGGCCCGGCGTGGGACTGGTCATAAGGCGTGATCGAACGGCAACTTACGCCTCCGCGGGGAGCGTCCCCCGCCCT CACGGAGTGCACCACGTGCCGGAACCCAAGCTCACGACCATCGCCGACCTCGAGGCTGCGGCCGCGCGCATCCGGGGGCACGTCCATC GCACCGGCCAAGCGGACTCCCGCTTCCTGGGCGACCGCGCCAACGCTCGCGTGTCCCTCAAGCTCGAACTCTTCCAGAAGACCGGCTC CTTCAAGGTGCGCGGCGTCATCAATACGCTGCAGCAGCTGACCGCCGGGGAGCGCGGACGCGGCGTGATCTCCATGTCAGCGGGGAAT CATGCCCAGGCCCTCGCGTGGGGCGCGTCCACGCTCGGCATTCCCGCCACCATCGTGATGCCCATGACCGCCGTGCCGGGAAAGTCG CGGCGACGCGGGGCTATGGCGGCGAGGTCGTGCAGACCGAGAGTGACCTCCTCGCCACCGCGCAGCAGTTGCAGCGCGATCGGGGCCT CACGCTCATTCATCCCTTCGACGACCCCCGCATCATCGCGGGGCAGGGCACGGTCGGCATGGAGATCGTCGACGACGTGCCCGACGTC GACGTGGTCCTGGTAAGCTGTGGCGGAGGCGGGCTGCTCTCCGGCGTCGCCGCGGCGATCAAGGCGCGGCGCCCCACCGCGCGCGTGA TCGGCATCGAACCCGAACACTCGAACGTGATGTCCCTCTCGCTCGCCGCGGGCTCACCCCAGCGCCTCACCGTCAACCGCACCGTGGC CGACGGCCTCGCGCCGCCATTCACGGGCCTGAACGCCTTCACGCATGTGCGCGAGCTGGTCGACGAGGTGATCACGATCCCCGATGCC GAGATCCTCGAGGGCATGCGCGTGCTCATGGAACGCTGCAAGCTCTTCGCCGAACCTTCAGCTGGCGCCGCGATCTCCCCGTTGCTCA CGGGCCGCATCACCGTGCCTGCCGGGAGCCGCGTGGTGCCCATCATCTGCGGCGGCAACATCGACCTGGCGCGACTGCGGGAGATCAC GGCATAGGGTCTGCGCACGATCAGTGGCGAAGATCAAGTGCTTCAACGCAGAGCCGCAGGGGGCGCAGAGGGTGCGCTGAGAACAAGA CAGAAGACTTGTTCCTGTGTCAGCGAGGCGACCCTCCTGCACTCGCGTGTCCGCAACAAGGTCACGTGCAGTTCCCTGCGCGGCTCTG CTACCCCTGCGCCGCTGCGCTGAAGTACTTGCCCTTGGTAGTTGCTCTTGCCAGTTGCCGGCTAAGCGAGCGTGGCCTTGAGCGTGAT TGGCACCGCCTTCAGCGCGTTGCTGATGGGACAGCCGTCCTTCGCCCCGTTCGCGATCTGCTGGAATTGCTCGGCGCTCGCCCCCGGC ACCTTCCCCACGACCTCGAGCGTGATGCCCGTGATCTCGAAGCCGCCCGCGGCCTTGGGTTCGAGTTGGACGTGCGCCGTGGCCTTCA ACTCGTCAGGCGTGAGACCGGCACCGCTCAGGCCGAAGCTCAGGGCCATCGCAAAGCAGCCCGCATGTGCGGCGGCAATGAGTTCCTC GGGGTTCGTGCCCGCCTTGCCGTCCTCGTTACCGAAGCGCAGGCCTGCACTGTACGGCGTGTTGCTGAGCACACCGCTCGTGCTCGTC AGCGTGCCGCTGCCTTCCTTGCCACTGCCATTCCAGGTCGCGGTGGCTCGTCGCGTCAGTCCCATGGTCGTCTACGTGGGTGAAACCG TCGTGAAGTACACGCACACCGTCATCGGTGTGCAGGGAACGACGCAAGATACCCCGATACCACGGCGTCGTTACGGCTGCTTGCCCTT CACCTCCCGACGCCACCACCCACTCTCCCATCGCGCGCTCGTCCCGCGTACGTCGATGTGCACGAACGGCCCGCTCGGCCCCATTGCC GTATAGGTCCCGAGTCCACCCACGAGTCCCTTCTGTCGTGATTCCACGCGATTCAGCGCCACGGCAATCGGAGCGGTGTCCCCAAGGT CCGAACGGCCATTCCGGTTGAGGTCGTCCATCCGACCGTCACCGTTGTCGTCGATGATGATGTCCGCCGCGTCGCCGAACTGGTGCCG GCTCCCACGCGCCATTCCCTCGCCAACGCCGCGATCGTTGTAGTACGGGGCCCGGAAGCCCGACAGCACCACCACCTTCCGCGTGGAG ATGCCGCGCGCGTTCAGCTCCTGCAGGATCAGCTCGAGCTTGTCGAGCAGCTTTTCCTCGAGGACGACGTACTTGGGCCAGCGGTCGC GCTGGTCGTGCGTCACGAAGTCGCCTAACGTGAAATGCGCCGACAGCATGAGCGACGCGTTCTCCTGCGTTACCTCCACGAAGCCGTC GGGATTGTAGTAGTTGCGCGACATGATCCAGCGCTCCGACGGCCAGCGACCCAGGCGATACCCGTTGAGTACGTCGCCGCGCTTCTCA CCGAACGGTCGCAGCACGAGGTAGGAAAAGGGCTGGCCCTCCGACGTCGGTACGACATGCGCGGCCGGCGTGTGAATGGCCTTCTCGC CAAGCACGTCGATGAACCCTGGAACCGCGATCGCCTCAGCGGGAGTCAGCGTGCGAAAGCGCAACGCGCGGCTGTGCCCAAGCAGCGA ATCGGGCACCTCGACGACCGCAGCCTTTGCGCGGATCTCGGGCAGCGGCGGCACGTCGAGCGCACCACTGCCGCCGGTGGAGCCTTGC AGGTCCCTGAAGGCCACGATCAGCCACGCCACGCCAAAAAGTGCGGCGACAACCGCGACCCCGAGGAGGAGCCGCCGAACAACTACGC GCAACATCGCGGGCCGTCAGCCAGCACCCGTCCACCCGTCCGCACCATCACCACGCCGTCCCGAACGCCTCGCGCCGGAAGTCCGAGC CCACCATCAGGGCGCGCGACACCGGATGCACGAGGATCATCTGCGCGCCGCCGAACTCCGCGCTCGGCGGCTGCACTGCCACCTGGTG ACCGCGGCGGACGAGCGCCGCACGCACGTCATCGGACAGGCCCGGCTCCACGCCAAGGCGCCCGGCACCGTAGACGCGCCAACGCGGC GCTTCCACCGCCTGCTGCGGGGTCATCCCGAAGCGCAGCGCGTTGTTCAGGATCTGGATCAGCGTCTGCGGCTGGCCATCGCCACCGG GCGTGCCCAGCACCATCGCCACCGACTGGTCGACGTTGAGCACCATCGCGGGGCTCAGCGTGTGGAAGGGACGCTTGCCCGGAGCGAT GATGTTCGGATGACTGGGGTCCAGCGAGTAGAGCGATCCGCGGTTGTGGAGCACGATGCCGGTCCCCGGCACCATCCGACCGCTGCCG AACCCGGCAAACAGGCTCTGGATCAGCGACACCGCATTGCCGTCCTTGTCGATCACGCACAGGTAGACCGTGTCCCCGTTGCCGTCAC GGTCGGGCGTTCCGCCAGGCGCCACGATCGTGTCGCGCCGGATGCGACGGGCCAGTTCGCGGGCATACTCCATGGAAAGGAGCCGATC GGTCGGCACGGGCGACATGCGGGTGTCGGCCACCAGGCGGTCGCGGTCGGCATACGCCAGTTTGGCTCCCTCGACCAGCACGTGGATG TAATCTGCCGACGTGCGCCCCATCGCCGTCAGGTCGTCCTGCGACGCGATGTTCAGCATCTGCAGGAACGTCACCCCCTGCGTGTTGG GCGGGAACGCGAGCACTTCCTTGTCGAGGTACGTCGTGCGGATCGGCGTCGTCCACTCGGTGCGATGCGCGGCGAGGTCGCGCGCCGT GACGAATCCGCCTTCGGCCTGGATGAAGCCACTCACGCGCTTCGCGAGCGTTCCCGTGTACAGGTCCCGCGCACCGAATTGCGCGAGA 
CGCCGCAACGTGCCGGCGAGGTCCTTCTGTATAAGGAGCGTCCCGGGAGCGGGCGCCTTGCCATCCACCAGGTACGTGCGCGCGAGCT CGGCGTCCGCCCCGACCTTTCGCACCTCGCCCGCAATGTCGAGCGAGAGTCGCGTCGAAACCGGAAAGCCCTGGTCGGCATACCCGAT CGCCGGGCCGAGTGCCTGTGCGAGCGTGGTCGTTCCGTATCGGGCGAGCGCATCTTCCCACGCGCGCACCGCCCCCGGCACCGAAACG GACATGATCCCGGTCGAGGGAACGCTCGTCAGGTTCTTCGCCGCGAAGGCCTGGGGCGTCGCGCCGGAACCCGCCGCTCCCGATCCGT TCAGCGCGACGACGCGCCCCGTTTTCGCATCGCGATACAGCATGAACAGGTCCCCTCCCACCCCGTTCATGTGCGGTCGCACGACGGC GAGCACCCCCGCCATCGCAATGGCCGCATCCACCGCGTTGCCGCCACGACGAAGGACGGCGGCGCCCGCCGCGGTCGCCAGGGCATGA TCCGATGACAAGGCCGCCGATCGGCCCATCACGTCGGGACGCATCATCTGCGTTTGCGCCGGAAGTGCCGAGACAGAGGCGACGAGCA GAAAAGCCACGCGCGAGGCGCGGGAGGCGAGGCAGGCTCTCATGGGATGCGCGGCCACTCGAGGGACATGGAAGGGTCAGCGGCGTTC GGCAGAGAGTTTACACCCTCACCCCGCCCACGTAACCGGTGGGGGTCCAGCCAGCCTCCATGGTCACTATGTCATCGAAATGTGCAAA TTGCGCACTTTTTGTTGCACATTGTGCGCATCTCGGCTAGGTTCCCTGCCTTCTTGGGCCTGTTTCGTGCATATTCAGCACGAAAATG GCTACAGGACGCTGAAAATCGCCTCGACAAACTGCCCTCTACATACCCTCACCACTTCATCGCATGCCGAGCACGTCCCGAAAAGCAG CGGTATCAGCCATCGCCGGACGAACGACCACGCCTGCTTCCTCGAACGGCGCAGGGTCCGTCGCCGATTACTTCGGTATCAACACCTT TGGCGCGCGCCAGATGCGCACCAAGCTGCCTAAGGACGCGTTTGCCAAGCTCCAGGCCGCGATTCGGCTCGGCAAGAAGCTCGACTCC GAGATCGCGCCCACCGTGGCCCAGGCCATCAAGGAGTGGGCGGTTTCGCGCGGCGCGACGCACTTCTCCCACTGGTTCCTCCCGCAGA CCGGGATGACCGCCGAGAAGCACGATGCCTTCCTGGGCTTCGACGAGAACAAGTCGCCCATCGAGCAGTTCTCCGGCGCGCAGCTCAT TCAGTCCGAGCCCGACGCGTCGTCGTTCCCGTCCGGTGGCCTCCGCGCCACATGGGAAGCGCGCGGCTACACCGCGTGGAACCCCGCC TCGCCCGTCTTCATCGTCGAGTCGGGCAACGTCCGCACGCTCTGCATCCCGTCGGTCTTCATCGGCTACAACGGCGAAGCGCTCGATG AGATGACGCCGCTCCTCCGCTCGAGCGACGTGCTCAGCGAGAAGGCGATCAAGCTCCTTTCGCTCCTCGGCGACAAAGGCGTGCAGCG CGTCTACACCACCCTCGGCCCCGAGCAGGAATACTTCCTCATCGACCGCACGCACTTCGCGCTGCGCCCCGACCTGGTGATGGCCAAC CGCACCCTGCTTGGTGCGCCGCCGCCGCGTGGGCAGCAGCTCGAGGACCACTACTTTGGCGGCATCCCGGAGCGCATCCAGGCCTGCA TTGCCGAGGTGGAGCACGAGCTGTACAAGCTCGGCGTGCCGATCATGACGCGGCACAATGAGGTGGCTCCATCCCAGTTCGAGATGGC GCCCCTCTTCGAGGAGACGGACATCGCGGTCGACCACAACCAGCTCGTCATGGCGATCCTGCGGCGTGTCGCCATGCGCCACGGCCTG CAGGCCCTCGTGCACGAGAAGCCCTTTGCCGGCGTGAACGGCTCGGGCAAGCACTGCAACTGGTCGATGTCCATCGCCACCGACGGTG AGCTCGACGGCTTCAACCTGCTCCGCCCCGGCAAGACCCCGCACCAGAACGTCCGCTTCCTCCTCTTCCTCGCCGCAGTCCTCAAGGG CGTGCACAAGCACGCCGGGGTCCTCCGTGCCGGGATCGCCACGTCCGGCAACGAACATCGCCTCGGCGCCAACGAGGCGCCGCCGGCC ATCATCTCGGTGTTCATGGGCAAGACCCTGACCCAGCTCATCGAGGACATCGCCGCCGGGAAGCAGGCGGGCAAGGGCGCCGCGGAGG CCCTCATCTCGTTAGGCGTGAACCGCCTCCCCGAGATCGAGAAGGACAACACCGACCGCAATCGCACGTCGCCCTTCGCCTTCACCGG CAACAAGTTCGAGTTCCGCGCGGTGGGCGCGTCGCAGGCGATCGCCTGGCCCGTCACGATCCTCAACGCCGCCGTCGCCGAAGCGATC GAGGAACTCACGGAGCAGCTGGCCGCGGAGCTCAAGAAGACGAAGCGCGTCGACGATGCCGTGCTCAAGGTCGTACGCATCGCGTTCC GCTCCACGAGCGCCGTCCGCTTCGAGGGGAACAACTACTCCGACGAGTGGGTCAAGGAGGCCGAGAAGCGCGGCCTGCTCAACCTGCG CCGCTCGCCGGAGGCCCTCGCGCAGCTCACCACGAACGCCGCGAAGAAGCTCTTCACGACGCTCGGGATCCTCAGCAAGGAGGAGCTC GAATCGCGCTACCACATCCGGGTCGAGCGTTACCTGAAGGACTTGCTGATCGAGATGCACACCCTCACGGAAATCGCCGACACCATGA TCCTCCCGGCGGCGTACGCGTATCAGGGGGGGCTCGCCCGCAGTGCGGCCGATGCGAAGGCCGCGGGCATCAAGGAGGTGCCGCAGGT TGACCGTGCCAACGAGGTCGGAGCACTCGCGAAGAGGCTCAAGGCGAGCCGCGACATCCTCGCAAAGCTCACCATCAAGGCCGAACAC ATGCACGACAAGCCTGAGGAGTGCGCGCGGCTTGTGACCAGTGCTGGCGCCGACGCGATCGCTGACGTCCGGGCATCGTGCGACGCCC TCGAGGTGCTGGTAGCCGACGACATGTGGCCGCTCCCCAAGTACCGGGAGATGCTCTTCCCGGTGTAATGCGCTCCGGCGAGGCAGCC GGCGACAGGAGATGAAGGGTCGGGCGTTCGGTAGGTGAACGCCCGACCCTTCTTGCCCTATTGGGAGACTCGCCGAGCCCGACCCTGT CGTATTCTCGGTGCGATGTGAGAGAATGCGACCCTCACCACCGTTTCTGCGCAATGCAAGGCTGGAACCGGGGAATCCGGTTCCGACT CGTCGTCGCTTTCCAGTTCCTCTGGAGGTTCCCGTGCCCTCGCTCCATCACCTGCCTCGGCTCCCCCTTCTCTTCGCCTTCGTGCTCG CCGCTTGCGGCGGCGGTGATGGCGGCACGACACCCACGCCGACGCCGGCCGGCTTCACGGTCGCGCTGTCCAGCACGACGCTCTCTGT GGAGCAGGGGGCCAGCGGAAGCGTCACCGCCACGATTGGCCGCACGGGGAGCTTCTCCGGAACGGTCAACCTCGCGGTGACCGGCCTC CCGACGGGCCTCACGGCCTCGTTCAACCCGGCAGCGATCACCTCCGGCACCACATCGACTACGCTGAACGTGACGGCGGCCGCCTCGG TCGCTCCTGGTCAGTATCCCTTCACGGTCACGGGTTCGGCCACCGGCGTCTCCAGCCAGACGGCGACCTTCACCGTGACCGTGACGGC ACGACCGGCCATTGCGATGACGCTCTCCTCCGCGACGTCGACGGCACAACAGGGCGCGAACGCCACGTTCACGGCCACCATTGCCCGC ACGAACTTCACCGGCGCCGTGGCAGTCGCCATCACCGGTGCCAACGCCATTACCCCCGCCGTCACGAATGTCGGCGACGTGTACACGG TGGTCCTCGCGGTGAATCCGGCCGCTCCGGTCGGTGCGCAGACACTCACGGTCACGGCGACCGGTACCGGCGTGACCGCGGCCACGGC GACTCACACGATCACGGTGACCGCGGCGCCCCAAGCGAGCATCGCGATGACGCTCTCCTCGGCGACATCGACCGCACAACAGGGGGCG AACGCCACGTTCACCGCCACGATCGCCCGCACGAACTTCGCGGGTGCCGTCGCAGTCGCGATCACGGGCGCCAACGGGATTACTCCCA CCGTCACGAACGTCGGTGATGTATACACGGTGGTCCTGGCCGTGAATCCGCTGGCTCTCGTCGGCCCGCAGACCCTGACGGTTACCGC CACGGGTACAGGAGTGACCGCTGCGACTGCGACTCACACGATCACGGTGACCGCGGCGCCCGCAGGGAGCATCACACTTGCCGCTTCG CCGACTGCGATCACCATGCAGGCCGGAAGCGCGGCACAGGACGTCACGATCACCATCACGCGCGTCAGCTTCACCGGCACGGTGGTTA CCGCCGTGCAGTCCGGGCTCGTTACCGGCCTCACGGCGACCGTCAGCCCTGTCGGCCCGCAGCAGGGCAACACGGCGACCGTCACGTT CCAGGCAGGTGTGAACACCGCGCCGGGGACCTACAACGTCGTGGTCCAGGGTGCCGGCGCGGGCGCGACTGCGGGCACTGTCACGATA GCGGTCACGATCACCGCAGCACCGGCCAGCAGCATCTCCCTGGCCGCATCGCCGACCGCGCTGCTCGCTACGGCGGGGGGCAACACGG CAACCACCACGATCACGATCACGCGAAGCAACTTCGCAGGCGCCGTGACCATTGCGCCGAACACCGGTGGCGTCGGCGGCATCTCGTC AGCCACCACGCCGTCGTCAACGACGGGCAACACGGCCTCGATCGTGTTCACGGCCGCGGCGGGCACCACGCCGGGCACGTATCCCGTG ACCATCACGGGTTCCGGCACCGGTATCACTGACGCGACCGTCGTCGTTCAGCTGCAGGTCGTGGCGCTCGCCTCGAGCATCGGGATCA GCCTGTCACCCTCGACGTTATCGCTGCAGGCGGGGGCGTCCGGTTCCTCGACCGTGACCATCGCGCGCACGAACTTCGCCGGAGCCGT CACGATCGCCGCCACTGGTCAGCCGGCCGGCATCACGGTCACCCCGACGGGGTCGCCGACCACGACCAACACGCTGACGCTCAACGTG TCCGTCGGCGCCGGTGTCGCGGCGGGGTCGTATCCCGTGACCATCACGGGCTCCGGCACTGGCCTCACCAATGCGACCGCCACGCTCA CCGTCGCCGTTACGCCAGCATCGAGCGGCGGCAACACGACGTGGCAGTTCTGCGCCCTGACCGGGATCCCGATCTGGTTCGCTGCGCA GAACGGCAACGCCAGCGCTCCATTCGTTCAGGTCTCGGCCGGTACGAACAATACGTTCTCCTTCGACATCACCACCGTGGGCGCCGTC GCGTACGTGTCGCAGACGGGGAGCAGCTACGGCCTCAACGTGGTATACGGCACGCGCGCCGAGCTTTCGGCGCAGGGAACGGGTGGAG CATGCGTGGGATCCGGCGTTGGGAAGACGGTCACCGGGACCGTCGCCGGTCTGACTTCCGCGCTCGAATTCGGCGCGATCACGCTCGG GGGCGCGTCTGCACAAGCGCAGCAAGCACAGCCGAACTTCACGCTGAACAACGTGCAAGACGGCAATCGCGACCTCGTCGCCACGCGC AGCGCCGTGAATCTCACGACGGGATCACTCTCCGTGATCAAGGCCATCATCCGGCGGAACCTCAATCCGGCGAACAACAGCGTGCTTC CCCTGATCGATTTCGGAGCCAGCGAGGCCTTCAGCCCGGTCAACAAGCAGCTCACCATCGCAGGCGGGGCCGGTGGATCGGAGATCCT GAGTGCCTTCAACTACTTCTATTCCTCCAACGGAACCTTCGCCCTGCTTGGACTGGGCGCCCTGGCGGGAGCGGTATACGACGTGCCC ACGGTGCCGCAGGCGAACACCGTGTCCGGTGACGTGAACGTCATCACTGCTATCGGCACCAGTTTCACGGGTGGTGACCCGTCGGCCA TTCGTTCGACCTTCGCCTCCTACCGTGATCCGGCGAACCAGACGTTGACGCTGGGTCCGCAGCTGAATGTTCCGGCCATCTCGGTCGT CTCCACCACAGGCTATGCCCGGCTTCGCGCGATGGTGGCGCGTCAATCGGAGTACGACAATGCCTGGCAGGCGATCTTCTCACAGAGC ATCGGAGCCACGAATCGGCAGGCCGGATTGCAGGTCCTGCCCGGCTACATGGGCAGCGCGACCAATTTCGATGTCTCGATCCCGGACT TCACCGGAGTCGGTGGCTGGCAAAATACGTGGGCGCCACAGACAGGGACGGAGACGACCTGGGTCGTCGCGTTCACGGGGTGGATCAA CCTGAGCGGCCTGTTTACCGACGGCTCTGTGTTCCGTACAGCGCAACGACTGGGTAAAGTGACCCCGTAGGGCGCTGCGCGATCCGAT CTCGAAGGGCCCGACGGCACGACGCGTCGGGCCCTTCTGGCTTTGCATCCGGTCGTTCAAGTTCAGCCCGTTCCCATCGGAGAGATAT CGTGAACCGCGCCCCGCACCGAGCCCTCCTCTACGCCTTCGCTGGCCTGGCCATGCTGGCCTGCGGCGGTGGCGATAAGGGCACGACG CCAACTCCCGTTCCCGCGGGATTCACGGTCACGCTCTCCAGCACGACGCTGACCGTCGAGCAAGGCGCGGCGGGTACCATCACGGCGA 
ACATCGGACGCACCGGCAGTTTTGCCGGGACTGTGAACCTCTCGCTGGAGAGCGTTCCCACCGGCATCGCGGCGTCCTTCACGCCGGC CAGCATTACCTCTGGTACGACGTCGACCACGCTCACCGTCACCGTCGGATCCACGGTGGCTCCCGGCTCGTACACCTTCACGCTGCGC GGTCAGGCGGCCGGCCTCAGCGACCAGACTGCTCCCGTCTCGCTGACCGTCACGCCGAGGCCCGCGATCGCGATGACCCTTGCGCCGC CATCAGCGACCGTCGCTGCCGGCACGAACGCAACGTTCGCCGCGACCATCGCCCGCACGAACTTCGGCGGAAGCGTCACCATCGCCAT CACCGGCGCGCCGACGGGCGTCACGACCAGCGTGAGTACCACCGGTGACGTGCACACGGCCACGGTCAACGTCGCGGGAACGGTCACG CCGGGGCAGTACACGCTTACGGCCATGGCCAGCGGCACCGGAGTCCTCGCGGTGAGCGCACCGTTCACGCTGACCGTCACCGCGGCAC CCGTCGCGACGATTGCCCTCACGGCGGCCCCCACGGCATTCACCGTGCAGCCCGGCAGCACGCCTGTAGGCACCGTGGTCTCGATCAC GCGCAGCAACTTCTCGGGAGCCGTGACACTCGCGGTGCAATCGGGGCTTCCCGCCGGGCTCACGGCAGCATTCAGCCCTGCGGGGGCG ACGACCGGGAACAGCGTGATCGCCAACTTCTCCGCCACCTCCGGGACTCCCGCCGGGACCTACAACGTCGTCCTGCAGGGAACGGGAA CCGGCGCCACGACCGGGACCGTGCAACTGATCATTACGGTGGCCGGCCTGCCGGCGAGCGCCATTGCGCTCACGGCCGTTCCCTCCAC GGTCTCCACCGCGCAGGGAACGAGCGTGGGTACGGTCATCAACATCGTGCGCACCAACATCACCGGCCCCGTCACCCTCACCAGCACC AACGTGCCGGCGGGGATCACCGCCACCTTTGGCGCTCCCGTCACCACGCAGAACAGCGCATCGCTCAACCTCGCCGTCGATGCGTCGG TCCCCGTTGGTTCGTACCCGATTACCATCACCGGGGCGGCCACTGGCGTTACCAACGTGTCCATCACGGTGACGCTGAACGTCACCCA GGGCCAGGGCGGGAGCGGGAACGTGACGTTCACCTTCTGCGGCGCGGCCTCGACCATTCCCCTGTGGGTCGCCGTGCAGAACGCGTTC GGCCAGTGGCAGCGCGCCACCCCGGTTGCCACCAACACGTACTCCTTCACGATCAACACCATCGGCGGCGTGGCGTGGGTTACGCAGT CGGGGCCCGACGCGTATGGGATGAACATCGCGTACGGCACCTTTGCGGACCTCAACGCGCGCGGCGCGTCAACGTGCCTCTCGCCAAC GACCAAGACCGTGACTGGCACGGTCGCGGGGCTGGCGGCGCCGACCGACATCGTCAGCGTCGCGCTGGGACGTGCCGTCGCGTCCCCA CCCCCGACACAGGCCAGCCCGGCCTTCACCATCACCGGGGTCCCGGCCGGCACGCTCGACCTCCTGGCAACGCGCACGAGCTTCAACC TCGCCAACCCGACGCCGCTCGTCCTCGAGCGCATCTACCTGCGTCGTGGCCTCACCCCTGCCGACGGGAGCTCCATCGGCACCGTCGA TTTCGGCAGTACGACTGATGCAGTTGCCCCCGACTTCAGGCAGCTCACCACGATCGGCGTGAACGTCGGTGAGCAAGTCACGGCACTC TCGACCTTCACGTCCGCCAGCGGGGCCTCGGCAGCATTGGGCTCCGGGGTCGGTTCGTCCACGCTCAACTACCCGGCCGTCCCGTCAT CGCGCACGGCCGTCGGCGACCTGCATTCCCTCTTTGCCCTCGCGACGACGATCAGCCAGGGGGTGACGACCGCTGCGCGCGGGGTCAC CGCCTGGTTCCGCGACCCGGCCGCCAACACCAATCTCACGTTAGGCACCCCCCTCGGCATCCCCACGATCACGACGGCCGCGAGTGCA CCATATGCCAGGCTGCGGTCGGTCCTCTCGCGTCAGGGGGAGTACGACAACGCCTGGAGCACGGCGTTCACCCAGGCGAAGCGCAGCG TCACGATCACCGTCAGCCAGGGCTACCAGTCCAACAATGGCGCCGTCGACGTGACCGTCCCGGACTTCACCGCCGTTAGTGGCTGGCA GAACACCTGGGGATTGCTCGCGGGCACCAGCACTGCGTGGAACGTCAGCGCCTTCGGGTGGGTGGTGGGCGGCGGCGCCAACGCCGAA GGCGCCATCACGCGCATCGCCTTCCGCGCGGGGACGATCACGCCGTAGCCGGCGGGTGCGGACGCGACGAAGCCCGGGAGCCGCAAGG CTCACCAGGCTTCGTTGCGCTCGCCCGCAGCGCGAATCACGCCTTGTGGCGCACTCCGACGACGACCAGCGCGATGCCTCCAAGGAGC GCGAGGCCTGCAGCCCACGGACGGACGGGATGCTGTTCCTCGGCAGAAATCTTGAGCGGACCCACGTCCACCACGTCACGCCGCGTCG TGATGCTCCCACCCGTGAAGAGGAAGTACCCGCCGGCGAGGATGAGGACGATGCCCACAAGGGTGGCGACTTTCATGATGGAGGCCTC GCTGGTGAAGGTGGATCAGGTCGAACGCTCAAGCGTAGCAGGCCCTGCCGGCCGAGGCCAGTGTCCGTGCGGACGTCGCTCGCCTACC CCTCGCGGGAGAGGACGTCCGGCATCGCTGCTGCGCGTTAGGCTCCCGACCCGGTCACCGCTGTCCAGCGCTCGTGCGCAATGTTGCC GCCACAGATCACGACCGCGACCCGCGATCCATCGATCCGGCCCGCATCACGCAGGCAGGCAGCGACCGCCACGCCGGCCGCTCCCTCG ATTTCCCCGGAGTGGTGTTTCGCCCACAGGCGCATCGCGCCAGCGATCTCCTCTTCGCTGACAGTCACCCAGTCATGCACCAGGGTCC GGCAAACCTCGAAGGTCACCGAGTCGGCCTCCATTCCTCCCGCCGTTCCGTCGGAAAGCGTGGGCAATGTCGGCATTTCGACGACGTG CCCCGCGGCCACCGAAACAGACATGACGGGGGATGCCTCGGGGAGGGCACCGATCACGCGCACATCCGGGGCGAACTCCGCCAGGTAG CTCGCCATCCCGCCGATCAACCCGCCACCCCCAACGGCCACGTAGACCCGCGACAGATCCGGGACCTGACGCAGCAGCTCAACGGTGA GCGTCCCCTGACCCGCCATCACGGCGACATCATTGTACGGGGAGACGTAGCACCTCTCGCTCTCATTGGCGACGCGCCTCGCCTCGAT CTCGGTATCGAGCCCGTCGGTGCCGAAATGCACGACTTCGGCGCCCTTGGCCCGGATCCTGTCGACCTTTGCCCGCGACGCCCCCGCC GGTACGAAGACCTGGGCCCGAATCCCGAGCGCGTGACAGGCGTGAGCCACAGCCGCGCCGTGATTCCCGCTCGAGGCTGCTACGACTC CCCTCTGCCGATCGTCCTCTGACAGGGTAAGGAGCTTGTTGAACGCCCCCCGAAGCTTGAACGACCCCGTCACCTGCTCCTGCTCGAC CTTCACCATGACGTCTGCGCCCGTGAGAGCGGAGAGTGCGGGACTCGGCTGCACCGCCGTCATGAGAATGTGGGGCCGGATGCGACGT TCAGCCTCGAGGACCAGGGCAGCAGGGAGCATGGAAAAGAGTCTCATCGGTAGGCGCCATTTCTCTGCCTCAAGAGAACTACATCGCC GCGAGCCGGCGCTAGTAGTATTCCTGCACACTCATCGTTCATCTGTGACCGCTTTCGTGCGTGCCTCGCTCGTCGCTGCCCTGATGCT TTCCCCGGTTGTCGGGGTGGCACAGCTCGCGCCCGACACCAGCCTGGTCCCGCCCACGTCTCCAGTTCGCGCGTTCCTCGCCGGCCCG ACACTCGCAGGAGCGCGGTGGCCGGGTATCGAGGACGTGTCGGCCGATGTGCAGCGTGCGTACGAGCGCGTGAGTTGGGCGCTGCTGT GGAGCGACAAGGGCAGGCCAACGACGTCGGCACAGGGAGTCGTGAAGTTTCTCGGCGCCGTCGATTCGCTCGGGCTCAATCCTCGTGA CTTCGACGCCGCGCTGCTCGACTCTCTCGCCACGGCCGCTGCTGCCTCGCCCCTCGATGAGGACACACAGGCGCGATTCGAGGCGACC CTCAGCGTCGCGACGGCCCGCGTGCTCAGCGCACTTCGTTGGGGACGCGCGCGCCAGACAAAAGCCTATCCGACCCTTCGCCGGTCGC GCGACGACTACGACCTCGGCGCTGGCGTCTATGCGGTGTCGCGCACACCGGATCCTCTTCCGGTCTTCGACCAGGCGGCGCCGCAATG GACGCCGTATCGCCAGCTCGTCGCCGCACTCCCAAGGGCGCGGCGCATTGCGGATGACTCGCTGCTCGTTGCGGAGCCGGTGAAGAAG GGCGCGACGTTCCACGCCGCGCCGCAGCTCCGGAGCCTGCTCGCGCACTATGGGATCCCGGCGGATTCCGCGACGCCCCCGCCGTCGA GCGACACCACCGTCGACGCCTCGCTCGCGCGCTTGCTGCGCAAGTTCCAGAAGGAGAACAAGGTGCCGCAGACCGGCGCCTTCGATGT CGCCACGCGCGATCGCATGCGCGCCGTCTTTCGCGGACGCGTGCGCGATGCCGTGCTCTCGCTCGAGCGCTGGCGCTGGTTGCCGCGC ACCGCGGACGGACGCGCCATCATCGTCAACGTGCCCGAGTACCGGCTCCGCGTCTACGACGAAGTGCAGGGGGGCCACGCGCCGGCGT TCGGCATGAAGGTCGTCGTCGGGCGCGGGGAGGAAGATCGCTACACGCCGCTCTTCACCGACGAGGTCGAGCACCTGATCTTCTCGCC GTTCTGGGAAGTCCCCAAGACCATCGCCCTCGACGAGATCGTCCCGAAGATCCACAAGGATTCCACGTACCTCTCGCGCAATCGCTAC ATCCTCGTGCGCGGGACCTCCGACACCGCGAAGGCGCTGACCCCTGATTCGGCCACCATCGCGAAGATCGGCAAGAGCGTGCGCGTAC GGCAGCTGCCGGGGGACTACAACTCGCTCGGTCGCATCAAGTTCATGCTCCCGAACCACCTGAACATTTACCTGCACGACACCAACGA GAAGCAGTTCTTCAAGCGCGACGAGCGCGCGTTGAGCCACGGCTGCATCCGCGTCGCGGAACCCACGCGCCTCGCCCAGTGGATCCTC GGCGGCGACACGGCGTGGACCGATGAGCGCATGAAGAAGGCAATGAAGCAGGACACGCCGGAGACCGTGCGCCTCAGCTCGCACATCC CGGTGCTCATCGTCTACCACACCGCCGGCGTCGACGACCACGGCGTGCTGCGCTCGTTCAAGGACGTGTACAAGTACGACGAGGAGCT GGAGAAGATGCTCGGCCGCGGCTTCCCGTACGCACGTTAGGCGACCTTCGGGGCGGGATGGACGGGTAGACGGGATGGACGGGTACGG GTGGAACTACCCGCCCATATCGCTCCGCCGAAGGCAGGAGCCCAGCGTTGTTGCCCTTCCGGCCCGCCTGCCCGCCCGCCCCCCCGCC CGCCCGTCAGTACTTGAGCAGGTACCGGTCCAGCTCCCACTGATGCACCTGCGTGATGTACTCGTGCCACTCCTGCCGCTTCGCGTCG AGAAAGTGCTTCGCGACGTGCTCGCCTAACGCGCCCATGATCACGTCGTCCTTCTCCAGCTCGTCGCAGGCCTCGTTCAGGTCCTTCG GCAGGTCGTCGATGCGCAGCCGGCGCTTCTCGCGGAACGACATCTCGAAGATGTTCGTGTCCACGGGCTCGCGGTAATCGGCGTCGGT CGCCACGCCATCCAGCCCCGCCGCGAGCATCACGGCAAGCGCGAGGTAGGGGTTGGCCGCCGGGTCGGGTTGGCGTACCTCGATGCGG GTCCCCGGGCCGCGGCGCGCCGGCACGCGCACCAGCGGCGATCGATTGCGCATCGACCACGCCACGTTCACCGGGGCCTCGAACCCCG GTACCAGCCGCTTGTACGAATTCACCAACGGGTTCGTCACGGCGCAGAACCCGCGCGCATGTCGCAGCACACCGCCGATGTAGTGCAG CGCAACCGGACTCAACTCCCATTCGGCGTTCGGCGCAAAGAACGCGTTCTTGCCGTCGCGAAAGAGTGACTGGTGCGTGTGCATCCCG CTGCCGTTCTGCCCGTAGATCGGCTTCGGCATGAACGACGCGAACAGGCCGAACTGGTTGGCGATGTACTTCACCACGAACCGGAACG TCGCGATGTTGTCCGCGGTCGTCAGCGCATCGGCATAGCGGAAGTCGATCTCGTGCTGGCCGTGGGCCACCTCATGGTGCGCGGCTTC CACCTCGAAGCCCATCTGCTCGAGCGCTGACACGATCGCGCGGCGCGCGTCCTCGCCAAGGTCGGCGGGAGCCAGGTCGAAGTACGAT CCCACGTCCTGTGTGACCGTCGCGAGAGCCTGCTGGCCCGTCTTGAAAACGAAGAACTCCGCTTCCATTCCCGCATTCATCACGAAGC CCATCTCCGCCGCGCGCGCGATCTGCCGCTTGAGGACCTGCCTGGGGTCCCCGTCGAAGGGGGTGCCATCGGGCCGGTGCACGTCGCA GATGAGTCGGGCGACCCGACTGTCCGGATCCCCCCACGGAAACACCCGAAAAGTCGAGATGTCGGGCACGAGGAGCATGTCGGACTCC 
TCGATGCGCACGAAGCCCTCGATCGACGAGCCGTCGAACAGGATGTCGCCCGACAACGCTTTCTCGAACTGCGACCGGGGCAATTCCA CGTTCTTGTTGACGCCGAGGATGTCGGTGAACTGCAGCCGGAGGAAGCGCACGTTGTGCGCCGCGGCGTAGTCCATCACGTCCTTGGG CGTCGCTCCGGCAAAGGTGTTCGGCATCGGTCGGGAGAAGAAATGCGGGGGCGATTCGCGCGGATAGGGATAAGGGATATCCCTCCAC GAAAGAAGGGGGTGACGCGACAGCAGTCCCGCCGGATGGCTGCAAGAATCCGGGCCACCGACGGCTCACCCGTCCCCGCTCGACCGCC TATCTTCCGCACCATGTCACACAGCTCGTCTCCGGCCGCCACGGTTCCGTGCCCCAGCTGCGGAACGCCGGCCTCTGGTAAATTCTGT GGCGAATGCGGCGCCGCACTCATGGGTGTGAGGTGCACGTCCTGCAGCGCGCTCCTTACCCCCGGTGCCCTGTTCTGCCATCGCTGTG GCGCCGGGGTCGGTGGGCGCCCAGGTCTCTCGGCAGCTGCGCTCGCCGCTCCTGCCGCCCGCGGAGCTCCGTTCGGCCAGCGCTCGAT CCTCCCCTGGGTGCTTGGCGGTGCGGCACTGCTCGCGTTGGTCATCATGGTCGCCGCCCAACAGGGCGCGTCCTCGGCAGGCAACGCT CCGACCGCAGCAATGCCCCTCGGCGCAGCGCCATCGATGGGTGGCACACGGGCGCCCGACATTTCGTCGATGTCCCCACGTGAGCGCG CTGACCGCCTGTTCGATCGCGTCATGAACATGTCGGCACAGGGGAAGGCCGATTCTGCCGCCTTCTTTGCCCAAATGGCCGTCGGTGC CTATGAGTCCGTCGGCCCGCTCGACCTCGACCTGCGCTATGACTACGGGCGCATGGCCGAGATGGCGGGAGACCTTCCCCTCGCGAAG GCCCAGGCTGACAGCATACTGCGCGAGAATCCCGACCACCTGCTCGGCCTCATCCTCGCCGCACGCGTTGCCCAGGCAAAGAGCGACG ACGCGGCCGCGAACCGATACCTCGCGCAGGTCGTCCGCGCGGAGAAGACCGAGTTGGCCAAGAGCTTGGACGAGTACACTCGCCACAA GAACGACATCGACGCCGCTATCGCGTTGACGAAGAAGTAATGCGTGCCGCTCCCCAGGCGTCCGCACGCGGCCTCATCGCTGGCGCGC GCGTACCCGGCTACTCCCCCGACACTTGCCCGTGACCGTGCCTCGCACCATCACTGTTTGCCACAGCCCCGATAGCGACGACGCGTTC ATGTTCTACGCGCTCGCCGCGGGGAAGATCGACACCGGCGACCTCCGATACGAGCACGAGCTGCAGGACATCGAGTCGCTGAACCAGC GCGCGCTCCGCGGTGAGCTCGAGGTCACGGCAGTCTCAATTCACGCCTACGCGTACCTCGCCAATCGCTACGCGCTCCTCCCCCATGG CGCCTCCATGGGCGACCAGTATGGCCCTCGCCTCGTCGGTCGCACGCCCATGTCGAAGGAGGAGATCAAGGGCAAGCGAATTGCGATT CCGGGGCCGATGACGAGCGCGTATCTCGCGCTGCGGCTCTTCGAGCCGAACTTCGTCGCCGTCCCCACCCCCTTCGACCAGATCGAAG AGGCGGTGGCGAGTGGCGCTGTCGATCTCGGATTGCTGATCCACGAAGGGCAGCTGACCTACAAGGATCAGGGGCTGCACCTCATCGT GGACCTCGGCGAATGGTGGTATGGCGAAACGGGTCTTCCTCTCCCTTTGGGCGGAAACGTCGTTCGAAAAGACCTTGGCGATGACCTC ATCAAGACGCTATCAAAGCACTTACGCGCCAGTATCGCCTATTCACTGGATCATCGACAGGCAGCGCTCGACCACGCCATGACCTATG CTCGTGGGCTCGAACGGGAGAAGGCCGACACGTTCGTTGGCATGTACGTCAACCAGCGGACGCTCGACTATGGAGCGGACGGTAAGGA AGCGGTGCGCCTGTTCCTCAAGCGAGGCTTCGAGGCTGGCGTGATTCCTCACCCCGTAAATGTTGAATTCGTAGAGGATTAGGGCCAC TGTGAGGTTGCGCACACAGTGACCGGGCCGTCCTCCGGGAGTGAACACGGCGACGTTCTACCTTCTTCGGTGAACCTCAACACCCCAC CATCGCAACCGCGCGAGACGGGCCGCGGCGAAGATGACGTGCTGCGCGCGGTCCGCGCGCTGAACGCCACCGCCGAACAGCCCCAGCG CGTCGCGTCCGTCGTGCTCAACCTCCTCAACTCGGAGGTCGACTGCGACGGAAGCCTGGTGGCCATGATCGACGGCGGTGCATTGACC GTCATCGAGGGGTTCCGCACCCTGAAGGAAGTCGTCGGCCAGTCCTTCCTCACGGCGGACTCGCTGGCCGCAACCGCGATCGAGGATC GGGTGCTCGTCGTTCACAACGACATGCCGCCGGCGGGAATGGACCCGCGATTCATCGAGCGCTTTTCCATTCAGCGCTTCGCCGTCGC TCCGCTCATCGCCGGCGGTGTTGCCATCGGAGCGCTCATCGCGATCAATCCGCGAAGCGGCCCGTTCTCGGAGGAGCAGTGCAACCTC CTGTCTCGCCTCGCCGACCTCGGGGCCCTCGCGATTCGCAACGCCTGGTTGCTCGCGCGCGAGCGGCAGCTGGCCAATGAATCGACCG CGCTCGCCGAGATCATCCAACAGCTCAACCAGTCCCTCGAGTTCGAACGCGTCGCTCGGCTGGTCGCCGAAAAGAGCGCCGCGTTGCT CGGCGGCCAGGGGTCGGCACTCGCGCTGATCGACAACGACGAAGTGGTCATCGCGGGAGCCTTCGGGCTTGGTGCGCCACTCCTCGGG TACCGTATCCCGGCAGAGTCCACGCTCGTACTGCGCGTCGCGCAGGGGCGAAGGGTCGTCCGGACGCGCGACCTCCAACAGCTCTCCG GCGGTCATGCGATCGCGGCCGCTCTTGGTCCGGAACCGGCCAATGGCATCGCAGCTCCATTGCTCGTGGCCGATCGTCCCATCGGTGC CTTGATCGTCGCCGCGAACCCGACGCGCGACTTCACCGAGCGCGACGAAGAACTGATTGCGTCCCTTGCCTCGCACGCCGCGGTGGCG ATCGAGAACGCCCGCCTGTATCGCGCCGCGGCACACACCGCGCGTCATGCCGAGACCTTGTCCTCGGCCGCGCGCTCGCTCTCGCATG CGGTCGACGCCTCCACGTTCTTCGACGAACTCGCTCGGGTCGCGAGGGAACTGCTCGGCGCGTCGGGACTCACCGTGTATTCGGTCGA CCAGGCGAGCCAGTCCGTCGGCGTGCGCTATGTCGCGGGAATCGGTGCGGAGACGCTCGAGCGCGTCGCCGCGCGCATCGTGCAAAGC CCCGAATACGCGAACCCGCTGATCGCCGGCGTCGAGGGCTTCTATGAGGACGTGCGCACCGAAGCCGTGGCGAGCGTGTGGAGCATTT CCGCACGGACGCCGTTGCCGGCGGAGATCGCGTCCCTCGCACGATTGCCGCTCATCGTCGAGGGACGTGTGCGCGGCGCGCTCGCGCT GCGTTGGCGCGCACGGCATGCGTTCCCTGAAGACGAGCGTTTCCTGCTTCGCGATGTTGCGACGCAGGTTGCCCTTGCCTTCCGGAAC GCCGAACAATTCGACGCCGAGCGACGCTCCCGCGAAGTGGCAGAGGCGGCCGCCGCGATCGCGCGCAGCGTGCTGGGCGCCTCGAATC CAACCCGCACCGCCCGCCTCGCGCTGGAAGCCATAGACCGGGCGGTGCCTGCCTCGGGGCGGGCCATCGCCTTTGTCGACGCCAGCGG AAGTTCGTTGCGGTACCTGGCGGCCTCGGGATCCCTCGAGCAGCTCGATGGTCTCACCATCCCCGTCGCTGATAGTGCCACGAGCTTG TCATCCCCGCTGGTGGTGCAGGAGGTGGAGGACGAGGCCCGCGCTCGCATCGGCGAGGGGGCGCTGGTCCCATCCGGGTGCACCCTCA TTCCGCTCGTCGCCCGCGAACAGCTCCTCGGGGTCCTTTGGTCCGTGAGCAATGCGAACGGTCGCGTGGCCGCCGCCGAACTCGAGAC GCTTCGCAACCTCGCCGCGTCCCTCGCGCTCGCCGCGGACGTGTTGCTGCTCAACGAGGAGGAACAGAAGCGACGCGCGCGCGAGCAC ATGCTGGCCACCGCTCTCGCGACGATGGATCAGGCGGTGCTCATCATCGGCCTCGACCGTCAGGTGCTCTACGCGAATGCCGCGGCCA TCGCCGAGTACGGATATCCCTTCGACAGCCTGCCCGCCGTGGCGTTCGATCGACTCGTCGATTCCGCGACCGTGGCGCGTCGCGTCGG GCCCGATGCGACGTCCGAGGAAGCCGGCGTATGGGAGGCCGAGCACATCCACCGCCGGCGCGACGGATCGACGTTCCCGGCGTCGGTG CTCCTCAGCTACATCCGCGACGTGCACGAGGTCCCGATCGCGCAGGTGGTCACCGTGCGCAACCTCACCGCGGAGCGTCGCATCGAGG AGCAGCTGCGCCAGAGCGAGAAGCTGGCGGCCCTCGGGGAACTCGTCGCCGGCGTGGCCCACGAGCTGAACAACCCGCTCGCAGGCAT TTCCGCGTTTGCCCAGCTCCTCATGGAGGACGAACTCAACGAGGAGCAGCACGAGTCGGTGCGGCTCATCAAGCGCGAAGCGGATCGG GCGGTCGGCGTCATCCGCGACCTCCTGCTCTTCTCGCGAAAGACCGGACCCTCGCAGACCCTCGTCGACATCAACGAGATGGTGGAGC GCACGCTGCGCCTCCGTGGCTATGGCCTGCGCTCCGCGGGCATCGACGTGCGCGTGGAGCTGGATCCCACCGTGCCGCCCGTCGCGGG GGACAACCAGCGCCTGCAGCAGGTCCTGCTCAACCTCGTGATCAATGCCGAGTACGCGCTGCAGCGGGCCGATGCCAAGCGCCTGGTG ATCCGGTCGGAGCGCACGCGTGATGGCGTCGCCCTGCACGTCGAGGACTCGGGCATCGGCATGGACGAGGACACCCGGCAACGGATCT TTGAACCCTTCTTCACCACCAAGCCGGCGGGTGAAGGCACCGGCCTCGGGCTGAGCGTGAGCTACGGCATCGTCCGCGCCCACGGTGG CTTCATCGTGGTGGAGAGCTCACCCGGCCGTGGCACGACCTTTCGCGTGGAATTCCCCCGGGCCCGCGAACAAACCTCGCTCGCCACG GCCTAGCCACCGGGACGGCGTCCGGAGCCTCCGGCAGTGACTCAGCGGAAACACGCCGGTCCCGCCTGCGACGACGACTCGTCCACGA GCCGCTTGACGGATTCCCCCCGCAATTGTACAAGGGTGTCTCCCGGGCCGCGCACAATGCGCTGCTACGTCCGACCGAAGTCACGCGC GGCCCGGCACACGCAGTCCCTGACCCATTTTGGCCGACTTCAGCACGGAGGAATACATGGCAAGCGGTGACTCGCGGGATGGCACCTT GCGGTTCGGCGACGATGACGAGATGGACGACGTCGGATACGGAGGTGGCGGTGCGTCGTACGACGATGATGACGACGAGGACGATGGG TGGGGCTCGACGAAGCACGACGACAGCCTCTGGGAGGATCCCGACGAAGCCGCGCTCGAGGAAGAGGAAGAGGTCGAGCCCGTAGAGG GTGGCGCCGTCGTTGAGGAGGAGCCCGAAGACGAGGAAGTCGTCTTCGGTGCCGCCCCCGCGCGTCGTCGTGCTGGTCGTCCGCCGGC GGCCGCGCCCGCCGCGGCCGCAAAGCCGGCAGCCCCCGTCGCAAAGGCCGCTCCCGCCGCCAAGGCTGCCCCTCCAGCCAAGGCTGCC CCTCCGGCGAAGGCCGCTGCTCCGGCCAAGGCCACGAAGCCTGCGCTGGCCCCCACGAAGCCTGCCGCCAAGCCAGCTCCCGCAGCAA AGAAGGCCGCTGCCAAGGCCGCCGCTCCAGCGAAGAAGGCGGCGGTAAAGAAGGCCGCACCAAAGAAGGCCGTAAAGAAGGCTGCCCC CGCAAAGGCCGCGAAGAAGGGAGCAAAGAAGCCCGCCCCAAAGAACGCCGCGGCAAAGAAGCCGGCCAGGAAGGCTGCCCCGAAGAAG TCCGCGAAAAAGAAGCGCTGAGCCTCGAAACAGGCCTCGAAGCGAGTGGCCGACTTCCGTCGGTCACTCGTTTCTTCTTTCCCGGAAC TCCACATTGCCCGGAACTCGTTTGGTGAGTGCATGCCGGACTTCGCTCGACACGTCCTCGATGCCCTGCCGAGTACCGTCTACACCAC GGACCTCGAGGGGCGGATCACGAGCGCCAACCGCTCGTGGTCCCGCTTTGCGGTCGAGAACGGCGCGCCCGCCCTCGCCAATGAGGCA TCCGTGCGGGGCACCTCGCTCCTGGATGCGTTCAACGATCCCGGGTATCGCACCCAGGTCATGCAGGCCCTCGACCTGCTTCGCTCGG GAGCTGTTCCCAAGATCACGTGGGAGTTCCCCTGCAGCTCGCCAACCGAGGAACGCGTGTTCCTCATGCACATCACGCCGTTGCGCGA AGGCGGGCTTCCCATCACGGGATTCGTCTTCTCCACCGTCGACATCACGCCGAGCCATCGGTCGCGTGAAGCGCTGATGGACACGAGC CTGGCCCTCGCCCGACCGATCGACATCGACCGCGTCTTCGTCGAAGTCGGCCACCAGCTGCGGCGCGCCGTCCCTGCCCTCGAGTTCT 
CCGTCTGGATCACGGAATCCGACGGCGTGAGCACCCGGTTGGTCTACGCGCTGGCCGAGGATGGCGATGTCTCCGGCACAGAAGCGCG CTTTTCGATGGTCGTGCGCGAGGCCATCGCCCGGCAGGACGTCGCGATGTCAGTGACGGCGAGCGGTCAAACGCTCGCGGCGCCGATG GAAGCCGCGGGTCAGGCGCTCGGTGCGATGGCGCTCTATTCCGAGTCGCTGGGCACGCGGCAGGAAGTCGAAGAGGCGGCTCGCGTCC TCGCCACGATCGCTGCGCAGGCCGGCGCGGCCATCGACCGTTCGAGGCTTGTGCAGCGAGTCGGCCAGAAGCGTCGTCTCGAAGCGAT CGGCGAGGTGGCGACAGGCGTTGCGCATGAGCTCCGGAACCCCTTGTTCGGGATCTCGTCAGCCGCACAGCTGCTGCGCTTCCGCGCT CGCGAGGACGTGGTTGTCGAGAAGAACGTCGGGCGCATCCTCCGAGAAGTGGACCGGCTCAGCCGCATGGTCACGTCGCTGCTCGAGT TCGGCCGCCCCAAGCCCACGACGCTGGCCCCCTTCGATCCGGACCTCGCGTGGGATGAGGTACTCGAGGGACAGCGCGGGCTGCTGGA GTCGCGGTCGCTCCTCATTCGCCGGGTTCGGCCCCCGCGTCCGACGGTGATTCGGGCCGACGCCGAAAAGATCGCGCAGGTGTTCCTG AACCTCCTGGTGAACGCCGCCGACCACGCGCCGGTCGCGTCGGACCTCGCACTCGAATCCACGCTGCTCCCGTCGGGCGCCTGGCGCA TGCAACTGACGAATCCGGGGCCGACGGTGCCCCCGGACGTGCTCGAGCGCGTGTTCGAGATGTTCTACTCGACGAAATCCGGGGGCAC CGGCATCGGCCTCGCGCTGTGCCAGCGCATCGTGGAGGAACACGGTGGGCACATCGCCATGCGAAGCTCGGCGGAGGCGGGAACAACC GTGTCCATCGAGCTCCCGGCCTCCCCTCCGGCGCCGGCGCAACAGCCGTGAACTTCGCGGGGGTCTCGAGCGTTCACCCTGCACCTTC TGCAGCCAGACTGCCGTCCAAGCCCATATGCCGCGCCCCATCCTGATCATCGAAGACGAGCAATCCATCCGGGACGCCCTCGCGGACC TGTTTGACGTGGCCGCGACGGCAGTGACCGCGGTCGCGACACTCGACGAGGCCAAGGCGGCACTGGCCGCTCGCCCCTACGACCTGAT CCTGAGCGACATTCGGCTGGGTGGAAAGCGTGACGGTGGGCTGCAGGTCATGGCGGCGGCTGGGCTGCTCTCCCCGGAGGCCACGGTC ATCGCCCTGACGGCTTTCCCCGATCAGGACAACCGCCTCGCCTCGCTCCGACTCGGCGCCACGTACTTCCTGGAGAAGCCGGTGGACC TCGAGACGATCGCGTCGGTGGCCGCGAAGCACGGCATCGCGTCGTCGCTCTATCCCGACCCGCCCGCGGCAAGCGTCGAGACGAACGC GACGAGCGCGTAGTTGCCGCGGGGCCACGGGCACAGGCCCGGGCTCCTGCGTGTTGACGCCTGACGAGTTGCTTGCTCGCTCGTCTGG CGCCCTCCCACGGACGCCGCGTAATCTACCGGAATGGCGGAGTCCCCCGTTGCCCTCTTGCGCGCGCACGCGCGGTTTGCCCCGTGGA ACGCGCGAGGCCTGGCGGCGCACGTCTCCGGACTCGTCGACGCGGTCGGTGTGCGTCCCACCAATGCGTCTGCGCGCGCCGCCCCCTC CGCGCGTGCGGTGCGCTTCTACGTGTCCAATCGGCTGATGGACCGCCCGGAAGGTGCGGGCACATCGGCGACCTACAGCTATCGGCAC TTCCTCCAGCTCCTGTCGATCAAGATCCGGCAGCGCGAGGGGCAGAATCTCGAGACCATCCGCGGCGAGTTGAAGGAAGTCACCGGCG ACCTGCTGGAACGTCGCGTCGCCGGGTGGCTGTCCAATGCGCTCGCCGCGGGCGTCCCCGCGGCGGCCGGCAATGACGGGAACGGCTC GCATTCGTGGCGTCGCATCGCGGTGGCCGACGGTGTTGAGCTGCACGTGCGCGACGACTCGAGCGCCGCCAGCGAGGACGCGATCATC GGGTTGCGTGAGGCGCTGCGCACCGCGATCGGTCGCGTCGAGAAGGCATGAACGTCCCGCGAATGGATGGTCGCGTTGTCGTGATCAC GGGCGTGGGCCGGTCAGGCCAGGTGGGCGAAGCCGTGGCCGGTGCCTTCGGATCGTTAGGCGCGCGGTGCGTCCTCCTCGATCGCACG CCCGGTGAAGTCGCCGCACGCGCGGCGGAACTCCAGGCCCGCGGCGCCACCGCCTCCGCCCACGCCTGCGACCTCACCGATGCCGCTG CCCTCGACGCCGTCGTGCAGGAAGTGACTGCGACGGCGCCCGACGGCGTCCACGCGCTCGTCTGCCTCGCGGGAGGCTTCGCCCCGGG GTCCGCGATCGCCGAGACGCCCCCCGATGCGTGGCAGCGCATGTTCGCCATCAACCTCACGACGGCGTACCTCACGACCCGGGCGTTC ATTCCCCTGCTCCGGAAGTCCCGCGGCGCCATTGTCTACTTTGCCTCCGCGGCGGCACTCCCCGGCGGAAAGGTGTCGGGCATGGCGG CATACAGTGCCGCCAAGACCGGCGTCGTCACCCTGATGCGCGCCGTGGCAGCGGAAGAGCGCAGCCATGGCGTTCGCGCCAACGCGCT CGCACCAACCGCCATTCGCACGGCAGCCAACCTCGCCAGCATGGACGCCGACACCGTCTACGTGGAACGCGAGACGGTGGCCGATTGG GTCACCATGCTTTGCTCGGATGCGTCCGGCCCGGTCAACGGGCAGGTCGTCAAGCTCGGATGAACGCACGCGCCCGCGAGTTCTCCGG CGGCGATGAGCGCCGCCGCCCCGCGCCCCCTCGGCGCCCACCCGGCAAGCACATCGTTCTGGACCGGGCCCTGGAGTCCCTCCCACTC TTTCGCCTGAGCGACTCCGCCGAGGAAGCGTCCATTCTCTACACGCCGCCAGCTGGCGGACGCTGGCGAGTGCTCCCCAGCCCCGGCG ATCGGCTTCCCGGCACGTTCGACCAGGACGTCTACGTCGAGATCTGTCGCCGATTCCTCGATGCCGGTGAGCCGGACGATGGGTCGGT CTCCTTTACGCTGCACGCGTTCCTGCGTTCGATCGGCCGCCGCGCCGATGGCCGGACCTACGAACAGCTCCGCGCAGCCCTCAGCCGG CTCGAACGCACCTCCCTCGAGTCCAGCGCCGCCTACTTCAATGCGTCCTCGGGGCAGGCCCTGGACGGGCGATTCACCGTCCTGTCCG CTGTGTCCATCGATCGACGACGTGTGTCCGACCGGGAACAGCTCGCGCTCTTCCCCAACGTCACGACGGCGGAACCGGGCGACGCGCG GGTCACCCTGTCGCCCCTCCTCCGGGGCAACATCGCCCGGGGACACGCCACCTCGCTCGTCGCCTCGCAGTACCAGGCGCTGTCGTCT CCGGTGGCCCGGAGGTTGTATCGTTTGCTCGAGGTCGCACGAGCCGAAGACACGGTCACCTGGCGGATCGAGCTGGAGGCGCTCGCGG AACAGATGCCCCTCGTCCAGCGGTATCCCTCACACCTGCAGCGCGTCCTGCAGCCGGCACACGAAATGCTCCTCACGGCCGGCATCGT GCGCGACGCCAAGGTGCACCAGCAGGACCGGACCTGGTACGTCGACTACGTGCTCGCCATGCGCACTGCCTAACGATTGGAGGCCCCA TGTCACCACGCGATCCCGCGCCGCCCCACGGCGCCTTCCTCCCCGAACCACCGGTCGTCCCGCCGTCGCCACGCCCCCCGGTCCGCCC ACCGGAGCCCGGGTGCAGCACCCTGCCCGTGACGCGCGTACCTGAACTGCCGTCCCTGTCGCAGGTGCTTGGGGTGCCGAAGCTTCGG TAAGTGTCACTCGGTCGGCCCCGCCCCGGTGCAGGAGCGCCGCAGCCGGGCACGACTGGTCCCTCGCGGAGGAACTCACCCGCCGCGT GGGCGTATTCGTTCTGAGTTACCGTGTCCGTCCCTCACTGGATGACCGCATGAAATCCATCAGGAAGCTGGCCCTCGGGGTCGTCGTC GTCGCTCCGCTCGTCGCGGGCGGGTTCATTGCCCAGGAGCGGGCCACGCAGGACGGCGGTCGCCTCCTCGGACAGGTCCTCGAT

\subsection{Das Cosmid slc_2j}

\subsubsection{Lage der offenen Leserahmen (ORFs)}

\begin{tabular}{|l|l|l|l|l|}
\hline ORF & Annotation & Start & Stopp & $\begin{array}{l}\text { Orien- } \\
\text { tierung }\end{array}$ \\
\hline 1201 & Hypothetisches Protein & 318 & 1283 & - \\
\hline 1202 & Potentielle Aminopeptidase & 1348 & 3309 & - \\
\hline 1203 & Konserviertes Protein (COG3804) & 3390 & 4388 & + \\
\hline 1204 & Uroporphyrinogen III-Synthase/Methyltransferase (EC 4.2.1.75) & 4452 & 5999 & - \\
\hline 1205 & Hypothetisches Membran-assoziiertes Protein & 5996 & 6922 & - \\
\hline 1206 & Hypothetisches Membran-assoziiertes Protein & 6907 & 7806 & - \\
\hline 1207 & Hypothetisches Membran-durchspannendes Protein & 8163 & 8573 & + \\
\hline
\end{tabular}




\begin{tabular}{|c|c|c|c|c|}
\hline 1208 & Konserviertes Protein (potentiell AtpB, F0F1-Typ ATP-Synthase, Untereinheit A) & 8577 & 9521 & + \\
\hline 1209 & Hypothetisches Protein & 9561 & 9809 & + \\
\hline 1210 & Konserviertes Protein (potentiell AtpB, F0F1-Typ ATP-Synthase, Untereinheit B) & 9897 & 10400 & + \\
\hline 1211 & Konserviertes hypothetisches Protein & 10415 & 11338 & + \\
\hline 1212 & Hypothetisches Protein & 11683 & 13011 & - \\
\hline 1213 & Potentielle membranständige GTPase (Stress-Antwort) & 13048 & 14886 & - \\
\hline 1214 & Hypothetisches Protein (Hypothetisches Fe-S-Cluster) & 14939 & 15442 & + \\
\hline 1215 & Menaquinol-c-Reduktase, Cytochrom B-Untereinheit & 15445 & 17016 & + \\
\hline 1216 & Konserviertes Protein (potentielle Dipeptidylaminopeptidase/Acylaminoacylpeptidase) & 17105 & 20086 & + \\
\hline 1217 & Hypothetisches Protein & 20209 & 20964 & - \\
\hline 1218 & Hypothetisches Protein & 20515 & 21006 & + \\
\hline 1219 & Hypothetisches Protein & 21072 & 21590 & + \\
\hline 1220 & Hypothetisches Protein & 21749 & 23398 & + \\
\hline 1221 & Hypothetisches Membran-assoziiertes Protein & 23401 & 25164 & + \\
\hline 1222 & Dehydrogenase von verzweigten $\alpha$-Ketosäuren E1 (KOG0525) & 25174 & 27339 & + \\
\hline 1223 & & 27362 & 27772 & + \\
\hline 1224 & Konserviertes Membran-durchspannendes Protein (COG0705) & 27810 & 28580 & - \\
\hline 1225 & Virulenz-Faktor MviN & 28603 & 30141 & - \\
\hline 1226 & Konserviertes hypothetisches Protein (COG1610) & 30430 & 30879 & - \\
\hline 1227 & Hypothetisches Protein & 30889 & 32031 & - \\
\hline 1228 & Konserviertes Protein & 32036 & 33019 & - \\
\hline 1229 & Hypothetisches Protein & 33024 & 34067 & - \\
\hline 1230 & $\begin{array}{l}\text { Hypotheisches Protein UbiE, Methylase involviert in Ubiquinon/Menaquinon-Biosynthese } \\
(\text { COG2226) }\end{array}$ & 34067 & 34915 & - \\
\hline 1231 & Hypothetisches Protein & 35028 & 35969 & + \\
\hline 1232 & Hypothetisches Protein & 36034 & 36558 & - \\
\hline 1233 & Hypothetisches Membran-durchspannendes Protein & 36693 & 38276 & - \\
\hline 1234 & Dolichol-phosphat-Mannosyltransferase (EC 2.4.1.83) & 38395 & 39159 & + \\
\hline
\end{tabular}

\subsubsection{Das Cosmid slc_2j}

ACGGCGTCATGCAGCGACGCGTTCAGGCTGTCGAACGCCTCCCCGAGATCCACCCGGGCCACGGGGATCGAGAAGGTATTCGCGACGA GTCGCGCGTCCTCTTCATCCTGCGGATGGCTGTAGCAGGGCAGCAGGACGCCCAGCACCCGCTGGGGAAACGCGAGCTGACACAACTT CGCGACGACCGCCGAGTCGATGCCGCCGCTCAGGCCAAAGACGTAGCCCTGCGCGCCGGCGCTGCCGGCCCGATCGCGCAACCAGTTG GAAATGCGTTCCGCCCGCGTCATGAGAGAAGTATCCATCAATCACTCAGTCCATCAATCACTCAATTTCCTGAGCGCTTCAGCCGCCG GTGACTCGGGCCACACGGGCTCGGGCGCGGCAACATAGTTCGCATGCGCGAGTTCGCCCTGGAAGAACACCGTTTCCGACGCCATGAA CGCGAGGCGTCCCCAGATCCGCAACAGCAGGTAGATCTGGGTGACGAGCAGCGCCAGCCACGGCGCTGCGGTGGCGGCGGGCGCCGAG GAGTACCACAGCCGCGCGACGACGAGCGCGGCGGCGAGGTTGAGCAGGTAGAGGCCGGTCGTGCGGAACGGACGCCGGCGGATGAACC GCAGCGATGACGACACGGCACTCAACATGCTCCGGCGATCCTCGACGACCGTCCGGACCTTCGCGAAGTCCGCCACGAGGTTCACGAA CGCCAGCCCAGCGAAGAAGACGAGGTAGAGCACGGCGCGGAGGGCGATCGCGTCCCGTTCCTCGGTCATCTCGCGCGTCCACCGGTTG TAGAGCGTGCCGAAGAGAACGGGATGCAGCCACGAGAAGAGCCACCAATACGCCGCGCCGATCACGACAGCCAGTCTGAGGAACCGGA AGAAGTAGGTGCCGCACGCGGAGAAGAAGGCACCCGTGCGCACCGGCCGGCCGCGGGCGAACCGATCGATGATGCCGCCCGACATGAA GACCCAGAGCGCGATGTACACGGCAATCGCCCAGGCGAGCGACGGATTCAACGGTTCGTAGTCGATGAACCGGCTGACGGTCGCCATC GTGGCACCGAAGCCGAGTATCTCGAACGTGAAGGTGCGCGAGAGGCCAGTGGCCGCGGCATCGAACTCAGCGGCCCAGCCGGCGTTCC ATCCCGCGGCGACGGTCTCGGCTTCGAGACTCGAACCGAGATGCGTGGAGATGGACCGATGGACCACGGCGGTCATCGGCAACGCGAA CAGGAATGTGGCGCCCATCACGCCCGCCGCGAGCGCCGGCGCGCGAATCACGCGGCGCCAGCCCTCGAGGAACGCACCAAGAGTCGGC GTCCTCGGCCGGGCCACCGGAGCGACGTCAGGCGAAGAAGGCATACGTCAGCAGGACCTCCTGCACCCACGTGAGCCAGCGCAAGGCC CACTTGCCGGCGGCATCGGCGGTCTGCGGCCGCGCCGACCAACTGTTGTTCGTGTAATTCACGTCGAGCAGTAGAACGCGATCGGGGT CGACTTCGACGCGAGTGATGGGCGAAGCGTCGCGCACGTCGAACGCTTTCCAGCGATCCGCGCCATCCCACGTCAGGAGCCGGACAGT GCCGCCGCAGGTGACGCGCACGGTCGTCGGGAACACGCCGTCCCCGAGGCGGCGCACGACCACCGTGTGTCTGAATCCCTCGGGCGCC GGTTCGGACGTGACCTGACCGACGCCGTAGTCGAACGTCGCGGAGCTTCGGTGCACGGCGTCGAAGAACCACGTGAGGTCCTTGCCGT GGATCTCGTTGGCGATCGCGAAGAACTCCTCGGGGGTCGGATGCCGGTAGAGGCCGCGGCGGAAGTGCGTCGCGAGAATCGTTCGCAC GGCATCCCAGCCGATCGTGCGTTCGAGCGTCGCCAGCCACAACGCGGTCTTGTTGTAGCTGGTGGCGCTGGCCGAGCCGGGCCAGTAC TTCCACGTCGGCGTGGACTGGTTCTCGTACGACGACACAGGCCGGAAGGCGTTCAGACGATTGCCGTCGATGGCGCGCGACCACGCCA CATCCGTGTATTCCCAGCCGGCCAGGCCACCGAAGTAGCGGCCGCTGGCGACGAAGCGACCCGGGAAGGCTTCGTCCAGTACTCGTGC CGTCGAATACGTGTTCAGACCCTCGTCCATCCAGGCGTGCTCGAACTCGTTCGTGGCGATCAGGCCGTACCAGAACTGATGGCCGGCC 
TCGTGCACGGTCACGCTCTCGGGCTGCGTCCCACGCGCCGGTGGCCACCACCGCGTACCCGCCGTGAACAACGTCGGGTATTCCATGC CACCCGTGTTCTCGCCCTGCGACGCGGGATTGAAGATCGTGACCGGGTCGACGATGGTGATGTGCCCGTACGGATACGGGCCGAACCA GGTGCCGTAGTACTTGAGCGCCGCCCGCGTGGCGCGGAAATGCCGCGACTCCTGGCCGGCGTGCTCGCGCTGCAGCAGCAGCCGCATC TCCACCGGCGGCAGACCGGGTTCCTCGAATCGTTCGCGATGCTCGACGAAGTCGGGGCTGGTCGTCCACACGAAGTCGTGCACGTCCG CCTGAACGAATCGGTGCCGCACGCCGCCGGCGTCGCCGTCCGTGGCAGACGCCAGCGTGCCTGTCGCTCCGACGGTCCATCCCCGGGG CACGGTCAGCGTGACGTCGTATGTGCCGAAATCCGAAAAGAATTCTGTCGCCGCATGAAACTGATGCGCGTTCCAGCCCTCGTCTTCC AGGACGCCGATCTTCGGAAACCACTGCGCGACGAAGTAATAGCTGCCGATGCGACCCGTGCGGGCAAACGTGCGCGGCACGCGTGCGG TCCAGCCGAGTTCGAGGTCGATGGACGCGCCCGGAGCCACCGGTGAGTCGAGCGGTACCGCCAACAGCGTGCGATCGTCGGCGTTCCC GTCGTCAGGCGCGACGAACGTGGCGCCGGCAAGCAGGCTTCTGCCGCCGGTCGCGAGGGTGGTGACGTCGATGCCGCCGAAGTCGTCC GCCGGGCGGCGGGCGAGGGAACGGTTGCGCCCGAGCGCCTGCTCGCGCATCCAGGACGAACGCGTGTCGCGCCAGGCGTTCCAGTACA AATGGAAGCGGAGTTCCGCCACCGGGTGGCGCGAAATGTTGCGCCAGGCCAGCCGGCCCGTCGCGACGATCTCATTCCTGCCGGGATC GAGGGCGGCCGTGATCGTGTAGTTGGCATTCCGGGGAGACGCGGGCGTCGCCGCGTCCTGCGGGACTCGCGCCTGCGGAACCGGGGAC GCGAGCGCTACGACGGCCAGCGCGGTCGCACCCGCAATCGTCCACCGTGCCATGCACGCAGAATCCTACTTGATCCAGCTACAATCTA TTGTTTGTCCGTACGGCATCGGCGGATGCAAAGGAGCGTTGGATCGTGCCTATCAAGACGTTACACATCGGACTCGGACCCATCGGTG CGGGAGTGGTACGCCAGGTGGCGTCCCGCAGGGGATTCAGGATTGTCGGCGCCGTGGACATCGACCCGAACAAGACGGGGAAGGACCT CGGCGACGTCTGCGGCGTCGGCCGCAAGCTGCGCGTGAAGATCGCCGCGGACATCGCGAAGACGATTCGCGCGACGAAGCCCGACGTG GCCGTGCTCTGCACGAGCTCGAGCCTCAAGCGCGTCGTGCCCGAGTTCGAAGCGGTGCTGAAGCTCAAGGTACCGATCGTGTCGACCA CCGAGGAACTGGCCTATCCCGTCCGCAGCAATTCCGCGGCCGCGAAGAGGATCGACGCGCTGGCTAGGCGCGCCCGCGTGGCGGTGCT GGGGACCGGCGTCAATCCCGGTTTCACGATGGACGCACTGCCGATCGCGCTGACGGGCGTCTGCGAGAACGTGACCGCGATCGAAGTG GCGCGCGTCCAGGACGCGAGCATCCGGCGCCTGCCGTTTCAGCAGAAAATCGGCGCGGGTCTCACGCCGGAGGAGTTCATGAAGAAGG TGGACAGCGGCACCGTCCGCCACGTCGGCCTCGCCGAGTCCATCACGATGATCGCCGACGCGATGGGCTGGAAACTCGACAAGGTCAC CGATGAGATCCAACCGAAGATCTGCGAGCGGGTGACGTCGAGCCAGTTCCTCACGGTTCAGCCGGGCCAGGTGTGCGGCATCGTCCAG GACGGCATCGGGTACCGGAAGGGCGAAGCCCTCATCAAGCTCCACATGGAGGCGTATCTCGGCGCCCCTGAATCGTTCGATGCTGTTC GGATCAGCGGCAGCCCGGCCATCTCGTCGATGATCGCCGGCGGCGTTCATGGCGACATCGCCACCGCGGCCATCACCGTCAACTCGCT CCCGAAGGTCCTCCAGGCCCAGCCGGGATTGCGCACGATGCGGGACATGGCGCTGCCGTCGTATTTCGGTGGGTAGAACGAAAGCGTA GTGCTTGGTGCGAGGTGCTGAGTGCTTGGTGCAGCACGAAGCACCAGGCACTCAGCACCCAGCACTGTTCGTGAAGTGCCGCACCAGT CCCTGCACCAGTCCCTCGACGGTGAACCGGTCGGCGACGATCGTGGGACTGATGCCGAGTTCCAGCGCGGCGGCCGCCGTGACGGGGC CGATGGCGGCGACCACGGTCATGCCGAGCAGGTCCGCGGCCTGCTCCTCGCCGATGAGCGCGGCGAAACGCTTCACCGCGGTCGGGCT CGTGAACGTGACCGCATCCACCTGACCATCGAGGAGCAGGCGGTAGATGCGCTGGGCGGCCGGTGAATCCGGCGGATCGGCCTCGGTC CTGTACGCCACGAGGTCGGTCACGCTGGCGCCGCGTTCCGTCAGCGCGTCGGCCACGACGTTGCGCTCGTGGTCGGGGCGCACCACGA GGATCGATCGTCCGTCCACCGTGGAGTGCGCCACCATCGCATCGGTGACACCCTCGACCCGCAGTTCCGGAATTACGACATCCGCCTT GAGTCCGTACGCGGCGAGCTGGTCCGCGGTGGAGGGACCCACGGCGCACAGTGACGCGCGGCCCAGCGCGCGCATGTCGCGCGGTCCG CGCGCGATCGCCGCGAGCAGCCGTGCGGCTGACACCGCCGACTCGAACACAATCCAGTCGAACCGATCGACCGACGCGGCAATGCGAT CGAGCGCCTCGGGATCCTCAGGCGCGCGAATCCTGAACGTCGGCGCGATGATCGCCTCGGCACCCAGATTCTCGAGCGGGTCGCTCAG CTCGCGCGCGCGGTCGATCGACCTGGTCACGATGATGCGCTTGCCGAAAAGGGGCCGCTGGTCGAACCACCGCGCGTGCTCCCGGAGG TTGACGACGTCGCCGACCAGGAGCCATCCCGGTTCCGACGCGGCGTCGCCGCTCGTGAAGATTTCGAGCAGGCTGGCAATGGTGCCGG TGAGCGTGCGCTGCGAGGACTGCGTGCCGCGGTAGATGAGCGCCGCCGATTCGTCGGCGGAGCGTCCGTGGTCGATGAGCTGCTGGAG CACCGTCGCGGCCAGCCTGGGCGTGGCCCAGCAGGCCAGCGTGCCTTCGAGTGCGGCCGCCGCCGGCCACGCGATCTCCGGGCCGTCG TCCTCGGCGGTGCCTTCGCTGCCGCGAATGAGCAGCAGCGAGTCGCCGGCGCTCGGATGCGTCAGCGGGATGCCGGCGTATGCCGACG CGCCCAGCAGGGCGGGCACGCCCGGTACAACTTCGAACGCGATGCCCTGTTCGTGCAGAAACATCGCTTCCTTCGCGCCGCTGTCGAA GACGAACGGATCGCCCCACTTCAGCCGTGCGACGGTGTGGCCGTCGCGGGCTTTCTCGGCGAGCAGCATCGAGATCGCATCCTGCGCG ACGTCGCGTTCCGCGGGGCCGCCGGCGTCGATGCGCTCGGCGTCCGGCGCCGCCCAGCGGAGCACCGGCTCGGCGGCGCGGTCGTACA CGACCACATCGGCTTGCGCGAGAAGCCTGGCGCCGCGCGCCGTGACCAGTCCGGGATCGCCCGGCCCGGCGCCGATGATAACCACGCG GCCGGTCGCGCTCACGGCGCGCCCTTCGGCCCGAAGTAGCCGGCTTTGGTGCGCGCCGTCATGTTGCCGCGCGCGATCTGCACGTTGA TCTTGCGGAAGGCGCCGTCGCGCTTCACGTTCTTCGATGCATACGCCAGCGTGTACTGATTGGCCAGTTCGTCCGCGATCTGGCCGTA CACGCCGGGGAGTTGCTTCAGTTCGGTCACGGCGTAGGCCCGGCCGCCGGTTTCGCGCGCGAGCGTGCGCAGCACGAAATCGGCCTCG TTCCACCCGGCGTTCTTCTGCGCGTCCTTGTCGACGATGCCGATGCAGTAGGCGACCACTTCGGAGCGCCGCGCCAGTTCCAGCACGT CCTCGTAGGGAACGATGCTGGACGTGTCCTGGCCGTCGGAGAGCAGCACGATCGCCTGGCGGCGCAGGTCCGGGCCGGACTCCGCGCG GATGCGCCGCAGTTCGCTCAGGGAGGTGTACAGCGCGTTGTAGAGCGACGTCGATCCGCCGGCTTCCATCCGCGCGACGGCGCGATCC AACGCCTCGCGATCCCCGGTGAACGGCTGCAGGATCTTGGCCTGGTTGTCGAAGTCGATGACCTGCCCGACGTCCGCCGGACCCATGC GCTTGATGAATCCGCCGGCCGCCTCGCGCGCGATCGGCAGTTTGAGGTCCATGCTCGTGCTCGTGTCGATGACGAGCGAGAGCGCGAT GGGCTGCGCCTGCCGCGAGAAATTCGTCGCATCCTGCAGCACGCCGTCTTCGTAGATCTGGAAATCCGACTGGTCGAGCCCGGCCACG AGGCGGTTCTGACCATCGGCGACCGTAATGGTGAGTAGAACGAGGTCGGTGCCGCCGCGGAACTTCTGCTGGCCGCCGACCGAAACCT GGAGCAGAGCGGCGACGGCCGCTGTGGCGGCCAGCCGCGCGATCACTGACCGGCCCACTTCGACGAGCGCACACGGACGTCCTTGCGG CGCGACGTGACTTCAATGCGATCAGGCGGAATCAGCGACTCCGGGCGACCGTAGATCACGAGGTACCGCGACGCAATCAGGTTCGTCA CGGTGGTGAATGCCGATTCGATGCCCTGGGCCGAGAGCACGACCTTGTTCATGCCGCCGCTGTCGCGGGTCACGTCGCCGAGGACGGC GGCGCGTTCGCGCGTCGCGCCGCTCTGGGCAGACCCGCCCGGCTGAAGCGTCACGACCCACAGGGATGCGCCGGATGACTTGAGCGCG TCTCTGATCTGCGTGTGGAGCTCGCTCGAAAACTCCGGCCCGTTCTCGGCGACGAACGCGACGATCACCGGCGATGGCGCCTCGCGCT TCTTCAGGTCACGCGTGGCGTCCATGATGGCCTGGAGGAAATAGGCCCCGGACCCGGCGATGGAGAAGTAGCGCTTCGCGACATCCAG CAGCGCGTCGGGGTTCGGCGTGAAGTCCACACGCCGAGTCGGCCGTTCGCCGAATGTCATGAATGCCTGGTGTGGCGCCGGGCTCAGG GCCGCGATCTTCGCGACGAACGTCGTCAACGTCGGCCGGAGGTACTGCACGAGCGACTGGGTCGCCTGGCTGTCGTCCACCAGAAAGT AGACGTGGGACGGCGGCGGCGCCGGCGAGGCCCGGAGGACCTCGCGAGCGACGCCGTTCTCGCGGACCAGAAAGTCCGTCGCCTGCAT GTCGGCCACCGGGAGGTCGTTGTTCGTCGCGGCACTGACCAGCACGCCGCGCTCGCGCTGCTCGCGCTGGTCGGCCGACGTTGAGGAG GATGAAACGGAGATGGCGATGACTCCGGCCATACCGGCGGCGAAAACGAATTTGCCACGCATACCTCGGAGTATAGTTGGCCGCAACG CTAGTGAACTAATTCACAAGGTGTTGTAATATCTGTGGGTTCCGGAGGGCGTCCAAGGACGCGCTGGGGCGCACGTGGCGCGTGAGGT GACTCTGTGGCCGTGGGCGACGAGCGCGGACCGACGTGGCTCAGGACACTTCGGTCCTTCCATACAGGCCTGCAGCAGGCCGGTCCCG CGGCGACGAGTGGTTATTCACTCATAGGCGCCATCGCATTCTGCGGCGGGCTCGGATACCTGGCAGACCGGATGTTCGGGATCGCGCC GACCGGACTGGTGGCCGGCATGCTCTTCGGGGTTGTCGCGGGTATGTATCTCGTGGCCAAGGAACTATGGCGTCGTTGACGCCGGCGG CGGTGATGGCCGTGGCCGCCATTCTCGCGGCGCTCGGCGTGATCGCGGTCGCGACGGGCCTGGGGTACGAGAAGATCGCGCGGCCGGT GTTTGGCGGCATGATCGGGCCGCTCGTCGCGGTCGTTGCGACCTGGATCGTGACGGTGCGAACCTATCGCCGCAATCCGGCGGAGGTT TCGGCCCTGATGATGCGGGCCTTCCTCATGAAGGTCCTGTTTTTTGCGGCGTACGTTGTGGTGATGGTGAGAGTGGCGGAACTTCCAG TGCGACCCTTCGGACTGAGCTTCACGGCGTTTTTCATCGGCCTGTACGCGGTCGAAGCCGGGTATCTCGCACGTCTGTCTCGCCTGCC GGGGCTCACGCCCCGGTCTACTTCCGGGAGCCGGTAGTCGATGCGCTTGGATTGGATCCTTCGGGCCACACTGGCAAACTCCGACGGC GGCGGCGCCGCGTCGGATGGCGCCCAGAAGGGCCTCGACTTCGTCGGGCACGTCGCCAACGGCGAGCACGCGCTGTTTCACCTGCCGA CGATCTTCGGCATCGACTTTTCCATCACCAAGCATGTGCTGATGCTGTGGGTGGTGGCGATCCTCGTCTTCCTGTTCGTCTCCGCGGC GGTCCGCCGCTACCTCCGCGCCGGCAGCCATGTGCCGTCCGGTGCCCGCATCAATGCGCTGGAGATCGTCGTCGAGTTCGTACGCGAC ACCATCGCCATGCCGAACGTCGGCAAGAAGTGGCTGTGGACGTGGACGCCGCTGCTGCTGACGTTCTTTTTCTTCATCCTTGGCGCGA 
ACGCGATCGGCCTGGTTCCGATTTTCGACTTCATCGGGCTCGTCGATCACCTGTTCATACACTCGGCCGAGGACTCGTTCCTCAAGCA CCTGATCCACGGCGGCGCGACGGCGACCGGCAACTTCAACGTGACCGCGGGGCTGGCGTCGATCACGTTCGTCGCGATCATCGCCGCC GGTTCGAAGGCGCACGGCTTCGTGCAGCACTGGATGAACCTGGTGCCCCACGGCCTGCCGAAGGCGCTCTACCTGCTGCTGATACCGC TGGAGATCATCGGCCTGTTCGTCCGGCCGTTCGCGCTGACGATGCGACTCGCCGCCAACATGACCGGCGGCCATATCGCCATTCTCGC GATCCTTTCGTTCGTGTTCACGTTCGCCGGCATGATGGGCCCGCTGGCCGGCATCGGCGTCGGCGTCGGATTCTCGGTGCCGCTCGCG GCCGCGATTTCGGGCCTCGAGATCATCGTCGTGCTCGTCCAGGCGTACGTGTTCACGCTGTTGTCGGCCGTGTTCATTGGCATGGCCA TTCACTCGCACCACTAATCAGGTACCGCTTAACCACGTCCCTCTAAGGAGATTCGCATGCAGGAAGCCGCTCAAGCTACTTCGATTGC CGTTGCTTACGCCGGAGCCGGCCTTGGCGCCGGTCTGGCCGTCATCGGCGCGGGCATTGGCATCGGCAAGCTCGCCGCTGGCGCGGCG GAAGGCATCGCGCGCCAGCCGAGCGCGACGCCGCAGATCACGAGCGCGACGCAGCTGCCGCTCTTCCTGCTCGAAGGCGTCGCGATTC TCGCGGTCGTGGCCTGCCTGCTCGTCATTCTGACCAAGTAACTCGGTCGGGCCCAGGCGCGCGAGGCGCGCCGTTGGAAGCGAGGGCG CGGACCGCGCGCCCCGGTAGAAGAGGAAAGGACGGCTGCTGTGCAGAATCCGCTCGTCCAAGTCGATCCAGGCCTGTACATCTGGACG ATCTCGACGTTTCTTGTGCTCGCGTGGGCGCTGTCGAAGTTCGCCTGGAAGCCCTTGATGAAGGCGCTCGAGGAGCGGCAGAAGACGA TTGCCGCCGCCGTCGATGACGCGCGTCAGGCCAGGGAGCAGCTCGAGCGCGCCCAGCAGGACGCCGGTAAGCTGCTCGCGCAGGCCCG GGTGGACGCCGAAGATCTCCTGAACCGTGGCCGCGCCGACGCGGATCGCTTCCGCCAGGAACTGCGAGACAAGGCGATCGCCGAGGCC GCCAACATCCGCAAGGAAGCCGAGCGAACGATCCAGCGGGAAACGGCGAAAGCGATCGATCAGATCCGCGCGGAGGCCGTCGACCTGT CCGTGGCCATCGCCTCCAAGCTCATCCGCCGCGAGATCAAGGCGACGGATCAGGACGTGCTGCTGAACGAAGCGCTTCGGGAAATTCA GGGCACGAAGCAGTAAGCCGGCCAGGTGCCATGCGCCGGATTGACGTCCTTCTCGTCCTGATGGTCGTCATCTGGGGCGTCAACTACA GCATCATCAAACAGGCGTTCGACGAGATCCCACCCCAGCCGTTCAATGCCATGCGGCTGGTGCTGGCGTCCGCGGTCTTTCTCGTCGC CATCCGCGTGACACGCGGCCGCACCGGGCCGATGTCGTCCGTCTTCTTCACGCCCAATCCCCTGACGCGCGCGGACGAATGGGGCCTC TTCTGGCTCGGTATCGTCGGCCACCTCGGGTATCAGTATTGTTTCGTCGGCGGCGTGGCCGCGACGAGCGTGTCGAACGCCGCACTCA TCATCGGCGCCACGCCCGTCGTTGTGGCCGTCGCATCCGCCGTCCTCGGGCGCGAGCGTATCGGGCCGTTGCACTGGCTGGGGGCGGC AATCTCGGTGTCCGGCCTCTACTTCGTGGTCGGCCACGGCGCGTCGTTGGGAGGCCGGACTCTCGGCGGCGACCTGCTCATCATGTTG TCGGTGCTCTGCTGGGCGACGTACACGATCGGCGCCAGCCGGCTCATCGCGCGCCACTCGCCGCTCTTCGTCACGGGTATGACGATGG CGATTGGCGTCGTGCCGTACGTGGCGCTGACGTTCCCCCAGTTTCTCGGCCTCGACTGGGCGCGCGTCAGCCTCTACACGTGGGCCTC GCTCGTGCTCTCGGCGTTACTTGCGCTCAACGTGGCGTACCTGATTTGGTACACGGGCGTGCAGACAATCGGCGCGGCGCGCACGTCG ATGTACTCGAACCTGGTGCCGGTGGTGGCCATGAGTTTTGCGGCGTTGCTGCTCGGAGAGCAGGTGACCAGCGACAAGTTCATCGGGG CCGGCGCGGTGCTGACAGGAGTCCTGCTGACCCGGCTTGGTCGTAAGCCACCCGCGGTACCCATTGAGGAATGACACGGAGGAGTCAT GAAGGTTCTTGCCACGCTGTTTGCGATCACGCTCGCCATGCCGGTCGCGGCGCTCAAATTCACCGCTCCTGCGGGCTGGGTGTCGAAG GCGCCGAGCTCGTCGATGAGGCTTGCCGACTTCACCCTGCCGAAAGTGGCCGGTGACGCAGAAGACGCGACGGCGACACTCTACTTTT TTGGCGGCACGGGCGGATCCGTGCAGGCGAACCTGGATCGCTGGATCGGACAGGTGGCGCAGCCGAACGGCGGTCGGTCGATCGACGC GGCAAAGACCACGACGCTGGCGAGCGCCGCGGGCCTCAAAATCACGCTCGTTGATGTGGCGGGGACCTACGTGGCTGAAATCACGCCG GGATCGGCGGAGCGCTTCAACAAGCCGGGATTCCGGCTACTCGGGGCCGTGGTCGAGACGCCGGCGGGGCCGCACTTCGTGAAGGTGG TCGGCCCGGCGCGTACGGTGGCGAAGTGGGAAGCGAGCGTGACGGCGTTTCTGAAGAGCGTGGCCTGGGCTACGCCAGCTTCTTCATT CTGAGATTCACGAGACAGACCGCGAGCATCATCGTCCCGATCGTCAGGACGCCGGCGCTCATGAGCGTGCGATAGGCGGCGCGGCCGA TGAGGTCGTACATCGTGAAGCTCACGAGCGCGATCGCGATGCCGGCCGCGAGGCGCCAGGGACGACCGACGTGTGTCCAGCGATCGAT CAGGCACACCATGGCCGGCGTGGCGACCAGCAGGACGTAGTCCCAGCCCTGCGGAGAGATCACCGGAATCAGCAGGGTCAGCAATCCG AATTCGAGGTAGAGCGGCTCGGTCACGTCCTTGCGCCGGCTGACCACGAACGCCACGAGGACGACCGCGATCGCAATGGTCCCGAGCG CGAACCAGGCGACGTGCGGCCCCTCGCCGGTCCATTTGGTCCAGGCCGACATGGCGGACACGTTTTCGGCGTTCAGGAGATTCGGCAG CGTCGTCGTGTCGGCCACGGTGCGGTACCAGGCTGCGAGCTGATCGAGATTTCCCTGCCAGCCGTAGACCAGGGCGGGTGCGAGCAGT CCAAGGGCCACGACGAGCACGGCCGCGGCGACCGCTGGCAGACCGCCGGCCAGCAGCAGCCACGGCACGAGGATCAGGGCGTAGACCT TGACGAAGACACCCATGCCGACGAGGACGCCGGCCGTCCTGCGCGCGTCCACCAGCGCCGCCAGGAGCGCGCCCGTCAGCAACGCCGC GAGCACCACGTTCGTCTGGCCCAGCAGGAGTTCCCGGGCAAAGAACTTGAGGGTGACGAGGGCGGTGAGCCAGATGAGGACACGCTCG CTCCGGTTGCGCTCCGGCAGGGCGCGGACCGACCATCGGAGCAGGATCACGAGCAGCGCGCAGGAGAGTGCGTACCATCCAGTTCGTG CGGCCGGTGCCTGCACGGCCGCGAGGGGACGCGCGACGATGGCGAACAGCGGCAGGTACTTGAACTGATAGTGCCCGTCGTCGGCGCG GTACAGATTCTCGGCATGCACCGCCCGCACGGCCGCGCGGCGGTACACGTCGAAGTCCACCATTTCCCGGTGCACGCGCATCGCGTAG AGAGCCGCAAACACTGCAGCGAGCAGCAGCGGCGCCGTGACCGCCTTCAGGGCGCCAGGGACTTGCATCCGCCAAGTCACCAGATCAC CGAATCACCGAATCACCAAATCCTCAGGTCTCTCGCCTCGGTCTCATGTTCGCCGCGAGGACCCGCTTGCGCAACCGCAGGAAGTGCG GCGTGACCTCCACGAGTTCATCGTCGTTGATGAACTCGATGGCCTGCTCGAGGCTGAGGCGGCGTGGCGGAATCAGGCGGATGCCTTC GTCGGCCGACGACGCCCGCATGTTCGTCTGCTTCTTCTCGCGCGTGATGTTCACGTCGAGGTCGTTGTCGCGTGAGTTCTCGCCGACG ATCATGCCCTCGTAGACGTCGGTCGCGGGATCCACGAACATCTCGCCGCGCTCCTGCAGGCCGGCGATCGCGTAGGCCGTGACCTTGC CTGGTCGATCCGAGACCAGCGCGCCCGTCGGACGCGCCGGAATCGGTCCGTGCCACGGTTCCCAGCCCTCGAAGTTGTGATGCATCAG TCCCGTCCCGCGCGTTTCGGTGAGGAATTGCGTGCGAAATCCAATCAGGCCGCGCGCCGGAATCCTGAATTCGAGGCGGATGCGGCCG CTGCCGTGGTTGATCATCTTGGTCATCATGCCCTTGCGCATGCCGACCTGGGCGATGACCATGCCCTGGTACTCCTCCGCCACGTCCA CGACGAGCTCTTCCACGGGCTCCATGCGCGTCCCGTTGATCTCCTTCGTGACGATCTCGGGCCGCGACACTTGCAGCTCGTAGCCCTC GCGGCGCATCATCTCGATCAGGATCGAGAGCTGGAGCTCGCCGCGGCCGACGACCTTCATCTGTTCGGGCGTCTCGGTGGGCTCCACG CGGATGGACACGTTGCCGACGAGCTCGCGATCGAGCCGGTCCTTGATCTGCCGCGAGGTCACGAACTGGCCGTCCCGTCCGGCGAATG GCGACGTATTGACGCCGAAGATCATCGAGACCGTCGGCTCGTCGATGGCGATGGTGGCGATGGCTTGAGGATTCTCGGCGTCGGCGAT CGTCTCGCCGATCATGATGCCCTCGATGCCCGCGAGGCAGATGATGTCCCCGGCGGACGCCGCGGCCGCGTCGACGCGCTTGAGCCCT TCGAACGTGTAGAGCTTGGTGACCACCGTCCGCTGCACGGACCCATCGAGCTTACAGACGCCGATCGGGTCGCCCACCTTGACCCGGC CGTTGAAGATGCGGCCGATGGCGAGCCGGCCCAGGTAGTCGCTCGAGTCGAGATTGGCGACGAGCGCCTGGAGCGGCGCGTCGGCGGA CCCGCGCGGCGGCGGCATGTGCTTCACGACCGCGTCGAACAACGGCCGGAGGTCCTCGCCGGGCTCCTCGAGCTTCGCCGTCGCCGTG CCCTGCCGGGCATTCGTGTACAGGACAGGGAAGTCGAGCTGATCCTCGGTGGCGTCGAGGTCGATGAAGAGGTCGTACACCTCGTTCA GCACCGCGGGCGTCCGCGCGTCCGAGCGATCGATCTTGTTGATGACGACCATGGGCGTCAGCCGCCGCTCGAGGGCCTTGCGCAGGAC GAAGCGGGTCTGGGGCAGCGGGCCCTCGGACGCGTCCACCAGCAGCATGATGCCATCGACCATCGACAGCGTGCGCTCGACTTCGCCG CCGAAGTCGGCGTGGCCCGGCGTGTCCACGATGTTGATGAGGTGGTCGTGATAGTGCACGGCCGTGTTCTTCGCGAGAATCGTGATGC CGCGCTCGCGTTCGAGCTCATTCGAGTCCATGACGCGCTCGGCGACCCGCTCGTTGGACCGGAAGATGCCGCTCTGGTGGAGCAGGGC GTCCACGAGCGTCGTTTTGCCGTGGTCAACGTGCGCCACGATGGCGATGTTTCTGAGGGCGGGATTGGCCACACCCTGCGCGAACGGA ATGGGTCGGGACATCTCACCAGTATAGACACTTGCCTTGGTGATTTGGAGAATTGGTGATCTGGCAATGTGGCCAGTTCAAGTATCAT TTCGCGACCAAATGTCGTCGCATTTCGAGAATCGTCGCCGTGCACTCGTCCGGTTCGTGAATGGCGGAATGGCGCTGATTACGGCGGC GTTGGCCGGTCTGGTCGGCGCCGCGGCCACGCCCAGGCGCGAGGCGGCCTCGCGGCGGTGGCGGAAGGCCGGGACGATCTTCGACCTG CCTGCCGATGCGCCGTTTGCCGCCGTCCTCGCGGAGCGCAAAGCGGACGGATGGCTCGAGACCAGCAGGCAGTCGGTCGTCTACATCG ACAAGCGAGGCGACACGATTCAGGCGTTCTCGGCGACGTGTTCGCACCTGGGCTGCCGTGTGACGTGGAACGAGACGAAGACGCAGTA CCTCTGTCCATGCCACGGCGGTGTCTACGATCGTGACGGACGCGTCGTCTCCGGTCCGCCGCCTGCGCCGCTCGCCCGCGTCAACGTT CGCGTGAACGCGCAGACGTCCGAGATTGAGGTCGAACTGTGAGCATGTTCGCGAAGGTCGCGAACTGGCTCGACGACCGTACCGGCTT CCGCATGTTGCGGCGGCACGCGCTCGACGAGCCGCTGCCGCCCGGCACCGGCTGGTGGTTCACGCTCGGCAGCCTGCTGACGTTCGGC ATCGGCGTGCAGTTCCTCACCGGCATCGCGCTCGCGCTCTTCTACGCGCCGACCCCGGACCATGCGTGGGACAGCGTGCGCTTCATCA CGGACAGCGTGCGCGGCGGGTCGTTTCTGCGCGGCCTGCACCACTGGGGCGCGAGTCTGCTGGTCGTCGCCGCCGTCCTGCATCTTTG 
CCGCGTCGTCTTCTTCGGCAGCTACCGCAAGCCCAGGGAAGTGAACTGGATCATCGGCCTGATCCTGTTGCACGTGATTCTCGCGTTC GGCCTGACCGGCTACCTGCTGCCGTGGGATCAACGCGCGTACTGGGCCACCGTCGTCACCATCAACATTTCGAAACTGACGCCCGGCG CAGGGGAGATGATCGCGTCGATCCTGCAGGGCGGCTCCGACATCGGCGCGCTGACGCTGACGCGCTGGTACGCCGCGCATGTGCTCGT GCTGCCGCCGCTCCTGGTCGGCCTGGTCGTGGCGCACCTCTATTTGATGCGGCGGCACGGCATCTCAGGACCGGTGACGCCGAGGGCC GGACGGTCCGAAATGTTCTTCCCGCATCAGATGGCCCGCGACTTGACGGTGGCGATCGTGGCCGGCCTCCTGCTGGCAGCGCTGGCGT ACAAGGGGGCGCCGCCGCTCGAAGCGCCCGCCGATCCCACCTCGAGTGACTACATCCCGCGGCCGGACTGGTATTTCCTCGGGCTGTT TCAGTTGTTGAAGTATTTCCCCGGGAAGTGGGAAGTCGTCGGTGCGCTGTTCATTCCAGGCATCGTGATGGCGTTCCTGGCGTTGCTG CCGTGGCTCGATCGCGGCCGCACGCGGCAGGCGCGCCAGCGCCTCTCGGTGCTGTTGCCGTTTACCGCCGGACTCACCGTCGTCGTGG CGCTCACGATCATGGGCGCCCGGGATCTTCCGGCGCAGGGCGGGGCTGCGTGGAACATCCGGGAGATCGGCGGCGCCGCGCTCGTGGA ATCGAGCGACCGATGCCTCAGGTGCCATCGCCCGGAGGGCGTGGCGTCGCCCGTCGAGGCGGGCCGCATCGGCAAACCGGCCACTTGG CTCGCGATGCATGTCGCCGATCCGGAAGTCATAGCCCCGGGTGTGCGCGAAGCGCCGCAGTCAAATCAGGCGGAGTTGCAGTCCGTGC TTGCGGCGCTCGCAAAGATGCGCTCCGGGCCGCCGCCGGTCGTGGACGCGAACACAAAGAAGAACTACACGCTCTTCAGCAAGTTCTG CGTCAATTGCCACATCGTGGATGGCGTGGGCGGCAAGGAAGGTCCCGACCTCACGCGCGCCGGTCGCGAGCTGAGCCCGGCGGCCATC GAACAGCGCATCATCGATCCGGCGGCCATCGATCCTCTGGCCGAGATGCCGTCATTCGGCGGCCGCATCTCGCCCGAGGACATCAGGA TGCTCGCGACGTGGCTGGCGGCGAGGAAGTAGCCGCTCACGGTTGGCGCCGCTAATGTCATGGGCGTCGTTGTAATATGCTGTCCCGA CTTTTCCCAGTCCCCATGAGTCCCGGAGGCCTATGAAGACTCGCTCGTCGCTCAACATTCGCCGCGGCTGGTCGCGGCGGACGCGCAT CGTCATCATCGCGATCGCGTCAATGCTGCCACTGACGCTGGTGGCCCAACAGGCTGCTGCGCCCCAGGCGTCGAAGTCGTTACTGCCG CCCGGCGCGGCCACGGCCGTCCCGTTCACCGGCGATGGCTGGCAGGACAAGGTCCTGACGCACGAGGGCTACGTAATGCCGCCCCGTG AGCTGGCGGACGCCGTGCTCGCGCCGCGCGAAATGAACGTGGCGCTCGGCAACCCGAGCCCGGACCGCAAGTGGTTCCTTGACGATAT TGGCGACGGCCCGGTGGCGATGTCGATCTTCGGCAAGCCCTTCGACGAACTCGGCGGCGTCTTCATCGACTTCAAGGCGAATCGCCAG CGCGCGATGACGCGCCGCAACACGATCGGCCTCCAGATCATTTCCGCGGCCGACGGTTCCAGAAAGGCGCTCGCGACGCCCGCGAACA CCCGCGTGACCAACGCGCGGTGGACGCTGGATGGCTCAGGCGTGATGTACGTCACGCTTGGCGACGATGCCACGCATCTCTGGATCAC GGATGTCGCGACGAACAAGCCGCGCCTAATTTCGAAGGTGTCGCTCCTGACGACCTTCGTGACCAACTTCGACCTGATCAACGGCGGC AAGTCCATCGTCGCCGTGTTCCCGCCGGACGGCCGCACGCCAAGGCCGCTGCCGCCGCCCGTGCCTGCCGGCCCGGAGCTGGCCATTT CCATGGACGCGGATCGGAACCGCCTGCGGACGTATCCCAGCCTGATGAAGACGCCGTACGACCAGCAGCTGCTCGAGTGGCATGCGAC GGGGCAGATCGGGATTGTTGATGTGGCGACGGGCGCCATCAGGAAGTTCGGCAAGCCCGCGATGATCACGGCCCTGGACATGGCTCCT GACGGCAAGCACGCCCGCGTGACGCGCATGACCAAGCCGTTCTCGTACGTCGTGCCGGTCAGCAGCTTCGGATCGATTGAAGAAGTGT GGGACGCGGCCGGAACCGCGCTCACGAAGCTCAGCGAACGCGCGTTGAATCTCGGCGTCGCCGCGGCGGCTGGTCCGGATCCCATCGT GGGCGATCCGACGAATCCCCAGGTAGGGCCGCCGGGTCAGGCAGCGGGCGGTGGACGTGGAGGTGCCGGCGGCGCAGCCAACGGCAGG CGCGAACTGATGTGGCGCGAGGATGGTCAGGGCTTCAATTACCTCCAGTTGGAACCGGCGCCGGCTGCGACTATTGGAGGACGCGGAG GAAGAGCCGGAGGGAACGGAGCGGGGGTGAACGGAGGTAACGCTGATCCGACGCAGGCAGCCGGAGGCGCGCAGCAGCCGCCCGCGGG CCAGACAGCGCAGGCTCCTGGCGGACGCGGCGCGAACGCGCCGCAGACGCCGCGCAAGGATCGACTGATGCACTGGGCGCCGCCGTTC ACGGACGCCAGCGCGAAGCTCATTTACGAGAACCCCACGCAGATGTCCAACGTCCGCTTCTCGCCGGACGGGTCGATCATCTTCTTCA CGGAAAGCAACAACACCGTCGCGATGTTCGTGAATGACATGACGACGAAGTACACGATCATGCGTGGCGGCGGTGGCCGTGGCGGCGA CGCCGGTCGCGCCGGCGGCGGCCAGGCTGCCGGACGCGGCGGCCAGGGCGGTGGTGACACGCAGGCCGGCACGTTGATGTCGGCGGTC GGTTCGGTGTCGGCCAAGAGCTTTGGCGGTGGCGTGCCGGTGATGATCTCGGCTGACGGTACGAGCGTCTACCTTCAGAGCGGCGGCG GGGCCGGCGGTCGGGGCGGTGGTGGTGGCGGACGTGGCGCGAACGCGGTGCCTCCGAAGCCGTTCATCGACAAGGTGAACATCAAGAC CGGCGAAAAGATTCGCCTCTTCGAGGGTGAGAACACGGGCATTACCGAGTCGATCTCGGCCGTCATCGATCCCGAGCAGAAGAAGCTC GTGCTGACGCGCCAGAACGCGACGACGGTGCCGCAGCAGTTCCTCTACGACAACGGCACCCGGAAGCAGCTCACGAACAACGAGGATC TGTTCCCGGACATGACCAGGATGATCGTGAAACGCCTCGAAGTGACGCGCGCGGATGGCATCACGTTCAGAACAATCGTGTATCTGCC GTCAGACTATAAGGAAGGCACGCGGCTGCCGGGCTTCTTCTGGTTCTATCCGTACGAGTACACCTCCCAGGAGGAGTTCAACAACGCG GCGAACGGCGGCGCGTCGCCGGCGTTCTCGCTGAACGATCCCACGAACTTCCCGAACTTCGGATCGCTCACGAAGCAGTTCTTCACGC GGCTCGGCTACGCCGTCATCGAGAACCAGTCGCCCATCATCGGCGCGGCCGGCGCGATGAACAACAACTACGTGAACGACCTTCGCAA CAACCTCGCGGCGACGATCGACGAGCTCGACAAGCGCATGCTGGTCGATCGCACGAGGCTCGGGATCGGCGGGCACAGCTACGGCGCG TTCTCGACGGTGAACGCCATGGTCAATACGCCGTTCTTCAAGGCCGGCATCGCGGGTGACGGCGCGTACAACCGCACGCTTACGCCGC TCGGCTTCCAGAGCGAGCGCCGCGACCTGTGGGAGGCGCCGAACGTGTACCTCGAGATGTCGCCGTTCCTCAGGGCCAACCAGCTCTC AGGCGCGCTGCTGATGTATCACGGCCTGCACGACCAGAACGTCGGCACCGACCCCGTGAACTCGAAGCGCCTGTTTCATGCCTTGAAC GGCCTCGGCAAGACCGTGGCGCTCTACAACTATCCGTTCGAGGATCATGGCCCGGCGAGTCGCGAGACGCTGCTCGACCTGTGGTCGC GCTGGGCGGCGTGGCTCGACAAGTACGTCAAGCATCCGCAGCCGCTGACCAAGCCCGCTCCGGCGGCGACGCCGAATCGGGGTGGCGG GGGCGGCGGCGGCGGGCGCTGACGCGCCCGTCTTAAACGACGCCAACGACGTTAACGACGACAACGACGCCAATCGAAGGCACTTGCT CTTCGGCACGCGCTTTTGGTTGGCGTCGTTGTCGTCGTTGGCGTTCGTTCGCGTCGTTACTTCGTGTTGAACTCGTAACACCCCGGCG TCACGAGCACGCGTCCGTCTTTCGTGAAGAAGAGGCTGTTGGCGGCGATGGCGCCGGCGCCTCTGAACTGCACCGTCCGGGTCTTCTG GCCCGCCTTGTCGTACACGTAGCTGTACGGCCCAATCAGCGACACCCACAGTCGTCCTGACGGATCGACCGCCGCCGCGCGTACGAGG GGCGGGACGATTGGGAGTCCACGTCCTTCGCCCGCGTCGCGCCGTGGCCACGTCGTCGGCAGCGACTGGATGTGGCTGTCGAGTTCGA CGCCTTCGATGTGCCGTTCGAAGACGAGCGCGCCCTTCGCGTCGTACTTCTGGAACTTCGGGACGCCCGTCATGAACACGAAGTAGTA GCCGCCGGCGGGATCCGCGAGCGGCAGGCCGATGTTCATCGCGAGATGGAGGTCGGGGTCGCGTTCGTAGCCGGTCGGCCGCAGCGTG CCGATCTGTCGAATCACGGCGCCGCGGTTGTCGATTTCCGAGAAGAGGGCGCCGGTCTCCGGCCGGTTCACGAGGAACGTCTTGCCGG TGAACGACATCGAGCCGACACCGTTCAGGACAAGCGGGCCGAGCGACAGTCGCGGCGCGGACCGGCTCTGCAGGTAGAAGCCGCCGAT AAGGGTGCCGGCCGTGCTGAAGTATTGAATCCGCTCGAGCGAATTGGGTGCGTCGGCGACGGCGAAGATGTCGTCGCCCGAGAGCGCC AGTACGCCCGGCCGCAGCACCTTGCCCTCCTCGAAGCCGACGACGAGCACCTTGCGCATTGATGTCTTCTGTCTGTTGACGGAGTAGA CCGTGTGTTCGCGTCGATCAAGGACGATCGAATCGCCCGTTGACGTCTCCGCGAAGCCTATGGGGTCGGACAACTGACCGGCGAGGTG CGCAGGGAGGCCACCGGTGGCGGAGAGAACTTCGAGAGAACCTGCCCGGTCCGAGGGCGCGAGACCAGCTGCCAGTAGGATCGCCGGT AGGATACCGAGTCGGAGATTCACCCTGGCGTCATTATGCTCGACGCTCCTTCTCTGCCTCACGGTGCGTGCCATCGCCTGTTCTCTGC ACGTCGGCCGCCCGGGAGGCTCGTGACTGGCGCGTTCTACCGCCGCCCACCGCCGGGTCAGGCTGTGATTCCGGGTCAACCAGAGACC CGTCGGTGTCTAATGGGCGCGGGAGACAGCCGTTATGCGAATGCTCCGAGAGGTGCCGATGCTGGCGGCGCTGGCCCTTGCCGCGGGT GTCGTCGCGGCCCAGCAGCCTGCCCCGGCGCAGGCGCCGCCAGCCACCGGCTTCATCATGGGTCGCACCGTTGACGGTACTACGGGCC GTCCGATCGGCAGCGTCAACCTGTTTCTGAATCCCGCTGGCACGCCTGCTTCGACGGCCCTTCGTTTTCCGGTCCGATTGGTCACCGA CGCCACCGGCGTCTTCGTTTTTCGGAACCTCCCCGCGGGAAGCTACCTGATCAGCGGCGGTCCTGGCGGTTACGCGCCATCTGGGTTC GGAAGAACGTCGATGGCCGACGGCGCGGGCAGCCGGGCCATCGTGCTCGCCGAAGGGGAGCGGCGCGGTGGCGTCGTGATTCGCTTCT GGAGGTTCGGCGCGATCTCCGGCCGCGTGGTGGACGAGGCGGGCGAGCCGCTGGTTGGTCTTCCGGTTCGCGTGTTCCGGCGCGCGAT GGTTGCGGGACATCCGAGATGGACCAGCGATGGCACCGGAACGGCACCCCCGACCGATGATCGAGGCATCTACAGGATGTCGGCGCTT CCACCCGGAGAGTACCTGGTGGCGGTCATCACCTCTCAGACGAGCGTGCCCGCGTCGCTCCAGGAGGCGCTGTCAGCAGCAGCGAAGA ACGGGACAGCACGCGACCTTGAGCGCAATCTCGAACGTTCGTCACATCTCTCGACTGCGCCCACCATGGCATTCGGAAGGCGAGTCGG TCCTTGGATACTCCAGACGGCCGGCGAGCCTACCGCGCAGGCCGCGACGAATGCAGTTGTCACCGAGGATCGCATCTTCGTCTACCCA ACTACCTACTATCCGGCGGCACCGTCGCTTTCTTCGGCGACGTCTATATCCGTCGGTTCGGGCGAGGAGCGTACGGGAGTCGATTTCC AACTTCGACCTGTCCCCACGACTCGAGTCTCTGGCAGGCTCGTGGGTCCAGACGGGCCGCTCCCTTACACAACCATGTCGCTCCTGCC AGCCGCCTCGGAAGAGTTTCAGCGTGAGGCGGACCTGGTGGCTGCAGCGACAACGACGGACCAGAGCGGCGCGTTTGCGTTTCTCGGC 
GTGGTGCCCGGCAGCTACGACATTCGCGTCATGAAGCTGCCGCCGCCTCCGGCGACCCAAACGGGGACGAGCACTGTGGTCCAAGCGG GTGGTTCGACGATCGTCAGCACCATCAACTCTCGAGTACCGCAGACGCTTTCCGACGAGCCGACCTGGTGGGCTGCCCAGCCGGTCGC GGTCGCCGAGCGAGAGGTCGCCGGCCTCACGGTGACGCTGCGAGAGGGCGCAAGAATCACGGGGCGGATCGAGTTCGATGGGTCCGCC CCCCCTCTGAGCGGGGATCGCCTCCACCAGATCGGGATTCGCGCCGAATCGGCCGATTCCAGATTGATCTCCCTACGGGAGTTCATGC TGTCGAGCGGAGTCGTCGATGCGACCGGCCGGTTCAGAACCTACCAGTTGCCGCCGGCGAAGTACGTAATTCGAGCGAGTGGACCGGC CAACTGGGTACTAAAGAGCCTCCGCTTGGGCGGCCGCGACGTGACCGACGTTCCCGTCGAGCTCAGGGGGGACGAACTTGCGGATGTC GTAGTCGTGCTGACGACGCGACTCGGGCAGGTGGTCGGCTCAGTCCGCGGCCGTCAGGATCAATCCCCGACTGTGCTGCTCTTTCCTG TCGAGCCATCGATGTGGCTCGACCATGGGACGAATCCCCGCCGCCTTCGCATGGTGAGGCCGGCCACGGACGGGTCGTACCGTATGTC GAACTTGCCCGCGGGGGAGTACTTCGCCGTTGCTGTCTCGACCAGCGTGTCGATCGACTGGCAGGATCCACGTTATCTCCACAAGCTG GCGGCCGTCGCCGCGCGCGTGACCGTCGGTAACGGCGAGACGAAGACGGTCGATCTCGACGTCCGCGAGGTGCGGTAGCCGTGCGTCG GGGGCTTATTGCCGCGCTAGCGTGCGCGATGACCGCGAGTCCGTCTGCGACCGCCGCGCAGACACCAGCGCGTGACGCTGGTGTGGCA ACGAGCCTCACTGGTACGGCGGCGATCTCCGGTACCGTCCTGAACGACATTACCGGGCTCCCGCTTCGCCGCGCCGCCGTCAGTCTCA CGAACAACGAATTGGGACTGCGCCTCAGCGCTGTCACTGAAGATGCCGGCACGTTTGCGTTTTCGGAACTCCCCGCGGGCCGGTACCT CATTGGCGCGAGCAAGCCGGGATTCGTGGCGACCAACTATGGAGCCGCTCGTCCGCGCCGGCCGGGCACTTCCGTGGCCGTAGTCGCA GGAGAGCGACGGACCGGCGTCGTAGTGCGTATGCCTCCTGGGGCCGTCGTCACCGGCGCCGTTCGGAATCGGCTCGGCGATCCGGTGG CGAACGTTCGGGTGATCGTGCTCCGGCCGACGGTGGCCGCCGAAACTGGCCAGCCGACCCTCGAGCCAGCCCGTGGGCCCATCGGCCA GCAGACGGACGACCGCGGCGAGTACCGGATCTTCGGCATCCCCGCAGGCGAGTATTTCGTCGTCGCCGTGGCGGCTCTAGGCGCGCGG TATTCGACCGACCTCCGGGAGACGACCGCTCCAGAGGTTGAGTGGGCGACGAGGCAACTTCAGTCCCCCTTCGCCGCGCAGACGCCTG GGGCGGGTCCCGCTGTCGAGTTCGTGCCGACGTTCTTCCCCGGAGTTCCAACTCAGGACCGTGCCACGAGAGTGGTTCTGCGGGCCGG TGAAGAAAGGGGAGGCGTCGACATCCTCATGGATCTGACTCCGACCGCGCGCATCGCAGGGCAGGTCGTCTTGCCGACTGGGGTCGTG TCCGCCACCACACAGATCACGGTCGTTTCGCACAATTCCATACCCGGCATTCCGCTGGTGGGCTTCGGCTCCACGCTCGTCGACGACG CGAAGAAATTTTCGACCGCAGGTTTTCCGCCAGGCACTTACACCGTGGTGGCACGTGCCACAGCTCCGACCGACCCCTCTGGGCCCCC GACGGCGTTGTTCGCTGTCGAGACGGTCTCGGTGGACGGCGGCGAGACGAACCTGACTTTGACTCTGCGCCGTGGCGTCACCGTGAGT GGCCGCGTCGTGTTTGGCGGCAAGGTCAGCAAGCCGCCTGAGGATCTCACGCGAGTCGGCGTGAGCCTGCTGGCAGCTCCGTCACCCG CGCCGTCACTCGGCGTCGGCGCGTCCAAGATGGCGCCTGACGGCGCATTCGTGTTCAGCGGTGTCGCCCCAGGTCGCTATCGAATTAT TGGCAGTGCCCCAGGCGGCTGGGCGATTCGGACAGCGTCCGTTGCCGGTCGTGACATCCTCGACGGCTTCGTCGAGATTGGCGACACC GATCTCGCAAACCTCGAGGTGACGTTCACGGATCTGCAGACCGAGATCAGTGGCGATCTCGTTGACCCTTCGGGCAAGCCCACCCCCG AATACTTCGTCATTGTCTATCCAGCTAACCGCGGCTACTGGATGCCGCAATCGCGCCGCATCATGTCGGCGCGTCCTGGGACGGATGG CCGATTCCGCTTCCAGAACCTACCGCCGGGAGACTACCTGATTGCCGCGGTGACCGACGTCGAACAAGGCGAGTGGTTCGATCCGAGA TTCCTGGAGCAGCTCGTCGCAGCCTCGACGAAATTGTCACTCACCGACGGCGAGAAGAAAGTTCAGAGCTTGAGAATCCGCTAGTGGC GGCGGTCAGTACTCTGCCGTGTCCTTGATCGCCTTCAGCACATCCGCCGAACCCGGGAGAATCACTTCCTCGAGGTCGGGGCAGTAGG CCACCGGCACGTCCATCGCACCCACGCGGCGGACGGGCGCATCCAGGTACTCGAACAGGTCGCCGGCGACACGTGCGGCCAGCTCGGC ACCGAAGCCGCAGGTCAGCTGATCCTCATGCGCGATCACGATGCGGCTGGTCTCCTTGACGGCTGAGGCGATCGCGTCCCAGTCGAAG GGCATGATCGTGCGAAGGTCCAGCACTTTGACACTGATGCCGTCCTTCTCGGCCTGCTGCGCCGCGAGGAGGGTTCGCTGCACGAGCG CGCCCCAGGTCACGACGACCACGTCGGTCCCTTCGCGTTTGACGGCGGCCTTGCCGAAGGGAATCGTGTAGTTCGAACCCGGATATTC GGCCTTGTTGTAGGTCTGGCGGTACAGGTGCTTGTGCTCCAGGAACAGGACGGGGTCGTCGCAGCGCATCGCCGTGCGGAGCAGACCC GCGGCATCCTGCGCGTTCGACGGATACACCACGCGGATACCGGGGCAGTGCGCGAAGATGCTCTCGCCCGACTGGGAGTGGTACGGCG CGCCGCCGCGCAGATAGCCGCCGCTCGCGGTGCGAATCACCATCGGGCACGAGAACGCGTTGCTCGATCGGTACCTGAGCATCGCGAC TTCGTTCCGAATCTGCATCATCGCCGGCCAGATGTAGTCAAAGAACTGAATCTCGACGACCGGCTTGATGCCGCGCACGGCCATGCCG AGCGCGCGGCCGACGATGTTGGCCTCGGCGAGCGGGGAATTGAATACGCGGTCAGCCCCGAACGCCTTCTGGAGGCCGTGCGTGACCT TGAAGACGCCGCCCTTGCCCTGGACTTCCTTGAGATTCTCTTCGTGCGTGGCGTCCGCCACGTCTTCCCCGAACATGACGATGCGCGG GTTCGCCGCCATCTCGTCCTTCATGGTCCGGTTGATGGCCGCGACCATCGTGTCCGGCTTGCCTTCGGGCGCCGGCACGGACTCGAAC GCCTCCGACGCCGGATCGACGTCTGGCGAGTAGACCCAGAGCCCGGCGGTCTTCTTTGCGGGTTTTTCGGCCTTCACCGCGGCATCTG CCGCCTCGTTCACTTCACGATCAACGTCCTTGGCGATGACGGCCAGATCCTCGTCGGTCACCAGGCCACGGTCCTTCAGGACCTTGGC CAGCTTCGGGATGGGATCGCGGGTCGCTTCTTCCGCGCGCTCGGCCGGCGTCTTGTACAGCTTCTCGTCGTCCGACAGGGAGTGTGAA TACGGACGCGTGACCTTGGCGTGGACGAGCGCGGGCCCCTTGCGCGCGCGGCAATAGTCCACGGCGTCCTGTATGGCCCGATGGCTCT CGAAGATATCCGTGCCGTCGCACTTGACGACCTTGAGCCCGGGGAAGGTCCGGACGACGTCGGAAATGCTGCCGCCAGGCGTCTGCAC CTCGACGGGAACCGAGATCGCATAGCCGTTGTCCTCGATGACGAAGACCACCGGCAGCTGCCGCACGCAGGCGGTGCTGAGCGACTCC CAGAACTCGCCCTCGGACGTGGTGCCGTCGCCAATCGAGACGTAGACGACCTCGTCTTTCTTGAACTTGCTCTCGGCGTTCGCGACGC CCTCGAGCTTGCCGTAGAGGAGCCCCGCTTCGGCGCAGCCGACGGCATGGAGACACTGCGTGCCGGTCGGACTCGACTGCGAGACGAT GTTGAGGTTCTTGTGGCCCCAGTGCGACGGCATCTGGCGGCCACCGCTGTTTGGGTCGTCCTTCGCGCCCACGCCCGAGAGGAACATC TCCAGCGGCGTCATGCCGAGCTCAAGGCACAGGGCGCGGTCGCGATAGTAGGGGAAGAACCAGTCGTAGCCGGGCTTCAGGACGAGAC CGGCGGCCACCATGATGGCTTCGTGGCCCGCGCCGCTGATCTGGAAGAAGATCAGGCTCTGGTTCTTGAGCTGGATTTCCTTGTCATC GATCCGGCGCGACAGCAGCATCGTCCGGTAGATGCGGATGAGCTCGTCCTTCGAGAAACCGTCCACCGTGGCTGACGCCGCGCCGGTT CTCGGCGCCTCTGCGGTCTGTGCGTGCAATTTGCCGTTGGTGTGTGGGAGAGGCTTCATCCGTCGGTGTCCTCAAACGTCGATGCTTG TGGGGCCGCGCGGTGACCCCGCAACCGGTCGATTATACTCCGACGACTTCATGCCGGATGCGCCACCAAACCTCTTCCGCTGGGCCGA TATCGAGCTCGACAAAGTGACAGAAATGGTGTCGCGCAAGGAAATTCTGTGCGACGGTGAGTCGCTCGTGCAGACCTACCTGAAGAAG GGGGCGCAGGTGCCGAGGCACTCGCACGCCGGCCACCAGTGGGTCTACGTCCTTCAGGGCGTGCTGCGGGTGACGTCGGCTGGCGACT CGGTCATCGCTAAGGAGGGCGATGTCGTGCGAATTTCGGCCGGATCCGATCACCAGGCCGAGGCGCTCGAAGATACGTTCGTGCTCGT CATGACAGGTGACGACGGGTCACGACAGGTGACGACAGGTGACGACGGGTGACGACGGGTGACGACAGGTGACGACGGGTGACGACGG GTTAGTGGATTGTGAAGTTGCCGCCGCTGCCACCACCACGGCCGCCTTGGTGGATGTTGAACTTCTTCCGCATCCGATCCATCCGCCA CTTCGTCAGCCGGTACTGAATCGCGAGCTTCAGGCTCGTCGGGCCGCTGAGGTAGAACCAGCCCACCAGTAATCCGGCGAGGTGCGTG GCTTCTGCCACCGAGCCATTGCGGCCGGTGATTGCCGCGAGGAACGCCATGCCGCCCATCAGCGCCGCCGCTACGCGCGCCGGCAGCG GGAAGATGAACATGAACAGCATCTGTCGGTGCGGAAACAGGAGCGCCCACGCGAGCAGCAGGCCATACACCGCGCCTGATGCGCCGAT GGTCGTCGCCGCGTAGATGTCCCGCGCGACGTCGTACGGCAGCAACGAAACGAGCACCGTCGCGATGCCCGATCCAATGCCGGTGAGG GCGTAGTACTTCACGAAGCCGCGGGTGCCCCAGCGTCGTTCGAGATCGACGCCGAACATCCACAACGCCAGCATGTTGAACAGGATGT GCATGAAGCCCTGCGCGTCATGCACAAAGAGATACGTGCCGAGCCGCCACAGCTGCGCGCCCTCGATAACCGCCCGTGGTGAGAGGCC CAGGACGTCAGAGATGACCTGCGACCCACCAAAGGCTGCCAGTAGAAAGTGGGGCAGGAACACCGCGACGTTCGCGATGACGATGGCC TTCACGGCGGGCGTCATGGGGCCGGGACCGATCACGACCGCAGGCCCCTGAGGGGCGTGGCGACTCACCAGACGATGCTACCGCAGGT GCCTACGTTGCCTGGGTGGAACGGAGCTTGGCGAGAATCCGGGCCATGGCAACCTTGAATTCCTCGATATGGAGGAGTTGGGCAGACA GGGCGAGCACGCCCATCGCGATGGTGATGGCGCCGAACACGGAGATGGCTCGGTGGAGGTCGGAGGCGTCAGAGAACTGGCCCGTGAG CCAGGCGTGTGAGTAGTACGCGGCCACGGCCATCGCGGCCGAGGCGACGCAGGTCTTGGCGAAGGTCACGAGGATCCGCCGTGAGTCG CCGCCGCCAAGCCGCCTCGAGATCAGGTACATCAGCAGGCCGGCATTCAGGATGGCGGCGATGGCGGTGCCCAGCGCCAGGCCGCGGA ATCCGTAGAGCGAGTTCAGCCAGAGGTTCAGCGCGAGGTTGGTGGCGATGGTCACGAGGCTCACGAGGACCGGTGTGCGCGGCTCGCC CAGCGAATAGAACGTCGGCGAGACGATCTTGACGATCGAATAGCCGATGATGCCCGGCGCGTAGCAGAGGAGAGCCGGCGCGGTCATG GCCGTTGACCATGCGTCGAAGCGGCCGCGCTGGAAGATGAGCTCGACAATGGGGTGCGCCAACACCATCAGACCCACGATCGACGGCA CCGAAAGCACGAGCATCAACCTGATGCCCCAGGACAGCGTCGATACCATGGCCTTGTGGGCACCCTCGGCCGCTTGCCGCGCGAGCTC 
GGGTATTGACGCGGTCGCCACGGAGACGCCGAAGATGCCGATCGGCAGGTACATCAACGTGAACGCGTACCTCAGCGCTGACGCTGCG CCGGGCTCGCTCGTCGCCAGCCACGTGTTCACGAGGAGGTTGATCTGCGCCGCCGCCGCACCGATGGTGCCGGGCCCCATCAGAAACA TGACTTCGCGCAATGCCGGGTCGCGGAAGTTGAGCCGCCACTGATGGCGATAGCCCTCTGCGCGGAGACCGGGAACCTGGACGAGCAG CTGCGCCACGCCGCCGGCCAGCATGCCAACCGACAGCGCCATGATGGGTTCGATGCCCATCTGCGAGAACACCGTGTAGCCGACGACG GTTGAGAGGATGAAGACGACGTTGTACATCGCCGGGGCCGTCGCTGGTGTGAAGAACCGGCGCAGTGCGTTCTGGATGCCCATGCCGG CGGCAGCCACGGCGATCAACGTGAGGAACGGCAGGTTCATCCGCGTCAGCCACACGGTGAGATCGAGCTGACCAGGAATCTCGAGGAA CTTGTCGTCGACCACCAGTTCCGTGAGCGGTCTGGCGAACAGCCATCCGAGCACCACCAGCAGACCCGTCACGAGCAGCAGTCCGTTG ATTACCTGCGAGGAGAGACGCCACGCCGCTTCCTTGCCTTCTTTCGTCAGCGTGCGTGTGAGCGCCGGCACGAACGCCGCGCTCATCG CGCCTTCGGCAAACAGCTCCCGGAGCAGCGTGGGGATGCGCGTCGCGACGACGAAGGCTTCGAACTGGGGGCCCGTGCCGAAGTACGC CGCCTGCACCTGATCCCGAACCAGTCCGAAGAGGCGGCTGGTCAATGTCGCGATCGCGATCAGGCCGGCCGCTCCGCCGATGCGTCGT TTCCGATGCGCGGCGTCAGGCACGATGGTGGTGTCGGAAGTGTCGCGGAGGCGTGACGATCGTGTGACCGACTTTGTTAGCGCGCAGA ATAAAAGGGAGGTTACCGGAAATAAGAAGGGGCCTCAACCCCTGTGTTGAGGCCCCTGCCCGGAGGATGGATGAGAGGCGCTTGCGAT TGCCTTTCATCAGTCTTAGACGGGGGCCTCGCGGAAAAAGTTTGGGCGCCGATTGTTAAGAACTCGCAATCAGGACAGCCGCTTCTTG ACCGCATCGCTCAGCCCGCGCCCATCGACGGAAAGACCGGCGAGGCGCGCCATTGTGGCCTTCATGACCTTGCCCATTTCCTTCACGG TCGTCGCGCCGGTCTCCGCCACGGCCGCCTCGATCGCCGCGGCGATGGCCGTCGTGTCCGCGGCAGGTGGCTGAAAACGTTCAAGAAA CGTAATCTCCGCGAGTTCCCGGTCGGCGAGTTCCTGGCGACCGGCCGCTGAGAACTGGTCCGCGGCGTCACGGCGCTGCTTTACAAGT ACGCCGACAACCTGAAGCGACTCGGTCTCGTCTAACGTACGTCCCTTTTCGACTTCCTTGTTCATCAGCGCGGCCTTGAGCATGCGCA GCGGGGCGAGCGACGCTTGATCCTTGCGGCGCATCGCGTCCGCGATGTCCGTGGTCACGGTGTCAAAGAGGGAAGGCATGACGTCAGT CTATCCCAGCGATTGGCGGTATAGGCCGGCATAGGCGGCCGTTACGGCGCGGAGACTGAAATGCGCGCCGACCTGCGCGGCCGTCGAC GGCCTCACGCGACGAGGATGGTCGATCGCCTGCGTCAACGCGCCTGACAGAAGTTCGACGTTGCCCTTCGGGACGACGTGGACATCAT CTCCAAATAATTCGTGCAGCTCGACGCCGCCGGGGTGATCCGCTGACACCACGGGTGTACCCGAGGCGAGCGCTTCCACGGCAACGGT GGGCAGCGCCTCGAGCAGCGAGGGTAGCGCGAAGACGTCTGCCAGCGCCGCGTACTTCGCGACGACCGCGTTCTCGACAAGCCCGGCG AACGTCACGCGTGTGTCGATGCCACGATCTCGCGCCTGGGTCATGAGCGCATCACGCAGCGGGCCCGTGCCGCAGATCACCAGGCGCA CGTCCTGGCGGCCGCGCGCGATTCGCGCGAAGGCGTCGATCAGATACTGCTGGCCGGCCAATTCGTGCAGTCGCTTCACGTTCAGGAT GACGCGGGGTTCCACAATCCCCAGTTCTGCGCGCAGCGCCTGCCGTGCCGGCTCATCGGCGGGCTGAAAGGCCGCTCCGATCGCGGGA TACACCACGCGTCCCCGAGGATGTTCGAGTCCGACGCCGAGACCGTGTTCGAGCAGCTTGCGGCTGTAGAACGTCACGGCGGCCGCCC GCTCGAACGCGCGTGCGAAGGGATCGATCGGCCGCCGGCGCTGGTAGTGCCAGACCTCCGTGCCGTACAGCGTGAGGATGTACGGCTT CTTCCGGGACGCCGCCCAGGCGGCCGCAACCTCGACGATGAGCCCGTTGCTGTGCAGATGCAGCACATCCGCGTCGATGGCGGCGTCC ATGAGCGCCGCGCGGATCCGGCCTGCCTGGCGGATCGACTCCGTCCGGAGGAGGCGGCCCAATCCGGTGGTGGGCTTCTTGCGCGGCA GGTGCCAAACGCGACCGGCCGTCATTGGCGCCGCCGTGCGCCCCTGTGCCGGCTCATGCGTGACGAGCGTGACCGTGTGGCCTTCGCG GGCGGCCCATCCAGCGAGTTCGGCCGGCAGCAGCGCGTTGGCCGCCTGATCGGGAGGAAGATGCGGCGTCACGTGACAGATGCGCATG GCCTCAGGCCGTCCGGCGCCGGCCGGCCACGAACATCCGGCGGTACTCCTCGAACGTCATGCCCTCCGCTCCGAGTTCCTTCGTGGCG AAGGTGAGGATCTGTCCGAGGCGCTCGAGAAACCCGTCGAGCTCCCCCTGGGTCTTGTTGTACGGGCTGCCACCGACGATCGCTTCAC TCGAGTGAAACAGCAGATTGAGGATCGGCGCACCCCGCCTGATGACCTGCCGCGCCAGCGCCATCATGTCGGCGCTGGAGCTGTAGGA CGGGCGCAGCCATCGCACGCGCGCGATCCGCGCTAGCCGCAGGACACGCTTCGTCGTGTAGTTCCACGGCGCGCGGGCGTAGATCCGT TCGATCGATTCCGGGACGCTCCGGTTCAGCGCCGCCGAGATCGGTAGCTCCAGGACGTTGCTCGATCCCGCCCGCGTCGCATCGTCGT AGGCCAGAAAGTACGGCGTGAGCGGCGCGCCCACGAAGTCGGGGCCCTGTTTGTGTGCTTCGTAGAAAAGTGGCGCCACCGAGGAGTC CACGAGGTAGCCGGCGCGCTCGAGCGAGGAGACGTGCGAGGCTGAGAAGCCGAAGCGCCCCGATCGGTAGGACACGGGCCGAATTCCA ACAGCGCGCTCGATGGCAACGGTGAGGTTGTCCAACTGCGCATCAAACTGTGTCAGCGGCAGTGACAGCGCGTACGGATGGCGGTCCA CGTCGTCGGGTCCGAAGGGCGGCGTCTCCCAGGCGTGATGATGCGCACCGATCTCGCACGTGCCCCTGGCCAGGAGCGATCGCAGCAC TTCAGCCGACCGCGGATCCTCCGCGACCGGATGCGTGGTGACGTACGTCGGCCGCACGCCATGCTTTTCGAAGAACTCATGCAGCCGG CCGAGCGCGTACAGATTTTCGAAGGTCTGGTCGCGCCGGCTGGCGGCGTCCCACTGATTGTCGCCCTCGGTATCGATCGCGACGAGCA GCGCGGGTCTCGCACTCATCGGTTCATCGGTCCTGGTCCGAGTCGCCGAGCGTCACGTGCCACCGGCTCGTGTCGTCGAAGAACGACG CCGGCACGTCCACGGCATTGATCTTGGTGACGAAGTCCATGGTGGACTTGACGGCGTAGTAGCCGGACTTCTTCAGGTGTTTCCGGTA TCCCTCGTGCAGCGCGAATGTTCGGATCTTGTCGGAGTCCACGCGCCGGGCTTCGCGGTCGATCCATCGCAACAGCGTCTTGACGGCC GACGGGTCGTCCGGATCGGCCAACCAGTCCACGAGCAGCGTCACGCGGCCGCGCGGCTCCTGCACGTGGCGGTACACGACGTAGCCCG CGACGTCGTCACCGCGCTGGAGCGCGGCCACGGTGTAGCGCACGTGCGGAGGCTGCGTGTACTTCCAGTTCAAATACGCCGCGTCACG CCGTACGGCGAAGGCGAATTTCGCGGCGACCCGTGCCCAGAGCGTTGTGAAGCGCTCGTCGAACTTGGTCACGATCTGAATCTCTCCC TCGAGAGGGCGGTTCCGCGACACCAACCGGATCCACGGCAACGTGACCGCGGACACCAGGCGATTCAGCGCCATCGGCCACTGCGGTC TGCGGAGCGCGCGCCGGCTCAGCGGCTTGACGAGACACGGCACCTGCCCGAGGTCGGGCCACTTCAGTTTCTGGAAGAGCCGGTAGGA CGATTCGGAGAGGCCGAGACCGAGCGATGCACCGACGTTGCGGTCCCAGGTGCGGAAGAGCACATCGCCCAGACCCTGCCGCTGGCGT TCCGGGGCCACCATCACGTCCATGCCCCATGCCGCGCCGATCTCCTGGTCATTTACCTGCAGGCGGACGGGCATGGCCGCGTACTGAC CGACGATCGCCTGGCCCTCGCGTGCGACCCAGATCAGCGGACCGGTCGCCGGCGTGTTCGGATTGCGCCGGTACTGCCAGTCCCATCG CAGACGATTGGCTTCCGCCATGTCGTTGCCGAAGACGCGGCGATACAGCGCTTCGATCTGCTTCCGATCATCGGGCCGGTACCGGTCA ATCTCGGCCATCAGGTGCTCGGCTGCTCGGGTGCGAGGACGTACTCCATGTTGCTGATGAGTGCGTTCTGCGTGAGCGGGCTCGATCC GAGCCAGCGCCCGATGGCGCCAGGCATGCGGCGGACCGTTGAGGTCACATGCAGTTCTTCGCGTTCTGTGCGGAAGCCCGCGTCCGCG ATCTGGCCGCGCAGGCGGTTCACCGTCACCAGTTCCAGCAGGTCGTCGTGCTTGACGATGCCGTTTCTGGCGTCACGAATGAAGGAGT TCTCATGCGCCGGCTCCTTCAGTGTCCAGGGCGCATGACGGGCGAGCAGCCGGAACGTCCGGAAGGCGATCGCGCGCCCGACGATCAG GTGCAGCGGCACGGGAATCCGCAGCCGGGGGAGATGCGCTCCGGCGAACGACAGGTACGGCGCCGTCGAGAGAAACAGCAGGCCGCCG GGCTTCAGCACGCGCCGGCACTCGCGCAGATACAACGGCGCGTCCGCGACGTGCTCGATGACGGCGTGGGAGAGCACCAGATCGAACG ATCCCGACTTGAACGGCAGGGCCATGCCGTCAGCCTGGAGAAAGTGGAGACGCGTCAGACCCTTCTCGCGCGCGAGCTTCGATCCCGC CTGACTGAACCGGTCGATCGGATCGATGCCGACAACCTCGTCGGCGTGTTCGGCCAGGGACAGCGGCATGCCGCCACCGCCACACCCG GCGTCGAGCACACGTCCGTGGATCCGGACACCCGCACGTTCGAGAAACGCGATGACCTTGGCGCTGCGGTAGTACTCGAAGAGCGCGT AGTCGTATTCGGATCGGAAGCGGCGATCGGCGTGTGCCTTGATCTCGGCTTCGTTAATCTGGCGCACGATGGTGTCCTGGGGCCGCAG CCGCGCGCGGGGCTGGGGGTGACTTCTCGATCAGCCACGCCTCGTCGATACCCGGGGTCTCGTCGATCGCGAACTTCCCGATGATCCG CCGGTGGGTGTAGCGATCGAGAATTTCTTGCATGAGACCAGGTTGACTCTCGTATCCAACCTTCGGCAAACCGTACGTCAGTATATAG CGCGCATCGTCGCGTTCGAATCGGTCGTCGTAGTTGCCGAAGCCGCGGCCGACGAAGATCGGACGGATGCGATTCTCGAGGGCGAGGC CATTCGCGAGCTTGCCCTGCACGAGCGTGCCCGGCGCAAGTTCCACCCCGAGCGCGACAGACGCTCGGTAGTTGAGGTCCGAACTCGA CTGCGCCCATCGCGCGTACTGTCCGAGATCCCAGGCCACAAGAATGGTCGCGAGCGTGACGCCGACGGCCATCGGAATCCGCCGGCCC GCGAGCCAGGCAGTCGTCTGCGGCCAGAACGCCAGGGCCACGGAGGTCGCGATCAGCACGAGTCCGGTCGCCAGTCGAACGGTCATCC TGTAGTCCCGGACCGCGACGTCTTCGTGGAAGACCAACCGGAGCGCGGACGCGACCACGACGAAGCCGAGCGCCAGGATCAACGGCGC GGCCAGCGCGCGCTGCAGCCACCCTGGCCGGGCGAAATACGCCGGCAGCCACGCCTTGCCCGAGCCGGCCAGACCGGCCGCGAGCGCG ATGAGCGCTGGCACGAACATCACGTAGCGCCGCTCGTTACCCGCGTCATGAACGATCAATTCGAGAAAGCCGATCAACAGCCACAGGA CAAGCAGCCGCTCGCCCGGCTTCGACTCGCGCCATCGGGCCACGATGCCGGCCATCGCGATTACGGCGCCGAGGGCCACGAACCACAT CCGCGAGAAGAAATCGTGGCTGACGGGCAGCCACGAGGCGTTGCGGACGAACGCCGCGAGGCTGTACGTCGGCTTCCGCTGCACGCTC ATCTGCCAGTTGTAGAACTGCACCTCGTTCCAGTAGGGAATGACGAAGTACAGGCCGACAAATAGTCCGGCCACGCCGAAGCCTGCGA GCGTGAGCCAGGCCGTCTGCACGATCCGCGGCTCCGGCCGACTAAGTCCCAGCCGCGTCCGAAACCCGGCGAGCCGATCGGCGGCGAT 
GACCCAGAGCGCGTCGGCGAAAATCGCGGCGACAAAGAAGGCCGCTGACGCCTTGGTGAAGAAGGCCAGGACGGCCGCGCTGCCCGCC ACGATCCCCCAGGCCGATCGCCGCTCGCCCATGGAATACGCGGCCCACGCGAGCACGATGAAGGCCGTCATCGTGGATTCCATCAGCG CCGCGCGGTTCCACATGACCCAGGTGAAGTTGACCGAGAGCAGCGCACCACCAATCAGCGCGATCCTTCTCCCAGGCTGTTCTCCGCG CGATCCCCACAGTGCGGCGAGGCCCATCATCAGGGCCGCCACGCCGACGAGGCCCGACACGACCGGCACCGTGCGTGCCTGCCAGGTA CCGACGCCGAACGCCGAGAACGCGACGTACTCGAGCGCCGTGAAGACCGGTGTGAGATAGGCGGGGTTCCAGTTGTCCGTCTGCCAGA CGCCCCACAGCGCCTGGTTTCTGGCGTTGTGCGTCCACGCACCTTCGTCGTGCCAGACGATACCGACCGAGAAAGTCGGCGGATCCGC GCGGAGCCACGCGACTCGCAATGCGGCACCGGCAAGGAGAATCAGGGCGGCCAGCGCCAGGAAACGACTGCGTGTCATATCACCTCAG CGCCGCCGCCAGACAGAGAACAGTTCGTCCTCGTAGGCCGTCGTGTAGCCGGCGTCCAGCCACTCGCGCAAATGCGGCGTCGTCATGA AGAAGTCGAGAGAGTCTTGCACATCTTCTGCCAGTCCCCAGTCGTGTTTCTGAAGAGCGATGACTTCGGGACGGGCGCGTTCGAGGTC GGCAAGCATGCCGACGGATCCATAGCCGGGTCGGCCGCGCTCGAACTCGAGCACCACCGGCCGGCTCCAGAAGAACCGCGAGGCGCTT GGGCGGTCGCTCTTGACGTAGACCCCGCCGGACGCGAAGCCGAAGACGAACGTCGGCGTAGCCTCGGGGGTGTGCAGGCTTACGTACG CCGCCAGGCGCTCGACGGCGGCGGGAGAGAACTTGCCCGGGCCCTCCCGATCGAATCTCGCGAGATACTCGGCCCGGCCGATGCGTCC GGCCATGAACCGGGCGTCAAACAGCATGTTCTCCACCGCCTGCGGGACGCCGAACAGTCTCGGCTGCAGAGCCGGCGTGGGTTCGATA CCGACCCTCCACGCGCCCGCGACAATCAGCAAGGCGGCCGCGGCCGCTAACACCCGTCCGACCGAGCCGTCCCGTCGTCCGCGCAAGG TGAGCGCCAGACCGGCCGCAGCGGTGAGGGCCAGCGCCGGCTGGGCCTGTACGAAGTACTGCGGCAGGCCTCGCGCGCCATTGATGGC GATCGACAGCACGCTCGCGACGACCCAGGACAGCGCGACAGCGTGTGCTCGGGAGAACGACGACCTGCCGAGCAGCACCCCGATCGCG CCGAGTCCGCCCATGAACCAGAGCCCGTCTACCTTCGCGCGATGGAAGAGAAGCGTGGCGGGATACTCCGCGACGTGCGCCGCGTTGC GGTAGGTTTCGCCGGAGTACGCGAGGTTGTAGGCCACGGTGCCGGCCCAGAGATCGCCGAGCGCGCCGCCGGCGGCAAAGTACAGCAG GCCGATCGCGATGATTGAGGTTCCGCCGGCGGCGATCCATGCCAGGGATCGGAGCCGTGACGGGAACGGCGACCCTGAGTCCAGCAGA CCCGCGGCCAATGCCACGGGCACGATGTACACGATGGCGTTGTACTTCAGCCACACCGCCAGGCCGCAGAGGGCGCCTGCCAGCAGCA ACCGCAGGATGCTGCCCCGGGCGGACCACGCCGCGACCACCGCCGCGGTCACGGCCAAGGCAATGAACGTTTCGCACTGCGCGCGCAC GTTCATCCCGCCGAGCCGCTGGATTCCGGGGTCGCCGAGGAGCAGGAGCAACGCCGCGGCTACGGCACCAGCGGCCCCTCCGAACATC CGGCCTCCGAGGCGCAACAGCAGCCACGCCGCCATCGCCGCGGCCACGAGGTCCGCACCCGCGACCGCCGATTCGTGGGGCCAGAGGC CCCACATCACGGCATACGCGGCAAACACGCCTGGCGGCTTCTGTTCGAACGCGTCGCGGTAGGGCACGTTGCCGTCGAGGATCCTGTC GGCCACGTAGCTGTAGAGCAGTTGATCGCCGCCGGCCGGCTGCGCGACCGAGGGGACGCGGCACGCGACCAGCAGGATCAGCACGACG AGCCATTTCTGCGATCCTGAAGTTCGTGTCCGGTTTTCCTGCGTCATGCAATGGGTCGCGTAGAGCTTGAATTATAGTTCTCGGGTGA CGTCCAGAGAGACGGCCGATCTGACGATGGTCGTGCCCACCTACAACGAAAGAGACCGGCTGGCCGAACTCGTCTCCAGGTTGTTCGA ATCCGCGGAACAGGCCGGTCTCGCGCTGGAGCTGGTGGTCGTGGACGACAATTCTCCGGACGGCACGGGCCCGCTCGCGGACGAGCTG GCGAAGACCTACAGGATGAAGGTAGTGCATCGCGCGGGCAAGCTCGGACTCGGGACCGCCGTTGTCGAGGGCTTCGCGGTTGCGACCG CGGATGCGGTGGGCGTGATGGACGCGGACTTCAGCCATCCTCCGGCGCTCGTGCCCAAGCTCTACGCCGCCTTCAAGCGCACGCGGGC GGACGTGATTGTGGCCAGCCGGTACATCGCCGGCGGGAGCACACCGAGCTGGCCGTTCACGCGCCGCCTGATGTCGCGCGTCGCGTGC CTCCTGGCCCGGCCGCTGTCGCCGATTCGCGACGCCGCGTCGGGGTTCTTCATCATCCGCCGCGAAATTACCCAGCGAGTGAGCATCA AAGCCGGCGGCTTCAAGATCTGCCTGGAGCTGATTGTGCGAGGCTGGCCGACGCGGCTCGTCGAGCTGCCGTATCAATTCGATGACCG GGAACTCGGCGAGAGCAAGATGAGCAAGCGCGAGGCCGCCGGCTATCTGGTGCAGTTGAAGGACTTGTTGTTGTTGCGTTTGTCGAAT CCCGGCCGGGCGCGCCGGCACTACCAGCAGCTGACGGTGGACGACGTCGCGAATCTCACCCTGCGGTCGAGCGCGGATCGCGCCTAGT TTGCAGGCGAGCGCTGGTCGCCCTCTCGCGCGATCGCGCCCGCCGGCGGCGCGGCCACGGTCACCGGCGATCCGAACAACACTCGCGA TCCCACGTGCCAGGCGAGGCTCCACTTGGTGGACGCGAGTCGTACGATGTCCGGCGTGTGCCTGAGGAGATAACCCGGTCTCAGATAG AAGCGGCGCTTCGCGCGGTTGATCGCGTCGAGCACGATGGGCTCGTCCAGCCCATTCCCCTTGAGCAGATAGAAGGAATACTCCATGC GCGACCACTCTTCGCTCGCGAGCAGTCCATCGCGCTTGGCCTTGGCGTAGAGA

\subsection{Bakterielle 16S rRNA-Gensequenzen}

Sl1106

AATTACTGGGCGTAAAGCGCACGTAGGCGGATATTTAAGTCAGGGGTGAAATCCCAGAGCTCAACTCTGGAGCTGCCTTTGATACTGG GTATCTTGAGTATGGAAGAGGTAAGTGGAATTCCGAGTGTAGAGGTGAAATTCGTAGATATTCGGAGGAACACCAGTGGCGAAGGCGG CTTACTGGTCCATTACTGACGCTGAGGTGCGAAAGCGTGGGGAGCAAACAGGATTAGATACCCTGGTAGTCCACGCCGTAAACGATGA ATGTTAGCCGTCGGGCAGTTGACTGTTCGGTGGCGCAGCTAACGCATTAAACATTCCGCCTGGGGAGTACGGTCGCAAGATTAAAACT CAAAGGAATTGACGGGGGCCCGCACAAGCGGTGGAGCATGTGGTTTAATTCGAAGCAACGCGCAGAACCTTACCAGCTCTTGACATTC GGGGTATGGGCAGTGGAGACATTGTCCTTCAGTTCGGCTGGCCCTAGAACAGGTGCTGCATGGCTGTCGTCAGCTCGTGTCGTGAGAT GTTGGGTTAAGTCCCGCAACGAGCGCAACCCTCGCCCTTAGTTGCCAGCATTCAGTTGGGCACTCTAAGGGGACTGCCGGTGATAAGC CGAGAGGAAGTGGGGATGACGTCAAGTCCTCATGGCCCTTACGGGCTGGGCTA

Sl1108

ACTGGGCGTAAAGGGTGCGTAGGTGGTTTGATAAGTTGGGTGTGAAATTCCTGGGCTTAACCTGGGAACTGCGCTCAATACTGTTGAG CTAGAGTATTGTAGAGGAAAGTGGAATTTCCAGTGTAGCAGTGAAATGCGTAGATATTGGAAGGAACATCAGTGGCGAAGGCGACTTT CTGGACAGATACTGACACTGAGGCACGAAAGCGTGGGGAGCAAACAGGATTAGATACCCTGGTAGTCCACGCCCTAAACGATGCGAAC TGGATGTTGGGTGCAACTAGGCACTCAGTATCGAAGCTAACGCGTTAAGTTCGCCGCCTGGGGAGTACGGTCGCAAGACTGAAACTCA AAGGAATTGACGGGGGCCCGCACAAGCGGTGGAGTATGTGGTTTAATTCGATGCAACGCGAAGAACCTTACCTGGTCTTGACATCCAC GGAACTTTCCAGAGATGGATTGGTGCCTTCGGGAACCGTGAGACAGGTGCTGCATGGCTGTCGTCAGCTCGTGTCGTGAGATGTTGGG TTAAGTCCCGCAACGAGCGCAACCCTTGTCCTTAGTTACCAGCACGTAATGGTGGGAACTCTAAGGAGACCGCCGGCGACAAGCCGGA GGAAGGTGGGGATGACGTCAAGTCATCATGGCCCTTACGACCAGGGCTACACACGTACTACAATGGAGAGGACAGAGGGCAGCAAACT CGCGAGAGTGAGCCAATCCCAGAAACCTCTTCTCAGTCCGGATTGGAGTCTGCAACTCGACTCCATGAAGTCGGAATCGCTAGTAATC GCAGATCAGCATTGCTGCGGTGAATACGTTCCCGGGCCTTGTACACACCGCCCGTCACACCATGGGAGTTTGTTGCACCAGAAGCAGG TAGCTTAACCGCAAGGGGGGCGCTTGCCACGGTGTGGCCGATGACTGGGGTGAAGTCGTAACAAGGT Sl1109

AGAGTTTGATCATGGCTCAGAATCAACGCTGGCGGCGTGCCTCAGACATGCAAGTCGAACGCGAAAGTCCCCTTCGGGGGATAAGTAG AGTGGCGCACGGGTGAGTAACACGTAGGTAATCTACCTTCGGGTGGGGAATAACCCAGGGAAACTTGGGCTAACACCGCATAATGCAG CGGCACCACATGGTGACAGTTGTTAAAGCGGGGGATTTTAGGACCTCGCGCCTGAAGAGGAGCCTGCGGCAGATTAGCTAGTTGGTAA GGTAACGGCTTACCAAGGCGACGATCTGTAACCGGCCTGAGAGGGCGGTCGGTCACACTGACACTGACATACGGGTCAGACTCCTACG GGAGGCAGCAGTCGGGAATTTTGGGCAATGGGCGAAAGCCTGACCCAGCAACGCCGCGTGAAGGATGAAATCCCTCGGGATGTAAACT TCGCAAAATTGGGAAGAATTAGTAGGGGTTAATACCCCCTATGATGACGGTACCTTTTGTAAGCTCCGGCTAACTCCGTGCCAGCAGC CGCGGTAATACGGGGGGAGCAAGCGTTGTTCGGATTTACTGAGCGTAAAGGGCGCGTAGGCGGTCAGCACAAGTCAGTTGTGAAATCT 
CCGGGCTTAACTCGGAAAGGTCAACTGATACTGTGCGACTAGAGTGCAGAAGGGGCAACTGGAATTCTCGGTGTAGCGGTGAAATGCG TAGATATCGAGAGGAACACCTGCGGCGAAGGCGGGTTGCTGGGCTGACACTGACGCTGAGGCGCGAAAGCCAGGGGAGCGAACGGGAT TAGATACCCCGGTAGTCCTGGCCTTAAACGATGGATGCTTGGTGTCTGGAGTTATATAGTCTCCGGGTGCCGCAGCTAACGCGTTAAG CATCCCGCCTGGGGAGTACGGTCGCAAGACTGAAACTCAAAGGAATTGACGGGGACCCGCACAAGCGGTGGAGCATGTGGTTCAATTC GACGCAACGCGAAGAACCTTACCTGGGCTAGAATGCCTCTGACAACTCCAGAGATGGAGCCTCCTAGGGAAACCTAGGCAGAGTGCAG GGTGCTGCATGGCTGTCGTCAGCTCGTGTCGTGAGATGTTGGGTTAAGTCCCGCAACGAGCGCAACCCTTATCGATAGTTGCTAGCGG TTCGGCCGAGCACTCTATTGAGACTGCCGTTGACAAAACGGAGGAAGGTGGGGATGACGTCAAGTCCTCATGGCCTTTATGTCCAGGG CTACACACGTGCTACAATGGCAAGTACAAAGCGCTGCAAACTCGCGAGAGGGAGCCAATCGCAAAAAGCTTGTCTCAGTTCGGATTGG AGTCTGCAACTCGACTCCATGAAGCTGGAATCGCTAGTAATCGCAGATCAGCACGCTGCGGTGAATACGTTCCCGGGTCTTGTACACA CCGCCCGTCACATCACGAAAGTGGGTTGTACTAGAAGTCGTCAAGCCAACCGCAAGGAGGCAGACGCCTACGGTATGATCCATGATTG GGGTGAAGTCGTAACAAGGT

Sl1117

AGAGTTTGATCATGGCTCAGATTGAACGCTGGCGGAATGCTTTACACATGCAAGTCGAACGGCAGCACGGGGGGAACCCTGGTGGCG AGTGGCGAACGGGTGAGTAACACATCGGAACGCGTCCTGTAATGGGGGATAACCTGGCGAAAGCCAGGCTAATACCGCATACGTCCTG AGGGAGAAAGCGGGGGATTGGAAACGACCTCGCGTTATAGGAGTGGCCGATGTCGGATTAGCTAGTTGGTGGGGTAAAGGCCTACCAA GGCGACGATCCGTAGCTGGTCTGAGAGGACGACCAGCCACACTGGGACTGAGACACGGCCCAGACTCCTACGGGAGGCAGCAGTGGGG AATTTTGGACAATGGGGGCAACCCTGATCCAGCCATTCCGCGTGAGTGAAGAAGGCCTTCGGGTTGTAAAGCTCTTTCGGCCGGGAAG AAATCGCATCTTCTAATACGGGGTGTGGATGACGGTACCGGAAGAAGAAGCACCGGCTAACTACGTGCCAGCAGCCGCGGTAATACGT AGGGTGCGAGCGTTAATCGGAATTACTGGGCGTAAAGGGTGCGCAGGCGGCGCCATAAGACAGATGTGAAATCCCCGGGCTTAACCTG GGAACTGCGTTTGTGACTGTGGTGCTCGAGTGCGGCAGAGGGGGGTGGAATTCCACGTGTAGCAGTGAAATGCGTAGAGATGTGGAGG AACACCGATGGCGAAGGCAGCCCCCTGGGTCGACACTGACGCTCATGCACGAAAGCGTGGGGAGCAAACAGGATTAGATACCCTGGTA GTCCACGCCCTAAACGATGCGAACTAGGTGTTGGGGAAGGAGACTTCTTTAGTACCGTAGCTAACGCGTGAAGTTCGCCGCCTGGGGA GTACGGTCGCAAGATTAAAACTCAAAGGAATTGACGGGGACCCGCACAAGCGGTGGATGATGTGGATTAATTCGATGCAACGCGAAAA ACCTTACCTACCCTTGACATGCCCGGAACCCTGCTGAGAGGTGGGGGTGCCCGAAAGGGAATCGGGACACAGGTGCTGCATGGCTGTC GTCAGCTCGTGTCGTGAGATGTTGGGTTAAGTCCCGCAACGAGCGCAACCCTTGTCATTAATTGCCATCATTTGGTTGGGCACTTTAA TGAGACTGCCGGTGACAAACCGGAGGAAGGTGGGGATGACGTCAAGTCCTCATGGCCCTTATGGGTAGGGCTTCACACGTCATACAAT GGTCGGTACAGAGGGTTGCCAAGCCGCGAGGTGGAGCCAATCCCAGAAAGCCGATCGTAGTCCGGATCGGAGTCTGCAACTCGACTCC GTGAAGTCGGAATCGCTAGTAATCGCGGATCAGCATGTCGCGGTGAATACGTTCCCGGGTCTTGTACACACCGCCCGTCACACCATGG GAGCGGGTTCTACCAGAAGCAGTTAGCCTAACCGCAAGGGGGGGATTGCCACGGTAGGATTCGTGACTGGGGTGAAGTCGTAACAAG GT

Sl1118

GTGAACGCTGGCGGTAGACCTAACACATGCAAGTCGAACGGCAGCACAGGAGAGCTTGCTCTCTGGGTGGCGAGTGGCGGACGGGTGA GGAATACATCGGAATCTACTCTGTCGTGGGGGATAACGTAGGGAAACTTACGCTAATACCGCATACGACCTACGGGTGAAAGCAGGGG ACCTTCGGGCCTTGCGCGATTGAATGAGCCGATGTCGGATTAGCTAGTTGGCGGGGTAAAGGCCCACCAAGGCGACGATCCGTAGCTG GTCTGAGAGGATGATCAGCCACACTGGAACTGAGACACGGTCCAGACTCCTACGGGAGGCAGCAGTGGGGAATATTGGACAATGGGCG CAAGCCTGATCCAGCCATACCGCGTGGGTGAAGAAGGCCTTCGGGTTGTAAAGCCCTTTTGTTGGGAAAGAAATCCAGCTGGCTAATA CCCGGTTGGGATGACGGTACCCAAAGAATAAGCACCGGCTAACTTCGTGCCAGCAGCCGCGGTAATACGAAGGGTGCAAGCGTTACTC GGAATTACTGGGCGTAAAGCGTGCGTAGGTGGTCGTTTAAGTCCGTTGTGAAAGCCCTGGGCTCAACCTGGGAACTGCAGTGGATACT GGACGACTAGAGTGTGGTAGAGGGTAGCGGAATTCCTGGTGTAGCAGTGAAATGCGTAGAGATCAGGAGGAACATCCATGGCGAAGGC AGCTACCTGGACCAACACTGACACTGAGGCACGAAAGCGTGGGGAGCAAACAGGATTAGATACCCTGGTAGTCCACGCCCTAAACGAT GCGAACTGGATGTTGGGTGCAATTTGGCACGCAGTATCGAAGCTAACGCGTTAAGTTCGCCGCCTGGGGAGTACGGTCGCAAGACTGA AACTCAAAGGAATTGACGGGGGCCCGCACAAGCGGTGGAGTATGTGGTTTAATTCGATGCAACGCGAAGAACCTTACCTGGCCTTGAC ATGTCGAGAACTTTCCAGAGATGGATCGGTGCCTTCGGGAACTCGAACACAGGTGCTGCATGGCTGTCGTCAGCTCGTGTCGTGAGAT GTTGGGTTAAGTCCCGCAACGAGCGCAACCCTTGTCCTTAGTTGCCAGCACGTAATGGTGGGAACTCTAAGGAGACCGCCGGTGACAA ACCGGAGGAAGGTGGGGATGACGTCAAGTCATCATGGCCCTTACGGCCAGGGCTACACACGTACTACAATGGTAGGGACAGAGGGCTG CAAGCCGGCGACGGTAAGCCAATCCCAGAAACCCTATCTCAGTCCGGATTGGAGTCTGCAACTCGACTCCATGAAGTCGGAATCGCTA GTAATCGCAGATCAGCATTGCTGCGGTGAATACGTTCCCGGGCCTTGTACACACCGCCCGTCACACCATGGGAGTTTGTTGCACCAGA AGCAGGTAGCTTAACCTTCGGGAGGGCGCTTGCCACGGTGTGGCCGATGACTGGGGTGAAGTCGTAACAAGGTA Sl1121

AGAGTTTGATCATGGCTCAGATTGAACGCTGGCGGCAAGCCTAACACATGCAAGTCGAGCGCGAAAGGCTTTCGGGCTGAGTAGAGCG GCGGACGGGTGAGTAACGCGTAGGAATCTACCTGGTAGTGGGGGACAACTTGGGGAAACTCAAGCTAATACCGCATACGCCCCACGGG GGAAAGCGGGGGACCTTCGGGCCTCGCGCTATCAGATGAGCCTGCGTAGGATTAGCTTGTTGGTGAGGTAAAGGCTCACCAAGGCGAC GATCCTTAGCTGGTCTGAGAGGATGATCAGCCACACTGGGACTGAGACACGGCCCAGACTCCTACGGGAGGCAGCAGTGGGGAATATT GCGCAATGGGGGCAACCCTGACGCAGCCATGCCGCGTGTGTGAAGAAGGCCTTCGGGTTGTAAAGCACTTTAAGTGGGGAGAAAAGGG TAGCTGTTAATAGCGGTTACCTGTGATGTTACCCACAGAATAAGCACCGGCTAACTCCGTGCCAGCAGCCGCGGTAATACGGAGGGTG CGAGCGTTAATCGGAATTACTGGGCGTAAAGCGCGCGTAGGTGGTTTGTTAAGTCAGCTGTGAAAGCCCCGGGCTCAACCTGGGAACT GCAGTTGATACTGGCCGACTAGAGTACGAGAGAGGGAGGTAGAATTCCATGTGTAGCGGTGAAATGCGTAGATATATGGAGGAATACC GGTGGCGAAGGCGGCCTCCTGGCTCGATACTGACGCTGAGGTGCGAAAGCGTGGGGATCAAACAGGATTAGATACCCTGGTAGTCCAC GCCGTAAACGATGTCTACTAGCCGTTGGGAGACTTGATTTCTTAGTGGCGCAGCTAACGCAATAAGTAGACCGCCTGGGGAGTACGGC CGCAAGGTTAAAACTCAAATGAATTGACGGGGGCCCGCACAAGCGGTGGAGCATGTGGTTTAATTCGATGCAACGCGAAGAACCTTAC CAGGTCTTGACATCCAGAGAACTTTCCAGAGATGGATTGGTGCCTTCGGGAGCTCTGAGACAGGTGCTGCATGGCTGTCGTCAGCTCG TGTCGTGAGATGTTGGGTTAAGTCCCGTAACGAGCGCAACCCTTGTCCTTAGTTGCCAGCGAGTAATGTCGGGAACTCTAAGGAGACT GCCGGTGACAAACCGGAGGAAGGTGGGGACGACGTCAAGTCATCATGGCCCTTACGACCTGGGCTACACACGTGCTACAATGGAACGC ACAGAGGGCTGCAAAGGCGCGAGCTGGAGCCAATCCCACAAAACGTTTCGTAGTCCGGATCGGAGTCTGCAACTCGACTCCGTGAAGT CGGAATCGCTAGTAATCGTGGATCAGAATGCCACGGTGAATACGTTCCCGGGCCTTGTACACACCGCCCGTCACACCATGGGAGTGGG TTGCTCCAGAAGTGGTTAGCCTAACCTTCGGGGGGGCGATCACCACGGAGTGATTCATGACTGGGGTGAAGTCGTAACAAGGT Sl1124

AGAGTTTGATCATGGCTCAGATTGAACGCTGGCGGCATGCCTAACACATGCAAGTCGAACGGTAACAGGCCTTCGGGCGCTGACGAGT GGCGGACGGGTGAGGAATGCGTAGGAATCTACCCAGTAGCGGGGGACAACTTAGGGAAACTTAAGCTAATACCGCATACGCCCTACGG GGGAAAGCAGGGGATCTTCGGACCTTGCACTATTGGATGAGCCTACGTCGGATTAGTTAGTTGGTAGGGTAAAAGCCTACCAAGGCGA CGATCCGTAGCTGGTCTGAGAGGACGATCAGCCACACTGGGACTGAGACACGGCCCAGACTCCTACGGGAGGCAGCAGTGGGGAATAT TGGACAATGGGGGCAACCCTGATCCAGCAATGCCGCGTGTGTGAAGAAGGCCTGCGGGTTGTAAAGCACTTTCGGTAGGGACGAAAAG CTGAGGGCTAATATCCTTCAGTCTTGACTTAACCTAAA

Sl1126

AGAGTTTGATCATGGCTCAGGATGAACGCTAGCGGCAGGCCTAACACATGCAAGTCGAGGGGTAGAGGAAGCTTGCTTCCTTGAGACC GGCGCACGGGTGCGTAACGCGTATGCAATCTACCTTATACAGAGGGATAGCCCAGAGAAATTTGGATTAATACCTCATAGTATTATGA AATCGCATGGTTTTATAATTAAAGTTCCAACGGTATAAGATGAGCATGCGTCCCATTAGTTAGTTGGTAAGGTAACGGCTTACCAAGA 
CAATGATAGGTAGGGGTCCTGAGAGGGAGATCCCCCACACTGGTACTGAGACACGGACCAGACTCCTACGGGAGGCAGCAGTGAGGAA TATTGGACAATGGGCGCAAGCCTGATCCAGCCATGCCGCGTGCAGGAAGACGCATCTATGGTGTGTAAACTGCTTTTGTACGGGAAGA AACACTCCTTCGTGAAGGAGCTTGACGGTACCGTAAGAATAAGGATCGGCTAACTCCGTGCCAGCAGCCGCGGTAATACGGAGGATCC AAGCGGTATCCGGAATCATTGGGTTTAAAGGGTCCGTAGGCGGTTTAATAAGTCAGTGGTGAAATCTGGTCGCTCAACGATCAAACGG CCATTGATACTGTTAGACTTGAATTATTAGGAAGTAACTAGAATATGTAGTGTAGCGGTGAAATGCTTAGATATTACATGGAATACCA ATTGCGAAGGCAGGTTACTACTAATGGATTGACGCTGATGGACGAAAGCGTGGGGAGCGAACAGGATTAGATACCCTGGTAGTCCACG CCGTAAACGATGGATACTAGCTGTTGGGCGCAAGTTCAGTGGCTAAGCGAAAGTGATAAGTATCCCACCTGGGGAGTACGTTCGCAAG AATGAAACTCAAAGGAATTGACGGGGGCCCGCACAAGCGGTGGAGCATGTGGTTTAATTCGATGATACGCGAGGAACCTTACCAAGGC TTAAATGTAGATTGACAGGACTGGAAACAGTTTTTTCTTCGGACAATTTACAAGGTGCTGCATGGTTGTCGTCAGCTCGTGCCGTGAG GTGTCAGGTTAAGTCCTATAACGAGCGCAACCCCTGTTGTTAGTTGCCAGCGAGTCAAGTCGGGAACTCTAACAAGACTGCCAGTGTA AACTGTGAGGAAGGTGGGGATGACGTCAAATCATCACGGCCCTTACGCCTTGGGCTACACACGTGCTACAATGGACGGTACAGAGAGC AGCCACTGGGTGACCAGGAGCGAATCTACAAAACCGTTCTCAGTTCGGATCGGAGTCTGCAACTCGACTCCGTGAAGCTGGAATCGCT AGTAATCGGATATCAGCCATGATCCGGTGAATACGTTCCCGGGCCTTGTACACACCGCCCGTCAAGCCATGGAAGCTGGGGGTACCTG AAGTCGGTGACCGTAAGGAGCTGCCTAGGGTAAAACTGGTAACTGGGGCTAAGTCGTAACAAGGTA

Sl1127

AGAGTTTGATCATGGCTCAGAACGAACGCTGGCGGCGTGCTTAACACATGCAAGTCGAACGCGAAATTTTTCTTCGGAAAGAGAGTAG AGTGGCGCACGGGTGAGTAACGCGTAAGTTATCTACCCCGGCATCTGGAATAACTCACCGAAAGGTGTGCTAATACCGGATACGTTGA GAGATCAAGAAAGGTGGCCTCTGGATATGCTACCGTGCTGGGATGAGCTTGCGTACCATTAGCTAGTTGGTAGGGTAAAGGCCTACCA AGGCGACGATGGTTAGCGGGTCTGAGAGGATGATCCGCCACACTGGAACTGGAACACGGACCAGACTCCTACGGGAGGCAGCAGTGAG GAATATTGCGCAATGGGGGCAACCCTGACGCAGCGACGCCGCGTGGATGATGAAGGCCTTCGGGTCGTAAAATCCTGTCAGATGGAAA GAAGTGTATGGTGGATAATACCTGCTGTACTTGACGGTACCATCGAAGGAAGCACCGGCTAACTCCGTGCCAGCAGCCGCGGTAATAC GGAGGGTGCAAGCGTTGTTCGGAATTACTGGGCGTAAAGCGCGCGTAGGCGGTTTGCTAAGTCAGATGTGAAAGCCCATGGCTCAACC ATGGACGTGCATTTGAAACTGGCGGACTTGAGTATTGGAGGGGGTGGTGGAATTCCCGGTGTAGAGGTGAAATTCGTAGATATCGGGA GGAATACCGGTGGCGAAGGCGACCACCTGGCCAAATACTGACGCTGATGTGCGAAAGCGTGGGGAGCAAACAGGATTAGATACCCTGG TAGTCCACGCCGTAAACGATGTCAACTAGGTGTTGGGACGGTTAATCGTCTCATTGCCGCAGCTAACGCATTAAGTTGACCGCCTGGG GAGTACGGTCGCAAGATTAAAACTCAAAGGAATTGACGGGGGCCCGCACAAGCGGTGGAGTATGTGGTTTAATTCGACGCAACGCGCA GAACCTTACCTGGTCTTGACATCCTGGGAATCCTGTGGAAACACGGGAGTGCCTCTTACGAGGAGCCCGGTGACAGGTGCTGCATGGC TGTCGTCAGCTCGTGTCGTGAGATGTTGGGTTAAGTCCCGCAACGAGCGCAACCCTTGTCTTTAGTTGCCAGCATTAAGTTGGGCACT CTAAAGAGACTGCCGGTGTCAAACCGGAGGAAGGTGGGGATGACGTCAAGTCCTCATGGCCTTTATGACCAGGGCTACACACGTACTA CAATGGCATAAACAAAGGGCAGCGACATCGCGAGGTGAAGCGAATCCCGAAATTATGTCTCAGTCCGGATTGGAGTCTGCAACTCGAC TCCATGAGGTTGGAATCGCTAGTAATCGTGGATCAGCACGCCACGGTGAATACGTTCCCGGGCCTTGTACACACCGCCCGTCACACCA CGGGAGTTGGTTGTACCAGAAGCAGTTGAGCCAACCGTTTACGGAGGCAGGCTGCCAAGGTATGGCGAGTAACTGGGGTGAAGTCGTA ACAAGGTA

Sl1128

AGAGTTTGATCATGGCTCAGATTGAACGCTGGCGGCATGCTTTACACATGCAAGTCGAACGGCAGCGGGGGCTTCGGCCTGCCGGCGA GTGGCGAACGGGTGAGTAATGCATCGGAACGTGCCCATGTTGTGGGGGATAACTACGCGAAAGCGTAGCTAATACCGCATAAGCCCTG AGGGGGAAAGCGGGGGATTCTTCGGAACCTCGTGCGATTGGAGCGGCCGATGTCGGATTAGCTAGTAGGTGAGGTAAAGGCTCACCTA GGCGACGATCCGTAGCGGGTCTGAGAGGATGATCCGCCACACTGGGACTGAGACACGGCCCAGACTCCTACGGGAGGCAGCAGTGGGG AATTTTGGACAATGGGCGCAAGCCTGATCCAGCCATGCCGCGTGAGTGAAGAAGGCCTTCGGGTTGTAAAGCTCTTTCGGCCGGGAAG AAATCGTGTTCTCTAACATAGGACATGGATGACGGTACCGGACTAAGAAGCACCGGCTAACTACGTGCCAGCAGCCGCGGTAATACGT GGGGTGCGAGCGTTAATCGGAATTACTGGGCGTAAAGCGTGCGCAGGCGGTTTTGTAAGACAGATGTGAAATCCCCGGGCTTAACCTG NGAACTGCGTTTGTGACTGCAAGGCTCGAGT

Sl1131

AGAGTTTGATCATGGCTCAGGATGAACGCTGGCGGCAGGCCTAACACATGCAAGTCGAGCGGATGAAAGGAGCTTGCTCCTGGATTCA GCGGCGGACGGGTGAGTAATGCCTAGGAATCTGCCTGATAGTGGGGGACAACGTTTCGAAAGGAACGCTAATACCGCATACGTCCTAC GGGAGAAAGCAGGGGACCTTCGGGCCTTGCGCTATCAGATGAGCCTAGGTCGGATTAGCTAGTTGGTGAGGTAATGGCTCACCAAGGC GACGATCCGTAACTGGTCTGAGAGGATGATCAGTCACACTGGAACTGAGACACGGTCCAGACTCCTACGGGAGGCAGCAGTGGGGAAT ATTGGACAATGGGCGAAAGCCTGATCCAGCCATGCCGCGTGTGTGAAGAAGGTCTTCGGATTGTAAAGCACTTTAAGTTGGGAGGAAG GGTTGTAGATTAATACTCTGCAATTTTGACGTTACCGACAGAATAAGCACCGGCTAACTCTGTGCCAGCAGCCGCGGTAATACAGAGG GTGCAAGCGTTAATCGGAATTACTGGGCGTAAAGCGCGCGTAGGTGGTTTGTTAAGTTGGATGTGAAATCCCCGGGCTCAACCTGGGA ACTGCATCCAAAACTGGCAAGCTAGAGTATGGTAGAGGGTGGTGGAATTTCCTGTGTAGCGGTGAAATGCGTAGATATAGGAAGGAAC ACCAGTGGCGAAGGCGACCACCTGGACTGATACTGACACTGAGGTGCGAAAGCGTGGGGAGCAAACAGGATTAGATACCCTGGTAGTC CACGCCGTAAACGATGTCAACTAGCCGTTGGGAGCCTTGAGCTCTTAGTGGCGCAGCTAACGCATTAAGTTGACCGCCTGGGGAGTAC GG

sl1143

AGTTTGATCATGGCTCAGATTGAACGCTGGCGGAATGCTTTACACATGCAAATCGAGCGGCAGCGCGGGGCAACCTGGCGGCGAGCGG CGAACGGGTGAGTAACATATCGGAACGTATCCTGTAATGGGGGATAACCACTCGAAAGAGTGGCTAATACCGCATACGATCAAGAGAT GAAAGTGGGGGACCGCAAGGCCTCACGTTATAGGAGCGGCCGATATCTGATTAGCTAGTTGGGGGGGTAAAAGCCCACCAAGGCGATG ATCAGTAGCTGGTCTGAGAGGACGACCAGCCACACTGGGACTGAGACACGGCCCAGACTCCTACGGGAGGCAGCAGTGGGGAATTTTG GACAATGGGGGAAACCCTGATCCAGCCATTCCGCGTGAGTGAAGAAGGCCTTCGGGTTGTAAAGCTCTTTCGGCAGGGAAGAAACGGT CCAGGCTAATACTCTGGACTAATGACGGTACCTGAAGAAGAAGCACCGGCTAACTACGTGCCAGCAGCCGCGGTAATACGTAGGGTGC GAGCGTTAATCGGAATTACTGGGCGTAAAGCGTGCGCAGGCGGTTTTGTACGTTCGATGTGAAAGCCCCGGGCTTAACCTGGGAACTG CGTTGAAAACGGCAAGACTAGAGTGTGTCAGANGGGGGTAGAATTCCACGTGTAGCAGTGAAATGCGTAGAGATGTGGAGGAATACCG ATGGCGAAGGCAGCCCCCTGNGATAACATTGACGCTGANGCACGAAAGCGTGGGGAGCAAAC Sl1147

AGAGTTTGATCATGGCTCAGAGCGAACGCTGGCGGTGTGCTTAACACATGCAAGTCGAACGCGAAAGTTTTCTTCGGAAGACGAGTAG AGTGGCGCACGGGTGAGTAACGCGTAAGTAATCTGCCCTGGTATCTGGGATAACCCACCGAAAGGTGTGCTAATACGGGATACGCTGA TTTATCAGGAAAGGTGGCCTCTTCATGAAAGCTACTGTACCAGGAGGAGCTTGCGTACCATTAGCTAGTTGGTAGGGTAATGGCCTAC CAAGGCGACGATGGTTAGCGGGTCTGAGAGGATGATCCGCCACACTGGAACTGAAACACGGACCAGACTCCTACGGGAGGCAGCAGTG AGGAATATTGCGCAATGGGGGAAACCCTGACGCAGCGACGCCGCGTGGATGATGAAGGCCTTCGGGTCGTAAAATCCTGTCAGATGGA AAGAAATGTAGTATGCCTAATACGTGTACTATTTGACGGTACCATCAAAGGAAGCACCGGCTAACTCCGTGCCAGCAGCCGCGGTAAT ACGGAGGGTGCAAGCGTTGTTCGGAATTACTGGGCGTAAAGCGCGCGTAGGCGGCTACGTAAGTCAGATGTGAAAGTCCACGGCTCAA CCGTGGAAGTGCATTTGAAACTGGATGGCTTGAGTACTGGAGGGGGTGGTGGAATTCCCGGTGTAGAGGTGAAATTCGTAGATATCGG GAGGAATACCGGTGGCGAAGGCGACCACCTGGCCAGATACTGACGCTGAGGTGCGAAAGCGTGGGGAGCAAACAGGATTAGATACCCT GGTAGTCCACGCCGTAAACGATGTCAACTAGGTGTTGGGACGGTTAATCGTCTCATTGCCGCAGCTAACGCAATAAGTTGACCGCCTG GGGAGTACGGTCGCAAGATTAAAACTCAAAGGAATTGACGGGGGCCCGCACAAGCGGTGGAGTATGTGGTTTAATTCGACGCAACGCG CAGAACCTTACCTGGTCTTGACATCCCGAGAATCTTTTGGAAACAAGAGAGTGCCTCTTTGAGGAGCTCGGTGACAGGTGCTGCATGG 
CTGTCGTCAGCTCGTGTCGTGAGATGTTGGGTTAAGTCCCGCAACGAGCGCAACCCTTGTCTTTAGTTGCCAGCATTCAGTTGGGCAC TCTAAAGAGACTGCCGGTGTCAAACCGGAGGAAGGTGGGGATGACGTCAAGTCCTCATGGCCTTTATGACCAGGGCTACACACGTACT ACAATGGCATAAACAGAGGGCAGCGACATCGCGAGGTGAAGCGAATCCCAAAATTATGTCTCAGTCCGGATTGGAGTCTGCAACTCGA CTCCATGAAGTTGGAATCGCTAGTAATCGCGGATCAGCATGCCGCGGTGAATACGTTCCCGGGCCTTGTACACACCGCCCGTCACACC ACGGGAGTTGGTTGTACCAGAAGCAGTTGAGCTAACCGTAAGGAGGCAGGCTGCCAAGGTATGATTGGTAACTGGGGTGAAGTCGTAA CAAGGT

Sl1149

AGAGTTTGATCATGGCTCAGAATCAACGCTGGCGGCGTGCCTCAGACATGCAAGTCGAACGATTAAAGCTCTCTTCGGAGAGTGTATA GAGTGGCGCACGGGTGAGTAACACGTAAGTAATCTACCCTCGAGTGGGGAATAACGTCCGGAAACGGACGCTAATACCGCATAATGCA GCGGCACCGCAAGGTGACAGTTGTTAAAGATTTATCGCTTGAGGAGGAGCTTGCGGCAGATTAGCTAGTTGGTAAGGTAATGGCTTAC CAAGGCTACGATCTGTAACCGGTCTTAGAGGACGGTCGGTCACACTGACACTGAATAACGGGTCAGACTCCTACGGGAGGCAGCAGTC GGGAATTTTGGGCAATGGGCGAAAGCCTGACCCAGCAACGCCGCGTGAAGGATGAAGTATTTCGGTATGTAAACTTCGAAAGAATAGG AAGAATAAATGACGGTACTATTTATAAGGTCCGGCTAACTACGTGCCAGCAGCCGCGGTAATACGTAGGGACCAAGCGTTGTTCGGAT TTACTGGGCGTAAAGGGCGCGTAGGCGGCTTGCCAAGTCACTTGTGAAATCTCTGGGCTTAACCCAGAACGGCCAAGTGAAACTGGCA TGCTAGAGTGCAGAAGGGGCAATCGGAATTCTTGGTGTAGCGGTGAAATGCGTAGATATCAAGAGGAACACCTGAGGTGAAGACGGGT TGCTGGGCTGACACTGACGCTGAGGCGCGAAAGCCAGGGGAGCAAACGGGATTAGATACCCCGGTAGTCCTGGCCCTAAACGATGAAT ACTTGGTGTCTGGAGTAATTTGTGCTCCGGGTGCCGTCGCTAACGTTTTTAGTATTCCGCCTGGGGAGTACGCTCGCAAGAGTGAAAC TCAAAGGAATTGACGGGGACCCGCACAAGCGGTGGAGCATGTGGTTTAATTCGACGCAACGCGAAGAACCTTACCTAGGCTAGAATGT GAGGGAATGTTGGGTAACACCATCAGTCTGGGAAACCAGACCCAAAACAAGGTGCTGCATGGCTGTCGTCAGCTCGTGTCGTGAGATG TTGGGTTAAGTCCCGCAACGAGCGCAACCCCTATTGATAGTTGCTAACATTAAGTTGAGAACTCTATCAAGACTGCTGTTGATAAAAC GGAGGAAGGTGGGGATGATGTCAAGTCATCATGGCCTTTATGCTTAGGGCTACACACGTGCTACAATGGTCGGTACAAAACGTCGCAA TCCCGTAAGGGGGAGCTAATCGCAAAAACCGATCTCAGTTCGGATTGAAGTCTGCAGCTCGACTTCATGAAGTTGGAATCGCTAGTAA TCGCGGATCAGAACGCCGCGGTGAATACGTTCCCGGGTCTTGTACACACCGCCCGTCACATCACGAAAGTAGGTTGTACTAGAAGTAG GAGGGCTAACTCGCAAGAGAGGCATCTTACCACGGTATGATTTATGATTGGGGTGAAGTCGTAACAAGGT Sl1151

AGAGTTTGATCATGGCTCAGGATGAACGCTAGCGGCAGGCTTAATACATGCAAGGGGAGGGGCAGCATGAGTGTAGCAATACATTTGA TGGCGACCGGCAAACGGGTGCGGAACACGTACAGAACCTTCCTTCGAGCGGGGAATAGCCCAGAGAAATTTGGATTAATACCCCATAG TATTACGGAGTGGCATCACTTTGTAATTAAAGATTTATCACTTGAAGATGGCTGTGCGGCTGATTAGGTAGTTGGCGGGGTAATGGCC CACCAAGCCTGCGATCAGTAACTGGTGTGAGAGCACGACCAGTCACACGGGCACTGAGACACGGGCCCGACTCCTACGGGAGGCAGCA GTAAGGAATATTGGTCAATGGACGAGAGTCTGAACCAGCCATGCCGCGTGGAGGATGAAGGTCCTCTGGATTGTAAACTTCTTTTATA TGGGACGAAAAAAGGCTTTTCCAAGTCGTCTGACGGTACCATATGAATAAGCACCGGCTAACTCCGTGCCAGCAGCNCGNGGTAATAC GGGAGGTGCAAGCGTTATCCGGATTCACTGGGTTTAAAGGGTGCGTAGGTGGATTGGTAAGTCAGTGGTGAAATCCCCGAGCTTAACT TGGGAACTGCCATTGATACTATTAGTCTTGAATACCGTGGAGGTCAGCGGAATATGTCATGTAGCGGTGAAATGCTTAGATATGACAT AGAACACCAATTGCGAAGGCAGCTGGCTACACGAGTATTGACACTGAGGCACGAAAGCGTGGGGATCAAACAGGATTAGATACCCTGG TAGTCCACGCCCTAAACTATGGATACTCGACATTTGCGATACACAGCAAGTGTCTGAGCGAAAGCATTAAGTATCCCACCTGGGAAGT ACGATCGCAAGATTGAAACTCAAAGGAATTGGCGGGGGTCCGCACAAGCGGTGGAGCATGTGGTTTAATTCGATGATACGCGAGGAAC CTTACCTGGGCTAGAATGCTGGGAGACCGTGGGTGAAAGCTCACTTTGTAGCAATACACTGCCAGTAAGGTGCTGCATGGCTGTCGTC AGCTCGTGCCGTGAGGTGTTGGGTTAAGTCCCGCAACGAGCGCAACCCCCATCACTAGTTGCCATCAGGTAACGCTGGGAACTCTAGT GAAACTGCCGTCGTAAGACGTGAGGAAGGAGGGGATGATGTCAAGTCATCATGGCCTTTATGCCCAGGGCTACACACGTGCTACAATG GGGCGTACAAAGGGCTGCAACACAGTGATGTGAAGCTAATCCCAAAAAACGCCTCTCAGTTCAGATTGAAGTCTGCAACTCGACTTCA TGAAGCTGGAATCGCTAGTAGTCGTATATCAGCAATGATACGGTGAATACGTTCCCGGACCTTGCACACACCGCCCGTCAAGCCATGG AAGTCGGGTGTACCTAAAGTCGGTAACCGTAAGGAGCCGCCTAGGGTAAAACTGGTGACTGGGGCTAAGTCGTAACAAGGTA Sl1152

AGAGTTTGATCATGGCTCAGGATGAACGCTAGCGGCAGGCTTAATACATGCAAGTCGAGGGGCAGCAGGAATAGCAATATTTGCTGGC GACCGGCGCACGGGTGCGTAACACGTATACAATCTGCCTTTAACAGGGGGATAGCCCGGAGAAATCCGGATTAATACCCCATAACAAT AGAACAAGCATTTGTTTTATTTAAAAGCTCCGGCGGTTAGAGATGAGTATGCGTCTGATTAGCTAGTTGGTGAGGTAACGGCTCACCA AGGCGACGATCAGTAGGGGATCTGAGAGGATTAACCCCCACACGGATACTGAGACACGGATCCGACTCCTACGGGAGGCAGCAGTAAG GAATATTGGACAATGCCCGCAAGGGTGATCCAGCCATGCCGCGTGCAGGAAGACGGCCCTATGGGTTGTAAACTGCTTTTGTACCGGA GAAAACCTCCCCTCGTGAGGGGAGCTGATAGTATGGTAAGAATAAGCATCGGCTAACTTCGTGCCAGCAGCCGCGGTAAGACGAAGGA TGCAAGCGTTATCCGGATTCATTGGGTTTAAAGGGAGCGTAGGTGGGTTTGTAAGTCAGTGGTGAAAGCCGGTCGCTTAACGATCGAA TTGCCATTGATACTGCAGACCTTGAGTACAGATGCTGTGGGCGGAATATGACATGTAGTGGTGAAATACATAGAGATGTCATAGAACA CCGATTGCGAAGGCAGCTCACAAAACTGTAACTGACACTGAGGCTCGAAAGTGCGGGGATCAAACAGGATTAGATACCCTGGTAGTCC GCACTGTAAACGATGATTACTCGCTGCTGGGAGGTAACTTTCAGTGGCTTAGCGAAAGCGATAAGTAATCCCCTGGGGAGTACGCCGG CAACGGTGAAACTCAAAGGAATTGACGGGGGCCCGCACAAGCGGAGGAGCATGTGGTTTAATTCGATGATACGCGAGGAACCTTACCA GGGCTTGAAAGTTAGTGACCGCTTCTGAAAGGAAGCTTTCCGCAAGGACACGAAACTAGGTGCTGCATGGCTGTCGTCAGCTCGTGCC GTGAGGTGTTGGGTTAAGTCCCGCAACGAGCGCAACCCCTACCATTAGTTGCTAGCAGGTCATGCTGAGGACTCTAATGGAACTGCCC GCGCAAGCGGTGAGGAAGGTGGGGATGACGTCAAGTCATCACGGCCCTTACGTCCTGGGCTACACACGTGCTACAATGGCTATTACAG AGGGCAGCTACACAGCAATGTGATGCTAATCTTCAAAAATAGTCTCAGTTCGGATTGGGGTCTGCAACTCGACCCCATGAAGCTGGAT TCGCTAGTAATCGTGGATCAGCATGTCACGGTGAATACGTTCCCGGGTCTTGTACACACCGCCCGTCACACCATGGGAGTGGGTTCCA CCAGAAGTAGTTAGCCTAACCGCAAGGAGGGCGACTACCACGGTGAGATTCATGACTGGGGTGAAGTCGTAACAAGGT

Sl1158

AGAGTTTGATCATGGCTCANGATGAACGCTAGCGGGAGGCTTAACACATGCAAGTCGAGGGGCAGCACGAGGTAGCAATACTTTGGTG GCGACCGGCGCACGGGTGAGTAACGCGTATGCAACCTACCCTGTACTGGGGGATAGCCCGGAGAAATCCGGATTAATACCCCATAAAG ATATGAGATGGCATCATTTTATATTTAAAGTTCCGACGGTACGGGATGGGCATGCGTAACATTAGCTAGTTGGTAGGGTAACGGCCTA CCAAGGCTGCGATGTTTAGGGGTCCTGAGAGGGTGATCCCCCACACTGGTACTGAGACACGGACCAGACTCCTACGGGAGGCAGCAGT GAGGAATATTGGTCAATGGGCGCAAGCCTGAACCAGCCATCCCGCGTGCAGGAAGAAGGCGCTATGCGTCGTAAACTGCTTTTCCAGG GGAAGAAATTTATCTACGTGTAGGTAATTGCCGGTACCCTGGGAATAAGCATCGGCTAACTCCGTGCCAGCAGCCGCGGTAATACGGA GGATGCAAGCGTTATCCGGATTTATTGGGTTTAAAGGGTGCGTAGGCGGATTAATAAGTCAGTGGTGAAATACTGCAGCTTAACTGTA GAATTGCCGTTGATACTGTTAGTCTTGAGTACGGTCAAGGTAGGCGGAATGTGTAATGTAGCGGTGAAATGCTTAGATATTACACAGA ACACCGATTGCGAAGGCAGCTTACTGGGCCATTACTGACGCTGAGGCACGAAAGCGTGGGGAGCGAACAGGATTAGATACCCTGGTAG TCCACGCCGTAAACGATGATCACTCGCTGTTGGCGATACACAGTCAGCGGCTAAGCAAAAGCATTAAGTGATCCACCTGGGGAGTACG GCCGCAAGGCTGAAACTCAAAGGAATTGACGGGGGCCCGCACAAGCGGAGGAGCATGTGGTTTAATTCGATGATACGCGAGGAACCTT ACCCGGGCTTGAAAGTTACTGAAGATACCAGAGACGGTATCGTCCTTCGGGACAGGAAACTAGGTGCTGCATGGCTGTCGTCAGCTCG TGCCGTGAGGTGTTGGGTTAAGTCCCGCAACGAGCGCAACCCCTATGTTTAGTTGCCAGCGCGTAGCGGCGGGGACTCTAAACAGACT GCCTGTGCAAACAGTGAGGAAGGCGGGGACGACGTCAAGTCATCATGGCCCTTACGTCCGGGGCTACACACGTGCTACAATGGTCGGT ACAGAGGGCAGCCAGCCAGCAATGGTGCGCGAATCCCTTAAAGCCGATCACAGTTCGGATCGGGGCCTGCAACTCGGCCCCGTGAAGC 
TGGATTCGCTAGTAATCGCGTATCAGCAATGACGCGGTGAATACGTTCCCGGGCCTTGTACACACCGCCCGTCAAGCCATGAAAGCTG GGGGTGCCTAAAGCATGTAACCGCAAGGAGCGTGTTAGGGCAATACCGGTAATTGGGGCTAAGTCGTAACAAGGT Sl1165a AGAGTTTGATCATGGCTCAGGACGAACGTTGGCGGCGTGCTTAATACATGCAAGTCAACTGAAGCATCGGTAGCAATACTGATGTGGA GGTGGCGCACGGGTGAGTAACACGTAGGTAATCTGCCTTCAGGTCTGACATAACCCCGGGAAACCGGGGCTAATATCAGATGATGCAG CGGCTTGACATCAAGACAGTTGTTAAAGCTTCGGTGCCTGAAGATGAGCCTGCGTCTGATTAGCTAGTTGGCGGAGTAATGGCCCACC AAGGCTACGATCAGTAACTGGTCTGAGAGGATGATCAGTCACACTGGAACTGAGACACGGTCCAGACTCCTACGGGAGGCAGCAGTAA GGAATATTGCTCAATGGGAGAAATCCTGAAGCAGCAACGCCGCGTGAGGGATGAAGGGCTTTTGCTCGTAAACCTCTGTAGTGAGGGA AAAAATTTCCACTCTGTGGAATATGATGGTACCTCAAAAGTAAGCCCCGGCTAACTACGTGCCAGCAGCCGCGGTAATACGTAGGGGG CAAACGTTGTCCGGATTTACTGGGTGTAAAGGGTGCTCAGGCGGTTTTGTAAGTCAGAAGTGAAATCCTAGAGCTTAACTCTGGAACT GCTTTTGATACTGCAAGGCTTGAATGTGGAAGAGGAGGATGGAATTTCTGGTGTAGCAGTGAAATGCGTAGATATCAGAAAGAACACC AGTGGCGAAGGCGATCCTCTGGTCCACTATTGACGCTAAAGCACGAAAGCGTGGGGAGCAAACAGGATTAGATACCCTGGTAGTCCAC GCCTTAAACGATGAATACTAGACGTTGGGGTTAAACTCAGTGTCGCAGCTAACGCATT

Sl1165b

AGGTGCTGCATGGCTGTCGTCAGCTCGTGTCGTGAGATGTTGGGTTAAGTCCCGTAACGAGCGCAACCCTTGTCCTTAGTTGCCAGCG CGTAATGGCGGGAACTCTAAGGAGACTGCCGGTGACAAACCGGAGGAAGGTGGGGATGACGTCAAGTCATCATGGCCCTTACGACCTG GGCTACACACGTGCTACAATGGGCGGTACAAAGGGTTGCCAAACCGCGAGGTGGAGCTAATCCCGTAAAACCGTTCGTAGTCCGGATT GGAGTCTGCAACTCGACTCCATGAAGTCGGAATCGCTAGTAATCGTAAATCAGAACGTTACGGTGAATACGTTCCCGGGCCTTGTACA CACCGCCCGTCACACCATGGGAGTGGGTTGCAAAAGAAGTAGCTAGTCTAACCGCAAGGGGGACGGTTACCACTTTGTGATTCATGAC TGGGGTGAAGTCGTAACAAGGTA

Sl1167

AGAGTTTGATCATGGCTCANATTGAACGCTGGCGGCAGGCCTAACACATGCAAGTCGAGCGCGAAAGGCTTTCGGGCTGAGTAGAGCG GCGGACGGGTGAGTAACGCGTAGGAATCTACCTGGTAGTGGGGGACAACTTGGGGAAACTCAAGCTAATACCGCATACGCCCCAAGGG GGAAAGCGGGGGATCTTCGGACCTCGCGCTATCGGATGAGCCTGCGTAGGATTAGCTTGTTGGTGAGGTAAAGGCTCACCAAGGCGAC GATCCTTAGCTGGTCTGAGAGGATGATCAGCCACACTGGAACTGAGACACGGTCCAGACTCCTACGGGAGGCAGCAGTGGGGAATATT GCGCAATGGGCGAAAGCCTGACGCAGCCATGCCGCGTGTGTGAAGAAGGCCCTAGGGTTGTAAAGCACTTTAAGCGGGGAGAAAAGGG TGGCCGTTAATAGCGGTCACCTGTGATGTTACCCACAGAATAAGCACCGGCTAACTCCGTGCCAGCAGCCGCGGTAATACGGAGGGTG CGAGCGTTAATCGGAATTACTGGGCGTAAAGCGCGCGTAGGCGGTTTGTTAAGTCAGCTGTGAAAGCCCCGGGCTCAACCTGNGAACT GCAGTTGATACTGGCCGACTAGAGTACGAGAGAGGGA

Sl1171

AGAGTTTGATCATGGCTCAGAGCGAACGCTGGCGGCGTGCCTAACACATGCAAGTCGCACGAGAAAGGGGTAGCAATACCCCCTGTAC AGTGGCGAACGGGTGAGTAACACGTGGGTAATTTACCTCAGGGTTGGGAATAACCTGCCGAAAGGCGGGCTAATACCGGATAACGTCG CGGGGCCACATGGTCCAGCGACCAAAGCCGACCTCTTCCTGAAAGTTGGCGCCTGGAGAGAAACCCGCGTCCCATTAGCTAGTTGGTG AGGTTACGGCTCACCAAGGCTCCGATGGGTAGCCGGCCTGAGAGGGCGACCGGCCACAGTGGAACTGAGACACGGTCCACACTCCTAC GGGAGGCAGCAGTGAGGAATCTTGCGCAATGGGCGAAAGCCTGACGCAGCGACGCCGCGTGGACGATGAAGGCCTTCGGGTCGTAAAG TCCTGTCGGGTGGGAAGAAAATTCCGGAGCTAATATCTCCGGGACTTGACTGTACCACCAGAGGAAGCCCCGGCTAACTCCGTGCCAG CAGCCGCGGTAATACGGAGGGGGCCAGCGTTGCTCGGAATTATTGGGCGTAAAGGGCGCGTAGGCGGCCTTGCAAGTCTGATGTGAAA GCCCACGGCTCAACCGTGGAAGTGCATCTTATACTGCTTGGCTGGAGTCTGGGAGAGGGAAGCGGAATTCCCGGTGTAGCGGTGAAAT GCGTAGATATCGGGAGGAACACCAGTGGCGAAGGCGGCTTCCTGGACCAGTACTGACGCTGAGGCGCGAAAGCTAGGGGAGCAAACAG GATTAGATACCCTGGTAGTCCTAGCCATAAACGATGTGCACTTGGTGTTGGGGGTATCGACCCCTCCAGTGCCGTAGCAAACGCATTA AGTGCACCGCCTGGGGAGTACGGTCGCAAGGCTGAAACTCAAAGGAATTGACGGGGGCCCGCACAAGCGGTGGAGCATGTGGTTTAAT TCGACGCAACGCGAAGAACCTTACCGGGGTTTGAACTGCCGGTGACAGCCCCAGAAATGGGGTCTTCCTTCGGGACGCCGGTAGAGGT GCTGCATGGCTGTCGTCAGCTCGTGTCGTGAGATGTTGGGTTAAGTCCCGCAACGAGCGCAACCCCTATCCTTAGTTACCATCGGGTC ATGCCGGGGACTCTAGGGAGACTGCCCCGGAAAACGGGGAGGAAGGTGGGGATGACGTCAAGTCCTCATGGCCTCTATGTCCCGGGCC ACACACGTGCTACAATGGGCGGTACAAAGGGTCGCAATACCGCGAGGTGGAGCTAATCCCACAAAACCGTCCCCAGTTCGGATTGGAG TCTGCAACTCGACTCCATGAAGTTGGAATCGCTAGTAATCGCGGATCAGCACGCCGCGGTGAATACGTTCCCGGGCCTTGTACACACC GCCCGTCACATCACGAAAGTTGGCTGCACTTGAAGTCGNTGGGCTAACCCGCAAGGGAGGCAGGCGCCGATGGTGTGGTTGATGATTG GGGTGAAGTCGTAACAAGGT

Sl1174

GAAGGCGGCTCTCTGGACCATCACTGACACTGAGGCACGAAAGCGTGGGGGAGCAAACAGGATTAGATACCCTGGTAGTCCACGCCCT AAACGATGCGAACTGGACGTTGGGATCAATTGAGATTTCAGTGTCGAAGCTAACGCGTTAAGTTCGCCGCCTGGGGAGTACGGTCGCA AGACTGAAACTCAAAGGAATTGACGGGGGCCCGCACAAGCGGTGGAGTATGTGGTTTAATTCGATGCAACGCGAAGAACCTTACCTGG TCTTGACATGTACGGAATCCTTTAGAGATAGAGGAGTGCCTTCGGGAACCGTAACACAGGTGCTGCATGGCTGTCGTCAGCTCGTGTC GTGAGATGTTGGGTTAAGTCCCGCAACGAGCGCAACCCCTGTCCTTAGTTGCCAGCACGTAATGGTGGGAACTCTAAGGAGACTGCCG GTGACAAACCGGAGGAAGGTGGGGATGACGTCAAGTCATCATGGCCCTTACGACCAGGGCTACACACGTACTACAATGGTCGGGACAG AGGGTCGCAATACCGCGAGGTGGAGCCAATCCCAGAAACCCGATCTTAGTCCGGATCGCAGTCTGCAACTCGACTGCGTGAAGTCGGA ATCGCTAGTAATCGCGAATCAGCATTGTCGCGGTGAATACGTTCCCGGGCCTTGTACACACCGCCCGTCACACCATGGGAGTTTGTTG CACCAGAAGCAGGTAGCTTAACCGTAAGGGGGGCGCTTGCCACGGTGTGGCCGATGACTGGGGTGAAGTCGTAACAAGGT

Sl1176

TTAATTCGAAGCAACGCGCAGAACCTTACCAGCGTTTGACATCCTTGTCGCGGATTTCAGAGATGATTTCCTTCAGTTCGGCTGGACA AGTGACA*GGTGCTGCATGGCTGTCGTCAGCTCGTGTCGTGAGATGTTGGGTTAAGTCCCGCAACGAGCGCAACCCTCATCTTTAGTT GCCATCATTCAGTTGGGCACTCTAAAGAAACTGCCGGTGATAAGCCGGAGGAAGGTGGGGATGACGTCAAGTCCTCATGGCCCTTACA CGCTGGGCTACACACGTGCTACAATGGCGGTGACAGTGGGCAGCAACCGGGCGACCGGTAGCTAATCTCCAAAAGCCGTCTCAGTTCG GATTGTTCTCTGCAACTCGAGAGCATGAAGGCGGAATCGCTAGTAATCGCGGATCAGCATGCCGCGGTGAATACGTTCCCAGGCCTTG TACACACCGCCCGTCACACCATGGGATTTGGATTCACCCGAAGGCGTTGCGCTAACCTAGCAATAGGAGGCAGGCGACCACGGTGGGT TTAGAGACTGGGGTGAAGTCGTAACAAGGTA

Sl1177

CGGCTTACCAAGGCTTCGATGGTTAGCTGGTCTGAGAGGATGATCAGCCACACTGGAACTGACACACGGTCCAGACTCCTACGGGAGG CAGCAGTGAGGAATTTTGCGCAATGGGGGAAACCCTGACGCAGCAACGCCGCGTGAGTGATGAAGGCTTTCGAGTCGTAAAGCTCTGT CAAGTGGGAAGAATCTAAAATATGATAATACCATATTTTACTGACGGTACCACTGAAGGAAGCACCGGCTAACTCCGTGCCAGCAGCC GCGGTAATACGGAGGGTGCAAGCGTTATTCGGAATTATTGGGCGTAAAGGGCGCGTAGGCGGCTTCTTAAGTCAGATGTGAAAGCCCG GGGCTTAACCCCGGAAGTGCATTTGAAACTAAGTGGCTTGAGTATGGGAGAGGGAAGTGGAATTCCTGGTGTAGAGGTGAAATTCGTA GATATCAGGAGGAACACCGGTGGCGAAGGCGACTTCCTGGACCAATACTGACGCTGAGGCGCGAAGGCGTGGGGAGCAAACAGGATTA GATACCCTGGTAGTCCACGCAGTAAACGGTGAACACTAGGTGTAGCGGGTATTGACCCCTGCTGTGCCGCAGTTAACGCATTAAGTGT TCCGCCTGGGGAGTACGACCGCAAGGTTAAAACTCAAAGGAATTGACGGGGGCCCGCACAAGCGGTGGAGCATGTGGTTTAATTCGAC 
GCAACGCGAAGAACCTTACCTGGGCTTGACATCCCGAGAATCCTGATGAAAGTCGGGAGTGCCCTTCGGGGAACTCGGTGACCGGTGC TGCATGGCTGTCGTCAGCTCGTGTCGTGAGATGTTGGGTTAAGTCCCGTAACGAGCGCAACCCTTGCCCTTAGTTGCCAGCGAGTAAT GTC

Sl1178

TGACGGTACCAGAGGAATAAGCACCGGCTAACTCCGTGCCAGCAGCCGCGGTAATACGAAGGGTGCAAGCGTTACTCGGAATTACTGA GCGTAAAGCGTGCGTAGGTGGTTTGTTAAGTCAGATGTGAAAGCCCCGGGCTCAACCTGGGAATTGCATTTGATACTGGCTAACTAGA GTGAGGTAGAGGAGAGTGGAATTCCCGGTGTAGCAGTGAAATGCGTAGAGATCGGGAGGAACATCAGTTGCGAAGGCGGCTCTCTGGA CCATCACTGACACTGAGGCACGAAAGCGTGGGGAGCAAACAGGATTAGATACCCTGGTAGTCCACGCCCTAAACGATGCGAACTGGAC GTTGGGATCAATTGAGATTTCAGTGTCGAAGCTAACGCGTTAAGTTCGCCGCCTGGGGAGTACGGTCGCAAGACTGAAACTCAAAGGA ATTGACGGGGGCCCGCACAAGCGGTGGAGTATGTGGTTTAATTCGATGCAACGCGAAGAACCTTACCTGGTCTTGACATGTACGGAAT CCTTTAGAGATAGAGGAGTGCCTTCGGGAACCGTAACACAGGTGCTGCATGGCTGTCGTCAGCTCGTGTCGTGAGATGTTGGGTTAAG TCCCGCAACGAGCGCAACCCCTGTCCTTAGTTGCCAGCACGTAATGGTGGGAACTCTAA

Sl1185

AGAGTTTGATCATGGCTCAGGATGAACGCTGGCGGCGTGCCTAACACATGCAAGTCGAACGGGAGTTGTTTTCGGACAACAAGAGTGG CGCACGGGTGAGTAACACGTAGCTAACCTGCCCCGAAGCTCGGGATAACGTTCCGAAAGGAATGCTAATACCGGATAAGCTCATGGAC TGTAGAGGCCTGTGAGAAAAGGAGCAATCCACTTTGGGATGGGGCTGCGACCCATCAGCTAGTTGGTGAGGTAACGGCTTACCAAGGC GACGACGGGTAGGGGACCTGAGAGGGTGACCCCCCACACTGGGACTGAGACACGGCCCAGACTCCTACGGGAGGCAGCAGTGAGGAAT ATTGCACAATGGGCGCAAGCCTGATGCAGCGACGCCGCGTGGGTGAAGAAGGTTTTCGGATCGTAAAGCCCTTTTCTGTGTGACGAGA CAAGGACGGTAGCACAGGAATAAGTGTCGGCTAACTACGTGCCAGCAGCCGCGGTAAAACGTAGGACACAAGCG Sl1187

GGGGAATATTGGACAATGGGGGCAACCCTGATCCAGCGACGCCGCGTGTGTGAAGAAGGCCTGCGGGTTGTAAAGCACTTTTAGTGGG GATGAAAAGTTCAGGGCTAACACCCTTGGATCTTGACCTAACCCAAAGAAAAAGCACCGGCTAACTCTGTGCCAGCAGCCGCGGTAAT ACAGAGGGTGCAAGCGTTAATCGGAATTACTGGGCGTAAAGCGTGCGCAGTCGGTTATTTAAGTCGGATGTGAAATCCCCGGGCTCAA CCTGGGAATTGCATTCGATACTGGATAGCTAGAGTTCGGCAGAGGGAAGTGGAATTTCAGGTGTAGCGGTGAAATGCGTAGATATCTG AAGGAACATCAGTGGCGAAAGCGACTTCCTGGACCAGAACTGACGATCAGGCACGAAAGCGTGGGGAGCAAACAGGATTAGATACCCT GGTAGTCCACGCCATAAACGATGACAACTAGACGTTGGAGGCATTTGGCCCACAGTGTCGCAGCTAACGCGTTAAGTTGTCCGCCTGG GGAGTACGGCCGCAAGGTTGAAACTCAAAGGAATTGACGGGGACCCGCACAAGCGGTGGAGCATGTGGTTTAATTCGATGCAACGCGA AGAACCTTACCTGGTCTTGACATGTCTGGAATCCCGAAGAGATTTGGGAGTGCCGCAAGGAACCAGAACACAGGTGCTGCATGGCTGT CGTCAGCTCGTGTCGTGAGATGTTGGGTTAAGTCCCGCAACGAGCGCAACCCTTGTCCTTAGTTGCCATCATTAAGTTGGGAACTCTA AGGAGACCGCCGGTGACAAACCGGAGGAAGGTGGGGATGACGTCAAGTCATCATGGCCTTTATGACCAGGGCTACACACGTGCTACAA TGGCAGGTACAGAGGGAAGCCAACCCGCGAGGGGGAGCTAATCCCAGAAAGCCTGTCTTAGTCCGGATTGGAGTCTGCAACTCGACTC CATGAAGTTGGAATCGCTAGTAATCGCAGATCAGCATTGCTGCGGTGAATACGTTCCCGGGTCTTGTACACACCGCCCGTCACACCAT GGGAGTTGATTGCACCAGAAGCAGGTAGCCTGACCGCAAGGAAGGCGCTTACCACGGTGTGGTTAATGACTGGGGTGAAGTCGTAACA AGGTA

Sl1193

CTTGTTGGTGAGGTAACGGCTCACCAAGGCTTCGACGGGTAGCTGGTCTGAGAGGACGATCAGCCACACTGGCACTGCGACACGGGCC AGACTCCTACGGGAGGCAGCAGTAAGGAATATTGCGCAATGGGCGAAAGCCTGACGCAGCGACGCCGCGTGGGGGCTGAAGGTCTTCG GATTGTAAACCCCTTTCGGGAGGGAAGATGGAATGGGGTAACCCATTCGGACGGTACCTCCAGAAGCAGCCACGGTAACTTCGTGCCA GCAGCCGCGGTAATACGAAGGTGGCAAGCGTTATTCGGATTTACTGGGCGTACAGGGAGCGTAGGCGGTTCGGTAAGCCCTTTGTGAA ATCTTCAGGCTTAACCTGGAACAGTCGGAGGGGACTGCCGGGCTAGAGGACGGGAGAGGAGCGCGGAATTCCCGGTGTAGCGGTGAAA TGCGTAGAGATCGGGAGGAAGGCCGGTGGCGAAGGCGGCGCTCTGGAACGTTTCTGACGCTGAGGCTCGAAAGCGTGGGGAGCAAACA GGATTAGATACCCTGGTAGTCCACGCCTTAAACTATGAATACTAAGTGTCGGCGGGTTACCGCCGGTGCCGCAGCTAACGCATTAAGT ATTCCGCCTGGGAAGTACGGCCGCAAGGTTGAAACTCAAAGGAATTGACGGGGGCCCGCACAAGCGGTGGAGCATGTGGTTTAATTCG ACGCAACGCGAAGAACCTTACCCAGGCTGGACATGCAGGTAGTAGAAGGGTGAAAGCCCAACGAGGTAGCAATACCATCCTGCTCAGG TGCTGCATGGCTGTCGTCAGCTCGTGCCGTGAGGTGTTGGGTTAAGTCCCGCAACGAGCGCAACCCCTGTCTTCAGTTACCAACGGGT CATGCCGGGAACTCTGGAGAGACTGCCCAGGAGAACGGGGAGGAAGGTGGGGATGACGTCAAGTCAGCATGGCCTTTATGCCTGGGGC TACACACGTGCTACAATGGCCGGTACAAAGGGCTGCAAACCCGTAAGGGGAAGCGAATCTCAAAAAACCGGCCTCAGTTCAGATCGAG GTCTGCAACTCGACCTCGTGAAGGCGGAATCGCTAGTAATCCCGGATCAGCACGCCGGGTGAATACGTTCCCGGGCCTTGTACACAC CGCCCGTCACACCACGAAAGTTTGTTGTACCTGAAGTCGTTGGCGCCAACCGCAAGGAGGCAGACGCCCACGGTATGACCGATGATTG GGGTGAAGTCGTAACAAGGTA

Sl1207

AGAGTTTGATCATGGCTCAGAGTGAACGCTGGCGGCAGGCCTAACACATGCAAGTCGAACGGCAGCACAGCAGTAGCAATACTGTGGG TGGCGAGTGGCGGACGGGTGAGGAATACATCGGGATCTACCTTTTCGTGGGGGATAACGTAGGGAAACTTACGCTAATACCGCATACG CCCTACGGGGGAAAGCGGCGGACCGCAAGGCGTCGCGCGATGAGATGAACCGATGTCCGATTAGCTAGTTGGCGGGGTAAAGGCCCAC CAAGGCGACGATCGGTAGCTGATCTGAGAGGATGATCAGCCACACTGGAACTGAGACACGGTCCAGACTCCTACGGGAGGCAGCAGTG GGGAATATTGGACAATGGGCGCAAGCCTGATCCAGCCATGCCGCGTGGGTGAAGAAGGCCTTCGGGTTGTAAAGCCCTTTTGTCCGGA AAGAAAAGCACGGGATTAATACCCTCGTGTGATGACGGTACCGGAAGAATAAGCACCGGCTAACTTCGTGCCAGCAGCCGCGGTAATA CGAAGGGTGCAAGCGTTACTCGGAATTACTGGGCGTAAAGCGTGCGTANGTGGTTTGNTAAGTCTGTCGTGAAATCCCCGGGCTCAAC CTGGGAATGGCGATGGATACTGGCAAGCTAGAGTGAGGTAGAGGAGAGTGGAATTCCCGGTGTAGCAGTGAAATGCGTAGAGATCGGG AGGAACATCAGTTGCGAAGGCGGCTCTCTGGACCATCACTGACACTGANGCACGAAAGCGTGGGGAGCAAACAGGATTAGATACCCTG GTAGTCCACGCCCTAAACGATGCGAACTGGACGTTGGGCTCAATTAGGAGCTCAGTGTCGAAGCTAACGCGTTAAGTTCGCCGCCTGG GGAGTACGGTCGCAAGACTGAAACTCANAGGAATTGACGGGGGCCCGCACAAGCGGTGGAGTATGTGGTTTAATTCGATGCAACGCGC AGAACCTTACCTGGTCTTGACATCCACGGAATCCTTTAGAGATAGAGGAGTGCCTTCGGGAACCGTGAGACAGGTGCTGCATGGCTGT CGTCAGCTCGTGTCGTGAGATGTTGGGTTAAGTCCCGCAACGAGCGCAACCCCTGTCCTTAGTTGCCAGCACGTAATGGTGGGAACTC TAAGGAGACTGCCGGTGACAAACCGGAGGAAGGTGGGGATGACGTCAAGTCATCATGGCCCTTACGACCAGGGCTACACACGTACTAC AATGGTGGGGACAGAGGGTCGCGAAGCCGCGAGGTGGAGCCAATCCCAGAAACCCTATCTTAGTCCGGATTGGAGTCTGCAACTCGAC TCCATGAAGTCGGAATCGCTAGTAATCGCGGATCAGCATTGCCGCGGTGAATACGTTNCCGGGCCTTGTACACACCGCCCGTCACACC ATGGGAGTTTGTTGCACCAGAAGCAGGTAG

Sl1224

AGAGTTTGATCATGGCTCAGAGTGAACGCTGGCGGCAGGCCTAACACATGCAAGTCGAACGGCAGCACAGCAGTAGCAATACTGTGGG TGGCGAGCGGCGGACGGGTGAGGAATACATCGGGATCTACCTTTTCGTGGGGGATAACGTAGGGAAACTTACGCTAATACCGCATACG CCCTACGGGGGAAAGCGGCGGACCGCAAGGCGTCGCGCGATGAGATGAACCGATGTCCGATTAGCTAGTTGGCGGGGTAAAGGCCCAC CAAGGCGACGATCGGTAGCTGATCTGAGAGGATGATCAGCCACACTGGAACTGAGACACGGTCCAGACTCCTACGGGAGGCAGCAGTG GGGAATATTGGACAATGGGCGCAAGCCTGATCCAGCCATGCCGCGTGTGTGAAGAAGGCCTTCGGGTTGTAAAGCACTTTTGTCC Sl1241

AGAGTTTGATCATGGCTCAGAACGAACGCTGGCGGCGTGCCTAACACATGCAAGTCGTACGAGAAATCCTGGGCAACCGGGAGAGTAA AGTGGCGCACGGGTGAGTAACGCGTGGGTAACCTATCCTAAAATTGGGGATAACTCTTCGAAAGGGGAGTTAATACCGAATAATATTA 
CAATTCCTCCGGGAGTTGGAATTAAAGGTGGCCTCTGCATGCAAGCTATCGTTTATGGATGGGCCCGCGTACCATTAGCTAGTTGGTA GGGTAACAGCCTACCAAGGCAACGATGGTTAGCTGGTCTGAGAGGATGGCCAGCCACACTGGAACTGAGACACGGTCCAGACTCCTAC GGGAGGCAGCAGTGGGGAATCTTGCGCAATGGGGGAAACCCTGACGCAGCAACGCCGCGTGGGTGATGAAGGCCTTCGGGTCGTANAG CCCTGTCAGGTGGGAAGAAACCTGTGGATGCTAATACCACCCACAATTGACGGTACCACCGGAGGAAGCACCGGCTAACTCCGTGCCA GCAGCCGCGGTAATACGGAGGGTGCAAGCGTTGTTCGGAATTATTGGGCGTAAAGCGCGTGTAGGTGGTCGTGTAAGTCAGATGTGAA AGCCTTCTGCTTAACAGAAGAAGTGCATTTGAAACTGCTCGGCTAGAGTACGGGAGAGGAGAGTGGAATTCCCGGTGTAGAGGTGAAA TTCGTAGATATCGGGAGGAACACCAGTGGCGAAGGCGGCTCTCTGGTCCGATACTGACGCTGAGACGCGAAAGCGTGGGGAGCAAACA GGATTAGATACCCTGGTAGTCCACGCCGTAAACGATGGGCACTAGGTGTAGGAGGTATTGACCCCTTCTGTGCCGAAGCTAACGCATT AAGTGCCCCGCCTGGGGAGTACGGCCGCAAGGCTAAAACTCAAAGGAATTGACGGGGGCCCGCACAAGCGGTGGAGCATGTGGTTCAA TTCGACGCAACGCGAAGAACCTTACCTGGGCTTGACATCCGCTGACACTCCCGGAAACGGGATTTTCTCCGCAAGGGGACAGCGAGAC AGGTGCTGCATGGCTGTCGTCAGCTCGTGTCGTGAGATGTTGGGTTAAGTCCCGCAACGAGCGCAACCCTCATCCTTAGTTGCCATCA TTGAGTTGGGAACTCTAAGGAAACTGCCTCGGTTAACGGGGAGGAAGGTGGGGATGACGTCAAGTCCTCATGGCCTTTATGTCCAGGG CTACACACGTGCTACAATGGGTGGTACAAAGGGTTGCAATCCCGCAAGGGGGAGCTAATCTCAAAAAGCCACTCTCAGTTCAGATTGG AGTCTGCAACTCGACTCCATGAAGGCGGAATCGCTAGTAATTGCGGATCAGCATGCCGCGGTGAATACGTTCCCGGGCCTTGTACACA CCGCCCGTCACACCATGAGAGCTGACTGTACCAGAAGTCGCTCGGCTAACCCGTAAGGGAAGCAGGCGCCTAAGGTATGGTTGGTGAT TGGGGTGAAGTCGTAACAAGGT

Sl1248

AGAGTTTGATCATGGCTCAGATTGAACGCTGGCGGTATGCTTAACACATGCAAGTCGAACGGTAGCAGGCCTTCGGGCGCTGACGAGT GGCGGACGGGTGAGTAACGCGTAGGAATCTGCCTTATAGTGGGGGACAACGTGGGGAAACCCACGCTAATACCGCATACGCCCTACGG GGGAAAGCGGGGGCTCTTCGGACCTCGCGCTATGAGATGAGCCTGCGTTAGATTAGCTAGTTGGTAAGGTAAAGGCCTACCAAGGCGA CGATCTATAGCTGGTCTGAGAGGACGATCAGCCACACTGGGACTGAGACACGGCCCAGACTCCTACGGGAGGCAGCAGTGGGGAATAT TGGACAATGGGCGCAAGCCTGATCCAGCAATACCGCGTGTGTGAAGAAGGCCCTAGGGTTGTAAAGCACTTTCAATTGGGAGGAAAAC CTGCCGGTCAATACCCGGTAGCTTGACATTACCTTTAGAAGAAGCACCGGCTAACTCCGTGCCAGCAGCCGCGGTAATACGGAGGGTG CAAGCGTTAATCGGAATTACTGGGCGTAAAGCGTGCGTAGGCGGTTCGTTAAGTCAGATGTGAAAGCCCCGGGCTTAACCTGGGAACT GCATTTGAAACTGGCGAACTAGAGTTGAGTAGAGGGGAGTGGAATTTCAGGTGTAGCGGTGAAATGCGTAGATATCTGAAGGAACACC AGTGGCGAAGGCGACTCCCTGGACTCAAACTGACGCTGAGGTACGAAAGCGTGGGTAGCAAACAGGATTAGATACCCTGGTAGTCCAC GCTGTAAACGATGTCAACTAGCCGTTGGTCCTATTTACAGGATTAGTGGCGCAGCTAACGCATTAAGTTGACCGCCTGGGGAGTACGG CCGCAAGGTTAAAACTCAAATGAATTGACGGGGGCCCGCACAAGCGGTGGAGCATGTGGTTTAATTCGATGCAACGCGAAGAACCTTA CCTACCCTTGACATCCAGAGAATCTGTTAGAGATAGTGGAGTGCCTTCGGGAGCTCTGAGACAGGTGCTGCATGGCTGTCGTCAGCTC GTGTCGTGAGATGTTGGGTTAAGTCCCGTAACGAGCGCAACCCTTATCCTTAGTTGCCAGCGGGTGATGCCGGGAACTCTAGGGAGAC TGCCGGTGATAAACCGGAGGAA

Sl1255

AGAGTTTGATCATGGCTCAGAACGAACGCTGGCGGCAGGCTTAACACATGCAAGTCGAACGCCCCGCAAGGGGAGTGGCAGACGGGTG AGTAACGCGTGGGAACGTACCTTTCAGTTCGGAATAACTCAGGGAAACTTGTGCTAATACCGGATACGCCCGTAAGGGGAAAGATTTA TCGCTGAAAGATCGGCCCGCGTTGGATTAGCTAGTTGGTGGGGTAAAGGCCTACCAAGGCGACGATCCATAGCTGGTCTGAGAGGATG ATCAGCCACACTGGGACTGAGACACGGCCCAGACTCCTACGGGAGGCAGCAGTGGGGAATATTGGACAATGGGCGAAAGCCTGATCCA GCCATGCCGCGTGTGTGATGAAGGCCTTAGGGTTGTAAAGCACTTTCACCGATGAAGATAATGACGGTAGTCGGAGAAGAAGCCCCGG CTAACTTCGTGCCAGCAGCCGCGGTAATACGAAGGGGGCTAGCGTTGTTCGGAATCACTGGGCGTAAAGCGCACGTAGGCGGATTGTT AAGTGAGGGGTGAAATCCCGGGGCTCAACCCCGGAACTGCCTTTCATACTGGCAGTCTTGAGTTCGAGAGAGGTAAGTGGAATTCCGA GTGTAGAGGTGAAATTCGTAGATATTCGGAGGAACACCAGTGGCGAAGGCGGCTTACTGGATCGATACTGACGCTGAGGTGCGAAAGC GTGGGGAGCAAACAGGATTAGATACCCTGGTAGTCCACGCCGTAAACTATGAGAGCTAGCCGTCGGCAAGTACACTTGTCGGTGGCGC AGCTAACGCATTAAGCTCTCCGCCTGGGGAGTACGGTCGCAAGATTAAAACTCAAAGGAATTGACGGGGGCCCGCACAAGCGGTGGAG CATGTGGTTTAATTCGAAGCAACGCGCAGAACCTTACCAGCCCTTGACATCCCGGTCGCGGTTTCCAGAGATGGATTCCTTCAGTTCG GCTGGACCGGTGACAGGTGCTGCATGGCTGTCGTCAGCTCGTGTCGTGAGATGTTGGGTTAGGTCCCGCAACGAGCGCAACCCTC Sl1263

CGGCCGCAAGGTTGAAACTCAAAGGAATTGACGGGGACCCGCACAAGCAGTGGAGTATGTGGTTTAATTCGACGCAACGCGAAGAACC TTACCTAGGCTTGACATCCACGGAACCCTTTGGAAACATCGGGGTGCCCTTCGGGGAGCCGTGAGACAGGTGCTGCATGGCTGTCGTC AGCTTGTGTCGTGAGATGTTGGGTTAAGTCCCGCAACGAGCGCAACCCCTACCCTTAGTTGCCAGCATTGAGTTGGGCACTCTATGGG GACTGCCGCAGACAATGTGGAGGAAGGTGGGGATGACGTCAAGTCCTCATGGCCTTTATGCCTAGGGCTACACACGTACTACAATGGC CGTTACAGAGGGCAGCAAGCTCGCGAGGGTAAGCAAATCCCAGAAAGACGGCCTCAGTTCGGATTGGAGTCTGCAACTCGACTCCATG AAGTCGGAATTGCTAGTAATCGCTGATCAGCAGGCAGCGGTGAATACGTTCCCGGGCCTTGTACACACCGCCCGTCACACCACGAAAG TCTGTTATACCCGAAGTCGGTGGGCTAACCGCAAGGGGGCAGCTGCCTAAGGTATGGCCGATGATTGGGGTGAAGTCGTAACAAGGT Sl1269

CGTAAACGATGGATACTCGACATTTGCGATATACTGTAAGTGTCTGAGCGAAAGCATTAAGTATCCCACCTGGGAAGTACGACCGCAA GGTTGAAACTCAAAGGAATTGACGGGGGTCCGCACAAGCGGTGGAGCATGTGGTTTAATTCGATGATACGCGAGGAACCTTACCTGGG CTAGAATGCTGGGGGAATATGGGTGAAAGCTCATAGGGTAGCAATACCCCGCCAGTAAGGTGCTGCATGGCTGTCGTCAGCTCGTGCC GTGAGGTGTTGGGTTAAGTCCCGCAACGAGCGCAACCCCTATCACTAGTTGCCATCAGGTAATGCTGGGAACTCTAGTGAAACTGCCG TCGTAAGACGCGAGGAAGGAGGGGATGATGTCAAGTCATCATGGCCTTTATGCCCAGGGCTACACACGTGCTACAATGGTGAATACAA AGGGCAGCTACCTGGTAACAGGATGCTAATCTCAAAAAATTCATCTCAGTTCGAATTGGGGTCTGCGACTCGACCTCATGAAGCTGGA ATCGCTAGTAATCGTATATCAGCAATGATACGGTGAATACGTTCCCGGACCTTGTACACACCGCCCGTCAAGCCATGGAAGCCGGGGG GACCTGAAGTCGGTAACCGCAAGGAGCCGCCTAGGGTAAGACCGGTAACTGGGGCTAAGTCGTAACAAGGTA Sls1271

AGAGTTTGATCATGGCTCAGAATGAACGCTGGCGGCGTGCTTAACACATGCAAGTCGAACGAGAAACCCCGGCTTGCCGGGGGAGTAA AGTGGCGCACGGGTGAGTAACGCGTGGGTAATCTACCCTCGAATTGGGGATAACCCGCCGAAAGGCGGGCTAATACCGAATAAGACCA CGGTGGTTTCGGCCACTGAGGTCAAAGATGGCCTCTGCTTGCAAGCTGTCGTTTGAGGATGAGCCCGCGTCCCATTAGCTAGTTGGTG GGGTAAAAGCCTACCAAGGCGACGATGGGTAGCTGGTCTGAGAGGATGGCCAGCCACACTGGAACTGACACACGGTCCAGACTCCTAC GGGAGGCAGCAGTGAGGAATTTTGCGCAATGGGGGAAACCCTGACGCAGCAACGCCGCGTGAGTGATGAAGGCCTTCGGGTTGTAAAG CTCTGTCGAGTGGGAAGAATTTTTTTCGGCTGAATAATCCGAAAAATTGACGGTACCGCTGAAGGAAGCACCGGCTAACTCCGTGCCA GCAGCCACGGTAATACGGAGGGTGCAAGCGTTATTCGGATTTATTGGGCGTAAAGGGCGTGTAGGCGGTTTGAATAGTCAGGTGTGAA AGCCCTTGGCTT

sls1271

CGGGGGCCCGCACAAGCGGTGGAGCATGTGGTTTAATTCGACGCAACGCGAAGAACCTTACCTGGGCTTGACATCCCTTGACCGTCTA TGAAAGTAGGCTTTCCTTTCGGGGACAAGGAGACAGGTGCTGCATGGCTGTCGTCAGCTCGTGTCGTGAGATGTTGGGTTAAGTCCCG CAACGAGCGCAACCCTCGTCTTTAGTTGCCAGTATTAAGTTGGGCACTCTAAAGATACTGCCTCGGTTAACGGGGAGGAAGGTGGGGA TGACGTCAAGTCCTCATGGCCTTTATGCCCAGGGCTACACACGTGCTACAATGGGCGGTACAAACGGTTGCAATCCCGCGAGGGGGAG CTAATCCGAAAAAGCCGTCCTCAGTTCGGATCGGAGTCTGCAACTCGACTCCGTGAAGTTGGAATCGCTAGTAATCGTGGATCAGCAT 
GCCACGGTGAATACGTTCCCGGGCCTTGTACACACCGCCCGTCACACCACGAAAGTTGGTTGTACCAGAAGTGCGTGAGCTAATCCAC TTCGGTGGAAGGCAGCGCCCTAAGGTGTGGCTGATAATTGGGGTGAAGTCGTAACAAGGT

Sl1278

AGAGTTTGATCATGGCTCAGATTGAACGCTGGCGGCATGCTTTACACATGCAAGTCGAGCGGCAGCGCGGGGCAACCTGGCGGCGAGC GGCGAACGGGTGAGTAACATATCGGAACGTATCCTGTAATGGGGGATAACCACTCGAAAGAGTGGCTAATACCGCATACGATCGAGAG ATGAAAGTGGGGGACCGCAAGGCCTCACGTTATAGGAGCGGCCGATATCTGATTAGCTAGTTGGGGGGGTAAAGGCCCACCAAGGCGA TGATCAGTAGCTGGTCTGAGAGGACGACCAGCCACACTGGGACTGAGACACGGCCCAGACTCCTACGGGAGGCAGCAGTGGGGAATTT TGGACAATGGGGGCAACCCTGATCCAGCCATTCCGCGTGAGTGAAGAAGGCCTTCGGGTTGTAAAGCTCTTTCGTGAGGGAAGAAACG GTCCAAGCTAATACTTTGGACTAATGACGGTACCTCAAGAAGAAGCACCGGCTAACTACGTGCCAGCAGCCGCGGTAATACGTAGGGT GCGAGCGTTAATCGGAATTACTGGGCGTAAGGCGTGCGCAGGCGGTTTTGTACGTTCGATGTGAAAGCCCCGGGCTTAACCTGGGAAC TGCGTTGAAAACGGCAAGACTAGAGTGTGTCAGAGGGGGGTAGAATTCCACGTGTAGCAGTGAAATGCGCAGAGATGTGGAGGAATAC CGATGGCGAAGGCAGCCCCCTGGGATAACACTGACGCTCATGCACGAAAGCGTGGGGAGCAAACAGGATTAGATACCCTGGTAGTCCA CGCCCTAAACGATGTCAACTAGTTGTTGGGTGACTTGTTCACTTAGTAACGTAGCTAACGCGAGAAGTTGACCGCCTGGGGAGTACGG TCGCAAGATTAAAACTCAAAGGAATTGACGGGGGCCCGCACAAGCGGTGGATTATGTGGATTAATTCGATGCAACGCGAAAAACCTTA CCTACCCTTGACATGCCAGGAAGCTGACAGAGATGTCGGCGTGCCCGAAAGGGAATCTGGACACAGGTGCTGCATGGCTGTCGTCAGC TCGTGTCGTGAGATGTTGGGTTAAGTCCCGCAACGAGCGCAACCCTTGTCATTAATTGCCATCATTTAGTTGGGCACTTTAATGAGAC TGCCGGTGACAAACCGGAGGAAGGTGGGGATGACGTCAAGTCCTCATGGCCCTTATGGGTAGGGCCTCACACGTAATACAATGGTCGG TACAGAGGGTCGCCAACCCGCGAGGGGGAGCCAATCCCAGAAAGCCGATCGTAGTCCGGATTGGAGTCTGCAACTCGACTCCATGAAG TCGGAATCGCTAGTAATCGCGGATCAGCATGTCGCGGTGAATACGTTCCCGGGCCTTGTACACACCGCCCGTCACACCATGGGAGTGG GTTATACCAGAAGTAGGTAGCCTAACCGTAAGGAGGGCGCTTACCACGGTGTGATTCATGACTGGGGTGAAGTCGTAACAAGGTA Sl1283

AGAGTTTGATCATGGCTCAGAATGAACGCTGGCGGCGTGCATAACACATGCAAGTCGAACGAGAAAGGGGCTTCGGCCCCGAGTAAAG TGGCGCACGGGTGAGTAACGCGTGGGTAACCTACCCTGGAATCTGGGATAACACTGCGAAAGTGGTGCTAATACCGGGTACGATCCTC GAGCGGGAGTTTGGGGATGAGAGCCGGCCTCTTGTTAAAGCTGGTGTTCTGGGATGGGCTCGCGTCCTATCAGCTAGTTGGTGGGGTA ATGGCCTACCAAGGCGGCGACGGGTAGCTGGTCTGAGAGGATGATCAGCCACACTGGCACTGGAACACGGGCCAGACTCCTACGGGAG GCAGCAGTGAGGAATTTTGCGCAATGGGGGAAACCCTGACGCAGCAACGCCGCGTGGGTGA Sl1288

AGAGTTTGATCATGGCTCAGATTGAACGCTGGCGGCATGCCTTACACATGCAAGTCGAACGGTAACGCGGGGCAACCTGGCGACGAGT GGCGAACGGGTGAGTAATATATCGGAACGTGCCCAACAGTGGGGGATAGCCCGGCGAAAGCCGGATTAATACCGCATACGACCTCAGG GTGAAAGCGGGGGATCGCAAGACCTCGCGCCGTTGGAGCGGCCGATATCAGATTAGGTAGTTGGTGGGGTAAAAGCCCACCAAGCCGA CGATCTGTAGCTGGTCTGAGAGGACGACCAGCCACACTGGGACTGAGACACGGCCCAGACTCCTACGGGAGGCAGCAGTGGGGAATTT TGGACAATGGGCGCAAGCCTGATCCAGCCATGCCGCGTGCGGGAAGAAGGCCTTCGGGTTGTAAACCGCTTTTGTCAGGGAAGAAATC CTTTGAGCTAATACCTCGGAGGGATGACGGTACCTGAAGAATAAGCACCGGCTAACTACGTGCCAGCAGCCGCGGTAATACGTAGGGT GCGAGCGTTAATCGGAATTACTGGGCGTAAAGCGTGCGCAGGCGGTCTTGCAAGACAGGTGTGAAATCCCCGGGCTTAACCTGGGAAC TGCACTTGTGACTGCAAGGCTCGAGTACGGCAGAGGGGGATGGAATTCCGCGTGTAGCAGTGAAATGCGTAGATATGCGGAGGAACAC CGATGGCGAAGGCAATCCCCTGGGCCTGTACTGACGCTCATGCACGAAAGCGTGGGGAGCAAACAGGATTAGATACCCTGGTAGTCCA CGCCCTAAACGATGTCAACTGGTTGTTGGACGGCTTGCTGTTCAGTAACGAAGCTAACGCGTGAAGTTGACCGCCTGGGGAGTACGGC CGCAAGGTTGAAACTCAAAGGAATTGACGGGGACCCGCACAAGCGGTGGATGATGTGGTTTAATTCGATGCAACGCGAAAAACCTTAC CTACCCTTGACATGTCTGGAATCCCGCAGAGATGTGGGAGTGCTCGAAAGAGAGCCAGAACACAGGTGCTGCATGGCCGTCGTCAGCT CGTGTCGTGAGATGTTGGGTTAAGTCCCGCAACGAGCGCAACCCTTGTCATTAGTTGCTACGAAAGGGCACTCTAATGAGACTGCCGG TGACAAACCGGAGGAAGGTGGGGATGACGTCAGGTCCTCATGGCCCTTATGGGTAGGGCTACACACGTCATGCAATGGCCGGTACAGA GGGCTGCCAACCCGCGAGGGGGAGCCAATCCCAGAAAACCGGTCGTAGTCCGGATCGCAGTCTGCAACTCGACTGCGTGAAGTCGGAA TCGCTAGTAATCGCGGATCAGCTTGCCGCGGTGAATACGTTCCCGGGTCTTGTACACACCGCCCGTCACACCATGGGAGCGGGTTCTG CCAGAAGTAGTTAGCCTAACCGCAAGGAGGGCGATTACCACGGCAGGGTTCGTGACTGGGGTGAAGTCGTAACAAGGTAA Sl1289

AGAGTTTGATCATGGCTCAGATTGAACGCTGGCGGCATGCTTTACACATGCAAGTCGAACGGCAGCACGGGGCAACCTGGTGGCGAGT GGCGAACGGGTGAGTAATATATCGGAACATGTCCGGAAGTGGGGGATAACGTAGCGAAAGTTACGCTAATACCGCATATGCCCTGAGG GGGAAAGGAGGGGATCGTAAGACCTTTCGCTTTCGGAGTGGCCGATATCAGATTAGCTAGTTGGTGGGGTAAAGGCCTACCAAGGCAA CGATCTGTAGCTGGTCTGAGAGGACGACCAGCCACACTGGGACTGAGACACGGCCCAGACTCCTACGGGAGGCAGCAGTGGGGAATTT TGGACAATGGGGGCAACCCTGATCCAGCCATGCCGCGTGAGTGAAGAAGGCCTTCGGGTTGTAAAGCTCTTTCAGCCGGAAAGAAATC GTGCAACCTAATACGTTGTATGGATGACGGTACCGGAAGAAGAAGCACCGGCTAACTACGTGCCAGCAGCCGCGGTAATACGTAGGGT GCGAGCGTTAATCGGAATTACTGGGCGTAAAGCGTGCGCAGGCGGTTTTGTAAGACAGATGTGAAATCCCCGGGCTTAACCTGGGAAC TGCATTTGTGACTGCAAGGCTAGAGTACGGCAGAGGGGGGTAGAATTCCACGTGTAGCAGTGAAATGCGTAGATATGTGGAGGAATAC CGATGGCGAAGGCAGCCCCCTGGGTCGATACTGACGCTCATGCACGAAAGCGTGGGGAGCAAACAGGATTAGATACCCTGGTAGTCCA CGCCCTAAACGATGTCAACTAGGTGTTGGGGGAGGAGACTCTCTTAGTACCGCAGCTAACGCGTGAAGTTGACCGCCTGGGGAGTACG GCCGCAAGGTTGAAACTCAAAGGAATTGACGGGGACCCGCACAAGCGGTGGATTATGTGGATTAATTCGATGCAACGCGAAAAACCTT ACCTACCCTTGACATGGTCGGAATCCTGAAGAGATTTAGGAGTGCTCGAAAGAGAACCGATACACAGGTGCTGCATGGCTGTCGTCAG CTCGTGTCGTGAGATGTTGGGTTAAGTCCCGCAACGAGCGCAACCCTTGTCATTAATTGCCATCATTTAGTTGGGCACTTTAATGAGA CTGCCGGTGATAAACCGGAGGAAGGTGGGGATGACGTCAAGTCCTCATGGCCCTTATGGGTAGGGCTTCACACGTAATACAATGGTCG GTACAGAGGGTTGCCAACCCGCGAGGGGGAGCTAATCTCAGAAAGCCGATCGTAGTCCGGATTGTTCTCTGCAACTCGAGAGCATGAA GTCGGAATCGCTAGTAATCGCGGATCAGCATGTCGCGGTGAATACGTTCCCGGGCCTTGTACACACCGCCCGTCACACCATGGGAGTG GGTTGCAAAAGAAGTAGGTAGCTTAACCTTCGGGAGGGCGCTTACCACTTTGTGATTCATGACTGGGGTGAAGTCGTAACAAGGT S11293

CGGCCGCAAGGTTAAAACTCAAATGAATTGACGGGGGCCCGCACAAGCGGTGGAGCATGTGGTTTAATTCGATGCAACGCGAAGAACC TTACCAGGTCTTGACATCCTCGGAACTATCCAGAGATGGATGGGTGCCTTCGGGAACCGAGAGACAGGTGCTGCATGGCTGTCGTCAG CTCGTGTCGTGAGATGTTGGGTTAAGTCCCGTAACGAGCGCAACCCTTGTCCTTAGTTGCCAGCACGTAATGGTGGGAACTCTAAGGA GACTGCCGGTGACAAACCGGAGGAAGGTGGGGACGACGTCAAGTCATCATGGCCCTTACGACCTGGGCTACACACGTGCTACAATGGA ACGCACAGAGGGCAGCAAAAGCGCGAGCTGGAGCCAATCCCACAAAACGTTTCGTAGTCCGGATCGGAGTCTGCAACTCGACTCCGTG AAGTCGGAATCGCTAGTAATCGTGGATCAGAATGCCACGGTGAATACGTTCCCGGGCCTTGTACACACCGCCCGTCACACCATGGGAG TGGGTTGCTCCAGAAGTGGTTAGCCTAACCTTCGGGGGGGCGATCACCACGGAGTGGTTCATGACTGGGGTGAAGTCGTAACAAGGTA Sl1302

AGAGTTTGATCATGGCTCAGATTGAACGCTGGCGGAATGCTTTGCACATGCAAGTCGAGCGGCAGCGCGGGGCAACCTGGCGGCGAGC GGCGAACGGGTGAGTAACATATCGGAACGTATCCTGTAATGGGGGATAACCACTCGAAAGAGTGGCTAATACCGCATACGATCGAGAG ATGAAAGTGGGGGACCGCAAGGCCTCACGTTATAGGAGCGGCCGATATCTGATTAGCTAGTTGGGGGGGTAAAGGCCCACCAAGGCGA TGATCAGTAGCTGGTCTGGGAGGACGACCAGCCACACTGGGACTGAGACACGGCCCAGACTCCTACGGGAGGCAGCAGTGGGGAATTT TGGACAATGGGGGCAACCCTGATCCAGCCATTCCGCGTGAGTGAAGAAGGCCTTCGGGTTGTAAAGCTCTTTCGTGAGGGAAGAAACG GTCCAAGCTAATACTTTGGACTAATGACGGTACCTCAAGAAGAAGCACCGGCTAACTACGTGCCAGCAGCCGCGGTAATACGTAGGGT 
GCGAGCGTTAATCGGAATTACTGGGCGTAAAGCGTGCGCAGGCGGTTTTGTACGTTCGATGTGAAAGCCCCGGGCTTAACCTGGGAAC TGCGTTGAAAACGGCAAGACTAGAGTGTGTCAGAGGGGGGTAGAATTCCACGTGTAGCAGTGAAATGCGTAGAGATGTGGAGGAATAC CGATGGCGAAGGCAGCCCCCTGGGATAACACTGACGCTCATGCACGAAAGCGTGGGGAGCAAACAGGATTAGATACCCTGGTAGTCCA CGCCCTAAACGATGTCAACTAGTTGTTGGGTGACTTGTTCACTTAGTAACGTAGCTAACGCGAGAAGTTGACCGCCTGGGGAGTACGG TCGCAAGATTAAAACTCAAAGGAATTGACGGGGGCCCGCACAAGCGGTGGATTATGTGGATTAATTCGATGCAACGCGAAAAACCTTA CCTACCCTTGACATGCCAGGAAGCTGACAGAGATGTCGGCGTGCCCGAAAGGGAATCTGGACACAGGTGCTGCATGGCTGTCGTCAGC TCGTGTCGTGAGATGTTGGGTTAAGTCCCGCAACGAGCGCAACCCTTGCCATTAATTGCCATCATTTAGTTGGGCACTTTAATGGGAC TGCCGGTGACAAACCGGAGGAAGGTGGGGATGACGTCAAGTCCTCATGGCCCTTATGGCCAGGGCTTCACACGTAATACAATGGTCGG TACAGAGGGTTGCCAACCCGCGAGGGGGAGCCAATCCCAGAAAGCCGATCGTAGTCCGGATTGTAGTCTGCAACTCGACTACATGAAG TCGGAATCGCTAGTAATCGCGGATCAGCATGTCGCGGTGAATACGTTCCCGGGCCTTGTACACACCGCCCGTCACACCATGGGAGTGG GTTTTACCAGAAGTAGGTAGTCTAACCGCAAGGAGGACGCTTACCACGGTAGTATTCATGACTGGGGTGAAGTCGTAACAAGGTA Sl1305

AAAGTTTGATCATGGCTCAGGATGAACGCTAGCGGCAGGCTTAACACATGCAAGTCGAGGGGTATAGTAGCAATACTAGAGACCGGCG CACGGGTGCGTAACGCGTATGCAATCTACCTTTCACAGAGGGATAGCCCAGAGAAATTTGGATTAATACCTCATAGTATTATAGTATG GCATCATATTATAATTAAAGTCACAACGGTGAAAGATGAGCATGCGTCCCATTAGCTAGTTGGTATGGTAACGGCATACCAAGGCAAC GATGGGTAGGGGTCCTGAGAGGGAGATCCCCCACACTGGTACTGAGACACGGACCAGACTCCTACGGGAGGCAGCAGTGAGGAATATT GGACAATGGGCGCAAGCCTGATCCAGCCATGCCGCGTGCAGGATGACGGTCCTATGGATTGTAAACTGCTTTTGTACAGGAAGAAACA CTCCGACGTGTCGGAGCTTGACGGTACTGTAAGAATAAGGATCGGCTAACTCCGTGCCAGCAGCCGCGGTAATACGGAGGATCCAAGC GTTATCCGGAATCATTGGGTTTAAAGGGTCCGTAGGCGGGCTAATAAGTCAGTGGTGAAATCTCCCGGCTCAACCGGGAAATGGCCAT TGATACTGTTAGTCTTGAATTATTAGGAAGTAACTAGAATATGTAGTGTAGCGGTGAAATGCTTAGAGATTACATGGAATACCAATTG CGAAGGCAGGTTACTACTAATGGATTGACGCTGATGGACGAAAGCGTGGGTAGCGAACAGGATTAGATACTCTGGTAGTCCACGCCGT AAACGATGGATACTAGCTGTTGGGTGCAAACTCAGTGGCTAAGCGAAAGTGATAAGTATCCCACCTGGGGAGTACGTTCGCAAGAATG AAACTCAAAGGAATTGACGGGGGCCCGCACAAGCGGTGGAGCATGTGGTTTAATTCGATGATACGCGAGGAACCTTACCAAGGCTTAA ATGTAGATTGACCGGTTTGGAAACAGACTTTTCGCAAGACAATTTACAAGGTGCTGCATGGTTGTCGTCAGCTCGTGCCGTGAGGTGT CAGGTTAAGTCCTATAACGAGCGCAACCCCTGTTGTTAGTTGCCAGCGAGTCATGTCGGGAACTCTAACGAGACTGCCAGTGCAAACT GTGAGGAAGGTGGGGATGACGTCAAATCATCACGGCCCTTACGCCTTGGGCTACACACGTGCTACAATGGCCGGTACAGAGAGCAGCC ACTGGGCGACCAGGAGCGAATCTATAAAACCGGTCACAGTTCGGATCGGAGTCTGCAACTCGACTCCGTGAAGCTGGAATCGCTAGTA ATCGGATATCAGCCATGATCCGGTGAATACGTTCCCGGGCCTTGTACACACCGCCCGTCAAGCCATGGAAGCTGGGGGTGCCTGAAGT CGGTGACCGCAAGGAGCTGCCTAGGGTAAAACTGGTAACTGGGGCTAAGTCGTAACAAGGTA Sl1307

AGAGTTTGATCATGGCTCAGGATGAACGCTAGCGGCAGGCTTAATACATGCAAGTCGAGGGGCAGCGCAGTGTAGCAATACATGGGCG GCGACCGGCAAACGGGTGCGGAACACGTACGCAATCTACCCAAAACTGATGAATAGCCCTCCGAAAGGAGGATTAATACATCGTAACC TAATGAAGTGGCATCGCTTTATTAGTATAGCTCCGGCGGTTTTGGATGAGCGTGCGCCTGATTAGGTAGTTGGCGGGGTAACGGCCCA CCAAGCCTGCGATCAGTAACTGGTGTGAGAGCACGACCAGTCACACGGGCACTGAGACACGGGCCCGACTCCTACGGGAGGCAGCAGT AAGGAATATTGGTCAATGGACGCAAGTCTGAACCAGCCATGCCGCGTGAAGGATGAAGGTCCTCTGGATTGTAAACTTCTTTTATATG GGACGAAACCTCTTTTTCTAAGGAGACTGACGGTACCATAGGAATAAGCACCGGCTAACTCCGTGCCAGCAGCCGCGGTAATACGGAG GGTGCAAGCGTTATCCGGATTCACTGGGTTTAAAGGGTGCGTAGGAGGGCAGGTAAGTCAGTGGTGAAATCTTCGAGCTTAACTCGGA AACTGCCGTTGATACTATCTGTCTTGAATACCGTGGAGATGAGCGGAATATGTCATGTAGCGGTGAAATGCTTAGATATGACATAGAA CACCAATTGCGAAGGCAGCTCGTTACACGAATATTGACTCTGAGGCACGAAAGCGTGGGGATCAAACAGGATTAGATACCCTGGTAGT CCACGCCCTAAACGATGGATACTCGACATACGCGATACACTGTGTGTCTGAGCGAAAGCATTAAGTATCCCACCTGGGAAGTACGACC GCAAGGTTGAAACTCAAAGGAATTGGCGGGGGTCCGCACAAGCGGTGGAGCATGTGGTTTAATTCGATGATACGCGAGGAACCTTACC TGGGCTAGAATGCAGTCTGACCGTGGGTGAAAGCTCATTTTGTAGCAATACACAGATTGTAAGGTGCTGCATGGCTGTCGTCAGCTCG TGCCGTGAGGTGTTGGGTTAAGTCCCGCAACGAGCGCAACCCCCATCAGTAGTTGCCATCAGGTAACGCTGGGAACTCTACTGAAACT GCCGTCGTAAGACGCGAGGAAGGAGGGGATGATGTCAAGTCATCATGGCCTTTATGCCCAGGGCTACACACGTGCTACAATGGGGCGT ACAAAGGGCTGCCACTTAGCGATAAGGAGCCAATCCCAAAAAACGCCTCTCAGTTCAGATTGGAGTCTGCAACTCGACTCCATGAAGC TGGAATCGCTAGTAATCGTATATCAGCAATGATACGGTGAATACGTTCCCGGACCTTGCACACACCGCCCGTCAAGCCATGGAAGCTG GGTGTACCTAAAGTCGGTAACCGCAAGGAGCCGCCTAGGGTAAAACTAGTAACTGGGGCTAAGTCGTAACAAGGTA

Sl1309

AGAGTTTGATCATGGCTCAGGATGAACGCTAGCGGCAGGCTTAATACATGCAAGTCGAGGGGGATTAGTTGTCTAGCAATAGATGATT ATGAGACCGGCAAACGGGTGCGGAACACGTACGCAACCTTCCCAAAACTGGTGAATAGCCCTCCGAAAGGAGGATTAATGCACCGTAA CATATAGAGATGGCATCATTTTTATATTATAGCTCCGGCGGTTTTGGATGGGCGTGCGCCTGATTAGGTAGTTGGTGAGGGTAACGGC CCACCAAGCCTTCGATCAGTAACTGGTGTGAGAGCACGACCAGTCACACGGGCACTGAGACACGGGCCCGACTCCTACGGGAGGCAGC AGTAAGGAATATTGGTCAATGGACGCAAGTCTGAACCAGCCATGCCGCGTGAAGGATGACGGCCCTCTGGGTTGTAAACTTCTTTTAT CTGGGACGAAAAAAGGGCTTTCTAGCTCGACTGACGGTACCAGAGGAATAAGCACCGGCTAACTCCGTGCCAGCAGCCGCGGTAATAC GGAGGGTGCAAGCGTTATCCGGATTTACTGGGTTTAAAGGGTGCGTAGGTGGGTCTGTAAGTCAGTGGTGAAATCTCCGAGCTTAACT CGGAAACTGCCATTGATACTATAGGTCTTGAATTATCTGGAGGTAAGCGGAATATGTCATGTAGCGGTGAAATGCTTAGATATGACAT AGAACACCAATTGCGAAGGCAGCTTACTACGGATTGATTGACACTGAGGCACGAAAGCGTGGGGATCAAACAGGATTAGATACCCTGG TAGTCCACGCCCTAAACGATGGATACTCGACATACGCGATATACTGTGTGTGTCTGAGCGAAAGCATTAAGTATCCCACCTGGGAAGT ACGATCGCAAGATTGAAACTCAAAGGAATTGACGGGGGTCCGCACAAGCGGTGGAGCATGTGGTTTAATTCGATGATACGCGAGGAAC CTTACCTGGGTTAGAATGCGGTTTGACCGTAGGTGAAAGCTTATTTTGTAGCAATACACAGATCGTAAGGTGCTGCATGGCTGTCGTC AGCTCGTGCCGTGAGGTGTTGGGTTAAGTCCCGCAACGAGCGCAACCCCTATCACTAGTTGCCATCAGGTAATGCTGGGAACTCTAGT GAAACTGCCGTCGTAAGGCGTGAGGAAGGAGGGGATGATGTCAAGTCATCATGGCCTTTATGCCCAGGGCTACACACGTGCTACAATG GCGAGTACAAAGGGCAGCTACCTGGTGACAGGATGCTAATCTCAAAAAACTCGTCTCAGTTCGAATTGGAGTCTGCAACTCGACTCCA TGAAGCTGGAATCGCTAGTAATCGTATATCAGCAATGATACGGTGAATACGTTCCCGGACCTTGTACACACCGCCCGTCAAGCCATGG AAGCTGGGTGTACCTAAAGTCGGTAACCGCAAGGAGCCGCCTAGGGTAAAACTAGTAACTGGGGTTAAGTCGTAACAAGGTA Sl1310

AGAGTTTGATCATGGCTCAGAACGAACGCTGGCGGCGTGCTTAACACATGCAAGTCGAACGCGAAAGGGACTTCGGTCCCGAGTAGAG TGGCGCACGGGTGAGTAACGCGTAAGTAATCTACCCCTGTATTTGGAATAACCCACCGAAAGGTGAGCTAATACCGGATACGTTCAGA CTGGTGCGAATCAGTGTGAAGAAAGATGGCCTCTTCTTGAAAGCTATTGTACAGGGACGAGCTTGCGTACCATTAGCTAGTTGGTAGG GTAATGGCCTACCAAGGCAACGATGGTTAGCGGGTCTGAGAGGATGATCCGCCACACTGGAACTGGAACACGGACCAGACTCCTACGG GAGGCAGCAGTGAGGAATATTGCGCAATGGGGGCAACCCTGACGCAGCGACGCCGCGTGGATGATGAAGGCCCTTGGGTCGTAAAATC CTGTCAGGTGGAAAGAACGGTATATATGCTAATATCGTATATATTTGACGGTACCACCAAAGGAAGCACCGGCTAACTCCGTGCCAGC AGCCGCGGTAATACGGAGGGTGCAAGCGTTGTTCGGAATTACTGGGCGTAAAGCGCGCGTAGGCGGTGTGTCAAGTCAGATGTGAAAG CCCTCGGCTCAACCGGGGACGTGCATTTGAAACTGGCAGACTTGAGTATTGGAGGGGGTGGTGGAATTCCCGGTGTAGAGGTGAAATT CGTAGATATCGGGAGGAATACCGGTGGCGAAGGCGACCACCTGGCCAAATACTGACGCTGAGGTGCGAAAGCGTGGGGAGCAAACAGG ATTAGATACCCTGGTAGTCCACGCCGTAAACGATGTCAACTAGGTGTTGGGATGGTTAATCGTCTCATTGCCGCAGCTAACGCATTAA GTTGACCGCCTGGGGAGTACGGTCGCAAGATTAAAACTCAAAGGAATTGACGGGGGCCCGCACAAGCGGTGGAGTATGTGGTTTAATT 
CGACGCAACGCGCAGAACCTTACCTGGTCTTGACATCCCGGGAATTTCCTGGAAACAGGAGAGTGCCTCGCAAGAGGAACCTGGTGAC AGGTGCTGCATGGCTGTCGTCAGCTCGTGTCGTGAGATGTTGGGTTAAGTCCCGCAACGAGCGCAACCCTTATCTTTAGTTGCCATCA TTGAGTTGGGCACTCTAAAGAGACTGCCGGTGTCAAACCGGAGGAAGGTGGGGATGACGTCAAGTCCTCATGGCCTTTATGACCAGGG CTACACACGTACTACAATGGCCGGTACAAAGGGCAGCGACACAGCGATGTGAAGCCAATCCCATAAAGCCGGTCTCAGTCCGGATTGG AGTCTGCAACTCGACTCCATGAAGTTGGAATCGCTAGTAATCGTGGATCAGCACGCCACGGTGAATACGTTCCCGGGCCTTGTACACA CCGCCCGTCACACCACGGGAGTTGGTTGTACCAGAAGCAGTTGAGCTAACCGCAAGGAGGCAGGCTGCCAAGGTATGGCTAGTAACTG GGGTGAAGTCGTAACAAGGTA

Sl1312

AGAGTTTGATCATGGCTCAGAGCGAACGCTGGCGGCAGGCCTAACACATGCAAGTCGAGCGGCCGTAGCAATACGGCAGCGGCAGACG GGAGAGTAACACGTGGGAACGTACCTTTCAGTTCGGAACAACCCAGGGAAACTTGGGCTAATACCGGATACGCCCTTACGGGGAAAGA TTTATCGCTGAAAGATCGGCCCGCGTCTGATTAGCTAGTTGGTGGGGTAATGGCCCACCAAGGCGACGATCAGTAGCTGGTCTGAGAG GATGATCAGCCTCACTGGGACTGAGACACGGCCCAGACTCCTACGGGAGGCAGCAGTGGGGAATATTGGACAATGGGCGCAAGCCTGA TCCAGCCATGCCGCGTGGGTGATGAAGGCCCTAGGGTTGTAAAGCCCTTTCGGCGGGGAAGATAATGACGGTACCCGCAGAAGAAGCC CCGGCTAACTTCGTGCCAGCAGCCGCGGTAATACGAAGGGGGCTAGCGTTGCTCGGAATCACTGGGCGTAAAGCGCACGTAGGCGGCT TGTTAAGTCAGGGGTGAAATCCTGGAGCTCAACTCCAGAACTGCCCTTGATACTGGCGAGCTCGAGTTCGGGAGAGGTGAGTGGAACT GCGAGTGTAGAGGTGAAATTCGTAGATATTCGCAAGAACACCAGTGGCGAAGGCGGCTCACTGGCCCGATACTGACGCTGAGGTGCGA AAGCGTGGGGAGCAAACAGGATTAGATACCCTGGTAGTCCACGCCGTAAACGATGGATGCTAGCCGTTGGCGGGTTTACTCGTCAGTG GCGCAGCTAACGCTTTAAGCATCCCGCCTGGGGAGTACG

Sl1313

AGAGTTTGATCATGGCTCAGATTGAACGCTGGCGGAATGCTTTACACATGCAAGTCGAGCGGCAGCGCGGGGCAACCTGGCGGCGAGC GGCGAACGGGTGAGTAACATATCGGAACGTATCCTGTAATGGGGGATAACCACTCGAAAGAGTGGCTAATACCGCATACGATCGAGAG ATGAAAGTGGGGGACCGCAAGGCCTCACGTTATAGGAGCGGCCGATATCTGATTAGCTAGTTGGGGGGGTAAAGGCCCACCAAGGCGA TGATCAGTAGCTGGTCTGAGAGGACGACCAGCCACACTGGGACTGAGACACGGCCCAGACTCCTACGGGAGGCAGCAGTGGGGAATTT TGGACAATGGGGGAAACCCTGATCCAGCCATTCCGCGTGAGTGAAGAAGGCCTTCGGGTTGTAAAGCTCTTTCGGCAGGGAAGAAACG GTTCAAGCTAATACTTTGAACTAATGACGGTACCTGAAGAAGAAGCACCGGCTAACTACGTGCCAGCAGCCGCGGTAATACGTAGGGT GCGAGCGTTAATCGGAATTACTGGGCGTAAAGCGTGCGCAGGCGGTTTTGTACGTTCGATGTGAAAGCCCCGGGCTTAACCTGGGAAC TGCATTCGATACTGCCGAGCTAGAGTGTGTCAGAGGGGGGTAGAATTCCACGTGTAGCAGTGAAATGCGTAGAGATGTGGAGGAATAC CGATGGCGAAGGCAGCCCCCTGGGATAACACTGACGCTCATGCACGAAAGCGTGGGGAGCAAACAGGATTAGATACCCTGGTAGTCCA CGCCCTAAACGATGTCAACTAGTTGTTGGGTGACTTGTTCACTTAGTAACGTAGCTAACGCGAGAAGTTGACCGCCTGGGGAGTACGG TCGCAAGATTAAAACTCAAAGGAATTGACGGGGGCCCGCACAAGCGGTGGATTATGTGGATTAATTCGATGCAACGCGAAAAACCTTA CCTACCCTTGACATGCCAGGAAGCTGACAGAGATGTCGGCGTGCCCGAAAGGGAATCTGGACACAGGTGCTGCATGGCTGTCGTCAGC TCGTGTCGTGAGATGTTGGGTTAAGTCCCGCAACGAGCGCAACCCTTGTCATTAATTGCCATCATTTAGTTGGGCACTTTAATGAGAC TGCCGGTGACAAACCGGAGGAAGGTGGGGATGACGTCAAGTCCTCATGGCCCTTATGGGTAGGGCCTCACACGTAATACAATGGTCGG TACAGAGGGTCGCCAACCCGCGAGGGGGAGCCAATCCCAGAAAGCCGATCGTAGTCCGGATTGGAGTCTGCAACTCGACTCCATGAAG TCGGAATCGCTAGTAATCGCGGATCAGCATGTCGCGGTGAATACGTTCCCGGGCCTTGTACACACCGCCCGTCACACCATGGGAGTGG GTTATACCAGAAGTAGGTAGCCTAACCGTAAGGAGGGCGCTTACCACGGTGTGATTCATGACTGGGGTGAAGTCGTAACAAGGTA Sl1316

AGAGTTTGATCATGGCTCAGAGTGAACGCTGGCGGCAGGCCTAACACATGCAAGTCGAACGGCAGCACAGAGGAGCTTGCTCCTTGGG TGGCGAGTGGCGGACGGGTGAGGAAAACGTCGGAATCTGCCTATTTGTGGGGGATAACGTAGGGAAACTTACGCTAATACCGCATACG ACCTACGGGTGAAAGCGGAGGACCTTCGGGCTTCGCGCAGATAGATGAGCCAACGTCGGATTAGCTAGTTGGCGGGGTAAAGGCCCAC CAAGGCGACGATCCGTAGCTGGTCTGAGAGGATGATCAGCCACACTGGAACTGAGACACGGTCCAGACTCCTACGGGAGGCAGCAGTG GGGAATATTGGACAATGGGCGCAAGCCTGATCCAGCCATGCCGCGTGTGTGAAGAAGGCCTTCGGGTTGTAAAGCACTTTTGTCCGGA AAGAAAAGCACTGGGTTAATACCCTGGTGTCATGACGGTACCGGAAGAATAAGCACCGGCTAACTTCGTGCCAGCAGCCGCGGTAATA CGAAGGGTGCAAGCGTTACTCGGAATTACTGGGCGTAAAGCGTGCGTAGGCGGTTTGTTAAGTCTGATGTGAAAGCCCTGGGCTCAAC CTGGGAATGGCATTGGATACTGGCAACCTAGAATGTGGTAGAGGGTGGCGGAATTCCCGGTGTAGCAGTGAAATGCGTAGATATCGGG AGGAACATCCGTGGCGAAAGCGGCCACCTGGACCAACATTGACGCTGAGGCACGAAAGCGTGGGGAGCAAACAGGATTAGATACCCTG GTAGTCCACGCCCTAAACGATGCGAACTGGATGTTGGGCTCAATTGAGAGCTCAGTATCGAAGCTAACGCGTTAAGTTCGCCGCCTGG GAAGTACGGTCGCAAGACTGAAACTCAAAGGAATTGACGGGGGCCCGCACAAGCGGTGGAGTATGTGGTTTAATTCGATGCAACGCGA AGAACCTTACCTGGCCTTGACATGTCCGGAACCCTTGAGAGATCGAGGGGTGCCTTCGGGAACCGGAACACAGGTGCTGCATGGCTGT CGTCAGCTCGTGTCGTGAGATGTTGGGTTAAGTCCCGCAGCGAGCGCAACCCTTGTCCTTAGTTGCCAGCACGTAATGGTGGGAACTC TAAGGAGACTGCCGGTGACAAACCGGAGGAAGGTGGGGATGACGTCAAGTCATCATGGCCCTTACGGCCAGGGCTACACACGTACTAC AATGGTAGGGACAGAGGGCTGCAAACCCGCGAGGGCAAGCCAATCCCAGAAACCCTATCTCAGTCCGGATCGGAGTCTGCAACTCGAC TCCGTGAAGTCGGAATCGCTAGTAATCGCAGATCAGCATTGCTGCGGTGAATACGTTCCCGGGCCTTGTACACACCGCCCGTCACACC ATGGGAGTGGGTTTTACCAGAAGTAGGTAGTCTAACCGCAAGGGGGGCGCTTACCACGGTAGTATTCATGACTGGGGTGAAGTCGTAA CAAGGTA

Sl1317

TTAATTCGAAGCAACGCGCAGAACCTTACCAGCGTTTGACATCCTTGTCGCGGATTTCAGAGATGATTTCCTTCAGTTCGGCTGGACA AGTGACA*GGTGCTGCATGGCTGTCGTCAGCTCGTGTCGTGAGATGTTGGGTTAAGTCCCGCAACGAGCGCAACCCTCATCTTTAGTT GCCATCATTCAGTTGGGCACTCTAAAGAAACTGCCGGTGATAAGCCGGAGGAAGGTGGGGATGACGTCAAGTCCTCATGGCCCTTACA CGCTGGGCTACACACGTGCTACAATGGCGGTGACAGTGGGCAGCAACCGGGCGACCGGTAGCTAATCTCCAAAAGCCGTCTCAGTTCG GATTGTTCTCTGCAACTCGAGAGCATGAAGGCGGAATCGCTAGTAATCGCGGATCAGCATGCCGCGGTGAATACGTTCCCAGGCCTTG TACACACCGCCCGTCACACCATGGGATTTGGATTCACCCGAAGGCGTTGCGCTAACCTAGCAATAGGAGGCAGGCGACCACGGTGGGT TTAGAGACTGGGGTGAAGTCGTAACAAGGTA

Sl1319

AGAGTTTGATCATGGCTCAGGATGAACGCTAGCGGCAGGCTTAACACATGCAAGTCGAGGGGTATAGTAGCAATACTAGAGACCGGCG CACGGGTGCGTAACGCGTATGCAACCTACCTTTTACAGGGGAATAGCCCAGAGAAATTTGGATTAATGCCCCATGGTATAATTGAGTC GCATGGTTTAATTATTAAAGTTCCAACGGTAAAAGATGGGCATGCGTCCTATTAGCTAGATGGTAAGGTAACGGCTTACCATGGCTAC GATAGGTAGGGGTCCTGAGAGGGAGATCCCCCACACTGGTACTGAGACACGGACCAGACTCCTACGGGAGGCAGCAGTGAGGAATATT GGACAATGGGCGCAAGCCTGATCCAGCCATGCCGCGTGCAGGAAGACGCATCTATGGTGTGTAAACTGCTTTTGTACGGGAAGAAACA CTCCTTCGTGAAGGAGCTTGACGGTACCGTAAGAATAAGGATCGGCTAACTCCGTGCCAGCAGCCGCGGTAATACGGAGGGTGCAAGC GTTATCCGGAATCATTGGGTTTAAAGGGTCCGCANGCGGATTTATAAGTCAGTGGTGAAAGCCTACAGCTTAACTGTAGAACTGCCAT TGATACTGTAAGTCTTGAATTCGGTCGAAGTGGGCGGAATATGTCATGTAGCGGTGAAATGCTTAGATATGACATAGAACACCGATNG CGAAGGCAGCTCACTAGGCCTGGATTGACGCTCAGGGACGAAAGCGTGGGGAGCGAACAGGATTAGATACCCTGGTAGTCCACGCCGT AAACTATCAATACTCGTTTTCGGCGATATAATGTCGGAGACTAAGCGAAAGTGATAAGTATTGCACCTGGGGAGTACGATCGCAAGGT TGAAACTCAAAGGAATTGACGGGGGCCCGCACAAGCGGTGGAGCATGTGGTTTAATTCGATGATACGCGAGGAACCTTACCAGGGCTT AAATGTAGAGGGAATATATTGGAAACAGTATAGCCTTCGGGCCGTCTACAAGGTGCTGCATGGCTGTCGTCAGCTCGTGCCGTGAGGT 
GTTGGGTTAAGTCCCGCAACGAGCGCAACCCCTATCTTTAGTTGCCAGCGAGTCATGTCGGGGACTCTAAAGAAACTGCCTACGCAAG TAGTGAGGAAGGCGGGGACGACGTCAAGTCATCACGGCCCTTACGTCCTGGGCCACACACGTGCTACAATGGTAGATACAGAGGGCAG CTACCCCGCGAGGGGATGCGAATCTCGAAAGTCTATCTCAGTTCGGATCGGAGTCTGCAACTCGACTCCGTGAAGCTGGAATCGCTAG TAATCGGATATCAGCCATGATCCGGTGAATACGTTCCCGGGCCTTGTACACACCGCCCGTCAAGCCATGGAAGCTGGGGGTACCTGAA GTCGGTGACCGTAAGGAGCTGCCTAGGGTAAAACTGGTAACTGGGGCTAAGTCGTAACAAGGT Sl1320

AGAGTTTGATCATGGCTCAGGATGAACGCTAGCGGCAGGCCTAACACATGCAAGTCGAGGGGTAGAGGAAGCTTGCTTCCTTGAGACC GGCGCACGGGTGCGTAACGCGTATGCAATCTACCTTATACAGAGGGATAGCCCAGAGAAATTTGGATTAATACCTCATAGTATTATGA AATCGCATGGTTTTATAATTAAAGTTCCAACGGTATAAGATGAGCATGCGTCCCATTAGTTAGTTGGTAAGGTAACGGCTTACCAAGA CAATGATGGGTAGGGGTCCTGAGAGGGAGATCCCCCACACTGGTACTGAGACACGGACCAGACTCCTACGGGAGGCAGCAGTGAGGAA TATTGGTCAATGGACGCAAGTCTGAACCAGCCATGCCGCGTGCAGGATGACGGTCCTATGGATTGTAAACTGCTTTTATACAGGAAGA AACACTCCCTCGTGAGGGAGCTTGACGGTACTGTAGGAATAAGGATCGGCTAACTCCGTGCCAGCAGCCGCGGTAATACGGAGGATCC AAGCGTTATCCGGAATCATTGGGTTTAAAGGGTCCGTAGGCGGTTTAATAAGTCAGTGGTGAAAGCCTATCGCTTAACGATAGAACGG CCATTGATACTGTTAGACTTGAATTAGTGGGAAGTAACTAGAATATGTAGTGTAGCGGTGAAATGCTTAGATATTACATGGAATACCA ATTGCGAAGGCAGGTTACTATCACTATATTGACGCTGATGGACGAAAGCGTGGGGAGCGAACAGGATTAGATACCCTGGTAGTCCACG CCGTAAACGATGGATACTAGCTGTTCGGAGCAATCTGAGTGGCTAAGCGAAAGTGATAGGTATCCCACCTGGGGAGTACGTTCGCAAG AATGAAACTCAAAGGAATTGACGGGGGCCCGCACAAGCGGAGGAGCATGTGGTTTAATTCGATGATACGCGAGGAACCTTACCAGGGC TTAAATGGGAGACGACAGGACTGGAAACGGTTTTTTCTTCGGACGTCTTTCAAGGTGCTGCATGGTTGTCGTCAGCTCGTGCCGTGAG GTGTCAGGTTAAGTCCTATAACGAGCGCAACCCCTATTGTTAGTTGCCAGCGGGTCATGCCGGGAACTCTAACAAGACTGCCGGTGCA AACCGTGAGGAAGGTGGGGATGACGTCAAATCATCACGGCCCTTACGTCCTGGGCTACACGCGTGCTACAATGGGCGGTACAGAGAGC AGCCACCACGCAAGTGGGCGCGAATCTTCAAAACCGTTCTCAGTTCGGATCGGAGTCTGCAACTCGACTCCGTGAAGCTGGATTCGCT AGTAATCGCATATCAGCCATGATGCGGTGAATACGTTCCCGGGCCTTGTACACACCGCCCGTCAAGCCATGGAAGCTGGGGGTACCTG AAGTCGGTGACCGCAAGGAGCTGCCTAGGGTAAAACTGGTAACTGGGGCTAAGTCGTAACAAGGTA

Sl1322

AGAGTTTGATCATGGCTCAGGACGAACGCTGGCGGCGTGCCTAACACATGCAAGTCGAGCGGAGGAAGCAGTAATGTTTCTTCAGCGG CGGACGGGTGAGTAACACGTGGGTAACCTGCCTCGAAATGGGGGATAGCCTTCCGAAAGGAAGATTAATACCGCATAACCTCGGATCT CCGCATGGAGGACCGAGAAAAGGAGAAATCCGTTTCGAGATGGACCCGCGGCGCATTAGCTAGTTGGTGAGGTAACGGCCCACCAAGG CGACGATGCGTAGCCGACCTGAGAGGGTGATCGGCCACATTGGAACTGAGACACGGTCCAGACTCCTACGGGAGGCAGCAGTGGGGAA TATTGCACAATGGGCGAAAGCCTGATGCAGCAACGCCGCGTGAGTGATGAAGGCCTTCGGGTCGTAAAGCTCTTTGATCAGGGACGAT AATGACGGTACCTGAAAAACAAGCCACGGCTAACTACGTGCCAGCAGCCGCGGTAATACGTAGGTGGCAAGCGTTGTCCGGATTTACT GGGCGTAAAGAATGCGTAGGTGGATATTTAAGTGGGATGTGAAATCCCCGGGCTCAACCCGGGAACTGCATTCCAAACTGGATATCTG GAGTGCAGGAGAGGAAAGCGGAATTCCTAGTGTAGCGGTGAAATGCGTAGATATTAGGAGGAACACCAGTGGCGAANGCGGCTTTCTG GACTGTAACTGACACTGAGGCATGAAAGCGTGGGGAGCAAACAGGATTAGATACCCTGGTAGTCCACGCCGTAAACTATGGGTACTAG GTGTAGGGGGTATCGACTCCCCCTGTGCCGTCGTTAACACAATAAGTACCCCGCCTGGGGAGTACGGTCGCAAGACTAAAACTCAAAG GAATTGACGGGGGCCCGCACAAGCAGCGGAGCATGTGGTTTAATTCGAAGCAACGCGAAGAACCTTACCTAGACTTGACATCTCCTGA ATTACCCTTAACCGGGGAAGCCCTTCGGGGCAGGAAGACAGGTGGTGCATGGTTGTCGTCAGCTCGTGTCGTGAGATGTTGGGTTAAG TCCCGCAACGAGCGCAACCCTTATTTTTAGTTGCTACCATTAGGTTGAGCACTCTAAAGAGACTGCCCGGGTTAACCGGGAGGAAGGT GGGGATGACGTCAAATCATCATGCCCCTTATGTCTAGGGCTACACACGTGCTACAATGGTGAGGACAAAGAGACGCAAGACCGCGAGG TGGAGCAAATCTCACAAACCTCATCCCAGTTCGGATTGCAGGCTGAAACTCGCCTGCATGAAGCCGGAGTTGCCAGTAATCGCGAATC AGCATGTCGCGGTGAATACGTTCCCGGGCCTTGTACACACCGCCCGTCACACCATGAGAGTTGGCAATACCCGAAGTCCGTGGGGTAA CCTTTATTGGAGCCAGCGGCCGAAGGTAGGGTCAGCGATTGGGGTGAAGTCGTAACAAGGTA

Sl1323

AGAGTTTGATCATGGCTCAGATTGAACGCTGGCGGCATGCTTAACACATGCAAGTCGAACGGCAGCACGGTTTGTAGCAATACAAATT GGTGGCGAGTGGCGGACGGGTGAGTAACGCGTAGGAATCTGCCTTAAAGAGGGGGACAACCCGAGGAAACTCGGGCTAATACCGCATA ATCTCGCGAGAGAAAAGCTGGGTGGTAACACCTGGCGCTTTAAGAGGAGCCTGCGTCCGATTAGCTAGTTGGTGGGGTAAAGGCCTAC CAAGGCGATGATCGGTAGCTGGTCTGAGAGGATGATCAGCCACACTGGGACTGAGACACGGCCCAGACTCCTACGGGAGGCAGCAGTG GGGAATATTGGACAATGGGGGAAACCCTGATCCAGCAATGCCGCGTGTGTGAAGAAGGCCTTCGGGTTGTAAAGCACTTTAGGTGGGG AAGAAGGTGTGTAGTTTAAGAGACAGCACATTTGACGGTACCTGCAGAATAAGCACCGGCTAACTCTGTGCCAGCAGCCGCGGTAATA CAGAGGGTGCGAGCGTTAATCGGAATTACTGGGCGTAAAGGGCGCGTAGGCGGTTAGATAAGTGAGATGTGAAATCCCTGGGCTTAAC CTAGGAACTGCATCTCATACTGTTTGACTGGAGTACTGTAGAGGGTAGTGGAATTTCCGGTGTAGCGGTGAAATGCGTAGATATCGGA AGGAACACCAGTGGCGAAGGCGGCTACCTGGGCAGATACTGACGCTGAGGCGCGAGAGCGTGGGGAGCAAACAGGATTAGATACCCTG GTAGTCCACGCTGTAAACGATGAGAACTAGATGTTGGCAGGCTTGACCTGTTAGTATCGAAGCTAACGCGATAAGTTCTCCGCCTGGG GAGTACGGCCGCAAGGTTAAAACTCAAAGGAATTGACGGGGGCCCGCACAAGCGGTGGAGCATGTGGTTTAATTCGATGCAACGCGAA GAACCTTACCTACCCTTGACATCCTAGGAATCCTGCAGAGATGTGGGAGTGCCGAAAGGAACCTAGAGACAGGTGCTGCATGGCTGTC GTCAGCTCGTGTTGTGAGATGTTGGGTTAAGTCCCGTAACGAGCGCAACCCTTATCCTTAGTTACCATCATTTAGTTGGGGACTCTAA GGAGACTGCTGGTGATGAACCGGAGGAAGGCGGGGACGACGTCAAGTCATCATGGCCTTTATGGGTAGGGCTACACACGTGCTACAAT GGTCGGTACAGAGGGTAGCCAACCCGCGAGGGGGAGCCAATCCCAGAAAGCCGATCGTAGTCCGGATTGGAGTCTGCAACTCGACTCC ATGAAGTCGGAATCGCTAGTAATCGCGAATCAGAATGTCGCGGTGAATACGTTCCCGGGCCTTGTACACACCGCCCGTCACACCATGG GAGTGGGTTGTACCAGAAGTAGGTAGAGTAACCGCAAGGGGCTCGCTTACCACGGTATGGTTCATGACTGGGGTGAAGTCGTAACAAG GTA

Sl1325

AAAGTTTGATCATGGCTCAGGATGAACGCTAGCGGCAGGCCTAACACATGCAAGTCGAGGGGTAGAGGTTGCTTGCAACCTTGAGACC GGCGCACGGGTGCGTAACGCGTATGCAATCTACCTTATACAGAGGGATAGCCCAGAGAAATTTGGATTAATACCTCATAGTATTATTG AATGGCATCATTTAATAATTAAAGTCACAACGGTATAAGATGAGCATGCGTCCCATTAGTTAGTTGGTAAGGTAACGGCTTACCAAGA CAATGATGGGTAGGGGTCCTGAGAGGGAGATCCCCCACACTGGTACTGAGACACGGACCAGACTCCTACGGGAGGCAGCAGTGAGGAA TATTGGTCAATGGGCGCAAGCCTGAACCAGCCATGCCGCGTGCAGGATGACGGTCCTATGGATTGTAAACTGCTTTTGTACAGGAAGA AACACTGGTTCGTGAACCAGCTTGACGGTACTGTAAGAATAAGGATCGGCTAACTCCGTGCCAGCAGCCGCGGTAATACGGAGGATCC AAGCGTTATCCGGAATCATTGGGTTTAAAGGGTCCGTAGGCGGTCAGATAAGTCAGTGGTGAAAGCCCATCGCTCAACGGTGGAACGG CCATTGATACTGTCTGACTTGAATTATTAGGAAGTAACTAGAATATGTAGTGTAGCGGTGAAATGCTTAGAGATTACATGGAATACCA ATTGCGAAGGCAGGTTACTACTAATGGATTGACGCTGATGGACGAAAGCGTGGGTAGCGAACAGGATTAGATACCCTGGTAGTCCACG CCGTAAACGATGGATACTAGCTGTTGGAAGCAATTTCAGTGGCTAAGCGAAAGTGATAAGTATCCCACCTGGGGAGTACGTTCGCAAG AATGAAACTCAAAGGAATTGACGGGGGCCCGCACAAGCGGTGGAGCATGTGGTTTAATTCGATGATACGCGAGGAACCTTACCAAGGC TTAAATGTAGATTGACCGGTTTGGAAACAGACTTTTCGCAAGACAATTTACAAGGTGCTGCATGGTTGTCGTCAGCTCGTGCCGTGAG GTGTCAGGTTAAGTCCTATAACGAGCGCAACCCCTGTTGTTAGTTGCCAGCGAGTCATGTCGGGAACTCTAACGAGACTGCCAGTGCA AACTGAGAGGAAGGTGGGGATGACGTCAAATCATCACGGCCCTTACGCCTTGGGCTACACACGTGCTACAATGGCCGGTACAGAGAGC AGCCACTGGGTGACCAGGAGCGAATCTATAAAACCGGTCACAGTTCGGATCGGAGTCTGCAACTCGACTCCGTGAAGCTGGAATCGCT 
AGTAATCGGATATCAGCCATGATCCGGTGAATACGTTCCCGGGCCTTGTACACACCGCCCGTCAAGCCATGGAAGCTGGGGGTGCCTG AAGTCGGTGACCGCAAGGAGCTGCCTAGGGTAAAACTGGTAACTAGGGNTAAGTCGTAACAAGGTA

Sl1326

AAAGTTTGATCATGGCTCAGGATGAACGCTAGCGGCAGGCCTAACACATGCAAGTCGAGGGGTAGAGGTTGCTTGCAACCTTGAGACC GGCGCACGGGTGCGTAACGCGTATGCAATCTACCTTATACAGAGGGATAGCCCAGAGAAATTTGGATTAATACCTCATAGTATTATTG AATGGCATCATTTAATAATTAAAGTCACAACGGTATAAGATGAGCATGCGTCCCATTAGTTAGTTGGTAAGGTAACGGCTTACCAAGA CAATGATGGGTAGGGGTCCTGAGAGGGAGATCCCCCACACTGGTACTGAGACACGGACCAGACTCCTACGGGAGGCAGCAGTGAGGAA TATTGGTCAATGGGCGCAAGCCTGAACCAGCCATGCCGCGTGCAGGATGACGGTCCTATGGATTGTAAACTGCTTTTGTACAGGAAGA AACACTGGTTCGTGAACCAGCTTGACGGTACTGTAAGAATAAGGATCGGCTAACTCCGTGCCAGCAGCCGCGGTAATACGGAGGATCC AAGCGTTATCCGGAATCATTGGGTTTAAAGGGTCCGTAGGCGGTCAGATAAGTCAGTGGTGAAAGCCCATCGCTCAACGGTGGAACGG CCATTGATACTGTCTGACTTGAATTATTAGGAAGTAACTAGAATATGTAGTGTAGCGGTGAAATGCTTAGAGATTACATGGAATACCA ATTGCGAAGGCAGGTTACTACTAATGGATTGACGCTGATGGACGAAAGCGTGGGTAGCGAACAGGATTAGATACCCTGGTAGTCCACG CCGTAAACGATGGATACTAGCTGTTGGAAGCAATTTCAGTGGCTAAGCGAAAGTGATAAGTATCCCACCTGGGGAGTACGTTCGCAAG AATGAAACTCAAAGGAATTGACGGGGGCCCGCACAAGCGGTGGAGCATGTGGTTTAATTCGATGATACGCGAGGAACCTTACCAAGGC TTAAATGTAGATTGACCGGTTTGGAAACAGACTTTTCGCAAGACAATTTACAAGGTGCTGCATGGTTGTCGTCAGCTCGTGCCGTGAG GTGTCAGGTTAAGTCCTATAACGAGCGCAACCCCTGTTGTTAGTTGCCAGCGAGTCATGTCGGGAACTCTAACGAGACTGCCAGTGCA AACTGAGAGGAAGGTGGGGATGACGTCAAATCATCACGGCCCTTACGCCTTGGGCTACACACGTGCTACAATGGCCGGTACAGAGAGC AGCCACTGGGTGACCAGGAGCGAATCTATAAAACCGGTCACAGTTCGGATCGGAGTCTGCAACTCGACTCCGTGAAGCTGGAATCGCT AGTAATCGGATATCAGCCATGATCCGGTGAATACGTTCCCGGGCCTTGTACACACCGCCCGTCAAGCCATGGAAGCTGGGGGTGCCTG AAGTCGGTGACCGCAAGGAGCTGCCTAGGGTAAAACTGGTAACTAGGGCTAAGTCGTAACAAGGTA

Sl1327

AGAGTTTGATCATGGCTCAGGATGAACGCTAGCGGCAGGCTTAATACATGCAAGTCGAGGAGTATAGTTCTTCGGAACTAGAGACCGG CGCACGGGTGCGTAACGCGTATGCAATCTACCTTTCACAGAGGGATAGCCCAGAGAAATTTGGATTAATACCTCATAGTATTATAGAG TGGCATCATTTTATAATTAAAGTCACAACGGTGAAAGATGAGCATGCGTCCCATTAGCTAGTTGGTAAGGTAACGGCTTACCAAGGCA ACGATGGGTAGGGGTCCTGAGAGGGAGATCCCCCACACTGGTACTGAGACACGGACCAGACTCCTACGGGAGGCAGCAGTGAGGAATA TTGGACAATGGGCGCAAGCCTGATCCAGCCATGCCGCGTGCAGGATGACGGTCCTATGGATTGTAAACTGCTTTTGTACAGGAAGAAA CACTGGTTCGTGAACCAGCTTGACGGTACTGTAAGAATAAGGATCGGCTAACTCCGTGCCAGCAGCCGCGGTAATACGGAGGATCCAA GCGTTATCCGGAATCATTGGGTTTAAAGGGTCCGTAGGCGGTTTAGTAAGTCAGTGGTGAAAGCCCATCGCTCAACGGTGGAACGGCC ATTGATACTGCTAAACTTGAATTATTAGGAAGTAACTAGAATATGTAGTGTAGCGGTGAAATGCTTAGAGATTACATGGAATACCAAT TGCGAAGGCAGGTTACTACTAATGGATTGACGCTGATGGACGAAAGCGTGGGTAGCGAACAGGATTAGATACCCTGGTAGTCCACGCC GTAAACGATGGATACTAGCTGTTGGAAGCAATTTCAGTGGCTAAGCGAAAGTGATAAGTATCCCACCTGGGGAGTACGTTCGCAAGAA TGAAACTCAAAGGAATTGACGGGGGCCCGCACAAGCGGTGGAGCATGTGGTTTAATTCGATGATACGCGAGGAACCTTACCAAGGCTT AAATGTAGATTGACCGGTTTGGAAACAGACTTTTCGCAAGACAATTTACAAGGTGCTGCATGGTTGTCGTCAGCTCGTGCCGTGAGGT GTCAGGTTAAGTCCTATAACGAGCGCAACCCCTGTTGTTAGTTGCCAGCGAGTCATGTCGGGAACTCTAACGAGACTGCCAGTGCAAA CTGAGAGGAAGGTGGGGATGACGTCAAATCATCACGGCCCTTACGCCTTGGGCTACACACGTGCTACAATGGCCGGTACAGAGAGCAG CCACTGGGTGACCAGGAGCGAATCTATAAAACCGTTCTCAGTTCGGATCGGAGTCTGCAACTCGACTCCGTGAAGCTGGAATCGCTAG TAATCGGATATCAGCCATGATCCGGTGAATACGTTCCCGGGCCTTGTACACACCGCCCGTCAAGCCATGGAAGCTGGGGGTGCCTGAA GTCGGTGACCGCAAGGAGCTGCCTAGGGTAAAACTGGTAACTGGGGCTAAGTCGTAACAAGGTAAAGCCGAATTCCAGCACACTGGCG GCCGTTACTAGTGGATCCGAGCTCGGTACCAAGC

Sl1330

AGAGTTTGATCATGGCTCAGGATGAACGCTGGCGGCGTGCCTAACACATGCAAGTCGAACGGTCGATGAATAATCGATAGTGGCGAAC GGGTGAGTAACACGTAGTTTACCTGCCCCGAAGAGGGGGATAACGTTCCGAAAGGAATGCTAATACCCCATAAGCTCACATCGAATAG TAAGGTGTGAGAAAAGGAGTAATCCGCTTTGGGATGGGACTGCGGTCCATCAGCTAGTTGGTGAGGTAAAGGCTCACCAAGGCGACGA CGGATAGGGGGCCTGAGAGGGTGAACCCCCACACTGGAACTGAGACACGGTCCAGACTCCTACGGGAGGCAGCAGTGAGGAATATTGC TCAATGGGCGCAAGCCTGAAGCAGCAACGCCGCGTGGGCGATGAAGGTTTTCGGATCGTAAAGCCCTTTTCTAGGTGACGAGGAAGGG CGGTAGCCTAGGAATAAGTGTCGGCTAACTACGTGCCAGCAGCCGCGGTAAAACGTAGGACGCAAGCGTTATCCGGAGTTACTGGGCG TAAAGAGCGCGCAGGCGGGTCGTTAAGTCATTTATGAAAGCCCTAGGCTAAACTTGGGGAGTGTGAATGATACTGGCGGTCTAGAGTG AGGAAGAGGGATGTGGAATTCCGCGTGTAGTGGTGAAATGCGTAGATATGCGGAGGAACACCAGTGGCGAAGGCGACATCCTGGTCCT TAACTGACGCTGAGGCGCGAAAGCATGGGTAGCGAACGGGATTAGAGACCCCGGTAGTCCATGCCGTAAACGATGTACACTAAATGTT CGTTATCGAGAGGTAATGGGTATTGAAGCTAACGCGATAAGTGTACCGCCTGGGGAGTACGGTCGCAAGGCTAAAACTCAAAGGAATT GACGGGGGCCCGCACAAGCAGCGGAGCGTGTGGTTTAATTCGAGGCTACGCGAAAAACCTTACCTGGGTTTGACATCGCGTGACATCT GGTGAAAGCCAGACTTCCCGCAAGGGACACAAAGACAGGTGCTGCATGGCTGTCGTCAGCTCGTGCCGTGAGGTGTTCGGTTAAGTCC GCAAACGAGCGCAACCCCTATTGCCAGTTACAAGTGTCTGGCGAGACTGCCCGTGGTAAACGGGAGGAAGGTGGGGATGATGTCAAGT CAGCATGGCCTTTATATCCAGGGCTACACACACGCTACAATGGCGCATACAATGGGTCGCAAAGCCGCGAGGTGGAGCCAATCCTAAA AAGTGCGTCACAGTTCGGATTGTAGGCTGCAACTCGCCTGCATGAAGTCGGAGTTGCTAGTAACCGCGCGTCAGCATAGTGCGGTGAA TACGTTCCCGGGCCTTGTACACACCGCCCGTCACGTCATGGGAGCTGGTTATGCCTGAAGTCGGGAAGCTAACCGCAAGGGGGCTACT GCCGAGGGCAGAATTGGTGACTGGGACGAAGTCGTAACAAGGT

Sl1331

AGAGTTTGATCATGGCTCAGGATGAACGCTAGCGGCAGGCCTAACACATGCAAGTCGAGGGGTAGAGGAAGCTTGCTTCCTTGAGACC GGCGCACGGGTGCGTAACGCGTATGCAATCTACCTTATACAGAGGGATAGCCCAGAGAAATTTGGATTAATACCTCATAGTATTATGA AATCGCATGGTTTTATAATTAAAGTTCCAACGGTATAAGATGAGCATGCGTCCCATTAGTTAGTTGGTAAGGTAACGGCTTACCAAGA CAATGATGGGTAGGGGTCCTGAGAGGGAGATCCCCCACACTGGTACTGAGACACGGACCAGACTCCTACGGGAGGCAGCAGTGAGGAA TATTGGTCAATGGACGCAAGTCTGAACCAGCCATGCCGCGTGCAGGATGACGGTCCTATGGATTGTAAACTGCTTTTATACAGGAAGA AACACTCGGACGTGTCCGAGCTTGACGGTACTGTAGGAATAAGGATCGGCTAACTCCGTGCCAGCAGCCGCGGTAATACGGAGGATCC AAGCGTTATCCGGAATCATTGGGTTTAAAGGGTCCGTAGGCGGTTTAATAAGTCAGTGGTGAAAGCCTATCGCTTAACGATAGAACGG CCATTGATACTGTTAGACTTGAATTAGTGGGAAGTAACTAGAATATGTAGTGTAGCGGTGAAATGCTTAGATATTACATGGAATACCA ATTGCGAAGGCAGGTTACTATCACTATATTGACGCTGATGGACGAAAGCGTGGGGAGCGAACAGGATTAGATACCCTGGTAGTCCACG CCGTAAACGATGGATACTAGCTGTTCGGAGCAATCTGAGTGGCTAAGCGAAAGTGATAAGTATCCCACCTGGGGAGTACGTTCGCAAG AATGAAACTCAAAGGAATTGACGGGGGCCCGCACAAGCGGAGGAGCATGTGGTTTAATTCGATGATACGCGAGGAACCTTACCAGGGC TTAAATGGGAGACGACAGGACTGGAAACAGTTTTTTCTTCGGACGTCTTTCAAGGTGCTGCATGGTTGTCGTCAGCTCGTGCCGTGAG GTGTCAGGTTAAGTCCTATAACGAGCGCAACCCCTATTGTTAGTTGCCAGCGGGTCATGCCGGGAACTCTAACAAGACTGCCGGTGCA AACCGTGAGGAAGGTGGGGATGACGTCAAATCATCACGGCCCTTACGTCCTGGGCTACACACGTGCTACAATGGGCGGTACAGAGAGC AGCCACCACGCAAGTGGGCGCGAATCTTCAAAACCGTTCTCAGTTCGGATCGGAGTCTGCAACTCGACTCCGTGAAGCTGGATTCGCT AGTAATCGCATATCAGCCATGATGCGGTGAATACGTTCCCGGGCCTTGTACACACCGCCCGTCAAGCCATGGAAGCTGGGGGTACCTG AAGTCGGTGACCGCAAGGAGCTGCCTAGGGTAAAACTGGTAACTGGGGCTAAGTCGTAACAAGGTA Sl1335 
AGAGTTTGATCATGGCTCAGATTGAACGCTGGCGGCATGCCTTACACATGCAAGTCGAACGGCAGCACGGGAGCAATCCTGGTGGCGA GTGGCGAACGGGTGAGTAATATATCGGAACGTGCCCAGTCGTGGGGGATAACGCAGCGAAAGCTGTGCTAATACCGCATACGATCTCT GGATGAAAGCGGGGGACTCGCAAGAGCCTCGCGCGATTGGAGCGGCCGATATCAGATTAGCTAGTTGGTGGGGTAAAGGCCTACCAAG GCGACGATCTGTAGCTGGTCTGAGAGGACGACCAGCCACACTGGAACTGAGACACGGTCCAGACTCCTACGGGAGGCAGCAGTGGGGA ATTTTGGACAATGGGCGAAAGCCTGATCCAGCAATGCCGCGTGCAGGATGAAGGCCTTCGGGTTGTAAACTGCTTTTGTGCGGAACGA AACGGTTCGCCTTAATACGGTGGGCTAATGACGGTACCGTAAGAATAAGCACCGGCTAACTACGTGCCAGCAGCCGCGGTAATACGTA GGGTGCGAGCGTTAATCGGAATTACTGGGCGTAAAGCGTGCGCAGGCGGTTATATAAGACAGATGTGAAATCCCCGGGCTCAACCTGG GACCTGCATTTGTGACTGTATAGCTAGAGTACGGTAGAGGGGGATGGAATTCCGCGTGTAGCAGTGAAATGCGTAGATATGCGGAGGA ACACCGATGGCGAAGGCAATCCCCTGGACCTGTACTGACGCTCATGCACGAGAGCGTGGGGAGCAAACAGGATTAGATACCCTGGTAG TCCACGCCCTAAACGATGTCAACTGGTTGTTGGGTCTTCACTGACTCAGTAACGAAGCTAACGCGTGAAGTTGACCGCCTGGGGAGTA CGGCCGCAAGGTTGAAACTCAAAGGAATTGACGGGGACCCGCACAAGCGGTGGATGATGTGGTTTAATTCGATGCAACGCGAAAAACC TTACCCACCTTTGACATGTACGGAAGTCGCTAGAGATAGCTTCGTGCTCGAAAGAGAGCCGTAACACAGGTGCTGCATGGCTGTCGTC AGCTCGTGTCGTGAGATGTTGGGTTAAGTCCCGCAACGAGCGCAACCCTTGTCATTAGTTGCTACATTCAGTTGGGCACTCTAATGAG ACTGCCGGTGACAAGCCGGAGGAAGGTGGGGATGACGTCAAGTCCTCATGGCCCTTATAGGTGGGGCTACACACGTCATACAATGGCT GGTACAAAGGGTTGCCAACCCGCGAGGGGGAGCTAATCCCACAAAGCCAGTCGTAGTCCGGATCGTAGTCTGCAACTCGACTACGTGA AGTCGGAATCGCTAGTAATCGTGGATCAGAATGTCACGGTGAATACGTTCCCGGGTCTTGTACACACCGCCCGTCACACCATGGGAGC GGGTTCTGCCAGAAGTAGTTAGCCTAACCGCAAGGAGGGCGATTACCACGGCAGGGTTCGTGACTGGGGTGAAGTCGTAACAAGGTA Sl1336

AGAGTTTGATCATGGCTCAGAGTGAACGCTGGCGGTAGGCCTAACACATGCAAGTCGAACGGCAGCACAGGAGAGCTTGCTCTCTGGG TGGCGAGTGGCGGACGGGTGAGGAATACATCGGAATCTACCTTTTCGTGGGGGATAACGTAGGGAAACTTACGCTAATACCGCATAAG ACCTTCGGGTGAAAGCCGGGGACCTTCGGGCCTGGCGCGGATAGATGAGCCGATGTCGGATTAGCTTGTTGGCGGGGTAAAAGCCCAC CAAGGCGACGATCCGTAGCTGGTCTGAGAGGATGATCAGCCACACTGGAACTGAGACACGGTCCAGACTCCTACGGGAGGCAGCAGTG GGGAATATTGGACAATGGGCGCAAGCCTGATCCAGCCATACCGCGTGGGTGAAGAAGGCCTTCGGGTTGTAAAGCCCTTTTGTTGGGA AAGAAATCCTGTCGGTTAATAACCGGTAGGGATGACGGTACCCAAAGAATAAGCACCGGCTAACTTCGTGCCAGCAGCCGCGGTAATA CGAAGGGTGCAAGCGTTACTCGGAATTACTGGGCGTAAAGCGTGCGTAGGTGGTTGTTTAAGTCTGTCGTGAAAGCCCTGGGCTCAAC CTGGGAATTGCGATGGATACTGGGCGACTAGAGTGTGGTAGAGGACAGTGGAATTTCCGGTGTAGCAGTGAAATGCGTAGAGATCGGA AGGAACATCTGTGGCGAAGGCGACTGTCTGGGCCAACACTGACACTGAGGCACGAAAGCGTGGGGAGCAAACAGGATTAGATACCCTG GTAGTCCACGCCCTAAACGATGCGAACTGGATGTTGGGCACAACTTGGTGCCCAGTATCGAAGCTAACGCGTTAAGTTCGCCGCCTGG GGAGTACGGTCGCAAGACTGAAACTCAAAGGAATTGACGGGGGCCCGCACAAGCGGTGGAGTATGTGGTTTAATTCGATGCAACGCGA AGAACCTTACCTGGTCTTGACATCCACGGAACTTTCCAGAGATGGATTGGTGCCTTCGGGAACCGTGAGACAGGTGCTGCATGGCTGT CGTCAGCTCGTGTCGTGAGATGTTGGGTTAAGTCCCGCAACGAGCGCAACCCTTGTCCCTAGTTGCCATCATTCAGTTGGGCACTCTA GGGAGACTGCCGGTGACAAACCGGAGGAAGGTGGGGATGACGTC

Sl1337

CTAACTTCGTGCCAGCAGCCGCGGTAATACGAATGGTGCAAGCGTTACTCGGAATTACTGGGCGTAAAGCGTGCGTAGGTGGTTTGTT AAGCGAGATGTGAAAGCCCTGGGCTCAACCTAGGAATAGCATTTCGAACTGGCGAACTAGAGTCTTGTAGAGGGGGGTAGAATTCCAG GTGTAGCGGTGAAATGCGTAGAGATCTGGAGGAATACCGGTGGCGAAGGCGGCCCCCTGGACAAAGACTGACGCTCATGCACGAAAGC GTGGGGAGCAAACAGGATTAGATACCCTGGTAGTCCACGCCGTAAACGATGTCTACTCGGAGTTTGGTGTCTTGAACACTGGGCTCTC AAGCTAACGCATTAAGTAGACCGCCTGGGGAGTACGGCCGCAAGGTTAAAACTCAAATGAATTGACGGGGGCCCGCACAAGCGGTGGA GCATGTGGTTTAATTCGATGCAACGCGAAGAACCTTACCTACTCTTGACAACCACGGAATTCGCTAGAGATAGCTTAGTGCCTTCGGG AACCGTGAGACAGGTGCTGCATGGCTGTCGTCAGCTCGTGTTGTGAAATGTTGGGTTAAGTCCCGCAACGAGCGCAACCCCTATCCTT ATTTGCCAGCACGTAATGGTGGGAACTCTAGGGAGACTGCCGGTGATAAACCGGAGGAAGGTGGGGACGACGTCAAGTCATCATGGCC CTTACGAGTAGGGCTACACACGTGCTACAATGGCGAGTACAGAGGGTTGCAAAGCCGCGAGGTGGAGCTAATCTCACAAAGCTCGTCG TAGTCCGGATTGGAGTCTGCAACTCGACTCCATGAAGTCGGAATCGCTAGTAATCGTGGATCAGAATGCCACGGTGAATACGTTCCCG GGCCTTGTACACACCGCCCGTCACACCATGGGAGTGGGCTGCAAAAGAAGTGGGTAGCTTAACCTTCGGGGGGGCGCTCACCACTTTG TGGTTCATGACTGGGGTGAAGTCGTAACAAGGTA

Sl1339

AGAGTTTGATCATGGCTCAGATTGAACGCTGGCGGCATGCTTTACACATGCAAGTCGAACGGCAGCACGGGGGAACCCTGGTGGCGA GTGGCGAACGGGTGAGTAATATATCGGAACGTACCCGGAAATGGGGGATAACGTAGCGAAAGTTACGCTAATACCGCATATGCCCTAA GGGGGAAAGCGGGGGATTCGCAAGGACCTCGCGTTTTCGGAGCGGCCGATATCGGATTAGCTAGTAGGTGAGGTAAAGGCTCACCTAG GCGACGATCCGTAGCTGGTCTGAGAGGACGACCAGCCACACTGGAACTGAGACACGGTCCAGACTCCTACGGGAGGCAGCAGTGGGGA ATTTTGGACAATGGGCGCAAGCCTGATCCAGCCATGCCGCGTGAGTGAAGAAGGCCTTCGGGTTGTAAAGCTCTTTCAGCCGGAAAGA AAACGCACGGGTTAATAACCTGTGTGGATGACGGTACCGGAAGAAGAAGCACCGGCTAACTACGTGCCAGCAGCCGCGGTAATACGTA AGGTGCGAGCGTTAATCGGAATTACTGGGCGTAAAGCGTGCGCAGGCGGTTTTGTAAGACAGATGTGAAATCCCCGGGCTTAACCTGG GAACTGCATTTGTAACTGCAAGGCTAGAGTACGGCAGAAGGGGGTAGAATTCCACGTGTAGCAGTGAAATGCGTAGATATGTGGAGGA ATACCGATGGCGAAGGCAGCCCCCTGGGTCGATACTGACGCTCATGCACGAAAGCGTGGGGAGCAAACAGGATTAGATACCCTGGTAG TCCACGCCCTAAACGATGTCAACTAGGTGTTGGGGGAGGAGACTTCCTTAGTACCGCAGCTAACGCGTGAAGTTGACCGCCTGGGGAG TACGGTCGCAAGATTAAAACTCAAAGGAATTGACGGGGACCCGCACAAGCGGTGGATTATGTGGATTAATTCGATGCAACGCGAAAAA CCTTACCTACCCTTGACATGCCAGGAACTTGCCAGAGATGGCTTGGTGCCCGAAAGGGAACCTGGACACAGGTGCTGCATGGCTGTCG TCAGCTCGTGTCGTGAGATGTTGGGTTAAGTCCCGCAACGAGCGCAACCCTTGTCATTAATTGCCATCATTTAGTTGGGCACTTTAAT GAGACTGCCGGTGACAAACCGGAGGAAGGTGGGGATGACGTCAAGTCCTCATGGCCCTTATGGGTAGGGCTTCACACGTAATACAATG GCCGGTACAGAGGGTTGCCAACCCGCGAGGGGGAGCTAATCTCAGAAAGCCGATCGTAGTCCGGATTGGAGTCTGCAACTCGACTCCA TGAAGTCGGAATCGCTAGTAATCGCGGATCAGCATGTCGCGGTGAATACGTTCCGGGGTCTTGTACACACCGCCCGTCACACCATGGG AGCGGGTTCTACCAGAAGCAGCTAGCCTAACCGCAAGGGGGGCGGTTGCCACGGTAGGGTTCGTGGCTGGGGTGAAGTCGTAACAAGG TA

Sl1340

AGAGTTTGATCATGGCTCAGAGTGAACGCTGGCGGCAGGCCTAACACATGCAAGTCGAACGGCAGCACAGCAGTAGCAATACTGTGGG TGGCGAGTGGCGGACGGGTGAGGAATACATCGGGATCTACCTTTTCGTGGGGGATAACGTAGGGAAACTTACGCTAATACCGCATACG CCCTACGGGGGAAAGCGGCGGACCGCAAGGCGTCGCGCGATGAGATGAACCGATGTCCGATTAGCTAGTTGGCGGGGTAAAGGCCCAC CAAGGCGACGATCGGTAGCTGATCTGAGAGGATGATCAGCCACACTGGAACTGAGACACGGTCCAGACTCCTACGGGAGGCAGCAGTG GGGAATATTGGACAATGGGCGCAAGCCTGATCCAGCCATGCCGCGTGGGTGAAGAAGGCCTTCGGGTTGTAAAGCCCTTTTGTCCGGA AAGAAAAGCACGTAATTAATACCTATGTGTGATGACGGTACCGGAAGAATAAGCACCGGCTAACTTCGTGCCAGCAGCCGCGGTAATA CGAAGGGTGCAAGCGTTACTCGGAATTACTGGGCGTAAAGCGTGCGTAGGTGGTTTGTTAAGTCTGTCGTGAAATCCCCGGGCTCAAC CTGGGAATGGCGATGGATACTGGCAAGCTAGAGTGAGGTAGAGGAGAGTGGAATTCCCGGTGTAGCAGTGAAATGCGTAGAGATCGGG AGGAACATCAGTTGCGAAGGCGGCTCTCTGGACCATCACTGACACTGAGGCACGAAAGCGTGGGGAGCAAACAGGATTAGATACCCTG GTAGTCCACGCCTTAAACGATGCGAACTGGACGTTTGGCTCAATTAGGAGCTCAGTGTCGAAGCTAACGCGTTAAGTTCGCCGCCTGG GGAGTACGGTCGCAAGACTGAAACTCAAAGGAATTGACGGGGGCCCGCACAAGCGGTGGAGTATGTGGTTTAATTCGATGCAACGCGC AGAACCTTACCTGGTCTTGACATCCACGGAATCCTTTAGAGATAGAGGAGTGCCTTCGGGAACCGTGAGACAGGTGCTGCATGGCTGT 
CGTCAGCTCGTGTCGTGAGATGTTGGGTTAAGTCCCGCAACGAGCGCAACCCCTGTCTTTAGTTGCCAGCACGTAATGGTGGGAACTC TAAGGAGACTGCCGGTGACAAACCGGAGGAAGGTGGGGATGACGTCAAGTCATCATGGCCCTTACGACCAGGGCTACACACGTACTAC AATGGTGGGGACAGAGGGTCGCGAAGCCGCGAGGTGGAGCCAATCCCAGAAACCCTATCTTAGTCCGGATTGGAGTCTGCAACTCGAC TCCATGAAGTCGGAATCGCTAGTAATCGCGGATCAGCATTGCCGCGGTGAATACGTTCCCGGGCCTTGTACACACCGCCCGTCACACC ATGGGAGTTTGTTGCACCAGAAGCAGGTAGCTTAACCGTAAGGGGGGGCTTGCCACGGTGTGGCCGATGACTGGGGTGAAGTCGTAA CAAGGTAA

Sl1342

GAACGAACGCTGGCGGCGCGCCTAACACATGCAAGTCGAACGAGAATCCGGGGCAACCTGGTAGTAAAGTGGCAAACGGGTGAGGAAT ACATGGGTAACCTGCCCTTGAGAAGGGAATAACCCGCCGAAAGGTGAGCTAATACCCTATACGCTCCTTTTTCTACGGAAAGGGAAGG AAAGCTAAGCCGTGGGCTCGGCGCTCAAGGAGGGGCTCATGTCCTATCAGCTTGTTGGTGGGGTAACGGCCTACCAAGGCTACGACGG GTAGCTGGTCTGAGAGGATGATCAGCCACACTGGCACTGAGATACGGGCCAGACTCCTACGGGAGGCAGCAGTGAGGAATATTGCGCA ATGGGCGAAAGCCTGACGCAGCGACGCCGCGTGGGGGATGAAGGTTTTCGGATTGTAAACCCCTTTCATGAGGAAAGATAAAGTGGGT AACCACTTAGACGGTACCTCAAGAAGAAGCCACGGCTAACTTCGTGCCAGCAGCCGCGGTAATACGAAGGTGGCAAGCGTTGTTCGGA TTTACTGGGCGTAAAGAGCACGTAGGCGGTTGGGTAAGCCTCTTGGGAAATCTCTCGGCTTAACCGGGAAAGGTCGAGGGGAACTACT CAGCTAGAGGACGGGAGAGGAGCGCGGAATTCCCGGTGTAGCGGTGAAATGCGTAGATATCGGGAAGAAGGCCGGTGGCGAAGGCGGC GCTCTGGAACGTACCTGACGCTGAGGTGCGAAAGCGTGGGGAGCAAACAGGATTAGATACCCTGGTAGTCCACGCCCTAAACGATGGG TACTAAGTGTCGGCGGTTTACCGCCGGTGCCGCAGCTAACGCAGTAAGTACCCCGCCTGGGGAGTACGGCCGCAAGGTTGAAACTCAA AGGAATTGACGGGGGCCCGCACAAGCGGTGGAGCATGTGGTTTAATTCGACGCAACGCGAAGAACCTTACCCAGGTTGGACATGCTCG TGGTACGAACCTGAAAGGGTGAGGACCTCGAAAGGGGAGCGAGCTCAGGTGCTGCATGGCTGTCGTCAGCTCGTGCCGTGAGGTGTTG GGTTAAGTCCCGCAACGAGCGTAACCCCTGTCTTCAGTTGCCATCGGGTCATGCCGAGCACTCTGGAGAGACTGCCCAGGATAACGGG GAGGAAGGTGGGGATGACGTCAAGTCAGCATGGCCTTTATGCCTGGGGCTACACACGTGCTACAATGACCGGTACAGAGGGTTGCAAT CCCGCAAGGGGGAGCCAATCTCAAAAAACCGGCCTCAGTTCAGATTGGGGTCTGCAACTCGACCCCATGAAGGTGGAATCGCTAGTAA TCGCGGATCAGCACGCCGCGGTGAATACGTTCCCGGGCCTTGTACACACCGCCCGTCACACCACGAAAGTCAGCTGTACCAGAAGTCA CTGGCGCCAACCCGAAAGGGAGGCAGGTGCCCAAGGTATGGTTGGTAATTGGGGTGAAGTCGTAACAAGGTA Sl1344

AGAGTTTGATCATGGCTCAGAGTGAACGCTGGCGGCAGGCCTAACACATGCAAGTCGAACGGCAGCACAGCAGTAGCAATACTGTGGG TGGCGAGTGGCGGACGGGTGAGGAATACATCGGGATCTACCTTTTCGTGGGGGATAACGTAGGGAAACTTACGCTAATACCGCATACG CCCTACGGGGGAAAGCGGCGGACCGCAAGGCGTCGCGCGATGAGATGAACCGATGTCCGATTAGCTAGTTGGCGGGGTAAAGGCCCAC CAAGGCGACGATCGGTAGCTGATCTGAGAGGATGATCAGCCACACTGGAACTGAGACACGGTCCAGACTCCTACGGGAGGCAGCAGTG GGGAATATTGGACAATGGGCGCAAGCCTGATCCAGCCATGCCGCGTGGGTGAAGAAGGCCTTCGGGTTGTAAAGCCCTTTTGTCCGGA AAGAAAAGCACGGGATTAATACCCTCGTGTGATGACGGTACCGGAAGAATAAGCACCGGCTAACTTCGTGCCAGCAGCCGCGGTAATA CGAAGGGTGCAAGCGTTACTCGGAATTACTGGGCGTAAAGCGTGCGTAGGTGGTTTGTTAAGTCTGTCGTGAAATCCCCGGGCTCAAC CTGGGAATGGCGATGGATACTGGCAAGCTAGAGTGAGGTAGAGGAGAGTGGAATTCCCGGTGTAGCAGTGAAATGCGTAGAGATCGGG AGGAACATCAGTTGCGAAGGCGGCTCTCTGGACCATCACTGACACTGAGGCACGAAAGCGTGGGGAGCAAACAGGATTAGATACCCTG GTAGTCCACGCCCTAAACGATGCGAACTGGACGTTGGGCTCAATTAGGAGCTCAGTGTCGAAGCTAACGCGTTAAGTTCGCCGCCTGG GGAGTACGGTCGCAAGACTGAAACTCAAAGGAATTGACGGGGGCCCGCACAAGCGGTGGAGTATGTGGTTTAATTCGATGCAACGCGC AGAACCTTACCTGGTCTTGACATCCACGGAATCCTTTAGAGATAGAGGAGTGCCTTCGGGAACCGTGAGACAGGTGCTGCATGGCTGT CGTCAGCTCGTGTCGTGAGATGTTGGGTTAAGTCCCGCAACGAGCGCAACCCCTGTCCTTAGTTGCCAGCACGTAATGGTGGGAACTC TAAGGAGACTGCCGGTGACAAACCGGAGGAAGGTGGGGATGACGTCAAGTCATCATGGCCCTTACGACCAGGGCTACACACGTACTAC AATGGTGGGGACAGAGGGTCGCGAAGCCGCGAGGTGGAGCCAATCCCAGAAACCCTATCTTAGTCCGGATTGGAGTCTGCAACTCGAC TCCATGAAATCGGAATCGCTAGTAATCGCGGATCAGCATTGCCGCGGTGAATACGTTCCCGGGCCTTGTACACACCGCCCGTCACACC ATGGGAGTTTGTTGCACCAGAAGCAGGTAGCTTAACCGTAAGGGGGGCGCTTGCCACGGTGTGGCCGATGACTGGGGTGAAGTCGTAA CAAGGTA

Sl1345

AGAGTTTGATCATGGCTCAGATTGAACGCTGGCGGCATGCTTTACACATGCAAGTCGAACGGCAGCGGGGGCTTCGGCCTGCCGGCGA GTGGCGAACGGGTGAGTAATGCATCGGAACGTGCCCATGTCGTGGGGGATAACGTATCGAAAGTTACGCTAATACCGCATACGTCCTG AGGGAGAAAGCGGGGGACTCGCAAGAGCCTCGCGCGATTGGAGCGGCCGATGTCGGATTAGCTAGTTGGTAGGGTAAAAGCCTACCAA GGCGACGATCCGTAGCTGGTCTGAGAGGATGATCAGCCACACTGGGACTGAGACACGGCCCAGACTCCTACGGGAGGCAGCAGTGGGG AATTTTGGACAATGGGGGAAACCCTGATCCAGCCATGCCGCGTGAGTGAAGAAGGCCTTCGGGTTGTAAAGCTCTTTCAGACGGAAAG AAAACTTTTGGGCTAACACCCTGAGAGGATGACGGTACCGTAAGAAGAAGCACCGGCTAACTACGTGCCAGCAGCCGCGGTAATACGT AGGGTGCGAGCGTTAATCGGAATTACTGGGCGTAAAGCGTGCGCAGGCGGTTGTGCAAGACAGGTGTGAAATCCCCGGGCTTAACCTG GGAACTGCGCTTGTGACTGCACAACTAGAGTACGGCAGAGGGGGGTGGAATTCCTGGTGTAGCAGTGAAATGCGTAGATATCAGGAGG AACATCGATGGCGAAGGCAGCCCCCTGGGCCAGTACTGACGCTCATGCACGAAAGCGTGGGGAGCAAACAGGATTAGATACCCTGGTA GTCCACGCCCTAAACGATGTCGACTAGTTGTTCGGAGGGTAAAACCTCTGAGTAACGTAGCTAACGCGTGAAGTCGACCGCCTGGGGA GTACGGCCGCAAGGTTAAAACTCAAAGGAATTGACGGGGACCCGCACAAGCGGTGGATGATGTGGATTAATTCGATGCAACGCGAAAA CCTTACCTACCCTTGACATGTCAGGAACCCTGCTGAAAAGTGGGGGTGCTCGAAAGAGAGCCTGAACACAGGTGCTGCATGGCTGTCG TCAGCTCGTGTCGTGAGATGTTGGGTTAAGTCCCGCAACGAGCGCAACCCTTGTCATTAGTTGCTACGCAAGAGCACTCTAGTGAGAC TGCCGGTGACAAACCGGAGGAAGGTGGGGATGACGTCAAGTCCTCATGGCCCTTATGGGTAGGGCTTCACACGTCATACAATGGTCGG TACAGAGGGTTGCCAAGCCGCGAGGTGGAGC

Sl1347a

ATCGGGTTGCGTCCCATTAGCTTGTTGGTAGGGTAATGGCCTACCAAGGCGACGATGGGTAGCTGGTCTGAGAGGATGATCAGCCACA CTGGAACTGAAACACGGTCCAGACTCCCACGGGAGGCAGCAGTTGGGAATATTGGACAATGGGGGAAACCCTGATCCAGCAATGCCGC GTGAATGATGAAGGCCTTAGGGTCGTAAAGTTCTTTTAGTGGGGAAGAAGGGTAACTTGACGGTACCCACAGAAAAAGCACCGGCTAA CTCCGTGCCAGCAGCCGCGGTAATACGGAGGGTGCAAGCGTTGTTCGGAATTATTGGGCGTAAAGCGCGTGTAGGCGGCTATGAAAGT CTGGTGTGAAAGCCCGGGGCTTAACCCCGGAAGTGCACTGGATACTACATAGCTAGAGGGTTAGAGAGGAAAGCGGAATTCTTGGTGT AGGGGTGAAATCCGTAGATATCAAGAGGAACACCGATGGCGAAGGCAGCTTTCTGGCTAACATCTGACGCTGAGACGCGAAAGCGTGG GTAGCAAACAGGATTAGATACCCTGGTAGTCCACGCCCTAAACGATGGATACT

Sl1348b

AAGTACGGTCGCAAGATTAAAACTCAAAGGAATTGACGGGGGTCCGCACAAGCGGTGGAGCATGTGGTTTAATTCGATGATACGCGAG GAACCTTACCTAGGCTAGAATGTGAGTGACAGATGGTGAAAGCCGTTCTTCCTTCGGGACACGAAACAAGGTGCTGCATGGTTGTCGT CAGCTCGTGCCGTGAGGTGTTGGGTTAAGTCCCGCAACGAGCGCAACCCCTATTGTTAGTTACCAGCACGTTAAGGTGGGGACTCTAG CAAGACTGCCGGCGTAAGCCGCGAGGAAGGTGGGGATGACGTCAAATCATCATGGCCTTTATGCCTAGGGCGACACACGTGCTACAAT GGCCGGCACAGAGGGCTGCGAGACCGCGAGGTTTAGCCAATCCCATAAAGCCGGTCCCAGTTCGGATTGGAGTCTGCAACTCGACTCC ATGAAGGTGGAATCGCTAGTAATCGCGCATCAGCCATGGCGCGGTGAATACGTTCCCGGACCTTGTACACACCGCCCGTCAAGCCATG GAAGTTGGGGGTACCTAAAGATGGTGACTTTACGGGGAGCTATCTAAGGTAAAACCAGTAACTGGGGCTAAGTCGTAACAAGGTA sl1349 
AGAGTTTGATCATGGCTCAGAATCAACGCTGGCGGCGTGCCTAACACATGCAAGTCGAACGCGAAAAGGGCTTCGGCCCTTAGTAGAG TGGCGTACGGGTGAGTAACACGTGGGTAATCTACCTTTGGGTGGGGAATAACTCAGGGAAACTTGAGCTAATACCGCATAATGCAGCG GCTCGACATCGAGACAGTTGTTAAAGTAGTAATACGCCTGAAGAGGAGCCCGCGCCTGATTAGCTAGTTGGTGGGGTAACGGCCTACC AAGGCTACGATCAGTAGCTGGTCTGAGAGGACGGCCAGCCACAATGGCACTGAAACACGGGCCATACTCCTACGGGAGGCAGCAGTGG GGAATTTTGCGCAATGGGCGAAAGCCTGACGCAGCAACGCCGCGTGAAGGATGAAATCTTTCGGGATGTAAACTTCGCAAGTGTGGGA AGAATACAATGACGGTACCACAAGTAAGCCCCGGCTAACTCCGTGCCAGCAGCCGCGGTAATACGGGGGGGGCAAGCGTTGTTCGGAA TTACTGGGCGTAAAGGGCGCGTAGGCGGGTCTTCAAGTCAGCCGTGAAATCTCCAGGCTTAACCTGGAAGGGTCGGTTGATACTGTCG AGCTAGAGTGTAGAAGAGGCAACTGGAATTCCGTGTGTAGCGGTGAAATGCGTAGATATACCGAGGAACACCTGCGGCGAAAGCGGGT TGCTGGGCTAACACTGACGCTGAGGCGCGAAAGCTAGGGTAGCAAACGGGATTAGATACCCCGGTAGTCCTAGCCTTAAACGATGCTG ACTTGGTGTCCCGGGTTTTAAGTCCCGGGGTGCTGGAGCTAACGCGTTAAGTCAGCCGCCTGGGGAGTACGGTCGCAAGGCTGAAACT CAAAGGAATTGACGGGGACCCGCACAAGCGGTGGAGCATGTGGTTTAATTCGACGCAACGCGAAGAACCTTACCTGGGCTAGAATGCG GTGGATAAGTCTCAGAGATGAGACGATCCGAGTAATCGGCTCCTGCCTGCAAGGTGCTGCGTGGCTGTCGTCAGCTCGTGTCGTGAGA TGTTGGGTTAAGTCCCGCAACGAGCGCAACCCTTACCGTGAGTTACCATCATTTAGTTGGGGACTCTCGCGGAACTGCCGGTGATAAA CCGGAGGAAGGTGGGGATGACGTCAAGTCCTCATGGCCTTTATGTCCAGGGCTACACACGTGCTACAATGGACGGTACAAACCGCTGC GAAATCGCGAGATGGAGCTAATCGGAAAAAACCGTTCTCAGTTCGGATTGGAGTCTGCAACTCGACTCCATGAAGTTGGAATCGCTAG TAATCGCAGATCAGCATGCTGCGGTGAATACGTTCCCGGGTCTTGTACACACCGCCCGTCACATCACGAAAGTGGGCTGTACTAGAAG ACGTTGAGCTAACCGCAAGGAGGCAGGCGTCCACGGTATGGTTCATGATTGGGGTGAAGTCGTAACAAGGTA

Sl1350

AGAGTTTGATCATGGCTCAGGATGAACGCTAGCGGCAAGCTTAATACATGCAAGTCGAGGGGCAGCGCAGTGTAGCAATACATGGGCG GCGACCGGCAAACGGGTGCGGAACACGTACAGAACCTTCCTTCGAGCGGGGAATAGCCCAGAGAAATTTGGATTAATACCCCATAGTA TATTGGGGTGGCATCACTTTAATATTAAAGATTTATCACTTGAAGATGGCTGTGCGGCTGATTAGATAGTTGGCGGGGTAACGGCCCA CCAAGTCTGCGATCAGTAACTGGTGTGAGAGCACGACCAGTCACACGGGCACTGAGACACGGGCCCGACTCCTACGGGAGGCAGCAGT AAGGAATATTGGTCAATGGACGAAAGTCTGAACCAGCTATGACGCGTGGAGGATGAAGGCCCTCTGGGTTGTAAACTTCTTTTATATG GGACGAAAAAGGGTCTTTCTAGATCAACTGACGGTACCATGTGAATAAGCACCGGCTAACTCCGTGCCAGCAGCCGCGGTAATACGGA GGGTGCAAGCGTTATCCGGATTCACTGGGTTTAAAGGGTGCGTAGGTGGGTTGGTAAGTCAGTGGTGAAATCTCCGAGCTTAACTTGG AAACTGCCATTGATACTATCAGTCTTGAATATTGTGGAGGTTAGCGGAATATGTCATGTAGCGGTGAAATGCTTAGATATGACATAGA ACACCAATTGCGAAGGCAGCTGGCTACACATATATTGACACTGAGGCACGAAAGCGTGGGGATCAAACAGGATTAGATACCCTGGTAG TCCACGCCCTAAACTATGGATACTCGACATATGCGATACACTGTATGTGTCTGAGCGAAAGCATTAAGTATCCCACCTGGGAAGTACG ATCGCAAGATTGAAACTCAAAGGAATTGGCGGGGGTCCGCACAAGCGGTGGAGCATGTGGTTTAATTCGATGATACGCGAGGAACCTT ACCTGGGCTAGAATGCGGTTTGACCGTGGGTGAAAGCTCATTTTGTAGCAATACACAGATCGTAAGGTGCTGCATGGCTGTCGTCAGC TCGTGCCGTGAGGTGTTGGGTTAAGTCCCGCAACGAGCGCAACCCCTATCACTAGTTGCCATCAGGTAATGCTGGGAACTCTAGTGAA ACTGCCGTCGTAAGGCGTGAGGAAGGAGGGGATGATGTCAAGTCATCATGGCCTTTATGCCCAGGGCTACACACGTGCTACAATGGCG AGTACAAAGGGCAGCTACCTGGTGACAGGATGCTAATCTCAAAAAACTCGTCTCAGTTCGAATTGGAGTCTGCAACTCGACTCCATGA AGCTGGAATCGCTAGTAATCGTATATCAGCAATGATACGGTGAATACGTTCCCGGACCTTGTACACACCGCCCGTCAAGCCATGGAAG CTGGGTGTACCTAAAGTCGGTAACCGCAAGGAGCCGCCTAGGGTAAAACTAGTAACTGGGGCTAAGTCGTAACAAGGTA Sl1351

AGAGTTTGATCATGGCTCAGATTGAACGCTGGCGGCATGCTTTACACATGCAAGTCGAACGGCAGCGCGGGGCAACCTGGCGGCGAGT GGCGAACGGGTGAGTAATATATCGGAACGTACCCAAGAGTGGGGGATAACGTAGCGAAAGTTACGCTAATACCGCATACGATCTAAGG ATGAAAGCAGGGGACCGCAAGGCCTTGTGCTCCTGGAGCGGCCGATATCTGATTAGCTAGTTGGTAGGGTAAAGGCCTACCAAGGCTA CGATCAGTAGCTGGTCTGAGAGGACGACCAGCCACACTGGAACTGAGACACGGTCCAGACTCCTACGGGAGGCAGCAGTGGGGAATTT TGGACAATGGGCGCAAGCCTGATCCAGCAATGCCGCGTGAGTGAAGAAGGCCTTCGGGTTGTAAAGCTCTTTTGTCAGGGAAGAAACG GTAGAGGCTAATATCCTTTGCTAATGACGGTACCTGAAGAATAAGCACCGGCTAACTACGTGCCAGCAGCCGCGGTAATACGTAGGGT GCAAGCGTTAATCGGAATTACTGGGCGTAAAGCGTGCGCAGGCGGTTTTGTAAGTCTGTCGTGAAATCCCCGGGCTCAACCTGGGAAT TGCGATGGAGACTGCAAGGCTAGAATCTGGCAGAGGGGGGTAGAATTCCACGTGTAGCAGTGAAATGCGTAGAGATGTGGAGGAACAC CGATGGCGAAGGCAGCCCCCTGGGTCAAGATTGACGCTCATGCACGAAAGCGTGGGGAGCAAACAGGATTAGATACCCTGGTAGTCCA CGCCCTAAACGATGTCTACTAGTTGTCGGGTTTTAATTAACTTGGTAACGCAGCTAACGCGTGAAGTAGACCGCCTGGGGAGTACGGT CGCAAGATTAAAACTCAAAGGAATTGACGGGGACCCGCACAAGCGGTGGATGATGTGGATTAATTCGATGCAACGCGAAAAACCTTAC CTACCCTTGACATGGAAGGAATCCTGGAGAGATCTGGGAGTGCCCGAAAGGGAACCTTTACACAGGTGCTGCATGGCTGTCGTCAGCT CGTGTCGTGAGATGTTGGGTTAAGTCCCGCAACGAGCGCAACCCTTGTCATTAGTTGCTACGAAAGAGCACTCTAATGAGACTGCCGG TGACAAACCGGAGGAAGGTGGGGATGACGTCAAGTCCTCATGGCCCTTATGGGTAGGGCTTCACACGTCATACAATGGTACATACAGA GGGCCGCCAACCCGCGAGGGGGAGCTAATCCCAGAAAGTGTATCGTAGTCCGGATTGTAGTCTGCAACTCGACTACATGAAGTTGGAA TCGCTAGTAATCGCGGATCAGCATGTCGCGGTGAATACGTTCCCGGGTCTTGTACACACCGCCCGTCACACCATGGGAGCGGGTTTTA CCAGAAGTAGGTAGCTTAACCGCAAGGAGGGCGCTTACCACGGTAGGATTCGTGACTGGGGTGAAGTCGTAACAAGGTA Sl1352

AGAGTTTGATCATGGCTCAGAATGAACGCTGGCGGCGTGGTTAAGACATGCAAGTCGAACGGGACTTTATTCGTAGCAATACGCGTGA AGTTCAGTGGCGAACGGGTGCGTAACACGTGAACAATCTACCTATAAGTGTGGAATAGCTCGCCGAAAGGCGAATTAATACCGCATGT GGTGGTTCTCCGCATGGAGAGCCTACTAAAGTCGGGGACCGCAAGGCCTGACGCTAATAGAGGAGTTCGCGGCCTATCAGCTAGTTGG CGAGGTAACGGCTCACCAAGGCAAAGACGGGTAGCTGGTCTAAGAGGACGGTCGGACACACTGACACTGAATAACGGGTCAGACTCCT ACGGGAGGCAGCAGTCGGGAATTTTGGGCAATGGGCGAAAGCCTGACCCAGCAACGCCGCGTGAAGGATGAAGTATTTCGGTATGTAA ACTTCGAAAGAATGGGAAGAATAAATGACGGTACCATTTATAAGCTCCGGCTAACTACGTGCCAGCAGCCGCGGTAATACGTAGGGAG CAAGCGTTGTTCGGATTTACTGGGCGTAAAGGGCGCGTAGGCGGCGCGGTAAGTCACTTGTGAAATCTCTGAGCTTAACTCAGAACGG CCAAGTGATACTGCAGTGCTAGAGTGTAGAAGGGGCAATCGGAATTCTTGGTGTAGCGGTGAAATGCGTAGATATCAAGAGGAACACC TGAGGTGAAGACGGGTTGCTGGTCTAACACTGACGCTGAGGCGCGAAAGCCAGGGGAGCAAACGGGATTAGATACCCCGGTAGTCCTG GCCCTAAACGATGAATACTTGGTGTCCGGGGTTTCAAGACCCTGGGTGCCGTCGCTAACGTTTTAAGTATTCCGCCTGGGGAGTACGC TCGCAAGAGTGAAACTCAAAGGAATTGACGGGGACCCGCACAAGCGGTGGAGCATGTGGTTTAATTCGACGCAACGCGAAGAACCTTA CCTGGACTAGAATGTGAGGGGATATCGGGTAATGCCGGTAGTCCGGGAAACCGGACCCAAAACAAGGTGCTGCATGGCTGTCGTCAGC TCGTGTCGTGAGATGTTGGGTTAAGTCCCGCAACGAGCGCAACCCTTATCAACAGTTGCCATCATTAAGTTGGGAACTCTGTTGAGAC TGCCGTTGATAAAACGGAGGAAGGTGGGGATGATGTCAAGTCATCATGGCCTTTATGTTCAGGGCTACACACGTGCTACAATGGATGG TACAAAACGTCGCAATCCCGCGAGGGGGAGCCAATCGCGAAAACCATCCTCAGTTCGGATTGAAGTCTGCAACTCGACTTCATGAAGT TGGAATCGCTAGTAATCGCAGATCAGCATGCTGCGGTGAATACGTTCCCGGGTCTTGTACACACCGCCCGTCACATCACGAAAGTAGG TTGTACTAGAAGTAGCTGGGCCAACTCGCAAGAGGGGTAGGTTACCACGGTATGATTTATGATTGGGGTGAAGTCGTAACAAGGTA Sl1354

AGAGTTTGATCATGGCTCAGATTGAACGCTGGCGGCATGCTTTACACATGCAAGTCGAACGGCAGCGCGGGGCAACCTGGCGGCGAGT GGCGAACGGGTGAGTAATATATCGGAACGTACCCAGAAGTGGGGGATAACGTAGCGAAAGTTACGCTAATACCGCATACGATCTACGG ATGAAAGTGGGGGACCTTCGGGCCTCATGCTTTTGGAGCGGCCGATATCTGATTAGCTAGTTGGTGAGGTAAAGGCTCACCAAGGCGA CGATCAGTAGCTGGTCTGAGAGGACGACCAGCCACACTGGAACTGAGACACGGTCCAGACTCCTACGGGAGGCAGCAGTGGGGAATTT TGGACAATGGGCGCAAGCCTGATCCAGCAATGCCGCGTGAGTGAAGAAGGCCTTCGGGTTGTAAAGCTCTTTTGTCAGGGAAGAAACG 
GTCTAGGTTAATACCTTGGGCTAATGACGGTACCTGAAGAATAAGCACCGGCTAACTACGTGCCAGCAGCCGCGGTAATACGTAGGGT GCAAGCGTTAATCGGAATTACTGGGCGTAAAGCGTGCGCAGGCGGTTTTGTAAGTCTGTCGTGAAAGCCCCGGGCTCAACCTGGGAAT TGCGATGGAGACTGCAAGGCTTGAATCTGGCAGAGGGGGGTAGAATTCCACGTGTAGCAGTGAAATGCGTAGAGATGTGGAGGAACAC CGATGGCGAAGGCAGCCCCCTGGGTCAAGATTGACGCTCATGCACGAAAGCGTGGGGAGCAAACAGGATTAGATACCCTGGTAGTCCA CGCCCTAAACGATGTCTACTAGTTGTCGGGTTTTAATTAACTTGGTAACGCAGCTAACGCGTGAAGTAGACCGCCTGGGGAGTACGGT CGCAAGATTAAAACTCAAAGGAATTGACGGGGACCCGCACAAGCGGTGGATGATGTGGATTAATTCGATGCAACGCGAAAAACCTTAC CTACCCTTGACATGGAAGGAAGTCCGGAGAGATCTGGATGTGCCCGAAAGGGAACCTTCACACAGGTGCTGCATGGCTGTCGTCAGCT CGTGTCGTGAGATGTTGGGTTAAGTCCCGCAACGAGCGCAACCCTTGTCATTAGTTGCTACATTTAGTTGAGCACTCTAATGAGACTG CCGGTGACAAACCGGAGGAAGGTGGGGATGACGTCAAGTCCTCATGGCCCTTATGGGTAGGGCTTCACACGTAATACAATGGCGCGTA CAGAGGGTTGCCAACCCGCGAGGGGGAGCCAATCCCAGAAAGCCGATCGTAGTCCGGATTGTAGTCTGCAACTCGACTACATGAAGTC GGAATCGCTAGTAATCGCGGATCAGCATGTCGCGGTGAATACGTTCCCGGGCCTTGTACACACCGCCCGTCACACCATGGGAGCGGGT TTTACCAGAAGTAGGTAGCTTAACCGCAAGGGGGGCGCTTACCACGGTAGGATTCGTGACTGGGGTGAAGTCGTAACAAGGTA Sl1355

AGAGTTTGATCATGGCTCAGAATGAACGCTGGCGGCGTGGTTAAGACATGCAAGTCGAACGGGACTTTATTCGTAGCAATACGCGTGA AGTTCAGTGGCGAACGGGTGCGTAACACGTGAACAATCTACCTATAAGTGTGGAATAGCTCGCCGAAAGGCGAATTAATACCGCATGT GGTGGTTCTCCGCATGGAGAGCCTACTAAAGTCGGGGACCGCAAGGCCTGACGCTAATAGAGGAGTTCGCGGCCTATCAGCTAGTTGG CGAGGTAACGGCTCACCAAGGCAAAGACGGGTAGCTGGTCTAAGAGGACGGTCGGACACACTGACACTGAATAACGGGTCAGACTCCT ACGGGAGGCAGCAGTCGGGAATTTTGGGCAATGGGCGAAAGCCTGACCCAGCAACGCCGCGTGAAGGATGAAGTATTTCGGTATGTAA ACTTCGAAAGAATGGGAAGAATAAATGACGGTACCATTTATAAGCTCCGGCTAACTACGTGCCAGCAGCCGCGGTAATACGTAGGGAG CAAGCGTTGTTCGGATTTACTGGGCGTAAAGGGCGCGTAGGCGGCGCGGTAAGTCACTTGTGAAATCTCTGAGCTTAACTCAGAACGG CCAAGTGATACTGCAGTGCTAGAGTGTAGAAGGGGCAATCGGAATTCTTGGTGTAGCGGTGAAATGCGTAGATATCAAGAGGAACACC TGAGGTGAAGACGGGTTGCTGGTCTAACACTGACGCTGAGGCGCGAAAGCCAGGGGAGCAAACGGGATTAGATACCCCGGTAGTCCTG GCCCTAAACGATGAATACTTGGTGTCCGGGGTTTCAAGACCCTGGGTGCCGTCGCTAACGTTTTAAGTATTCCGCCTGGGGAGTACGC TCGCAAGAGTGAAACTCAAAGGAATTGACGGGGACCCGCACAAGCGGTGGAGCATGTGGTTTAATTCGACGCAACGCGAAGAACCTTA CCTGGACTAGAATGTGAGGGGATATCGGGTAATGCCGGTAGTCCGGGAAACCGGACCCAAAACAAGGTGCTGCATGGCTGTCGTCAGC TCGTGTCGTGAGATGTTGGGTTAAGTCCCGCAACGAGCGCAACCCTTATCAACAGTTGCCATCATTAAGTTGGGAACTCTGTTGAGAC TGCCGTTGATAAAACGGAGGAAGGTGGGGATGATGTCAAGTCATCATGGCCTTTATGTTCAGGGCTACACACGTGCTACAATGGATGG TACAAAACGTCGCAATCCCGCGAGGGGGAGCCAATCGCGAAAACCATCCTCAGTTCGGATTGAAGTCTGCAACTCGACTTCATGAAGT TGGAATCGCTAGTAATCGCAGATCAGCATGCTGCGGTGAATACGTTCCCGGGTCTTGTACACACCGCCCGTCACATCACGAAAGTAGG TTGTACTAGAAGTAGCTGGGCCAACTCGCAAGAGGGGTAGGTTACCACGGTATGATTTATGATTGGGGTGAAGTCGTAACAAGGTA Sl1359

AGAGTTTGATCATGGCTCAGATTGAACGCTGGCGGCATGCCTTACACATGCAAGTCGAACGGTAACGCGGGGCAACCTGGCGACGAGT GGCGAACGGGTGAGTAATACATCGGAACGTGCCCAGTAGTGGGGGATAGCCCGGCGAAAGCCGGATTAATACCGCATACGACCTACGG GTGAAAGCGGGGGATCGCAAGACCTCGCGCTATTGGAGCGGCCGATGTCAGATTAGGTAGTTGGTGAGGTAAAGGCTCACCAAGCCTT CGATCTGTAGCTGGTCTGAGAGGACGACCAGCCACACTGGGACTGAGACACGGCCCAGACTCCTACGGGAGGCAGCAGTGGGGAATTT TGGACAATGGGCGCAAGCCTGATCCAGCCATGCCGCGTGCGGGAAGAAGGCCTTCGGGTTGTAAACCGCTTTTGTCAGGGAAGAAACG CTCTGGGCTAATACCCCGGGGTAATGACGGTACCTGAAGAATAAGCACCGGCTAACTACGTGCCAGCAGCCGCGGTAATACGTACGGT GCAAGCGTTAATCGGAATTACTGGGCGTAAAGCGTGCGCAGGCGGTCTTGCAAGACAGATGTGAAATCCCCGGGCTCAACCTGGGAAC TGCATTTGTGACTGCAAGGCTGGAGTGCGGCAGAGGGGGATGGAATTCCGCGTGTAACAGTGAAATGCGTAGATATGCGGAGGAACAC CGATGGCGAAGGCAATCCCCTGGGCCTGCACTGACGCTCATGCACGAAAGCGTGGGGAGCAAACAGGATTAGATACCCTGGTAGTCCA CGCCCTAAACGATGTCAACTGGTTGTTGGACGGCTTGCTGTTCAGTAACGAAGCTAACGCGTGAAGTTGACCGCCTGGGGAGTACGGC CGCAAGGTTGAAACTCAAAGGAATTGACGGGGACCCGCACAAGCGGTGGATGATGTGGTTTAATTCGATGCAACGCGAAAAACCTTAC CTACCCTTGACATGTCAAGAATCTTGCAGAGATGTGAGAGTGCTCGAAAGAGAACTTGAACACAGGTGCTGCATGGCCGTCGTCAGCT CGTGTCGTGAGATGTTGGGTTAAGTCCCGCAACGAGCGCAACCCTTGTCATTAGTTGCTACGAAAGGGCACTCTAATGAGACTGCCGG TGACAAACCGGAGGAAGGTGGGGATGACGTCAGGTCCTCATGGCCCTTATGGGTAGGGCTACACACGTCATACAATGGCCGGTACAGA GGGCTGCCAACCCGCGAGGGGGAGCTAATCCCAGAAAACCGGTCGTAGTCCGGATCGCAGTCTGCAACTCGACTGCGTGAAGTCGGAA TCGCTAGTAATCGCGGATCAGCTTGCCGCGGTGAATACGTTCCCGGGTCTTGTACACACCGCCCGTCACACCATGGGAGCGGGTTCTG CCAGAAGTAGTTAGCCTAACCGCAAGGAGGGCGATTACCACGGCAGGGTTCGTGACTGGGGTGAAGTCGTAACAAGGT Sl1360

AGAGTTTGATCATGGCTCAGGATGAACGCTAGCGGCAGGCCTAACACATGCAAGTCGAGGGGTAGAGGAAGCTTGCTTCCTTGAGACC GGCGCACGGGTGCGTAACGCGTATGCAATCTACCTTATACAGAGGGATAGCCCAGAGAAATTTGGATTAATACCTCATAGTATTATTG AATGGCATCATTTGATAATTAAAGTTCCAACGGTATAAGATGAGCACGCGTCCCATTAGTTAGTTGGTAAGGTAACGGCTTACCAAGA CAATGATGGGTAGGGGTCCTGAGAGGGAGATCCCCCACACTGGTACTGAGACACGGACCAGACTCCTACGGGAGGCAGCAGTGAGGAA TATTGGTCAATGGACGCAAGTCTGAACCAGCCATGCCGCGTGCAGGATGACGGTCCTATGGATTGTAAACTGCTTTTATACAGGAAGA AACACTCCCTCGTGAGGGAGCTTGACGGTACTGTAGGAATAAGGATCGGCTAACTCCGTGCCAGCAGCCGCGGTAATACGGAGGATCC AAGCGTTATCCGGAATCATTGGGTTTAAAGGGTCCGTAGGCGGTTTAATAAGTCAGTGGTGAAAGCCTATCGCTTAACGATAGAACGG CCATTGATACTGTTAGACTTGAATTAGTGGGAAGTAACTAGAATATGTAGTGTAGCGGTGAAATGCTTAGATATTACATGGAATACCA ATTGCGAAGGCAGGTTACTATCACTATATTGACGCTGATGGACGAAAGCGTGGGGAGCGAACAGGATTAGATACCCTGGTAGTCCACG CCGTAAACGATGGATACTAGCTGTTCGGAGCAATCTGAGTGGCTAAGCGAAAGTGATAAGTATCCCACCTGGGGAGTACGTTCGCAAG AATGAAACTCAAAGGAATTGACGGGGGCCCGCACAAGCGGAGGAGCATGTGGTTTAATTCGATGATACGCGAGGAACCTTACCAGGGC TTAAATGGGAGACGACAGGACTGGAAACAGTTTTTTCTTCGGACGTCTTTCAAGGTGCTGCATGGTTGTCGTCAGCTCGTGCCGTGAG GTGTCAGGTTAAGTCCTATAACGAGCGCAACCCCTATTGTTAGTTGCCAGCGGGTCATGCCGGGAACTCTAACAAGACTGCCGGTGCA AACCGTGAGGAAGGTGGGGGTGACGTCAAATCATCACGGCCCTTACGTCCTGGGCTACACACGTGCTACAATGGGCGGTACAGAGAGC AGCCACTACGCAAGTAGGCGCGAATCTTCAAAACCGTTCTCAGTTCGGATCGGAGTCTGCAACTCGACTCCGTGAAGCTGGATTCGCT AGTAATCGCATATCAGCCATGATGCGGTGAATACGTTCCCGGGCCTTGTACACACCGCCCGTCAAGCCATGGAAGCTGGGGGTACCTG AAGTCGGTGACCGCAAGGAGCTGCCTAGGGTAAAACTTGTAACTGGGGCTAAGTCGTAACAAGGT Sl1361

AGAGTTTGATCATGGCTCAGAACGAACGCTGGCGGCGTGCTTAACACATGCAAGTCGAACGTGATCCGGAGCTTGCTCCGGTGAAAGT GGCGCACGGGTGAGTAACGCGTGGATAACCTGCCCTGGTATCTGGGATAACATCTCGAAAGGGGTGCTAATACCGGATAAGCCCACGG ACTCCTCGGAGTCTGCGGGAAAAGGTGGCCTCTATTTATAAGCTACCGTATCAGGATGGGTCCGCGTACCATTAGCTAGTTGGTGGGG TAATGGCCTACCAAGGCTACGATGGTTAGCTGGTCTGAGAGGATGATCAGCCACACTGGAACTGAGACACGGTCCAGACTCCTACGGG AGGCAGCAGTGGGGAATTTTGCGCAATGGGGGAAACCCTGACGCAGCAACGCCGCGTGAGTGATGAAGGCTTTCGGGTCGTAAAGCTC TGTCGGAGGGGAAGAAATGGAAACGGTTAATACCCGTTTTTCTTGACGGTACCCTCAAAGGAAGCACCGGCTAACTCCGTGCCAGCAG CCGCGGTAATACGGAGGGTGCAAGCGTTGTTCGGATTTATTGGGCGTAAAGCGCGTGTAGGCGGTTTTTTAAGTCTGATGTGAAAGCC CTGGGCTCAACCCAGGAAGTGCATTGGATACTGGAAGACTTGAATACGGGAGAGGGTAGTGGAATTCCTAGTGTAGGAGTGAAATCCG TAGATATTAGGAGGAACACCGGTGGCGAAGGCGGCTACCTGGACCGATATTGACGCTGAGACGCGAAAGCGTGGGGAGCAAACAGGAT TAGATACCCTGGTAGTCCACGCCGTAAACGATGAGAACTAGGTGTTGCGGGTATTGACCCCTGCAGTGCCGCAGCTAACGCATTAAGT 
TCTCCGCCTGGGAAGTACGGTCGCAAGACTAAAACTCAAAGGAATTGACGGGGGCCCGCACAAGCGGTGGAGCATGTGGTTTAATTCG ACGCAACGCGCAGAACCTTACCTGGGCTTGACATCTGTGGAATCTTCGTGAAAGCGAGGAGTGCCCTCGGGAGCCACAAGACAGGTGC TGCATGGCTGTCGTCAGCTCGTGTCGTGAGATGTTGGGTTAAGTCCCGCAACGAGCGCAACCCCTATCCTTAGTTGCCATCATTCAGT TGGGCACTCTAAGGAGACTGCCGGTGTCAAACCGGAGGAAGGTGGGGATGACGTCAAGTCCTCATGGCCCTTATGTCCAGGGCTACAC ACGTGCTACAATGGCCGGTACAAAGGGTTGCAATACCGCGAGGTGGAGCCAATCTCAAAAAGCCGGCCTCAGTTCGGATTGGAGTCTG CAACTCGACTCCATGAAGTTGGAATCGCTAGTAATCGCGGATCAGCATGCCGCGGCGAATACGTTCCCGGGCCTTGTACACACCGCCC GTCACACCACGGGAGTCGGTTGGTCCCGAAGTGCGTGAGCTAACCCGCAAGGGAGGCAGCGTCCTAAGGAATGGCCGGTGACTGGGGT GAAGTCGTAACAAGGTA

Sl1362

AGAGTTTGATCATGGCTCAGATTGAACGCTGGCGGCATGCTTAACACATGCAAGTCGAACGGTAACAGGACGCTAGGATCCCTTCGGG GTGACTTTGTCGCTGACGAGTGGCGGACGGGTGAGTAATGCATAGGAATCTACCCAGTAGTGGGGGATAACGTGGAGAAATCCACGCT AATACCGCATATGTCCTACGGGACAAAGCAGGGGACCTTCGGGCCTTGCGCTATTGGATGAGCCTATGTTGGATTAGCTTGTTGGTGA GGTAAAGGCTCACCAAGGCTACGATCCATAGCTGGTCTGAGAGGATGATCAGCCACACTGGGACTGAGACACGGCCCAGACTCCTACG GGAGGCAGCAGTGGGGAATATTGCACAATGGGCGCAAGCCTGATGCAGCAATGCCGCGTGTGTGAAGAAGGCCTGCGGGTTGTAAAGC ACTTTTATTAGGAAAGAAAAACCCGGAGCTAATACCTCCGGCATTGACGGTACCTAAAGAATAAGCACCGGCTAACTCAGTGCCAGCA GCCGCGGTAATACTGAGGGTGCAAGCGTTAATCGGAATTACTGGGCGTAAAGCGAGTGTAGGCGGCTACTTAAGTCGGATGTGAAAGC CCCGGGCTCAACCTGGGAATTGCATTCGATACTGGGTAGCTAGAGTTTGGTAGAGGTAAGTGGAATTCCAGGTGTAGCGGTGAAATGC ATAGATATCTGGAGGAACATCAGTGGCGAAGGCGGCTTACTGGACCAAAACTGACGCTGAGGCTCGAAAGCGTGGGGAGCAAACAGGA TTAGATACCCCGGTAGTCCACGCCCTAAACGATGTCAACTAGACGTTGGGTTCATTAAGGAACTTAGTGTCGAAGCTAACGCGTTAAG TTGACCGCCTGGGGAGTACGGCCGCAAGGTTGAAACTCAAAGGAATTGACGGGGGCCCGCACAAGCGGTGGAGCATGTGGTTTAATTC GATGCAACGCGAAGAACCTTACCAGCCCTTGACATCCTGGGAACTTTGTAGAGATACATTGGTGCCTTCGGGAATCCAGTGACAGGTG CTGCATGGCTGTCGTCAGCTCGTGTCGTGAGATGTTGGGTTAAGTCCCGCAACGAGCGCAACCCTTATCCTTAGTTGCCAGCACGTTA TGGTGGGAACTCTAAGGAGACTGCCGGTGATAAACCGGAGGAAGGTGGGGATGACGTCAAGTCATCATGGCCCTTATGGGCTGGGCTA CACACGTGCTACAATGGTCGGTACAGAGGGTCGCAATCCCGCGAGGGGGAGCTAATCCCAGAAAGCCGATCTTAGTCCGGATCGCAGT CTGCAACTCGACTGCGTGAAGTCGGAATCGCTAGTAATCGCGAATCAGCAATGTCGCGGTGAATACGTTCCCGGGCCTTGTACACACC GCCCGTCACACCATGGGAGTGGGTTGCACCAGAAGTAGCTAGCTTAACCTTCGGGAGAGCGGTTACCACGGTGTGATTCATGACTGGG GTGAAGTCGTAACAAGGTA

Sl1364a

AGAGTTTGATCATGGCTCAGAACGAACGCTGGCGGCGTGCCTAACACATGCAAGTCGAACGGAATTAAGGGGCTTGCTCCTTAATTTA GTGGCGCACGGGTGAGTAATGCGTGGATAACCTACCCTGGTATCCTGGATAACATCTCGAAAGGGGTGCTAATACGGGATAAGCCCAC GGGGTCTTCGGACCCTGCGGGAAAAGGTGGCCTCTGACTCAAGCTACTGTATCAGGATGGGTCCACGTACCATTAGCTAGTTGGTGGG GTAAAGGCCTACCAAGGCTACGATGGTTAGCTGGTCTGAGAGGATGATCAGCCACACTGGAACTGAGACACGGTCCAGACTCCTACGG GAGGCAGCAGTGGGGAATTTTGCGCAATGGGGGAAACCCTGACGCAGCAACGCCGCGTGAGTGATGAAGGCCTTCGGGTCGTAAAGCT CTGTCAGAGGGAAAGAAGTGTATTATGGTTAATACCCATGATACTTGACGGTACCCTCAAAGGAAGCACCGGCTAACTCCGTGCCAGC AGCCGCGGTAATACGGAGGGTGCGAGCGTTGTTCGGAATTATTGGGCGTAAAGCGCGTGTAGGCGGCTCCTTAAGTCTGATGTGAAAG CCCCGGGCTCAACCTGGGAAGTGCATTGGAAACTGGGGAACTTGAATACGGGAGAGGGTAGTGGAATTCCTGGTGTAGGAGTGAAATC CGTAGATATCAGGAGGAACACCGGTGGCGAAGGCGGCTACCTGGACCGATATTGACGCT Sl1364b

AGACGCGAAAGCGTGGGGAGCAAACAGGATTAGATACCCTGGTAGTCCACGCCGTAAACGATGTCTACTAGCCGTTGGGAGCCTTGAG CTCTTAGTGGCGCAGCTAACGCACTAAGTAGACCGCCTGGGGAGTACGGTCGCAAGATTAAAACTCAAATGAATTGACGGGGCCCGC ACAAGCGGTGGAGCATGTGGTTTAATTCGACGCAACGCGAAGAACCTTACCAGGTCTTGACATCCAGAGAACTTTCCAGAGATGGATT GGTGCCTTCGGGAGCTCTGAGACAGGTGCTGCATGGCTGTCGTCAGCTCGTGTCGTGAGATGTTGGGTTAAGTCCCGTAACGAGCGCA ACCCTTGTCCTTAGTTGCCAGCGCGTAATGGCGGGAACTCTAAGGAGACTGCCGGTGACAAACCGGAGGAAGGTGGGGATGACGTCAA GTCATCATGGCCCTTACGACCTGGGCTACACACGTGCTACAATGGGCGGTACAAAGGGTTGCCAAACCGCGAGGTGGAGCTAATCCCA TAAAACCGTTCGTAGTCCGGATTGGAGTCTGCAACTCGACTCCATGAAGTCGGAATCGCTAGTAATCGTAAATCAGAACGTTACGGTG AATACGTTCCCGGGCCTTGTACACACCGCCCGTCACACCATGGGAGTGGGTTGCAAAAGAAGTAGCTAGTCTAACCGCAAGGGGGACG GTTACCACTTTGTGATTCATGACTGGGGTGAAGTCGTAACAAGGTA

Sl1366

AGAGTTTGATCATGGCTCAGAACGAACGCTGGCGGCAGGCTTAACACATGCAAGTCGAACGCCCCGCAAGGGGAGTGGCAGACGGGTG AGTAACGCGTGGGAACGTACCTTTCAGTTCGGAATAACTCAGGGAAACTTGTGCTAATACCGGATACGCCCGCAAGGGGAAAGATTTA TCGCTGAAAGATCGGCCCGCGTTGGATTAGCTAGTTGGTGGGGTAAAGGCCTACCAAGGCGACGATCCATAGCTGGTCTGAGAGGATG ATCAGCCACACTGGGACTGAGACACGGCCCAGACTCCTACGGGAGACAGCAGTGGGGAATATTGGACAATGGGCGAAAGCCTGATCCA GCCATGCCGCGTGTGTGATGAAGGCCCTCGGGTTGTAAACCGCTTTCAGTAGGGAAGAAAATGACGGTACCTACAGAAGAAGCCCCGG CCAACTACGTGCCAGCAGCCGCGGTAACACGTAGGGGGCGAGCGTTGTCCGGATTTATTGGGCGTAAAGAGCTCGTAGGCGGTTTCGT AAGTCGGATGTGAAAACTCCAGGCTCAACTTGGAGACGCCATTCGATACTGCGATGACTAGAGTCCGGTAGGGGAGTGTGGAATTCCT GGTGTAGCGGTGAAATGCGCAGATATCAGGAGGAACACCGGCGGCGAAGGCGGCACTCTGGGCCGGTACTGACGCTGAGGAGCGAAAG CGTGGGTAGCAAACAGGATTAGATACCCTGGTAGTCCACGCCGTAAACGATGATCACTAGCTGTTGGCGATACACCGATCAGCGGCAA AGCAAAAGCATTAAGTGATCCACCTGGGGAGTACGGCCGCAAGGCTGAAACTCAAAGGAATTGACGGGGGCCCGCACAAGCGGAGGAA CATGTGGTTTAATTCGATGATACGCGAGGAACCTTACCTGGGCTTAAATGTAGAGTGCATTGAGAGGAAACTTTCATTTTCTTCGGAA CTCTTTACAAGGTGCTGCATGGTTGTCGTCAGCTCGTGCCGTGAGGTGTCGGGTTAAGTCCCATAACGAGCGCAACCCCTATTACCAG TTACAAGTGTCTGGCGAAACTGCCGGTGTAAACCGAGAGGAAGGTGGGGATGACGTCAAATCAGCGTGGCTCTTACGCCTTGGGCGAC ACACGTGCTACAATGGGATGTTACAAAGGGACGCCAAGGAGTAGTCCGGAGCAAATCCTATAAACCATCCCCCAGTTCGGATTGAGGG CTGCAACTCGCCCTCATGAAGCCGGAATCGCTAGTAACCGTAGATCAGCCTCGCTACGGTGAATACGTTCTCGGGTTTTGTACACACC GCCCGTCAAGCCATGGAAGTGGGTAGCGGATGAAGCGTCCATTTATTTGGGCTCCAATCCGAGACTCGTAACTGGGGCTAAGTCGTAA CAAGGTA

Sl1367a

AGAGTTTGATCATGGCTCAGGATGAACGCTAGCGGCAGGCTTAATACATGCAAGTCGAGGGGGATTAGTTTTCTAGCAATAGAAGATT ATGAGACCGGCAAACGGGTGCGGAACACGTACGCAACCTTCCCAAAACTGGTGGATAGCCCTCCGAAAGGAGGATTAATACACCGTAA CATAATGAAGTGGCATCACTTTATTATTATAGCTCCGGCGGTTTTGGATGGGCGTGCGCCTGATTAGGTAGTTGGCGGGGTAACGGCC CACCAAGCCTTCGATCAGTAACTGGTGTGAGAGCACGACCAGTCACACGGGCACTGAGACACGGGCCCGACTCCTACGGGAGGCAGCA GTAAGGAATATTGGTCAATGGACGCAAGTCTGAACTAGCCATGCCGCGTGAAGGATGACGGCCCTCTGGGTTGTAAACTTCTTTTATC TGGGACGAAAAAAGGGCTTTCTAGCTCGACTGACGGTACCAGAGGAATAAGCACCGGCTAACTCCGTGCCAGCAGCCGCGGTAATACG GAGGGTGCAAGCGTTATCCGGATTTACTGGGTTTAAAGGGTGCGTAGGTGGGTCTGTAAGTCAGTGGTGAAATCTCCGAGCTTAACTC GGAAACTGCCATTGATACTATAGGTCTTGAATTATCTGGAGGTAAGCGGAATATGTCATGTAGCGGTGAAATGCTTAGATATGACATA GAACACCAATTGCGAAGGCAGCTTACTACGGATCGATTGACACTGAGGCACGAAAGCGTGGGGATCAAACAGGATTAGATACCCTGGT AGTCCACGCCCTAAACGATGGATACTCGACATTTGCGATATACTGTAAGTGTCTGAGCGAAAGCATTAAGTATCCCACCTGGGAAGTA 
CGATCGCAAGATTGAAACTCAAAGGAATTGACGGGGGTCCGCACAAGCGGTGGAGCATGTGGTTTAATTCGATGATACGCGAGGAACC TTACCTGGGCTAGAATGCGGTTTGACCGTGGGTGAAAGCTCATTTTGTAGCAATACACAGATCGTAAGGTGC

Sl1367b

GCATGGCTGTCGTCAGCTCGTGCCGTGAGGTGTTGGGTTAAGTCCCGCAACGAGCGCAACCCTTGTCATTAATTGCCATCATTCAGTT GGGCACTTTAATGAAACTGCCGGTGACAAACCGGAGGAAGGTGGGGATGACGTCAAGTCCTCATGGCCCTTATGGGTAGGGCTTCACA CGTAATACAATGGCGCGTACAGAGGGTTGCCAACCCGCGAGGGGGAGCTAATCTCAGAAAGCGCGTCGTAGTCCGGATCGGAGTCTGC AACTCGACTCCGTGAAGTCGGAATCGCTAGTAATCGCGGATCAGCATGTCGCGGTGAATACGTTCCCGGGTCTTGTACACACCGCCCG TCACACCATGGGAGTGGGTTTCACCAGAAGCAGGTAGTCTAACCGCAAGGAGGGCGCTTGCCACGGTGAGATTCATGACTGGGGTGAA GTCGTAACAAGGTA

Sl1372

AAGGCGTCGCGCGATGAGATGAACCGATGTCCGATTAGCTAGTTGGCGGGGTAAAGGCCCACCAAGGCGACGATCGGTAGCTGATCTG AGAGGATGATCAGCCACACTGGAACTGAGACACGGTCCAGACTCCTACGGGAGGCAGCAGTGGGGAATATTGGACAATGGGCGCAAGC CTGATCCAGCCATGCCGCGTGGGTGAAGAAGGCCTTCGGGTTGTAAAGCCCTTTTGTCCGGAAAGAAAAGCACGGGATTAATACCCTC GTGTGATGACGGTACCGGAAGAATAAGCACCGGCTAACTTCGTGCCAGCAGCCGCGGTAATACGAAGGGTGCAAGCGTTACTCGGAAT TACTGGGCGTAAAGCGTGCGTAGGTGGTGCGTTAAGTCTGTCGTGAAATCCCCGGGCTCAACCTGGGAATGGCGATGGATACTGGCGC GCTAGAGTGAGGTAGAGGAGAGTGGAATTCCCGGTGTAGCAGTGAAATGCGTAGAGATCGGGAGGAACATCAGTTGCGAAGGCGGCTC TCTGGACCATCACTGACACTGAGGCACGAAAGCGTGGGGAGCAAACAGGATTAGATACCCTGGTAGTCCACGCCCTAAACGATGCGAA CTGGACGTTGGGCTCAATTAGGAGCTCAGTGTCGGAGCTAACGCGTTAAGTTCGCCGCCTGGGGAGTACGGTCGCAAGACTGAAACTC AAAGGAATTGACGGGGGCCCGCACAAGCGGTGGAGTATGTGGTTTAATTCGATGCAACGCGCAGAACCTTACCTGGTCTTGACATCCA CGGAATCCTTTAGAGATAGAGGAGTGCCTTCGGGAACCGTGAGACAGGTGCTGCATGGCTGTCGTCAGCTCGTGTCGTGAGATGTTGG GTTAAGTCCCGCAACGAGCGCAACCCCTGTCCTTAGTTGCCAGCACGTAATGGTGGGAACTCTAAGGAGACTGCCGGTGACAAACCGG AGGAAGGTGGGGATGACGTCAAGTCATCATGGCCCTTACGACCAGGGCTACACACGTACTACAATGGTGGGGACAGAGGGTCGCGAAG CCGCGAGGTGGAGCCAATCCCAGAAACCCTATCTTAGTCCGGATTGGAGTCTGCAACTCGACTCCATGAAGTCGGAATCGCTAGTAAT CGCGGATCAGCATTGCCGCGGTGAATACGTTCCCGGGCCTTGTACACACCGCCCGTCACACCATGGGAGTTTGTTGCACCAGAAGCAG GTAGCTTAACCGTAAGGGGGGCGCTTGCCACGGTGTGGCCGATGACTGGGGTGAAGTCGTAACAAGGTA

Sl1373

AAAGTTTGATCATGGCTCANATTGAACGCTGGCGGCATGCTTTACACATGCAAGTCGAACGGCAGCGGGGGCTTCGGCCTGCCGGCGA GTGGCGAACGGGTGAGTAATGCATCGGAACGTACCCATGTTGTGGGGGATAACGTAGCGAAAGCTACGCTAATACCGCATAAGCCCTG AGGGGGAAAGCGGGGGATTCTTCGGAACCTCGCGCAATTGGAGCGGCCGATGTCAGATTAGCTAGTTGGCAGGGTAAAGGCCTACCAA GGCGACGATCTGTAGCGGGTCTGAGAGGATGATCCGCCACACTGGGACTGAGACACGGCCAGACTCCTACGGGAGGCAGCAGTGGGGA ATTTTGGACAATGGGGGCAACCCTGATCCAGCCATGCCGCGTGAGTGAAGAAGGCCTTCGGGTTGTAAAGCTCTTTCAGTTGGGAAGA AACGGGGTTCTCTAACATAGGATCCTAATGACGGTACCGACAGAAGAAGCACCGGCTAACTACGTGCCAGCAGCCGCGGTAATACGTA GGGTGCGAGCGTTAATCGGAATTACTGGGCGTAAAGCGCGCGCAGGCGGTTTTGTAAGACAGGTGTGAAATCCCCGGGCTTAACCTGG GAACTGCGCTTGTGACTGCAAGGCTAGAGTACGGCAGAGGGGGGTGGAATTCCACGTGTAGCAGTGAAATGCGTAGATATGTGGAGGA ACACCGATGGCGAAGGCAGCCCCCTGGGCCGATACTGACGCTCATGCACGAAAGCGTGGGGAGCAAACAGGATTAGATACCCTGGTAG CCCACGCCCTAAACGATGTCGACTAGTTGTTCGGAGCGGTAACGCACTGAGTAACGTAGCTAACGCGTGAAGTCGACCGCCTGGGGAG TACGGTCGCAAGATTAAAGCTCAAAGGAATTGACGGGGACCCGCACAAGCGGTGGATGATGTGGATTAATTCGATGCAACGCGAAAAA CCTTACCTACCCTTGACATGTCTGGAATCCTTGAGAGATCAGGGAGTGCCTTCGGGAGCCAGAACACAGGTGCTGCATGGCTGTCGTC AGCTCGTGTCGTGAGATGTTGGGTTAAGTCCCGCAACGAGCGCAACCCTTGTCGCTAATTGCCATCATTTGGTTGGGCACTTTAGCGA GACTGCCGGTGACAAACCGGAGGAAGGTGGGGATGACGTCAAGTCCTCATGGCCCTTATGGGTAGGGCTTCACACGTCATACAATGGT CGGTACAGAGGGTTGCCAAGCCGCGAGGTGGAGCTAATCTCAAAAAGCCGATCGTAGTCCGGATCGTAGTCTGCAACTCGACTACGTG AAGTCGGAATCGCTAGTAATCGTGGATCAGCATGCCACGGTGAATACGTTCCCGGGTCTTGTACACACCGCCCGTCACACCATGGGAG TGGGTTTCACCAGAAGTAGGTAGCTTAACCTTCGGGAGG

Sl1374/sl1375

AGAGTTTGATCATGGCTCAGAGTGAACGTTGGCGGCGTGGATTAGGCATGCAAGTCGCGCGATAAATTTTCTTCGGAAGATGGAAAGC GGCGGAAGGGAGAGGATAAGGTAGAAATCTACCCTCGGGACGGGGATAGCTGCGGGAAACTGCTGGTAATACCCGATAATATCTTTGG ATCAAAGGTGTGATTCCGCCTGGGGATGAGTCTACTTCCTATTAGCTAGTTGGCAGGGTAATGGCCTACCAAGGCAACGATGGGTAGC GGGTGTGAGAGCATGACCCGCCTCACTGGGACTGAGAACTGCCCAGACACCTACGGGTGGCTGCAGTCGAGAATCTTCGGCAATGGGC GCAAGCCTGACCGAGCGACGCCGCGTGCGGGATGAAGGCCTTCGGGTTGTAAACCGCTGTCGTAGGGGAACAAATGTAAAGGGGTTCT CCCTTTTACTTGAGTGATCCTAGGAGGAAGGGGAGGCTAAGCTCGTGCCAGCAGCCGCGGTAAGACGAGCTCCCCGAACGTTATTCGG TATTACTGGGCTTAAAGAGTTCGTAGGCGGCCCGACAGGTGAGGTGTGAAATCCCTCGGCTCAACCGAGGAACTGCGCTTCAAACCGT CAGGCTTGAGGGAGATAGAGGTGAGCGGAACAGATGGTGGAGCGGTGAAATGCGTTGATATCATCTGGAACACCGGTGGCGAAAGCGG CTCACTGGATCTTTTCTGACGCTGAGGAACGAAAGCTAGGGTAGCGAACGGGATTAGATACCCCGGTAGTCCTAGCCGTAAACGATGA GCACTAGCCCGTGGGGACTCTCACATCCTCTCGGGCGTAGCGAAAGTGTTAAGTGCTCCGCCTGGGGAGTATGGTCGCAAGGCTGAAA CTCAAAGGAATTGACGGGGGCTCACACAAGCGGTGGAGGATGTGGCTTAATTCGAGGCTACGCGAAGAACCTTATCCTAGTCTTGACA TGCTTAAGAATCTGACTGAAAGGTTGGAGTGCCCTTCGGGGAGCTTTTGCACAGGTGCTGCATGGCTGTCGTCAGCTCGTGTCGTGAG ATGTCGGGTTAAGTCCCTTAACGAGCGAAACCCTTGTCTCTAGTTGCCAGCGAGTAAAGTCGGGGACTCTAGAGAGACTGCCGGTGTT AAACCGGAGGAAGGTGGGGATGACGTCAAGTCCTCATGGCCTTTATGATTAGGGCTGCACACGTCCTACAATGCGGCATACAAAGGGA AGCAAACCCGTGAGGGGGAGCAAACCCCAAAAAGTGTCGCTCAGTTCGGATTGCAGGCTGCAACTCGCCTGCATGAAGCTGGAATCGC TAGTAATCGCGGGTCAGCATACCGCGGTGAATGTGTTCCTGAGCCTTGTACACACCGCCCGTCAAGCCACGAAAGTTGGGAGGGCCCG AAGTCGCTGAGCAAACCGCACGGGTGCAGGCGCCGAAGGTCAGCTCGACAATTGGGACTAAGTCGTAACAAGGTA Sl1376

AGAGTTTGATCATGGCTCAGATTGAACGCTGGCGGCAGGCCTAACACATGCAAGTCGAGCGGCAGCACGGGTACTTGTACCTGGTGGC GAGCGGCGGACGGGTGAGTAATGCCTAGGAATCTGCCTGGTAGTGGGGGATAACGCTCGGAAACGGACGCTAATACCGCATACGTCCT ACGGGAGAAAGCAGGGGACCTTCGGGCCTTGCGCTATCAGATGAGCCTAGGTCGGATTAGCTAGTTGGTGAGGTAATGGCTCACCAAG GCGACGATCCGTAACTGGTCTGAGAGGATGATCAGTCACACTGGAACTGAGACACGGTCCAGACTCCTACGGGAGGCAGCAGTGGGGA ATATTGGACAATGGGCGAAAGCCTGATCCAGCCATGCCGCGTGTGTGAAGAAGGTCTTCGGATTGTAAAGCACTTTAAGTTGGGAGGA AGGGCAGTTACCTAATACGTATCTGTTTTGACGTTACCGACAGAATAAGCACCGGCTAACTCTGTGCCAGCAGCCGCGGTAATACAGA GGGTGCAAGCGTTAATCGGAATTACTGGGCGTAAAGCGCGCGTAGGTGGTTTGTTAAGTTGGATGTGAAATCCCCGGGCTCAACCTGG GAACTGCATTCAAAACTGACAAGCGAGAGTATGGTAGAGGGTGGTGGAATTTCCTGTGTAGCGGTGAAATGCGTAGATATAGGAAGGA ACACCAGTGGCGAAGGCGACCACCTGGACTGATACTGACACTGAGGTGCGAAAGCGTGGGGAGCAAACAGGATTAGATACCCTGGTAG TCCACGCCGTAAACGATGTCAACTAGCCGTTGGGAGCCTTGAGCTCTTAGTGGCGCAGCTAACGCATTAAGTTGACCGCCTGGGGAGT ACGGCCGCAAGGTTAAAACTCAAATGAATTGACGGGGGCCCGCACAAGCGGTGGAGCATGTGGTTTAATTCGAAGCAACGCGAAGAAC CTTACCAGGCCTTGACATCCAATGAACTTTCCAGAGATGGATTGGTGCCTTCGGGAACATTGAGACAGGTGCTGCATGGCTGTCGTCA GCTCGTGTCGTGAGATGTTGGGTTAAGTCCCGTAACGAGCGCAACCCTTGTCCTTAGTTACCAGCACGTCATGGTGGGCACTCTAAGG AGACTGCCGGTGACAAACCGGAGGAAGGTGGGGATGACGTCAAGTCATCATGGCCCTTACGGCCTGGGCTACACACGTGCTACAATGG TCGGTACAGAGGGTTGCCAAGCCGCGAGGTGGAGCTAATCCCAGAAAACCGATCGTAGTCCGGATCGCAGTCTGCAACTCGACTGCGT 
GAAGTCGGAATCGCTAGTAATCGCGAATCAGAATGTCGCGGTGAATACGTTCCCGGGCCTTGTACACACCGCCCGTCACACCATGGGA GTGGGTTGCACCAGAAGTAGCTAGTCTAACCTTCGGGAGGACGGTTACCACGGTGTGATTCATGACTGGGGTGAAGTCGTAACAAGGT A

Sl1377

CTCTAAGATAGTGGACGTTACTCGCAGAATAAGCACCGGCTAACTCTGTGCCAGCAGCCGCGGTAATACAGAGGGTGCAAGCGTTAAT CGGATTTACTGGGCGTAAAGGGTACGTAGGTGGTCTTTTAAGTCGGATGTGAAATCCCTGAGCTTAACTTAGGAATTGCATTCGATAC TGAAAGACTAGAGTATGGGAGAGGATGGTAGAATTCCAGGTGTAGCGGTGAAATGCGTAGAGATCTGGAGGAATACCGATGGCGAAGG CAGCCATCTGGCCTAATACTGACACTGAGGTACGAAAGCATGGGGAGCAAACAGGATTAGATACCCTGGTAGTCCATGCCGTAAACGA TGTCTACTAGCCGTTGGGGTCTTTGAGACTTTAGTGGCGCAGCTAACGCGATAAGTAGACCGCCTGGGGAGTACGGTCGCAAGACTAA AACTCAAATGAATTGACGGGGGCCCGCACAAGCGGTGGAGCATGTGGTTTAATCCGATGCAACGCGAAGAACCTTACCTGGTCTTGAC ATAGTAAGAACTTTCCAGAGATGGATTGGTGCCTTCGGGAGCTTACATACAGGTGCTGCATGGCTGTCGTCAGCTCGTGTCGTGAGAT GTTGGGTTAAGTCCCGCAACGAGCGCAACCCTTTTCCTTATTTGCCAGCGGGTTAAGCCGGGAACTTTAAGGATACTACCAGTGACAA ACTGGAGGAAGGCGGGGACGACGTCAAGTCATCATGGCCCTTACGACCAGGGCTACACACGTGCTACAATGGTCGGTACAAAGGGTTG CTACCTAGCGATAGGATGCTAATCTCAAAAAGCCGATCGTAGTCCGGATTGGAGTCTGCAACTCGACTCCATGAAGTCGGAATCGCTA GTAATCGCGGATCAGAATGCCGCGGTGAATACGTTCCCGGGCCTGTACACACCGCCCGTCACACCATGGGAGTTTGTTGCACCAGAAG TAGGTAGTCTAACCGCAAGGAGGACGCTTACCACGGTGTGGCCGACGACTGGGGTGAAGTCGTAACAAGGTA Sl1378

AGAGTTTGATCATGGCTCAGGATGAACGCTAGCGGCAGGCTTAACACATGCAAGTCGAGGGGTATAGTTCTTCGGAACTAGAGACCGG CGCACGGGTGCGTAACGCGTATGCAATCTACCTTTCACAGAGGGATAGCCCAGAGAAATTTGGATTAATACCTCATAGTATAATTGAA TGGCATCATTTAATTATTAAAGTCACAACGGTGAAAGATGAGCATGCGTCCCATTAGCTTGTTGGTAAGGTAACGGCTTACCAAGGCA ACGATGGGTAGGGGTCCTGAGAGGGAGATCCCCCACACTGGTACTGAGACACGGACCAGACTCCTACGGGAGGCAGCAGTGAGGAATA TTGGTCAATGGGCGCAAGCCTGAACCAGCCATGCCGCGTGCAGGATGAGGGTCCTATGGATTGTAAACTGCTTTTGTACAGGAAGAAA CACTGGTTCGTGAACCAGCTTGACGGTACTGTAAGAATAAGGATCGGCTAACTCCGTGCCAGCAGCCGCGGTAATACGGAGGATCCAA GCGTTATCCGGAATCATTGGGTTTAAAGGGTCCGTAGGCGGTCAGATAAGTCAGTGGTGAAAGCCCATCGCTCAACGGTGGAACGGCC ATTGATACTGTCTGACTTGAATTATTAGGAAGTAACTAGAATATGTAGTGTAGCGGTGAAATGCTTAGAGATTACATGGAATACCAAT TGCGAAGGCAGGTTACTACTAATGGATTGACGCTGATGGACGAAAGCGTGGGTAGCGAACAGGATTAGATACCCTGGTAGTCCACGCC GTAAACGATGGATACTAGCTGTTGGGAGCAATCTCAGTGGCTAAGCGAAAGTGATAAGTATCCCACTTGGGGAGTACGTTCGCAAGAA TGAAACTCAAAGGAATTGACGGGGGCCCGCACAAGCGGTGGAGCATGTGGTTTAATTCGATGATACGCGAGGAACCTTACCAAGGCTT AAATGTAGATTGACCGGTTTGGAAACAGATCTTTCGCAAGACAATTTACAAGGT Sl1379a

AGTTTGATCATGGCTCAGAATGAACGTTGGCGGCGTGGATTAGGCATGCAAGTCGAGCGCGAACCTCGCAAGAGGTAAGAGCGGCGAA AGGGAGAGTAACGCGTAGGTATCTACCCATGGGTCTGGGATAGCGGCGGGAAACTGCCGGTAATACCAGATAACGTCTCCGGACCAAA GGTGTGATTCCACCTGTGGAGGAGCCTACGGCCTATTAGCTAGTTGGCAGGGTAACGGCCTACCAAGGCTTGGATGGGTACGGGGTGT GAGAGCATGCCCCCGCTCACTGGGACTGAGACACTGCCCAGACACCTACGGGTGGCTGCAGTCGAGAATCTTCGGCAATGGGCGCAAG CCTGACCGAGCGACGCCGCGTGCGGGATGAAGGCCTTCGGGTTGTAAACCGCTGTCGTAGGGAATGAAACGTAGGTGAGTTATCTCAT CTATTTGACTGAACCTAGGAGGAAGGGCCGGCTAATCTCGTGCCAGCAGCCGCGGTAATACGAGAGGCCCAAACGTTATTCGGATTTA CTGGGCTTAAAGAGTTCGTAGGCGGCACGGAAAGTGGGGTGTGAAATCCCTCGGCTCAACCGAGGAACTGCGCTCCAAACTATCGTGC TAGAGGGGGATAGAGGTAAGCGGAACTGATGGTGGAGCGGTGAAATGCGTTGATATCATCAGGAACACCGGAGGCGAAGGCGGCTTAC TGGGTCCTTTCTGACGCTGAGGAACGAAAGCTAGGGGAGCAAACGGGATTAGATACCCCGGTAGTCCTAGCCGTAAACGGTGAGCACT GGACCGGAGCTCTGCACAGGGTTTCGGTCGTAGCGAAAGTGTTAAGTGCTCCGCCTGGGGAGTATGGTCGCAAGGCTGAAACTCAAAG GAATTGACGGGGGCTCACACAAGCGGTGGAGGATGTGGCTTAATTCGAGGCTACGCGAAGAACCTTATCCTAGTCTTGATATGCTTAA GAACCTTCCTGAAAGGGAGGGGTGCCCGCA

Sl1379b

GGGAGCTTTTGCACAGGTGCTGCATGGCTGTCGTCAGCTCGTGTCGTGAGATGTCAGGTTAAGTCCTATAACGAGCGCAACCCCTATT GTTAGTTGCCAGCGGGTCATGCCGGGACTCTAACAAGACTGCCAGTGCAAACTGTGAGGAAGGTGGGGATGACGTCAAATCATCACG GCCCTTACGTCCTGGGCTACACACGTGCTACAATGGGCGGTACAGAGAGCAGCCACTACGCAAGTAGGCGCGAATCTTCAAAACCGTT CTCAGTTCGGATCGGAGTCTGCAACTCGACTCCGTGAAGCTGGATTCGCTAGTAATCGCATATCAGCCATGATGCGGTGAATACGTTC CCGGGCCTTGTACACACCGCCCGTCAAGCCATGGAAGCTGGGGGTACCTGAAGTCGGTGACCGCAAGGAGCTGCCTAGGGTAAAACTG GTAACTGGGGCTAAGTCGTAACAAGGTA

Sl1380

AGGATGATCAGCCACACTGGAACTGAGACACGGTCCAGACTCCTACGGGAGGCAGCAGTGGGGAATATTGGACAATGGGCGCAAGCCT GATCCAGCCATGCCGCGTGGGTGAAGAAGGCCTTCGGGTTGTAAAGCCCTTTTGTCCGGAAAGAAAAGCACGGGATTAATACCCTCGT GTGATGACGGTACCGGAAGAATAAGCACCGGCTAACTTCGTGCCAGCAGCCGCGGTAATACGAAGGGTGCAAGCGTTACTCGGAATTA CTGGGCGTAAAGCGTGCGTAGGTGGTGCGTTAAGTCTGTCGTGAAATCCCCGGGCTCAACCTGGGAATGGCGATGGATACTGGCGCGC TAGAGTGAGGTAGAGGAGAGTGGAATTCCCGGTGTAGCAGTGAAATGCGTAGAGATCGGGAGGAACATCAGTTGCGAAGGCGGCTCTC TGGACCATCACTGACACTGAGGCACGAAAGCGTGGGGAGCAAACAGGATTAGATACCCTGGTAGTCCACGCCCTAAACGATGCGAACT GGACGTTGGGCTCAATTAGGAGCTCAGTGTCGGAGCTAACGCGTTAAGTTCGCCGCCTGGGGAGTACGGTCGCAAGACTGAAACTCAA AGGAATTGACGGGGGCCCGCACAAGCGGTGGAGTATGTGGTTTAATTCGATGCAACGCGCAGAACCTTACCTGGTCTTGACATCCACG GAATCCTTTAGAGATAGAGGAGTGCCTTCGGGAACCGTGAGACAGGTGCTGCATGGCTGTCGTCAGCTCGTGTCGTGAGATGTTGGGT TAAGTCCCGCAACGAGCGCAACCCCTGTCCTTAGTTGCCAGCACGTAATGGTGGGAACTCTAAGGAGACTGCCGGTGACAAACCGGAG GAAGGTGGGGATGACGTCAAGTCATCATGGCCCTTACGACCAGGGCTACACACGTACTACAATGGTGGGGACAGAGGGTCGCGAAGCC GCGAGGTGGAGCCAATCCCAGAAACCCTATCTTAGTCCGGATTGGAGTCTGCAACTCGACTCCATGAAGTCGGAATCGCTAGTAATCG CGGATCAGCATTGCCGCGGTGAATACGTTCCCGGGCCTTGTACACACCGCCCGTCACACCATGGGAGTTTGTTGCACCAGAAGCAGGT AGCTTAACCGTAAGGGGGGCGCTTGCCACGGTGTGGCCGATGACTGGGGTGAAGTCGTAACAAGGTA Sl1384

AGAGTTTGATCATGGCTCAGAATCAACGCTGGCGGCGTGCCTCAGACATGCAAGTCGAACGATTAAAGCTCTCTTCGgAGAGTGCATA GAGTGGCGCACGGGTGAGTAACACGTAAGTAATCTACCTCTGAGTGGGGAATAACGTCCGGAAACGGACGCTAATACCGCATAATGCA GCGGCACCGCAAGGTGACAGTTGTTAAAGATTTATCGCTTGGAGAGGAGCTTGCGGCAGATTAGCTAGTTGGTAAGGTAATGGCTTAC CAAGGCTACGATCTGTAACCGGTCTTAGAGGACGGTCGGTCACACTGACACTGAATAACGGGTCAGACTCCTACGGGAGGCAGCAGTC GGGAATTTTGGGCGATGGGCGAAAGCCTGACCCAGCAACGCCGCGTGAAGGATGAAGTATTTCGGTATGTAAACTTCGAAAGAATGGG AAGAATAAATGACGGTACCATTTATAAGGTCCGGCTAACTACGTGCCAGCAGCCGCGGTAATACGTAGGGACCAAGCGTTGTTCGGAT TTACTGGGCGTAAAGGGCGCGTAGGCGGCGTGGTAAGTCACTTGTGAAATCTCTGAGCTTAACTCAGAACGGCCAAGTGATACTGCTG TGCTAGAGTGCAGAAGGGGCAGTCGGAATTCTTGGTGTAGCGGTGAAATGCGTAGATATCAAGAGGAACACCTGAGGTGAAGACGGGT TGCTGGGCTGACACTGACGCTGAGGCGCGAAAGCCAGGGGAGCAAACGGGATTAGATACCCCGGTAGTCCTGGCCCTAAACGATGAAT ACTTGGTGTCTGGAGTTATTAGTGCTCCGGGTGCCGTCGCTAACGTTTTTAGTATTCCGCCTGGGGAGTACGCTCGCAAGAGTGAAAC TCAAAGGAATTGACGGGGACCCGCACAAGCGGTGGAGCATGTGGTTTAATTCGACGCAACGCGAAGAACCTTACCTAGGCTAGAATGT GAGGGAAGTCTGCGTAACAGCAGGCGTCTGGGAAACCAGACCCAAAACAAGGTGCTGCATGGCTGTCGTCAGCTCGTGTCGTGAGATG 
TTGGGTTAAGTCCCGCAACGAGCGCAACCCCTATTGATAGTTGCTAACATTAAGTTGAGAACTCTATCAAGACTGCTGTTGATAAAAC GGAGGAAGGTGGGGATGATGTCAAGTCATCATGGCCTTTATGCTTAGGGCTACACACGTGCTACAATGGCCGGTACAAAACGTCGCAA TCCCGTAAGGGGGAGCTAATCGCAAAAACCGGTCTCAGTTCGGATTGAAGTCTGCAACTCGACTTCATGAAGTTGGAATCGCTAGTAA TCGCGGATCAGAACGCCGCGGTGAATACGTTCCCGGGTCTTGTACACACCGCCCGTCACATCACGAAAGTAGGTTGTACTAGAAGTAG CTGGGCCAACTCGCAAGAGAGGCAGGTTACCACGGTATGATTTATGATTGGGGTGAAGTCGTAACAAGGTA Sl1385

GGAACTGAGACACGGCCCAGACTCCTACGGGAGGCAGCAGTGGGGAATTGTTCGCAATGGGCGCAAGCCTGACGACGCAACGCCGCGT GGAGGATGAAGGTCTTCGGATTGTAAACTCCTGTTGATCGGGACGAAAAGCTCCAACCTAATACGTTGGAGACTGACGGTACCGGTTG AGGAAGCCACGGCTAACTCTGTGCCAGCAGCCGCGGTAATACAGAGGTGGCAAGCGTTGTTCGGAATTACTGGGCGTAAAGGGCGCGT AGGCGGCCTTCTAAGTCGGACGTGAAAGCCCCAGGCTTAACCTGGGAACTGCGTCTGATACTGGGAGGCTTGGATTCGGGAGAGGGAT GTGGAATTCCAGGTGTAGCGGTGAAATGCGTAGATATCTGGAGGAACACCGGTGGCGAAGGCGGCATCCTGGACCGAGATCGACGCTG AGGCGCGAAAGCTAGGGGAGCAAACGGGATTAGATACCCCGGTAGTCCTAGCCCTAAACGATGAGTGCTTGGTGTGGCGGGTATCGAT CCCTGCCGTGCCGAAGCTAACGCATTAAGCACTCCGCCTGGGGAGTACGGTCGCAAGGCTGAAACTCAAAGGAATTGACGGGGGCCCG CACAAGCGGTGGAGCATGTGGTTCAATTCGACGCAACGCGAAGAACCTTACCTGGGCTTGAACTGTAGATGACATCCGGCGAAAGTCG GCTTCCGCAAGGACATCTGCAGAGGTGCTGCATGGCTGTCGTCAGCTCGTGTCGTGAGATGTTGGGTTAAGTCCCGCAACGAGCGCAA CCCTCGTCCTCTGTTGCCATCAGGTTATGCTGGGCACTCTGGGGAGACTGCCGGTGATAAACCGGAGGAAGGTGGGGATGACGTCAAG TCAGCATGGCCTTTATGTCCAGGGCTACACACGTGCTACAATGGTCGGTACAAAGCGTCGCAAGCCCGCGAGGGTGAGCTAATCGCAG AAAGCCGGTCTCAGTTCGGATTGTAGGCTGCAACTCGCCTGCATGAAGTTGGAATCGCTAGTAATCGCGGATCAGCATGCCGCGGTGA ATACGTTCCCGGGCCTTGTACACACCGCCCGTCACATCACGAAAGCTGGCTGTACTAGAAGTAACTGCTCCAACCCGCAAGGGAGGAA GGTTCCTAAGGTATGGTTAGTGATTGGGGTGAAGTCGTAACAAGGTA

Sl1389

AAAGTTTGATCATGGCTCAGGATGAACGCTAGCGGCAGGCTTAACACATGCAAGTCGAGGGGTATAGTTCTTCGGAACTAGGGACCGG CGCACGGGTGCGTAACGCGTATGCAATCTACCTTTCACAGAGGGATAGCCCAGAGAAATTTGGATTAATACCTCATAGTATAATTGAA TGGCATCATTTAATTATTAAAGTCACAACGGTGAAAGATGAGCATGCGTCCCATTAGCTTGTTGGTAAGGTAACGGCTTACCAAGGCA ACGATGGGTAGGGGTCCTGAGAGGGAGATCCCCCACACTGGTACTGAGACACGGACCAGACTCCTACGGGAGGCAGCAGTGAGGAATA TTGGTCAATGGGCGCAAGCCTGAACCAGCCATGCCGCGTGCAGGATGACGGTCCTATGGATTGTAAACTGCTTTTGTACAGGAAGAAA CACTGGTTCGTGAACCAGCTTGACGGTACTGTAAGAATAAGGATCGGCTAACTCCGTGCCAGCAGCCGCGGTAATACGGAGGATCCAA GCGTTATCCGGAATCATTGGGTTTAAAGGGTCCGTAGGCGGTCAGATAAGTCAGTGGTGAAAGCCCATCGCTCAACGGTGGAACGGCC ATTGATACTGTCTGACTTGAATTATTAGGAAGTAACTAGAATATGTAGTGTAGCGGTGAAATGCTTAGAGATTACATGGAATACCAAT TGCGAAGGCAGGTTACTACTAATGGATTGACGCTGATGGACGAAAGCGTGGGTAGCGAACAGGATTAGATACCCTGGTAGTCCACGCC CTAAACGATGCGAACTGGACGTTGGGCTCAATTAGGAGCTCAGTGTCGAAGCTAACGCGTTAAGTTCGCCGCCTGGGGAGTACGGTCG CAAGACTGAAACTCAAAGGAATTGACGGGGGCCCGCACAAGCGGTGGATCATGTGGTTTAATTCGAAGCAACGCGCAAAACCTTACCT GGGTTTGACATCCTCGGACCGCCGTAGAAATACGGTTTTTGTAGCAATACAACCGAGAGACAGGTGCTGCATGGCTGTCGTCAGCTCG TGTGGTGACATGTTGGGTTAAGTCCCGCAACGAGCGCAACCCCTATCTTTAGTTGCCAGCGGATAATGCCGGGGACTCTAAAGAAACT GCCAGCGCAAGCTGAGAGGAAGGCGGGGACGACGTCAAGTCATCACGGCCCTTACGTCCTGGGCCACACACGTGCTACAATGGTAGGT ACAGAGGGCAGCTACCCCGCGAGGGGATGCGAATCTCTAAAGCCTATCTCAGTTCGGATTGGAGTCTGCAACT

Sl1390

AGAGTTTGATCATGGCTCAGGATGAACGCTAGCGGCAGGCTTAACACATGCAAGTCGAGGGGTATAGTTCTTCGGAACTAGAGACCGG CGCACGGGTGCGTAACGCGTATGCAATCTACCTTTCACAGAGGGATAGCCCAGAGAAATTTGGATTAATACCTCATAGTATTATAGAG TGGCATCACTTTATAATTAAAGTCACAACGGTGAAAGATGAGCATGCGTCCCATTAGCTAGTTGGTAAGGTAACGGCTTACCAAGGCA ACGATGGGTAGGGGTCCTGAGAGGGAGATCCCCCACACTGGTACTGAGACACGGACCAGACTCCTACGGGAGGCAGCAGTGAGGAATA TTGGACAATGGGCGCAAGCCTGATCCAGCCATGCCGCGTGCAGGATGACGGTCCTATGGATTGTAAACTGCTTTTGTACAGGAAGAAA CACTGGTTCGTGAACCAGCTTGACGGTACTGTAAGAATAAGCATCGGCTAACTCCGTGCCAGCAGCCGCGGTAATACGGAGGATCCAA GCGTTATCCGGATTCATTGGGTTTAAAGGGTGCGTAGGCGGAACGATAAGTCAGTGGTGAAAGCCCTCAGCTTAACTGAGGAACTGCC ATTGATACTGTCGATCTTGAGTACATTTGATGTGGGCGGAATGTGTCATGTAGCGGTGAAATGCTTAGATATGACACAGAACACCGAT TGCGAAGGCAGCTCACAAAACTGTAACTGACGCTGAGGCACGAAAGCGTGGGTATCAAACAGGATTAGATACCCTGGTAGTCCACGCT GTAAACTATGATTACTCGATGTTTGCGATACACTGTAAGCGTCTAAGCGAAAGCGATAAGTAATCCACCTGGGGAGTACGCTCGCAAG AGTGAAACTCAAAGGAATTGACGGGGGCCGCACAAGCGGAGGAGTATGTGGTTTAATTCGATGATACGCGAGGAGCCTTACCTGGGC TTGAAAGTTAGTGACCGTTCCTGAAAGGGAATTTCCCGCAAGGGCACGAAACTAGGTGCTGCATGGCTGTCGTCAGCTCGTGCCGTGA GGTGTTGGGTTAAGTCCCGCAACGAGCGCAACCCCTATCATTAGTTGCCAGCACGTAATGGTGGGAACTCTAGTGAAACTGCCCGCGC AAGCGGTGAGGAAGGTGGGGATGACGTCAAGTCAGCACGGCCCTTACGTCCAGGGCTACACACGTACTACAATGGCAAGTACAAAGGG TTGCTACATGGTGACATGATGCTAATCTCTAAAGCTTGTCCCAGTTCGGATTGAAGTCTGCAACTCGACTTCATGAAGCTGGATTCGC TAGTAATCGAAAATCAGCAATGTTTCGGTGAATACGTTCCCGGGCCTTGTACACACCGCCCGTCAAACAATGGAAGTTGGGAGTATCT AAAGTCGATAACCGCAAGGAGTCGCCTAGGGTAAAACCAGTAACTGGTGTTAAGTCGTAACAAGGTA

Sl1392

AAGCACCGGCTAACTACGTGCCAGCAGCCGCGGTAATACGTAGGGTGCAAGCGTTGTTCGGAATCATTGGGCGTAAAGCGCGCGTAGG TGGTTTGTTAAGTTGGATGTGAAATCCCCGGGCTCAACCTGGGAACTGCATTCAAAACTGACAAGCTAGAGTATGGTAGAGGGTGGTG GAATTTCCTGTGTAGCGGTGAAATGCGTAGATATAGGAAGGAACACCAGTGGCGAAGGCGACCACCCGGACTGATACTGACACTGAGG TGCGAAAGCGTGGGGAGCAAACAGGATTAGATACCCTGGTAGTCCACGCCGTAAACGATGTCAACTAGCCGTTGGGAGCCTTGAGCTC TTAGTGGCGCAGCTAACGCATTAAGTTGACCGCCTGGGGAGTACGGCCGCAAGGTTAAAACTCAAATGAATTGACGGGGGCCCGCACA AGCGGTGGAGCATGTGGTTTAATTCGAAGCAACGCGAAGAACCTTACCAGGCCTTGACATCCAATGAACTTTCCAGAGATGGATTGGT GCCTTCGGGAACATTGAGACAGGTGCTGCATGGCTGTCGTCAGCTCGTGTCGTGAGGTGTTGGGTTAAGTCCCGTAACGAGCGCAACC CTTGTCCTTAGTTACCAGCACGTAATGGTGGGCACTCTAAGGAGACTGCCGGTGACAAACCGGAAGAAGGTGGGGATGACGTCAAGTC ATCATGGCCCTTACGGCCTGGGCTACACACGTGCTACAATGGTACATACAGAGGGCCGCCAACCCGCGAGGGGGAGCTAATCCCAGAA AGTGTATCGTAGTCCGGATTGTAGTCTGCAACTCGACTACATGAAGTTGGAATCGCTAGTAATCGCGGATCAGCATGTCGCGGTGAAT ACGTTCCCGGGTCTTGTACACACCGCCCGTCACACCATGGGAGCGGGTTTCACCAGAAGTAGGTAGCTTAACCGCAAGGAGGGCGCTT ACCACGGTGGGATTCGTGACTGGGGTGAAGTCGTAACAAGGTA

sl1393

CCTTCGGGTTGTAAAGCACTTTAAGTTGGGAGGAAGGGTTGTAGATTAATACTCTGCAATTTTGACGTTACCGACAGAATAAGCACCG GCTAACTCTGTGCCAGCAGCCGCGGTAATACAGAGGGTGCAAGCGTTAATCGGAATTACTGGGCGTAAAGCGCGCGTAGGTGGTTTGT TAAGTTGGATGTGAAAGCCCCGGGCTCAACCTGGGAACTGCATTCAAAACTGACAAGCTAGAGTATGGTAGAGGGTGGTGGAATTTCC TGTGTAGCGGTGAAATGCGTAGATATAGGAAGGAACACCAGTGGCGAAGGCGACCACCTGGACTGATACTGACACTGAGGTGCGAAAG CGTGGGGAGCAAACAGGATTAGATACCCTGGTAGTCCACGCCGTAAACGATGTCAACTAGCCGTTGGGAGCCTTGAGCTCTTAGTGGC GCAGCTAACGCATTAAGTTGACCGCCTGGGGAGTACGGCCGCAAGATTAAAACTCAAATGAATTGACGGGGGCCCGCACAAGCGGTGG AGCATGTGGTTTAATTCGAAGCAACGCGAAGAACCTTACCAGGCCTTGACATCCAATGAACTTTCCAGAGATGGATTGGTGCCTTCGG GAACATTGAGACAGGTGCTGCATGGCTGTCGTCAGCTCGTGTCGTGAGATGTTGGGTTAAGTCCCGTAACGAGCGCAACCCTTGTCCT TAGTTACCAGCACGTAATGGTGGGCACTCTAAGGAGACTGCCGGTGACAAACCGGAGGAAGGTGGGGATGACGTCAAGTCATCATGGC 
CCTTACGGCCTGGGCTACACACGTGCTACAATGGTCGGTACAGAGGGTTGCCAAGCCGCGAGGTGGAGCTAATCCCATAAAACCGATC GTAGTCCGGATCGCAGTCTGCAACTCGACTGCGTGAAGTCGGAATCGCTAGTAATCGCGAATCAGAATGTCGCGGTGAATACGTTCCC GGGCCTTGTACACACCGCCCGTCACACCATGGGAGTGGGTTGCACCAGAAGTAGCTAGTCTAACCTTCGGGAGGACGGTTACCACGGT GTGATTCATGACTGGGGTGAAGTCGTAACAAGGTA

Sl1394

AGAGTTTGATCATGGCTCAGGATGAACGCTGGCGGCGTGCCTAACACATGCAAGTCGAACGGTAGCAGGTCTAGTTTACTAGATGCTG ACGAGTGGCGGACGGCTGAGTAACGCGTGGGAACGTGCCCTAAAGTGAGGGATAACGCACCGAAAGGTGTGCTAATACCGCATATGAT CTTCGGATTAAAGAATTTATTCGCTTTAGGAGCGGCCCGCGTCGGATTAGGTTGTTGGTGAGGTAATGGCTCACCAAGCCGACGATCC GTAGCTGGTCTGAGAGGATGACCAGCCAGACTGGAACTGAGACACGGTCCAGACTCCTACGGGAGGCAGCAGTGAGGAATCTTCCACA ATGGGCGAAAGCCTGATGGAGCAACGCCGCGTGCGGGATGAAGGCCTTCGGGTCGTAAACCGCTTTTATTAGTGAAGAATATGACGGT AACTAATGAATAAGGATCGGCTAACTACGTGCCAGCAGCCGCGGTCATACGTAGGATCCGAGCGTTATCCGGAGTGACTGGGCGTAAA GAGTTGCGTAGGTGGTTAGTAAAGCGAATAGTGAAATCTGGCGGCTCAACCGTACAGGCTATTATTCGAACTCACTAACTCGAGAATG GTAGAGGTAACTGGAATTTCTTGTGTAGGAGTGAAATCCGTAGATATAAGAAGGAACACCAATGGCGTAGGCAGGTTACTGGACCATT TCTGACACTGAGGCACGAAAGCGTGGGGAGCGAACCGGATTAGATACCCGGGTAGTCCACGCCGTAAACGATGGATACTAGCTGTTGG AGGTATCGACCCCTTCAGTAGCGAAGCTAACGCGTTAAGTATCCCGCCTGTGGAGTACGGTCGCAAGACTAAAACATAAAGGAATTGA CGGGGACCCGCACAAGCGGTGGATCGTGTTCTTTAATTCGATGCTAAACGAAGAACCTTACCAGGGTTTGACATCCTTGGAATCTCTG CGAAAGTAGAGAGTGCTTTATTGAACCAAGTGACAGGTGATGCATGGCCGTCGTCAGCTCGTGTCGTGAGATGTTTGGTTAAGTCCAT CAACGAGCGCAACCCTTGTGAATAGTTGTATTTTTCTATTCAGACTGCCCCGGTAACGGGGAGGAAGGAGGGGATGATGTCAGGTCAG TATTTCCCTTACATCCTGGGCTAGAAACACGATACAATGGCTAGTACAATGCGCAGCGAAGCCGCGAGGTGAAGCAAATCGCATCAAA GCTAGTCCCAGTTCGGATTGGAGGCTGAAACTCGCCTCCATGAAGTCGGAATCGCTAGTAATCGCAGATCAGCAAGCTGCGGTGAATA CGTTCCCGGGTCTTGTACACACCGCCCGTCAAACCATGAAAGTGACCAACACCCGAAGTCCGATTCGTCGGCCTAAGGTGGGGGGCAT GATTGGGGTTAAGTCGTAACAAGGTA

Sl1395

AGAGTTTGATCATGGCTCAGAACGAACGCTGGCGGCGCGCCTAATACATGCAAGTCGAGCGAGAAGGTGTAGCAATACACTTGTAAAG CGGCGAACGGGTGAGGAACACATGGGTAACCTACCATCGAGTGGGGAATAACCAGCCGAAAGGTTGGCTAATACCGCGTACGCCTCCG AGTCTTCGGATTCGGAGGGAAAGCCACGCTGAGAGTGTGGCGCTCTTTGATGGGCTCATGTCCTATCAGCTTGTTGGTAGGGTAACGG CCTACCAAGGCTTTGACGGGTAGCTGGTCTGAGAGGACGATCAGCCACACTGGCACTGCGACACGGGCCAGACTCCTACGGGAGGCAG CAGTAAGGAATATTGCGCAATGGGCGAAAGCCTGACGCAGCGACGCCGCGTGGGGGATGAAGGTCTTCGGATTGTAAACCCCTTTCGG GAGGGAAGATGGGACGAGCAATCGTTCGGACGGTACCTCCAGAAGCAGCCACGGCCAACTTCGTGCCAGCAGCCGCGGTAATACGAAG GTGGCAAGCGTTGTTCGGATTC

S13202

CCGTAAACGATGTCAACTAGCCGTTGGGAGCCTTGAGCTCTTAGTGGCGCAGCTAACGCATTAAGTTGACCGCCTGGGGAGTACGGCC GCAAGGTTAAAACTCAAATGAATTGACGGGGGCCCGCACAAGCGGTGGAGCATGTGGTTTAATTCGAAGCAACGCGGAGAACCTTACC AGGCCTTGACATCCAATGAACTTTCCAGAGATGGATTGGTGCCTTCGGGAACATTGAGACAGGTGCTGCATGGCTGTCGTCAGCTCGT GTCGTGAGATGTTGGGTTAAGTCCCGTAACGAGCGCAACCCTTGTCCTTAGTTACCAGCACGTAATGGTGGGCGCTCTAAGGAGACTG CCGGTGACAAACCGGAGGAAGGTGGGGATGACGTCAAGTCATCATGGCCCTTACGGCCTGGGCTACACACGTGCTACAATGGTCGGTA CAGAGGGTTGCCAAGCCGCGAGGTGGAGCTAATCCCAGAAAACCGATCGTAGTCCGGATCGCAGTCTGCAACTCGACTGCGTGAAGTC GGAGTCGCTAGTAATCGCGAATCAGAATGTCGCGGTGAATACGTTCCCGGGCCTTGTACACACCGCCCGTCACACCATGGGAGTGGGT TGCACCAGAAGTAGCTAGTCTAACCTTCGGGAGGACGGTTACCACAGTGTGATTCATGACTGGGGTGAAGTCGTAACAAGGTAGCCGT AGGGGAACCTGCGGCTGGATCACCTC

Sl3207

GTAGTCCCGGCCGTAAACTATGGGTGCTAGCCGTCGGATAGCTTGCTATTCGGTGGCGCAGCTAACGCATTAAGCACCCCGCCTGGGG AGTACGGCCGCAAGGTTAAAACTCAAAGGAATTGACGGGGGCCCGCACAAGCGGTGGAGCATGTGGTTTAATTCGACGCAACGCGAAG AACCTTACCAGCTCTTGACATTTACTGATCGTTTCCAGAGATGGATTCATCCCAGCAATGGGCAGTAGGACAGGTGCTGCATGGCTGT CGTCAGCTCGTGTCGTGAGATGTTGGGTTAAGTCCCGCAACGAGCGCAACCCTCGCCATTAGTTGCCATCATTCAGTTGGGCACTCTA GTGGGACTGCCGGTGATAAGCCGGGGGAAGGTGGGGATGACGTCAAGTCATCATGGCCCTTATGTGCTGGGCTACACACGTGCTACAA TGGCGGTGACAGTGGGCAGCTACACAGCGATGTGATGCTAACCTCAAAAAGCCGTCTCAGTTCGGATTGGACTCTGCAACTCGAGTCC ATGAAGTCGGAATCGCTAGTAATCGCGGATCAGAACGCCGCGGTGAATACGTTCCCGGGCTTGTACACACCGCCCGTCACACCATGG GAGTTGGTTTTACCCGAAGACGATGTGCTAACCGCAAGGAGGCAGTCGGCCACGGTAAGGTCAGCGACTGGGGTGAAGTCGTAACAAG GTAGCCGTAGGGGAACCTGCGGCTGGATCACCTC

Sl3209

GTAGTCCCGGCCGTAAACGATGATTGCTAGTTGTCGGGATGCATGCATTTCGGTGACGCAGCTAACGCATTAAGCAATCCGCCTGGGG AGTACGGTCGCAAGATTAAAACTCAAAGGAATTGACGGGGGCCCGCACAAGCGGTGGAGCATGTGGTTTAATTCGAAGCAACGCGCAG AACCTTACCACCTTTTGACATGCCTGGACCGCCACGGAGACGTGGCTTTCCCTTCGGGGACTAGGACACAGGTGCTGCATGGCTGTCG TCAGCTCGTGTCGTGAGATGTTGGGTTAAGTCCCGCAACGAGCGCAACCCTCGCCATTAGTTGCCATCATTTAGTTGGGAACTCTAAT GGGACTGCCGGTGCTAAGCCGGAGGAAGGTGGGGATGACGTCAAGTCCTCATGGCCCTTACAGGGTGGGCTACACACGTGCTACAATG GCGACTACAGAGGGTTAATCCTTAAAAGTCGTCTCAGTTCGGATTGTCCTCTGCAACTCGAGGGCATGAAGTTGGAATCGCTAGTAAT CGCGGATCAGCAAGCCGCGGTGAATACGTTCCCGGGCCTTGTACACACCGCCCGTCACACCATGGGAGTTGGTTCTACCCGAAGGCGC TGCGCTGACCGCAAGGGGGCAGGCGACCACGGTAGGGTCAGCGACTGGGGTGAAGTCGTAACAAGGTAGCCGTAGGGGAACCTGCGGC TGGATCACCTC

S13210

GTAGTCCTGGCCGTAAACGATGATTGCTAGTTGTCGGGAAGCTTGCTTCTCGGTGACGCAGCTAACGCATTAAGCAATCCGCCTGGGG AGTACGGTCGCAAGATTAAAACTCAAAGGAATTGACGGGGGCCCGCACAAGCGGTGGAGCATGTGGTTTAATTCGAAGCAACGCGCAG AACCTTACCACCTTTTGACATGCCCGGACCGCCACAGAGATGTGGCTTTCCCTTCGGGGACTGGGACACAGGTGCTGCATGGCTGTCG TCAGCTCGTGTCGTGAGATGTTGGGTTAAGTCCCGCAACGAGCGCAACCCTCGCCATTAGTTGCCATCATTTAGTTGGGAACTCTAAT GGGACTGCCGGTGCTAAGCCGGAGGAAGGTGGGGATGACGTCAAGTCCTCATGGCCCTTACAGGGTGGGCTACACACGTGCTACAATG GCGACTACAGAGGGTTAATCCTTAAAAGTCGTCTCAGTTCGGATTGTCCTCTGCAACTCGAGGGCATGAAGTTGGAATCGCTAGTAAT CGCGGATCAGCATGCCGCGGTGAATACGTTCCCGGGCCTTGTACACACCGCCCGTCACACCATGGGAGTTGGTTCTACCCGAAGGCGA TGCGCTAACCCGCAAGGGAGGCAGTCGACCACGGTAGGGTCAGCGACTGGGGTGAAGTCGTAACAAGGTAGCCGTAGGGGAACCTGCG GCTGGATCACCTCC

S13212

GTAGTCCTGGCCGTAAACGATGATAACTAGTTGTTCGGGCACTTGGTGCTTGAGTGACGCAGCTAACGCATTAAGTTATCCGCCTGGG GAGTACGGTCGCAAGATTAAAACTCAAAGGAATTGACGGGGGCCTGCACAAGCGGTGGAGCATGTGGTTTAATTCGAAGCAACGCGCA GAACCTTACCAACGTTCGACATGTCTAGTATGGTTTCCAGAGATGGATTCCTTCAGTTCGGCTGGCTAGAACACAGGTGCTGCATGGC TGTCGTCAGCTCGTGTCGTGAGATGTTGGGTTAAGTCCCGCAACGAGCGCAACCCTCATCCCTAGTTGCCAGCATTAAGTTGGGCACT CCAGGGAAACTGCCGGTGATAAGCCGGAGGAAGGTGGGGATGACGTCAAGTCCTCATGGCCCTTACGCGTTGGGCTACACACGTGCTA CAATGGCGGTGACAGTGGGCAGCAAACTCGCGAGAGTGAGCTAATCTCCAAAAGCCGTCTCAGTTCGGATCGTTCTCTGCAACTCGAG 
AGCGTGAAGGCGGAATCGCTAGTAATCGCGGATCAGCATGCCGGGTGAATACGTTCCCAGGCCTTGTACACACCGCCCGTCGCACCAT GGGAGTTGGTTTCACCCGAAGGCAGTGCTCTAACCCGCAAGGGAGGAAGCTGACCACGGTGGGATCAGCGACTGGGGTGAAGTCGTAA CAAGGTAGCCGTAGGGGAACCTGCGGCTGGATCACCTCC

Sl3214

GTAGTCCTGGCCGTAAACGATGAGCACTAGACCGGAGGACTGCACAGTTTTCCGGTCGTAGCGAAAGTGAAAGTGCTCCGCCTGGGGA GTATGGTCGCAAGGCTGAAACTCAAAGGAATTGACGGGGGCTCACACAAGCGGTGGAGGATGTGGCTCAATTCGAGGCTACGCGAAGA ACCTTATCCTAGTCTTGACATGCTTTAGAATCCTCCTGAAAGGGAGGAGTGCTCGCAAGAGAGCTTTAGCACAGGTGCTGCATGGCTG TCGTCAGCTCGTGTCGTGAGATGTCGGGTTAAGTCCCTTAACGAGCGAAACCCTTGTCCTTAGTTACCAGCGGGTCATGCCGGGAACT CTAAGGAGACTGCCGGTGTTAAACCGGAGGAAGGTGGGGATGACGTCAAGTCCTCATGGCCTTTATGACTAGGGCTGCACACGTCCTA CAATGGTACACACAAAGCGACGCAAACTCGCAAGAGCCAGCAAATCGCAAAAATTGTACCCCAGTTCGGATTGCAGGCTGCAACTCGC CTGCATGAAGCCGGAATCGCTAGTAATCGCGGGTCAGCATACCGCGGTGAATGTGTTCCTGAGCCTTGTACACACCGCCCGTCAAGCC ACGAAAGTGGGGGGCGCCCAACAGCACTGTCGTAACCGCAAGGAACAAGGTGCCTAAGGCGAACTCCGTGATTGGGACTAAGTCGTAA CAGGGTAGCCGTAGGGGAACCTGCGGCTGGATCACCTC

Sl3215

GTAGTCCTGGCCGTAAACGATAGGTACTAGGTAGTAGGCTAACATGGGCTTACTGCCGGAGCTAAAGTGCTTAGTACCCCGCCTGGGG AGTATGGTCGCAAGGCTGAAACTCAAAGGAATTGACGGGGGCTCACACAAGCGGTGGAGCATGTGGCTTAATTCGAGGCTACGCGAAG AACCTTACCTAGGCTTGACATGTGCGAAAGCGGCAGGAAGTAGAACCCGGAAACGGGGACGAACGGTATCCAGTCCGGAACTTGCACA GGTGCTGCATGGCTGTCGTCAGCTCGTGTCGTGAGATGTCGGGTTAAGTCCCATAACGAGCGAAACCCTTACCATCAGTTGCAATTGG ACTCTGGTGGGACTGCCGGTGTCAAACCGGAGGAAGGTGGGGATGACGTCAAGTCCTCATGGCCTTTATGACTAGGGCTGCACACGTG CTACAATAGCGTGAACAAAGGGACGCCAACCCGAGAGGGGGAGCAAATCCCAAAAAACACGCTCCAGTTCAGATCGCAGGCTGCAACT CGCCTGCGTGAAGTCGGAATCGCTAGTAATCGCGGGTCAGCAACACCGCGGTGAATGTGTTCCTGAGCCTTGTACACACCGCCCGTCA AGCCACGAAAGGATGGAGTGCCCGAAGTCGCCTTTACCGGCGCCGAAGGCAATACGTCTGATTGGGACTAAGTCGTAACAAGGTAACC GTAGGGGAACCTGCGGCTGGATCACCTCC

S13217

TACGGTCGCAAGGCTGAGACTCAAAGGAATTGACGGGGGCCCGCACAAGCGGTGGAGCATGTGGTTCAATTCGACGCAACGCGAAGAA CCTTACCTGGGCTCGAAGTGCAGATGACCATCGGCGAAAGTCGACTTCCGCAAGGACATCTGTATAGGTGCTGCATGGCTGTCCTCAG CTCGTGTCGTGAGATGTTGGGTTAAGTCCCGCAACGAGCGCAACCCTTGTTTCCTGTTGCCATCAGGTAAAGCTGGGCACTCTGGAGA GACTGCCGGTGACAAACCGGAGGAAGGTGGGGATGACGTCAAGTCAGCATGGCCTTTATGTCCAGGGCTACACACGTGCTACAATGGC CGATACAAAGCGTTGCAAACTCGCGAGGGTGAGCTAATCGCATAAAGTCGGTCTCAGTTCGGATTGTAGGCTGCAACTCGCCTGCATG AAGTCGGAATCGCTAGTAATCGCGGATCAGCGTGCCGCGGTGAATACGTTCCCGGGCCTTGTACACACCGCCCGTCACATCACGAAAG CTGGCTGTACTAGAAATCGCTACGCTAACCCGCAAGGGGGGCAGGCGCTTAAGGTGTGGTCAGTGATTGGGGTGAAGTCGTAACAAGG TAGCTGTAGGAGAACCTGCGGCTGGATCACCTC

Sl3218

GTANTCCCGGCCGTAAACGATGGACACTAGGTGTTGGTGGTATCAACCCCACCAGTGCCGAAGCTAACGCATTAAGTGTCCCGCCTGG GGAGTACGGCCGCAAGGCTAAAACTCAAAGGAATTGACGGGGCCCCGCACAAGCAGCGGAGCGTGGGGTTTAATTCGATGCAACGCGA AGAACCTTACCAAGGCTTGACATGACCAGGAATCCGGCGGAAACGTCGGCGCCCCGCAAGGGGCCTGGCCACAGGTGTTGCATGGCTG TCGTCAGCTCGTGTCGTGAGATGTTGGGTTAAGTCCCGCAACGAGCGCAACCCCTATCGTGTGTTGTATCACTCACACGAGACTGCCG AGAGAAACTCGGAGGAAGGCGGGGATGACGTCAAGTCAGCATGGCCCTTACGTCTTGGGCTACACCCACGCTACAATGGCCGGTACAA CGGGCGGCGAAACCGCGAGGTGGAGCAAATCCCTTAAAGCCGGTCTCAGTTCGGATTGTAGGCTGCAACTCGCCTACATGAAGCCGGA GTTGCTAGTAACCGCCGGTCAGCATACGGCGGTGAATATGTTCCCGGGGCTTGTACACACCGCCCGTCACGTCATGAAAGCTGGCAAC ACCCGAAGCCGGTGGGCCAACCCGCAGGGGAGGCAGCCGTCGAAGGTGGGGTCGGTGATTGGGACGAAGTCGTAACAAGGTAGCCGTA CCGGAAGGTGCGGCTGGATCACCTC

Sl3222

GTAGTCCTGGCCGTAAACGATGAATACTTGGTGTCTGGAACTATTAAGTTCTGGGTGCCGTCGCTAACGTTTTAAGTATTCCGCCTGG GGAGTACGCTCGCAAGAGTGAAACTCAAAGGAATTGACGGGGACCCGCACAAGCGGTGGAGCATGTGGTTTAATTCGACGCAACGCGA AGAACCTTACCTAGGCTAGAATGTGAGGGAAGAGAGGGTAATTCCGATCGTCTGGGAAACCAGACCCAAAACAAGGTGCTGCATGGCT GTCGTCAGCTCGTGTCGTGAGATGTTGGGTTAAGTCCCGCAACGAGCGCAACCCTTATCAACAGTTGCCATCATTAAGTTGGGAACTC TGTTGAGACTGCCGTTGATAAAACGGAGGAAGGTGGGGATGATGTCAAGTCATCATGGCCTTTATGCTTAGGGCTACACACGTGCTAC AATGGATGGTACAAAACGTCGCAATCCCGTAAGGGGGAGCTAATCGCAAAAACCATTCTCAGTTCGGATTGAAGTCTGCAACTCGACT TCATGAAGTTGGAATCGCTAGTAATCGCGGATCAGCATGCCGCGGTGAATACGTTCCCGGGTCTTGTACACACCGCCCGTCACATCAC GAAAGTAGGTTGTACTAGAAGTAGGAGGGCTAACTCGCAAGAGAGGCATCTTACCACGGTATGATTTATGATTGGTGTGAAGTCGTAA CAAGGTAGCTGTAGGAGAACCTGCGGCTGGATCACCTCC

S13223

GGCTGTAAACGATGGATGCTAGGCGTTGGCAGACTCAATCCTGTCCGCGCCGAAGTTAACACGATAAGCATCCCGCCTGGGAAGTACG ACCGCAAGGTTAAAACTCAAAGGAATTGACGGGGACCCGCACAAGCAGCGGAGCGTGTGGTTTAATTCGATGCTACACGAAGAACCTT ACCCGGACTTGACATACTAGTGGTAGAGAGAAGAAATTTAATCGACCCGCAAGGGAGCTAATACAGGTGTTGCATGGCTGTCGTCAGC TCGTGTCGTGAGATGTTCGTTTAAGTACGCTAACGAGCGCAACCCTCATTGCCAGTTACAAGTGTCTGGCGAGACTGCCGGCCGCAAG CCGGAGGAAGGCGGGGATGACGTCAAGTCAGCATGGCCTTTATGTCCGGGGCTACACACACGCTACAATGGGATGGAACAATGGGAAG CCAAGCCGCGAGGCGGAGCAAATCCTAGTAAAACATTCCTCAGTTCAGATTGCAGGCTGCAACTCGCCTGCATGAAGTTGGAGTTGCT AGTAAACGCGCGTCAGCTATAGTGCGTTGAATACGTTCCCGGGTCTTGTACACACCGCCCGTCACACTGTGGGAGCTGGTAACACCTA AAGACATTGGCTTAACCGCAAGGAGAGTAATGTTTAGGGTGGGGTCGGTGACTGGAGTGAAGTCGTAACAAGGTAGCTGTACGGGAAC GTGCGGCTGGATCACCTC

Sl3224

GTAGTCCCGGCCGTAAACGATGGGTACTCGGTGTCGCGGGAATCAACCCCCGCGGTGCCTTAGCTAACGCGTTAAGTACCCCGCCTGG GGAGTACGGTCGCAAGGCTGAAACTCAAAGGAATTGACGGGGGCCCGCACAAGCGGTGGAGCATGTGGTTTAATTCGATGCAACGCGA AGAACCTTACCTGGGCTCGAACGGTGGTGGACAACCGTGGAAACACGGTCTCCTCTTCGGAGGTCGCCATCGAGGTGCTGCATGGCTG TCGTCAGCTCGTGTCGTGAGATGTTGGGTTAAGTCCCGCAACGAGCGCAACCCCTATTCTTAGTTGCCAGCGAGTCAAGTCGGGCACT CTAAGGAGACTGCCTCGGAAATCGAGGAGGAAGGTGGGGATGACGTCAAGTCCGCATGGCCTTTATGTCCAGGGCTACACACGTGCTA CAATGGGCGGTACAAAGGGTTGCAAAGCCGCGAGGCAGAGCTAATCTCAAAAAACCGTCCTCAGTTCGGATTGCAGTCTGCAACTCGA CTGCATGAAGCTGGAATCGCTAGTAATCCCGGATCAGCACGCCGGGGTGA

S13226

GTAGTCCCGGCCGTAAACGATGAGTGCTTGGTGTGGCGGGTATCGATCCCTGCCGTGCCGAAGCTAACGCATTAAGCACTCCGCCTGG GGAGTACGGTCGCAAGGCTGAAACTCAAAGGAATTGACGGGGGCCCGCACAAGCGGTGGAGCATGTGGTTCAATTCGACGCAACGCGA AGAACCTTACCTGGGCTTGAACTGTAGATGACATCCGGCGAAAGTCGGCTTCCGCAAGGACATCTGCAGAAGTGCTGCATGGCTGTCG TCAGCTCGTGTCGTGAGATGTTGGGTTAAGTCCCGCAACGAGCGCAACCCTCGTCCTCTGTTGCCATCAGGTTATGCTGGGCACTCTG AGGAGACTGCCGGTGATAAACCGGAGGAAGGTGGGGATGACGTCAAGTCAGCATGGCCTTTATGTCCAGGGCTACACACGTGCTACAA TGGTCGGTACAAAGCGTCGCAAGCCCGCGAGGGTGAGCTAATCGCAGAAAGCCGGTCTCAGCTCGGATTGTAGGCTGCAACTCGCCTG 
CATGAAGTTGGAATCGCTAGTAATCGCGGATCAGCATGCCGCGGTGAATACGTTCCCGGGCCTTGTACACACCGCCCGTCACATCACG AAAGCTGGCTGTACTAGAAGTAACTGCTCCAACCCGCAAGGGAGGAAGGTTCCTAAGGTATGGTTAGTGATTGGGGTGAAGTCGTAAC AAGGTAGCTGTAGGAGAACCTGCGGCTGGATCACCTCC

S13227

CCGTAAACGATGAGCACTAGTCTGAGGGACTCTCACAGTTTCTCGGACGTAGCGAAAGTGTTAAGTGCTCCGCCTGGGGAGTATGGTC GCAAGGCTGAAACTCAAAGGAATTGACGGGGGCTCACACAAGCGGTGGAGGATGTGGCTTAATTCGAGGCTACGCGAAGAACCTTATC CTAGTCTTGACATGCTTAAGAATCTGACTGAAAGGTTGGAGTGCCCGCAAGGGAGCTTTTGCACAGGTGCTGCATGGCTGTCGTCAGC TCGTGTCGTGAGATGTCGGGTTAAGTCCCTTAACGAGCGAAACCCTTATCTCTAGTTGCCAGCGGGTCATGCCGGGGACTCTAGAGAG ACTGCCGGTGTTAAACCGGAGGAAGGTGGGTATGACGTCAAGTCCTCATGGCCTTTATGATTAGGGCTGCACACGTCCTACAATGCAA CATACAAAGGGAACCGAAACCGCGAGGTCAAGGAAATCTCAAAAAGTGTTGCTCAGTTCGGATTGCAGGCTGCAACTCGCCTGCATGA AGCTGGAATCGCTAGTAATCGCGGGTCAGCATACCGCGGTGAATGTGTTCCTGAGCCTTGTACACACCGCCCGTCAAGCCACGAGAAT TGGGAGGGCCCGAAGTCGCTGAGCGAACCGCAAGGACGCAGGCGCCGAAGGTCAGCTTGATAATTGGGACTAAGTCGTAACAAGGTAG CCGTAGGGGAACCTGCGGCTGGATCACCTCC

Sl3228

GTAGTCCTGGCCGTAAACGATGAGCACTAGCCCGTGGGGACTCTCACATCCTCTCGGGCGTAGCGAAAGTGTTAAGTGCTCCGCCTGG GGAGTATGGTCGCAAGGCTGAAACTCAAAGGAATTGACGGGGGCTCACACAAGCGGTGGAGGATGTGGCTTAATTCGAGGCTACGCGA AGAACCTTATCCTAGTCTTGACATGCTTAGGAATCTGACTGAAAGGTCGGAGTGCCCTTCGGGGAGCCTTTGCACAGGTGCTGCATGG CTGTCGTCAGCTCGTGTCGTGAGATGTCGTGTTAAGTCCCTTAACGAGCGAAACCCTTGTCCCTAGTTGCCAGCGAGTAAAGTCGGGG ACTCTAGGGAGACTGCCGGTGTTAAACCGGAGGAAGGTGGGGATGACGTCAAGTCCTCATGGCCTTTATGATTAGGGCTGCACACGTC CTACAATGCGGCATACAAAGGGACGCAAACCCGTGAGGGGGAGCAAACCTCAAAAAGTGTCGCTCAGTTCGGATTGCAGGCTGCAACT CGCCTGCATGAAGCTGGAATCGCTAGTAATCGCGGGTCAGCATACCGCGGTGAATGTGTTCCTGAGCCTTGTACACACCGCCCGTCAA GCCACGAAAGTTGGGAGGGCCCGAAGTCGCTGAGCAAACCGCAAGGGTGCAGGCGCCGAAGGTCAACTTGACAATTGGGACTAAGTCG TAACAAGGTAGCCGTAGGGGGACCTGCGGCTGGATCACCTCC

S13232

GTAGTCCCGGCCGTAAACGATGTCAGCTAGATGTTCAGAGGGCGCAAGCCGTCGGGGTATCGAAGCAAACGCGATAAGCTGACCGCCT GGGGAGTACGGTCGCAAGGCTAAAACTCAAAGGAATTGACGGGGGCCCGCACAAGCAGCGGAGCGTGTGGTTTAATTCGAGGCTACAC GAAGAACCTTACCTGGGTTTGACATATACGTGGTAGTGAACTGAAAAGGGAACGACCTTCGGGAGCGTATACAGGTGCTGCATGGCTG TCGTCAGCTCGTGCCGTGAGGTGTTCGGTTAAGTCCGCAAACGAGCGCAACCCCTGGTGCTAGTTACACGTGTCTAGCGCAACTGCCC GTGAGAAACGGGAGGAAGGTGGGGACGACGTCAAGTCAGCATGGCCTTTATATCCAGGGCTACACACACGCTACAATGGGCGGTACAA TGGGTCGCGAAACCGCGAGGTGGAGCCAATCCTAAAAAGCCGTTCGTAGTTCGGATTGCAGGCTGCAACTCGCCTGCATGAAGTCGGA GTTGCTAGTAACCGCAGGTCAGCTATACTGCGGTGAATACGTTCCCGGGCCTTGTACACACCGCCCGTCACGTCATGGGAGCTGGTCA CGCCTGAAGTCGGGAAGCTAACTGCAAAGAGGCTACCGCCGAGGGCAGGGCCGGTGACTGGGACGAAGTCGTAACAAGGTAGCTGTAC CGGAAGGTGCGGCTGGATCACCTCC

S13233

GTAGTCCCGGCTGTAAACGATGAATGCCAGCTGTTGGGGTGCTTGCACCTCAGTAGCGCAGCTAACGCTTTAAGCATTCCGCCTGGGG AGTACGGTCGCAAGATTAAAACTCAAAGGAATTGACGGGGGCCCGCACAAGCGGTGGAGCATGTGGTTTAATTCGAAGCAACGCGCAG AACCTTACCATCCCTTGACATGGCATGTTACCCGGAGAGATTCGGGGTCCACTTCGGTGGCGTGCACGCAGGTGCTGCATGGCTGTCG TCAGCTCGTGTCGTGAGATGTTGGGTTAAGTCCCGCAACGAGCGCAACCCACGTCTTTAGTTGCCATCATTCAGTTGGGCACTCTAGG GAGACTGCCGGTGATAAGCCGCAAGGAAGGTGTGGATGACGTCAAGTCCTCATGGCCCTTACGGGATGGGCTACACACGTGCTACAAT GGCGGTGGCAGTGGGACGCGAAGGAGCGATCTGGAGCAAATCCCCAAAAACCGTCTCAGTTCAGATTGCACTCTGCAACTCGAGTGCA TGAAGGCGGAATCGCTAATAATCGTGGATCAGCATGCCACGGTGAATACGTTCCCGGGCCTTGTACACACCGCCCGTCACACCATGGG AGTTGGTCTTACCCGACGGCGCTGCGCCAACCGCAAGGAGGCAGGCGACCACGGTAGGGTCAGCGACTGGGGTGAAGTCGTAACAAGG TAGCCGTAGGGGAACCTGCGGCTGGATCACCTCC

S13234

GTAGTCCTGGCCGTAAACGATGGGCACTAGGTGTAGCGGGTATTGACCCCTGCTGTGCCGAAGTTAACGCATTAAGTGCCCCGCCTGG GGAGTACGGCCGCAAGGTTGAAACTCAAAGGAATTGACGGGGGCCCGCACAAGCGGTGGAGCATGTGGTTTAATTCGACGCAACGCGA AGAACCTTACCTGGGCTTGACATCCCTTGACCGTCTATGAAAGTAGGCTTTCCTTTCGGGGACAAGGAGACAGGTGCTGCATGGCTGT CGTCAGCTCGTGTCGTGAGATGTTGGGTTAAGTCCCGCAACGAGCGCAACCCTCGTCTTTAGTTGCCAGTATTAAGTTGGGCACTCTA AAGATACTGCCTCGGTTAACGGGGAGGAAGGTGTGGATGACGTCAAGTCCTCATGGCCTTTATGCCCAGGGCTACACACGTGCTACAA TGGGCGGTACAAACGGTTGCAATCCCGCGAGGGGGAGCTAATCCGAAAAAGCCGTCCTCAGTTCGGATCGGAGTCTGCAACTCGACTC CGTGAAGTTGGAATCGCTAGTAATCGTGGATCAGCATGCCACGGTGAATACGTTCCCGGGCCTTGTACACACCGCCCGTCACACCACG AAAGTTGGTTGTACCAGAAGTGCGTGAGCTAATCCGCTTCGGCGGAAGGCAGCGCCCTAAGGTGTGGCTGATAATTGGGGTGAAGTCG TAACAAGGTAGCCGTAGGGGAACCTGCGGCTGGATCACCTCC

S13236

GTAGTCCTGGCCGTAAACGATGATAACTAGCTGTCCGGGCTCTCAGAGCTTGGGTGGCGCAGCTAACGCATTAAGTTATCCGCCTGGG GAGTACGGTCGCAAGATTAAAACTCAAAGGAATTGACGGGGGCCTGCACAAGCGGTGGAGCATGTGGTTTAATTCGAAGCAACGCGCA GAACCTTACCAGCGTTTGACATCCTTGTCGCGGATTCCAGAGATGGTTTCCTTCAGTTCGGCTGGACAAGTGACAGGTGCTGCATGGC TGTCGTCAGCTCGTGTCGTGAGATGTTGGGTTAAGTCCCGCAACGAGCGCAACCCTCGTCCTTAGTTGCCATCATTAAGTTGGGCACT CTAAGGAAACTGCCGGTGATAAGCCGGAGGAAGGTGGGCATGACGTCAAGTCCTCATGGCCCTTACACGCTGGGCTACACACGTGCTA CAATGGCGGTGACAGTGGGCAGCAACCCTGCGAGGGGTAGCTAATCTCCAAAAACCGTCTCAGTTCGGATTGTTCTCTGCAACTCGAG AGCATGAAGGCGGAATCGCTAGTAATCGCGGATCAGCATGCCGCGGTGAATACGTTCCCAGGCCTTGTACACACCGCCCGTCACACCA TGGGATTTGGATTCACCCGAAGGCAGTGCGCTAACCGCAAGGAGGCAGCTGACCACGGTGGGTTTAGAGACTGGGGTGAAGTCGTAAC AAGGTAGCCGTAGGGGAACCTGCGGCTGGATCACCTCC

S13237

GGGTGGCGCAGCTAACGCATTAAGTTATCCGCCTGGGGAGTACGGTCGCAAGATTAAAACTCAAAGGAATTGACGGGGGCCTGCACAA GCGGTGGAGCATGTGGTTTAATTCGAAGCAACGCGCAGAACCTTACCAGCGTTTGACATCCCGCGCTAACCCAAGAGATTGGGTGTTC CCTTCGGGGACGCGGTGACAGGTGCTGCATGGCTGTCGTCAGCTCGTGTCGTGAGATGTTGGGTTAAGTCCCGCAACGAGCGCAACCC TCGTCCTTAGTTGCCATCATTTAGTTGGGCACTCTAAGGAAACCGCCGGTGATAAGCCGGAGGAAGGTGGGGATGACGTCAAGTCCTC ATGGCCCTTACACGCTGGGCTACACACGTGCTACAATGGCGGTGACAGTGGGCAGCCACCTCGCGAGAGGGAGCTAATCCCAAAAAGC CGTCTCAGTTCGGATTGTTCTCTGCAACTCGAGAGCATGAAGGCGGAATCGCTAGTAATCGCGGATCAGCATGCCGCGGTGAATACGT TCCCAGGCCTTGTACACACCGCCCGTCACACCATGGGAGTTGGGTTCACCCGAAGGCGTTGCGCTAACTCGCAAGAGAGGCAGGCGAC CACGGTGGGCTTAGCGACTGGGGTGAAGTCGTAACAAGGTAGCCGTAGGGGAACCTGCGGCTGGATCACCTCC S13238

GTAGTCCCGGCCGTAAACGATGATAACTAGCTGTCTGGTACTTGGTACTTAGGTGGCGCAGCTAACGCATTAAGTTATCCGCCTGGGG AGTACGGCCGCAAGGTTAAAACTCAAATGAATTGACGGGGGCCTGCACAAGCGGTGGAGCATGTGGTTTAATTCGAAGCAACGCGCAG AACCTTACCAGCGTTTGGCATGTCCGGACGATTTCCAGAGATGGATCTCTTCCCTTCGGGGACTGGAACACAGGTGCTGCATGGCTGT CGTCAGCTCGTGTCGTGAGATGTTGGGTTAAGTTCCGCAACGAGCGCAACCCTCGCCTTTAGTTACCATCATTCAGTTGGGGACTCTA 
AAGGAACCGCCGGTGATAAGCCGGAGGAAGGTGGGGATGACGCCAAGTCCTCATGGCCCTTACGCGCTGGGCTACACACGTGCTACAA TGGCAACTACAGTGGGCAGCAATCCCGCGAGGGTGAGCTAATCTCCAAAAGTTGTCTCAGTTCGGATTGCACTCTGCAACTCGAGTGC ATGAAGGCGGAATCGCTAGTAATCGCGGATCAGCATGCCGCGGTGAATACGTTCCCAGGCCTTGTACACACCGCCCGTCACACCATGG GAGTTGGATTCACCCGAAGGCGTTGCGCTAACTCGCAAGAGAGGCAGGCGACCACGGTGGGTTTAGCGACTGGGGTGAAGTCGTAACA AGGTAGCCGTAGGGGAACCTGCGGCTGGATCACCTCC

S13239

GTAGTCCCGGCCGTAAACGATGAGAACTAGATAGCGAGGGTGACATGCCCCCGCTGTCGGAGCAAAAGTGTTAAGTTCTCCGCCTGGG GAGTATGGTCGCAAGGCTGAAACTCAAAGGAATTGACGGGGGCTCACACAAGCGGTGGAGCATGTGGCTCAATTCGAGGCTACGCGAA GAACCTTATCCTGGACTTGACATATGCGAAAGCGCTAGCAAGTACCCTGCGGAAACGTTAGGGGAACGGTATCCAGTCCGGAAGCTAG TACAGGTGCTGCATGGCTGTCGTCAGCTCGTGTCGTGAGATGTCGGGTTAAGTCCCATAACGAGCGAAACCCTTGCCTTTAGTTGCCA GCGGGTAAAGCCGGGCACTCTAGAGGGACTGCCGGTGTCAAACCGGAGGAAGGTGGGGATGACGTCAAGTCCTCATGGCCTTTATGTC CAGGGCTGCACACGTGCTACAATGCCGTGGTACAAAGGGATGCCAACCCGCGAGGGGGAGCTAATCCCAAAAAACACGGCCCAGTTCA GATCGAAGGCTGCAACTCGCCTTCGTGAAGTTGGAATCGCTAGTAATCGCAGGTCAGCAACACTGCGGTGAATGTGTTCCTGAGCCTT GTACACACCGCCCGTCAAGCCACGAAAGGGAGGGACGTCCGAAGTCGCCTTTACCGGTGCCGAAGACGGACTTTCTGATTGGGACTAA GTCGTAACAAGGTAACCGTAGGGGAACCTGCGGCTGGATCACCTCC

S13240

GTAGTCCCGGCTGTAAACGATGTCTACTAGCCGTTGGGGCCTTTGAGGCTTTAGTGGCGCAGCTAACGCGATAAGTAGACCGCCTGGG GAGTACGGTCGCAAGACTAAAACTCAAATGAATTGACGGGGGCCCGCACAAGCGGTGGAGCATGTGGTTTAATTCGATGCAACGCGAA GAACCTTACCTGGTCTTGACATAGTAAGAACTTTCCAGAGATGGATTGGTGCCTTCGGGAACTTACATACAGGTGCTGCATGGCTGTC GTCAGCTCGTGTCGTGAGATGTTGGGTTAAGTCCCGCAACGAGCGCAACCCTTTTCCTTATTTGCCAGCGGGTTAAGCCGGGAACTTT AAGGATACTGCCAGTGACAAACTGGAGGAAGGCGGGGACGACGTCAAGTCATCATGGCCCTTACGACCAGGGCTACACACGTGCTACA ATGGTCGGTACAAAGGGTTGCTACCACGCGAGTGGATGCTAATCTCAAAAAGCCGATCGTAGTCCGGATTGGAGTCTGCAACTCGACT CCATGAAGTCGGAATCGCTAGTAATCGCGGATCAGAATGCCGCGGTGAATACGTTCCCGGGCCTTGTACACACCGCCCGTCACACCAT GGGAGTTTGTTGCACCAGAAGTAGGTAGTCTAACCGCAAGGAGGACGCTTACCACGGTGTGGCAGATGACTGGGGTGAAGTCGTAACA AGGTAGCCGTAGGGGAACCTGCGGCTGGATCACCTCC

Sl3241

GTAGTCCTGGCCGTAAACGATGAGCACTAGCCCGTGGGGACTCTCACATCCTCTCGGGCGTAGCGAAAGTGTTAAGTGCTCCGCCTGG GGAGTATGGTCGCAAGGCTGAAACTCAAAGGAATTGACGGGGGCTCACACAAGCGGTGGAGGATGTGGCTTAATTCGAGGCTACGCGA AGAACCTTATCCTAGTCTTGACATGCTTAAGAACCTTTCTGAAAGGAGAGGGTGCCCTTCGGGGAGCTTTTGCACAGGTGCTGCATGG CTGTCGCCAGCTCGTGTCGTGAGATGTCGGGTTAAGTCCCTTAACGAGCGAAACCCTTGTCTCTAGTTGCCAGCGAGTAAAGTCGGGG ACTCTAGAGAGACTGCCGGTGTTAAACCGGAGGGAGGTGGGGATGACGTCAAGTCCTCATGGCCTTTATGATTAGGGCTGCACACGTC CTACAATGCGGCATACAAAGGGAAGCAAACCCGTGAGGGGGAGCAAACCCCAAAAAGTGTCGCTCAGTTCGGATTGCAGGCTGCAACT CGCCTGCATGAAGCTGGAATCGCTAGTAATCGCGGGTCAGCATACCGCGGTGAATGTGTTCCTGAGCCTTGTACACACCGCCCGTCAA GCCACGAAAGTTGGGAGGGCCCGAAGTCGCTGAGCAAACCGCAAGGGTGCAGGCGCCGAAGGTCAGCTCGACGATTGGGACTAAGTCG TAACAAGGTAGCCGTAGGGGAACCTGCGGCTGGATCACCTCC

S13242

GTAGTCCTGGCCGTAAACACTGAACACTCGAGGAGGGGGGCTTCGGCCTTCTTTCTCTTAGCGAAAGCGTTAAGTGTTCCGCCTGGGG AGTATGGTCGCAAGGCTGAAACTCAAAGGAATTGACGGGGGCTCACACAAGCGGTGGAGCATGTGGCTTAATTCGAGGCAACGCGAAG AACCTTATCCTGGGCTTGACATGCATGGATCAACCCGATGAAAGTCGGGCCACACTCGCAAGAGCGGAACATGCACAGGTGCTGCATG GCTGTCGTCAGCTCGTGTCGTGAGATGTCGCGTTAAGTCGCTAAACGAGCGAAACCCCTATCCTTAGTTGCCAGCGAGTCATGTCGGG GACTCTAGGGAGACTGCCGGTGTCAAACCGGAGGAAGGCGGGGATGACGACAAGTCCTCATGGCCTTTATGCCCAGGGCTGCACACGT GCTACAATGGGGCGTACAAAGCGCCGCTAAGTCGCGAGACCACGCTAATCGCAAAAAGCGTCCCCCAGTACGGATTGCAGGCTGCAAC TCGCCTGCATGAAGCCGGAATCGCTAGTAATCGCCGATCAGCATTGCGGCGGTGAATGTGTTCCTGAGCCTTGTACACACCGCCCGTC AAGCCACGAAAGCGGGGGGCATCCGAAGTCGCCGAGCTAACCGCAAGGGAGCAGGTGCCGAAGATGAACTCCGTGATTGGGACTAAGT CGTAACAAGGTAGCCGTAGGGGAACCTGCGGCTGGATCACCTCC

S13244

GTAGTCCTGGCCGTAAACGATGAGCACTAGATGGAAGGGTCCTCCATAACCTTTCCATCGAAGCGAAAGTAATTAGTGCTCCGCCTGG GGAGTATGGTCGCAAGGCTGAAACTCAAAGGAAATGACGGGGGTTCACACAAGCGGTGGAGGATGTGGCTTAATTCGAGGCTACGCGA AGAACCTTATCCTAGTCTTGACATGCATGGATTAACCCGGTGAAAGCCGGGCCACGCCTTCGGGAGGAACATGCACAGGTGCTGCATG GCTGTCGTCAGCTCGTGTCGTGAGATGTCGGGTTAAGTCCCTTAACGAGCGAAACCCTTGTCACTAGTTGCCAGCGCGTAATGGCGGG GACTCTAGTGAGACTGCCGGTGTTAAACCGGAGGAAGGNGGGGATGACGTCAAGTCCTCATGGCCTTTATGATTAGGGCTGCACACGT CCTACAATGGCGCACACAAAGGGATGCAAACTCGCGAGAGCAAGCAAATCCCAAAAAATGTGCCCCAGTTCGGATTGCAGGCTGCAAC TCGCCTGCATGAAGCCGGAATCGCTAGTAATCGCGGGTCAGCATACCGCGGTGAATATGTTCCTGAGCCTTGTACACACCGCCCGTCA AGCCACGAAAGTGGGGGGTATCCGAAGTCGCCAAGCCAACCGCAAGGGGGCAAGCGCCGAAGATAAACTCCGCGATTGGGACTAAGTC GTAACAAGGTAGCCGTAGGGGAACCTGCGGCTGGATCACCTC

S13246

GGAGTACGGTCGCAAGATTAAAACTCAAAGGAATTGACGGGGGCCCGCACAAGCAGCGGAGCGTGTGGTTTAATTCGAGGCTACACGA AGAACCTTACCTGGGTTTGACATATAAGTGGTAGTGAAGCGAAAGCGGAACGACCTTCGGGAGCTTATACAGGTGCTGCATGGCTGTC GTCAGCTCGTGCCGTGAGGTGTTCGGTTAAGTCCGCAAACGAGCGCAACCCCCGGCGTTAGTTACAAGTGTCTAACGCAACTGCCCGT GAGAAACAGGAGGAAGGTGGGGATGACGTCAAGTCAGCATGGCCTTTATATCCAGGGCTACACACACGCTACAATGGGCGGTACAGAT GGTAGCGAAACCGCGAGGTGGAGCCAATCCACAAAGCCGTTCGTAGTTCGTATTGCAGGCTGCAACTCGCCTGCATGAAGTCGGAGTT GCTAGTAACCGCAGGTCAGCTATACTGCGGTGAATACGTTCCCGGGCCTTGTACACACCGCCCGTCACGTCATGGGAGCTGTCACGCC TGAAGTCGGGGAGCCAACCGCAAGGAGGCAACCGCCGAGGGCAGGGCTGGTGACTGGGACGAAGTCGTAACAAGGTAGCTGTACCGGA AGGTGCGGCTGGATCACCTCC

Sl3247

TAGTAACGGCCGCCAGTGTGCTGGAATTCGGCTTGGAGGTGATCCAGCCGCAGGTTCCCCTACGGCTACCTTGTTACGACTTCACCCC AGTCGCTGACCCTACCGTGGTTAGCTGCCTCCTTGCGGTTAGCGCACTACCTTCGGGTAAAACCAACTCCCATGGTGTGACGGGCGGT GTGTACAAGGCCCGGGAACGTATTCACCGCAGCATGCTGATCTGCGATTACTAGCGATTCCAACTTCATGCACTCGAGTTGCAGAGTG CAATCCGAACTGAGATGGCTTTTGGAGATTAGCTCGACATCGCTGTCTCGCTGCCCACTGTCACCACCATTGTAGCACGTGTGTAGCC CAGCCCGTAAGGGCCATGAGGACTTGACGTCATCCCCACCTTCCTCTCGGCTTATCACCGGCAGTCCCCTTAGAGTGCCCAACTAAAT GCTGGCAACTAAGGGCGAGGGTTGCGCTCGTTGCGGGACTTAACCCAACATCTCACGACACGAGCTGACGACAGCCATGCAGCACCTG TTCTGGGGCCAGCCTAACTGAAGGACAATGTCTCCACTGCCCAAACCCCGAATGTCAAGAGCTGGTA S13248

GTAGTCCCGGCCGTAAACGATGATAACTAGCTGTCCGGGCACTTGGTGCTTGGGTGGCCCAGCTAACGCATTAAGTTATCCGCCTGGG GAGTACGGTCGCAAGATTAAAACTCAAAGGAATTGACGGGGGCCTGCACAAGCGGTGGAGCATGTGGTTTAATTCGAAGCAACGCGCA GAACCTTACCAGCGTTTGACATCCTGATCGCGGATTAGAGAGATCTTTTCCTTCAGTTCGGCTGGATCAGTGACAGGTGCTGCATGGC TGTCGTCAGCTCGTGTCGTGAGATGTTGGGTTAAGTCCCGCAACGAGCGCAACCCTCGTCCTTAGTTGCCATCATTAAGTTGGGCACT 
CTAAGGAAACCGCCGGTGATAAGCCGGAGGAAGGTGGGGATGACGTCCAGTCCTCATGGCCCTTACACGCTGGGCTACACACGTGCTA CAATGGCGGTGACAGTGGGCAGCCACCCCGCGAGAGGGAGCTAATCCCAAAAAGCCGTCTCAGTTCGGATTGTTCTCTGCAACTCGAG AGCATGAAGGCGGAATCGCTAGTAATCGCGGATCAGCATGCCGCGGTGAATACGTTCCCAGGCCTTGTACACACCGCCCGTCACACCA TGGGAGTTGGATTCACTCGAAGGCGATGAGCTAACCCGCAAGGGAGGCAGGCGACCACAGTGGGTTTAGCGACTGGGGTGAAGTCGTA ACAAGGTAGCCGTAGGGGAACCTGCGGTTGGATCACCTC

S13249

GTAGTCCTGGCCGTAAACTATGGGTGCTAGCCGTCGGATAGCTTGCTATTCGGTGGCGCAGCTAACGCATTAAGCACCCCGCCTGGGG AGTACGGCCGCAAGGTTAAAACTCAAAGGAATTGACGGGGGCCCGCACAAGCGGTGGAGCATGTGGTTTAATTCGACGCAACGCGAAG AACCTTACCAGCTCTTGACATTTCCTGACTGGTTCCAGAGATGGGATCGTCCTAGCAATAGGCAGGAGGACAGGTGCTGCATGGCTGT CGTCAGCTCGTGTCGTGAGATGTTGGGTTAAGTCCCGCAACGAGCGCAACCCTCGCCATTAGTTGCCATCATTCAGTTGGGCACTCTA GTGGGACTGCCGGTGATAAGCCGGAGGAAGGTGGGGATGACGTCAAGTCATCATGGCCCTTATGGGCTGGGCTACACACGTGCTACAA TGGCGGTGACAGTGGGCAGCTACTCAGCGATGGGAAGCTAATCTCAAAAAGCCGTCTCAGTTCGGATTGGACTCTGCAACTCGAGTCC ATGAAGTCGGAATCGCTAGTAATCGCGGATCAGAACGCCGCGGTGAATACGTTCCCGGGCCTTGTACACACCGCCCGTCACACCATGG GAGTTGGTTTTACCCGAAGACGATGCGCTAACCGCAAGGAGGCAGTCGGCCACGGTAAGGTCAGCGACTGGGGTGAAGTCGTAACAAG GTAGCCGTAGGGGAACCTGCGGCTGGATCACCTCC

S13251

GTAGTCCCGGCCGTAAACGATGATAACTAGCTGTCCGGGCTCATGGAGTCTGGGTGGCGCAGCTAACGCATTAAGTTATCCGCCTGGG GAGTGCGGTCGCAAGATTAAAACTCAAAGGAATTGACGGGGGCCTGCACAAGCGGTGGAGCATGTGGTTTAATTCGAAGCAACGCGCA GAACCTTACCAGCGTTTGACATCCTCATCGCGATTTCCAGAGATGGATTTCTTCAGTTCGGCTGGATGAGTGACAGGTGCTGCATGGC TGTCGTCAGCTCGTGTCGTGAGATGTCGGGTTAAGTCCCGCAACGAGCGCAACCCTCGTCCTTAGTTGCCATCATTTAGTTGGGCACT CTAAGGAAACCGCCGGTGATAAGCCGGAGGAAGGTGGGGATGACGTCAAGTCCTCATGGCCCTTACACGCTGGGCTACACACGTGCTA CAATGGCGATGACAGTGAGCAGCTAGCCCGCGAGGGTCTGCTAATCTCTAAAAGTCGTCTCAGTTCGGATTGTTCTCTGCAACTCGAG AGCATGAAGGCGGAATCGCTAGTAATCGCGGATCAGCATGCCGCGGTGAATACGTTCCCAGGCCTTGTACACACCGCCCGTCACACCA TGGGAGTTGGTTTCACCCGAAGGCGCTACGCTAACCCGCAAGGGAGGCAGGCGACCACGGTGGGATCAGCGACTGGGGTGAAGTCGTA ACAAGGTAGCCGTAGGGGAACCTGCGGCTGGATCACCTCC

S13253

GTAGTCCCGGCCGTAAACGATGAATGCCAGTCGTCGGGTAGCATGCTATTCGGTGACACACCTAACGGATTAAGCATTCCGCCTGGGG AGTACGGCCGCAAGGTTAAAACTCAAAGGAATTGACGGGGGCCCGCACAAGCGGTGGAGCATGTGGTTTAATTCGAAGCAACGCGCAG AACCTTACCAACCCTTGACATGGGTATCGCGGGGCCAGAGATGGTCCTTTCAGTTCGGCTGGATACCACACAGGTGCTGCATGGCTGT CGTCAGCTCGTGTCGTGAGATGTTCGGTTAAGTCCGGCAACGAGCGCAACCCACATTTTCAGTTGCCATCATTCAGTTGGGCACTCTG GAGAAACTGCCGGTGGTAAGCCGGAGGAAGGTGTGGATGACGTCAAGTCCTCATGGCCCTTACGGGTTGGGCTACACACGTGCTACAA TGGTGGTGACAATGGGTTAATCCCCAAAAGCCATCTCAGTTCGGATTGGGGTCTGCAACTCGACCCCATGAAGTCGGAATCGCTAGTA ATCGCGTAACAGCATGACGCGGTGAATACGTTCCCGGGCCTTGTACACACCGCCCGTCACACCATGGGAATTGGATCTACCCGAAGGT GGTGCGCCAACCTGCAAAGGAGGCAGCCAACCACGGTAGGTTCAGTGACTGGGGTGAAGTCGTAACAAGGTAGCCGTAGGGGAACCTG CGGCTGGATCACCTCC

S13255

GTAGTCCCGGCCGTAAACGATGTCAGCTAGATGTTCAGAGGGCGCAAGCCGTCGGGGTATCGAAGCAAACCCGATAAGCTGACCGCCT GGGGAGTACGGTCGCAAGGCTAAAACTCAAAGGAATTGACGGGGGCCCGCACAAGCAGCGGAGCGTGTGGTTTAATTCGAGGCTACAC GAAGAACCTTACCTGGGTTTGACATATACGTGGTAGTGAACTGAAAAGGGAACGACCTTCGGGAGCGTATACAGGTGCTGCATGGCTG TCGTCAGCTCGTGCCGTGAGGTGTTCGGTTAAGTCCGCAAACGAGCGCAACCCCTGGTGCTAGTTACACGTGTCTAGCGCAACTGCCC GTGAGAAACGGGAGGAAGGTGGGGATGACGTCAAGTCAGCATGGCCTTTATATCCAGGGCTACACACACGCTACAATGGGCGGTACAA TGGGTCGCGAAACCGCGAGGTGGAGCCAATCCTAAAAGGCCGTTCGTAGTTCGGATTGCAGGCTGCAACTCGCCTGCATGAAGTCGGA GTTGCTAGTAACTGCAGGTCAGCTATACTGCGGTGAATACGTTCCCGGGCCTTGTACACACCGCCCGTCACGTCATGGGAGCTGGTCA CGCCTGAAGTCGGGAAGCTAACTGCAAAGAGGCTACCGCCGAGGGCAGGGCCGGTGACTGGGACGAAGTCGTAACAAGGTGGCTGTAC CGGAAGGTGCGGCTGGATCACCTCC

S13257

GTAGTCCCGGCCGTAAACGATGAATGCCAGTCGTCGGGTAGCATGCTATTCGGTGACACACCTAACGGATTAAGCATTCCGCCTGGGG AGTACGGCCGCAAGGTTAAAACTCAAAGGAATTGACGGGGGCCCGCACAAGCGGTGGAGCATGTGGTTTAATTCGAAGCAACGCGCAG AACCTTACCAACCCTTGACATGGGTATCGCGGGGCCAGAGATGGTCCTTTCAGTTCGGCTGGATACCACACAGGTGCTGCATGGCTGT CGTCAGCTCGTGTCGTGAGATGTTCGGTTAAGTCCGGCAACGAGCGCAACCCACATTTTCAGTTGCCATCATTCAGTTGGGCACTCTG GAGAAACTGCCGGTGGTAAGCCGGAGGAAGGTGTGGATGACGTCAAGTCCTCATGGCCCTTACGGGTTGGGCTACACACGTGCTACAA TGGTGGTGACAATGGGTTAATCCCCAAAAGCCATCTCAGTTCGGATTGGGGTCTGCAACTCGACCCCATGAAGTCGGAATCGCTAGTA ATCGCGTAACAGCATGACGCGGTGAATACGTTCCCGGGCCTTGTACACACCGCCCGTCACACCATGGGAATTGGATCTACCCGAAGGT GGTGCGCCAACCTGCAAAGGAGGCAGCCAACCACGGTAGGTTCAGTGACTGGGGTGAAGTCGTAACAAGGTAGCCGTAGGGGACCTG CGGCTGGATCACCTCC

S13258

GTAGTCCCGGCCGTAAACGATGATAACTAGCTGTTCGGGATCTACGATCCTGAGTGGCGCAGCTAACGCATTAAGTTATCCGCCTGGG GAGTACGGTCGCAAGATTAAAGCTCAAAGGAATTGACGGGGGCCTGCACAAGCGGTGGAGCATGTGGTTTAATTCGAAGCAACGCGCA GAACCTTACCAGCGTTTGACATCCTAATCGCGGTTTTCAGAGATGATTACCTTCAGTTCGGCTGGATTAGTGACAGGTGCTGCATGGC TGTCGTCAGCTCGTGTCGTGAGATGTTGGGTTAAGTCCCGCAACGAGCGCAACCCTCGTCCTTAGTTGCCATCATTCAGTTGGGCACT CTAAGGAAACTGCCGGTGATAAGCCGGAGGAAGGTGGGGATGACGTCAAGTCCTCATGGCCCTTACACGCTGGGCTACACACGCGCTA CAATGGCGGTGACAGTGGGCAGCAACCGGGCGACCGGTAGCTAATCTCTAAAAACCGTCTCAGTTCGGATTGTTCTCTGCAACTCGAG AGCATGAAGGCGGAATCGCTAGTAATCGCGGATCAGCATGCCGCGGTGAATACGTTCCCAGGCCTTGTACACACCGCCCGTCACACCA TGGGATTTGGATTCACCCGAAGGCAGTGCGCTAACCGCAAGGAGGCAGCTGACCACGGTGGGTTTAGAGACTGGGGTGAAGTCGTAAC AAGGTAGCCGTAGGGGAACCTGCGGCTGGATCACCTCC

s13261

GTAGTCCTGGCCGTAAACGATGGGCACTTGNCNGGGGGGTAACCTATGGTCCTCTCTGCCGAAGCAAATGTGCTAAGTGCCCCGCCTG GGGAGTACGCTCGCAAGGGTAAAACTCAAAGAAATTGACGGGGGCTCACACAAGCGGTGGAGCATGTGGTTTAATTCGAAGCAACGCG AAGAACCTTACCTGGCCTTGACATGCACGGATTAGTCCCATGAAGGTGGGGCAACAGCCCTTCGGGGTCGGAACGTGCACAGGTGTTG CATGGCTGCCGTCAGCTCGTGTCGTGAGATGTTGGGTTAAGTCCCGTAACGAGCGAAACCCCTATCACTAGTTGCCAGCGGGTCATGC CGGGAACTCTAGTGAGACTGCCGTTGTTAAGACGGAGGAAGGTGGGGACGACGTCAAGTCATCATGGCCCTTATGGCCAGGGCGACAC ACGTGCTACAATGGTCTGTACAAAGGGTTCCAAAACCGCGAGGTCGAGGCAATCCCAAAAAGCAGGCCCCAGTTCGGATTGAAGGCTG CAATTCGCCTTCATGAAGCCGGAATCGCTAGTAATCGCGCATCAGCCATGGCGCGGTGAATATGTTCCTGAGCCTTGTACACACCGCC CGTCAAGCCACGAAAGCGGGGAGCGCTCGAAGTCGCTATGTCCAACCGCAAGGGGGACGGTGCCTAAAGCAAGCTCCGTGATTGGGAC TAAGCCGTAACAAGGTAGCCGTAGGGGAACCTGCGGCTGGATCACCTC S13262 
GTAGTCCCGGCCGTAAACGATGATTGCTAGTTGTCGGGAAGCTTGCTTCTCGGTGACGCAGCTAACGCATTAAGCAATCCGCCTGGGG AGTACGGTCGCAAGATTAAAACTCAAAGGAATTGACGGGGGCCCGCACAAGCGGTGGAGCATGTGGTTTAATTCGAAGCAACGCGCAG AACCTTACCACCTTTTGACATGCCCGGACCGCCACAGAGATGTGGCTTTCCCTTCGGGGACTGGGACACAGGTGCTGCATGGCTGTCG TCAGCTCGTGTCGTGAGATGTTGGGTTAAGTCCCGCAACGAGCGCAACCCTCGCCATTAGTTGCCATCATTTAGTTGGGAACTCTAAT GGGACTGCCGGTGCTAAGCCGGAGGAAGGTGGGGATGACGTCAAGTCCTCATGGCCCTTACAGGGTGGGCTACACACGTGCTACAATG GCGACTACAGAGGGTTAATCCTTAAAAGTCGTCTCAGTTCGGATTGTCCTCTGCAACTCGAGGGCATGAAGTTGGAATCGCTAGTAAT CGCGGATCAGCATGCCGCGGTGAATACGTTCCCGGGCCTTGTACACACCGCCCGTCACACCATGGGAGATGGTTCTACCCGAAGGCGA TGCGCTAACCCGCAAGGGAGGCAGTCGACCACGGTAGGGTCAGCGACTGGGGTGAAGTCGTAACAAGGTAGCCGTAGGGGACCTGCG GCTGGATCACCTCC

Sl3263

GTAGTCCCGGCCGTAAACGTTGGACACTAGGTGTGAGGGGTATCGACCCCCCTCGTGCCGAAGTTAACACATTAAGTATCCCGCCTGG GGAGTACGGCCGCAAGGTTGAAACTCAAAGGAATAGACGGGGGCCCGCACAAGCGGTGGAGCATGTGGTTCAATTCGACGCAACGCGA AGAACCTTACCCAGGCTCGAAATGTGGGGGACAGCTGTGGAAACACAGTCTCTTCCCGCAAGGGAAGTCCTCATATAGGTGCTGCATG GCTGTCGTCAGCTCGTGTCGTGAGATGTTGGGTTAAGTCCCGCAACGAGCGCAACCCTTGTCGTTAGTTACCAGCGGGTAATGCCGGG GACTCTAACGAGACTGCCTGTGATAAACAGGAGGAAGGTGGGGATGACGTCAAGTCCTCATGGCCCTTACGTCTGGGGCTACACACGT GCTACAATGGCCGGCACAGAGAGAAGCAAGACCGCAAGGTGGAGCAAATCTTCAAAGCCGGTCCCAGTTCGGATCGGAGTCTGCAATT CGACTCCGTGAAGTTGGAATCGCTAGTAATCGCGGATCAGCACGCCGCGGTGAATACGTTCCCGGGCCTTGTACACACCGCCCGTCAC ACCACGAAAGTCAGTTGTACCAGAAGTCGGTGTACCAACCCGCAAGGGAGGAAGCCGCCGAAGGTATGGCCGGTGATTGGGGTGAAGT CGTAACAAGGTAGCCGTATCGGAAGGTGCGGCTGGATCACCTCC

Sl3265

GTAGTCCTGGCCGTAAACGATGGAAGCCAGCTGTCGGCAAGTTTACTTGTCGGTGGCGCAGCTAACGCATTAAGCTTCCCGCCTGGGG AGTACGGTCGCAAGATTAAAACTCAAAGGAATTGACGGGGGCCCGCACAAGCGGTGGAGCATGTGGTTTAATTCGAAGCAACGCGCAG AACCTTACCAGCCCTTGACATCCCGGTCGCGGGTACCAGAGATGGTACCCTTCAGTTAGGCTGGACCGGTGACAGGTGCTGCATGGCT GTCGTCAGCTCGTGTCGTGAGATGTTGGGTTAAGTCCCGCAACGAGCGCAACCCTCGCCCTTAGTTGCCAGCATTAAGTTGGGCACTC TAAGGGGACTGCCGGTGATAAGCCGGAGGAAGGTGGGGATGATGTCAAGTCNTNATGGCCNTTACGGGNTGGGCTACACACGTGCTAC AATGGTGGTGACAGTGGGCAGCGAGNCCGCGAGGTCGAGCTAATCTCCAAAAGCCATGTCAGTTCGGATTGCACTCTGCAACTCGAGT GCATGAAGTTGGAATCGCTAGTAATCGCGGATCAGCATGCCGCGGTGAATACGTTCCCGGGCCTTGTACACACCGCCCGTCACACCAT GGGAGTTGGCTTTACCCGAAGGCGCTGCGCTGACCGCAAGGAGGCAGGCGACCACGGTAGGGTCAGTGACTGGGGTGAAGTCGTAACA AGGTAGCCGTAGGGGAACCTGCGGCTGGATCACCTCC S13266

GTAGTCCTGGCCGTAAACGATGAATACTAGGTGTCGGGCGTCAAAACTCGGTGCCGCAGCTAACGCATTAAGTATTCCGCCTGGGGAG TACGCACGCAAGTGTGAAACTCAAAGGAATTGACGGGGACCCGCACAAGCAGCGGAGCATGTGGTTTAATTCGAAGCAACGCGAAGAA CCTTACCAGGTCTTGACATCCTCTTGCAAGCGTCCTAATAGGCGCCCTCCTTCAGGACAAGAGAGACAGGTGGTGCATGGTTGTCGTC AGCTCGTGTCGTGAGATGTTGGGTTAAGTCCCGCAACGAGCGCAACCCTCACCTTTAGTTGCCAACAGGTTAAGCTGTGCACTCTAAA CAGACTGCCGTGGATAACACGGAGGAAGGTGGGGATGACGTCAAATCATCATGCCCCTTATGATCTGGGCTACACACGTGCTACAATG GTCGGTACAACGGGCAGCGAAAGAGCGATCTGGAGCGAATCCTAAAAAGCCGATCCCAGTTCGGATTGCAGGCTGAAACTCGCCTACA TGAAGTTGGAGTTGCTAGTAATCGCGAATCAGAATGTCGCGGTGAATGCGTTCCCGGGTCTTGTACACACCGCCCGTCACACCATGGA AGTTGAGGGCGCCCGAAGCCAGTGGTCCAACCCGTAAGGGAGGAAGCTGTCGAAGGTGAAATCAATGACTGGGGTGAAGTCGTAACAA GGTAGCCGTATCGGAAGGTGCGGCTGGATCACCTCC

Sl3267

GTAGTCCCGGCCGTAAACGATGAATGCTTGGTGTGGCGGGTATCGATCCCTGCCGTGCCGAAATTAACGCGATAAGCATTCCGCCTGG GGAGTACGGTCGCAAGGCTGAAACTCAAAGGAATTGACGGGGGCCCGCACAAGCGGTGGAGCATGTGGTTTAATTCGACGCAACGCGA AGAACCTTACCCAGGCTCGAAATGCAGTTGACCATCGGTGAAAGCCGACTCCCGCAAGGGCAACTGTATAGGTGCTGCATGGCTGTCG TCAGCTCGTGTCGTGAGATGTTGGGTTAAGTCCCGCAACGAGCGCAACCCTTGTTTCCTGTTGCCATCACGTAAGGTGGGCACTCTGG AGAGACTGCCGGTGACAAACCGGAGGAAGGTGGGGATGACGTCAAGTCAGCATGGCCTTTATGTCTGGGGCTACACACGTGCTACAAT GGCCGATACAAAGCGCTGCCAACTCGCGAGAGTGAGCTAATCGCATAAAGTCGGTCTCAGTTCGGATTACAGGCTGCAACTCGCCTGC ATGAAGTTGGAATCGCTAGTAATCGCGGATCAGCATGCCGCGGTGAATACGTTCCCGGGCCTTGTACACACCGCCCGTCACATCACGA AAGCTGGCTGTACTAGAAATCGCCGCGCTAACCCGCAAGGGAGGCAGGCGCTTAAGGTATGGTTAGTGATTGGGGTGAAGTCGTAACA AGGTAGCTGTAGGAGAACCTGCGGCTGGATCACCTCC

S13268

GTAGTCCCGGCCGTAAACGATGATAACTAGCTGTCCGGGCACTTGGTGCTTGGGTGGCGCAGCTAACGCATTAAGTTATCCGCCTGGG GAGTACGGTCGCAAGATTAAAACTCAAAGGAATTGACGGGGGCCTGCACAAGCGGTGGAGCATGTGGTTTAATTCGAAGCAACGCGCA GAACCTTACCAGCCTTTGACATCCCGCGCTATCCTGAGAGATCAGGGGTTCCCTTCGGGGACGCGGTGACAGGTGCTGCATGGCTGTC GTCAGCTCGTGTCGTGAGATGTTGGGTTAAGTCCCGCAACGAGCGCAACCCTCGTCCTTAGTTGCCATCATTAAGTTGGGCACTCTAA GGAAACCGCCGGTGATAAGCCGGAGGAAGGTGGGGATGACGTCAAGTCCTCATGGCCCTTACAGGCTGGGCTACACACGTGCTACAAT GGCGGTGACAGTGAGCAGCTAACCCGCGAGGGTGTGCTAATCTCCAAAAGCCGTCTCAGTTCGGATTGTTCTCTGCAACTCGAGAGCA TGAAGGCGGAATCGCTAGTAATCGCGGATCAGCATGCCGCGGTGAATACGTTCCCAGGCCTTGTACACACCGCCCGTCACACCATGGG AGTTGGCTTCACCCGAAGGCGTTGCGCTAACTCGCAAGAGAGGCAGGCGACCACGGTGGGCTTAGCGACTGGGGTGAAGTCGTAACAA GGTAGCCGTAGGGGAACCTGCGGCTGGATCACCTC

S13269

CTGTAAACGATGAATACTTGGTGTCTGGAATTATTATTGTTCCGGGTGCCGTCGCTAACGTTTTAAGTATTCCGCCTGGGGAGTACGC ACGCAAGTGTGAAACTCAAAGGAATTGACGGGGACCCGCACAAGCGGTGGAGCATGTGGTCTAATTCGACGCAACGCGAAGAACCTTA CCTGGACTAGAATGTGAGGGAAGGACTCCTAATAGAGTCCGTCCGGGAAACCGGACCCAAAACAAGGTGCTGCATGGCTGTCGTCAGC TCGTGTCGTGAGATGTTGGGTTAAGTCCCGCAACGAGCGCAACCCTTATCAACAGTTGCCATCATTAAGTTGGGAACTCTGTTGAGAC TGCCGTTGATAAAACGGAGGAAGGTGGGGATGATGTCAAGTCATCATGGCCTTTATGTTCAGGGCTACACACGTGCTACAATGGATGG TACAAAACGTCGCAATCCCGCAAGGGGGAGCTAATCGCAAAAACCATTCTCAGTTCGGATTGAAGTCTGCAACTCGACTTCATGAAGT TGGAATCGTTAGTAATCGCGGATCAGAACGCCGCGGTGAATACGTTCCCGGGTCTTGTACACACCGCCCGTCACATCACGAAAGTAGG TTGTATTAGAAGTAGCTGGGCCAACTCGCAAGAGAGGCAGGTTACCACGGTATGATTTATGATTGGGGTGAAGTCGTGACAAGGTAGC TGTAGGAGAACCTGCGGCTGGATCACCTCC S13270

GTAGTCCCGGCCGTAAACGATGAGAACTGAGCGGGGGGGGGCTTGCCCTTCCCGGCTGTAGCGAAAGCGTTAAGTTCTCCGCCTGGGG AGTATGGTCGCAAGGCTGAAACTCAAAGGAATTGACGGGGGCTCACACAAGCGGTGGAGCATGTGGCTTAATTCGAGGCAACGCGAAG AACCTTATCCTAGATTTGACATGCTTGGATTAGTCAGTGGAAACATTGATGACGCTCGCAAGAGTGGAACAGGCACAGGTGCTGCATG GCTGTCGTCAGCTCGTGCCGTGAGGTGTCGGGTTAAGTCCTTTAACGAGCGAAACCCCTGTCGTCAGTTGCCAGCATTTAGTTGGGGA CTCTGACGAGACCGCCGGCGTCAAGCCGGAGGAAGGCGGGGACGACGTCAAGTCATCATGGCCTTTATGTCTAGGGCTGCACACGTGC TACAATGCCGCGTATAAAGGGAAGCAAGACCGCGAGGTGGAGCAAATCCCAAAAAGCGCGGCCCAGTTCGGATTGCAGGCTGCAACTC GCCTGCATGAAGCCGGAATCGCTAGTAATCGCAGATCAGCTATGCTGCGGTGAATGTGTTCCTGAGCCTTGTACACACCGCCCGCCAA 
GCCACGAAAGGGGGGAGCGTCCGAAGTCACTGAGTGAACCGCAAGGACACAGGTGCCGAAGACGAGCTCCCTGATTGGGACTAAGTCG TAACAAGGTAGCCGTAGGGGAACCTGCGGCTGGATCACCTCC

S13272

CCGTAAACGGTGCGCGTTTGGTGTGGGAGGATTCGTCCCCTTCTGTGCCGGAGCTAACGCGTTAAACGCGCCGCCTGGGGAGTACGGT CGCAAGATTAAAACTCAAAGAAATTGACGGGGGCCCGCACAAGCGGTGGAGTATGTGGCTTAATTCGATGCAACGCGAAGAACCTTAC CTAGCCTTGACATGCATCTCTAAGTCGGTGAAAGCCGGCGACTGTAGCAATACAGAATTTGCACAGGCGCTGCATGGCTGTCGTCAGC TCGTGTCGTGAGATGTTGGGTTAAGTCCCGCAACGAGCGCAACCCCTGTGAACTGTTGCCACCGGCCTCCGGGCCGAGCACTCTGTTC AGACTGCCCTGTGAAACGGGGAGGAAGGTGGGGATGACGTCAAGTCAGCATGGCCCTTACGGCTAGGGCTGCACACGTACTACAATGC TCAGTACAGAACGAACCAAAACCGCGAGGTGGAGGAAATCTCAAAAACTGAGCCCAATTCGGATTGGAGGCTGCAACTCGCCTCCATG AAGCCGGAATCGCTAGTAATGGCGCATCAGCTACGGCGCCGTGAATACGTTCCCGGGCCTTGTACACACCGCCCGTCACATCATGGAA GTCACTTGTACCCGAAGTGCATGCGCCAACCGCAAGGAGGCAGTGCCCTAAGGTATGGGTGGTAACTGGGATGAAGTCGTAACAAGGT AGCCGTAGGGGAACCTGCGGCTGGATCACCTCC

S13273

GTAGTCCTGGCCGTAAACGATGTCAACTAGCCGTTGGGAGCCTTGAGCTCTTAGTGGCGCAGCTAACGCATTAAGTTGACCGCCTGGG GAGTACGGCCGCAAGGTTAAAACTCAAATGAATTGACGGGGGCCCGCACAAGCGGTGGAGCATGTGGTTTAATTCGAAGCAACGCGAA GAACCTTACCAGGCCTTGACATCCAATGAACTTTCCAGAGATGGATTGGTGCCTTCGGGAACATTGAGACAGGTGCTGCATGGCTGTC GTCAGCTCGTGTCGTGTGATGTTGGGTTAAGTCCCGTAACGAGCGCAACCCTTGTCCTTAGTTACCAGCACGTAATGGTGGGCACTCT AAGGAGACTGCCGGTGACAAACCGGAGGAAGGTGGGGATGACGTCAAGTCATCATGGCCCTTACGGCCTGGGCTACACACGTGCTACA ATGGTCGGTACAGAGGGTTGCCAAGCCGCGAGGTGGAGCTAATCCCAGAAAACCGATCGTAGTCCGGATCGCAGTCTGCAACTCGACT GCGTGAAGTCGGAATCGCTAGTAATCGCGAATCAGAATGTCGCGGTGAATACGTTCCCGGGCCTTGTACACACCGCCCGTCACACCAT GGGAGTGGGTTGCACCAGAAGTAGCTTGTCTAACCTTCGGGAGGACGGTTACCACGGTGTGATTCATGACTGGGGTGAAGTCGTAACA AGGTAGCCGTAGGGGAACCTGCGGCTGGATCACCTCC

Sl3274

GTAGTCCTGGCCGTAAACGATGTGTGCTAGTTGCTGGATTGCTTAGCTTTTCAGTGACGCAGCTAACGCATTAAGCACACCGCCTGGG GAGTACGGTCGCAAGATTAAAACTCAAAGGAATTGACGGGGACCCGCACAAGCGGTGGAGCATGTTGTTTAATTCGACGCAACGCGAA GAACCTTACCTACGCTTGACATACCGGTTGAGGTCTTCAGAGATGAGGGTCGTCATTTAGTTGGACCGGATACAGGTGCTGCATGGCT GTCGTCAGCTCGTGTCGTGAGATGTTGGGTTAAGTCCCGCAACGAGCGCAACCCCTATCGTATGTTGCCATCATTTAGTTGGGCACTC ATGCGAGACCGCCGGTGTCAAGCCGGAGGAAGGTGGGGACGACGTCAAGTCATCATGGCCCTTACGCGTAGGGCTACAAACGTGCTAC AATGGCAGTGACAATGGGCAGCAAGTCCGCAAGGATGAGCAAATCCCCAAAAGCTGTCTCAGTTCAGATTGTCCTCTGCAACTCGAGG GCATGAAGTTGGAATCGCTAGTAATCGTGGATCAGCATGCCACGGTGAATACGTTCCCGGGTCTTGTACACACCGCCCGTCACACCAT GGGAGTTGGTTCTACCTGAAGGCGCTGCGCTAACCGCAAGGGGGCAGGCGACCACGGTAGGGTCAATGACTGGGGTGAAGTCGTAACA AGGTAGCCGTATCGGAAGGTGCGGCTGGATCACCTCC S13275

GTAGTCCTGGCCGTAAACGATGAATGCCAGACGTCGGCANGCATGCTTGTCGGTGTCACACCTAACGGATTAAGCATTCCGCCTGGGG AGTACGGCCGCAAGGTTAAAACTCAAAGGAATTGACGGGGGCCCGCACAAGCGGTGGAGCATGTGGTTTAATTCGAAGCAACGCGCAG AACCTTACCAACCCTTGACATGGGTATCGCGGGACCGGAGACGGTCCTTTCAGTTCGGCTGGATACCACACAGGTGCTGCATGGCTGT CGTCAGCTCGTGTCGTGAGATGTTCGGTTAAGTCCGGCAACGAGCGCAACCCACACTTTCAGTTGCCATCATTCAGTTGGGCACTCTG GAAGAACTGCCGGTGATAAGCCGGAGGAAGGTGTGGATGACGTCAAGTACTCATGGCCCTTACGGGTTGGGCTACACACGTGCTACAA TGGTGGTGACAATGGGTTAATCCCCAAAAGCCATCTCAGTTCGGATTGGGGTCTGCAACTCGACCCCATGAAGTCGGAATCGCTAGTA ATCGCGTAACAGCATGACGCGGTGAATACGTTCCCGGGCCTTGTACACACCGCCCGTCACACCATGGGAATTGGGTCTACCCGACGAC GGTGCGCCAACCTCGCAAGAGGAAGCAGCCGGCCACGGTAGGCTCAGTGACTGGGGTGAAGTCGTAACAAGGTAGCCGTAGGGGAACC TGCGGCTGGATCACCTC

Sl3277

GGAATTGACGGGGGCCCGCACAAGCAGCGGAGCGTGTGGTTTAATTCGAGGCTACACGAAGAACCTTACCTGGGTTTGACATACAAGT AGTAGTGAAGCGAAAGCGGAACGACCTTCGGGAGCTTGTACAGGTGCTGCATGGCTGTCGTCAGCTCGTGCCGTGAGGTGTTCGGTTA AGTCCGCAAACGAGCGCAACCCTCGGCGTTAGTTACAAGTGTCTAACGCAACTGCCCGTGAGAAACGGGAGGAAGGTGGGGATGACGT CAAGTCAGCATGGCCTTTATATCCAGGGCTACACACACGGTACAATGGGCGGTACAACGGGTCGCGAAGCCGCGAGGTGGAGCCAATC CATAAAGCCGTTCGTAGTTCGGATTGCAGGCTGCAACTCGCCTGCATGAAGTCGGAGTTGCTAGTAACCGCAGGTCAGCTATACTGCG GTGAATACGTTCCCGGGCCTTGTACACACCGCCCGTCACGTCATGGGAGCTGGTCACGCCTGAAGTCGGGGAGCTAACCTAACGGAGG CAACCGCCGAGGGCAGGGCTGGTGACTGGGACGAAGTCGTAACAAGGTAGCTGTACCGGAAGGTGCGGCTGGATCACCTCC Sl3279

GTAGTCCCGGCCGTAAACGATGATAACTAGCTGTCGGGGCCCATAGGGTTTCGGTGGCGCAGCTAACGCATTAAGTTATCCGCCTGGG GAGTACGGCCGCAAGGTTAAAACTCAAAGAAATTGACGGGGGCCTGCACAAGCGGTGGAGCATGTGGTTTAATTCGAAGCAACGCGCA GAACCTTACCAGCGTTTGACATCCTCATCGCGGGATCCAGAGATGGATTCCTTCAGTTCGGCTGGATGAGTGACAGGTGCTGCATGGC TGTCGTCAGCTCGTGTCGTGAGATGTTGGGTTAAGTCCCGCAACGAGCGCAACCCTCGTCCTTAGTTGCCATCATTTAGTTGGGCACT CTAAGGAAACCGCCGGTGATAAGCCGGAGGAAGGTGGGGATGACGTCAAGTCCTCATGGCCCTTACGCGCTGGGCTACACACGTGCTA CAATGGCGGTGACAGTGGGCAGCAAACCCGCGAGGGTGAGCTAATCTCCAAAAGCCGTCTCAGTTCGGATTGTTCTCTGCAACTCGAG AGCATGAAGGCGGAATCGCTAGTAATCGCGGATCAGCACGCCGCGGTGAATACGTTCCCAGGCCTTGTACACACCGCCCGTCACACCA TGGGAGTTGGATTGACCCGAAGGCGCTGAGCTAACCCGCAAGGGAGGCAGGCGACCACGGTCGGTTCAGCGACTGGGGTGAAGTCGTA ACAAGGTAGCCGTAGGGGAACCTGCGGCTGGATCACCTCC

S13280

GTAGTCCTGGCCGTAAACGATGATAACTAGCTGTTCGGGGTCTACGATCCTGAGTGGCGCAGCTAACGCATTAAGTTATCCGCCTGGG GAGCACGGTCGCAAGATTAAAACTCAAAGGAATTGACGGGGGCCTGCACAAGCGGTGGAGCATGTGGTTTAATTCGAAGCAACGCGCA GAACCTTACCAGCGTTTGACATCCTAATCGCGGTTTTCAGAGATGATTACCTTCAGTTCGGCTGGATTAGTGACAGGTGCTGCATGGC TGTCGTCAGCTCGTGTCGTGAGATGTTGGATTAAGTCCCGCAACGAGCGCAACCCTCGTCCTTAGTTGCCATCATTCAGTTGGGCACT CTAAGGAAACTGCCGGTGATAAGCCGGAGGAAGGTGGGGATGACGTCAAGTCCTCATGGCCCTTACACGCTGGGCTACACACGTGCTA CAATGGCGGTGACAGTGGGCAGCAACCGGGCGACCGGTAGCTAATCTCCAAAAACCGTCTCAGTTCGGATTGTTCTCTGCAACTCGAG AGCATGAAGGCGGAATCGCTAGTAATCGCGGATCAGCATGCCGCGGTGAATACGTTCCCAGGCCTTGTACACACCGCCCGTCACACCA TGGGATTTGGATTCACCCGAAGGCAGTGCGCTAACCGCAAGGAGGCAGCTGACCACGGTGGGTTTAGAGACTGGGGTGAAGTCGTAAC AAGGTAGCCGTAGGGGAACCTGCGGCTGGATCACCTC

S13281

GTAGTCCCGGCCGTAAACGATGGATGCTAGCCGTCGGATAGCATGCTTGTCGGTGTCACACCTAACGGATTAAGCATTCCGCCTGGGG AGTACGGCCGCAAGGTTAAAACTCAAAGGAATTGACGGGGGCCCGCACAAGCGGTGGAGCATGTGGTTTAATTCGAAGCAACGCGCAG AACCTTACCAACCCTTGACATGGGTATAGCGG - ACCGGAGACGG - C - ATTC - TATCGACTGGAT -

CCACACAGGTGCTGCATGGCTGTCGTCAGCTCGTGTCGTGAGATGTTCGGTTAAGTCCGGCAACGAGCGCGACCCACACTTTCAGTTG CCATCATTCAGTTGGGCACTCTGGAAGAACTGCCGGTGATAAGCCGGAGGAAGGTGTGGATGACGTCAAGTCCTCATGGCCCTTACGG GTTGGGCTACACACGTGCTACAATGGTGGTGACAATGGGTTAATCCCCAAAAGCCATCTCAGTTCGGATTGGGGTCTGCAACTCGACC 
CCATGAAGTCGGAATCGCTAGTAATCGCGTAACAGCATGACGCGGTGAATACGTTCCCGGGCCTTGTACACACCGCCCGCCACACCAT GGGAATTGGGTCTACCCGACGACGGTGCGCCAACCTCGCAAGAGGAAGCAGCCGGCCACGGTAGGCTCAGTGACTGGGGTGAAGTCGT AACAAGGTAGCCGTAGGGGAACCTGCGGCTGGATCACCTC

S13283

GTAGTCCCGGCCGTAAACGATGAGTGCTGGACGGGAGGGGGTTCGCCCTTACCGGTCGGAGCGAAAGCGGGAAGCACTCCGCCTGGGG AATATGGTCGCAAGGCTGAAACTCAAAGGAATTGACGGGGGCCCACACAAGCGGTGGAGCATGTGGCTTAATTCGAGGCAACGCGAAG AACCTTATCCTAGGCTTGACATGCATGGATTAACTCTCTGAGAGGAGAGCCACGCCTTCGGGTGGAACATGCACGGGTGCTGCATGGC TGTCGTCAGCTCGTGCCGTGAGGTGTCGGGTTAAGTCCTTCAACGAGCGAAACCCTTGTCTCCAGTTGCCAGCATTCAGTTGGGGACT CTGGAGAGACCGCCGGCGTCAAGCCGGAGGAAGGCGGGGACGACGTCAAGTCATCATGGCCTTTATGCCTAGGGCTGCACACGTGCTA CAATGCCGCGTACAAAGGGACGCCAAACCGCGAGGTGGAGCCAATCCCAGAAAGCGCGGCTCAGTTCGGATTGCAGGCTGCAACTCGC CTGCATGAAGCTGGAATCGCTAGTAATCGCAGGTCAGCTATACTGCGGTGAATGTGTTCCTGAGCCTTGTACACACCGCCCGTCAAGC CACGAAAGCGGGGGGCATCGCAAGTGATCGCGCGAACCGCAAGGACGCAGATCCCTAAGATGAACTCCGTGATTGGGACTAAGTCGTA ACATGGTAACCGTAGGGGAACCTGCGGCTGGATCACCTCC

S13285

CCCGGCTGTAAACGATGAGCACTGGATTGAAGGGTCCTCCATAGCCTTTCAGTCGCAACGAAAGCGTTAAGTGCTCCGCCGGGGGAGT ATGGTCGCAAGGCTGAAACTCAAAGGAATTGACGGGGGCTCACACAAGCGGTGGAGGATGTGGCTTAATTCGAGGCTACGCGAAGAAC CTTATCCTAGTCTTGACATGCACGGATTAACTCCTGGAAACAGGAGCCAGGCCTTCGGGTACAACGTGCACAGGTGCTGCATGGCTGT CGTCAGCTCGTGTCGTGAGATGTCGGGTTAAGTCCCTTAACGAGCGAAACCCTTGTCACTAGTTGCCAGCGCGTCATGGCGGGGACTC TAGTGAGACTGCCGGTGTTAAACCGGAGGAAGGTGGGGATGACGTCAAGTCCTCATGGCCTTTATGACTAGGGCTGCACACGTCCTAC AATGCCACGTACAAAGGGAAGCAAACTCGCGAGAGCAAGCAAATCTCAAAAAACGTGGCCCAGTTCGGATTGCAGGCTGCAACTCGCC TGCATGAAGCCGGAATCGCTAGTAATCGCGGGTCAGCATACCGCGGTGAATGTGTTCCTGAGCCTTGTACACACCGCCCGTCAAGCCA CGAAAGTGGGGGGTATCCGAAGTCACTGAGGTAACCGCAAGGAGCCAAGTGCCGAAGATAAACTCCGCGATTGGGACTAAGTCGTAAC AAGGTAGCCGTAGGGGAACCTGCGGCTGGATCACCTCC

S13286

GTAGTCCTGGCCGTAAACGATGGGCACTAGGCAATGGATCATCCCTATGGGGTTCATTGCCGTAGCAAATGTGTTAAGTGCCCCGCCT GGGGAGTACGCTCGCAAGGGTAAAACTCAAAGGAATTGACGGGGGATCACACAAGCGGTGGAGCATGTGGTTTAATTCGAAGCAACGC GAAGAACCTTACCAGGCCTTGACATGCACGGATTAGCTCTGTGAAAGCAGGGTGACAGCTCTTCGGAGTCGGAACGTGTGCAGGTGTT GCATGGCTGTCGTCAGCTCGTGCCGTGAGGTGTTGGGTTAAGTCCCGTAACGAGCGAAACCCTTATCGTTAGTTGCCAGCGGGTCAAG CCGGGGACTCTAGCGAGACTGCCGTTGTTAAAACGGAGGAAGGTGGGGACGACGTCAAGTCATCATGGCCCTTATGGCCTGGGCTACA CACGTGCTACAATGGCCTATACAAAGGGTCCCGAAGCCGCGAGGTAGTGGTAATCCCATAAAGTAGGCCCCAGTTCGGATTGTAGGCT GAAATTCGCCTACATGAAGCCGGAATCGCTAGTAATCGCGTATCAGCCATGTCGCGGTGAATATGTTCCTGATCCTTGTACACACCGC CCGTCAAGCCATGGGAGCGGGGAGCGCTCGAAGTCGTTTTGTCCAACCGCAAGGGGGACGGCGCCGAAAGCGAGCTCCGTGACTGGGA CTAAGTCGTAACAAGGTAGCCGTAGGGGAACCTGCGGCTGGATCACCTCC

S13289

AGTCCCGGCTGTAAACGATGAGCACTAGCCCGTGGGGACTCTCACATCCTCTCGGGCGTAGCGAAAGTGTTAAGTGCTCCGCCTGGGG AGTATGGTCGCAAGGCTGAAACTCAAAGGAATTGACGGGGGCTCACACAAGCGGTGGAGGATGTGGCTTAATTCGAGGCTACGCGAAG AACCTTATCCTAGTCTTGACATGCTTAAGAACCTTTCTGAAAGGAGAGGGTGCCCTTCGGGGAGCTTTTGCACAGGTGCTGCATGGCT GTCGTCAGCTCGTGTCGTGAGATGTCGGGTTAAGTCCCTTAACGAGCGAAACCCTTGTCTCTAGTTGCCAGCGAGTAAAGTCGGGGAC TCTAGAGAGACTGCCGGTGTTAAACCGGAGGAAGGTGGGGATGACGTCAAGTCCTCATGGCCTTTATGATTAGGGCTGCACACGTCCT ACAATGCGGCATACAAAGGGAAGCAAACCCATGAGGGGGAGCAAACCCCAAAAAGTGTCGCTCAGTTCGGATTGCAGGCTGCAACTCG CCTGCATGAAGCTGGAATCGCTAGTAATCGCGGGTCAGCATACCGCGGTGAATGTGTTCCTGAGCCTTGTACACACCGCCCGTCAAGC CACGAAAGTTGGGAGGGCCCGAAGTCGCTGAGCAAACCGCAAGGGTGCAGGCGCCGAAGGTCAGCTCGACGATTGGGACTAAGTCGTA ACAAGGTAGCCGTAGGGGAACCTGCGGCTGGATCACCTCC

S13292

GTAGTCCTGGCCGTAAACGATGAGTACTAGTGGGGAGGGAGTTCGCCTCCTTCCTCACGGAGCGAAAGTTTTAAGTACTCCGCCTGGG GAGTATGGTCGCAAGGCTGAAACTCAAAGGAATTGACGGGGGCTCACACAAGCGGTGGAGCATGTGGCTTAATTCGAGGCAACGCGAA GAACCTTATCCTGGGTTTGACATGCAGGGATTAACTCTGTGAAAGCAGAGCCACGCCTTCGGGTGGAACCTGCACAGGTGCTGCATGG CTGTCGTCAGCTCGTGTCGTGAGATGTCGGGTTAAGTCCCTTAACGAGCGAAACCCTTGTCACTAGTTGCCAGCGAGTCATGTCGGGG ACTCTAGTGAGACCGCCGGTGTTAAACCGGAGGAAGGCGGGGACGACGTCAAGTCATCATGGCCTTTATGCCCAGGGCTGCACACGTG CTACAATGGCGCGTACAAAGGGAAGCAAACTCGCAAGAGCCAGCAAATCTCAAAAAGCGCGCCCCAGTTCAGATTGCAGGCTGCAACT CGCCTGCATGAAGCCGGAATCGCTAGTAATCGCAGATCAGCTTTGCTGCGGTGAATGTGTTCCTGAGCCTTGTACACACCGCCCGTCA AGCCACGAAAGCGGGGAGCATCCGAAGTTGCTGCGTGAACCGTAAGGACACAGGTACCTAAGATGAGCTCCGTGATTGGGACTAAGTC GTAACAAGGTAGCCGTAGGGGAACCTGCGGCTGGATCACCTCC

S13294

GTAGTCCTGGCCGTAAACGATGAATGTTAGCCGTCGGGCAGTTGACTGTTCGGTGGCGCAGCTAACGCATTAAACATTCCGCCTGGGG AGTACGGTCGCAAGATTAAAACTCAAAGGAATTGACGGGGGCCCGCACAAGCGGTGGAGCATGTGGTTTAATTCGAAGCAACGCGCAG AACCTTACCAGCTCTTGACATCTGGGTCGCGGTTACCGGAGACGGTAACCTTCAGTTCGGCTGGACCCAAGACAGGTGCTGCATGGCT GTCGTCAGCTCGTGTCGTGAGATGTTGGGTTAAGTCCCGCAACGAGCGCAACCCTCGCCCTTAGTTGCCAGCATTCAGTTGGGCACTC TAAGGGGACTGCCGGTGATAAGCCGAGAGGAAGGTGGGGATGACGTCAAGTCCTCATGGCCCTTACGGGCTGGGCTACACACGTGCTA CAATGGTGGTGACAGTGGGCAGCGAGACAGCGATGTCGAGCTAATCTCCAAAAGCCATCTCAGTTCGGATTGCACTCTGCAACTCGAG TGCATGAAGTTGGAATCGCTAGTAATCGCAGATCAGCATGCTGCGGTGAATACGTTCCCGGGCCTTGTACACACCGCCCGTCACACCA TGGGAGTTGGTTTTACCCGAAGGTAGTGCGCTAACCGCAAGGAGGCAGCTAACCACGGTAGGGTCAGCGACTGGGGTGAAGTCGTAAC AAGGTAGCCGTAGGGGAACCTGCGGCTGGATCACCTCC

S13296

GAATTGACGGGGGCCCGCACAAGCAGCGGAGCGTGTGGTTTAATTCGAGGCTACACGAAGAACCTTACCTGGGTTTGGCATACAAGTA GTAGTGAAGCGAAAGCGGAACGACCTTCGGGAGCTTGTACAGGTGCTGCATGGCTGTCGTCAGCTCGTGCCGTGAGGTGTTCGGTTAA GTCCGCAAACGAGCGCAACCCTCGGCGTTAGTTACAAGTGTCTAACGCAACTGCCCGTGAGAAACGGGAGGAAGGTGGGGATGACGTC AAGTCAGCATGGCCTTTATATCCAGGGCTACACACACGCTACAATGGGCGGTACAACGGGTCGCGAAGCCGCGAGGTGGAGCCGATCC ATAAAGCCGTTCGTAGTTCGGATTGCAGGCTGCAACTCGCCTGCATGAAGTCGGAGTTGCTAGTAACCGCAGGTCAGCTATACTGCGG TGAATACGTTCCCGGGCCTTGTACACACCGCCCGTCACGTCATGGGAGCTGGTCACGCCTGAAGTCGGGGAGCTAACCTCACGGAGGC AACCGCCGAGGGCAGGGCTGGTGACTGGGACGAAGTCGTAACAAGGTAGCTGTACCGGAAGGTGCGGCTGGATCACCTCC 


\title{
7.14 Archaeelle 16S rRNA-Gensequenzen
}

\begin{abstract}
S13104
GGATCCGCGGCCGCTGCAGATCTGGTTGATCCTGCCGGAGGTTACTGCTATCGAGGTTCGACTAAGCCATGCGAGTCGAATGTAGCAA TACATGGCGTACTGCTCAGTAACACGTGGACAACCTACCCTTAGGGCGGGGATAAACCCGGGAAACTGGGTATAATACCCGATAGTCC TCGACTGCTGGAATGCATCGAGGACTAAAGCTCCGGCGCCTAAGGATGGGTCTGCGGCCTATCAGGTAGTAGTGGGTGTAGCGTACCT ACTAGCCTACGACGGGTACGGGTTGTGAGAGCAAGAGCCCGGAGATGGATTCTGAGACACGAATCCAGGCCCTACGGGGTGCAGCAGG CGCGAAGACTTTACAATGCTGGAAACAGCGATAAGGGGACCTCGAGTGCCAGGTTACAAATCTGGCTGTCGTGATGCCTAAAAAGCAT TGCATAGCAAGGGCCGGGCAAGACCGGTGCCAGCCGCCGCGGTAACACCGGCGGCTCGAGTGGTAACCGTTATTATTGGGTCTAAAGG GTCTGTAGCCGGCCGGATAAGTCTCTTGGGAAATCTGGCAGCTTAACTGTCAGGCTTTCAGGAGATACTGTCTGGCTCGAGGCCGGGA GAGGTGAGAGGTACTTCAGGGGTAGGAGTGAAATCTTGTAATCCTTGAAGGACCACCAGTGGCGAAGGCGTCTCACCAGAACGGACCT GACGGCAAGGGACGAAAGCTAGGGGCACGAACCGGATTAGATACCCGGGTAGTCCTAGCCGTAAACGATACTCGCTAGGTGTCGGCCA CGGTGCGACCGTTGTCGGTGCCGTAGGGAAGCCGTGAAGCGAGCCACCTGGGAAGTACGGCCGCAAGGCTGAAACTTAAAGGAATTGG CGGGGGAGCACCACAACGG
\end{abstract}

S13106

AACACGCGGATAACCTACCCTTGGGTCTGGGATAACCCCGGGAAACTGGGACTAATACCGGATAGATCAAAGAAACTGGAATGTTCTC TGGTTTAAAACTCTGGTGCCCAAGGATGGGTCTGCGGCCCATCAGGTAGTAGTGGGTGTAACGTACCTACTAGCCTACGACGGGTAAG GGTTGTGAGAGCAAGAGCCCTGAGATGGATTCTGAGACATGAATCCAGGCCCTACGGGGTGCAGCAGGCGCGAAAACTTTACAATGCG GGAAACCGCGATAAGGGGACCCCGAGTGCCAGCACCTAGTGCTGGCTGTCCAGCTGTTCAAATAACAGTTGTTAGCAAGGGCCGGGCA AGACCGGTGCCAGCCGCCGCGGTAACACCGGCGGCCCGAGTGGTAGCCGTTATTATTGGGTTTAAAGGGTCCGTAGCCGGCCTATTAA GTCTCTTGGGAAATCTGGCGACTCAATCGTCAGGCGTCCAAGAGATACTGGTAGGCTTGGGACTGGGAGAGGTGGGAGGTACTCCAGG GGTAGGGGTGAAATCTCGTAATCCTTGGGGGACCACCGATGGCGAAGGCATCCCACCAGAACGGGTCCGACGGTGAGGGACGAAAGCT GGGGGCACGAACCGGATTAGATACCCGGGTAGTCCCAGCCGTAAACGATGCTCGCTAGGTGTCAGGTGCGGTGCGACCGCATCTGGTG CCGCAGTGAAAACTTGAAGCGAGTCACCTGGGAAGTACGGTCGCAAGGCTGAAACTTAAAGGAATTGGCGGGGGAGCACCACAACGG

S13109

GCGGATCCGCGGCCGCTGCAGATCTGGTCGATCCTGCCGGAGGTTACTGCTATCGAGGTTCGACTAAGCCATGCGAGTCGAATGTAGC AATACATGGCGTACTGCTCAGTAACACGTGGATAACCTACCCTTGAGACGGGGATAAACCCGGGAAACTGGGTATAATACCCGATAGA TCTCGACTGCTGGAATGCATCGAGCTTTAAAGCTCCGGCGCTCAAGGATGGATCTGCGGCCTATCAGGTAGTAGTGGGTGTAGCGTAC CTACTAGCCTACGACGGGTACGGGTTGTGAGAGCAAGAGCCCGGAGATGGATTCTGAGACACGAATCCAGGCCCTACGGGGTGCAGCA GGCGCGAAAACTTTACAATGCTGGAGACAGCGATAAGGGGACCTCGAGTGCCAGGTTACAAATCTGGCTGCCGTGATGCCTAAAAAGC ATTGCATAGCAAGGGCCGGGCAAGACCGGTGCCAGCCGCCGCGGTAACACCGGCGGCTCGAGTGGTAACCGTTATTATTGGGTCTAAA GGGTCTGTAGCCGGCCGGATAAGTCTCTTGGGAAATCCAGCAGCTCAACTGTTGGGCTTTCAGGAGATACTGTCTGGCTCGAGGCCGG GAGAGGTGAGAGGTACTTCAGGGGTAGGGGTGAAATCTTGTAATCCTTGAAGGACCACCAGTGGCGAAGGCGTCTCACCAGAACGGAC CTGACGGCAAGGGACGAAAGCTAGGGGCACGAACCGGATTAGATACCCGGGTAGTCCTAGCCGTAAACGATACTCGCTAGGTGTCGGC CACGGTGCGACCGTTGTCGGTGCCGTAGGGAAGCCGTGAAGCGAGCCACCTGGGAAGTACGGCCGCAAGGCTGAAACTTAAAGGAATT GGCGGGGGAGCACCACAAC

Sl3110

ATCCTGCCGGAGGCCACTGCTATCAGAGTTCGATTAAGCCATGCGAGTCGAGAGGTGCAAGACCTCGGCATACTGCTCAGTAACACGT GGACAACCTACCCTGCAGAGGGGGATAACCCCGGGAAACTGGGGATAATACCCCATAGACTATAGATGCTGGAATGCTTTGTAGTTGA AAGGTCCGCCGCCATAGGATGGGTCTGCGGCCGATTAGGTTGTTGTTGGGGTAACGGCCCAACAAGCCTGTAATCGGTACGGGTTGTG GGAGCAAGAGCCCGGAGATGGATTCTGAGACACGAATCCAGGCCCTACGGGGCGCAGCAGGCGCGAAAACTTTACAATGCGGGAAACC GTGATAAGGGAACTCCGAGTGCCCGTAAAATCGGGCTGTCCATCTGTTTAAATAACAGGTGAAGAAAGGGCCGGGCAAGACCGGTGCC AGCCGCCGTGGTAATACCGGCGGCTCGAGTGGTGGCCACTATTACTGGGCTTAAAGCGTTCGTAGCTGGTCTGTTAAGTCTCTGGGGA AATCTACTGGCTTAACCAATAGGCGTCTCAGGGATACTGGCAGACTAGGGACCGGGAGAGGTGAGAGGTACTCCAGGGGTAGGAGTGA AATCCTGTAATCCTTGGGGGACCACCTGTGGCGAAGGCGTCTCACCAGAACGGCTCCGACAGTGAGGGACGAAAGCTGGGGGAGCAAA CCGGATTAGATACCCGGGTAGTCCCAGCCGTAAACGATGCGCGTTAGGTGTATCGGTGACCACGAGTCACCGACGTGCCGAAGAGAAA TCGTGAAACGTGCCGCCTGGGAAGTACGGTCGCAAGGCTGAAACTTAGAGGAATTGGCGGGGGAGCACCACAACGG

S13113

GCGGATCCGCGGCCGCTGCAGATCTGGGTCATCCTGCCGGAGGTTACTGCTATCGGGGTCCGATTAAGCCATGCGAGTTGAGAGGGGT AAGCCCTCGGCATACTGCTCAGTAATACGCGGATAACCTACCCTTGGGTCTGGGATAACCCCGGGAAACTGGGACTAATACCGGATAG ATCAGAGAAACTGGAATGTTCTCTGGTTTAAAACTCCGGTGCCCAAGGATGGGTCTGCGGCCTATCAGGTAGTAGTGGGTGTAACGTA CCTACTAGCCTACGACGGGTACGGGTTGTGAGAGCAAGAGCCCGGAGATGGATTCTGAGACATGAATCCAGGCCCTACGGGGTGCAGC AGGCGCGAAAACTTTACACTGCGGGAAACCGCGATAAGGGGACCCCGAGTGCCAGCACCTAGTGCTGGCTGTCCATCTGTTCAAAAAA CAGTTGTTAGCAAGGGCCGGGCAAGACCGGTGCCAGCCGCCGCGGTAACACCGGCGGCCCGAGTGGTAGCCGTTATTATCGGGTTTAA AGGGTCCGTAGCCGGCTTATTAAGTCTCTTGGGAAATCTGGCGACTCAATCGTCAGGCGTCCAAGAGATACTGATATGCTTGGGACCG GGAGAGGTGGGAGGTACTCCAGGGGTAGGGGTGAAATCTCGTAATCCTTGGGGGACCACCGATGGCGAAGGCATCCCACCAGAACGGG TCCGACGGTGAGGGACGAAAGCTGGGGGCACGAACCGGATTAGATACCCGGGTAGTCCCAGCTGTAAACGATGCTCGCTAGGTGTCAG GTGCGGTGCGACCGCATCTGGTGCCGTAGTGAAAACTTGAAGCGAGTCACCTGGGAAGTACGGTCGCAAGGCTGAAACTTAAAGGAAT TGGCGGGGGAGCACCACAAC

S13115

GATCCGCGGCCGCTGCAGATCTGGTCGATCCTGCCGGAGGTTACTGCTATCGAGGTTCGACTAAGCCATGCGAGTCGAATGTAGCAAT ACATGGCGTACTGCTCAGTAACACGTGGATAACCTACCCTTGAGACGGGGATAAACCCGGGAAACTGGGTATAATACCCGATAGATCT CGACTGCTGGAATGCATCGAGCTTTAAAGCTCCGGCGCCTAAGGATGGGTCTGCGGCCTATCAGGTAGTAGTGGGTGTAGCGTACCTA CTAGCCTACGACGGGTACGGGTTGTGAGAGCAAGAGCCCGGAGATGGATTCTGAGACACGAATCCAGGCCCTACGGGGTGCAGCAGGC GCGAAAACTTTACAATGCTGGAAACAGCGATAAGGGGACCTCGAGTGCCAGGTTACAAATCTGGCTGTCGTGATGCCTAAAAAGCATT 
GCATAGCAAGGGCCGGGCAAGACCGGTGCCAGCCGCCGCGGTAACACCGGCGGCTCGAGTGGTAACCGTTATTATTGGGTCTAAAGGG TCTGTAGCCGGCCGGATAAGTCTCTTGGGAAATCCAGCAGCTCAACTGTTGGGCTTTCAGGAGATACTGTCTGGCTCGAGGCCGGGAG AGGTGAGAGGTACTTCAGGGGTAGGGGTGAAATCTTGTAATCCTTGAAGGACCACCAGTGGCGAAGGCGTCTCACCAGAACGGACCTG ACGGCAAGGGACGAAAGCTAGGGGCACGAACCGGATTAGATACCCGGGTAGTCCTAGCCGTAAACGATACTCGCTAGGTGTCGGCCAC GGTGCGACCGTTGTCGGTGCCGTAGGGAAGCCGTGAAGCGAGCCACCTGGGAAGTACGGCCGCAAGGCTGAAACTTAAAGGAATTGGC GGGGGAGCACCACAAC

S13116

GGATCCGCGGCCGCTGCAGACCTGGTTGATCCTGCCAGAGGTTACTGCTATCGAGGTTCGACTAAGCCATGCGAGTCGAATGTAGCAA TACATGGCGTACTGCTCAGTAACACGTGGACAACCTACCCTCAGGACGGGTATAAACCCGGGAAACTGGGTATAATCCCCGATAGTCC TCGACTGCTGGAATGCATTGAGGACTAAAGCTCCGGCGCCTGAGGATGGGTCTGCGGCCTATCAGGTAGTAGTGGGTCTAATGTACCT ACTAGCCTACGACGGGTACGGGTTGTGAGAGCAAGAGCCCGGAGATGGATTCTGAGACACGAATCCAGGCCCTACGGGGTGCAGCAGG CGCGAAAACTTTACAATGCCGGCAACGGCGATAAGGGAACCTCGAGTGCCAGGTTACAAATCTGGCTGTCGTGATGCCTAAAAAGCGT TGCACAGCAAGGGCCGGGCAAGACCGGTGCCAGCCGCCGCGGTAACACCGGCGGCTCGAGTGGTAACCGTTATTATTGGGTCTAAAGG GTCTGTAGCCGGCCGGATAAGTCTCTTGGGAAATCCAGCAGCTCAACTGTTGGGCCTTCAGGAGATACTGTCTGGCTCGAGGCCGGGA GAGGTGAGAGGTACTTCAGGGGTAGGGGTGAAATCTTGTAATCCTTGAAGGACCACCAGTGGCGAAGGCGTCTCACCAGAACGGACCT GACGGCAAGGGACGAAAGCTAGGGGCACGAACCGGATTAGATACCCGGGTAGTCCTAGCCGTAAACGATACTCGCTAGGTGTCGGCCA CGGTGCGACCGTGGTCGGTGCCGTAGGGAAGCCGTGAAGCGAGCCACCTGGGAAGTACGGCCGCAAGGCTGAAACTTAAAGGAATTGG CGGGGGAGCACCACAACGG

S13117

GGATCCGCGGCCGCTGCAGATCTGGTTGATCCTGCCGGAGGCCACTGCTATCGGAGTTCGATTAAGCCATGCGAGTCGAGAGGTGCAA GACCTCGGCATACTGCTCAGTAACACGTGGACAACCTACCCTATGGAGGGGGATAACCCCGGGAAACTGGGGATAATACCCCATAGAC TATAGATGCTGGAATGCTTTGTAGTTGAAAGGTCCGCCGCCATAGGATGGGTCTGCGGCCGATTAGGTTGTTGTTGGGGTAACGGCCC AACAAGCCTGTAATCGGTACGGGTTGTGGGAGCAAGAGGCCGGAGATGGATTCTGAGACACGAATCCAGGCCCTACGGGGCGCAGCAG GCGCGAAAACTTTACAATGCGGGAAACCGTGATAAGGGAACTCCGAGTGCCCGTAAAATCGGGCTGTCCATCTGTTTAAATAACAGGT GAAGAAAGGGCCGGGCAAGACCGGTGCCAGCCGCCGCGGTAATACCGGCGGCTCGAGTGGTGGCCACTATTACTGGGCTTAAAGCGTT CGTAGCTGGTCTGTTAAGTCTCTGGGGAAATCTACTGGCTTAACCAATAGGCGTCTCAGGGATACTGGCAGACTAGGGACCGGGAGAG GTGAGAGGTACTCCAGGGGTAGGAGTGAAATCCTGTAATCCTTGGGGGACCACCTGTGGCGAAGGCGTCTCACCAGAACGGCTCCGAC AGTGAGGGACGAAAGCTGGGGGAGCAAACCGGATTAGATACCCGGGTAGTCCCAGCCGTAAACGATGCGCGTTAGGTGTATCGGTGAC CACGAGTCACCGACGTGCCGAAGAGAAATCGTGAAACGTGCCGCCTGGGAAGTACAGTCGCAAGGCTGAAACTTAAAGGAATTGGCGG GGGAGCACCACAACGG

S13118

GTTGTGGTGCTCCCCCGCCAATTCCTTTAAGTTTCAGCCTTGCGGCCGTACTTCCCAGGTGGCTCGCTTCACGGCTTCCCTGCGGCAC CAGACACGGTCGCGCCATGCCTGACACCTAGCGAGCATCGTTTACGGCTGGGACTACCCGGGTATCTAATCCGGTTCGTGCCCCCAGC TTTCGTCCCTCACCGTCGAACCCGTTCTGGTAAGACGCCTTCGCCACAGGTGGTCTCACAGGGATTACAAGATTTCACTCCTACCCCT GTAGTACCTCTTACCTCTCCCGGTTCCAAGCCTGGCAGTATCCCCAGACAGCCTAATAGTTGAGCTATCAGATTTCCCTGAGGACTGA CCAAACCGGCTACGGACCCTTTAGACCCAATAATCACGATCACCACTCGGGCCGCCGGTGTTACCGCGGCGGCTGGCACCGGTCTTGC CCGGCCCTTGCTAACAGGTGTATTTTACACACCCGGACAGCCAGCATATGATGCTGGCACTCGGTGTCCCCTTATCACGGTTTCCCGC ATTGTAAAGTTTTCGCGCCTGCTGCGCCCCGTAGGGCCTGGATTCATGTCTCAGAATCCATCTCCGGGCTCTTGCTCTCACAACCCGT ACCCGTTGTCGGCTAGTAGGTCCATTACACCTACTACTACCTGATAGGCCGCAGACCCATCCTTGGGCAGACGAATCCATTTCACGCA TAAAGCATTCCAGCACATATGCGGTATCCGGAATTATCCCCAGTTTCCCGGGGTTATGCCGGACCCAAAGGCAGGTTATCCACGTGTT ACTGAGCAGTACGCCATGTATTGCTACATATGACTCGCATGGCTTAGGCGAACACCGATAGCAGTAACCTCCGGCAGGATCGACAGAT CTGCAGCGGCCGCGGATCCGC

S13119

CGGATCCGCGGCCGCTGCAGATCTGGTTGATTCTGCCGGAGGCCACTGCTATCGGAGTTCGATTAAGCCATGCGAGTCGAGAGGTGCA AGACCTCGGCATACTGCTCAGTAACACGTGGACAACCTAACCTAAGGTGGGGGATAACCCCGGGAAACTGGGGATAATACCCCATAGG CTATGAATGCTGGAATGCTTCGTAGTTGAAAGGTCAGCCGCCATAGGATGGGTCTGCGGCCGATTAGGTAGTTGTTGGGGTAACGGCC CAACAAGCCTGTAATCGGTACGGGTTGTGGGAGCAAGAGCCCGGAGATGGATTCTGAGACACGAATCCAGGCCCTACGGGGCGCAGCA GGCGCGAAAACTTTACAATGCGGGAAACCGTGATAAGGGAACTCCGAGTGCCCGTTAAATCGGGCTGTCCACCAGTTTAAATAACTGG TGAAGAAAGGGCCGGGCAAGACCGGTGCCAGCCGCCGCGGTAATACCGGCGGCTCGAGTGGTGGCCACTATTACTGGGCTTAAAGCGT TCGTAGCTGGTTTGTTAAGTCTCTGGGGAAATCTGCCGGCTCAACCGGCAGGCGTTCCAGGGATACTGGCAGACTAGGGACCGGGAGA GGTGAGGGGTACTCCAGGGGTAGGAGTGAAATCCTGTAATCCTTGGGGGACCACCTGTGGCGAAGGCGCCTCACCAGAACGGCTCCGA CAGTGAGGGACGAAAGCTGGGGGAGCAAACCGGATTAGATACCCGGGTAGTCCCAGCCGTAAACGATGCGCGTTAGGTGTATCGGTGA CCACGAGTCACCGAGGTGCCGAAGAGAAATCGTGAAACGTGCCGCCTGGGAAGTACGGTCGCAAGGCTGAAACTTAAAGGAATTGGCG GGGGAGCACCACAACGG

S13122

GCGGATCCGCGGCCGCTGCAGATCTGGTCGATTCTGCCAGAGGCCACTGCTATCGGGGCTCGATTAAGCCATGCGAGTCGAGAGGTGC AAGACCTCGGCATACTGCTCAGTAACACGTGGACAACCTACCCTAAGGAGGGGGATAACCCCGGAAAACTGGGGATAATACCCCATAG ACTACAGAAGCTGGAATGCTCTGTAATCGAAAGGTCCGCCGCCTTAGGATGGGTCTGCGGCTGATTAGGTTGTTGTTGGGGTAACGGC CCAACAAGCCTGTAATCAGTACGGGTTGTGGGAGCAAGAACCCGGAGATGGATTCTGAGACACGAATCCAGGCCCTACGGGGCGCAGC AGGCGCGAAAACTTTACAATGCGAGAAATCGTGATAAGGGAACCCCGAGTGCCCGTAAATTCGGGCTGTTAATCTGTGTAAAAAGCAG GTGGAGAAAGGGCCGGGCAAGACCGGTGCCAGCCGCCGCGGTAATACCGGCGGCTCGAGTGGTGGCCACTATTACTGGGCTTAAAGCG TCCGTAGCTGGATTGTTAAGTCTCTTGGGAAATCTACCGGCTTAACCGATAGGCGTTCAAGGGATACTGGCAATCTAGGGACCGGAAG AGGTGAGAGGTACTCCAGGGGTAGGAGTGAAATCCTGTAATCCTTGGGGGACCGCCTGTGGCGAAGGCGTCTCACCAGAACGGCTCCG ACAGTGGGGGACGAAAGCTGGGGGAGCAAACCGGATTAGATACCCGGGTAGTCCCAGCTGTAAACGATGTGCGTTAGGTGTATCGGTG ACCACGAGTCGCCGAGGTGCCGAAGAGAAATCGTGAAACGTACCGCCTGGGAAGTACGGTCGCAAGGCTGAAACTTAAAGGAATTGGC GGGGGAGCACCACAAC

S13125

GCGGATCCGCGGCCGCTGCAGATCTGGTTGATCCTGCCGGAGGTTACTGCTATCGAGGTTCGACTAAGCCATGCGAGTCGAATGTAGC AATACATGGCGTACTGCTCAGTAACACGTGGACAACCTACCCTTAGGTCGGGGATAAACCCGGGAAACTGGGTATAATACCCGATAGA 
TCTCGACTGCTGGAATGCATCGAGATCGAAAGCTCCGGCGCCTAAGGATGGGTCTGCGGCCTATCAGGTAGTAGTGGGTGTAGCGTAC CTACTAGCCTACGACGGGTACGGGTTGTGAGAGCAAGAGCCCGGAGATGGATTCTGAGACACGAATCCAGGCCCTACGGGGTGCAGCA GGCGCGAAAACTTTACAATGCTGGAAACAGCGATAAGGGGACCTCGAGTGCCAGGTTACAAATCTGGCTGTCGTGATGCCTAAAAAGC ATTGCATAGCAAGGGCCGGGCAAGACCGGTGCCAGCCGCCGCGGTAACACCGGCGGCTCGAGTGGTAACCGTTATTATTGGGTCTAAA GGGTCTGTAGCCGGCCGGATAAGTCTCTTGGGAAATCCAGCAGCTCAACTGTTGGGCTTTCAGGAGATACTGTCTGGCTCGAGGCCGG GAGAGGTGAGAGGTACTTCAGGGGTAGGGGTGAAATCTTGTAATCCTTGAAGGACCACCAGTGGCGAAGGCGTCTCACCAGAACGGAC CTGACGGCAAGGGACGAAAGCTAGGGGCACGAACCGGATTAGATACCCGGGTAGTCCTAGCCGTAAACGATACTCGCTAGGTGTCGGC CACGGTGCGACCGTTGTCGGTGCCGTAGGGAAGCCGTGAAGCGAGCCACCTGGGAAGTACGGCCGCAAGGCTGAAACTTAAAGGAATT GGCGGGGGAGCACCACAAC

S13127

CGGATCCGCGGCCGCTGCAGATCTGGTTGATTCTGCCGGAGGCCACTGCTATCAGAGTTCGATTAAGCCATGCGAGTCGAGAGGTGCA AGACCTCGGCATACTGCTCAGTAACACGTGGACAACCTACCCTGTGGAAGAGGATAATCCCGGGAAACTGGGGATAATACCCTATAGA CTATAGACGCTGGAATGCTCTGTAGCCGAAAGGTCCGCCGCCATAGGATGGGTCTGCGGCCGATTAGGTTGTTGTTGGGGTAACGGCC CAACAAGCCTGTAATCGGTACGGGTTGTGGGAGCAAGAGCCCGGAGATGGATTCTGAGACACGAATCCAGGCCCTACGGGGCGCAGCA GGCGCGAAAACTTTACAATGCGGGAAACCGTGATAAGGGAACTCTGAGTGCCCGTAAAATCGGGCTGTCCATCAGTTTAAAAAACTGG TGAAGAAAGGGCCGGGCAAGACCGGTGCCAGCCGCCGCGGTAATACCGGCGGCTCGAGTGGTGGCCACTATTACTGGGCTTAAAGCGT TCGTAGCTGGTTTGTTAAGTCTCTGGGGAAATCTTCCGGCTTAACCGGAAGGCGTCTCAGGGATACTGGCAGACTAGGGACCGGGAGA GGTGAGAGGTACTCCAGGGGTAGGAGTGAAATCCTGTAATCCTTGGGGGACCACCTGTGGCGAAGGCGTCTCACCAGAACGGCTCCGA CAGTGAGGGACGAAAGCTGGGGGAGCAAACCGGATTAGATACCCGGGTAGTCCCAGCCGTAAACGATGTGCGTTAGGTGTATCGGTGA CCACGAGTCACCGAGGTGCCGAAGAGAAATCGTGAAACGTACCGCCTGGGAAGTACGGTCGCAAGGCTGAAACTTAAAGGAATTGGCG GGGGAGCACCACAACGG

S13128

GCGGATCCGCGGCCGCTGCAGACCTGGTCGATTCTGCCGGAGGTTACTGCTATCGAGGTTCGACTAAGCCATGCGAGTCGAATGTAGC AATACATGGCGTACTGCTCAGTAACACGTGGACAACCTACCCTTGAGACGGGAATAAACCCGGGAAACTGGGTATAATACCCGATAGA TCTCGACTGCTGGAATGCATCGAGATCCAAAGCTCCGGCGCTCAAGGATGGATCTGCGGCCTATCAGGTAGTAGTGGGTGTAGCGTAC CTACTAGCCTACGACGGGTACGGGTTGTGAGAGCAAGAGCCCGGAGATGGATTCCGAGACACGAATCCAGGCCCTACGGGGTGCAGCA GGCGCGAAAACTTTACAATGCTGGAAACAGCGATAAGGGGACCTCGAGTGCCAGGTTACAAATCTGGCTGTCGTGATGCCTAAAAAGC ATTGCATAGCAAGGGCCGGGCAAGACCGGTGCCAGCCGCCGCGGTAACACCGGCGGCTCGAGTGGTAACCGTTATTATTGGGTCTAAA GGGTCTGTAGCCGGCCAGATAAGTCTCTTGAGAAATCCAGCAGCTCAACTGTTGGGCTTTCAGGAGATACTGTCTGGCTCGAGGCCGG GAGAGGTGAGAGGTACTTCAGGGGTAGGGGTGAAATCTTGTAATCCTTGAAGGACCACCAGTGGCGAAGGCGTCTCACCAGAACGGAC CTGACGGCAAGGGACGAAAGCTAGGGGCACGAACCGGATTAGATACCCGGGTAGTCCTAGCCGTAAACGATACTCGCTAGGTGTCGGC CACGGTGCGACCGTTGTCGGTGCCGTAGGGAAGCCGTGAAGCGAGCCACCTGGGAAGTACGGCCGCAAGGCTGAAACTTAAAGGAATT GGCGGGGGAGCACCACAAC

S13130

GCGGATCCGCGGCCGCTGCAGATCTGGTCGATCCTGCCGGAGGTTACTGCTATCGAGGTTCGACTAAGCCATGCGAGTCGAATGTAGC AATACATGGCGTACTGCTCAGTAACACGTGGATAACCTACCCTTGAGATGGGGATAAACCCGGGAAACTGGGTATAATACCCGATAGA TCTCGGTTGCTGGAATGCACCGAGCTTGAAAGCTCCGGCGCTCAAGGATGGATCTGCGGCCTATCAGGTAGTAGTGGGTGTAGCGTAC CTACTAGCCTACGACGGGTACGGGTTGTGAGAGCAAGAGCCCGGAGATGGATTCTGAGACACGAATCCAGGCCCTACGGGGTGCAGCA GGCGCGAAAACTTTACAGTGCTGGAAACAGCGATAAGGGGACCTCGAGTGCCAGGTTACAAATCTGGCTGTCGTGATGCCTAAAAAGC ATTGCATAGCAAGGGCCGGGCAAGACCGGTGCCAGCCGCCGCGGTAACACCGGCGGCTCGAGTGGTAACCGTTATTATTGGGTCTAAA GGGTCTGTAGCCGGCCGGATAAGTCTCTTGGGAAATCTGGCAGCTTAACTGTCAGGCTTTCAGGAGATACTGTTCGGCTCGAGGCCGG GAGAGGTGAGAGGTACTTCAGGGGTAGGGGTGAAATCTTGTAATCCTTGAAGGACCACCAGTGGCGAAGGCGTCTCACCAGAACGGAC CTGACGGCAAGGGACGAAAGCTAGGGGCACGAACCGGATTAGATACCCGGGTAGTCCTAGCCGTAAACGATACTCGCTAGGTGTCGGC CACGGTACGACCGTTGTCGGTGCCGTAGGGAAGCCGTGAAGCGAGCCACCTGGGAAGTACGGCCGCGAGGCTGAAACTTAAAGGAATT GGCGGGGGAGCACCACAACGG

S13131

GCGGATCCGCGGCCGCTGCAGATCTGGTTGATCCTGCCGGAGGTTACTGCTATCGAGGTTCGACTAAGCCATGCGAGTCGAATGTAGC AATACATGGCGTACTGCTCAGTAACACGTGGATAACCTACCCTTGAGTCGGGGATAAACCCGGGAAACTGGGTATAATACCCGATAGA TCTCGACTGCTGGAATGCATCGAGCTCTAAAGCTCCGGCGCTCAAGGATGGATCTGCGGCCTATCAGGTAGTAGTGGGTGTAGCGTAC CTACTAGCCTACGACGGGTACGGGTTGTGAGAGCAAGAGCCCGGAGATGGATTCTGAGACACGAATCCAGGCCCTACGGGGTGCAGCA GGCGCGAAAACTTTACAATGCTGGAAACAGCGATAAGGGGACCTCGAGTGCCAGGTTACAAATCTGGCTGTCGTGATGCCTAAAAAGC ATTGCATAGCAAGGGCCGGGCAAGACCGGTGCCAGCCGCCGCGGTAACACCGGCGGCTCGAGTGGTAACCGTTATTATTGGGTCTAAA GGGTCTGTAGCCGGCCGGATAAGTCTCTTGGGAAATCCAGCAGCTCAACTGTTGGGCTTTCAGGAGATACTGTCTGGCTCGAGGCCGG GAGAGGTGAGAGGTACTTCAGGGGTAGGGGTGAAATCTTGTAATCCTTGAAGGACCACCAGTGGCGAAGGCGTCTCACCAGAACGGAC CTGACGGCAAGGGACGAAAGCTAGGGGCACGAACCGGATTAGATACCCGGGTAGTCCTAGCCGTAAACGATACTCGCTAGGTGTCGGC CACGGTGCGACCGTTGTCGGTGCCGTAGGGAAGCCGTGAAGCGAGCCACCTGGGAAGTACGGCCGCAAGGCTGAAACTTAAAGGAATT GGCGGGGGAGCACCACAAC

S13132

GGATCCGCGGCCGCTGCAGACCTGGTTGATTCTGCCGGAGGTTACTGCTATCGAGGTTCGACTAAGCCATGCGAGTTGAATGCAGCAA TACATGGCGAACTGCTCAGTAACACGTGGACAACCTGCCCTTAGGTTGGGTATAAACCCGGGAAACTGGGTATAATACCCGATAGGTC TCGATTGCTGGAATGCATCGAGATTTAAAGCTCCGGCGCCTAAGGATGGGTCTGCGGCCTATCAGGTAGTAGTGGGTGTAGCGTACCT ACTAGCCTACGACGGGTACGGGTTGTGAGAGCAAGAGCCCGGAGATGGATTCTGAGACACGAATCCAGGCCCTACGGGGTGCAGCAGG CGCGAAAACTTTACAATGCTGGCAACAGCGATAAGGGGACCTCGAGTGCCAGGTTACAAATCTGGCTGTCGTGATGCCTAAAAAGCAT TGCATAGCAAGGGCCGGGCAAGACCGGTGCCAGCCGCCGCGGTAACACCGGCGGCTCGAGTGGTAACCGTTATTATTGGGTCTAAAGG GTCTGTAGCCGGCCGGATAAGTCTCTTGGGAAATCTGGCAGCTTAACTGTCAGGCTTTCAGGAGATACTGTCTGGCTCGAGGCCGGGA GAGGTGAGAGGTACTTCAGGGGTAGGGGTGAAATCTTGTAATCCTTGAAGGACCACCAGTGGCGAAGGCGTCTCACCAGAACGGACCT GACGGCAAGGGACGAAAGCTAGGGGCACGAACCGGATTAGATACCCGGGTAGTCCTAGCCGTAAACGATACTCGCTAGGTGTCGGCCA CGGTGCGACCGTTGTCGGTGCCGTAGGGAAGCCGTGAAGCGAGCCACCTGGGAAGTACGGCCGCAAGGCTGAAACTTAAAGGAATTGG CGGGGGAGCACCACAACGG 
S13134

GCGGATCCGCGGCCGCTGCAGATCTGGTTGATTCTGCCGGAGGTTACTGCTATCGAGGTTCGACTAAGCCATGCGAGTCGAATGTAGC AATACATGGCGTACTGCTCAGTAACACGTGGATAACCTACCCTTGAGATGGGGATAAACCCGGGAAACTGGGTATAATACCCGATAGA TCTCGAAGGCTGGAATGCATCGAGATCGAAAGCTCCGGCGCCTAAGGATGGGTCTGCGGCCTATCAGGTAGTAGTGGGTGTAACGTAC CTACTAGCCTACGACGGGTACGGGTTGTGAGAGCAAGAGCCCGGAGATGGATTCTGAGACACGAATCCAGGCCCTACGGGGTGCAGCA GGCGCGAAAACTTTACACTGCGGGAAACCGCGATAAGGGGACCCCGAGTGCCAGCACCTAGTGCTGGCTGTCCAGCTGTCCAAATAAC AGTTGTTAGCAAGGGCCGGGCAAGACCGGTGCCAGCCGCCGCGGTAACACCGGCGGCTCGAGTGGTAACCGTTATTACTGGGCTTAAA GCGTTCGTAGCTGGTTTGTTAAGTCTCTGGGGAAATCTGCCGGCTCAACCGGCAGGAGTTCCAGGGATACTGGCAGACTAGGGACCGG GAGAGGTGTGGGGTACTCCAGGGGTAGGAGTGAAATCCTGTAATCCTTGAAGGACCACCAGTGGCGAAGGCGTCTCACCAGAACGGAC CTGACGGCAAAGGACGAAAGCTAGGGGCACGAACCGGATTAGATACCCGGGTAGTCCTAGCCGTAAACGATACTCGCTAGGTGTCGGC CACGGTGCGACCGTTGTCGGTGCCGTAGGGAAGCCGTGAAGCGAGCCACCTGGGAAGTACGGCCGCAAGGCTGAAACTTAAAGGAATT GGCGGGGGAGCACCACAAC

S13135

GCGGATCCGCGGCCGCTGCAGATCTGGTTGATTCTGCCGGAGGCCACTGCTATCGGAGTTCGATTAAGCCATGCGAGTCGAGAGGTGC AAGACCTCGGCATACTGCTCAGTAACACGTGGACAACCTAACCTATGGAGGGGGATAACCCCGGGAAACTGGGGATAATACCCCATAG ACTATGGATGCTGGAATGCTCTGTAGTTGAAAGGTCCGCCGCCATAGGATGGGTCTGCGGCCGATTAGGTTGTTGTTGGGGTAACGGC CCAACAAGCCTGTAATCGGTACGGGTTGTGGGAGCAAGAGCCCGGAGATGGATTCTGAGACACGAATCCAGGCCCTACGGGGCGCAGC AGGCGCGAAAACTTTACAATGCGGGAAACCGTGATAAGGGAACTCCGAGTGCCCGTAAAATCGGGCTGTCCATCTGTTTAAATAACAG GTGAAGAAAGGGCCGGGCAAGACCGGTGCCAGCCGCCGCGGTAATACCGGCGGCTCGAGTGGTGGCCACTATTACTGGGCTTAAAGCG TTCGTAGCTGGTTTGTTAAGTCTCTGGGGAAATCTGCCGGCTCAACCGGCAGGCGTTCCAGGGATACTGGCAGACTAGGGACCGGGAG AGGTGAGGGGTACTCCAGGGGTAGGAGTGAAATCCTGTAATCCTTGGGGGACCACCTGTGGCGAAGGCGCCTCACCAGAACGGCTCCG ACAGTGAGGGACGAAAGCTGGGGGAGCAAACCGGATTAGATACCCGGGTAGTCCCAGCCGTAAACGATGCGCGTTAGGTGTATCGGTG ACCACGAGTCACCGAGGTGCCGAAGAGAAATCGTGAAACGTGCCGCCTGGGAAGTACGGTCGCAAGGCTGAAACTTAAAGGAATTGGC GGGGGAGCACCACAACGG

S13137

GGATCCGCGGCCGCTGCAGATCTGGTTGATTCTGCCGGAGGTTACTGCTATCGAGGTTCGACTAAGCCATGCGAGTCGAATGTAGCAA TACATGGCGTACTGCTCAGTAACACGTGGATAACCTACCCTTGAGACGGGGATAAACCCGGGAAACTGGGTATAATACCCGATAGATC TCGACTGCTGGAATGCATCGAGCTTGAAAGCTCCGGCGCTCAAGGATGGGTCTGCGGCCTATCAGGTAGTAGTGGGTGTAGCGTACCT ACTAGCCTACGACGGGTACGGGTTGTGAGAGCAAGAGCCCGGAGATGGATTCTGAGACACGAATCCAGGCCCTACGGGGTGCAGCAGG CGCGAAAACTTTACAATGCTGGAAACAGCGATAAGGGGACCTCGAGTGCCAGGTTACAAATCTGGCTGTCGTGATGCCTAAAAAGCAT TGCATAGCAAGGGCCGGGCAAGACCGGTGCCAGCCGCCGCGGTAACACCGGCGGCTCGAGTGGTAACCGTTATTATTGGGTCTAAAGG GTCTGTAGCCGGCCGGATAAGTCTCTTGGGAAATCTGGCAGCTTAACTGTCAGGCTTTCAGGAGATACTGTCTGGCTCGAGGCCGGGA GAGGTGAGAGGTACTTCAGGGGTAGGGGTGAAATCTTGTAATCCTTGAAGGACCACCAGTGGCGAAGGCGTCTCACCAGAACGGACCT GACGGCAAGGGACGAAAGCTAGGGGCACGAACCGGATTAGATACCCGGGTAGTCCTAGCCGTAAACGATACTCGCTAGGTGTCGGCAA CGGTGCGACCGTTGTCGGTGCCGTAGGGAAGCCGTGAAGCGAGCCACCTGGGAAGTACGGCCGCAAGGCTGAAACTTAAAGGAATTGG CGGGGAGCACCACAACGGG

S13138

GGATCCGCGGCCGCTGCAGACCTGGTTGATCCTGCCGGAGGTTACTGCTATCGGGGTTCGATTAAGCCATGCGAGTCAAATGTTCTTC GTGAACATGGCGAACTGCTCAGTAACACGTGGATAATCTACCCTTAGGTCTGGAATAACCCCGGGAATCTGGGGATAATACCGGATAG ATCATAGATGCTGGAATGCCCTATGTTCTAAAGCTCCGGCGCCTAAGGATGAGTCTGCGGTCTATCAGGTTGTAGTGGGTGTAACGTA CCTACTAGCCGACGACGGATACGGGTTGTGAGAGCAAGAGCCCGGAGATGGATTCTGAGACACGAATCCAGGCCCTACGGGGTGCAGC AGGCGCGAACACTTTACAATGCGGGAAACCGCGATAAGGGAACCCCGAGTGCCAGCACCAAGTGTTGGCTGTCCAGATGATTAAATCT CATTTGTTAGCAAGGGCCGGGCAAGACCGGTGCCAGCCGCCGCGGTAACACCGGCGGCCCGAGTGGTAGCCGTTATTATTGGGTTTAA AGGGTCCGTAGCCGGCTTATTAAGTCTCTTGGGAAATCTGGCGACTCAATCGTCAGGCGTTCAAGGGATACTGGTAGGCTTGGGACCG GGAGAGGTGGGAGGTACTCCAGGGGTAAGGGTGAAATCTCGTAATCCTTGGGGGACCACCGATGGCGAAGGCATCCCTCCAGAACGGG TCCGACGGTGAGGGACGAAAGCTGGGGGCACGAACCGGATTAGATACCCGGGTAGTCCCAGCCGTAAACGATGCTCGCTAGGTGTCAG GTGCGGTGCGACCGCATCTGGTGCCGTAGTGAAAACTTGAAGCGAGTCACCTGGGAAGTACGGTCGCAAGGCTGAAACTTAAAGGAAT TGGCGGGGGAGCACCACAACGG

S13139

GGATCCGCGGCCGCTGCAGACCTGGTTGATCCTGCCGGAGGCTACTGCTATTGGGATTCGACTAAGCCATGCGAGTCGAGAGGGTTCG GCCCTCGGCTGACGGCTCAGTAACACGTGGATAATCTGCCCTAAGGTGGAGGATAACCTCGGGAAACTGAGAATAATACTCCATAGGT CTAGGATGCTGGAATGCACTTAGGCTTAAAACTTCGGTGCCTTAGGATGAGTCTGCGGACTATCAGGTTGTAGTCAGGGTAAAGACCT GACTAGCCTACGACGGATACGGGTTGTGAGAGCAATAACCCGGAGATGATATCTGAGACACGATATCAGGCCCTACGGGGCGCAGCAG GCGCGAAAACTTCGCACTGCGCGAAAGCGCGACGAGGGAATCCCAAGTGTATGCACGTAAGTGTATACTGTTTCTCTGTCTAAAAAGC AGAGAGAGTAAGAGCTGGGTAAGACGGGTGCCAGCCGCCGCGGTAATACCTGCAGCTCTAGTGGTGATCGTTATTATTGGGCCTAAAA CGTCCGTAGCCGGTCTTCTAAATGCCTGGGTAAATCGTATGGCTTAACCATACGAATTCTGGGTAGACTGTTAGACTTGAGACCGGGA GAGGCTAGAGGTACTCCTGGGGTAGAGGTGAAATTCTGTAATCCTAGGGGGACGACCAGTGGCGAAGGCGTCTAGCTAGAACGGGTCT GACGGTGAGGGACGAAGCCCTGGGGCGCAAACGGGATTAGATACCCCGGTAGTCCAGGGTGTAAACGCTGCTTGCTTGATGTTAGTCT GGCTCCGAGCCAGATTAGTGTCGGAGAGAAGTTGTTAAGCAAGCTGCCTGGGAAGTGCGGCCGCAAGACTGAAACTTAAAGGAATTGG CGGGGGAGCACCACAACGG

S13142

GCGGATCCGCGGCCGCTGCAGATCTGGTTGATCCTGCCGGAGGTTACTGCTATCGAGGTTCGACTAAGCCATGCGAGTCGAATGTAGC AATACATGGCGTACTGCTCAGTAACACGTGGATAACCTACCCTTGAGTCGGGGATAAACCCGGGAAACTGGGTATAATACCCGATAGA TCTCGACTGCTGGAATGCATCGAGCTTTAAAGCTCCGGCGCTCAAGGATGGATCTGCGGCCTATCAGGTAGTAGTGGGTGTAGCATAC CTACTAGCCTACGACGGGTACGGGTTGTGAGAGCAAGAGCCCGGAGATGGATTCTGAGACACGAATCCAGGCCCTACGGGGTGCAGCA GGCGCGAAAACTTTACAATGCTGGAAACAGCGATAAGGGGACCTCGAGTGCCAGGTTACAAATCTGGCTGTCGTGATGCCTAAAAAGC ATTGCATAGCAAGGGCCGGGCAAGACCGGTGCCAGCCGCCGCGGTAACACCGGCGGCTCGAGTGGTAACCGTTATTATTGGGTCTAAA GGGTCTGTAGCCGGCCGGATAAGTCTCTTGGGAAATCCAGCAGCTCAACTGTTGGGCTTTCAGGAGATACTGTCTGGCTCGAGGCCGG GAGAGGTGAGAGGTACTTCAGGGGTAGGGGTGAAATCTTGTAATCCTTGAAGGACCACCAGTGGCGAAGGCGTCTCACCAGAACGGAC CTGACGGCAAGGGACGAAAGCTAGGGGCACGAACCGGATTAGATACCCGGGTAGTCCTAGCCGTAAACGATACTCGCTAGGTGTCGGC 
CACGGTGCGACCGTTGTCGGTGCCGTAGGGAAGCCGTGAAGCGAGCCACCTGGGAAGTACGGCCGCAAGGCTGAAACTTAAAGGAATT GGCGGGGGAGCACCACAAC

S13143

GGATCCGCGGCCGCTGCAGATCTGGTTGATCCTGCCGGAGGTTACTGCTATCGAGGTTCGACTAAGCCATGCGAGTCGAATGTAGCAA TACATGGCGTACTGCTCAGTAACACGTGGACAGCCTACCCTTAGGACGGGGATAAACCCGGGAAACTGGGTATAATACCCGATAGTCC TCGACTGCTGGAATGCATCGAGAACTAAAGCTCCGGCGCCTAAGGATGGGTCTGCGGCCTATCAGGTAGTAGTGGGTGTAACGTACCT ACTAGCCTACGACGGGTAAGGGTTGTGAGAGCAAGAGTCCTGAGATGGATTCTGAGACATGAATCCAGGCCCTACGGGGTGCAGCAGG CGCGAAAACTTTACACTGCGGGAAACCGCGATAAGGGGACCCCGAGTGCCAGCACCTAGTGCTGGCTGTCCAGCTGTTCAAAAAACAG TTGTTAGCAAGGGCCGGGCAAGACCGGTGCCAGCCGCCGCGGTAACACCGGCGGCCCGAGTGGTAGCCGTTATTATTGGGTCTAAAGG GTCTGTAGCCGGCCGGATAAGTCTCTTGGGAAATCCAGCAGCTCAACTGTTGGGCTTTCAGGAGATACTGTCTGGCTCGAGGCCGGGA GAGGTGAGAGGTACTTCAGGGGTAGGGGTGAAATCTTGTAATCCTTGAAGGACCACCAGTGGCGAAGGCGTCTCACCAGAACGGACCT GACGGCAAGGGACGAAAGCTAGGGGCACGAACCGGATTAGATACCCGGGTAGTCCTAGCCGTAAACGATACTCGCTAGGTGTCGGCCA CGGTGCGACCGTTGTCGGTGCCGTAGGGAAGCCGTGAAGCGAGCCACCTGGGAAGTACGGCCGCAAGGCTGAAACTTAAAGGAATTGG CGGGGGAGCACCACAACGG

S13144

GGATCCGCGGCCGCTGCAGATCTGGTCGATCCTGCCGGAGGTTACTGCTATCGAGGTTCGACTAAGCCATGCGAGTCGAATGTAGCAA TACATGGCGTACTGCTCAGTAACACGTGGACAACCTGCCCTTGAGACGGGGATAAACCCGGGAAACTGGGTATAATACCCGACAGATC TCGATTGCTGGAATGCATCGAGCTTGAAAGCTCCGGCGCTCAAGGATGGGTCTGCGGCCTATCAGGTAGTAGTGGGTGTAGCGTACCT ACTAGCCTACGACGGGTACGGGTTGTGAGAGCAAGAGCCCGGAGATGGATTCTGAGACACGAATCCAGGCTCTACGGGGTGCAGCAGG CGCGAAAACTTTACAATGCCGGCAACGGCGATAAGGGGACCTCGAGTGCCAGGTTACAAATCTGGCTGTCGTGATGCCTAAAAAGCAT TGCATAGCAAGGGCCGGGCAAGACCGGTGCCAGCCGCCGCGGTAACACCGGCGGCTCGAGTGGTAACCGTTATTATTGGGTCTAAAGG GTCTGTAGCCGGCCGGATAAGTCTCTTGAGAAATCCAGCAGCTCAACTGTTGGGCTTTCAGGAGATACTGTCTGGCTCGAGGCCGGGA GAGGTGAGAGGTACTTCAGGGGTAGGGGTGAAATCTTGTAATCCTTGAAGGACCACCAGTGGCGAAGGCGTCTCACCAGAACGGACCT GACGGCAAGGGACGAAAGCTAGGGGCACGAACCGGATTAGATACCCGGGTAGTCCTAGCCGTAAACGATACTCGCTAGGTGTCGGCCA CGGTGCGACCGTTGTCGGTGCCGTAGGGAAGCCGTGAAGCGAGCCACCTGGGAAGTACGGCCGCAAGGCTGAAACTTAAAGGAATTGG CGGGGGAGCACCACAACGG

S13145

GGATCCGCGGCCGCTGCAGACCTGGTTGATTCTGCCGGAGGCCACTGCTATCAGAGTTCGATTAAGCCATGCGAGTCGAGAGGTGCAA GACCTCGGCATACTGCTCAGTAACACGTGGACAACCTAACCTAAGGTGGGGGATAACCCCGGGAAACTGGGGATAATACCCCATAGAC TATGGAAGCTGGAATGCTCTGTAGCTGAAGGGTCAGCCGCCATAGGATGGGTCTGCGGCCGATTAGGTAGTTGTTGGGGTAACGGCCC AACAAGCCTGTAATCGGTACGGGTTGTGGGAGCAAGAGCCCGGAGATGGATTCTGAGACACGAATCCAGGCCCTACGGGGCGCAGCAG GCGCGAAAACTTTACAATGCGGGAAACCGTGATAAGGGAACTCTGAGTGCCCGTTAAATCGGGCTGTCCACCAGTTTAAAAAACTGGT GAAGAAAGGGCCGGGCAAGACCGGTGCCAGCCGCCGCGGTAATACCGGCGGCTCGAGTGGTGGCCACTATTACTGGGCTTAAAGCGTT CGTAGCTGGTTTGTTAAGTTTCTGGGGAAATCTTCCGGCTTAACCGGAAGGCGTCCCAGGGATACTGGCAGACTAGGGACCGGAAGAG GTGAGGGGTACTCCAGGGGTAGGAGTGAAATCCTGTAATCCTTGGGGGACCACCTGTGGCGAAGGCGCCTCACCAGGACGGCTCCGAC AGTGAGGGACGAAAGCTGGGGGAGCAAACCGGATTAGATACCCGGGTAGTCCCAGCCGTAAACGATGTGCGTTAGGTGTATCGGTGAC CACGAGTCACCGAGGTGCCGAAGAGAAATCGTGAAACGTACCGCCTGGGAAGTACGGTCGCAAGGCTGAAACTTAAAGGAATTGGCGG GGGAGCACCACAACGG

S13146

GCGGATCCGCGGCCGCTGCAGATCTGGTTGATCCTGCCGGAGGTTACTGCTATCGAGGTTCGACTAAGCCATGCGAGTCGAATGTAGC AATACATGGCGTACTGCTCAGTAACACGTGGACAACCTACCCTTAGGACGGGGATAAACCCGGGAAACTGGGTATAATACCCGATAGT CCTCGACTGCTGGAATGCATCGAGAACTAAAGCTCCGGCGCCTAAGGATGGGTCTGCGGCCTATCAGGTAGTAGTGGGTGTAGTGTAC CTACTAGCCTACGACGGGTACGGGTTGTGAGAGCAAGAGCCCGGAGATGGATTCTGAGACACGAATCCAGGCCCTACGGGGTGCAGCA GGCGCGAAAACTTTACAATGCTGGAAACAGCGATAAGGGGACCTCGAGTGCCAGGTTACAAATCTGGCTGTCGTGATGCCTAAAAAGC ATTGCATAGCAAAGGCCGGGCAAGACCGGTGCCAGCCGCCGCGGTAACACCGGCGGCTCGAGTGGTAACCGTTATTATTGGGTCTAAA GGGTCTGTAGCCGGCCGGATAAGTCTCTTGGGAAATCCAGCAGCTCAACTGTTGGGCTTTCAGGAGATACTGTCTGGCTCGAGGCCGG GAGAGGTGAGAGGTACTTCAGGGGTAGGGGTGAAATCTTGTAATCCTTGAAGGACCACCAGTGGCGAAGGCGTCTCACCAGAACGGAC CTGACGGCAAGGGACGAAAGCTGGGGGCACGAACCGGATTAGATACCCGGGTAGTCCTAGCCGTAAACGATACTCGCTAGGTGTCGGC CACGGTGCGACCGTTGTCGGTGCCGTAGGGAAGCCGTGAAGCGAGCCACCTGGGAAGTACGGCCGCAAGGCTGAAACTTAAAGGAATT GGCGGGGGAGCACCACAAC

S13148

CGTTGTGGTGCTCCCCCGCCAATTCCTTTAAGTTTCAGCCTTGCGACCGTACTTCCCAGGCGGTACGTTTCACGATTTCTCTTCGGCA CCTCGGTGACTCGTGGTCACCGATACACCTAACGCACATCGTTTACGGCTGGGACTACCCGGGTATCTAATCCGGTTTGCTCCCCCAG CTTTCGTCCCTCACTGTCGGAGCCGTCCTGGTGAGGCGCCTTCGCCACAGGTGGTCCCCCAAGGATTACAGGATTTCACTCCTACCCC TGGAGTACCCCTCACCTCTTCCGGTCCCTAGTCTGCCAGTATCCCTGAGACGCCTTCCGGTTAAGCCGGAAGATTTCCCCAGAGACTT AACAAACCAGCTACGAACGCTTTAAGCCCAGTAATAGTGGCCACCACTCGAGCCGCCGGTATTACCGCGGTGGCTGGCACCGGTCTTG CCCGGCCCTTTCTTCACCAGTTTTTTAAACTGATGGACAGCCCGATTTAACGGGCACTCGGAGTTCCCTTATCACGGTTTCCCGCATT GTAAAGTTTTCGCGCCTGCTGCGCCCCGTAGGGCCTGGATTCGTGTCTCAGAATCCATCTCCGGGCTCTTGCTCCCACAACCCGTACC GATTACAGGCTTGTTGGGCCGTTACCCCAACAACTACCTAATCGGCCGCAGACCCATCCTATGGCGGCTGACCTTTCAACTACGAAGC ATTCCAGCATTCATAGCCTATGGGGTATTATCCCCAGTTTCCCGGGGTTATCCCCCACCTTAGGTTAGGTTGTCCACGTGTTACTGAG CAGTATGCCGAGGTCTTGCACCTCTCGACTCGCATGGNTTAATCGAGCTCCGATAGCAGTGGCCTCCGGCAGGATCCCCCAGATCTGC AGCGGCCGCGGATCCGC

S13151

GGATCCGCGGCCGCTGCAGACCTGGTCGATCCTGCCGGAGGTTACTGCTATCGAGGGTCGACTAAGCCATGCGAGTCGAATGTAGCAA TACATGGCGTACTGCTCAGTAACACGTGGACAACCTGCCCTTGAGACGGGGATAAACCCGGGAAACTGGGTATAATACCCGATAGTCC TCGACTGCTGGAATGCATCGAGAACTAAAGCTCCGGCGCCTAAGGATGGGTCTGCGGCCTATCAGGTAGTAGTGGGTGTAGTGTACCT ACTAGCCTACGACGGGTACGGGTTGTGAGAGCAAGAGCCCGGAGATGGATTCTGAGACACGAATCCAGGCCCTACGGGGTGCAGCAGG CGCGAAAACTTTACAATGCTGGAAACAGCGATAAGGGGACCTCGAGTGCCAGGTTACAAATCTGGCTGTCGTGATGCCTAAAAAGCAT TGCATAGCAAGGGCCGGGCAAGACCGGTGCCAGCCGCCGCGGTAACACCGGCGGCTCGAGTGGTAACCGTTATTATTGGGTCTAAAGG 
GTCTGTAGCCGGCCGGATAAGTCTCTTGGGAAATCTGGCAGCTTAACTGTCAGGCTTTCAGGAGATACTGTCTGGCTCGAGGCCGGGA GAGGTGAGAGGTACTTCAGGGGTAGGGGTGAAATCTTGTAATCCTTGAAGGACCACCAGTGGCGAAGGCGTCTCACCAGAACGGACCT GACGGCAAGGGACGAAAGCTAGGGGCACGAACCGGATTAGATACCCGGGTAGTCCTAGCCGTAAACGATACTCGCTAGGTGTCGGCCA CGGTGCGACCGTTGTCGGTGCCGTAGGGAAGCCGTGAAGCGAGCCACCTGGGAAGTACGGCCGCAAGGCTGAAACTTAAAGGAATTGG CGGGGGAGCACCACAACGG

\section{S13152}

GCGGATCCGCGGTCGCTGCAGATCTGGTTGATTCTGCCGGAGGCCACTGCTATCAGAGTTCGATTAAGCCATGCGAGTCGAGAGGTGC AAGACCTCGGCATACTGCTCAGTAACACGTGGACAACCTACCCTGTGGAAGGGGATAACCCCGGGAAACTGGGGATAATACCCTATAG ACTATAGATGCTGGAATGCTCTGTAGCCGAAAGGTCCGCCGCCACAGGATGGGTCTGCGGCCGATTAGGTTGTTGTTGGGGTAACGAC CCAACAAGCCTGTAATCGGTACGGGTTGTGAGAGCAAGAGCCCGGAGATGGATTCTGAGACACGAATCCAGGCCCTACGGGGCGCAGC AGGCGCGAAAACTTTACAATGCGGGAAACCGTGATAAGGGAACTCCGAGTGCCCGTAAAATCGGGCTGTCCACCAGTTTAAATAACTG GTGAAGAAAGGGCCGGGCAAGACCGGTGCCAGCCGCCGCGGGTAATACCGGCGGCTCGAGTGGTGGCCACTATTACTGGGCTTAAAGC GTTCGTAGCTGGTCTGTTAAGTCTCTGGGGAAATCTGCTGGCTTAACCAACAGGCGTCTCAGGGATACTGGCAGACTAGGGACCGGGA GAGGTGAGAGGTACTCCAGGGGTAGGAGTGAAATCCTGTAATCCTTGGGGGACCACCTGTGGCGAAGGCGCCTCACCAGGACGGCTCC GACAGTGAGGGACGAAAGCTGGGGGAGCAAACCGGATTAGATACCCGGGTAGTCCCAGCCGTAAACGATGTGCGTTAGGTGTATCGGT GACCACGAGTCACCGAGGTGCCGAAGAGAAATCGTGAAACGTACCGCCTGGGAAGTACGGTCGCAAGGCTGAAACTTAAAGGAATTGG CGGGGGAGCACCACAAC

S13153

GCGGATCCGCGGCCGCTGCAGATCTGGTCGATCCTGCCGGAGGTTACTGCTATCGAGGTTCGACTAAGCCATGCGAGTCGAATGTAGC AATACATGGCGTACTGCTCAGTAACACGTGGACAACCTACCCTTAGGTCGGGGATAAACCCGGGAAACTGGGTATAATACCCGATAGA TCTCGACTGCTGGAATGCATCGAGATCGAAAGCTCCGGCGCCTAAGGATGGGTCTGCGGCCTATCAGGTAGTAGTGGGTGTAGCGTAC CTACTAGCCTACGACGGGTACGGGTTGTGAGAGCAAGAGCCCGGAGATGGATTCTGAGACACGAATCCAGGCCCTACGGGGTGCAGCA GGCGCGAAGACTTTACAATGCTGGAAACAGCGATAAGGGGACCTCGAGTGCCAGGTTACAAATCTGGCTGTCGTGATGCCTAAAAAGC ATTGCATAGCAAGGGCCGGGCAAGACCGGTGCCAGCCGCCGCGGTAACACCGGCGGCTCGAGTGGTAACCGTTATTATTGGGTCTAAA GGGTCTGTAGCCGGCCGGATAAGTCTCTTGGGAAATCCAGCAGCTCAACTGTTGGGCTTTCAGGAGATACTGTCTGGCTCGAGGCCGG GAGAGGTGAGAGGTACTTCAGGGGTAGGGGTGAAATCTTGTAATCCTTGAAGGACCACCAGTGGCGAAGGCGTCTCACCAGAACGGAC CTGACGGCAAGGGACGAAAGCTAGGGGCACGAACCGGATTAGATACCCGGGTAGTCCTAGCCGTAAACGATACTCGCTAGGTGTCGGC CACGGTGCGACCGTTGTCGGTGCCGTAGGGAAGCCGTGAAGCGAGCCACCTGGGAAGTACGGCCGCAAGGCTGAAACTTAAAGGAATT GGCGGGGGAGCACCACAAC

S13155

GGATCCGCGGTCGCTGCAGATCTGGTTGATCCTGCCGGAGGTTACTGCTATCGAGGTTCGACTAAGCCATGCGAGTCGAATGTAGCAA TACATGGCGTACTGCTCAGTAACACGTGGACAACCTACCCTTAGGGCGGGGATAAACCCGGGAAACTGGGTATAATACCCGATAGTCC TCGACTGCTGGAATGCATCGAGGACTAAAGCTCCGGCGCCTAAGGATGGGTCTGCGGCCTATCAGGTAGTAGTGGGTGTAGCGTACCT ACTAGCCTACGACGGGTACGGGTTGTGAGAGCAAGAGCCCGGAGATGGATTCTGAGACACGAATCCAGGCCCTACGGGGTGCAGCAGG CGTGAAAACTTTACAATGCTGGAAACAGCGATAAGGGGACCTCGAGTGCCAGGTTACAAATCTGGCTGTCGTGATGCCTAAAAAGCAC TGCATAGCAAGGGCCGGGCAAGACCGGTGCCAGCCGCCGCGGTAACACCGGCGGCTCGAGTGGTAACCGTTATTATTGGGTCTAAAGG GTCTGTAGCCGGCCGGATAAGTCTCTTGGGAAATCTGGCAGCTTAACTGTCAGGCTTTCAGGAGATACTGTCTGGCTCGAGGCCGGGA GAGGTGAGAGGTACTTCAGGGGTAGGGGTGAAATCTTGTAATCCTTGAAGGACCACCAGTGGCGAAGGCGTCTCACCAGAACGGACCT GACGGCAAGGGACGAAAGCTAGGGGCACGAACCGGATTAGATACCCGGGTAGTCCTAGCCGTAAACGATACTCGCTAGGTGTCGGCCA CGGTGCGACCGTTGTCGGTGCCGTAGGGAAGCCGTGAAGCGAGCCACCTGGGAAGTACGGCCGCAAGGCTGAAACTTAAAGGAATTGG CGGGGGAGCACCACAACGG

S13157

CGGATCCGCGGCCGCTGCAGATCTGGTCGATCCTGCCGGAGGCCACTGCTATCGGAGTTCGATTAAGCCATGCGAGTCGAGAGGTGCA AGACCTCGGCATACTGCTCAGTAACACGTGGACAATCTAACCTAAGGTGGGGGATAACCCCGGGAAACTGGGGATAATACCCCATAGA CTATGAATGCTGGAATGCTTTGTAGTCGAAAGGTCAGCCGCCTTAGGATGGGTCTGCGGCCGATTAGGTAGTTGTTGGGGTAACGGCC CAACAAGCCTGTAATCGGTACGGGTTGTGGGAGCAAGAGCCCGGAGATGGATTCTGAGACACGAATCCAGGCCCTACGGGGCGCAGCA GGCGCGAAAACTTTACAATGCGGGAAACCGTGATAAGGGAACTCCGAGTGCCCGTAAAATCGGGCTGTCCATCTGTTTAAATAACAGG TGAAGAAAGGGCCGGGCAAGACCGGTGCCAGCCGCCGCGGTAATACCGGCGGCTCGAGTGGTGGCCACTATTACTGGGCTTAAAGCGT TCGTAGCTGGTCTGTTAAGTCTCTGGGGAAATCTACTGGTTTAACCAATAGGCGTCTCAGGGATACTGGCAGACTAGGGACCGGGAGA GGTGAGAGGTACTCCAGGGGTAGGAGTGAAATCCTGTAATCCTTGGGGGACCACCTGTGGCGAAGGCGTCTCACCAGAACGGCTCCGA CAGTGAGGGACGAAAGCTGGGGGAGCAAACCGGATTAGATACCCGGGTAGTCCCAGCCGTAAACGATGCGCGTTAGGTGTATCGGTGA CCACGAGTCACCGACGTGCCGAAGAGAAATCGTGAAACGTGCCGCCTGGAAGTACGGTCGCAAGGCTGAAACTTAAAGGAATTGGCGG GGGAGCACCACAAC

S13158

GGATCCGCGGCCGCTGCAGATCTGGTTGATCCTGCCGGAGGTTACTGCTATCGAGGTTCGACTAAGCCATGCGAGTCGAATGTAGCAA TACATGGCGTACTGCTCAGTAACACGTGGATAACCTACCCTTGAGACGGGGATAAACCCGGGAAACTGGGTATAATACCCGATAAATC TCGACTGCTGGAATGCATCGAGCTTGAAAGCTCCGGCGCTCAAGGATGGGTCTGCGGCCTATCAGGTAGTAGTGGGTGTAGCGTACCT ACTAGCCTACGACGGGTACGGGTTGTGAGAGCAAGAGCCCGGAGATGGATTCTGAGACACGAATCCAGGCCCTACGGGGTGCAGCAGG CGCGAAAACTTTACAATGCTGGAAACAGCGATAAGGGGTCCTCGAGTGCCAGGTTACAAATCTGGCTGTCGTGATGCCTAAAAAGCAT TGCATAGCAAGGGCCGGGCAAGACCGGTGCCAGCCGCCGCGGTAACACCGGCGGCTCGAGTGGTAACCGTTATTATTGGGTCTAAAGG GTCTGTAGCCGGCCGGATAAGTCTCTTGGGAAATCTGGCAGCTTAACTGTCAGGCTTTCAGGAGATACTGTCTGGCTCGAGGCCGGGA GAGGTGAGAGGTACTTCAGGGGTAGGGGTGAAATCTTGTAATCCTTGAAGGATCACCAGTGGCGAAGGCGTCTCACCAGAACGGACCT GACGGCAAGGGACGAAAGCTAGGGGCACGAACCGGATTAGATACCCGGGTAGTCCTAGCCGTAAACGATACTCGCTAGGTGTCGGCAA CGGTGCGACCGTTGTCGGTGCCGTAGGGAAGCCGTGAAGCGAGCCACCTGGGAAGTACGGCCGCAAGGCTGAAACTTAAAGGAATTGG CGGGGGAGCACCACAACGG

S13162

GCGGATCCGCGGCCGCTGCAGATCTGGTTGATCCTGCCGGAGGCCACTGCTATCAGAGCTCGATTAAGCCATGCGAGTCGAGAGGTGC AAGACCTCGGCATACTGCTCAGTAACACGTGGACAATCTAACCTACGGAAGGGGATAACCCCGGGAAACTGGGGATAATACCCTATAG ACTATGGATGCTGGAATGCTCTGTAGCCGAAAGGTCCGCCGCCGTAGGATGGGTCTGCGGCCGATTAGGTTGTTGTTGGGGTAACGGC 
CCAACGAGCCTGTAATCGGTACGGGTTGTGGGAGCAAGAGCCCGGAGATGGATTCTGAGACACGAATCCAGGCCCTACGGGGCGCAGC AGGCGCGAAAACTTTACAATGCGGGAAACCGTGATAAGGGAACTCTGAGTGCCCGTTAAATCGGGCTGTCCATCAGTTTAAAAAGCTG GTGAAGAAAGGGCCGGGCAAGACCGGTGCCAGCCGCCGCGGTAATACCGGCGGCTCGAGTGGTGGCCACTATTACTGGGCTTAAAGCG TTCGTAGCTGGTTTGTTAAGTCTCTGGGGAAATCTTCCGGCTTAACCGGAAGGCGTCTCAGGGATACTGGCAGACTAGGGACCGGAAG AGGTGAGAGGTACTCCAGGGGTAGGAGTGAAATCCTGTAATCCTTGGGGGACCACCTGTGGCGAAGGCGTCTCACCAGGACGGCTCCG ACAGTGAGGGACGAAAGCTGGGGGAGCAAACCGGATTAGATACCCGGGTAGTCCCAGCCGTAAACGATGTGCGTTAGGTGTATCGGTG ACCACGAGTCACCGAGGTGCCGAAGAGAAATCGTGAAACGTACCGCCTGGGAAGTACGGTCGCAAGGCTGAAACTTAAAGGAATTGGC GGGGGAGCACCACAAC

S13163

GGATCCGCGGTCGCTGCAGACCTGGCCGATTCTGCCGGAGGCCACTGCTATCGGAGTTCGATTAAGCCATGCGAGTCGAGAGGTGCAA GACCTCGGCATACTGCTCAGTAACACGTGGACAACCTAACCTACAGAGGGGGATAACCCCGGGAAACTGGGGATAATACCCCATAGAC TATGGATGCTGGAATGCTTCGTAGTTGAAAGGTCCGCCGCTGTAGGATGGGTCTGCGGTCGATTAGGTTGTTGTTGGGGTAACGGCCT AACAAGCCTGTAATCGGTACGGGTTGTGGGAGCAAGAGCCCGGAGATGGATTCTGAGACACGAATCCAGGCCCTACGGGGCGCAGCAG GCGCGAAAACTTTGCAATGCGGGAAACCGTGACAAGGGAACTCTGAGTGCCCGTTAAATCGGGCTGTCCATCGGTTTAAATAACCGGT GAAGAAAGGGCCGGGCAAGACCGGTGCCAGCCGCCGCGGTAATACCGGCGGCTCGAGTGGTGGCCACTATTACTGGGCTTAAAGCGTT CGTAGCTGGTTTGTTAAGTTTCTGGGGAAATCTTCCGGCTTAACCGGAAGGCGTCTCAGGGATACTGGCAGACTAGGGACCGGAAGAG GTGAGGGGTACTCCAGGGGTAGGAGTGAAATCCTGTAATCCTTGGGGGACCACCTGTGGCGAAGGCGCCTCACCAGGACGGCTCCGAC AGTGAGGGACGAAAGCTGGGGGAGCAAACCGGATTAGATACCCGGGTAGTCCCAGCCGTAAACGATGTGCGTTAGGTGTATCGGTGAC CACGAGTCACCGAGGTGCCGAAGAGAAATCGTGAAACGTACCGCCTGGGAAGTACGGTCGCAAGGCTGAAACTTAAAGGAATTGGCGG GGGAGCACCACAACG

S13164

GCGGATCCGCGGTCGCTGCAGACCTGGTTGATCCTGCCGGAGGCCACTGCTATCGGAGTTCGATTAAGCCATGCGAGTCGAGAGGGGA AAGCCCTCGGCATACTGCTCAGTAACACGTGGATAACCTGCCCTGCGGTGGGAAATAACCCCGGGAAACTGGGGATAATGTCCCATAG GCTACGGATGCTGGAATGCTCTGTAGCTCAAAGATTTATCGCCACAGGATGGGTCTGCGGCCGATTAGGTAGTTGTTGGGGTAACGGC CCAACAAGCCTTTGATCGGTACGGGTTGTGGGAGCAAGAGCCCGGAGATGGATTCTGAGACACGAATCCAGGCCCTACGGGGCGCAGC AGGCGCGAAAACTTTACAATGCGGGAAACCGTGATAAGGGAACTCCGAGTGTCCGTAAATGCGGACTGTCCGTATGTTTAAAAAGCAT GCGAAGAAAGGGCCGGGCAAGACCGGTGCCAGCCGCCGCGGTAATACCGGCGGCTCGAGTGGTGGCCACTATTACTGGGCTTAAAGCG TTCGTAGCTGGGTCGTTAAGTCTCTTGGGAAATCTACCGGCTTAACCGATAGGCGTCCAAGGGATACTGGCGGTCTAGGGACCGGGAG AGGTGAGGGGTACTTCAGGGGTAGGAGTGAAATCCTGTAATCCTTGGGGGACCACCTGTGGCGAAGGCGCCTCACCAGAACGGCTCCG ACAGTGAGGGACGAAAGCTGGGGGAGCAAACCGGATTAGATACCCGGGTAGTCCCAGCCGTAAACGATGTGCGTTAGGTGTATCGGTG ACCACGAGTCACCGAGGTGCCGAAGAGAAATCGTGAAACGTACCGCCTGGGAGGTACGGTCGCAAGGCTGAAACTTAAAGGAATTGGC GGGGGAGCACCACAACGG

S13165

GCGGATCCGCGGTCGCTGCAGACCTGGTTGATCCTGCCGGAGGCCACTGCTATCGGAGTTCGATTAAGCCATGCGAGTCGAGAGGTGC AAGACCTCGGCATACTGCTCAGTAACACGTGGACAACCTAACCTATGGAGGGGGATAACCCCGGGAAACTGGGGATAATGCCCCATAG ACTATGGAAGCTGGAATGCTCTGTAGTTGAAAGGTCCGCCGCCATAGGATGGGTCTGCGGCCGATTAGGTTGTTGTTGGGGTAACGGC CCAACAAGCCTGTAATCGGTACGGGTTGTGGGAGCCAGAGCCCGGAGATGGATTCTGAGACACGAATCCAGGCCCTACGGGGCGCAGC AGGCGCGAAAACTTTACAATGCGGGAAACCGTGATAAGGGAACTCCGAGTGCCCGTAAAATCGGGCTGTCCATCTGTTTAAATAACAG GTGAAGAAAGGGCCGGGCAAGACCGGTGCCAGCCGCCGCGGTAATACCGGCGGCTCGAGTGGTGGCCACTATTACTGGGCTTAAAGCG TTCGTAGCTGGTCTGTTAAGTCTCTGGGGAAATCTACTGGCTTAACCAATAGACGTTTCAGGGATACTGGCAGACTAGGGACCGGGAG AGGTGAGAGGTACTCCAGGGGTAGGAGTGAAATCCTGTAATCCTTGGGGGACCACCTGTGGCGAAGGCGTCTCACCAGAACGGCTCCG ACAGTGAGGGACGAAAGCTGGGGGAGCAAACCGGATTAGATACCCGGGTAGTCCCAGCCGTAAACGATGTGCGTTAGGTGTATCGATG ACCACGAGTCATCGAGGTGCCGAAGAGAAATCGTGAAACGTACCGCCTGGGAAGTACGGTCGCAAGGCTGAAACTTAAAGGAATTGGC GGGGGAGCACCACAAC

S13166

GGATCCGCGGCCGCTGCAGACCTGGTTGATCCTGCCGGAGGTTACTGCTATCGAGGTTCGACTAAGCCATGCGAGTCGAATGTAGCAA TACATGGCGTACTGCTCAGTAACACGTGGACAACCTACCCTCCGGACGGGGATAAACCCGGGAAACTGGGTATAATACCCGATAGATC TCGACTGCTGGAATGCATCGAGATCGAAAGCTCCGGCGCCAGAGGATGGGTCTGCGGCCTATCAGGTAGTAGTGGGTGTAGCGTACCT ACTAGCCTACGACGGGTACGGGTTGTGAGAGCAAGAGCCCGGAGATGGATTCTGAGACACGAATCCAGGCCCTACGGGGTGCAGCAGG CGCGAAAACTTTACAATGCCGGCAACGGCGATAAGGGGACCTCGAGTGCCAGGTTACAAATCTGGCTGTCGTGATGCCTAAAAAGCAT TGCATAGCAAGGGCCGGGCAAGACCGGTGCCAGCCGCCGCGGTAACACCGGCGGCTCGAGTGGTAACCGTTATTATTGGGTCTAAAGG GTCTGTAGCCGGCCGGATAAGTCTCTTGGGAAATCCAGCAGCTCAACTGTTGGGCTTTCAGGAGATACTGTCTGGCTCGAGGCCGGGA GAGGTGAGAGGTACTTCAGGGGTAGGGGTGAAATCTTGTAATCCTTGAAGGACCACCAGTGGCGAAGGCGTCTCACCAGAACGGACCT GACGGCAAGGGACGAAAGCTAGGGGCACGAACCGGATTAGATACCCGGGTAGTCCTAGCCGTAAACGATACTCGCTAGGTGTCGGCCA CGGTGCGACCGTGGTCGGTGCCGTAGGGAAGCCGTGAAGCGAGCCACCTGGGAAGTACGGCCGCAAGGCTGAAACTTAAAGGAATTGG CGGGGGAGCACCACAACGG

S13169

GGCGGATCCGCGGCCGCTGCAGATCTGGTTGATCCTGCCGGAGGCCACTGCTATCGGAGTTCGATTAAGCCATGCGAGTCGGGAGGTG CAAGACCTCGGCATACTGCTCAGTAACACGTGGACAACCTAACCTATGGAGGGGGATAACCCCGGGAAACTGGGGATAATACCCCATA GACTATGGATGCTGGAATGCTCTGTAGTTGAAAGGTCCGCCGCCATAGGATGGGTCTGCGGCCGATTAGGTTGTTGTTGGGGTAACGG CCCAACAAGCCTGTAATCGGTACGGGTTGTGGGAGCAAGAGCCCGGAGATGGATTCTGAGACACGAATCCAGGCCCTACGGGGCGCAG CAGGCGCGAAAACTTTACAATGCGGGAAACCGTGATAAGGGAACTCCGAGTGCCCGTAAAATCGGGCTGTCCATCTGTTTAAATAACA GGTGAAGAAAGGGCCGGGCAAGACCGGTGCCAGCCGCCGCGGTAATACCGGCGGCTCGAGTGGTGGCCACTATTACTGGGCTTAAAGC GTTCGTAGCTGGTTTGTTAAGTCTCTGGGGAAATCTGCCGGCTCAACCGGCAGGCGTTCCAGGGATACTGGCAGACTAGGGACCGGGA GAGGTGAGGGGTACTCCAGGGGTAGGAGTGAAATCCTGTAATCCTTGGGGGACCACCTGTGGCGAAGGCGCCTCACCAGAACGGCTCC GACAGTGAGGGACGAAAGCTGGGGGAGCAAACCGGATTAGATACCCGGGTAGTCCCAGCCGTAAACGATGCGCGTTAGGTGTATCGGT GACCACGAGTCACCGAGGTGCCGAAGAGAAATCGTGAAACGTGCCGCCTGGGAAGTACGGTCGCAAGGCTGAAACTTAAAGGAATTGG CGGGGGAGCACCACAACGG 
GGATCCGCGGCCGCTGCAGACCTGGTTGATCCTGCCGGAGGTTACTGCTATCGAGGTTCGACTAAGCCATGCGAGTCGAATGTAGCAA TACATGGCGTACTGCTCAGTAACACGTGGACAACCTACCCTCCGGACGGGGATAAACCCGGGAAACTGGGTATAATACCCGATAGATC TCGGCTGCTGGAATGCACCGAGGTCGAAAGCTCCGGCGCCAGAGGATGGGTCTGCGGCCTATCAGGTAGTAGTGGGTGTAGCGTACCT ACTAGCCTACGACGGGTACGGGTTGTGAGAGCAAGAGCCCGGAGATGGATTCTGAGACACGAATCCAGGCCCTACGGGGTGCAGCAGG CGCGAAAACTTTACAATGCTGGAAACAGCGATAAGGGGACCTCGAGTGCCAGGTTACAAATCTGGCTGTCGTGATGCCTAAAAAGCAT TGCATAGCAAGGGCCGGGCAAGACCGGTGCCAGCCGCCGCGGTAACACCGGCGGCTCGAGTGGTAACCGTTATTATTGGGTCTAAAGG GTCTGTAGCCGGCCGGATAAGTCTCTTGGGAAATCTGGCAGCTTAACTGTCAGGCTTTCAGGAGATACTGTCTGGCTCGAGGCCGGGA GAGGTGAGAGGTACTTCAGGGGTAGGGGTGAAATCTTGTAATCCTTGAAGGACCACCAGTGGCGAAGGCGTCTCACCAGAACGGACCT GACGGCAAGGGACGAAAGCTAGGGGCACGAACCGGATTAGATACCCGGGTAGTCCTAGCCGTAAACGATACTCGCTAGGTGTCGGCCA CGGTGCGACCGTTGTCGGTGCCGTAGGGAAGCCGTGAAGCGAGCCACCTGGGAAGTACGGCCGCAAGGCTGAAACTTAAAGGAATTGG CGGGGGAGCACCACAACGG

S13171

GCGGATCCGCGCCGCTGCAGATCTGGTCGATTCTGCCAGAGGTTACTGCTATCGAGGTTCGACTAAGCCATGCGAGTCGAATGTAGCA ATACATGGCGTACTGCTCAGTAACACGTGGACAACCTACCCTTAGGTCGGGGATAAACCCGGGAAACTGGGTATAATACCCGATAGAT CTCGACTGCTGGAATGCATCGAGATCGAAAGCTCCGGCGCCTAAGGATGGGTCTGCGGCCTATCAGGTAGTAGTGGGTGTAGCGTACC TACTAGCCTACGACGGGTACGGGTTGTGAGAGCAAGAGCCCGGAGATGGATTCTGAGACACGAATCCAGGCCCTACGGGGTGCAGCAG GCGCGAAAACTTTACAATGCTGGAAACAGCGATAAGGGGACCTCGAGTGCCAGGTTACAAATCTGGCTGTCGTGATGCCTAAAAAGCA TTGCATAGCAAGGGCCGGGCAAGACCGGTGCCAGCCGCCGCGGTAACACCGGCGGCTCGAGTGGTAACCGTTATTATTGGGTCTAAAG GGTCTGTAGCCGGCCGGATAAGTCTCTTGGGAAATCCAGCAGCTCAACTGTTGGGCTTTCAGGAGATACTGTCTGGCTCGAGGCCGGG AGAGGTGAGAGGTACTTCAGGGGTAGGGGTGAAATCTTGTAATCCTTGAAGGACCACCAGTGGCGAAGGCGTCTCACCAGAACGGACC TGACGGCAAGGGACGAAAGCTAGGGGCACGAACCGGATTAGATACCCGGGTAGTCCCAGCCGTAAACGATGCTCGCTAGGTGTCAGGC ATGGCGCGACCGTGTCTGGTGCCGCAGGGAAGCCGTGAAGCGAGCCACCTGGGAAGTACGGCCGCAAGGCTGAAACTTAAAGGAATTG GCGGGGGAG

S13172

GGATCCGCGGTCGCTGCAGACCTGGTTGATTCTGCCGGAGGTTACTGCTATCGAGGGGCGACTAAGCCATGCGAGTCGAATGTAGCAA TACATGGCGTACTGCTCAGTAACACGTGGATAACCTACCCTTGAGACGGGGATAAACCCGGGAAACTGGGTATAATACCCGATAGATC TCGACTGCTGGAATGCATCGAGCTTGAAAGCTCCGGCGCTCAAGGATGGGTCTGCGGCCTATCAGGTAGTAGTGGGTGTAGCGTACCT ACTAGCCTACGACGGGTACGGGTTGTGAGAGCAAGAGCCCGGAGATGGATTCTGAGACACGAATCCAGGCCCTACGGGGTGCAGCAGG CGCGAAAACTTTACAATGCTGGAAACAGCGATAAGGGGACCTCGAGTGCCAGGTTACAAATCTGGCTGTCGTGATGCCTAAAAAGCAT TGCATAGCAAGGGCCGGGCAAGACCGGTGCCAGCCGCCGCGGTAACACCGGCGGCTCGAGTGGTAACCGTTATTATTGGGTCTAAAGG GTCTGTAGCCGGCCGGATAAGTCTCTTGGGAAATCTGGCAGCTTAACTGTCAGGCTTTCAGGAGATACTGTCTGGCTCGAGGCCGGGA GAGGTGAGAGGTACTTCAGGGGTAGGGGTGAAATCTTGTAATCCTTGAAGGACCACCAGTGGCGAAGGCGTCTCACCAGAACGGACCT GACGGCAAGGGACGAAAGCTAGGGGCACGAACCGGATTAGATACCCGGGTAGTCCTAGCCGTAAACGATACTCGCTAGGTGTCAGGCA TGGCGCGACCGTGTCTGGTGCCGCAGGGAAGCCGTGAAGCGAGCCACCTGGGAAGTACGGCCGCAAGGCTGAAACTTACAGGAATTGG CGGGGGAGCACCACAACGG

S13174

GGATCCGCGGCCGCTGCAGACCTGGTCGATCCTGCCGGAGGTTACTGCTATCGAGGTTCGACTAAGCCATGCGAGTCGAATGTAGCAA TACATGGCGTACTGCTCAGTAACACGTGGACAACCTGCCCTTGAGACGGGGATAAACCCGGGAAACTGGGTATAATACCCGATAGTCC TCGACTGCTGGAATGCATCGAGAACTAAAGCTCCGGCGCCTAAGGATGGGTCTGCGGCCTATCAGGTAGTAGTGGGTGTAGTGTACCT ACTAGCCTACGACGGGTACGGGTTGTGAGAGCAAGAGCCCGGAGATGGATTCTGAGACACGAATCCAGGCCCTACGGGGTGCAGCAGG CGCGAAAACTTTACAATGCTGGAAACAGCGATAAGGGGACCTCGAGTGCCAGGTTACAAATCTGGCTGTCGTGATGCCTAAAAAGCAT TGCATAGCAAGGGCCGGGCAAGACCGGTGCCAGCCGCCGCGGTAACACCGGCGGCTCGAGTGGTAACCGTTATTATTGGGTCTAAAGG GTCTGTAGCCGGCCGGATAAGTCTCTTGGGAAATCTGGCAGCTTAACTGTCAGGCTTTCAGGAGATACTGTCTGGCTCGAGGCCGGGA GAGGTGAGAGGTACTTCAGGGGTAGGGGTGAAATCTTGTAATCCTTGAAGGACCACCAGTGGCGAAGGCGTCTCACCAGAACGGACCT GACGGCAAGGGACGAAAGCTAGGGGCACGAACCGGATTAGATACCCGGGTAGTCCTAGCCGTAAACGATACTCGCTAGGTGTCGGCCA CGGTGCGACCGTTGTCGGTGCCGTAGGGAAGCCGTGAAGCGAGCCACCTGGGAAGTACGGCCGCAAGGCTGAAACTTAAAGGAATTGG CGGGGGAGCACCACAACGG

S13176

GGATCCGCGGCCGCTGCAGATCTGGTTGATTCTGCCAGAGGTTACTGCTATCGAGGTTCGACTAAGCCATGCGAGTCGAATGTAGCAA TACATGGCGTACTGCTCAGTAACACGTGGACAACCTACCCTTAGGACGGGGATAAACCCGGGAAACTGGGTATAATACCCGATAGTCC TCGACTGCTGGAATGCATCGAGAACTAAAGCTCCGGCGCCTAAGGATGGGTCTGCGGCCTATCAGGTAGTAGTGGGTGTAGTGTACCT ACTAGCCTACGACGGGTACGGGTTGTGAGAGCAAGAGCCCGGAGATGGATTCTGAGACACGAATCCAGGCCCTACGGGGTGCAGCAGG CGCGAAAACTTTACAATGCTGGAAACAGCGATAAGGGGACCTCGAGTGCCAGGTTACAAATCTGGCTGTCGTGATGCCTAAAACGCAT TGCATAGCAAGGGCCGGGCAAGACCGGTGCCAGCCGCCGCGGTAACACCGGCGGCTCGAGTGGTAACCGTTATTGTTGGGTCTAAAGG GTCTGTAGCCGGCCGGATAAGTCTCTTGGGAAATCTGGCGGCTTAACTGTCAGGCTTTCAGGAGATACTGTCTGGCTCGAGGCCGGGA GAGGTGAGAGGTACTTCAGGGGTAGGGGTGAAATCTTGTAATCCTTGAAGGACCACCAGTGGCGAAGGCGTCTCACCAGAACGGACCT GACGGCAAGGGACGAAAGCTAGGGGCACGAACCGGATTAGATACCCGGGTAGTCCTAGCCGTAAACGATACTCGCTAGGTGTCGGCCA CGGTGCGACCGTTGTCGGTGCCGTAGGGAAGCCGTGAAGCGAGCCACCTGGGAAGTACGGCCGCAAGGCTGAAACTTAAAGGAATTGG CGGGGGAGCACCACAACGG

S13177

GCGGATCCGCGGCCGCTGCAGATCTGGTCGATCCTGCCGGAGGCCACTGCTATCGGAGTTCGATTAAGCCATGCGAGTTGAGAGGTGC AAGACCTCGGCATACTGCTCAGTAACACGTGGACAACCTAACCTACAGAAGGGGATAACCCCGGGAAACTGGGGATAATACCCTATAG ACTATGGATGCTGGAATGCTCTGTAGCCGAAAGGTCCGCCGCTGTAGGATGGGTCTGCGGCCGATTAGGTTGTTGTTGGGGTAACGGC CCAACAAGCCTGTAATCGGTACGGGTTGTGGGAGCAAGAGCCCGGAGATGGATTCTGAGACACGAATCCAGGCCCTACGGGGCGCAGC AGGCGCGAAAACTTTACAATGCGGGAAACCGTGATAAGGGAACTCCGAGTGCCCGTAAAATCGGGCTGTCCATCTGTTTAAATAACTG GTGAAGAAAGGGCCGGGCAAGACCGGTGCCAGCCGCCGCGGTAATACCGGCGGCTCGAGTGGTGGCCACTATTACTGGGCTTAAAGCG TTCGTAGCTGGTCTGTTAAGTCTCTGGGGAAATCTACTGGCTTAACCAATAGACGTTTCAGGGATACTGGCAGACTAGGGACCGGGAG AGGTGAGAGGTACTCCAGGGGTAGGAGTGAAATCCTGTAATCCTTGGGGGACCACCTGTGGCAAAGGCGTCTCACCAGAACGGCTCCG ACAGTGAGGGACGAAAGCTGGGGGAGCAAACCGGATTAGATACCCGGGTAGTCCCAGCCGTAAACGATGTGCGTTAGGTGTATCGATG 
ACCACGAGTCATCGCGGTGCCGAAGAGAAATCGTGAAACGTACCGCCTGGGAAGTACGGTCGCAAGGCTGAAACTTAAAGGAATTGGC GGGGGAGCACCA

S13178

GCGGATCCGCGGCCGCTGCAGATCTGGTTGATTCTGCCGGAGGCCACTGCTATCGGAGTTCGATTAAGCCATGCGAATCGAGAGGTGC AAGACCTCGGCATACTGCTCAGTAACACGTGGACAACCTAACCTACAGAGGGGGATAACCCCGGGAAACTGGGGATAATACCCCATAG ACTATGGATGCTGGAATGCTTCGTAGTTGAAAGGTCCGCCGCTGTAGGATGGGTCTGCGGCCGATTAGGTTGTTGTTGGGGTAACGGC CCAACAAGCCTGTAATCGGTACGGGTTGTGGGAGCGAGAGCCCGGAGATGGATTCTGAGACACGAATCCAGGCCCTACGGGGCGCAGC AGGCGCGAAAACTTTGCAATGCGGGAAACCGTGACAAGGGAACTCTGAGTGCCCGTTAAATCGGGCTGTCCATCGGTTTAAATAACCG GTGAAGAAAGGGCCGGGCAAGACCGGTGCCAGCCGCCGCGGTAATACCGGCGGCTCGAGTGGTGGCCACTATTACTGGGCTTAAAGCG TTCGTAGCTGGTCTGTTAAGTCTCTGGGGAAATCTACTGGCTTAACCAATAGGCGTTTCAGGGATACTGGCAGACTAGGGACCGGGAG AGGTGAGAGGTACTCCAGGGGTAGGAGTGAAATCCTGTAATCCTTGGGGGACCACCTGTGGCGAAGGCGTCTCACCAGAACGGCTCCG ACAGTGAGGGACGAAAGCTGGGGGAGCAAACCGGATTAGATACCCGGGTAGTCCCAGCCGTAAACGATGCGCGTTAGGTGTATCGGTG ACCACGAGTCACCGACGTGCCGAAGAGAAATCGTGAAACGTGCCGCCTGGGAAGTACGGTCGCAAGGCTGAAACTTAAAGGAATTGGC GGGGGAGCACCACAAC

S13179

GCGGATCCGCGGCCGCTGCAGATCTGGTCGATCCTGCCGGAGGCCACTGCTATCGGAGTTCGATTAAGCCATGCGAGTTGAGAGGTGC AAGACCTCGGCATACTGCTCAGTAACACGTGGACAACCTAACCTACAGAAGGGGATAACCCCGGGAAACTGGGGATAATACCCTATAG ACTATGGATGCTGGAATGCTCTGTAGCCGAAAGGTCCGCCGCTGTAGGATGGGTCTGCGGCCGATTAGGTTGTTGTTGGGGTAACGGC CCAACAAGCCTGTAATCGGTACGGGTTGTGGGAGCAAGAGCCCGGAGATGGATTCTGAGACACGAATCCAGGCCCTACGGGGCGCAGC AGGCGCGAAAACTTTACAATGCGGGAAACCGTGATAAGGGAACTCCGAGTGCCCGTAAAATCGGGCTGTCCATCTGTTTAAATAACTG GTGAAGAAAGGGCCGGGCAAGACCGGTGCCAGCCGCCGCGGTAATACCGGCGGCTCGAGTGGTGGCCACTATTACTGGGCTTAAAGCG TTCGTAGCTGGTCTGTTAAGTCTCTGGGGAAATCTACTGGCTTAACCAATAGACGTTTCAGGGATACTGGCAGACTAGGGACCGGGAG AGGTGAGAGGTACTCCAGGGGTAGGAGTGAAATCCTGTAATCCTTGGGGGACCACCTGTGGCAAAGGCGTCTCACCAGAACGGCTCCG ACAGTGAGGGACGAAAGCTGGGGGAGCAAACCGGATTAGATACCCGGGTAGTCCCAGCCGTAAACGATGTGCGTTAGGTGTATCGATG ACCACGAGTCATCGCGGTGCCGAAGAGAAATCGTGAAACGTACCGCCTGGGAAGTACGGTCGCAAGGCTGAAACTTAAAGGAATTGGC GGGGGAGCACCACAAC

S13180

GCGGATCCGCGGCCGCTGCAGACCTGGTCGATCCTGCCGGAGGTCACTGCTATTGGGATTCGACTAAGCCATGCGAGTCGAATGTAGC AATACATGGCGTACTGCTCAGTAACACGTGGACAACCTACCCTTAGGTCGGGGATAAACCCGGGAAACTGGGTATAATACCCGATAGA TCTCGACTGCTGGAATGCATCGAGATCGAAAGCTCCGGCGCCTAAGGATGGGTCTGCGGCCTATCAGGTAGTAGTGGGTGTAGCGTAC CTACTAGCCTACGACGGGTACGGGTTGTGAGAGCAAGAGCCCGGAGATGGATTCTGAGACACGAATCCAGGCCCTACGGGGTGCAGCA GGCGCGAAAACTTTACAATGCTGGAAACAGCGATAAGGGGACCTCGAGTGCCAGGTTACAAATCTGGCTGTCGTGATGCCTAAAAAGC ATTGCATAGCAAGGGCCGGGCAAGACCGGTGCCAGCCGCCGCGGTAACACCGGCGGCTCGAGTGGTAACCGTTATTATTGGGTCTAAA GGGTCTGTAGCCGGCCGGATAAGTCTCTTGGGAAATCCAGCAGCTCAACTGTTGGGCTTTCAGGAGATACTGTCTGGCTCGAGGCCGG GAGAGGTGAGAGGTACTTCAGGGGTAGGGGTGAAATCTTGTAATCCTTGAAGGACCACCAGTGGCGAAGGCGTCTCACCAGAACGGAC CTGACGGCAAGGGACGAAAGCTAGGGGCACGAACCGGATTAGATACCCGGGTAGTCCTAGCCGTAAACGATACTCGCTAGGTGTCGGC CACGGTGCGACCGTTGTCGGTGCCGTAGGGAAGCCGTGAAGCGAGCCACCTGGGAAGTACGGCCGCAAGGCTGAAACTTAAAGGAATT GGCGGGGGAGCACCACAAC

S13181

GCGGATCCGCGGCCGCTGCAGACCTGGTTGATTCTGCCGGAGGTTACTGCTATCGAGGTTCGACTAAGCCATGCGAGTCGAATGTAGC AATACATGGCGTACTGCTCAGTAACACGTGGACAACCTACCCTTAGGACGGGGATAAACCCGGGAAACTGGGTATAATACCCGATAGT CCTCGACTGCTGGAATGCATCGAGAACTAAAGCTCCGGCGCCTAAGGATGGGTCTGCGGCCTATCAGGTAGTAGTGGGTGTAGTGTAC CTACTAGCCTACGACGGGTACGGGTTGTGAGAGCAAGAGCCCGGAGATGGATTCTGAGACACGAATCCAGGCCCTACGGGGTGCAGCA GGCGCGAAAACTTTACAATGCTGGAAACAGCGATGAGGGGACCTCGAGTGCCAGGTTACAAATCTGGCTGTCGTGATGCCTAAAAAGC ATTGCATAGCAAGGGCCGGGCAAGACCGGTGCCAGCCGCCGCGGTAACACCGGCGGCTCGAGTGGTAACCGTTATTATTGGGTCTAAA GGGTCTGTAGCCGGCCGGATAAGTCTCTTGGGAAATCCAGCAGCTCAACTGTTGGGCTTTCAGGAGATACTGTCTGGCTCGAGGCCGG GAGAGGTGAGAGGTACTTCAGGGGTAGGGGTGAAATCTTGTAATCCTTGAAGGACCACCAGTGGCGAAGGCGTCTCACCAGAACGGAC CTGACGGCAAGGGACGAAAGCTAGGGGCACGAACCGGATTAGATACCCGGGTAGTCCTAGCCGTAAACGATACTCGCTAGGTGTCGGC CACGGTGCGACCGTTGTCGGTGCCGTAGGGAAGCCGTGAAGCGAGCCACCTGGGAAGTACGGCCGCAAGGCTGAAACTTAAAGGAATT GGCGGGGGAGCACCACAAC

S13182

GCGGATCCGCGGCCGCTGCAGATCTGGTTGATTCTGCCGGAGGCTACTGCTATCGGGGTCCGATTAAGCCATGCGAGTCGAGAGGTGC AAGACCTCGGCATACTGCTCAGTAACACGTGGACAACCTAACCTATGGAGGGGGATAACCCCGGGAAACTGGGGATAATACCCCATAG ACTATGGATGCTGGAATGCTCTGTAGTTGAAAGGTCCGCCGCCATAGGATGGGTCTGCGGCCGATTAGGTTGTTGTTGGGGTAACGGC CCAACAAGCCTGTAATCGGTACGGGTTGTGGGAGCAAGAGCCCGGAGATGGATTCTGAGACACGAATCCAGGCCCTACGGGGCGCAGC AGGCGCGAAAACTTTACAATGCGGGAAACCGTGATAAGGGAACTCCGAGTGCCCGTAAAATCGGGCTGTCCATCTGTTTAAATAACAG GTGAAGAAAGGGCCGGGCAAGACCGGTGCCAGCCGCCGCGGTAATACCGGCGGCTCGAGTGGTGGCCACTATTACTGGGCTTAAAGCG TTCGTAGCTGGTTTGTTAAGTCTCTGGGGAAATCTGCCGGCTCAACCGGCAGGCGTTCCAGGGATACTGGCAGACTAGGGACCGGGAG AGGTGAGGGGTACTCCAGGGGTAGGAGTGAAATCCTGTAATCCTTGGGGGACCACCTGTGGCGAAGGCGCCTCACCAGAACGGCTCCG ACAGTGAGGGACGAAAGCTGGGGGAGCAAACCGGATTAGATACCCGGGTAGTCCCAGCCGTAAACGATGCGCGTTAGGTGTATCGGTG ACCACGAGTCACCGAGGTGCCGAAGAGAAATCGTGAAACGTGCCGCCTGGGAAGTACGGTCGCAAGGCTGAAACTTAAAGGAATTGGC GGGGGAGCACCACAACGG

\section{S13186}

GCGGATCCGCGGCCGCTGCAGATCTGGTTGATCCTGCCGGTGGCCACTGCTATCGGGGTTCGATTAAGCCATGCGAGTCGAGAGGTGT AAGACCTCGGCATACTGCTCAGTAACACGTGGACAACCTACCCTGAGGAGGGGGATAACCCCGGAAAACTGGGGATAATACCCCATAG ATTAGGGAGGCTGGAATGCCCCCTAGTTCAAAGGTCCGCCGCCTCAGGATGGGTCTGCGGCCGATTAGGTTGTTGTTGGGGTAAAGGC CCAACAAGCCTTTGATCGGTACGGGTTGTGGGAGCAAGAGCCCGGAGATGGATTCTGAGACACGAATCCAGGCCCTACGGGGCGCAGC AGGCGCGAAAACTTTACAATGCGAGAAATCGTGATAAGGGAACCCCGAGTGCCCGTAAATTCGGGCTGTCCGCCAGTGCAAAAAACTG GTGAAGAAAGAGCCGGGCAAGACCGGTGCCAGCCGCCGCGGTAATACCGGCGGCTCGAGTGGTGGCCACTATTACTGGGCTTAAAGCG 
TCCGTAGCTTGGTTGTTAAGTCTTCTGGGAAATCCATCGGCTTAACCGATGGGAGTTCAGGAGATACTGGCAACCTAGGGACCGGGAG CGGTGAGAGGTACTCCAGGGGTAGGAGTGAAATCCTGTAATCCTTGGGGGACCACCTGTGGCGAAGGCGTCTCACTAGAACGGCTCCG ACAGTGAGGGACGAAAGCTGGGGGAGCAAACCGGATTAGATACCCGGGTAGTCCCAGCTGTAAACGATGCGCGTTAGGTGTATCGGTG ACCACGAGTCACCGAGGTGCCGAAGGGAAACCGTGAAACGTGCCGCCTGGGAAGTACGGTCGCAAGGCTGAAACTTAAAGGAATTGGC GGGGGAGCACCACAAGGG

S13187

GCGGATCCGCGGCCGCTGCAGATCTGGTTGATCCTGCCGGAGGTTACTGCTATCGAGGTTCGACTAAGCCATGCGAGTCGAATGTAGC AATACATGGCGTACTGCTCAGTAACACGTGGACAACCTACCCTTGGGACGGGGATAAACCCGGGAAACTGGGTATAATACCCGATAGT CCTCAACTGCTGGAATGCATCGAGGTCGAAAGCTCCGGTGCCCAAGGATGGGTCTGCGGCCTATCAGGTAGTAGTGGGTGTAGCGTAC CTACTAGCCTACGACGGGTACGGGTTGTGAAAGCAAGAGCCCGGAGATGGACTCTGAGACACGAATCCAGGCCCTACGGGGTGCAGCA GGCGCGAAAACTTTACAATGCTGGAAACAGCGATAAGGGAACCTCGAGTGCCAGGTTACAAATCTGGCTGTCGTGATGCCTAAAAAGC ATTGCATAGCAAGGGCCGGGCAAGACCGGTGCCAGCCGCCGCGGTAACACCGGCGGCTCGAGTGGTAACCGTTATTATTGGGTCTAAA GGGTCTGTAGCCGGCCGGATAAGTCTCTTGGGAAATCTGGCAGCTTAACTGTCAGGCTTTCAGGAGATACTGTCCGGCTCGAGGCCGG GAGAGGTGAGAGGTACTTCAGGGGTAGGGGTGAAATCTTGTAATCCTTGAAGGACCACCAGTGGCGAAGGCGTCTCACCAGAACGGAC CTGACGGCAAGGGACGAAAGCTAGGGGCACGAACCGGATTAGATACCCGGGTAGTCCTAGCCGTAAACGATACTCGCTAGGTGTCGGC CACGGTGCGACCGTGGTCGGTGCCGTAGGGAAGCCGTGAAGCGAGCCACCTGGGAAGTACGGCCGCAAGGCTGAAACTTAAAGGAATT GGCGGGGGAGCACCACAAC

S13189

GCGGATCCGCGGCCGCTGCAGATCTGGTTGATTCTGCCGGAGGCTACTGCTATCGGGGTCCGACTAAGCCATGCGAGTTGAGAGGGGT AAGCCCTCAGCATATTGCTCAGTAACACGCGGATAACCTGCCCTTGGGTTCGGGATAACCCCGGGAAACTGGGACTAATACCGGATAG ATCAAAGAAACTGGAATGTTCTCTGGTTAAAAACTCCGGTGCCCAAGGATGGGTCTGCGGCCTATCAGGTAGTAGTGGGTGTAACGTA CCTACTAGCCTACGACGGGTAAGGGTTGTGAGAGCAAGAGCCCTGAGATGGATTCTGAGACATGAATCCAGGCCCTACGGGGTGCAGC AGGCGCGAAAACTTTACACTGCGGGAAACCGCGATAAGGGGACCCCGAGTGCCAGCACCTAGTGCTGGCTGTCCAGCTGTCCAAATAA CAGTTGTTAGCAAGGGCCGGGCAAGACCGGTGCCAGCCGCCGCGGTAACACCGGCGGCCCGAGTGGTAGCCGTTATTATTGGGTTTAA AGGGTCCGTAGCCGGCCTATTAAGTCTCTTGGGAAATCTGGCGACTCAATCGTCAGGCGTCCAAGAGATACTGGTAGGCTTGGGACCG GGAGAGGTGGGAGGTACTCCAGGGGTAGGGGTGAAATCTCGTAATCCTTGGGGGACCACCGATGGCGAAGGCATCCCACCAGAACGGG TCCGACGGTGAGGGACGAAAGCTGGGGGCACGAACCGGATTAGATACCCGGGTAGTCCTAGGCGTAAATGATGCGAGTTAAGTGTGGG GGCATCTACGAGATGGCCCTGTGCTGTAGGGTAGCCGTTAAACTCGCCGCCTCGGGAGTACGGTCGCAAGGCTGAAACTTAAAGGAAT TGGCGGGGGAGCACCACAAGGG

S13191

GGATCCGCGGCCGCTGCAGACCGGTCGATCCTGCCGGAGGTTACTGCTATCGAGGTTCGACTAAGCCATGCGAGTCGAATGTAGCAAT ACATGGCGTACTGCTCAGTAACACGTGGACAACCTACCCTTGGGACGGGGATAAACCCGGGAAACTGGGTATAATACCCGATAGTCCT CGACTGCTGGAATGCATCGAGGTCGAAAGCTCCGGTGCCCAAGGATGGGTCTGCGGCCTATCAGGTAGTAGTGGGTGTAGCGTACCTA CTAGCCTACGACGGGTACGGGTTGTGAGAGCAAGAGCCCGGAGATGGATTCTGAGACACGAATCCAGGCCCTACGGGGTGCAGCAGGC GCGAAAACTTTACAATGCTGGAAACAGCGATAAGGGGACCTCGAGTGCCAGGTTACAAATCTGGCTGTCGTGATGCCTAAAACGCATT GCATAGCAAGGGCCGGGCAAGACCGGTGCCAGCCGCCGCGGTAACACCGGCGGCTCGAGTGGTAACCGTTATTATTGGGTCTAAAGGG TCTGTAGCCGGCCGGATAAGTCTCTTGGGAAATCTGGCAGCTTAACTGTCAGGCTTTCAGGAGATACTGTCTGGCTCGAGGCCGGGAG AGGTGAGAGGTACTTCAGGGGTAGGGGTGAAATCTTGTAATCCTTGAAGGACCACCAGTGGCGAAGGCGTCTCACCAGAACGGACCTG ACGGCAAGGGACGAAAGCTAGGGGCACGAACCGGATTAGATACCCGGGTAGTCCTAGCCGTAAACGATACTCGCTAGGTGTCGGCCAC GGTGCGACCGTTGTCGGTGCCGTAGGGAAGCCGTGAAGCGAGCCACCTGGGAAGTACGGCCGCAAGGCTGAAACTTAAAGGAATTGGC GGGGGAGCACCACAACGG

S13192

TTACGGCTGGGACTACCCGGGTATCTAATCCGGTTTGCTCCCCCAGCTTTCGTCCCTCACTGTCGGAGCCGTCCTGGTGAGGCGCCTT CGCCACAGGTGGTCCCCCAAGGATTACAGGATTTCACTCCTACCCCTGGAGTACCCCTCACCTCTTCCGGTCCCTAGTCTGCCAGTAT CCCTGGGACGCCTTCCGGTTAAGCCGGAAGATTTCCCCAGAAACTTAACAAACCAGCTACGAACGCTTTAAGCCCAGTAATAGTGGCC ACCACTCGAGCCGCCGGTATTACCGCGGCGGCTGGCACCGGTCTTGCCCGGCCCTTTCTTCACCAGTTTTTTAAACTGGTGGACAGCC CGATTTAACGGGCACTCAGAGTTCCCTTATCACGGTTTCCCGCATTGTAAAGTTTTCGCGCCTGCTGCGCCCCGTAGGGCCTGGATTC GTGTCTCAGAATCCATCTCCGGGCTCTTGCTCCCACAACCCGTACCGATTACAGGCTTGTTGGGCCGTTACCCCAACAACTACCTAAT CGGCCGCAGACCCATCCTATGGCGGCTGACCCTTCAGCTACAGAGCATTCCAGCTTCCATAGTCTATGGGGTATTATCCCCAGTTTCC CGGGGTTATCCCCCACCTTAGGTTAGGTTGTCCACGTGTTACTGAGCAGTATGCCGAGGTCTTGCACCTCTCGACTCGCATGGCTTAA TCGAACTCTGATAGCAGTGGCCTCCGGCAGAAT

s13193

GCGGATCCGCGGTCGCTGCAGATCTGGTTGATTCTGCCGGAGGCCACTGCTATCGGAGTTCGATTAAGCCATGCGAGTCGAGAGGTGC GAGACCTCGGCATACTGCTCAGTAACACGTGGACAACCTACCCTATGGAGGGGGATAACCCCGGGAAACTGGGGATAATACCCCATAG ATTATGAATGCTGGAATGCTTTGTAGTTGAAAGGTCCGCCGCCATAGGATGGGTCTGCGGCCGATTAGGTTGTTGTTGGGGTAACGGC CCAACAAGCCTGTAATCGGTACGGGTTGTGGGAGCAAGAGCCCGGAGATGGATTCTGAGACACGAATCCAGGCCCTACGGGGCGCAGC AGGCGCGAAAACTTTACAATGCGGGAAACCGTGATAAGGGAACTCCGAGTGCCCGTAAAATCGGGCTGTCCATCTGTTTAAATAACAG GTGAAGAAAGGGCCGGGCAAGACCGGTGCCAGCCGCCGCGGTAATACCGGCGGCTCGAGTGGTGGCCACTATTACTGGGCTTAAAGCG TTCGTAGCTGGTCTGTTAAGTCTCTGGGGAATTCTTCCGGCTTAACCGGAAGGCGTCTCAGGGATACTGGCAGACTAGGGACCGGAAG AGGTGAGGGGTACTCCAGGGGTAGGAGTGAAATCCTGTAATCCTTGGGGGACCACCTGTGGCGAAGGCGCCTCACCAGGACGGCTCCG ACAGTGAGGGACGAAAGCTGGGGGAGCAAACCGGATTAGATACCCGGGTAGTCCCAGCCGTAAACGATGTGCGTTAGGTGTATCGGTG ACCACGAGTCACCGAGGTGCCGAAGAGAAATCGTGAAACGTACCGCCTGGAAGTACGGTCGCAAGGCTGAAACTTAAAGCAATT

S13194

GGATCCGCGGCCGCTGCAGACCTGGTCGATCCTGCCGGAGGTTACTGCTATCGAGGTTCGACTAAGCCATGCGAGTCGAATGTAGCAA TACATGGCGTCCCGCTCAGTAACACGTGGATAACCTACCCTTGAGACGGGGATAAACCCGGGGAACTGGGTATAATACCCGATAGATC TCGACTGCTGGAATGCGTCGAGCTTTAAAGCTCCGGCGCTCAAGGATGGATCTGCGGCCTATCAGGTAGTAGTGGGTGTAGCGTACCT ACTAGCCTACGACGGGTACGGGTTGTGAGAGCAAGAGCCCGGAGATGGATTCTGAGACACGAATCCAGGCCCTACGGGGTGCAGCAGG CGCGAAAACTTTACAATGCTGGAAACAGCGATAAGGGGACCTCGAGTGCCAGGTTACAAATCTGGCTGTCGTGATGCCTAAAAAGCAT TGCATAGCAAGGGCCGGGCAAGACCGGTGCCAGCCGCCGCGGTAACACCGGCGGCTCGAGTGGTAACCGTTATTATTGGGTCTAAAGG 
ATCTGTAGCCGGCCGGATAAGTCTCTTGGGAAATCTGGCAGCTTAACTGTCAGGCTTTCAGGAGATACTGTCTGGCTCGAGGCCGGGA GAGGTGAGAGGTACTTCAGGGGTAGGGGTGAAATCTTGTAATCCTTGAAGGACCACCGATG

\subsection{Das Insert desPlasmides pEry1}

\subsubsection{Lage der offenen Leserahmen (ORFs)}

\begin{tabular}{|c|c|c|c|c|}
\hline ORF & Annotation & Start & Stopp & $\begin{array}{l}\text { Orien- } \\
\text { Tierun } \\
\text { g }\end{array}$ \\
\hline 1 & Hypothetisches Protein & 1 & 1017 & - \\
\hline 2 & Dehydrogenase mit konservierter Domäne COG0111 & 1304 & 2293 & + \\
\hline 3 & Hypothetisches Protein & 2303 & 3958 & + \\
\hline 4 & Hypothetisches Protein & 4050 & 4703 & + \\
\hline 5 & Hypothetisches Protein & 4742 & 5005 & + \\
\hline
\end{tabular}

\subsubsection{Sequenz}

GCTTGTTGTAGGTATCGTTGCCGACGGGATCGGCGTGCCCGAACACGGACAGGGGGAATCCCGGCTGGTCCCCGAGCTTCGAGGTCGG GGGATGCTCCTTCACAAGGCGATCGAGGGCCTTGAGCTCCTTCTCGGTCTTGGGGTCGACGAACGAAGAGTCGAACTTGAAGCGAACG TCCTCCAGGCGCCAGCACGCGACGGGAATGATCCCCGTCCGAATCGTGTTGTGCTCGCTCCCGGTGGCGGGTCCCACGAACGCGGCCA CGTGCGGATGCGGCGGAAGCTTGGCCGCGATGCCGCCTTCCGAGGTCAAAGGGGACGAAATCGTGTCAGCGGCACTCAAGGCGCTCTC CAGTCCGGTGCAACGATGCTAGCGGGCACGCCGGGGACGGTCAAGGACGCGATCACCCTCGCCTCCGCCACTGGCGGAGTGCCAGGGC AAAGGGTTTGAGCTCATGAGTTGCACACGGCTCACGCTCCGCCAGCCGCACCACCCTGTATTCGAGCCGCAGCACGCGACTTCCATTT GTATCTCGACGAAGCCTACGGCTCCGCTACATTGAGGCCGGCGCCTTCAGCTGACCTGGTCGAAACGGTCACGCCACGAGCACACCGG AGGAGGGAGGCCCATGAAGATCGCAGTCATTCACGACTACGCTGACGTGTTCCGGACGACCCGCGCGTACCAGCGGCTGCGAGGGCAC GAGGTCGTCGTGCACACCGACGCCTACACCGAGCCGGCGCGTGTCGTCGAGCAGGTGGCCGGCTGTGAGGCGGTGCTGCTCACGCAGC AGCGGGTGCCGGTGACCCGCGAGATCGTCGCGCGGCTGCCCGACCTCAGGTTCATCAGCCAGACGAGCGCCAACGTCTACCACATCGA CGTCGCCGCCTGCACCGAGCACGGCGTGGTGGTGTCGGCCGGGCGGGGGGGCGCGCGTACGGCCTTCTCGACGACGGCGGAGCTGACG TGGGGTTTGATCATCGCGTCGCTGCGTCATCTGCCGTTCGAGGTGGAGCGACTCAAGCAGGGCTTCTGGCACTCGACCGTGGGCACGC GCCTGGAGGGTCAGACGCTCGGGATCTACGCCTTCGGTCACATCGGCGCGGCGGTGGCCAGGGTCGGCCGTGCGTTCGGCATGAAGGT CGTGAGCTGGGGCCGTGAGGGCTCGACCGCGCGTGCCCGGGCCGAGGGCTTCGAGGTGGCCCCGAGCCGAGAGGCTTTCTTCGAGGGG GCCGACGTTGTCAGCCTGCACCTGCCCGGCGGCACGGAGACCCGCGGCATCGTCACGGCCGACGATCTCGCGCGCATGAAGCCCACGG CGCTGCTGGTCAACACGAGCCGCGCTCCGATCATCGAGGAGGGCGCGCTCGTTGCCGCGCTCGGCAAGGGCCGCCCGGGCTTCGCGGC GGTGGATGTCTTCGAGACGGAACCGGTCGTCGGCGCCGCGCACCCGCTGCTGAAGATGCCGAACGCGCTGTGCACGCCGCATCTCGGC TACGGGGAGAGGGAGGGCTACGAAGGCATCTACGCCGGTGGCGTCGAGCGCCTGCTCGCCTGGGTGGCCGGCACGCCCATCGACGTGA TCAATCCGGAAGCGCTGGAGCGGCAGAAGCGGTGACGAGGAGCCATGTCCGGCCGGGCGCCTGATCCAGAGGCCGAACGGCAGCCGAC CACTCCAGGGCGCCCCGACAGCGGCTCGGCGGCGGACCAGCTGTGGTGGTTCCGCGACGCGCGCGAGCCTCTGCCGCCCCCTCCCTCC CGCTGGCTGCGGTGGCCCCAACGCAAACACACGATTGACGCCCTTGCGTGCCTCTCCCTGTCGACGCTCTGCTTCAGCCAGGCGCGCA GCGAGATGCTGTTCCGACCGAGCTTGGACTTCTACCACCTGACGCCGCTTCGGGCACCGGCGCTGGCGGCATTCGTGCTGAATGTCGT CGGGCTCGCCGCCGTCGGCTTTCTGATTGTGCAATGGATTCGACGCGTCAGGCGACCGGCGGGGCAGCGTCTCGCCGCCGGCGCCGCC GTCGTGACCCTTCTCGCCTCCATGAACTTCGCGCGCATGACGCACGAGGCGGTCGGCCGATGGACCGATGTCATCGGATGGCCTGGAC TGCTGGTCCTTGCCGCCCTGGCGCTCACCGCGTCGCTGAGCATCCCGCACCCGGCCCTGCGGGTGGTGCGCGGCGTTGCGGTGGCCGT CTCACCCCTGGCGGTCGGCACGATGGCCCTCGCCCTCTGGATGTTCCTCGAGGTGGCGGCCGGCCCGGCGTGGCGATGGGTCGACCCG ACGCCCCTCGACCGGCCGCGACCGAGTCTCCGGCGCGTGGTCTGGATCGTGTTCGAGGAGCTCGACCAGCGCGTCACGTTCGAGGCGC GACCGACTGGTCTCGAGCTGCCGGAGCTCGATCGTCTGAGGCGGGAGTCGCTCTACGCCCACGCCGCGCGCTCGCCGGCGGGCACGAC TGACGTGACGATCCCCGCGCTCATCACCGGGCGTCCGGTCGTCGCGGTGGCCCCCCTGAATCCGAGGGACCTCCAGCTCACGTTCGCG GACGGCAAGACGGCGCAATGGAGCGCCGAGCCGAACGTGTTCTCCCGCGCGCGAACGCTCGGCTACGACACGGCGCTGATCGGATGGC ATCTGCCGTATCCGCGGGTGCTCGGCGGCTCGCTCGCGGTCGCGCACTGGAAACCGTCCGTCGCGTTCGAGCAGGTGCGTGGCGACAC ATTCGCCGGGTCGCTGTGGAGGCAGTGGGCGAGCCTCGCGCCCCCGCTGAATGTCCGTCGGCAGTTCTCCGAGCGGGTTGCCGAGCTC ACGAGCCTGGCGATCCGCACCGCGGCCGACGACCGCTTCGGCCTCGTCTTTCTCCACCTGCCGGTTCCCCAGCCACCGGGTATCTACG ACCGGGCCACGGAACGTCTCACGGCATGGAACTTCAGCGGTGCGGCCGGGGGCTACTTCGACAATCTCGCGCTCGCCGACCGGGTCGT CGGCGAGTTGCGGCGTGGGCTGGACCGTGTGCGCCTCGGCGACCGCACGTGGATCGTGGTGACCTCCACTCGATCGTGGCAGGCGTCC GCTCAGTACGACGGGCAGACCGATCCGCGCGTACCGTTCCTCCTGCGGCCGCCGGAAGGCGGCCGGACACGGCACGTGGACGCTCCGT TTGGCACGCAGGCCACACACGATCTGGTGCTGGCCATCTTGCGCGGCTCCATCAGCGACACGAGCGCCGCCGCCGCTTGGCTCTCGCG CCCAGCCGTGGCGCCGCCGAGGGACTAGCCCATCGGGCGCAGCATCGACATCGAAGGCATCGGCGACCCCCAGATCTGCCCAAAGACG ATGCGGGCAGTTCGTCAATCGGAGCTGTCGCGTGGTGATCCAGTCAGCACACCGCGCTCGCGTGCACGGGTCCTCCAGCACACCTCCG AACGGGCACGCGGGAGGCAACTGTCCGTCGTGTCGCGCTCCACCAATGGCACGACGCGTGCCTCTGAGGACGGGCATGGACCACGACG GGGACTCGACGACGCGGTTGGAATGGCGTCGTCGAAGTGAAACGACACTCCGGCACGCACGAGCGACCGTGGGCCGGGCCATCCGCTC GAAATACGTGGACACGACCCACGGCGTGTTTCCCCTCAAGCGCTTCCCCCGGCCGGGGATGCGGGCGCGCAGGGGCAGGCTGGCCACG AGGACCGTGAAGACGCAGCGCCGCGGCTCATTGCCGGCGAGGAATTGCCAACAGCCGCTTTCCGACCGCGTTCGCGCCCGCGCTCGCG CAGCGCGGGTATCCCATCGCCCGGCGCAGGGTGGCCAAGTACCGAGACGAATTCGCCATCCCGTCCGGCCGGCGGCGGAAGCGGATGG 
GGTCCGCGGTGTGCCCCACCGCCGAGGTTTCCCCCAGAACCGCCGACCGTTCACCCACGACCCCCGCCCGGCGCGTACCCGGCCTCGC TCGCAACTCTCTGAAACTCAGGGCCGTTCACATTGGCATGGGGCTCGCACCGTCGGCCTCTCAGCATGAGTCGAGCGGCCCTCACGGG CACGGAAGGAGAACAAGTCATGACGATCGGAACCCCGCTCGCGTCGCTGGTTTGTTCGCCGCCTTCCCGGACCGAGGCGGAGGGGGCT GAGCTCGACTCCGTCCTCGTATGGGAGGCGCGAGCCGTTGTCGTCGACTGCGCCGGCGGGCACGATCTGGTCCGCGTGCAGGACCTGG TGTTCCTGTGCCTGAAGGCCGGACCGACCGAGCGGCGCTACATCCTCCGGGTGCCGCCCACGATGCGCACGGTGGGACAGGCGATCTC CTGGACCTTCGGGCGATGACCGCCAAGGCGGGCGCCGGAGGGCACGCTCATGACTGAGACGATGGCCGCGGGGATGCTGGTCACGCTG GTCGCCATGCTCGCTCTGGCGGGGCTGCTGCTGTTCAGTCCGCCGGCTCGGCGGACAACGTGTTGCCGCTGGAGGCGAAGGCGGTCCT CAACGTCCGGATCC 


\section{Vielen Dank!}

Als erstes möchte ich mich Rolf Daniel bedanken, der mir die Arbeit an diesem Thema ermöglichte. Er schaffte es, mit etwas Humor meist auch die „schwereren wissenschaftlichen Stunden“ erträglicher zu machen. Vielen Dank, Rolf, für die nette und hilfreiche Betreuung in den letzten Jahren!

Ein herzlicher Dank geht an die anderen aktuellen und ehemaligen „Fäkalforscher“ aus dem Labor (E. coli ist nun mal ein Darmbakterium!). Es war eine schöne Zeit! Ein Riesendank geht vor allem an Hanna und Jörg, die auf meiner Laborseite immer gute Stimmung verbreiteten und es immer schafften, mich zum Lachen zu bringen, selbst in den seltenen Fällen, wenn ich es eigentlich nicht wollte. Tanja möchte ich für die große Hilfsbereitschaft danken und Frank und Caro für so manches interessante Gespräch. Vielen Dank, Anja, Sönke, Frank, Jörg, Hanna, Sebastian, Baris, Susanne, Claudia und Caro.

Eine angenehme Atmosphäre fand ich auch immer in unserer neuen Abteilung vor. Ich möchte mich ganz besonders auch bei Volker und Jörg für ihr Bereitschaft, mir zu helfen, aber auch bei allen anderen bedanken. Ich war immer gerne bei Euch.

Sonja und Caroline möchte ich für ihre offenen Ohren danken. Es tut immer gut, sich so aufgenommen zu fühlen, auch wenn es einem mal nicht so gut geht.

Ein Dankeschön geht an die Mitglieder der anderen Abteilungen im Haus. Ganz besonders hervorheben möchte ich das G2L mit seinen Silkes, Mechthild und Iwona, ohne die meine Arbeit nicht möglich gewesen wäre. Danke, Heiko, für Deine Hilfe! Ich verstand zum Teil zwar nicht viel, geholfen hast Du mir aber immer und das mit viel Geduld. Danken will ich auch Anke für das Anlernen und die Hilfe bei kniffligen Problemen.

Viel Hilfsbereitschaft traf ich auch immer in der Werkstatt an. Auch dann, wenn das Problem nicht ein defekter Autoklav, sondern vielleicht auch mal ein nicht zu öffnendes Fahrradschloss war.

Lossy, Du bist spitze! 
Ein besondere Dank geht an meine Familie, Britta und Nicki, die mir sehr geholfen haben und die die größten Schätze sind, die ich auf der Welt habe! Schön, dass es Euch gibt! Und Mama, dafür, dass Du eigentlich die Naturwissenschaften nicht magst, hattest du bei den „GradientEngeln“, Sau3A, den Verdauen und den vielen HHHs viel Ausdauer. Vielen Dank! 


\section{Lebenslauf}

\section{Persönliche Daten}

Geburtstag: $\quad$ 04. September 1976

Geburtsort: Hamburg

Familienstand: ledig

$\begin{array}{lll}\text { Schulbildung } & 1983-1987 & \text { Grundschule in Flensburg } \\ & \text { 1987-1996 } & \text { Gymnasium in Flensburg } \\ \text { 28. Mai 1996 } & \text { Allgemeine Hochschulreife }\end{array}$

Studium 1996-2001

Biologie (Diplom) an der Universität

Göttingen

15. Oktober 1998

Vordiplom

27. August 2001

Diplom

Thema der Diplomarbeit:

„Identifizierung von Chitinasen und der sie kodierenden Gene“

September 2001

Beginn der Arbeiten zur vorliegenden

Dissertation

2000 bis Januar 2005

Lehramt für Gymnasien mit den Fächern

Chemie und Biologie an der Universität

Göttingen

4. Juli 2002

Zwischenprüfung in Chemie 